\title{
Nucleosylaminosäuren als Bausteine zur Synthese modifizierter Oligonucleotide
}

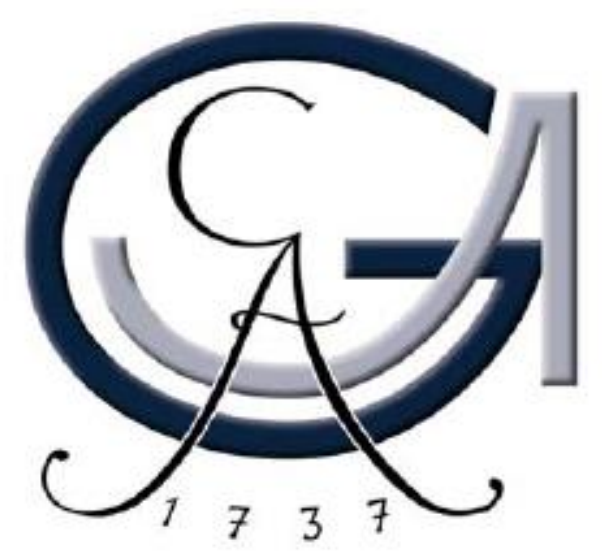

\begin{abstract}
Dissertation
zur Erlangung des mathematisch-naturwissenschaftlichen Doktorgrades

„Doctor rerum naturalium“

der Georg-August-Universität Göttingen

Im Promotionsprogramm

Biomolecules: Structure-Function-Dynamics
\end{abstract}

vorgelegt von

Boris Schmidtgall

aus Nishnjaja Tura

Göttingen, im März 2014 
Die vorliegende Arbeit wurde in der Zeit von April 2010 bis Dezember 2011 am Institut für Organische und Biomolekulare Chemie der Georg-August-Universität Göttingen und in der Zeit von Januar 2012 bis März 2014 am Department Chemie der Universität Paderborn unter der Leitung von Prof. Dr. Christian Ducho angefertigt.

\section{Betreuungsausschuss:}

Prof. Dr. Christian Ducho, Department für Pharmazeutische und Medizinische Chemie, Universität des Saarlandes, Saarbrücken

Prof. Dr. Ulf Diederichsen, Institut für Organische und Biomolekulare Chemie, GeorgAugust-Universität Göttingen

Dr. Claudia Höbartner, Max-Planck-Institut für Biophysikalische Chemie, Göttingen

\section{Mitglieder des Prüfungskomitees:}

Referent: Prof Dr. Christian Ducho, Department für Pharmazeutische und Medizinische Chemie, Universität des Saarlandes, Saarbrücken

Korreferent: Prof. Dr. Ulf Diederichsen, Institut für Organische und Biomolekulare Chemie, Georg-August-Universität Göttingen

\section{Weitere Mitglieder des Prüfungskomitees:}

Dr. Claudia Höbartner, Max-Planck-Institut für Biophysikalische Chemie, Göttingen

Prof. Dr. Kai Tittmann, Albrecht-von-Haller-Institut für Pflanzenwissenschaften, Georg-August-Universität Göttingen

Prof. Dr. Guido Clever, Institut für Anorganische Chemie, Georg-August-Universität Göttingen

Prof. Dr. Claudia Steinem, Institut für Organische und Biomolekulare Chemie, GeorgAugust-Universität Göttingen

Tag der mündlichen Prüfung: 09.05.2014 
Hiermit versichere ich, dass ich die vorliegende Dissertation mit dem Titel: „Nucleosylaminosäuren als Bausteine zur Synthese modifizierter Oligonucleotide“ selbständig und nur unter Verwendung der angegebenen Literatur und Hilfsmittel angefertigt habe.

Göttingen, den

Boris Schmidtgall 


\section{Danksagung}

Mein besonderer Dank gilt Herrn Prof. Dr. Christian Ducho für die interessante Aufgabenstellung, seine stete Diskussions- und Hilfsbereitschaft und die angenehme Atmosphäre in seinem Arbeitskreis.

Herrn Prof. Dr. Ulf Diederichsen danke ich für die Übernahme des Zweitgutachtens.

Für die schnellen und zuverlässigen Messungen zahlreicher NMR-Spektren danke ich der NMR-Abteilung um Herrn Dipl.-Chem.Reinhard Machinek in Göttingen sowie der NMR-Abteilung um Herrn Dr. Hans Egold in Paderborn. Ebenso gilt mein Dank der Abteilung für Zentrale Analytik und Massenspektrometrie um Herrn Dr. Holm Frauendorf in Göttingen und der Abteilung für Massenspektrometrie um Herrn Dr. Heinz Weber in Paderborn für die Aufnahme vieler Massenspektren.

Bei den Mitarbeitern der Arbeitsgruppe Ducho Martin Büschleb, Anke Lemke, Yevgeniy Lesch, Christin Leyerer, Anne Ochmann, Oliver Ries, Malte-Ole Schneemann, Anatol Spork, Daniel Wiegmann, Marius Wirth und Stephanie Wohnig bedanke ich mich für das angenehme Arbeitsklima und die hilfreichen Diskussionen.

Für die engagierte und kompetente Unterstützung bei der Synthese und Untersuchung der modifizierten Oligonucleotide bedanke ich mich bei Frau Dr. Claudia Höbartner und Herrn Dr. Falk Wachowius.

Mein besonderer Dank gilt meiner Familie, meinen Freunden in Göttingen und Paderborn für die moralische Unterstützung und meiner Frau Julia für die schöne gemeinsame Zeit während des gesamten Studiums in Hamburg, Göttingen und Paderborn. 


\begin{tabular}{|c|c|}
\hline$[\alpha]_{\mathrm{D}}^{20}$ & Drehwert (Polarimetrie) \\
\hline$A$ & Adenin \\
\hline$\AA$ & Angström \\
\hline AAV & allgemeine Arbeitsvorschrift \\
\hline Abb. & Abbildung \\
\hline abs. & absolut \\
\hline Ac & Acetyl \\
\hline aeg & aminoethylglycin \\
\hline APS & Ammoniumperoxodisulfat \\
\hline Äq & Äquivalente \\
\hline ber. & berechnet \\
\hline Bidest. & bidestillatus, doppelt destilliert \\
\hline $\mathrm{Bn}$ & Benzyl \\
\hline Boc & tert-Butyloxycarbonyl \\
\hline BOM & Benzyloxymethyl \\
\hline $\mathrm{BMT}$ & 5-Bezylmercaptotetrazol \\
\hline BNA & bicyclic nucleic acid \\
\hline $\mathrm{Bu}$ & Butyl \\
\hline $\mathrm{Bz}$ & Benzoyl \\
\hline $\mathrm{Cbz}$ & Benzyloxycarbonyl \\
\hline D-CNA & dioxaphosphiran constrained nucleic acid \\
\hline C & Cytosin \\
\hline${ }^{\circ} \mathrm{C}$ & Grad Celsius \\
\hline${ }^{\circ} \mathrm{C} / \mathrm{Mod}$. & Grad Celsius pro Duplex-Modifikation \\
\hline CD & Circulardichroismus \\
\hline COSY & Correlation Spectroscopy \\
\hline CPG & controlled pore glass \\
\hline$d$ & dublett \\
\hline DBU & 1,8-Diazabicyclo[5.4.0]undec-7-en \\
\hline DC & Dünnschichchromatographie \\
\hline DCA & dichloroacetic acid \\
\hline $\mathrm{DCM}$ & Dichlormethan \\
\hline$\Delta$ & Differenz \\
\hline$\delta$ & chemische Verschiebung in ppm \\
\hline $\mathrm{DDQ}$ & 2,3-Dichloro-5,6-dicyano-para-benzochinon \\
\hline
\end{tabular}


dest. destilliert

DIAD Diisopropylazodicarboxylat

DMAP N,N-Dimethyl-4-aminopyridin

DMF N,N-Dimethylformamid

DMP Dess-Martin-Periodinan

DMTr 4,4'-Dimethoxytriphenylmethyl

DNA deoxyribonucleic acid

DNG deoxynucleic guanidine

DNmt deoxynucleic methylthiourea

DPPA Diphenylphosphorylazid

dU 2'-Desoxyuridin

EDC 1-Ethyl-3-(3-dimethylaminopropyl)carbodiimid

EDTA Ethylendiamintetraessigsäure

ENA ethylene nucleic acid

ESI Elektrosprayionisation (MS)

EtOAc Ethylacetat

$\varepsilon$

molarer dekadischer Extinktionskoeffizient in $[\mathrm{L} /(\mathrm{mol} \cdot \mathrm{cm})]$

FDA food and drug administration

et al. und andere

$\mathrm{FmocCl}$ 9-Fluorenylmethoxycarbonyl chlorid

FmocOSu $\quad \mathrm{N}$-(9-Fluorenylmethoxycarbonyloxy)succinimid

FT Fouriertransformation

g Gramm

G Guanin

gef. gefunden

ges. gesättigt

h Stunde(n)

Hex Hexan

HOBt 1-Hydroxybenzotriazol

HPLC high pressure liquid chromatography

HSQC heteronuclear single quantum coherence (NMR)

$\mathrm{Hz} \quad$ Hertz

IBX 2-lodoxybenzoesäure

$i \quad$ iso

IR Infrarot 


\begin{tabular}{|c|c|}
\hline$J$ & skalare Kopplungskonstante \\
\hline Kat. & Katalysator \\
\hline konz. & konzentriert \\
\hline $\mathrm{KO}^{t} \mathrm{Bu}$ & Kalium-tert-Butanolat \\
\hline$\lambda$ & Wellenlänge in Nanometern \\
\hline LNA & locked nucleic acid \\
\hline lys & Lysin \\
\hline $\mathrm{m}$ & Multiplett \\
\hline M & molar \\
\hline $\mathrm{MeCN}$ & Acetonitril \\
\hline $\mathrm{MeOH}$ & Methanol \\
\hline $\min$ & Minute(n) \\
\hline miRNA & mikro-RNA \\
\hline $\mathrm{mL}$ & Milliliter \\
\hline MPI & Max-Planck-Institut \\
\hline mRNA & messenger-RNA \\
\hline MS & Massenspektrometrie \\
\hline Ms & Methylsulfonsäure \\
\hline$\tilde{v}$ & Wellenzahl in $\left[\mathrm{cm}^{-1}\right]$ \\
\hline NAA & Nucleosylaminosäure \\
\hline $\mathrm{NaH}$ & Natriumhydrid \\
\hline N-Konformation & northern-Konformation (bei Riboseringen) \\
\hline NMR & nuclear magnetic resonance \\
\hline $\mathrm{NEt}_{3}$ & Triethylamin \\
\hline$\Omega$ & Ohm \\
\hline ON & Oligonucleotid \\
\hline$p$ & para \\
\hline PE & Petrolether \\
\hline PNA & peptide nucleic acid \\
\hline pm & Pikometer \\
\hline PMB & $p$-Methoxybenzyl \\
\hline ppm & parts per million \\
\hline PMO & Phosphordiamidat-Morpholino-Oligonucleotid \\
\hline $\operatorname{Pr}$ & Propyl \\
\hline PS-ON & Phosphorthioat-Oligonucleotid \\
\hline
\end{tabular}




$\begin{array}{ll}\text { q } & \text { Quartett } \\ \text { qPCR } & \text { quantitative Polymerase-Kettenreaktion } \\ R_{f} & \text { Retentionsfaktor (Dünnschichtchromatographie) } \\ \text { RISC } & \text { RNA-induced silencing complex } \\ \text { RNA } & \text { ribonucleic acid } \\ \text { RNAi } & \text { RNA-Interferenz } \\ \text { RNG } & \text { ribonucleic guanidine } \\ \text { RT } & \text { Raumtemperatur } \\ \text { S } & \text { Sekunde/Singulett } \\ \text { s. } & \text { siehe } \\ \text { Sdp. } & \text { Siedepunkt } \\ \text { S-Konformation } & \text { southern-Konformation (bei Riboseringen) } \\ \text { Smp. } & \text { Schmelzpunkt } \\ \text { t } & \text { triplett } \\ t & \text { tert } \\ \text { T } & \text { Thymin } \\ \text { TAA } & \text { thymidinyl amino acid } \\ \text { Tab. } & \text { Tabelle } \\ \text { TBAF } & \text { Tetrabutylammoniumfluorid } \\ \text { TBDMS } & \text { tert-Butyldimethylsilyl } \\ \text { TBE } & \text { Tris-Borsäure-EDTA } \\ \text { TEN } & \text { Tris(hydroxymethyl)-aminomethan, EDTA, NaCl } \\ \text { tert-BuOH } & \text { tert-Butanol } \\ \text { TFA } & \text { trifluor acetic acid } \\ \text { TFO } & \text { triplex forming oligonucleotides } \\ \text { Tf } f_{2} O & \text { Trifluoressigsäureanhydrid } \\ \text { THF } & \text { Tetrahydrofuran } \\ \text { T }_{m} & \text { Schmelzpunkt von Duplices (Nucleinsäuren und chem. Analoga) } \\ \text { TMEDA } & \text { N,N,N',N'-Tetramethylethan-1,2-diamin (Tetramethylethylendiamin) } \\ \text { TMS } & \text { Trimethylsilyl } \\ \text { TOCSY } & \text { total correlation spectroscopy } \\ t_{R} & \text { Retentionszeit (HPLC) } \\ \text { UV } & \text { Ultraviolette elektromagnetische Strahlung } \\ \text { VIS } & \text { Wichtbare elektromagnetische Strahlung } \\ \text { W } & \end{array}$




\section{Inhaltsverzeichnis}

1 Einleitung .................................................................................. 1

2 Kenntnisstand.................................................................................. 4

2.1 Arten von Modifikationen der Nucleinsäuren.............................................. 4

2.2 Modifikationen der Desoxyriboseeinheit........................................................ 5

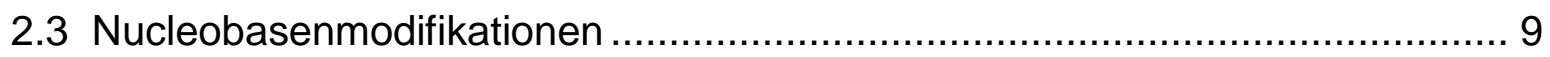

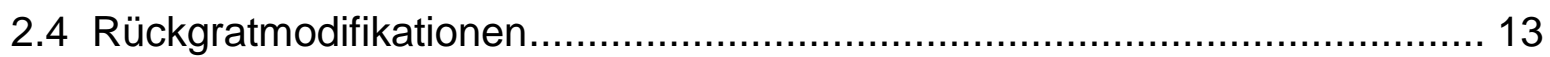

2.4.1 Anionische Rückgratmodifikationen ............................................... 14

2.4.2 Elektroneutrale Rückgratmodifikationen .......................................... 15

2.4.3 Kationische und zwitterionische Rückgratmodifikationen ...................... 19

2.4.4 Modifikationen des gesamten Zuckerphosphatrückgrats ......................... 22

2.5 Nucleosylaminosäure (NAA)-modifizierte ON ......................................... 26

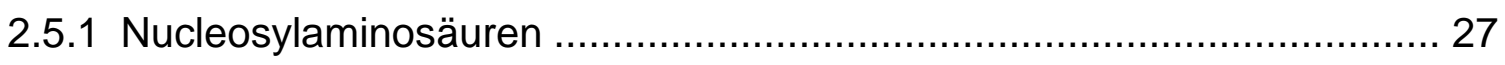

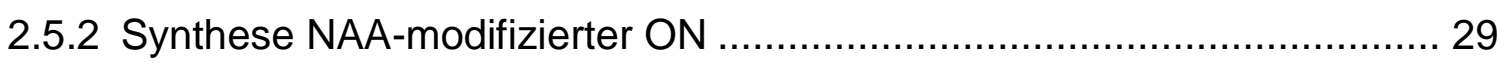

2.5.3 Erste Untersuchungen NAA-modifizierter ON....................................... 31

3 Zielsetzung und Planung der Arbeit................................................33

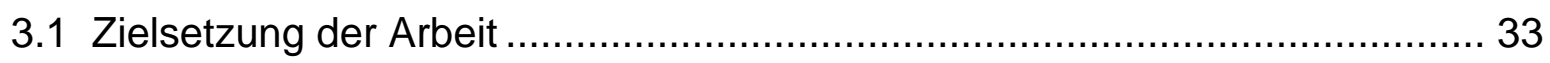

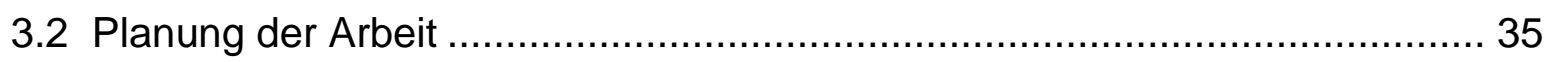

3.2.1 NAA als Bausteine für die Synthese zwitterionischer ON ...................... 35

3.2.2 NAA-Derivate für die Synthese uniform kationischer ON....................... 43

4 Resultate und Diskussion .......................................................46

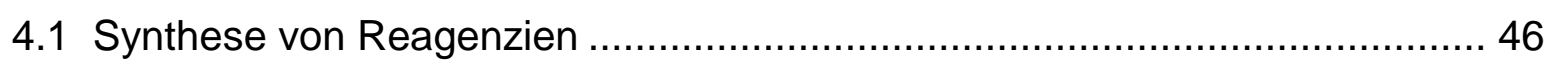

4.1.1 Synthese des Phosphitylierungs-Reagenzes..................................... 46

4.1.2 Synthese der Phosphonate .................................................................. 46

4.1.3 Synthese der Oxidationsmittel IBX und DMP.................................... 48

4.2 Synthese der NAA-Bausteine für den Aufbau zwitterionischer ON ............... 49

4.2.1 Synthese der 3'-O-TBDMS-Thymidinylaldehyde .................................... 49

4.2.2 Synthese der 3'-O-TBDMS-5',6'-Didehydro-TAA ................................. 51

4.2.3 Asymmetrische Hydrierung der 3'-O-TBDMS-5',6'-Didehydro-TAA......... 54

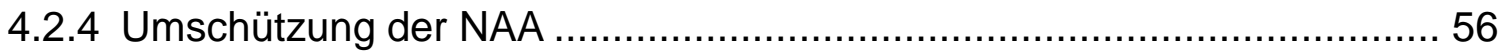

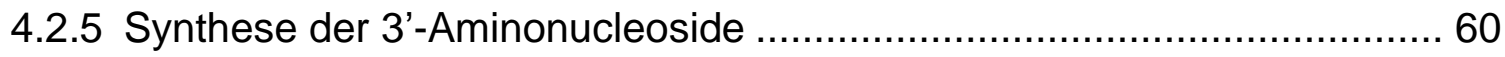

4.3 Synthese der NAA-Bausteine für den Aufbau oligokationischer ON ............. 78

4.3.1 Synthese der 3'- $\mathrm{N}_{3}$-Thymidinylaldehyde ........................................... 78

4.3.2 Synthese der geschützten 3'-NHCbz-Thymidinylaldehyde …................. 79 
4.3.3 Synthese der 3'- $\mathrm{N}_{3}$ - und 3'-NHCbz-5',6'-Didehydro-TAA ...................... 81

4.3.4 Asymmetrische Hydrierung der 5'-6'-Didehydro-TAA ........................... 83

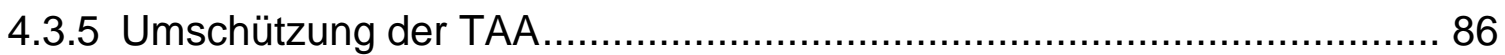

4.4 Synthese der NAA-modifizierten ON............................................. 89

4.5 Untersuchung der NAA-modifizierten ON ........................................... 93

4.5.1 Schmelzkurvenanalyse ........................................................ 93

4.5.2 Circulardichroismus-(CD)-Spektroskopie...................................... 100

4.5.3 Abschließende Beurteilung der NAA-Modifikation ............................. 104

5 Zusammenfassung...................................................................106

6 Ausblick ...................................................................................116

7 Experimentalteil.......................................................................122

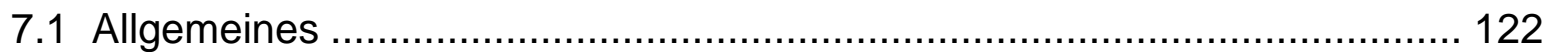

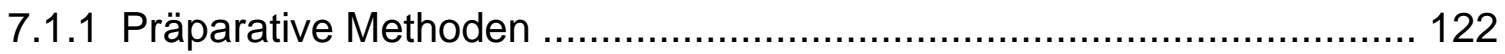

7.1.2 Edukte und Reagenzien ............................................................ 122

7.1.3 Lösungsmittel.......................................................................... 123

7.1 .4 Absolute Lösungsmittel....................................................... 123

7.1 .5 Chromatographie ............................................................... 124

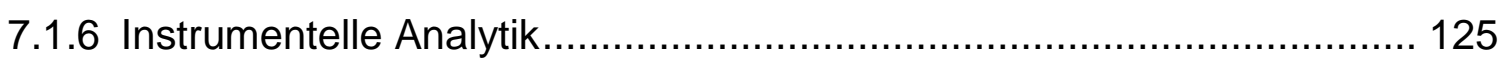

7.1.7 Allgemeine Arbeitsvorschriften .............................................. 130

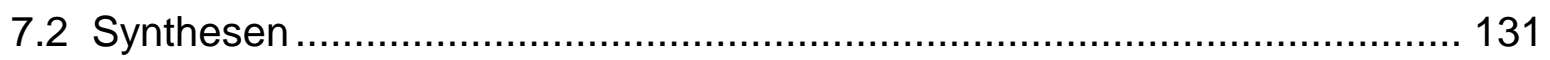

7.2.1 Synthese der Reagenzien..................................................... 131

7.2.2 Synthese der 3'-O-TBDMS-Thymidinylaminosäuren (TAA) ................. 139

7.2.3 Synthese der 3'-Aminonucleoside ............................................... 162

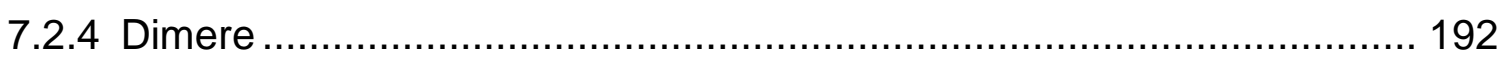

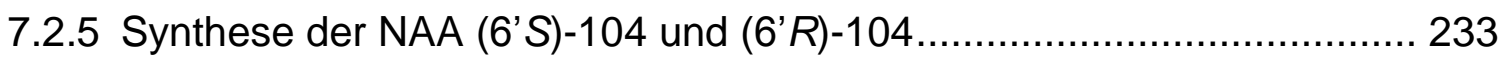

7.2 .6 Oligonucleotide ................................................................... 260

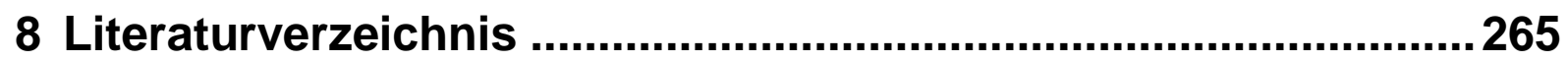

9 Anhang ............................................................................ 282

9.1 HPLC-Chromatogramme .......................................................... 282

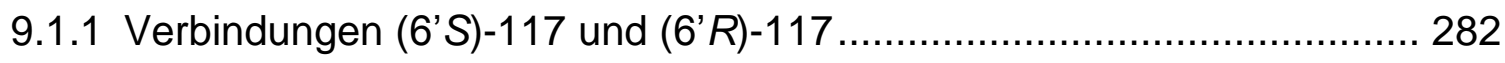

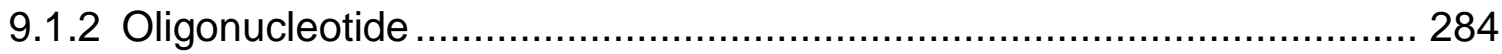

9.2 Daten zur Schmelzkurvenanalyse .................................................. 303

9.2.1 Schmelzpunkte der untersuchten Duplices ...................................... 303

9.2.2 Schmelzkurvendiagramme ....................................................... 307

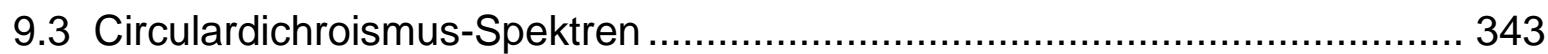




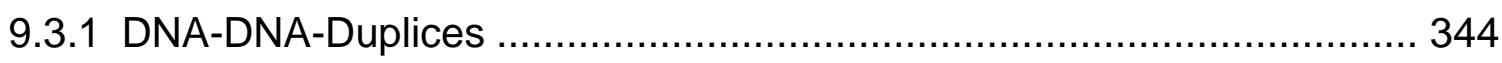

9.3.2 DNA-RNA-Duplices .......................................................... 359

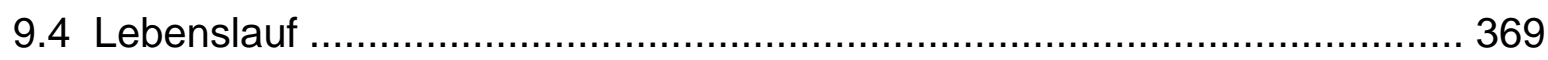





\section{Einleitung}

Nucleinsäuren sind aufgrund ihrer zentralen Bedeutung für sämtliche physiologische Prozesse in Organismen und ihrer ungewöhnlichen molekularen Eigenschaften nach wie vor ein attraktiver Forschungsgegenstand. Die Entdeckung dieser Biopolymere gelang Miescher im Jahre 1869 durch Fällung mit verdünnter Salzsäure aus einem Zellextrakt. ${ }^{[1]}$ Danach lag das Hauptaugenmerk über 80 Jahre auf der Bestimmung der Struktur dieses Makromoleküls. Zuerst wurden die Einzelbausteine von Kossel isoliert und beschrieben. ${ }^{[2-3]}$ Genauere Aussagen über deren Konnektivität im Polymer (Primärstruktur) konnten von Levene durch Ammonolyse von DNA und Charakterisierung der Monomere gemacht werden. ${ }^{[4]}$ Eine weitere Beobachtung, die einen wichtigen Hinweis auf das Prinzip der Basenpaarung darstellte, machte Chargaff im Jahr 1950: Innerhalb einer lebenden Spezies ist das Stoffmengenverhältnis von Adenosin zu Thymidin und dasjenige von Cytidin zu Guanosin stets 1:1. ${ }^{[5]}$ Nur zwei Jahre später folgte die dreidimensionale Strukturaufklärung der DNADoppelhelix durch Watson und Crick, wobei die Charakterisierung sich ausschließlich auf die rechtsgängige B-Helix der DNA bezog. Diese Arbeit diente als Ausgangspunkt für die Entschlüsselung vieler Details der Informationsübertragung von der DNA zum Protein. ${ }^{[6]}$ Seitdem ist das Interesse an einem tieferen Verständnis der Eigenschaften von Nucleinsäuren keinesfalls zurückgegangen, sondern wurde durch zahlreiche überraschende Entdeckungen gesteigert. Bereits vier Jahre nach der Charakterisierung der B-DNA-Struktur wurde nachgewiesen, dass Polynucleotide spontan zu Tripelhelices aggregieren können. ${ }^{[7]}$ Ein weiterer faszinierender Aspekt der Nucleinsäurestruktur war die von Wang beobachtete linksgängige ZKonformation der DNA. ${ }^{[8]}$ In dieser Zeit ging die Motivation für die Erforschung der Strukturprinzipien von Nucleinsäuren mit der Erwartung einher, dadurch zu einer gründlichen Einsicht in die Vorgänge der Proteinbiosynthese zu gelangen. Die Forschung beschränkte sich allerdings auf die natürlich vorkommenden Nucleinsäuren. Denn die zur Synthese von Nucleinsäureanaloga notwendigen Methoden waren damals noch nicht etabliert. Erst durch die Entwicklung der festphasengestützten Synthese von Oligonucleotiden (ON) Ende der 1970er Jahre konnte der Aufwand für die chemische Synthese von Nucleinsäuren und deren chemische Analoga deutlich minimiert werden ${ }^{[9]}$ Auf diese Weise wurde der Weg für die intensive Untersuchung chemisch modifizierter Nucleinsäure-Analoga bereitet. 
Die Gründe für das zunehmende wissenschaftliche Interesse an NucleinsäureAnaloga waren vielseitig. Mit der Entdeckung, dass die Proteinbiosynthese durch Einschleusen bestimmter Nucleotidsequenzen in die Zelle reguliert werden kann, ${ }^{[10]}$ kam die Hoffnung auf ein rationales Prinzip für die Konzeption von Therapeutika auf. Das Design würde demnach auf den grundlegenden Watson-Crick-Regeln der Duplexbildung beruhen. Folglich sollten die in eine Zelle eingebrachten ON durch Hybridisierung mit komplementären mRNA-Molekülen deren Translation verhindern. Die Entwicklung von Oligonucleotid-basierten Therapeutika erschien auch aufgrund der hohen Selektivität der Erkennung komplementärer Stränge durch Nucleinsäuren sinnvoll, da dies eine gute Grundlage für geringe Nebenwirkungen sein könnte. Zudem sollte die Inhibierung auf der Ebene der Transkription oder Translation eine wesentlich effizientere Vorgehensweise sein als etwa die Inhibierung eines Enzyms, da ein mRNA-Molekül in $10^{2}-10^{4}$ Proteine translatiert wird. ${ }^{[11]}$ Ein weiterer Anreiz für die Entwicklung von Oligonucleotid-basierten Therapeutika ergab sich durch die Entdeckung der RNA-Interferenz (RNAi) durch Fire und Mello. ${ }^{[12]}$ Bei diesem Vorgang wird die Expression von mRNA durch eine RISC(RNA-inducedsilencing complex)-vermittelte Hydrolyse inhibiert. Der Enzymkomplex RISC wird von kleinen RNA-Molekülen (20-30 bp) aktiviert, die zur mRNA-Zielsequenz komplementär sind. Mittlerweile ist die Stummschaltung von Genen durch RNAi zu einem Routineverfahren für die Genfunktionsanalyse geworden. ${ }^{[13]}$ Die Notwendigkeit der chemischen Modifikation von Nucleinsäuren für die Wirkstoffentwicklung rührt daher, dass unmodifizierte Nucleinsäuren eine geringe Halbwertszeit (ca. 5 min) in biologischen Medien und eine unzureichende Membrangängigkeit aufweisen. ${ }^{[14]}$ Motiviert durch diese Sachverhalte sind viele Nucleinsäure-Analoga auf ihre potentielle Verwendbarkeit als Wirkstoffe gegen unterschiedliche Krankheiten untersucht worden, wenn auch nur mit mäßigem Erfolg. Mögliche Gründe hierfür sind die unterschätzte Komplexität der Sekundärstruktur von Nucleinsäuren und deren artifizieller Analoga sowie pharmakokinetische Aspekte.

Neben ihrer Einfachheit, Reversibilität und Spezifität ist die Hybridisierung von Nucleinsäuren äußerst empfindlich gegenüber Fehlpaarungen. Zudem zeichnen Nucleinsäure-Einzelstränge sich durch eine ausgeprägte konformationelle Flexibilität aus, während Doppelstränge bis zu einer Länge von ca. 150 bp (Persistenzlänge) ausgesprochen rigide sind. ${ }^{[15]}$ Diese Eigenschaften ermöglichen die Verwendung der Nucleinsäuren als Bausteine für programmierbare Nanokonstrukte. ${ }^{[16]}$ Dazu gehören 
statische Bauelemente wie 3D-Gitter, die für die Röntgenstrukturanalyse von schweroder nicht-kristallisierbaren Gastmolekülen genutzt werden können oder dynamische Einheiten wie Pinzetten ${ }^{[17]}$ oder Scheren. ${ }^{[15]}$ Chemische Modifikationen ermöglichen ein vielseitigeres Design solcher Nanoarchitekturen. Darüber hinaus werden modifizierte ON zur Detektion und Funktionsanalyse genetischen Materials eingesetzt. ${ }^{[18]}$ Hierbei können Oligonucleotidanaloga mit erhöhter Affinität zu Nucleinsäuren für die Entwicklung möglichst empfindlicher, sequenzspezifischer DNA- oder RNA-Detektoren nützlich sein. Auf dieser Grundlage beruhen Detektionssysteme, die z. B. in der Forensik oder der Umweltanalytik Gebrauch finden. Ein Maß für die Affinität von ON gegenüber komplementären Strängen stellt der $T_{m}$-Wert dar. Dieser ist definiert als die Temperatur, bei welcher die Hälfte der DNA- oder RNA-Doppelstränge denaturiert ist. ${ }^{[19]}$

Trotz der umfangreichen Kenntnisse über die strukturellen und dynamischen Eigenschaften der Nucleinsäuren sind einige grundlegende Fragen nach wie vor ungeklärt. Zahlreiche Arbeiten sind der Frage nach dem Ursprung dieser Biopolymere gewidmet. Insbesondere mit ihrer limitierten chemischen Stabilität lässt sich eine Entstehung unter geologischen Bedingungen kaum vereinbaren. ${ }^{[20]}$ Daher wurden die chemisch robusteren PNA (peptide nucleic acids, s. Kap. 2.4.4) als Vorgänger der genetischen Moleküle in Betracht gezogen und in diesem Zusammenhang untersucht. ${ }^{[21]}$ Weitere interessante Erörterungen zur Beschaffenheit der Nucleinsäurestruktur stammen von Westheimer und Benner. ${ }^{[22-23]}$ In der ersteren Veröffentlichung ${ }^{[22]}$ wird unter Vergleich mit denkbaren alternativen Internucleotidbrücken begründet, weshalb gerade Phosphate die verknüpfende Einheit zwischen den Nucleotiden darstellen. In dem Artikel von Benner ${ }^{[23]}$ wird eine Hypothese zur Erklärung der polyanionischen Struktur der Nucleinsäuren diskutiert. Auch in diesem Zusammenhang können sich die Erkenntnisse aus Untersuchungen modifizierter $\mathrm{ON}$ als nützlich erweisen. So schrieb Benner: „The paradigm of physical organic chemistry, which involves systematic synthesis of analogs of DNA and

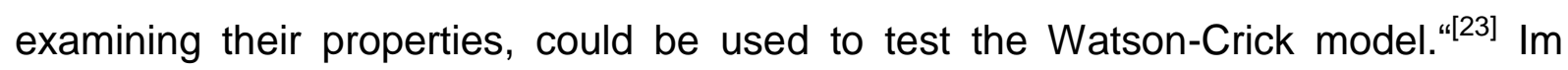
Folgenden sollen einige Aspekte der chemischen Modifikationen der Nucleinsäurestruktur angeführt und deren Relevanz für das Verständnis der strukturellen Eigenschaften dieser Biopolymere diskutiert werden. Im Sinne einer Einschränkung sollen nur solche Modifikationen diskutiert werden, die die Bildung helikaler Strukturen ermöglichen und deren Rückgrat isoster zur DNA/RNA ist. 


\section{Kenntnisstand}

\subsection{Arten von Modifikationen der Nucleinsäuren}

Durch chemische Modifikationen können gezielte Veränderungen der Eigenschaften von ON erfolgen. Entsprechend der jeweiligen Zielsetzung (z. B. Optimierung der oben beschriebenen Parameter von $\mathrm{ON}$ ) sind zahlreiche chemisch modifizierte Analoga dargestellt worden, die in drei Gruppen eingeteilt werden können (Abb. 2.1). Eine Vielzahl von Variationen sind an der (Desoxy-)Riboseeinheit durchgeführt worden (a). Diese Modifikationen führen häufig zu einer Veränderung der Vorzugskon-formation der Nucleinsäuren. Zudem kann die Lipophilie durch das Einführen von entsprechenden Resten an der 2'-Position (Substituent R, Abb. 2.1) deutlich erhöht werden. Zu der

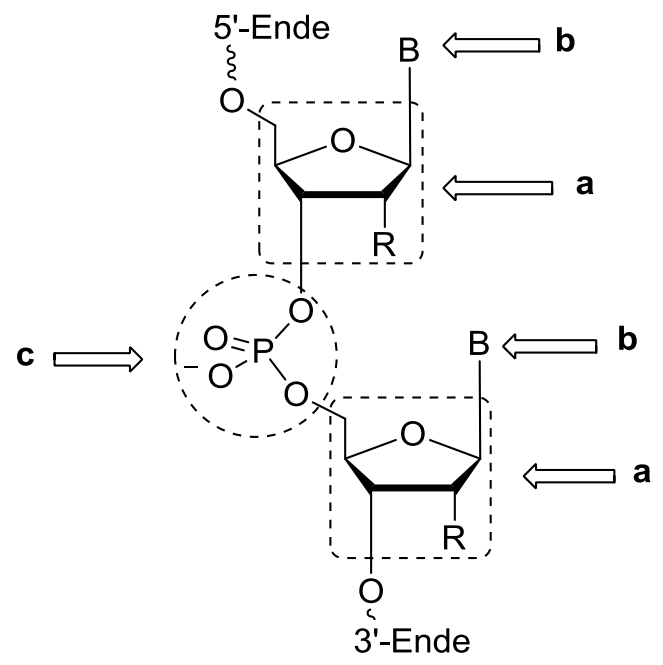

$B=A, C, G, T$ $\mathrm{R}=\mathrm{H}, \mathrm{OH}$

$\Longrightarrow$ chemisch modifizierte Bereiche

a: Modifikation der (Desoxy-)Riboseeinheit

b: Modifikation der Stickstoffbase

c: Modifikation der Verbrückung

Abb. 2.1: Einteilung der Arten von Modifikationen. zweiten Gruppe modifizierter ON sind solche mit derivatisierten Stickstoffbasen zu zählen (b). Sie ermöglichen u. a. eine Manipulation der $\pi$-Stacking-Interaktionen der Nucleobasen. Dadurch kann insbesondere die Affinität von ON zu komplementären Strängen oder auch Duplices erhöht werden. Am gründlichsten untersucht worden sind Modifikationen des polyanionischen Rückgrats der Nucleinsäuren (c). Solche Veränderungen können die Beständigkeit gegenüber hydrolytischem Abbau (Spaltung des Phosphatdiesters) durch intrazellulär vorkommende Endonucleasen oder Exonucleasen erhöhen, wenn die Erkennung der Nucleinsäurestruktur durch das jeweilige Enzym gestört wird oder wenn die neue Einheit gegenüber der hydrolytischen Spaltung weniger empfindlich ist als die Phosphatdiestereinheit. Zudem kann eine Reduzierung des polyanionischen Charakters dieser Makromoleküle deren Membrangängigkeit bedeutend erhöhen. Schließlich sind Modifikationen untersucht worden, in denen zugleich die Desoxyriboseeinheit und die Phosphateinheit ersetzt worden sind. 


\subsection{Modifikationen der Desoxyriboseeinheit}

Ursächlich für die topologische Vielfalt der Sekundärstrukturen von Nucleinsäuren ist neben ungewöhnlichen Basenpaarungsmustern und der freien Rotierbarkeit der Phosphatdiesterbindungen die konformationelle Flexibilität der Zuckereinheit. So kann der Abstand der Phosphatdiestereinheiten um bis zu $1 \AA$ in Abhängigkeit von den unterschiedlichen Ringkonformeren der (Desoxy-)Riboseeinheit variieren. ${ }^{[24]}$ Sie kann daher als dehnbares Element des Nucleinsäure-Rückgrats bezeichnet werden. Die Derivatisierungsmöglichkeiten der (Desoxy-)Riboseeinheit sind bedeutend vielseitiger als im Fall der Verbrückungen oder der Basenmodifikationen. Zu den drei wichtigsten Strategien sind Substitution von 4'-O, Modifikationen an der 2'-Position und die Verknüpfung von C-Atomen des Furanoserings durch zusätzliche Ringsysteme zu zählen. Die Substitution von 4'-O durch ein Schwefel- oder Selenatom führte hinsichtlich struktureller Parameter zu überraschenden Ergebnissen. In beiden Fällen nahmen die auf diese Weise modifizierten Nucleotideinheiten 1 und 2 (Abb. 2.2) bevorzugt die für die B-Helix-Struktur typische C-2'-endo-Konformation ein. ${ }^{[25-26]}$ Es erscheint naheliegend, dass eine solche Vorzugskonformation zu einer Destabilisierung der A-Helix bzw. zur Stabilisierung einer B-Helix führen sollte. Ein möglicher Grund dafür kann der geringere zu erwartende Betrag an Reorganisierungsenergie im Fall der B-Helix sein. Bei Untersuchungen der thermischen Stabilität von DNA/RNA-Hybriden mit punktuell eingebauten 4'-S- oder 4'-Se-Nucleosiden wurden jedoch eine erhöhte Affinität gegenüber RNA-Strängen und eine verminderte Affinität gegenüber DNA-Strängen beobachtet. ${ }^{[26-27]}$ Ein weiterer unerwarteter Befund war die durch die Einführung von Selenatomen anstelle von 4'-O hervorgerufene Störung der Basenstapelung. ${ }^{\text {[26] }}$

Eine ausgeprägte Steigerung der Affinität von ON gegenüber komplementären RNASequenzen wurde durch die Einführung von Fluoratomen an der 2'-Position von Nucleosiden erreicht (Abb. 2.2). Substituenten mit hoher Elektronegativität in 2'-Position bewirken eine Verschiebung des Gleichgewichts in Richtung der mit der A-Helix kompatiblen 3'-endo-Konformation der Nucleotiduntereinheit. ${ }^{[28]}$ Hierbei handelt es sich anscheinend um einen stereoelektronischen Effekt, denn die antiperiplanare Anordnung von 2'-F und 3'-H sollte energetisch begünstigt sein. Eine erhebliche Steigerung der Duplex-Stabilität liegt vor allem im Fall von uniformen 2'-FON vor. ${ }^{[29]}$ Es wurden noch zahlreiche Modifikationen an der 2'-Position untersucht, 
darunter auch 2'-O-Alkyl-Derivate. Dieser Ansatz wurde mit dem Ziel verfolgt, die Membrangängigkeit der $\mathrm{ON}$ zu erhöhen.

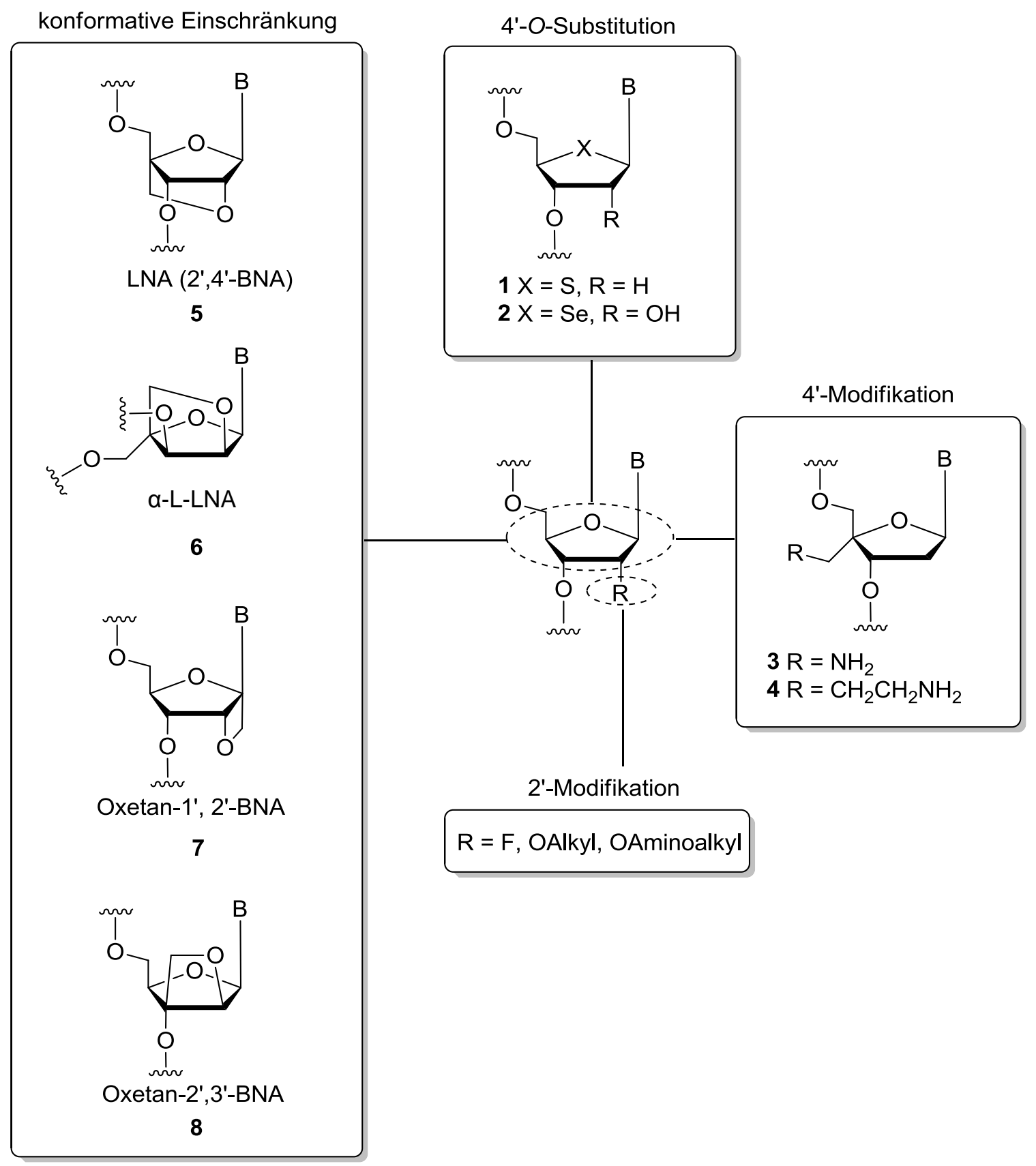

Abb. 2.2: Motive zur Variation der (Desoxy-)Riboseeinheit.

Die Untersuchung von Alkylresten unterschiedlicher Größe in 2'-Position ergab abnehmende Duplexstabilitäten bei zunehmendem sterischen Anspruch der Alkylreste. ${ }^{[28]}$ Als Begründungen wurden sterische Interaktionen der Alkylgruppe mit anderen Teilen der Duplex sowie eine Störung der Hydrathülle der Helix angeführt. ${ }^{[28]}$ Positiv geladene Substituenten in 2'-Position wie O-Aminoalkyl-Einheiten fördern die Bildung von Tripelhelices mit Nucleinsäure-Doppelsträngen, wobei es zu einer 
spezifischen Wechselwirkung des kationischen Rests mit der benachbarten Phosphatdiestereinheit (pro-R-O-Atom) eines der beiden Gegenstränge kommt. Dadurch resultiert sowohl eine thermodynamische Stabilisierung der Triplices als auch eine Beschleunigung der Assoziation um den Faktor 1000. ${ }^{[30]}$ Die Einführung von Aminoalkyl-Einheiten in 4'-Position (Abb. 2.2, Strukturen 3 und 4) wurde von Matsuda realisiert. Auf diese Weise modifizierte DNA-Einzelstränge bildeten mit komplementären RNA-Strängen bei geringer lonenstärke $(0.01 \mathrm{M} \mathrm{NaCl})$ Duplices von größerer Stabilität $\left(\Delta \mathrm{T}_{\mathrm{m}}=0\right.$ bis $+4.5^{\circ} \mathrm{C} / \mathrm{Mod}$.) als unmodifizierte Hybride. Dagegen war bei höherer lonenstärke generell eine Destabilisierung der Duplices zu beobachten. ${ }^{[31]}$

Hinsichtlich der Duplexstabilität zeichnete sich das Konzept der konformativen Einschränkung als besonders erfolgreich aus. Die auf dieser Grundlage von Wenge $^{[32-33]}$ und Imanish $^{[34]}$ voneinander unabhängig entwickelten $\mathrm{ON}$, die aus bicyclischen Nucleotiden bestehen oder diese enthalten, werden allgemein als "LNA“ (locked nucleic acids) (Abb. 2.2, Strukturen 5 und 6 ) oder „BNA“ (bicyclic nucleic acids) bezeichnet (Abb. 2.2, Strukturen 7 und 8). ${ }^{[35-36]}$ Allerdings wurde bereits vor der synthetischen Realisierung dieser Nucleinsäure-Analoga angenommen, dass die Reduktion der Entropieabnahme bei der Hybridisierung zu einer erheblichen DuplexStabilisierung führen könnte. ${ }^{[37]}$ Wird die Riboseeinheit eines Nucleotids über eine Verknüpfung zwischen 2'-C und 4'-C auf der $\beta$-Seite kovalent verbunden, erfolgt eine Festlegung dieser Einheit auf die 3'-endo-Konformation (N-Konformation). Der entgegengesetzte Effekt, nämlich die Festlegung auf die 2'-endo-Konformation, kann durch Anbringen einer analogen Verknüpfung auf der a-Seite der Riboseeinheit bewirkt werden. In diesem Fall werden die ON als „ $\alpha$-L-LNA“ bezeichnet. Zusätzlich ist bei a-L-LNA die Konfiguration in 3'-Position umgekehrt zu derjenigen von LNA. Wie bereits erwähnt, erscheint es naheliegend, dass die Vorzugskonformation der Nucleotide sich im Sinne einer Stabilisierung der Duplex auswirken sollte, sofern die bevorzugte Konformation der (Desoxy-)Riboseeinheit (3'-endo (N) oder 2'-endo (S)) zu der Helixart (A oder B) „passt“. Erstaunlicherweise fanden Rajwanshi et al. bei dem Vergleich der beiden Isomere $\alpha$-L-LNA und LNA hinsichtlich der Hybridisierung mit RNA-Strängen heraus, dass die signifikante Erhöhung der Duplexstabilität in beiden Fällen recht ähnlich ist $\left(\Delta T_{m}=+5.3\right.$ für a-L-LNA bzw. $\Delta T_{m}=+7.3^{\circ} \mathrm{C} / \mathrm{Mod}$. für LNA mit komplementärer RNA. ${ }^{[36]}$ Auch im Fall von Duplices aus LNA und DNA wurde eine deutliche Stabilisierung von $\Delta T_{m} / \bmod .=+3$ bis $+5^{\circ} \mathrm{C}$ beobachtet. ${ }^{[33]}$ 
Diese Befunde wären auf Basis der Geometrie nicht erwartet worden, da die Riboseeinheit der $\alpha$-L-LNA in einer für die Hybridisierung mit RNA-Strängen „ungeeigneten“ Konformation (S-Konformation) festgelegt ist. Ebenso sollte auch die Präorganisation von LNA-Bausteinen (N-Konformation) nicht mit der B-HelixGeometrie harmonieren. Die Gegenwart der Verknüpfungen zwischen 2'-C und 4'-C zog jedoch in beiden Fällen keine Störung der Helixstruktur nach sich. ${ }^{[38]}$ Vielmehr wurde gezeigt, dass die Präorganisation der Riboseringe bei der Helix die entsprechende Geometrie induziert. Während $\alpha$-L-LNA die B-Helix-Form hervorruft, ${ }^{[38]}$ weisen LNA-Bausteine die Neigung auf, die A-Helix-Struktur einzuführen. ${ }^{[39]}$ Darüber hinaus zeichnet die LNA sich gegenüber natürlichen Nucleinsäuren durch eine erhöhte Mismatch-Erkennung aus. ${ }^{[32]}$ Allerdings bilden LNA-modifizierte ON sehr stabile Homoduplices oder Haarnadel-Strukturen, insbesondere wenn LNA-LNA-Paarungen innerhalb der Duplex vorliegen. ${ }^{[40]}$ LNA sind bereits im Rahmen von Untersuchungen zu einem potentiellen Krebstherapeutikum in vivo auf ihre Wirksamkeit geprüft worden. ${ }^{[41]}$ Allerdings wurde für LNA-ON auch Lebertoxizität nachgewiesen. ${ }^{[42]}$ Aktuell befinden sich fünf verschiedene LNA-basierte Therapeutika in der klinischen Testphase. ${ }^{[40]}$ Weitere potentielle Anwendungen der LNA sind die Entwicklung von hochaffinen miRNADetektoren $^{[43]}$ oder spezifischen Proben ${ }^{[44]}$ für die real-time QPCR (quantitative polymerase chain reaction). Aufbauend auf dem Konzept der konformationellen Restriktion wurden weitere Versuche unternommen, um allgemeine Verbesserungen der biophysikalischen und pharmakologischen Eigenschaften von ON zu erzielen. Es wurden Oxetan-Ringe ${ }^{[45]}$ zur Verknüpfung von 1'-C und 2'-C oder 2'-C und 3'-C an der (Desoxy-)Riboseeinheit eingeführt oder die entsprechenden Ringe erweitert, wie im Fall der „ENA“ (ethylene nucleic acids). ${ }^{[46]}$ Die ENA sind den LNA recht ähnlich, wobei ihr entscheidender Vorteil in der wesentlich höheren Nuclease-Stabilität liegt. ${ }^{[47]}$ Das Potential in diesem Bereich scheint aber noch nicht erschöpft zu sein. Kumar et al. berichteten über eine Strategie zum Einbau von Interkalatoren in Oligonucleotide über eine neuartige Variante von $\alpha$-L-LNA. Durch diese Derivatisierung wurde infolge der Verstärkung des $\pi$-Stacking der Stickstoffbasen die thermische Stabilität der mit komplementären DNA-Strängen gebildeten Tripelhelices drastisch erhöht (bis zu $+19.5{ }^{\circ} \mathrm{C} / \mathrm{Mod}$.). ${ }^{[48]}$ Es sind auch Rückgratmodifikationen bekannt, die eine vollständige Ersetzung des (Desoxy-)Ribose-phosphat-Rückgrats implizieren. Einige Beispiele für solche Analoga sind in Kap. 2.4.4 angeführt. 


\subsection{Nucleobasenmodifikationen}

Chemische Modifikationen von Basen wurden zunächst mit der Zielsetzung konzipiert, Triplex-bildende Oligonucleotide (TFO) herzustellen. TFO könnten als Reagenzien für die Einführung ortsspezifischer Mutationen ${ }^{[49]}$ oder als antivirale Wirkstoffe ${ }^{[50]}$ eingesetzt werden. Die Interaktionen der Nucleobasen über $\pi$ Stapelkräfte und Wasserstoffbrückenbindungen sind von zentraler Bedeutung für die Duplexbildung und es erscheint naheliegend, dass eine Vergrößerung des т-Elektronensystems zu einer Erhöhung der $\pi$-Stapelkräfte und folglich zu einer größeren Duplexstabilität führen würde. Daher wurden einige vergrößerte Ringsysteme synthetisiert oder diverse Untereinheiten an verschiedenen Positionen der Nucleobasen eingeführt. Die Auswirkung von Substituenten an Pyrimidinbasen auf die Duplexstabilität ist sowohl von der Position als auch von der Art der Substituenten abhängig. Während Halogene in Position 5 keinen Einfluss zeigen, verursacht das Vorhandensein einer Propargylgruppe (Abb. 2.3, Struktur 9) in der gleichen Position eine Stabilisierung von DNA/RNA-Duplices um +0.9 bis $+2.6^{\circ} \mathrm{C} /$ Mod. $^{[28]}$ Ein vergleichbar stabilisierender Effekt konnte bei DNA/RNADuplices mit 5-Methylthiazol-substituiertem dU 10 (Abb. 2.3) beobachtet werden. ${ }^{[51]}$ Substitution des H-Atoms in 6-Position durch eine Methylgruppe oder das Einführen einer Propylen-Verbrückung zwischen der 5- und der 6-Position (Abb. 2.3, Strukturen 11 und 12) führten zu deutlich herabgesetzten $T_{m}$-Werten (-2.7 bis $-3.9^{\circ} \mathrm{C} / \mathrm{Mod}$.) von DNA/RNA-Duplices. ${ }^{[28]}$ Eine mögliche Erklärung hierfür ist die Einschränkung der konformativen Flexibilität der Nucleobasen, die aufgrund des sterischen Anspruchs der Reste in 6-Position nicht mehr die anti-Konformation einnehmen konnten. ${ }^{[52]}$ Auch kationische Substituenten sind an Pyrimidin-Nucleobasen - bevorzugt an den Positionen 4 oder 5 - eingeführt worden. Dazu gehören $\omega$-Aminohexyl-[53] 13, Spermin- ${ }^{[54]} 14$ und 1-Propargylamino-Gruppen ${ }^{[55]} 15$ oder über einen Propargyllinker verknüpfte Guanidineinheiten ${ }^{[56]} 16$ (Abb. 2.3). Solche Subsitutionen erhöhen generell die thermische Stabilität von DNA/DNA- und DNA/RNA-Duplices. Auch wird bis auf wenige Ausnahmen ${ }^{[57]}$ die Tendenz zur Triplexbildung gesteigert. Die Vermutung, dass die Ursache dafür in der positiven Ladung liegt, wurde durch den Nachweis verringerter Stabilität der entsprechend modifizierten Duplices bei höheren pH-Werten bestätigt. ${ }^{[54-55]}$ Im Fall von komplett zwitterionischen Oligonucleotiden wurde die interessante Beobachtung gemacht, dass die Duplexstabilität gegenüber der lonenstärke der Lösung nahezu unempfindlich ist. ${ }^{[53]}$ 


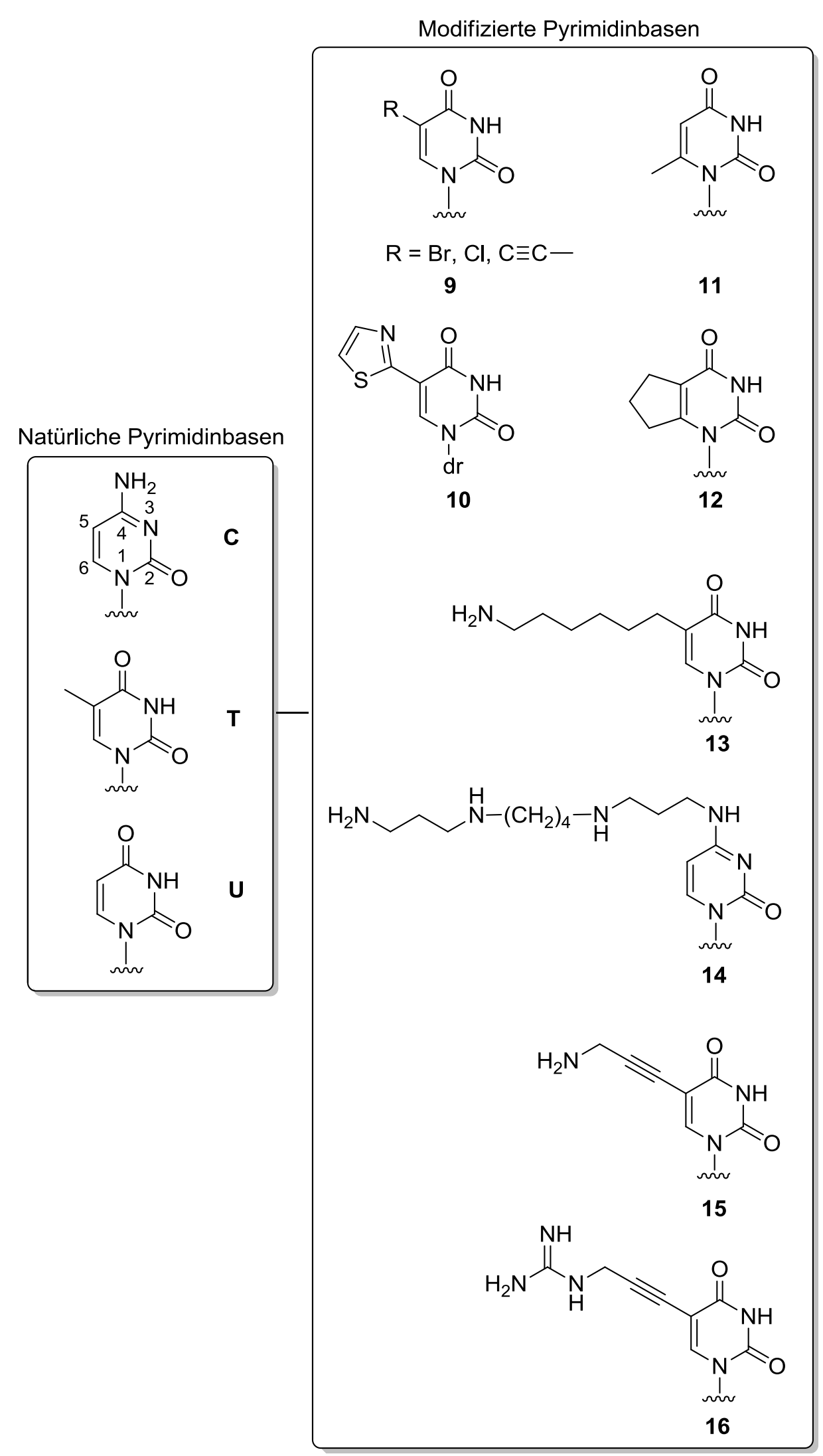

Abb. 2.3: Einige Motive zur Variation der Pyrimidinbasen. 
Bei Erweiterungen der Nucleobasen durch Ringsysteme können generell zwei Auswirkungen erwartet werden. Zum einen kann die Helixstruktur durch größere Basen aufgrund ihres sterischen Anspruchs verzerrt werden, woraus eine Destabilisierung resultieren würde. Zum anderen kann die Stabilität durch zusätzliche Stapelkräfte erhöht werden. Um das Verhältnis dieser gegenläufigen Effekte zu analysieren, wurden um einen Benzolring erweiterte Derivate $17(d x A)$ und $18(d x T)$ (Abb. 2.4) von Thymidin und Desoxyadenosin synthetisiert und in verschiedene ON eingeführt. ${ }^{[58]}$ Bei vereinzelter Modifikation natürlicher Duplices durch 17 (dxA) oder $18(\mathrm{dxT})$ resultierte eine Destabilisierung der Duplex, während 10 bp-Duplices, die nur aus $17(\mathrm{dxA})$-T- und 18 (dxT)-dA-Basenpaaren aufgebaut waren, deutlich erhöhte thermische Stabilitäten $\left(\Delta \mathrm{T}_{\mathrm{m}}=+3.4\right.$ bis $+5^{\circ} \mathrm{C} / \mathrm{Mod}$.) aufwiesen, obwohl der Abstand gegenüberliegender Desoxyriboseeinheiten mit $12.9 \AA$ um etwa $2 \AA$ größer ist als bei der B-Helix. ${ }^{[58]}$ Auf diese Weise konnte gezeigt werden, dass genetische Systeme nicht notwendigerweise auf die Größenparameter bekannter Helices beschränkt sind. Nach ähnlichen Prinzipien wurden weitere artifizielle genetische Systeme konzipiert, um Hypothesen zur graduellen Entstehung des natürlich vorkommenden, genetischen Vier-Basen-Systems experimentell zu prüfen oder eine Grundlage für neuartige Informationsverarbeitungssysteme zu schaffen. Ein alternativer genetischer Code, der nur Purinbasen enthält, wurde von Heuberger und Switzer untersucht. ${ }^{[59]}$ Dabei wurden 7-Deazapurine 19 und 20, Isoguanin 21 und Diaminopurin 22 verwendet (Abb. 2.5), um Basenpaarungen nach dem Hoogsteen-Muster auszuschließen und damit einhergehende komplexe Assoziationen wie Triplices oder Quadruplices zu verringern. Entgegen den Erwartungen traten jedoch in einigen Fällen Selbstassoziation und Ausbildung von Strukturen höherer Ordnung auf. ${ }^{[59]}$ Auch erscheint es unklar, wie ein solches System durch chemische Prozesse graduell den natürlichen Vier-Basen-Code hervorgebracht haben könnte.

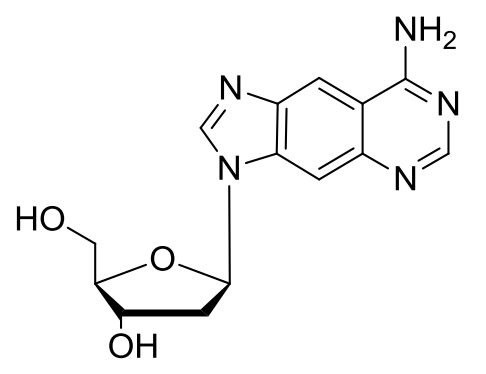

$17(d x A)$

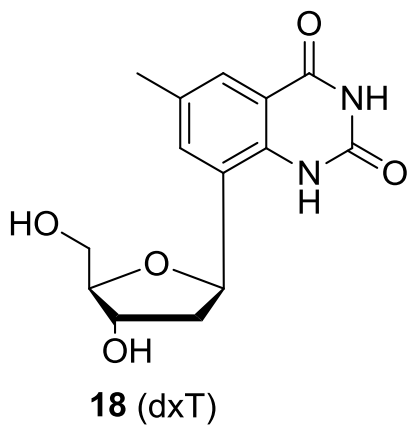

Abb. 2.4: Strukturen der modifizierten Nucleoside $\mathrm{dxA}$ und $\mathrm{dxT}$ mit vergrößerten Basen. 

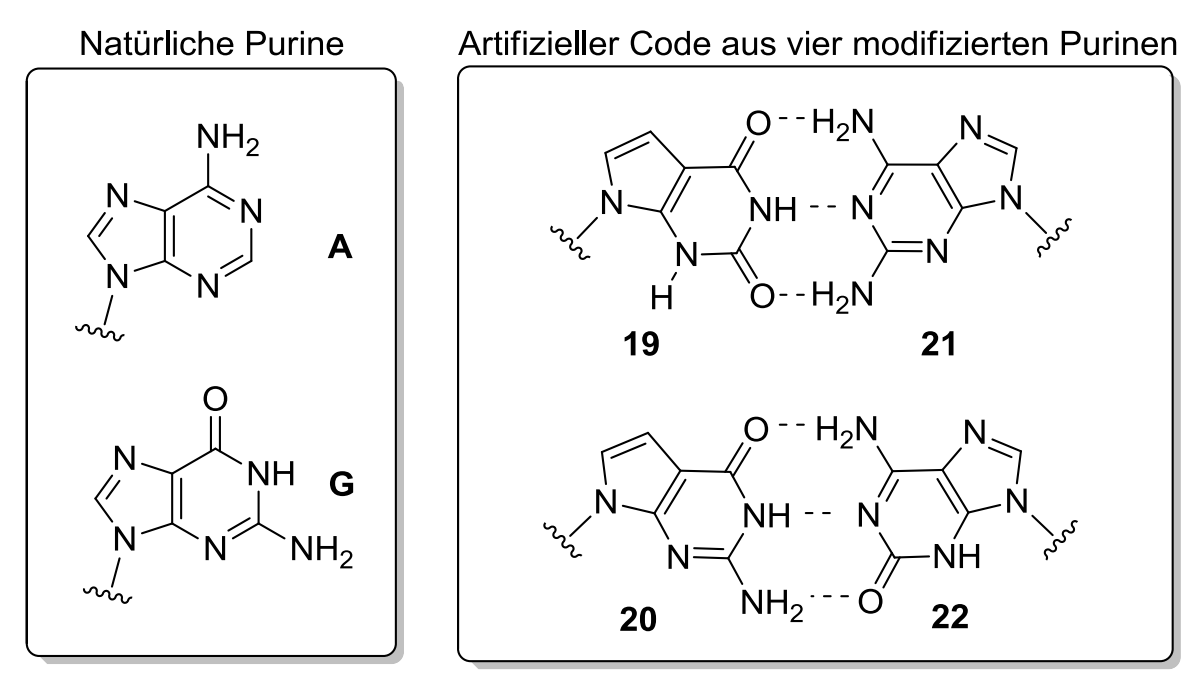

Abb. 2.5: Strukturen der natürlichen Purine und Paarung der vier nicht-natürlichen Purinbasen 19-22.

Ein artifizielles genetisches System mit vier Pyrimidin-Basen 23-26 (Abb. 2.6), die über Alkinyl-Linker durch eine C-glykosidische Bindung an die Desoxyriboseeinheit gebunden waren, wurde von Doi et al. konzipiert. ${ }^{[60]}$ Experimentelle Daten ließen auf ähnliche Eigenschaften der Duplices (rechtsgängige Helices, vergleichbare thermische Stabilität) wie im Fall der kanonischen Basen schließen. ${ }^{[60]}$ Im Unterschied zum natürlichen System beruht die molekulare Erkennung in diesem artifiziellen System jedoch nicht auf der Größenkompatibilität der Nucleobasen, sondern ausschließlich auf Wasserstoff-Brückenbindungen. Dennoch wurde im Fall von Mismatches eine vergleichbar große Destabilisierung der Duplices nachgewiesen. ${ }^{[60]}$ Aufgrund der C-glykosidischen Bindungen sollten diese Nucleinsäure-Analoga gegenüber dem Abbau durch Mikroorganismen unempfindlich sein und könnten daher als Material für die Informationsspeicherung genutzt werden.
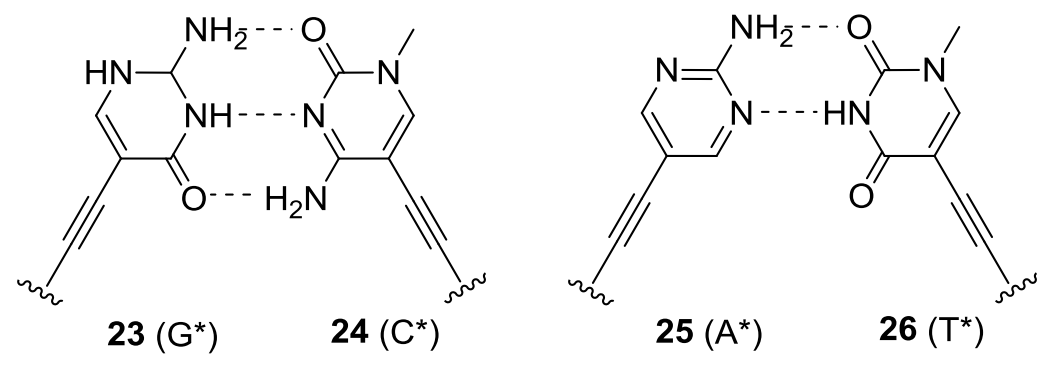

Abb. 2.6: Paarung der vier nicht-natürlichen Pyrimidinbasen 23-26.

Es ist noch eine große Vielzahl an Nucleobasenmodifikationen bekannt, auf die hier jedoch aufgrund der vergleichsweise geringen Relevanz für den Kontext der Arbeit nicht eingegangen werden soll. 


\subsection{Rückgratmodifikationen}

Ungeachtet ihrer geringen Reaktivität - sei es als Abgangsgruppe in nucleophilen Substitutionen und Eliminierungen oder auch als Nucleophil - sind Phosphatgruppen in sämtlichen biochemischen Prozessen eine vielseitig verwendete molekulare Einheit. Zahlreiche chemische Aktivierungsprozesse im Lipid-, Aminosäure- und Kohlehydratstoffwechsel verlaufen unter Beteiligung von Phosphatgruppen. Auch auf der Ebene der genetischen Moleküle DNA und RNA sind die Phosphate essentiell. Beispiele dafür sind die Wechselwirkung der DNA mit den Histonoktameren oder die Schlüsselfunktion der Phosphatdiester bei der Replikation, Transkription und der Spleißreaktion von mRNA-Vorläufern. Daher schrieb Westheimer in einer vielzitierten Veröffentlichung: ${ }^{[22] ~ " G r a n t e d ~ t h a t ~ P h o s p h a t e s ~ a r e ~ u b i q u i t o u s ~ i n ~ b i o c h e m i s t r y, ~ w h a t ~}$ do they do? The answer is that they can do everything." Ein wichtiges Charakteristikum von natürlichen Phosphatdiesterbrücken ist deren hohe Acidität. Folglich sollten unmodifizierte $\mathrm{ON}$ unter physiologischen Bedingungen von ausgeprägt anionischer Natur sein. Massenspektrometrischen Untersuchungen zufolge sind im zeitlichen Mittel nur 20-30\% der Phosphatdiesterbrücken einer aus 20 Nucleotiden bestehenden Sequenz deprotoniert, woraus eine tatsächliche Ladung von -4 bis -6 resultieren würde. ${ }^{[61]}$ Es ist jedoch fraglich, ob dieser Befund die tatsächliche Situation in der Zelle widerspiegelt. Die negative Ladung von Phosphatdiesterbrücken führt bei einer Wechselwirkung zweier ON zur Repulsion und folglich zur Destabilisierung von DNA- bzw. RNA-Doppelsträngen. In der Zelle wird die negative Ladung der Phosphatdiester durch das Vorhandensein von Kationen wie $\mathrm{Na}^{+}, \mathrm{Ka}^{+}$oder $\mathrm{Mg}^{2+}$ teilweise abgeschirmt. Des Weiteren bewirkt die negative Ladung der Phosphatdiester auch eine Repulsion von Nucleophilen. Dies ist besonders für die Inertheit genetischen Materials gegenüber der unkatalysierten und folglich unkontrollierten Hydrolysereaktion notwendig. Ein Vergleich der Hydrolyseraten des einfach negativ geladenen Dimethylphosphations und derjenigen des neutralen Trimethylphosphats erwies, dass die negativ geladene Spezies unter alkalischen Bedingungen um einen Faktor von $10^{5}$ langsamer hydrolysiert wird. ${ }^{[62]}$

In zahlreichen Arbeiten umfasste die Konzeption von artifiziellen Internucleosidbrücken neben der Erhöhung der Nucleasestabilität auch oft die Eliminierung der negativen Ladung oder deren Ersetzung durch positive Ladung, um eine Erhöhung des $T_{m}$-Werts von Hybriden der ON mit DNA- oder RNA-Strängen zu 
ermöglichen oder ihre Membrangängigkeit zu verbessern. Eine wichtige Randbedingung stellt dabei die einzuhaltende strukturelle Ähnlichkeit der artifiziellen Verbrückungen mit den natürlichen dar. Anderenfalls kann die strukturelle Verzerrung der gebildeten Doppelhelix zu einer empfindlichen Störung der Geometrie der Basenpaarung führen, wodurch die thermische Stabilität der Duplex herabgesetzt wird. Als typisches Beispiel hierfür sei die 2'-5'-Squaryldiamid-Modifikation 27 (Abb. 2.7) angeführt. ${ }^{[63]}$ Diese Analoga bilden deutlich weniger stabile $\left(\Delta \mathrm{T}_{\mathrm{m}}=-15.3^{\circ} \mathrm{C} / \mathrm{Mod}\right.$. $)$ und strukturell verzerrte Duplices mit komplementären DNA-Strängen. ${ }^{[63]}$ Zwar argumentieren die Autoren, dass die SquaryldiamidModifikation im Hinblick auf elektronische Eigenschaften der Phosphatdiester-Einheit ähnlich sei. Doch erscheint es naheliegend, dass die planare Anordnung der Atome der Squarylamideinheit und die eingeschränkte Rotationsfreiheit der N-C-Bindungen mit partiellem Doppelbindungscharakter zu ungünstigen Torsionswinkeln führen, die eine Verzerrung der Helixgeometrie verursachen.

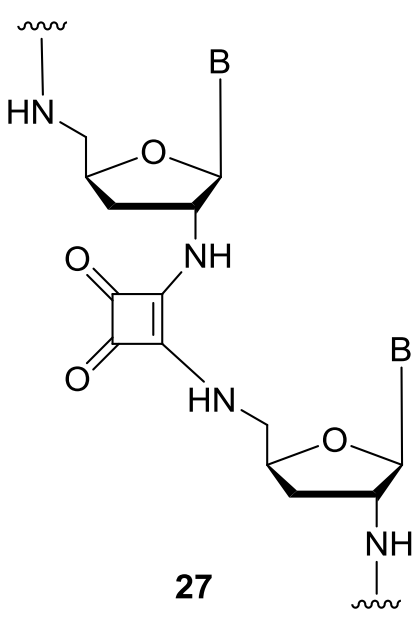

Abb. 2.7: 2'-5'-Squaryldiamid-Verbrückung 27.

\subsubsection{Anionische Rückgratmodifikationen}

Ausgehend von der Annahme, dass für eine Verwendung von OligonucleotidAnaloga als Therapeutika deren Struktur derjenigen natürlicher Nucleinsäuren möglichst ähnlich sein müsse, wurden Nucleinsäureanaloga mit geringfügig modifizierten Verbrückungen hergestellt. In vielen Fällen wurde nur ein Sauerstoffatom durch eine andere chemische Einheit substituiert, ohne dabei die negative Ladung zu entfernen oder durch eine positive zu ersetzen. Zu dieser Klasse gehören die bereits Ende der 1980er Jahre von Eckstein etablierten PhosphorthioatON 28 (PS-ON, Abb. 2.8). ${ }^{[64]}$ Sie sind aufgrund ihrer erhöhten Stabilität gegenüber intrazellulär vorkommenden Nucleasen und der Stimulierung des RNaseHvermittelten Abbaus von RNA-Zielsequenzen nach wie vor ein Gegenstand der medizinischen Forschung. ${ }^{[65]}$ Der von der Firma ISIS-Pharmaceuticals entwickelte Wirkstoff Fomivirsen (Vitravene®) gehört zu den Phosphorthioaten und wurde durch die FDA zur Behandlung von Cytomegalovirus-Retinitis zugelassen. Aufgrund des stereogenen Charakters der PS-ON-Einheit sind zwei stereoisomere Verbrückungen 
möglich. Uniforme $S_{p}$-Phosphorthioate bilden mit komplementären RNA-Strängen bedeutend weniger stabile Duplices als uniforme $R_{\mathrm{p}}$-Phosphortioate. ${ }^{[66]}$ Weitere ON mit negativ geladenen Verbrückungen sind die von Caruthers untersuchten Phosphonoformiate ${ }^{[67]} 29$, Phosphonoacetate ${ }^{[68]} 30$ und Thiophosphonoacetate ${ }^{[68]} 31$ (Abb. 2.8).

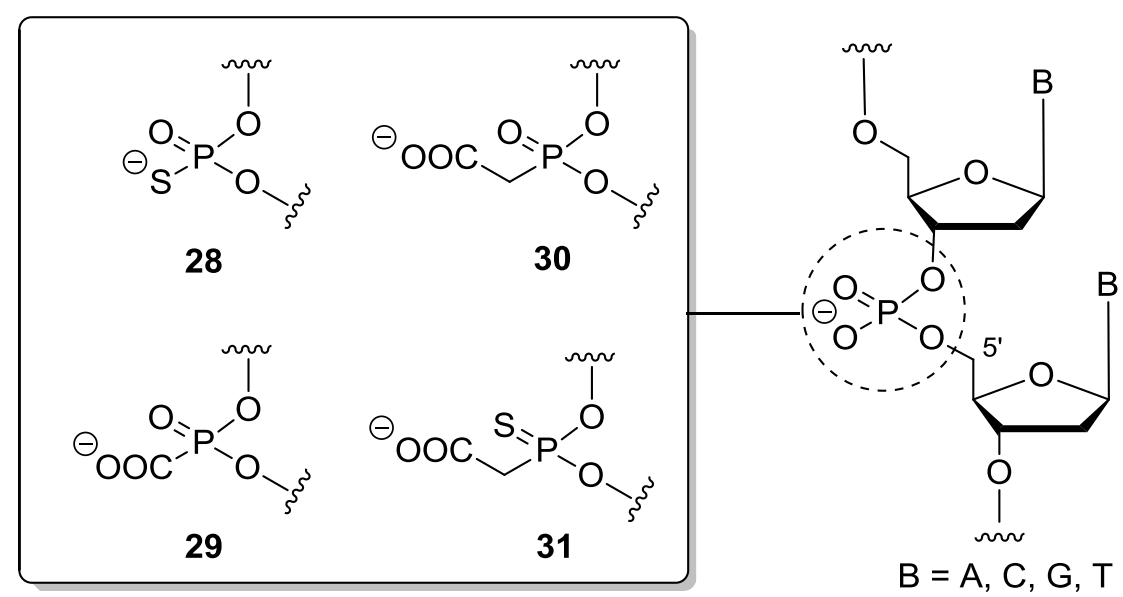

Abb. 2.8: Anionische Rückgratmodifikationen 28-31.

Gemeinsame Merkmale dieser Internucleotidbrücken sind deren stereogener Charakter und eine am Phosphoratom befindliche Carboxylatgruppe (Formyl- oder Acetylgruppe). Während die Phosphonoformiate 29 (Abb. 2.8) leicht stabilisierend auf DNA/RNA-Duplices wirken, wurde im Fall der anderen Modifikationen eine leichte Verringerung der Duplex-Stabiltät $\left(-0.3\right.$ bis $-1.8^{\circ} \mathrm{C} / \mathrm{Mod}$.) verzeichnet. Insgesamt erweisen sich Brückenmodifikationen, in denen die negative Ladung und das Phosphoratom beibehalten werden, hinsichtlich ihrer Eigenschaften den Phosphatdiestern als relativ ähnlich.

\subsubsection{Elektroneutrale Rückgratmodifikationen}

Ein anderer Ansatz für die Konzeption modifizierter Internucleotidbrücken besteht darin, die negative Ladung zu eliminieren, ohne dabei die Phosphatdiestereinheit komplett zu ersetzen. Der ausgeprägt anionische Charakter der unmodifizierten Nucleinsäuren verhindert deren Diffusion durch die Zellmembran. Auch die zelluläre Aufnahme von ON, die über Rezeptor-vermittelte, adsorptive Endocytose verläuft, ist schwach ausgeprägt und strukturspezifisch. ${ }^{[69]}$ Daher wurden zahlreiche 
elektroneutrale Internucleotidbrücken konzipiert, um die Bioverfügbarkeit der Oligonucleotide $\mathrm{zu}$ verbessern. ${ }^{[70]}$ Abgesehen von eher anwendungsbezogenen Arbeiten sind auch Untersuchungen an elektroneutralen Internucleotidbrücken durchgeführt worden, um die Relevanz der negativen Ladung für die physikochemischen Eigenschaften der Nucleinsäuren einschätzen zu können. Die bereits Ende der 1970er Jahre synthetisierten uniformen Methylphosphonate 32 (Abb. 2.9) - damals noch zu potentiellen bioanalytischen Zwecken - wiesen im Vergleich zu natürlichen Nucleinsäuren eine wesentlich geringere Löslichkeit in Wasser auf. ${ }^{[71]}$ Zudem konnte anhand der Röntgenstrukturanalyse von Methylphosphonat-modifizierten Dinucleotideinheiten gezeigt werden, dass die Hydrathülle der Methylphosphonateinheiten stark verzerrt ist. ${ }^{[72-73]}$ Ähnliche Phänomene wurden auch bei den gründlich untersuchten Dimethylensulfonen $\mathbf{3 3}$ (Abb. 2.9) beobachtet. Des Weiteren wurde gezeigt, dass die Löslichkeit uniformer Dimethylensulfon-modifizierter ON von ihrer Primärstruktur abhängig ist. Dies steht im Gegensatz zu Nucleinsäuren, deren physikalische Eigenschaften (Wasserlöslichkeit, Basenpaarung, Geschwindigkeit in der Gelelektrophorese) bei gleicher Länge nahezu sequenzunabhängig sind. ${ }^{[23]}$

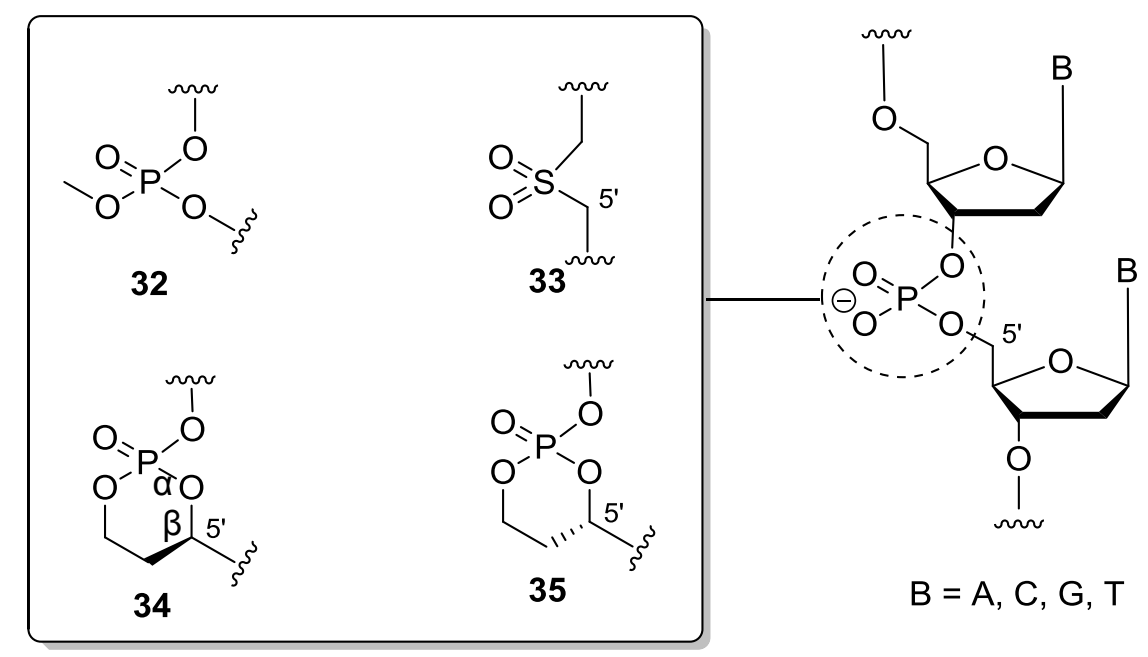

Abb. 2.9: Elektroneutrale Rückgratmodifikationen 32-35.

Auch das Aggregationsverhalten der uniformen elektroneutralen Dimethylensulfone 33 (Abb. 2.9) unterscheidet sich deutlich von demjenigen natürlicher Nucleinsäuren. Oligomere von acht oder mehr Monomeren tendieren zur Bildung sehr stabiler Sekundärstrukturen durch Faltung und nicht durch Hybridisierung mit komplementären Strängen. ${ }^{[23]}$ Dies geschieht auch dann, wenn die Basensequenz 
nicht auf eine Bildung von Haarnadel-Strukturen schließen lässt. Werden dagegen neutrale Modifikationen unter Beibehaltung des Phosphatdiesters vereinzelt in Nucleinsäure-Duplices eingeführt, resultiert fast ausschließlich eine DuplexDestabilisierung. ${ }^{[28]}$ Eine weitere interessante Rückgratmodifikation, in der die negative Ladung unter Erhalt der Phosphatdiestereinheit eliminiert wurde, ist die $\alpha, \beta$ D-CNA (dioxaphosphorinan constrained nucleic acids). Durch die Einführung einer Ethyleneinheit, die das C-5'-Atom mit einem Sauerstoffatom der Phosphatdiestereinheit verknüpft, konnten zwei konformationell eingeschränkte und ungeladene Internucleotidbrücken unterschiedlicher Konfiguration $\left(R_{C 5} / S_{\mathrm{p}} 34\right.$ und $S_{\mathrm{C} 5} / R_{\mathrm{p}}$ 35, Abb. 2.9) erhalten werden. ${ }^{[74]}$ Auf diese Weise wurden die Torsionswinkel $\alpha$ (P-O-Bindung, Abb. 2.9) und $\beta$ (5'-C-O-Bindung, Abb. 2.9) entsprechend der jeweiligen Geometrie der Phosphatdiestereinheit festgelegt. Die $R_{\mathrm{C}_{5}} / S_{\mathrm{p}}$ Einheit 34 wurde als "kanonisch" bezeichnet, da sie die Phosphatdiestereinheit in der gauche $(-)$-Konformation $(g)$ festlegt, die auch in gewöhnlichen A- und B-Helixformen unmodifizierter Nucleinsäuren vorliegt. Die Einführung einer einzigen Modifikation dieses Typs ergab im Fall von DNA/DNA-Duplices (9mer) eine deutliche $\left(\Delta \mathrm{T}_{\mathrm{m}}=+2.9\right.$ bis $+5.9^{\circ} \mathrm{C} / \mathrm{Mod}$ ) und im Fall von DNA/RNA-Duplices (9mer) eine geringe Erhöhung $\left(\Delta \mathrm{T}_{\mathrm{m}}=+0.9^{\circ} \mathrm{C} /\right.$ Mod. $)$ der thermischen Stabilität. ${ }^{[74-75]} \mathrm{Im}$ Gegensatz dazu wurden sowohl DNA/DNA- als auch DNA/RNA-Duplices durch die Einführung einer "nichtkanonischen" $S_{\mathrm{C} 5} / R_{\mathrm{p}}$-Einheit 35 ( $g^{+}$-Konformation) deutlich destabilisiert $\left(\Delta \mathrm{T}_{\mathrm{m}}=-9.0\right.$ bzw. $\left.-6.1^{\circ} \mathrm{C}\right) .{ }^{[74-75]}$ Anhand von einem 3D-Strukturmodell und CD-spektroskopischen Untersuchungen konnte bestätigt werden, dass die „kanonische“ D-CNA bei der Hybridisierung keine signifikante Veränderung der Torsionswinkel herbeiführt und insbesondere mit der B-Helixform kompatibel ist, während die "nicht-kanonische“ D-CNA strukturelle Verzerrungen verursacht, die auch bei Interaktionen der Nucleinsäuren mit Proteinen beobachtet werden. ${ }^{[74]}$ Außerdem stabilisiert die nichtkanonische D-CNA-Modifikation Haarnadelstrukturen beträchtlich $\left(\Delta T_{m}=+7.4^{\circ} \mathrm{C}\right)$, sofern sie in der loop-Region lokalisiert ist. ${ }^{[75]}$

Es sind vermehrt auch neutrale Internucleotidbrücken untersucht worden, in denen eine komplette Ersetzung der Phosphatdiestereinheit vorgenommen wurde. Einer der wichtigsten Repräsentanten dieser Klasse sind die von de Mesmaeker entwickelten Amid-Verbrückungen 36-38 (Abb. 2.10). ${ }^{[76]}$ Sie gehören zu den punktuellen Rückgrat-Modifikationen, deren Einbau durch Einfügen von Amid-verknüpften Nucleosid-Dimeren in eine Nucleotidsequenz mittels festphasengestützter ON- 
Synthese möglich ist. Innerhalb einer solchen Sequenz liegen demnach alternierende Phosphatdiester- und Amidbrücken vor. Die Hauptgründe für die intensiven Untersuchungen dieser Variante der Verbrückung sind neben deren Elektroneutralität die Nicht-Stereogenität und der ausgesprochen hohe Grad an Inertheit gegenüber Hydrolyse (Nuclease-Abbau). Der Einfluss der AmidVerbrückung auf die thermische Stabilität der DNA/RNA-Hybride ist insbesondere von der Position der Amidbindung innerhalb der Verbrückung abhängig. ${ }^{[76-78]}$ Die besten Resultate hinsichtlich der Duplexstabilität mit komplementären RNA-Strängen wurden erzielt, wenn die Amidbindung in der Mitte der Verbrückung (Abb. 2.10 Struktur 36) angeordnet war $\left(\Delta \mathrm{T}_{\mathrm{m}}=+0.5 \mathrm{bis}+3^{\circ} \mathrm{C} / \mathrm{Mod}\right.$.). ${ }^{[76]}$ Als Begründung hierfür wurde eine durch die Amidbindung induzierte Vorzugskonformation ( $3^{\prime}$-endo) der Riboseeinheit diskutiert. ${ }^{[78]}$ Die Vorzugskonformation rührt daher, dass die hinsichtlich der Rotation eingeschränkte Amidbindung bevorzugt in der transKonformation vorliegt und die Torsionswinkel der anderen Bindungen der Verbrückung verzerrt. Dies wurde anhand von molekularmechanischen Simulationen bestätigt. ${ }^{[76]}$ Die dadurch erzeugte Geometrie der (Desoxy-)Riboseeinheit (3'-endo) ist vorteilhaft für die Hybridisierung im Sinne einer A-Helix. Dazu passt auch der Befund, dass modifizierte DNA/RNA-Duplices durch die Modifikation 36 stabilisiert und DNA/DNA-Duplices destabilisiert wurden. ${ }^{[77]}$ Andere Positionen der Amidbindung 37 und 38 (Abb. 2.10) führten hingegen in den meisten Fällen zu einer Destabilisierung $\left(\Delta \mathrm{T}_{\mathrm{m}}=-0.5\right.$ bis $-2.9^{\circ} \mathrm{C} / \mathrm{Mod}$.) von DNA/DNA- und von DNA/RNADuplices. $^{[78-79]}$

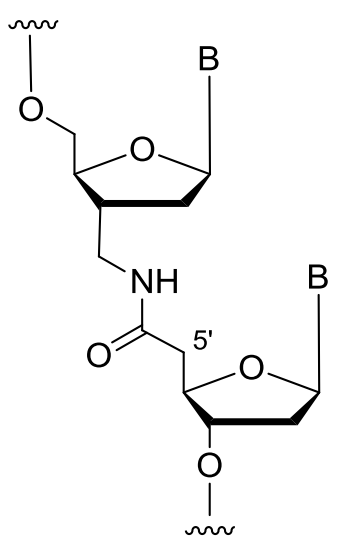

36

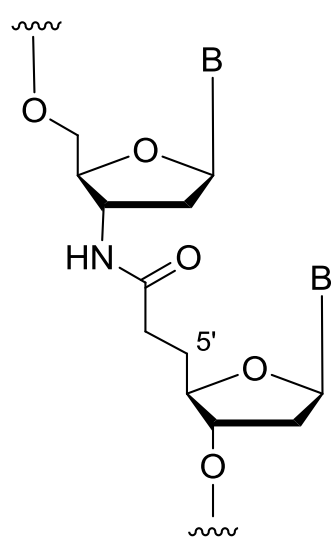

37

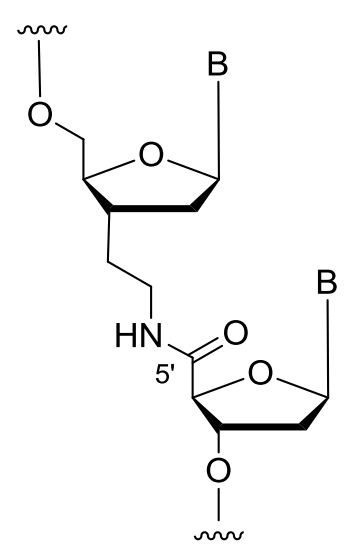

38

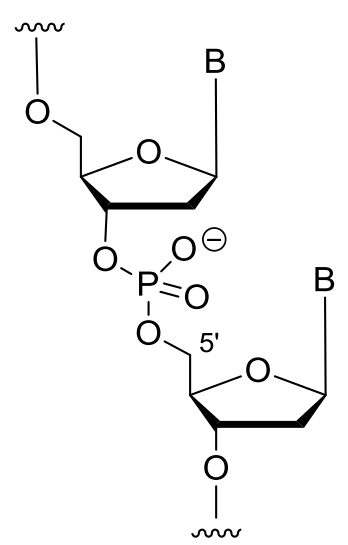

DNA

$B=$ Nucleobase

Abb. 2.10: Amidmodifikationen 36-38 nach De Mesmaeker. 
Dieser Sachverhalt wurde ebenfalls anhand der Vorzugskonformationen der Internucleosidbrücken $\mathbf{3 7}$ und $\mathbf{3 8}$ begründet. ${ }^{[78-79]}$ Substitutionen von Phosphateinheiten durch Amide wurden auch an RNA/RNA-Doppelsträngen durchgeführt. Überraschenderweise traten selbst bei der Substitution von zehn Phosphateinheiten durch Amide in einem 26mer nur geringfügige Veränderungen der physikochemischen Eigenschaften wie Hydratation, Duplexstabilität $\left(\Delta T_{m}=-0.5^{\circ} \mathrm{C} /\right.$ Mod. ) oder Geometrie auf. ${ }^{[80]}$ Insgesamt wird also deutlich, dass bei singulären oder alternierenden elektroneutralen Brücken-Modifikationen die Auswirkung der Vorzugskonformation über den elektrostatischen Effekt dominiert. Ein uniform ungeladenes Rückgrat führt hingegen zu Eigenschaften des Biopolymers, die für Proteine typisch sind.

\subsubsection{Kationische und zwitterionische Rückgratmodifikationen}

Im Unterschied zu den bisher angeführten neutralen oder negativ geladenen Rückgratmodifikationen sind bisher nur vereinzelt Methoden entwickelt worden, um Nucleinsäureanaloga mit einem zwitterionischen oder vollständig kationischen Rückgrat herzustellen. Obwohl die ersten Oligonucleotide mit kationischen Internucleotidbrücken bereits 1988 von Letsinger etabliert worden sind, beschränken sich die bisher veröffentlichten Arbeiten auf Phosphoramidate ${ }^{[81-85]}$ 39-41, $\mathrm{DNG} / \mathrm{RNG}^{\left[{ }^{[6-89]}\right.}$ (deoxyribonucleic/ribonucleic guanidine) 42 und $\mathrm{DNm}{ }^{[86,90-92]}$ (deoxynucleic methylthiourea) $\mathbf{4 3}$ (Abb. 2.11). Die Phosphoramidate sind zunächst synthetisiert worden, um die Auswirkung komplementär geladener Rückgratstrukturen auf die Hybridisierung zweier DNA-Einzelstränge zu untersuchen. ${ }^{\left[{ }^{[1]}\right.}$ Bei physiologischen Bedingungen sind Doppelstränge aus DNA und Phosphoramidat-Analoga stabiler $\left(\Delta \mathrm{T}_{\mathrm{m}}=+2\right.$ bis $+3{ }^{\circ} \mathrm{C} / \mathrm{Mod}$. $)$ als unmodifizierte Duplices. Die Variation der Parameter des Mediums ergab, dass die Affinität der oligokationischen Stränge gegenüber unmodifizierten DNA-Sequenzen im Wesentlichen von zwei Parametern abhängig ist: der lonenstärke und dem pH-Wert. Während die thermische Stabilität natürlicher DNA-Doppelstränge mit zunehmender Ionenstärke ansteigt, zeigt sich im Fall komplementär geladener Rückgratstrukturen der entgegengesetzte Trend. ${ }^{[81]}$ Für eine Duplex, in der ein Strang in jeder zweiten Position eine positiv geladene Phosphoramidat-Einheit aufwies, wurde eine ausgeprägte Unempfindlichkeit gegenüber der Variation der lonenstärke gezeigt. 
Dieses Ergebnis wurde durch eine spätere Arbeit ${ }^{[33]}$ von Michel und Gryaznov an zwitterionischen Phosphoramidaten bestätigt und stimmt sehr gut mit den Befunden der Untersuchungen an Basen-modifizierten, zwitterionischen ON überein (s. 2.3). Eine plausible Begründung dafür ist durch den Einfluss des zwitterionischen Ladungsmusters auf die Entropieänderung der Hybridisierung gegeben. ${ }^{[53]}$ Infolge der Assoziation zweier negativer Polymere wird die Ladungsdichte erhöht. Dies wird durch die Anlagerung zusätzlicher Kationen aus der Lösung kompensiert. Diese zusätzlichen Kationen gehen bei der Dissoziation des Doppelstrangs wieder in den hydratisierten Zustand über. Dieser Effekt trägt zur Entropiezunahme bei der Dissoziation zweier gleichnamig geladener Polymere bei. Da die Assoziation eines zwitterionischen mit einem uniform geladenen Strang nicht zu einer Erhöhung der Ladungsdichte führt, lagern sich keine zusätzlichen Kationen an und der Beitrag zur Entropieänderung entfällt. Die Auswirkung des pH-Werts entspricht ebenfalls den Erwartungen. Mit steigendem pH-Wert wurde eine abnehmende Stabilität von Duplices mit ergänzendem Ladungsmuster verzeichnet. ${ }^{\left[{ }^{[1]}\right.}$

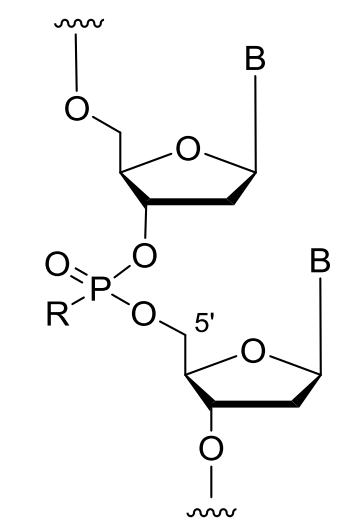

$39 \mathrm{R}=-\mathrm{NHCH}_{2} \mathrm{CH}_{2} \stackrel{+}{\mathrm{N}} \mathrm{HR}_{2}$, -OAlkyl

$$
40 \mathrm{R}=-\mathrm{NH}\left(\mathrm{CH}_{2}\right)_{4} \mathrm{HN}
$$

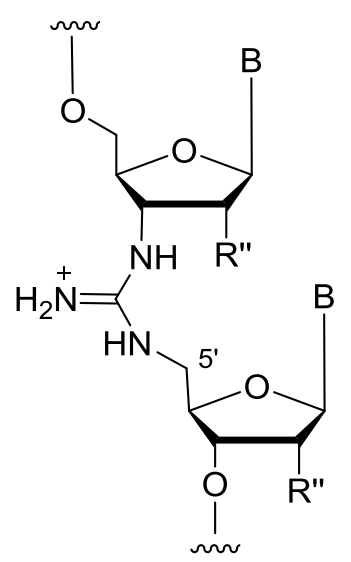

$42 \mathrm{~B}=\mathrm{A}, \mathrm{C}, \mathrm{T}, 7$-deazaG $\mathrm{R}^{\prime \prime}=\mathrm{H}, \mathrm{OH}$

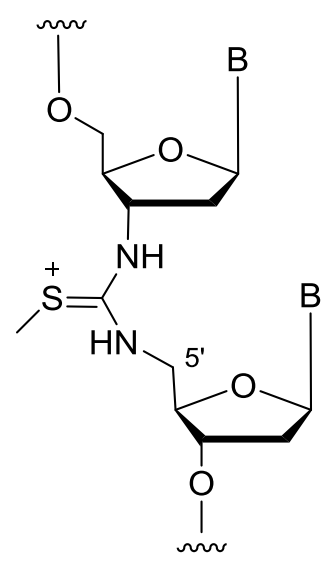

$43 \mathrm{~B}=\mathrm{T}$

Abb. 2.11: Kationische Rückgratmodifikationen 39-43.

Auch hier ist eine Übereinstimmung mit den Ergebnissen der Untersuchungen an zwitterionischen, Basen-modifizierten ON gegeben (s. Kap. 2.3). Die Phosphoramidat-Modifikation ermöglicht zudem die Variation ihres Protolyseverhaltens, da an dem Linker verschiedene basische Untereinheiten mit 
unterschiedlichen $\mathrm{pK}_{\mathrm{b}}$-Werten eingeführt werden können. Dazu gehören die stark basichen $N, N$-Dialkyl-ethylendiamin-Gruppen ${ }^{[82-83]} 39$ und Guanidin-Reste ${ }^{[85]} 40$ oder die schwächer basischen Morpholidate ${ }^{[81]} 41$ (Abb. 2.11). Spätere Arbeiten fokussierten sich vorwiegend auf die Verwendung von Phosphoramidat-Analoga als TFO für die Entwicklung von therapeutischen Wirkstoffen. ${ }^{[82-84]}$

Eine erhebliche Abwandlung im Vergleich zur Struktur der Phosphatdiester stellen die von Bruice entwickelten DNG/RNG 42 und DNmt 43 dar (Abb. 2.11). ${ }^{[86]}$ Die DNG/RNG-Internucleosidbrücken liegen wegen ihrer hohen Basizität bei physiologischen Bedingungen als Kationen vor. Die einzige strukturelle Gemeinsamkeit der Guanidin- bzw. Methylthioharnstoffbrücken mit natürlichen Phosphatdiestern ist die Anzahl der zwischen den Nucleosiden liegenden Bindungen. Aufgrund ihrer trigonal-planaren Geometrie beträgt der Bindungswinkel dieser Modifikationen $120^{\circ}$ im Unterschied zu den $109^{\circ}$ der tetraedrischen Phosphateinheit. Folglich ist der Abstand benachbarter Nucleobasen etwas größer als bei Nucleinsäuren. Ungeachtet dessen bilden uniforme DNG/RNG und DNmt mit komplementären DNA- und RNA-Strängen sehr stabile Duplices $\left(\Delta \mathrm{T}_{\mathrm{m}}=\sim 15\right.$ $20{ }^{\circ} \mathrm{C} /$ Mod.) und Tripelhelices. ${ }^{[86]}$ Nach Bruice ist dies auf die Coulomb-Attraktion ungleichnamiger Ladungen zurückzuführen. Der überaus große Unterschied zu anderen kationischen Verbrückungen hinsichtlich der Duplexstabilisierung wird mit einer optimalen Interaktion der Guanidin- bzw. Methylthioharnstoff-Einheit mit den Phosphatdiestern des komplementären DNA- oder RNA-Strangs erklärt. ${ }^{[86]}$ Allerdings erscheint die ausschließlich auf der Coulomb-Attraktion beruhende Argumentation fragwürdig. Durchaus denkbar ist ein Einfluss der geometrischen Faktoren: Die Guanidin- und Methylharnstoff-Einheiten dürften die freie Rotation der Polymerbausteine einschränken. Trotz der recht hohen Affinität gegenüber natürlichen DNA-Strängen weisen uniforme DNG/RNG und DNmt eine empfindliche Erkennung von Fehlpaarungen auf. Schon eine einzige Fehlpaarung im Inneren einer Sequenz aus acht A-T-Basenpaaren DNG-modifizierter ON resultierte in einem um $14.8^{\circ} \mathrm{C}$ niedrigeren $\mathrm{T}_{\mathrm{m}}$-Wert. ${ }^{[87]}$ Etwas weniger empfindlich waren DNmtmodifizierte ON mit einem Absinken des $\mathrm{T}_{\mathrm{m}}$-Werts um $9{ }^{\circ} \mathrm{C}$ bei $20 \% \mathrm{C}$-MismatchPositionen innerhalb einer 19meren Oligo-AT-Sequenz. ${ }^{[1]}$ Die von Bruice entwickelten Modifikationen wurden auch vereinzelt über die PhosphoramiditStrategie in DNA-Sequenzen eingeführt. ${ }^{[88,92]}$ Solche $z$. T. zwitterionischen Chimären bilden bei niedrigen lonenstärken mit komplementären DNA-Strängen Duplices von 
ähnlicher Stabilität wie unmodifizierte DNA/DNA-Doppelstränge ${ }^{[88,92]}$ Bei steigender lonenstärke nahmen die $T_{m}$-Werte singulär DNG/RNG- oder DNmt-modifizierter DNA-Doppelstränge ab $\left(\Delta \mathrm{T}_{\mathrm{m}}=-0.8\right.$ bis $-1.7^{\circ} \mathrm{C} / \mathrm{Mod}$. $) .{ }^{[8,92]}$

\subsubsection{Modifikationen des gesamten Zuckerphosphatrückgrats}

In den bisher beschriebenen Nucleinsäuremodifikationen wurden nur Teile der natürlichen Nucleinsäurestruktur ersetzt oder derivatisiert. Es sind jedoch auch zahlreiche Nucleinsäureanaloga entwickelt worden, in denen das Zuckerphosphatrückgrat komplett ersetzt worden ist. Eine der ersten Rückgratarchitekturen dieser Klasse ist die Phosphordiamidat-MorpholinoModifikation (PMO) 44 (Abb. 2.12). Bei den PMO ist der Furanring durch einen Morpholinring ersetzt und anstelle eines Sauerstoffatoms liegt eine Dimethylaminoeinheit an der Verbrückung vor. Die Verbindung ist somit elektroneutral. Die Affinität uniformer PMO gegenüber nativen RNA-Strängen ist im Vergleich mit derjenigen von unveränderten DNA-Strängen leicht erhöht (ca. $+0.2^{\circ} \mathrm{C} / \mathrm{Mod}$.). ${ }^{[94]} \mathrm{PMO}$ sind besonders für die medizinische Forschung von Interesse, da gezeigt werden konnte, dass sie als Agentien zur Korrektur des Spleißvorgangs von mRNA-Vorläufern eingesetzt werden können. ${ }^{[95-96]}$ In einer neueren Publikation sind die strukturell ähnlichen, jedoch kationischen und singulär in DNA-Sequenzen eingeführten Morpholinoamidine $\mathbf{4 5}$ beschrieben worden (Abb. 2.12). ${ }^{[97]}$

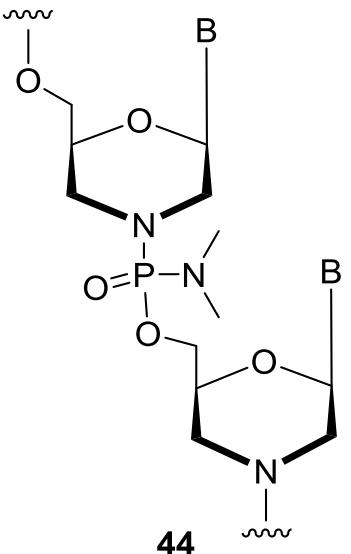

44

$B=A, C, G, U$

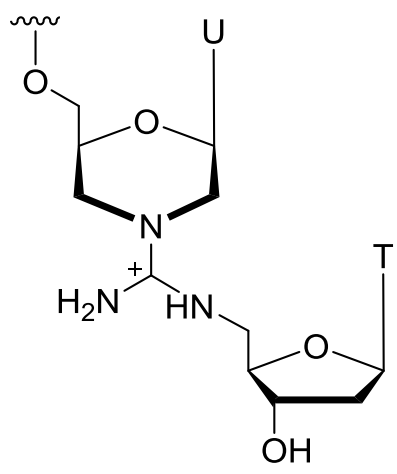

45

Abb. 2.12: Strukturen der Morpholino-Modifikationen 44 und 45. 
Die Stabilität der mit komplementärer DNA gebildeten Duplices ist stark abhängig von der Position der Modifikation innerhalb des Strangs. Am 3'-Ende befindliche Modifikationen führten zu einer leichten Erhöhung der thermischen Duplex-Stabilität $\left(\Delta \mathrm{T}_{\mathrm{m}}=+1.5^{\circ} \mathrm{C} / \mathrm{Mod}\right.$.), während Modifikationen in der Mitte der Sequenz eine erhebliche Destabilisierung $\left(\Delta \mathrm{T}_{\mathrm{m}}=-8.0^{\circ} \mathrm{C}\right)$ ergaben. ${ }^{[97]}$

Einer der am gründlichsten untersuchten und in der Literatur beschriebenen Typen von artifiziellen Nucleinsäuren ist die PNA (peptide nucleic acids). Die anfänglich von Nielsen als potentieller Triplexbildner konzipierte aeg( $N$-(2-Aminoethyl)glycin)PNA 46 (Abb. 2.13) ist ein acyclisches Nucleinsäure-Analogon mit einem elektroneutralen Polypeptid-Rückgrat. ${ }^{[98]}$ Ähnlich wie andere uniform elektroneutrale NucleinsäureAnaloga zeichnen PNA-Stränge sich durch Basensequenz-abhängige physikalische Eigenschaften (Löslichkeit, Mobilität in der Elektrophorese) und die Tendenz zur Faltung (> 20 Monomere) aus. ${ }^{[23]}$ Die aegPNA weist zum einen flexible Einfachbindungen aber auch hinsichtlich der Rotation eingeschränkte Amidbindungen im Rückgrat auf und bildet sehr stabile Duplices mit Nucleinsäuren und Homoduplices gemäß den Watson-Crick-Prinzipien. ${ }^{[99-100]}$ Für ein 15mer, das alle vier Nucleobasen enthielt, waren die Stabilitäten der PNA/DNA-Duplex $\left(\Delta \mathrm{T}_{\mathrm{m}}=+16.2^{\circ} \mathrm{C}\right)$ und der PNA/RNA-Duplex $\left(\Delta \mathrm{T}_{\mathrm{m}}=+21.7^{\circ} \mathrm{C}\right.$, im Vergleich mit RNA/DNA) bedeutend höher als diejenigen natürlicher Duplices. ${ }^{[101]}$ Dieser Effekt wurde der fehlenden elektrostatischen Abstoßung bei der Hybridisierung der PNA mit Nucleinsäuren zugeschrieben, da die Entropieänderung dieses Vorgangs für PNA/Nucleinsäure-Duplices nahezu derjenigen von Nucleinsäure-Duplices gleicht. ${ }^{[101]}$ Interessanterweise ist die thermische Stabilität von PNA-Homoduplices noch wesentlich höher als diejenige der PNA/Nucleinsäure-Hybride, wie der Vergleich der $T_{m}$-Werte von Duplices 10merer gemischter Sequenzen zeigte (PNA/PNA $T_{m}=67^{\circ} \mathrm{C}$, PNA/DNA $T_{m}=51^{\circ} \mathrm{C}$, DNA/DNA $\left.T_{m}=33.5^{\circ} \mathrm{C}\right) .{ }^{[102]}$ Die hohe Stabilität von PNA/DNA-Hybriden ist auch der Grund dafür, dass es (besonders bei Homopyrimidinen) $z u$,invasiven“ Bildungen von (PNA) 2 /DNA-Triplices kommt, d. h. der Verdrängung eines komplementären DNA-Stranges durch eine PNA-Sequenz und die Anlagerung eines weiteren PNA-Stranges über HoogstenBasenpaarungen. ${ }^{[100]}$ Die Einführung von Fehlpaarungen führt sowohl bei PNAHomoduplices als auch bei Nucleinsäure-Assoziaten zu einer deutlichen Stabilitätsminderung $\left(\sim 8-20^{\circ} \mathrm{C}\right)$, die stets größer ist als bei natürlichen NucleinsäureDoppelsträngen. ${ }^{[101-102]}$ Des Weiteren konnte anhand der Messung von Wasserstoff- 
Austauschraten mittels NMR-Spektroskopie belegt werden, dass die Geschwindigkeit sowohl der Dissoziation als auch der Assoziation von aegPNA/DNA-Duplices langsamer ist als im Fall von DNA-Doppelsträngen. ${ }^{[103]}$ Insgesamt deuten diese Daten (thermische Stabilität, Mismatch-Erkennung, Hybridisierungskinetik) auf eine höhere Rigidität der aegPNA im Vergleich zur DNA hin. Untersuchungen der Strukturen von Assoziaten der PNA mit Nucleinsäuren mittels Röntgenstrukturanalyse oder NMR-Spektroskopie haben ergeben, dass die aegPNA sich der Helixgeometrie der jeweiligen komplementären Nucleinsäure anpasst. Für PNA/RNA-Duplices wurde die A-Form der Helix experimentell bestätigt. ${ }^{[104]}$
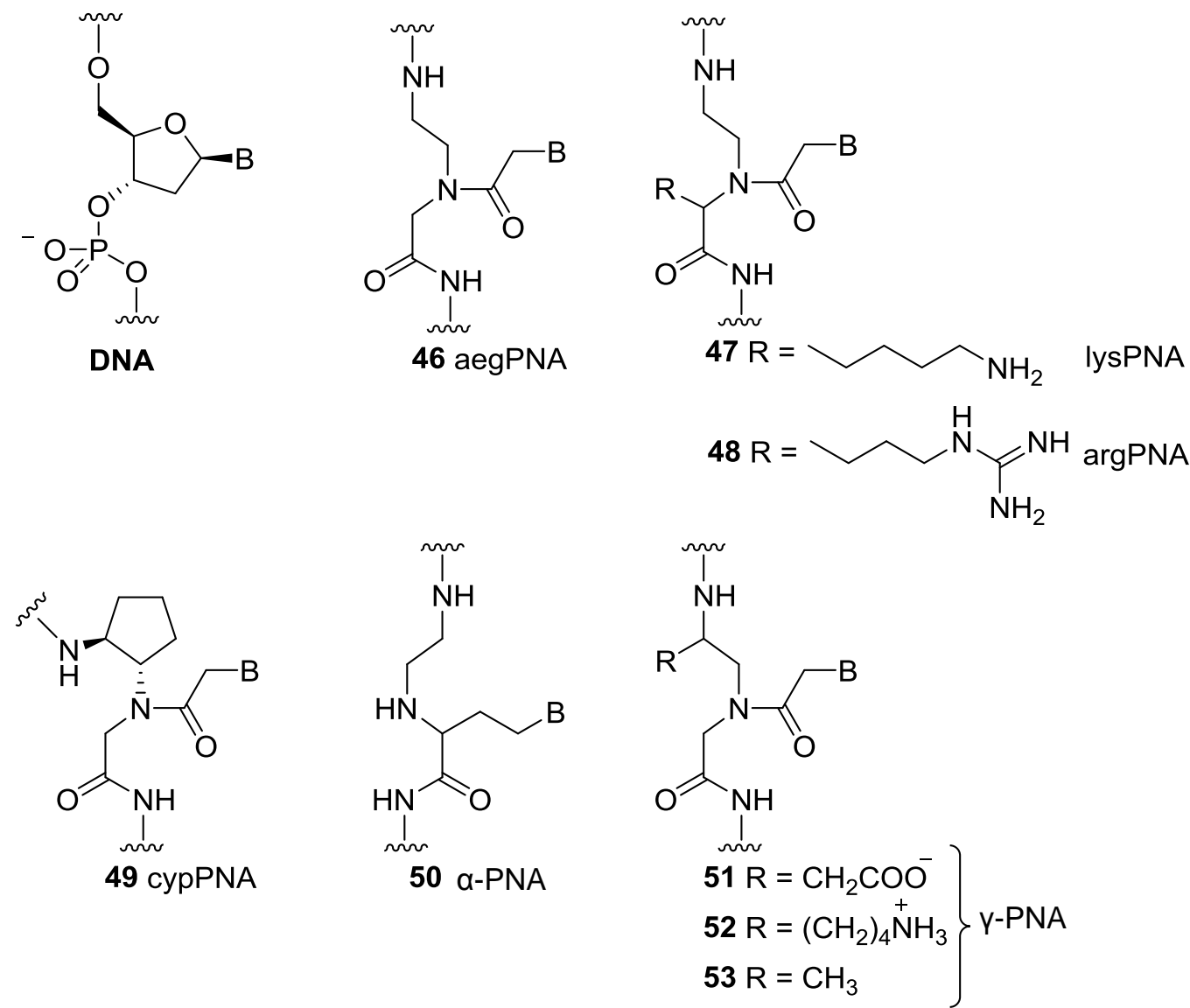

Abb. 2.13: Strukturen der im Text beschriebenen PNA 46-53.

PNA/DNA-Hybride ergeben eine Helixgeometrie, die sowohl Merkmale der A-Helix als auch der B-Helix aufweist. ${ }^{[105]}$ Dagegen wurde mittels RöntgenstrukturUntersuchungen für die PNA/PNA-Helix eine bis zum damaligen Zeitpunkt unbekannte Form nachgewiesen: die P-Helix. ${ }^{[106]}$ Sie unterscheidet sich von den häufig vorkommenden A- und B-Formen durch ihren etwas größeren Durchmesser (28 ̊, A-Form: $25.5 \AA$, B-Form: $23.7 \AA$ ), eine sehr große Ganghöhe (8.3 A, A-Form: 
2.3 $\AA$, B-Form: $3.4 \AA$ ) und sehr lange Windungen (58 $\AA$, A-Form: $25.3 \AA$, B-Form: 35.4 $\AA$ ) mit einer hohen Basenzahl/Windung (18 bp/turn, A-Form: 11 bp/turn, B-Form: $10 \mathrm{bp} /$ turn). ${ }^{[106]} \mathrm{Da}$ die aegPNA achiral ist, liegen die linksgängigen und rechtsgängigen PNA/PNA-Duplices in der kristallisierten Form im Verhältnis 1:1 vor. ${ }^{[106]}$ Es wurde ebenfalls eine große Vielzahl an strukturellen Varianten der aegPNA hergestellt und analysiert. Positive Ladungen wurden am Rückgrat der PNA angebracht, indem die Glycineinheit durch Lysin (lysPNA 47, Abb. 2.13) oder Arginin (argPNA 48, Abb. 2.13) ausgetauscht wurde, um die Membranpermeabilität der PNA zu verbessern. ${ }^{[107-108]}$ Die konformationelle Beweglichkeit des Rückgrats wurde durch das Einführen von Ringstrukturen (z. B. Cyclopentan, cypPNA 49, Abb. 2.13) eingeschränkt ${ }^{[99]}$ oder die Anknüpfungsposition der Nucleobase wurde auf das $\alpha$-CAtom der Aminosäureeinheit verlagert, sodass $\mathrm{APNA}^{[109]} 50$ (Abb. 2.13) erhalten wurde. Verglichen mit der aegPNA erwiesen sich die meisten der genannten Derivate der PNA als weniger geeignete Hybridisierungspartner für Nucleinsäuren. Eine der wenigen Substitutionen am PNA-Rückgrat, mit der eine Verbesserung der Hybridisierungseigenschaften einherging, war die Y-PNA 51-53 (Abb. 2.13). ${ }^{[110-111]}$ Eine Verbesserung der Affinität war insbesondere bei $(S)$-Konfiguration an der $y$ Position gegeben. Durch diese Chiralitätszentren wird eine Präorgansation der PNA für die rechtsgängige Helix induziert. ${ }^{[111]}$ Folglich wird die Entropieabnahme der Assoziation geringer. Kürzlich wurde auch $y$-PNA (Substituent in $y$-Position) mit negativ oder positiv geladenem Rückgrat hergestellt, um die Relevanz elektrostatischer Effekte auf die Duplexstabilität von PNA/NucleinsäureDoppelsträngen zu untersuchen. ${ }^{[112]}$ Dabei ergab sich, dass die Affinität von $\mathrm{y}$-PNA mit positiv geladenem Rückgrat gegenüber Nucleinsäuren bei geringer lonenstärke maximal ist und zu hohen lonenstärken hin abnimmt. Dagegen verhielt es sich mit negativ geladenen $\mathrm{Y}$-PNA-Strängen umgekehrt. Für die Affinität elektroneutraler Stränge gegenüber Nucleinsäuren wurden eine schwache Abnahme zu hoher lonenstärke hin (PNA/DNA) oder annähernd gleich bleibende Werte (PNA/RNA) verzeichnet. Durch diese Ergebnisse wurde die bereits früher aufgestellte Hypothese ${ }^{[113]}$ bestätigt, dass die durch Wasserstoffbrückenbindungen vermittelte Präorganisation des PNA-Rückgrats die Ursache für die erhöhte Stabilität von PNA/Nucleinsäure-Duplices ist und nicht hauptsächlich die Coulomb-Attraktion oder-Repulsion. ${ }^{[112]}$ 
Wie die bisherigen Ausführungen zeigen, gibt es bei den Eigenschaften von Nucleinsäure-Analoga auffallende Übereinstimmungen. Das vollständige Entfernen der negativen Ladung führt zu Nucleinsäuren mit Protein-ähnlichen Eigenschaften. Der Austausch von negativer Ladung durch positive kehrt die Abhängigkeit der Affinität zu Nucleinsäuren von der lonenstärke um. Die Hybridisierung zwitterionischer oder ungeladener ON mit Nucleinsäuren ist nahezu unabhängig von der lonenstärke. Konformative Restriktionen erhöhen die Affinität und MismatchEmpfindlichkeit, wenn die Kompatibilität der induzierten Vorzugskonformation mit der Helixgeometrie gegeben ist. In vielen Fällen wurde gezeigt, dass elektroneutrale Modifikationen der Verbrückung zu einer Abschwächung der molekularen Erkennung und Eignung zur Funktion als Templat führen. Auf diesen Erkenntnissen aufbauend formulierte Benner eine Hypothese über den Zusammenhang des polyanionischen Charakters von Nucleinsäuren und ihrer Funktion als Templat in der Replikation: „The polyanionic nature of the backbone appears to be critical to prevent the single strands from folding, permitting them to act as templates, guiding the interaction between two strands to form a duplex in a way that simple rules to guide the molecular recognition event, and buffering the sensitivity of its physicochemical properties to changes in sequence." Allerdings sind die Befunde über die Eigenschaften der Nucleinsäuren und ihrer Analoga noch nicht ausreichend für genaue Aussagen über die Relevanz des oligoanionischen Charakters von genetischen Molekülen. Insbesondere fehlt es an experimentellen Daten zu den Eigenschaften kationischer Brückenmodifikationen, die hinsichtlich ihrer Eigenschaften der Phosphatdiestereinheit möglichst ähnlich wären.

\subsection{Nucleosylaminosäure (NAA)-modifizierte ON}

Als ein weiterer Beitrag zu der oben angeführten Fragestellung wurde in der Arbeitsgruppe Ducho die neuartige NAA(nucleosyl amino acid)-Modifikation konzipiert und in DNA-Sequenzen eingeführt (Abb. 2.14). ${ }^{[114]}$ Bei dieser Rückgratmodifikation handelt es sich um ein Derivat der von De Mesmaeker entwickelten Amid-Verbrückung 37 (Abb. 2.10), die als ein geeignetes Mimetikum der Phosphatdiesterein-heit gilt. Die NAA-Internucleosid-brücke ist isoster zur Phosphatdiestereinheit und unterscheidet sich von den bisher beschriebenen AmidModifikationen 36-38 (Abb. 2.10) durch ihren stereogenen Charakter und die primäre 
Aminogruppe in der 6'-Position, die bei physiologischem $\mathrm{pH}$-Wert positiv geladen ist (Abb. 2.14).

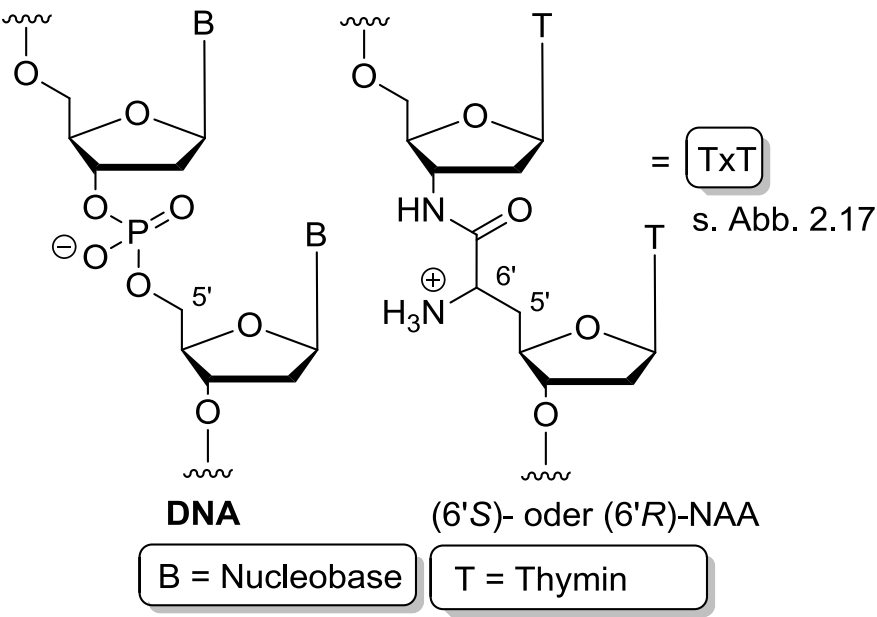

Abb. 2.14: Strukturen der NAA-Modifikation und der DNA im Vergleich.

\subsubsection{Nucleosylaminosäuren}

Das Verknüpfen einer Glycin-Einheit über das $\alpha$-C-Atom mit einem in 5'-Position formal desoxygenierten Nucleosid über eine C-C-Einfachbindung ergibt Verbindungen des Typs 54 (Abb. 2.15), für welche von Ducho und Mitarbeitern der Begriff Nucleosylaminosäuren (NAA) eingeführt wurde. ${ }^{[115]}$ In der Natur kommen NAA als Substrukturen in den antibiotisch wirksamen Muraymycinen (z. B. Muraymycin A1 55, Abb 2.15), Caprazymycinen oder Liposidomycinen vor. ${ }^{[16]}$

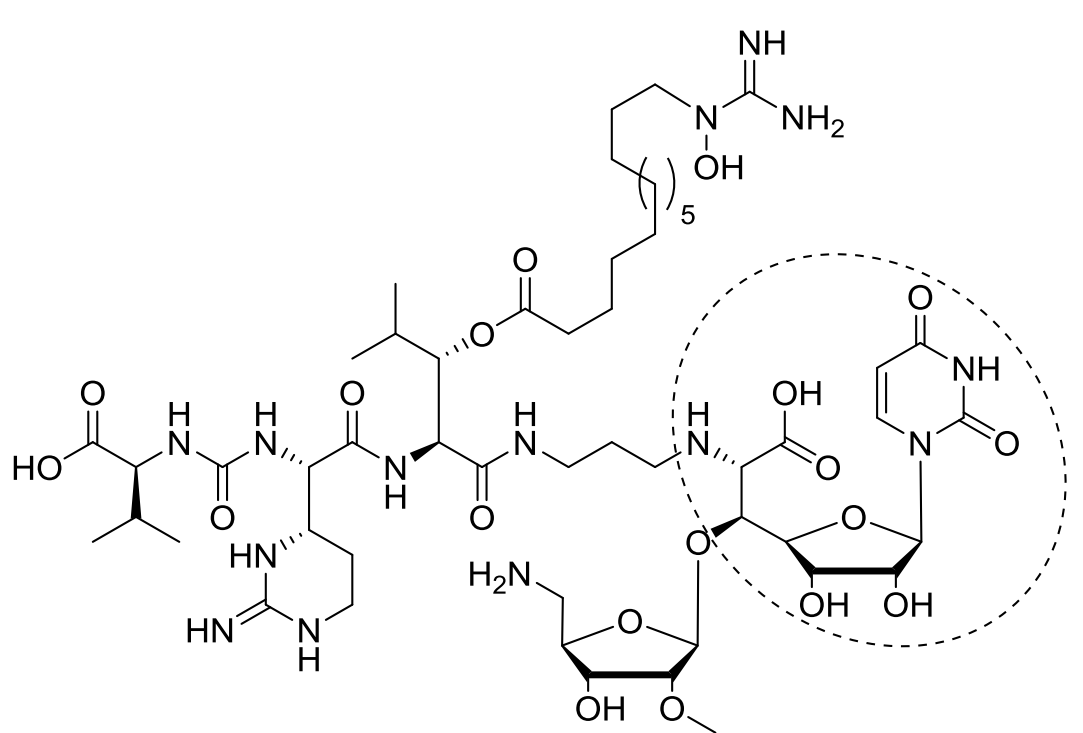

Muraymycin A1 55

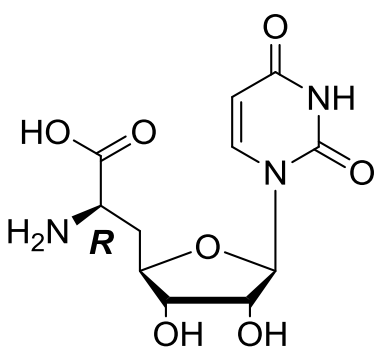

$\left(6^{\prime} R\right)-54$

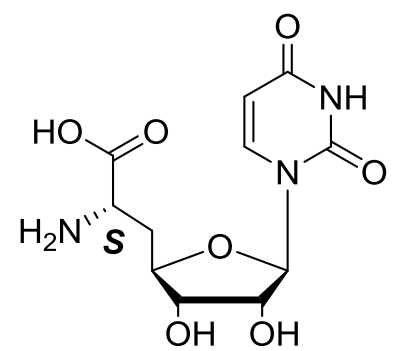

(6'S)-54

Abb. 2.15: Strukturen des Muraymycins A1 und der davon abgeleiteten Nucleosylaminosäuren 54. 
Im Rahmen von Studien zur Synthese verschiedener Muraymycin-Analoga ist eine generelle Methode zur Darstellung verschiedener Uridinyl-Aminosäurederivate entwickelt worden (Abb.2 16).<smiles>O=c1ccn(C2OCC(O)C(CO)O2)c(=O)[nH]1</smiles>

56

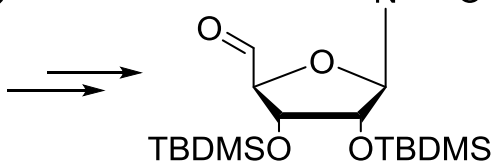

$57 \mathrm{R}=\mathrm{PMB}, 66 \%$ über 4 Stufen $58 \mathrm{R}=\mathrm{H}, 91 \%$ über 3 Stufen $59 \mathrm{R}=\mathrm{BOM}, 62 \%$ über 4 Stufen
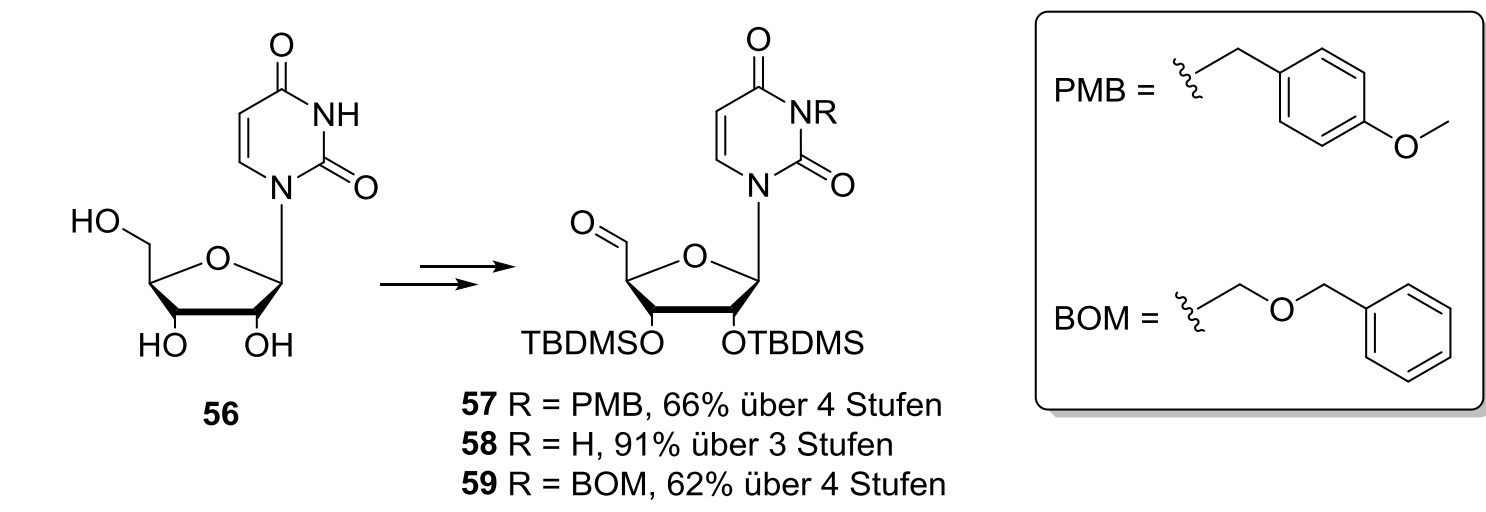

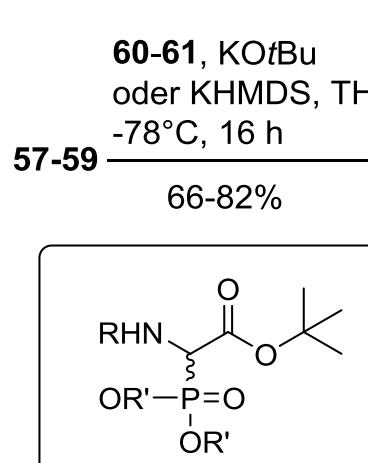

60: $R=B o c, R^{\prime}=E t$ 61: $\mathrm{R}=\mathrm{Cbz}, \mathrm{R}^{\prime}=\mathrm{Me}$

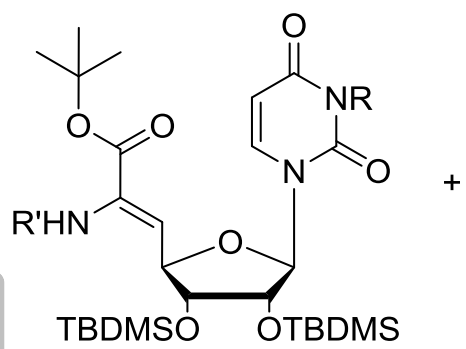

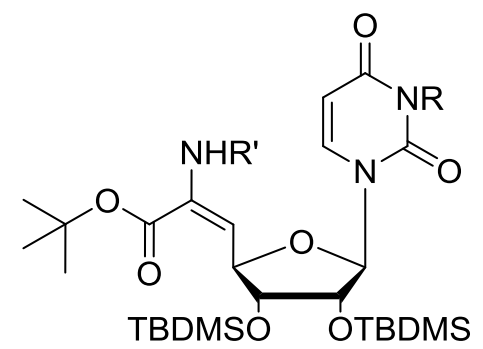

$57 \longrightarrow(Z)-62$

$58 \longrightarrow(Z)-63$

$Z / E=97: 3$

Z/E $>98: 2$

$59 \longrightarrow(Z)-64$

Z/E $=91: 9$

$(E)-62 \mathrm{R}=\mathrm{PMB}, \mathrm{R}^{\prime}=\mathrm{Boc}$

(E)-63 $\mathrm{R}=\mathrm{H}, \mathrm{R}^{\prime}=\mathrm{Cbz}$

(E)-64 R = BOM, R' = Cbz

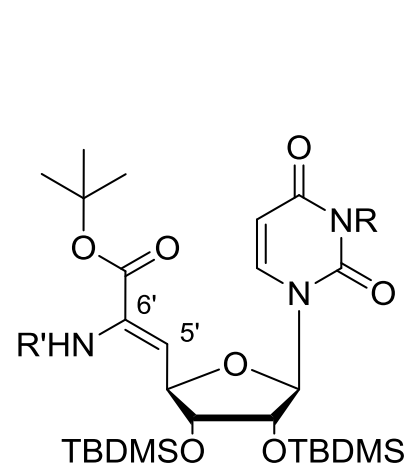

(Z)-62-64

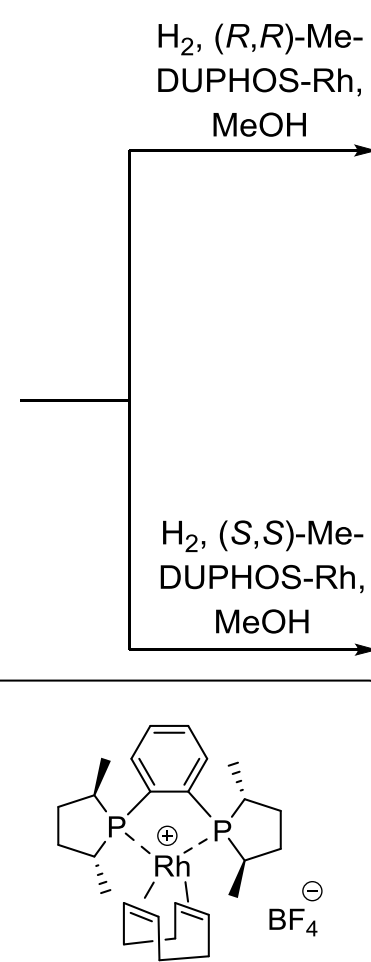

$(S, S)$-Me-DUPHOS-Rh $\quad(R, R)-M e-D U P H O S-R h$

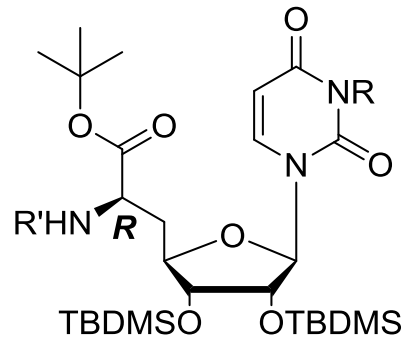

(R)-65: $\mathrm{R}=\mathrm{PMB}, \mathrm{R}^{\prime}=\mathrm{Cbz} 80 \%$ (R)-66: $\mathrm{R}=\mathrm{BOM}, \mathrm{R}^{\prime}=\mathrm{Cbz} 93 \%$

$(R)-67: \mathrm{R}=\mathrm{H}, \mathrm{R}^{\prime}=\mathrm{Cbz} 93 \%$

(R)-68: $\mathrm{R}=\mathrm{PMB}, \mathrm{R}^{\prime}=$ Boc $95 \%$

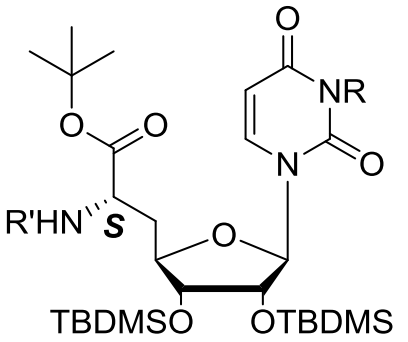

(S)-65: R = PMB, R' = Cbz 86\%

(S)-66: R = BOM, R' $=\mathrm{Cbz} 94 \%$

(S)-67: R = H, R' = Cbz 94\%

(S)-68: R = PMB, R' = Boc $92 \%$

Abb. 2.16: Synthese der vollständig geschützten Uridinylaminosäuren 65-68. 
Ausgehend von Uridin 56 wurden die Aldehyde 57-59 in vier Stufen mit guten bis exzellenten Gesamtausbeuten erhalten. ${ }^{[17-118]}$ Durch die anschließende WittigHorner-Reaktion der Aldehyde 57-59 mit den Phosphonaten 60 oder 61 wurden die Didehydroaminosäuren 62-64 mit hoher (Z)-Selektivität erhalten. ${ }^{[115,118]}$ Darauf folgte eine asymmetrische Hydrierung der 5',6'-Doppelbindung der Didehydroaminosäuren in Gegenwart der chiralen Katalysatoren $(S, S)$ - bzw. $(R, R)$-Me-DuPHOS- $\mathrm{Rh}^{[119]}$, sodass (6'S)- oder (6'R)-Uridinylaminosäuren 65-68 in sehr hoher Diastereoselektivität erhalten wurden. Die beiden letztgenannten Reaktionen stellen die gerüstbildenden Schlüsselschritte des Verfahrens dar (Abb. 2.16). ${ }^{[15,118]}$

\subsubsection{Synthese NAA-modifizierter $O \mathrm{~N}^{[114]}$}

Die positionsselektive Einführung der NAA-Rückgratmodifikation in DNA-Sequenzen gelang durch die Synthese des Phosphoramidit-Bausteins (6'S)-69 und dessen Verwendung für die Darstellung der ON 70 und 71 durch automatisierte DNASynthese. Der Phosphoramidit-Baustein (6'S)-69 wurde durch Peptidkupplung des 3'-Aminonucleosids 72 mit der Thymidinylaminosäure (6'S)-73 zu Verbindung (6'S)74, der nachfolgenden Spaltung beider Silylether, einer regioselektiven Einführung der DMTr-Gruppe in 5"-Position unter Bildung von (6'S)-75 und einer Phosphitylierung in 3'-Position erhalten (Abb. 2.17). Die Synthese des epimeren Phosphoramiditbausteins (6'R)-69 wurde zunächst nur bis zur Vorstufe (6'R)-75 ausgeführt. Während die Synthese des Aminonucleosids 72 nach einem Verfahren der Arbeitsgruppe um Matsuda ${ }^{[120]}$ durchgeführt wurde, kam in der Synthese der Thymidinylaminosäuren (6'S)-73 und (6'R)-73 die oben beschriebene Vorgehensweise nach Spork und Ducho zum Einsatz (Abb. 2.16). 


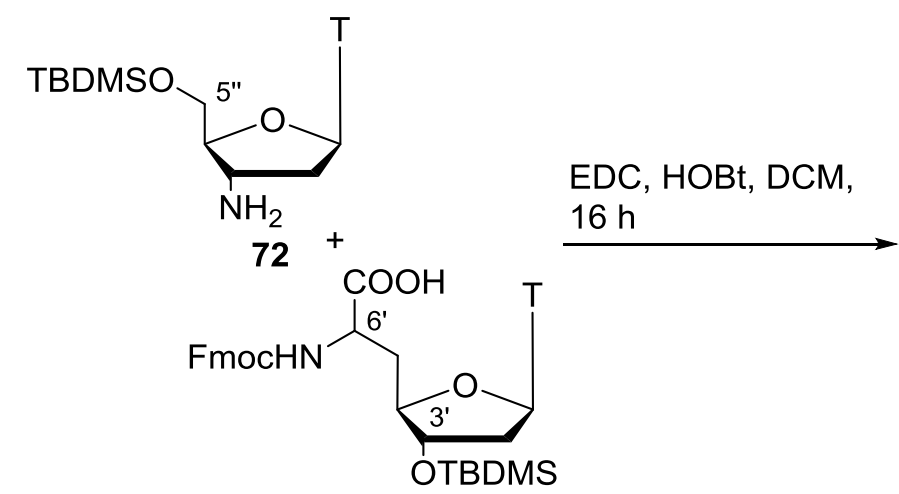

(6'S)-73

$\left(6^{\prime} R\right)-73$
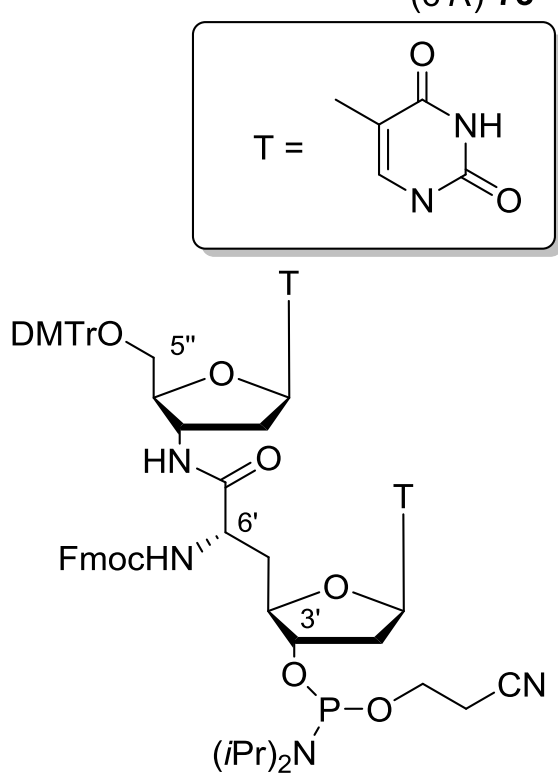

(6'S)-69 $\stackrel{\text { Oligonucleotidsynthese }}{\longrightarrow}$ TXT

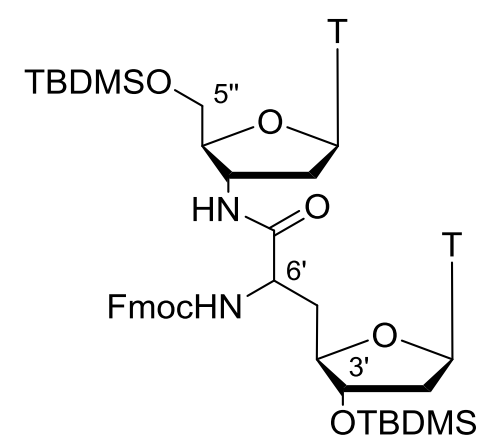

(6'S)-74 79\%

(6'R)-74 78\%

2.) $\mathrm{AcCl}, \mathrm{MeOH}$, $24 \mathrm{~h}$

3.) DMTrCl, DMAP, Pyridin, $16 \mathrm{~h}$

(6'S)-75, 76, NEt THF, $0{ }^{\circ} \mathrm{C}, 1.5 \mathrm{~h}$

$28 \%$

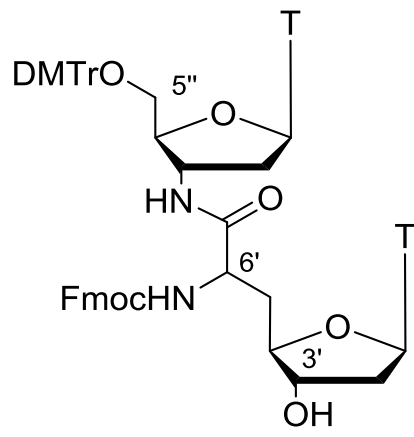

(6'S)-75 69\%

(6'R)-75 58\%

s. Abb 2.14

70: 5'-TTTTTTTT TxT TTTTTTTT-3' 71: 5'-ATCTGCACTGTCAGCACT TXTA-3'

Abb. 2.17: Synthese des Phosphoramiditbausteins (6'S)-69 und der NAA-modifizierten ON 70 und 71.

Ausgehend von Thymidin 77 wurde der Aldehyd 78 in vier Stufen mit einer Ausbeute von $53 \%$ erhalten. Dieser wurde anschließend in einer hoch diastereoselektiven Wittig-Horner-Reaktion ${ }^{[121-122]}$ mit dem Phosphonat 79 zur geschützten Didehydroaminosäure (Z)-80 umgesetzt $(Z / E=28: 1)$. Nachfolgend wurde die 5',6'Doppelbindung in Gegenwart der chiralen Katalysatoren $(S, S)$ - bzw. $(R, R)$-DuPHOSRh unter Bildung der vollständig geschützten NAA (6'S)- bzw. (6'R)-81 reduziert. In beiden Fällen war die Diastereomerenreinheit der NAA 81 sehr hoch (d.r. > 95\%). Nach drei weiteren Schritten, welche der Abspaltung bzw. der Einführung von Schutzgruppen dienten, wurden die Nucleosylaminosäuren (6'S)-73 und (6'R)-73 erhalten (Abb. 2.18). 

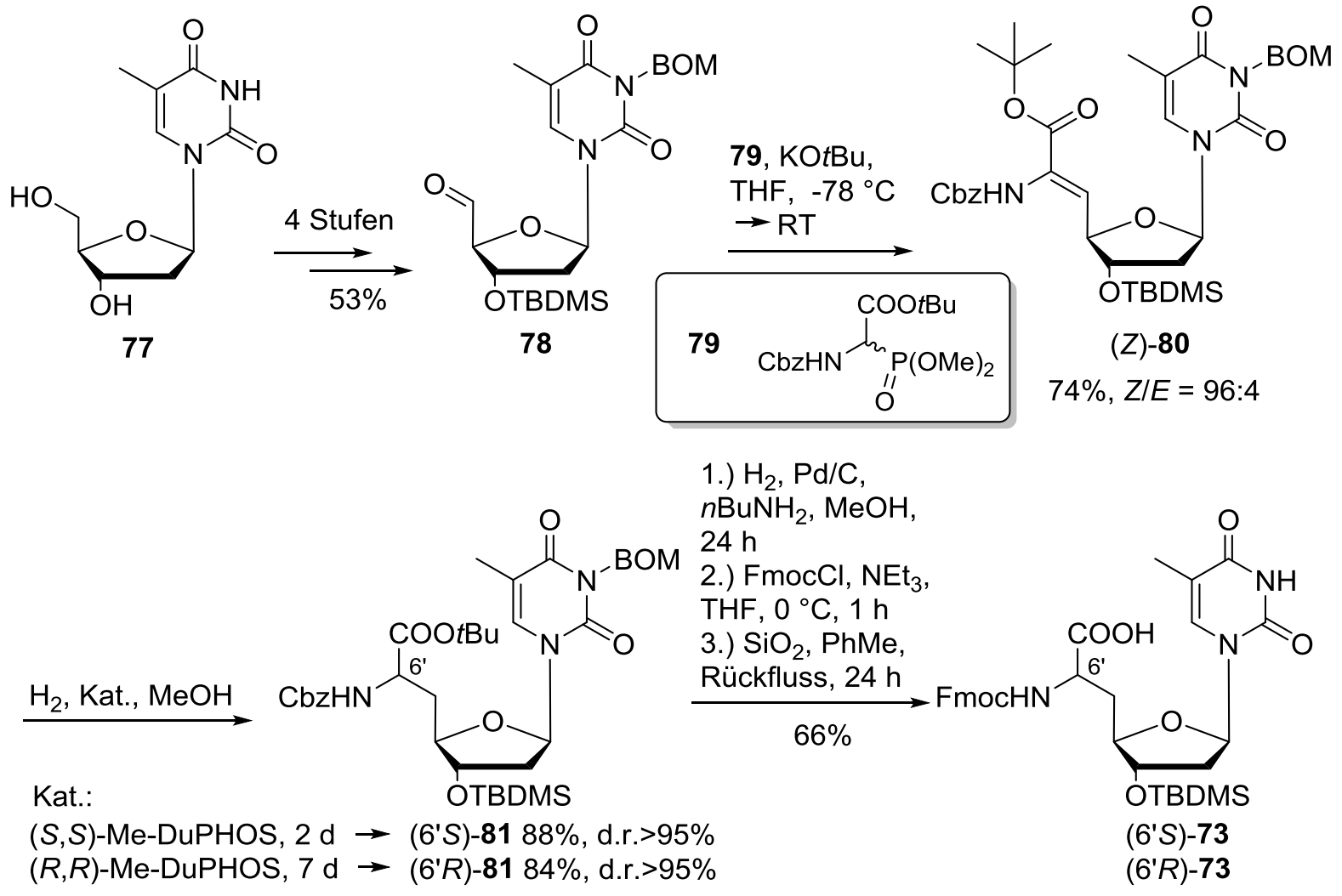

Abb. 2.18: Synthese der NAA (6'S)- und (6'R)-73.

\subsubsection{Erste Untersuchungen NAA-modifizierter ON}

Die thermodynamische Stabilität der aus $\mathbf{7 0}$ und $\mathbf{7 1}$ mit den jeweils komplementären Sequenzen gebildeten Doppelstränge (D1 und D2) sowie entsprechender unmodifizierter Referenz-Doppelstränge (D3 und D4) ist anhand von $T_{m}$-WertMessungen dokumentiert worden (Abb. 2.19).

modifizierte Duplex:

D1

$$
\begin{aligned}
& \text { 5'-TTTTTTTTTхTTTTTTTTT-3' } \\
& \text { 3'-AAAAAAAAAAAAAAAAAA-5' }
\end{aligned}
$$

D2

5'-ATCTGCACTGTCAGCACTTXTA-3' 3'-TAGACGTGACAGTCGTGAAAT-5'
Referenz:

D3

5'-TTTTTTTTTTTTTTTTTT-3'

3'-AAAAAAAAAAAAAAAAAA-5'

D4 5'-ATCTGCACTGTCAGCACTTTA-3' 3'-TAGACGTGACAGTCGTGAAAT-5'

$\mathbf{x}=$ NAA-Verbrückung

Abb. 2.19: Strukturen der analysierten DNA-Doppelstränge D1-D4.

Der Vergleich der $\mathrm{T}_{\mathrm{m}}$-Werte von D1 und D3 ergab als Differenz $\Delta \mathrm{T}_{\mathrm{m}}=-3.1^{\circ} \mathrm{C}$, womit - zumindest für diese Sequenz - eine Destabilisierung der Helix durch die Rückgratmodifikation gezeigt wurde. Die Differenz der $T_{m}$-Werte zwischen D2 und D4 
beträgt hingegen nur $-0.1^{\circ} \mathrm{C}$. Die Duplex-Stabilität ist in diesem Fall also nicht beeinträchtigt. Anhand dieser Daten konnte jedoch keine generelle Beurteilung der eingeführten Rückgrat-Modifikation vorgenommen werden. Des Weiteren ist der Einfluss der NAA-Verbrückung auf die B-Helix-Struktur der Duplices mittels CDSpektroskopie untersucht worden. Eine deutliche Beeinträchtigung der Helix-Struktur konnte jedoch nicht nachgewiesen werden. 


\section{Zielsetzung und Planung der Arbeit}

\subsection{Zielsetzung der Arbeit}

\section{Nucleosylaminosäuren als Bausteine zur Synthese modifizierter Oligonucleotide}

Das Ziel dieser Arbeit war die Synthese einer Reihe von Nucleosylaminosäure(NAA)modifizierten Nucleinsäure-Analoga mit zwitterionischer (NAA-mod. DNA) bzw. oligokationischer (oligoNAA) Ladung des Rückgrats und die Untersuchung ihrer Eigenschaften (Abb. 3.1). Diese Modifikationen können als Verknüpfung von 3'-Aminonucleosiden mit Nucleosylaminosäuren (NAA, s. Abb. 2.17) über eine AmidBindung beschrieben werden. Im Fall der NAA-mod. DNA, die gemäß dem bereits früher etablierten Verfahren ${ }^{[114]}$ synthetisiert werden sollte, ist die Einführung von NAA-Modifikationen an maximal jeder zweiten Position möglich, sodass Oligomere mit gemischtem Ladungsmuster entstehen. In Ergänzung dazu wurde ein Vorgehen zur Synthese von Oligomeren konzipiert, in denen jede Phosphatdiester-Einheit durch NAA-Modifikationen ersetzt ist. Diese Oligomere besitzen ein durchgehendes Polypeptid-Rückgrat und können daher auch als PNA-artig aufgefasst werden. Im Unterschied zu bisher beschriebenen PNA-artigen Oligomeren wurden die FuranoseRinge beibehalten, sodass ebenfalls eine größere strukturelle Verwandtschaft zu Nucleinsäuren besteht.

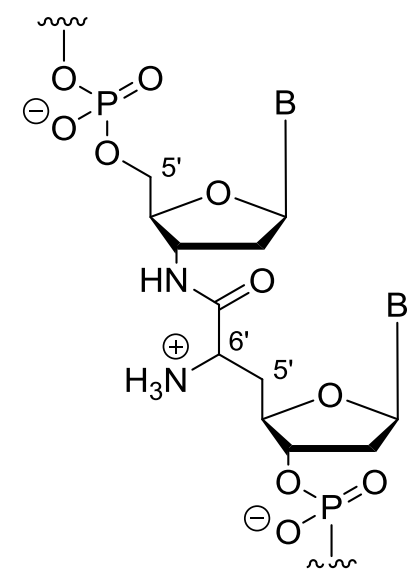

(6'S) oder (6'R)

NAA-mod. DNA

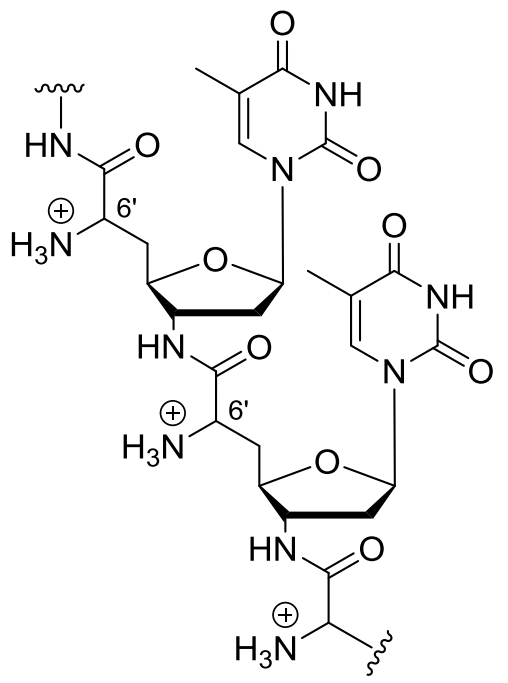

(6'S) oder (6'R) oligoNAA

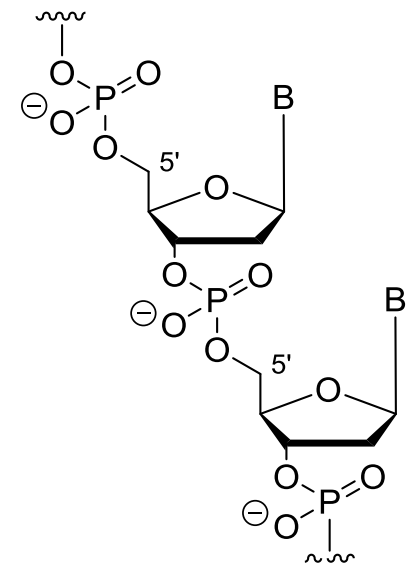

$B=$ Nucleobase

DNA

Abb. 3.1: Strukturen der ON-Analoga NAA-mod. DNA und oligoNAA im Vergleich mit der DNA. 
Bei beiden konzipierten Nucleinsäure-Analoga entspricht die Anzahl der Bindungen zwischen den zwei Furanose-Ringen derjenigen der natürlichen PhosphatdiesterVerbrückung. Der stereokontrollierte Aufbau der Chiralitätszentren in 6'-Position von NAA-mod. DNA und oligoNAA ist ein wichtiger Bestandteil der weiterführenden Syntheseplanung. Untersuchungen der biophysikalischen Eigenschaften NAAmodifizierter ON-Analoga sollen zu einem tiefgründigeren Verständnis der Relevanz des oligoanionischen Charakters von Nucleinsäuren beitragen. Die NAA-Modifikation ist in diesem Zusammenhang aufgrund verschiedener Aspekte eine vielversprechende, neuartige Rückgratmodifikation von Nucleinsäuren. Diese Modifikation ermöglicht den Aufbau von Nucleinsäure-Analoga, in denen positive Ladungen direkt im Rückgrat der Nucleinsäure-Analoga befindlich sind. Untersuchungen von Duplices mit eingeführten NAA-Modifikationen dürften daher ein realistisches Bild der Auswirkung positiver Ladungen anstelle der negativen Ladung der Phosphatdiester auf die Duplex-Stabilität ergeben. Im Gegensatz dazu waren positive Ladungen in vielen der bisher synthetisch realisierten zwitterionischen oder positiv geladenen Nucleinsäureanaloga entweder an der Nucleobase eingeführt oder über verschiedene Linker an der 2'-Position bzw. an der Verbrückung angebracht. Es war daher oft schwierig genaue Aussagen über den Zusammenhang der räumlichen Ausrichtung der positiven Ladung und beobachteten Eigenschaften der Analoga zu machen. Die einzigen bisher bekannten Modifikationen, in welchen die positiven Ladungen direkt im Rückgrat befindlich sind - die DNG und DNmt von Bruice weisen jedoch stärkere Abweichungen von der typischen Nucleinsäurestruktur auf. ${ }^{[86]}$ Daher können die erhöhten Affinitäten dieser Analoga auch auf geometrische Faktoren zurückzuführen sein (s. Kap. 2.4.3). Hingegen deutet die Beschaffenheit der NAA-Modifikation an, dass es sich um ein gutes Mimetikum der PhosphatdiesterEinheit handeln könnte. Untersuchungen an elektroneutralen Modifikationen ähnlichen Typs durch De Mesmaeker ${ }^{[70,76-79,123]}$ und Rozners ${ }^{[00]}$ haben auf eindrucksvolle Weise gezeigt, dass es sich bei Amid-Verbrückungen um sehr gute Mimetika von Phosphatdiestern handelt (s. Kap. 2.4.2). Die konformationelle Flexibilität von Amid-Verbrückungen ist im Vergleich zu Phosphatdiestern nur geringfügig reduziert. Auch die Isosterie zur Phosphatdiesterverknüpfung ist in hinreichendem Maß gegeben, sodass nahezu keine Störung der Basenpaarung auftreten sollte. Im Folgenden ist die detaillierte Planung der Synthese und Untersuchung der zwei Typen von Oligomeren (NAA-mod. DNA in Kap. 3.2.1 und oligoNAA in Kap. 3.2.2) beschrieben. 


\subsection{Planung der Arbeit}

\subsubsection{NAA als Bausteine für die Synthese zwitterionischer ON}

\subsubsection{1 Überlegungen zur Wahl der Sequenzen der modifizierten ON}

Für eine weiterführende Untersuchung der Eigenschaften der zuvor beschriebenen NAA-Verbrückung wären die Synthese von weiteren NAA-modifizierten zwitterionischen Oligonucleotiden und die Analyse ihres Hybridisierungsverhaltens sowie struktureller Eigenschaften notwendig. Insbesondere wurde angestrebt, Erkenntnisse über den Einfluss der folgenden Faktoren auf die Eigenschaften von NAA-modifizierten Nucleinsäure-Duplices zu gewinnen:

1. Stereochemie der NAA-Verbrückung (Konfiguration des Stereozentrums in 6'-Position der NAA-Modifikation (s. Abb. 3.2))

2. Anzahl der NAA-Modifikationen und ihre Position/Distanz im Strang

3. Basensequenz

Zu diesem Zweck war die Synthese von 24 ON vorgesehen, die in 3 verschiedene Typen ON a-ON c (Abb. 3.2) unterteilt werden können. Als Verfahren für die Herstellung der ON sollte analog zur Vorarbeit die von Beaucage und Caruthers entwickelte Phosphoramidit-Methode verwendet werden. ${ }^{[9]}$ Dabei war die Wahl der Sequenzen zunächst dadurch eingeschränkt, dass ein synthetisches Verfahren nur für die T-T-dimeren Phosphoramiditbausteine (6'S)-69 und (6'R)-69 (Abb. 3.2) etabliert war. Ferner waren die nachfolgend angeführten Randbedingungen zu berücksichtigen. Die aus modifizierten ON mit komplementären DNA- und RNASträngen gebildeten Duplices sollten selbst im Fall einer erheblichen Destabilisierung der Duplex deutlich oberhalb der Raumtemperatur liegende $T_{m}$-Werte aufweisen. Dies ist von Vorteil, da selbst bei einer größeren Zahl an Modifikationen der Nachweis der Hybridisierung wahrscheinlicher ist und auch eine eventuelle Assoziation zu höher geordneten Komplexen (Triplices, Quadruplices) bei niedrigeren Temperaturen beobachtet werden kann. Zudem können die experimentellen Bedingungen für die Aufnahme von CD-Spektren einfach gehalten werden. Daher wurden Sequenzen der Länge von 20-22 Monomeren eingeplant. 


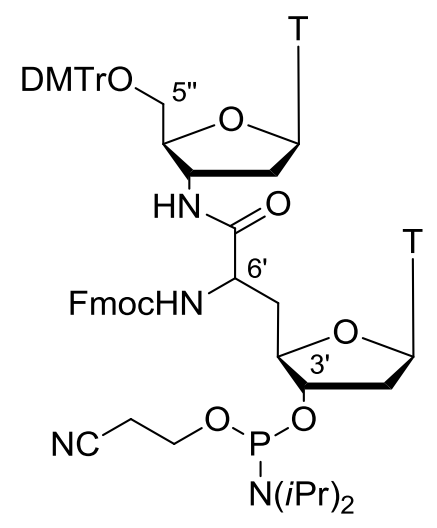

(6'S)-69 $\left(6^{\prime} R\right)-69$
Oligonucleotidsynthese

Konzipierte Sequenzen:

ON a 5'-GGCACGGTTTTTTTTTGGCACGG-3'

ON b 5'-GTTGACGTTGACGTTGACGTTG-3'

ON c 5'-GCGCTTGCTTAAGCAAGCGC-3'

TT: Position für mögliche NAA-Modifikation

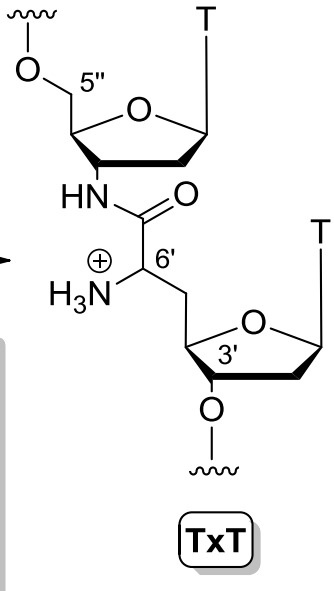

(6'S) oder (6'R)

\begin{tabular}{|c|c|c|c|}
\hline $\mathrm{Nr}$. & Sequenz & 6'-Konfiguration von $\mathbf{x}$ & ON-Typ \\
\hline 1 & 5'-GGCACGG TxT TT TT TxT GGCACGG-3' & $S$ & ON a \\
\hline 2 & & $R$ & \\
\hline 3 & 5'-GGCACGG TxT TT TxT TT GGCACGG-3' & $S$ & \\
\hline 4 & & $R$ & \\
\hline 5 & 5'-GGCACGG TxT TxT TT TT GGCACGG-3' & $s$ & \\
\hline 6 & & $R$ & \\
\hline 7 & 5'-GGCACGG TxT TT TT TT GGCACGG-3' & $s$ & \\
\hline 8 & & $R$ & \\
\hline 9 & 5'-GGCACGG TxT TxT TxT TxT GGCACGG-3' & $s$ & \\
\hline 10 & & $R$ & \\
\hline 11 & 5'-G TxT GACG TT GACG TT GACG TT G-3' & $S$ & ON b \\
\hline 12 & & $R$ & \\
\hline 13 & 5'-G TT GACG TxT GACG TT GACG TT G-3' & $S$ & \\
\hline 14 & & $R$ & \\
\hline 15 & 5'-G TT GACG TT GACG TxT GACG TT G-3' & $S$ & \\
\hline 16 & & $R$ & \\
\hline 17 & 5'-G TT GACG TT GACG TT GACG TxT G-3' & $S$ & \\
\hline 18 & & $R$ & \\
\hline 19 & 5'-G TxT GACG TxT GACG TxT GACG TxT G-3' & $S$ & \\
\hline 20 & & $R$ & \\
\hline 21 & 5'-GCGC TxT GC TT AAGCAAGCGC-3' & $S$ & ON c \\
\hline 22 & & $R$ & \\
\hline 23 & 5'-GCGC TT GC TxT AAGCAAGCGC-3' & $S$ & \\
\hline 24 & & $R$ & \\
\hline
\end{tabular}

Abb. 3.2: Zu synthetisierende NAA-modifizierte ON.

Des Weiteren wurden die Nucleobasensequenzen so gewählt, dass die Bildung von Haarnadel-Strukturen oder Selbstassoziation vermieden werden (außer im Fall von 
ON c, Abb. 3.2), um ausschließlich die Hybridisierung mit komplementären DNAoder RNA-Strängen sicherzustellen. Der Sequenztyp ON a ist ein 22mer und weist eine Gapmer-Struktur mit acht aufeinander folgenden Thymidin-Bausteinen in der Mitte auf. Innerhalb dieser acht T-Einheiten ist eine variable Positionierung von maximal vier NAA-Modifikationen möglich. Neben der Variation der Position und Anzahl der NAA-Brücken ist auch die Anordnung der NAA-Modifikationen in unterschiedlichen Abständen innerhalb der Folge der acht T-Einheiten möglich. Auf diese Weise sollten mögliche Auswirkungen unterschiedlicher Distanzen der positiven Ladungen auf die Eigenschaften der Duplex nachweisbar sein. Dazu war die Synthese der ON a (Nr. 1-8, Abb. 3.2) vorgesehen. Anhand der Sequenzen mit vier NAA-Substitutionen (Nr. 9 und 10, Abb. 3.2) sollte der Effekt einer erhöhten Anzahl von NAA-Verbrückungen beobachtet werden können. Der Sequenztyp ON b ist ein $21 \mathrm{mer}$, in dem vier dimere T-T-Einheiten in einem regelmäßigen Abstand von vier Nucleotiden angeordnet sind. Durch die Synthese der ON b (Nr. 11-18, Abb. 3.2) sollte eine Reihe von Oligonucleotiden erhalten werden, anhand derer Auswirkungen unterschiedlicher Positionierungen einer NAA-Modifikation auf die Eigenschaften der Nucleinsäure-Duplex beobachtet werden können. Die Sequenzen mit vier NAAModifikationen vom Typ ON b (Nr. 19 und 20, Abb. 3.2) sollten ebenfalls dazu verwendet werden, die Auswirkung einer höheren Anzahl an NAA-Brücken nachzuweisen. Die palindromen Sequenzen vom Typ ON $\mathbf{c}$ besitzen zwei Stellen, an denen eine Einführung von NAA-Einheiten möglich ist. Durch die Bildung von Duplices aus diesen Sequenzen durch Selbstassoziation können zwei positive Ladungen in gegenüber liegenden Strängen befindlich sein, nicht jedoch im selben Strang. Um beobachten zu können, wie die NAA-Modifikation sich auf Duplices unterschiedlicher Basensequenzen auswirkt, wäre die Synthese weiterer modifizierter ON, in denen die NAA-Einheit sich an anderen Positionen als zwischen zwei Thymidin-Bausteinen befinden würde, sinnvoll. Die Voraussetzung hierfür wäre die Entwicklung von Synthesewegen für Analoga der Phosphoramiditbausteine 69 mit anderen Nucleobasen als Thymin. 


\subsubsection{2 Überlegungen zur Synthese der Phosphoramidit-Bausteine (6'S)-69 und (6'R)-69}

Die in Abb. 3.2 angeführten Strukturen $\left(6^{\prime} S\right)$ - und $\left(6^{\prime} R\right)$-TxT sollten in einer für die festphasengestützte Oligonucleotid-Synthese verwendbaren Form dargestellt werden. Die literaturbekannte Phosphoramidit-Strategie ${ }^{[9]}$ für die ON-Synthese nach Caruthers erfordert eine Dimethoxytrityl-Schützung an 5"-O und die Derivatisierung von $3^{\prime}-O$ zu einer $\beta$-Cyanoethyl- $N, N$-diisopropylphosphoramidit-Funktionalität. ${ }^{[124]}$ Zudem sollte die basenlabile Fmoc-Schutzgruppe ${ }^{[125]}$ an der $6^{\prime}$-Aminofunktion eingeführt werden, um Nebenreaktionen während der ON-Synthese zu vermeiden. Die Entfernung der Fmoc-Gruppe geschieht bei der basenvermittelten Abspaltung (wässrige Ammoniaklösung/Ethanol $3: 1,55^{\circ} \mathrm{C}, 24 \mathrm{~h}$ ) der $\mathrm{ON}$ von der festen Phase. Im Verlauf der erneuten Synthese der Phosphoramiditbausteine (6'S)- und (6'R)-69 sollte das etablierte Verfahren ${ }^{[114]}$ optimiert werden. Hierfür wurden insbesondere hinsichtlich zweier Aspekte Verbesserungsmöglichkeiten angenommen. Im etablierten Verfahren wurden die Wittig-Horner-Reaktion und die asymmetrische Hydrierung der 5',6'-Doppelbindung - die beiden Schlüsselschritte der Synthese der NAA 81 - mit geschützter Nucleobase durchgeführt (s. Abb. 2.18). Kurz vor Beginn dieser Arbeit konnte die gleiche Reaktionssequenz an entsprechenden Basenungeschützten Uridin-Analoga mit hervorragenden Ergebnissen sowohl hinsichtlich der Ausbeute als auch der Stereoselektivität durchgeführt werden. ${ }^{[18]}$ Daher erschien es naheliegend, diese Vorgehensweise auch auf die Synthese der Thymidin-Analoga (6'S)- und (6'R)-73 zu übertragen. Dies würde die Synthese insgesamt deutlich vereinfachen, da bei der hydrogenolytischen Spaltung der Schutzgruppen von (6'S)- und (6'R)-83 kein $n$-Butylamin zur Reaktion mit entstehendem Formaldehyd hinzugefügt werden müsste, dessen vollständige Entfernung nur durch chromatographische Reinigung möglich ist. Außerdem wäre die Einführung der BOM-Schutzgruppe an der Nucleobase bei der Synthese des Aldehyds 84 nicht mehr notwendig (Abb. 3.3). 

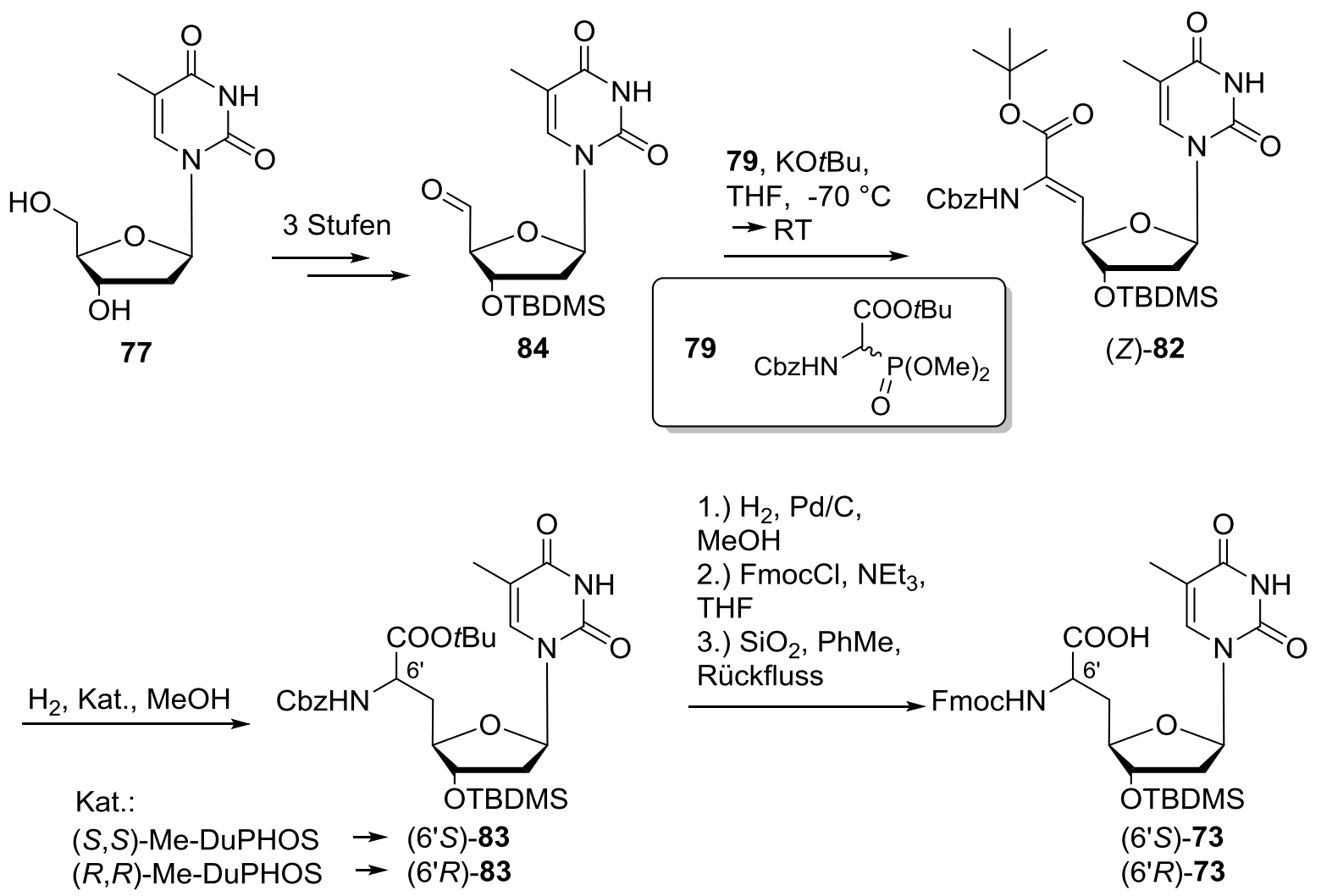

Abb. 3.3: Geplante Synthese der NAA 73 ohne BOM-Schützung.

Der zweite zu optimierende Aspekt des etablierten Verfahrens zur Synthese der Phosphoramidit-Reagenzien (6'S)- und (6'R)-69 war der letzte Schritt der Reaktionssequenz: die Phosphitylierung. Diese Reaktion wurde zunächst unter basischen Bedingungen $\left(\mathrm{NEt}_{3}\right)$ durchgeführt. Es resultierte jedoch eine teilweise Spaltung der Fmoc-Gruppe, sodass die Ausbeute mit 28\% nicht zufriedenstellend war. Daher wurde für die Phosphitylierung ein mild saures Verfahren (Phosphitylierungs-Reagenz 85, Dicyanoimidazol 86, Abb. 3.4) als Alternative vorgesehen.
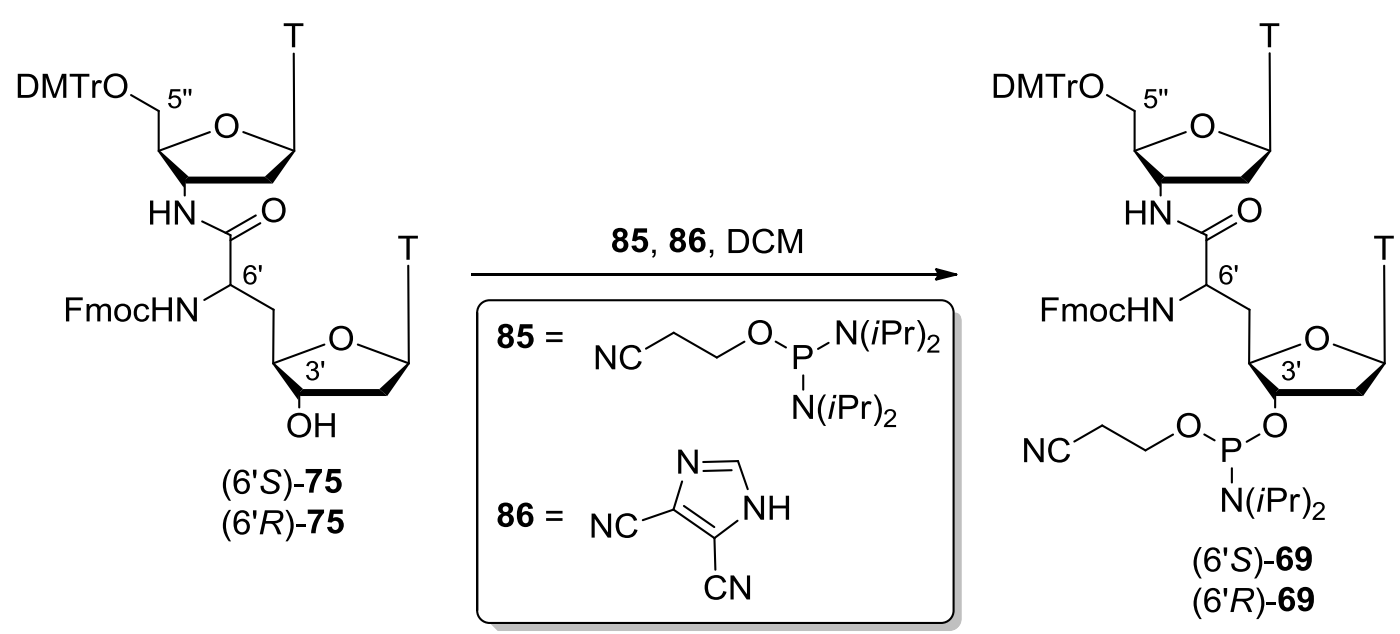

Abb. 3.4: Alternative Vorgehensweise zur Phosphitylierung von (6'S)- und (6'R)-75. 


\subsubsection{3 Überlegungen zur Synthese der weiteren Phosphoramidit-Bausteine}

Das etablierte Syntheseverfahren für die Phosphoramiditbausteine (6'S)- und (6'R)-69 ermöglichte nur die Synthese von ON mit NAA-Modifikationen zwischen zwei Thymidin-Einheiten. Um die Herstellung von ON mit NAA-Modifikationen zwischen anderen Nucleosiden zu realisieren, wurde die Synthese von Phosphoramiditbausteinen mit anderen Nucleobasen als Thymin angestrebt. Im Sinne eines dem Zeitplan angemessenen Syntheseaufwands wurden die Zielverbindungen zunächst auf (6'S)- und (6'R)-87-89 beschränkt (Abb. 3.5).

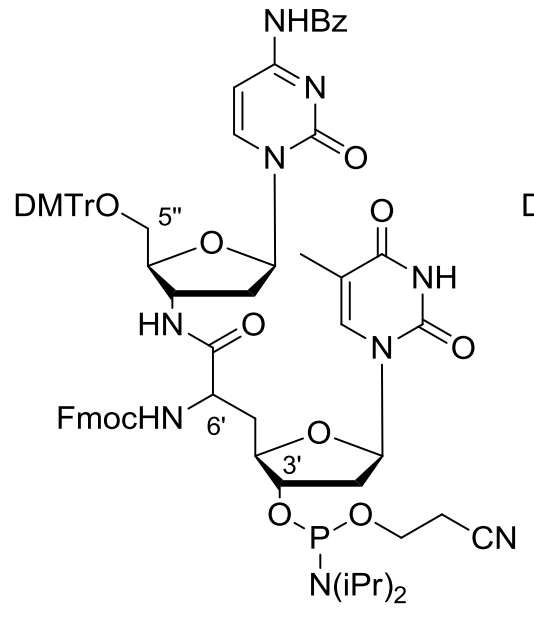

(6'S)- oder (6'R)-87

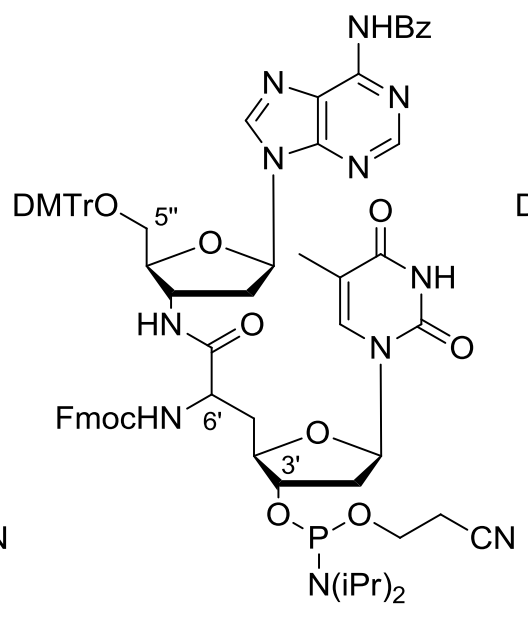

(6'S)- oder (6'R)-88

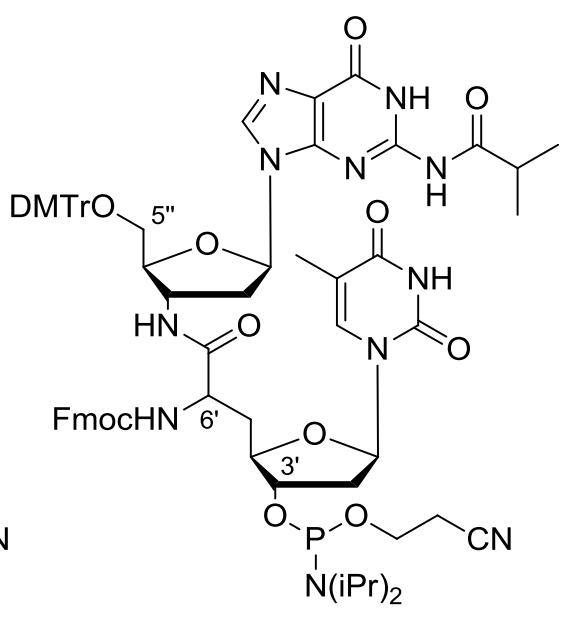

(6'S)- oder (6'R)-89

Abb. 3.5: Weitere Phosphoramiditreagenzien 87-89 zur Synthese NAA-modifizierter ON.

Ein weiterer Grund für diese Einschränkung waren erhebliche Schwierigkeiten bei Syntheseversuchen von Nucleosylaminosäuren mit anderen Nucleobasen anstelle von Uracil oder Thymin. ${ }^{[126-127]}$ Daher sollten vorerst die zugänglichen Thymidinylaminosäuren (6'S)- und (6'R)-73 und die 3'-Aminonucleoside des Cytosins 90, Adenosins 91 und Guanosins 92 für den Aufbau der Zielverbindungen 87-89 verwendet werden. Die hierfür vorgesehene Synthesestrategie sollte sich prinzipiell an der bereits erfolgreich verwendeten Vorgehensweise zur Synthese der ThymidinDimere (6'S)- und (6'R)-69 orientieren. ${ }^{[14]}$ Diese bestand aus einer Peptidkupplung des 3'-Aminothymidins mit den NAA 73, nachfolgender Spaltung der Silylether an 5"- und an 3'-Position, einer regioselektiven Einführung einer DMTr-Gruppe an 5"-Position und schließlich der Phosphitylierung am 3'-O (Abb. 2.17 und Abb. 3.6). 


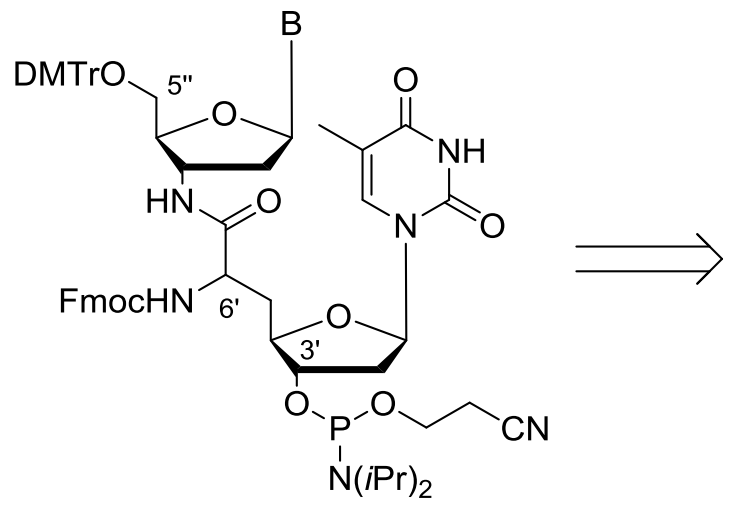

(6'S) oder (6'R)

87: $\mathrm{B}=\mathrm{C}^{\mathrm{BZ}}$

88: $B=A^{B z}$

89: $B=G^{i B u}$

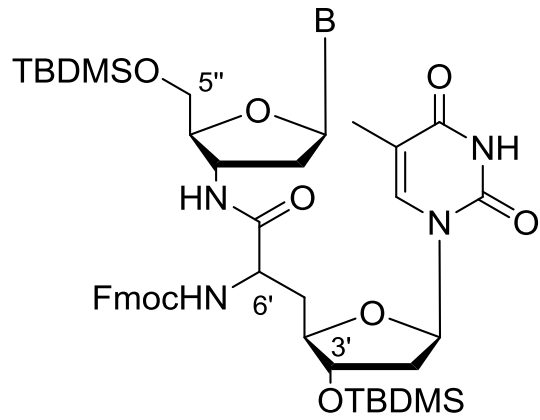

(6'S) oder (6'R)

93: $\mathrm{B}=\mathrm{C}^{\mathrm{Bz}}$

94: $B=A^{B z}$

95: $B=G^{i B u}$

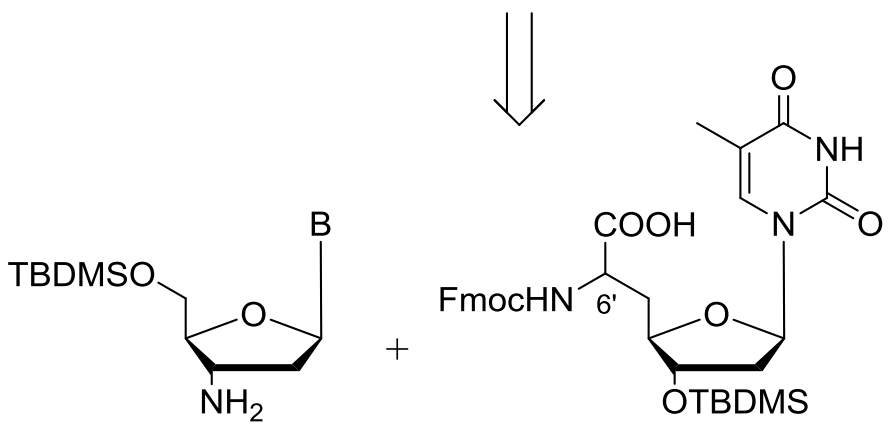

90: $\mathrm{B}=\mathrm{C}^{\mathrm{Bz}}$

91: $B=A^{B z}$

92: $B=G^{i B u}$

$\left(6^{\prime} S\right)-\operatorname{oder}\left(6^{\prime} R\right)-73$

Abb. 3.6: Retrosynthese der Verbindungen (6'S)- und (6'R)-87-89.

Allerdings wurde angenommen, dass aufgrund der Säurelabilität der $\mathrm{N}$-glykosidischen Bindung von Purin-2'-Desoxynucleosiden andere Methoden für die Spaltung der 3'-O- und 5"-O-Silylether von 93 und 94 (Abb. 3.6) verwendet werden müssten als die früher eingesetzte Säure-katalysierte Solvolyse in $\mathrm{MeOH} .{ }^{[128]}$

\subsubsection{Planung der Synthese der 3'-Aminonucleoside 90-92}

Im Gegensatz zum Thymin weisen die Nucleobasen Adenin, Cytosin und Guanin exocyclische Aminogruppen auf, die aufgrund ihrer Nucleophilie bekanntermaßen Nebenreaktionen bei der ON-Synthese verursachen. Daher wurden Schutzgruppen für diese Funktionalitäten vorgesehen. Diese wurden auch hier so gewählt, dass eine Kompatibilität mit der Methode zur Synthese der ON gegeben war. Gleichzeitig sollten die Schutzgruppen unter den Bedingungen der Abspaltung vom Träger entfernt werden können. Für diesen Zweck haben sich die Benzoyl- (für Adenin und Cytosin) und die ßBu-(Isobutyryl)-Schutzgruppen (für Guanin) bewährt. ${ }^{[129-130]}$ Über 
die stereoselektive Darstellung der 3'-Aminonucleoside 90-92 (Abb. 3.5) ist bereits in einigen Veröffentlichungen berichtet worden. ${ }^{[131-136]}$ Insbesondere erscheint die Vorgehensweise von Richert aufgrund ihrer Einfachheit im Vergleich zu den anderen Methoden als vorteilhaft. ${ }^{[137]}$ Demnach verläuft die Synthese von 3'-Amino-5'-O(TBDMS)-2'-desoxycytidin 90 über die bicyclische Verbindung 96, deren Ringöffnung durch $\mathrm{NaN}_{3}$ unter Einführung der Azid-Funktionalität in 3'-Position, nachfolgende Umschützung in 5'-Position und Reduktion des Azids 97 zum Amin 90 (Abb. 3.6).
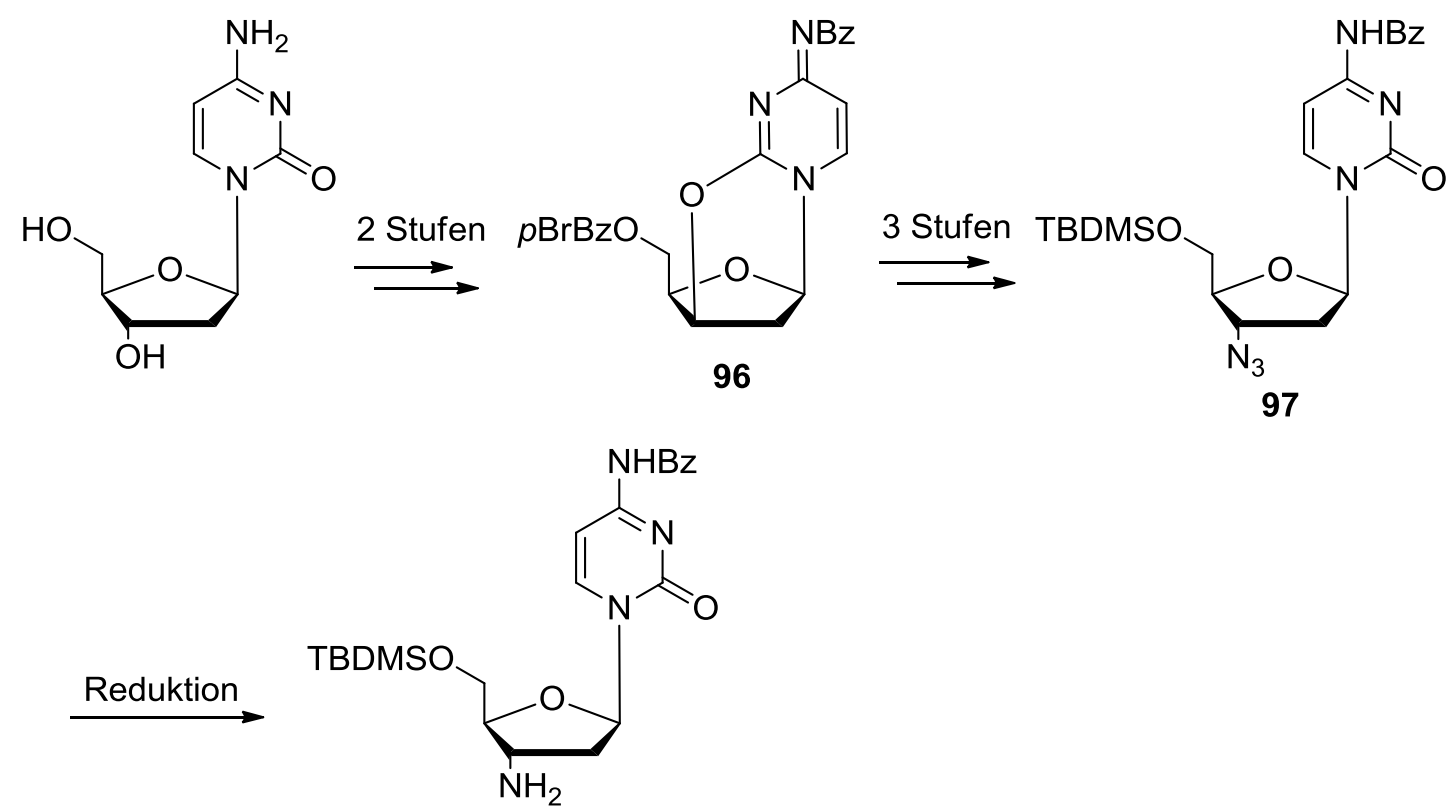

90

Abb. 3.7: Syntheseweg für das Cytidin-Derivat 90.

Im Unterschied dazu beinhaltet die Synthesestrategie für den Zugang zu den Purin3'-Aminonucleosiden $\mathbf{9 1}$ und $\mathbf{9 2}$ die Synthese der geschützten Verbindungen $\mathbf{9 8}$ und 99, Inversion der Konfiguration am 3'-C durch eine DMP-Oxidation zum 3'-Keton und anschließende Naborhydrid-Reduktion zu den xylo-Verbindungen 100 und 101. Die Substitution der 3'-Hydroxygruppen dieser xylo-Derivate durch Azideinheiten und deren Reduktion sollten die 3'-Aminonucleoside 91 und 92 ergeben. Zur Aktivierung der 3'-Hydroxygruppen der xylo-Verbindungen sind zahlreiche unterschiedliche Reagenzien verwendet worden. Eine eindeutige Präferenz für eine der Aktivierungsmethoden allein auf Basis der publizierten Daten war nicht möglich. 


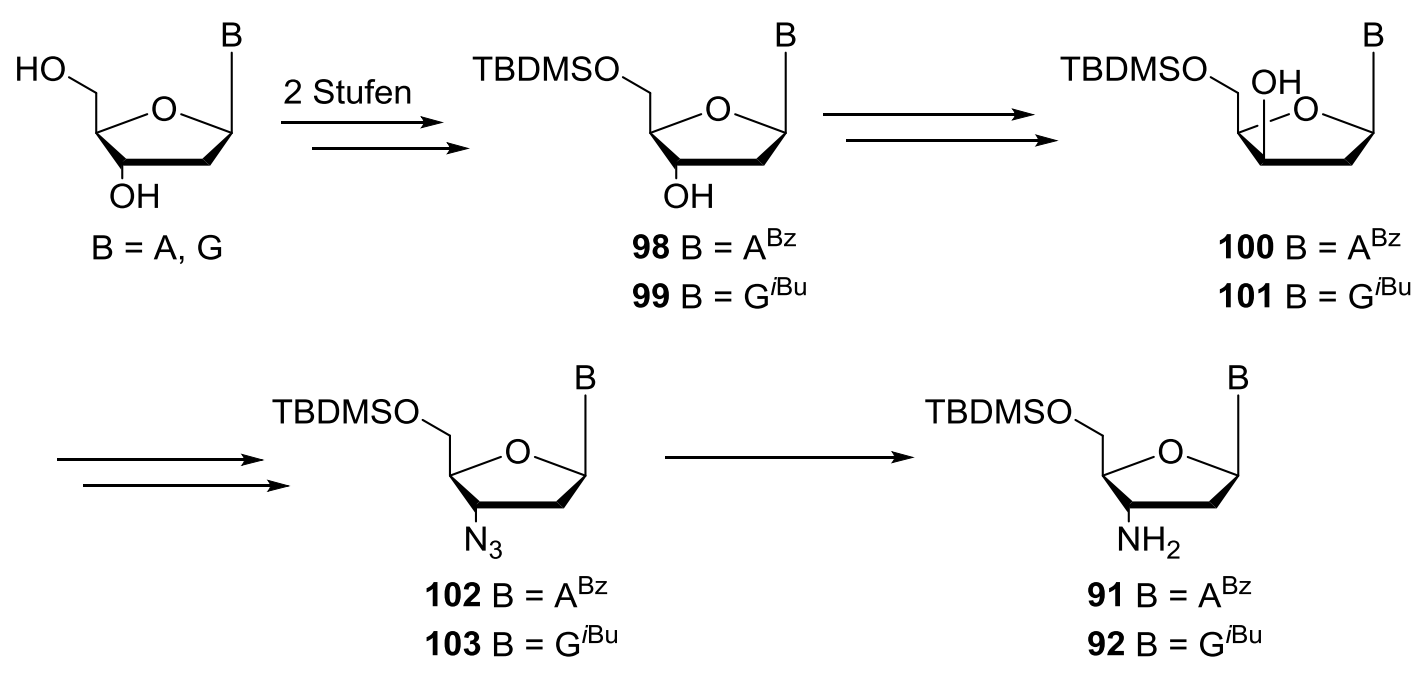

Abb. 3.8: Bekannter Syntheseweg für die Verbindungen 91 und 92.

\subsubsection{NAA-Derivate für die Synthese uniform kationischer ON}

Die bisher veranschaulichte Methode zur Herstellung NAA-modifizierter Oligonucleotide ermöglicht nur die Synthese zwitterionischer ON, da die kationische NAA-Modifikation maximal in jeder zweiten Position einer Sequenz angeordnet sein kann. In Ergänzung dazu wurde ein Oligomer (oligoNAA) konzipiert, das an jeder monomeren Einheit eine positive Ladung trägt und sowohl der DNA als auch der PNA strukturell verwandt ist (Abb. 3.9). Die Synthese eines solchen NucleinsäureAnalogons sollte unter Verwendung der Bausteine (6'S)- oder $\left(6^{\prime} R\right)-104$ durch Festphasen-Peptidsynthese durchgeführt werden können. Bei den Verbindungen (6'S)- und (6'R)-104 handelt es sich um NAA-Derivate, an deren 3'-Position die Hydroxygruppe durch eine Aminogruppe ersetzt ist. Die geplante Verwendung dieser Bausteine für die Oligopeptidsynthese gemäß der Fmoc-Strategie ${ }^{[138]}$ erfordert eine Fmoc-Schützung der zu kuppelnden $\mathrm{NH}_{2}$-Gruppe (3'-Position) und eine säurelabile Schutzgruppe (Boc) an der nicht reagierenden $\mathrm{NH}_{2}$-Gruppe (6'-Position). Letztere Schutzgruppe sollte bei der Abspaltung der Oligomere vom Träger vollständig entfernt werden können. 


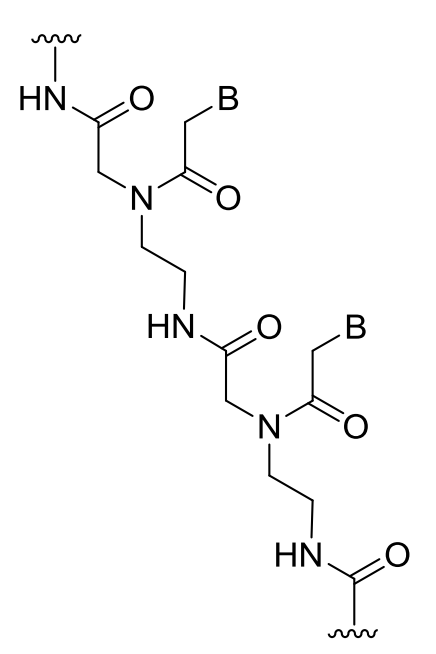

aegPNA

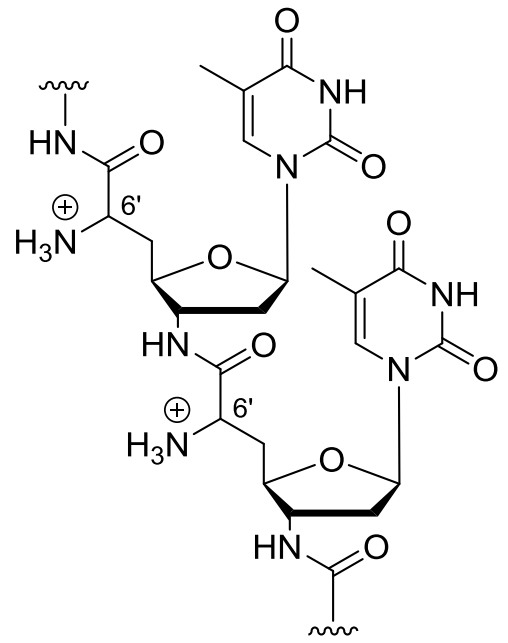

oligoNAA

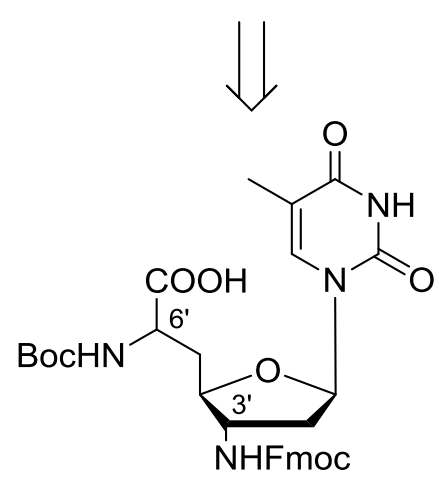

(6'S)- oder (6'R)-104

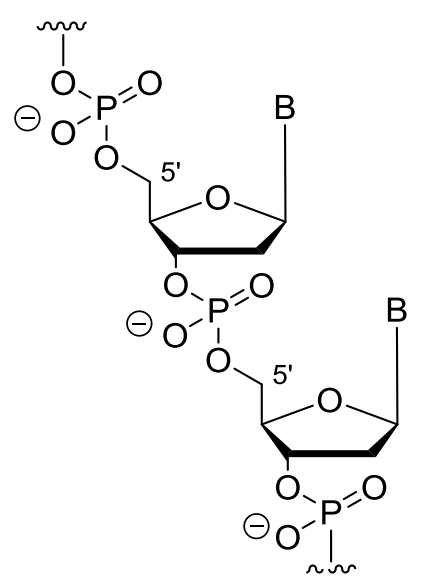

DNA

Abb. 3.9: Strukturen der oligoNAA, aegPNA und DNA; Retrosynthese der oligoNAA.

Für die Synthese der Verbindungen (6'S)- und (6'R)-104 sind prinzipiell zwei Strategien in Betracht gezogen worden, die im Wesentlichen auf der bewährten Methode zur generellen Herstellung von NAA beruhen. Dies impliziert wiederum die Kondensation eines Nucleosylaldehyds 105-108 mit dem Phosphonat 109 in einer Wittig-Horner-Reaktion, eine asymmetrische Hydrierung der resultierenden 5',6'-Doppelbindung von 110-113 unter Bildung der (6'S)- und (6'R)-NAA 114-117 und anschließende Schutzgruppenmanipulation für den Zugang zu den Zielverbindungen (6'S)- und (6'R)-104 (Abb. 3.10). Der Unterschied der beiden Vorgehensweisen liegt in der Wahl der funktionellen Gruppe in 3'-Position und der sich daraus ergebenden Länge der Syntheseroute. Die erste Möglichkeit besteht darin, eine Azidogruppe an der 3'-Position einzusetzen. Demnach wäre Azid 118 das Startmaterial, welches in nur drei Stufen aus Thymidin zugänglich ist. In der alternativen Vorgehensweise wird 120 als Ausgangsmaterial verwendet. An dessen 3'-Position befindet sich eine NHCbz-Funktionalität anstelle der Azidogruppe. Die Synthese dieser Verbindung aus Thymidin ist um zwei Stufen länger als diejenige 
des Azids 118. Beide Syntheserouten sollten durchgeführt und miteinander verglichen werden. Des Weiteren sollte auch hier geprüft werden, ob eine Synthese der Zielverbindungen 104 auch ohne die Verwendung von NucleobasenSchutzgruppen möglich ist.

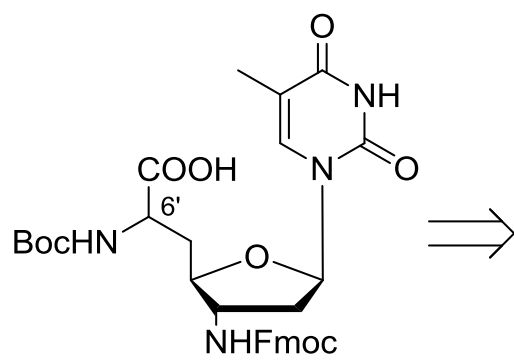

(6'S)- oder (6'R)-104

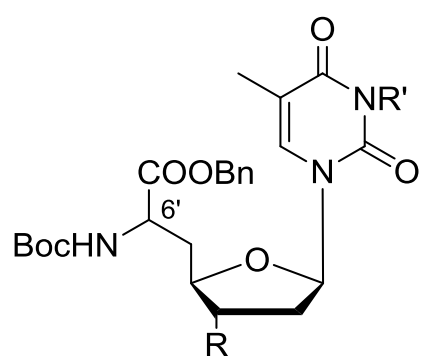

(6'S) oder (6'R)

$114 \mathrm{R}=\mathrm{N}_{3}, \mathrm{R}^{\prime}=\mathrm{H}$

$115 \mathrm{R}=\mathrm{N}_{3}, \mathrm{R}^{\prime}=\mathrm{BOM}$

$116 \mathrm{R}=\mathrm{NHCbz}, \mathrm{R}^{\prime}=\mathrm{H}$

$117 \mathrm{R}=\mathrm{NHCbz}, \mathrm{R}^{\prime}=\mathrm{BOM}$

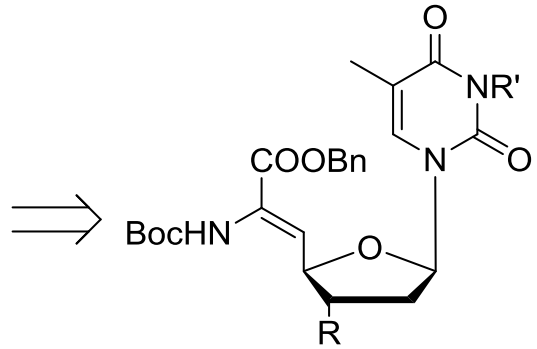

$110 \mathrm{R}=\mathrm{N}_{3}, \mathrm{R}^{\prime}=\mathrm{H}$

$111 \mathrm{R}=\mathrm{N}_{3}, \mathrm{R}^{\prime}=\mathrm{BOM}$

$112 \mathrm{R}=\mathrm{NHCbz}, \mathrm{R}^{\prime}=\mathrm{H}$

$113 \mathrm{R}=\mathrm{NHCbz}, \mathrm{R}^{\prime}=\mathrm{BOM}$

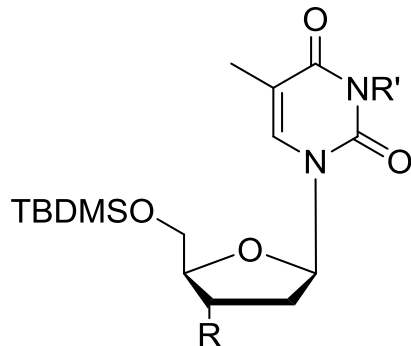

$118 \mathrm{R}=\mathrm{N}_{3}, \mathrm{R}^{\prime}=\mathrm{H}$

$119 \mathrm{R}=\mathrm{N}_{3}, \mathrm{R}^{\prime}=\mathrm{BOM}$

$120 \mathrm{R}=\mathrm{NHCbz}, \mathrm{R}^{\prime}=\mathrm{H}$

$121 \mathrm{R}=\mathrm{NHCbz}, \mathrm{R}^{\prime}=\mathrm{BOM}$<smiles>[R]C1C[C@H](n2cc(C)c(=O)[nH]c2=O)O[C@@H]1C(=O)OCc1ccccc1</smiles>

$105 \mathrm{R}=\mathrm{N}_{3}, \mathrm{R}^{\prime}=\mathrm{H}$

$106 \mathrm{R}=\mathrm{N}_{3}, \mathrm{R}^{\prime}=\mathrm{BOM}$

$107 \mathrm{R}=\mathrm{NHCbz}, \mathrm{R}^{\prime}=\mathrm{H}$

$108 \mathrm{R}=\mathrm{NHCbz}, \mathrm{R}^{\prime}=\mathrm{BOM}$

Abb. 3.10: Retrosynthese der Bausteine 104 für die Synthese von polyNAA.

Insgesamt sind die Schutzgruppen so gewählt worden, dass in dem vorletzten Schritt eine möglichst große Zahl in einer Reaktion reduktiv (Bn, BOM, Cbz) abgespalten werden kann. Die Synthese sollte vorerst auf Thymidinderivate beschränkt werden, um dem zeitlichen Rahmen der Arbeit gerecht zu werden. Nach Synthese der Zielverbindungen sollen im Rahmen einer Kooperation mit Dr. T. Grossmann (CGC Dortmund) zukünftig 16mere Oligo-T-Sequenzen (all-6'S oder all-6' $R$ ) aus den modifizierten Bausteinen hergestellt und deren Hybridisierungseigenschaften untersucht werden. 


\section{Resultate und Diskussion}

\subsection{Synthese von Reagenzien}

\subsubsection{Synthese des Phosphitylierungs-Reagenzes}

Das für die mild-saure Phosphitylierung von Dinucleosiden (s. Kap 4.4) verwendete Reagenz 2-Cyanoethyl-N,N,N,N-tetraisopropylphosphordiamidit 85 („Bis-Reagenz") wurde nach einem bekannten Verfahren synthetisiert. ${ }^{[139]}$ Demnach wurde Phosphortrichlorid in absolutem Diethylether und in Gegenwart von Pyridin als Base zuerst mit einem Äq. 3-Hydroxypropionitril zur Reaktion gebracht. Nach einer Filtration unter Argon wurde das resultierende Zwischenprodukt 122 wiederum in absolutem Diethylether mit zwei Äq. Diisopropylamin zu 85 umgesetzt, welches nochmals durch Filtration unter Argon von dem als Niederschlag anfallenden Pyridiniumsalz befreit wurde. Die Ausbeute der Reaktionssequenz betrug $66 \%$ über zwei Schritte (Abb. 4.1).

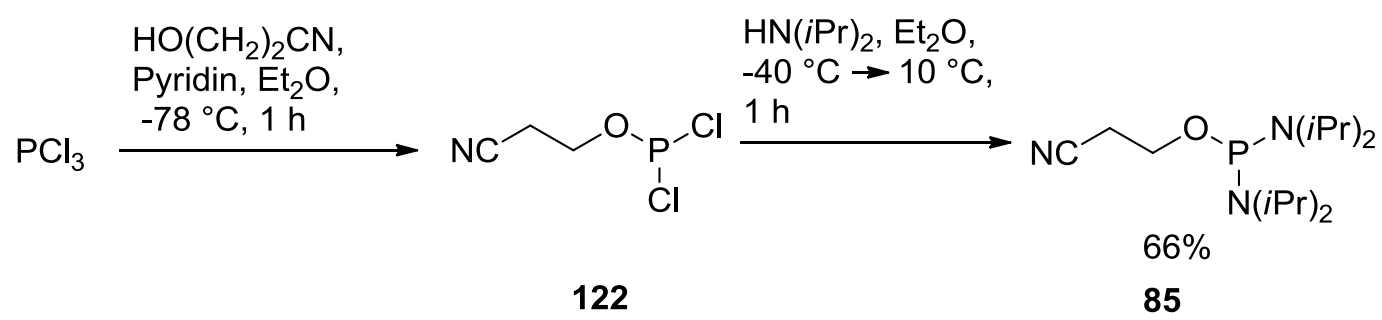

Abb. 4.1: Synthese des Phosphitylierungs-Reagenzes 85.

\subsubsection{Synthese der Phosphonate}

Die Synthese der Phosphonate 79 und 109 erfolgte gemäß in der Literatur beschriebenen Methoden. ${ }^{[140-143]}$ Ausgehend vom O-Methylaminal 123, das in der Arbeitsgruppe Ducho zu den regelmäßig synthetisierten Verbindungen gehörte, wurde durch Erhitzen mit Phosphor(III)-chlorid in Toluol und nachfolgender Zugabe von Trimethylphosphit in einer Michaelis-Arbuzov-artigen ${ }^{[144]}$ Reaktion der Glycinmethylester 124 in einer Ausbeute von 76\% erhalten (Abb. 4.2). ${ }^{[140]}$ Um zum Phosphonat 79 zu gelangen, bedurfte es einer Umwandlung des Methylesters in einen tert-Butylester. Hierzu wurde gemäß einer von Spork optimierten Methode vorgegangen. ${ }^{[141]}$ Zunächst erfolgte eine Verseifung des Methylesters von 124 durch wässrige Natriumhydroxid-Lösung in Dioxan (Abb. 4.2). ${ }^{[142]}$ Durch die anschließende 
saure Aufarbeitung wurde das Carboxylation in die entsprechende Carbonsäure überführt, die ohne weitere Reinigung in der nachfolgenden Veresterung eingesetzt werden konnte. Die Aktivierung der Carbonsäure erfolgte durch $\mathrm{N}$-Ethoxycarbonyl-2ethoxy-1,2-dihydrochinolin (EEDQ), während tert-Butanol, das als Nucleophil fungierte, als Lösungsmittel eingesetzt wurde. ${ }^{[143]}$

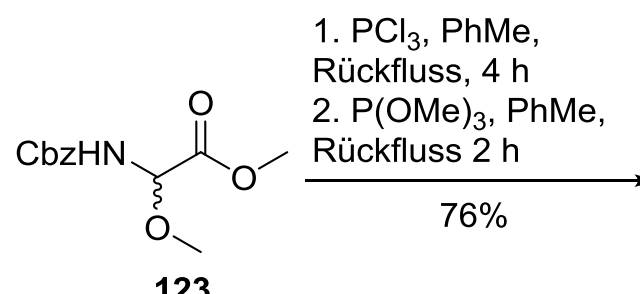

123

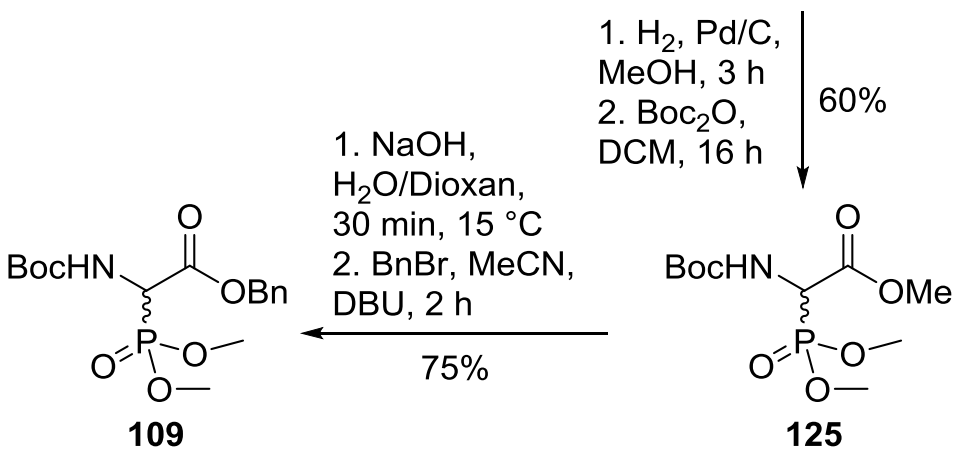

Abb. 4.2: Synthesen der Phosphonate 109 und 79.
1. $\mathrm{NaOH}$,

$\mathrm{H}_{2} \mathrm{O} /$ Dioxan,

$30 \mathrm{~min}, 15^{\circ} \mathrm{C}$

2. EEDQ, $t$-BuOH,

Molsieb, $16 \mathrm{~h}$

$65 \%$<smiles>COP(=O)(OC)OC</smiles>

124

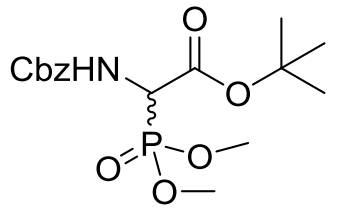

79

Auf diese Weise konnte das Phosphonat 79 in einer Ausbeute von 65\% über zwei Stufen erhalten werden. Dagegen beinhaltete der Syntheseweg zum Phosphonat 109 den Austausch beider Schutzgruppen des Methylesters 124. Zuerst erfolgte die Entfernung der Cbz-Schutzgruppe durch heterogen katalysierte Hydrogenolyse in Methanol unter gewöhnlichen Bedingungen (1 bar $\mathrm{H}_{2}, 10 \% \mathrm{Pd} / \mathrm{C}$ ). Aufgrund der bekannten Labilität des erhaltenen Zwischenprodukts ${ }^{[140]}$ wurde auf eine Reinigung verzichtet und das Rohprodukt direkt mit Di-tert-butyl-dicarbonat umgesetzt, sodass 125 in einer Ausbeute von 60\% über zwei Stufen generiert wurde. Die Verseifung des Methylesters von 125 wurde analog zum bereits oben beschriebenen Verfahren durchgeführt, während die darauf folgende Veresterung durch eine Alkylierung mit Benzylbromid in Gegenwart von DBU als Base erfolgte. ${ }^{[145]}$ Die Ausbeute dieser zweistufigen Reaktion betrug 75\%. 


\subsubsection{Synthese der Oxidationsmittel IBX und DMP}

Für die Oxidation von primären und sekundären Alkoholen hat sich die hypervalente lod(V)-Verbindung o-lodoxybenzoesäure (IBX) 126 als vielseitig verwendbares Reagenz erwiesen. ${ }^{[146]}$ Auch in dieser Arbeit wurde es vielfach für die Oxidation der 5'-Hydroxygruppe verschiedener Nucleosid-Derivate zu den entsprechenden Aldehyden verwendet. Für die Herstellung von IBX wurde auf eine in der Literatur beschriebene Vorgehensweise zurückgegriffen. ${ }^{[147]}$ Dieser Methode folgend wurde IBX durch die Oxidation von o-lodbenzoesäure 127 in saurer $\left(2 \mathrm{M} \mathrm{H}_{2} \mathrm{SO}_{4}\right)$, wässriger Suspension durch Kaliumbromat nach einfacher Filtration der Reaktionslösung in hervorragender Ausbeute von $98 \%$ erhalten. Aufgrund der Explosivität von IBX wurde darauf geachtet, dass die Substanz nicht in trockener Form erhitzt wird (z. B. an den Rändern der Reaktionslösung).

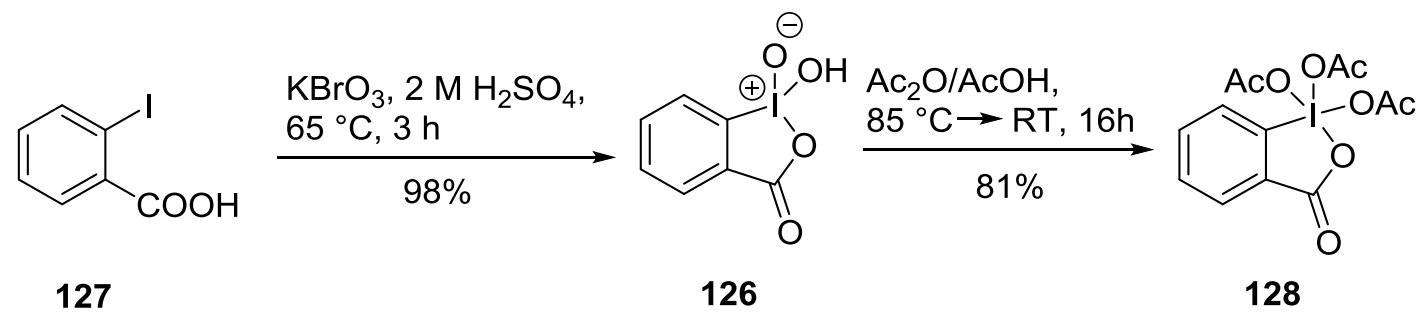

Abb. 4.3: Synthese der Reagenzien IBX 126 und DMP 128.

Die Synthese des Dess-Martin-Periodinan-Reagenz (DMP) 128 wurde in der gleichen Publikation beschrieben wie diejenige des IBX. Gemäß dieser Methode wurde IBX in einem 2:1-Gemisch aus Acetanhydrid und Essigsäure auf $85^{\circ} \mathrm{C}$ erwärmt und anschließend über Nacht abgekühlt, sodass das DMP als grobkörniger Niederschlag in einer Ausbeute von $81 \%$ erhalten wurde. DMP ist weniger polar als IBX und daher insbesondere für die Oxidation von primären und sekundären Alkoholen in Lösungsmitteln mäßiger Polarität geeignet. DMP fand besonders bei der Oxidation der 3'-Hydroxygruppe von Purinnucleosid-Derivaten zu den entsprechenden Ketonen Anwendung. 


\subsection{Synthese der NAA-Bausteine für den Aufbau zwitter- ionischer ON}

\subsubsection{Synthese der 3'-O-TBDMS-Thymidinylaldehyde}

Die Methode zur Synthese des BOM-geschützten Thymidinylaldehyds 78 (Abb. 4.4) wurde bereits in der Vorarbeit etabliert. ${ }^{[114]}$ Gemäß dieser Strategie wurden durch Reaktion mit TBDMS-Chlorid zugleich an 5'-O und an 3'-O des Thymidins 77 Silylether generiert, sodass die Verbindung 129 in quantitativer Ausbeute erhalten wurde (Abb. 4.4). Als Lösungsmittel wurde das mild-basische Pyridin verwendet, welches den gebildeten Chlorwasserstoff neutralisiert und dadurch die thermodynamische Triebkraft der Reaktion erhöht. Zwecks Reaktionsbeschleunigung wurde Imidazol zugesetzt, das in einer $S_{N} 2-$ Reaktion ein reaktives Imidazol-TBDMSIntermediat bildet. Anschließend wurde an 3-N die BOM-Schutzgruppe unter Bildung von 130 in einer Ausbeute von 96\% eingeführt. Bei dieser Reaktion handelt es sich um eine chemoselektive $N$-Alkylierung durch Benzyloxymethylchlorid unter basischen Bedingungen (NaH). Für die Chemoselektivität dieser Reaktion sprechen die ${ }^{13} \mathrm{C}$-NMR-Befunde. Bei O-Alkylierungen wäre eine Änderung der chemischen Verschiebung von C-4 (163.5) bzw. C-2 (150.9) im Vergleich zum Edukt 130 zu erwarten. Dies wurde jedoch nicht beobachtet. Im nächsten Schritt erfolgte die selektive Spaltung des Silylethers in 5'-Position, um zum Alkohol 131 zu gelangen (Abb. 4.4). Hierfür wurden im Gegensatz zur früher verwendeten Methode nach $Z_{h u^{[148]}}$ (TFA in $\mathrm{H}_{2} \mathrm{O} / \mathrm{THF}$ ) mildere Reaktionsbedingungen gemäß der von Khan ${ }^{[128]}$ publizierten Vorgehensweise eingesetzt. In dieser Reaktion aktiviert der durch Zugabe von katalytischen Mengen Acetylchlorid in Methanol gebildete Chlorwasserstoff durch Protonierung des Sauerstoffatoms die Si-O-Bindung, sodass anschließend eine Nucleophile Substitution durch Methanol am Si-Atom erfolgt. Diese Reaktion ist insbesondere entropisch begünstigt. Ein Vorteil dieser Methode gegenüber derjenigen von Zhu (TFA in $\mathrm{H}_{2} \mathrm{O} / \mathrm{THF}$ ) ist die vollständige Löslichkeit des Edukts im verwendeten Lösungsmittel. Zudem ist die Neutralisation der geringen Menge an Acetylchlorid im Vergleich zu der Methode von Zhu (viel TFA) sehr günstig. Die Ausbeute der 5'-O-Silyletherspaltung von 130 nach Khan war jedoch mit $59 \%$ nur geringfügig höher als diejenige der zuvor verwendeten TFA-vermittelten Reaktion (53\%). Auch für die Synthese der Basen-ungeschützten Verbindung 132 wurde die Silyletherspaltung durch katalytische Mengen Acetylchlorid in Methanol 
angewendet. In diesem Fall war die Ausbeute mit $66 \%$ etwas höher als bei der Basen-geschützten Verbindung 131 (Abb. 4.4). Interessanterweise ergaben selektive 5'-O-TBDMS-Entschützungen von Ribonucleosid-Derivaten stets bedeutend höhere Ausbeuten (73-99\%) als im Fall der hier diskutierten DesoxyribonucleosidDerivate. $^{[141,148]}$ Ein möglicher Grund hierfür ist die gegenseitige sterische Abschirmung der 2'- und 3'-O-TBDMS-Einheiten.
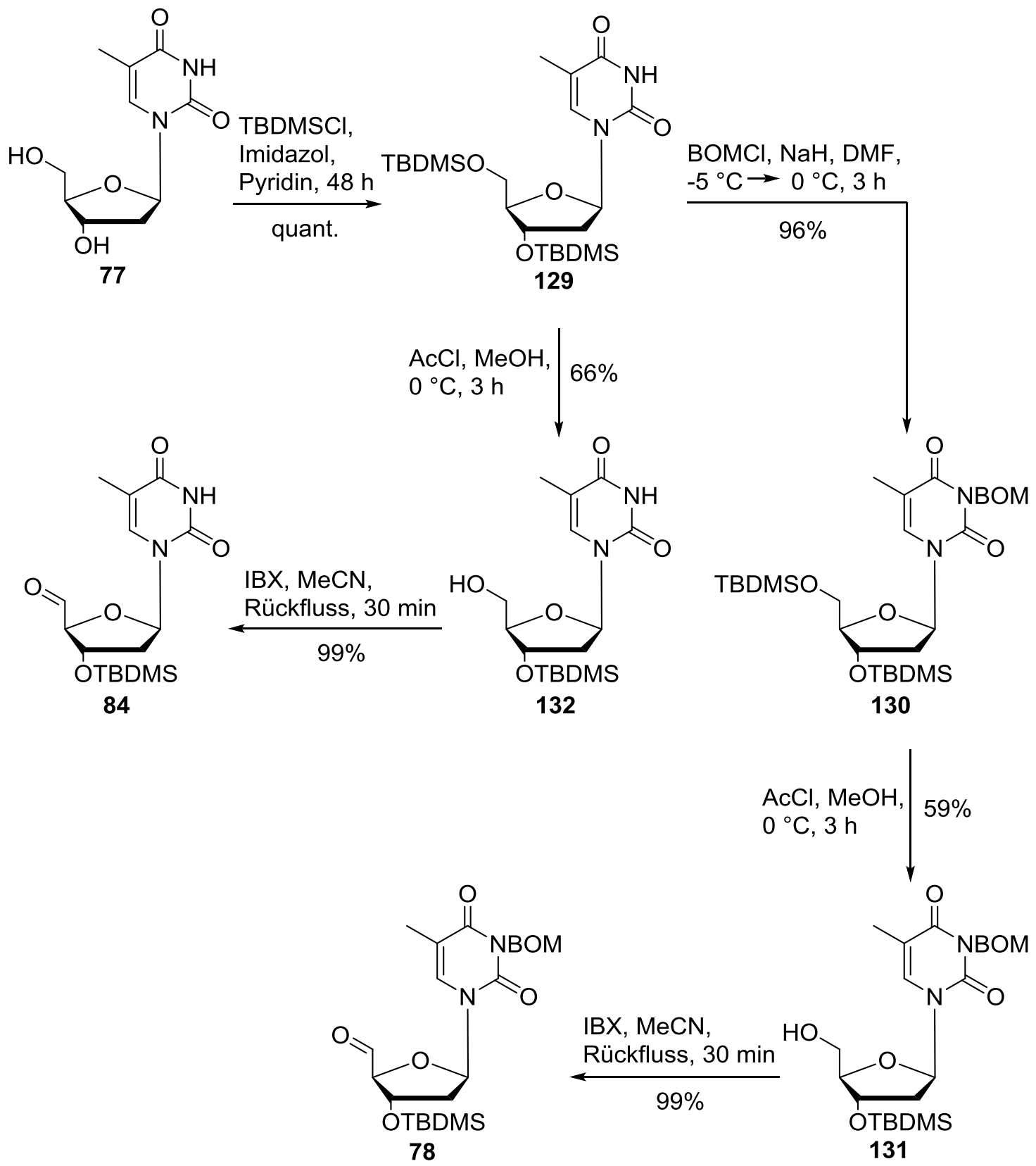

Abb. 4.4: Synthese der Aldehyde 78 und 84.

Schließlich wurden die beiden 5'-Alkohole 131 und 132 durch kurzes Erhitzen in einer Suspension aus IBX in Acetonitril mit annähernd quantitativen Ausbeuten in die entsprechenden Aldehyde 78 und 84 überführt (Abb. 4.4). ${ }^{[149]}$ Auf eine 
chromatographische Reinigung dieser Verbindungen wurde aufgrund ihrer Labilität verzichtet. Außerdem war deren ${ }^{1} \mathrm{H}$-NMR-spektroskopisch ermittelte Reinheit für die weitere Verwendung stets ausreichend.

\subsubsection{Synthese der 3'-O-TBDMS-5',6'-Didehydro-TAA}

Die Darstellung der 5',6'-Didehydro-TAA (E/Z)-80 und (E/Z)-82 erfolgte gemäß der von Schmidt etablierten Phosphorylglycinester-Methode. ${ }^{[142]}$ Hierbei stellt die WittigHorner-Reaktion der Thymidinylaldehyde 78 und 84 mit dem Phosphonat 79 in THF den Schlüsselschritt dar. Zur Deprotonierung des Phosphonats 79 in a-Position wurde die sterisch anspruchsvolle Base Kalium-tert-butanolat verwendet (Abb. 4.5). In beiden Fällen wurde die Reaktion bei $-70^{\circ} \mathrm{C}$ angesetzt und über einen langen Zeitraum (16 h) auf Raumtemperatur erwärmt.

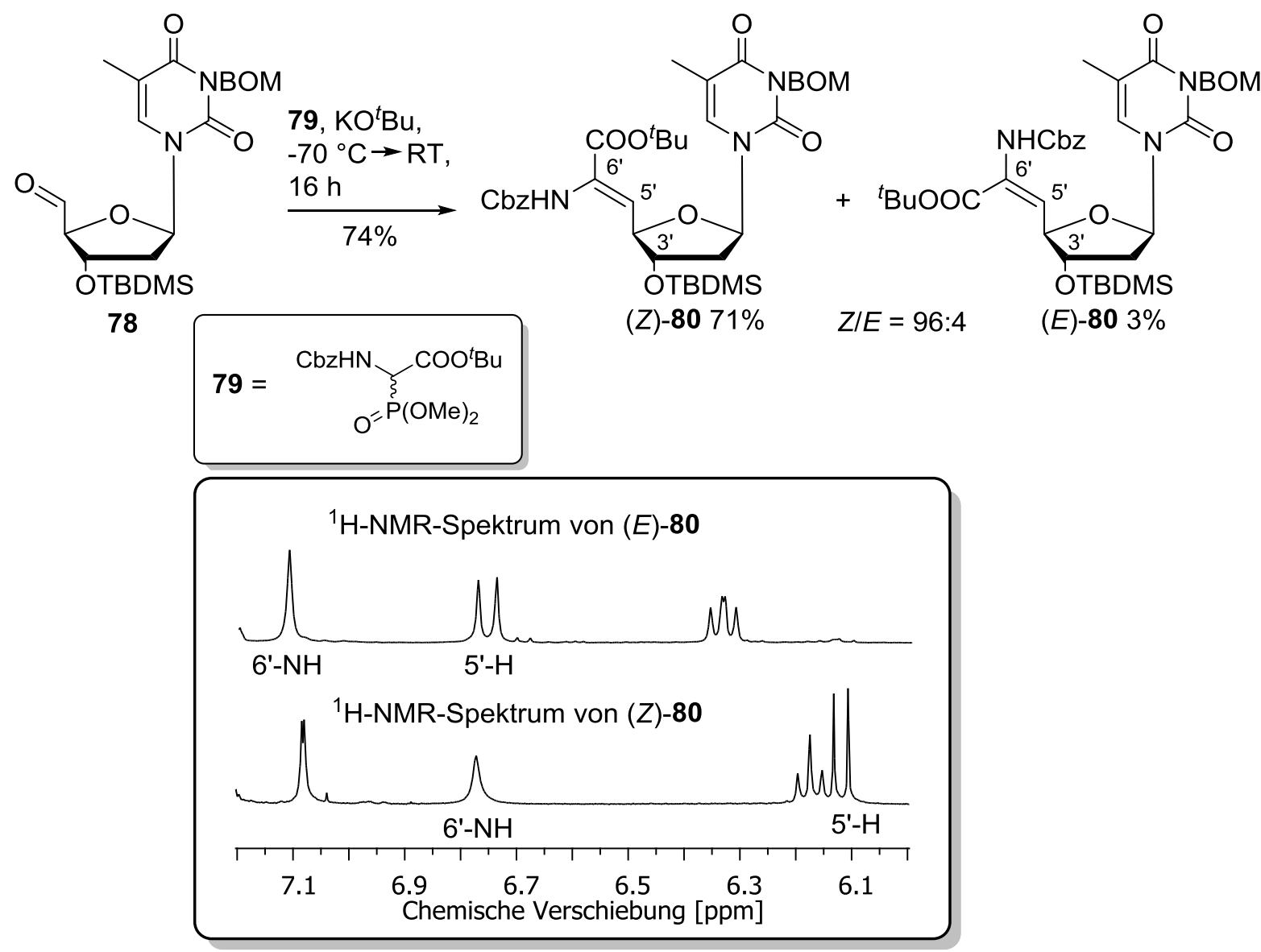

Abb. 4.5: Synthese der Didehydroaminosäure (Z)-80.

Alle beteiligten Reagenzien (Phosphonat, Aldehyd, Base) wurden in äquimolaren Mengen eingesetzt. Die Reaktionsbedingungen wurden so gewählt, um einer $E$-Z- 
Isomerisierung entgegenzuwirken, die bei einem Überschuss an Base möglich wäre. Es ist bekannt, dass unter sauren oder basischen Bedingungen bei Raumtemperatur $(E / Z)$-Isomerengemische mit einem (E)-Anteil von $20 \%$ und in seltenen Fällen sogar einem Überschuss an $(E)$-Isomer entstehen können. ${ }^{[150]}$ Die Bildung des $(E)$-Isomers ist unerwünscht, da dessen nachfolgende asymmetrische Hydrierung wesentlich langsamer und mit geringerer Diastereoselektivität verläuft als diejenige des (Z)Isomers. ${ }^{[119,150]}$ Die Kondensation des Basen-geschützten Aldehyds 78 mit dem Phosphonat ergab ein Gemisch der (E/Z)-Olefine $\mathbf{8 0}$ in einem Verhältnis von $Z / E=96: 4$ (Rohprodukt), dessen Trennung durch Chromatographie an Kieselgel gelang. Die Ausbeute des weiterverwendeten (Z)-Isomers betrug $71 \%$. Beide Komponenten konnten anhand von ${ }^{1} \mathrm{H}$-NMR-spektroskopischen Untersuchungen unterschieden werden. Die Zuordnung der jeweiligen Konfiguration erfolgte auf Basis der von Mazurkiewicz aufgestellten Kriterien. ${ }^{[151]}$ Demnach gilt für die chemische Verschiebung der olefinischen $\beta$-Protonen $\left(5^{\prime}-\mathrm{H}\right.$ im Fall von 80) und der am Carbamat-Stickstoff befindlichen Protonen von N-Acyl- $\alpha, \beta$-Didehydroaminosäureestern in $\mathrm{CDCl}_{3}$ :
1.) $\delta_{\beta H}(E)>\delta_{\beta H}(Z)$
2.) $\delta_{\mathrm{NH}}(E)>\delta_{\mathrm{NH}}(Z)$

Dies bedeutet, dass die Signale der beiden Protonen im Fall der $(E)$-Konfiguration der Doppelbindung stets weiter Tieffeld-verschoben sind. Für die beiden Isomere der BOM-geschützten Verbindung $\mathbf{8 0}$ wurden diese Kriterien erfüllt (Abb. 4.5). Ferner stimmt das Resultat dieser Umsetzung gut mit den Befunden der Reaktion des analogen Uridinylaldehyds $\mathbf{5 8}$ mit dem Phosphonat $\mathbf{6 1}$ überein. Dort wurde in etwas höherer Ausbeute (82\%) ausschließlich die (Z)-Didehydroaminosäure 64 erhalten (Abb. 2.16). ${ }^{[18]}$

Etwas andere Ergebnisse wurden bei der Wittig-Horner-Reaktion des Basenungeschützten Aldehyds 84 mit dem Phosphonat 79 erhalten (Abb. 4.6). Die Ausbeute der Reaktion lag mit $67 \%$ etwas niedriger als im Fall des geschützten Aldehyds 78. Auch in dieser Reaktion wurde ein E/Z-Diastereomerengemisch erhalten, wobei sich eine vollständige Trennung der beiden Komponenten durch Säulenchromatographie als nicht praktikabel erwies. Erst nach mehreren Trennungen konnte das in geringerer Menge vorliegende $(E)$-Diastereomer für die 
NMR-spektroskopische Charakterisierung angereichert werden. Das Diastereomerenverhältnis wurde aus den Verhältnissen der ${ }^{1} \mathrm{H}$-NMR-Signale zu Z/E $=91: 9$ (Rohprodukt) bestimmt. Die Zuordnung der Konfiguraion konnte auch in diesem Fall anhand der Kriterien von Mazurkiewicz vorgenommen werden (Abb. 4.6). Die in der Abb. 4.6 angegebene Ausbeute von $67 \%$ bezieht sich auf das $(E / Z)$-Diastereomerengemisch, das auch in weiteren Experimenten in dieser Form eingesetzt wurde.
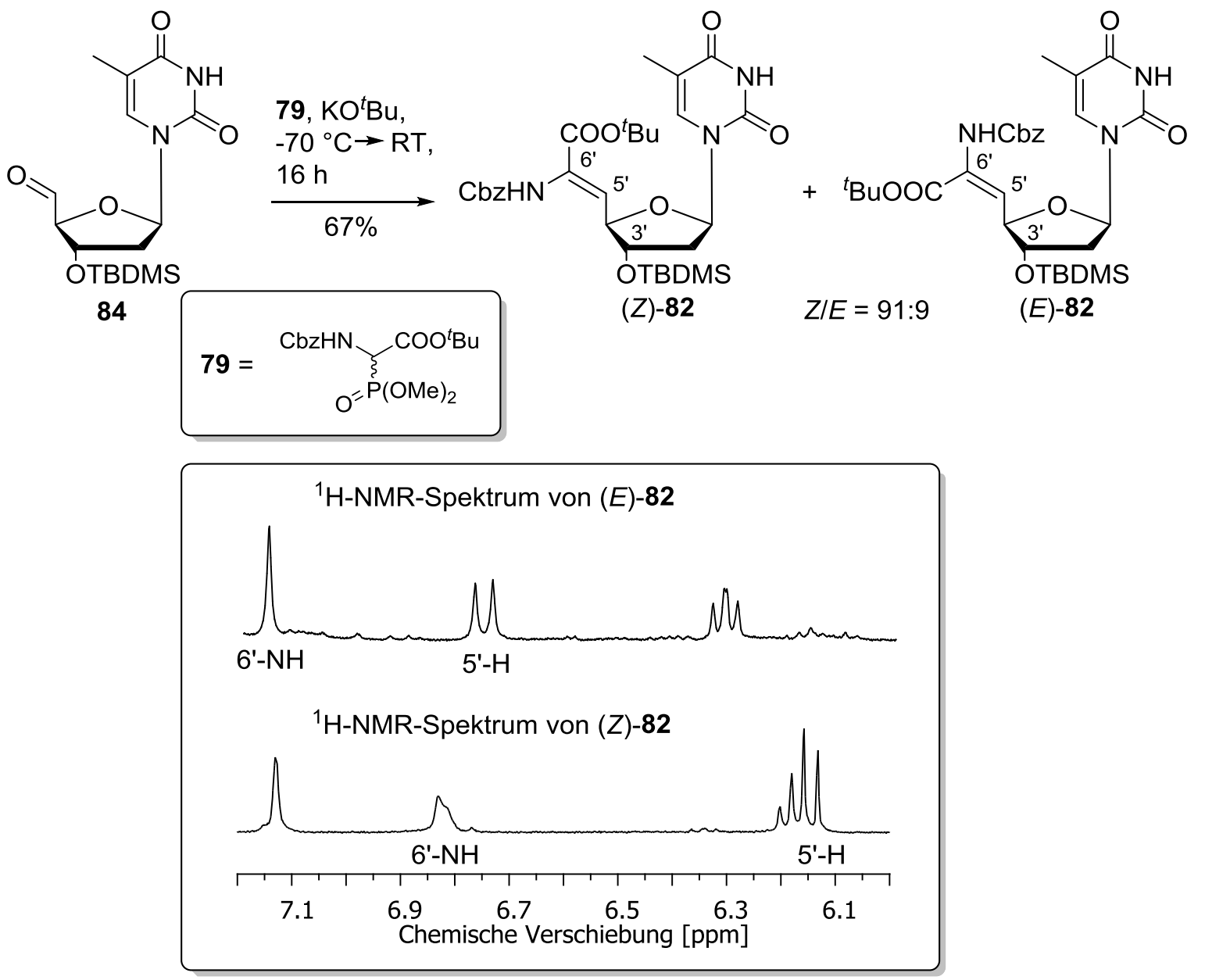

Abb. 4.6: Synthese der Basen-ungeschützten Didehydroaminosäure (Z)-82.

Das erhaltene Verhältnis der (E/Z)-Diastereomere 82 ist im Hinblick auf die Ergebnisse mit analogen Basen-ungeschützten Uridinderivaten überraschend. Denn für die Wittig-Horner-Reaktion des Phosphonats $\mathbf{7 9}$ mit dem analogen ungeschützten Uridinylaldehyd 59 (Abb. 2.16) wurden sowohl bezüglich der Ausbeuten (82\%) als auch der Diastereoselektivität (ausschließlich (Z)-Produkt) die besten Resultate erzielt. $^{[118]}$ Der vergleich der Wittig-Horner-Reaktionen der Thymidinylaldehyde 78 und 84 mit denjenigen der Uridinylaldehyde 58 und 59 bestätigt ferner die Zuverlässigkeit der (Z)-Selektivität der Wittig-Horner-Reaktion, da auch im Fall 
verschiedener Uridinylaldehyde unter ähnlichen Reaktionsbedingungen stets ein großer Überschuss an (Z)-Isomer gebildet wurde. ${ }^{[141]}$

\subsubsection{Asymmetrische Hydrierung der 3'-O-TBDMS-5',6'-Didehydro- TAA}

Die 5',6'-Doppelbindungen der (Z)-Didehydro-TAA wurden durch Reaktion mit Wasserstoff unter katalytischer Wirkung der chiralen, kationischen Rhodium(I)Komplexe (S,S)-MeDuPHOS-Rh oder $(R, R)$-Me-DuPHOS-Rh in Methanol reduziert. ${ }^{[152]}$ Diese Reaktionen wurden unter einer Wasserstoffatmosphäre (1 bar) und aufgrund der Oxidationsempfindlichkeit der Katalysatoren bei striktem Sauerstoffausschluss geführt. Des Weiteren wurde, wie bereits oben ausgeführt, die Gegenwart einer größeren Menge an (E)-Didehydroaminosäure im Reaktionsgemisch vermieden. Es gilt als hinlänglich bekannt, dass die katalytische Wirkung des $(S, S)$-Komplexes mit sehr hoher Selektivität zur Bildung der jeweiligen L-Aminosäuren führt, während durch die Verwendung des enantiomeren $(R, R)$ Komplexes D-Aminosäuren erhalten werden. ${ }^{[152-154]}$ Daher wurde ausgehend von diesen Befunden auch für die synthetisierten (6'S)- und (6'R)-NAA 81 (Abb. 2.18) diese Zuordnung getroffen. ${ }^{[14]}$ Die Korrektheit dieser Annahme wurde kürzlich anhand von Röntgenstrukturuntersuchungen an Derivaten der Uridinylaminosäuren (6'S)- und (6'R)-67 (Abb. 2.16) weiter bestätigt. ${ }^{[18]}$ Erwartungsgemäß waren die beobachteten Reaktionsgeschwindigkeiten der Hydrierungen aufgrund der doppelten Stereodifferenzierung der Reaktion recht unterschiedlich. Während die Reduktion der BOM-geschützten Verbindung (Z)-80 in Gegenwart von1-2 mol\% (S,S)-Me-DuPHOS$\mathrm{Rh}$ bereits nach 2 Tagen vollständig abgelaufen war, bedurfte die asymmetrische Reduktion des gleichen Substrats unter Katalyse durch 1-2 mol\% $(R, R)$-Me-DuPHOS einer Reaktionsdauer von 7 Tagen. Daher erscheint es naheliegend, dass der Übergangszustand der Reaktion zu (6'S)-81 energieärmer ist als derjenige der Bildung von (6'R)-81. In diesem Zusammenhang wird von einem matched pair (schnellere Reaktion) oder einem mismatched pair (langsamere Reaktion) gesprochen. Ein Hinweis auf eine schwach ausgeprägte, intrinsische Stereoselektivität (Substratkontrolle) wurde durch die Hydrierung von (Z)-80 in Gegenwart des achiralen Wilkinson-Katalysators $\mathrm{Rh}\left(\mathrm{PPh}_{3}\right)_{3} \mathrm{Cl}$ erhalten. Dabei resultierte ein 2:1-Gemisch der (6'S)- und (6'R)-NAA 81. Diese kinetischen Faktoren 
wirkten sich jedoch in keiner Weise auf die Resultate der asymmetrischen Hydrierungen von (Z)-80 aus. Die beiden Diastereomere (6'S)-81 und (6'R)-81 wurden in sehr hohen Ausbeuten (94\% bzw. 99\%) und hervorragenden Diastereoselektivitäten (d.r. $\geq 98: 2$ ) erhalten. Die gleichen Reaktionen wurden auch mit der 5',6'-Didehydroaminosäure (Z)-82 durchgeführt, deren Nucleobase ungeschützt war.

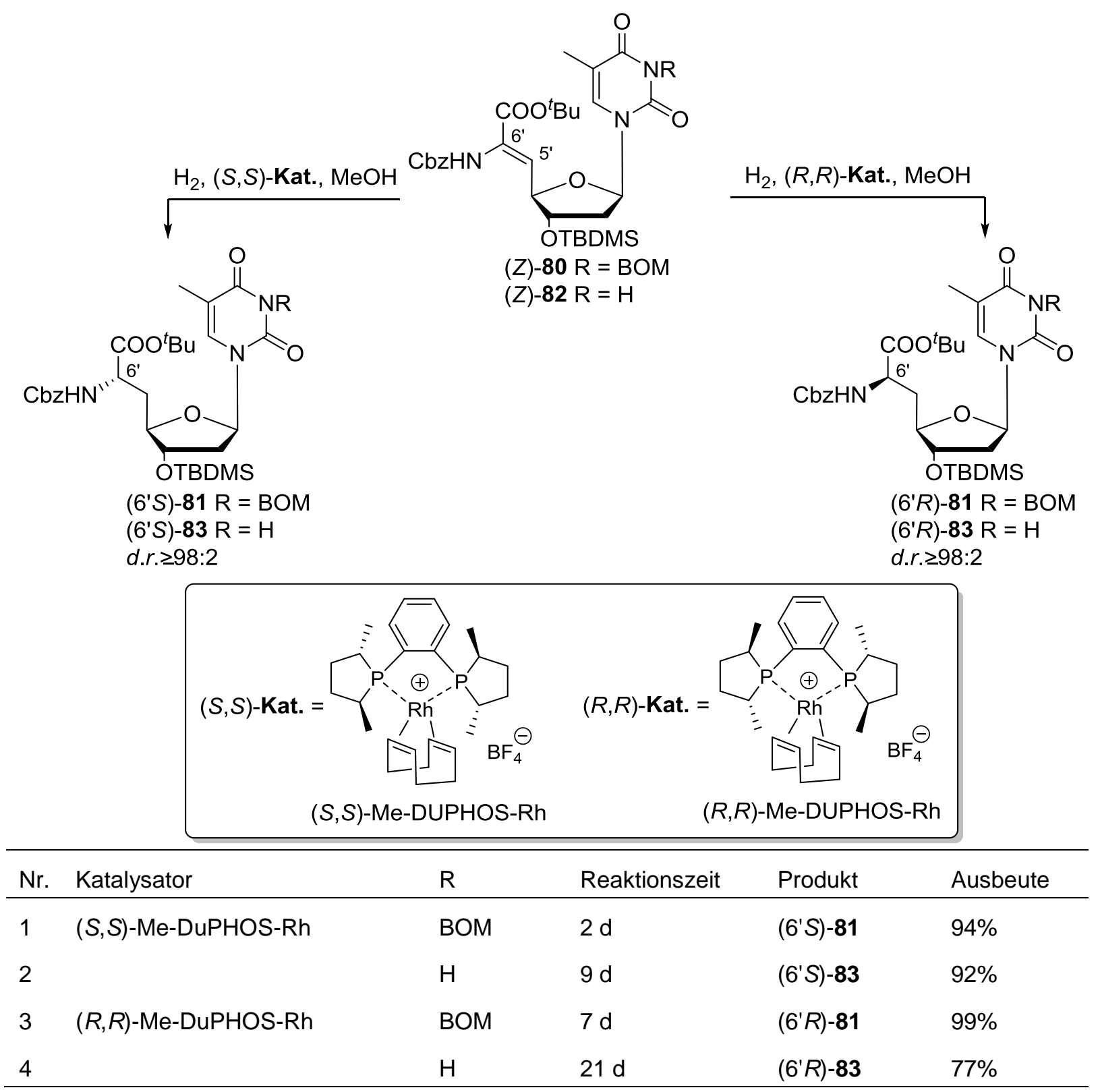

Abb. 4.7: Asymmetrische Hydrierung von (Z)-80 und (Z)-82.

Dieser Unterschied in der Struktur der Nucleobase verursachte eine wesentlich geringere Reaktivität der Verbindung (Z)-82 in der asymmetrischen Hydrierung. Wurde als katalytische Spezies der Komplex (S,S)-Me-DuPHOS-Rh eingesetzt, betrug die Reaktionszeit 9 Tage. Bedeutend länger (21 Tage) dauerte die Reduktion 
von (Z)-82 unter katalytischer Wirkung von $(R, R)$-Me-DuPHOS-Rh. Zudem musste die Menge an Katalysator (4 mol\%) im Reaktionsgemisch gegenüber den Bedingungen der Hydrierung von (Z)-80 (1-2 mol\%) deutlich erhöht werden, damit die Reaktion in akzeptablen Zeiträumen durchgeführt werden konnte. Dabei wurde die Menge an Katalysator durch Portionsweise Zugabe im Abstand von 2-3 Tagen erhöht bis die Reaktion vollständig abgelaufen war. Im Gegensatz zu der Reaktion des BOM-geschützten Substrats (Z)-80 wurden die Resultate der Hydrierungen durch die längere Reaktionszeit geringfügig beeinträchtigt. Während die Diastereomerenreinheit der erhaltenen Verbindungen (6'S)-82 und (6'R)-82 weiterhin hoch (d.r. $\geq 98: 2$ ) war, ergab besonders die $(R, R)$-Me-DuPHOS-vermittelte Reduktion eine deutlich geringere Ausbeute (77\%) als im Fall des BOM-geschützten Substrats (Z)-80. Dieser Sachverhalt erschwerte besonders die Synthese der Verbindungen $\left(6^{\prime} S\right)$ - und (6'R)-83 in größerem Maßstab (> $1 \mathrm{~g}$ ). Auch diese Ergebnisse stimmen sehr gut mit den Befunden entsprechender Untersuchungen an Uridin-abgeleiteten 5',6'-Didehydroaminosäuren (6'S)- und (6'R)-67 (Abb. 2.16) überein. ${ }^{[141]}$ Eine mögliche Erklärung für die geringere Reaktivität der Basen-ungeschützten Didehydro-NAA besteht in einer koordinativen Interaktion der ungeschützten Nucleobase mit dem Metallzentrum der katalytischen Spezies.

\subsubsection{Umschützung der NAA}

Gemäß der älteren Strategie zur Synthese der NAA 73 (Weg A, Abb. 4.8) wurden zunächst die reduktiv spaltbaren BOM und Cbz-Schutzgruppen unter Bildung von 133 simultan entfernt. Unter gewöhnlichen Bedingungen der heterogen katalysierten Hydrogenolyse $\left(\mathrm{H}_{2}, 10 \% \mathrm{Pd} / \mathrm{C}, \mathrm{MeOH}\right)$ trat dabei als Nebenreaktion eine Methylierung der 6'- $\mathrm{NH}_{2}$-Gruppe durch Reaktion mit Formaldehyd auf, der bei der Spaltung der BOM-Gruppe freigesetzt wurde. ${ }^{[14]}$ Daher wurde dem Reaktionsgemisch $n$-Butylamin in großem Überschuss (20 Äq) zugesetzt, das zum Abfangen des Formaldehyds diente. Zudem bewirkte die Gegenwart von $n$-Butylamin im Reaktionsgemisch eine deutliche Beschleunigung der Umsetzung. Eine mögliche Begründung hierfür ist die Erhöhung der Triebkraft der Reaktion durch das Entfernen einer Komponente auf der Produktseite. Bei dieser Vorgehensweise wurden die entschützten (6'S)- und (6'R)-NAA 133 in sehr guten Ausbeuten von 93\% bzw. 92\% erhalten. Allerdings konnte das $n$-Butylamin nur durch chromatographische 
Reinigung vollständig entfernt werden. Dies war notwendig, da selbst geringe Mengen an $n$-Butylamin auf die nachfolgende Einführung der Fmoc-Schutzgruppe am 6'-NH störend wirken würden. Daher ermöglichte die Abwesenheit der BOMSchutzgruppe in den Verbindungen 83 die Reaktionsführung ohne $n$-Butylamin. Folglich konnten die reduktiv entschützten NAA 133 für die nachfolgende FmocSchützung ohne chromatographische Reinigung weiterverwendet werden (Weg B, Abb. 4.8).

Weg A:
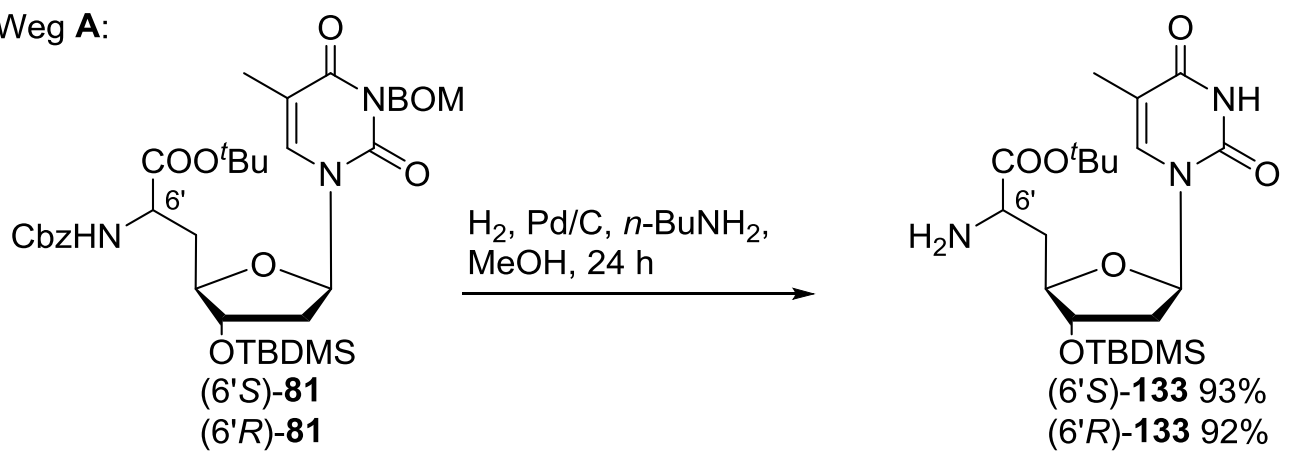

FmocCl, $\mathrm{NEt}_{3}, \mid\left(6^{\prime} \mathrm{S}\right): 95 \%$ THF, $0{ }^{\circ} \mathrm{C}, 1 \mathrm{~h} \downarrow\left(6^{\prime} R\right): 97 \%$

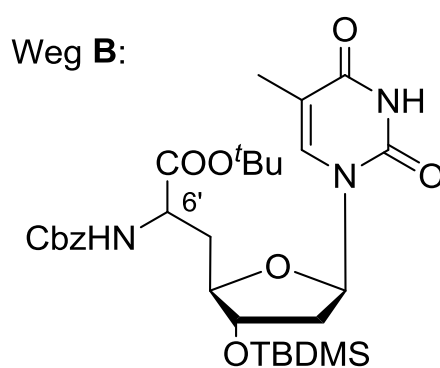

$(6 ' S)-83$

$\left(6^{\prime} R\right)-83$

1. $\mathrm{H}_{2}, \mathrm{Pd} / \mathrm{C}, \mathrm{MeOH}, 1 \mathrm{~h}$

2. $\mathrm{FmocCl}, \mathrm{NEt}_{3}$, THF, $0{ }^{\circ} \mathrm{C}, 1 \mathrm{~h}$

(6'S): $84 \%$

$\left(6^{\prime} R\right): 78 \%$
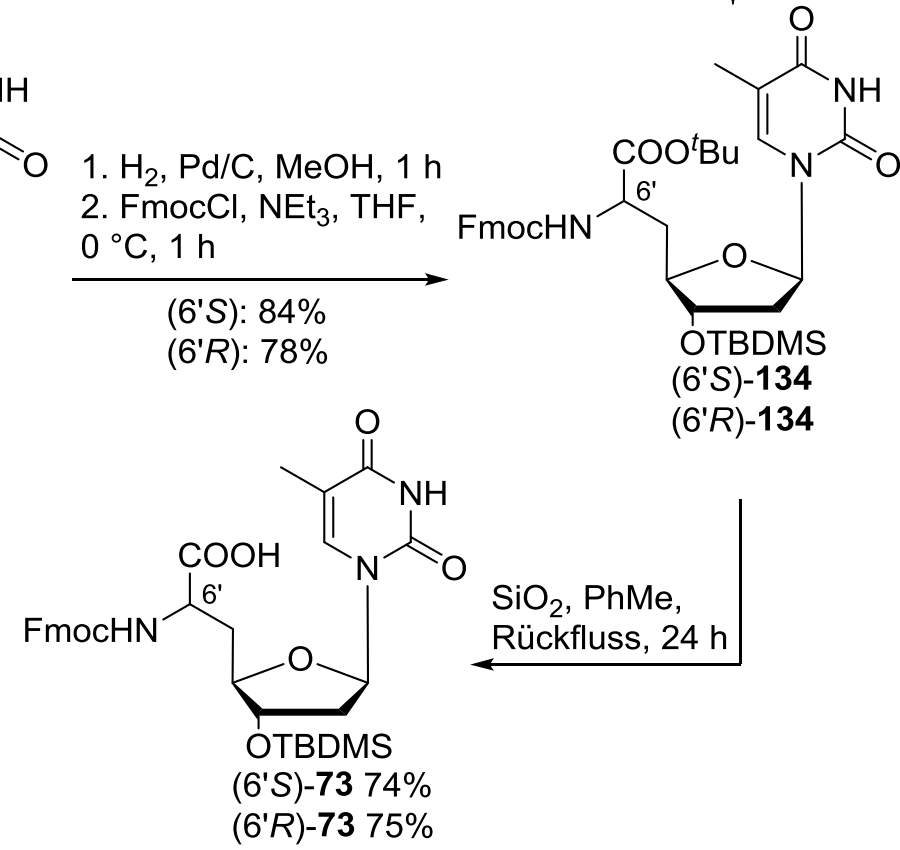

Abb. 4.8: Synthese der NAA (6'S)- und (6'R)-73 über die Wege $\mathbf{A}$ und $\mathbf{B}$.

Durch Vergleich der ${ }^{1} \mathrm{H}-\mathrm{NMR}$-Spektren konnte bestätigt werden, dass unabhängig vom gewählten Reaktionsweg (A oder B) identische Produkte $\mathbf{1 3 4}$ erhalten wurden (Abb. 4.9). 

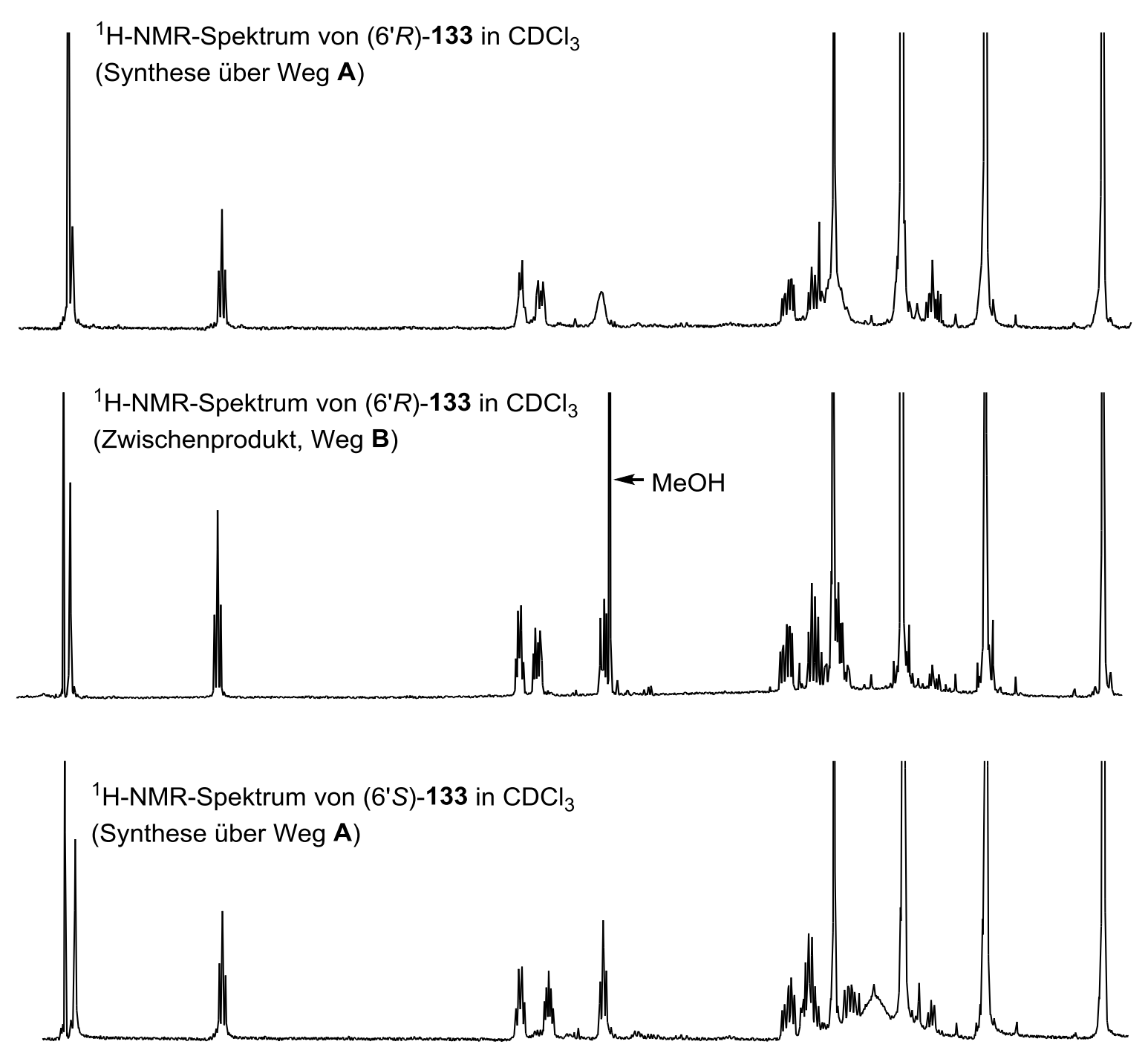

${ }^{1} \mathrm{H}-\mathrm{NMR}$-Spektrum von (6'S)-133 in $\mathrm{CDCl}_{3}$

(Zwischenprodukt, Weg B)

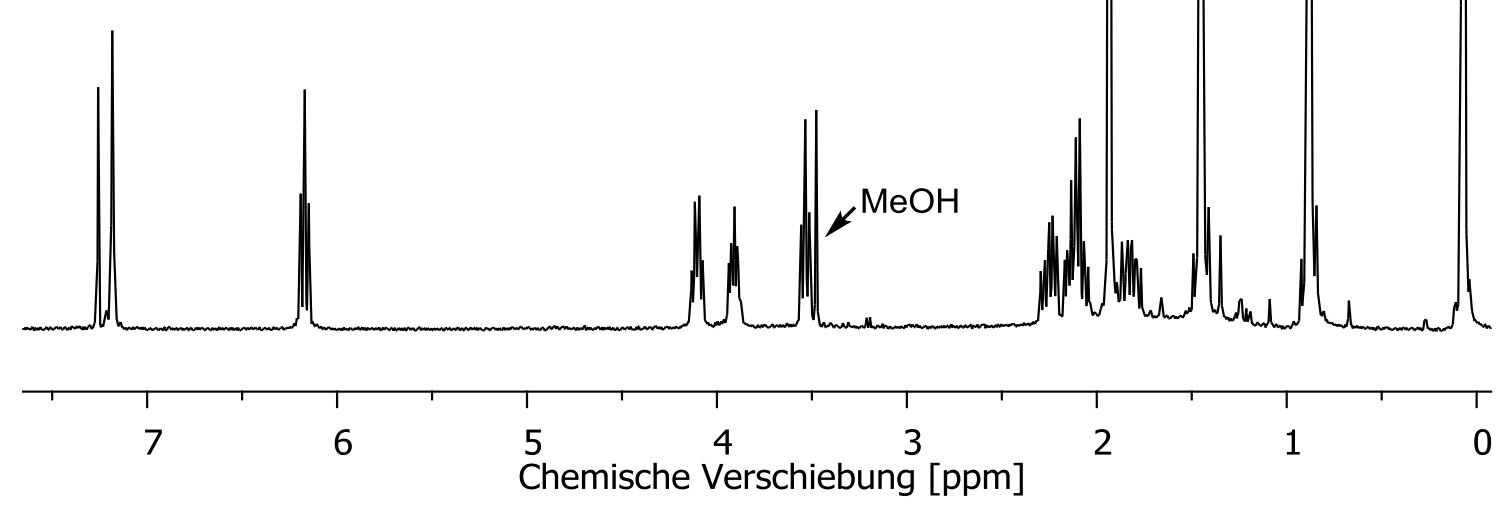

Abb. 4.9: Vergleich der ${ }^{1} \mathrm{H}-\mathrm{NMR}-\mathrm{Spektren}$ der unterschiedlich hergestellten NAA 133.

Nach Abspaltung der Cbz- und der BOM-Schutzgruppen wurde zunächst an der $\mathrm{NH}_{2}$-Funktionalität von (6'S)- und $\left(6^{\prime} R\right)-134$ die basenlabile Fluorenylmethoxycarbonyl-(Fmoc)-Schutzgruppe eingeführt (Abb. 4.8). Hierzu wurden die TAA 133 in THF bei $0^{\circ} \mathrm{C}$ in Gegenwart eines Überschusses an Triethylamin (2.5 Äq) mit 
Fmoc-Chlorid zur Reaktion gebracht. Besonders wichtig war dabei das Einhalten der niedrigen Reaktionstemperatur und einer kurzen Reaktionszeit (30 min-1 h), da anderenfalls das überschüssige Triethylamin zu einer Spaltung des gebildeten Carbamats führte. Die Spaltung des Carbamats ist irreversibel und thermodynamisch wegen der Bildung von $\mathrm{CO}_{2}$ und Dibenzofulven stark begünstigt. ${ }^{[125]}$ Die Produkte wurden in Ausbeuten von 95\% ((6'S)-NAA 134) bzw. 97\% ((6'R)-NAA 134) erhalten. Die Ausbeuten der direkt geführten Reaktionsfolge ausgehend von 83 waren mit 84\% (von (6'S)-83) und 78\% (von (6'R)-83) etwas geringer als ausgehend von den BOM-geschützten Verbindungen 81 über zwei Stufen. Nach Einführung der FmocGruppe wurden sämtliche NMR-Spektren bei erhöhten Temperaturen aufgenommen $\left(\mathrm{T}>50^{\circ} \mathrm{C}\right)$. Bei Raumtemperatur hingegen lagen in den ${ }^{1} \mathrm{H}-\mathrm{NMR}$-Spektren der NAA 134 zwei deutlich getrennte Signalsätze von Rotameren mit unterschiedlicher Intensität (Verhältnis ca. 3:1) vor. Hierbei stellt sich die Frage, weshalb dieses Phänomen bei Vorliegen der Cbz-Schutzgruppe nicht beobachtet wurde. Dies kann durch eine deutliche Erhöhung der Rotationsbarriere der C-N-Bindung bei Ersatz der Cbz- durch die Fmoc-Schutzgruppe plausibel gemacht werden. Im Fall der CbzSchutzgruppe wäre die Rotationsbarriere recht klein, da die Koaleszenztemperatur unterhalb der Raumtemperatur liegt. Dagegen lassen sich die Befunde bei Vorliegen der Fmoc-Gruppe durch eine höhere Rotationsbarriere (höhere Koaleszenztemperatur) deuten. Bekanntlich wird die Höhe der Rotationsbarriere um die amidische $\mathrm{C}-\mathrm{N}$-Bindung auch durch elektronische Effekte von Substituenten am NAtom beeinflusst. ${ }^{[155]}$ Aufgrund der identischen Substituenten am N-Atom wurde jedoch in dem hier diskutierten Fall angenommen, dass vor allem der sterische Anspruch der Carbamat-Einheiten den Unterschied ausmacht. Zur Entschützung der Carboxygruppe der NAA 134 war die Spaltung des tert-Butylesters erforderlich. Dies wurde durch Erhitzen der NAA in Toluol unter Rückfluss für $24 \mathrm{~h}$ mit Kieselgel (1.6 g/mmol NAA) erreicht (Abb. 4.8). Die NAA 73 wurden in Ausbeuten von 74\% ((6'S)-NAA 73) und 75\% ((6'R)-NAA 73) erhalten. Andere Verfahren zur Spaltung von $t$-Butyl-Schutzgruppen in aprotisch-unpolaren Solventien beruhen auf der Aktivierung der $\mathrm{C}_{\text {tert }} \mathrm{O}$-Bindung durch Lewis-acide, stark hygroskopische Salze (z. B. $\mathrm{Mgl}_{2}$ oder $\left.\mathrm{ZnBr}_{2}\right),{ }^{[156-157]}$ die nach längerer Lagerung und häufiger Verwendung Wasser enthalten können und daher zur Spaltung von TBDMS-Schutzgruppen führen. Methoden zur Spaltung des tert-Butyl-Esters durch Säuren in protischen Lösungsmitteln wurden nicht untersucht, da dies generell mit der Gegenwart von TBDMS-Schutzgruppen in den Verbindungen 134 unvereinbar ist (Abb. 4.8). Darüber 
hinaus ist auch eine alkalische Methode zur Spaltung von tert-Butylestern bekannt. ${ }^{[158]}$ Wegen der basenlabilen Fmoc-Schutzgruppe wurde jedoch auf die Anwendung dieser Vorgehensweise verzichtet. Es sei noch erwähnt, dass die Synthese der NAA 73 über die Route mit der BOM-Schutzgruppe im Fall von (6'S)-73 zu geringfügig schlechteren Ergebnissen führte (9 Stufen, 31\%) als die Route ohne BOM-Schutzgruppe (8 Stufen, 34\%). Bei (6'R)-73 erwies sich jedoch die Synthese mit BOM-Schutzgruppe als deutlich vorteilhaft (27\%) gegenüber der Synthese ohne BOM-Schutzgruppe (20\%). Auch der höhere Verbrauch an Katalysator bei der asymmetrischen Hydrierung und deren längere Reaktionszeit sprechen gegen die Schutzgruppenfreie Methode.

\subsubsection{Synthese der 3'-Aminonucleoside}

Gemäß der in Kap. 3.2.1.4 veranschaulichten Strategie sollte die Herstellung der Dinucleosid-Bausteine durch Peptid-Kupplung der NAA 73 (Abb. 4.8) mit verschiedenen 3'-Aminonucleosiden erfolgen. Hinsichtlich der Synthesemethoden gibt es einen grundlegenden Unterschied zwischen der Vorgehensweise, die zur Herstellung von 3'-Aminonucleosiden mit Pyrimidinbasen verwendet wird und derjenigen zur Herstellung von 3'-Aminonucleosiden mit Purinbasen. Obwohl in der Literatur Synthesen derartiger Verbindungen beschrieben sind, ergaben sich unerwartete Schwierigkeiten, die es zu bewältigen galt.

\subsubsection{Synthese der Pyrimidin-3'-Aminonucleoside}

Für die Synthese des 5'-O-TBDMS-3'-Aminothymidins und des analogen Basengeschützten Cytidin-Derivats wurde generell nach der in Kap. 3.2.1.4 geschilderten Methode vorgegangen (Abb. 3.7, 4.10 und 4.11). Die Synthese des ThymidinDerivats war mit nur vier Stufen bedeutend kürzer als diejenige des Cytidin-Derivats. Zuerst wurde in Analogie zu der Silylierung in Kap. 4.2.1 an der 5'-Position ein Silylether erzeugt. In diesem Fall war die erhaltene Ausbeute an 135 mit 89\% etwas geringer als bei der zuvor diskutierten Zweifach-Silylierung. Der Grund dafür ist die selbst bei geringem Überschuss an Reagenz (TBDMSCl) stattfindende Reaktion zum zweifach silylierten Thymidin. Es folgte die Überführung des monosilylierten Thymidins 135 in die tricyclische Anhydro-Verbindung 136. Bei dieser Reaktion 
handelt es sich um eine intramolekulare nucleophile Substitution der Hydroxygruppe durch das 2-O der Nucleobase. Für diesen Vorgang bedarf es der Aktivierung der Hydroxygruppe an 3'-Position. Dazu wurde im Sinne einer Mitsunobu-Reaktion ${ }^{[159-160]}$ die Kombination aus Triphenylphosphin und DIAD in DMF als Lösungsmittel verwendet. Gegenüber der zuvor eingesetzten, zweistufigen Reaktionsführung über die Bildung des 3'-O-Methansulfonsäureesters und dessen nachfolgende Substitution in basischem Milieu (nach Matsuda ${ }^{[120]}$ ) stellt dies eine bequemere Alternative dar. Auch die Ausbeute dieser Reaktion ist mit 95\% bedeutend höher als diejenige der früher angewendeten Reaktionsfolge (77\%). Die erhaltene Anhydroverbindung 136 weist eine mäßige Ringspannung auf und ist auf der $\beta$-Seite wirksam abgeschirmt, sodass die nachfolgende $S_{N} 2$-artige Ringöffnungsreaktion durch Natriumazid nur unter Bildung des (3'S)-konfigurierten Azidothymidins 118 verläuft.
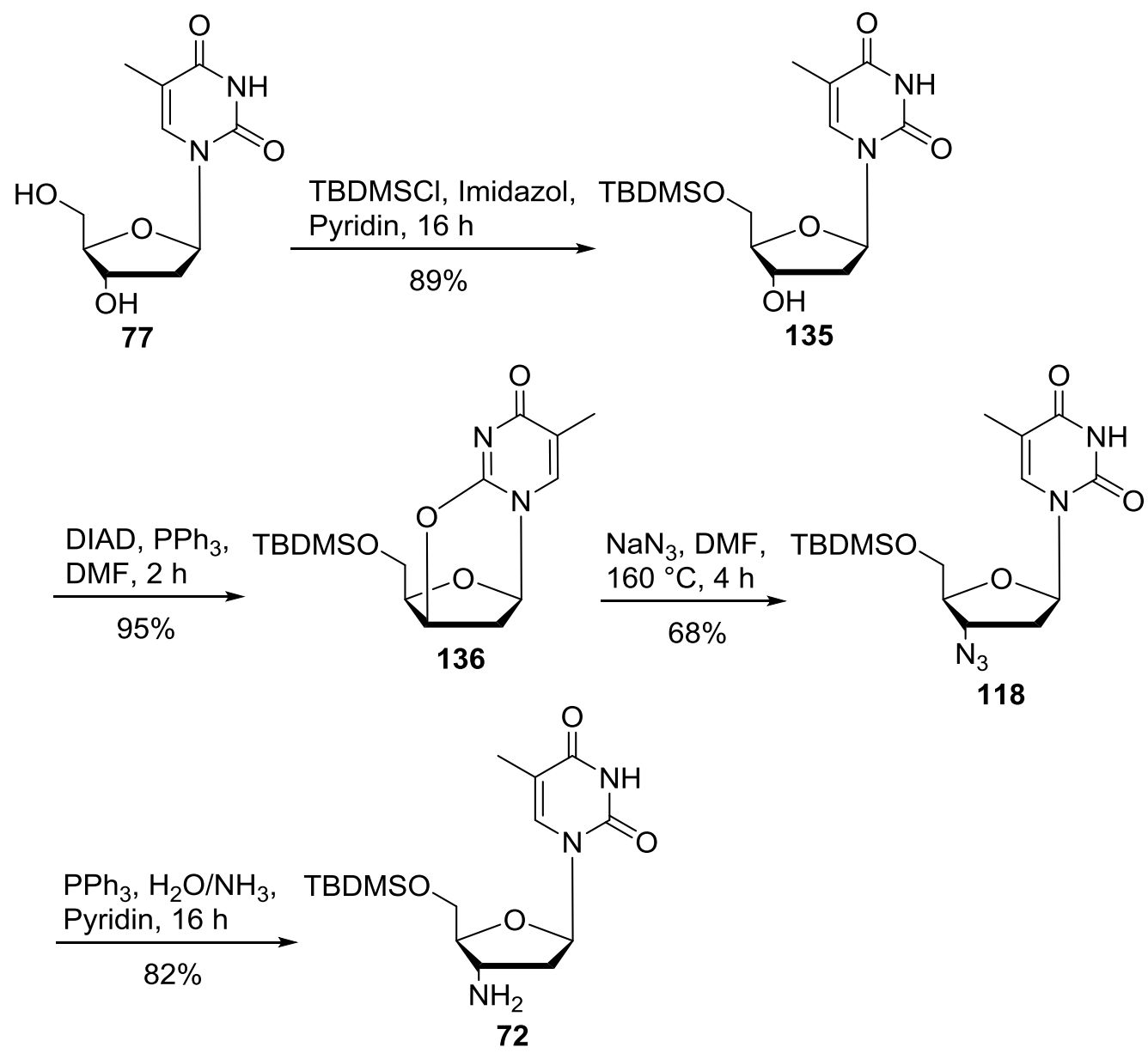

Abb. 4.10: Synthese des 5'-O-TBDMS-3'-Aminothymidins 72.

Als Lösungsmittel wurde im Unterschied zum früher verwendeten 9:1-Gemisch aus $\mathrm{DMF} / \mathrm{H}_{2} \mathrm{O}$ reines DMF eingesetzt, sodass die Ausbeute mit $68 \%$ etwas höher lag als 
in der Vorarbeit (57\%). Die Verwendung von Lithiumazid anstelle von Natriumazid führt bekanntermaßen zu deutlich besseren Ausbeuten. Dieser Sachverhalt ist leicht verständlich, wenn die beiden Kationen $\mathrm{Na}^{+}$und $\mathrm{Li}^{+}$hinsichtlich ihrer Oxophilie verglichen werden. Das Lithiumion stabilisiert das bei der Substitution gebildete Oxyanion wesentlich besser als das Natriumion. Dennoch wurde das Natriumazid wegen seiner leichten Verfügbarkeit und vergleichsweise sicheren Handhabung bevorzugt. Um die Azidfunktion von 118 in ein Amin zu überführen, wurde von einer Staudinger-Reduktion ${ }^{[161-162]}$ Gebrauch gemacht. Bei dieser Reaktion wird das entsprechende Azid in basischem Milieu (Pyridin) durch Triphenylphosphin reduziert. Die Hydrolyse des intermediär gebildeten Iminophosphorans wird durch Zugabe von wässriger Ammoniak-Lösung (25\%) bewirkt. Die Reaktion besitzt auf Grund der stabilen Produkte (Stickstoff, Triphenylphosphinoxid, Amin) eine große Triebkraft. Daher wurde die wässrige Ammoniak-Lösung bei $0^{\circ} \mathrm{C}$ über einen Zeitraum von ca. 30 min. zugegeben. Die Reaktion verlief mit einer guten Ausbeute von $82 \%$ an 3'-Aminothymidin 72. Die Synthese des geschützten 3'-Aminodesoxycytidins 90 unterscheidet sich durch zwei Aspekte von derjenigen des oben beschriebenen Thymidin-Derivats 72. Zum einen besteht wegen möglicher Nebenreaktionen in der ON-Synthese die Notwendigkeit, die exocyclische 4-Aminogruppe des Cytosins zu schützen. Zum anderen erfolgt die Einführung der TBDMS-Schutzgruppe am 5'-O gemäß der zugrunde gelegten Syntheseplanung nach Richert ${ }^{[137]}$ erst im vorletzten Schritt. Daher begann die Synthese des 3'-Aminocytidin-Derivats 90 mit der Einführung einer Benzoyl-Gruppe an der 4-Aminogruppe der Nucleobase des Desoxycytidins 137 (Abb. 4.11). Für diese Transformation hat sich die Methode der transienten Schützung etabliert. ${ }^{[163]}$ Dabei werden die 5'- und 3'-Hydroxygruppen unter mild-alkalischen Bedingungen (Pyridin) in sehr labile Silylether (TMS) überführt, sodass anschließend nur die exocyclische Aminogruppe der Nucleobase für die Reaktion mit Benzoylchlorid zur Verfügung steht. Die Abspaltung der Silylether erfolgte durch Zugabe von Wasser unter Kühlung des Reaktionsgemischs auf $0{ }^{\circ} \mathrm{C}$. Die gesamte Reaktionsfolge konnte als Eintopfverfahren durchgeführt werden. Abweichend vom publizierten Verfahren wurde das resultierende Rohprodukt chromatographisch gereinigt, da dessen Umkristallisation stets ein hohes Maß an Verunreinigung durch Benzoesäure nach sich zog. Die Verbindung 138 konnte auf diese Weise in einer Ausbeute von $75 \%$ erhalten werden. Es folgte in ähnlicher Weise zur erläuterten Synthese des Anhydrothymidins 136 (Abb. 4.10) die Cyclisierung des N-4-Benzoyldesoxycytidins 138 zur Verbindung 96. Im Unterschied 
zum Ringschluss des Thymidin-Derivats 135 wurden hier je zwei Portionen DIAD und Triphenylphosphin in einem zeitlichen Abstand von $1 \mathrm{~h}$ hinzugefügt, wobei mit der ersten Portion p-Brombenzoesäure dazugegeben wurde (Abb. 4.11).

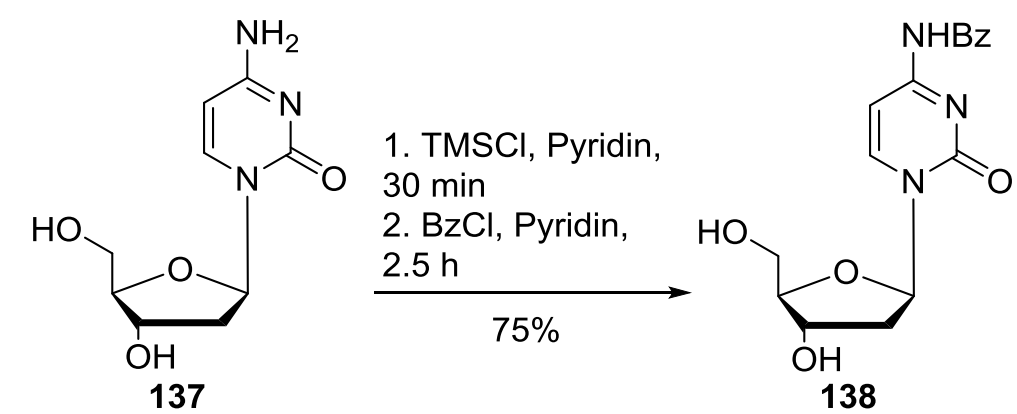

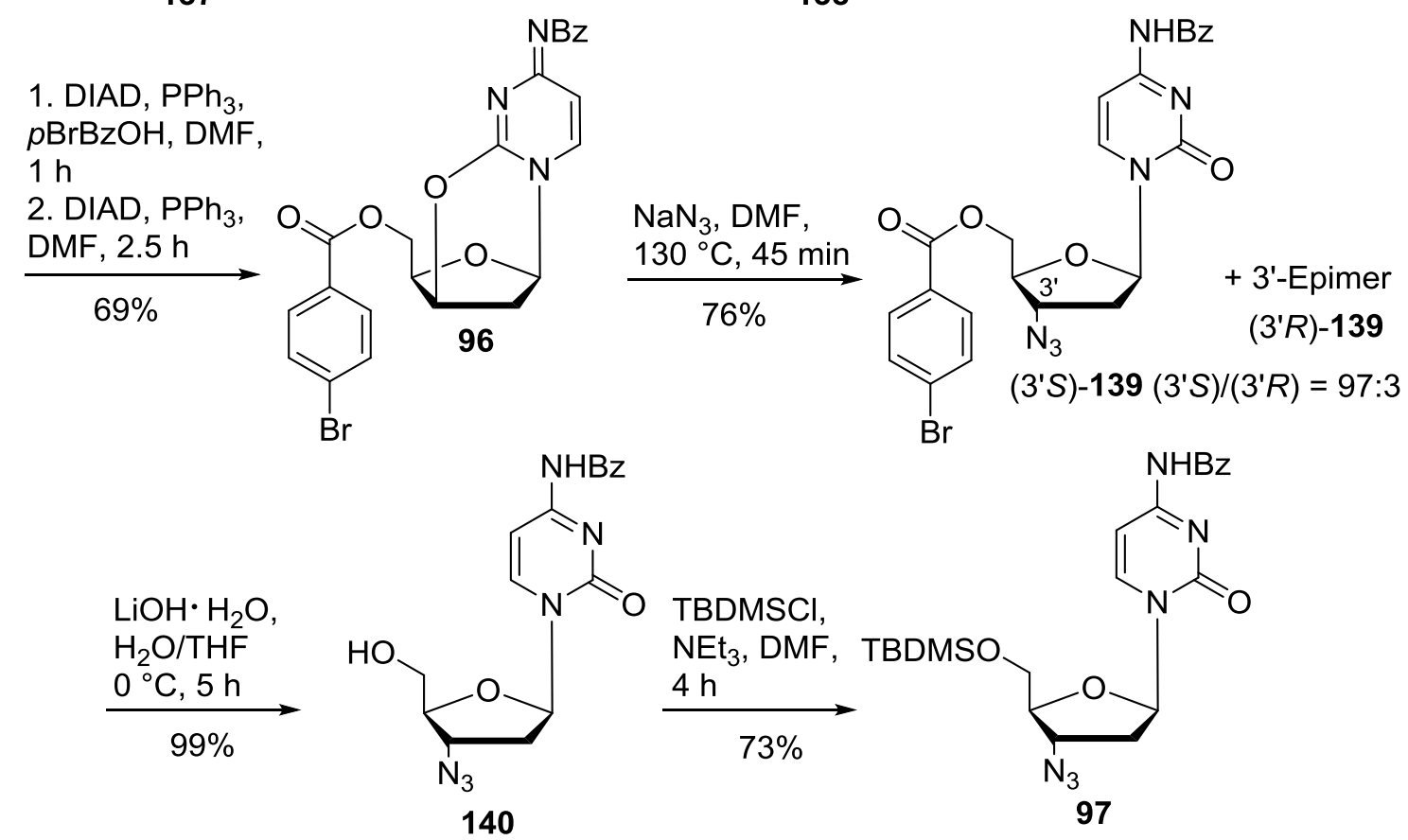

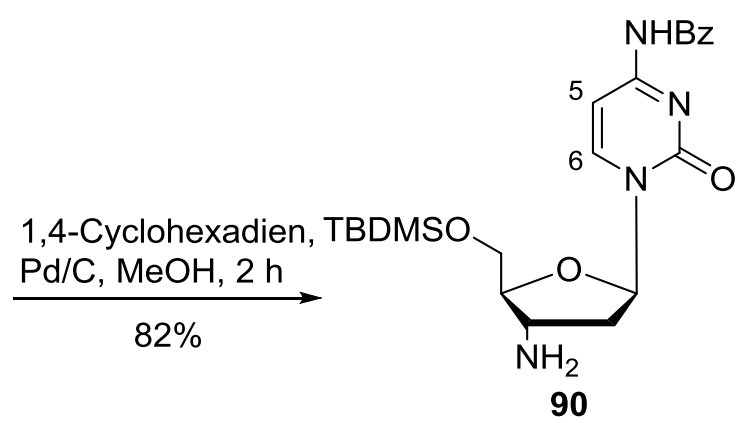

Abb. 4.11: Synthese des geschützten 3'-Aminocytidins 90.

Die erste Teilreaktion diente der Einführung einer Esterfunktion an der 5'-Position durch Nucleophile Substitution der Hydroxygruppe, während die zweite Teilreaktion die bereits erwähnte Cyclisierung der Verbindung herbeiführte. Beide Teilreaktionen verliefen gemäß dem Mechanismus der Mitsunobu-Reaktion (s.o.). Zur Reinigung des Rohprodukts von 96 wurde eine Fällung aus Diethylether verwendet. Dieses 
Vorgehen ist aufgrund der hohen Polarität der Verbindung 96 und folglich sehr geringen Löslichkeit in Diethylether gegenüber der gewöhnlichen Chromatographie an Kieselgel vorteilhaft, da sämtliche Verunreinigungen (Hydrazin-Derivat, Triphenylphosphinoxid) aufgrund ihrer Lipophilie in Diethylether gelöst bleiben. Die stereoselektive Einführung der Azidfunktion an 3'-Position zur Bildung von (3'S)-139 wurde unter milderen Bedingungen (kürzere Reaktionszeit, niedrigere Temperatur) durchgeführt als die analoge Reaktion zum 3'-Azidothymidin 118 (Abb. 4.10). Es erscheint naheliegend, dass der Grund hierfür darin liegt, dass das Benzoylgeschützte Cytosin eine bessere Abgangsgruppe als Thymin darstellt, denn die negative Ladung kann auch auf die Acylgruppe übertragen werden. Folglich wird der Übergangszustand der Reaktion besser stabilisiert. Interessanterweise wurde bei dieser Reaktion in geringer Menge (3\% des Rohprodukts) das 3'-epimere Azid $\left(3^{\prime} R\right)$-139 erhalten. Eine plausible Erklärung für diesen Befund ist ein teilweiser Verlauf der Reaktion über den $\mathrm{S}_{N} 1$-Mechanismus. Nur wenn in geringen Mengen unter vorgelagerter Ringöffnung ein Carbokation am 3'-C gebildet wird, kann das Nucleophil unter Retention der Konfiguration am 3'-C eintreten. Diese Annahme harmoniert überdies gut mit der bereits erwähnten Tatsache, dass das Benzoylgeschützte Cytosin eine wesentlich bessere Abgangsgruppe darstellt als Thymin. Um in 5'-Position eine TBDMS-Schutzgruppe einführen zu können, wurde zunächst der $p$-Brombenzoesäureester durch Einwirkung von Lithiumhydroxid-Monohydrat in einem THF/Wasser-Lösungsmittel-Gemisch gespalten. Abweichend von der publizierten Vorschrift nach Richert ${ }^{[137]}$ wurde die Reaktion durchgängig in dem Temperaturintervall von $0^{\circ} \mathrm{C}-5^{\circ} \mathrm{C}$ geführt. Das Produkt 140 wurde in einer exzellenten Ausbeute von $99 \%$ erhalten und konnte auch ohne chromatographische Reinigung in der nächsten Reaktion verwendet werden. Die Generierung des TBDMS-Ethers am 5'-O von 140 ergab überraschenderweise unter den StandardBedingungen (Pyridin, TBDMSCl) selbst nach einer Reaktionszeit von $16 \mathrm{~h}$ eine unvollständige Umsetzung und nur mäßige Ausbeute (54\%). Eine deutliche Verbesserung der Ausbeute auf $73 \%$ und Verkürzung der Reaktionszeit auf $4 \mathrm{~h}$ ermöglichte der Ersatz von Pyridin durch DMF und die Zugabe von $\mathrm{NEt}_{3}$ als Base. Für die abschließende Reduktion der 3'-Azidgruppe von 97 zum Amin wurde mit der Transfer-Reduktion durch 1,4-Cyclohexadien in Methanol unter heterogener Katalyse durch $\mathrm{Pd} / \mathrm{C}$ auf ein relativ mildes Verfahren zurückgegriffen. ${ }^{[164]}$ Auf diesem Weg wurde das Produkt 90 in einer guten Ausbeute von $82 \%$ erhalten. Andere Methoden wurden wegen möglicher Nebenreaktionen nicht untersucht. Bei der Staudinger- 
Reaktion wäre die Spaltung der Benzoyl-Schutzgruppe durch die wässrige Ammoniak-Lösung $\mathrm{zu}$ erwarten. Bei der heterogen katalysierten $(\mathrm{Pd} / \mathrm{C})$ Hydrogenolyse von Cbz-Schutzgruppen durch molekularen Wasserstoff in Methanol trat im Fall von Uridin-Derivaten die Reduktion der 6,5-Doppelbindung der Nucleobase als Begleiterscheinung auf. ${ }^{[141]}$ Beide Nebenreaktionen wurden durch die Verwendung der Transfer-Hydrierung vermieden.

\subsubsection{Synthese der Purin-3'-Aminonucleoside}

Die Synthese der Purin-3'-Aminonucleoside sollte gemäß der in Kap. 3.1.3.2 beschriebenen Vorgehensweise erfolgen. Wie bereits im Zusammenhang mit der Synthese des geschützten 3'-Amino-2'-desoxycytidins erläutert, ist eine Schützung der exocyclischen Aminogruppen der Nucleobasen erforderlich. Während für das Adenin wie im Fall des Cytosins die Benzoyl-Schutzgruppe vorgesehen war, sollte die Aminogruppe des Guanins mit einer Isobutyryl-Schutzgruppe versehen werden. Hierfür wurde die generelle Methode zur Acylierung von Nucleobasen-Aminogruppen verwendet, die bereits im Kontext mit der Synthese des geschützten 2'-Desoxy3'-aminocytidins 90 erläutert wurde (Kap. 4.2.5.1, Abb. 4.11). Die Acylierung des 2'-Desoxyadenosins lieferte das Produkt 141 in einer Ausbeute von 85\%, während die entsprechende Reaktion zur Bildung des 2'-Desoxyguanosin-Derivats 142 mit einer Ausbeute von 67\% verlief (Abb. 4.12).

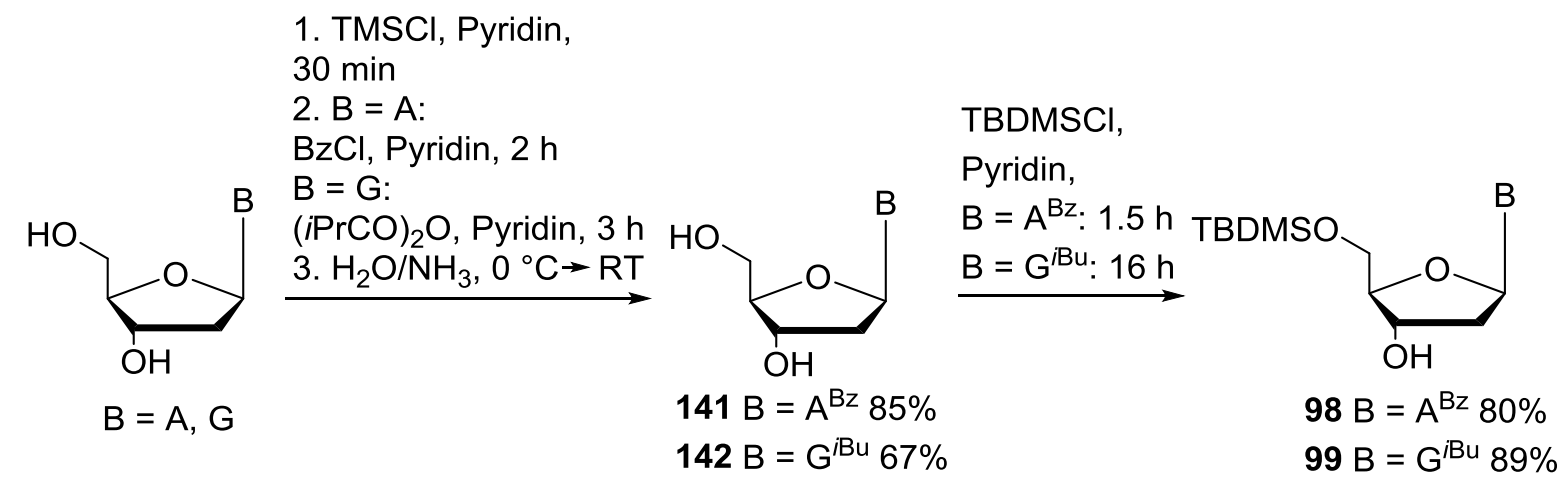

Abb. 4.12: Synthese der 5'-O-geschützten Purinnucleoside 98 und 99.

Auch in diesen Fällen erwies sich die Reinigung der Rohprodukte durch Umkristallisation als ineffizient, sodass von der aufwendigeren Chromatographie Gebrauch gemacht wurde. Es folgte die selektive Bildung eines Silylethers (TBDMS) in 5'-Position unter üblichen Bedingungen (TBDMSCl, Pyridin). Sowohl das silylierte 
2'-Desoxyadenosin 98 als auch das entsprechende 2'-Desoxyguanosin-Derivat 99 wurden in guten Ausbeuten (80\% bzw. $89 \%)$ isoliert. Die anschließende Transformation, deren Produkte die 2'-Desoxy-3'-xylo-Derivate 100 und 101 waren, stellt eine Inversion der Konfiguration am 3'-C-Atom dar. Hierfür wurde ein zweistufiges Eintopf-Verfahren angewendet. Diese Reaktionsfolge erwies sich als sehr empfindlich und bedurfte einer Optimierung (Abb. 4.13).

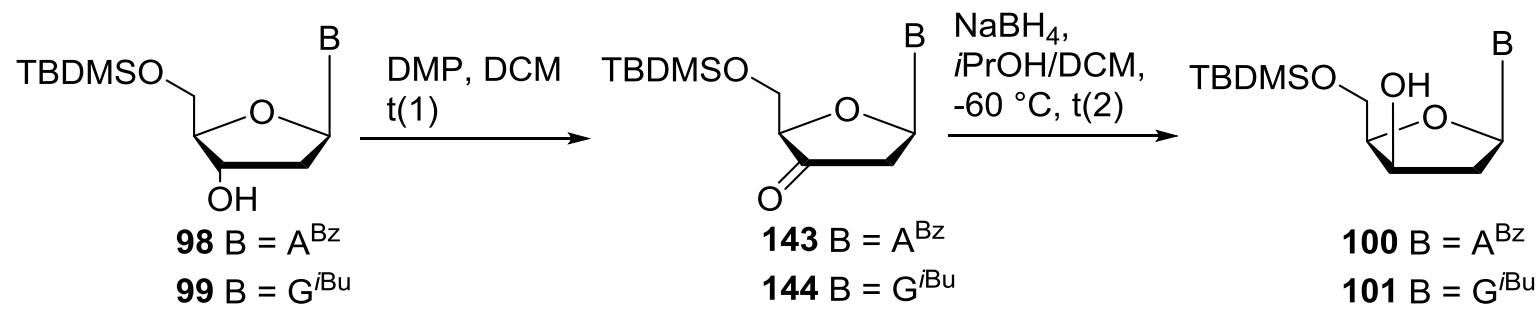

Ergebnisse der Synthesen von $\mathbf{1 0 0}\left(B=A^{\mathrm{Bz}}\right)$

\begin{tabular}{|c|c|c|c|c|c|c|c|}
\hline $\mathrm{Nr}$. & Edukt [g] & $\begin{array}{l}\text { Äq } \\
(\mathrm{DMP})\end{array}$ & $\begin{array}{l}\mathrm{Äq} \\
\left(\mathrm{NaBH}_{4}\right)\end{array}$ & $\begin{array}{l}\mathrm{c}(\text { Edukt }) \\
{[\mathrm{mmol} / \mathrm{mL}]}\end{array}$ & $\begin{array}{l}t(1) \\
{[h]}\end{array}$ & $\begin{array}{l}\mathrm{t}(2) \\
{[\mathrm{h}]}\end{array}$ & Ausbeute \\
\hline 1 & 0.050 & 3.0 & 2.5 & 0.106 & 7 & 16 & $<60 \%{ }^{*}$ \\
\hline 2 & 0.100 & 2.25 & 2.0 & 0.106 & 3 & 3.5 & $<61 \%{ }^{*}$ \\
\hline 3 & 0.100 & 2.25 & 2.0 & 0.106 & 4 & 3 & $<63 \%{ }^{*}$ \\
\hline 4 & 0.200 & 2.25 & 2.0 & 0.106 & 3 & 16 & $<20 \%{ }^{*}$ \\
\hline 5 & 0.200 & 1.5 & 2.0 & 0.106 & 4.5 & 16 & $74 \%$ \\
\hline 6 & 0.500 & 2.7 & 2.5 & 0.106 & 3 & 3 & $<30 \%{ }^{*}$ \\
\hline 7 & 1.00 & 2.25 & 2.5 & 0.141 & 7 & 16 & $<57 \%{ }^{*}$ \\
\hline 8 & 2.00 & 1.5 & 2.0 & 0.106 & 9 & 16 & $67 \%$ \\
\hline 9 & 2.00 & 1.5 & 2.0 & 0.106 & 14 & 7 & $75 \%$ \\
\hline
\end{tabular}

*verunreinigt

Ergebnisse der Synthesen von $101\left(B=G^{B u}\right)$

\begin{tabular}{llllllll}
\hline Nr. & Edukt [g] & $\begin{array}{l}\text { Äq } \\
\text { (DMP) }\end{array}$ & $\begin{array}{l}\text { Äq } \\
\left(\mathrm{NaBH}_{4}\right)\end{array}$ & $\begin{array}{l}\mathrm{c}(\text { Edukt }) \\
{[\mathrm{mmol} / \mathrm{mL}]}\end{array}$ & $\begin{array}{l}\mathrm{t}(1) \\
{[\mathrm{h}]}\end{array}$ & $\begin{array}{l}\mathrm{t}(2) \\
{[\mathrm{h}]}\end{array}$ & Ausbeute \\
\hline 1 & 0.050 & 1.5 & 2.0 & 0.106 & 4 & 16 & $64 \%$ \\
2 & 0.200 & 1.5 & 2.0 & 0.106 & 3 & 16 & $50 \%$ \\
3 & 0.200 & 1.5 & 2.0 & 0.106 & 4.5 & 16 & $80 \%$ \\
4 & 1.00 & 1.5 & 2.0 & 0.141 & 4 & 16 & $70 \%$ \\
5 & 2.00 & 1.5 & 2.0 & 0.106 & 7 & 16 & $74 \%$ \\
6 & 2.00 & 1.5 & 2.0 & 0.106 & 8 & 16 & $80 \%$ \\
\hline
\end{tabular}

Abb. 4.13: Synthese der 2'-Desoxy-3'-xylo-Derivate 100 und 101. 
Im ersten Schritt erfolgte eine Oxidation der 3'-Hydroxygruppen der Verbindungen 98 und 99 zu den intermediär gebildeten Ketonen 143 und 144 durch DMP in DCM. Auf die Isolierung der Ketone wurde aufgrund ihrer Labilität verzichtet. ${ }^{[165-166]} \mathrm{Im}$ Unterschied zu der Vorschrift von Richert wurden für die Synthese der Verbindung 100 im optimierten Verfahren nur 1.5 Äq DMP eingesetzt. Reaktionen, in denen die angegebene Menge von 2.25 Äq DMP dazugegeben wurde, ergaben nur geringe bis mäßige Ausbeuten an 100 (20-60\%) bei schlechter Reproduzierbarkeit. Zudem konnte bei einem Einsatz von mehr als 1.5 Äq an DMP das Produkt 100 nicht vollständig von den resultierenden Verunreinigungen befreit werden. Weitere Ungenauigkeiten in dem Protokoll von Richert betrafen das angegebene Zeitintervall für die Oxidation $(3 \mathrm{~h})$ und die Konzentration der Reaktionslösung $(0.5 \mathrm{mmol} / \mathrm{mL}$ bezüglich der Edukte 98 und 99). Bei kleinen Ansätzen $(200 \mathrm{mg}$ ) war die Oxidation erst nach $4 \mathrm{~h}$ abgelaufen und bei größeren Ansätzen (>1.5 g) nach mindestens $7 \mathrm{~h}$. Die Reaktionsdauer der Oxidation war nachweislich abhängig von dem gewählten Reaktionsmaßstab. Des Weiteren wurden die besten Ergebnisse für die Reaktionsfolge bei einer bedeutend niedrigeren Konzentration der Reaktionslösung $(0.106 \mathrm{mmol} / \mathrm{mL}$ bezüglich der Edukte 98 und 99$)$ erzielt. Nach der Oxidation wurde zum Desaktivieren des DMP und als Lösungsmittel für die nachfolgende Reaktion absolutes Isopropanol dazugegeben und die Temperatur der Reaktionsmischung auf $-60{ }^{\circ} \mathrm{C}$ heruntergekühlt. Letzteres war für die Stereoselektivität der nachfolgenden Reduktion der Ketone zu den Desoxy-3'-xylo-derivaten durch Natriumborhydrid von grundlegender Bedeutung. Der nucleophile Angriff an der annähernd trigonalplanaren 3'-Ketogruppe durch das $\mathrm{BH}_{4}$-Anion verläuft bevorzugt über die weniger abgeschirmte $\alpha$-Seite. Diese kinetische Diskriminierung nimmt zu tieferen Temperaturen hin deutlich zu. Nach einer Reaktionszeit von $16 \mathrm{~h}$ wurde das Natriumborhydrid durch Zugabe von Aceton gequencht und die Reaktion aufgearbeitet. Besonders wichtig ist das Einhalten der niedrigen Temperatur $\left(-60^{\circ} \mathrm{C}\right)$ über die gesamte Reaktionszeit bis zur Aufarbeitung. Ein Aufwärmen der Reaktion vor der Aufarbeitung führt zur teilweisen Zersetzung der gebildeten Produkte $\mathbf{1 0 0}$ und 101. Eine mögliche Ursache für dieses Phänomen ist die Spaltung der $\mathrm{N}$-glykosidischen Bindung durch Essigsäure, die bei der Reduktion von DMP freigesetzt wird. Folglich ist eine mild-alkalische Aufarbeitung $\left(\mathrm{NaHCO}_{3}\right)$ unverzichtbar. Das optimierte Verfahren ermöglichte die Synthese der 2'-Desoxy-3'xylo-nucleoside 100 und 101 in guten Ausbeuten von 72\% bzw. 80\%. Die wesentlichen Abweichungen gegenüber der Vorschrift nach Richert betrafen die 
eingesetzte Menge an DMP (1.5 Äq), die Konzentration der Edukte 98 und 99 in DCM $(0.106 \mathrm{mmol} / \mathrm{mL})$ und die Zeitintervalle der Teilreaktionen (Oxidation: 4-7 h, Reduktion $16 \mathrm{~h}$ ). Die erhaltenen Verbindungen 100 und 101 sollten wiederum unter Inversion der Konfiguration am 3'-C in die 2',3'-Didesoxy-3'-azidonucleoside 102 und 103 überführt werden. Die generelle Methode für diese Transformation besteht in einer Aktivierung der 3'-Hydroxygruppe und nachfolgender $\mathrm{S}_{\mathrm{N}} 2$-Reaktion mit einem Azid-Ion als Nucleophil (Abb. 4.14).

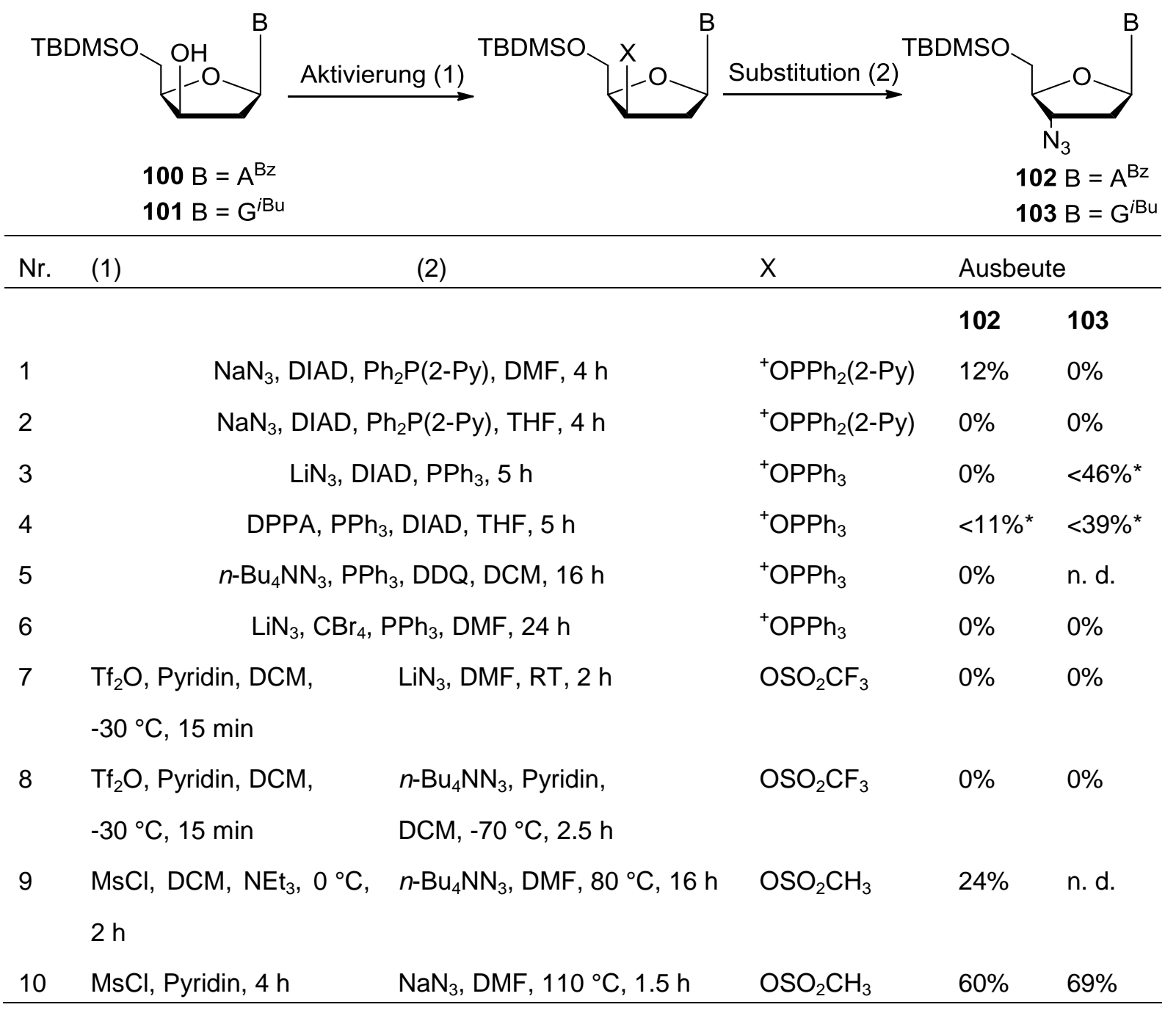

*verunreinigt, n. d. = nicht durchgeführt

Abb. 4.14: Synthese der 2'-Desoxy-3'-Azidonucleoside 102 und 103.

Das hierfür von Richert verwendete Verfahren impliziert eine Aktivierung der Hydroxygruppe gemäß der bereits erwähnten Mitsunobu-Reaktion durch eine Kombination aus Diphenyl-2-pyridylphosphin und DIAD in DMF. Als Azid-Quelle wurde dabei $\mathrm{NaN}_{3}$ genutzt. Die berichteten Ergebnisse konnten jedoch nicht reproduziert werden, da unter den beschriebenen Bedingungen ein nahezu 
untrennbares Gemisch resultierte. Das 2',3'-Didesoxyadenosin-Derivat 102 konnte auf diese Weise in einer maximalen Ausbeute von 12\% erhalten werden, während das entsprechende Derivat des Guanosins nicht in einer akzeptablen Form isoliert werden konnte. Bei Ersatz des Lösungsmittels DMF durch THF wurde unter ansonsten gleichbleibenden Bedingungen kein Produkt erhalten. Daher wurde zunächst ein ähnliches Verfahren nach Hirschbein eingesetzt. ${ }^{[134]}$ Anstelle von Diphenyl-2-pyridylphosphin wurde demnach das etwas elektronenreichere Triphenylphosphin $\left(\mathrm{PPh}_{3}\right)$ verwendet und das nur wenig in $\mathrm{DMF}$ lösliche $\mathrm{NaN}_{3}$ wurde durch das reaktivere und in DMF besser lösliche $\mathrm{LiN}_{3}$ ersetzt. Es konnte jedoch auch in diesem Fall nur stark verunreinigtes Produkt in geringer Ausbeute bzw. kein Produkt erhalten werden. Eine alternative Azid-Quelle, die aufgrund ihrer guten Löslichkeit in organischen Solventien als vielversprechend erschien, ist Diphenylphosphorylazid (DPPA). ${ }^{[167]}$ Dieses Reagenz wurde von Strazewski zur Einführung der Azid-Funktionalität an der 3'-Position eingesetzt. ${ }^{[168]}$ Die Reaktion beider 2'-Desoxy-3'-xylo-nucleoside 100 und 101 mit einer Kombination aus DPPA, $\mathrm{PPh}_{3}$ und DIAD in THF ergab jedoch ebenfalls geringe Ausbeuten (11\% bzw. 39\%) stark verunreinigter Produkte 102 und 103 (Abb. 4.14). Ein weiteres, prizipiell ähnlich funktionierendes System zur Überführung verschiedener Funktionalitäten in Azide wurde von Iranpoor et al. beschrieben. ${ }^{[169]}$ Demnach wird der Alkohol durch die Interaktion mit einem $\mathrm{PPh}_{3}$-DDQ(2,3-Dichlor-5,6-dicyanobenzochinon)-Komplex aktiviert. Als Azid-Quelle dient dabei das ausgesprochen reaktive aber relativ teure Salz Tetrabutylammoniumazid (TBAA), welches aufgrund der hohen Lipophilie des Tetrabutylammonium-Kations selbst in wenig polaren Lösungsmitteln als Solvensgetrenntes lonenpaar vorliegt. Unter diesen Bedingungen konnte allerdings kein Produkt erhalten werden. Ein möglicher Grund ist die als Nebenreaktion stattfindende Spaltung des Silylethers. Zwar berichteten Iranpoor et al. von einer ausgeprägten Präferenz der Substitution sekundärer Alkohole in Gegenwart primärer Silylether durch $\mathrm{N}_{3}$. Aufgrund der sterischen Abschirmung der 3'-Hydroxygruppe ist es jedoch naheliegend, dass die Spaltung des 5'-Silylethers als Nebenreaktion ein signifikantes Ausmaß annimmt. Nach diesen Versuchen erscheint es plausibel, dass die Reaktionssysteme gemäß Mitsunobu-Reaktion vor allem wegen der schwer trennbaren Produktgemische generell unvorteilhaft sind. Die Ursache für den geringen Reaktionsumsatz könnte die unzureichende Acidität der Gegenionen ( $\mathrm{Na}^{+}$, $\mathrm{Li}^{+}$, Diphenylphosphoryl-Kation) der eingesetzten Nucleophile sein. Gemäß dem bekannten Mechanismus der Mitsunobu-Reaktion wird ein zwitterionischer $\mathrm{PPh}_{3^{-}}$ 
DIAD-Komplex 145 als Intermediat gebildet (Abb. 4.15). ${ }^{[170]}$ Für die Stabilisierung dieser Spezies bedarf es eines ausreichend sauren Gegenions des Nucleophils. In der ursprünglich von Mitsunobu beschriebenen Reaktion wurden Carbonsäuren als Nucleophile eingesetzt, sodass die zwitterionische Spezies 145 durch das äußerst acide Proton sehr gut stabilisiert wurde. ${ }^{[159]}$ Eine vergleichbare Stabilisierung ist bei einem Ersatz dieses Protons durch die erwähnten Kationen wahrscheinlich nicht gegeben.

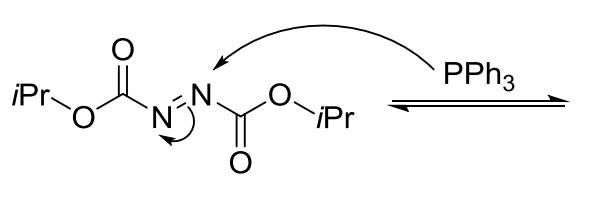

DIAD

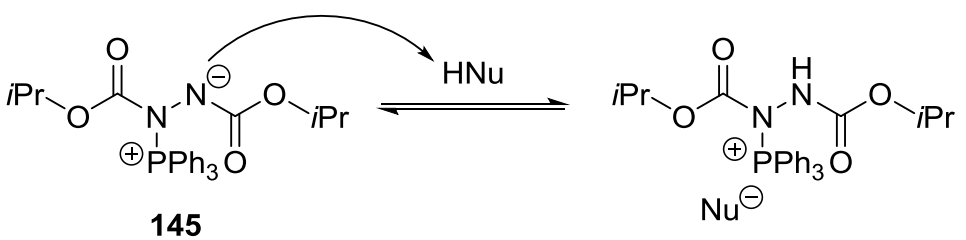

145

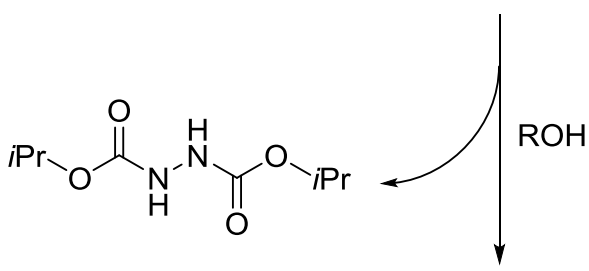

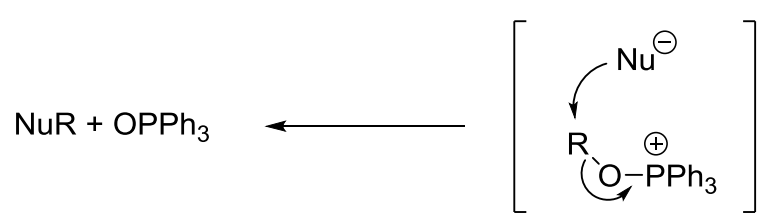

Abb. 4.15: Mechanismus der Mitsunobu-Reaktion. ${ }^{[170]}$

Folglich wurden gänzlich andere Verfahren auf ihre Brauchbarkeit für die Einführung der Azid-Funktionalität in der 3'-Position der 2'-Desoxy-3'-xylo-nucleoside untersucht. Eine interessante Variante der Substitution von Hydroxygruppen durch eine Azidfunktion unter Konfigurationsumkehr in 3'-Position, die ebenfalls getestet wurde, ist zu den Redoxkondensationen nach Mukaiyama ${ }^{[171]}$ oder Appel-Reaktionen ${ }^{[172]} \mathrm{zu}$ zählen. ${ }^{[133]}$ Bei dieser Reaktion, die in DMF geführt wurde und mechanistisch der Mitsunobu-Inversion verwandt ist, wird Triphenylphosphin durch eine Reaktion mit Tetrabromkohlenstoff zu Triphenylphosphoniumbromid oxidiert, das anschließend die Hydroxygruppe durch eine $\mathrm{S}_{\mathrm{N}} 2$-Reaktion unter Austritt des Bromidions aktiviert. Zusätzlich wurde zur Reaktion Lithiumazid dazugegeben, sodass das Azidion die aktivierte Phosphoniumspezies in 3'-Position substituieren sollte. Es wurde jedoch nur Zersetzung der Edukte 100 und 101 (Abb. 4.14) beobachtet. In den bisher diskutierten Reaktionen wurde die 3'-Hydroxygruppe stets durch reaktive Phosphonium-Intermediate aktiviert, die aus Redoxreaktionen hervorgegangen waren. Die prinzipiell andere Möglichkeit zur Überführung der Hydroxy-Funktionalität 
in eine gute Abgangsgruppe ist die Bildung von Sulfonsäureestern. Eine Methode dieser Art stellt die Aktivierung der 3'-Hydroxygruppe durch die Bildung des Trifluormethansulfonsäure(Tf)-Esters mit anschließender Substitution der Abgangsgruppe durch das aus Lithiumazid generierte Azidion dar. Über die Anwendung dieser Vorgehensweise zur Einführung der Azid-Funktionalität an 3'-Position oder an 2'-Position von verschiedenen Purin-Nucleosidderivaten ist berichtet worden. ${ }^{[131-132,173]}$ Dem Protokoll nach Herdewijn folgend wurde die Lösung des jeweiligen Nucleosids in DCM mit Pyridin als Base zunächst auf $-30^{\circ} \mathrm{C}$ heruntergekühlt und mit $\mathrm{Tf}_{2} \mathrm{O}$ versetzt. Anschließend wurde das Gemisch auf Raumtemperatur gebracht und in DMF gelöstes Lithiumazid dazugegeben. Es wurde jedoch ausschließlich die Zersetzung der Edukte beobachtet. Auch die Reaktionsführung bei $-70^{\circ} \mathrm{C}$ und Einsatz von Tetrabutylammoniumazid anstelle von Lithiumazid unter ansonsten gleich bleibenden Bedingungen ergab keine Produkte 102 oder 103 (Abb. 4.14). Der Grund dafür ist die Labilität der intermediär gebildeten 3'-Triflat-Ester, die vor allem durch Eliminierung der Estereinheit zerfallen. Im Unterschied dazu waren die von Herdewijn verwendeten Substrate in 5'-Position durch einen Benzoylester geschützt. Dieser Umstand ermöglicht die schnelle Stabilisierung der Triflatester durch die Seitengruppen-Substitution der Triflatestereinheit unter Entstehung eines anellierten Fünfrings, der im weiteren Verlauf durch das Azidion als Nucleophil geöffnet wird. Deutlich milder als die Aktivierung der Hydroxygruppe über den Triflat-Ester ist die Generierung des Methylsulfonsäure(Ms)-Esters. Dieses Verfahren wurde bereits in der Vorarbeit zur Synthese des 5'-O-TBDMS-3'-azidothymidins erfolgreich angewendet. ${ }^{[114]}$ Die Reaktionsbedingungen für die Synthese des 3'-O-Ms-Esters des 5'-geschützten Thymidins ( $\mathrm{MsCl}, \mathrm{DCM} \mathrm{NEt}_{3}, 0^{\circ} \mathrm{C}, 2 \mathrm{~h}$ ) ließen sich jedoch nicht auf die Herstellung des Purin-Nucleosids 102 übertragen. Zwar konnte die Bildung der entsprechenden 3'-O-Ms-Ester per Dünnschichtchromatogramm nachgewiesen werden. Allerdings konnte der 3'-O-Ms-Ester von $\mathbf{1 0 0}$ selbst nach direkter Weiterverwendung in der Nucleophilen Substitution mit TBAA in DMF nur in einer Ausbeute von $24 \%$ in das 2',3'-Didesoxy-3'-azidonucleosid überführt werden. Schließlich wurde die Bildung der 3'-O-Ms-Ester in Pyridin als Lösungsmittel durchgeführt. Im Unterschied zur Kombination aus DCM und $\mathrm{NEt}_{3}$ ist Pyridin aufgrund ihrer geringeren Basizität die mildere Alternative. Unter diesen Bedingungen wurden die 3'-O-Ms-Ester (Ms-100 bzw. Ms-101) der Verbindungen 100 und 101 in nahezu quantitativer Ausbeute erhalten. Diese Verbindungen wurden aufgrund ihrer Labilität ohne 
chromatographische Reinigung in der darauf folgenden Reaktion zu den 2',3'Didesoxy-3'-azidonucleosiden 102 und 103 umgesetzt, die in akzeptablen Ausbeuten erhalten wurden (60\% bzw. 69\%). Die Reduktion der Azide zu den Zielverbindungen 91 und 92 gelang in hohen Ausbeuten (in beiden Fällen 92\%) durch heterogen katalysierte Hydrierung unter Standardbedingungen (1 bar $\mathrm{H}_{2}, \mathrm{Pd} / \mathrm{C}, \mathrm{MeOH}$, Abb. 4.16).

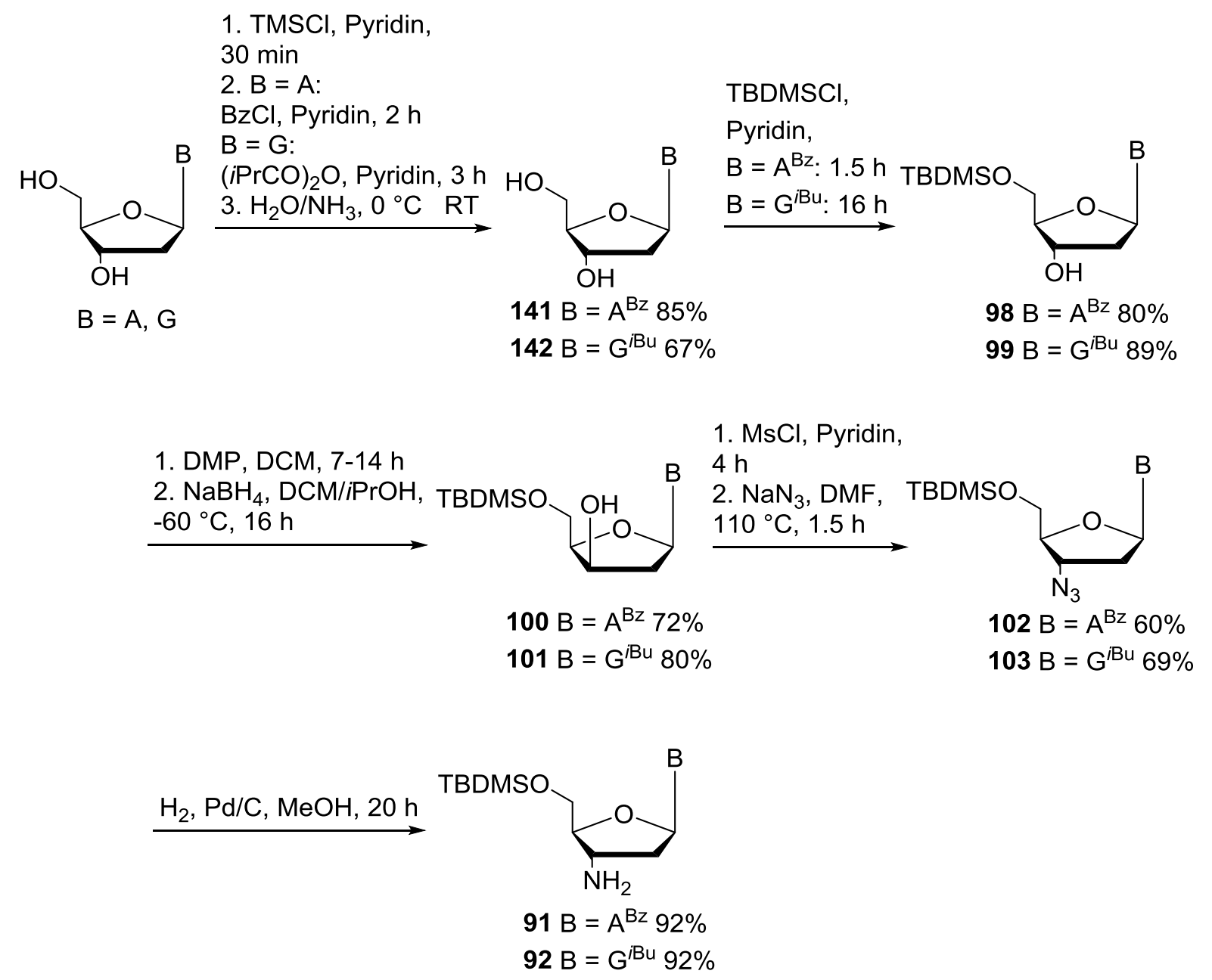

Abb. 4.16: Optimierte Synthese der Purin-2',3'-didesoxy-3'-aminonucleoside 91 und 92.

\subsubsection{Synthese der NAA-verbrückten Dinucleoside (Dimere)}

Dem Syntheseplan nach Kap. 3.2.1.3 weiter folgend wurden aus den bisher beschriebenen NAA 73 und den 3'-Aminonucleosiden 72 und 90-92 verschiedene Dinucleoside aufgebaut. Für die Verknüpfung der NAA mit den Nucleosiden wurde das gängige Verfahren zur Peptidkupplung verwendet. Zunächst wurden demnach die Carbonsäuren durch Reaktion mit EDC und HOBt in Aktivester überführt. Dies dient einer Unterdrückung von Nebenreaktionen wie Epimerisierungen, die bei 
direkter Aktivierung durch z. B. DCC ein bedeutendes Ausmaß annehmen können. Die resultierenden Carbonsäure-HOBt Aktivester wurden mit 3'-Aminonucleosiden zur Reaktion gebracht, sodass über Peptidbindungen verknüpfte Dinucleoside 74, 93-95 entstanden (Abb. 4.17). Diese zweistufige Reaktion wurde stets in DCM als Lösungsmittel geführt und ergab moderate bis gute Ausbeuten (58-79\%). Die besten Ergebnisse wurden bei der Kupplung der NAA 73 mit dem 5'-geschützten 3'Aminothymidin erzielt (79\% bzw 78\%). Etwas geringere Ausbeuten resultierten bei der Kupplung der NAA 73 mit 5'-geschützten Purin-3'-Aminonucleosiden (66-74\%). Noch schlechtere Ergebnisse wurden bei der Bindungsknüpfung mit dem entsprechenden Cytidin-Derivat 90 (59\% bzw. 63\%) erhalten.

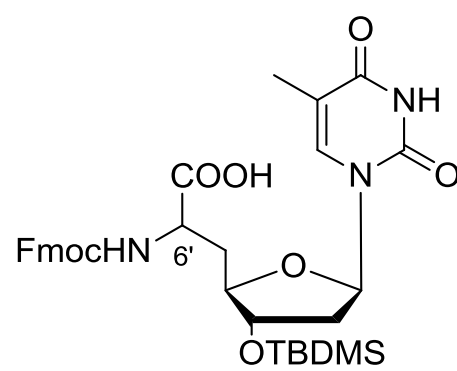

(6'S)- oder (6'R)-73

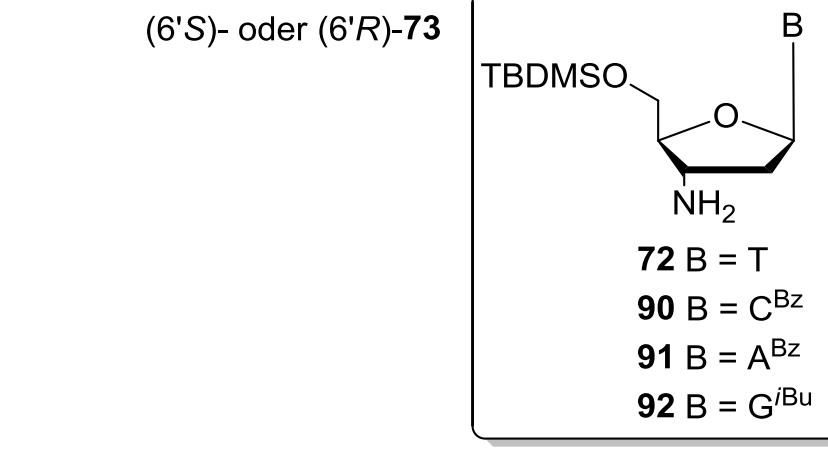

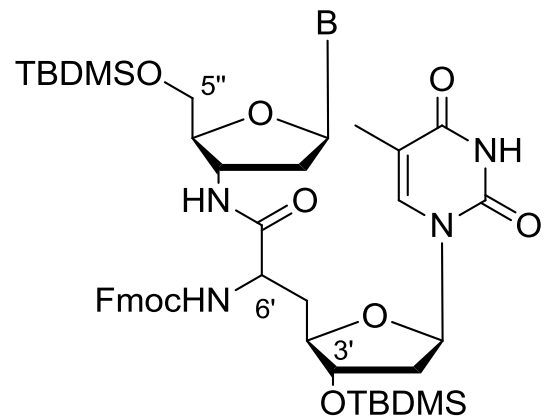

(6'S) oder (6'R)

$74 \mathrm{~B}=\mathrm{T}$

$93 B=C^{B z}$

$94 B=A^{B z}$

$95 B=G^{i B u}$

\begin{tabular}{lllll}
\hline Nr. & 3'-Aminonucleosid & Produkt & \multicolumn{2}{l}{ Ausbeute in \% } \\
\hline & & & $\left(6^{\prime} S\right)$ & $\left(6^{\prime} R\right)$ \\
1 & $72 \mathrm{~B}=\mathrm{T}$ & 74 & 79 & 78 \\
2 & $90 \mathrm{~B}=\mathrm{C}^{\mathrm{Bz}}$ & 93 & 58 & 63 \\
3 & $91 \mathrm{~B}=\mathrm{A}^{\mathrm{Bz}}$ & 94 & 71 & 68 \\
4 & $92 \mathrm{~B}=\mathrm{G}^{\mathrm{Bu}}$ & 95 & 66 & 74 \\
\hline
\end{tabular}

Abb. 4.17: Peptidkupplung der NAA 73 mit verschiedenen 3'-Aminonucleosiden zu 74, 93-95.

Bei der zuletzt erwähnten Reaktion wurde ein Nebenprodukt gebildet, dessen Charakterisierung aufgrund der äußerst komplexen NMR-Spektren im Rahmen dieser Arbeit nicht in Angriff genommen wurde. Die Trennung dieses Nebenprodukts von dem Hauptprodukt durch Chromatographie war nur unter Verlust an Ausbeute 
möglich. Eine denkbare Ursache für diesen Befund sind Reaktionen an der Bzgeschützten exocyclischen Aminogruppe. Optimierungen der Peptidkupplung wurden aufgrund der geringen Menge an aufwändig herzustellenden NAA 73 nicht unternommen. Im nächsten Schritt wurden beide TBDMS-Schutzgruppen der Verbindungen 74, 93-95 entfernt. Während für die 5'- und 3'-Desilylierung der Verbindung 74 weiterhin das bewährte Verfahren (kat. $\mathrm{AcCl}$ in $\mathrm{MeOH}$ ) mit guten Resultaten angewendet wurde, bedurfte die gleiche Entschützung der Verbindungen 93-95 einer anderen Herangehensweise. Der Versuch, die sauer katalysierte Entschützung bei der Verbindung 93 anzuwenden, ergab ein untrennbares Produktgemisch. Eine mögliche Nebenreaktion ist die Spaltung der BenzoylSchutzgruppe. Die Verbindungen $\mathbf{9 4}$ und 95 erwiesen sich unter den gleichen Reaktionsbedingungen über einen Zeitraum von über $22 \mathrm{~h}$ als inert. Auch nach Zugabe von weiteren 0.25 Äquivalenten Acetylchlorid wurde im Verlauf von $7 \mathrm{~h}$ kein Reaktionsumsatz beobachtet. Bei weiterer Erhöhung der Menge an Acetylcholrid um 0.5 Äq wurde die Bildung zahlreicher Nebenprodukte per DC beobachtet. Daher wurden für die Desilylierungen mild-alkalische oder andere mild-saure Bedingungen mit Fluoridquellen als Spaltungsreagenzien auf ihre Eignung für diese Entschützung untersucht. Die Notwendigkeit der Kompatibilität dieser Methoden mit der ausgeprägt Basen-labilen Fmoc-Schutzgruppe an der 6'-Aminogruppe schränkte die Auswahl jedoch stark ein. So wurde z. B. TBAF in THF als für seine Basizität bekanntes System nicht in Erwägung gezogen. Eine weitere Einschränkung für Optimierungsversuche stellte die aufgrund der langen Synthese nur geringe Menge der Edukte 93-95 dar. Es wurde daher ausschließlich mit Ansätzen in einem Maßstab von ca. $10 \mathrm{mg}$ Edukt gearbeitet. Ein als mild ausgewiesenes Spaltungsreagenz ist TAS-F (Tris(dimethylamino)sulfonium-difluortrimethylsilicat). ${ }^{[174]}$ Bei der Reaktion mit TAS-F in DMF konnte bei allen Dinucleosiden jedoch ausschließlich Zersetzung des Edukts nachgewiesen werden. Der charakteristische, hellblau fluoreszierende Spot des Dibenzofulvens bei hohen $R_{\mathrm{f}}$-Werten belegte die Abspaltung der Fmoc-Gruppe. Weitere vielversprechende Methoden zur selektiven Spaltung von Silylgruppen sind im Zusammenhang mit der ON-Synthese (RNA) erforscht worden. ${ }^{[175-176]}$ Für die Entschützung von silylierten Nucleosiden und Nucleotiden ist der saure TriethylaminTrihydrofluorid-Komplex (3HF-NEt ${ }_{3}$ ) verwendet worden. ${ }^{[177]}$ Die Reaktion der Dimere 93-95 mit $10 \mathrm{Äq}$ an 3HF-NEt $\mathrm{N}_{3}$ in THF ergab jedoch nach $26 \mathrm{~h}$ einen nur sehr geringem Umsatz. Möglicherweise war hier die Konzentration des $3 \mathrm{HF}^{-N_{E} t_{3}-}$ Komplexes für diese Substrate zu gering. Ein Versuch, die Silyl-Spaltung nach dem 


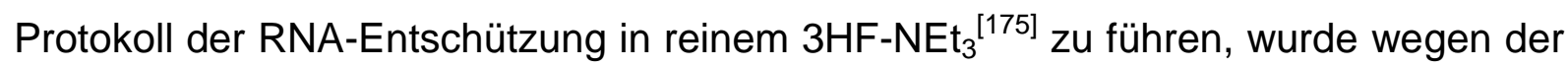
geringen verbliebenen Menge an Edukt nicht unternommen. Die besten Ergebnisse wurden bei Anwendung der Entschützungsmethode für synthetisierte RNA-Stränge mit Ammoniumfluorid in Methanol erhalten. ${ }^{[176]}$

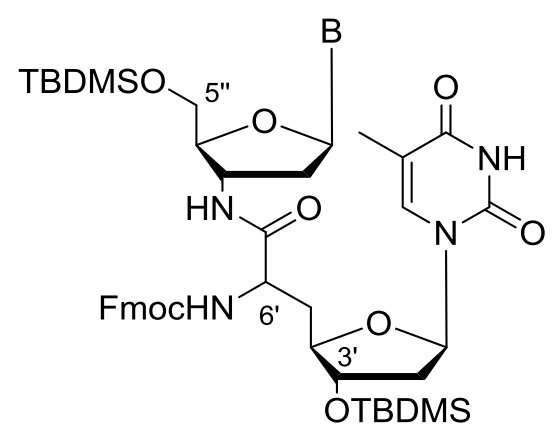

(6'S) oder (6'R)

$74 \mathrm{~B}=\mathrm{T}$

$93 B=C^{B Z}$

$94 B=A^{B z}$

$95 B=G^{i B u}$
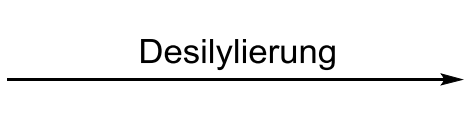

Frmothry

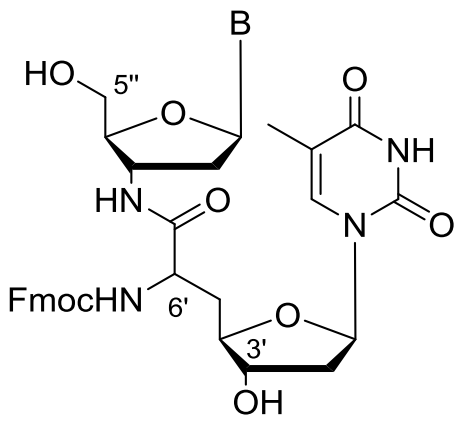

(6'S) oder (6'R)

$146 \mathrm{~B}=\mathrm{T}$

$147 \mathrm{~B}=\mathrm{C}^{\mathrm{Bz}}$

$148 B=A^{B z}$

$149 B=G^{i B u}$

\begin{tabular}{|c|c|c|c|c|c|}
\hline Nr. & Edukt & Bedingungen & Produkt & Ausbeute in $\%$ & \\
\hline & & & & $\left(6^{\prime} S\right)$ & $\left(6^{\prime} R\right)$ \\
\hline 1 & $74 \mathrm{~B}=\mathrm{T}$ & $\mathrm{AcCl}, \mathrm{MeOH}, 24 \mathrm{~h}$ & $146 \mathrm{~B}=\mathrm{T}$ & 92 & 89 \\
\hline 2 & $93 \mathrm{~B}=\mathrm{C}^{\mathrm{Bz}}$ & $\mathrm{AcCl}, \mathrm{MeOH}, 24 \mathrm{~h}$ & $147 B=C^{B z}$ & $<59^{*}$ & n. d. \\
\hline 3 & & TAS-F, DMF, $1 \mathrm{~h}$ & & Zersetzung & n. d. \\
\hline 4 & & $3 \mathrm{HF} \mathrm{NEt}_{3}, \mathrm{THF}, 26 \mathrm{~h}$ & & 0 & n. d. \\
\hline 5 & & $\mathrm{NH}_{4} \mathrm{~F}, \mathrm{MeOH}, 60^{\circ} \mathrm{C}, 6 \mathrm{~h}$ & & 46 & n. d. \\
\hline 6 & $94 B=A^{B z}$ & $\mathrm{AcCl}, \mathrm{MeOH}, 24 \mathrm{~h}$ & $148 B=A^{B z}$ & 0 & n. d. \\
\hline 7 & & TAS-F, DMF, $1 \mathrm{~h}$ & & Zersetzung & n. d. \\
\hline 8 & & 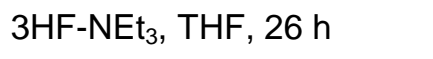 & & 0 & n. d. \\
\hline 9 & & $\mathrm{NH}_{4} \mathrm{~F}, \mathrm{MeOH}, 60^{\circ} \mathrm{C}, 4.5 \mathrm{~h}$ & & 66 & 66 \\
\hline 10 & $95 B=G^{B u}$ & $\mathrm{AcCl}, \mathrm{MeOH}, 29 \mathrm{~h}$ & $149 B=G^{B u}$ & 0 & n. d. \\
\hline 11 & & TAS-F, DMF, $1 \mathrm{~h}$ & & Zersetzung & n. d. \\
\hline 12 & & 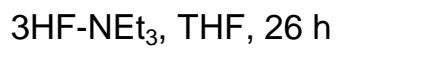 & & 0 & n. d. \\
\hline 13 & & $\mathrm{NH}_{4} \mathrm{~F}, \mathrm{MeOH}, 60^{\circ} \mathrm{C}, 4.5 \mathrm{~h}$ & & 41 & 38 \\
\hline
\end{tabular}

*verunreinigt, $n$. d. = nicht durchgeführt

Abb. 4.18: Synthese der entschützten Dinucleoside 146-149.

Dazu wurden die jeweiligen Dimere 93-95 in Methanol mit Ammoniumfluorid bei $60{ }^{\circ} \mathrm{C}$ gerührt. Um akzeptable Ausbeuten zu erhalten, wurde die Reaktion nach maximal $6 \mathrm{~h}$ beendet und das nicht umgesetzte Startmaterial nach dessen Isolierung 
nochmals einer Entschützung unterzogen. Als Nebenreaktion trat auch hier die Spaltung der Fmoc-Gruppe auf. Wegen der hohen Polarität der resultierenden Diole wurde stets auf die wässrige Aufarbeitung verzichtet. Die Ausbeuten der Reaktionen sind in Abb. 4.18 angegeben. Sämtliche Optimerungsversuche wurden mit den (6'S)Diastereomeren durchgeführt, da deren Synthese zuverlässiger und mit weniger Zeitaufwand verbunden war (s. Kap. 4.2.3). Die Synthese von (6'R)-147 wurde aus Zeitgründen nicht mehr fortgesetzt. Die regioselektive Einführung der DMTrSchutzgruppe an der 5"-Position der erhaltenen Diole 146-149 erfolgte gemäß dem allgemein bekannten Verfahren. Demnach wurden die Dinucleoside 146, 148 und 149 mit einem geringen Überschuss an $\mathrm{DMTrCl}(1.1 \mathrm{Äq})$ in Pyridin zur Reaktion gebracht. Eine andere Lösungsmittelzusammensetzung war im Fall der TritylSchützung von Verbindung (6'S)-147 erforderlich.

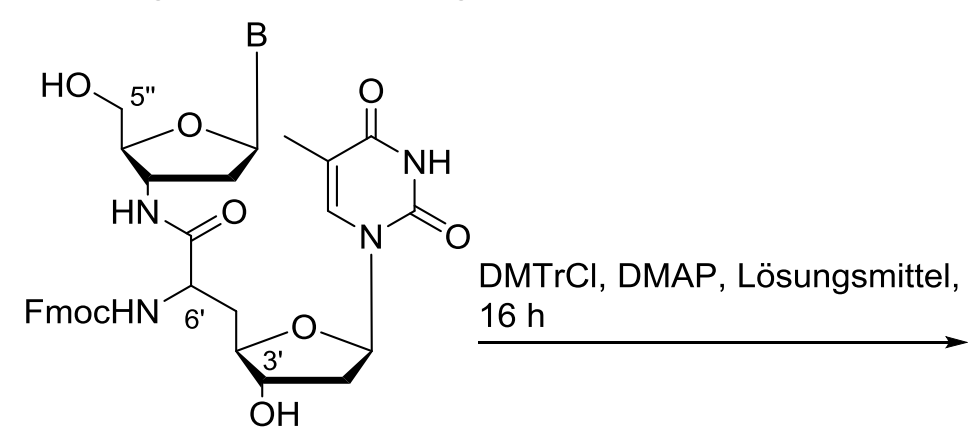

(6'S) oder (6'R)

$146 \mathrm{~B}=\mathrm{T}$

$147 \mathrm{~B}=\mathrm{C}^{\mathrm{Bz}}$

$148 B=A^{B z}$

$149 B=G^{i B u}$

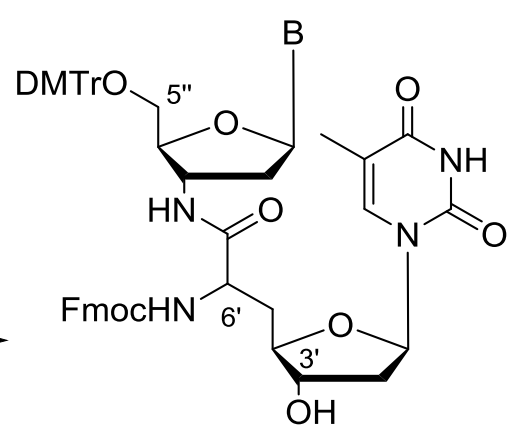

(6'S) oder $\left(6^{\prime} R\right)$

$75 \mathrm{~B}=\mathrm{T}$

$150 \mathrm{~B}=\mathrm{C}^{\mathrm{Bz}}$

$151 \mathrm{~B}=\mathrm{A}^{\mathrm{Bz}}$

$152 B=G^{i B u}$

\begin{tabular}{|c|c|c|c|c|c|}
\hline \multirow[t]{2}{*}{$\mathrm{Nr}}$. & \multirow[t]{2}{*}{ Edukt } & \multirow[t]{2}{*}{ Lösungsmittel } & \multirow[t]{2}{*}{ Produkt } & \multicolumn{2}{|c|}{ Ausbeute in \% } \\
\hline & & & & $\left(6^{\prime} S\right)$ & $\left(6^{\prime} R\right)$ \\
\hline 1 & $146 \mathrm{~B}=\mathrm{T}$ & Pyridin & $75 \mathrm{~B}=\mathrm{T}$ & 75 & 75 \\
\hline 2 & $147 B=C^{B z}$ & Pyridin/DMF 1:1 & $150 B=C^{B z}$ & 73 & nicht durchgeführt \\
\hline 3 & $148 B=A^{B z}$ & Pyridin & $151 B=A^{B z}$ & 72 & 81 \\
\hline 4 & $149 B=G^{B u}$ & Pyridin & $152 B=G^{B u}$ & 76 & 84 \\
\hline
\end{tabular}

Abb. 4.19: Synthese der 5"-O-DMTr-geschützten Dinucleoside 75, 150-152.

Aufgrund der geringfügigen Löslichkeit dieser Verbindung in reinem Pyridin wurde ein 1:1-Gemisch aus Pyridin/DMF als Lösungsmittel verwendet. Der Reaktion wurde stets DMAP in katalytischer Menge zugesetzt. DMAP bildet durch Nucleophile Reaktion mit DMTrCl ein reaktives Intermediat und beschleunigt auf diese Weise die Gesamtreaktion zum 5"-O-DMTr-geschützten Produkt. Zur Reinigung der Produkte 
75, 150-152 wurde ausschließlich Chromatographie verwendet, wobei in allen Fällen Eluenten mit einem Anteil von ca $0.5 \%$ Pyridin verwendet wurden, um die Spaltung der DMTr-Schutzgruppe durch das leicht saure Kieselgel auszuschließen. Es wurden in allen Reaktionen gute Ausbeuten erhalten (72-84\%, Abb. 4.19). Um zu Bausteinen für die automatisierte DNA-Festphasensynthese zu gelangen, wurden die 3'Hydroxygruppen der Verbindungen (6'S)- und (6'R)-75 phosphityliert. Die Verbindungen 150-152 wurden im Rahmen dieser Arbeit nicht in die Phosphoramidite überführt, da deren direkte Verwendung für die ON-Synthese aus zeitlichen Gründen nicht mehr möglich war. Es wäre nämlich eine längerfristige Lagerung dieser Verbindungen nötig gewesen, die jedoch aufgrund ihrer bekannten Labilität riskant ist. Für die Phosphitylierung der Dinucleoside 75 wurde in der Vorarbeit eine prinzipiell andere Methode als in der Vorarbeit verwendet.

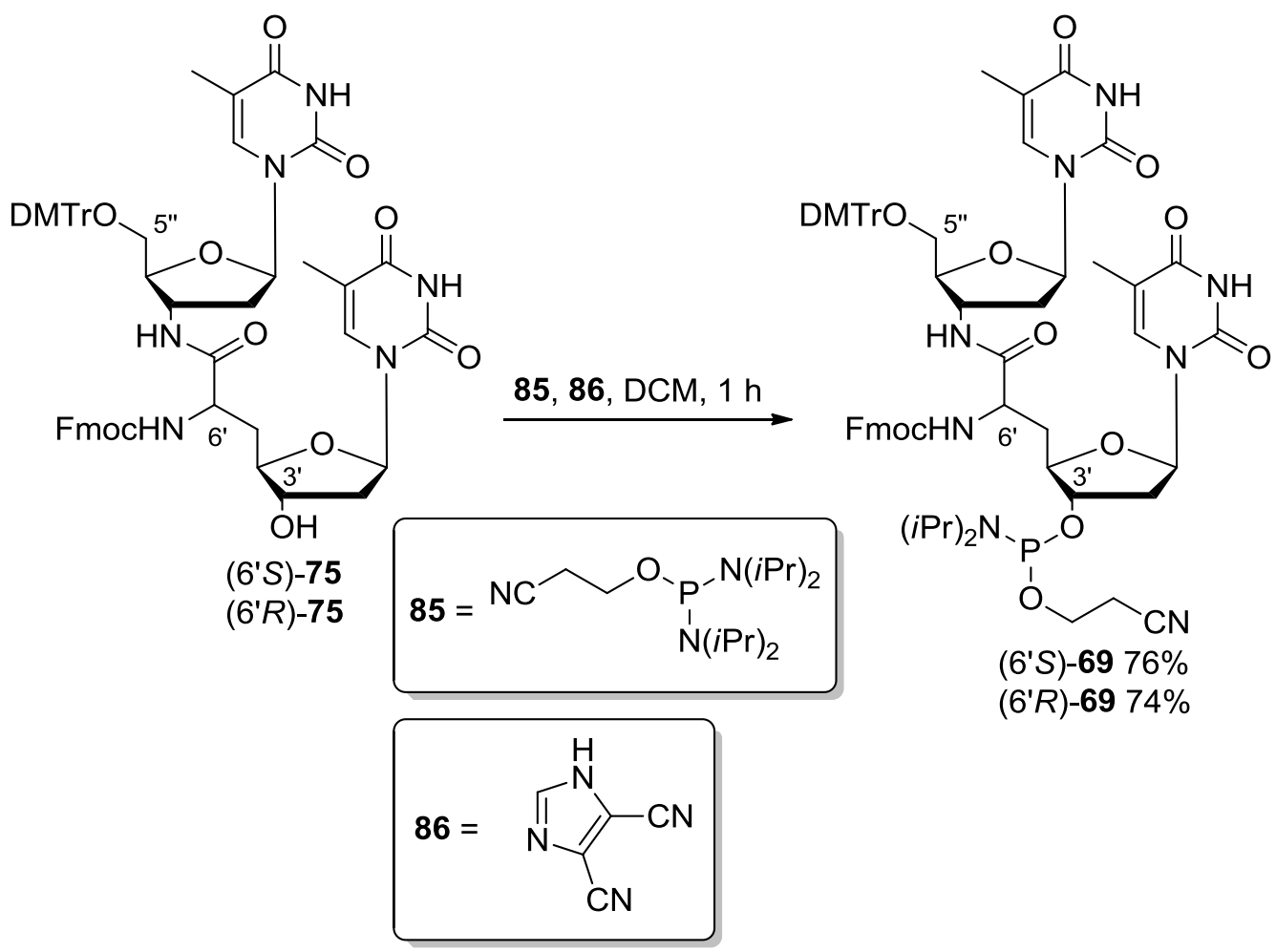

Abb. 4.20: Synthese der Bausteine (6'S)- und (6'R)-69 für die automatisierte ON-Synthese.

Während früher als Phosphitylierungsreagenz ein Monochlorphosphit in alkalischem Medium eingesetzt wurde ( $28 \%$ Ausbeute), konnten unter Verwendung des Phosphordiamidit-Reagenzes 85 in schwach saurem Milieu signifikant bessere Ergebnisse (76\% bzw. 74\%) erzielt werden (Abb. 4.20). Dabei enthielt auch der zur Chromatographie verwendete Eluent anstelle von Triethylamin Pyridin, sodass bei der Konzentration der gesammelten Fraktionen keine Abspaltung der Fmoc- 
Schutzgruppe resultierte. Die auf diese Weise erhaltenen Bausteine (6'S)- und (6'R)69 wurden für die automatisierte Festphasen-Synthese NAA-modifizierter zwitterionischer ON verwendet (Kap. 4.4).

\subsection{Synthese der NAA-Bausteine für den Aufbau oligo- kationischer ON}

Gemäß Kap 3.2.2 sollten für die Synthese der NAA-Bausteine zum Aufbau uniform kationischer Nucleinsäure-Analoga zwei unterschiedliche Herangehensweisen möglich sein. Der wesentliche Unterschied der Strategien liegt in der Wahl der funktionellen Gruppe in 3'-Position des jeweiligen Ausgangsmaterials. Die Gemeinsamkeit beider Synthesewege ist die zugrunde gelegte Vorgehensweise, die bereits für die Herstellung der NAA 73 Anwendung fand (s. Kap. 4.2.1-4.2.4).

\subsubsection{Synthese der 3'- $\mathrm{N}_{3}$-Thymidinylaldehyde}

Ausgehend vom 5'-silylierten 3'-Azidothymidin 118 (s. Kap. 4.2.5.1) wurde zunächst die Basen-geschützte Verbindung 119 durch Einführung der BOM-Schutzgruppe erhalten. Dazu wurde das Ausgangsmaterial 118 in Analogie zur bereits angeführten Synthese BOM-geschützter Thymidin-Derivate (s. Kap. 4.2.1) in Gegenwart der starken Base Natriumhydrid mit BOM-Chlorid in DMF als Lösungsmittel zur Reaktion gebracht (Abb. 4.21). Das Produkt wurde, ähnlich zum bereits vorher beschriebenen Thymidin-Derivat 131 (s. Kap. 4.2.1, Abb. 4.4), in quantitativer Ausbeute erhalten. Es folgte die sauer katalysierte Spaltung $(\mathrm{AcCl}$ in $\mathrm{MeOH})$ des Silyl-Ethers unter Bildung von Alkohol 153 in einer ebenfalls sehr hohen Ausbeute von 90\%. Für die Überführung des Alkohols 153 in den entsprechenden Aldehyd 106 wurde wiederum die bewährte IBX-Oxidation in siedendem Acetonitril verwendet. Diese Synthese wurde zudem ohne BOM-Schutzgruppe durchgeführt, indem das 5'-O-TBDMS-3'Azidothymidin 118 direkt mit Acetylchlorid in Methanol desilyliert (Ausbeute 63\%) und anschließend in gleicher Weise mit IBX oxidiert wurde (91\%). Überraschender Weise ergab die direkte Desilylierung von 118 zur Bildung von 154 selbst nach $20 \mathrm{~h}$ keinen vollständigen Umsatz. 


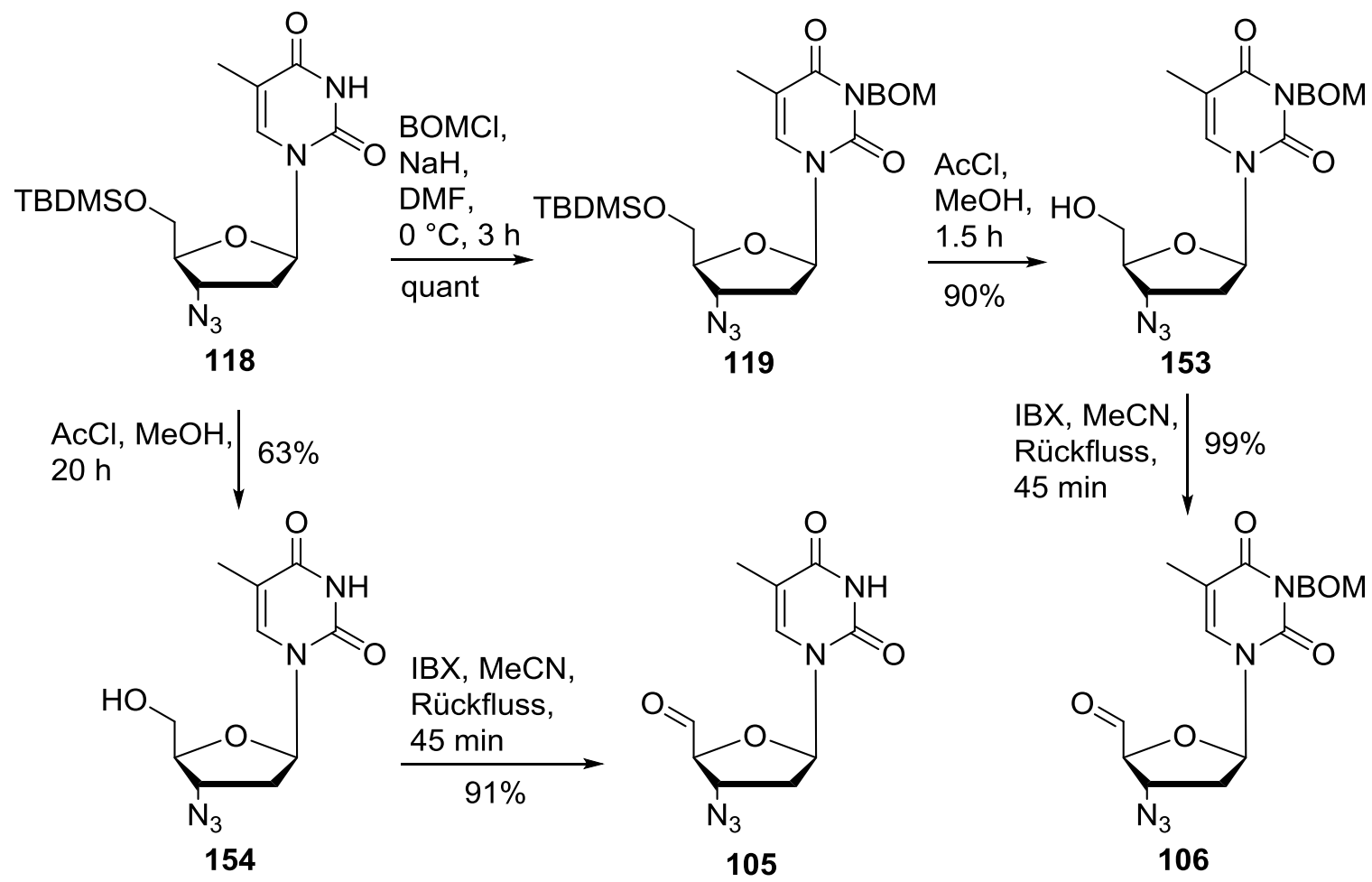

Abb. 4.21: Synthese der 3'- $\mathrm{N}_{3}-$ Thymidinylaldehyde 105 und 106.

\subsubsection{Synthese der geschützten 3'-NHCbz-Thymidinylaldehyde}

Für die alternative Syntheseroute wurde zuerst an der 3'-Aminogruppe von 5'-OTBDMS-3'-Aminothymidin $\mathbf{7 2}$ eine Carbamat-Schutzgruppe (Cbz) eingeführt (Abb. 4.22). Dazu wurden das Amin 72, das als Base fungierende Triethylamin und eine katalytische Menge an DMAP in einem 1:1-Lösungsmittelgemisch aus Dioxan/Wasser aufgenommen und mit Chlorameisensäurebenzylester ( $\mathrm{CbzCl})$ versetzt. ${ }^{[178]}$ Die Synthese des Carbamats 120 nach dieser Methode führte jedoch nur in kleinen Ansätzen zu guten Ausbeuten (75-93\%), während Synthesen eines Maßstabs von über $200 \mathrm{mg}$ mit geringeren Ausbeuten einhergingen (60\%). Alternativ wurde die Reaktion in THF als Lösungsmittel geführt. Diese Veränderung ermöglichte konstant sehr gute Resultate (85\%) bis hin zu Synthesen in einem Maßstab von über $5 \mathrm{~g}$. Ein möglicher Grund dafür ist die bessere Löslichkeit des 3'Aminonucleosids 72 in THF als in dem relativ polaren Lösungsmittelgemisch Dioxan/Wasser. Es folgte die Einführung der BOM-Schutzgruppe am 3- $N$ der Nucleobase von 120 (Abb. 4.22). Diese Reaktion war im Unterschied zu den bisher diskutierten BOM-Schützungen durch den Umstand erschwert, dass in dem Eduktmolekül zwei NH-Gruppen von ähnlicher Reaktivität vorliegen (3-NH und $\left.3^{\prime}-\mathrm{NH}\right)$. 

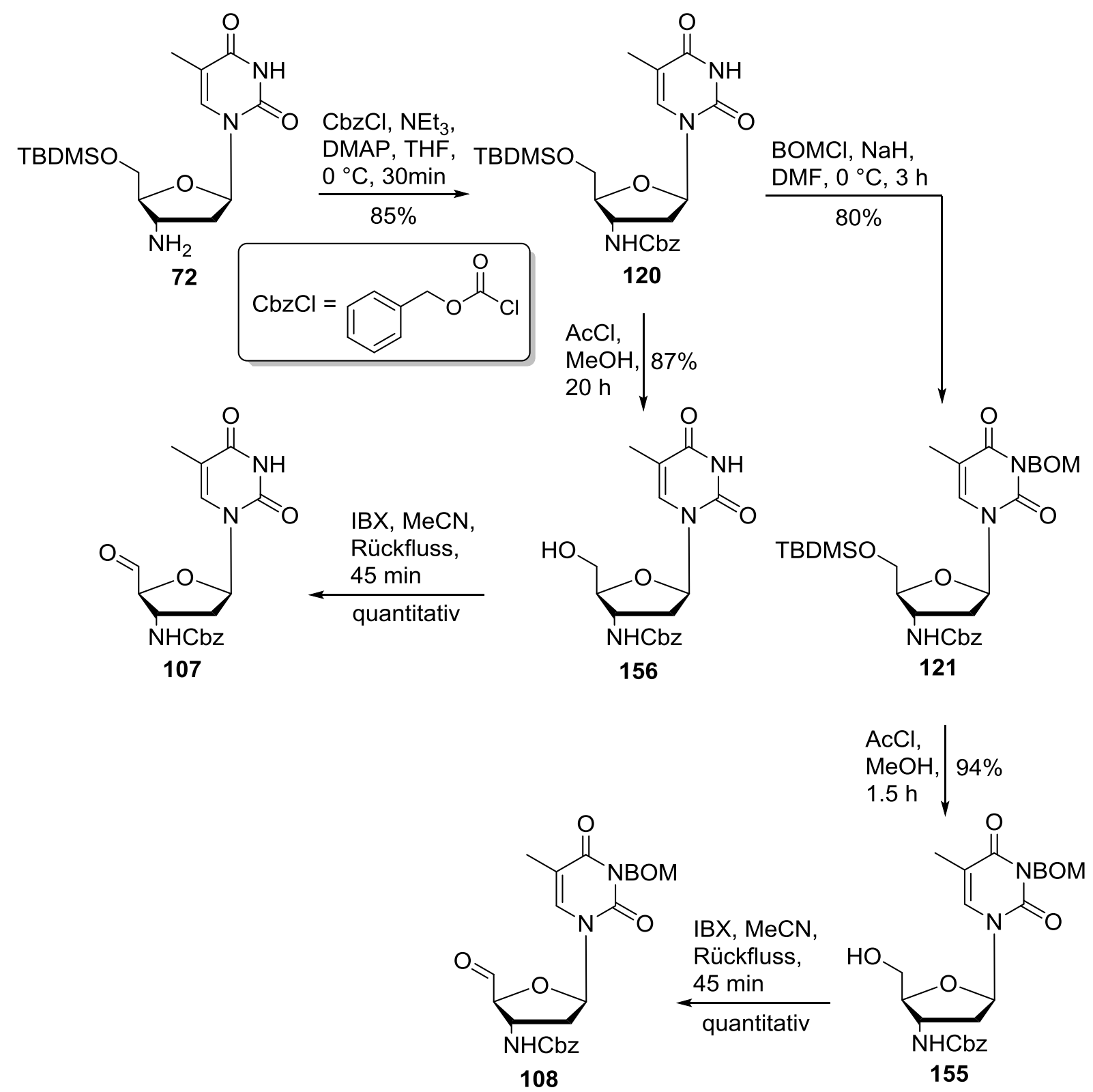

Abb. 4.22: Synthese der geschützten 3'-NHCbz-Thymidinylaldehyde 107 und 108.

Zunächst wurde davon ausgegangen, dass die Acidität der Imid-Funktionalität der Nucleobase wegen des -M-Effekts zweier benachbarter Carbonylgruppen und des aromatischen Charakters der Nucleobase höher ist als diejenige der 3'-NH-Gruppe. Daher wurden bei dieser Reaktion äquimolare Mengen an Edukt, Base und BOMChlorid eingesetzt. In den zuvor diskutierten Einführungen der BOM-Schutzgruppe waren dagegen 1.2 Äq BOM-Chlorid und 1.8 Äq Natriumhydrid üblich. Auf diese Weise konnte das Basen-geschützte Nucleosid 121 in einer Ausbeute von 80\% erhalten werden (Abb. 4.22). Der Versuch, die Äquivalente an Base und Alkylierungsreagenz zu erhöhen führte zur Bildung eines schwer trennbaren ZweiKomponenten-Gemischs. Die angenommene Selektivität der Reaktion wurde anhand NMR-spektroskopischer Befunde aus der Analyse des nachfolgend durch Abspaltung 
der Silyl-Schutzgruppe gebildeten Alkohols 156 bestätigt (Abb. 4.23). Es konnte durch die beobachtete Kopplung des 3'-NH-Signals mit dem 3'-H (COSY) eindeutig nachgewiesen werden, dass die 3'-NH-Gruppe in diesem Molekül noch vorliegt. Die Spaltung des Silylethers von 121 gelang wiederum in sehr hoher Ausbeute (94\%) durch die sauer katalysierte $(\mathrm{AcCl})$ Solvolyse in Methanol. Ebenso wurde auch der Alkohol 156 ohne BOM-Schutzgruppe in sehr guter Ausbeute (87\%) direkt aus dem Carbamat 120 durch die sauer katalysierte Silylspaltung synthetisiert. Für die Überführung dieser Alkohole in die entsprechenden Aldehyde in quantitativer Ausbeute wurde die übliche IBX-Oxidation verwendet.

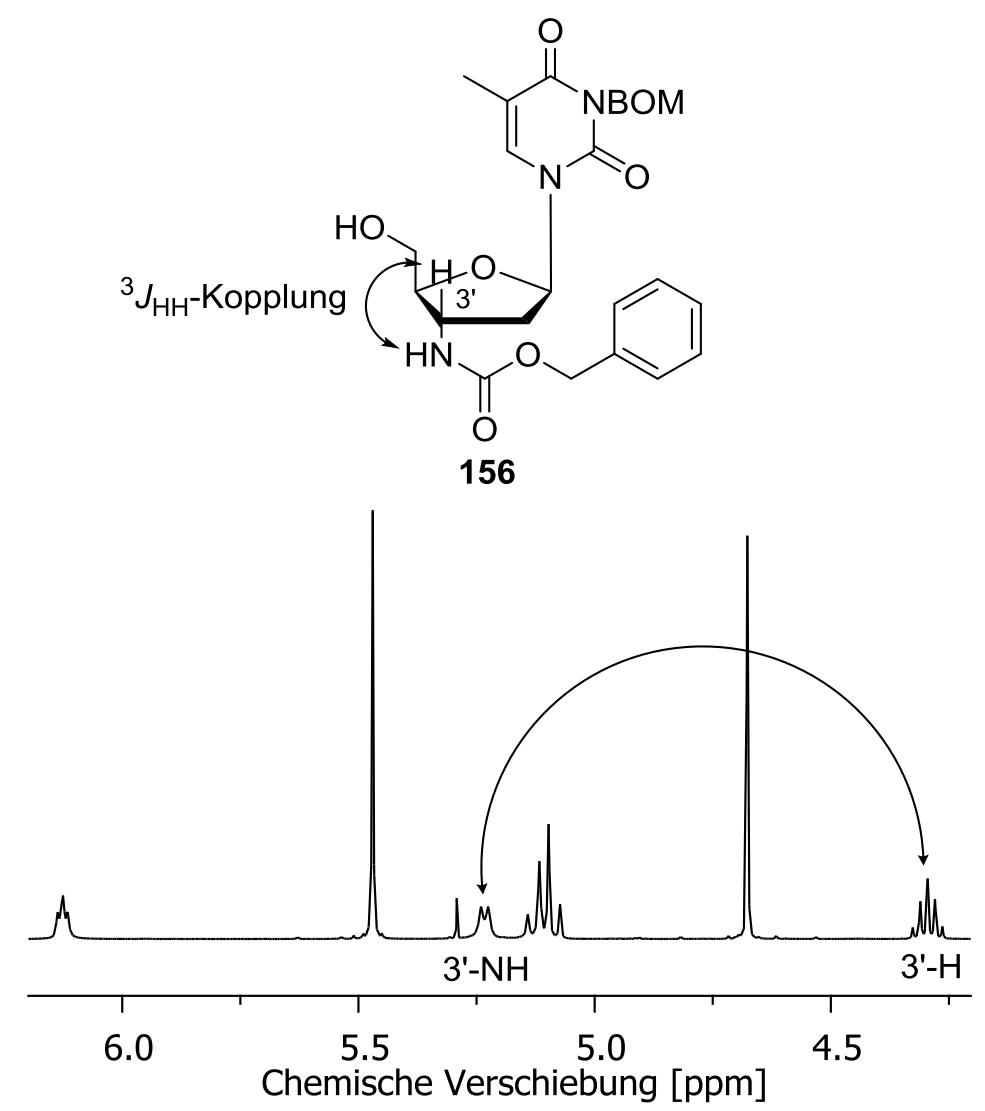

Abb. 4.23: Beweis der Regioselektivität der BOM-Schützung von 120.

\subsubsection{Synthese der 3'- $\mathrm{N}_{3}$ - und 3'-NHCbz-5',6'-Didehydro-TAA}

Die Thymidinylaldehyde 105-108 (Abb. 4.21 und 4.22) wurden gemäß der bereits in Kap. 4.2.2 diskutierten Vorgehensweise jeweils mit dem Phosphonat 109 (Abb. 4.2) in Wittig-Horner-Reaktionen umgesetzt (Abb. 4.24). Bei diesen Reaktionen wurden die beteiligten Komponenten (Phosphonat, Base, Nucleosylaldehyd) daher ebenfalls 
in äquimolaren Mengen bei $-70^{\circ} \mathrm{C}$ in THF als Lösungsmittel eingesetzt. Als Base wurde wiederum das sterisch anspruchsvolle Kalium-tert-butanolat verwendet. Unter diesen Bedingungen ergab die Reaktion des BOM-geschützten 3'-Azidothymidinaldehyds 106 mit dem Phosphonat 109 ein Diastereomerengemisch von $(Z / E)-5^{\prime}, 6$ '-Didehydro-TAA 111 in einem Verhältnis von $Z / E=93: 7$ und einer Ausbeute von $73 \%$ dieses Gemischs. Das Verhältnis der Diastereomere wurde anhand der Integration der ${ }^{1} \mathrm{H}$-NMR-Signale bestimmt. Versuche, die Komponenten chromatographisch zu trennen, waren nicht erfolgreich. Die auf Basis voriger Resultate der Wittig-Horner-Reaktion angenommene (Z)-Konfiguration der 5',6'Doppelbindung des Hauptprodukts konnte jedoch durch ${ }^{1} \mathrm{H}$-NOE-Experimente bestätigt werden.

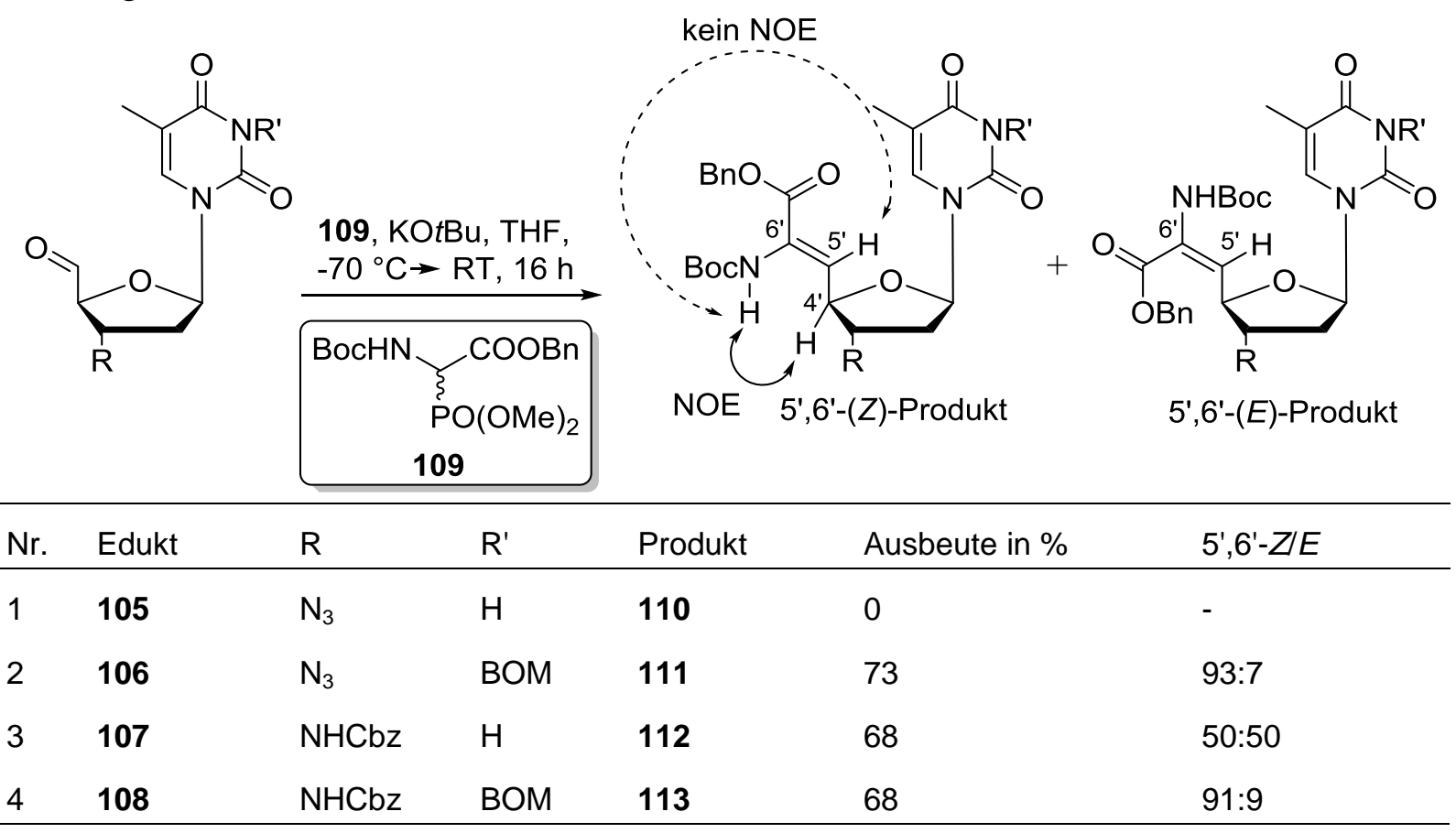

Abb. 4.24: Syntheseversuche der 5',6'-Didehydro-TAA 110-113.

Während zwischen dem 6'-NH und 4'-H eindeutig eine Übertragung von Spinpolarisation nachgewiesen werden konnte, war dies zwischen dem 5'-H und 6'-NH nicht gegeben. Im Unterschied zu allen bisher diskutierten Wittig-HornerReaktionen reagierte der ungeschützte 3 '- $\mathrm{N}_{3}$-Thymidinaldehyd 105 nicht mit dem Phosphonat 109. Das eingesetzte Startmaterial konnte nach der Reaktion in unveränderter Form nachgewiesen werden. Die Wittig-Horner-Reaktion des 3-NBOM-geschützten 3'-NHCbz-Thymidinaldehyds 108 mit dem Phosphonat 109 ergab ebenfalls ein Gemisch der zwei diastereomeren 5',6'-Didehydro-TAA (Z)-113 und $(E)-113$ in einer Ausbeute von 68\%. Das Mengenverhältnis der Diastereomere wurde 
durch Vergleich der Integrale der beobachteten Signalsätze sowohl im ${ }^{1} \mathrm{H}-\mathrm{NMR}$ - als auch im ${ }^{13} \mathrm{C}$-NMR-Spektrum zu 91:9 bestimmt. Auch in diesem Fall erwies sich die Isolierung des in geringerer Menge vorhandenen Isomers als nicht praktikabel. Daher wurde zur Bestimmung der Konfiguration der 5',6'-Doppelbindung der Hauptkomponente auf ${ }^{1} \mathrm{H}-\mathrm{NOE}-$ Experimente zurückgegriffen. Es konnte wiederum nachgewiesen werden, dass eine Übertragung von Spinpolarisation zwischen 4'-H und 6'-NH vorliegt, während dieses Phänomen zwischen dem 5'-H und dem 6'-NH nicht beobachtet wurde. Auf diese Weise konnte bestätigt werden, dass das in großem Überschuss vorliegende Isomer eine Z-konfigurierte Doppelbindung aufweist. Versuche zur Synthese der 3'-NHCbz-TAA ohne BOM-Schutzgruppe resultierten stets in ungefähr äquimolaren Gemischen an $(Z)$ - und $(E)$-Didehydro-TAA 112. Auch der Einsatz von KHMDS als Base anstelle von Kalium-tert-Butanolat bewirkte keine Veränderung des Resultats. Diese Resultate sind - ähnlich wie diejenigen der 3'-N $\mathrm{N}_{3}$-Didehydro-TAA - vor dem Hintergrund der Wittig-HornerReaktionen mit BOM-geschützten und -ungeschützten 3'-O-TBDMS-TAA wie auch der Befunde im Fall von entsprechenden Uridin-Derivaten überraschend. Für eine schlüssige Erklärung dieses Sachverhalts genügen die vorliegenden Befunde nicht. Denkbar ist auch der Einfluss konformativer Effekte. Es bleibt aber festzuhalten, dass die BOM-Schutzgruppe für die Wittig-Horner-Reaktion mit den Aldehyden 105-108 im Gegensatz zu den bisher diskutierten Reaktionen dieses Typs notwendig ist.

\subsubsection{Asymmetrische Hydrierung der 5',6'-Didehydro-TAA}

Die BOM-geschützten 3'- $\mathrm{N}_{3}$ - und 3'-NHCbz-5',6'-Didehydro-TAA 111 und 113 wurden in ähnlicher Weise wie die 3'-O-TBDMS-5',6'-Didehydro-TAA 80 und 82 (s. Kap. 4.2.3, Abb. 4.7) asymmetrischen Hydrierungen unter Katalyse durch $(S, S)$ - oder $(R, R)$-Me-DuPHOS-Rh unterzogen (Abb. 4.25). Da die Entfernung der $(E)$-Isomere nicht gelang, wurden die Reduktionen im Rahmen dieser Arbeit mit den (Z/E)Diastereomerengemischen der 5',6'-Didehydro-TAA 111 und 113 durchgeführt. Dies war aufgrund der bedeutend schnelleren Reduktion der 5',6'-Doppelbindeung der $(Z)$-Isomere und der geringen Mengen an $(E)$-Isomer in Eduktgemisch möglich. Die Hydrierung der Doppelbindung von (Z)-111 unter katalytischer Wirkung von $(S, S)$ Me-DuPHOS wurde wie die anderen Reaktionen diesen Typs in einer $\mathrm{H}_{2}$ Atmosphäre (1 bar) und unter striktem Sauerstoff-Ausschluss geführt. Die 
Reaktionsdauer bis zum vollständigen Reaktionsumsatz (NMR-kontrolliert) betrug 7 Tage, wobei im Vergleich zur Hydrierung der analogen (Z)-3'-O-TBDMS-DidehydroTAA 80 (Abb. 4.7) etwa die doppelte Katalysatormenge benötigt wurde.

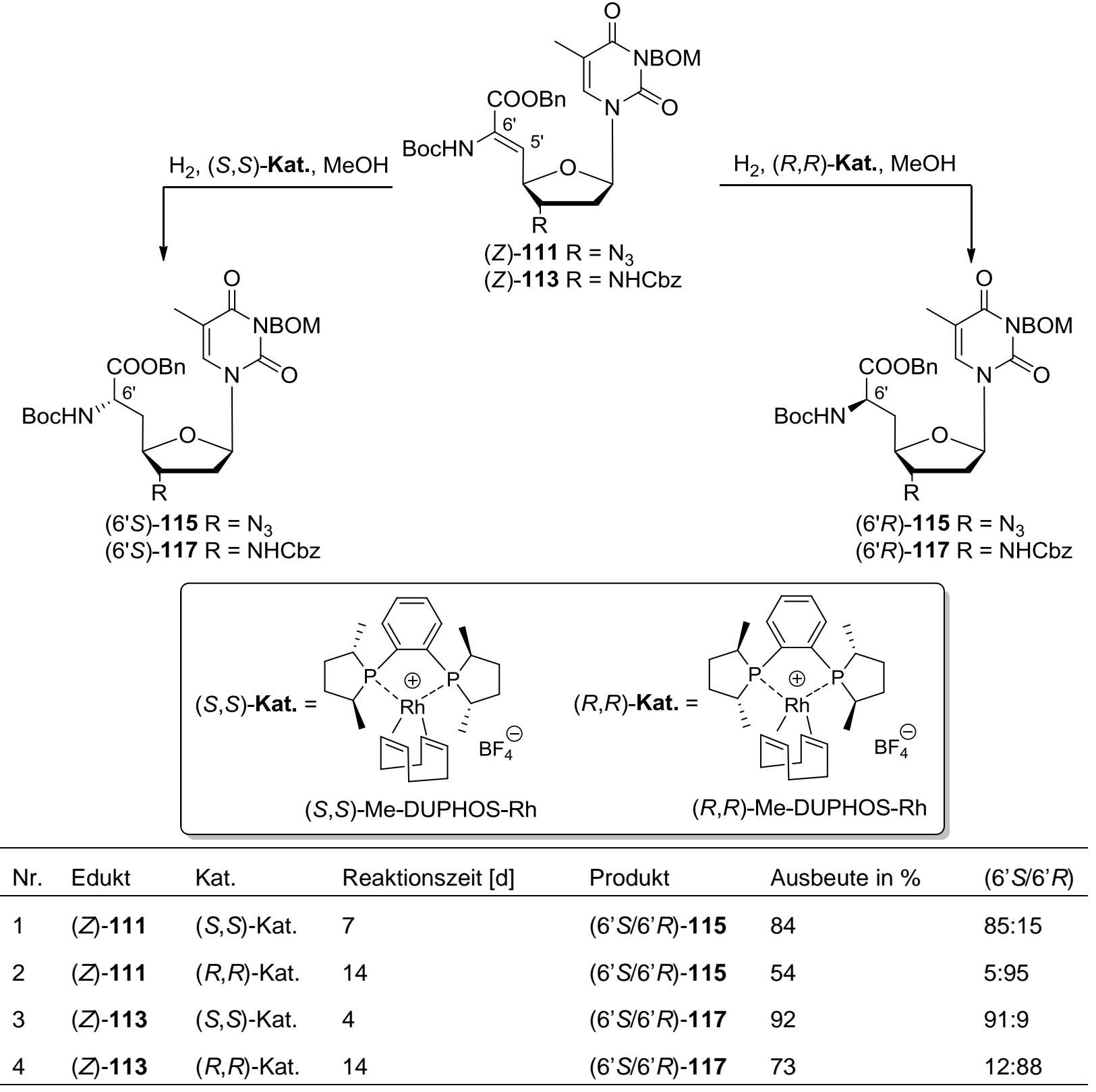

Abb. 4.25: Synthese der TAA (6'S)- und (6'R)-115 und 117.

Als Produkt wurde ein 85:15-Gemisch der Diastereomere (6'S)- und (6'R)-115 in einer Ausbeute von 84\% erhalten. Das Verhältnis der Diastereomere wurde mittels ${ }^{1} \mathrm{H}-\mathrm{NMR}-$ und ${ }^{13} \mathrm{C}-\mathrm{NMR}$-spektroskopischer Untersuchungen bestimmt. Die Hydrierung des gleichen Substrats in Gegenwart des $(R, R)$-Me-DuPHOSKatalysators war bei ungefähr gleicher Katalysatormenge selbst nach 14 Tagen nicht vollständig abgelaufen, sodass Reste des unumgesetzten Edukts chromatographisch abgetrennt wurden. Daher lag die Ausbeute an (6'R)-115 mit 54\% deutlich niedriger 
als im Fall von (6'S)-115. Wie bei der Reduktion der 3'-O-TBDMS-5',6'-DidehydroTAA 80 (Abb. 4.7) ist also auch diese Reaktion im Wesentlichen Katalysatorkontrolliert. Auch bilden hier die Kombinationen des Edukts (Z)-111 mit dem $(S, S)$ Katalysator das matched pair und (Z)-111 mit dem $(R, R)$-Katalysator das mismatched pair. Interessanterweise war jedoch die Diastereoselektivität der Reduktion zum (6'R)-Diastereomer 115 mit einem Verhältnis von 5:95 (6'S/6'R) bedeutend höher als diejenige zum (6'S)-Diastereomer 115 (85:15, s. o.). Eine mögliche Erklärung ist eine schwache intrinsische Präferenz für die Bildung von $\left(6^{\prime} R\right)$-115. Diese Vermutung wurde jedoch im Rahmen dieser Arbeit nicht durch Kontrollexperimente mit achiralen Katalysatoren verifiziert. Die asymmetrische Hydrierung der (Z)-3'-NHCbz-Didehydro-TAA 113 lieferte etwas bessere Ergebnisse als diejenige der (Z)-3'- $\mathrm{N}_{3}$-Didehydro-TAA 111. Die Reduktion von (Z)-113 zu (6'S)117 durch die Wirkung des $(S, S)$-DuPHOS-Rh-Katalysators in Methanol unter einer sauerstofffreien $\mathrm{H}_{2}$-Atmosphäre war nach vier Tagen vollständig. Als Produkt wurde ein Gemisch der Diastereomere (6'S/6'R)-117 in einer sehr guten Ausbeute von 92\% erhalten. Das Diastereomerenverhältnis betrug einer Untersuchung mittels analytischer HPLC an einer chiralen stationären Phase zufolge $\left(6^{\prime} S\right) /\left(6^{\prime} R\right)=91: 9$. Dies stimmte gut mit NMR-spektroskopischen Befunden überein. Passend zu den bisher diskutierten Resultaten benötigte die vollständige Reduktion von (Z)-113 zu dem Diastereomer (6'R)-117 einen Zeitraum von 14 Tagen - bei doppelter Menge an Katalysator im Vergleich zur Reduktion von (Z)-80 (Abb. 4.7). Im Unterschied zu allen bisher untersuchten asymmetrischen Hydrierungen wurde dabei ein Nebenprodukt gebildet, sodass nach der chromatographischen Reinigung das Diastereomerengemisch $\left(6^{\prime} R / 6^{\prime} S\right)-117$ in einer Ausbeute von 73\% erhalten wurde. Das Verhältnis der Diastereomere war mit $\left(6^{\prime} S\right) /\left(6^{\prime} R\right)=12: 88$ etwas schlechter als im Fall des (6'S)-Diastereomers. Beide Diastereomere von 117 wurden durch semipräparative HPLC an einer chiralen stationären Phase vollständig von Verunreinigungen befreit und getrennt. Die Chromatogramme der reinen Verbindungen und der Koinjektion beider Diastereomere sind im Anhang Kap. 9.1 angefügt. Insgesamt bestätigen die Hydrierungen der Substrate 111 und 113 die im Zusammenhang mit der Reduktion der Didehydro-TAA 80 (Abb. 4.7) beobachteten Tendenzen. Hydrierungen in Gegenwart des $(R, R)$-Katalysators verlaufen wesentlich langsamer als in Gegenwart des $(S, S)$-Katalysators. Auffällige Unterschiede zu der Hydrierung von (Z)-80 sind die allgemein längeren Reaktionszeiten und die schlechteren Diastereoselektivitäten der Hydrierungen der 3'- $\mathrm{N}_{3}$ - und 3'-NHCbz-5',6'- 
Didehydro-TAA. Eine mögliche Begründung für die längeren Reaktionszeiten kann die Gegenwart einer größeren Menge an $(E)$-Isomer im Edukt sein. Dieses könnte im Sinne einer kompetitiven Inhibierung der Hydrierung des (Z)-Isomers wirken. Eine schlüssige Erklärung für die geringere Selektivität der Hydrierungen von DidehydroTAA mit $\mathrm{N}_{3}$ - und NHCbz-Substituenten in 3'-Position ist auf Basis der bisherigen Befunde nicht möglich. Die Beobachtungen sprechen jedoch gegen eine Abhängigkeit des Reaktionsverlaufs vom sterischen Anspruch der Funktionalität in 3'Position. Der Trend scheint hier eher in die entgegengesetzte Richtung zu weisen: die sterisch sehr anspruchsvolle 3'-O-TBDMS-Gruppe fördert eher kurze Reaktionszeiten und hohe Diastereoselektivitäten, während die Substrate mit der weniger sperrigen 3'-NHCbz-Funktionalität zu längeren Reaktionszeiten und geringeren Selektivitäten neigen. Die schlechtesten Resultate wurden im Fall der mit Abstand kleinsten funktionellen Gruppe $\left(\mathrm{N}_{3}\right)$ in der 3'-Position erhalten. Ein weiterer möglicher Grund für die beobachteten unterschiedlichen Reaktivitäten der DidehydroTAA könnten konformative Aspekte sein.

\subsubsection{Umschützung der TAA}

Um von den Verbindungen 115 oder 117 zu Bausteinen zu gelangen, die sich zum Aufbau von Oligomeren mittels Oligopeptid-Synthese eignen, ist eine globale reduktive Entschützung nebst Einführung einer Fmoc-Schutzgruppe an der resultierenden 3'-Amino-Gruppe notwendig (Abb. 4.26). Zunächst wurde als mildeste Variante die heterogen katalysierte $(\mathrm{Pd} / \mathrm{C})$ simultane Hydrogenolyse durch 1,4-Cyclohexadien in Methanol verwendet. Bei drei Äquivalenten 1,4-Cyclohexadien im Reaktionsgemisch wurde nach mehreren Stunden kein Umsatz beobachtet. Durch eine Erhöhung der Menge an 1,4-Cyclohexadien auf zehn Äquivalente konnte zwar die Spaltung der NHCbz-Schutzgruppe von (6'S)-117 bzw. die Reduktion der AzidGruppe von (6'R)-115 beobachtet werden. Die BOM-Schutzgruppe blieb jedoch stets intakt. Daher wurde der Versuch unternommen, direkt nach der Spaltung der CbzGruppe bzw. Reduktion der Azid-Einheit unter Bildung von 157 die FmocSchutzgruppe durch Reaktion mit $\mathrm{FmocCl}$ einzuführen, um danach unter schärferen Hydrierungsbedingungen die BOM-Schutzgruppe zu entfernen (Abb. 4.26). 


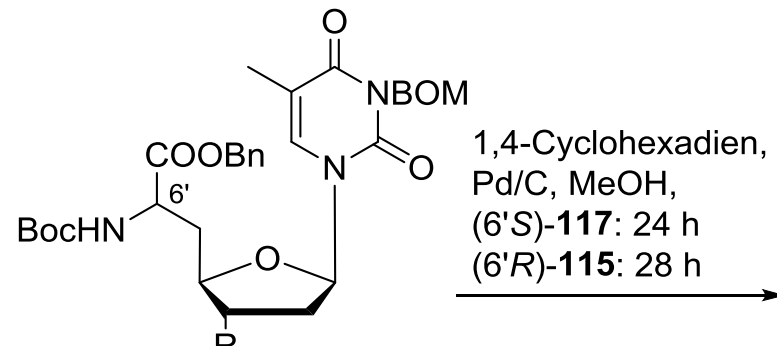

(6'S) $-\operatorname{oder}\left(6^{\prime} R\right)-115 \mathrm{R}=\mathrm{N}_{3}$

$\left(6^{\prime} S\right)-\operatorname{oder}\left(6^{\prime} R\right)-117 \mathrm{R}=\mathrm{NHCbz}$

$\left(6^{\prime} S\right)-117$ bzw.
$\left(6^{\prime} R\right)-117$
$\mathrm{H}_{2}, \mathrm{Pd}^{-b l a c k}$,
$n-\mathrm{BuNH}_{2}$,
$\mathrm{MeOH}, 24 \mathrm{~h}$

$\left.\right|_{\mathrm{NH}_{2}} ^{(6)}$

(6'S)-160

$\left(6^{\prime} R\right)-160$

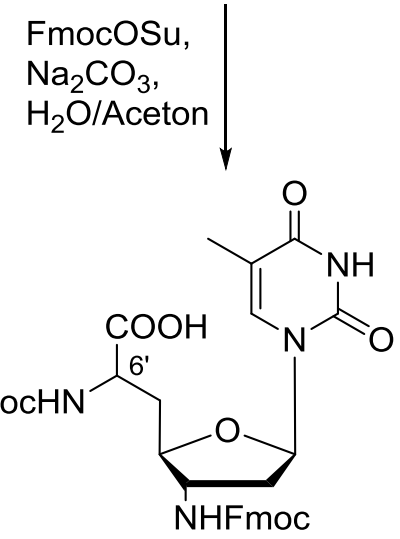

(6'S)-104 58\% über 2 Stufen von (6'S)-117

$\left(6^{\prime} R\right)-10448 \%$ über 2 Stufen von $\left(6^{\prime} R\right)-117$<smiles>CCCCn1c(=O)c(C)cn(C2C[C@H]3NC2[C@@H](C[C@H](NC(=O)OCc2ccccc2)C(=O)O)O3)c1=O</smiles>

(6'S)-157 aus (6'S)-117

$\left(6^{\prime} R\right)-157$ aus $\left(6^{\prime} R\right)-115$

$$
\begin{array}{l|l}
\text { FmocCl, NEt } & ,\left(6^{\prime} R\right)-157: \\
\text { THF, } 0{ }^{\circ} \mathrm{C}, & 23 \% \text { über } \\
30 \mathrm{~min} & 2 \text { Stufen }
\end{array}
$$

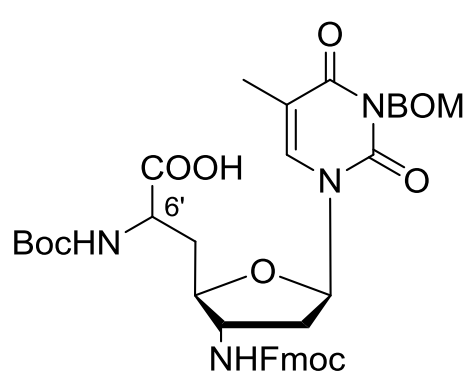

$\left(6^{\prime} R\right)-158$

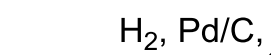

$\mathrm{H}_{2}$, Pd-black, geringe $\mathrm{MeOH}$, $24 \mathrm{~h}$ Menge<smiles>Cc1cn(C2CC3OC(C[C@H](NC(=O)OC(C)(C)C)C(=O)O)[C@@H](C2)N3C)c(=O)[nH]c1=O</smiles>

$\left(6^{\prime} R\right)-159$

Abb.4.26: Synthese der Verbindungen (6'S)- und (6'R)-104

Der Austausch einer Cbz-Schutzgruppe durch eine Fmoc-Schutzgruppe in einem Eintopfverfahren wurde erfolgreich an einigen Aminosäurederivaten durchgeführt. ${ }^{[19]}$ Für die Verbindungen (6'S)- und (6'R)-157 wurde aufgrund starker Verunreinigung keine Ausbeute angegeben. Im Unterschied zu dem publizierten Verfahren wurde als Base bei der Einführung der Fmoc-Gruppe Triethylamin verwendet. Auf diese Weise konnte die Carbonsäure (6'R)-158 isoliert werden. Allerdings konnte nachfolgend die BOM-Schutzgruppe unter hierfür gewöhnlich eingesetzten Bedingungen $\left(\mathrm{H}_{2}, 10 \%\right.$ 
$\mathrm{Pd} / \mathrm{C}, \mathrm{MeOH}$ ) nicht abgespalten werden. Daher wurde anstelle von $10 \% \mathrm{Pd} / \mathrm{C}$ das wesentlich reaktivere Palladium black als heterogener Katalysator zur Reaktion gegeben. Anhand von massenspektrometrischen Untersuchungen konnte jedoch nur das Produkt 159 nachgewiesen werden. Dies deutet darauf hin, dass die FmocSchutzgruppe in Gegenwart von Palladium black instabil ist. Zudem resultierte in Analogie zu früheren Beobachtungen auch hier eine reduktive Methylierung der entschützten 3'-Aminogruppe durch Formaldehyd, das durch die Spaltung der BOMSchutzgruppe gebildet worden war. In einem weiteren Versuch wurden die Verbindungen (6'S)-117 und (6'R)-115 einer heterogen katalysierten Hydrierung mit Wasserstoffgas in Methanol unterzogen. Als katalytische Spezies wurde dabei Palladium black eingesetzt und $n$-Butylamin in großem Überschuss zum Abfangen des gebildeten Formaldehyds. Diese Reaktion resultierte nur bei den Verbindungen (6'S)- und (6'R)-117 als Edukt in der vollständigen Hydrierung zu den Verbindungen (6'S)- und (6'R)-160. Die andere Reaktion war selbst nach einem Tag Reaktionszeit unvollständig. Folglich wurde die globale Entschützung in größerem Maßstab durchgeführt. Die auf diese Weise entschützten Verbindungen (6'S)- und (6'R)-160 wurden wegen ihrer hohen Polarität nicht chromatographisch gereinigt, sondern als Rohprodukte in den folgenden Versuchen zur Fmoc-Schützung verwendet. Zunächst wurde die bewährte Methode zur Einführung der Fmoc-Gruppe durch $\mathrm{FmocCl}$ und Triethylamin als Base angewendet. Als Lösungsmittel wurde aufgrund der hohen Polarität des Eduktes anstelle von reinem THF ein 2:1-Gemisch aus THF und DMF genutzt. Es konnte dabei jedoch kein Produkt 104 erhalten werden. Möglicherweise war die Löslichkeit des Edukts $\mathbf{1 6 0}$ in dem THF/DMF-Gemisch zu gering. Als Alternative wurde die Kombination aus $\mathrm{FmocCl}$, einer wässrigen NatriumcarbonatLösung als Base und Dioxan als Lösungsmittel verwendet. In diesem Fall wurde das Produkt (6'S)-104 in einer äußerst geringen Ausbeute von 10\% isoliert. Schließlich wurde in einem weiteren Versuch mit 1:1 Wasser/Aceton ein Lösungsmittelgemisch von noch höherer Polarität eingesetzt. Als Reagenz diente dabei das im Vergleich zu $\mathrm{FmocCl}$ etwas weniger reaktive $\mathrm{FmocOSu}$ und als Base Natriumcarbonat. Diese Methode ermöglichte die Isolierung der Zielverbindungen (6'S)- und (6'R)-104 in Ausbeuten von $58 \%$ bzw. $48 \%$ über zwei Stufen. Diese Verbindungen werden zurzeit auf ihre Eignung für die Peptidsynthese untersucht. 


\subsection{Synthese der NAA-modifizierten ON}

Die Synthese und Untersuchung der modifizierten ON erfolgte in Kooperation mit der Arbeitsgruppe von Dr. C. Höbartner (MPI für Biophysikalische Chemie, Göttingen). Dabei wurde auf die bereits in der Vorarbeit erfolgreich angewendete Phosphoramidit-Methode nach Beaucage und Caruthers zurückgegriffen. ${ }^{[9]}$ Das Grundprinzip dieses Verfahrens besteht in der Kupplung von aktivierten NucleosidDerivaten an Träger-gebundene Mono- oder Polynucleotide durch periodische Reaktionszyklen, die jeweils vier Schritte beinhalten (Abb. 4.27). Das Kettenwachstum erfolgt in diesem Prozess in $3^{\prime} \rightarrow 5^{\prime}$-Richtung.

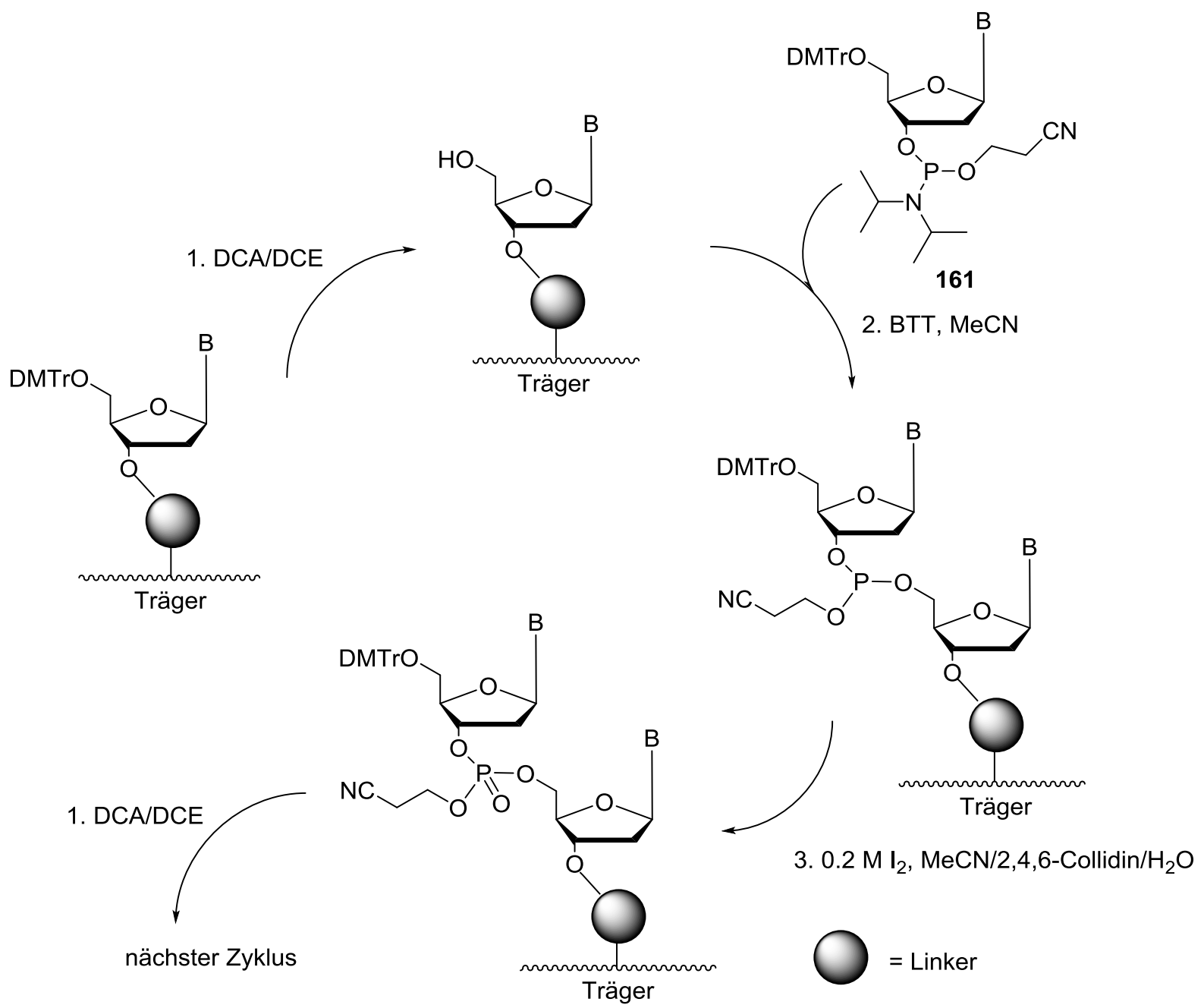

Abb. 4.27: Der Reaktionszyklus der ON-Synthese (das Capping in Schritt 4. ist im Sinne der Übersichtlichkeit nicht dargestellt).

1. Ein Reaktionszyklus beginnt mit der Entfernung der in der 5'-Position befindlichen DMTr-Schutzgruppe durch Spülen des Trägers mit der Lösung einer mittelstarken Säure. Hierfür wurde in dieser Arbeit 3\% Dichloressigsäure (DCA) in Dichlorethanol 
(DCE) oder 3\% Trichloressigsäure (TCA) in Dichlormethan verwendet. Durch die niedrige Konzentration der Säure sollten Nebenreaktionen wie etwa die Spaltung der $\mathrm{N}$-glykosidischen Bindung vermieden werden.

2. Es folgt die Bildung eines Phosphit-Triesters durch Reaktion der entschützten 5'-Hydroxygruppe und einem aktivierten Phosphoramidit-Reagenz 161 (Abb. 4.27), das in gelöster Form zur Matrix gegeben wird. Wie in den gängigen Verfahren üblich, waren alle Phosphoramidit-Reagenzien in Acetonitril gelöst. Die Aktivierung des Reagenzes 161 erfolgt durch schwache Säuren. Hierfür wurde das im Gegensatz zum Tetrazol weniger explosionsgefährliche Benzylthiotetrazol (BTT) eingesetzt. Als Schutzgruppe der Phosphittriester wurde die von Köster eingeführte, mild-alkalisch abspaltbare ( $\beta$-Eliminierung) $\beta$-Cyanoethylgruppe verwendet. ${ }^{[124]}$

3. Die gebildete Phosphit-Triestereinheit wird durch Oxidation in eine PhosphatTriestereinheit überführt. Zu diesem Zweck wurde eine wässrige, leicht alkalische lod-Lösung verwendet (lod in Pyridin/ $\mathrm{H}_{2} \mathrm{O}$ oder lod in abs. MeCN/2,4,6-Collidin/ $\mathrm{H}_{2} \mathrm{O}$ ).

4. Abschließend werden restliche nicht umgesetzte Monomere oder Stränge an der festen Phase an der reaktiven 5'-Hydroxygruppe acetyliert (Capping). Auf diese Weise soll die Bildung von Nebenprodukten unterdrückt werden. Hierzu wurde von mild alkalischen Acetylierungsmethoden $\left(\mathrm{Ac}_{2} \mathrm{O}, 1\right.$-Methylimidazol, Pyridin in THF oder $\mathrm{Ac}_{2} \mathrm{O}$, DMAP, 2,4,6-Collidin in $\mathrm{MeCN}$ ) Gebrauch gemacht.

Unter Verwendung dieser Methode sind die in Kap. 3.2.1.1 angeführten 24 NAAmodifizierten ON synthetisiert worden. Die NAA-Modifikationen wurden an den vorgesehenen Positionen innerhalb der jeweiligen Sequenz durch Einsetzen der Reagenzien (6'S)- oder (6'R)-69 (Abb. 4.20) anstelle von 161. Kupplungen der Reagenzien 69 verliefen laut Trityl-Monitoring stets schlechter als diejenigen von Phosphoramiditen gewöhnlicher Nucleoside. Daher resultierten bei der Synthese der NAA-modifizierten ON oft kürzere Stränge als Nebenprodukte. Dies wurde durch die Beobachtungen bei der Reinigung der ON bestätigt (s.u.). Nach abgeschlossener Synthese wurden die ON durch alkalische Hydrolyse des Linkers von dem Träger abgespalten. Hierzu wurde der noch beladene Träger in einer 3:1-Mischung aus wässriger Ammoniaklösung (25\%) und Ethanol für $20 \mathrm{~h}$ bei $55^{\circ} \mathrm{C}$ inkubiert. Bei diesem Vorgang ist eine Epimerisierung der chiralen NAA-Gruppen aufgrund der Acidität des a-Protons denkbar. Um zu überprüfen, ob tatsächlich eine Epimerisierung stattgefunden hat, wurde die Verbindung (6'S)-146 den Bedingungen der Abspaltung vom Träger ausgesetzt (Abb. 4.28). 


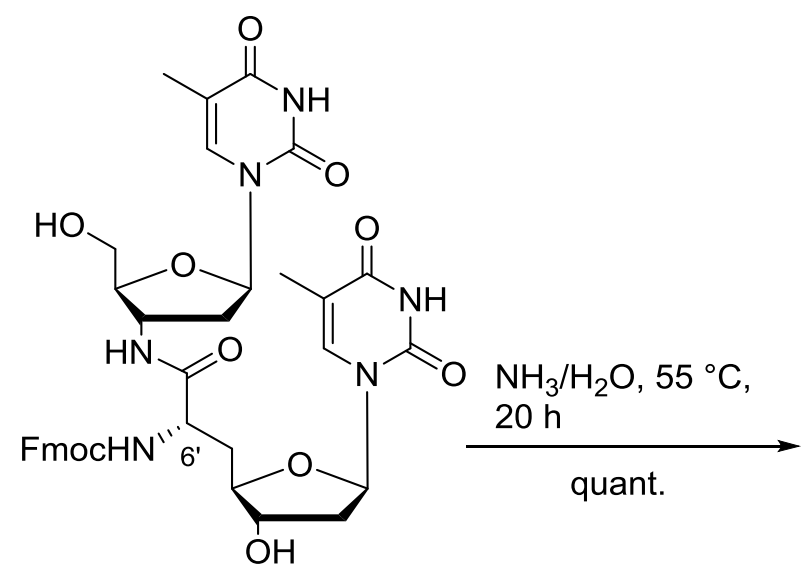

(6'S)-146

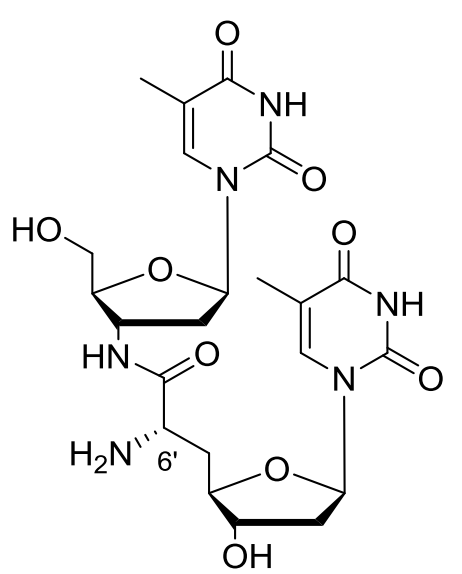

$\left(6^{\prime} S\right)-162$

Abb. 4.28: Kontrollversuch zur möglichen Epimerisierung von NAA-Einheiten.

Das auf diese Weise erhaltene Produkt konnte auf Basis von NMRspektroskopischen und massenspektrometrischen Untersuchungen zweifelsfrei als (6'S)-162 identifiziert werden (Abb. 4.28). Damit wurde der Beweis erbracht, dass unter den Bedingungen der Abspaltung vom Träger keine Epimerisierung der NAAEinheiten stattfindet. Durch Messung der UV-Absorption der erhaltenen wässrigen Lösungen der Rohprodukte wurden die Ausbeuten der ungereinigten ON bestimmt (s. Kap. 7.2.6.1, Tab. 1). Die Ausbeuten liegen in den meisten Fällen im Bereich zwischen $20 \%$ und $40 \%$, wobei einige der höchsten Ausbeuten bei ca. $70 \%$ liegen. Insgesamt wurden unter Verwendung von CPG (controlled pore glass) als Trägermaterial etwas höhere Werte erhalten als im Fall der alternativ verwendeten Polystyrolmatrix. Es folgte die Reinigung der ON per Gelelektrophorese. Das hierzu verwendete Gel wurde durch Polymerisation von Acrylamid (Initiator: Ammoniumperoxodisulfat (APS)) in gepufferter wässriger Lösung (Tris-BorsäurePuffer, $\mathrm{pH}=8$ ) hergestellt. Für jede Trennung wurden $40 \mathrm{nmol}$ des ungereinigten $\mathrm{ON}$ sowie ein Indikatorgemisch, das der Visualisierung des Verlaufs der Elektrophorese diente, auf das Elektrophoresegel aufgetragen. Nach Ablauf der Elektrophorese wurden die ON-haltigen Segmente anhand ihrer UV-Aktivität sichtbar gemacht. Hierbei wurden insbesondere bei mehrfach NAA-modifizierten ON Banden von Nebenprodukten, die als Folge der geringeren Reaktivität der PhosphoramiditReagenzien 69 (Abb. 4.20) entstanden waren, beobachtet (Abb. 4.29). 


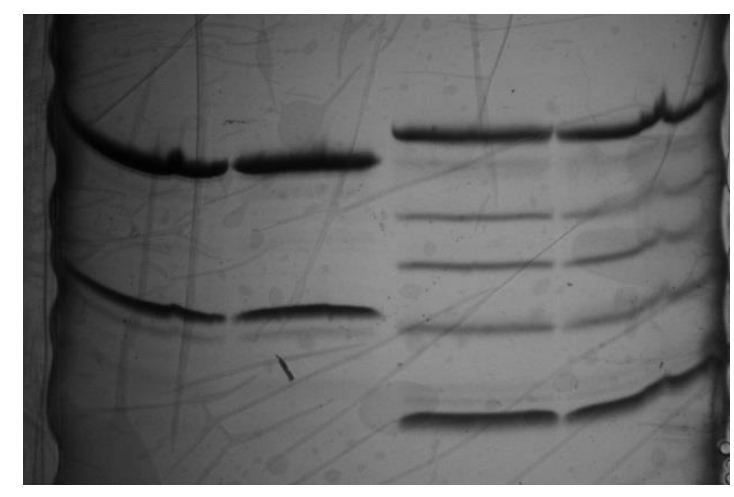

ON 7

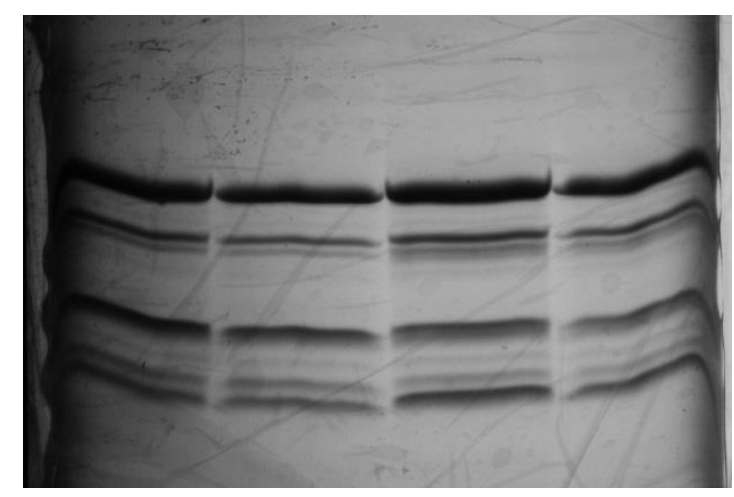

ON 19
ON 20

ON 7 5'-GGCACGG TxT TT TT TT GGCACGG-3', $\sigma(\mathbf{x}): S$

ON 9 5'-GGCACGG TxT TxT TxT TxT GGCACGG-3', $\sigma(\mathbf{x}): S$

ON 19 5'-G TxT GACG TxT GACG TxT GACG TxT G-3', $\sigma(x): S$

ON 20 5'-G TxT GACG TxT GACG TxT GACG TxT G-3', $\sigma(\mathbf{x}): R$

$\mathbf{x}=$ NAA-Modifikation, $\sigma(\mathbf{x})$ : NAA-Konfiguration

Abb.4.29: Bilder der Banden in den Gelen der ON 7, 9, 19 und 20.

Da das Trennprinzip der Elektrophorese auf Größenausschluss durch die Poren des Polyacrylamid-Netzwerks beruht, konnte davon ausgegangen werden, dass die Bande mit dem kürzesten zurückgelegten Weg das Hauptprodukt darstellt. Diese Bande wurde ausgeschnitten und mit einer wässrigen gepufferten Salzlösung (TENPuffer, $\mathrm{pH}=8$ ) extrahiert. Die ON wurden schließlich durch eine Ethanolfällung in reiner Form erhalten. Die Korrektheit der ON-Synthese wurde durch massenspektrometrische Untersuchungen bei allen 24 synthetisierten $\mathrm{ON}$ bestätigt (s. Tab. 2, Kap. 7.2.6). Alle ON wurden durch HPLC-Untersuchungen auf ihre Reinheit geprüft (Chromatogramme, s. Kap. 9.1.2.1). Die Ausbeuten der ON nach der Reinigung (s. Kap. 7.2.6. Tab. 1) lagen in den meisten Fällen im Bereich zwischen $20 \%$ und $50 \%$. Es ist auffällig, dass ON mit vier NAA-Modifikationen die niedrigsten Ausbeuten aufweisen. Die Erklärung hierfür sind die bereits erwähnten Verluste durch bei der ON-Synthese gebildete Abbruchfragmente. Aus sämtlichen experimentellen Befunden wurden keine Hinweise auf Nebenreaktionen der entschützten 6'-Aminogruppen mit Acrylnitril erhalten. 


\subsection{Untersuchung der NAA-modifizierten ON}

\subsubsection{Schmelzkurvenanalyse}

Wie bereits in Kap. 2 ausgeführt können chemische Modifikationen der Nucleinsäuren einen mehr oder weniger signifikanten Effekt auf die Eigenschaften der Duplices bewirken. Von grundlegender Bedeutung ist hierbei das Hybridisierungsverhalten modifizierter Nucleinsäuren mit unmodifizierten Gegensträngen. Der Denaturierungsvorgang eines Nucleinsäure-Doppelstrangs ist generell reversibel und verläuft kooperativ, $d$. $h$. dass die Dissoziation eines Basenpaars diejenige der benachbarten Basenpaare fördert. ${ }^{[180]}$ Die Denaturierung von DNA- oder RNA-Doppelsträngen kann durch Messung der UV-Absorption verfolgt werden, die von einer $\pi-\pi^{*}$-Elektronenanregung herrührt. ${ }^{[181]}$ Andere Möglichkeiten bestehen in der Messung der Intensität der Fluoreszenz oder eines NMR-Peaks. ${ }^{[182-183]}$ Bei einer vollständigen Dissoziation von in einer Probe vorliegenden Doppelsträngen steigt die UV-Absorbanz um ca. 40\%. Die Ursache für den Anstieg der Absorption ist eine Änderung der Konfiguration der aromatischen T-Elektronensysteme der Nucleobasen infolge abnehmender Überlappung der T-Orbitale. ${ }^{[181]}$ Wird die UV-Absorption gegen die Temperatur aufgetragen, ergibt sich ein sigmoidaler Kurvenverlauf, aus dessen steil ansteigendem Bereich der $\mathrm{T}_{\mathrm{m}}$ Wert bestimmt werden kann. Um Aufschluss über die Auswirkung der NAAModifikation auf die Stabilität der mit unmodifizierten Sequenzen gebildeten Duplices zu erhalten, wurden Schmelzkurven verschiedener Duplices aller NAA-modifizierten ON (Abb. 3.1) über einen Temperaturbereich von 0 bis $95^{\circ} \mathrm{C}$ aufgenommen. Es wurden Duplices mit komplementären DNA- und RNA-Sequenzen und mit nicht komplementären untersucht. Zum Vergleich wurden Referenzkurven von Duplices ohne NAA-Modifikation bzw. ohne Mismatch aufgenommen. Sämtliche ON lagen in gereinigter Form (HPLC) vor, wobei auch die von Sigma-Aldrich bezogenen unmodifizierten Sequenzen (Referenzen, komplementäre und nicht-komplementäre Gegenstränge, Tab. 1) mittels HPLC gereinigt wurden. Die Reinheit aller verwendeten ON ist anhand von analytischer HPLC überprüft worden (Diagramme s. Kap. 9.1.2). Die $T_{m}$-Wert-Messungen wurden stets in wässrigen, gepufferten Lösungen $\quad\left(\mathrm{NaH}_{2} \mathrm{PO}_{4}, \quad \mathrm{pH}=7\right) \quad$ durchgeführt. Zur Vermeidung von Konzentrationsänderungen durch Verdunstung waren die Lösungen mit Paraffinöl überschichtet. 
Tab. 1: In Denaturierungsexperimenten eingesetzte $\mathrm{ON}^{*}$

\begin{tabular}{|c|c|c|}
\hline Nr. & Sequenz & ON-Typ \\
\hline \multicolumn{3}{|c|}{ NAA-modifizierte ON (TT = mögliche Position für NAA-Modifikation, s. Abb. 3.1) } \\
\hline $1-10$ & 5'-GGCACGGTTTTTTTTTGGCACGG-3' & ON a \\
\hline $11-20$ & 5'-GTTGACGTTGACGTTGACGTTG-3' & ON b \\
\hline 21-24 & 5'-GCGCTTGCTTAAGCAAGCGC-3' & ON c \\
\hline \multicolumn{3}{|c|}{ Unmodifizierte ON (für Referenzmessungen) } \\
\hline $1 u$ & 5'-GGCACGGTTTTTTTTTGGCACGG-3' & ON a \\
\hline $2 \mathbf{u}$ & 5'-GTTGACGTTGACGTTGACGTTG-3' & ON b \\
\hline $3 \mathbf{u}$ & 5'-GCGCTTGCTTAAGCAAGCGC-3' & ON c \\
\hline \multicolumn{3}{|c|}{ Komplementäre Gegenstränge } \\
\hline $1 \mathrm{a}$ & 5'-CCGTGCCAAAAAAAACCGTCCC-3' & ON a \\
\hline $2 a$ & 5'-CAACTGCAACTGCAACTGCAAC-3، & ON b \\
\hline $1 \mathrm{ra}$ & 5'-CCGUGCCAAAAAAAACCGUCCC-3' (RNA) & ON a \\
\hline 2ra & 5'-CAACUGCAACUGCAACUGCAAC-3' (RNA) & ON b \\
\hline \multicolumn{3}{|c|}{ Nicht-komplementäre Gegenstränge (für Mismatch-Messungen, $\underline{T_{n}} \underline{C_{1}} \underline{G}=$ Mismatch) } \\
\hline $1 \mathrm{mt}$ & 5'-CCGTGCCAAATAAAACCGTCCC-3' & ON a \\
\hline $2 \mathrm{mt}$ & 5'-CAACTGCATCTGCAACTGCAAC-3، & ON b \\
\hline $1 \mathrm{mc}$ & 5'-CCGTGCCAAAC्AAAACCGTCCC-3' & ON a \\
\hline $2 \mathrm{mc}$ & 5'-CAACTGCA드TGCAACTGCAAC-3، & ON b \\
\hline $1 \mathrm{mg}$ & 5'-CCGTGCCAAAGAAAACCGTCCC-3' & ON a \\
\hline $2 \mathrm{mg}$ & 5'-CAACTGCAGCTGCAACTGCAAC-3' & ON b \\
\hline
\end{tabular}

*DNA-ON außer wenn anderweitig angegeben

Die Gesamtkonzentration an ON in den Proben betrug 2.0 $\mu \mathrm{M}$. In allen Experimenten wurden drei Aufwärm- und zwei Abkühlkurven bei vier verschiedenen Wellenlängen aufgenommen (250, 260, 270, $280 \mathrm{~nm})$. Zur Bestimmung der Schmelzpunkte wurden stets die Abkühlkurven herangezogen. Bei keiner der untersuchten Duplices wurde eine signifikante Hysterese beobachtet. Dies deutet auf eine annähernde Äquivalenz der Aktivierungsenergie von Assoziation und Dissoziation der Doppelstränge hin. Exakte Aussagen über thermodynamische und kinetische Parameter der Denaturierung sind jedoch erst nach Durführung mehrerer Messreihen mit 
unterschiedlichen ON-Konzentrationen und Temperaturgradienten (Geschwindigkeit der Temperaturän-derung) möglich. Im Rahmen dieser Arbeit waren solche Messreihen nicht vorgesehen. Für die Bestimmung der $\mathrm{T}_{\mathrm{m}}$-Werte aus den aufgenommenen Kurven sind zwei Methoden bekannt. Als sehr präzise gilt die „Basislinien-Methode“. Diese Vorgehensweise setzt die willkürliche Wahl zweier Tangenten durch je eine Reihe von Datenpunkten am Anfang und am Ende der Schmelzkurve voraus. Der Schnittpunkt der Mittelwertgeraden und der Schmelzkurve ist als $\mathrm{T}_{\mathrm{m}}$-Wert definiert. Aufgrund der sehr hohen Anzahl an auszuwertenden Kurven konnte nicht von dieser aufwändigen Methode Gebrauch gemacht werden. Daher wurde als Alternative der Schmelzpunkt als das Maximum der ersten Ableitung der Schmelzkurven entnommen. Um die Vergleichbarkeit der Kurven zu ermöglichen, wurde auf der Ordinate der Schmelzkurvendiagramme stets die relative Änderung (Hyperchromizität) der Absorption angeführt.

$\%$ Hyperchromizität $=100 \times \frac{A(T)-A(\min )}{A(\min )}$

\section{A: Absorbanz}

$A(T)$ ist die bei einer bestimmten Temperatur gemessene Absorption, während $A(\min )$ den niedrigsten Absorptionswert einer Schmelzkurve darstellt. Die geschätzte Standardabweichung bei dieser Methode beträgt ca. $1-1.5^{\circ} \mathrm{C} .^{[19]}$ Die für eine genauere Aussage bezüglich der Standardabweichung erforderlichen wiederholten Messungen konnten im vorgegebenen zeitlichen Rahmen nicht durchgeführt werden. Für die Diskussion sind hauptsächlich die $\Delta T_{m}$-Werte von Interesse. Diese wurden als Differenz zwischen dem $T_{m}$-Wert einer NAA-modifizierten Duplex und dem $T_{m}$ Wert der entsprechenden unmodifizierten Duplex berechnet. Auf die Darstellung von Schmelzkurvendiagrammen und Tabellen wurde hier im Sinne der Übersichtlichkeit verzichtet. Sämtliche Diagramme und Tabellen sind im Anhang Kap. 9.2 angeführt.

Aus den berechneten $\Delta T_{m}$-Werten (s. auch 9.2.1.1, Tab. 1-3) konnten eindeutige Tendenzen erkannt werden (Abb. 4.30). Insgesamt bewirken NAA-Modifikationen trotz ihrer positiven Ladung eine geringfügige bis mäßige Destabilisierung sowohl der DNA/DNA- als auch der DNA/RNA-Duplices. Dabei ist allerdings die Destabilisierung von DNA/RNA-Duplices (grüne und blaue Kurve in Abb. 4.30) bedeutend größer als diejenige von DNA/DNA-Duplices (rote und orange Kurve in Abb. 4.30). Die Schmelzkurven zur folgenden Abb. 4.30 sind im Anhang Kap. 9.2.2.1 angeführt. 


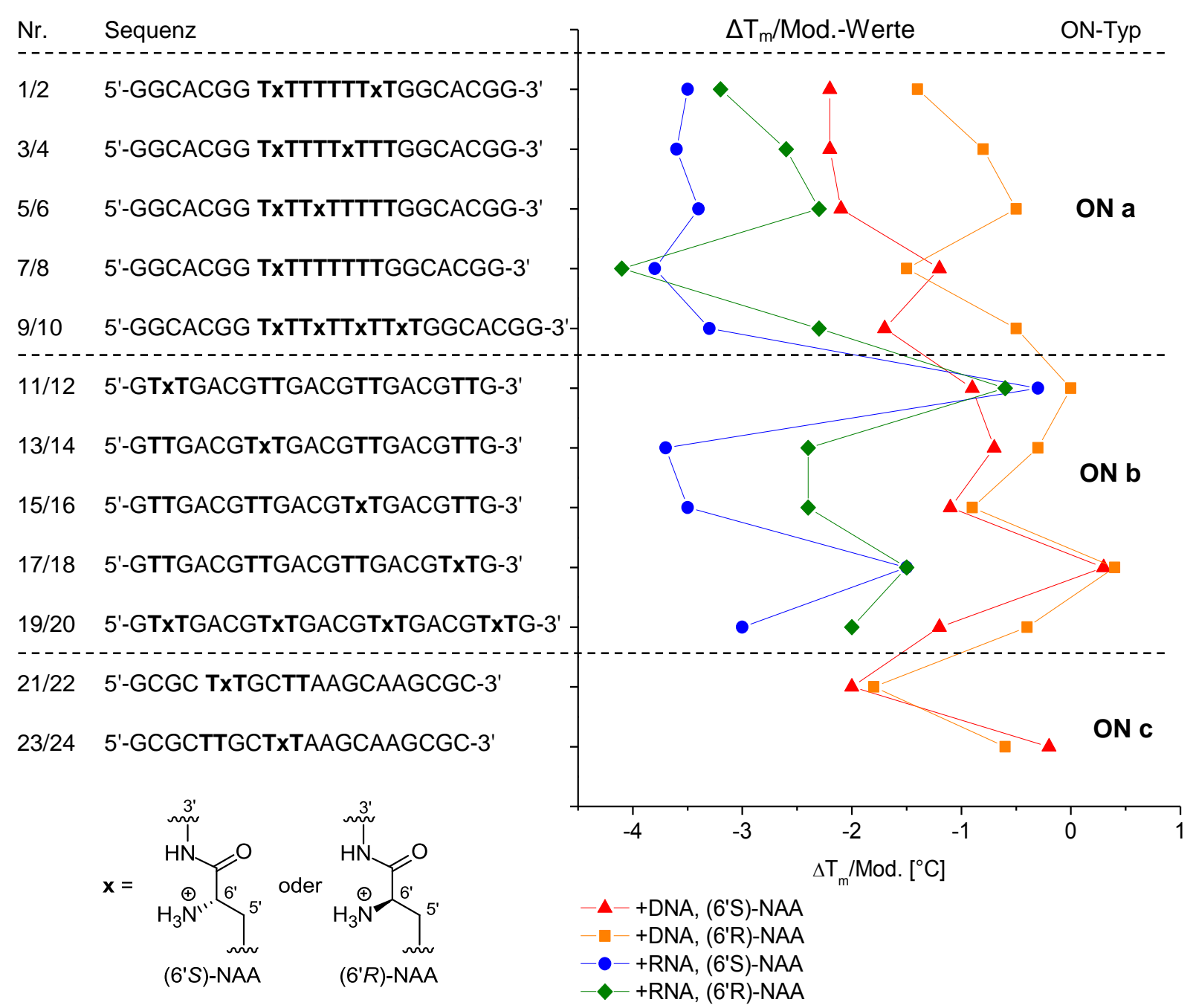

Abb. 4.30: $\triangle T_{\mathrm{m}}$-Werte der Duplices aller NAA-modifizierter ON mit komplementären DNA- und RNA Gegensträngen.

Deutliche Unterschiede der Auswirkung von NAA-Modifikationen auf Duplices verschiedener Basensequenz gehen dabei aus den $\Delta T_{m}$-Werten nicht hervor. Ein auffälliger Aspekt ist die Abhängigkeit der Duplex-Destabilisierung von der Konfiguration der NAA-Modifikation. Mit Ausnahme weniger $\Delta T_{m}$-Werte $(7 / 8,17 / 18$ und $23 / 24)$ treten im Fall der (6'R)-NAA-Modifikation regelhaft um ca. $0.5-2.0^{\circ} \mathrm{C}$ höhere Werte auf als im Fall von (6'S)-NAA-Modifikationen. Dies gilt sowohl für DNA/RNA- als auch für DNA/DNA-Doppelstränge nahezu unabhängig von der Anzahl der NAA-Modifikationen. Die Signifikanz dieses Unterschieds wird besonders deutlich, wenn die absoluten Werte der Destabilisierung der vierfach NAAmodifizierten Duplices betrachtet werden (Sequenzen $9 / 10$ und 19/20). Für RNA/DNA-Duplices liegt dieser Unterschied bei ca. $6^{\circ} \mathrm{C}$ und für DNA/DNA-Duplices bei $4{ }^{\circ} \mathrm{C}$. Des Weiteren konnte keinerlei kooperatives Wirken der NAA-Modifikation auf die Duplexstabilität nachgewiesen werden. Die Destabilisierung der Duplices 
verhält sich annähernd linear zur Anzahl der NAA-Modifikationen. Eine nähere Betrachtung der ON a lässt nicht auf eine signifikante Abstands-Abhängigkeit des Effekts der NAA-Modifikation schließen, da der Wert der Destabilisierung für jede Sorte von Duplex (RNA/DNA oder DNA/DNA) und Modifikation ((6'S)-NAA oder $\left.\left(6^{\prime} R\right)-N A A\right)$ annähernd konstant ist. Bezüglich der Positionsabhängigkeit der NAAModifikation (ON b) gibt es einen auffälligen Unterschied zwischen den untersuchten Duplexsorten. NAA-Modifikationen im Stranginneren (13/14 und 15/16) gehen bei RNA/DNA-Hybriden mit einer ausgeprägten Stabilitätsminderung einher $\left(-3.5^{\circ} \mathrm{C}\right.$ bei (6'S)-NAA und $-2.0^{\circ} \mathrm{Cbei}\left(6^{\prime} R\right)$-NAA), während endständige NAA-Modifikationen (11/12 und 17/18) die Duplex-Stabilität nicht beeinflussen. Im Gegensatz dazu erweisen sich die $\Delta T_{m}$-Werte von DNA/DNA-Duplices als nahezu unabhängig von der Position der NAA-Modifikation. DNA-Hybride der palindromen ON c wiesen aufgrund ihres höheren GC-Gehalts deutlich höhere $\mathrm{T}_{\mathrm{m}}$-Werte $\left(>80^{\circ} \mathrm{C}\right)$ auf als alle anderen untersuchten Duplices. Diese Duplices wurden ebenfalls durch NAAModifikationen generell leicht destabilisiert. Bei Duplices mit zwei NAAModifikationen in gegenüber liegenden Strängen wurden etwas höhere Destabilisierungen beobachtet als im Fall von nur einer Modifikation. Eine Abhängigkeit der $\Delta T_{m}$-Werte von der relativen Positionierung der NAA-Modifikationen in gegenüber liegenden Strängen wurde nicht beobachtet. Dies harmoniert wiederum gut mit den Befunden der Untersuchungen an den DNA-Hybriden der ON a, da auch hier der Abstand der NAA-Modifikationen keine Auswirkung auf die Duplex-Stabilität hat.

Als weiteres wichtiges Charakteristikum von Nucleinsäuren wurde im Zusammenhang mit der NAA-Modifikation die Mismatch-Erkennung untersucht (Abb. 4.31). Hierzu wurden exemplarisch Schmelzpunkte einiger NAA-modifizierter DNA/DNA-Duplices, in denen der unmodifizierte DNA-Strang in der Nähe einer NAAModifikation eine Fehlpaarung gegenüber der T-Base aufweist, bestimmt. Für Fehlpaarungen wurde jeweils eine der drei anderen kanonischen Basen an Position 12 (ON a) oder Position 14 (ON b) des Gegenstrangs gesetzt (C, G, T). Als Referenzen wurden Duplices mit entsprechenden Fehlpaarungen jedoch ohne NAAModifikation Denaturierungsexperimenten unterzogen. Die tabellierten $\Delta T_{m}$-Werte wurden durch Differenzbildung der $\mathrm{T}_{\mathrm{m}}$-Werte der Duplices mit Mismatch mit denjenigen ohne Mismatch berechnet (9.2.1.1, Tab. 4). Die Schmelzkurven sind im Anhang Kap. 9.2.2.2 angeführt. 


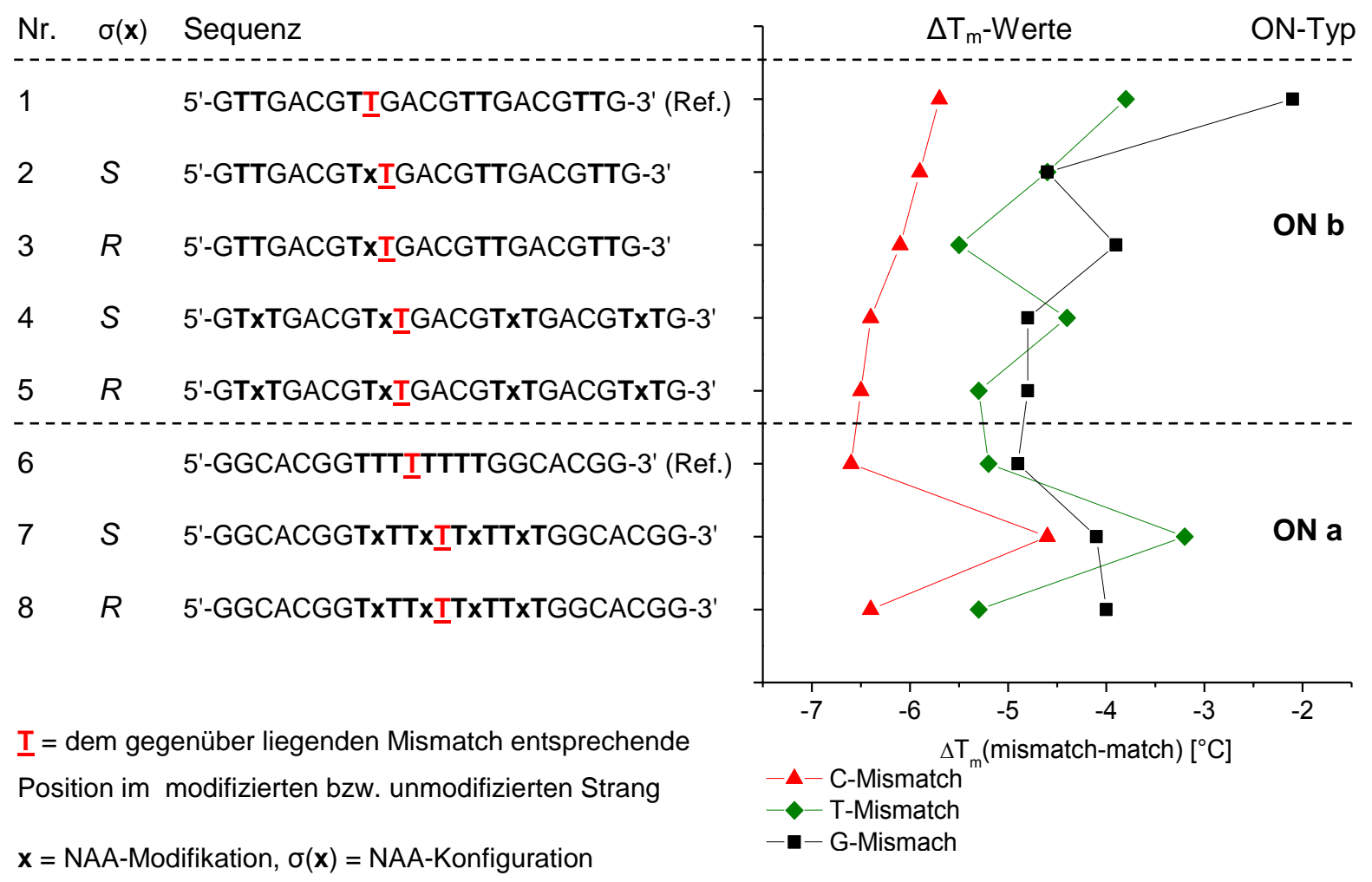

Abb. 4.31: $\Delta \mathrm{T}_{\mathrm{m}}$-Werte der Duplices mit Fehlpaarungen.

Insgesamt geht aus den Kurven in Abb. 4.31 hervor, dass die Empfindlichkeit NAAmodifizierter Duplices vom Typ ON b gegenüber Fehlpaarungen im Vergleich zu unmodifizierten Duplices nur geringfügig zunimmt. Besonders ausgeprägt ist diese Neigung im Fall der G-T-Fehlpaarung und am schwächsten im Fall der C-TFehlpaarung. Die Ergebnisse entsprechender Untersuchungen an den $\mathbf{O N a}$ vermitteln den Eindruck, dass die Mismatch-Erkennung unverändert bleibt, wobei die Messung Nr.7 (Abb. 4.31) möglicherweise einen Ausreißer darstellt. Eine Abhängigkeit der Mismatch-Erkennung von der Anzahl der NAA-Modifikationen ist anhand dieser Befunde für beide ON-Typen nicht nachweisbar. Wie bereits in Kap. 2 erwähnt, nimmt die Mismatchempfindlichkeit mit der Rigidität der hybridisierenden Stränge zu, da flexible Stränge gegenüber strukturellen Verzerrungen besser anpassungsfähig sind. Daher kann aus diesen Befunden gefolgert werden, dass die für Nucleinsäuren typische Flexibilität durch die NAA-Modifikation nur geringfügig beeinflusst wird.

Von Interesse war ferner das Verhalten der RNA- und DNA-Hybride NAAmodifizierter ON bei variierender lonenstärke (s. auch Kap. 9.2.1.2, Tab. 1-4). Dazu wurden Denaturierungsexperimente an einigen NAA-modifizierten Duplices bei 
erhöhten NaCl-Konzentrationen durchgeführt (0.5 M, 1.0 M). Die in den Abb. 4.32 und 4.33 dargestellten absoluten Veränderungen $\left(\Delta \mathrm{T}_{\mathrm{m}}\right.$-Werte) wurden durch Differenzbildung zwischen den Schmelzpunkten der Duplices bei erhöhter $\mathrm{NaCl}$ Konzentration und den Schmelzpunkten der gleichen Duplices unter Standardbedingungen $\quad(150 \mathrm{mM} \quad \mathrm{NaCl})$ berechnet. Entsprechende Referenzmessungen wurden an unmodifizierten Duplices durchgeführt. Erwartungsgemäß stiegen in allen Fällen die $T_{m}$-Werte deutlich an (Abb. 4.32 und 4.33). Die Schmelzkurven zu den Abb 4.32 und 4.33 sind in Kap. 9.2.2.3 angeführt.

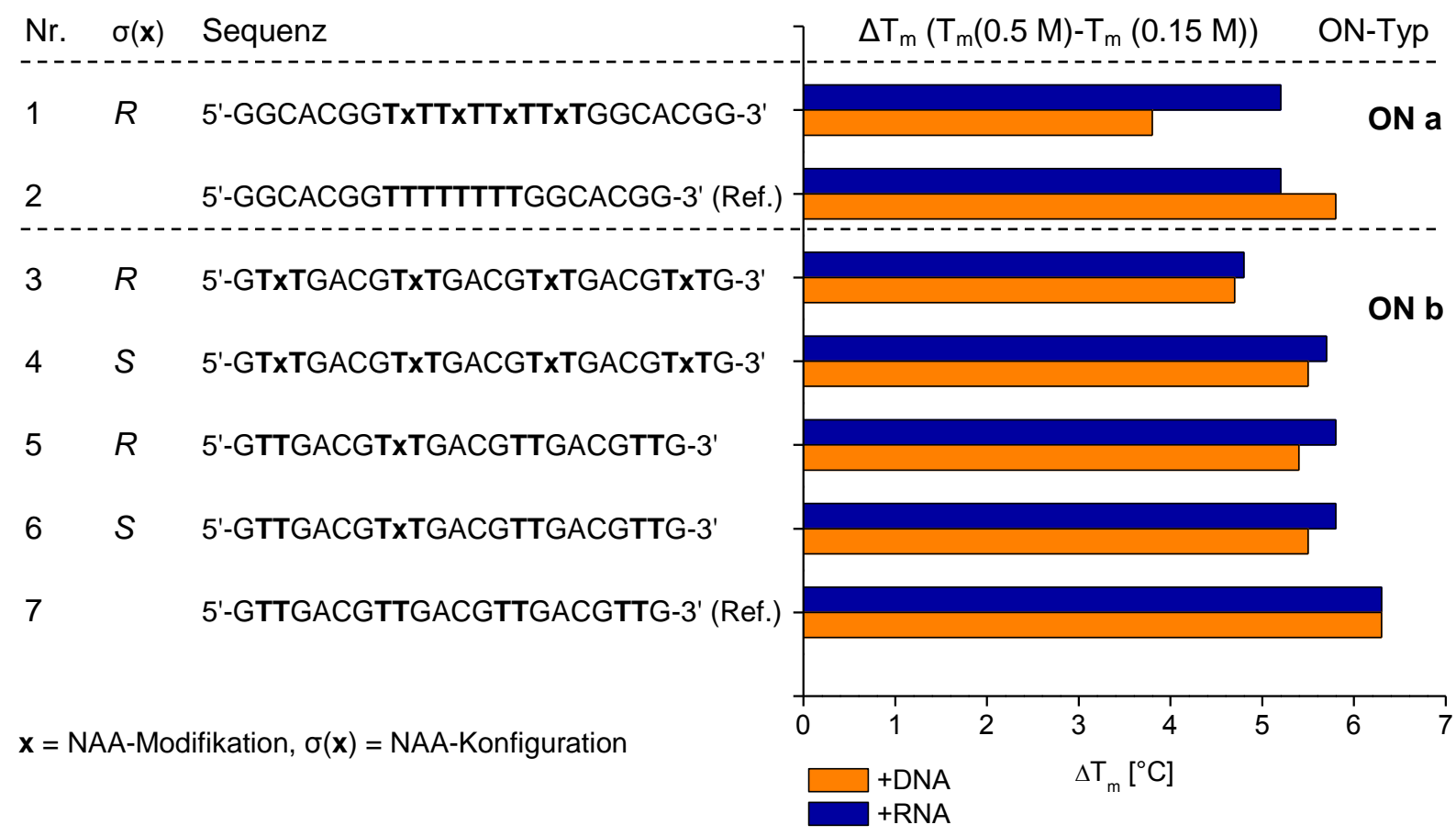

Abb. 4.32: $\Delta T_{m}-$ Werte der Denaturierungsexperimente bei $0.5 \mathrm{M} \mathrm{NaCl}$.

Bei einer $\mathrm{NaCl}$-Konzentration von $0.5 \mathrm{M}$ wies der Unterschied des $\Delta \mathrm{T}_{\mathrm{m}}$-Anstiegs zwischen NAA-modifizierten und unmodifizierten ON (Ref.) in Abhängigkeit der Duplexart unterschiedliche Werte auf (Abb. 4.32). Während die Unterschiede bei DNA/RNA-Duplices (blaue Balken, Abb 4.32) kaum signifikant sind, kann im Fall der DNA/DNA-Duplices (orange Balken, Abb. 4.32) ein geringfügiger, regelhaft auftretender Unterschied beobachtet werden. Demnach ist die Stabilitätszunahme mit steigender lonenstärke bei NAA-modifizierten Duplices geringer als bei unmodifizierten. Dieser Trend gilt sowohl für $\mathbf{O N}$ a als auch für $\mathbf{O N} \mathbf{b}$. 


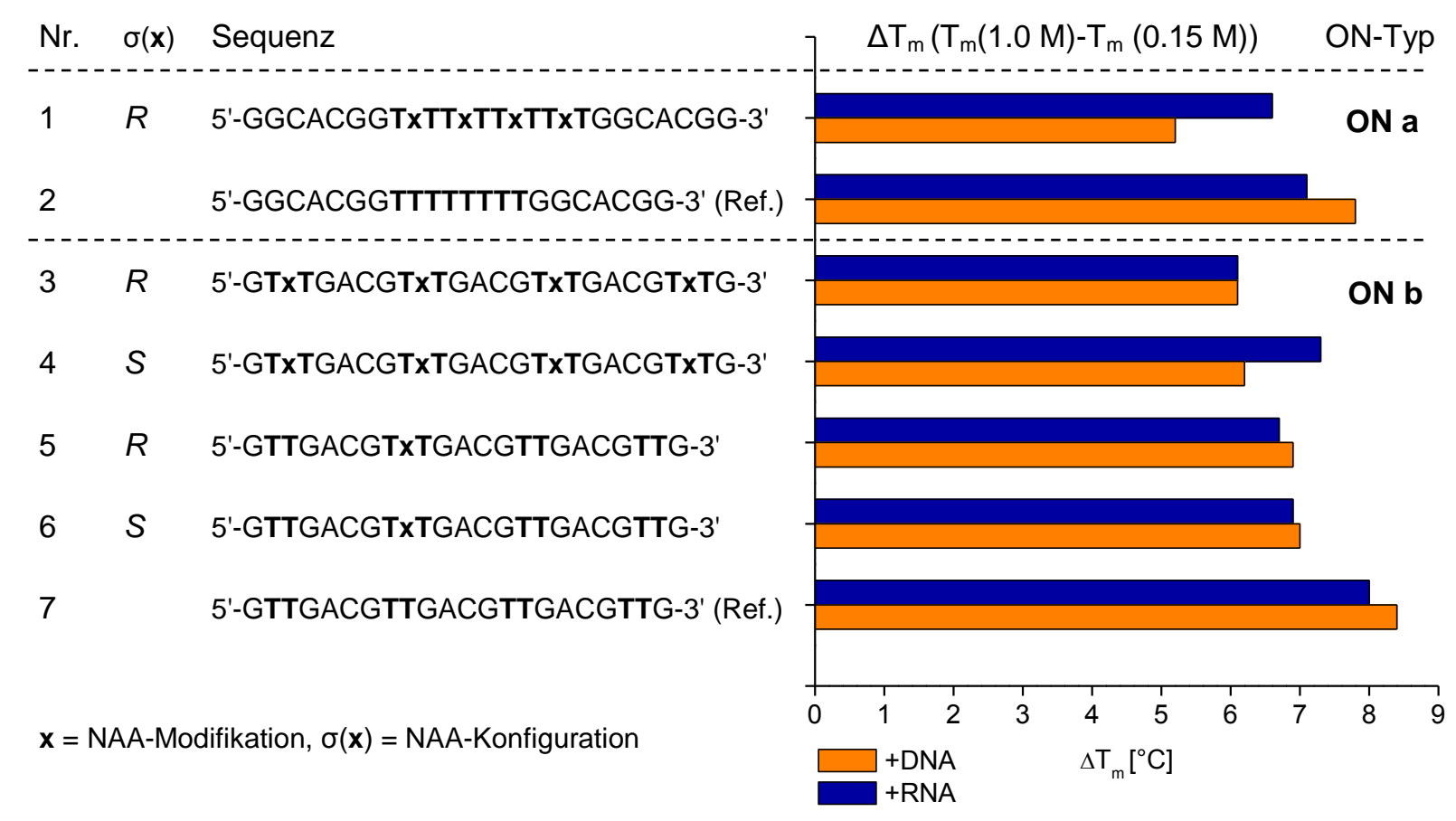

Abb. 4.33: $\Delta \mathrm{T}_{\mathrm{m}}$-Werte der Denaturierungsexperimente bei $1.0 \mathrm{M} \mathrm{NaCl}$.

Weitere Denaturierungsexperimente bei einer $\mathrm{NaCl}$-Konzentration von $1.0 \mathrm{M}$ bestätigten den oben beschriebenen Trend, wobei die Unterschiede hier noch deutlicher sind (Abb. 4.33). Die Stabilisierung unmodifizierter $\mathrm{ON}$ ist hier ebenfalls größer als diejenige NAA-modifizierter ON. Etwas stärker ausgeprägt ist dieser Effekt wiederum bei DNA/DNA-Duplices und etwas geringer bei DNA/RNA-Duplices. Überraschend ist allerdings, dass die $\Delta T_{\mathrm{m}}$-Werte einfach und vierfach modifizierter ON sich kaum unterscheiden. Wie bereits in Kap. 2.4.3 ausgeführt, weist die DuplexStabilität von Nucleinsäure-Duplices, die aus einem elektroneutralen oder zwitterionischen Strang und einem negativ geladenen gebildet werden, eine geringere Empfindlichkeit gegenüber der Variation der lonenstärke auf. Dieser Effekt wurde hier tendenziell ebenfalls - wenn auch in nur geringem Ausmaß - beobachtet.

\subsubsection{Circulardichroismus-(CD)-Spektroskopie}

Circular polarisiertes Licht ist ein chirales Phänomen und dessen Wechselwirkung mit chiralen Molkülen von diastereotoper Natur. Daher kann die Absorbanz (A) eines chiralen Moleküls hinsichtlich rechts und links circular polarisierten Lichts unterschiedlich groß sein und ist eine Funktion der Wellenlänge $\lambda$ des Lichts. Auf dieser physikalischen Grundlage beruht die Strukturanalyse chiraler Moleküle mittels CD- 
Spektroskopie. Die Messung der Absorbanz erfolgt im UV/VIS-Bereich. Da die quantenchemische Interpretation von CD-Spekren sehr komplex ist, kann auf AtomEbene keine Information über große Moleküle wie Nucleinsäuren gewonnen werden. Daher wird die CD-Spektroskopie in diesem Fall vorwiegend empirisch verwendet. Für DNA- und RNA-Moleküle, die eine Sekundärstruktur aufweisen, sind zahlreiche CD-Spektren im Wellenlängenbereich von 180-300 nm aufgenommen worden. Durch den Vergleich der CD-Spektren von nativen DNA- bzw. RNA-Molekülen mit denjenigen von modifizierten Analoga können qualitative Rückschlüsse auf Veränderungen der Geometrie und Konformation gezogen werden. CD-Spektren von B-Helices weisen ein typisches Muster auf, das durch die breite positive Absorptionsbande im Wellenlängenbereich von 260-280 nm und eine tiefe negative Absorptionsbande um $245 \mathrm{~nm}$ charakterisiert werden kann. ${ }^{[184]}$ Geringfügige lokale Variationen dieses Musters kommen durch unterschiedliche Basensequenzen zustande. Alle Duplices der NAA-modifizierten ON (Abb. 3.2 Nr. 1-24) mitsamt der unmodifizierten Referenz-Duplices sind anhand dieser Methode untersucht worden (CD-Spektren s. 9.3). Die erhaltenen Kurven der NAA-modifizierten Duplices wurden durch Superposition in einem Diagramm mit den jeweiligen Kurven unmodifizierter Referenz-Duplices verglichen. Dabei ergaben sich in vielen Fällen nahezu identische Spektren modifizierter und unmodifizierter Duplices. Daraus wurde darauf geschlossen, dass die NAA-Modifikationen höchstens geringfügige lokale Störungen der Duplex-Geometrie hervorrufen. Dieses Resultat harmoniert gut mit den Befunden der thermischen Denaturierungsexperimente, in denen ebenfalls nur geringe bis mäßige Stabilitätsverluste durch die Einführung der NAA-Modifikation aufgetreten waren. Die Gestalt der CD-Spektren von DNA/DNA-Hybriden (s. Kap. 9.3.1.1) stimmt im Wesentlichen gut mit den typischen Merkmalen des B-Helix-Musters überein, wobei die Spektren je nach Sequenz durchaus charakteristische Ausprägungen aufweisen. DNA/DNA-Duplices vom Typ ON a weisen bei ca. $265 \mathrm{~nm}$ ein für oligoAT-Sequenzen typisches lokales Minimum ${ }^{[185]}$ und eine tiefe enge Absorptionsbande bei ca. $250 \mathrm{~nm}$ auf. Ersteres rührt daher, dass bei den ON a in der Mitte der Sequenz eine Folge von acht Thymidin-Bausteinen vorliegt (Abb. 4.34). 


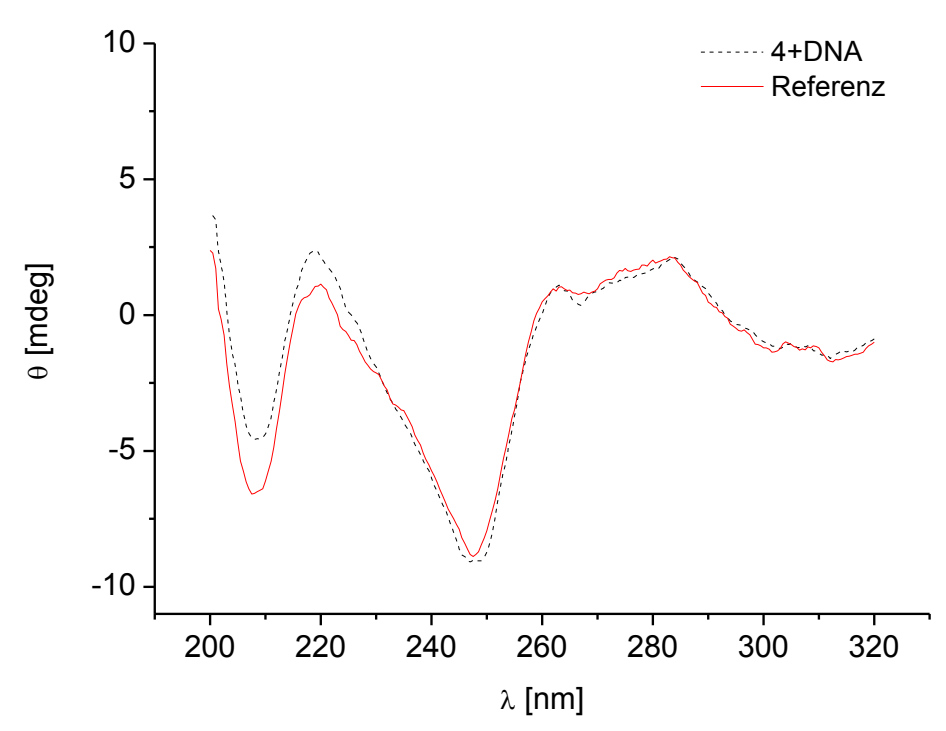

Oligonucleotid $4(R)$ : 5'-GGCACGG TxT TT TxT TT GGCACGG-3'

Abb. 4.34: Exemplarisches CD-Spektrum einer DNA/DNA-Duplex vom Typ ON a.

Im Gegensatz dazu liegt in den CD-Spektren der DNA/DNA-Duplices von Typ ON b im Bereich von $275 \mathrm{~nm}$ ein lokales Maximum vor, während das Minimum bei $265 \mathrm{~nm}$ fehlt. Darüber hinaus ist die negative Absorptionsbande bei $250 \mathrm{~nm}$ wesentlich breiter und weniger intensiv (Abb. 4.35).

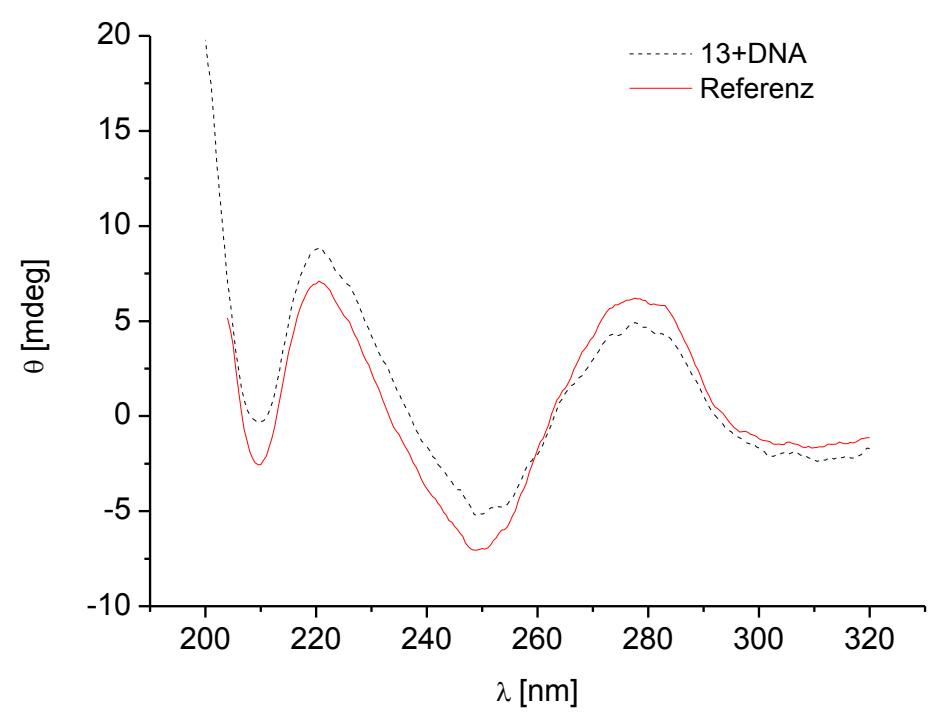

Oligonucleotid 13 (S): 5'-G TT GACG TxT GACG TT GACG TT G-3'

Abb. 4.35: Exemplarisches CD-Spektrum einer DNA/DNA-Duplex vom Typ ON b. 
CD-Spektren der DNA/DNA-Duplices vom Typ ON $\mathbf{c}$ sind denjenigen von ON b recht ähnlich, daher wurde auf eine Darstellung an dieser Stelle verzichtet. Diese Spektren sind im Anhang Kap. 9.3.1.2 angeführt.

Die CD-Spektren von DNA/RNA-Duplices (Kap. 9.3.2) können von ihrer Gestalt her als Mischform zwischen A-Helix und B-Helix aufgefasst werden. Für die CD-Spektren von A-Helices ist eine sehr intensive und breite Absorptionsbande zwischen 250 und $290 \mathrm{~nm}$ sowie eine schmale und intensive negative Bande bei $210 \mathrm{~nm}$ charakteristisch. $^{[184]}$ Interessanterweise sind die CD-Spektren von DNA/RNADuplices der ON a (Abb. 4.36) denen der DNA/RNA-Duplices von ON b (Abb. 4.37) recht ähnlich.

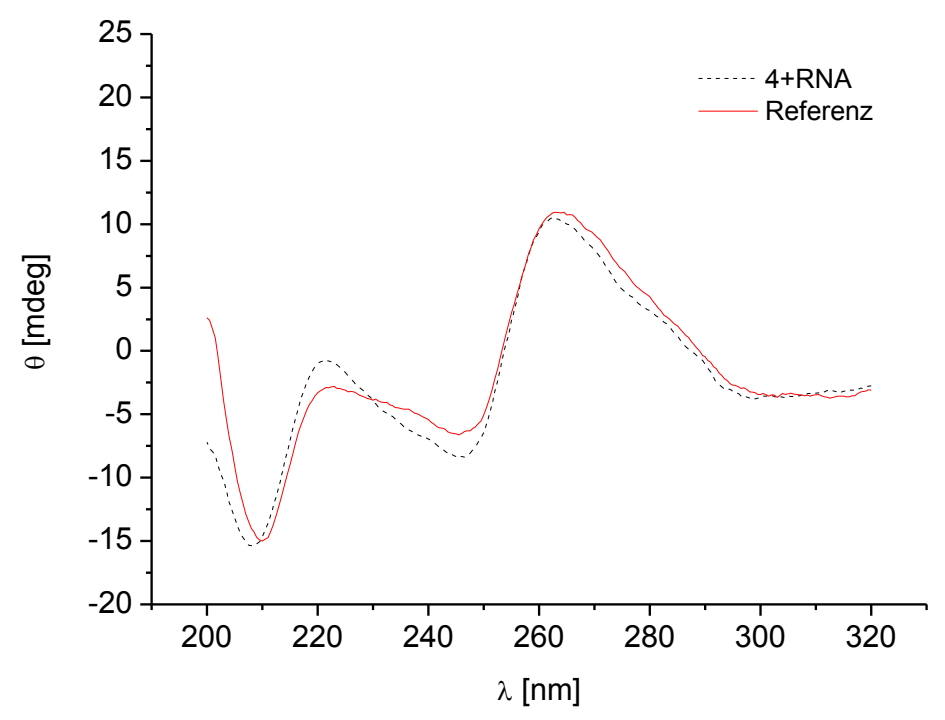

Oligonucleotid $4(R)$ : 5'-GGCACGG TxT TT TxT TT GGCACGG-3'

Abb. 4.36: Exemplarisches CD-Spektrum einer DNA/RNA-Duplex vom Typ ON a.

Die Spektren der DNA/RNA-Duplices der ON b unterscheiden sich durch etwas weniger intensive negative Banden bei $210 \mathrm{~nm}$ und die etwas intensiveren positiven Banden bei $220 \mathrm{~nm}$. Somit weisen die DNA/RNA-Duplices der ON b ein wenig mehr B-Helix-Charakter auf als diejenigen der ON a. Dabei fällt zudem auf, dass die Übereinstimmung der CD-Spektren der DNA/RNA-Duplices der ON a mit den entsprechenden Referenz-Spektren etwas geringer ist als im Fall der ON b. Dies kann im Sinne einer geringeren Kompatibilität der NAA-Modifikation mit der A-HelixGeometrie erklärt werden und stimmt wiederum gut mit den Befunden der thermischen Denaturierungsexperimente überein. 


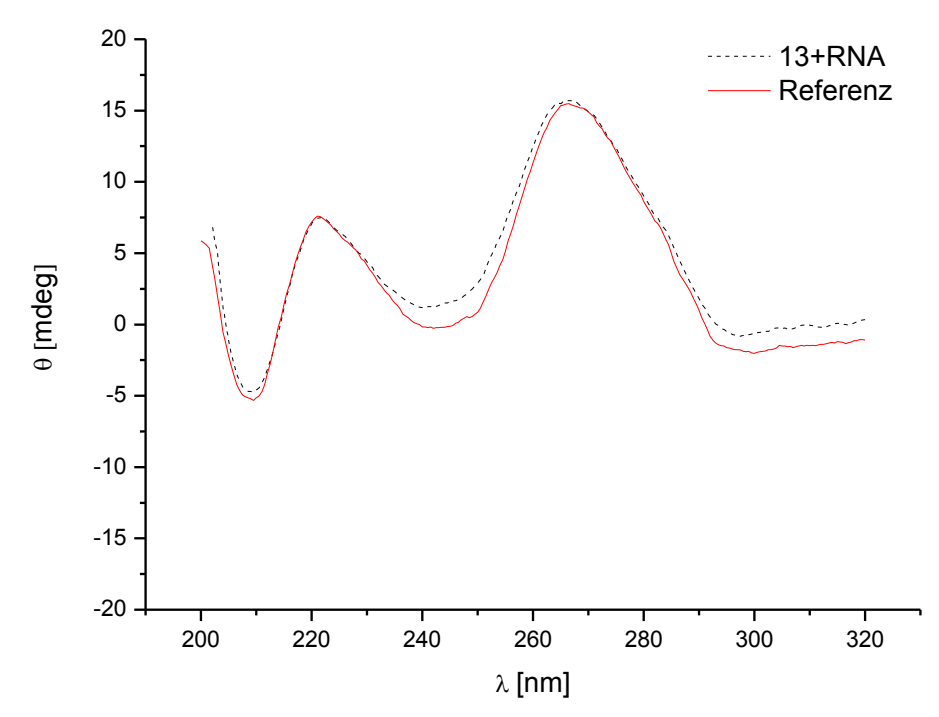

Oligonucleotid 13 (S): 5'-G TT GACG TxT GACG TT GACG TT G-3'

Abb. 4.37: Exemplarisches CD-Spektrum einer DNA/RNA-Duplex vom Typ ON b.

Tatsächlich sind die Werte der Duplex-Destabilisierung im Fall der DNA/RNADuplices der $\mathbf{O N}$ a ein wenig höher als diejenigen der ON b. Ein weiterer Aspekt, der diese Annahme stützt, ist die geringere Destabilisierung der NAA-modifizierten DNA/DNA-Duplices im Vergleich mit den NAA-modifizierten DNA/RNA-Duplices. Insgesamt kann folglich festgehalten werden, dass die strukturelle Kompatibilität der NAA-Modifikation insbesondere bei ausgeprägtem B-Helix-Charakter der Duplex gegeben ist, während im Gegensatz dazu Duplices mit ausgeprägtem A-HelixCharakter die NAA-Modifikation etwas weniger tolerieren.

\subsubsection{Abschließende Beurteilung der NAA-Modifikation}

Bei der Beurteilung der Ergebnisse sind im Wesentlichen zwei Effekte von Bedeutung. Zum einen sollte die Amino-Gruppe der NAA-Einheit unter den eingestellten Bedingungen ( $\mathrm{pH}=7,150 \mathrm{mM} \mathrm{NaCl}$ ) protoniert, $d$. h. positiv geladen sein, weshalb eine Erhöhung der thermischen Stabilität auf Grund der Minimierung der Coulomb-Repulsion zu erwarten wäre. Zum anderen aber bewirkte die eingeschränkte konformationelle Beweglichkeit um die Amidbindung der von de Mesmaeker etablierten elektroneutralen Amid-Verbrückungen bis auf einige Ausnahmen eine Destabilisierung der mit komplementären DNA- und RNA-Strängen gebildeten Duplices. ${ }^{[76]} \mathrm{Da}$ die beobachteten thermischen Stabilitäten NAA- 
modifizierter Duplices generell niedriger sind als diejenigen unmodifizierter Duplices, überwiegt offenbar die Störung der Duplex-Geometrie durch den restriktiven Charakter der Amid-Bindungen die Ladungskompensation. Dass geometrische Aspekte die Stabilität NAA-modifizierter Duplices dominieren, geht auch aus den unterschiedlichen Effekten der (6'S)-NAA und (6'R)-NAA auf die Duplex-Stabilität hervor. Die diskutierten Daten belegen eindeutig, dass die (6'R)-NAA-Modifikation in höherem Maße mit der Helix-Geometrie harmoniert als die (6'S)-NAA-Modifikation. Die verschiedenen Stabilitätsminderungen NAA-modifizierter RNA/DNA- und DNA/DNA-Duplices verdeutlichen ebenfalls die geringfügige Bedeutung des elektrostatischen Effekts im Vergleich zu geometrischen Faktoren auf die DuplexStabilität. Vielmehr zeigt sich dadurch, dass die NAA-Modifikation eher zur B-Helix passt als zur A-Helix. Allerdings können die von der NAA-Modifikation induzierten "Störungen" nicht von erheblichem Ausmaß sein, da die Destabilisierung der Duplices mit $\Delta \mathrm{T}_{\mathrm{m}}$-Werten von 0 bis $-4{ }^{\circ} \mathrm{C} / \mathrm{Mod}$. stets gering bis moderat ausfiel. Zudem wurde die Mismatch-Erkennung durch die NAA-Modifikation kaum beeinträchtigt. Daraus kann gefolgert werden, dass die NAA-Modifikation trotz der konformationell eingeschränkten Amid-Bindungen die Flexibilität der Nucleinsäuren höchstens geringfügig beeinflusst. Ein weiterer Hinweis auf die geringe Wirkung der positiven Ladung der NAA-Modifikation ist durch die gemessenen Duplex-Stabilitäten bei erhöhter lonenstärke gegeben. Hinsichtlich der Zunahme der Duplex-Stabilität mit der lonenstärke wiesen die NAA-modifizierten Duplices nur geringfügige Unterschiede zu unmodifizierten Duplices auf. Die Ergebnisse der thermischen Denaturierungsexperimente werden durch die Befunde der CD-Spektroskopie bestätigt. Die Übereinstimmung der CD-Spektren NAA-modifizierter Duplices mit denjenigen unmodifizierter Referenz-Duplices ist in den meisten Fällen sehr hoch. Die aufgenommenen Spektren sind bekannten Mustern der A- bzw. B-Helix sehr ähnlich. Die auffällig geringe Abweichung der Eigenschaften NAA-modifizierter ON von denjenigen unmodifizierter $\mathrm{ON}$ ist im Hinblick auf die strukturellen Unterschiede zwischen der NAA-Verbrückung und Phosphatdiestereinheiten überraschend. Selbst bei vierfach NAA-modifizierten ON sind nur mäßige Abweichungen hinsichtlich molekularer Erkennung, thermischer Stabilität und Topologie festgestellt worden. Diese Befunde bestätigen nicht die Hypothese von Benner, derzufolge die polyanionische Beschaffenheit für deren physikochemische Eigenschaften (WatsonCrick-Hybridisierung, Sequenz-Unabhängigkeit der physikalischen Eigenschaften, Eignung zur Funktion als Templat) notwendig ist. ${ }^{[23]}$ 


\section{Zusammenfassung}

Der zentrale Aspekt dieser Arbeit war die Konzeption und Synthese von NAABausteinen für den Aufbau zwitterionischer (NAA-mod. DNA) oder oligokationischer (oligoNAA) Nucleinsäure-Analoga (Abb. 5.1). Experimentelle Befunde über die Eigenschaften solcher Analoga könnten für das grundlegende Verständnis der Relevanz des Ladungsmusters genetischer Moleküle nützlich sein.

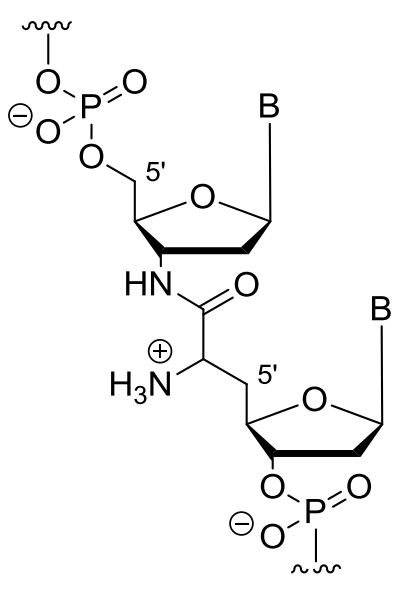

NAA-mod. DNA

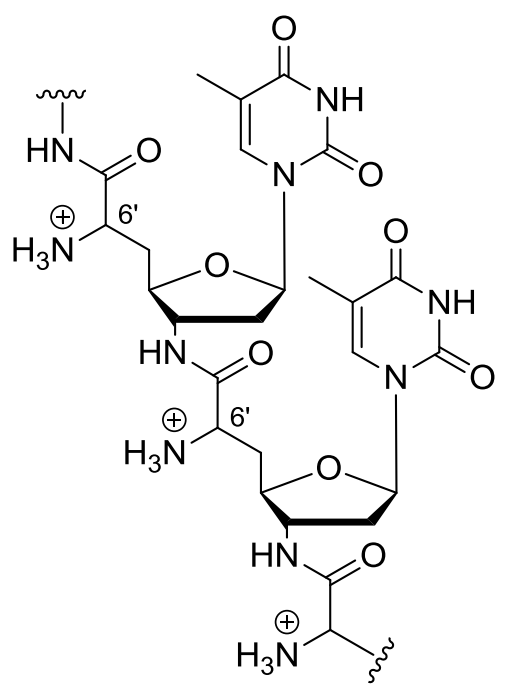

oligoNAA

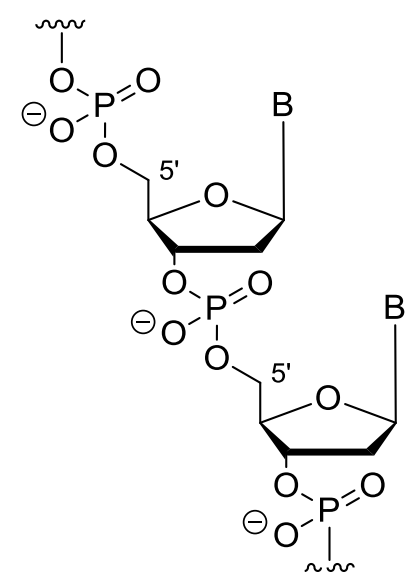

DNA

Abb. 5.1: Konzipierte Nucleinsäureanaloga im Vergleich mit der DNA.

Unter Verwendung der Phosphoramidit-Bausteine (6'S)- und (6'R)-69 wurden 24 verschiedene zwitterionische ON der drei Typen ON a, ON b und ON c synthetisiert, die an bestimmten Positionen die neuartige NAA-Modifikation enthalten (Abb. 5.2). Mit dem Ziel der Synthese weiterer ON mit NAA-Modifikationen an anderen Positionen als zwischen zwei Thymidin-Einheiten wurde zudem der synthetische Zugang zu den Dinucleosiden (6'S)-150, 151 und 152 erschlossen. Diese Verbindungen stellen die Vorstufen der für die Festphasensynthese verwendbaren Phosphoramidite 87-89 (Abb. 3.5) dar. Die Synthese der Dinucleoside 75 und 150152 erfolgte durch Peptid-Kupplung der (6'S)-und (6'R)-NAA 73 mit verschiedenen 3'-Aminonucleosiden $\mathbf{7 2}$ und 90-92, anschließende simultane Desilylierung in 3'- und 5"-Position, regioselektive Einführung der Trityl-Schutzgruppe in 5"-Position und Phosphitylierung im Fall der T-T-Dinucleoside 75. Während die T-T-Dinucleoside 75 mit insgesamt guten Ausbeuten erhalten wurden (59\% von 73 aus), erwies sich die Anwendung dieses Verfahrens auf die Synthese der Dinucleoside 150-152 als nicht 
unproblematisch. Insbesondere für die zweifache Desilylierung der Verbindungen 9395 konnte keine gut geeignete Methode gefunden werden. Verfahren, die auf der Verwendung saurer Reagenzien zur Spaltung der Silylether beruhen, führten entweder zu keiner Silylether-Spaltung oder verursachten Nebenreaktionen wie z. B. die Spaltung der $N$-glykosidischen Bindung.
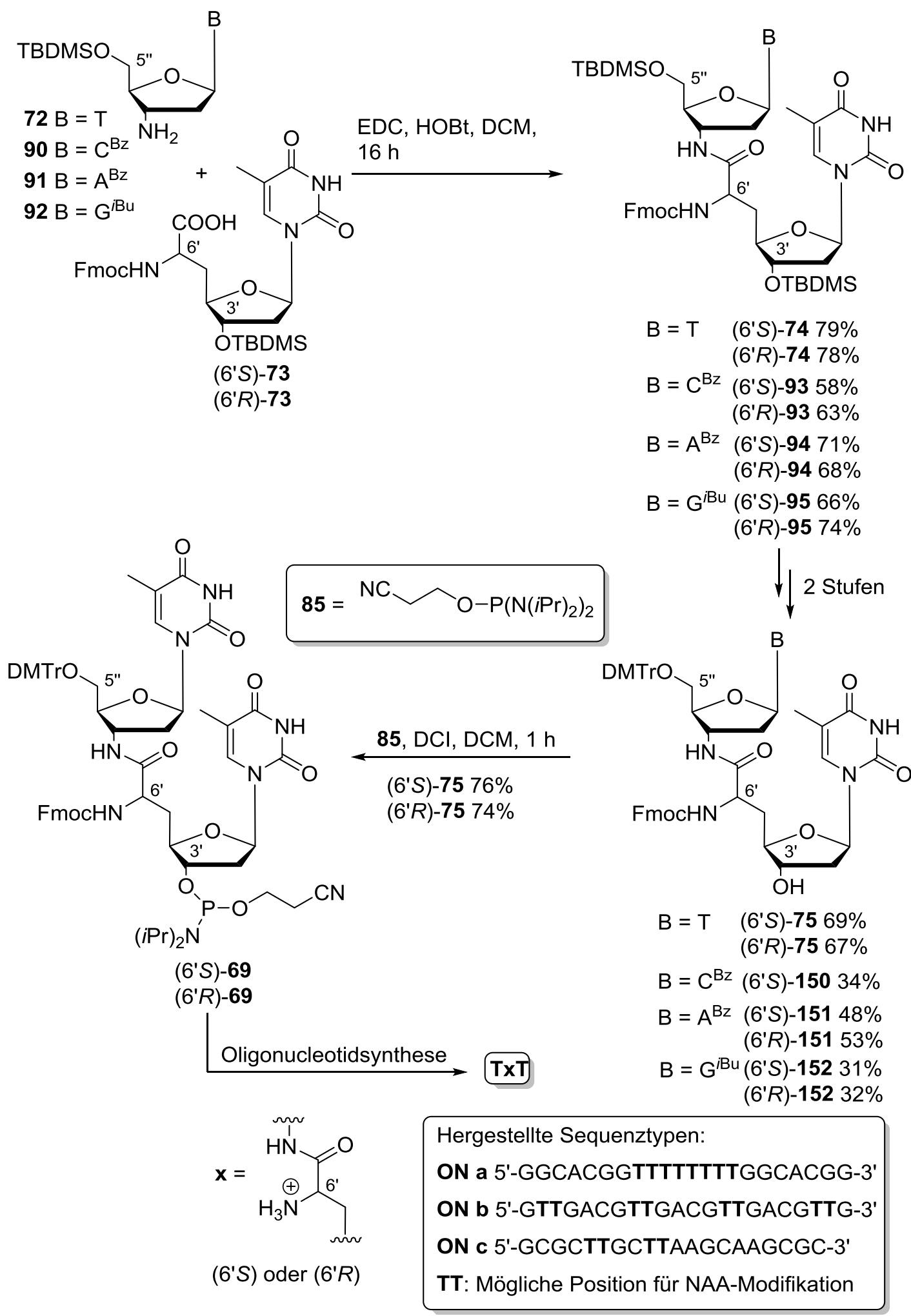

Abb. 5.2: Synthese der Dinucleoside 75, 150-152 und der Phosphoramidite 69. 
Vorgehensweisen, in denen basische Reagenzien verwendet wurden, führten häufig zu einer Spaltung der Fmoc-Schutzgruppe. Als einzige brauchbare Methode wurde daher Ammoniumfluorid in Methanol eingesetzt. Auf diese Weise konnten die Dinucleoside 150-152 in Ausbeuten von 31-53\% (von 73 aus) erhalten werden. Für die Synthese der NAA 73 wurde die bereits zuvor etablierte Synthesemethode verwendet. ${ }^{[114]}$ In dieser Arbeit wurde geprüft, ob eine analoge Vorgehensweise auch ohne die BOM-Schutzgruppe anwendbar ist (Abb. 5.3). Ausgehend von den synthetisch leicht zugänglichen Thymidinylaldehyden $\mathbf{7 8}$ und $\mathbf{8 4}$ wurden durch WittigHorner-Reaktionen mit dem Phosphonat 79 die 5',6'-DidehydroThymidiylaminosäuren (Z)-80 bzw. (Z)-82 in Ausbeuten von 74\% bzw. $67 \%$ erhalten. Die Diastereoselektivität der Reaktion war im Fall des BOM-geschützten Aldehyds als Ausgangsverbindung deutlich höher $(Z / E=96: 4)$ als bei der entsprechenden Reaktion der ungeschützten Verbindung $82(Z / E=91: 9)$. Die Zuordnung der Konfiguration der Doppelbindung wurde auf der Grundlage der empirischen Kriterien von Mazurkiewicz für die ${ }^{1} \mathrm{H}-\mathrm{NMR}$-Signale der Verbindungen vorgenommen. ${ }^{[151]}$ Die Ergebnisse der nachfolgend durchgeführten asymmetrischen Hydrierungen der Verbindungen (Z)-80 und (Z)-82 bestätigten diese Zuordnung, da asymmetrische Hydrierungen von (E)-5',6'-Didehydroaminosäuren bekanntermaßen wesentlich langsamer und mit geringerer Selektivität verlaufen. ${ }^{[119,153]}$ Die Produkte der asymmetrischen Hydrierungen von (Z)-80 und (Z)-82 unter Katalyse durch $(S, S)$ oder $(R, R)$-Me-DuPHOS-Rh wurden stets in sehr hoher Diastereomerenreinheit erhalten (d.r. $\geq 98: 2)$. Allerdings bedurften die Reaktionen der Verbindung ohne BOM-Schutzgruppe (Z)-82 wesentlich längerer Zeiträume (9-21 d) als die Reaktionen des Nucleobasen-geschützten Analogons (Z)-80 (2-7 d). Die Ausbeuten dieser Hydrierungen lagen mit Ausnahme der Synthese von (6'R)-83 (77\%) bei sehr guten Werten (92-99\%). Der stereochemische Verlauf dieser asymmetrischen Hydrierungen gilt als hinlänglich bekannt. ${ }^{[119,153]}$ Zudem konnte für Uridin-Analoga der Verbindungen $\mathbf{8 1}$ und $\mathbf{8 3}$ die Zuordnung der Konfiguration an der 6'-Position durch Röntgenstrukturuntersuchungen eindeutig belegt werden. ${ }^{[18]}$ Daher wurde im Rahmen dieser Arbeit auf den exakten Nachweis der Konfiguration der NAA 81 bzw. 83 verzichtet. Beide Diastereomere der Verbindungen 81 und 83 wurden nachfolgend durch reduktive Spaltung der BOM- und Cbz-Schutzgruppen, Einführung einer Fmoc-Schutzgruppe an der 6'- $\mathrm{NH}_{2}$-Funktionalität und mild-saure Spaltung der tert-Butylester durch Kieselgel in siedendem Toluol in die NAA (6'S)bzw. (6'R)-73 überführt. 


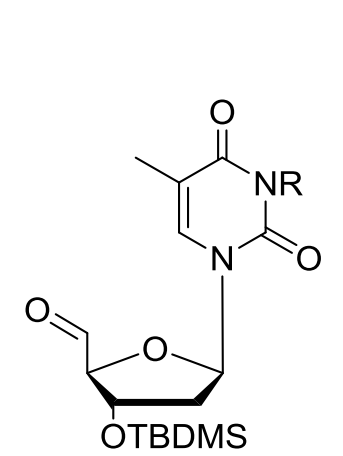

$78 \mathrm{R}=\mathrm{BOM}$

In 4 Stufen aus Thymidin 56\%

$84 \mathrm{R}=\mathrm{H}$

In 3 Stufen aus Thymidin 66\%

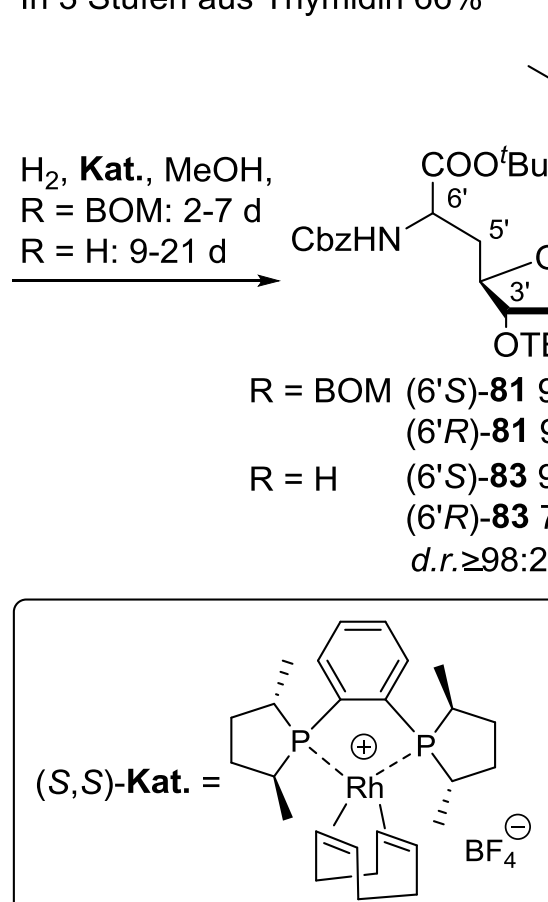

(S,S)-Me-DUPHOS-Rh
$(R, R)-$ Kat. $=$

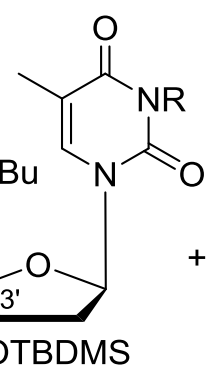

$+{ }^{t} \mathrm{BuOOC}$<smiles>[13CH3+]N</smiles>
$\mathrm{CbzHN}$<smiles>CC=C(C)CC</smiles>

$\begin{array}{ll}\mathrm{R}=\mathrm{BOM}(Z)-80 \\ \mathrm{R}=\mathrm{H} & (Z)-82\end{array}$

$Z I E=96: 4$

$Z I E=91: 9$

(E)-80

$(E)-82$

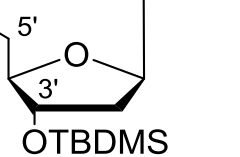


bekannte Vorgehensweise angewendet. Die Substitution der Hydroxygruppe in 3'-Position durch eine Aminogruppe unter Retention der Konfiguration wurde durch Synthese tricyclischer Nucleosid-Derivate 136 und 96, deren Ringöffnung durch $\mathrm{S}_{\mathrm{N}} 2-$ Reaktion mit Natriumazid und Reduktion der Azidfunktionalität zum entsprechenden Amin erreicht. ${ }^{[137]}$

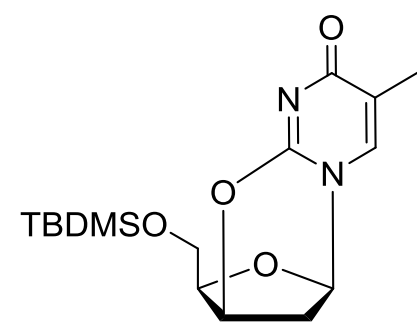

136

Aus Thymidin in 2 Stufen $84 \%$

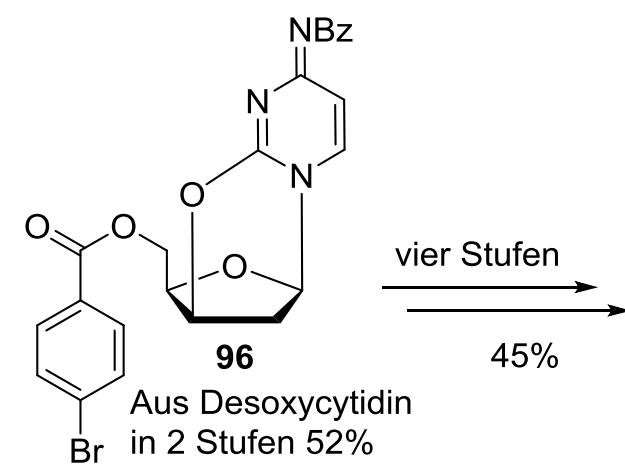

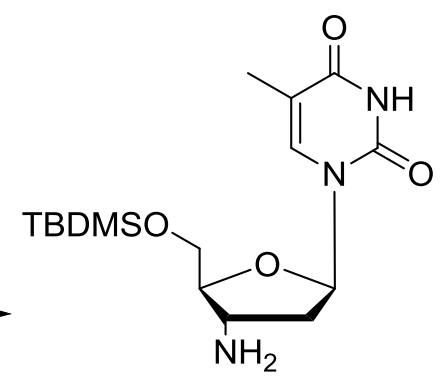

72

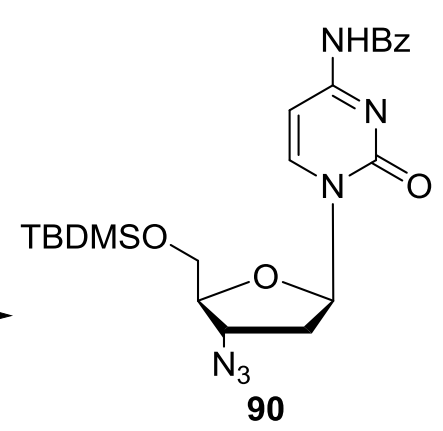

Abb. 5.4: Synthese der Pyrimidin-2',3'-didesoxy-3'-aminonucleoside 72 und 90.

Für die Herstellung der Purin-2',3'-didesoxy-3'-aminonucleoside 91 und 92 wurde zunächst der Versuch unternommen, die von Richert publizierte Methode anzuwenden. ${ }^{[137]}$ Der Schlüsselschritt dieser Reaktionssequenz ist die Aktivierung der 3'-Hydroxygruppe von 2'-Desoxy-3'-xylo-nucleosiden durch DIAD und Triphenylphosphin sowie die nachfolgende Substitution durch ein Azidnucleophil im Sinne einer Mitsunobu-Reaktion. Die in der Publikation von Richert angegebenen Ergebnisse konnten jedoch nicht reproduziert werden. Daher wurden zahlreiche alternative Methoden für die Aktivierung und Substitution der 3'-Hydroxygruppe untersucht, darunter weitere Mitsunobu-Reaktionen, eine Mukaiyama-Kondensation und verschiedene zweistufige Aktivierungs- und Substitutionsmethoden über Triflatund Methansulfonsäureester. Die besten Resultate wurden bei der Überführung der 2'-Desoxy-3'-xylo-nucleoside 100 und 101 in die entsprechenden 3'-Methansulfonsäureester und deren Reaktion mit Natriumazid in Pyridin bei erhöhter Temperatur erzielt. Die auf diese Weise erhaltenen 3'-Azidonucleoside 
wurden durch heterogen katalysierte Hydrierung $\left(\mathrm{H}_{2}, \mathrm{Pd} / \mathrm{C}, \mathrm{MeOH}\right)$ in die Zielverbindungen 91 und 92 überführt.

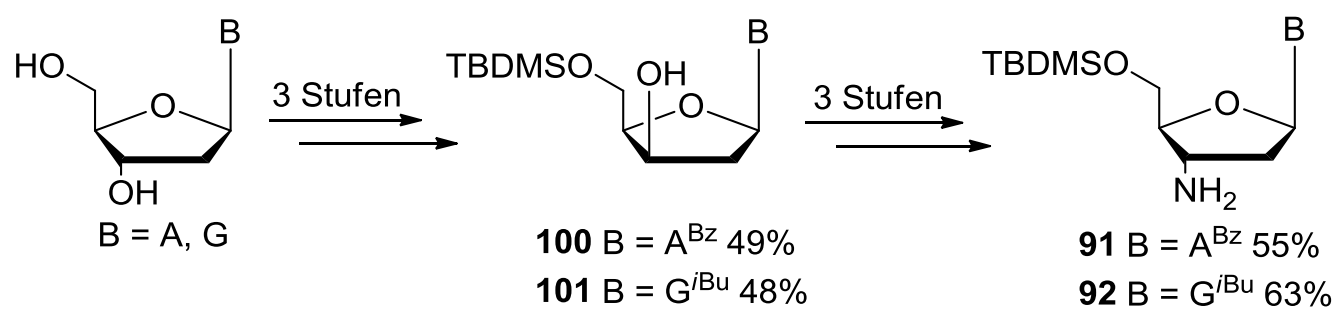

Abb. 5.5: Synthese der 2',3'-Didesoxy-3'-aminonucleoside 91 und 92.

Für die Synthese der polykationischen oligoNAA (Abb. 5.1) wurden die NAA-Derivate 104 konzipiert (Abb. 5.6), deren Verknüpfung zum Oligomer mittels Festphasengestützter Peptid-Synthese möglich sein sollte. Um die chemische Synthese dieser Bausteine zu verwirklichen, wurde die für NAA-Derivate etablierte Synthesemethode angewendet. ${ }^{[114,118]}$ Hierbei wurden unterschiedliche Syntheserouten untersucht, um auf möglichst effizientem Weg zu den Zielmolekülen (6'S)- und (6'R)-104 zu gelangen. Es wurden die vier Thymidinylaldehyde 105-108 synthetisiert und mit dem Phosphonat 109 in Wittig-Horner-Reaktionen umgesetzt. Unter den oft verwendeten Bedingungen der Wittig-Horner-Reaktion $\left(-70^{\circ} \mathrm{C}, \mathrm{KOtBu}\right.$, THF) konnte keine Reaktion zwischen dem einfachsten Aldehyd 105 und dem Phosphonat 109 nachgewiesen werden. Hingegen konnte im Fall des Derivats 106, dessen Nucleobase mit einer BOM-Schutzgruppe versehen war, die 5',6'-Didehydro-TAA (Z)-111 in einer guten Ausbeute (73\%) und hoher Diastereoselektivität $(Z / E=93: 7)$ erhalten werden. Die Reaktion der Basen-ungeschützten Verbindung 107 ergab ein ungefähr äquimolares Diastereomerengemisch von (Z)-112 und $(E)$-112 in einer Ausbeute von 68\%. Ein besseres Ergebnis wurde wiederum mit dem Basengeschützten Aldehyd 108 als Edukt erzielt. Die 5',6'-Didehydro-TAA (Z)-113 wurde mit mäßig hoher Diastereoselektivität $(Z / E=91: 9)$ und in einer Ausbeute von 68\% erhalten. Insgesamt erwies sich hier die Schützung der Nucleobase im Gegensatz zu den zuvor beschriebenen Synthesen der TAA 73 (Abb. 5.3) als unverzichtbar für ein brauchbares Reaktionsprodukt. Die zunächst nach empirischen Kriterien vorgenommene Zuordnung der Konfiguration der Doppelbindung der Verbindungen (Z)-111 und (Z)-113 konnte durch Befunde von ${ }^{1} \mathrm{H}$-NOE-Experimenten bestätigt werden. Die 5',6'-Doppelbindungen der 5',6'-Didehydro-TAA (Z)-111 und (Z)-113 wurden nachfolgend in Gegenwart der asymmetrischen Katalysatoren $(S, S)$ - oder $(R, R)$-Me-DuPHOS-Rh hydriert. 


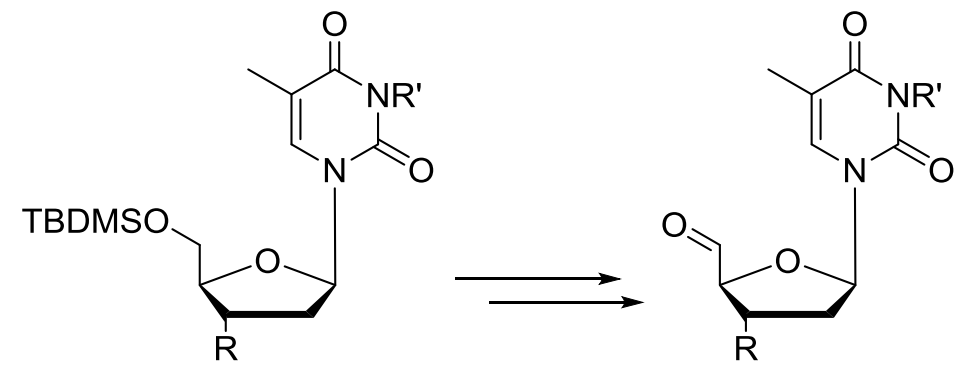
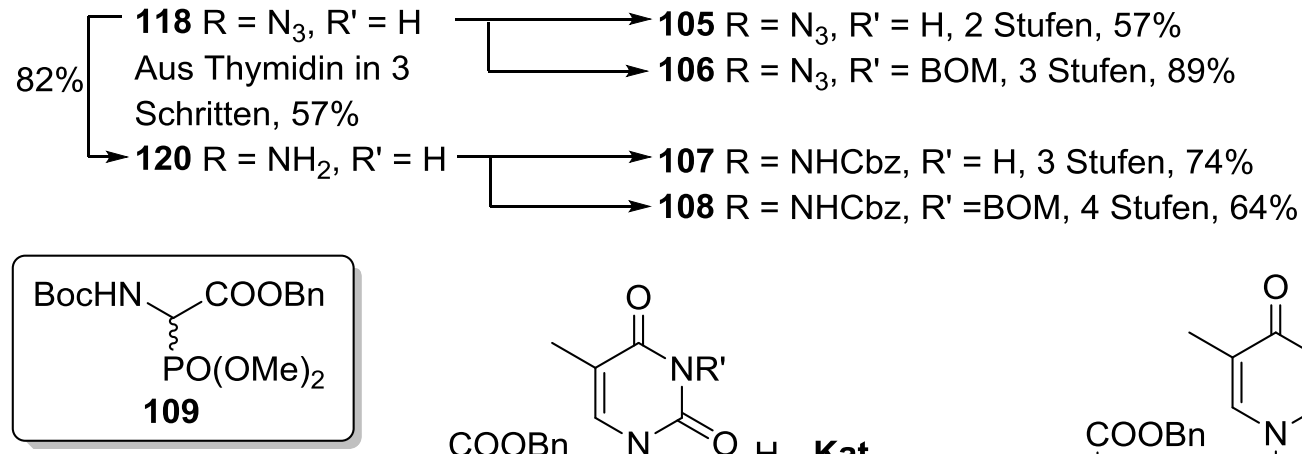

109, KOtBu, THF, $-70^{\circ} \mathrm{C} \rightarrow \mathrm{RT}, 16 \mathrm{~h}$

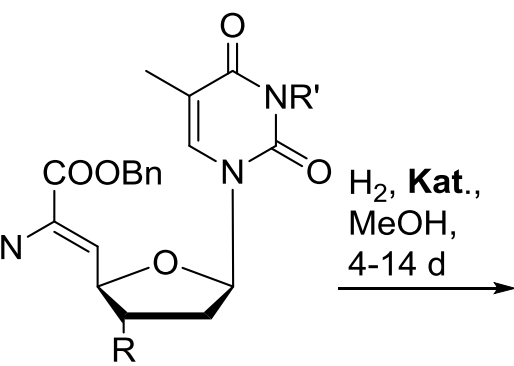

ZIE<smiles>[R]C1CC(n2cc(C)c(=O)[nH]c2=O)OC1C[C@H](NC(=O)OCc1ccccc1)C(=O)OCc1ccccc1</smiles>

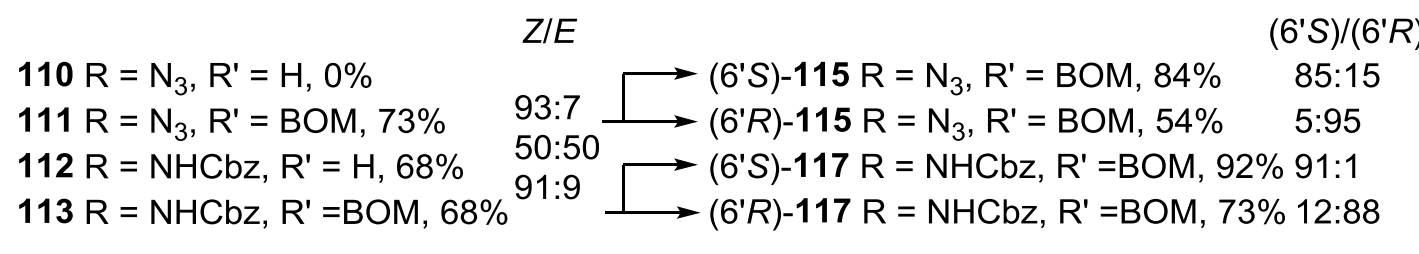

$(S, S)$-Kat.

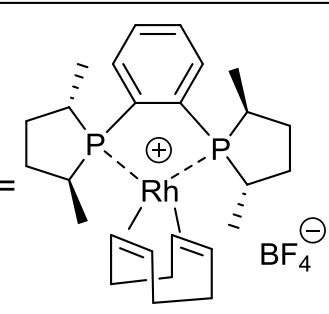

$(S, S)$-Me-DUPHOS-Rh
$(R, R)$-Kat. =

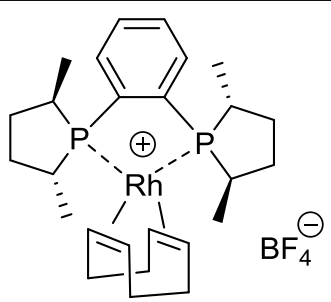

$(R, R)-\mathrm{Me}-\mathrm{DUPHOS}-\mathrm{Rh}$

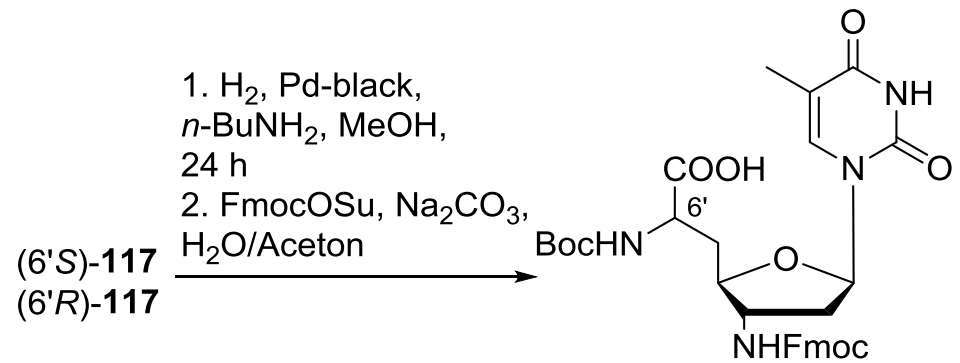

(6'S)-104 58\%

(6'R)-104 48\%

Abb. 5.6: Synthese der NAA (6'S)- und (6'R)-104.

Hinsichtlich der Reaktionsdauer wurden ähnliche Tendenzen beobachtet wie bei den Hydrierungen der Olefine (Z)-80 und (Z)-82. Unter Katalyse durch (S,S)-MeDuPHOS-Rh wurden die Produkte (6'S)-115 (d.r. = 85:15) und (6'S)-117 (d.r. = 91:9) 
in 4-7 Tagen erhalten. Deutlich längere Reaktionszeiten (14 Tage) wurden für die entsprechenden Reaktionen unter Katalyse durch $(R, R)$-Me-DuPHOS-Rh benötigt. Interessanterweise verlief die asymmetrische Hydrierung von (Z)-111 in Gegenwart des $(R, R)$-Me-DuPHOS-Rh-Katalysators mit deutlich höherer Diastereoselektivität ( $\left.6^{\prime} S / 6^{\prime} R=5: 95\right)$ als diejenige, die in Gegenwart des entgegengesetzt konfigurierten Katalysators (s. o.) geführt wurde. Insgesamt waren die Ergebnisse der asymmetrischen Hydrierungen von (Z)-111 und (Z)-113 sowohl hinsichtlich der Ausbeuten als auch der Diastereoselektivitäten ungünstiger als diejenigen der Olefine (Z)-80 und (Z)-82 (Abb. 5.3). Eine genaue Begründung für diese Beobachtungen konnte auf Basis der bisherigen Befunde nicht angegeben werden. Bemerkenswert ist jedoch, dass der am wenigsten sterisch anspruchsvolle Rest $\left(\mathrm{N}_{3}\right)$ in 3'-Position der 5',6'-Didehydro-TAA mit den kleinsten Ausbeuten und den geringsten Diastereoselektivitäten einherging. Die Verbindungen (6'S)-117 und (6'R)117 konnten durch HPLC an einer chiralen stationären Phase in sehr hoher Diastereomerenreinheit (d.r.>99:1) erhalten werden und wurden in zwei weiteren Reaktionsschritten in die Zielverbindungen (6'S)- und (6'R)-104 überführt. Zunächst wurden die Schutzgruppen $\mathrm{Cbz}, \mathrm{Bn}$ und $\mathrm{BOM}$ reduktiv gespalten, wobei der Reaktion wiederum $n$-Butylamin zugesetzt wurde, um eine Methylierung der entschützten 3'-Aminogruppe zu verhindern. Anschließend erfolgte die Einführung der FmocSchutzgruppe an der 3'-Aminofunktionalität. Die Verwendung der Bausteine (6'S)und (6'R)-104 in einer Oligopeptid-Synthese wird gegenwärtig in Kooperation mit Dr. T. Grossmann (CGC Dortmund) erprobt.

NAA-modifizierte Nucleinsäureanaloga wurden durch Festphasen-gestützte ONSynthese nach der Methode von Caruthers und Beaucage unter Verwendung der Phosphoramidit-Reagenzien (6'S)- und (6'R)-69 (Abb. 5.2) synthetisiert. ${ }^{[9]}$ Die Reaktivität der NAA-modifizierten Phosphoramidit-Reagenzien 69 erwies sich als geringer im Vergleich zu derjenigen von Phosphoramidit-Reagenzien kanonischer Nucleoside. Dies ging eindeutig aus den Daten des Trityl-Monitorings bei der ONSynthese und aus der Beobachtung von Abbruchfragmenten bei der Reinigung der ON mittels Gelelektrophorese hervor. Daher lagen die Ausbeuten an gereinigten ON im Bereich von 20-50\%, wobei die größeren Ausbeuteverluste bei Synthesen mehrfach NAA-modifizierter ON auftraten. Es wurden insgesamt 24 verschiedene NAA-modifizierte ON hergestellt (Tab. 1). Sämtliche NAA-modifizierte ON bildeten nachweislich Duplices mit komplementären DNA- und RNA-Sequenzen. In 
thermischen Denaturierungsexperimenten wiesen NAA-modifizierte Duplices je nach Position und Anzahl der Modifikationen Abweichungen im $\mathrm{T}_{\mathrm{m}}$-Wert von 0 bis $-4{ }^{\circ} \mathrm{C}$ pro Modifikation gegenüber unmodifizierten Referenz-Duplices auf.

\begin{tabular}{|c|c|c|c|}
\hline Nr. & Sequenz & Konfiguration von $\mathbf{x}$ & ON-Typ \\
\hline 1 & 5'-GGCACGG TxT TT TT TxT GGCACGG-3' & $S$ & ON a \\
\hline 2 & & $R$ & \\
\hline 3 & 5'-GGCACGG TxT TT TxT TT GGCACGG-3' & $s$ & \\
\hline 4 & & $R$ & \\
\hline 5 & 5'-GGCACGG TxT TxT TT TT GGCACGG-3' & $s$ & \\
\hline 6 & & $R$ & \\
\hline 7 & 5'-GGCACGG TxT TT TT TT GGCACGG-3' & $S$ & \\
\hline 8 & & $R$ & \\
\hline 9 & 5'-GGCACGG TxT TxT TxT TxT GGCACGG-3' & $s$ & \\
\hline 10 & & $R$ & \\
\hline 11 & 5'-G TxT GACG TT GACG TT GACG TT G-3' & $s$ & ON b \\
\hline 12 & & $R$ & \\
\hline 13 & 5'-G TT GACG TxT GACG TT GACG TT G-3' & $s$ & \\
\hline 14 & & $R$ & \\
\hline 15 & 5'-G TT GACG TT GACG TxT GACG TT G-3' & $s$ & \\
\hline 16 & & $R$ & \\
\hline 17 & 5'-G TT GACG TT GACG TT GACG TxT G-3' & $S$ & \\
\hline 18 & & $R$ & \\
\hline 19 & 5'-G TxT GACG TxT GACG TxT GACG TxT G-3' & $s$ & \\
\hline 20 & & $R$ & \\
\hline 21 & 5'-GCGC TxT GC TT AAGCAAGCGC-3' & $s$ & ON c \\
\hline 22 & & $R$ & \\
\hline 23 & 5'-GCGC TT GC TxT AAGCAAGCGC-3' & $s$ & \\
\hline 24 & & $R$ & \\
\hline
\end{tabular}

Die Destabilisierung der Nucleinsäure-Doppelstränge durch die NAA-Modifikation war im Fall von DNA/RNA-Duplices $\left(\Delta \mathrm{T}_{\mathrm{m}}=-0.3 \text { bis }-4.1\right)^{\circ} \mathrm{C} / \mathrm{Mod}$.) deutlich größer als bei DNA/DNA-Duplices $\left(\Delta \mathrm{T}_{\mathrm{m}}=+0.4 \text { bis }-2.2\right)^{\circ} \mathrm{C} / \mathrm{Mod}$.). Zudem wurden bei (6'S)-NAAmodifizierten Duplices häufig geringfügig höhere $\Delta T_{m} /$ Mod.-Werte als bei $\left(6^{\prime} R\right)$-NAAmodifizierten Duplices erhalten. Zwischen der Anzahl der NAA-Modifikationen und dem Ausmaß der Duplex-Destabilisierung wurde eine annähernd lineare Beziehung nachgewiesen. Der destabilisierende Effekt ist folglich nicht kooperativ. Der Abstand zweier NAA-Modifikationen innerhalb eines Stranges ( $O N$ a) oder auf gegenüber liegenden Strängen (ON c) wirkt sich gemäß der Resultate auf die DuplexDestabilisierung durch NAA-Modifikationen nicht signifikant aus. Ferner wurde bei 
DNA/RNA-Doppelsträngen vom Typ ON b eine Abhängigkeit der $\Delta T_{m}$-Werte von der Positionierung der Modifikation beobachtet. NAA-Modifikationen im Stranginneren bewirkten deutlich größere Duplex-Destabilisierungen $\left(\Delta \mathrm{T}_{\mathrm{m}}=-2.4 \text { bis }-3.7\right)^{\circ} \mathrm{C} / \mathrm{Mod}$.) als Modifikationen an den Strangenden $\left(\Delta \mathrm{T}_{\mathrm{m}}=-0.3 \text { bis }-1.5\right)^{\circ} \mathrm{C} / \mathrm{Mod}$.). Thermische Denaturierungsexperimente an NAA-modifizierten Duplices, die Fehlpaarungen enthielten, ergaben, dass NAA-modifizierte ON nur im Fall von T-G-Fehlpaarungen eine geringfügig höhere Mismatcherkennung aufweisen als unmodifizierte $O N$. Folglich werden die Geometrie und die inhärente Flexibilität von Nucleinsäuren nicht wesentlich gestört. Die Bestimmung von $\Delta T_{m}$-Werten bei erhöhten lonenstärken ergab nur geringfügige Unterschiede zwischen NAA-modifizierten und unmodifizierten Duplices bei einer $\mathrm{NaCl}$-Konzentration von $0.5 \mathrm{M}$. Etwas größere Unterschiede wurden bei einer $\mathrm{NaCl}$-Konzentration von 1.0 M beobachtet. Demnach nahm die Stabilität unmodifizierter Duplices zu höheren $\mathrm{NaCl}$-Konzentrationen hin um ca. 1.5 bis $3.0^{\circ} \mathrm{C}$ stärker zu als bei NAA-modifizierten Duplices. Dieser geringfügige Effekt kann auf den Einfluss der positiven Ladung der NAAModifikationen zurückgeführt werden. Der Vergleich von CD-Spektren NAAmodifizierter Duplices mit denjenigen unmodifizierter Duplices deutete ebenfalls auf keine signifikanten Veränderungen der typischen Geometrie von NucleinsäureDuplices hin. NAA-modifizierte DNA/DNA-Duplices und die entsprechenden unmodifizierten Duplices ergaben stets Spektren, die im Wesentlichen das typische B-Helix-Muster wiedergaben. Dagegen kann die Gestalt der CD-Spektren von NAAmodifizierten DNA/RNA-Duplices als Hinweis auf eine Zwischenform der A- und BHelix aufgefasst werden. Insgesamt deuten die beschriebenen Befunde der Analyse der NAA-Modifikation darauf hin, dass die Auswirkungen dieser Derivatisierung der Nucleinsäurestruktur auf deren chemische Eigenschaften als eher geringfügig einzustufen sind. Die beobachteten Effekte sind vornehmlich auf schwache geometrische Verzerrungen der Duplexstruktur durch die NAA-Modifikation zurückzuführen. Dabei sind NAA-Modifikationen in höherem Maße mit DNA/DNADuplices kompatibel als mit DNA/RNA-Duplices. Die Ladungskompensation durch die kationischen NAA-Einheiten hat offenbar keinen dominanten Einfluss auf die Eigenschaften der Nucleinsäure-Duplices. Diese Befunde bestätigen nicht die Hypothese von Benner, derzufolge die polyanionische Beschaffenheit für deren physikochemische Eigenschaften (Watson-Crick-Hybridisierung, SequenzUnabhängigkeit der physikalischen Eigenschaften, Eignung zur Funktion als Templat) notwendig ist. ${ }^{[23]}$ 


\section{Ausblick}

Die nächste unmittelbar bevorstehende Aufgabe ist die Synthese der Phosphoramidit-Bausteine 87-89 aus den bereits in der Arbeit beschriebenen Vorstufen 150-152. Diese Phosphoramidit-Reagenzien sollen die Synthese weiterer NAA-modifizierter ON mit NAA-Modifikationen an anderen Positionen als zwischen zwei Thymidin-Einheiten ermöglichen. Die Untersuchung solcher ON kann zu einem umfassenden Verständnis der Auswirkung von NAA-Modifikationen auf Nucleinsäure-Eigenschaften führen. Um eine Vergleichbarkeit mit bisher untersuchten Duplices zu gewährleisten, können NAA-modifizierte ON von ähnlichem Muster hergestellt werden. Eine Möglichkeit besteht in der Herstellung von Sequenzen des Typs ON 25, die anstelle der acht Thymidin-Einheiten vier aufeinander folgende AT-Dimere aufweisen (Abb. 6.1). Als ein weiterer Typ von ON wäre die biologisch relevante gemischte Sequenz ON 26 von Interesse, die zur micro-RNA 106b komplementär ist. MiR 106b wird in vielen Typen von Tumorzellen überexprimiert und mit der Proliferation maligner Zellen in Verbindung gebracht. ${ }^{[186]}$

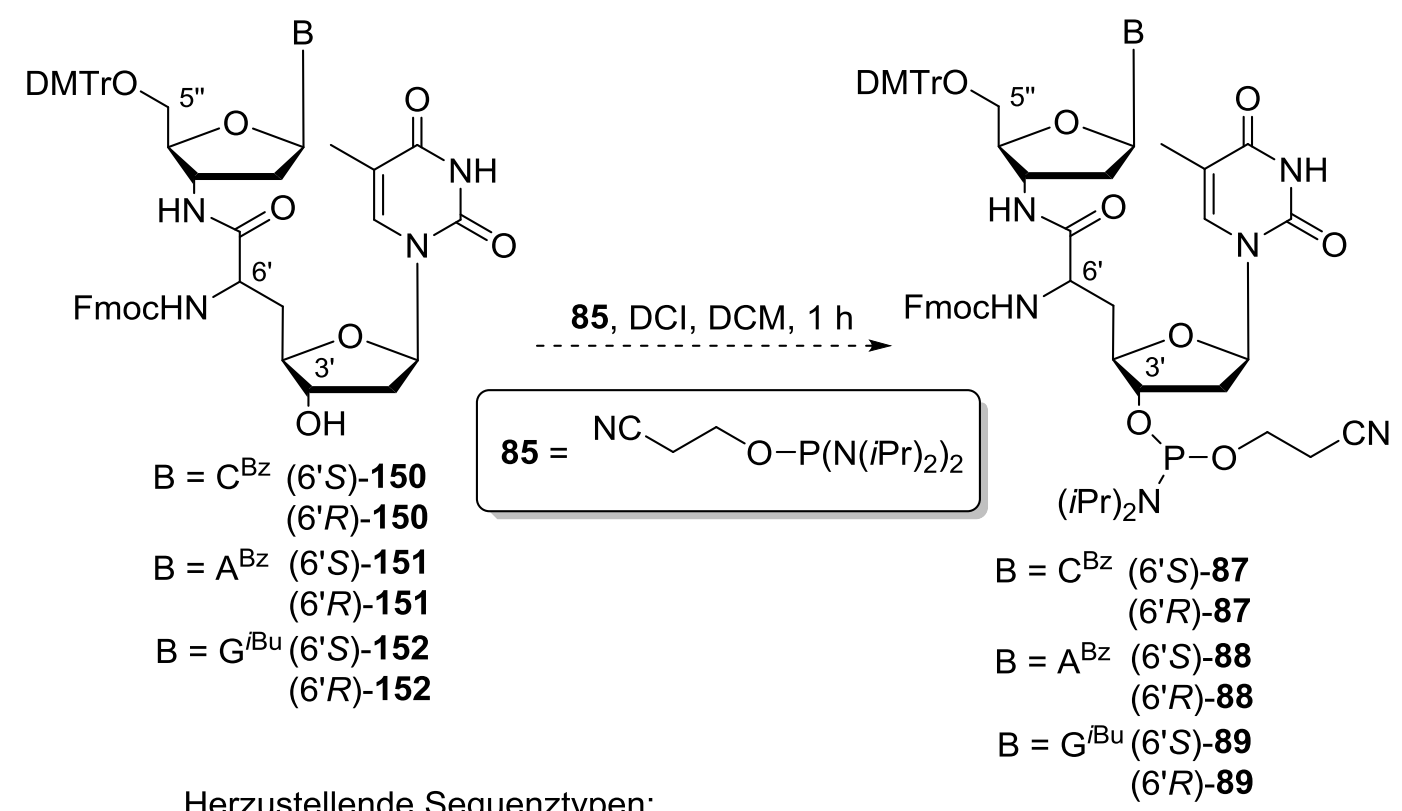

Herzustellende Sequenztypen:

ON-Synthese

ON 26 5'-ATCTGCACTGTCAGCACTTTA-3'

AT, CT, GT, TT = Mögliche Positionen für Modifikationen

Abb. 6.1: Geplante Synthese weiterer Phosphoamidit-Reagenzien 87-89 und ON 25 und 26. 
Daher könnten NAA-modifizierte ON 26 auch über die biophysikalischen Untersuchungen hinaus auf ihre biologische Wirksamkeit hin getestet werden. Mit den Bausteinen 87-89 wären zahlreiche Substitutionsmuster innerhalb der ON 26 möglich. Auf diese Weise könnten bei nachgewiesener biologischer Wirksamkeit NAA-modifizierter ON Optimierungsstudien durchgeführt werden. Weitere biophysikalische Untersuchungen, die an NAA-modifizierten ON durchgeführt werden könnten, wären Denaturierungsexperimente bei niedrigeren $\mathrm{NaCl}$-Konzentrationen als der Standard-Konzentration von 0.15 M. Dies wäre von Interesse, da bei einigen DNA- oder RNA-Duplices zwitterionischer oder polykationischer ON bei geringerer Ionenstärke höhere Stabilitäten beobachtet wurden als bei unmodifizierten Nucleinsäure-Doppelsträngen. ${ }^{[112]}$ Die Synthese der Vorstufen 150-152 der Bausteine 87-89 ist hinsichtlich eines Reaktionsschritts verbesserungswürdig. Die Ausbeuten der zweifachen Silylspaltung von 93-95 waren in den meisten Fällen nicht zufriedenstellend. Möglicherweise lohnt es sich, die Spaltung unter den Bedingungen der RNA-Entschützung (reines $\mathrm{NEt}_{3} \cdot 3 \mathrm{HF}$ ) auszuprobieren (Abb. 6.2). ${ }^{[175]}$ Die Schwierigkeit für ausgedehnte Optimierungsstudien dieser Reaktion stellt das nur unter hohem Aufwand verfügbare Ausgangsmaterial 93-95 dar.
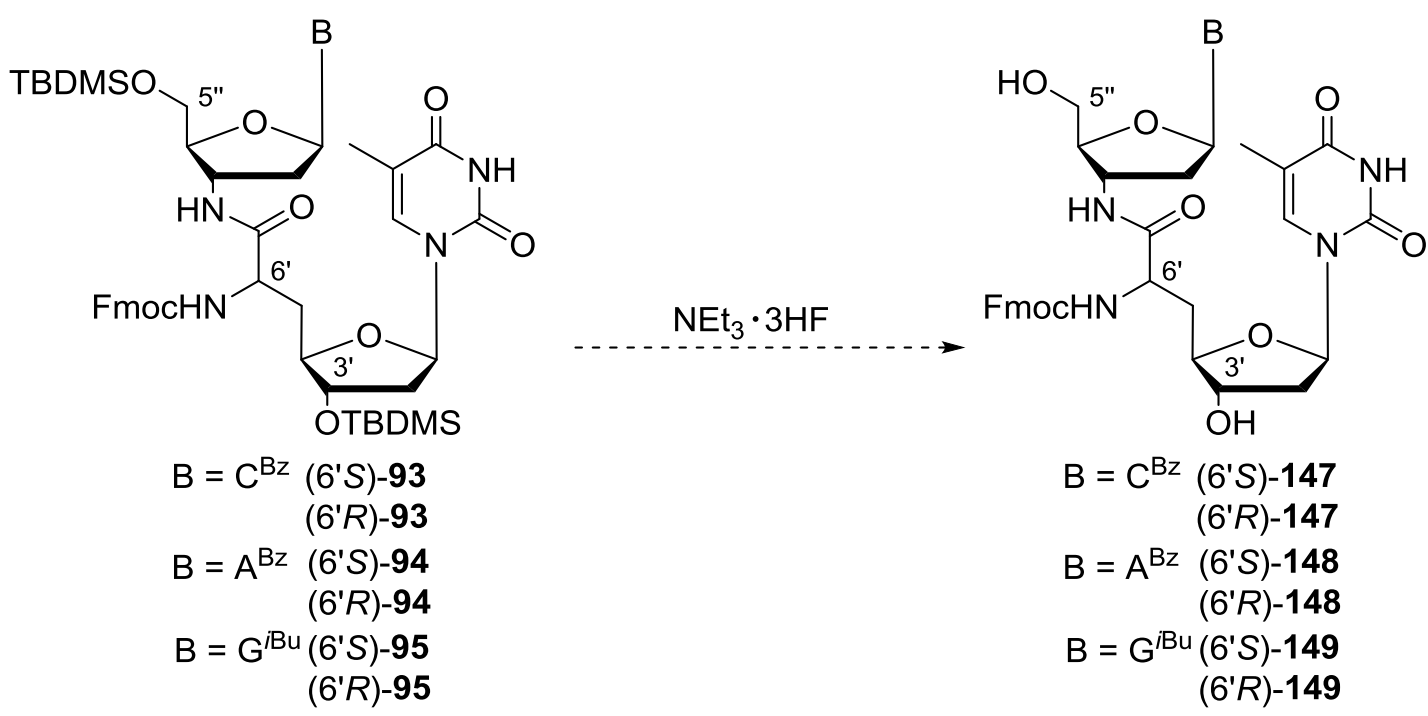

Abb. 6.2: Alternative Methode zur Herstellung der Verbindungen 147-149.

Über die in dieser Arbeit untersuchte Fragestellung (Auswirkung des gemischten Ladungsmusters auf die Eigenschaften von Nucleinsäuren) hinaus können NAAModifikationen auch in einem eher anwendungsorientierten Kontext Verwendung finden. Nach der Synthese von NAA-modifizieren ON besteht die Möglichkeit, die primäre Aminogruppe noch vor der Abspaltung der ON vom Träger selektiv zu entschützen (z. B. mit DBU in DMF) und nachfolgend zu derivatisieren. Diese 
Methode kann für die postsynthetische Einführung von Fluorophoren am Rückgrat von ON eingesetzt werden (Abb. 6.3). Eine Möglichkeit besteht darin, über eine reduktive Aminierung mit 4-Pentinal eine Alkinyl-Funktionalität einzuführen, die in einem weiteren Reaktionsschritt durch eine Kupfer(I)-katalysierte HuisgenCycloaddition $^{[187]}$ (CuAAC, Click-Reaktion) mit einem fluoreszierenden Azid derivatisiert werden kann.

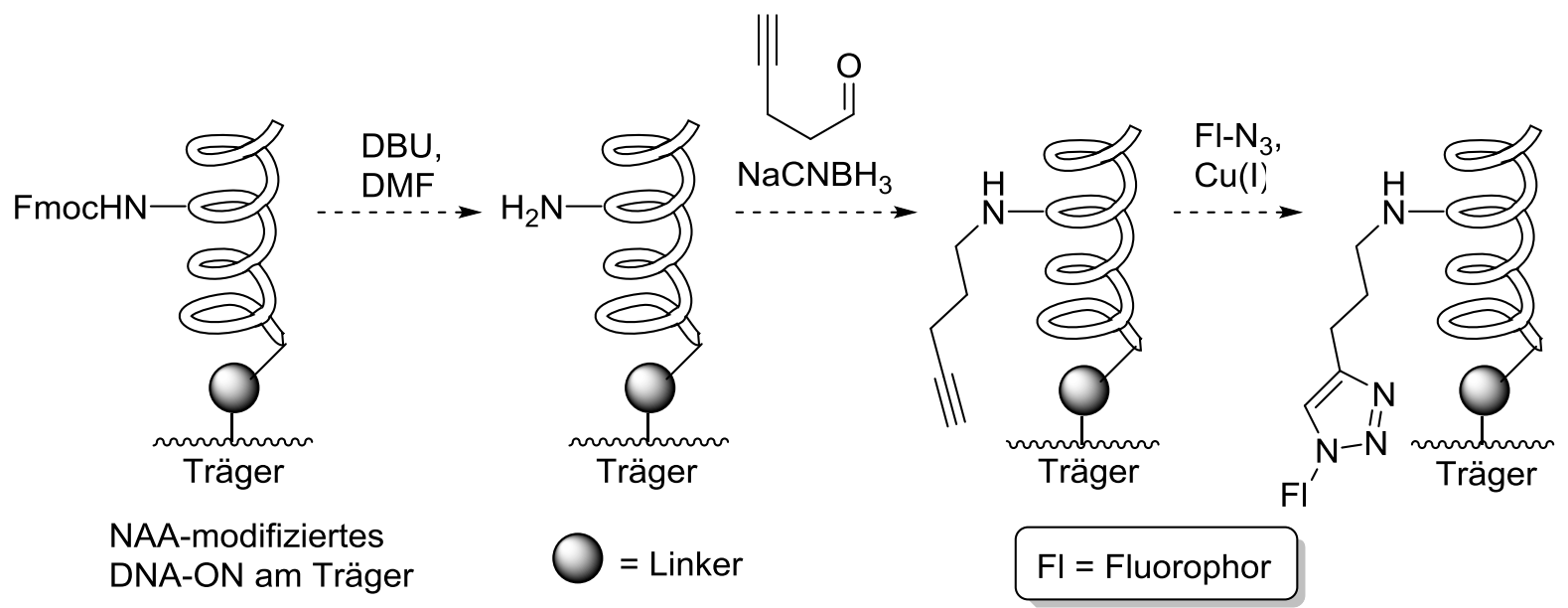

Abb. 6.3: Geplante dreistufige postsynthetische Fluoreszenzmarkierung von DNA.

Für die im Rahmen des thematisch verwandten Projekts hergestellten NAABausteine 104 ist die Verwendung zur Synthese oligokationischer NucleinsäureAnaloga (oligoNAA) durch Festphasen-gestützte Oligopeptidsynthese vorgesehen (Abb. 6.4).
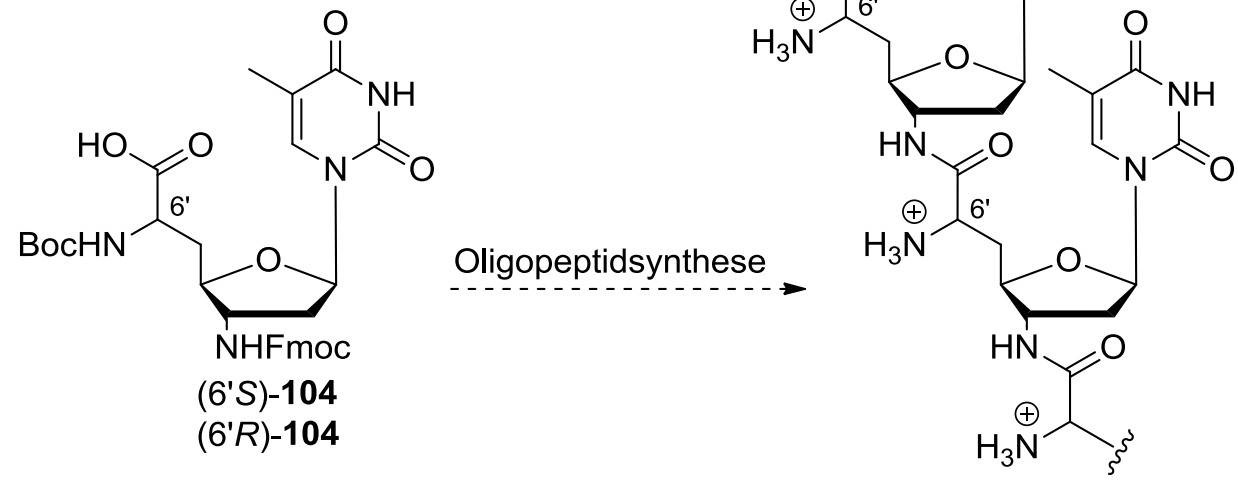

oligoNAA

Abb. 6.4: Geplante Synthese der polykationischen oligoNAA. 
Dabei sollen zunächst nur 14 mere oder 16 mere oligo-T-Sequenzen synthetisiert werden, da bisher nur Bausteine mit Thymin als Nucleobase synthetisch zugänglich sind. Die Oligomere sollen anhand der üblichen Methoden ( $T_{m}$-Experimente, $C D$ Spektroskopie) auf ihre biophysikalischen Eigenschaften hin untersucht werden. Im Gegensatz zur Synthese der NAA-Bausteine 75, 150-152 für den Aufbau zwitterionischer ON, die bis auf eine problematische Reaktion (Abb. 5.2) zuverlässig und in guten Ausbeuten verläuft, bedarf die Synthese der NAA-Bausteine 104 für den Aufbau oligokationischer Nucleinsäure-Analoga einer umfangreicheren Optimierung. Sowohl die Wittig-Horner-Reaktion zu den 5',6'-Didehydro-TAA 111 und 113 als auch die nachfolgenden asymmetrischen Hydrierungen gingen mit nur mäßig hoher Diastereoselektivität und verbesserungswürdigen Ausbeuten einher (Abb. 5.6). Die mäßig hohe Diastereoselektivität der asymmetrischen Hydrierungen von (Z)-113 hatte zur Folge, dass die NAA (6'S)- und (6'R)-117 nur durch sehr aufwendige chromatographische Reinigung (chirale HPLC) diastereomerenrein erhalten werden konnten. Bei der Wittig-Horner-Reaktion zu (Z)-111 oder (Z)-113 könnten verschiedene Basen anstelle von $\mathrm{KO}$ tBu oder alternative Lösungsmittel anstelle von THF eingesetzt werden. Eine Verbesserung der Ergebnisse der asymmetrischen Hydrierung könnte durch den Einsatz anderer Katalysatoren als $(S, S)$ - oder $(R, R)$ Me-DuPHOS-Rh resultieren. Weitere Möglichkeiten zur Realisierung einer diastereoselektiven Synthese der Verbindungen (6'S)- und (6'R)-104 bieten alternative Synthesestrategien (Abb. 6.5). So kann der Versuch unternommen werden, die Wittig-Horner-Reaktion und die asymmetrische Hydrierung ausgehend von dem tricyclischen Aldehyd 163 durchzuführen, welcher aus der bekannten Verbindung 136 leicht hergestellt werden kann. Danach wäre die Einführung der Azidfunktionalität in 3'-Position von (6'S)- bzw. (6'R)-164 und deren Reduktion zu einer Aminogruppe möglich. Auch eine Transformation der NAA 165 in die Verbindungen (6'S)- und (6'R)-104 über die cyclisierten NAA-Derivate 164 ist denkbar. Die NAA 83 (Abb. 5.3), an deren 3'-Position sich ebenfalls eine OTBDMSGruppe befindet, gingen ja stets in hoher Diastereoselektivität aus der Synthese hervor. Daher wäre die Erwartung, dass die auf ähnlichem Wege erhältlichen NAA 165 in vergleichbar hoher Diastereoselektivität dargestellt werden können, durchaus naheliegend. 
<smiles>Cc1cn2c(nc1=O)OC1CC(C2)[C@@H]2CO[C@@H]1O2</smiles>

136

1. Desilylierung

2. Oxidation<smiles></smiles>

163

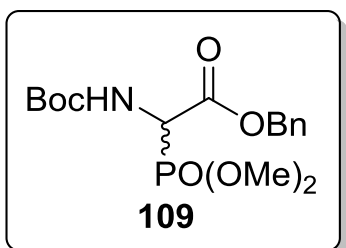

109

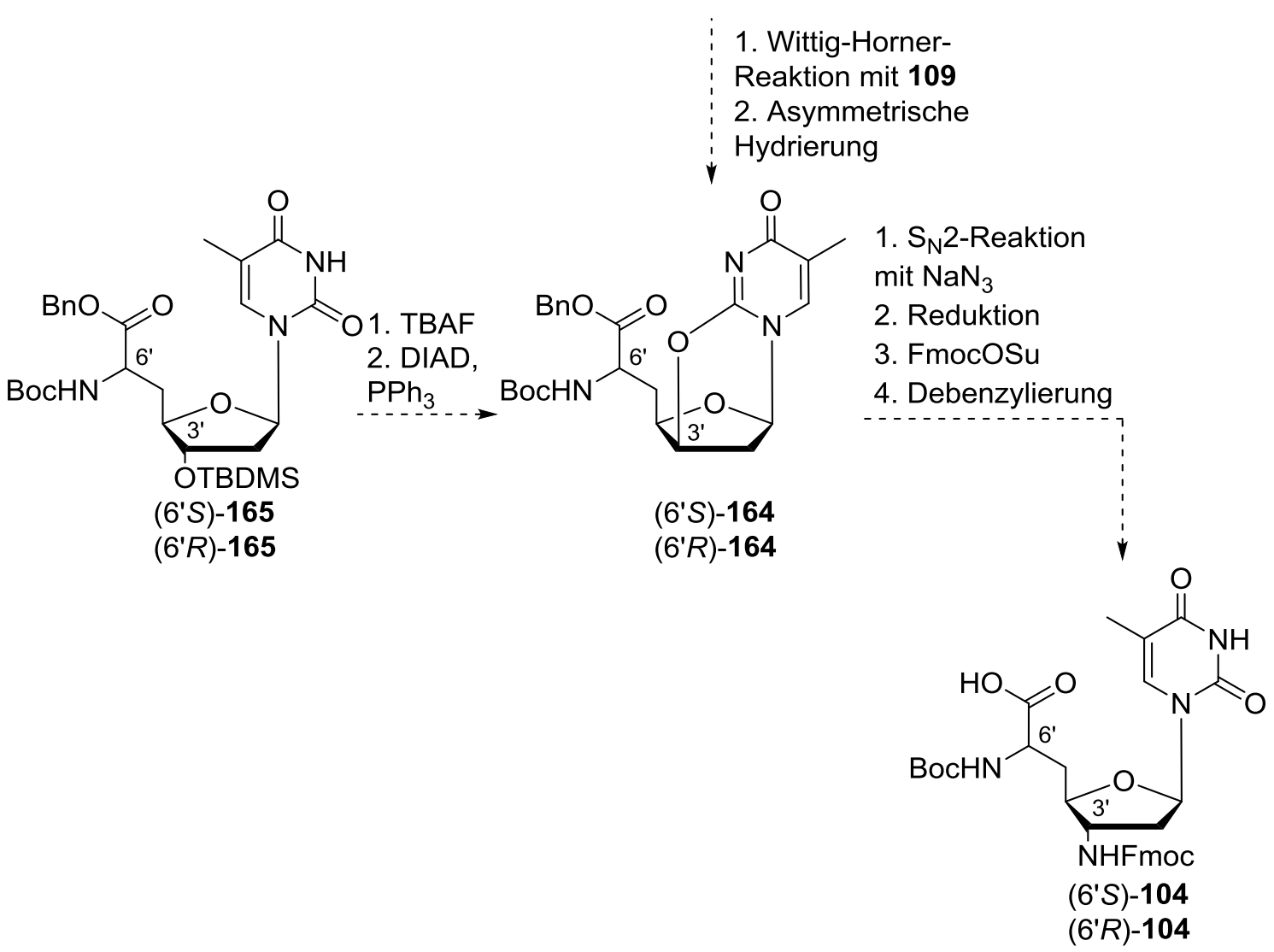

Abb. 6.5: Alternative Syntheserouten zu den Verbindungen (6'S)- und (6'R)-104.

Unter Verwendung der Bausteine 104 ist nur die Synthese von oliogo-T-Sequenzen möglich. Ein prinzipielles Fernziel ist aber auch die Synthese von oligokationischen gemischten Sequenzen. Dazu wäre der synthetische Zugang zu analogen Bausteinen zu den Verbindungen $\mathbf{1 0 4}$ mit anderen Nucleobasen anstelle von Thymin notwendig. Auch zu diesem Zweck könnten die in Abb. 6.5 angeführten Syntheserouten nützlich sein, da bisherige Versuche zur Synthese von NAA mit anderen Nucleobasen als Thymin oder Uracil erfolglos verlaufen sind..$^{[126-127]}$

Die bisherigen Ausführungen beschränken sich auf die Einführung von NAAModifikationen in DNA-Sequenzen. Es ist jedoch naheliegend, dieses Konzept auch zur Modifikation von RNA zu verwenden. Dies könnte insbesondere für die Synthese modifizierter doppelsträngiger (small interfering)siRNA von Interesse sein, da auf 
diese Weise Wirkstoffe entwickelt werden könnten, die für eine effektive Inhibierung der Translation pathogener Proteine durch RISC-vermittelte Spaltung entsprechender mRNA-Moleküle verwendbar wären (sog. RNA-Interferenz). Für die Synthese von NAA-modifizierten RNA-Sequenzen könnte eine Monomer-basierte Strategie eingesetzt werden. Für diese Vorgehensweise ist die inverse Synthese der RNA-Stränge (5'-3' anstelle von 3'-5') vorgesehen, da die Einführung der NAAModifikation an verschiedenen Positionen der jeweiligen Sequenzen am Synthesizer erfolgen soll. Die Einführung der NAA-Modifikation könnte durch Reaktion eines Überschusses einer aktivierten NAA mit einem 3'-terminalen 3'-Aminonucleotid erfolgen. Die beschriebene Strategie ist exemplarisch in Abb. 6.6 veranschulicht.

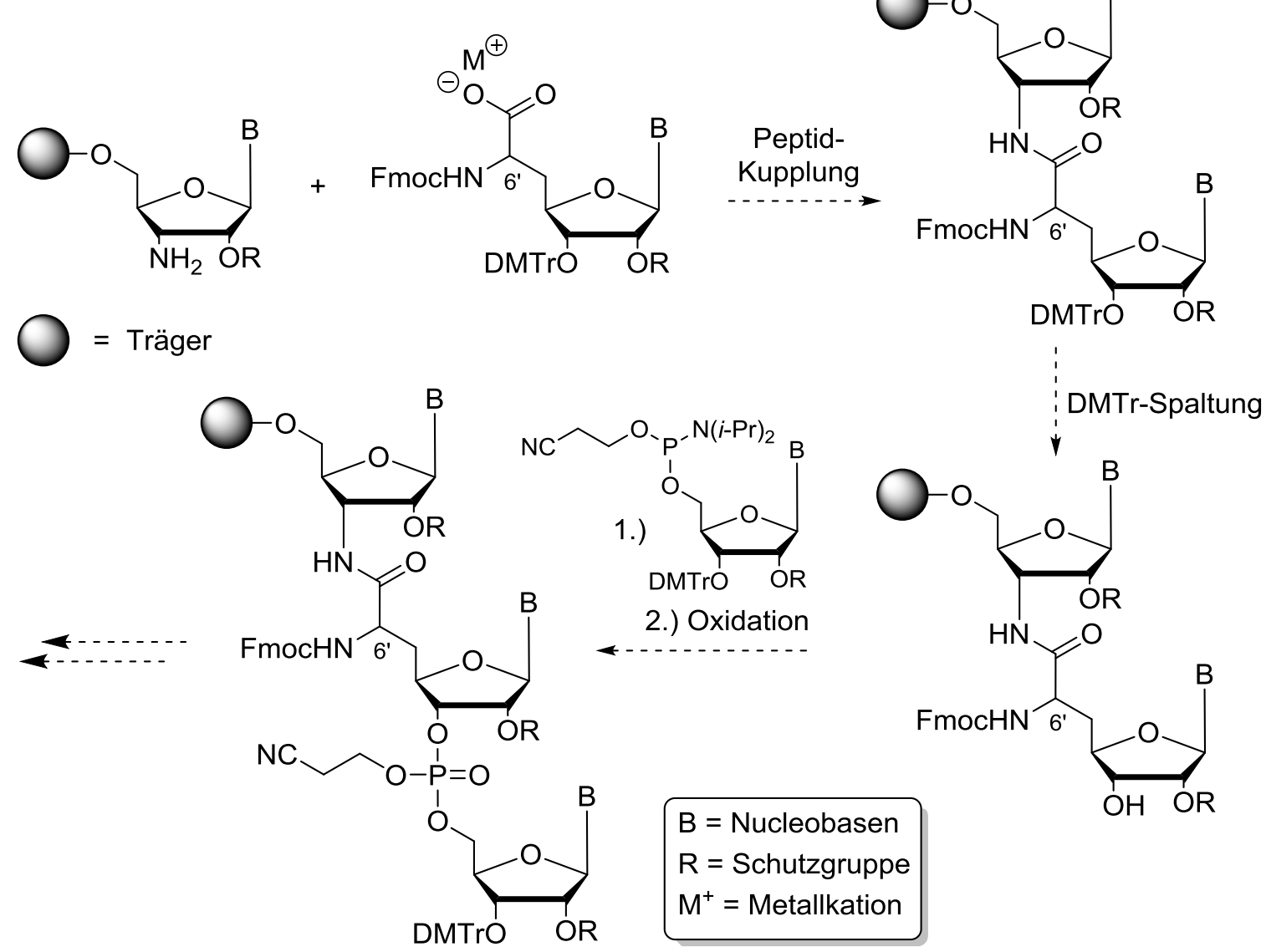

Abb. 6.6: Monomer-basierte Strategie zur Synthese NAA-modifizierter RNA.

Sollten die erhaltenen partiell zwitterionischen RNAs in der Lage sein, RNAInterferenz zu bewirken, so könnte die reduzierte negative Gesamtladung der modifizierten siRNAs zu einer verbesserten Zellaufnahme und erhöhten Stabilität dieser Agentien beitragen. 


\section{Experimentalteil}

\subsection{Allgemeines}

\subsubsection{Präparative Methoden}

Alle Reaktionen wurden, soweit nicht anders vermerkt, in mehrfach ausgeheizten Glasapparaturen unter Verwendung der Schlenktechnik durchgeführt. Als Inertgas diente über Phosphorpentoxid getrocknetes Argon. Zur Reaktionsführung bei tiefen Temperaturen wurden geeignete Kältemischungen $(\mathrm{NaCl}$ in Eis/Wasser, Trockeneis/Aceton, Trockeneis/Isopropanol, Aceton/flüssiger Stickstoff) oder ein Kryostat verwendet.

Die Oligonucleotidsynthesen wurden im Arbeitskreis Höbartner am Max-PlanckInstitut (MPI) für Biophysikalische Chemie Göttingen und im Arbeitskreis Diederichsen am Institut für Organische und Biomolekulare Chemie der GeorgAugust-Universität Göttingen durchgeführt. Es wurde der Synthesizer Gene Assembler Plus von der Firma Pharmacia LKB bzw. der Synthesizer H-8 von der Firma $K \& A$ verwendet.

\subsubsection{Edukte und Reagenzien}

Die verwendeten Reagenzien und Edukte wurden, sofern nicht anders angegeben, von den Firmen ABCR, Acros Organics, Alfa Aesar, Fluka, Bachem AG, GL Biochem, Merck, Roth, Sigma Aldrich, Sigma Proligo und VWR in Synthesequalität bezogen und ohne weitere Reinigung eingesetzt. Nucleoside wurden von der Firma ChemGenes bezogen. Die zur Oligonucleotidsynthese verwendete Polystyrolmatrix wurde von der Firma GE Healthcare bezogen. Das alternativ verwendete CPG wurde von der Firma Biosearch Technologies bezogen. Rhodium-haltige Katalysatoren mit chiralen Liganden wurden von der Firma Strem bezogen.

Triethylamin (NEt 3 ): $\mathrm{NEt}_{3}$ (Reinheitsgrad: „zur Analyse“) wurde entgast und über Molekularsieb (4 Å) aufbewahrt.

Unmodifizierte Oligonucleotide: wurden von der Firma Sigma-Aldrich bezogen. 


\subsubsection{Lösungsmittel}

Die folgenden Lösungsmittel wurden in technischer Qualität bezogen und vor ihrer Verwendung für Reaktionen ohne Inertgasbedingungen und Chromatographie wie folgt gereinigt:

Dichlormethan: destilliert.

Diethylether: $\quad$ über Kaliumhydroxid getrocknet und destilliert.

Ethylacetat: destilliert.

Petrolether 35/70 (PE): destilliert.

Andere Lösungsmittel wurden mit dem Reinheitsgrad "zur Analyse“ bezogen und ohne weitere Reinigung eingesetzt. Für sämtliche Analysen (HPLC, UV-Messung) der Oligonucleotide wurde Wasser von sehr hoher Reinheit verwendet (18 $\mathrm{M} \Omega / \mathrm{cm})$.

\subsubsection{Absolute Lösungsmittel}

Für Reaktionen unter Inertatmosphäre wurden absolute Lösungsmittel verwendet. Hierfür wurden die bezogenen Lösungsmittel durch die folgenden Verfahren (Reinheitsgrad: „zur Analyse“ oder „technische Qualität“) gereinigt:

Acetonitril: mehrere Tage in einer Argonatmosphäre über Phosphorpentoxid unter Rückfluss getrocknet, destilliert und über Molsieb (3 $\AA$ ) aufbewahrt.

Chloroform: $\quad$ über Molsieb $(4 \AA)$ getrocknet und aufbewahrt.

Dichlormethan: in einer Argonatmosphäre unter Rückfluss über Calciumhydrid getrocknet, destilliert und über Molsieb (4 Å) aufbewahrt.

N,N-Dimethylformamid: über Molsieb (4 $\AA$ ) getrocknet und aufbewahrt.

Methanol: entgast, über Molsieb (4 $\AA$ ) getrocknet und aufbewahrt.

Pyridin: in einer Argonatmosphäre unter Rückfluss über Calciumhydrid getrocknet, destilliert und über Molsieb (4 Å) aufbewahrt. 
Tetrahydrofuran: $\quad$ in einer Argonatmosphäre unter Rückfluss über Natrium mit Benzophenon als Indikator getrocknet, destilliert und über Molsieb (4 ̊) aufbewahrt.

Toluol: in einer Argonatmsphäre unter Rückfluss über Natrium mit Benzophenon als Indikator getrocknet, destilliert und über Molsieb (4 ̊̊) aufbewahrt.

\subsubsection{Chromatographie}

\section{Dünnschichtchromatographie}

Zur Detektion und Reaktionskontrolle wurden Kieselgel-beschichtete Aluminiumplatten $60 \mathrm{~F}_{254}$ mit Fluoreszenzindikator der Firma $V W R$ verwendet. Die Laufstrecke betrug ungefähr $3 \mathrm{~cm}$. UV-aktive Substanzen wurden unter Verwendung einer UVLampe bei einer Wellenlänge von $254 \mathrm{~nm}$ detektiert. Des Weiteren wurden eine Vanillin-Schwefelsäure-Lösung ( $4 \mathrm{~g}$ Vanillin, $25 \mathrm{~mL}$ konz. $\mathrm{H}_{2} \mathrm{SO}_{4}, 80 \mathrm{~mL} \mathrm{AcOH}$, $680 \mathrm{~mL} \mathrm{MeOH}$ ) und eine Ninhydrin-Lösung (100 mL Butanol, $3 \mathrm{~mL} \mathrm{AcOH}, 0.3 \mathrm{~g}$ Ninhydrin) und Kaliumpermanganat-Lösung (2 $\mathrm{g}$ Kaliumpermanganat, $3 \mathrm{~mL} 5 \%$ ige Natriumhydroxidlösung, $12 \mathrm{~g}$ Natriumcarbonat, $200 \mathrm{~mL}$ Wasser) als Anfärbereagenzien zur Detektion verwendet. Die $R_{\mathrm{f}}$-Werte wurden bei Kammersättigung bestimmt.

\section{Säulenchromatographie}

Für chromatographische Trennungen wurde von der Firma VWR bezogenes Kieselgel (Korngröße 40-63 $\mu \mathrm{m}$ ) verwendet.

\section{Reverse Phase (RP)-Säulenchromatographie}

Für Trennungen von Substanzgemischen durch RP-Säulenchromatographie wurde RP-Kieselgel $90 \mathrm{C}_{18}(0.040-0.063 \mathrm{~nm}$, Fluka) verwendet. 


\subsubsection{Instrumentelle Analytik}

\subsubsection{Polarimetrie}

Drehwertmessungen wurden an einem Polarimeter (Modell 241) der Firma PerkinElmer durchgeführt. Als Lösungsmittel wurden Chloroform (Reinheitsgrad: „zur Analyse“) oder Pyridin (Reinheitsgrad: „zur Analyse“) verwendet, wobei jeweils ungefähr $10 \mathrm{mg}$ der zu analysierenden Substanz in genau $1 \mathrm{~mL}$ Lösungsmittel gelöst wurden. Die Konzentration ist in $\mathrm{g} / 100 \mathrm{~mL}$ angegeben. Alle Drehwerte wurden bei $20^{\circ} \mathrm{C}$ mit einer Natriumdampflampe (D-Linie $\lambda \approx 589 \mathrm{~nm}$ ) gemessen.

\subsubsection{IR-Spektroskopie}

IR-Spektren wurden an einem IR-Spektrometer Modell Vector 22 der Firma Bruker, einem FT-IR-Spektrometer 4100 der Firma Jasco mit einer integrierten GladiATR ${ }^{\circledR}$ ATR (Attentuated Transmission Reflection)-Einheit der Firma PIKE Technologies oder einem IR-Spektrometer Vertex 70 der Firma Bruker mit einer Platinum ATREinheit aufgenommen. Je nach verwendetem Spektrometer wurden flüssige Substanzen als Film zwischen zwei $\mathrm{NaCl}$-Platten und Feststoffe als KBr-Presslinge oder direkt an der ATR-Einheit gemessen. Angegeben sind jeweils die zugehörigen Wellenzahlen $\tilde{v}\left[\mathrm{~cm}^{-1}\right]$ zu den neun Banden mit den stärksten Absorptionsintensitäten. Die Kalibrierung der FTIR-Spektren erfolgte über die Polystyrolbande bei $1601 \mathrm{~cm}^{-1}$.

\subsubsection{UV-Spektroskopie}

UV-Spektren von Oligonucleotidlösungen wurden an dem Gerät Cary 100 Bio der Firma Varian aufgenommen. Für die Aufnahme von UV-Spektren von ON wurde ein Wellenlängenbereich $\Delta \lambda$ von 320 bis $190 \mathrm{~nm}$ gewählt. Die ON-Konzentration lag bei ca. $2.0 \mu \mathrm{M}$. Für andere Substanzen wurden UV-Spektren mit einem UVSpektrometer (Modell: Lambda 2) der Firma Perkin-Elmer aufgenommen. Bei den Messungen wurden ungefähr $0.1 \mathrm{mg}$ der zu analysierenden Substanz in $10 \mathrm{~mL}$ Acetonitril (Reinheitsgrad: „für UV-Spektroskopie“) gelöst. Alle UV-Messungen erfolgten in einem Wellenlängenbereich $\Delta \lambda$ von 500 bis $190 \mathrm{~nm}$. Angegeben sind die 
Wellenlängen der Absorptionsmaxima $\lambda_{\max }$ in $\mathrm{nm}$ mit den dazugehörigen molaren Extinktionskoeffizienten $\varepsilon[\mathrm{L} /(\mathrm{mol} \cdot \mathrm{cm})]$. Für eine bessere Übersichtlichkeit sind die Werte von $\varepsilon$ als dekadische Logarithmen $\lg \varepsilon$ angegeben.

\subsubsection{Aufnahme der Duplex-Schmelzkurven}

Schmelzkurven wurden am MPI für Biophysikalische Chemie an dem Gerät Cary 100 Bio von der Firma Varian aufgenommen. Die Aufheizgeschwindigkeit der Proben betrug $0.7^{\circ} \mathrm{C} / \mathrm{min}$. Es wurden für jede Probe jeweils fünf Schmelzkurven (3 Aufwärmund 2 Abkühlkurven) bei den Wellenlängen $\lambda=250,260,270,280 \mathrm{~nm}$ aufgezeichnet. Die Werte der zwei Abkühlkurven wurden zur Schmelzpunktbestimmung herangezogen. Die Messungen erfolgten in einer auf $\mathrm{pH}=7$ gepufferten, wässrigen, mit Paraffinöl überschichteten (ca. 3-5 mm) Lösung (10 mM NaH${ }_{2} \mathrm{PO}_{4} / \mathrm{Na}_{2} \mathrm{HPO}_{4}$ 1:1, $150 \mathrm{mM} \mathrm{NaCl}$ ). Die Oligonucleotid-Konzentration der Proben betrug 2.0 $\mu \mathrm{M}$. Das Probenvolumen betrug $450 \mu \mathrm{L}$.

\subsubsection{Circulardichroismus-(CD)-Messung}

Die Aufnahme der CD-Spektren erfolgte an dem Gerät Chirascan von der Firma Applied Photophysics am MPI für Biophysikalische Chemie Göttingen. Für die Aufnahme der Spektren wurde der Wellenlängenbereich von 200 bis $320 \mathrm{~nm}$ gewählt. Die Zusammensetzung der Proben entsprach derjenigen, die für die Bestimmung der Schmelzpunkte beschrieben ist. Die Messungen erfolgten bei einer Temperatur von $25^{\circ} \mathrm{C}$. Die Datenpunkte wurden in einem Abstand von $0.5 \mathrm{~nm}$ aufgenommen. Der Zeitliche Abstand zwischen zwei Messungen betrug $2 \mathrm{~s}$. Für jede Probe wurden drei CD-Spektren aufgenommen und die Ordinatenwerte gemittelt. Bei allen Spektren wurde eine Hintergrundkorrektur durchgeführt.

\subsubsection{Kernresonanzspektroskopie (NMR)}

Die NMR-Spektren wurden in der NMR-Abteilung des Instituts für Organische und Biomolekulare Chemie der Georg-August-Universität Göttingen an den Geräten Mercury-300 ( ${ }^{1} \mathrm{H}-\mathrm{NMR}: 300 \mathrm{MHz},{ }^{13} \mathrm{C}-\mathrm{NMR}$ : $75 \mathrm{MHz},{ }^{31} \mathrm{P}-\mathrm{NMR}$ : $121 \mathrm{MHz}$ ), Unity-300 
( ${ }^{1} \mathrm{H}-N M R: 300 \mathrm{MHz},{ }^{13} \mathrm{C}-\mathrm{NMR}: 76 \mathrm{MHz}$ ), Inova-500 ( ${ }^{1} \mathrm{H}-\mathrm{NMR}: 500 \mathrm{MHz},{ }^{13} \mathrm{C}-\mathrm{NMR}$ : $126 \mathrm{MHz}$ ) und Inova-600 ( ${ }^{1} \mathrm{H}-\mathrm{NMR}: 600 \mathrm{MHz}$ ) der Firma Varian aufgenommen. Weitere NMR-Spektren wurden in der NMR-Abteilung des Departments Chemie der Universität Paderborn an den Geräten Avance-500 ( ${ }^{1} \mathrm{H}-\mathrm{NMR}: 500 \mathrm{MHz},{ }^{13} \mathrm{C}-\mathrm{NMR}$ : $126 \mathrm{MHz})$ und Avance-300 ( $\left.{ }^{13} \mathrm{C}-\mathrm{NMR}: 76 \mathrm{MHz},{ }^{31} \mathrm{P}-\mathrm{NMR}: 121 \mathrm{MHz}\right)$ der Firma Bruker aufgenommen. Die chemischen Verschiebungen sind in Einheiten der $\delta$-Skala in ppm angegeben. Als interner Standard diente das jeweilige Lösungsmittel. Die Signale der ${ }^{31} \mathrm{P}$-NMR-Spektren wurden gegen einen externen Standard von 85\%iger Phosphorsäure kalibriert. Zusätzlich zu den eindimensionalen Spektren wurden stets Korrelationsspektren aufgenommen (HSQC; ${ }^{1} \mathrm{H},{ }^{1} \mathrm{H}-\mathrm{COSY}$ ). In vielen Fällen war zusätzlich die Aufnahme von TOCSY-Spektren erforderlich, um eine möglichst sichere Zuordnung von Signalen unterschiedlicher Spinsysteme angeben zu können. Die Multiplizitäten der Signale wurden wie folgt gekennzeichnet: s (Singulett), d (Dublett), $\mathrm{t}$ (Triplett). Mehrfach aufgespaltene Signale wurden durch Kombinationen der Bezeichnungen gekennzeichnet (z. B. $d d=$ Dublett vom Dublett, $d t=$ Dublett vom Triplett). Die skalaren Kopplungskonstanten $J$ sind in $\mathrm{Hz}$ angegeben. Die genaue Bezeichnung der koppelnden Kerne erfolgte nur, wenn es sich nicht um eine ${ }^{1} \mathrm{H}-{ }^{1} \mathrm{H}-$ Kopplung handelte. Diastereotope Protonen wurden mit den tiefgestellten Indices „a“ (hochfeldverschobenes Proton) und "b“ (tieffeldverschobenes Proton) gekennzeichnet, sofern die Signale anhand der chemischen Verschiebung unterscheidbar waren. Gleiches gilt für diastereotope Kohlenstoffatome.

\subsubsection{Massenspektrometrie}

\section{Oligonucleotide}

Die Massenspektren der Oligonucleotide wurden in der Abteilung für Massenspektrometrie am MPI Göttingen an dem Gerät LTQ XL (linear ion trap) von Thermo Fisher im negativen Modus aufgenommen. Als Ionisierungstechnik wurde die ElectrosprayIonisation verwendet. Für die Messungen wurden wässrige $25 \mu \mathrm{M}$ OligonucleotidLösungen mit 30\% MeCN und 5\% Triethylamin hergestellt.

\section{Kleine Moleküle}

Die Massenspektren wurden in der Abteilung für Zentrale Analytik und Massenspektrometrie des Instituts für Organische und Biomolekulare Chemie der 
Georg-August-Universität Göttingen und der Abteilung für Massenspektrometrie des Departments Chemie der Universität Paderborn aufgenommen. Als Ionisierungstechnik wurde nur die Electrospray-Ionisation (ESI) verwendet. Zur Aufnahme der Spektren wurden ein Ion-Trap-Massenspektrometer (Modell: LCQ) der Firma Finnigan, ein time of flight (TOF)-Massenspektrometer (Modell: microTOF) der Firma Bruker oder ein Quadrupol-Flugzeit-Massenspektrometer "synapt 2G" der Firma Waters verwendet. Für ESI-Messungen wurden die Substanzen in $\mathrm{MeOH}$ gelöst, während $\mathrm{ESI}^{+}$-Messungen in $\mathrm{MeOH}$ mit $0.1 \%$ Ameisensäure durchgeführt wurden. Hochauflösende Spektren wurden an einem 7 Tesla Fourier Transform Ion Cyclotron Resonance (FTICR)-Massenspektrometer APEX IV der Firma Bruker aufgenommen. Das Verhältnis von Masse $m$ durch Ladung $z(\mathrm{~m} / \mathrm{z})$ ist jeweils in der Einheit Th $[T h=u / e]$ angegeben, wobei gilt $z=z^{\prime}$ e mit der Elementarladung e und deren Anzahl z'.

\subsubsection{Analytische Hochleistungsflüssigkeitschromatographie (analytische HPLC)}

\section{HPLC an chiralen stationären Phasen}

Die Trennung der Epimere (6'S)-117 und (6'R)-117 im analytischen Maßstab wurde am Institut für Organische und Biomolekulare Chemie der Georg-August-Universität Göttingen in der Abteilung Tietze durchgeführt. Es wurde eine HPLC-Anlage der Firma JASCO bestehend aus einer Pumpe (pu 2080 Plus), einem Autosampler mit Injektionsnadel (AS 2055 Plus) und einem Multiwavelength-Detektor (MD 2010 Plus) verwendet. Als stationäre Phase diente eine IB Chiralpak-Säule $(27.5 \times 0.8 \mathrm{~cm})$ der Firma Diacel Chemical Industries, LTD. Die Durchflussrate betrug $0.8 \mathrm{~mL} / \mathrm{min}$. Als flüssige Phase wurde ein 7:3-Gemisch aus $n$-Hexan und Ethylacetat (HPLC-Qualität) verwendet. Für einen Trenngang wurden $10 \mu \mathrm{L}$ einer $5.4 \mathrm{mM}(4 \mathrm{mg} / \mathrm{mL})$-Lösung des jeweiligen Diastereomerengemischs injiziert.

\section{Nicht-palindrome Oligonucleotid (ON)-Sequenzen}

Die Reinheitsanalyse der nicht-palindromen Oligonucleotide durch HPLC erfolgte an der Anlage Äktapurifier der Firma GE, bestehend aus einer HPLC-Pumpe (Modell: P580, Firma: Dionex), einem Fraktionssammler (Modell: ASI-100, Firma: Dionex), einer Heizvorrichtung für die Säule und einem UV-Detektor (Modell: UV170U, Firma: 
Dionex) mit vier Wellenlängenkanälen. Als stationäre Phase diente eine AnionenAustauscher-Säule (Modell: DNAPac PA100, $4 \times 250$ mm, Firma: Dionex). Die Durchflussrate betrug $1 \mathrm{~mL} / \mathrm{min}$ und die eingestellte Temperatur $80^{\circ} \mathrm{C}$. Als mobile Phase diente ein Gradient (0-60\% im Verlauf von $45 \mathrm{~min}$.) von Eluent B (25 mM TRIS- $\mathrm{HCl}, 0.5 \mathrm{M} \mathrm{NaClO}_{4}, 6 \mathrm{M}$ Harnstoff, $\mathrm{pH}=8$ ) in Eluent A (25 mM TRIS-HCl, $6 \mathrm{M}$ Harnstoff, $\mathrm{pH}=8$ ). Die Detektion erfolgte bei einer Wellenlänge von $260 \mathrm{~nm}$. Die Retentionszeiten $\mathrm{t}_{R}[\mathrm{~min}]$ sind ohne eine Bereinigung der Totzeit angegeben.

\section{Palindrome ON-Sequenzen}

Die Reinheitsanalyse von palindromen Oligonucleotiden erfolgte an dem Gerät Hitachi LaChrom Elite von VWR, bestehend aus einem Organizer, einer Pumpe (Modell L-2130), einer Heizvorrichtung für die Chromatographiesäule (Modell L2300), einem Autosampler (Modell: L-2200) und einem Diode Array Detector (Modell: L-2455) oder einem Fluorescence Detector (Modell: L-2485). Als stationäre Phase diente eine RP-Chromatographiesäule des Typs LiChroCART ${ }^{\circledR}$ Purospher ${ }^{\circledR}$ RP18e (5 $\mu \mathrm{m}, 125 \times 4 \mathrm{~mm}$ von Merck) mit der entsprechenden Vorsäule $(5 \mu \mathrm{m}, 4 \times 4 \mathrm{~mm})$, die ebenfalls von $V W R$ bezogen wurde. Die Durchflussrate betrug $1 \mathrm{~mL} / \mathrm{min}$. Als flüssige Phase wurde der folgend angeführte Gradient von Eluent A (Acetonitril) in Eluent $B$ (10 $\mathrm{mM} \mathrm{NEt}_{3} / \mathrm{AcOH}$ in bidestilliertem Wasser) eingesetzt:

$\mathrm{t}[\mathrm{min}] \quad 0 \quad 30 \quad 30.1$

A [\%] $\quad 3.5 \quad 20 \quad 100$

Die Chromatogramme wurden durch Messung der UV-Absorption bei $\lambda=260 \mathrm{~nm}$ aufgenommen. Die Retentionszeiten $t_{R}[\mathrm{~min}]$ sind ohne eine Bereinigung der Totzeit angegeben.

\subsubsection{Semipräparative chirale Hochleistungsflüssigkeitschromatographie}

Die Trennung der Epimere (6'S)-117 und (6'R)-117 im semipräparativen Maßstab wurde am Institut für Organische und Biomolekulare Chemie der Georg-AugustUniversität Göttingen in der Abteilung Tietze durchgeführt. Es wurde eine HPLCAnlage der Firma JASCO bestehend aus einer Pumpe (pu-2087 Plus), einem Injektionsventil und einem Multiwavelength-Detektor (MD 2010 Plus) verwendet. Als 
stationäre Phase diente eine IB Chiralpak-Säule $(28 \times 1.5 \mathrm{~cm})$ der Firma Diacel Chemical Industries, LTD. Die Durchflussrate betrug $5 \mathrm{~mL} / \mathrm{min}$. Als flüssige Phase wurde ein 73:27-Gemisch aus $n$-Hexan und Ethylacetat (HPLC-Qualität) verwendet. Für eine Trennung wurden $0.10 \mathrm{~mL}$ einer $1.35 \mathrm{M}(100 \mathrm{mg} / \mathrm{mL})$-Lösung des jeweiligen Diastereomerengemischs injiziert.

\subsubsection{Schmelzpunktbestimmung}

Schmelzpunkte organischer Verbindungen wurden unter Verwendung der Schmelzpunktbestimungsapparatur Melting Point B-545 der Firma Büchi gemessen.

\subsubsection{Allgemeine Arbeitsvorschriften}

\subsubsection{Peptidkupplungen (AAV 1)}

Eine Lösung der jeweiligen TAA in Dichlormethan $(\mathrm{c}=0.01 \mathrm{mmol} / \mathrm{mL})$ wurde mit 1-Hydroxybenzotriazol (1.1 Äq.) und $N$-(Dimethylaminopropyl)- $N$-ethyl-carbodiimid Hydrochlorid (1.1 Äq.) versetzt und $15 \mathrm{~min}$. bei Raumtemperatur gerührt. Anschließend wurde die jeweilige Kupplungskomponente (3'-Aminonucleosid, 1.1 Äq.) dazugegeben und die Lösung $16 \mathrm{~h}$ bei Raumtemperatur gerührt. Die Reaktionslösung wurde in Ethylacetat (ca. $160 \mathrm{~mL} / \mathrm{mmol}$ TAA) aufgenommen, mit ges. $\mathrm{NH}_{4} \mathrm{Cl}$-Lösung (ca. $100 \mathrm{~mL} / \mathrm{mmol}$ TAA), Wasser (ca. $70 \mathrm{~mL} / \mathrm{mmol}$ TAA) und ges. wässriger $\mathrm{NaCl}$-Lösung (ca. $70 \mathrm{~mL} / \mathrm{mmol}$ TAA) gewaschen. Die organische Phase wurde über $\mathrm{Na}_{2} \mathrm{SO}_{4}$ getrocknet und filtriert. Das Lösungsmittel wurde im Vakuum entfernt. Der Rückstand wurde chromatographisch an Kieselgel gereinigt, wobei je nach Produkt unterschiedliche Eluenten verwendet wurden.

\subsubsection{Einführung der 4,4'-Dimethoxytriphenylmethyl-Schutzgruppe (AAV 2)}

Das jeweilige Edukt wurde mit abs. Pyridin coevaporiert ( $3 \times$ ca. $5 \mathrm{~mL} / \mathrm{mmol}$ Edukt), in abs. Pyridin gelöst $(\mathrm{c}=0.43 \mathrm{mmol} / \mathrm{mL})$ und mit $N, N$-Dimethylaminopyridin (10 mol\%) und 4,4'-Dimethoxytriphenylmethylchlorid (1.2-1.5 Äq) versetzt. Die resultierende Lösung wurde $16 \mathrm{~h}$ bei Raumtemperatur gerührt. Das Lösungsmittel 
wurde im Vakuum entfernt, der Rückstand in Ethylacetat aufgenommen (ca. $90 \mathrm{~mL} / \mathrm{mmol}$ Edukt) und mit ges. wässriger $\mathrm{NaHCO}_{3}$-Lösung (ca. $50 \mathrm{~mL} / \mathrm{mmol}$ Edukt), Wasser (ca. $50 \mathrm{~mL} / \mathrm{mmol}$ Edukt) und ges. wässriger $\mathrm{NaCl}$-Lösung (ca. $50 \mathrm{~mL} / \mathrm{mmol}$ Edukt) gewaschen. Das Lösungsmittel wurde im Vakuum entfernt und der Rückstand chromatographisch an Kieselgel gereinigt, wobei je nach Produkt unterschiedliche Eluenten verwendet wurden, die ca. 1\% Pyridin enthielten.

\subsection{Synthesen}

\subsubsection{Synthese der Reagenzien}

\subsubsection{Bis-(N,N-Diisopropylamino)-(2-cyanoethyl)-phosphit $85^{[139]}$}<smiles>N#CCCOP(N=P)N[P+](=O)O</smiles>

\section{5}

Phosphortrichlorid $(13.4 \mathrm{~g}, \quad 8.55 \mathrm{~mL}, \quad 0.10 \mathrm{~mol})$ und Pyridin $(7.85 \mathrm{~mL})$ wurden bei $-78^{\circ} \mathrm{C}$ in abs. Diethyether $(20 \mathrm{~mL})$ gelöst. Die Lösung wurde über einen Zeitraum von $30 \mathrm{~min}$. mit 3-Hydroxypropionitril $(7.21 \mathrm{~g}, 6.80 \mathrm{~mL}, 0.10 \mathrm{~mol})$ versetzt und für eine Stunde bei $-78{ }^{\circ} \mathrm{C}$ gerührt. Die Lösung wurde auf Raumtemperatur gebracht und weitere $16 \mathrm{~h}$ gerührt. Die resultierende Lösung wurde unter Argon durch eine Glasfritte filtriert. Der Filterkuchen wurde mit abs. Diethylether gewaschen. Das Filtrat wurde eingeengt und der ölige Rückstand in abs. Diethylether $(100 \mathrm{~mL})$ gelöst. Die Lösung wurde auf $-40^{\circ} \mathrm{C}$ gekühlt und über einen Zeitraum von $45 \mathrm{~min}$ mit Diisopropylamin $(50 \mathrm{~g}, 70 \mathrm{~mL}, 0.50 \mathrm{~mol})$ versetzt. Die Lösung wurde auf $-10^{\circ} \mathrm{C}$ gebracht und $1 \mathrm{~h}$ bei dieser Temperatur gerührt. Anschließend wurde die Lösung auf Raumtemperatur gebracht und $16 \mathrm{~h}$ gerührt. Die resultierende Lösung wurde unter Argon über eine Glasfritte filtriert und im Vakuum eingeengt. Das verbliebene ÖI wurde über Calciumhydrid im Vakuum (0.3-0.7 mbar) destilliert (Übergangstemperatur $\left.120-135^{\circ} \mathrm{C}\right)$.

Ausbeute: $19.9 \mathrm{~g}\left(21.2 \mathrm{~mL}, 66 \mathrm{mmol}, 66 \%\right.$ bezogen auf $\left.\mathrm{PCl}_{3}\right)$ eines farblosen, hochviskosen Öls, das durch Aufbewahren bei $-18{ }^{\circ} \mathrm{C}$ für mindestens $3 \mathrm{~h} \mathrm{zu}$ einem weißen Feststoff kristallisierte. 
${ }^{1} \mathrm{H}$-NMR $\left(300 \mathrm{MHz}, \quad \mathrm{CDCl}_{3}\right): \delta=1.13 \quad\left(\mathrm{~d}, \quad J=6.8 \mathrm{~Hz}, \quad 12 \mathrm{H}, \quad \operatorname{PrCH}_{3}\right), 1.15$ (d, $J=6.8 \mathrm{~Hz}, 12 \mathrm{H}, 4^{\prime}-\mathrm{H}$ ), $2.58(\mathrm{dt}, J=6.4 \mathrm{~Hz}, J=0.9 \mathrm{~Hz}, 2 \mathrm{H}, 1-\mathrm{H}$ ), 3.51 (dsept, $J=11.0 \mathrm{~Hz}, J=6.8 \mathrm{~Hz}, 4 \mathrm{H}, \mathrm{PrCH}$ ), 3.73 (dt, $J=7.4 \mathrm{~Hz}, J=6.4 \mathrm{~Hz}, 2 \mathrm{H}, 2-\mathrm{H}$ ).

${ }^{13} \mathrm{C}$-NMR $\quad\left(75 \mathrm{MHz}, \quad \mathrm{CDCl}_{3}\right): \quad \delta=20.50 \quad\left(\mathrm{~d}, \quad{ }^{2} J_{\mathrm{CP}}=8.9 \mathrm{~Hz}, \quad \underline{\mathrm{C}} \mathrm{H}_{2} \mathrm{CN}\right), \quad 23.80 \quad(\mathrm{~d}$, $\left.{ }^{3} J_{\mathrm{CP}}=5.8 \mathrm{~Hz}, \operatorname{PrCH}_{3 \mathrm{a}}\right), 24.50\left(\mathrm{~d},{ }^{3} J_{\mathrm{CP}}=8.1 \mathrm{~Hz}, \operatorname{PrCH}_{3 \mathrm{~b}}\right), 44.48\left(\mathrm{~d},{ }^{2} J_{\mathrm{CP}}=12.4 \mathrm{~Hz}\right.$, $\mathrm{iPrCH}), 59.20\left(\mathrm{~d},{ }^{2} J_{\mathrm{CP}}=25.0 \mathrm{~Hz}, \mathrm{CH}_{2} \mathrm{O}\right), 118.00(\mathrm{CN})$.

${ }^{31}$ P-NMR $\left(121 \mathrm{MHz}, \mathrm{CDCl}_{3}\right): \delta=123.4$.

\subsubsection{N-(Benzyloxycarbonyl)-2-(dimethoxyphosphoryl)-gylcinmethylester} $124^{[140]}$

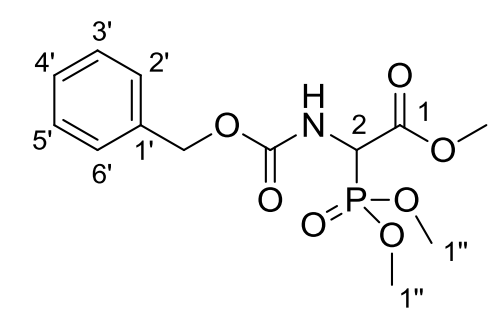

124

Zu einer auf $80^{\circ} \mathrm{C}$ erwärmten Lösung von $\mathrm{N}$-(Benzyloxycarbonyl)-2-methoxyglycin 123 (12.5 g, $49.4 \mathrm{mmol})$ in abs. Toluol $(50 \mathrm{~mL})$ wurde Phosphor(III)-chlorid (4.84 mL, $7.55 \mathrm{~g}, 55 \mathrm{mmol}$ ) getropft und $4 \mathrm{~h}$ zum Rückfluss erhitzt. Die Reaktionsmischung wurde mit Trimethylphosphit (6.64 mL, $6.93 \mathrm{~g}, 56 \mathrm{mmol})$ versetzt, $2 \mathrm{~h}$ zum Rückfluss erhitzt und anschließend das Lösungsmittel im Vakuum entfernt. Der flüssige orange Rückstand wurde in Ethylacetat $(300 \mathrm{~mL})$ aufgenommen und mit ges. wässriger $\mathrm{NaHCO}_{3}$-Lösung $(3 \times 100 \mathrm{~mL})$ gewaschen. Die organische Phase wurde über $\mathrm{Na}_{2} \mathrm{SO}_{4}$ getrocknet, filtriert und das Lösungsmittel im Vakuum entfernt. Der resultierende viskose Rückstand wurde in $n$-Hexan $(50 \mathrm{~mL})$ aufgenommen und 30 min bei Raumtemperatur gerührt. Die entstandene Suspension wurde filtriert und der farblose Rückstand mit auf $0^{\circ} \mathrm{C}$ gekühltem Hexan $(3 \times 10 \mathrm{~mL})$ gewaschen. Der erhaltene weiße Feststoff wurde im Vakuum von Lösungsmittelresten befreit.

Ausbeute: $12.5 \mathrm{~g}(38.8 \mathrm{mmol}, 76 \%)$ eines weißen Feststoffs.

DC: $R_{\mathrm{f}}(\mathrm{DCM} / \mathrm{MeOH} 20: 1)=0.29$.

${ }^{1} \mathrm{H}-\mathrm{NMR}\left(300 \mathrm{MHz}, \mathrm{CDCl}_{3}\right): \delta=3.73\left(\mathrm{~d},{ }^{3} \mathrm{JPP}_{\mathrm{HP}}=10.9 \mathrm{~Hz}, 3 \mathrm{H}, 1\right.$ "'- $\left.\mathrm{H}_{\mathrm{a}}\right) 3.77(\mathrm{~s}, 3 \mathrm{H}$, $\left.\mathrm{COOCH}_{3}\right), 3.78\left(\mathrm{~d},{ }^{3} \mathrm{JPP}_{\mathrm{HP}}=10.3 \mathrm{~Hz}, 3 \mathrm{H}, 1^{\prime \prime}-\mathrm{H}_{\mathrm{b}}\right), 4.90\left(\mathrm{dd},{ }^{2} \mathrm{~J}_{\mathrm{HP}}=22.4 \mathrm{~Hz}, J=8.8 \mathrm{~Hz}\right.$, 
$1 \mathrm{H}, 2-\mathrm{H}), 5.06\left(\mathrm{~d}, J=12.3 \mathrm{~Hz}, 1 \mathrm{H}, \mathrm{BnCH} \underline{\mathrm{H}}_{\mathrm{a}}\right), 5.11\left(\mathrm{~d}, J=12.3 \mathrm{~Hz}, 1 \mathrm{H}, \mathrm{BnCH} \underline{H}_{\mathrm{b}}\right.$ ), $5.80(\mathrm{~d}, J=8.8 \mathrm{~Hz}, 1 \mathrm{H}, \mathrm{NH}), 7.23-7.34(\mathrm{~m}, 5 \mathrm{H}, \mathrm{ArH})$.

${ }^{13} \mathrm{C}-\mathrm{NMR} \quad\left(126 \mathrm{MHz}, \quad \mathrm{CDCl}_{3}\right): \delta=51.95 \quad\left(\mathrm{~d}, \quad{ }^{1} \mathrm{~J}_{\mathrm{CP}}=148.7 \mathrm{~Hz}, \quad \mathrm{C}-2\right), 53.54 \quad(\mathrm{~d}$, $\left.{ }^{2} J_{\mathrm{CP}}=6.8 \mathrm{~Hz}, \mathrm{C}_{\mathrm{a}}-1^{\prime \prime}\right), 53.98\left(\mathrm{~d},{ }^{2} J_{\mathrm{CP}}=6.5 \mathrm{~Hz}, \mathrm{C}_{\mathrm{b}}-1^{\prime \prime}\right), 67.46\left(\mathrm{BnCH}_{2}\right), 127.99$ (C-4'), 128.17 (C-2', C-6'), 128.37 (C-3', C-5'), 135.75 (C-1'), 155.4 (d, ${ }^{3} J_{\mathrm{CP}}=7.8 \mathrm{~Hz}$, $\mathrm{C}(\mathrm{O}) \mathrm{ONH}), 167.6\left(\mathrm{~d},{ }^{2} \mathrm{~J}_{\mathrm{CP}}=3.0 \mathrm{~Hz}, \mathrm{C}-1\right)$.

${ }^{31}$ P-NMR $\left(121 \mathrm{MHz}, \mathrm{CDCl}_{3}\right): \delta=18.38$.

Schmelzpunkt: $66^{\circ} \mathrm{C}$.

IR $(\mathrm{KBr}): \tilde{v}=1742,1713,1523,1270,1232,1212,1027,784,755$.

UV (MeCN): $\lambda_{\max }(\lg \varepsilon)=204$ (2.88).

MS $\left(\mathrm{ESI}^{+}\right): \mathrm{m} / \mathrm{z}=354.1[\mathrm{M}+\mathrm{Na}]^{+}$.

$\mathrm{C}_{13} \mathrm{H}_{18} \mathrm{NO}_{7} \mathrm{P}(331.26)$

ber.: $354.0719[\mathrm{M}+\mathrm{Na}]^{+}$

gef.: 354.0716 (ESI+-HRMS).

\subsubsection{N-(Benzyloxycarbonyl)-2-(dimethylphosphoryl)-glycin-tert-butylester} $79^{[142-143]}$<smiles>[3H]OP(=O)(O[I+](F)(F)F)C(NC(=O)OCc1ccccc1)C(=O)OC(C)(C)C</smiles>

79

Die erste Reaktion der zwei nachfolgend angeführten wurde nicht unter Inertgasbedingungen durchgeführt. Eine Lösung von N-(Benzyloxycarbonyl)-2(dimethoxyphosphoryl)-gylcinmethylester $124(8.59 \mathrm{~g}, 27.1 \mathrm{mmol})$ in Dioxan $(6 \mathrm{~mL})$ wurde auf $15^{\circ} \mathrm{C}$ gebracht und allmählich mit wässriger $\mathrm{NaOH}$-Lösung $(14.1 \mathrm{~mL}, 2 \mathrm{M}$, $28.3 \mathrm{mmol}$ ) versetzt. Die erhaltene Reaktionslösung wurde $30 \mathrm{~min}$. bei $15^{\circ} \mathrm{C}$ gerührt. Anschließend wurde die Lösung auf $0{ }^{\circ} \mathrm{C}$ gekühlt und bis zur Einstellung von $\mathrm{pH}=2$ mit auf $0{ }^{\circ} \mathrm{C}$ gekühlter $5 \mathrm{M}$ Salzsäure versetzt. Die resultierende Lösung wurde mit $40 \mathrm{~mL}$ Wasser und $80 \mathrm{~mL}$ Essigester versetzt. Die wässrige Phase wurde mit Ethylacetat $(4 \times 40 \mathrm{~mL})$ extrahiert und die vereinigten organischen Phasen über $\mathrm{Na}_{2} \mathrm{SO}_{4}$ getrocknet und filtriert. Das Lösungsmittel wurde im Vakuum entfernt und der Rückstand im Vakuum getrocknet. 
Eine Lösung des viskosen Rückstands in abs. DCM $(80 \mathrm{~mL})$ und abs. tert-Butanol $(310 \mathrm{~mL})$ wurde mit frisch aktiviertem Molekularsieb $(3 \AA)$ versetzt und $2.5 \mathrm{~h}$ bei Raumtemperatur gerührt. Zu der Reaktionslösung wurde $\mathrm{N}$-Ethoxycarbonyl-2-ethoxy1,2-dihydrochinolin $(8.00 \mathrm{~g}, 32.2 \mathrm{mmol})$ gegeben und $16 \mathrm{~h}$ bei Raumtemperatur gerührt. Die Lösung wurde anschließend durch Celite filtriert, die Celite mit Ethylacetat $(4 \times 150 \mathrm{~mL})$ nachgereinigt und das Lösungsmittel im Vakuum entfernt. Der verbliebene Rückstand wurde in Ethylacetat $(400 \mathrm{~mL})$ aufgenommen, auf $0{ }^{\circ} \mathrm{C}$ gekühlt und mit auf $0^{\circ} \mathrm{C}$ gekühlter Salzsäure $(3 \times 80 \mathrm{~mL}, 0.5 \mathrm{M})$ und ges. wässriger $\mathrm{NaHCO}_{3}$-Lösung $(2 \times 100 \mathrm{~mL})$ gewaschen. Die organische Phase wurde über $\mathrm{Na}_{2} \mathrm{SO}_{4}$ getrocknet, filtriert und das Lösungsmittel im Vakuum entfernt. Die Titelverbindung wurde nach chromatographischer Reinigung an Kieselgel (PE/EtOAc 1:1) erhalten.

Ausbeute: $6.58 \mathrm{~g}(17.6 \mathrm{mmol}, 65 \%)$ eines weißen Feststoffs.

DC: $R_{\mathrm{f}}(\mathrm{DCM} / \mathrm{MeOH} 50: 1)=0.23$.

${ }^{1} \mathrm{H}$-NMR $\left(300 \mathrm{MHz}, \mathrm{CDCl}_{3}\right): \delta=1.46\left(\mathrm{~s}, 9 \mathrm{H}, \mathrm{C}\left(\mathrm{CH}_{3}\right)_{3}\right), 3.74(\mathrm{~d}, J=10.8 \mathrm{~Hz}, 3 \mathrm{H}$, 1'- $\mathrm{H}_{\mathrm{a}}$ ), 3.77 (d, J=9.8 Hz, $3 \mathrm{H}, 1$ '"- $\left.\mathrm{H}_{\mathrm{b}}\right), 4.78(\mathrm{dd}, J=21.8 \mathrm{~Hz}, 1 \mathrm{H}, 2-\mathrm{H}), 5.07$ (d, $\left.J=12.3 \mathrm{~Hz}, 1 \mathrm{H}, \mathrm{BnCH} \underline{H}_{\mathrm{a}}\right), 5.12\left(\mathrm{~d}, J=12.1 \mathrm{~Hz}, 1 \mathrm{H}, \mathrm{BnCH} \underline{H}_{\mathrm{b}}\right), 5.65(\mathrm{~d}, J=8.5 \mathrm{~Hz}$, $1 \mathrm{H}, \mathrm{NH})$, 7.23-7.36 (m, $5 \mathrm{H}, \mathrm{ArH})$.

${ }^{13} \mathrm{C}-\mathrm{NMR}\left(126 \mathrm{MHz}, \mathrm{CDCl}_{3}\right): \delta=27.73\left(\mathrm{C}\left(\mathrm{C}_{3}\right)_{3}\right), 52.68\left(\mathrm{~d},{ }^{1} \mathrm{~J}_{\mathrm{CP}}=148.1 \mathrm{~Hz}, \mathrm{C}-2\right)$, $53.75\left(\mathrm{~d},{ }^{2} J_{\mathrm{CP}}=6.5 \mathrm{~Hz}, \mathrm{C}_{\mathrm{a}}-1\right.$ ") $), 53.80\left(\mathrm{~d},{ }^{2} \mathrm{~J}_{\mathrm{CP}}=6.3 \mathrm{~Hz}, \mathrm{C}_{\mathrm{b}}-1\right.$ ") $), 67.63\left(\mathrm{BnCH}_{2}\right), 83.71$ $\left(\mathrm{C}\left(\mathrm{CH}_{3}\right)_{3}\right), 128.02$ (C-2', C-6'), 128.15 (C-4'), 128.41 (C-3', C-5'), 135.88 (C-1'), $155.51\left(\mathrm{~d},{ }^{3} \mathrm{~J}_{\mathrm{CP}}=7.2 \mathrm{~Hz}, \mathrm{C}(\mathrm{O}) \mathrm{ONH}\right), 165.38\left(\mathrm{~d},{ }^{2} \mathrm{JPP}_{\mathrm{CP}}=2.5 \mathrm{~Hz}, \mathrm{C}-1\right)$.

${ }^{31}$ P-NMR $\left(121 \mathrm{MHz}, \mathrm{CDCl}_{3}\right): \delta=19.16$.

Schmelzpunkt: $86^{\circ} \mathrm{C}$.

IR $(\mathrm{KBr}): \tilde{v}=1742,1724,1708,1270,1227,1151,1045,1017,755$.

UV $(\mathrm{MeCN}): \lambda_{\max }(\lg \varepsilon)=206$ (2.96).

MS $\left(\mathrm{ESI}^{+}\right): \mathrm{m} / \mathrm{z}=396.1[\mathrm{M}+\mathrm{Na}]^{+}$.

$\mathrm{C}_{16} \mathrm{H}_{24} \mathrm{NO}_{7} \mathrm{P}$ (373.33) ber.: $396.1183[\mathrm{M}+\mathrm{Na}]^{+}$ gef.: 396.1181 (ESI+-HRMS). 


\subsubsection{4 $\mathrm{N}$-(tert-Butyloxycarbonyl)-2-(dimethylphosphoryl)-glycinmethylester} $125^{[140]}$<smiles>[3H]OP(=O)(O[I+])[C@@H](NC(=O)OC(C)(C)C)C(=O)OC</smiles>

125

Eine Lösung von $\mathrm{N}$-(Benzyloxycarbonyl)-2-(dimethoxyphosphoryl)-gylcinmethylester $124(1.00 \mathrm{~g}, 3.19 \mathrm{mmol})$ in abs. $\mathrm{MeOH}(30 \mathrm{~mL})$ wurde mit Palladium (200 mg, $189 \mu \mathrm{mol}, 10 \%$ auf Aktivkohle) versetzt und $3 \mathrm{~h}$ unter einer $\mathrm{H}_{2}$-Atmosphäre gerührt. Die Lösung wurde über Celite filtriert, die Celite mit $\mathrm{MeOH}(3 \times 10 \mathrm{~mL})$ nachgereinigt und das Lösungsmittel im Vakuum entfernt. Der verbliebene Rückstand wurde in $10 \mathrm{~mL}$ DCM aufgenommen und mit Di-tert-butyl-dicarbonat versetzt. Die Lösung wurde $16 \mathrm{~h}$ bei Raumtemperatur gerührt und anschließend in Ethylacetat $(20 \mathrm{~mL})$ aufgenommen. Die organische Phase wurde mit ges. wässriger $\mathrm{NaHCO}_{3}(2 \times 10 \mathrm{~mL})$ und ges. wässriger $\mathrm{NaCl}$-Lösung $(10 \mathrm{~mL})$ gereinigt, über $\mathrm{Na}_{2} \mathrm{SO}_{4}$ getrocknet, filtriert und im Vakuum eingeengt. Der viskose Rückstand wurde chromatographisch an Kieselgel gereinigt (DCM/MeOH 50:1).

Ausbeute: $546 \mathrm{mg} \mathrm{(1.84} \mathrm{mmol,} \mathrm{60 \% )} \mathrm{eines} \mathrm{farblosen,} \mathrm{feinkristallinen} \mathrm{Feststoffs.}$

DC: $R_{\mathrm{f}}(\mathrm{DCM} / \mathrm{MeOH} 20: 1)=0.34$.

${ }^{1} \mathrm{H}-\mathrm{NMR}\left(300 \mathrm{MHz}, \mathrm{CDCl}_{3}\right): \delta=1.42\left(\mathrm{~s}, 9 \mathrm{H}, \mathrm{C}\left(\mathrm{CH}_{3}\right)_{3}\right), 3.78(\mathrm{~d}, J=3.0 \mathrm{~Hz}, 3 \mathrm{H}$, 1"'- $\mathrm{H}_{\mathrm{a}}$ ), $3.80\left(\mathrm{~s}, 3 \mathrm{H}, \mathrm{COOCH}_{3}\right), 3.81\left(\mathrm{~d}, J=3.1 \mathrm{~Hz}, 3 \mathrm{H}, 1\right.$ '"- $\left.\mathrm{H}_{\mathrm{b}}\right), 4.85$ (dd, $\left.J_{\mathrm{HP}}=22.6 \mathrm{~Hz}, J=9.3 \mathrm{~Hz}, 1 \mathrm{H}, 2-\mathrm{H}\right), 5.34(\mathrm{~d}, J=9.1 \mathrm{~Hz}, 1 \mathrm{H}, \mathrm{NH})$.

${ }^{13} \mathrm{C}$-NMR $\left(126 \mathrm{MHz}, \mathrm{CDCl}_{3}\right): \delta=28.17\left(\mathrm{C}\left(\mathrm{CH}_{3}\right)_{3}\right), 51.68\left(\mathrm{~d},{ }^{1} J_{\mathrm{CP}}=147.7 \mathrm{~Hz}, \mathrm{C}-2\right)$, $53.21\left(\mathrm{C}(\mathrm{O}) \mathrm{O}_{\mathrm{C}} \mathrm{H}_{3}\right), 53.94\left(\mathrm{~d},{ }^{2} J_{\mathrm{CP}}=4.0 \mathrm{~Hz}, \mathrm{C}_{\mathrm{a}}-1\right.$ '), $54.03\left(\mathrm{~d},{ }^{2} J_{\mathrm{CP}}=4.3 \mathrm{~Hz}, \mathrm{C}_{\mathrm{b}}-1\right.$ '),

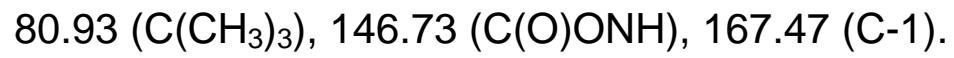

${ }^{31}$ P-NMR (121 MHz, $\left.\mathrm{CDCl}_{3}\right): \delta=18.85$.

Schmelzpunkt: $69^{\circ} \mathrm{C}$.

IR $(\mathrm{KBr}): \tilde{v}=1752,1709,1533,1299,1242,1204,1161,1032,789$.

MS $\left(\mathrm{ESI}^{+}\right): \mathrm{m} / \mathrm{z}=320.1[\mathrm{M}+\mathrm{Na}]^{+}$.

$\mathrm{C}_{13} \mathrm{H}_{18} \mathrm{NO}_{7} \mathrm{P}(297.24)$

ber.: $320.0870[\mathrm{M}+\mathrm{Na}]^{+}$ gef.: 320.0872 (ESI+-HRMS). 


\subsubsection{N-(tert-Butyloxycarbonyl)-2-(dimethylphosphoryl)-glycinbenzylester 109}

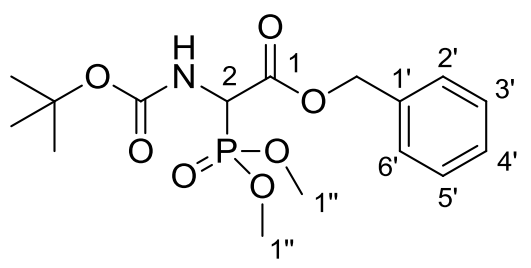

109

Die erste Reaktion der zwei nachfolgend angeführten wurde nicht unter Inertgasbedingungen durchgeführt. Eine Lösung von $\mathrm{N}$-(tert-butyloxycarbonyl)-2(dimethoxyphosphinyl)-gylcinmethylester $125(1.77 \mathrm{~g}, 5.96 \mathrm{mmol})$ in Dioxan (1.35 mL) wurde auf $15^{\circ} \mathrm{C}$ gebracht und allmählich mit wässriger $\mathrm{NaOH}$-Lösung (2.98 mL, 2 M, $5.96 \mathrm{mmol}$ ) versetzt. Die erhaltene Reaktionslösung wurde $30 \mathrm{~min}$. bei $15^{\circ} \mathrm{C}$ gerührt. Anschließend wurde die Lösung auf $0^{\circ} \mathrm{C}$ gekühlt und bis zur Einstellung von $\mathrm{pH}=2$ mit auf $0^{\circ} \mathrm{C}$ gekühlter, $5 \mathrm{M}$ Salzsäure versetzt. Die resultierende Lösung wurde mit $11 \mathrm{~mL}$ Wasser und $20 \mathrm{~mL}$ Ethylacetat versetzt. Die wässrige Phase wurde mit Ethylacetat $(5 \times 10 \mathrm{~mL})$ extrahiert und die vereinigten organischen Phasen über $\mathrm{Na}_{2} \mathrm{SO}_{4}$ getrocknet und filtriert. Das Lösungsmittel wurde im Vakuum entfernt und der Rückstand im Vakuum getrocknet.

Der verbliebene weiße Feststoff $(1.53 \mathrm{mg}, 5.41 \mathrm{mmol})$ wurde mit abs. Acetonitril coevaporiert $(3 \times 3 \mathrm{~mL})$ und in $3 \mathrm{~mL}$ Acetonitril gelöst. Die Lösung wurde mit DBU (807 $\mu \mathrm{L}, 823 \mathrm{mg}, 5.41 \mathrm{mmol})$ versetzt und $5 \mathrm{~min}$ bei Raumtemperatur gerührt. Anschließend wurde Benzylbromid (671 $\mu \mathrm{L}, 971 \mathrm{mg}, 5.68 \mathrm{mmol}$ ) dazugegeben und die erhaltene Lösung $2 \mathrm{~h}$ bei Raumtemperatur gerührt. Die Lösung wurde mit ges. wässriger $\mathrm{NaCl}$-Lösung $(20 \mathrm{~mL})$ versetzt. Das erhaltene Gemisch wurde mit Ethylacetat $(3 \times 10 \mathrm{~mL})$ extrahiert. Die vereinigten organischen Phasen wurden mit $1 \mathrm{M} \mathrm{HCl}$ gewaschen, über $\mathrm{Na}_{2} \mathrm{SO}_{4}$ getrocknet, filtriert und im Vakuum eingeengt. Der Rückstand wurde chromatographisch an Kieselgel gereinigt (PE/EtOAc 1:1).

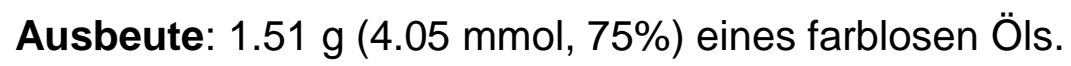

DC: $R_{\mathrm{f}}(\mathrm{DCM} / \mathrm{MeOH} 30: 1)=0.33$.

${ }^{1} \mathrm{H}-\mathrm{NMR}\left(300 \mathrm{MHz}, \mathrm{CDCl}_{3}\right): \delta=1.40\left(\mathrm{~s}, 9 \mathrm{H}, \mathrm{C}\left(\mathrm{CH}_{3}\right)_{3}\right), 3.68\left(\mathrm{~d},{ }^{3} J_{\mathrm{HP}}=9.5 \mathrm{~Hz}, 3 \mathrm{H}\right.$, 1'”- $\mathrm{H}_{\mathrm{a}}$ ), $3.71\left(\mathrm{~d}, J_{\mathrm{HP}}=10.9 \mathrm{~Hz}, 3 \mathrm{H}, 1{ }^{\prime \prime}-\mathrm{H}_{\mathrm{b}}\right), 4.87$ (dd, J JP $=22.6 \mathrm{~Hz}, J=9.0 \mathrm{~Hz}, 1 \mathrm{H}$, 2-H), $5.21\left(\mathrm{~d}, J=12.2 \mathrm{~Hz}, 1 \mathrm{H}, \mathrm{BnCH} \underline{H}_{\mathrm{a}}\right), 5.27$ (d, J=12.2 Hz, $\left.1 \mathrm{H}, \mathrm{BnCH} \underline{\mathrm{H}}_{\mathrm{b}}\right), 5.43$ (d, $J=9.0 \mathrm{~Hz}, 1 \mathrm{H}, \mathrm{NH}), 7.26-7.40(\mathrm{~m}, 5 \mathrm{H}, \mathrm{ArH})$. 
${ }^{13}$ C-NMR (126 MHz, $\left.\mathrm{CDCl}_{3}\right): \delta=28.11\left(\mathrm{C}\left(\underline{\mathrm{CH}}_{3}\right)_{3}\right), 51.85\left(\mathrm{~d},{ }^{1} J_{\mathrm{CP}}=148.5 \mathrm{~Hz}, \mathrm{C}-2\right)$, $53.90\left(\mathrm{~d},{ }^{2} \mathrm{~J}_{\mathrm{CP}}=6.6 \mathrm{~Hz}, \mathrm{C}_{\mathrm{a}}-1\right.$ ') $), 53.5\left(\mathrm{~d},{ }^{2} \mathrm{~J}_{\mathrm{CP}}=6.2 \mathrm{~Hz}, \mathrm{C}_{\mathrm{b}}-1\right.$ '), $68.00\left(\mathrm{BnCH}_{2}\right), 80.88$ $\left(\underline{\mathrm{C}}\left(\mathrm{CH}_{3}\right)_{3}\right), 128.38$ (C-2', C-6'), 128.47 (C-4'), 128.50 (C-3', C-5'), 134.77 (C-1'), $154.85\left(\mathrm{~d},{ }^{3} \mathrm{~J}_{\mathrm{CP}}=8.2 \mathrm{~Hz}, \underline{\mathrm{C}}(\mathrm{O}) \mathrm{ONH}\right), 166.81\left(\mathrm{~d},{ }^{3} \mathrm{~J}_{\mathrm{CP}}=2.9 \mathrm{~Hz}, \mathrm{C}-1\right)$.

${ }^{31}$ P-NMR (121 MHz, $\left.\mathrm{CDCl}_{3}\right): \delta=18.84$.

IR $(\mathrm{KBr}): \tilde{v}=1747,1709,1494,1303,1250,1156,1022,741,698$.

UV $(\mathrm{MeCN}): \lambda_{\max }(\lg \varepsilon)=205$ (3.14).

MS $\left(\mathrm{ESI}^{+}\right): \mathrm{m} / \mathrm{z}=396.1[\mathrm{M}+\mathrm{Na}]^{+}$.

$\mathrm{C}_{13} \mathrm{H}_{18} \mathrm{NO}_{7} \mathrm{P}$ (373.33)

ber.: $396.1183[\mathrm{M}+\mathrm{Na}]^{+}$

gef.: 396.1183 (ESI+-HRMS).

\subsubsection{2-lodoxybenzoesäure (IBX) $126^{[147]}$}<smiles>O=C1O[I-]([O-])(O)c2ccccc21</smiles>

126

In einem Dreihalskolben mit Rückflusskühler wurde Kaliumbromat (17.6 g, 0.107 mol) in $2 \mathrm{M} \mathrm{H}_{2} \mathrm{SO}_{4}(165 \mathrm{~mL})$ gelöst und allmählich auf $60^{\circ} \mathrm{C}$ erwärmt. Es wurde fein gepulverte 2-lodbenzoesäure 127 (18.0 g, $72.0 \mathrm{mmol}$ ) über einen Zeitraum von 40 min in Portionen zu je 3 bis $4 \mathrm{~g}$ dazugegeben, die Lösung auf $65^{\circ} \mathrm{C}$ erwärmt und weitere $3 \mathrm{~h}$ bei $65^{\circ} \mathrm{C}$ gerührt. Nach Abkühlen der Lösung auf Raumtemperatur wurde die Suspension auf $0^{\circ} \mathrm{C}$ gekühlt und filtriert. Der Filterkuchen wurde mit Ethanol und Wasser gewaschen und das Filtrat verworfen. Der erhaltene Feststoff wurde einige Stunden im Vakuum aufbewahrt und ohne weitere Reinigung verwendet.

Ausbeute: Es wurden $20.0 \mathrm{~g}(71.0 \mathrm{mmol}$, 98\%) eines leicht gelblichen Feststoffs erhalten.

${ }^{1} \mathrm{H}-N M R\left(300 \mathrm{MHz}, \mathrm{DMSO}-\mathrm{d}_{6}\right): \delta=7.84(\mathrm{dd}, J=7.6 \mathrm{~Hz}, J=7.6 \mathrm{~Hz}, 1 \mathrm{H}, 5-\mathrm{H}), 7.94-$ $8.08(\mathrm{~m}, 2 \mathrm{H}, 3-\mathrm{H}, 4-\mathrm{H}), 8.15(\mathrm{~d}, J=7.6 \mathrm{~Hz}, 1 \mathrm{H}, 6-\mathrm{H})$.

${ }^{13}$ C-NMR (75 MHz, DMSO-d 6 ): $\delta=129.90$ (C-5), 129.97 (C-3), 131.35 (C-2), 132.87 (C-6), 133.25 (C-4), $146.48(\mathrm{C}-2), 167.32(\mathrm{C}=\mathrm{O})$. 


\subsubsection{1,1,1-Triacetoxy-1,1-dihydro-1,2-benzoiodoxol-3(1H)-on (DMP) 128 ${ }^{[47]}$}

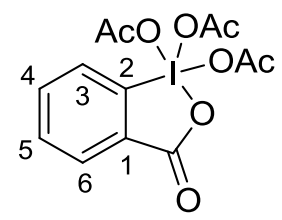

128

In einer Mischung aus Essigsäure $(76 \mathrm{~mL})$ und Acetanhydrid (152 mL) wurde IBX (39.0 g, $139 \mathrm{mmol}$ ) suspendiert. Die Suspension wurde unter Rühren allmählich auf $85^{\circ} \mathrm{C}$ erwärmt, bis eine klare Lösung entstand. Die Reaktionslösung wurde im noch heißen Ölbad belassen und langsam über Nacht abgekühlt. Der gebildete Niederschlag wurde durch Filtration unter Argon vom Lösungsmittel getrennt und mit abs. Diethylether $(3 \times 100 \mathrm{~mL})$ gewaschen. Der erhaltene, weiße Feststoff wurde mehrere Stunden unter vermindertem Druck von Lösungsmittelresten befreit.

Ausbeute: Es wurden $47.8 \mathrm{~g}$ (112 mmol, 81\%) eines weißen, kristallinen Feststoffs erhalten.

${ }^{1} \mathrm{H}-\mathrm{NMR}\left(300 \mathrm{MHz}, \mathrm{DMSO}-\mathrm{d}_{6}\right): \delta=1.99$ (s, $\left.6 \mathrm{H}, \mathrm{OAc}\right), 2.32$ (s, $\left.3 \mathrm{H}, \mathrm{OAc}\right), 7.89$ (td, $J=7.5 \mathrm{~Hz}, J=0.7 \mathrm{~Hz}, 1 \mathrm{H}, 5-\mathrm{H}), 8.07$ (td, $J=7.5 \mathrm{~Hz}, J=1.5 \mathrm{~Hz}, 1 \mathrm{H}, 4-\mathrm{H}), 8.28$ (d, $J=8.5 \mathrm{~Hz}, 1 \mathrm{H}, 3-\mathrm{H}), 8.30$ (dd, $J=7.5 \mathrm{~Hz}, J=1.5 \mathrm{~Hz}, 1 \mathrm{H}, 6-\mathrm{H})$.

${ }^{13}$ C-NMR $\left(75 \mathrm{MHz}, \mathrm{DMSO}-\mathrm{d}_{6}\right): \delta=20.24\left(\mathrm{CO}^{\mathrm{C}} \mathrm{H}_{3}\right), 20.39\left(\mathrm{CO}^{\mathrm{C}} \mathrm{H}_{3}\right), 126.03(\mathrm{C}-2)$, 126.49, 131.80, 133.80, 135.72 (C-3, C-4, C-5, C-6), $142.33(\mathrm{C}-1), 174.00\left(\mathrm{COCH}_{3}\right)$, 175.74 (ArCOO). 


\subsubsection{Synthese der 3'-O-TBDMS-Thymidinylaminosäuren (TAA)}

\subsubsection{3',5'-O-Bis-(tert-butyldimethylsilyl)-thymidin 129}

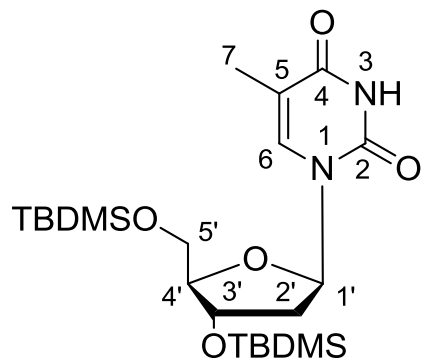

129

Thymidin 77 (10.0 g, $41.0 \mathrm{mmol})$ wurde mit Pyridin $(2 \times 40 \mathrm{~mL})$ coevaporiert und in $100 \mathrm{~mL}$ Pyridin gelöst. Es wurden Imidazol $(7.03 \mathrm{~g}, 103 \mathrm{mmol})$ und tertButyldimethylsilylchlorid $(15.5 \mathrm{~g}, 103 \mathrm{mmol})$ zugegeben und die Lösung $48 \mathrm{~h}$ bei Raumtemperatur gerührt. Es wurde auf $0^{\circ} \mathrm{C}$ gekühlt und die Lösung langsam mit $50 \mathrm{~mL}$ Wasser versetzt. Das Lösungsmittelgemisch wurde im Vakuum entfernt. Das Rohprodukt wurde in Ethylacetat $(500 \mathrm{~mL})$ gelöst und mit ges. wässriger $\mathrm{NaHCO}_{3}$ Lösung $(3 \times 250 \mathrm{~mL})$ und ges. NaCl-Lösung $(1 \times 100 \mathrm{~mL})$ gewaschen. Die organische Phase wurde über $\mathrm{Na}_{2} \mathrm{SO}_{4}$ getrocknet, filtriert und das Lösungsmittel im Vakuum entfernt. Das Rohprodukt wurde säulenchromatographisch an Kieselgel gereinigt (PE:EtOAc 4:1).

Ausbeute: $19.3 \mathrm{~g}(41.0 \mathrm{mmol}$, quantitativ) eines weißen Feststoffs.

DC: $R_{\mathrm{f}}(\mathrm{PE} / \mathrm{EtOAc} 1: 1)=0.56$.

${ }^{1} \mathrm{H}-\mathrm{NMR}\left(300 \mathrm{MHz}_{\mathrm{CDCl}}\right.$ ) : $\delta=0.06\left(\mathrm{~s}, 6 \mathrm{H}, \mathrm{SiCH}_{3}\right), 0.09\left(\mathrm{~s}, 6 \mathrm{H}, \mathrm{SiCH}_{3}\right), 0.87$ (s, $\left.9 \mathrm{H}, \mathrm{SiC}\left(\mathrm{CH}_{3}\right)_{3}\right), 0.90$ (s, $\left.9 \mathrm{H}, \operatorname{SiC}\left(\mathrm{CH}_{3}\right)_{3}\right), 1.89$ (d, J=1.2 Hz, $\left.3 \mathrm{H}, 7-\mathrm{H}\right), 1.97$ (ddd, $J=13.1 \mathrm{~Hz}, J=8.0 \mathrm{~Hz}, J=5.8 \mathrm{~Hz}, 1 \mathrm{H}, 2 '-\mathrm{H}_{\mathrm{a}}$ ), 2.22 (ddd, $J=13.1 \mathrm{~Hz}, J=5.8 \mathrm{~Hz}$, $\left.J=2.6 \mathrm{~Hz}, 1 \mathrm{H}, 2^{\prime}-\mathrm{H}_{\mathrm{b}}\right), 3.74$ (dd, J=11.4 Hz, J=2.5 Hz, $\left.1 \mathrm{H}, 5{ }^{\prime}-\mathrm{H}_{\mathrm{a}}\right) 3.85$ (dd, $J=11.4 \mathrm{~Hz}, J=2.5 \mathrm{~Hz}, 1 \mathrm{H}, 5^{\prime}-\mathrm{H}_{\mathrm{b}}$ ), 3.91 (dd, $\left.J=5.0 \mathrm{~Hz}, J=2.5 \mathrm{~Hz}, 1 \mathrm{H}, 4^{\prime}-\mathrm{H}\right), 4.35-$ $4.39\left(\mathrm{~m}, 1 \mathrm{H}, 3^{\prime}-\mathrm{H}\right), 6.32\left(\mathrm{dd}, J=8.0 \mathrm{~Hz}, J=5.8 \mathrm{~Hz}, 1 \mathrm{H}, 1^{\prime}-\mathrm{H}\right), 7.46(\mathrm{~d}, J=1.2 \mathrm{~Hz}$, $1 \mathrm{H}, 6-\mathrm{H}), 8.62(\mathrm{~s}, 1 \mathrm{H}, \mathrm{NH})$.

${ }^{13}$ C-NMR $\left(75 \mathrm{MHz}, \mathrm{CDCl}_{3}\right): \delta=-5.50\left(\mathrm{SiCH}_{3}\right),-5.41\left(\mathrm{SiCH}_{3}\right),-4.88\left(\mathrm{SiCH}_{3}\right),-4.68$ $\left(\mathrm{SiCH}_{3}\right), 12.49(\mathrm{C}-7), 17.96\left(\mathrm{Si} \underline{\mathrm{C}}\left(\mathrm{CH}_{3}\right)_{3}\right), 18.35\left(\mathrm{Si} \underline{\mathrm{C}}\left(\mathrm{CH}_{3}\right)_{3}\right), 25.71\left(\mathrm{SiC}\left(\underline{\mathrm{C}} \mathrm{H}_{3}\right)_{3}\right), 25.89$ $\left(\mathrm{SiC}\left(\underline{\mathrm{CH}}_{3}\right)_{3}\right), 41.34$ (C-2'), 62.92 (C-5'), 72.18 (C-3'), 84.77 (C-1'), 87.76 (C-4'), 110.80 (C-5), 135.41 (C-6), 150.36 (C-2), 163.92 (C-4). 
Drehwert: $[\alpha]_{D}^{20}=+17.0\left(\mathrm{c}=1.1, \mathrm{CHCl}_{3}\right)$.

Schmelzpunkt: $135^{\circ} \mathrm{C}$.

IR $(\mathrm{KBr}): \tilde{v}=2954,2858,1706,1473,1256,1197,1093,967,776$.

UV (MeCN): $\lambda_{\max }(\lg \varepsilon)=264.5(4.00)$.

MS $\left(\mathrm{ESI}^{+}\right): \mathrm{m} / \mathrm{z}=493.3[\mathrm{M}+\mathrm{Na}]^{+}$.

$\mathrm{C}_{22} \mathrm{H}_{42} \mathrm{~N}_{2} \mathrm{O}_{5} \mathrm{Si}_{2}(470.75) \quad$ ber.: $493.2530[\mathrm{M}+\mathrm{Na}]^{+}$, gef.: 493.2530 (ESI+-HRMS).

7.2.2.2 3',5'-O-Bis-(tert-butyldimethylsilyl)-3- $N$-(benzyloxymethyl)-thymidin 130

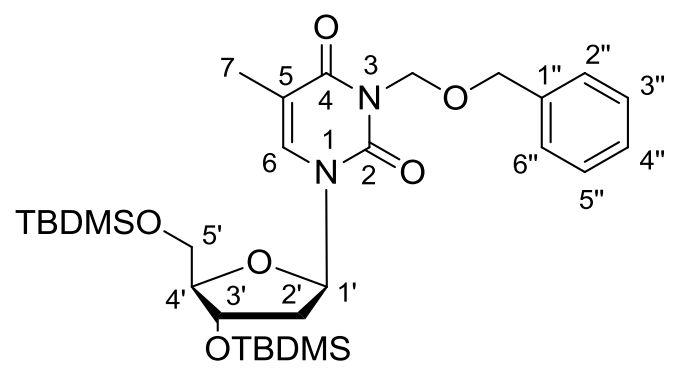

130

Zu einer auf $-10^{\circ} \mathrm{C}$ gekühlten Suspension von Natriumhydrid (461 mg, $19.2 \mathrm{mmol}$, $60 \%$ Suspension in Mineralöl) in DMF (30 mL) wurde eine Lösung von 3',5'-O-Bis(tert-butyldimethylsilyl)-thymidin $129(5.00 \mathrm{~g}, 10.6 \mathrm{mmol})$ in DMF $(17 \mathrm{~mL})$ langsam getropft. Die erhaltene Lösung wurde $20 \mathrm{~min}$. bei $-5^{\circ} \mathrm{C}$ gerührt und anschließend Benzylchlormethylether $(1.53 \mathrm{~mL}, 1.99 \mathrm{~g}, 12.8 \mathrm{mmol})$ allmählich dazugegeben. Die erhaltene Lösung wurde $3 \mathrm{~h}$ bei $0^{\circ} \mathrm{C}$ gerührt. Anschließend wurde die Reaktionslösung mit Ethylacetat $(200 \mathrm{~mL})$ verdünnt und langsam mit $\mathrm{H}_{2} \mathrm{O}(60 \mathrm{~mL})$ versetzt. Die organische Phase wurde mit ges. $\mathrm{NaHCO}_{3}$-Lösung $(2 \times 150 \mathrm{~mL})$ und mit ges. $\mathrm{NaCl}$-Lösung $(80 \mathrm{~mL})$ gewaschen, über $\mathrm{NaSO}_{4}$ getrocknet, filtriert und das Lösungsmittel im Vakuum entfernt. Das erhaltene Rohprodukt wurde säulenchromatographisch an Kieselgel gereinigt (PE/EtOAc 4:1).

Ausbeute: $6.00 \mathrm{~g}$ (10.2 mmol, 96\%) eines farblosen, hochviskosen Öls.

DC: $R_{\mathrm{f}}(\mathrm{PE} / \mathrm{EtOAc} 4: 1)=0.48$.

${ }^{1} \mathrm{H}-\mathrm{NMR}\left(300 \mathrm{MHz}, \mathrm{CDCl}_{3}\right): \delta=0.05\left(\mathrm{~s}, 3 \mathrm{H}, \mathrm{SiCH}_{3}\right), 0.06\left(\mathrm{~s}, 3 \mathrm{H}, \mathrm{SiCH}_{3}\right), 0.09$ (s, $\left.6 \mathrm{H}, \mathrm{SiCH}_{3}\right), 0.87\left(\mathrm{~s}, 9 \mathrm{H}, \mathrm{SiC}\left(\mathrm{CH}_{3}\right)_{3}\right), 0.91\left(\mathrm{~s}, 9 \mathrm{H}, \mathrm{SiC}\left(\mathrm{CH}_{3}\right)_{3}\right), 1.89$ (d, $J=0.9 \mathrm{~Hz}$, $3 \mathrm{H}, 7-\mathrm{H}$ ), 1.96 (ddd, $J=13.1 \mathrm{~Hz}, J=7.8 \mathrm{~Hz}, J=6.0 \mathrm{~Hz}, 1 \mathrm{H}, 2$ '- $\mathrm{H}_{\mathrm{a}}$ ), 2.24 (ddd, 
$\left.J=13.1 \mathrm{~Hz}, J=5.8 \mathrm{~Hz}, J=2.6 \mathrm{~Hz}, 1 \mathrm{H}, 2^{\prime}-\mathrm{H}_{\mathrm{b}}\right), 3.74(\mathrm{dd}, J=11.4 \mathrm{~Hz}, J=2.6 \mathrm{~Hz}$, $1 \mathrm{H}, 5^{\prime}-\mathrm{H}_{\mathrm{a}}$ ), 3.85 (dd, $J=11.4 \mathrm{~Hz}, J=2.6 \mathrm{~Hz}, 5-\mathrm{H}_{\mathrm{b}}$ ), 3.91 (dd, $J=4.5 \mathrm{~Hz}, J=2.6 \mathrm{~Hz}$, $\left.1 \mathrm{H}, 4^{\prime}-\mathrm{H}\right)$ 4.35-4.39 (m, $\left.1 \mathrm{H}, 3^{\prime}-\mathrm{H}\right), 4.68\left(\mathrm{~s}, 2 \mathrm{H}, \mathrm{NCH}_{2} \mathrm{OCH}_{2}\right), 5.47$ (s, $\left.2 \mathrm{H}, \mathrm{NCH}_{2} \mathrm{O}\right)$, $6.33\left(\mathrm{dd}, J=7.8 \mathrm{~Hz}, J=5.8 \mathrm{~Hz}, 1 \mathrm{H}, 1^{\prime}-\mathrm{H}\right), 7.23-7.43(\mathrm{~m}, 5 \mathrm{H}, \mathrm{ArH}), 7.28(\mathrm{~d}$, $J=0.9 \mathrm{~Hz}, 1 \mathrm{H}, 6-\mathrm{H})$.

${ }^{13} \mathrm{C}$-NMR $\left(75 \mathrm{MHz}, \mathrm{CDCl}_{3}\right): \delta=-5.47\left(\mathrm{SiCH}_{3}\right),-5.39\left(\mathrm{SiCH}_{3}\right),-4.86\left(\mathrm{SiCH}_{3}\right),-4.65$ $\left(\mathrm{SiCH}_{3}\right), 13.23(\mathrm{C}-7), 17.98\left(\mathrm{SiC}\left(\mathrm{CH}_{3}\right)_{3}\right), 18.38\left(\mathrm{Si} \underline{C}\left(\mathrm{CH}_{3}\right)_{3}\right), 25.72\left(\mathrm{SiC}\left(\underline{\mathrm{C}} \mathrm{H}_{3}\right)_{3}\right), 25.91$ $\left(\mathrm{SiC}\left(\underline{\mathrm{C}}_{3}\right)_{3}\right), 41.41 \quad\left(\mathrm{C}-2^{\prime}\right), 62.95 \quad\left(\mathrm{C}-5^{\prime}\right), 70.49 \quad\left(\mathrm{NCH}_{2} \mathrm{O}\right), 72.15 \quad\left(\mathrm{C}^{\prime} \mathbf{3}^{\prime}\right), \quad 72.23$ $\left(\mathrm{NCH}_{2} \mathrm{O}_{\mathrm{CH}}\right.$ ), 85.49 (C-1'), 87.80 (C-4'), 110.07 (C-5), 127.57 (C-4"), 127.65 (C-3", C-5"), 128.24 (C-2", C-6"), 134.18 (C-6), 138.01 (C-1"), 150.95 (C-2), 163.52 (C-4).

Drehwert: $[\alpha]_{D}^{20}=+17.7\left(\mathrm{c}=1.0, \mathrm{CHCl}_{3}\right)$.

IR $(\mathrm{KBr}): \tilde{v}=2929,1712,1670,1464,1361,1255,1106,836,775$.

UV (MeCN): $\lambda_{\max }(\lg \varepsilon)=205$ (4.30), 268 (3.94).

MS $\left(E S I^{+}\right): m / z=613.3[\mathrm{M}+\mathrm{Na}]^{+}$.

$\mathrm{C}_{30} \mathrm{H}_{50} \mathrm{~N}_{2} \mathrm{O}_{6} \mathrm{Si}_{2}(590.90)$

ber.: $613.3105[\mathrm{M}+\mathrm{Na}]^{+}$, gef.: 613.3109 (ESI+-HRMS).

\subsubsection{3'-O-(tert-Butyldimethylsilyl)-3-N-(benzyloxymethyl)-thymidin 131}

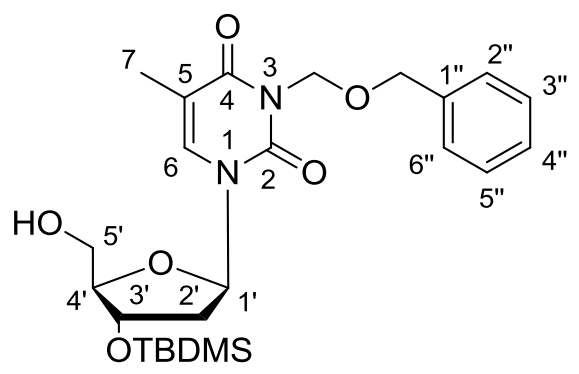

131

Zu einer auf $-10^{\circ} \mathrm{C}$ gekühlten Lösung von $130(6.00 \mathrm{~g}, 10.2 \mathrm{mmol})$ in Methanol $(300 \mathrm{~mL})$ wurde allmählich Acetylchlorid $(160 \mathrm{mg}, 145 \mu \mathrm{L}, 2.03 \mathrm{mmol})$ gegeben und die Lösung auf $0{ }^{\circ} \mathrm{C}$ gebracht. Die resultierende Reaktionslösung wurde ca. $3 \mathrm{~h}$ bei $0{ }^{\circ} \mathrm{C}$ gerührt und dünnschichtchromatographisch verfolgt $\left(\mathrm{SiO}_{2}, \mathrm{PE} / \mathrm{EtOAc} \mathrm{1:1)}\right.$. Es wurde ges. $\mathrm{NaHCO}_{3}$-Lösung $(10 \mathrm{~mL})$ dazugegeben und die Lösung weitere $15 \mathrm{~min}$ gerührt. Anschließend wurde die Reaktionslösung mit Ethylacetat $(300 \mathrm{~mL})$ verdünnt. Die organische Phase wurde mit ges. $\mathrm{NaHCO}_{3}(2 \times 100 \mathrm{~mL})$ und Wasser $(100 \mathrm{~mL})$ gewaschen, über $\mathrm{Na}_{2} \mathrm{SO}_{4}$ getrocknet und bei vermindertem Druck eingeengt. Das 
verbliebene farblose Öl wurde chromatographisch an Kieselgel gereinigt (PE/EtOAc $1: 1)$.

Ausbeute: $2.82 \mathrm{~g}(5.92 \mathrm{mmol}, 59 \%)$ eines farblosen, hochviskosen Öls.

DC: $R_{\mathrm{f}}(\mathrm{PE} / \mathrm{EtOAc} 1: 1)=0.38$.

${ }^{1} \mathrm{H}-\mathrm{NMR}\left(300 \mathrm{MHz}, \mathrm{CDCl}_{3}\right): \delta=0.06\left(\mathrm{~s}, 6 \mathrm{H}, \mathrm{SiCH}_{3}\right), 0.88\left(\mathrm{~s}, 9 \mathrm{H}, \mathrm{SiC}\left(\mathrm{CH}_{3}\right)_{3}\right), 1.88$ (d, $J=1.0 \mathrm{~Hz}, 3 \mathrm{H}, 7-\mathrm{H}), 2.15-2.31\left(\mathrm{~m}, 2 \mathrm{H}, 2^{\prime}-\mathrm{H}_{\mathrm{a}}, 2\right.$ '- $\mathrm{H}_{\mathrm{b}}$ ), 2.62 (brs, $\left.1 \mathrm{H}, \mathrm{OH}\right), 3.68-$ $3.76\left(\mathrm{~m}, 1 \mathrm{H}, 5^{\prime}-\mathrm{H}_{\mathrm{a}}\right), 3.84-3.93\left(\mathrm{~m}, 2 \mathrm{H}, 4^{\prime}-\mathrm{H}, 5^{\prime}-\mathrm{H}_{\mathrm{b}}\right), 4.43-4.42\left(\mathrm{~m}, 1 \mathrm{H}, 3^{\prime}-\mathrm{H}\right), 4.67(\mathrm{~s}$, $2 \mathrm{H}, \mathrm{NCH}_{2} \mathrm{OCH}_{2}$ ), $5.46\left(\mathrm{~s}, 2 \mathrm{H}, \mathrm{NCH}_{2} \mathrm{O}\right), 6.14\left(\mathrm{dd}, J=6.9 \mathrm{~Hz}, J=6.7 \mathrm{~Hz}, 1 \mathrm{H}, 1^{\prime}-\mathrm{H}\right)$, 7.21-7.35 (m, $5 \mathrm{H}, \mathrm{ArH}), 7.37$ (d, $J=1.0 \mathrm{~Hz}, 1 \mathrm{H}, 6-\mathrm{H})$.

${ }^{13} \mathrm{C}-\mathrm{NMR}\left(75 \mathrm{MHz}, \mathrm{CDCl}_{3}\right): \delta=-4.80\left(\mathrm{SiCH}_{3}\right),-4.63\left(\mathrm{SiCH}_{3}\right), 13.26(\mathrm{C}-7), 17.97$ $\left(\mathrm{Si} \underline{\mathrm{C}}\left(\mathrm{CH}_{3}\right)_{3}\right), 25.72\left(\mathrm{Si}\left(\mathrm{C}\left(\underline{\mathrm{C}} \mathrm{H}_{3}\right)_{3}\right), 40.66\left(\mathrm{C}-2^{\prime}\right), 61.99\left(\mathrm{C}-5^{\prime}\right), 70.49\left(\mathrm{NCH}_{2} \mathrm{O}\right), 71.56\right.$ (C-3'), $72.17\left(\mathrm{NCH}_{2} \mathrm{O} \underline{\mathrm{C}} \mathrm{H}_{2}\right), 87.24$ (C-1'), 87.45 (C-4'), 110.12 (C-5), 127.48 (C-4"), 127.51 (C-3", C-5"), 128.13 (C-2",C-6"), 135.41 (C-6), 137.81 (C-1"), 150.83 (C-2), 163.27 (C-4).

Drehwert: $[\alpha]_{\mathrm{D}}^{20}=+21.0\left(\mathrm{c}=1.1, \mathrm{CHCl}_{3}\right)$.

IR $(\mathrm{KBr}): \tilde{v}=2930,1667,1468,1362,1253,1101,835,776,698$.

UV (MeCN): $\lambda_{\max }(\lg \varepsilon)=205$ (4.28), 268 (3.96).

MS $\left(\mathrm{ESI}^{+}\right): \mathrm{m} / \mathrm{z}=499.2[\mathrm{M}+\mathrm{Na}]^{+}$.

$\mathrm{C}_{24} \mathrm{H}_{36} \mathrm{~N}_{2} \mathrm{O}_{6} \mathrm{Si}(476.64)$

ber.: $499.2240[\mathrm{M}+\mathrm{Na}]^{+}$, gef.: 499.2234 (ESI $\left.{ }^{+}-\mathrm{HRMS}\right)$.

\subsubsection{3'-O-(tert-Butyldimethylsilyl)-thymidin 132}

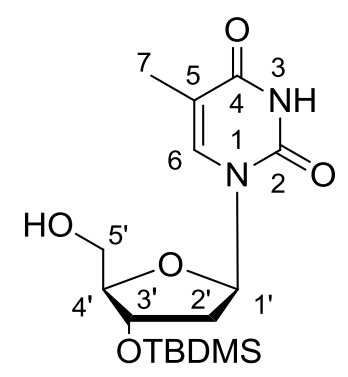

132

Zu einer auf $-10^{\circ} \mathrm{C}$ gekühlten Lösung von $129(7.00 \mathrm{~g}, 14.9 \mathrm{mmol})$ in Methanol $(340 \mathrm{~mL}$ ) wurde allmählich Acetylchlorid $(291 \mathrm{mg}, 265 \mu \mathrm{L}, 3.73 \mathrm{mmol})$ gegeben und die Lösung auf $0{ }^{\circ} \mathrm{C}$ gebracht. Die resultierende Reaktionslösung wurde ca. $3 \mathrm{~h}$ bei 
$0{ }^{\circ} \mathrm{C}$ gerührt und die Reaktion dünnschichtchromatographisch verfolgt $\left(\mathrm{SiO}_{2}\right.$, $\mathrm{PE} /$ EtOAc 1:1). Es wurde ges. $\mathrm{NaHCO}_{3}$-Lösung $(50 \mathrm{~mL})$ dazugegeben und die Lösung weitere $15 \mathrm{~min}$ gerührt. Anschließend wurde die Reaktionslösung mit Ethylacetat $(300 \mathrm{~mL})$ verdünnt. Die organische Phase wurde mit ges. $\mathrm{NaHCO}_{3}$ Lösung $(2 \times 100 \mathrm{~mL})$, Wasser $(100 \mathrm{~mL})$ und ges. NaCl-Lösung $(100 \mathrm{~mL})$ gewaschen, über $\mathrm{Na}_{2} \mathrm{SO}_{4}$ getrocknet und bei vermindertem Druck eingeengt. Das verbliebene farblose Öl wurde chromatographisch an Kieselgel gereinigt (PE/EtOAc 1:1).

Ausbeute: $3.50 \mathrm{~g}(9.83 \mathrm{mmol}, 66 \%)$ eines weißen Feststoffs.

DC: $R_{\mathrm{f}}(\mathrm{PE} / \mathrm{EtOAc} 1: 1)=0.15$.

${ }^{1} \mathrm{H}-\mathrm{NMR}\left(300 \mathrm{MHz}, \mathrm{CDCl}_{3}\right): \delta=0.05\left(\mathrm{~s}, 6 \mathrm{H}, \mathrm{SiCH}_{3}\right), 0.86\left(\mathrm{~s}, 9 \mathrm{H}, \mathrm{SiC}\left(\mathrm{CH}_{3}\right)_{3}\right), 1.86$ (d, $J=1.1 \mathrm{~Hz}, 3 \mathrm{H}, 7-\mathrm{H}$ ), 2.16 (ddd, $J=13.4 \mathrm{~Hz}, J=6.4 \mathrm{~Hz}, J=3.6 \mathrm{~Hz}, 1 \mathrm{H}, 2^{\prime}-\mathrm{H}_{\mathrm{a}}$ ), 2.31 (ddd, $J=13.4 \mathrm{~Hz}, J=6.7 \mathrm{~Hz}, J=6.7 \mathrm{~Hz}, 1 \mathrm{H}, 2^{\prime}-\mathrm{H}_{\mathrm{b}}$ ), 2.96 (brs, $1 \mathrm{H}, \mathrm{OH}$ ), 3.72 (dd, $J=12.2 \mathrm{~Hz}, J=3.3 \mathrm{~Hz}, 1 \mathrm{H}, 5^{\prime}-\mathrm{H}_{\mathrm{a}}$ ), 3.84-3.91 (m, $2 \mathrm{H}, 4^{\prime}-\mathrm{H}, 5^{\prime}-\mathrm{H}_{\mathrm{b}}$ ), 4.46 (ddd, $J=6.4 \mathrm{~Hz}, J=3.6 \mathrm{~Hz}, J=3.6 \mathrm{~Hz}, 1 \mathrm{H}, 3^{\prime}-\mathrm{H}$ ), $6.12(\mathrm{dd}, J=6.7 \mathrm{~Hz}, J=6.7 \mathrm{~Hz}, 1 \mathrm{H}$, $\left.1^{\prime}-\mathrm{H}\right), 7.37(\mathrm{~d}, J=1.1 \mathrm{~Hz}, 1 \mathrm{H}, 6-\mathrm{H})$.

${ }^{13} \mathrm{C}$-NMR $\left(75 \mathrm{MHz}, \mathrm{CDCl}_{3}\right): \delta=-4.90\left(\mathrm{SiCH}_{3}\right),-4.74\left(\mathrm{SiCH}_{3}\right), 12.44(\mathrm{C}-7), 17.91$ ( $\left.\mathrm{Si} \underline{\mathrm{C}}\left(\mathrm{CH}_{3}\right)_{3}\right), 25.67\left(\mathrm{Si}\left(\mathrm{C}\left(\underline{\mathrm{C}} \mathrm{H}_{3}\right)_{3}\right), 40.45\right.$ (C-2'), 61.89 (C-5'), 71.53 (C-3'), 86.74 (C-1'), 87.56 (C-4'), 110.93 (C-5), 137.03 (C-6), 150.40 (C-2), 163.96 (C-4).

Drehwert: $[\alpha]_{D}^{20}=+27.0\left(\mathrm{c}=1.0, \mathrm{CHCl}_{3}\right)$.

Schmelzpunkt: $109^{\circ} \mathrm{C}$.

IR $(\mathrm{KBr}): \tilde{v}=1690,1666,1108,1088,1056,1032,1017,831,774$.

UV (MeCN): $\lambda_{\max }(\lg \varepsilon)=207$ (3.99), 265 (4.02).

MS $\left(\mathrm{ESI}^{+}\right): \mathrm{m} / \mathrm{z}=379.2[\mathrm{M}+\mathrm{Na}]^{+}$

$\mathrm{C}_{16} \mathrm{H}_{28} \mathrm{~N}_{2} \mathrm{O}_{5} \mathrm{Si}(356.45)$

ber.: $379.1660[\mathrm{M}+\mathrm{H}]^{+}$, gef.: 379.1659 (ESI ${ }^{+}$-HRMS). 


\subsubsection{3'-O-(tert-Butyldimethylsilyl)-3-N-(benzyloxymethyl)-thymidin-5'- aldehyd 78}

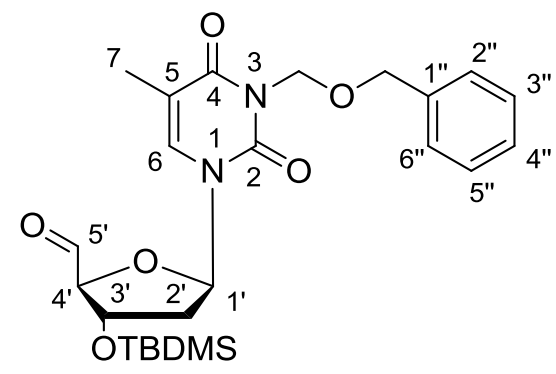

78

Eine Lösung von 3'-O-(tert-Butyldimethylsilyl)-3- $\mathrm{N}$-(benzyloxymethyl)-thymidin 131 $(1.00 \mathrm{~g}, 2.10 \mathrm{mmol})$ in Acetonitril $(20 \mathrm{~mL})$ wurde mit $1.47 \mathrm{~g}(5.25 \mathrm{mmol})$ 2-lodoxybenzoesäure versetzt und $30 \mathrm{~min}$ am Rückfluss erhitzt. Nachdem die Reaktionslösung auf Raumtemperatur abgekühlt war, wurde sie über eine Glasfritte filtriert und der Filterkuchen mit Ethylacetat $(3 \times 10 \mathrm{~mL})$ nachgewaschen. Das Filtrat wurde im Vakuum zur Trockne eingeengt und der so erhaltene Rückstand direkt weiterverwendet. Aufgrund der Empfindlichkeit der Substanz wurde auf eine chromatographische Reinigung verzichtet.

Ausbeute: $990 \mathrm{mg}$ (2.08 mmol, 99\%) eines farblosen Schaums.

DC: $R_{\mathrm{f}}(\mathrm{PE} / \mathrm{EtOAc} 1: 1)=0.30$.

${ }^{1} \mathrm{H}$-NMR $\left(300 \mathrm{MHz}, \mathrm{C}_{6} \mathrm{D}_{6}\right): \delta=-0.04\left(\mathrm{~s}, 3 \mathrm{H}, \mathrm{SiCH}_{3}\right),-0.03\left(\mathrm{~s}, 3 \mathrm{H}, \mathrm{SiCH}_{3}\right), 0.85$ (s, $\left.9 \mathrm{H}, \mathrm{SiC}\left(\mathrm{CH}_{3}\right)_{3}\right), 1.67$ (ddd, $J=13.6 \mathrm{~Hz}, J=7.4 \mathrm{~Hz}, J=5.8 \mathrm{~Hz}, 1 \mathrm{H}, 2^{\prime}-\mathrm{H}_{\mathrm{b}}$ ), 1.73 (d, $J=1.2 \mathrm{~Hz}, 3 \mathrm{H}, 7-\mathrm{H}$ ), 1.84 (ddd, $J=13.6 \mathrm{~Hz}, J=6.5 \mathrm{~Hz}, J=2.1 \mathrm{~Hz}, 1 \mathrm{H}, 2^{\prime}-\mathrm{H}_{\mathrm{a}}$ ), 4.04 (d, $J=2.1 \mathrm{~Hz}, 1 \mathrm{H}, 4^{\prime}-\mathrm{H}$ ), 4.40 (ddd, J=5.8 Hz, J=2.1 Hz, J=2.1 Hz, $1 \mathrm{H}, 3^{\prime}-\mathrm{H}$ ), $4.63\left(\mathrm{~s}, 2 \mathrm{H}, \mathrm{NCH}_{2} \mathrm{OCH}_{2}\right), 5.39\left(\mathrm{~s}, 2 \mathrm{H}, \mathrm{NCH}_{2} \mathrm{O}\right), 5.83(\mathrm{dd}, J=6.5 \mathrm{~Hz}, J=6.5 \mathrm{~Hz}$, $\left.1 \mathrm{H}, 1^{\prime}-\mathrm{H}\right), 6.68(\mathrm{~d}, J=1.2 \mathrm{~Hz}, 1 \mathrm{H}, 6-\mathrm{H}), 6.99\left(\mathrm{~d}, J=7.2 \mathrm{~Hz}, 1 \mathrm{H}, 4{ }^{\prime \prime}-\mathrm{H}\right), 7.07$ (dd, $J=7.5 \mathrm{~Hz}, J=7.5 \mathrm{~Hz}, 2 \mathrm{H}, 3$ "'-H, 5"-H), 7.29 (d, $J=7.5 \mathrm{~Hz}, 2 \mathrm{H}, 2$ "'-H, 6"-H), 9.27 (s, $\left.1 \mathrm{H}, 5^{\prime}-\mathrm{H}\right)$.

${ }^{13} \mathrm{C}$-NMR $\left(75 \mathrm{MHz}, \mathrm{C}_{6} \mathrm{D}_{6}\right): \delta=-4.76\left(\mathrm{SiCH}_{3}\right),-4.67\left(\mathrm{SiCH}_{3}\right), 13.40$ (C-7), 18.22 ( $\left.\left.\mathrm{SiC}\left(\mathrm{CH}_{3}\right)_{3}\right), 25.95\left(\mathrm{SiC}\left(\underline{\mathrm{C}} \mathrm{H}_{3}\right)_{3}\right), 39.79(\mathrm{C}-2)^{\prime}\right), 70.83\left(\mathrm{NCH}_{2} \mathrm{O}_{2} \mathrm{H}_{2}\right), 72.43\left(\mathrm{NCH}_{2} \mathrm{O}\right)$, 73.57 (C-3'), 90.47 (C-1'), 92.27 (C-4'), 110.13 (C-5), 127.59 (C-4"), 127.71 (C-3", C-5"), 128.11 (C-2",C-6"), 135.64 (C-6), 138.91 (C-1"), 150.83 (C-2), 163.27 (C-4), $198.73\left(C^{-}-5^{\prime}\right)$.

Drehwert: $[\alpha]_{D}^{20}=+20.9\left(\mathrm{c}=1.0, \mathrm{CHCl}_{3}\right)$. 
IR $(\mathrm{KBr}): \tilde{v}=2955,1669,1467,1362,1253,1074,834,775,697$.

UV $(\mathrm{MeCN}): \lambda_{\max }(\lg \varepsilon)=267$ (4.94).

MS $\left(\mathrm{ESI}^{-}\right): \mathrm{m} / \mathrm{z}=473.2[\mathrm{M}-\mathrm{H}]^{-}$.

$\mathrm{C}_{24} \mathrm{H}_{34} \mathrm{~N}_{2} \mathrm{O}_{6} \mathrm{Si}(474.62)$

ber.: $473.2113[\mathrm{M}-\mathrm{H}]$,

gef.: 473.2108 (ESI-HRMS).

7.2.2.6 (Z)-3-N-BOM-6'-N-Cbz-O-t-Bu-5',6'-didehydro-3'-O-TBDMS-TAA 80 und (E)-3-N-BOM-6'-N-Cbz-O-t-Bu-5',6'-didehydro-3'-O-TBDMS-TAA 80

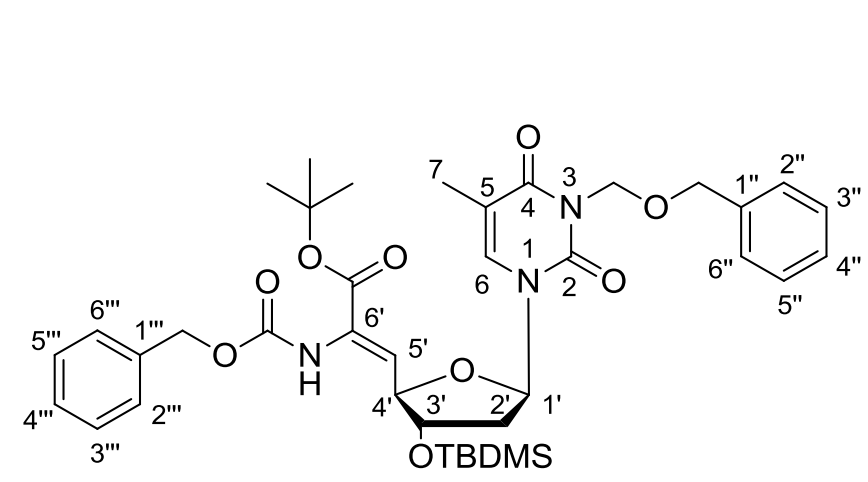

$Z-80$

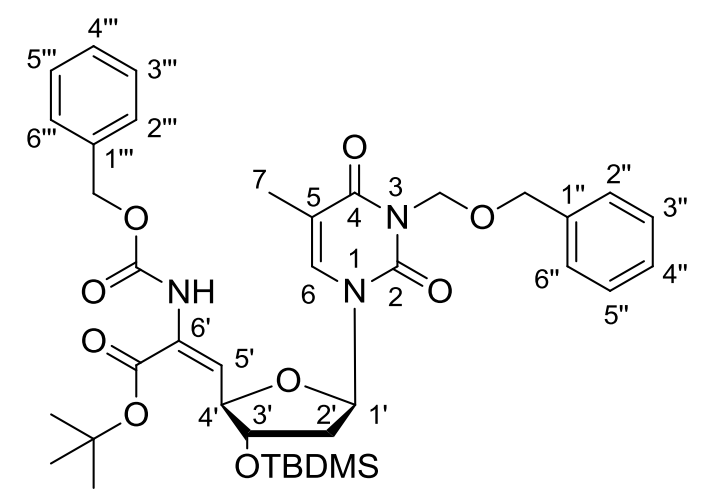

$E-80$

Zu einer auf $-78^{\circ} \mathrm{C}$ gekühlten Lösung von $\mathrm{KO}^{t} \mathrm{Bu}(828 \mathrm{mg}, 7.39 \mathrm{mmol})$ in abs. THF $(70 \mathrm{~mL})$ wurde eine Lösung des Phosphonats $79(2.97 \mathrm{~g}, 7.96 \mathrm{mmol})$ in abs. THF $(60 \mathrm{~mL})$ getropft und $5 \mathrm{~min}$ bei $-78^{\circ} \mathrm{C}$ gerührt. Es wurde eine Lösung von $3^{\prime}-\mathrm{O}$-(tertButyldimethylsilyl)-3- $N$-(benzyloxymethyl)-thymidin-5'-aldehyd $78(3.50 \mathrm{~g}, 7.39 \mathrm{mmol})$ in abs. THF (30 mL) bei $-78{ }^{\circ} \mathrm{C}$ zugegeben, die resultierende Lösung $16 \mathrm{~h}$ gerührt und im Laufe dieses Zeitraums langsam auf Raumtemperatur erwärmt. Die Reaktionslösung wurde auf $0^{\circ} \mathrm{C}$ gekühlt, mit Methanol $(5 \mathrm{~mL})$ versetzt und mit Ethylacetat $(300 \mathrm{~mL})$ verdünnt. Die organische Phase wurde mit Wasser $(3 \times 100 \mathrm{~mL})$ gewaschen, über $\mathrm{Na}_{2} \mathrm{SO}_{4}$ getrocknet und filtriert. Das Lösungmittel wurde im Vakuum entfernt. Beide Titelverbindungen wurden nach säulenchromatographischer Reinigung an Kieselgel (PE/EtOAc 4:1) erhalten.

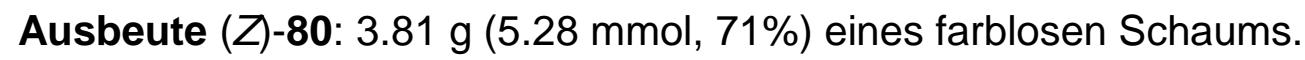

Ausbeute $(E)-80: 138 \mathrm{mg}(0.191 \mathrm{mmol}, 3 \%)$ eines farblosen Schaums.

Analytische Daten von (Z)-80:

DC: $R_{\mathrm{f}}(\mathrm{PE} / \mathrm{EtOAc} 1: 1)=0.51$. 
${ }^{1} \mathrm{H}$-NMR $\left(300 \mathrm{MHz}, \mathrm{CDCl}_{3}\right): \delta=0.08\left(\mathrm{~s}, 6 \mathrm{H}, \mathrm{SiCH}_{3}\right), 0.87\left(\mathrm{~s}, 9 \mathrm{H}, \mathrm{SiC}\left(\mathrm{CH}_{3}\right)_{3}\right), 1.46$ (s, $9 \mathrm{H}, t-$ Bu-CH$_{3}$ ), 1.91 (d, $J=1.2 \mathrm{~Hz}, 3 \mathrm{H}, 7-\mathrm{H}$ ), 2.10 (dd, $J=13.4 \mathrm{~Hz}, J=6.7 \mathrm{~Hz}$, 2' $-\mathrm{H}_{\mathrm{a}}$ ), 2.36 (ddd, $J=13.4 \mathrm{~Hz}, J=6.3 \mathrm{~Hz}, J=4.3 \mathrm{~Hz}, 1 \mathrm{H}, 2^{\prime}-\mathrm{H}_{\mathrm{b}}$ ), 4.32 (ddd, $J=6.3 \mathrm{~Hz}, J=4.3 \mathrm{~Hz}, J=4.3 \mathrm{~Hz}, 1 \mathrm{H}, 3^{\prime}-\mathrm{H}$ ), 4.68 (s, $2 \mathrm{H}, \mathrm{NCH}_{2} \mathrm{OC}_{2}$ ), 4.69 (dd, $\left.J=7.8 \mathrm{~Hz}, J=4.3 \mathrm{~Hz}, 1 \mathrm{H}, 4{ }^{\prime}-\mathrm{H}\right), 5.08-5.15\left(\mathrm{~m}, 2 \mathrm{H}, \mathrm{CbzCH}_{2}\right), 5.46\left(\mathrm{~s}, 2 \mathrm{H}, \mathrm{NCH}_{2} \mathrm{O}\right.$ ), $6.12\left(\mathrm{~d}, J=7.8 \mathrm{~Hz}, 1 \mathrm{H}, 5^{\prime}-\mathrm{H}\right), 6.18\left(\mathrm{dd}, J=6.7 \mathrm{~Hz}, J=6.7 \mathrm{~Hz}, 1 \mathrm{H}, 1^{\prime}-\mathrm{H}\right), 6.77$ (brs, $1 \mathrm{H}, \mathrm{NH}), 7.08(\mathrm{~d}, J=1.2 \mathrm{~Hz}, 1 \mathrm{H}, 6-\mathrm{H}), 7.22-7.36(\mathrm{~m}, 10 \mathrm{H}, \mathrm{ArH})$.

${ }^{13} \mathrm{C}-\mathrm{NMR}\left(75 \mathrm{MHz}, \mathrm{CDCl}_{3}\right): \delta=-4.93\left(\mathrm{SiCH}_{3}\right),-4.79\left(\mathrm{Si} \underline{\mathrm{C}} \mathrm{H}_{3}\right), 13.35$ (C-7), 17.87 $\left(\mathrm{Si} \underline{\mathrm{C}}\left(\mathrm{CH}_{3}\right)_{3}\right), 25.31\left(\mathrm{SiC}\left(\underline{\mathrm{CH}}_{3}\right)_{3}\right), 25.64\left(\mathrm{OC}\left(\underline{\mathrm{CH}}_{3}\right)_{3}\right), 40.53\left(\mathrm{C}-2{ }^{\prime}\right), 67.57\left(\mathrm{CbzCH}_{2}\right)$, $70.49\left(\mathrm{NCH}_{2} \mathrm{O}\right), 72.21\left(\mathrm{NCH}_{2} \mathrm{OCH}_{2}\right), 75.95\left(\mathrm{C}-3^{\prime}\right), 77.20\left(\mathrm{O} \underline{\mathrm{C}}\left(\mathrm{CH}_{3}\right)_{3}\right), 82.68\left(\mathrm{C}-4^{\prime}\right)$, 86.83 (C-1'), 110.07 (C-5), 124.72 (C-5'), 127.60 (C-4"), 127.64 (C-3", C-5"), 128.23 (C-2",C-6"), 128.24 (C-4"'), 128.34 (C-3"', C-5"'), 128.52 (C-2"', C-6"'), 130.39 (C-6'), 134.03 (C-6), 135.65 (C-1"), 137.94 (C-1'”), 150.71 (C-2), 153.52 (Cbz-C=O), 162.73 (C-4), 163.30 (Ester-C=O).

Drehwert: $[\alpha]_{D}^{20}=+51.1\left(\mathrm{C}=1.1, \mathrm{CHCl}_{3}\right)$.

IR $(\mathrm{KBr}): \tilde{v}=2930,1667,1466,1367,1257,1071,837,775,698$.

UV (MeCN): $\lambda_{\max }(\lg \varepsilon)=191$ (5.03), 205 (4.52), 263 (4.11).

MS $\left(\mathrm{ESI}^{+}\right): \mathrm{m} / \mathrm{z}=744.3[\mathrm{M}+\mathrm{Na}]^{+}$.

$\mathrm{C}_{38} \mathrm{H}_{51} \mathrm{~N}_{3} \mathrm{O}_{9} \mathrm{Si}$ (721.91)

ber.: $744.3292[\mathrm{M}+\mathrm{Na}]^{+}$, gef.: 744.3296 (ESI $\left.{ }^{+}-\mathrm{HRMS}\right)$.

Analytische Daten von $(E)-80$ :

DC: $R_{\mathrm{f}}(\mathrm{PE} / \mathrm{EtOAc} 4: 1)=0.16$.

${ }^{1} \mathrm{H}-\mathrm{NMR}\left(300 \mathrm{MHz}, \mathrm{CDCl}_{3}\right): \delta=0.04\left(\mathrm{~s}, 6 \mathrm{H}, \mathrm{SiCH}_{3}\right), 0.87\left(\mathrm{~s}, 9 \mathrm{H}, \mathrm{SiC}\left(\mathrm{CH}_{3}\right)_{3}\right), 1.52$ (s, $9 \mathrm{H}, t-\mathrm{Bu}_{-} \mathrm{CH}_{3}$ ), 1.91 (d, $J=0.9 \mathrm{~Hz}, 3 \mathrm{H}, 7-\mathrm{H}$ ), 2.02 (ddd, $J=13.4 \mathrm{~Hz}, J=7.7 \mathrm{~Hz}$, $J=5.3 \mathrm{~Hz}, 1 \mathrm{H}, 2^{\prime}-\mathrm{H}_{\mathrm{a}}$ ), 2.36 (ddd, $J=13.4 \mathrm{~Hz}, J=5.9 \mathrm{~Hz}, J=2.5 \mathrm{~Hz}, 1 \mathrm{H}, 2^{\prime}-\mathrm{H}_{\mathrm{b}}$ ), 4.19 (ddd, $J=5.3 \mathrm{~Hz}, J=2.5 \mathrm{~Hz}, J=2.5 \mathrm{~Hz}, 1 \mathrm{H}, 3^{\prime}-\mathrm{H}$ ), 4.67 (s, $2 \mathrm{H}, \mathrm{NCH}_{2} \mathrm{OC}_{2}$ ), $5.09\left(\mathrm{~d}, J=12.6 \mathrm{~Hz}, 1 \mathrm{H}, \mathrm{CbzCH} \underline{H}_{\mathrm{a}}\right), 5.14\left(\mathrm{~d}, J=12.6 \mathrm{~Hz}, 1 \mathrm{H}, \mathrm{CbzCH} \underline{H}_{\mathrm{b}}\right), 5.38$ (dd, $\left.J=9.8 \mathrm{~Hz}, J=2.5 \mathrm{~Hz}, 1 \mathrm{H}, 4{ }^{\prime}-\mathrm{H}\right), 5.47\left(\mathrm{~s}, 2 \mathrm{H}, \mathrm{NCH}_{2} \mathrm{O}\right), 6.34(\mathrm{dd}, J=7.7 \mathrm{~Hz}$, $\left.J=5.9 \mathrm{~Hz}, 1 \mathrm{H}, 1^{\prime}-\mathrm{H}\right), 6.76\left(\mathrm{~d}, J=9.8 \mathrm{~Hz}, 1 \mathrm{H}, 5^{\prime}-\mathrm{H}\right), 7.11(\mathrm{~s}, 1 \mathrm{H}, \mathrm{Cbz}-\mathrm{NH}, 7.18-7.39$ (m, $10 \mathrm{H}, \mathrm{ArH}), 7.28(\mathrm{~s}, 1 \mathrm{H}, 7-\mathrm{H})$.

${ }^{13} \mathrm{C}-\mathrm{NMR}\left(75 \mathrm{MHz}, \mathrm{CDCl}_{3}\right): \delta=-4.74\left(\mathrm{SiCH}_{3}\right),-4.68\left(\mathrm{Si}_{\mathrm{C}} \mathrm{H}_{3}\right), 13.24(\mathrm{C}-7), 18.02$ $\left(\mathrm{Si} \underline{\mathrm{C}}\left(\mathrm{CH}_{3}\right)_{3}\right), 25.73\left(\mathrm{SiC}\left(\underline{\mathrm{C}} \mathrm{H}_{3}\right)_{3}\right), 28.02\left(\mathrm{OC}\left(\underline{\mathrm{C}} \mathrm{H}_{3}\right)_{3}\right), 40.79\left(\mathrm{C}-2^{\prime}\right), 67.06\left(\mathrm{CbzCH}_{2}\right)$, $70.47\left(\mathrm{NCH}_{2} \mathrm{O}_{\mathrm{CH}}\right), 72.12\left(\mathrm{NCH}_{2} \mathrm{O}\right), 76.99\left(\mathrm{C}-3^{\prime}\right), 83.17\left(\mathrm{C}-4^{\prime}\right), 84.4\left(\mathrm{O} \underline{\mathrm{C}}\left(\mathrm{CH}_{3}\right)_{3}\right)$, 86.17 (C-1'), 110.37 (C-5), 120.17 (C-5'), 127.44 (C-4"), 127.55 (C-3", C-5”), 128.11 
(C-2",C-6"), 128.33 (C-4"'), 128.49 (C-3"',C-5'”), 128.67 (C-2"', C-6"'), 130.39 (C-6'), 133.97 (C-6), 135.62 (C-1"), 137.89 (C-1"'), 150.88 (C-2), 153.04 (Cbz-C=O), 161.54 (C-4), 163.34 (Ester-C=O).

Drehwert: $[\alpha]_{D}^{20}=+18.4\left(\mathrm{c}=1.1, \mathrm{CHCl}_{3}\right)$.

IR $(\mathrm{KBr}): \tilde{v}=2930,1666,1513,1456,1252,1047,836,736,698$.

UV (MeCN): $\lambda_{\max }(\lg \varepsilon)=191$ (4.96), 263 (4.12).

MS $\left(\mathrm{ESI}^{+}\right): \mathrm{m} / \mathrm{z}=744.3[\mathrm{M}+\mathrm{Na}]^{+}$.

$\mathrm{C}_{38} \mathrm{H}_{51} \mathrm{~N}_{3} \mathrm{O}_{9} \mathrm{Si}(721.91)$

ber.: $744.3292[\mathrm{M}+\mathrm{Na}]^{+}$, gef.: 744.3296 (ESI $\left.{ }^{+}-H_{R M S}\right)$.

\subsubsection{7 (Z)-6'- $N$-Cbz-O-t-Bu-5', 6'-didehydro-3'-O-TBDMS-TAA 82 und (E)-6'-N- Cbz-O-t-Bu-5',6'-didehydro-3'-O-TBDMS-TAA 82}

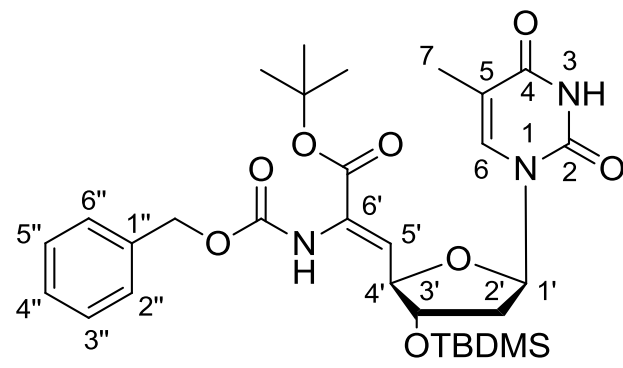

Z-82

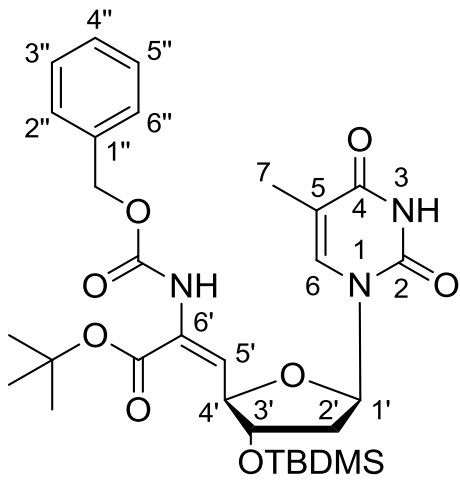

$E-82$

Synthese des Thymidinaldehyds 84:

Eine Lösung von 3'-O-(tert-Butyldimethylsilyl)-thymidin $132(3.46 \mathrm{~g}, 9.72 \mathrm{mmol})$ in Acetonitril $(90 \mathrm{~mL})$ wurde mit $6.80 \mathrm{~g}(24.3 \mathrm{mmol})$ 2-lodoxybenzoesäure versetzt und 30 min. am Rückfluss erhitzt. Nachdem die Reaktionslösung auf Raumtemperatur abgekühlt war, wurde sie über eine Glasfritte filtriert und der Filterkuchen mit Ethylacetat $(3 \times 30 \mathrm{~mL})$ nachgewaschen. Das Filtrat wurde im Vakuum zur Trockne eingeengt und der so erhaltene farblose Schaum $(3.44 \mathrm{~g}, 9.72 \mathrm{mmol})$ direkt weiterverwendet.

Synthese der Didehydroaminosäuren (Z)-82 und (E)-82:

$\mathrm{Zu}$ einer auf $-78^{\circ} \mathrm{C}$ gekühlten Lösung von $\mathrm{KO}^{t} \mathrm{Bu}(1.12 \mathrm{~g}, 9.96 \mathrm{mmol})$ in abs. THF $(95 \mathrm{~mL})$ wurde eine Lösung des Phosphonats $79(3.95 \mathrm{~g}, 10.6 \mathrm{mmol})$ in abs. THF $\left(75 \mathrm{~mL}\right.$ ) getropft und $5 \mathrm{~min}$. bei $-78^{\circ} \mathrm{C}$ gerührt. Es wurde eine Lösung von $3^{\prime}$-O-(tert- 
Butyldimethylsilyl)-thymidin-5'-aldehyd $84(3.44 \mathrm{~g}, 9.72 \mathrm{mmol})$ in abs. THF (40 mL) bei $-78^{\circ} \mathrm{C}$ zugegeben, die resultierende Lösung $16 \mathrm{~h}$ gerührt und im Laufe dieses Zeitraums langsam auf Raumtemperatur erwärmt. Die Reaktionslösung wurde auf $0{ }^{\circ} \mathrm{C}$ gekühlt, mit Methanol $(5 \mathrm{~mL})$ versetzt und mit Ethylacetat $(300 \mathrm{~mL})$ verdünnt. Die organische Phase wurde mit Wasser $(3 \times 100 \mathrm{~mL})$ gewaschen, über $\mathrm{Na}_{2} \mathrm{SO}_{4}$ getrocknet und filtriert. Das Lösungmittel wurde im Vakuum entfernt. Beide Titelverbindungen wurden nach säulenchromatographischer Reinigung an Kieselgel (PE/EtOAc 3:2) erhalten.

Ausbeute: Es wurden $3.83 \mathrm{~g}$ ( $6.37 \mathrm{mmol}, 66 \%$ über zwei Stufen) eines farblosen Schaums erhalten. Das Produkt wurde zunächst als Gemisch der (Z)- und (E)Isomere erhalten. Anhand von NMR-spektroskopischen Befunden wurde das Mengenverhältnis der zwei Diastereomere zu Z/E $10: 1$ bestimmt. Nach wiederholter chromatographischer Trennung (PE/EtOAc 3:2) konnte das (E)-Isomer in ausreichender Menge für die NMR-spektroskopische Charakterisierung erhalten werden.

Analytische Daten von (Z)-82:

DC: $R_{\mathrm{f}}(\mathrm{PE} / \mathrm{EtOAC} 3: 2)=0.33$.

${ }^{1} \mathrm{H}-\mathrm{NMR}\left(300 \mathrm{MHz}, \mathrm{CDCl}_{3}\right): \delta=0.06\left(\mathrm{~s}, 6 \mathrm{H}, \mathrm{SiCH}_{3}\right), 0.86\left(\mathrm{~s}, 9 \mathrm{H}, \mathrm{SiC}\left(\mathrm{CH}_{3}\right)_{3}\right), 1.45$ (s, $9 \mathrm{H}, t-B u-\mathrm{CH}_{3}$ ), 1.89 (d, $J=1.1 \mathrm{~Hz}, 3 \mathrm{H}, 7-\mathrm{H}$ ), 2.13 (ddd, $J=13.6 \mathrm{~Hz}, J=6.5 \mathrm{~Hz}$, $J=6.1 \mathrm{~Hz}, 2$ ' $-\mathrm{H}_{\mathrm{a}}$ ), 2.33 (ddd, $J=13.4 \mathrm{~Hz}, J=6.5 \mathrm{~Hz}, J=4.4 \mathrm{~Hz}, 1 \mathrm{H}, 2^{\prime}-\mathrm{H}_{\mathrm{b}}$ ), 4.33 (ddd, $J=6.1 \mathrm{~Hz}, J=4.4 \mathrm{~Hz}, J=4.4 \mathrm{~Hz}, 1 \mathrm{H}, 3^{\prime}-\mathrm{H}$ ), 4.67 (dd, $J=7.8 \mathrm{~Hz}, J=4.4 \mathrm{~Hz}$, $1 \mathrm{H}, 4^{\prime}-\mathrm{H}$ ), 5.09 (d, $J=12.1 \mathrm{~Hz}, 1 \mathrm{H}, \mathrm{BnCH}_{\mathrm{H}}$ ), $5.13\left(\mathrm{~d}, J=12.1 \mathrm{~Hz}, 1 \mathrm{H}, \mathrm{BnCH} \underline{\mathrm{H}}_{\mathrm{b}}\right.$ ), $6.13\left(\mathrm{~d}, J=7.8 \mathrm{~Hz}, 1 \mathrm{H}, 5^{\prime}-\mathrm{H}\right), 6.15\left(\mathrm{dd}, J=6.7 \mathrm{~Hz}, J=6.7 \mathrm{~Hz}, 1 \mathrm{H}, 1^{\prime}-\mathrm{H}\right), 6.88$ (brs, $1 \mathrm{H}, \mathrm{NH}), 7.08(\mathrm{~d}, J=1.1 \mathrm{~Hz}, 1 \mathrm{H}, 6-\mathrm{H}), 7.24-7.37(\mathrm{~m}, 10 \mathrm{H}, \mathrm{ArH})$.

${ }^{13} \mathrm{C}$-NMR $\left(75 \mathrm{MHz}, \mathrm{CDCl}_{3}\right): \delta=-4.98\left(\mathrm{SiCH}_{3}\right),-4.86\left(\mathrm{Sig}_{3}\right), 12.57$ (C-7), 17.83 $\left.\left(\mathrm{Si} \underline{\mathrm{C}}\left(\mathrm{CH}_{3}\right)_{3}\right), 25.61\left(\mathrm{SiC}(\underline{\mathrm{CH}})_{3}\right)_{3}\right), 27.80\left(\mathrm{OC}\left(\underline{\mathrm{C}} \mathrm{H}_{3}\right)_{3}\right), 40.37\left(\mathrm{C}-2^{\prime}\right), 67.48\left(\mathrm{BnCH}_{2}\right)$, 75.92 (C-3'), $82.48\left(\mathrm{O} \underline{\mathrm{C}}\left(\mathrm{CH}_{3}\right)_{3}\right), 82.59$ (C-4'), 86.14 (C-1'), 110.99 (C-5), 124.94 (C-5'), 128.15 (C-4"), 128.25 (C-3", C-5"), 128.52 (C-2", C-6"), 130.51 (C-6'), 135.41 (C-6), 135.68 (C-1"), 150.13 (C-2), 153.56 (Cbz-C=O), 162.73 (C-4), 163.84 (Ester$\mathrm{C}=\mathrm{O})$.

Drehwert: $[\alpha]_{D}^{20}=+69.9\left(\mathrm{c}=1.1, \mathrm{CHCl}_{3}\right)$

Schmelzpunkt: $79^{\circ} \mathrm{C}$.

IR (KBr): $\tilde{v}=1686,1465,1256,1223,1151,1046,831,774,693$. 
UV (MeCN): $\lambda_{\max }(\lg \varepsilon)=204$ (4.40), 259 (4.15).

MS $\left(\mathrm{ESI}^{-}\right): \mathrm{m} / \mathrm{z}=624.3[\mathrm{M}+\mathrm{Na}]^{+}$.

$\mathrm{C}_{30} \mathrm{H}_{43} \mathrm{~N}_{3} \mathrm{O}_{8} \mathrm{Si}(601.76)$ ber.: $624.2717[\mathrm{M}+\mathrm{Na}]^{+}$ gef.: 624.2705 (ESI+-HRMS).

Analytische Daten von (E)-82:

DC: $R_{\mathrm{f}}(\mathrm{PE} / \mathrm{EtOAc} 3: 2)=0.33$.

${ }^{1} \mathrm{H}-\mathrm{NMR}\left(300 \mathrm{MHz}, \mathrm{CDCl}_{3}\right): \delta=0.05\left(\mathrm{~s}, 6 \mathrm{H}, \mathrm{SiCH}_{3}\right), 0.87\left(\mathrm{~s}, 9 \mathrm{H}, \mathrm{SiC}\left(\mathrm{CH}_{3}\right)_{3}\right), 1.52$ (s, $9 \mathrm{H}, t-\mathrm{Bu}_{-} \mathrm{CH}_{3}$ ), 1.90 (s, $3 \mathrm{H}, 7-\mathrm{H}$ ), 2.08 (ddd, $J=13.5 \mathrm{~Hz}, J=7.7 \mathrm{~Hz}, J=5.6 \mathrm{~Hz}$, $1 \mathrm{H}, 2^{\prime}-\mathrm{H}_{\mathrm{a}}$ ), 2.33 (ddd, $J=13.5 \mathrm{~Hz}, J=6.1 \mathrm{~Hz}, J=2.6 \mathrm{~Hz}, 1 \mathrm{H}, 2^{\prime}-\mathrm{H}_{\mathrm{b}}$ ), 4.21 (ddd, $\left.J=5.3 \mathrm{~Hz}, J=2.6 \mathrm{~Hz}, J=2.6 \mathrm{~Hz}, 1 \mathrm{H}, 3^{\prime}-\mathrm{H}\right), 5.10\left(\mathrm{~d}, J=12.3 \mathrm{~Hz}, 1 \mathrm{H}, \mathrm{BnCHH}_{\mathrm{a}}\right.$ ), $5.15\left(\mathrm{~d}, J=12.3 \mathrm{~Hz}, 1 \mathrm{H}, \mathrm{BnCHH}_{\mathrm{b}}\right), 5.36\left(\mathrm{dd}, J=9.8 \mathrm{~Hz}, J=2.5 \mathrm{~Hz}, 1 \mathrm{H}, 4^{\prime}-\mathrm{H}\right), 6.31$ (dd, $\left.J=7.7 \mathrm{~Hz}, J=6.1 \mathrm{~Hz}, 1 \mathrm{H}, 1^{\prime}-\mathrm{H}\right), 6.76\left(\mathrm{~d}, J=9.8 \mathrm{~Hz}, 1 \mathrm{H}, 5^{\prime}-\mathrm{H}\right), 7.11(\mathrm{~s}, 1 \mathrm{H}$, Cbz-NH, 7.18-7.39 (m, $10 \mathrm{H}, \mathrm{ArH}), 7.28(\mathrm{~s}, 1 \mathrm{H}, 7-\mathrm{H})$.

${ }^{13} \mathrm{C}$-NMR $\left(75 \mathrm{MHz}, \mathrm{CDCl}_{3}\right): \quad \delta=-4.76\left(\mathrm{SiCH}_{3}\right),-4.68\left(\mathrm{SiCH}_{3}\right), 12.52(\mathrm{C}-7), 18.03$ $\left(\mathrm{SiC}\left(\mathrm{CH}_{3}\right)_{3}\right), 25.74\left(\mathrm{SiC}\left(\underline{\mathrm{C}} \mathrm{H}_{3}\right)_{3}\right), 28.02\left(\mathrm{OC}\left(\underline{\mathrm{CH}}_{3}\right)_{3}\right), 40.64\left(\mathrm{C}-2^{\prime}\right), 66.86\left(\mathrm{BnCH}_{2}\right)$, 77.00 (C-3'), 83.11 (C-4'), $84.38\left(\mathrm{O} \underline{\mathrm{C}}\left(\mathrm{CH}_{3}\right)_{3}\right), 85.58\left(\mathrm{C}-1^{\prime}\right), 111.12$ (C-5), 120.16 (C-5'), 127.99 (C-4"), 128.04 (C-3",C-5"), 128.38 (C-2", C-6"), 128.80 (C-6'), 135.39 (C-6), 136.12 (C-1"), 150.31 (C-2), 153.08 (Cbz-C=O), 161.60 (C-4), 163.81 (Ester$\mathrm{C}=\mathrm{O})$.

Diese Verbindung wurde nur in verunreinigter Form erhalten. Daher wurde auf eine Charakterisierung mittels weiterer analytischer Methoden verzichtet.

\subsubsection{6'-N-Cbz-O-t-Bu-3-N-BOM-3'-O-TBDMS-(S)-TAA 81}

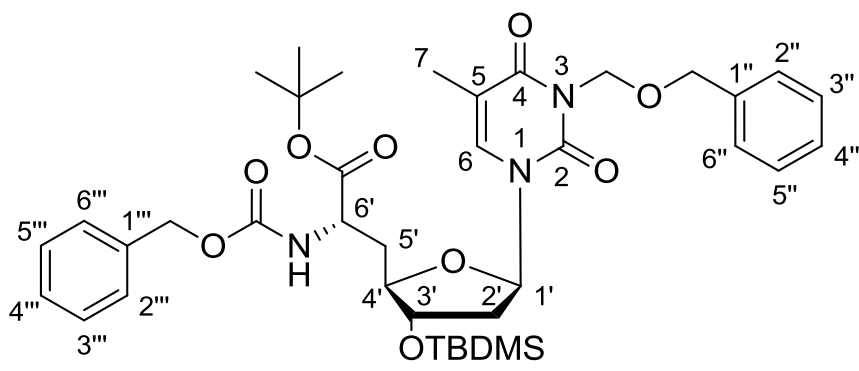

(6'S)-81

Es wurde unter striktem Sauerstoff-Ausschluss gearbeitet. Durch eine Lösung des (Z)-Olefins $80(1.50 \mathrm{~g}, 2.07 \mathrm{mmol})$ in abs. Methanol $(72 \mathrm{~mL})$ wurde $15 \mathrm{~min}$. ein 
Argonstrom durchgeleitet. Anschließend wurde die Lösung mit $(S, S)$-Me-DuPHOS$\mathrm{Rh}(25 \mathrm{mg}, 41 \mu \mathrm{mol})$ versetzt und $2 \mathrm{~d}$ bei Raumtemperatur unter einer WasserstoffAtmosphäre (1 bar) gerührt. Die Lösung wurde mit Kieselgel versetzt und das Lösungsmittel im Vakuum entfernt. Das so erhaltene Rohprodukt wurde säulenchromatographisch an Kieselgel gereinigt (PE/EtOAc 4:1).

Ausbeute: $1.41 \mathrm{~g} \mathrm{(1.96} \mathrm{mmol,} \mathrm{94 \% )} \mathrm{eines} \mathrm{farblosen} \mathrm{Öls.}$

DC: $R_{\mathrm{f}}(\mathrm{PE} / \mathrm{EtOAc} 7: 3)=0.40$.

${ }^{1} \mathrm{H}$-NMR $\left(300 \mathrm{MHz}, \mathrm{CDCl}_{3}\right): \delta=0.04\left(\mathrm{~s}, 6 \mathrm{H}, \mathrm{SiCH}_{3}\right), 0.86\left(\mathrm{~s}, 9 \mathrm{H}, \mathrm{SiC}\left(\mathrm{CH}_{3}\right)_{3}\right), 1.41$ (s, $\left.9 \mathrm{H}, t-\mathrm{Bu}_{-} \mathrm{CH}_{3}\right), 1.96(\mathrm{~s}, 3 \mathrm{H}, 7-\mathrm{H}), 1.98-2.08(\mathrm{~m}, 2 \mathrm{H}, 5$ '- $\mathrm{H}), 2.12-2.29(\mathrm{~m}, 2 \mathrm{H}$, 2'-H), 3.89-3.95 (m, $1 \mathrm{H}, 4$ '- $-\mathrm{H})$, 4.00-4.07 (m, $1 \mathrm{H}, 3$ '- $\mathrm{H})$, 4.37-4.41 (m, $1 \mathrm{H}, 6$ '- $\mathrm{H})$, 4.68 (s, $2 \mathrm{H}, \mathrm{NCH}_{2} \mathrm{OCH}_{2}$ ), 5.08 (s, $2 \mathrm{H}, \mathrm{CbzCH}_{2}$ ), 5.47 (s, $2 \mathrm{H}, \mathrm{NCH}_{2} \mathrm{O}$ ), 5.52 (d, $J=6.9 \mathrm{~Hz}, 1 \mathrm{H}, \mathrm{NH}), 6.20\left(\mathrm{dd}, J=6.0 \mathrm{~Hz}, J=6.0 \mathrm{~Hz}, 1 \mathrm{H}, \mathrm{H}-1^{\prime}\right), 7.23-7.37(\mathrm{~m}, 10 \mathrm{H}$, ArH).

${ }^{13}$ C-NMR $\left(75 \mathrm{MHz}, \mathrm{CDCl}_{3}\right): \delta=-4.78\left(\mathrm{SiCH}_{3}\right),-4.51\left(\mathrm{SiCH}_{3}\right), 13.09(\mathrm{C}-7), 17.94$ $\left(\mathrm{SiC}\left(\mathrm{CH}_{3}\right)_{3}\right), 25.69\left(\mathrm{SiC}\left(\underline{\mathrm{C}} \mathrm{H}_{3}\right)_{3}\right), 27.95\left(\mathrm{OC}\left(\underline{\mathrm{C}} \mathrm{H}_{3}\right)_{3}\right), 36.19$ (C-5'), 40.33 (C-2'), 52.04 (C-6'), $66.89\left(\mathrm{Cbz}_{\mathrm{C}} \mathrm{H}_{2}\right), 70.48\left(\mathrm{NCH}_{2} \mathrm{O}\right), 72.15\left(\mathrm{NCH}_{2} \mathrm{O}_{\mathrm{CH}}\right), 74.92\left(\mathrm{C}-3^{\prime}\right), 82.67$ $\left(\mathrm{O} \underline{\mathrm{C}}\left(\mathrm{CH}_{3}\right)_{3}\right), 83.08$ (C-4'), 85.67 (C-1'), 110.38 (C-5), 127.49 (C-4"), 127.56 (C-3", C-5"), 128.01 (C-2", C-6"), 128.10 (C-4"'), 128.15 (C-3"',C-5"'), 128.41 (C-2"',C-6"'), 134.32 (C-6), 136.13 (C-1"), 137.88 (C-1"'), 150.70 (C-2), 155.33 (Cbz-C=O), 163.32 (C-4), 170.32 (Ester-C=O).

Drehwert: $[\alpha]_{\mathrm{D}}^{20}=+50.6\left(\mathrm{c}=1.0, \mathrm{CHCl}_{3}\right)$.

IR (Film): $\tilde{v}=2930,1667,1466,1256,1066,837,775,736,698$.

UV (MeCN): $\lambda_{\max }(\lg \varepsilon)=206$ (4.43), 267 (3.97).

MS $\left(\mathrm{ESI}^{+}\right): \mathrm{m} / \mathrm{z}=746.4[\mathrm{M}+\mathrm{Na}]^{+}$.

$\mathrm{C}_{38} \mathrm{H}_{53} \mathrm{~N}_{3} \mathrm{O}_{9} \mathrm{Si}(723.93)$ ber.: $746.3449[\mathrm{M}+\mathrm{Na}]^{+}$, gef.: $746.3453\left(\mathrm{ESI}^{+}\right)$. 


\subsubsection{6'-N-Cbz-O-t-Bu-3-N-BOM-3'-O-TBDMS-(R)-TAA 81}

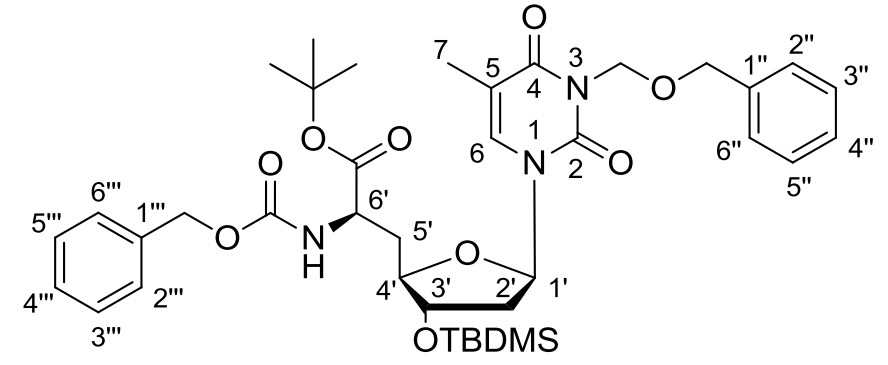

$\left(6^{\prime} R\right)-81$

Die Synthese von (6'R)-81 erfolgte gemäß der Vorschrift zur Synthese von (6'S)-81 mit einer Reaktionsdauer von $7 \mathrm{~d}$. Es wurden $1.00 \mathrm{~g}$ (1.38 mmol) (Z)-80, $20 \mathrm{mg}$ (33 $\mu \mathrm{mol})(R, R)$-Me-DuPHOS-Rh und $48 \mathrm{~mL}$ abs. Methanol eingesetzt.

Ausbeute: $990 \mathrm{mg}$ (1.36 mmol, 99\%) eines farblosen Öls.

DC: $R_{\mathrm{f}}(\mathrm{PE} /$ EtOAc 7:3) $=0.40$.

${ }^{1} \mathrm{H}-\mathrm{NMR}\left(300 \mathrm{MHz}, \mathrm{CDCl}_{3}\right): \delta=0.07\left(\mathrm{~s}, 6 \mathrm{H}, \mathrm{SiCH}_{3}\right), 0.88\left(\mathrm{~s}, 9 \mathrm{H}, \mathrm{SiC}\left(\mathrm{CH}_{3}\right)_{3}\right), 1.46$ (s, $\left.9 \mathrm{H}, t-\mathrm{Bu}_{-} \mathrm{CH}_{3}\right), 1.89(\mathrm{~s}, 3 \mathrm{H}, 7-\mathrm{H}), 1.96-2.11(\mathrm{~m}, 2 \mathrm{H}, 5-\mathrm{H})$ 2.14-2.29 (m, $2 \mathrm{H}$, 2'-H), 3.74-3.87 (m, $1 \mathrm{H}, 4$ '- $\mathrm{H}), 4.00-4.09(\mathrm{~m}, 1 \mathrm{H}, 3$ '- $\mathrm{H}), 4.42-4.50(\mathrm{~m}, 1 \mathrm{H}, 6$ '- $-\mathrm{H})$, 4.68 (s, $2 \mathrm{H}, \mathrm{NCH}_{2} \mathrm{OC}_{2}$ ), 5.08 (s, $2 \mathrm{H}, \mathrm{CbzCH}_{2}$ ), 5.47 (s, $2 \mathrm{H}, \mathrm{NCH}_{2} \mathrm{O}$ ), 5.57 (d, $J=6.9 \mathrm{~Hz}, 1 \mathrm{H}, \mathrm{NH}), 6.13\left(\mathrm{dd}, J=6.0 \mathrm{~Hz}, J=6.0 \mathrm{~Hz}, 1 \mathrm{H}, \mathrm{H}-1^{\prime}\right), 7.22-7.40(\mathrm{~m}, 10 \mathrm{H}$, ArH).

${ }^{13} \mathrm{C}-\mathrm{NMR}\left(75 \mathrm{MHz}, \mathrm{CDCl}_{3}\right): \delta=-4.84\left(\mathrm{SiCH}_{3}\right),-4.61\left(\mathrm{SiCH}_{3}\right), 13.28(\mathrm{C}-7), 17.86$ $\left(\mathrm{SiC}\left(\mathrm{CH}_{3}\right)_{3}\right), 25.65\left(\mathrm{SiC}\left(\underline{\mathrm{CH}}_{3}\right)_{3}\right), 27.95\left(\mathrm{OC}\left(\underline{\mathrm{C}} \mathrm{H}_{3}\right)_{3}\right), 35.12$ (C-5'), 40.24 (C-2'), 52.67 (C-6'), $66.90\left(\mathrm{Cbz}_{\mathrm{C}} \mathrm{H}_{2}\right), 70.49\left(\mathrm{NCH}_{2} \mathrm{O}\right), 72.20\left(\mathrm{NCH}_{2} \mathrm{OC}_{2}\right), 74.84$ (C-3'), 82.44 $\left(\mathrm{O} \underline{\mathrm{C}}\left(\mathrm{CH}_{3}\right)_{3}\right), 83.32$ (C-4'), 86.00 (C-1'), 110.38 (C-5), 127.60 (C-4”), 127.65 (C-3”, C-5”), 128.05 (C-2", C-6"), 128.17 (C-4"'), 128.24 (C-3"', C-5"'), 128.47 (C-2"', C-6"'), 133.91 (C-6), 136.18 (C-1"), 137.96 (C-1'”'), 150.62 (C-2), 155.96 (Cbz-C=O), 163.29 (C-4), 170.54 (Ester-C=O).

Drehwert: $[\alpha]_{D}^{20}=+40.0\left(\mathrm{c}=1.0, \mathrm{CHCl}_{3}\right)$.

IR (Film): $\tilde{v}=2930,1668,1465,1258,1095,837,775,736,699$.

UV (MeCN): $\lambda_{\max }(\lg \varepsilon)=206$ (4.36), 267 (3.90).

MS $\left(\mathrm{ESI}^{+}\right): \mathrm{m} / \mathrm{z}=746.4[\mathrm{M}+\mathrm{Na}]^{+}$.

$\mathrm{C}_{38} \mathrm{H}_{53} \mathrm{~N}_{3} \mathrm{O}_{9} \mathrm{Si}$ (723.93)

ber.: $746.3449[\mathrm{M}+\mathrm{Na}]^{+}$, gef.: 746.3452 (ESI+-HRMS). 


\subsubsection{6'-N-Cbz-O-t-Bu-3'-O-TBDMS-(S)-TAA 83}

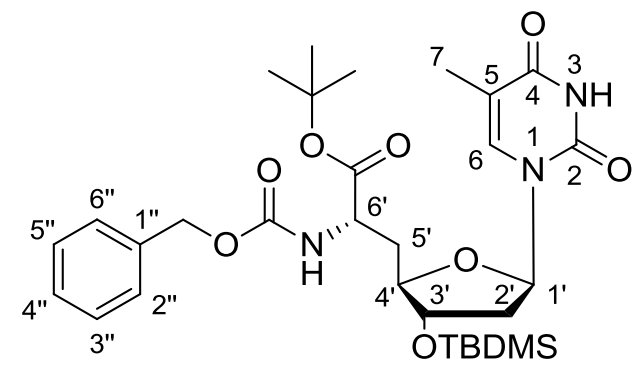

(6’S)-83

Es wurde unter striktem Sauerstoff-Ausschluss gearbeitet. Durch eine Lösung des (Z)-Olefins $82(1.80 \mathrm{~g}, 3.00 \mathrm{mmol})$ in abs. Methanol $(100 \mathrm{~mL})$ wurde $15 \mathrm{~min}$. ein Argonstrom durchgeleitet. Anschließend wurde die Lösung mit $(S, S)$-Me-DuPHOS$\mathrm{Rh}(100 \mathrm{mg}, 165 \mu \mathrm{mol}, 4 \mathrm{~mol} \%)$ versetzt und $9 \mathrm{~d}$ bei Raumtemperatur unter einer Wasserstoff-Atmosphäre (1 bar) gerührt. Die Lösung wurde mit Kieselgel versetzt und das Lösungsmittel im Vakuum entfernt. Das Rohprodukt wurde säulenchromatographisch an Kieselgel gereinigt (PE/EtOAc 3:2).

Ausbeute: Es wurden $1.67 \mathrm{~g}(2.77 \mathrm{mmol}, 92 \%)$ eines farblosen Öls erhalten.

DC: $R_{\mathrm{f}}(\mathrm{PE} / \mathrm{EtOAc} 3: 2)=0.45$.

${ }^{1} \mathrm{H}-\mathrm{NMR}\left(300 \mathrm{MHz}, \mathrm{CDCl}_{3}\right): \delta=0.05\left(\mathrm{~s}, 6 \mathrm{H}, \mathrm{SiCH}_{3}\right), 0.87\left(\mathrm{~s}, 9 \mathrm{H}, \mathrm{SiC}\left(\mathrm{CH}_{3}\right)_{3}\right), 1.43$ (s, $\left.9 \mathrm{H}, \mathrm{OC}\left(\mathrm{CH}_{3}\right)_{3}\right), 1.97(\mathrm{~s}, 3 \mathrm{H}, 7-\mathrm{H}), 2.00-2.10\left(\mathrm{~m}, 2 \mathrm{H}, 2^{\prime}-\mathrm{H}_{\mathrm{a}}, 5^{\prime}-\mathrm{H}_{\mathrm{a}}\right), 2.13-2.27(\mathrm{~m}$, $\left.2 \mathrm{H}, \quad 2^{\prime}-\mathrm{H}_{\mathrm{b}}, 5^{\prime}-\mathrm{H}_{\mathrm{b}}\right), 3.90-3.99\left(\mathrm{~m}, 1 \mathrm{H}, 3{ }^{\prime}-\mathrm{H}\right), 4.06$ (ddd, J=6.6 Hz, J=4.4 Hz, $J=4.4 \mathrm{~Hz}, 1 \mathrm{H}, 4^{\prime}-\mathrm{H}$ ), 4.42 (ddd, $J=7.1 \mathrm{~Hz}, J=4.7 \mathrm{~Hz}, J=4.7 \mathrm{~Hz}, 1 \mathrm{H}, 6^{\prime}-\mathrm{H}$ ), 5.10 (s, $\left.2 \mathrm{H}, \mathrm{BnCH}_{2}\right), 5.54\left(\mathrm{~d}, J=7.1 \mathrm{~Hz}, 1 \mathrm{H}, 6{ }^{\prime}-\mathrm{NH}\right), 6.18$ (dd, J=6.5 Hz, J=6.5 Hz, $1 \mathrm{H}, 1$ '-H), 7.29-7.40 (m, $5 \mathrm{H}, \mathrm{ArH}), 7.37$ (s, $1 \mathrm{H}, 6-\mathrm{H}), 8.34$ (brs, $1 \mathrm{H}, 3-\mathrm{NH}$ ).

${ }^{13}$ C-NMR $\left(75 \mathrm{MHz}, \mathrm{CDCl}_{3}\right): \delta=-4.92\left(\mathrm{SiCH}_{3 \mathrm{a}}\right),-4.67\left(\mathrm{SiCH}_{3 \mathrm{~b}}\right), 12.27(\mathrm{C}-7), 17.85$ $\left(\mathrm{SiC}\left(\mathrm{CH}_{3}\right)_{3}\right), 25.61\left(\mathrm{SiC}\left(\underline{\mathrm{CH}}_{3}\right)_{3}\right), 27.85\left(\mathrm{OC}\left(\underline{\mathrm{C}} \mathrm{H}_{3}\right)_{3}\right), 36.00$ (C-5'), $40.20\left(\mathrm{C}-2^{\prime}\right), 51.98$ (C-6'), $66.83\left(\mathrm{BnCH}_{2}\right), 74.89\left(\mathrm{C}-4^{\prime}\right), 82.64\left(\mathrm{O} \underline{\mathrm{C}}\left(\mathrm{CH}_{3}\right)_{3}\right), 83.03\left(\mathrm{C}-3^{\prime}\right), 85.07$ (C-1'), 111.13 (C-5), 128.04 (C-4"), 128.13 (C-3”, C-5”), 128.45 (C-2”, C-6”), 135.79 (C-6), 136.23 (C-1"), 150.18 (C-2), 155.46 (Cbz-C=O), 163.86 (C-4), 170.49 (COO).

Drehwert: $[\alpha]_{D}^{20}=+58.4\left(\mathrm{c}=1.2, \mathrm{CHCl}_{3}\right)$.

IR $(\mathrm{KBr}): \tilde{v}=1686,1466,1366,1251,1151,1093,1045,835,774$.

UV (MeCN): $\lambda_{\max }(\lg \varepsilon)=205$ (4.66), 264 (4.40).

MS $\left(\mathrm{ESI}^{+}\right): \mathrm{m} / \mathrm{z}=626.3[\mathrm{M}+\mathrm{Na}]^{+}$. 
$\mathrm{C}_{30} \mathrm{H}_{45} \mathrm{~N}_{3} \mathrm{O}_{8} \mathrm{Si}(603.29)$

ber.: $626.2868[\mathrm{M}+\mathrm{Na}]^{+}$

gef.: 626.2865 (ESI+-HRMS).

\subsubsection{6'-N-Cbz-O-t-Bu-3'-O-TBDMS-(R)-TAA 83}

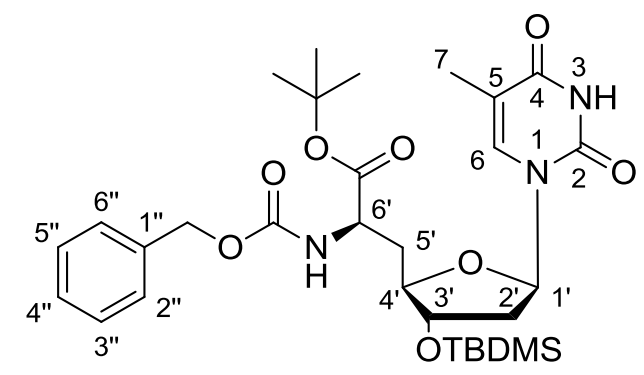

$\left(6^{\prime} R\right)-83$

Die Synthese von (6'R)-83 erfolgte gemäß der Vorschrift zur Synthese von (6'S)-83 mit einer Reaktionsdauer von $21 \mathrm{~d}$. Es wurden $920 \mathrm{mg}$ (1.53 mmol) (Z)-82, $60 \mathrm{mg}$ (96 $\mu \mathrm{mol}, 4 \mathrm{~mol} \%)(R, R)$-Me-DuPHOS-Rh und $40 \mathrm{~mL}$ abs. Methanol eingesetzt. Das Rohprodukt wurde säulenchromatographisch an Kieselgel gereinigt (PE/EtOAc 3:2).

Ausbeute: Es wurden $710 \mathrm{mg}(1.18 \mathrm{mmol}, 77 \%)$ eines farblosen Schaums erhalten.

DC: $R_{\mathrm{f}}(\mathrm{PE} / \mathrm{EtOAc} 3: 2)=0.42$.

${ }^{1} \mathrm{H}-\mathrm{NMR}\left(300 \mathrm{MHz}, \mathrm{CDCl}_{3}\right): \delta=0.04\left(\mathrm{~s}, 3 \mathrm{H}, \mathrm{SiCH}_{3 \mathrm{a}}\right), 0.04\left(\mathrm{~s}, 3 \mathrm{H}, \mathrm{SiCH}_{3 \mathrm{~b}}\right) 0.85$ (s, $\left.9 \mathrm{H}, \mathrm{SiC}\left(\mathrm{CH}_{3}\right)_{3}\right), 1.43\left(\mathrm{~s}, 9 \mathrm{H}, \mathrm{OC}\left(\mathrm{CH}_{3}\right)_{3}\right), 1.85(\mathrm{~s}, 3 \mathrm{H}, 7-\mathrm{H}), 2.01$ (ddd, $J=14.3 \mathrm{~Hz}$, $J=10.3 \mathrm{~Hz}, J=4.3 \mathrm{~Hz}, 1 \mathrm{H}, 2 \cdot-\mathrm{H}_{\mathrm{a}}$ ), 2.09 (ddd, $J=13.4 \mathrm{~Hz}, J=6.8 \mathrm{~Hz}, J=6.8 \mathrm{~Hz}$, $\left.1 \mathrm{H}, 5^{\prime}-\mathrm{H}_{\mathrm{a}}\right), 2.14-2.23\left(\mathrm{~m}, 2 \mathrm{H}, 2^{\prime}-\mathrm{H}_{\mathrm{b}}, 5^{\prime}-\mathrm{H}_{\mathrm{b}}\right), 3.78$ (ddd, $J=10.3 \mathrm{~Hz}, J=4.9 \mathrm{~Hz}$, $J=2.4 \mathrm{~Hz}, 1 \mathrm{H}, 3^{\prime}-\mathrm{H}$ ), 4.06 (ddd, $J=6.8 \mathrm{~Hz}, J=4.9 \mathrm{~Hz}, J=4.9 \mathrm{~Hz}, 1 \mathrm{H}, 4^{\prime}-\mathrm{H}$ ), $4.40-$ $4.45\left(\mathrm{~m}, 1 \mathrm{H}, 6^{\prime}-\mathrm{H}\right), 5.10\left(\mathrm{~s}, 2 \mathrm{H}, \mathrm{BnCH}_{2}\right.$ ), $5.63\left(\mathrm{~d}, J=8.6 \mathrm{~Hz}, 1 \mathrm{H}, 6^{\prime}-\mathrm{NH}\right), 6.08$ (dd, $\left.J=6.4 \mathrm{~Hz}, J=6.4 \mathrm{~Hz}, 1 \mathrm{H}, 1^{\prime}-\mathrm{H}\right), 7.07(\mathrm{~s}, 1 \mathrm{H}, 6-\mathrm{H}), 7.24-7.32(\mathrm{~m}, 5 \mathrm{H}, \mathrm{ArH}), 9.34$ (brs, $1 \mathrm{H}, 3-\mathrm{NH}$ ).

${ }^{13} \mathrm{C}-\mathrm{NMR}\left(75 \mathrm{MHz}, \mathrm{CDCl}_{3}\right): \delta=-4.88\left(\mathrm{SiCH}_{3 \mathrm{a}}\right),-4.67\left(\mathrm{SiCH}_{3 \mathrm{~b}}\right), 12.49(\mathrm{C}-7), 17.82$ ( $\left.\mathrm{Si} \underline{\mathrm{C}}\left(\mathrm{CH}_{3}\right)_{3}\right), 25.62\left(\mathrm{SiC}\left(\underline{\mathrm{CH}}_{3}\right)_{3}\right), 27.90\left(\mathrm{OC}\left(\underline{\mathrm{CH}}_{3}\right)_{3}\right), 35.04$ (C-5'), $40.10\left(\mathrm{C}-2^{\prime}\right), 52.64$ (C-6'), $66.79\left(\mathrm{BnCH}_{2}\right), 74.81\left(\mathrm{C}-4^{\prime}\right), 82.36\left(\mathrm{O} \underline{\mathrm{C}}\left(\mathrm{CH}_{3}\right)_{3}\right), 83.31\left(\mathrm{C}-3^{\prime}\right), 85.52\left(\mathrm{C}-1^{\prime}\right)$, 111.01 (C-5), 127.93 (C-4"), 128.07 (C-3", C-5"), 128.40 (C-2", C-6"), 135.36 (C-6), 136.20 (C-1"), 150.04 (C-2), 155.91 (Cbz-C=O), 163.77 (C-4), 170.57 (COO).

Drehwert: $[\alpha]_{D}^{20}=+62.3\left(\mathrm{c}=1.0, \mathrm{CHCl}_{3}\right)$.

Schmelzpunkt: $76^{\circ} \mathrm{C}$. 
IR $(\mathrm{KBr}): \tilde{v}=1690,1466,1361,1250,1151,1098,1055,831,779$.

UV (MeCN): $\lambda_{\max }(\lg \varepsilon)=202$ (4.31), 264 (4.01).

MS $\left(\mathrm{ESI}^{-}\right): \mathrm{m} / \mathrm{z}=602.3[\mathrm{M}-\mathrm{H}]^{-}$.

$\mathrm{C}_{30} \mathrm{H}_{45} \mathrm{~N}_{3} \mathrm{O}_{8} \mathrm{Si}$ (603.29)

ber.: $602.2903[\mathrm{M}-\mathrm{H}]$

gef.: 602.2903 (ESI-HRMS).

\subsubsection{O-t-Bu-3'-O-TBDMS-(S)-TAA 133}

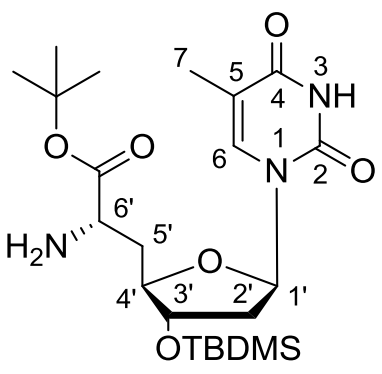

(6'S)-133

Eine Lösung der TAA (6'S)-81 (1.20 g, $1.65 \mathrm{mmol})$ in abs. Methanol (50 mL) wurde mit Palladium (360 mg, $0.34 \mu \mathrm{mol}, 10 \%$ auf Aktivkohle) und mit $n$-Butylamin (3.5 mL, $2.6 \mathrm{~g}, 35 \mathrm{mmol}$ ) versetzt und $24 \mathrm{~h}$ bei Raumtemperatur unter einer Wasserstoffatmosphäre (1 bar) gerührt. Die Lösung wurde über Celite durch eine Glasfritte filtriert. Der Filterkuchen wurde mit Methanol $(5 \times 10 \mathrm{~mL})$ gewaschen. Das Filtrat wurde bei vermindertem Druck eingeengt. Das Rohprodukt wurde säulenchromatographisch an Kieselgel gereinigt (DCM/MeOH 94:6).

Ausbeute: $719 \mathrm{mg}(1.53 \mathrm{mmol}, 93 \%)$ eines leicht gelben Feststoffs.

DC: $R_{\mathrm{f}}(\mathrm{DCM} / \mathrm{MeOH} 15: 1)=0.36$.

${ }^{1} \mathrm{H}-\mathrm{NMR}\left(300 \mathrm{MHz}_{\mathrm{CDCl}}\right.$ ): $\delta=0.05\left(\mathrm{~s}, 3 \mathrm{H}, \mathrm{SiCH}_{3}\right), 0.06\left(\mathrm{~s}, 3 \mathrm{H}, \mathrm{SiCH}_{3}\right), 0.86(\mathrm{~s}$, $\left.9 \mathrm{H}, \operatorname{SiC}\left(\mathrm{CH}_{3}\right)_{3}\right), 1.43\left(\mathrm{~s}, 9 \mathrm{H}, t-B u-\mathrm{CH}_{3}\right), 1.75-1.85\left(\mathrm{~m}, 1 \mathrm{H}, 2\right.$ '- $\left.\mathrm{H}_{\mathrm{a}}\right), 1.92(\mathrm{~s}, 3 \mathrm{H}, 7-\mathrm{H})$, 2.03-2.14 (m, $\left.2 \mathrm{H}, 5^{\prime}-\mathrm{H}\right), 2.19-2.28\left(\mathrm{~m}, 1 \mathrm{H}, 2^{\prime}-\mathrm{H}_{\mathrm{b}}\right), 3.52(\mathrm{dd}, J=6.2 \mathrm{~Hz}, J=6.2 \mathrm{~Hz}$, $\left.1 \mathrm{H}, 6^{\prime}-\mathrm{H}\right), 3.89$ (ddd, $\left.J=8.8 \mathrm{~Hz}, J=4.4 \mathrm{~Hz}, J=4.4 \mathrm{~Hz}, 1 \mathrm{H}, 4^{\prime}-\mathrm{H}\right), 4.06-4.12(\mathrm{~m}, 1 \mathrm{H}$, 3'-H), 6.16 (dd, J=6.5 Hz, J=6.5 Hz, $1 \mathrm{H}, 1$ '-H), 7.16 (s, $1 \mathrm{H}, 6-\mathrm{H})$.

${ }^{13} \mathrm{C}$-NMR $\left(75 \mathrm{MHz}, \mathrm{CDCl}_{3}\right): \delta=-4.87\left(\mathrm{SiCH}_{3}\right),-4.59\left(\mathrm{SiCH}_{3}\right), 12.60(\mathrm{C}-7), 17.87$ $\left(\mathrm{SiC}\left(\mathrm{CH}_{3}\right)_{3}\right), 25.64\left(\mathrm{SiC}\left(\underline{\mathrm{CH}}_{3}\right)_{3}\right), 27.96\left(\mathrm{OC}\left(\underline{\mathrm{C}} \mathrm{H}_{3}\right)_{3}\right), 38.06$ (C-5'), 40.40 (C-2'), 53.11 (C-6'), 74.97 (C-3'), $81.36\left(\mathrm{O} \underline{\mathrm{C}}\left(\mathrm{CH}_{3}\right)_{3}\right), 83.92$ (C-4'), 84.60 (C-1'), 111.06 (C-5), 135.64 (C-6), 150.17 (C-2), 163.72 (C-4), 174.19 (Ester-C=O).

Drehwert: $[\alpha]_{D}^{20}=+59.2\left(\mathrm{c}=1.0, \mathrm{CHCl}_{3}\right)$. 
Schmelzpunkt: $78^{\circ} \mathrm{C}$.

IR $(\mathrm{KBr}): \tilde{v}=2958,1697,1471,1367,1255,1155,1069,835,609$.

UV $(\mathrm{MeCN}): \lambda_{\max }(\lg \varepsilon)=265$ (3.92).

MS $\left(E S I^{+}\right): m / z=470.3[\mathrm{M}+\mathrm{H}]^{+}$.

$\mathrm{C}_{22} \mathrm{H}_{39} \mathrm{~N}_{3} \mathrm{O}_{6} \mathrm{Si}(469.65)$

ber.: $470.2686[\mathrm{M}+\mathrm{H}]^{+}$,

gef.: 470.2680 (ESI+-HRMS).

\subsubsection{O-t-Bu-3'-O-TBDMS-(R)-TAA 133}

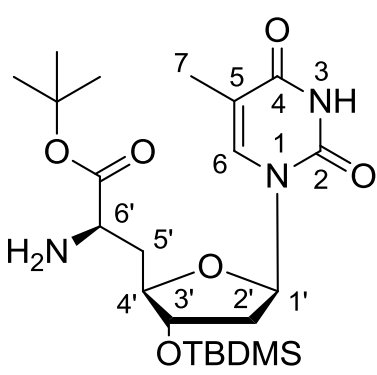

$\left(6^{\prime} R\right)-133$

Die Synthese von $\left(6^{\prime} R\right)$-133 erfolgte gemäß der Vorschrift zur Synthese von (6'S)-133. Es wurden $1.26 \mathrm{~g}(1.74 \mathrm{mmol})\left(6^{\prime} R\right)-81,360 \mathrm{mg}(0.340 \mu \mathrm{mol})$ Palladium (10\% auf Aktivkohle), $3.5 \mathrm{~mL}$ (2.6 g, $35 \mathrm{mmol}) n$-Butylamin und $50 \mathrm{~mL}$ abs. Methanol eingesetzt.

Ausbeute: $750 \mathrm{mg}$ (1.60 mmol, 92\%) eines leicht gelben Feststoffs.

DC: $R_{\mathrm{f}}(\mathrm{DCM} / \mathrm{MeOH} 15: 1)=0.36$.

${ }^{1} \mathrm{H}-\mathrm{NMR}\left(300 \mathrm{MHz}, \mathrm{CDCl}_{3}\right): \delta=0.07\left(\mathrm{~s}, 6 \mathrm{H}, \mathrm{SiCH}_{3}\right), 0.88\left(\mathrm{~s}, 9 \mathrm{H}, \mathrm{SiC}\left(\mathrm{CH}_{3}\right)_{3}\right), 1.46$ $\left(\mathrm{s}, 9 \mathrm{H}, t-\mathrm{Bu}_{-} \mathrm{CH}_{3}\right), 1.82-1.90\left(\mathrm{~m}, 1 \mathrm{H}, 2^{\prime}-\mathrm{H}_{\mathrm{a}}\right), 1.91(\mathrm{~s}, 3 \mathrm{H}, 7-\mathrm{H}), 2.01-2.10(\mathrm{~m}, 2 \mathrm{H}$, 5'-H), 2.25 (ddd, J=10.8 Hz, J=6.4 Hz, J=4.3 Hz, $1 \mathrm{H}, 2^{\prime}-\mathrm{H}_{\mathrm{b}}$ ), 3.51 (dd, J= $7.7 \mathrm{~Hz}$, $\left.J=4.1 \mathrm{~Hz}, 66^{\prime}-\mathrm{H}\right), \quad 3.94-4.03\left(\mathrm{~m}, 1 \mathrm{H}, 4^{\prime}-\mathrm{H}\right), 4.10$ (ddd, $J=6.1 \mathrm{~Hz}, J=4.3 \mathrm{~Hz}$, $\left.J=4.3 \mathrm{~Hz}, 1 \mathrm{H}, 3^{\prime}-\mathrm{H}\right), 6.19$ (dd, $\left.J=6.4 \mathrm{~Hz}, J=6.4 \mathrm{~Hz}, 1 \mathrm{H}, 1^{\prime}-\mathrm{H}\right), 7.20(\mathrm{~s}, 1 \mathrm{H}, 6-\mathrm{H})$.

${ }^{13} \mathrm{C}-\mathrm{NMR}\left(75 \mathrm{MHz}, \mathrm{CDCl}_{3}\right): \delta=-4.81\left(\mathrm{SiCH}_{3}\right),-4.65\left(\mathrm{SiCH}_{3}\right), 12.60(\mathrm{C}-7), 17.89$ $\left(\mathrm{SiC}\left(\mathrm{CH}_{3}\right)_{3}\right), 25.67\left(\mathrm{SiC}\left(\underline{\mathrm{CH}}_{3}\right)_{3}\right), 27.99\left(\mathrm{OC}\left(\underline{\mathrm{C}} \mathrm{H}_{3}\right)_{3}\right), 37.75$ (C-5'), 40.34 (C-2'), 52.78 (C-6'), 75.11 (C-3'), $81.35\left(\mathrm{O} \underline{\mathrm{C}}\left(\mathrm{CH}_{3}\right)_{3}\right), 83.61$ (C-4'), 84.91 (C-1'), 111.01 (C-5), 135.30 (C-6), 150.18 (C-2), 163.77 (C-4), 174.86 (Ester-C=O).

Drehwert: $[\alpha]_{D}^{20}=+44.6\left(\mathrm{c}=1.0, \mathrm{CHCl}_{3}\right)$.

Schmelzpunkt: $114^{\circ} \mathrm{C}$.

IR $(\mathrm{KBr}): \tilde{v}=2930,1695,1471,1368,1159,1033,837,778,602$. 
UV $(\mathrm{MeCN}): \lambda_{\max }(\lg \varepsilon)=264.5$ (3.90).

MS (ESI) $): \mathrm{m} / \mathrm{z}=468.2[\mathrm{M}-\mathrm{H}]^{-}$.

$\mathrm{C}_{22} \mathrm{H}_{39} \mathrm{~N}_{3} \mathrm{O}_{6} \mathrm{Si}$ (469.65)

ber.: $468.2535[\mathrm{M}-\mathrm{H}]$,

gef.: 468.2534 (ESI-HRMS).

\subsubsection{6'-N-Fmoc-O-t-Bu-3'-O-TBDMS-(S)-TAA 134}

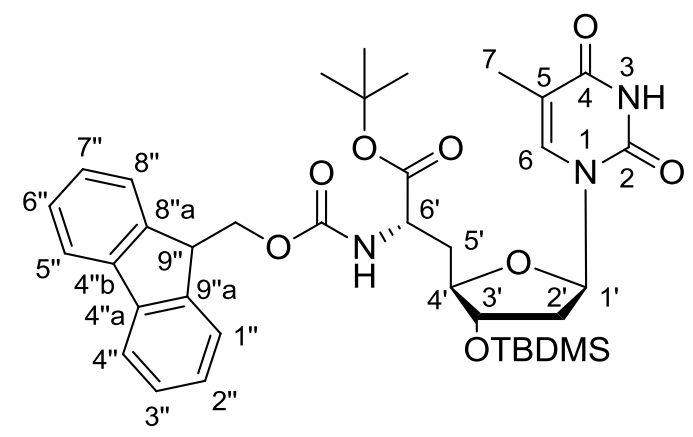

(6'S)-134

Ausgehend von (6'S)-133:

Eine Lösung der TAA (6'S)-133 (600 mg, $1.28 \mathrm{mmol}$ ) in $10 \mathrm{~mL}$ THF wurde auf $0{ }^{\circ} \mathrm{C}$ gekühlt, mit Triethylamin $(0.44 \mathrm{~mL}, 0.32 \mathrm{~g}, 3.2 \mathrm{mmol}$ ) und Fmoc-Chlorid $(413 \mathrm{mg}$, $1.60 \mathrm{mmol}$ ) versetzt und $1 \mathrm{~h}$ bei $0^{\circ} \mathrm{C}$ gerührt. Anschließend wurde die Reaktionslösung mit $1 \mathrm{~mL}$ Wasser versetzt und in $20 \mathrm{~mL}$ Ethylacetat aufgenommen. Die organische Phase wurde mit Wasser $(2 \times 10 \mathrm{~mL})$ und gesättigter $\mathrm{NaCl}$-Lösung $(10 \mathrm{~mL})$ gewaschen, über $\mathrm{Na}_{2} \mathrm{SO}_{4}$ getrocknet und filtriert. Das Lösungsmittel wurde im Vakuum entfernt und der Rückstand chromatographisch an Kieselgel gereinigt (PE/EtOAc 7:3).

Ausbeute: $855 \mathrm{mg}$ (1.24 mmol, 97\%) eines farblosen Schaums.

Ausgehend von (6'S)-83:

Eine Lösung der TAA (6'S)-83 (1.51 g, $2.50 \mathrm{mmol})$ in Methanol $(45 \mathrm{~mL})$ wurde mit Palladium ( $80 \mathrm{mg}, 75 \mu \mathrm{mol}, 10 \%$ auf Aktivkohle) versetzt und $1 \mathrm{~h}$ unter $\mathrm{H}_{2^{-}}$ Atmosphäre gerührt. Die Suspension wurde anschließend über Celite $\AA^{8}$ filtriert und das Filtrat bei vermindertem Druck zur Trockne eingeengt. Der Rückstand (1.16 g,

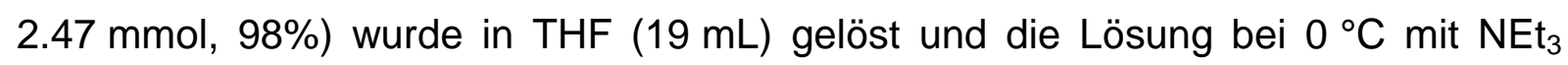
( $0.850 \mathrm{~mL}, 623 \mathrm{mg}, 6.17 \mathrm{mmol})$ und $\mathrm{FmocCl}(798 \mathrm{mg}, 3.09 \mathrm{mmol})$ versetzt. Nach $1 \mathrm{~h}$ Rühren bei $0{ }^{\circ} \mathrm{C}$ wurde die Suspension mit $1.5 \mathrm{~mL}$ dest. $\mathrm{H}_{2} \mathrm{O}$ versetzt und die 
resultierende klare Lösung in $50 \mathrm{~mL}$ EtOAc aufgenommen. Die organische Phase wurde mit Wasser $(2 \times 20 \mathrm{~mL})$ und gesättigter $\mathrm{NaCl}$-Lösung $(20 \mathrm{~mL})$ gewaschen, über $\mathrm{Na}_{2} \mathrm{SO}_{4}$ getrocknet und filtriert. Das Lösungsmittel wurde im Vakuum entfernt und der Rückstand chromatographisch an Kieselgel gereinigt (PE/EtOAc 7:3).

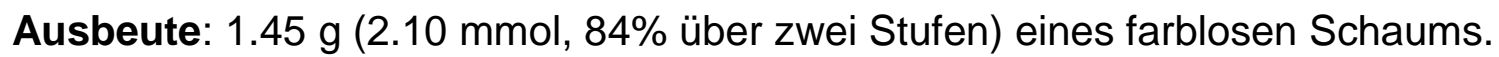

DC: $R_{\mathrm{f}}(\mathrm{DCM} / \mathrm{MeOH} 15: 1)=0.56$.

${ }^{1} \mathrm{H}-\mathrm{NMR}\left(300 \mathrm{MHz}, \mathrm{C}_{6} \mathrm{D}_{6}, 70{ }^{\circ} \mathrm{C}\right): \delta=0.01\left(\mathrm{~s}, 6 \mathrm{H}, \mathrm{SiCH}_{3}\right), 0.90\left(\mathrm{~s}, 9 \mathrm{H}, \mathrm{SiC}\left(\mathrm{CH}_{3}\right)_{3}\right)$, 1.31 (s, $\left.9 \mathrm{H}, t-\mathrm{Bu}-\mathrm{CH}_{3}\right), 1.86(\mathrm{~d}, J=0.9 \mathrm{~Hz}, 3 \mathrm{H}, 7-\mathrm{H}), 1.94-2.00\left(\mathrm{~m}, 3 \mathrm{H}, 2^{\prime}-\mathrm{H}_{\mathrm{a}}, 2^{\prime}-\mathrm{H}_{\mathrm{b}}\right.$, 5' $-\mathrm{H}_{\mathrm{a}}$ ), 2.15 (ddd, $J=14.1 \mathrm{~Hz}, J=6.8 \mathrm{~Hz}, J=3.4 \mathrm{~Hz}, 1 \mathrm{H}, 5^{\prime}-\mathrm{H}_{\mathrm{b}}$ ), 3.89-3.96 (m, $1 \mathrm{H}$, 4'-H), 4.00 (ddd, $J=6.8 \mathrm{~Hz}, J=4.5 \mathrm{~Hz}, J=4.5 \mathrm{~Hz}, 1 \mathrm{H}, 3^{\prime}-\mathrm{H}$ ), 4.08 (dd, $J=6.8 \mathrm{~Hz}$, $\left.J=6.8 \mathrm{~Hz}, 1 \mathrm{H}, 9{ }^{\prime \prime}-\mathrm{H}\right), 4.37\left(\mathrm{~d}, J=6.8 \mathrm{~Hz}, 2 \mathrm{H}, \mathrm{FmocCH}_{2}\right), 4.50-4.57\left(\mathrm{~m}, 1 \mathrm{H}, 6^{\prime}-\mathrm{H}\right)$, $5.48\left(\mathrm{~d}, J=7.4 \mathrm{~Hz}, 1 \mathrm{H}\right.$, Fmoc-NH), $6.00\left(\mathrm{dd}, J=6.1 \mathrm{~Hz}, J=6.1 \mathrm{~Hz}, 1 \mathrm{H}, 1^{\prime}-\mathrm{H}\right), 6.92$ (s,1 H, 6-H), 7.10-7.24 (m, $4 \mathrm{H}, 2$ 2"-H, 7"'-H, 3"-H, 6"-H), 7.44-7.50 (m, $2 \mathrm{H}, 4$ "'-H, 5"-H), 7.55-7.60 (m, $2 \mathrm{H}, 1$ "'-H, 8"-H), 8.56 (brs, $1 \mathrm{H}, 3-\mathrm{NH})$.

${ }^{13} \mathrm{C}-\mathrm{NMR}\left(75 \mathrm{MHz}, \mathrm{C}_{6} \mathrm{D}_{6}, 70{ }^{\circ} \mathrm{C}\right): \delta=-4.72\left(\mathrm{SiCH}_{3}\right),-4.52\left(\mathrm{SiCH}_{3}\right), 12.31(\mathrm{C}-7), 18.08$ $\left(\mathrm{Si} \underline{\mathrm{C}}\left(\mathrm{CH}_{3}\right)_{3}\right), 25.89\left(\mathrm{SiC}\left(\underline{\mathrm{CH}}_{3}\right)_{3}\right), 27.93\left(\mathrm{OC}\left(\underline{\mathrm{C}}_{3}\right)_{3}\right), 36.47\left(\mathrm{C}-5^{\prime}\right), 40.11\left(\mathrm{C}-2^{\prime}\right), 47.89$ (C-9"), 52.78 (C-6'), $67.25\left(\mathrm{FmocCH}_{2}\right), 75.70\left(\mathrm{C}-3^{\prime}\right), 82.12\left(\mathrm{O} \underline{\mathrm{C}}\left(\mathrm{CH}_{3}\right)\right), 83.59\left(\mathrm{C}-4^{\prime}\right)$, 86.32 (C-1'), 111.03 (C-5), 120.25 (C-4", C-5"), 125.35 (C-1", C-8”), 127.33 (C-3", C-6"), 128.29 (C-2", C-7"), 135.97 (C-6), 141.88 (C-4"b, C-4"a), 144.51 (C-8"a), 144.56 (C-9"a), 150.29 (C-2), 155.91 (Fmoc-C=O), 163.22 (C-4), 170.92 (Ester$\mathrm{C}=\mathrm{O})$.

Drehwert: $[\alpha]_{D}^{20}=+42.1\left(\mathrm{c}=1.1, \mathrm{CHCl}_{3}\right)$.

Schmelzpunkt: $84^{\circ} \mathrm{C}$.

IR $(\mathrm{KBr}): \tilde{v}=2954,1712,1470,1368,1253,1156,837,778,740$.

UV (MeCN): $\lambda_{\max }(\lg \varepsilon)=206$ (4.70), 265 (4.39), 287 (3.76), 299 (3.73)

MS $\left(\mathrm{ESI}^{+}\right): \mathrm{m} / \mathrm{z}=714.32[\mathrm{M}+\mathrm{Na}]^{+}$.

$\mathrm{C}_{37} \mathrm{H}_{49} \mathrm{~N}_{3} \mathrm{O}_{8} \mathrm{Si}$ (691.89)

ber.: $714.3181[\mathrm{M}+\mathrm{Na}]^{+}$ gef.: 714.3170 (ESI+-HRMS). 


\subsubsection{6'-N-Fmoc-O-t-Bu-3'-O-TBDMS-(R)-TAA 134}

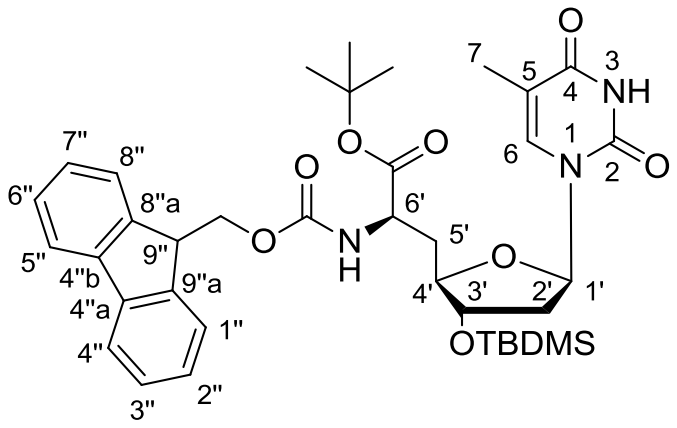

$\left(6^{\prime} R\right)-134$

Ausgehend von (6'R)-133:

Die Synthese von (6'R)-134 erfolgte gemäß der Vorschrift zur Synthese von (6'S)-134. Es wurden $570 \mathrm{mg}(1.22 \mathrm{mmol})$ (6'R)-TAA 133, $393 \mathrm{mg}$ (1.52 mmol) FmocCl, $0.42 \mathrm{~mL}(0.31 \mathrm{~g}, 3.0 \mathrm{mmol}) \mathrm{NEt}_{3}$ und $10 \mathrm{~mL}$ THF eingesetzt.

Ausbeute: $800 \mathrm{mg}(1.16 \mathrm{mmol}, 95 \%)$ eines farblosen Schaums.

\section{Ausgehend von (6'R)-83:}

Die Synthese von $\left(6^{\prime} R\right)-134$ erfolgte gemäß der Vorschrift zur Synthese von (6'S)-134 (ausgehend von 83). Es wurden $1.50 \mathrm{~g}$ (2.49 mmol) (6'R)-TAA 83, $80 \mathrm{mg}$ Palladium auf Aktivkohle $(75 \mu \mathrm{mol})$ und $45 \mathrm{ml}$ abs. MeOH zur Abspaltung der CbzSchutzgruppe verwendet. Es wurden $1.06 \mathrm{~g}$ (2.17 mmol, 87\%) an Zwischenprodukt 133 erhalten. Für die nachfolgende Einführung der Fmoc-Schutzgruppe wurden $798 \mathrm{mg}$ (3.09 mmol) $\mathrm{FmocCl}, 0.85 \mathrm{~mL}(0.62 \mathrm{~g}, 6.17 \mathrm{mmol}) \mathrm{NEt}_{3}$ und $19 \mathrm{~mL}$ THF eingesetzt.

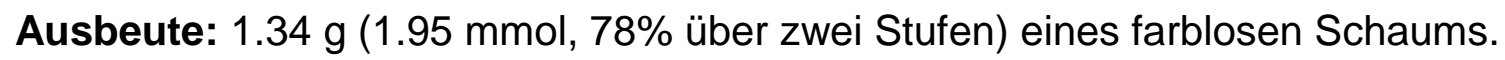

DC: $R_{\mathrm{f}}(\mathrm{DCM} / \mathrm{MeOH} 15: 1)=0.56$.

${ }^{1} \mathrm{H}-\mathrm{NMR}\left(300 \mathrm{MHz}, \mathrm{C}_{6} \mathrm{D}_{6}, 70{ }^{\circ} \mathrm{C}\right): \delta=0.01\left(\mathrm{~s}, 3 \mathrm{H}, \mathrm{SiCH}_{3}\right), 0.03\left(\mathrm{~s}, 3 \mathrm{H}, \mathrm{SiCH}_{3}\right), 0.90$ (s, $\left.9 \mathrm{H}, \mathrm{SiC}\left(\mathrm{CH}_{3}\right)_{3}\right), 1.35$ (s, $\left.9 \mathrm{H}, t-B u-\mathrm{CH}_{3}\right), 1.73$ (d, J=1.2 Hz, $3 \mathrm{H}, 7-\mathrm{H}$ ), 1.96 (dd, $\left.J=12.6 \mathrm{~Hz}, J=6.1 \mathrm{~Hz}, 2 \mathrm{H}, 2^{\prime}-\mathrm{H}\right), 2.10$ (dd, $\left.J=5.7 \mathrm{~Hz}, J=5.7 \mathrm{~Hz}, 2 \mathrm{H}, 5 '-\mathrm{H}\right), 3.87-$ $3.95\left(\mathrm{~m}, 1 \mathrm{H}, 4^{\prime}-\mathrm{H}\right), 4.04-4.13$ (m, $2 \mathrm{H}, 9$ '’-H, 3'-H), 4.31 (dd, J = $10.6 \mathrm{~Hz}, J=7.0 \mathrm{~Hz}$, $1 \mathrm{H}, \mathrm{FmocCH} \underline{\mathrm{H}}_{\mathrm{a}}$ ), 4.40 (dd, $J=10.6 \mathrm{~Hz}, J=7.0 \mathrm{~Hz}, 1 \mathrm{H}, \mathrm{FmocCH} \underline{\mathrm{H}}_{\mathrm{b}}$ ), 4.56 (ddd, $\left.J=8.5 \mathrm{~Hz}, J=5.7 \mathrm{~Hz}, J=5.7 \mathrm{~Hz}, 1 \mathrm{H}, 6{ }^{\prime}-\mathrm{H}\right), 5.69$ (d, $\left.J=8.5 \mathrm{~Hz}, 1 \mathrm{H}, \mathrm{Fmoc}-\mathrm{NH}\right)$, $5.76\left(\mathrm{dd}, J=6.1 \mathrm{~Hz}, J=6.1 \mathrm{~Hz}, 1 \mathrm{H}, 1^{\prime}-\mathrm{H}\right), 6.62(\mathrm{~d}, J=1.2 \mathrm{~Hz}, 1 \mathrm{H}, 6-\mathrm{H}), 7.12-7.25$ 
(m, $4 \mathrm{H}, 1$ '"-H, 4"-H, 5"-H, 8"-H), 7.45 (d, J= $7.3 \mathrm{~Hz}, 1 \mathrm{H}, 2$ "'-H), 7.51 (d, J = $7.3 \mathrm{~Hz}$, $1 \mathrm{H}, 7$ ''-H), 7.56 (d, J=7.2 Hz, 2 H, 3"'-H, 6"'-H), 9.20 (brs, 1 H, 3-NH).

${ }^{13} \mathrm{C}-\mathrm{NMR}\left(75 \mathrm{MHz}, \mathrm{C}_{6} \mathrm{D}_{6}, 70^{\circ} \mathrm{C}\right): \delta=-4.72\left(\mathrm{SiCH}_{3}\right),-4.56\left(\mathrm{SiCH}_{3}\right), 12.36(\mathrm{C}-7)$, $\left.18.08\left(\mathrm{Si} \underline{\underline{C}}\left(\mathrm{CH}_{3}\right)_{3}\right), 25.85\left(\mathrm{SiC}(\underline{\mathrm{CH}})_{3}\right)_{3}\right), 27.97\left(\mathrm{O} \underline{\mathrm{C}}\left(\mathrm{CH}_{3}\right)_{3}\right), 35.39$ (C-5'), 40.02 (C-2'), 47.79 (C-9'), 53.46 (C-6'), $67.33\left(\mathrm{FmocCH}_{2}\right), 75.72$ (C-3'), $81.86\left(\mathrm{O} \underline{\mathrm{C}}\left(\mathrm{CH}_{3}\right)\right), 83.59$ (C-4'), 87.28 (C-1'), 110.89 (C-5), 120.13 (C-4”), 120.29 (C-5”), 125.40 (C-1"), 125.58 (C-8"), 127.41 (C-6"), 127.92 (C-3"), 128.08 (C-7"), 128.40 (C-2"), 136.06 (C-6), 141.82 (C-4"a, C-4"b), 144.52 (C-8"a), 144.61 (C-9"a), 150.36 (C-2), 156.20 (Fmoc-C=O), 163.48 (C-4), 171.13 (Ester-C=O).

Drehwert: $[\alpha]_{D}^{20}=+47.9\left(\mathrm{c}=1.0, \mathrm{CHCl}_{3}\right)$.

Schmelzpunkt: $84^{\circ} \mathrm{C}$.

IR $(\mathrm{KBr}): \tilde{v}=2954,1714,1471,1368,1155,1051,837,778,740$.

UV (MeCN): $\lambda_{\max }(\lg \varepsilon)=205.5$ (4.73), 264.5 (4.43), 287.0 (3.81), 299.0 (3.78).

MS $\left(\mathrm{ESI}^{+}\right): \mathrm{m} / \mathrm{z}=714.4[\mathrm{M}+\mathrm{Na}]^{+}$.

$\mathrm{C}_{37} \mathrm{H}_{49} \mathrm{~N}_{3} \mathrm{O}_{8} \mathrm{Si}$ (691.89)

ber.: $714.3187[\mathrm{M}+\mathrm{Na}]^{+}$

gef.: 714.3180 (ESI+-HRMS).

\subsubsection{6'-N-Fmoc-3'-O-TBDMS-(S)-TAA 73}

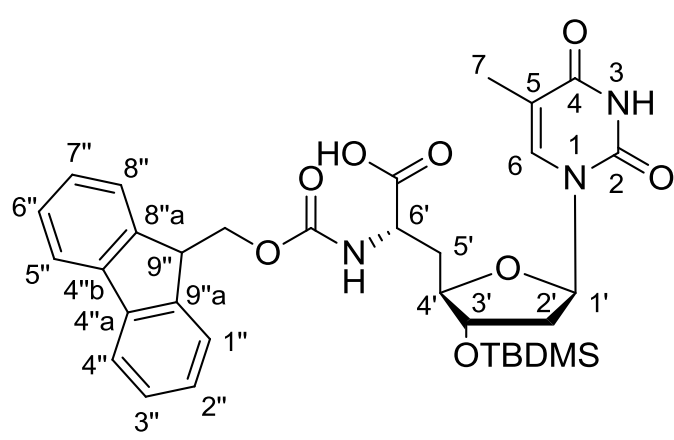

(6’S)-73

Eine Lösung von (6'S)-134 (770 mg, $1.11 \mathrm{mmol})$ in Toluol (25 mL) wurde mit $1.77 \mathrm{~g}$ Kieselgel versetzt und $20 \mathrm{~h}$ am Rückfluss erhitzt. Die Reaktionslösung wurde nach Abkühlen über eine Glasfritte filtriert. Das zurückgebliebene Kieselgel wurde mit einem DCM/MeOH (1:1)-Gemisch $(5 \times 5 \mathrm{~mL})$ gewaschen. Die vereinigten Filtrate wurden unter vermindertem Druck eingeengt. Lösungsmittelreste wurden im Vakuum entfernt.

Ausbeute: $526 \mathrm{mg}(0.828 \mathrm{mmol}, 74 \%)$ eines farblosen Feststoffs. 
DC: $R_{\mathrm{f}}(\mathrm{DCM} / \mathrm{MeOH} 12: 1)=0.19$.

${ }^{1} \mathrm{H}-\mathrm{NMR}\left(300 \mathrm{MHz}, \mathrm{CD}_{3} \mathrm{OD}, 50^{\circ} \mathrm{C}\right): \delta=0.08\left(\mathrm{~s}, 6 \mathrm{H}, \mathrm{SiCH}_{3}\right), 0.88 \quad(\mathrm{~s}, 9 \mathrm{H}$, $\left.\mathrm{SiC}\left(\mathrm{CH}_{3}\right)_{3}\right), 1.84(\mathrm{~s}, 3 \mathrm{H}, 7-\mathrm{H}), 1.97-2.11\left(\mathrm{~m}, 1 \mathrm{H}, 5^{\prime}-\mathrm{H}_{\mathrm{a}}\right), 2.14(\mathrm{dd}, J=6.8 \mathrm{~Hz}$, $\left.J=5.1 \mathrm{~Hz}, 2 \mathrm{H}, 2^{\prime}-\mathrm{H}\right), 2.18-2.31\left(\mathrm{~m}, 1 \mathrm{H}, 5^{\prime}-\mathrm{H}_{\mathrm{b}}\right), 3.93-4.04\left(\mathrm{~m}, 1 \mathrm{H}, 4^{\prime}-\mathrm{H}\right), 4.18$ (dd, $\left.J=6.7 \mathrm{~Hz}, J=6.7 \mathrm{~Hz}, 1 \mathrm{H}, 9^{\prime \prime}-\mathrm{H}\right), 4.22-4.28\left(\mathrm{~m}, 1 \mathrm{H}, 3^{\prime}-\mathrm{H}\right), 4.23-4.28\left(\mathrm{~m}, 3 \mathrm{H}, 6^{\prime}-\mathrm{H}\right.$, $\mathrm{FmocCH}_{2}$ ), $6.13\left(\mathrm{dd}, J=6.8 \mathrm{~Hz}, J=6.8 \mathrm{~Hz}, 1 \mathrm{H}, 1^{\prime}-\mathrm{H}\right), 7.26(\mathrm{dd}, J=5.1 \mathrm{~Hz}$, $J=1.2 \mathrm{~Hz}, 1 \mathrm{H}, 3$ "'-H), 7.28 (dd, $J=5.1 \mathrm{~Hz}, J=1.3 \mathrm{~Hz}, 1 \mathrm{H}, 6$ "'-H) 7.32-7.38 (m, $2 \mathrm{H}$, 2"-H, 7"-H), 7.42 (s, $1 \mathrm{H}, 6-\mathrm{H}), 7.61(\mathrm{~d}, J=6.8 \mathrm{~Hz}, 5$ "'-H), $7.62(\mathrm{~d}, J=7.3 \mathrm{~Hz}, 1 \mathrm{H}$, 4"'-H), 7.80 (d, J = 7.2 Hz, $2 \mathrm{H}, 1$ "'-H, 8"-H).

${ }^{13} \mathrm{C}-\mathrm{NMR}\left(75 \mathrm{MHz}, \mathrm{CD}_{3} \mathrm{OD}, 50{ }^{\circ} \mathrm{C}\right): \delta=-4.62\left(\mathrm{SiCH}_{3}\right),-4.50\left(\mathrm{SiCH}_{3}\right), 12.30(\mathrm{C}-7)$, $18.72\left(\mathrm{Si} \underline{\mathrm{C}}\left(\mathrm{CH}_{3}\right)_{3}\right), 26.24\left(\mathrm{SiC}\left(\underline{\mathrm{CH}}_{3}\right)_{3}\right), 36.74$ (C-5'), 40.71 (C-2'), 48.15 (C-9"), 53.25 (C-6'), $68.04\left(\mathrm{FmocCH}_{2}\right), 76.59\left(\mathrm{C}-3^{\prime}\right), 85.46\left(\mathrm{C}-4^{\prime}\right), 86.61$ (C-1'), 111.89 (C-5), 120.90 (C-1", C-8"), 126.12 (C-5"), 126.15 (C-4"), 128.10 (C-3"), 128.12 (C-6"), 128.75 (C-2", C-7"), 137.83 (C-6), 142.57 (C-4"a, C-4"b), 145.25 (C-8"a), 145.27 (C-9"a), 152.21 (C-2), 158.18 (Fmoc-C=O), 166.23 (C-4), $175.36(\mathrm{COOH})$.

Drehwert: $[\alpha]_{D}^{20}=+47.0^{\circ}\left(\mathrm{c}=1.05, \mathrm{CHCl}_{3}\right)$.

Schmelzpunkt: $119^{\circ} \mathrm{C}$.

IR (KBr): $\tilde{v}=2954,1708,1513,1450,1252,1052,836,778,739$.

UV (MeCN): $\lambda_{\max }(\lg \varepsilon)=205.5$ (4.70), 264.5 (4.41), 287.0 (3.79), 299.0 (3.74).

MS (ESI'): $\mathrm{m} / \mathrm{z}=634.3[\mathrm{M}-\mathrm{H}]^{-}$.

$\mathrm{C}_{33} \mathrm{H}_{41} \mathrm{~N}_{3} \mathrm{O}_{8} \mathrm{Si}$ (635.78)

ber.: $634.2590[\mathrm{M}-\mathrm{H}]^{-}$

gef.: 634.2590 (ESI-HRMS).

\subsubsection{6'-N-Fmoc-3'-O-TBDMS-(R)-TAA 73}

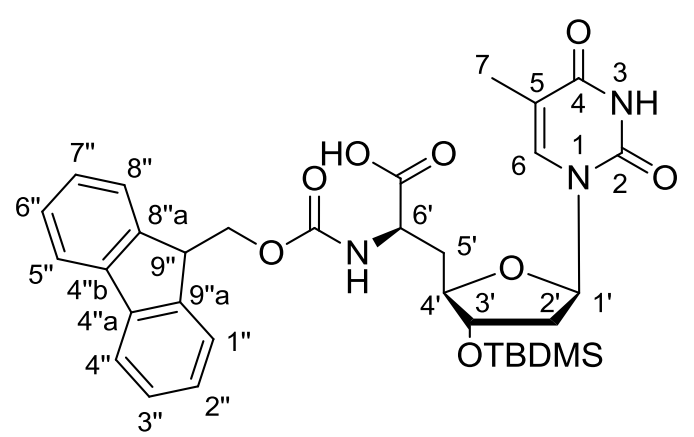

$\left(6^{\prime} R\right)-73$ 
Die Synthese von (6'R)-73 erfolgte gemäß der Vorschrift zur Synthese von (6'S)-73. Es wurden $730 \mathrm{mg}(1.06 \mathrm{mmol})\left(6^{\prime} R\right)-134,24 \mathrm{~mL}$ Toluol und $1.70 \mathrm{~g}$ Kieselgel eingesetzt.

Ausbeute: $500 \mathrm{mg}(0.787 \mathrm{mmol}, 75 \%)$ eines farblosen Feststoffs.

DC: $R_{\mathrm{f}}(\mathrm{DCM} / \mathrm{MeOH} 12: 1)=0.19$.

${ }^{1} \mathrm{H}-\mathrm{NMR}\left(300 \mathrm{MHz}, \quad \mathrm{CD}_{3} \mathrm{OD}, \quad 50{ }^{\circ} \mathrm{C}\right): \delta=0.09$ (s, $\left.6 \mathrm{H}, \mathrm{SiCH}_{3}\right), 0.89 \quad(\mathrm{~s}, 9 \mathrm{H}$, $\left.\operatorname{SiC}\left(\mathrm{CH}_{3}\right)_{3}\right), 1.83(\mathrm{~s}, 3 \mathrm{H}, 7-\mathrm{H}), 1.99-2.25\left(\mathrm{~m}, 2 \mathrm{H}, 5^{\prime}-\mathrm{H}_{\mathrm{a}}, 5^{\prime}-\mathrm{H}_{\mathrm{b}}\right), 2.18(\mathrm{dd}, J=6.7 \mathrm{~Hz}$, $J=4.7 \mathrm{~Hz}, 2 \mathrm{H}, 2^{\prime}-\mathrm{H}$ ), 3.92 (ddd, $J=9.7 \mathrm{~Hz}, J=3.5 \mathrm{~Hz}, J=3.5 \mathrm{~Hz}, 1 \mathrm{H}, 4^{\prime}-\mathrm{H}$ ), 4.17 (dd, J=6.9 Hz, J=6.9 Hz, $\left.1 \mathrm{H}, 9{ }^{\prime \prime}-\mathrm{H}\right), 4.23-4.29(\mathrm{~m}, 1 \mathrm{H}, 3$ '-H), 4.23-4.28 (m, $3 \mathrm{H}$, 6'-H, FmocCH $\mathrm{F}_{2}$ ), 6.19 (dd, $J=6.7 \mathrm{~Hz}, J=6.7 \mathrm{~Hz}, 1 \mathrm{H}, 1^{\prime}-\mathrm{H}$ ), 7.25 (dd, $J=7.4 \mathrm{~Hz}$, $J=7.4$ Hz, 2 H, 3"'-H, 6"'-H), 7.34 (dd, J=7.4 Hz, J=7.4 Hz, 2 H, 2"'-H, 7'--H), 7.40 (s, $1 \mathrm{H}, 6-\mathrm{H}), 7.60$ (d, J=6.9 Hz, $1 \mathrm{H}, 4$ "'-H), 7.61 (d, J=6.9 Hz, $1 \mathrm{H}, 5$ "-H), 7.70 (d, $J=7.5 \mathrm{~Hz}, 2 \mathrm{H}, 1$ '-H, 8"'-H).

${ }^{13} \mathrm{C}$-NMR $\left(75 \mathrm{MHz}, \mathrm{CD}_{3} \mathrm{OD}, 50{ }^{\circ} \mathrm{C}\right): \delta=-4.60\left(\mathrm{SiCH}_{3}\right),-4.54\left(\mathrm{SiCH}_{3}\right), 12.33(\mathrm{C}-7)$, $18.75\left(\mathrm{Si} \underline{\mathrm{C}}\left(\mathrm{CH}_{3}\right)_{3}\right), 26.26\left(\mathrm{SiC}\left(\underline{\mathrm{CH}}_{3}\right)_{3}\right), 36.51$ (C-5'), 40.64 (C-2'), 48.15 (C-9'), 53.21 (C-6'), $68.10\left(\mathrm{FmocCH}_{2}\right), 76.79$ (C-3'), 85.09 (C-4'), 86.84 (C-1'), 112.00 (C-5), 120.87 (C-1", C-8”), 126.17 (C-5”), 126.15 (C-4”), 128.09 (C-3”), 128.12 (C-6”), 128.74 (C-2", C-7”), 137.68 (C-6), 142.55 (C-4"a, C-4”b), 145.20 (C-8"a), 145.29 (C-9"'a), 152.23 (C-2), 158.44 (Fmoc-C=O), 166.18 (C-4), $176.04(\mathrm{COOH})$.

Drehwert: $[\alpha]_{\mathrm{D}}^{20}=+33.3\left(\mathrm{c}=1.0, \mathrm{CHCl}_{3}\right)$.

Schmelzpunkt: $119^{\circ} \mathrm{C}$.

IR (KBr): $\tilde{v}=2954,1707,1528,1450,1253,1047,835,778,739$.

UV (MeCN): $\lambda_{\max }(\lg \varepsilon)=206$ (4.65), 265 (4.35), 287 (3.73), 299 (3.70).

MS $\left(\mathrm{ESI}^{-}\right): \mathrm{m} / \mathrm{z}=634.3[\mathrm{M}-\mathrm{H}]^{-}$.

$\mathrm{C}_{33} \mathrm{H}_{41} \mathrm{~N}_{3} \mathrm{O}_{8} \mathrm{Si}$ (634.78)

ber.: $634.2590[\mathrm{M}-\mathrm{H}]^{-}$ gef.: 634.2590 (ESI'-HRMS). 


\subsubsection{Synthese der 3'-Aminonucleoside}

\subsubsection{5'-O-TBDMS-thymidin 135}

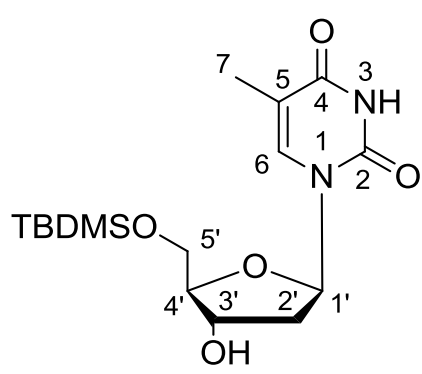

135

Thymidin 77 (7.00 g, $28.9 \mathrm{mmol})$ wurde mit abs. Pyridin $(2 \times 30 \mathrm{~mL})$ coevaporiert. Anschließend wurde das Thymidin in Pyridin (70 mL) gelöst und mit Imidazol (2.16 g, $31.8 \mathrm{mmol}$ ) und TBDMS-Chlorid $(4.77 \mathrm{~g}, 31.8 \mathrm{mmol})$ versetzt. Die Lösung wurde $2 \mathrm{~d}$ bei Raumtemperatur gerührt, mit Wasser $(30 \mathrm{~mL})$ versetzt und das Lösungsmittel im Vakuum entfernt. Der Rückstand wurde in Ethylacetat $(200 \mathrm{~mL})$ aufgenommen, mit ges. $\mathrm{NaHCO}_{3}$-Lösung $(3 \times 100 \mathrm{~mL})$ und mit ges. $\mathrm{NaCl}(50 \mathrm{~mL})$ gewaschen. Das Lösungsmittel wurde im Vakuum entfernt und der Rückstand mit Toluol $(2 \times 30 \mathrm{~mL})$ und DCM (2 x $30 \mathrm{~mL})$ koevaporiert. Das Rohprodukt wurde chromatographisch an Kieselgel (DCM/MeOH 95:5) gereinigt.

Ausbeute: $9.16 \mathrm{~g}(25.6 \mathrm{mmol}, 89 \%)$ eines weißen Feststoffs.

DC: $R_{\mathrm{f}}(\mathrm{DCM} / \mathrm{MeOH} 95: 5)=0.28$.

${ }^{1} \mathrm{H}-\mathrm{NMR}\left(300 \mathrm{MHz}, \mathrm{CDCl}_{3}\right): \delta=0.08\left(\mathrm{~s}, 3 \mathrm{H}, \mathrm{SiCH}_{3}\right), 0.09$ (s, $\left.3 \mathrm{H}, \mathrm{SiCH}_{3}\right), 0.89$ (s, $\left.9 \mathrm{H}, \mathrm{SiC}\left(\mathrm{CH}_{3}\right)_{3}\right), 1.88(\mathrm{~d}, J=1.2 \mathrm{~Hz}, 3 \mathrm{H}, 7-\mathrm{H}), 2.06$ (ddd, $J=13.4 \mathrm{~Hz}, J=8.3 \mathrm{~Hz}$, $J=5.7 \mathrm{~Hz}, 1 \mathrm{H}, 2^{\prime}-\mathrm{H}_{\mathrm{a}}$ ), 2.37 (ddd, J=13.4 Hz, J=5.6 Hz, J=2.0 Hz, $1 \mathrm{H}, 2{ }^{\prime}-\mathrm{H}_{\mathrm{b}}$ ), $3.80\left(\mathrm{dd}, J=11.4 \mathrm{~Hz}, J=2.2 \mathrm{~Hz}, 1 \mathrm{H}, 5^{\prime}-\mathrm{H}_{\mathrm{a}}\right.$ ), $3.87(\mathrm{dd}, J=11.4 \mathrm{~Hz}, J=2.2 \mathrm{~Hz}, 1 \mathrm{H}$, $5^{\prime}-\mathrm{H}_{\mathrm{b}}$ ), 4.04 (dd, J=4.5 Hz, J=2.2 Hz, $1 \mathrm{H}, 4^{\prime}-\mathrm{H}$ ), 4.42 (ddd, $J=5.7 \mathrm{~Hz}, J=2.2 \mathrm{~Hz}$, $\left.J=2.1 \mathrm{~Hz}, 1 \mathrm{H}, 3^{\prime}-\mathrm{H}\right), 6.37\left(\mathrm{dd}, J=8.3 \mathrm{~Hz}, J=5.6 \mathrm{~Hz}, 1 \mathrm{H}, 1^{\prime}-\mathrm{H}\right), 7.51(\mathrm{~d}, J=1.2 \mathrm{~Hz}$, $1 \mathrm{H}, 6-\mathrm{H})$.

${ }^{13}$ C-NMR $\left(75 \mathrm{MHz}, \mathrm{CDCl}_{3}\right): \delta=-5.50\left(\mathrm{SiCH}_{3}\right),-5.41\left(\mathrm{SiCH}_{3}\right), 12.51(\mathrm{C}-7), 18.32$ $\left(\mathrm{SiC}\left(\mathrm{CH}_{3}\right)_{3}\right), 25.89\left(\mathrm{SiC}\left(\underline{\mathrm{C}} \mathrm{H}_{3}\right)_{3}\right), 41.10$ (C-2'), 63.60 (C-5'), 72.57 (C-3'), 85.01 (C-1'), 87.31 (C-4'), 110.96 (C-5), 135.47 (C-6), 150.56 (C-2), 163.94 (C-4).

Drehwert: $[\alpha]_{D}^{20}=+1.96\left(\mathrm{c}=1.1, \mathrm{CHCl}_{3}\right)$.

Schmelzpunkt: $189^{\circ} \mathrm{C}$. 
IR $(\mathrm{KBr}): \tilde{v}=2929,1699,1472,1258,1122,1060,1003,834,779$.

UV (MeCN): $\lambda_{\max }(\lg \varepsilon)=205$ (4.01), 265 (3.97).

MS $\left(\mathrm{ESI}^{+}\right): \mathrm{m} / \mathrm{z}=379.2[\mathrm{M}+\mathrm{Na}]^{+}$.

$\mathrm{C}_{16} \mathrm{H}_{28} \mathrm{~N}_{2} \mathrm{O}_{5} \mathrm{Si}(356.49)$

ber.: $379.1665[\mathrm{M}+\mathrm{Na}]^{+}$, gef.: 379.1667 (ESI ${ }^{+}$-HRMS).

\subsubsection{5'-O-TBDMS-2,3'-anhydrothymidin 136}

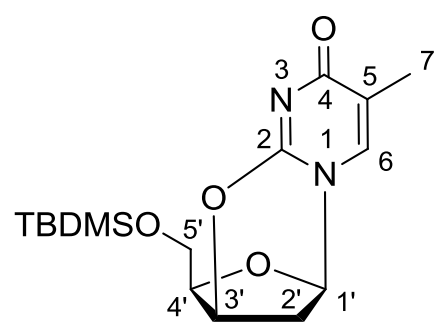

136

Eine Lösung von 5'-O-(tert-Butyldimethylsilyl)-thymidin $135(1.30 \mathrm{~g}, 3.65 \mathrm{mmol})$ in abs. DMF (9 mL) wurde mit einer Lösung von DIAD (1.11 g, $1.07 \mathrm{~mL}, 5.45 \mathrm{mmol})$ und Triphenylphosphin $(1.40 \mathrm{~g}, 5.48 \mathrm{mmol})$ in abs. DMF $(2 \mathrm{~mL})$ versetzt und $2 \mathrm{~h}$ bei Raumtemperatur gerührt. Anschließend wurde die Reaktionsmischung in DCM $(100 \mathrm{~mL})$ aufgenommen, mit Wasser $(3 \times 80 \mathrm{~mL})$ und ges. NaCl-Lösung $(80 \mathrm{~mL})$ gewaschen, über $\mathrm{Na}_{2} \mathrm{SO}_{4}$ getrocknet, filtriert und im Vakuum eingeengt. Das Rohprodukt wurde mittels Säulenchromatographie an Kieselgel (DCM/MeOH 100:3 $\rightarrow$ 94:6) gereinigt.

Ausbeute: $1.17 \mathrm{~g} \mathrm{(3.46} \mathrm{mmol,} \mathrm{95 \% )} \mathrm{eines} \mathrm{weißen} \mathrm{Feststoffs.}$

DC: $R_{\mathrm{f}}(\mathrm{DCM} / \mathrm{MeOH})=0.20$.

${ }^{1} \mathrm{H}-\mathrm{NMR}\left(300 \mathrm{MHz}_{\mathrm{CDCl}}\right.$ ): $\delta=0.03\left(\mathrm{~s}, 3 \mathrm{H}, \mathrm{SiCH}_{3}\right), 0.04\left(\mathrm{~s}, 3 \mathrm{H}, \mathrm{SiCH}_{3}\right), 0.86$ (s, $\left.9 \mathrm{H}, \operatorname{SiC}\left(\mathrm{CH}_{3}\right)_{3}\right), 1.91(\mathrm{~d}, J=0.7 \mathrm{~Hz}, 3 \mathrm{H}, 7-\mathrm{H}), 2.43$ (ddd, $J=12.8 \mathrm{~Hz}, J=3.8 \mathrm{~Hz}$, $\left.J=2.8 \mathrm{~Hz}, 1 \mathrm{H}, 2^{\prime}-\mathrm{H}_{\mathrm{b}}\right), 2.70\left(\mathrm{~d}, J=12.8 \mathrm{~Hz}, 1 \mathrm{H}, 2^{\prime}-\mathrm{H}_{\mathrm{a}}\right)$, 3.69-3.81 (m, $2 \mathrm{H}, 5$ '- $\left.\mathrm{H}\right)$, 4.25 (ddd, $J=7.3 \mathrm{~Hz}, J=6.1 \mathrm{~Hz}, J=2.4 \mathrm{~Hz}, 1 \mathrm{H}, 4$ '-H), 5.17 (s, $1 \mathrm{H}, 3$ '-H), 5.50 (d, $\left.J=2.8 \mathrm{~Hz}, 1 \mathrm{H}, 1^{\prime}-\mathrm{H}\right), 6.96(\mathrm{~d}, J=0.7 \mathrm{~Hz}, 6-\mathrm{H})$.

${ }^{13}$ C-NMR $\left(75 \mathrm{MHz}_{\mathrm{CDCl}}\right): \delta=-5.52\left(\mathrm{SiCH}_{3}\right),-5.47\left(\mathrm{SiCH}_{3}\right), 13.35(\mathrm{C}-7), 18.19$ $\left(\mathrm{SiC}\left(\mathrm{CH}_{3}\right)_{3}\right), 25.74\left(\mathrm{SiC}\left(\underline{\mathrm{CH}}_{3}\right)_{3}\right), 33.53$ (C-2'), 61.23 (C-5'), 76.42 (C-3'), 85.83 (C-4'), 87.49 (C-1'), 118.26 (C-5), 135.22 (C-6), 153.50 (C-2), 171.86 (C-4). 
Drehwert: $[\alpha]_{D}^{20}=-45.9\left(\mathrm{c}=1.1, \mathrm{CHCl}_{3}\right)$.

Schmelzpunkt: $174{ }^{\circ} \mathrm{C}$.

IR $(\mathrm{KBr}): \tilde{v}=2953,1660,1615,1529,1471,1257,1139,1076,837$.

UV $(\mathrm{MeCN}): \lambda_{\max }(\lg \varepsilon)=237$ (3.96).

MS $\left(\mathrm{ESI}^{+}\right): \mathrm{m} / \mathrm{z}=361.2[\mathrm{M}+\mathrm{Na}]^{+}$.

$\mathrm{C}_{16} \mathrm{H}_{26} \mathrm{~N}_{2} \mathrm{O}_{4} \mathrm{Si}(338.47)$

ber.: $361.1560[\mathrm{M}+\mathrm{Na}]^{+}$, gef.: 361.1554 (ESI+-HRMS).

\subsubsection{5'-O-TBDMS-3'-desoxy-3'-azidothymidin 118}

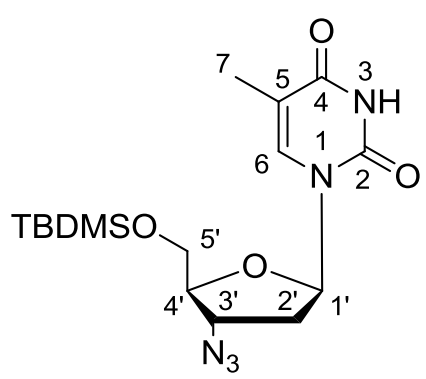

118

Eine Lösung von 5'-O-(tert-Butyldimethylsilyl)-2,3'-anhydrothymidin $136 \quad(8.00 \mathrm{~g}$, $23.5 \mathrm{mmol})$ DMF $(300 \mathrm{~mL})$ wurde mit Natriumazid $(7.64 \mathrm{~g}, 117 \mathrm{mmol})$ versetzt und $4 \mathrm{~h}$ bei $160^{\circ} \mathrm{C}$ gerührt. Anschließend wurde die Lösung mit EtOAc (800 mL) verdünnt, mit Wasser $(2 \times 400 \mathrm{~mL})$ und ges. NaCl-Lösung $(400 \mathrm{~mL})$ gewaschen, über $\mathrm{Na}_{2} \mathrm{SO}_{4}$ getrocknet und im Vakuum eingeengt. Das erhaltene Rohprodukt wurde chromatographisch an Kieselgel (Hex/EtOAc 3:2) gereinigt.

Ausbeute: $6.09 \mathrm{~g} \mathrm{(16.0} \mathrm{mmol,} \mathrm{68 \% )} \mathrm{eines} \mathrm{farblosen} \mathrm{Schaums.}$

DC: $R_{\mathrm{f}}(\mathrm{DCM}: \mathrm{MeOH} 15: 1)=0.47$.

${ }^{1} \mathrm{H}-\mathrm{NMR}\left(300 \mathrm{MHz}, \mathrm{CDCl}_{3}\right): \delta=0.12\left(\mathrm{~s}, 6 \mathrm{H}, \mathrm{SiCH}_{3}\right), 0.91$ (s, $9 \mathrm{H}, \mathrm{SiC}\left(\mathrm{CH}_{3}\right), 1.91$ (d, $J=1.2 \mathrm{~Hz}, 3 \mathrm{H}, 7-\mathrm{H}$ ), 2.21 (ddd, $J=13.7 \mathrm{~Hz}, J=7.1 \mathrm{~Hz}, J=7.1 \mathrm{~Hz}, 1 \mathrm{H}, 2^{\prime}-\mathrm{H}_{\mathrm{a}}$ ), 2.43 (ddd, $J=13.7 \mathrm{~Hz}, J=6.3 \mathrm{~Hz}, J=4.1 \mathrm{~Hz}, \quad 1 \mathrm{H}, \quad 2^{\prime}-\mathrm{H}_{\mathrm{b}}$ ), 3.79 (dd, $J=12.0 \mathrm{~Hz}$, $\left.J=2.9 \mathrm{~Hz}, 1 \mathrm{H}, 5^{\prime}-\mathrm{H}_{\mathrm{a}}\right), 3.91-3.96\left(\mathrm{~m}, 2 \mathrm{H}, 4^{\prime}-\mathrm{H}, 5^{\prime}-\mathrm{H}_{\mathrm{b}}\right), 4.23$ (ddd, $J=7.6 \mathrm{~Hz}$, $\left.J=4.1 \mathrm{~Hz}, J=4.1 \mathrm{~Hz}, 1 \mathrm{H}, 3^{\prime}-\mathrm{H}\right), 6.22\left(\mathrm{dd}, J=6.3 \mathrm{~Hz}, J=6.3 \mathrm{~Hz}, 1 \mathrm{H}, 1^{\prime}-\mathrm{H}\right), 7.43$ (d, $J=1.2 \mathrm{~Hz}, 1 \mathrm{H}, 6-\mathrm{H}), 8.65$ (brs, $1 \mathrm{H}, \mathrm{NH}$ ). 
${ }^{13} \mathrm{C}$-NMR $\left(75 \mathrm{MHz}, \mathrm{CDCl}_{3}\right): \delta=-5.47\left(\mathrm{SiCH}_{3}\right),-5.36\left(\mathrm{SiCH}_{3}\right), 12.55(\mathrm{C}-7), 18.35$ ( $\left.\mathrm{Si} \underline{\mathrm{C}}\left(\mathrm{CH}_{3}\right)_{3}\right), 25.90\left(\mathrm{SiC}\left(\underline{\mathrm{C}} \mathrm{H}_{3}\right)_{3}\right), 37.97$ (C-2'), 60.48 (C-3'), 62.88 (C-5'), 84.43 (C-4'), 84.51 (C-1'), 111.04 (C-5), 134.98 (C-6), 150.17 (C-2), 163.64 (C-4).

Drehwert: $[\alpha]_{D}^{20}=+46.5\left(\mathrm{c}=1.0, \mathrm{CHCl}_{3}\right)$.

IR $(\mathrm{KBr}): \tilde{v}=2929,2104,1706,1467,1261,1127,834,781,420$.

UV (MeCN): $\lambda_{\max }(\lg \varepsilon)=204$ (4.05), 264 (3.98).

MS $\left(E S I^{+}\right): m / z=404.2[\mathrm{M}+\mathrm{Na}]^{+}$.

$\mathrm{C}_{16} \mathrm{H}_{27} \mathrm{~N}_{5} \mathrm{O}_{4} \mathrm{Si}(381.50)$ ber.: $404.1730[\mathrm{M}+\mathrm{Na}]^{+}$, gef.: 404.1728 (ESI $\left.{ }^{+}-H R M S\right)$.

\subsubsection{5'-O-TBDMS-3'-desoxy-3'-aminothymidin 72}

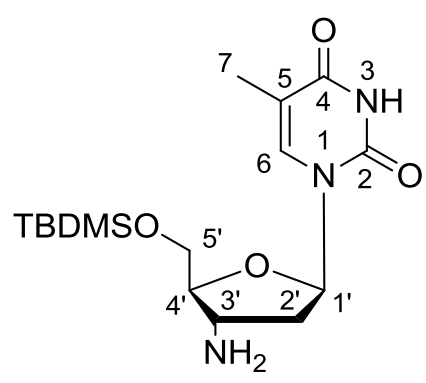

72

Eine Lösung von 5'-O-(tert-Butyldimethylsilyl)-3'-desoxy-3'-azidothymidin 118 (2.01 g, $5.28 \mathrm{mmol}$ ) in Pyridin $\left(40 \mathrm{~mL}\right.$ ) wurde auf $0^{\circ} \mathrm{C}$ gebracht und mit Triphenylphosphin $(2.77 \mathrm{~g}, 10.6 \mathrm{mmol})$ versetzt. Anschließend wurde eine 25\%ige wässrige AmmoniakLösung (3.2 mL) in einem Zeitraum von 30 min zur Reaktionslösung gegeben und das resultierende Gemisch $16 \mathrm{~h}$ gerührt. In diesem Zeitraum wurde die Lösung allmählich auf Raumtemperatur erwärmt. Das Lösungsmittel wurde im Vakuum entfernt. Der Rückstand wurde mit Toluol $(2 \times 50 \mathrm{~mL})$ und Dichlormethan $(2 \times 50 \mathrm{~mL})$ coevaporiert und dann in DCM $(100 \mathrm{~mL})$ aufgenommen. Die organische Phase wurde mit Wasser $(2 \times 80 \mathrm{~mL})$ und ges. $\mathrm{NaCl}(80 \mathrm{~mL})$ gewaschen, über $\mathrm{Na}_{2} \mathrm{SO}_{4}$ getrocknet und im Vakuum zur Trockne eingeengt. Das Rohprodukt wurde säulenchromatographisch an Kieselgel (DCM/MeOH 9:1) gereinigt.

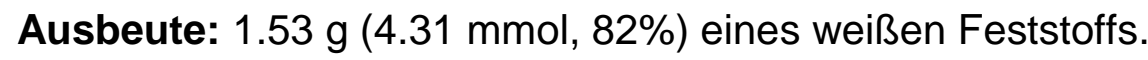

DC: $R_{\mathrm{f}}(\mathrm{DCM} / \mathrm{MeOH} 9: 1)=0.22$.

${ }^{1} \mathrm{H}-\mathrm{NMR}\left(300 \mathrm{MHz}, \mathrm{CDCl}_{3}\right): \delta=0.10\left(\mathrm{~s}, 6 \mathrm{H}, \mathrm{SiCH}_{3}\right), 0.92\left(\mathrm{~s}, 9 \mathrm{H}, \mathrm{SiC}\left(\mathrm{CH}_{3}\right)_{3}\right), 1.91$ (s, $3 \mathrm{H}, 7-\mathrm{H}$ ), 2.20 (dd, $\left.J=6.3 \mathrm{~Hz}, J=6.3 \mathrm{~Hz}, 2 \mathrm{H}, 2^{\prime}-\mathrm{H}\right)$, 3.59-3.79 (m, $\left.1 \mathrm{H}, 4^{\prime}-\mathrm{H}\right)$, 3.69-3.75 (m, $\left.1 \mathrm{H}, 3^{\prime}-\mathrm{H}\right), 3.83\left(\mathrm{dd}, J=11.3 \mathrm{~Hz}, J=2.7 \mathrm{~Hz}, 1 \mathrm{H}, 5^{\prime}-\mathrm{H}_{\mathrm{a}}\right.$ ), 3.92 (dd, 
$\left.J=11.3 \mathrm{~Hz}, J=2.7 \mathrm{~Hz}, 1 \mathrm{H}, 5^{\prime}-\mathrm{H}_{\mathrm{b}}\right), 6.26\left(\mathrm{dd}, J=6.2 \mathrm{~Hz}, J=6.2 \mathrm{~Hz}, 1 \mathrm{H}, 1^{\prime}-\mathrm{H}\right), 7.49$ (s, $1 \mathrm{H}, 6-\mathrm{H})$.

${ }^{13}$ C-NMR $\left(75 \mathrm{MHz}, \mathrm{CDCl}_{3}\right): \delta=-5.41\left(\mathrm{SiCH}_{3}\right),-5.36\left(\mathrm{SiCH}_{3}\right), 12.56(\mathrm{C}-7), 18.41$ $\left(\mathrm{SiC}\left(\mathrm{CH}_{3}\right)_{3}\right), 25.92\left(\mathrm{SiC}\left(\underline{\mathrm{C}} \mathrm{H}_{3}\right)_{3}\right), 41.70\left(\mathrm{C}-2^{\prime}\right), 51.52\left(\mathrm{C}-3^{\prime}\right), 62.98\left(\mathrm{C}-5^{\prime}\right), 84.46\left(\mathrm{C}-1^{\prime}\right)$, 87.38 (C-4'), 110.61 (C-5), 135.49 (C-6), 150.37 (C-2), 163.87 (C-4).

Drehwert: $[\alpha]_{D}^{20}=+13.1\left(\mathrm{C}=1.1, \mathrm{CHCl}_{3}\right)$.

Schmelzpunkt: $144^{\circ} \mathrm{C}$.

IR $(\mathrm{KBr}): \tilde{v}=2928,1697,1470,1282,1121,1013,835,779,426$.

UV (MeCN): $\lambda_{\max }(\lg \varepsilon)=200$ (4.07), 266 (3.97).

MS $\left(E S I^{+}\right): \mathrm{m} / \mathrm{z}=356.2[\mathrm{M}+\mathrm{H}]^{+}$.

$\mathrm{C}_{16} \mathrm{H}_{29} \mathrm{~N}_{3} \mathrm{O}_{4} \mathrm{Si}(355.50)$

ber.: $356.2006[\mathrm{M}+\mathrm{H}]^{+}$, gef.: 356.2010 (ESI+-HRMS).

\subsubsection{4-N-Benzoyl-2'-desoxycytidin $138^{[163]}$}

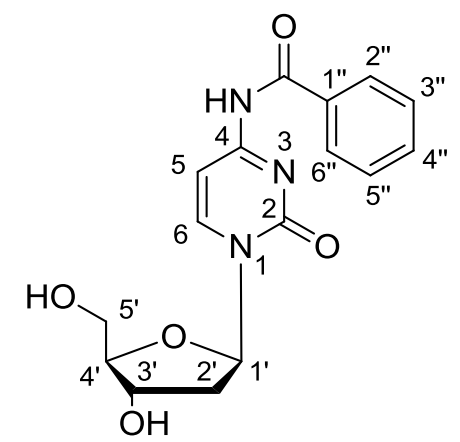

138

2'-Desoxycytidin 137 (5.00 g, $22.0 \mathrm{mmol})$ wurde mit Pyridin (3 x $60 \mathrm{~mL})$ koevaporiert und in Pyridin (95 mL) gelöst. TMSCl $(12.9 \mathrm{~g}, 119 \mathrm{mmol})$ wurde tropfenweise dazugegeben und die resultierende Lösung $30 \mathrm{~min}$ bei RT gerührt. Benzoylchlorid (16.7 g, $13.8 \mathrm{~mL}, 119 \mathrm{mmol}$ ) wurde allmählich dazugegeben und die Lösung weitere $2.5 \mathrm{~h}$ bei RT gerührt. Anschließend wurde die Reaktionslösung auf $0^{\circ} \mathrm{C}$ gekühlt, langsam mit dest. Wasser $(25 \mathrm{~mL})$ versetzt und $5 \mathrm{~min}$. bei $0{ }^{\circ} \mathrm{C}$ gerührt. Nachfolgend wurde bei $0^{\circ} \mathrm{C}$ wässrige Ammoniaklösung $(25 \%, 60 \mathrm{~mL})$ dazugegeben und das Gemisch 30 min gerührt, wobei die Erwärmung des Gemischs auf RT zugelassen wurde. Die resultierende Suspension wurde zur Trockne eingeengt und der Rückstand an Kieselgel (DCM/MeOH 95:5 $\rightarrow 9: 1)$ gereinigt.

Ausbeute: $5.45 \mathrm{~g}$ eines weißen Feststoffs. Die erhaltene Verbindung enthielt laut NMR-spektroskopischer Untersuchungen 0.75 Äquivalente Benzoesäure. Daher wurde für die Ausbeute an 138 ein Wert von 56\% (12.0 mmol) berechnet. 
DC: $R_{f}(\mathrm{DCM} / \mathrm{MeOH} 8: 2)=0.58$.

${ }^{1} \mathrm{H}-\mathrm{NMR}\left(300 \mathrm{MHz}, \mathrm{DMSO}-\mathrm{d}_{6}\right.$ ): $\delta=2.07$ (ddd, $J=13.4 \mathrm{~Hz}, J=6.4 \mathrm{~Hz}, J=6.4 \mathrm{~Hz}$, $1 \mathrm{H}, 2{ }^{\prime}-\mathrm{H}_{\mathrm{a}}$ ), 2.33 (ddd, $J=13.4 \mathrm{~Hz}, J=6.3 \mathrm{~Hz}, J=4.1 \mathrm{~Hz}, 1 \mathrm{H}, 2{ }^{\prime}-\mathrm{H}_{\mathrm{b}}$ ), 3.60 (dd, $\left.J=12.1 \mathrm{~Hz}, J=3.9 \mathrm{~Hz}, 1 \mathrm{H}, 5^{\prime}-\mathrm{H}_{\mathrm{a}}\right), 3.66\left(\mathrm{dd}, J=12.1 \mathrm{~Hz}, J=3.9 \mathrm{~Hz}, 1 \mathrm{H}, 5^{\prime}-\mathrm{H}_{\mathrm{b}}\right.$ ), 3.89 (ddd, $J=3.9 \mathrm{~Hz}, J=3.5 \mathrm{~Hz}, J=3.5 \mathrm{~Hz} 1 \mathrm{H}, 4^{\prime}-\mathrm{H}$ ), 4.26 (ddd, $J=6.4 \mathrm{~Hz}, J=3.5 \mathrm{~Hz}$, $\left.J=3.5 \mathrm{~Hz}, 1 \mathrm{H}, 3^{\prime}-\mathrm{H}\right), 6.15\left(\mathrm{dd}, J=6.4 \mathrm{~Hz}, J=6.4 \mathrm{~Hz}, 1 \mathrm{H}, 1^{\prime}-\mathrm{H}\right), 7.34(\mathrm{~d}, J=7.6 \mathrm{~Hz}$, $1 \mathrm{H}, 5-\mathrm{H}), 7.49$ (dd, J = 7.4 Hz, 2 H, 3"-H, 5"-H), 7.60 (t, J= 7.4 Hz, 1 H, 4"-H), 7.95 (d, J=7.4 Hz, $2 \mathrm{H}, 2$ "'-H, 6"-H), 8.40 (d, J=7.6 Hz, $1 \mathrm{~Hz}, 6-\mathrm{H})$.

${ }^{13}$ C-NMR (75 MHz, DMSO-d $\left.d_{6}\right): \delta=40.91$ (C-2'), 60.93 (C-5'), 69.88 (C-3'), 86.15 (C-1'), 87.87 (C-4'), 96.00 (C-5), 128.24, 129.06, 131.31, $132.33(\mathrm{Ar}-\mathrm{H}), 144.66$ (C-6), 154.10 (C-2), 162.66 (C-4), 167.33 (Bz-C=O).

Drehwert: $[\alpha]_{D}^{20}=+84.6$ (c=1.2, Pyridin).

MS $\left(\mathrm{ESI}^{+}\right): \mathrm{m} / \mathrm{z}=354.1[\mathrm{M}+\mathrm{Na}]^{+}$.

$\mathrm{C}_{16} \mathrm{H}_{17} \mathrm{~N}_{3} \mathrm{O}_{5} \mathrm{Si}(331.32)$

ber.: $354.1057[\mathrm{M}+\mathrm{Na}]^{+}$

gef.: 354.1060 (ESI+-HRMS).

\subsubsection{O-2,3'-Anhydro-4-N-benzoyl-5'-O-(p-brombenzoyl)-2'- desoxycytidin $96^{[137]}$}

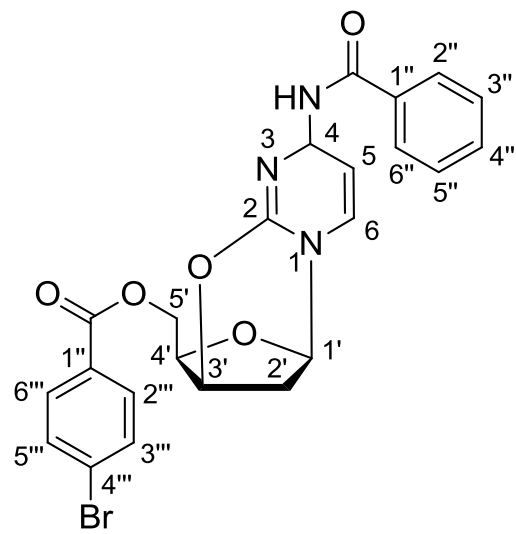

96

4-N-Benzoyl-2'-desoxycytidin $138(600 \mathrm{mg}, 1.81 \mathrm{mmol}$, verunreinigt mit $0.75 \mathrm{Äq}$ Benzoesäure) wurde in DMF $(6.0 \mathrm{~mL})$ gelöst und mit Triphenylphosphin $(713 \mathrm{mg}$, 2.72mmol), p-Brombenzoesäure (547 mg, $2.72 \mathrm{mmol}$ ) und DIAD (549 mg, $530 \mu \mathrm{L}$, $2.72 \mathrm{mmol}$ ) in der angegebenen Reihenfolge bei $0{ }^{\circ} \mathrm{C}$ versetzt. Die erhaltene Lösung wurde $1 \mathrm{~h}$ bei $\mathrm{RT}$ gerührt, auf $0^{\circ} \mathrm{C}$ gekühlt und mit Triphenylphosphin $(713 \mathrm{mg}$, $2.72 \mathrm{mmol}$ ) und DIAD (549 mg, $530 \mu \mathrm{L}, 2.72 \mathrm{mmol}$ ) versetzt. Nach weiterem Rühren für $2.5 \mathrm{~h}$ bei $\mathrm{RT}$ wurde die Reaktionslösung in auf $0^{\circ} \mathrm{C}$ gekühlten Diethylether $(50 \mathrm{~mL})$ gegeben. Die Suspension wurde $2 \mathrm{~h}$ bei $0^{\circ} \mathrm{C}$ aufbewahrt und danach filtriert. 
Der Niederschlag wurde mit auf $0^{\circ} \mathrm{C}$ gekühltem Diethylether $(3 \times 10 \mathrm{~mL})$ gewaschen und im Vakuum getrocknet.

Ausbeute: $620 \mathrm{mg}(1.25 \mathrm{mmol}, 69 \%)$ eines weißen Feststoffes.

DC: $R_{f}(\mathrm{DCM} / \mathrm{MeOH}, 8: 2)=0.33$.

${ }^{1} \mathrm{H}-\mathrm{NMR}\left(300 \mathrm{MHz}, \mathrm{DMSO}-\mathrm{d}_{6}\right.$ ): $\delta=2.58$ (ddd, $J=13.1 \mathrm{~Hz}, J=3.9 \mathrm{~Hz}, J=2.8 \mathrm{~Hz}$, $\left.1 \mathrm{H}, 2{ }^{\prime}-\mathrm{H}_{\mathrm{a}}\right), 2.69\left(\mathrm{dd}, J=13.1 \mathrm{~Hz}, J=1.4 \mathrm{~Hz}, 1 \mathrm{H}, 2^{\prime}-\mathrm{H}_{\mathrm{b}}\right), 4.44(\mathrm{dd}, J=7.3 \mathrm{~Hz}$, $\left.J=6.3 \mathrm{~Hz}, 1 \mathrm{H}, 5^{\prime}-\mathrm{H}_{\mathrm{a}}\right), 4.57-4.63\left(\mathrm{~m}, 2 \mathrm{H}, 4^{\prime}-\mathrm{H}^{\prime}, 5^{\prime}-\mathrm{H}_{\mathrm{b}}\right), 5.46-5.49\left(\mathrm{~m}, 1 \mathrm{H}, 3^{\prime}-\mathrm{H}\right), 6.00$ (d, $\left.J=3.9 \mathrm{~Hz}, 1 \mathrm{H}, 1^{\prime}-\mathrm{H}\right), 6.46(\mathrm{~d}, J=7.3 \mathrm{~Hz}, 1 \mathrm{H}, 5-\mathrm{H}), 7.43$ (dd, $J=7.4 \mathrm{~Hz}$, $J=7.4 \mathrm{~Hz}, 2 \mathrm{H}, 3$ "'-H, 5"-H), 7.52 (t, $J=7.4 \mathrm{~Hz}, 1 \mathrm{H}, 4$ "'-H), 7.66 (d, $J=7.3 \mathrm{~Hz}, 1 \mathrm{H}$, 6-H), 7.74 (d, J = 8.8 Hz, $2 \mathrm{H}, 2$ '"'-H, 6"'-H), 7.82 (d, J = 8.8 Hz, $2 \mathrm{H}, 3$ '”- $-\mathrm{H}, 5$ '”-H), 7.92-7.95 (m, $2 \mathrm{H}, 2$ "'-H, 6"-H).

${ }^{13} \mathrm{C}-N M R\left(75 \mathrm{MHz}\right.$, DMSO-d $\mathrm{d}_{6}$ ): $\delta=32.69$ (C-2'), 62.12 (C-5'), 77.59 (C-3'), 81.75 (C-4'), 86.94 (C-1'), 105.57 (C-5), 127.32 (C-4"), 127.87 (C-2", C-6"), 127.87 (C-4"'), 128.59 (C-3", C-5"), 130.69 (C-3"', C-5"'), 131.00 (C-1"), 131.36 (C-2"',C-6"'), 136.28 (C-1"'), 139.17 (C-6), 152 (C-2), 161.54 (C-4), 164.23 (Bz-C=O), 177.05 (COO).

Drehwert: $[\alpha]_{D}^{20}=+179.6\left(\mathrm{c}=0.51, \mathrm{CHCl}_{3}\right)$.

Schmelzpunkt: Zersetzung $>230^{\circ} \mathrm{C}$

IR (ATR): $\tilde{v}=1713,1648,1480,1456,1442,1280,1123,754,698,673$.

UV (MeCN): $\lambda_{\max }(\lg \varepsilon)=244$ (4.38), 315 (4.01).

MS $\left(E S I^{+}\right): m / z=496.1[M+H]^{+}$.

$\mathrm{C}_{23} \mathrm{H}_{18} \mathrm{BrN}_{3} \mathrm{O}_{5}$ (496.31)

ber.: $496.0500[\mathrm{M}+\mathrm{H}]^{+}$

gef.: 496.0503 (ESI+-HRMS). 


\subsubsection{3'-Azido-4-N-benzoyl-5'-O-(p-brombenzoyl)-2',3'-didesoxycytidin (3'S)-} 139 und 3'-Azido-4-N-benzoyl-5'-O-(p-brombenzoyl)-2',3'-didesoxy-3'xylo-cytidin (3'R)-139

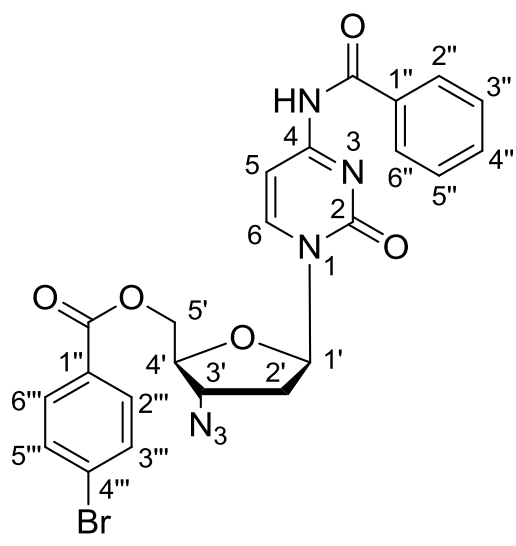

(3'S)-139

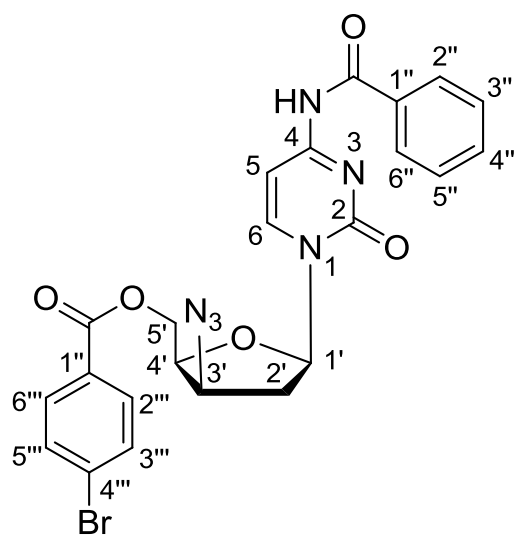

(3'R)-139

O-2,3'-Anhydro-4-N-benzoyl-5'-O-(p-brombenzoyl)-2'-desoxycytidin $\quad 96 \quad(1.27 \mathrm{~g}$, $2.56 \mathrm{mmol}$ ) und $\mathrm{NaN}_{3}(665 \mathrm{mg}, 10.2 \mathrm{mmol}$ ) wurden in DMF (33 mL) gegeben und die Suspension 45 min bei $130{ }^{\circ} \mathrm{C}$ gerührt. Die Reaktionslösung wurde in ges. $\mathrm{NH}_{4} \mathrm{Cl}$ Lösung $(60 \mathrm{~mL})$ gegeben und mit EtOAc $(3 \times 80 \mathrm{~mL})$ extrahiert. Die vereinigten organischen Phasen wurden über $\mathrm{Na}_{2} \mathrm{SO}_{4}$ getrocknet und bei verringertem Druck zur Trockne eingeengt. Der Rückstand wurde chromatographisch an Kieselgel gereinigt (Hex/EtOAc 1:6).

Ausbeute: Es wurden $1.05 \mathrm{~g}$ (1.94 mmol, 76\%) eines gelben Schaums erhalten. Es wurden außerdem $33 \mathrm{mg}(61 \mu \mathrm{mol}, 2.4 \%)$ des 3'-Epimers erhalten.

Analytische Daten von (3'S)-139:

DC: $R_{f}(\mathrm{Hex} / \mathrm{EtOAc} \mathrm{1:6)}=0.40$.

${ }^{1} \mathrm{H}-\mathrm{NMR}\left(300 \mathrm{MHz}, \mathrm{CDCl}_{3}\right): \delta=2.48$ (ddd, $J=14.2 \mathrm{~Hz}, J=7.2 \mathrm{~Hz}, J=5.0 \mathrm{~Hz}, 1 \mathrm{H}$, 2' $-\mathrm{H}_{\mathrm{a}}$ ), 2.83 (ddd, $J=14.2 \mathrm{~Hz}, J=6.5 \mathrm{~Hz}, J=6.3 \mathrm{~Hz}, 1 \mathrm{H}, 2^{\prime}-\mathrm{H}_{\mathrm{b}}$ ), 4.23 (ddd, $J=7.2 \mathrm{~Hz}, J=6.3 \mathrm{~Hz}, J=5.9 \mathrm{~Hz}, 1 \mathrm{H}, 3^{\prime}-\mathrm{H}$ ), 4.31 (ddd, $J=5.9 \mathrm{~Hz}, J=3.9 \mathrm{~Hz}$, $J=3.9 \mathrm{~Hz}, 1 \mathrm{H}, 4^{\prime}-\mathrm{H}$ ), $4.64\left(\mathrm{dd}, J=11.5 \mathrm{~Hz}, J=3.9 \mathrm{~Hz}, 1 \mathrm{H}, 5^{\prime}-\mathrm{H}_{\mathrm{a}}\right.$ ), 4.67 (dd, $\left.J=11.5 \mathrm{~Hz}, J=3.9 \mathrm{~Hz}, 1 \mathrm{H}, 5^{\prime}-\mathrm{H}_{\mathrm{b}}\right), 6.13\left(\mathrm{dd}, J=6.5 \mathrm{~Hz}, J=5.0 \mathrm{~Hz}, 1 \mathrm{H}, 1^{\prime}-\mathrm{H}\right), 7.51-$ $7.55(\mathrm{~m}, 3 \mathrm{H}, 3$ "'-H, 5"-H, 5-H), 7.61-7.65 (m, $1 \mathrm{H}, 4$ "- $-\mathrm{H}), 7.63$ (d, J=8.8 Hz, $2 \mathrm{H}$, 2"'-H, 6"'-H), 7.86-7.91 (m, 2 H, 2"-H, 6"-H), 7.88 (d, J=8.8 Hz, 2 H, 3'”-H, 5"'-H), 8.01-8.05 (m, $1 \mathrm{H}, 6-\mathrm{H})$.

${ }^{13} \mathrm{C}$-NMR $\left(75 \mathrm{MHz}, \mathrm{CDCl}_{3}\right.$ ): $\delta=38.80$ (C-2'), 60.06 (C-3'), 63.70 (C-5'), 82.69 (C-4'), 87.62 (C-1'), 96.37 (C-5), 127.48 (C-4"), 128.90 (C-2", C-6"), 128.94 (C-4"'), 130.96 
(C-3", C-5"), 131.35 (C-2"', C-6"'), 131.99 (C-1"), 132.78 (C-2'”,C-6"'), 133.15 (C-1"'), 143.61 (C-6), 154.36 (C-2), 162.27 (C-4), 165.22 (Bz-C=O), 171.12 (COO).

Drehwert: $[\alpha]_{D}^{20}=+77.2\left(\mathrm{c}=0.99, \mathrm{CHCl}_{3}\right)$.

Schmelzpunkt: $147^{\circ} \mathrm{C}$.

IR (ATR): $\tilde{v}=2100,1657,1480,1250,1088,1070,784,755,702,678$.

UV $(\mathrm{MeCN}): \lambda_{\max }(\lg \varepsilon)=248$ (4.46), 310 (3.92).

MS $\left(E S I^{+}\right): m / z=561.0[\mathrm{M}+\mathrm{Na}]^{+}$.

$\mathrm{C}_{23} \mathrm{H}_{19} \mathrm{BrN}_{6} \mathrm{O}_{5}$ (539.33) ber.: $561.0493[\mathrm{M}+\mathrm{Na}]^{+}$ gef.: 561.0484 (ESI+-HRMS).

Analytische Daten von (3'R)-139:

DC: $R_{f}($ Hex/EtOAc 1:6) $=0.55$

${ }^{1} \mathrm{H}-\mathrm{NMR}\left(300 \mathrm{MHz}, \mathrm{CDCl}_{3}\right): \delta=2.42$ (ddd, $J=13.6 \mathrm{~Hz}, J=9.2 \mathrm{~Hz}, J=7.2 \mathrm{~Hz}$, $1 \mathrm{H}, 2^{\prime}-\mathrm{H}_{\mathrm{a}}$ ), 3.01 (ddd, J=13.6 Hz, J=9.0 Hz, J=4.0 Hz, $1 \mathrm{H}, 2^{\prime}-\mathrm{H}_{\mathrm{b}}$ ), 4.14 (dd, $\left.J=7.2 \mathrm{~Hz}, \quad J=6.2 \mathrm{~Hz}, 1 \mathrm{H}, \quad 4^{\prime}-\mathrm{H}\right), 4.49-4.56\left(\mathrm{~m}, 2 \mathrm{H}, 3^{\prime}-\mathrm{H}^{\prime}, 5^{\prime}-\mathrm{H}_{\mathrm{a}}\right), 4.59$ (dd, $\left.J=11.6 \mathrm{~Hz}, J=4.7 \mathrm{~Hz}, 1 \mathrm{H}, 5^{\prime}-\mathrm{H}_{\mathrm{b}}\right), 6.16(\mathrm{~d}, J=7.8 \mathrm{~Hz}, 5-\mathrm{H}), 7.00-7.05(\mathrm{~m}, 1 \mathrm{H}, 6-\mathrm{H})$, 7.16 (dd, $\left.J=9.2 \mathrm{~Hz}, J=4.0 \mathrm{~Hz}, 1 \mathrm{H}, 1^{\prime}-\mathrm{H}\right), 7.42-7.46\left(\mathrm{~m}, 2 \mathrm{H}, 33^{\prime \prime}-\mathrm{H}, 5^{\prime \prime}-\mathrm{H}\right), 7.52-7.58$ (m, 3 H, 4"-H, 2"'-H, 6"'-H), 7.91 (d, J = 8.7 Hz, 2 H, 3'”-H, 5"'-H), 8.04-8.08 (m, 2"-H, 6"-H).

${ }^{13} \mathrm{C}-\mathrm{NMR}\left(75 \mathrm{MHz}, \mathrm{CDCl}_{3}\right): \delta=35.47$ (C-2'), 61.98 (C-3'), 64.91 (C-5"), 82.03 (C-4'), 82.60 (C-1'), 91.16 (C-5), 128.41 (C-3", C-5”), 128.55 (C-4"), 129.72 (C-2”, C-6"), 129.81 (C-4"'), 131.34 (C-3"', C-5"'), 131.77 (C-2"', C-6"'), 132.96 (C-1"), 134.93 (C-1"'), 136.97 (C-6), 150.22 (C-2), 154.74 (Bz-C=O), 165.80 (C-4), 177.35 (Ester$\mathrm{C}=\mathrm{O}$ ).

Drehwert: $[\alpha]_{D}^{20}=-41.2\left(\mathrm{c}=1.0, \mathrm{CHCl}_{3}\right)$.

Schmelzpunkt: $74^{\circ} \mathrm{C}$.

IR (ATR): $\tilde{v}=2098,1714,1586,1570,1269,1225,1108,1069,752,712$.

UV $(\mathrm{MeCN}): \lambda_{\max }(\lg \varepsilon)=242(4.51)$.

MS $\left(E S I^{+}\right): m / z=561.0[\mathrm{M}+\mathrm{Na}]^{+}$.

$\mathrm{C}_{23} \mathrm{H}_{19} \mathrm{BrN}_{6} \mathrm{O}_{5}$ (539.33) ber.: $561.0493[\mathrm{M}+\mathrm{Na}]^{+}$ gef.: 561.0490 (ESI $\left.{ }^{+}-\mathrm{HRMS}\right)$. 


\subsubsection{3'-Azido-4-N-benzoyl-2',3'-didesoxycytidin 140}

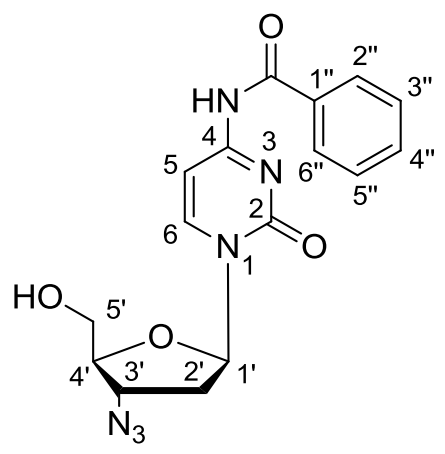

140

Eine Lösung von 3'-Azido-4-N-benzoyl-5'-O-( $p$-brombenzoyl)-2',3'-didesoxycytidin (3'S)-139 (1.78 g, $3.31 \mathrm{mmol})$ in THF (20 mL) wurde bei $0{ }^{\circ} \mathrm{C}$ über einen Zeitraum von $2 \mathrm{~h}$ mit einer $1 \mathrm{M}$ Lösung von $\mathrm{LiOH} \cdot \mathrm{H}_{2} \mathrm{O}(13.2 \mathrm{~mL}, 13.3 \mathrm{mmol})$ versetzt und bei $0-5{ }^{\circ} \mathrm{C}$ drei weitere Stunden gerührt, bis anhand von Dünnschichtchromatographie (DCM/MeOH 15:1) vollständiger Umsatz des Edukts nachgewiesen werden konnte. Die Reaktionslösung wurde in $\mathrm{DCM}(100 \mathrm{~mL})$ aufgenommen, mit ges. $\mathrm{NH}_{4} \mathrm{Cl}$-Lösung $(50 \mathrm{~mL})$ und ges. $\mathrm{NaCl}$-Lösung $(50 \mathrm{~mL})$ gewaschen und unter vermindertem Druck zur Trockne eingeengt.

Ausbeute: Es wurden $1.17 \mathrm{~g} \mathrm{(3.28} \mathrm{mmol,} \mathrm{99 \% )} \mathrm{eines} \mathrm{gelben} \mathrm{Feststoffs} \mathrm{erhalten.}$

DC: $R_{f}(\mathrm{DCM} / \mathrm{MeOH} 50: 3)=0.41$.

${ }^{1} \mathrm{H}-\mathrm{NMR} \quad\left(300 \mathrm{MHz}, \quad\right.$ DMSO- $\left.\mathrm{d}_{6}\right): \quad \delta=2.41 \quad(\mathrm{ddd}, \quad J=13.7 \mathrm{~Hz}, \quad J=6.8 \mathrm{~Hz}$, $J=5.5 \mathrm{~Hz}, 1 \mathrm{H}, 2^{\prime}-\mathrm{H}_{\mathrm{a}}$ ), 2.49 (ddd, $J=13.7 \mathrm{~Hz}, J=6.4 \mathrm{~Hz}, J=6.3 \mathrm{~Hz}, 1 \mathrm{H}, 2^{\prime}-\mathrm{H}_{\mathrm{b}}$ ), 3.65 (ddd, $J=12.1 \mathrm{~Hz}, J=5.2 \mathrm{~Hz}, J=3.8 \mathrm{~Hz}, 1 \mathrm{H}, \quad 5^{\prime}-\mathrm{H}_{\mathrm{a}}$ ), 3.73 (ddd, $J=12.1 \mathrm{~Hz}$, $J=5.2 \mathrm{~Hz}, J=3.8 \mathrm{~Hz}, 1 \mathrm{H}, 5$ '- $\mathrm{H}_{\mathrm{b}}$ ), 3.97 (ddd, $J=5.1 \mathrm{~Hz}, J=3.8 \mathrm{~Hz}, J=3.8 \mathrm{~Hz}, 1 \mathrm{H}$, 4'-H), 4.39 (ddd, $J=6.8 \mathrm{~Hz}, J=5.1 \mathrm{~Hz}, J=5.0 \mathrm{~Hz}, 1 \mathrm{H}, 3^{\prime}-\mathrm{H}$ ), 5.27 (dd, $J=5.2 \mathrm{~Hz}$, $1 \mathrm{H}, \mathrm{OH}), 6.09\left(\mathrm{dd}, J=6.3 \mathrm{~Hz}, J=5.5 \mathrm{~Hz}, 1 \mathrm{H}, 1^{\prime}-\mathrm{H}\right), 7.37(\mathrm{~d}, J=7.1 \mathrm{~Hz}, 1 \mathrm{H}, 5-\mathrm{H})$, 7.52 (dd, $J=7.5 \mathrm{~Hz}, J=7.5 \mathrm{~Hz}, 2 \mathrm{H}, 3$ "'-H, 5"-H), 7.63 (t, $J=7.5 \mathrm{~Hz}, 1 \mathrm{H}, 4$ "'-H), 8.03 (d, $J=7.5 \mathrm{~Hz}, 2 \mathrm{H}, 2^{\prime \prime}-\mathrm{H}, 6$ "'-H), 8.40 (d, J = 7.1 Hz, $1 \mathrm{H}, 6-\mathrm{H}$ ), 11.23 (brs, $1 \mathrm{H}, \mathrm{NH}$ ).

${ }^{13} \mathrm{C}$-NMR (75 MHz, DMSO-d $\mathrm{d}_{6}$ ): $\delta=38.14$ (C-2'), 59.97 (C-3'), 60.88 (C-5'), 85.43 (C-4'), 86.43 (C-1'), 96.52 (C-5), 128.89 (C-3", C-5"), 128.92 (C-2", C-6"), 133.17 (C-4"), 133.64 (C-1"), 145.37 (C-6), 154.76 (C-2), 163.52 (C-4), 167.80 (Bz-C=O).

Drehwert: $[\alpha]_{D}^{20}=+97.3^{\circ}(\mathrm{c}=1.00, \mathrm{MeOH})$.

Schmelzpunkt: $170{ }^{\circ} \mathrm{C}$.

IR (ATR): $\tilde{v}=2100,1638,1480,1384,1298,1242,1232,1050,788,698$. 
UV (MeCN): $\lambda_{\max }(\lg \varepsilon)=255$ (3.97), 310 (3.67).

MS $\left(E S I^{+}\right): m / z=379.1[\mathrm{M}+\mathrm{Na}]^{+}$.

$\mathrm{C}_{16} \mathrm{H}_{16} \mathrm{~N}_{6} \mathrm{O}_{4}$ (356.12)

ber.: $379.1125[\mathrm{M}+\mathrm{H}]^{+}$

gef.: 379.1127 (ESI+-HRMS).

\subsubsection{3'-Azido-4-N-benzoyl-5'-O-TBDMS-2',3'-didesoxycytidin 97}

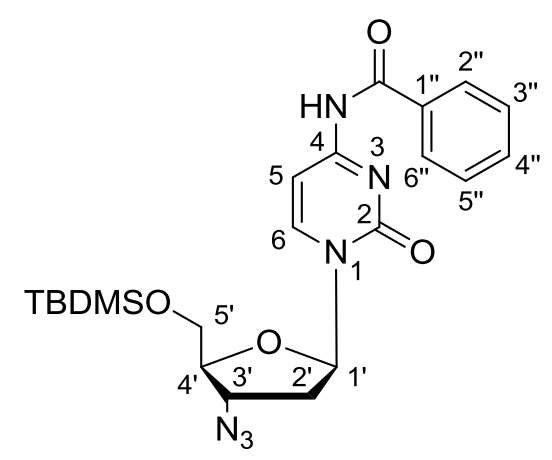

97

3'-Azido-4-N-benzoyl-2',3'-didesoxycytidin $(1.07 \mathrm{~g}, 3.00 \mathrm{mmol}) 140$ wurde mit abs. Toluol koevaporiert $(3 \times 7 \mathrm{~mL})$ und anschließend in DMF $(4 \mathrm{~mL})$ gelöst. Zu dieser Lösung wurden $\mathrm{NEt}_{3}(1.28 \mathrm{~mL}, 936 \mathrm{mg}, 9.27 \mathrm{mmol}$ ) und TBDMSCl $(698 \mathrm{mg}$, $4.64 \mathrm{mmol}$ ) gegeben und die so erhaltene Lösung $5 \mathrm{~h}$ bei Raumtemperatur gerührt. Die Reaktionslösung wurde in $50 \mathrm{~mL}$ EtOAc aufgenommen, mit dest. Wasser $(3 \times 30 \mathrm{~mL})$ und ges. wässriger $\mathrm{NaCl}$-Lösung $(30 \mathrm{~mL})$ gewaschen und unter vermindertem Druck zur Trockne eingeengt. Der erhaltene Rückstand wurde chromatographisch an Kieselgel gereinigt (Hex/EtOAc 2:3).

Ausbeute: Es wurden $1.03 \mathrm{~g}(2.19 \mathrm{mmol}, 73 \%)$ eines farblosen Schaums erhalten.

DC: $R_{f}(\mathrm{Hex} / \mathrm{EtOAc} 2: 3)=0.20$.

${ }^{1} \mathrm{H}-\mathrm{NMR}\left(300 \mathrm{MHz}, \mathrm{CDCl}_{3}\right): \delta=0.14\left(\mathrm{~s}, 3 \mathrm{H}, \mathrm{SiCH}_{3 \mathrm{a}}\right), 0.15\left(\mathrm{~s}, 3 \mathrm{H}, \mathrm{SiCH}_{3 \mathrm{~b}}\right), 0.94(\mathrm{~s}$, $9 \mathrm{H}, \mathrm{SiC}\left(\mathrm{CH}_{3}\right)_{3}$ ), 2.40 (ddd, $J=13.9 \mathrm{~Hz}, J=6.9 \mathrm{~Hz}, J=4.1 \mathrm{~Hz}, 1 \mathrm{H}, 2^{\prime}-\mathrm{H}_{\mathrm{a}}$ ), 2.66 (ddd, $\left.J=13.9 \mathrm{~Hz}, J=6.9 \mathrm{~Hz}, J=6.9 \mathrm{~Hz}, 1 \mathrm{H}, 2^{\prime}-\mathrm{H}_{\mathrm{b}}\right), 3.84(\mathrm{dd}, J=11.7 \mathrm{~Hz}, J=2.2 \mathrm{~Hz}$, $1 \mathrm{H}, 5^{\prime}-\mathrm{H}_{\mathrm{a}}$ ), 4.01 (ddd, $J=5.9 \mathrm{~Hz}, J=2.2 \mathrm{~Hz}, J=2.2 \mathrm{~Hz}, 1 \mathrm{H}, 4^{\prime}-\mathrm{H}$ ), 4.06 (dd, $J=11.7 \mathrm{~Hz}, J=2.2 \mathrm{~Hz}, 1 \mathrm{H}, 5^{\prime}-\mathrm{H}_{\mathrm{b}}$ ), 4.19 (dd, $\left.J=6.9 \mathrm{~Hz}, J=6.3 \mathrm{~Hz}, 1 \mathrm{H}, 3^{\prime}-\mathrm{H}\right), 6.19$ (dd, $\left.J=6.9 \mathrm{~Hz}, J=4.1 \mathrm{~Hz}, 1 \mathrm{H}, 1^{\prime} \cdot \mathrm{H}\right), 7.48-7.53\left(\mathrm{~m}, 3 \mathrm{H}, 5-\mathrm{H}, 3{ }^{\prime \prime}-\mathrm{H}, 5^{\prime \prime}-\mathrm{H}\right), 7.58-7.63$ (m, $1 \mathrm{H}, 4$ "'-H), 7.90 (d, J=7.5 Hz, $2 \mathrm{H}, 2$ "'-H, 6"-H), 8.41 (d, J=7.3 Hz, $1 \mathrm{H}, 6-\mathrm{H})$, $8.82($ brs, $1 \mathrm{H}, \mathrm{NH})$. 
${ }^{13}$ C-NMR $\left(75 \mathrm{MHz}, \mathrm{CDCl}_{3}\right): \delta=-5.55\left(\mathrm{SiCH}_{3}\right),-5.43\left(\mathrm{SiCH}_{3}\right), 18.37\left(\mathrm{SiC}\left(\mathrm{CH}_{3}\right)_{3}\right)$, $25.91\left(\mathrm{SiC}\left(\mathrm{CH}_{3}\right)_{3}\right), 39.08$ (C-2'), 58.46 (C-3'), 61.83 (C-5'), 85.29 (C-4'), 86.63 (C-1'), 96.20 (C-5), 127.56 (C-4”), 129.05 (C-2”, C-3”, C-5”, C-6”), 133.19 (C-1"), 144.48 (C-6), 154.69 (C-2), 162.28 (C-4).

Drehwert: $[\alpha]_{D}^{20}=+86.4\left(\mathrm{c}=1.0, \mathrm{CHCl}_{3}\right)$.

Schmelzpunkt: $68^{\circ} \mathrm{C}$.

IR (ATR): $\tilde{v}=2100,1661,1481,1313,1247,1113,1070,831,779,703$.

UV (MeCN): $\lambda_{\max }(\lg \varepsilon)=257$ (4.27), 310 (3.92).

MS $\left(E S I^{+}\right): m / z=471.2[\mathrm{M}+\mathrm{H}]^{+}$.

$\mathrm{C}_{22} \mathrm{H}_{30} \mathrm{~N}_{6} \mathrm{O}_{4} \mathrm{Si}(470.21)$

ber.: $471.2171[\mathrm{M}+\mathrm{H}]^{+}$

gef.: $471.2172\left(\mathrm{ESI}^{+}-\mathrm{HRMS}\right)$.

\subsubsection{3'-Amino-4-N-benzoyl-5'-O-TBDMS-2',3'-didesoxycytidin 90}

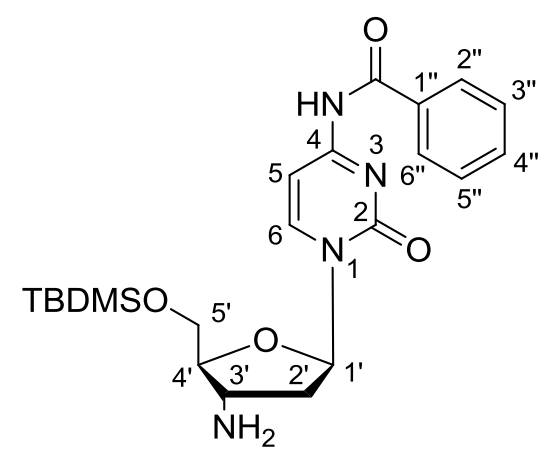

90

Eine Lösung von 3'-Azido-4-N-benzoyl-5'-O-TBDMS-2',3'-didesoxycytidin 97 (1.10 g, $2.33 \mathrm{mmol}$ ) in Methanol (6 mL) wurde mit Palladium (44 mg, $0.42 \mathrm{mmol}, 10 \%$ auf Aktivkohle) und 1,4-Cyclohexadien (933 mg, $1.09 \mathrm{~mL}, 11.7 \mathrm{mmol}$ ) versetzt. Die Lösung wurde $4 \mathrm{~h}$ gerührt. Anschließend wurde die Lösung filtriert und das Filtrat zur Trockne eingeengt. Der Rückstand wurde chromatographisch an Kieselgel (DCM/MeOH 9:1) gereinigt.

Ausbeute: Es wurden 855 mg (1.92 mmol, 82\%) eines gelben Schaums erhalten.

DC: $R_{f}(\mathrm{DCM} / \mathrm{MeOH} 9: 1)=0.28$.

${ }^{1} \mathrm{H}-\mathrm{NMR}\left(300 \mathrm{MHz}, \mathrm{CDCl}_{3}\right): \delta=0.13\left(\mathrm{~s}, 3 \mathrm{H}, \mathrm{SiCH}_{3}\right), 0.15\left(\mathrm{~s}, 3 \mathrm{H}, \mathrm{SiCH}_{3}\right), 0.95$ (s, $\left.9 \mathrm{H}, \quad \mathrm{SiC}\left(\mathrm{CH}_{3}\right)_{3}\right), \quad 2.34-2.39(\mathrm{~m}, 2 \mathrm{H}, 2 '-\mathrm{H}), \quad 3.57$ (ddd, $J=7.5 \mathrm{~Hz}, J=7.5 \mathrm{~Hz}$, $J=7.5 \mathrm{~Hz}, 1 \mathrm{H}, 3^{\prime}-\mathrm{H}$ ), 3.76 (ddd, $J=7.5 \mathrm{~Hz}, J=2.6 \mathrm{~Hz}, J=2.6 \mathrm{~Hz}, 1 \mathrm{H}, 4^{\prime}-\mathrm{H}$ ), 3.87 (dd, $J=11.6 \mathrm{~Hz}, J=2.6 \mathrm{~Hz}, 1 \mathrm{H}, 5-\mathrm{H}_{\mathrm{a}}$ ), 4.05 (dd, $J=11.6 \mathrm{~Hz}, J=2.6 \mathrm{~Hz}, 1 \mathrm{H}, 5^{\prime}-\mathrm{H}_{\mathrm{b}}$ ), $6.18\left(\mathrm{dd}, J=5.4 \mathrm{~Hz}, J=4.3 \mathrm{~Hz}, 1 \mathrm{H}, 1^{\prime}-\mathrm{H}\right), 7.40-7.53(\mathrm{~m}, 1 \mathrm{H}, 5-\mathrm{H}), 7.48-7.52$ (m, 
$2 \mathrm{H}, 3$ "'-H, 5"-H), 7.57-7.61 (m, $1 \mathrm{H}, 4$ "'-H), 7.90 (d, J= 7.3 Hz, $2 \mathrm{H}, 2$ "'-H, 6"-H), 8.53 (d, $J=7.4 \mathrm{~Hz}, 1 \mathrm{H}, 6-\mathrm{H})$.

${ }^{13} \mathrm{C}$-NMR $\left.\left(75 \mathrm{MHz}, \mathrm{CDCl}_{3}\right): \delta=-5.33\left(\mathrm{SiCH}_{3}\right), 18.45\left(\mathrm{Si} \underline{\mathrm{C}}\left(\mathrm{CH}_{3}\right)_{3}\right), 25.98\left(\mathrm{SiC}(\underline{\mathrm{CH}})_{3}\right)_{3}\right)$, 43.21 (C-2'), 49.25 (C-3'), 61.52 (C-5'), 86.52 (C-4'), 88.21 (C-1'), 95.97 (C-5), 127.54 (C-4"), 129.00 (C-2", C-3", C-5", C-6”), 133.08 (C-1"), 145.05 (C-6), 154.87 (C-2), 162.07 (C-4).

Drehwert: $[\alpha]_{D}^{20}=+65.3\left(\mathrm{c}=1.0, \mathrm{CHCl}_{3}\right)$

Schmelzpunkt: $70^{\circ} \mathrm{C}$.

IR (ATR): $\tilde{v}=1647,1480,1390,1303,1250,1123,831,779,707,673$.

UV (MeCN): $\lambda_{\max }(\lg \varepsilon)=256$ (4.34), 310 (3.98).

MS $\left(E S I^{+}\right): \mathrm{m} / \mathrm{z}=445.2[\mathrm{M}+\mathrm{H}]^{+}$.

$\mathrm{C}_{22} \mathrm{H}_{32} \mathrm{~N}_{4} \mathrm{O}_{4} \mathrm{Si}(444.22)$ ber.: $445.2266[\mathrm{M}+\mathrm{H}]^{+}$ gef.: 445.2265 (ESI+-HRMS).

\subsubsection{6-N-Benzoyl-2'-desoxyadenosin $141^{[163]}$}

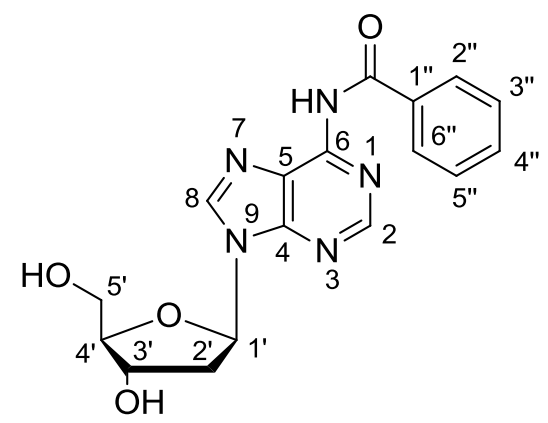

141

2'-Desoxyadenosin-Monohydrat $\quad(10.0 \mathrm{~g}, 37.2 \mathrm{mmol})$ wurde mit abs. Pyridin $(3 \times 100 \mathrm{~mL})$ coevaporiert und in abs. Pyridin $(170 \mathrm{~mL})$ suspendiert. Die Suspension wurde über einen Zeitraum von $10 \mathrm{~min}$ mit TMSCl $(21.8 \mathrm{~g}, 200 \mathrm{mmol}, 25.6 \mathrm{~mL}$ ) versetzt und $30 \mathrm{~min}$. bei RT gerührt. Zur resultierten Lösung wurde allmählich Benzoylchlorid $(28.1 \mathrm{~g}, 200 \mathrm{mmol}, 23.0 \mathrm{~mL}$ ) gegeben. Nach $2 \mathrm{~h}$ Rühren bei RT wurde die Lösung auf $0^{\circ} \mathrm{C}$ gekühlt und mit dest. Wasser $(50 \mathrm{~mL})$ versetzt. Nach weiteren 5 min. wurde wässrige Ammoniak-Lösung (113 mL, 25\%) dazugegeben und das Gemisch 30 min. gerührt, wobei eine Erwärmung der Lösung auf RT zugelassen wurde. Anschließend wurde die Lösung unter verringertem Druck zur Trockne eingeengt und der Rückstand chromatographisch an Kieselgel (DCM/MeOH $95: 5 \rightarrow 9: 1)$ gereinigt. 
Ausbeute: Es wurden $13.5 \mathrm{~g}$ eines weißen Feststoffs erhalten. Laut NMRspektroskopischen Befunden war das Produkt durch Benzoesäure (0.6 Äq.) verunreinigt. Daher ergab sich eine berechnete Ausbeute von $11.2 \mathrm{~g}(31.4 \mathrm{mmol}$, $85 \%)$.

DC: $R_{f}(\mathrm{DCM} / \mathrm{MeOH} 9: 1)=0.22$.

${ }^{1} \mathrm{H}-\mathrm{NMR}\left(300 \mathrm{MHz}, \mathrm{DMSO}-\mathrm{d}_{6}\right.$ ): $\delta=2.39$ (ddd, $J=13.2 \mathrm{~Hz}, J=6.5 \mathrm{~Hz}, J=3.5 \mathrm{~Hz}$, $1 \mathrm{H}, 2^{\prime}-\mathrm{H}_{\mathrm{a}}$ ), 2.81 (ddd, $J=13.2 \mathrm{~Hz}, J=7.3 \mathrm{~Hz}, J=6.0 \mathrm{~Hz}, 1 \mathrm{H}, 2^{\prime}-\mathrm{H}_{\mathrm{b}}$ ), 3.57 (dd, $J=11.7 \mathrm{~Hz}, J=4.6 \mathrm{~Hz}, 1 \mathrm{H}, 5^{\prime}-\mathrm{H}_{\mathrm{a}}$ ), 3.66 (dd, $J=11.7 \mathrm{~Hz}, J=4.6 \mathrm{~Hz}, 1 \mathrm{H}, 5^{\prime}-\mathrm{H}_{\mathrm{b}}$ ), 3.93 (ddd, $J=4.6 \mathrm{~Hz}, J=4.6 \mathrm{~Hz}, J=3.2 \mathrm{~Hz}, 1 \mathrm{H}, 4{ }^{\prime}-\mathrm{H}$ ), 4.48 (ddd, $J=6.0 \mathrm{~Hz}$, $J=3.2 \mathrm{~Hz}, J=3.2 \mathrm{~Hz}, 1 \mathrm{H}, 3^{\prime}-\mathrm{H}$ ), 6.50 (dd, $J=6.5 \mathrm{~Hz}, J=6.5 \mathrm{~Hz}, 1 \mathrm{H}, 1^{\prime}-\mathrm{H}$ ), $7.46-$ $7.50(\mathrm{~m}, 2 \mathrm{H}, 3$ "'-H, 5"-H), 7.63-7.67 (m, $1 \mathrm{H}, 4$ "'-H), 8.05-8.08 (m, $2 \mathrm{H}, 2$ "'-H, 6"-H), $8.69(\mathrm{~s}, 1 \mathrm{H}, 2-\mathrm{H}), 8.76(\mathrm{~s}, 1 \mathrm{H}, 8-\mathrm{H})$.

${ }^{13} \mathrm{C}$-NMR $\left(75 \mathrm{MHz}\right.$, DMSO-d $\mathrm{d}_{6}$ ): $\delta=40.00$ (C-2'), 62.10 (C-5'), 71.16 (C-3'), 84.23 (C-1'), 88.50 (C-4'), 126.38 (C-5), 128.83 (C-3", C-5"), 128.95 (C-2", C-6"), 132.76 (C-4"), 133.92 (C-1"), 143.50 (C-8), 150.07 (C-4), 150.82 (C-6), 151.95 (C-2), 166.19 (Bz-C=O).

Drehwert: $[\alpha]_{D}^{20}=-8.7\left(\mathrm{c}=0.52, \mathrm{H}_{2} \mathrm{O} /\right.$ Pyridin $\left.1: 1\right)$

MS $\left(E S I^{+}\right): m / z=356.1[M+H]^{+}$.

$\mathrm{C}_{17} \mathrm{H}_{17} \mathrm{~N}_{5} \mathrm{O}_{4}$ (355.35)

ber.: $356.1353[\mathrm{M}+\mathrm{H}]^{+}$

gef.: 356.1349 (ESI+-HRMS).

\subsubsection{6-N-Benzoyl-5'-O-TBDMS-2'-desoxyadenosin 98}

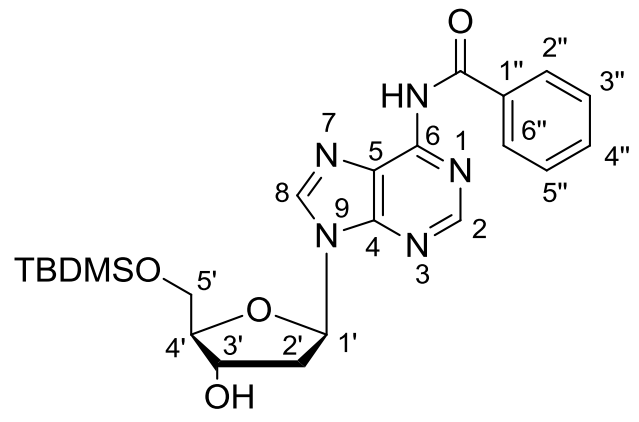

98

6- $N$-Benzoyl-2'-desoxyadenosin $141 \quad(14.0 \mathrm{~g}, \quad 39.4 \mathrm{mmol})$ wurde mit Pyridin $(2 \times 80 \mathrm{~mL})$ coevaporiert und in Pyridin $(80 \mathrm{~mL})$ gelöst. TBDMSCl $(8.31 \mathrm{~g}$, $55.16 \mathrm{mmol}$ ) wurde dazugegeben und die Reaktionslösung $1.5 \mathrm{~h}$ bei RT gerührt. Nach Zugabe von Methanol $(7 \mathrm{~mL})$ wurde das Lösungsmittel unter vermindertem 
Druck entfernt und der Rückstand in DCM (400 mL) aufgenommen, mit ges. $\mathrm{NaHCO}_{3}$-Lösung $(200 \mathrm{~mL})$ und ges. $\mathrm{NaCl}$-Lösung $(200 \mathrm{~mL})$ gewaschen und über $\mathrm{Na}_{2} \mathrm{SO}_{4}$ getrocknet. Die organische Phase wurde zur Trockne eingeengt und der Rückstand chromatographisch an Kieselgel (DCM/MeOH 95:5) gereinigt.

Ausbeute: Es wurden $14.7 \mathrm{~g}(31.2 \mathrm{mmol}, 80 \%)$ eines weißen Schaums erhalten.

DC: $R_{f}(D C M / M e O H ~ 95: 5)=0.20$.

${ }^{1} \mathrm{H}-\mathrm{NMR}\left(300 \mathrm{MHz}, \mathrm{CDCl}_{3}\right): \delta=0.10\left(\mathrm{~s}, 3 \mathrm{H}, \mathrm{SiCH}_{3}\right), 0.11\left(\mathrm{~s}, 3 \mathrm{H}, \mathrm{SiCH}_{3}\right), 0.91$ (s, $9 \mathrm{H}, \mathrm{SiC}\left(\mathrm{CH}_{3}\right)$ ), 2.60 (ddd, $J=13.3 \mathrm{~Hz}, J=6.6 \mathrm{~Hz}, J=4.4 \mathrm{~Hz}, 1 \mathrm{H}, 2^{\prime}-\mathrm{H}_{\mathrm{a}}$ ), 2.78 (ddd, $J=13.3 \mathrm{~Hz}, J=6.5 \mathrm{~Hz}, J=6.5 \mathrm{~Hz}, 1 \mathrm{H}, 2^{\prime}-\mathrm{H}_{\mathrm{b}}$ ), $3.89\left(\mathrm{~d}, J=4.1 \mathrm{~Hz}, 2 \mathrm{H}, 5^{\prime}-\mathrm{H}\right), 4.11$ (ddd, $J=4.0 \mathrm{~Hz}, J=4.0 \mathrm{~Hz}, J=4.0 \mathrm{~Hz}, 1 \mathrm{H}, 4^{\prime}-\mathrm{H}$ ), 4.72 (ddd, $J=6.0 \mathrm{~Hz}, J=3.8 \mathrm{~Hz}$, $J=3.8 \mathrm{~Hz}, 1 \mathrm{H}, \quad 3{ }^{\prime}-\mathrm{H}$ ), 6.55 (dd, $J=6.5 \mathrm{~Hz}, J=6.5 \mathrm{~Hz}, 1 \mathrm{H}, 1^{\prime}-\mathrm{H}$ ), 7.53 (dd, $J=7.6 \mathrm{~Hz}, J=7.5 \mathrm{~Hz}, 2 \mathrm{H}, 3$ "'-H, 5"-H), 7.61 (t, J=7.5 Hz, $1 \mathrm{H}, 4$ "'-H), 8.03 (d, $J=7.5 \mathrm{~Hz}, 2 \mathrm{H}, 2$ "'-H, 6"-H), $8.32(\mathrm{~s}, 1 \mathrm{H}, 2-\mathrm{H}), 8.81$ (s, $1 \mathrm{H}, 8-\mathrm{H})$.

${ }^{13} \mathrm{C}$-NMR $\left(75 \mathrm{MHz}, \mathrm{CDCl}_{3}\right): \delta=-5.45\left(\mathrm{SiCH}_{3}\right),-5.37\left(\mathrm{SiCH}_{3}\right), 18.39\left(\mathrm{SiC}\left(\mathrm{CH}_{3}\right)\right), 25.95$ $\left(\mathrm{SiC}\left(\mathrm{C}_{3}\right)\right), 41.06$ (C-2'), 63.48 (C-5'), 72.51 (C-3'), 84.58 (C-1'), 87.15 (C-4'), 123.26 (C-5), 127.91 (C-3", C-5”), 128.80 (C-2",C-6"), 132.73 (C-4"), 133.80 (C-1"), 141.37 (C-8), 149.44 (C-4), 151.32 (C-6), 152.66 (C-2), 164.72 (Bz-C=O).

Drehwert: $[\alpha]_{D}^{20}=-18.3\left(\mathrm{c}=1.0, \mathrm{CHCl}_{3}\right)$.

Schmelzpunkt: $59^{\circ} \mathrm{C}$.

IR (ATR): $\tilde{v}=2926,1695,1609,1580,1452,1247,1070,831,779,702$.

UV (MeCN): $\lambda_{\max }(\lg \varepsilon)=228$ (4.00), 281 (3.96).

MS $\left(E S I^{+}\right): \mathrm{m} / \mathrm{z}=470.2[\mathrm{M}+\mathrm{H}]^{+}$.

$\mathrm{C}_{23} \mathrm{H}_{31} \mathrm{~N}_{5} \mathrm{O}_{4} \mathrm{Si}(469.21)$

ber.: $470.2218[\mathrm{M}+\mathrm{H}]^{+}$ gef.: 470.2217 (ESI+-HRMS).

\subsubsection{6-N-Benzoyl-5'-O-TBDMS-2'-desoxy-3'-xylo-adenosin 100}

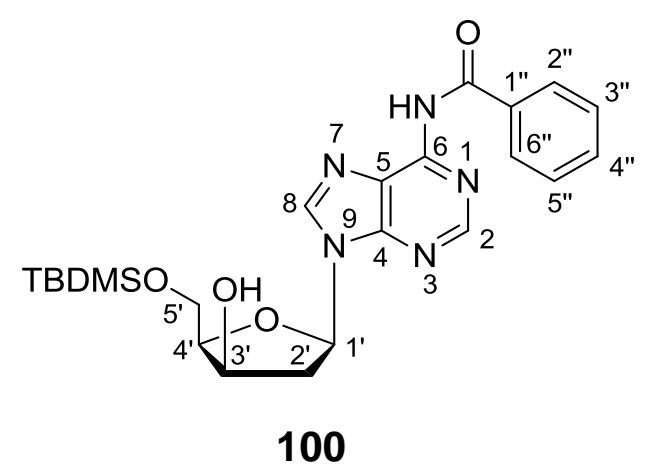


Eine Lösung von DMP $(2.70 \mathrm{~g}, 6.36 \mathrm{mmol})$ in DCM $(40 \mathrm{~mL})$ wurde bei $0{ }^{\circ} \mathrm{C}$ mit $6-\mathrm{N}$ Benzoyl-5'-O-TBDMS-2'-desoxyadenosin $98(2.00 \mathrm{~g}, 4.25 \mathrm{mmol})$ versetzt und $30 \mathrm{~min}$ bei $0{ }^{\circ} \mathrm{C}$ gerührt. Die Reaktionslösung wurde auf Raumtemperatur gebracht und weitere $14 \mathrm{~h}$ bei Raumtemperatur gerührt. Anschließend wurde die Reaktionslösung mit Isopropanol $(40 \mathrm{~mL})$ versetzt und auf $-60^{\circ} \mathrm{C}$ gekühlt. Frisch gemörsertes $\mathrm{NaBH}_{4}$ (320 mg, $8.46 \mathrm{mmol}$ ) wurde dazugegeben und die Reaktion $16 \mathrm{~h}$ bei $-60^{\circ} \mathrm{C}$ gerührt. Die erhaltene Lösung wurde mit Aceton $(40 \mathrm{~mL})$ versetzt und in EtOAc $(300 \mathrm{~mL})$ aufgenommen. Die organische Phase wurde mit ges. $\mathrm{NaHCO}_{3}$-Lösung $(2 \times 100 \mathrm{~mL})$ und ges. NaCl-Lösung $(100 \mathrm{~mL})$ gewaschen. Die wässrigen Phasen wurden vereint und mit EtOAc $(100 \mathrm{~mL})$ reextrahiert. Die vereinigten organischen Phasen wurden bei vermindertem Druck zur Trockne eingeengt und der Rückstand chromatographisch an Kieselgel gereinigt (DCM/MeOH 97:3).

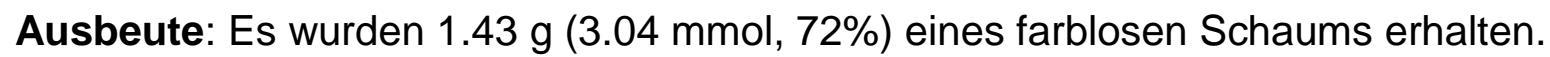

DC: $R_{f}(\mathrm{DCM} / \mathrm{MeOH} 95: 5)=0.30$.

${ }^{1} \mathrm{H}-\mathrm{NMR}\left(300 \mathrm{MHz}, \mathrm{CDCl}_{3}\right): \delta=0.04\left(\mathrm{~s}, 3 \mathrm{H}, \mathrm{SiCH}_{3}\right), 0.06\left(\mathrm{~s}, 3 \mathrm{H}, \mathrm{SiCH}_{3}\right), 0.87(\mathrm{~s}$, $\left.9 \mathrm{H}, \mathrm{SiC}\left(\mathrm{CH}_{3}\right)_{3}\right), 2.56$ (dd, $J=15.3 \mathrm{~Hz}, J=2.5 \mathrm{~Hz}, 1 \mathrm{H}, 2^{\prime}-\mathrm{H}_{\mathrm{a}}$ ), 2.86 (ddd, $J=15.3 \mathrm{~Hz}$, $\left.J=9.1 \mathrm{~Hz}, J=6.0 \mathrm{~Hz}, 1 \mathrm{H}, 2^{\prime}-\mathrm{H}_{\mathrm{b}}\right)$, 3.97-4.03 (m, $\left.2 \mathrm{H}, 4^{\prime}-\mathrm{H}, 5^{\prime}-\mathrm{H}_{\mathrm{a}}\right), 4.05-4.12(\mathrm{~m}, 1 \mathrm{H}$, 5'- $\left.\mathrm{H}_{\mathrm{b}}\right), 4.51-4.57\left(\mathrm{~m}, 1 \mathrm{H}, 3^{\prime}-\mathrm{H}\right), 5.72-5.80\left(\mathrm{~m}, 1 \mathrm{H}, 3^{\prime}-\mathrm{OH}\right), 6.30$ (dd, $J=9.1 \mathrm{~Hz}$, $J=2.5 \mathrm{~Hz}, 1 \mathrm{H}, 1^{\prime}-\mathrm{H}$ ), 7.51 (dd, $J=7.4 \mathrm{~Hz}, J=7.4 \mathrm{~Hz}, 2 \mathrm{H}, 3$ 3'-H, 5"-H), 7.59 (t, $J=7.4 \mathrm{~Hz}, 1 \mathrm{H}, 4$ "'-H), 8.00 (d, J=7.4 Hz, $2 \mathrm{H}, 2$ "'-H, 6"'-H), 8.33 (s, $1 \mathrm{H}, 2-\mathrm{H}), 8.77$ (s, $1 \mathrm{H}, 8-\mathrm{H}), 9.09(\mathrm{~s}, 1 \mathrm{H}, 6-\mathrm{NH})$.

${ }^{13} \mathrm{C}$-NMR $\left(75 \mathrm{MHz}, \mathrm{CDCl}_{3}\right): \delta=-5.40\left(\mathrm{SiCH}_{3}\right), 18.30\left(\mathrm{SiC}\left(\mathrm{CH}_{3}\right)_{3}\right), 25.86\left(\mathrm{SiC}\left(\mathrm{CH}_{3}\right)_{3}\right)$, 40.96 (C-2'), 62.13 (C-5'), 71.14 (C-3'), 84.19 (C-1'), 84.75 (C-4'), 123.83 (C-5), 127.87 (C-2", C-6”), 128.86 (C-3“, C-5”), 132.85 (C-4"), 133.59 (C-1"), 133.61 (C-8), 143.09 (C-4), 149.86 (C-6), 152.08 (C-2), 164.52 (Bz-C=O).

Drehwert: $[\alpha]_{D}^{20}=-28.0\left(\mathrm{c}=1.0, \mathrm{CHCl}_{3}\right)$.

Schmelzpunkt: $80^{\circ} \mathrm{C}$.

IR (ATR): $\tilde{v}=2926,1695,1609,1580,1452,1250,1065$, 832, 779, 702.

UV (MeCN): $\lambda_{\max }(\lg \varepsilon)=228$ (4.11), 281 (4.16).

MS $\left(E S I^{+}\right): \mathrm{m} / \mathrm{z}=470.2[\mathrm{M}+\mathrm{H}]^{+}$.

$\mathrm{C}_{23} \mathrm{H}_{31} \mathrm{~N}_{5} \mathrm{O}_{4} \mathrm{Si}(469.21)$ ber.: $470.2218[\mathrm{M}+\mathrm{H}]^{+}$ gef.: 470.2217 (ESI+-HRMS). 


\subsubsection{3'-O-Mesyl-6-N-Benzoyl-5'-O-TBDMS-2',3'-didesoxy-3'-xylo- adenosin Ms-100 ${ }^{[135]}$}

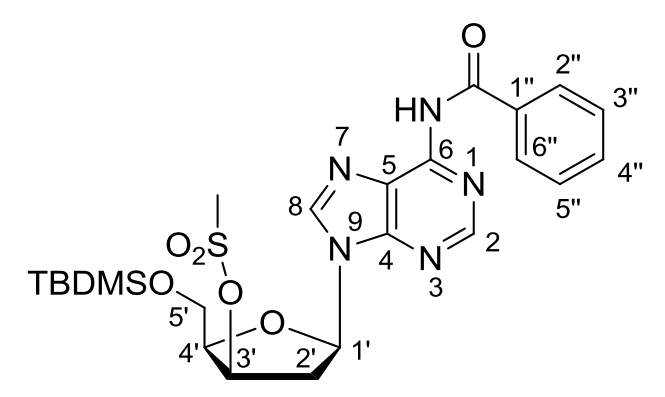

Ms-100

Eine Lösung von 6-N-Benzoyl-5'-O-TBDMS-2'-desoxy-3'-xyloadenosin 100 (500 mg, $1.06 \mathrm{mmol}$ ) in Pyridin $(8 \mathrm{~mL})$ wurde bei $0{ }^{\circ} \mathrm{C}$ langsam mit Methansulfonsäurechlorid $(410 \mu \mathrm{L}, 610 \mathrm{mg}, 5.30 \mathrm{mmol})$ versetzt. Anschließend wurde die Reaktionslösung auf Raumtemperatur gebracht und $4 \mathrm{~h}$ gerührt. Die Reaktionslösung wurde in Dichlormethan $(100 \mathrm{~mL})$ aufgenommen und mit ges. $\mathrm{NaHCO}_{3}$-Lösung $(1 \times 50 \mathrm{~mL})$ Wasser $(1 \times 50 \mathrm{~mL})$ und ges. NaCl-Lösung $(1 \times 50 \mathrm{~mL})$ gewaschen. Die organische Phase wurde über $\mathrm{Na}_{2} \mathrm{SO}_{4}$ getrocknet und zur Trockne eingeengt. Der ölige Rückstand wurde mit Toluol $(2 \times 4 \mathrm{~mL})$ und Dichlormethan $(1 \times 10 \mathrm{~mL})$ koevaporiert und die Lösungsmittelreste mittels Hochvakuum entfernt. Das Produkt wurde ohne weitere Reinigung in der nachfolgenden Reaktion eingesetzt.

Ausbeute: Es wurden $580 \mathrm{mg}$ eines rotbraunen, verunreinigten Öls erhalten (100\% Ausbeute: $580 \mathrm{mg}, 1.06 \mathrm{mmol}$ ).

${ }^{1} \mathrm{H}$-NMR $\left(300 \mathrm{MHz}, \mathrm{CDCl}_{3}\right): \delta=0.09\left(\mathrm{~s}, 3 \mathrm{H}, \mathrm{SiCH}_{3}\right), 0.10\left(\mathrm{~s}, 3 \mathrm{H}, \mathrm{SiCH}_{3}\right), 0.90$ (s, $\left.9 \mathrm{H}, \quad \mathrm{SiC}\left(\mathrm{CH}_{3}\right)_{3}\right), 2.94-2.97\left(\mathrm{~m}, 2 \mathrm{H}, 2^{\prime}-\mathrm{H}\right), 3.00\left(\mathrm{~s}, 3 \mathrm{H}, \mathrm{SO}_{2} \mathrm{CH}_{3}\right), 3.95$ (dd, $J=10.5 \mathrm{~Hz}, J=7.3 \mathrm{~Hz}, 1 \mathrm{H}, 5^{\prime}-\mathrm{H}_{\mathrm{a}}$ ), $3.98\left(\mathrm{dd}, J=10.5 \mathrm{~Hz}, J=5.6 \mathrm{~Hz}, 1 \mathrm{H}, 5^{\prime}-\mathrm{H}_{\mathrm{b}}\right.$ ), 4.24 (ddd, $J=7.3 \mathrm{~Hz}, J=5.6 \mathrm{~Hz}, J=3.5 \mathrm{~Hz}, 1 \mathrm{H}, 4^{\prime}-\mathrm{H}$ ), 5.37-5.40 (m, $1 \mathrm{H}, 3^{\prime}-\mathrm{H}$ ), $6.57\left(\mathrm{dd}, J=6.8 \mathrm{~Hz}, J=3.6 \mathrm{~Hz}, 1 \mathrm{H}, 1^{\prime}-\mathrm{H}\right.$ ), 7.49 (dd, $J=7.4 \mathrm{~Hz}, J=7.4 \mathrm{~Hz}, 2 \mathrm{H}$, 3"'-H, 5"-H), 7.58 (t, J= 7.4 Hz, $1 \mathrm{H}, 4$ "'-H), 8.01 (d, J=7.4 Hz, 2 H, 2"-H, 6"-H), 8.37 (s, $1 \mathrm{H}, 2-\mathrm{H}), 8.75(\mathrm{~s}, 1 \mathrm{H}, 8-\mathrm{H}), 9.17$ (brs, $1 \mathrm{H}, 6-\mathrm{NH})$.

${ }^{13} \mathrm{C}$-NMR $\left(75 \mathrm{MHz}, \mathrm{CDCl}_{3}\right): \delta=-5.38\left(\mathrm{SiCH}_{3}\right), 18.25\left(\mathrm{SiC}\left(\mathrm{CH}_{3}\right)_{3}\right), 25.83\left(\mathrm{SiC}\left(\mathrm{CH}_{3}\right)_{3}\right)$, 38.54 (C-2'), $39.89\left(\mathrm{SO}_{2} \mathrm{CH}_{3}\right.$ ), 60.25 (C-5'), 78.24 (C-3'), 83.08 (C-1'), 83.25 (C-4'), 123.16 (C-5), 127.91 (C-2", C-6"), 128.84 (C-3", C-5"), 132.75 (C-4",C-1"), 133.69 (C-8), 141.07 (C-4), 149.56 (C-6), 151.61 (C-2), 164.78 (Bz-C=O). 
Diese Substanz wurde nicht chromatographisch gereinigt und enthielt daher Verunreinigungen. Aus diesem Grund wurde auf eine Charakterisierung mittels weiterer analytischer Methoden verzichtet.

\subsubsection{3'-Azido-6-N-Benzoyl-5'-O-TBDMS-2',3'-didesoxyadenosin 102}

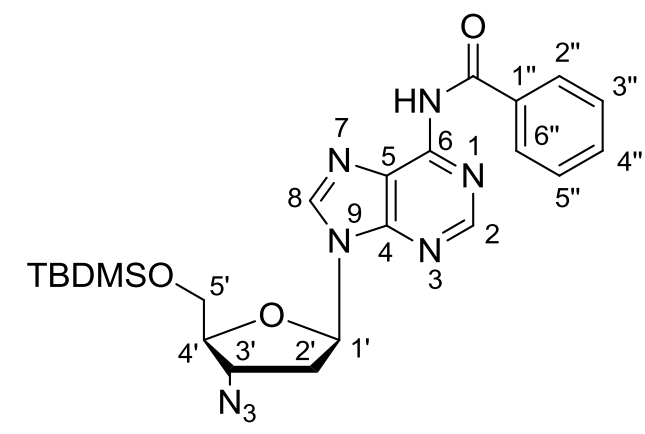

102

\section{Variante $1:^{[137]}$}

Eine Suspension von 100 (30 mg, $64 \mu \mathrm{mol})$ und $\mathrm{NaN}_{3}(13 \mathrm{mg}, 0.20 \mathrm{mmol})$ in abs. DMF $(0.2 \mathrm{~mL})$ wurde mit einer Lösung von DIAD (19 mg, $96 \mu \mathrm{mol})$ und Dipenyl-2Pyridylphosphin $(25 \mathrm{mg}, 96 \mu \mathrm{mol})$ in DMF $(0.1 \mathrm{~mL})$ versetzt und $4 \mathrm{~h}$ bei Raumtemperatur gerührt. Das Reaktionsgemisch wurde mit Wasser $(0.1 \mathrm{~mL})$ versetzt und in Ethylacetat $(5 \mathrm{~mL})$ aufgenommen. Die Phasen wurden getrennt und die organische Phase mit Wasser $(5 \mathrm{~mL})$ und ges. NaCl-Lösung $(5 \mathrm{~mL})$ gewaschen. Die organische Phase wurde über $\mathrm{Na}_{2} \mathrm{SO}_{4}$ getrocknet, filtriert und bei vermindertem Druck eingeengt. Der ölige Rückstand wurde chromatographisch an Kieselgel gereinigt (DCM/EtOAc 3:2). Es konnte kein Produkt isoliert werden.

Variante 2: ${ }^{[134]}$

Eine Lösung von $100(30 \mathrm{mg}, 64 \mu \mathrm{mol})$ in abs. DMF $(0.34 \mathrm{~mL})$ wurde mit $\mathrm{LiN}_{3}$ (9.4 mg, $0.19 \mathrm{mmol}), \mathrm{PPh}_{3}(25 \mathrm{mg}, 96 \mu \mathrm{mol})$ und DIAD (19 mg, $\left.96 \mu \mathrm{mol}\right)$ versetzt und $6 \mathrm{~h}$ bei RT gerührt. Das Reaktionsgemisch wurde mit Wasser $(0.1 \mathrm{~mL})$ versetzt und in Ethylacetat $(5 \mathrm{~mL})$ aufgenommen. Die Phasen wurden getrennt und die organische Phase mit Wasser $(5 \mathrm{~mL})$ und ges. NaCl-Lösung $(5 \mathrm{~mL})$ gewaschen. Die organische Phase wurde über $\mathrm{Na}_{2} \mathrm{SO}_{4}$ getrocknet, filtriert und bei vermindertem Druck eingeengt. Der ölige Rückstand wurde chromatographisch an Kieselgel gereinigt (DCM/MeOH 97:3). Es konnte kein Produkt isoliert werden. 


\section{Variante $3:^{[168]}$}

Eine Lösung von 100 (340 mg, $0.723 \mathrm{mmol})$ und $\mathrm{PPh}_{3}(285 \mathrm{mg}, 1.09 \mathrm{mmol})$ in abs. THF ( $3 \mathrm{~mL}$ ) wurde bei $0{ }^{\circ} \mathrm{C}$ mit einer Lösung von DPPA ( $243 \mu \mathrm{L}, 298 \mathrm{mg}, 1.09 \mathrm{mmol}$ ) und DIAD $(213 \mu \mathrm{L}, 219 \mathrm{mg}, 1.09 \mathrm{mmol})$ in abs THF (2 mL) versetzt. Anschließend wurde ein Erwärmen der Reaktionslösung auf RT zugelassen und für weitere $3 \mathrm{~h}$ gerührt. Es wurde Ethanol $(2 \mathrm{~mL})$ dazugegeben und die Lösung weitere $30 \mathrm{~min}$ gerührt. Das Reaktionsgemisch wurde in Ethylacetat $(50 \mathrm{~mL})$ aufgenommen, mit Wasser $(50 \mathrm{~mL})$ und ges. $\mathrm{NaCl}$-Lösung $(50 \mathrm{~mL})$ gewaschen, über $\mathrm{Na}_{2} \mathrm{SO}_{4}$ getrocknet, filtriert und bei vermindertem Druck eingeengt. Der ölige Rückstand wurde chromatographisch an Kieselgel gereinigt (DCM/MeOH 97:3).

Ausbeute: Es wurden $40 \mathrm{mg}$ eines gelben Öls erhalten (100\% Ausbeute: $357 \mathrm{mg}$, $0.723 \mathrm{mmol}$ ). Anhand von NMR-spektroskopischen Untersuchungen wurde nachgewiesen, dass die erhaltene Verbindung verunreinigt war (vermutlich aus dem DIAD gebildete Hydrazinderivate).

\section{Variante $4:[131-132]$}

Eine Lösung von 100 (50 mg, $0.11 \mathrm{mmol})$ in einem 10:1-Gemisch aus abs. DCM und abs. Pyridin $(1.1 \mathrm{~mL})$ wurde auf $-30^{\circ} \mathrm{C}$ heruntergekühlt und mit einer Lösung von $\mathrm{Tf}_{2} \mathrm{O}(26 \mu \mathrm{L}, \quad 45 \mathrm{mg}, \quad 0.16 \mathrm{mmol})$ in abs. $\mathrm{DCM}(0.23 \mathrm{~mL})$ versetzt. Die Reaktionsmischung wurde auf RT erwärmt und weitere 15 min gerührt. Anschließend wurde eine Lösung von $\mathrm{LiN}_{3}(52 \mathrm{mg}, 1.1 \mathrm{mmol})$ in abs. DMF (1 mL) dazugegeben. Die resultierende Lösung wurde $2 \mathrm{~h}$ bei Raumtemperatur gerührt und anschließend in ein Gemisch aus DCM (30 mL) und Wasser (10 mL) überführt. Die Phasen wurden getrennt und die organische Phase mit Wasser $(2 \times 10 \mathrm{~mL})$ gewaschen, über $\mathrm{Na}_{2} \mathrm{SO}_{4}$ getrocknet, filtriert und eingeengt. Der Rückstand wurde chromatographisch an Kieselgel gereinigt (DCM/MeOH 97:3). Es konnte kein Produkt isoliert werden.

\section{Variante $5:^{[133]}$}

100 (30 mg, $64 \mu \mathrm{mol})$ und $\mathrm{LiN}_{3}(31 \mathrm{mg}, 0.64 \mathrm{mmol})$ wurden mit abs. Toluol coevaporiert $(3 \times 1 \mathrm{~mL})$ und in abs. DMF $(0.2 \mathrm{~mL})$ gelöst. Es wurden Tetrabrommethan (42 $\mathrm{mg}, 0.13 \mathrm{mmol}$ ) und $\mathrm{PPh}_{3}(34 \mathrm{mg}, 0.13 \mathrm{mmol}$ ) dazugegeben. Die resultierende Lösung wurde $24 \mathrm{~h}$ bei RT gerührt. Es konnte per Dünnschichtchromatographie (DCM/MeOH 95:5) nur Zersetzung des Edukts nachgewiesen werden. 
Variante $6:^{[135]}$

Eine Suspension von 3'-O-Mesyl-6-N-Benzoyl-5'-O-TBDMS-2'-desoxy-3'-xyloadenosin Ms-100 (580 mg, $1.06 \mathrm{mmol}$ ) und $\mathrm{NaN}_{3}(640 \mathrm{mg}, 9.8 \mathrm{mmol})$ in abs. DMF $(16 \mathrm{~mL})$ wurde bei $110^{\circ} \mathrm{C} 1.5 \mathrm{~h}$ gerührt. Nach Abkühlen auf Raumtemperatur wurde die Lösung in Ethylacetat $(100 \mathrm{~mL})$ aufgenommen und mit ges. wässriger $\mathrm{NaHCO}_{3}$ $(2 \times 50 \mathrm{~mL})$, Wasser $(2 \times 50 \mathrm{~mL})$ und ges. wässriger $\mathrm{NaCl}(1 \times 50 \mathrm{~mL})$ gewaschen. Die organische Phase wurde über $\mathrm{Na}_{2} \mathrm{SO}_{4}$ getrocknet und bei vermindertem Druck zur Trockne eingeengt. Der Rückstand wurde chromatographisch an Kieselgel (DCM/MeOH 98:2) gereinigt.

Ausbeute: Es wurden $313 \mathrm{mg}(633 \mu \mathrm{mol}, 60 \%)$ eines gelben hochviskosen Öls erhalten.

DC: $R_{f}(\mathrm{iHex} /$ EtOAc 3:2) $=0.29$.

${ }^{1} \mathrm{H}-\mathrm{NMR}\left(300 \mathrm{MHz}, \mathrm{CDCl}_{3}\right): \delta=0.09\left(\mathrm{~s}, 3 \mathrm{H}, \mathrm{SiCH}_{3}\right), 0.10$ (s, $\left.3 \mathrm{H}, \mathrm{SiCH}_{3}\right), 0.91$ (s, $\left.9 \mathrm{H}, \mathrm{SiC}\left(\mathrm{CH}_{3}\right)_{3}\right), 2.61$ (ddd, $J=13.6 \mathrm{~Hz}, J=6.6 \mathrm{~Hz}, J=5.8 \mathrm{~Hz}, 1 \mathrm{H}, 2^{\prime}-\mathrm{H}_{\mathrm{a}}$ ), 2.91 (ddd, $J=13.6 \mathrm{~Hz}, J=6.6 \mathrm{~Hz}, J=5.8 \mathrm{~Hz}, 1 \mathrm{H}, 2^{\prime}-\mathrm{H}_{\mathrm{b}}$ ), 3.84 (dd, $J=11.3 \mathrm{~Hz}, J=3.3 \mathrm{~Hz}$, $1 \mathrm{H}, 5^{\prime}-\mathrm{H}_{\mathrm{a}}$ ), 3.95 (dd, J=11.3 Hz, J=4.1 Hz, $\left.1 \mathrm{H}, 5^{\prime}-\mathrm{H}_{\mathrm{b}}\right), 4.07-4.11\left(\mathrm{~m}, 1 \mathrm{H}, 4^{\prime}-\mathrm{H}\right)$, 4.49 (ddd, $J=6.6 \mathrm{~Hz}, J=6.6 \mathrm{~Hz}, J=5.3 \mathrm{~Hz}, 1 \mathrm{H}, 3^{\prime}-\mathrm{H}$ ), 6.43 (dd, $J=5.8 \mathrm{~Hz}$, $\left.J=5.8 \mathrm{~Hz}, 1 \mathrm{H}, 1^{\prime}-\mathrm{H}\right), 7.52\left(\mathrm{dd}, J=7.5 \mathrm{~Hz}, J=7.5 \mathrm{~Hz}, 2 \mathrm{H}, 3{ }^{\prime \prime}-\mathrm{H}, 5{ }^{\prime \prime}-\mathrm{H}\right), 7.60$ (t, $J=7.5 \mathrm{~Hz}, 1 \mathrm{H}, 4$ "'-H), 8.02 (d, J=7.5 Hz, $2 \mathrm{H}, 2$ '”-H, 6"-H), 8.30 (s, $1 \mathrm{H}, 2-\mathrm{H}), 8.79$ (s, $1 \mathrm{H}, 8-\mathrm{H}), 9.05$ (brs, $1 \mathrm{H}, 6-\mathrm{NH})$.

${ }^{13}$ C-NMR $\left(75 \mathrm{MHz}, \mathrm{CDCl}_{3}\right): \delta=-5.47\left(\mathrm{SiCH}_{3}\right),-5.36\left(\mathrm{SiCH}_{3}\right), 18.40\left(\mathrm{SiC}\left(\mathrm{CH}_{3}\right)_{3}\right)$, $25.93\left(\mathrm{SiC}\left(\mathrm{CH}_{3}\right)_{3}\right), 38.10$ (C-2'), 60.49 (C-3'), 62.75 (C-5'), 84.49 (C-4'), 85.13 (C-1'), 123.44 (C-5), 127.87 (C-2”, C-6”), 128.87 (C-3", C-5”), 132.76 (C-4”), 133.76 (C-6, C-1”), 141.36 (C-8), 149.58 (C-4), 151.20 (C-6), 152.67 (C-2), 164.57 (Bz-C=O).

Drehwert: $[\alpha]_{D}^{20}=-9.0\left(\mathrm{c}=1.0, \mathrm{CHCl}_{3}\right)$.

IR (ATR): $\tilde{v}=2926,2100,1695,1609,1452,1247,1070,835,774,702$.

UV $(\mathrm{MeCN}): \lambda_{\max }(\lg \varepsilon)=279$ (4.43).

MS $\left(E S I^{+}\right): m / z=495.2[M+H]^{+}$.

$\mathrm{C}_{23} \mathrm{H}_{30} \mathrm{~N}_{8} \mathrm{O}_{3} \mathrm{Si}$ (494.62)

ber.: $495.2283[\mathrm{M}+\mathrm{H}]^{+}$

gef.: 495.2284 (ESI $\left.{ }^{+}-H R M S\right)$. 


\subsubsection{3'-Amino-6-N-Benzoyl-5'-O-TBDMS-2',3'-didesoxyadenosin 91}

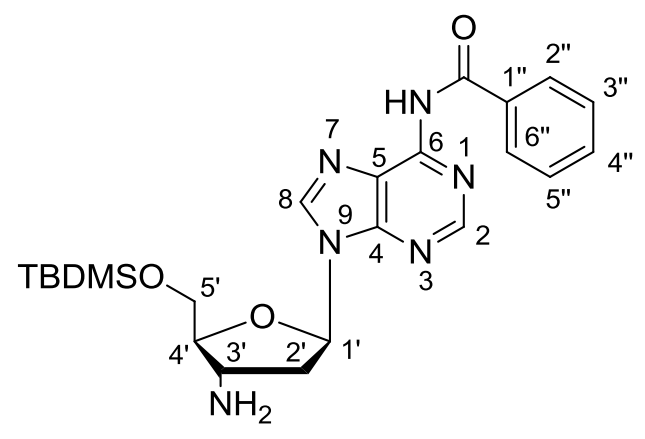

91

Eine Lösung von 3'-Azido-6-N-Benzoyl-5'-O-TBDMS-2',3'-didesoxyadenosin 102 $(2.34 \mathrm{~g}, 4.91 \mathrm{mmol})$ in Methanol $(150 \mathrm{~mL})$ wurde mit Palladium (52 mg, $0.49 \mathrm{mmol}$, auf Aktivkohle, 10\%) versetzt und $20 \mathrm{~h}$ unter einer Wasserstoff-Atmosphäre gerührt. Die Suspension wurde durch Filtration über Celite ${ }^{\circledR}$ vom Palladium-Katalysator befreit und das Filtrat bei vermindertem Druck zur Trockne eingeengt.

Ausbeute: Es wurden $1.45 \mathrm{~g}(3.10 \mathrm{mmol}, 92 \%)$ eines bräunlich-gelben Schaums erhalten.

DC: $R_{f}(\mathrm{DCM} / \mathrm{MeOH} 9: 1)=0.41$.

${ }^{1} \mathrm{H}-\mathrm{NMR}$ (300 MHz, MeOD): $\delta=0.09$ (s, $3 \mathrm{H}, \mathrm{SiCH}_{3}$ ), 0.10 (s, $3 \mathrm{H}, \mathrm{SiCH}_{3}$ ), 0.92 (s, $9 \mathrm{H}, \mathrm{SiC}\left(\mathrm{CH}_{3}\right)_{3}$ ), 2.50 (ddd, $J=13.6 \mathrm{~Hz}, J=7.4 \mathrm{~Hz}, J=7.4 \mathrm{~Hz}, 1 \mathrm{H}, 2{ }^{\prime}-\mathrm{H}_{\mathrm{a}}$ ), 2.83 (ddd, $\left.J=13.6 \mathrm{~Hz}, J=6.7 \mathrm{~Hz}, J=3.5 \mathrm{~Hz}, 1 \mathrm{H}, 2^{\prime}-\mathrm{H}_{\mathrm{b}}\right), 3.84-3.91\left(\mathrm{~m}, 2 \mathrm{H}, 3^{\prime}-\mathrm{H}, 4^{\prime}-\mathrm{H}\right), 3.93$ (dd, $\left.J=11.3 \mathrm{~Hz}, J=3.4 \mathrm{~Hz}, 1 \mathrm{H}, 5^{\prime}-\mathrm{H}_{\mathrm{a}}\right), 4.01$ (dd, $J=11.3 \mathrm{~Hz}, J=3.0 \mathrm{~Hz}, 1 \mathrm{H}$, 5'- $\left.\mathrm{H}_{\mathrm{b}}\right), 6.54$ (dd, J=7.4 Hz, J=3.5 Hz, $\left.1 \mathrm{H}, 1^{\prime}-\mathrm{H}\right), 7.58$ (dd, J=7.5 Hz, J=7.5 Hz, $2 \mathrm{H}, 3$ "'-H, 5"'-H), 7.67 (t, J=7.5 Hz, 1 H, 4"-H), 8.02 (d, J=8.3 Hz, 2 H, 2"'-H, 6"'-H), $8.68(\mathrm{~s}, 1 \mathrm{H}, 2-\mathrm{H}), 8.72(\mathrm{~s}, 1 \mathrm{H}, 8-\mathrm{H})$.

${ }^{13} \mathrm{C}$-NMR $(75 \mathrm{MHz}, \mathrm{MeOD}): \delta=-6.71\left(\mathrm{SiCH}_{3}\right), 17.90\left(\mathrm{SiC}\left(\mathrm{CH}_{3}\right)_{3}\right), 25.05\left(\mathrm{SiC}\left(\underline{\mathrm{C}} \mathrm{H}_{3}\right)_{3}\right.$, 38.10 (C-2'), 60.49 (C-3'), 62.75 (C-5'), 84.49 (C-4'), 85.13 (C-1'), 123.44 (C-5), 127.87 (C-2”, C-6”), 128.87 (C-3”, C-5”), 132.76 (C-4”), 133.76 (C-6, C-1”), 141.36 (C-2), 149.58 (C-4), 151.20 (C-2), 152.67 (C-8), 164.57 (Bz-C=O).

Drehwert: $[\alpha]_{\mathrm{D}}^{20}=-15.0\left(\mathrm{c}=1.0, \mathrm{CHCl}_{3}\right)$.

Schmelzpunkt: $70^{\circ} \mathrm{C}$.

IR (ATR): $\tilde{v}=$ 2926, 1685, 1609, 1580, 1447, 1250, 1070, 835, 779, 707.

UV (MeCN): $\lambda_{\max }(\lg \varepsilon)=223$ (3.86), 259 (3.48).

MS $\left(E S I^{+}\right): m / z=469.2[M+H]^{+}$. 
$\mathrm{C}_{23} \mathrm{H}_{32} \mathrm{~N}_{6} \mathrm{O}_{3} \mathrm{Si}(468.23)$

ber.: $469.2378[\mathrm{M}+\mathrm{H}]^{+}$

gef.: 469.2374 (ESI+-HRMS).

\subsubsection{2-N-Isobutyryl-2'-desoxyguanosin $142^{[163]}$}

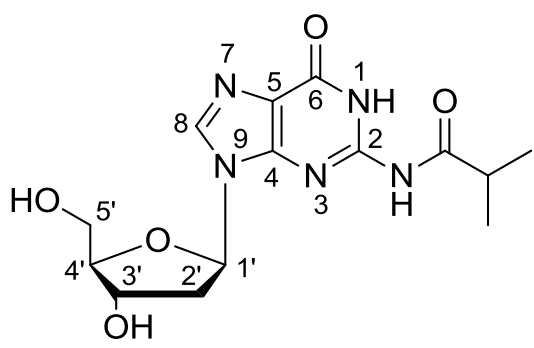

142

2'-Desoxyguanosin-monohydrat $(10.0 \mathrm{~g}, 35 \mathrm{mmol})$ wurde mit Pyridin coevaporiert $(3 \times 100 \mathrm{~mL})$ und anschließend in Pyridin $(170 \mathrm{~mL})$ suspendiert. Die Suspension wurde über einen Zeitraum von $10 \mathrm{~min}$ mit TMSCl (19.1 g, $175 \mathrm{mmol}, 22.4 \mathrm{~mL}$ ) versetzt und $15 \mathrm{~min}$ bei RT gerührt. Zur resultierenden Lösung wurde Isobuttersäureanhydrid $(27.7 \mathrm{~g}, 175 \mathrm{mmol}, 29.0 \mathrm{~mL}$ ) gegeben und die Lösung $3 \mathrm{~h}$ bei RT gerührt. Die Suspension wurde auf $0{ }^{\circ} \mathrm{C}$ gekühlt und dann mit Wasser $(35 \mathrm{~mL})$ versetzt und weitere 5 min gerührt. Es folgte die Zugabe einer $25 \%$ wässrigen Ammoniak-Lösung $(60 \mathrm{~mL})$. Die Lösung wurde weitere 30 min gerührt, wobei eine Erwärmung auf RT zugelassen wurde. Anschließend wurde das Lösungsmittel im Vakuum entfernt und der Rückstand chromatographisch an Kieselgel (DCM/MeOH $9: 1 \rightarrow 8: 2)$ gereinigt. Die gesammelten Fraktionen, die das Produkt enthielten, wurden zur Trockne eingeengt und der Rückstand in Wasser $(540 \mathrm{~mL})$ suspendiert. Die Suspension wurde unter Rühren auf ca $80^{\circ} \mathrm{C}$ erwärmt, sodass eine klare Lösung entstand. Nach Abkühlen der Lösung auf RT wurde der Niederschlag durch Filtration abgetrennt. Das Filtrat wurde mit $200 \mathrm{~mL} \mathrm{Et}_{2} \mathrm{O}$ überschichtet und über Nacht bei $5^{\circ} \mathrm{C}$ aufbewahrt. Der resultierende Niederschlag wurde wiederum abgetrennt und zum bereits bei der ersten Fällung erhaltenen Feststoff dazugegeben. Der erhaltene Feststoff wurde $12 \mathrm{~h}$ im Vakuum getrocknet.

Ausbeute: Es wurden $7.87 \mathrm{~g}(23.3 \mathrm{mmol}, 67 \%)$ eines weißen, feinpulvrigen Feststoffs erhalten.

DC: $R_{\mathrm{f}}(\mathrm{DCM} / \mathrm{MeOH} 8: 2)=0.43$. 
${ }^{1} \mathrm{H}-\mathrm{NMR}\left(300 \mathrm{MHz}\right.$, DMSO-d 6 ): $\delta=1.13\left(\mathrm{dd}, J=6.8 \mathrm{~Hz}, J=1.0 \mathrm{~Hz}, 6 \mathrm{H}, \mathrm{CH}_{3}\right), 2.28$ (ddd, $J=13.2 \mathrm{~Hz}, J=6.1 \mathrm{~Hz}, J=3.3 \mathrm{~Hz}, \quad 1 \mathrm{H}, 2^{\prime}-\mathrm{H}_{\mathrm{a}}$ ), 2.57 (ddd, $J=13.2 \mathrm{~Hz}$, $J=7.5 \mathrm{~Hz}, J=5.7 \mathrm{~Hz}, 1 \mathrm{H}, 2^{\prime}-\mathrm{H}_{\mathrm{b}}$ ), 2.78 (qq, $J=6.8 \mathrm{~Hz}, J=6.8 \mathrm{~Hz}, 1 \mathrm{H}, \mathrm{CH}\left(\mathrm{CH}_{3}\right)_{2}$ ), $3.52\left(\mathrm{dt}, J=11.7 \mathrm{~Hz}, J=4.8 \mathrm{~Hz}, 1 \mathrm{H}, 5^{\prime}-\mathrm{H}_{\mathrm{a}}\right.$ ), 3.58 (ddd, $J=11.7 \mathrm{~Hz}, J=4.8 \mathrm{~Hz}, 1 \mathrm{H}$, 5'- $\mathrm{H}_{\mathrm{b}}$ ), 3.85 (ddd, $J=4.8 \mathrm{~Hz}, J=4.8 \mathrm{~Hz}, J=2.8 \mathrm{~Hz}, 1 \mathrm{H}, 4^{\prime}-\mathrm{H}$ ), 4.38 (ddd, $J=3.7 \mathrm{~Hz}$, $J=3.3 \mathrm{~Hz}, J=2.8 \mathrm{~Hz}, 1 \mathrm{H}, 3^{\prime}-\mathrm{H}$ ), 4.92 (dd, $J=5.4 \mathrm{~Hz}, J=5.4 \mathrm{~Hz}, 1 \mathrm{H}, 5^{\prime}-\mathrm{OH}$ ), 5.28 (d, $\left.J=3.7 \mathrm{~Hz}, 1 \mathrm{H}, 3^{\prime}-\mathrm{OH}\right), 6.22\left(\mathrm{dd}, J=7.5 \mathrm{~Hz}, J=6.1 \mathrm{~Hz}, 1 \mathrm{H}, 1^{\prime}-\mathrm{H}\right), 8.23(\mathrm{~s}, 1 \mathrm{H}$, 8-H), 11.64 (brs, IBu-NH), 12.07 (brs, 1-NH).

${ }^{13} \mathrm{C}-N M R\left(75 \mathrm{MHz}, \mathrm{DMSO}-\mathrm{d}_{6}\right): \delta=19.32\left(\mathrm{CH}_{3}\right), 35.22\left(\underline{\mathrm{CH}}\left(\mathrm{CH}_{3}\right)_{2}\right), 39.93$ (C-2'), 61.96 (C-5'), 70.95 (C-3'), 83.41 (C-1'), 88.21 (C-4'), 120.66 (C-5), 137.84 (C-8), 148.54 (C-4), 148.84 (C-2), 155.30 (C-6), 180.57 (Pr-C=O).

Drehwert: $[\alpha]_{D}^{20}=-19.3(c=1.0$, Pyridin)

Schmelzpunkt: Zersetzung $>270^{\circ} \mathrm{C}$.

IR (ATR): $\tilde{v}=1704,1675,1600,1551,1212,1184,1156,1088,1055,1040$.

UV (MeCN): $\lambda_{\max }(\lg \varepsilon)=200$ (4.51), 257 (4.20), 283 (4.11).

MS $\left(\mathrm{ESI}^{+}\right): \mathrm{m} / \mathrm{z}=360.1[\mathrm{M}+\mathrm{Na}]^{+}$.

$\mathrm{C}_{14} \mathrm{H}_{19} \mathrm{~N}_{5} \mathrm{O}_{5} \mathrm{Si}$ (337.14)

ber.: $360.1282[\mathrm{M}+\mathrm{Na}]^{+}$

gef.: 360.1278 (ESI $\left.{ }^{+}-\mathrm{HRMS}\right)$.

\subsubsection{2-N-Isobutyryl-5'-O-TBDMS-2'-desoxyguanosin 99}

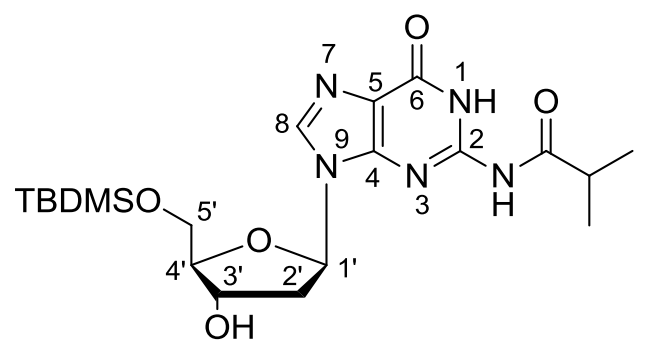

99

2- $N$-Isobutyryl-2'-desoxyguanosin $142(7.87 \mathrm{~g}, 23.4 \mathrm{mmol})$ wurde mit abs. Pyridin koevaporiert $(3 \times 40 \mathrm{~mL})$ und anschließend in abs. Pyridin $(50 \mathrm{~mL})$ suspendiert. Die Suspension wurde mit TBDMSCI (3.88 g, $25.7 \mathrm{mmol})$ versetzt und $16 \mathrm{~h}$ gerührt. Das Lösungsmittel wurde unter vermindertem Druck entfernt, der Rückstand in Dichlormethan $(300 \mathrm{~mL})$ aufgenommen und mit ges. $\mathrm{NaHCO}_{3}$-Lösung $(1 \times 150 \mathrm{~mL})$, Wasser $(1 \times 150 \mathrm{~mL})$ und ges. NaCl-Lösung $(1 \times 150 \mathrm{~mL})$ gewaschen. Die gesammelten wässrigen Phasen wurden mit $100 \mathrm{~mL}$ Dichlormethan reextrahiert. Die gereinigten organischen Phasen wurden über $\mathrm{Na}_{2} \mathrm{SO}_{4}$ getrocknet, filtriert und zur 
Trockne eingeengt. Der Rückstand wurde chromatographisch an Kieselgel (DCM/MeOH 9:1) gereinigt.

Ausbeute: Es wurden $9.39 \mathrm{~g}(20.8 \mathrm{mmol}, 89 \%)$ eines weißen Feststoffs erhalten.

DC: $R_{f}(\mathrm{DCM} / \mathrm{MeOH} 97: 3)=0.27$.

${ }^{1} \mathrm{H}-\mathrm{NMR}\left(300 \mathrm{MHz}, \mathrm{CDCl}_{3}\right): \delta=0.02\left(\mathrm{~s}, 6 \mathrm{H}, \mathrm{SiCH}_{3}\right), 0.83\left(\mathrm{~s}, 9 \mathrm{H}, \mathrm{SiC}\left(\mathrm{CH}_{3}\right)_{3}\right), 1.25$ (d, J = 6.8 Hz, $3 \mathrm{H}, \mathrm{CH}_{3 \mathrm{a}}$ ), 1.27 (d, J=6.8 Hz, $\left.3 \mathrm{H}, \mathrm{C}_{3 \mathrm{~b}}\right), 2.27-2.35$ (m, $2 \mathrm{H}, 2$ '- $\mathrm{H}$ ), 3.00 (qq, $J=6.8 \mathrm{~Hz}, J=6.8 \mathrm{~Hz}, 1 \mathrm{H}, \mathrm{CH}_{\mathrm{HCH}}$ ), 3.74-3.83 (m, $\left.2 \mathrm{H}, 5^{\prime}-\mathrm{H}\right)$, 4.05-4.09 (m, $\left.1 \mathrm{H}, 4^{\prime}-\mathrm{H}\right), 4.51-4.56\left(\mathrm{~m}, 1 \mathrm{H}, 3^{\prime}-\mathrm{H}\right), 4.75-4.81\left(\mathrm{~m}, 1 \mathrm{H}, 3^{\prime}-\mathrm{OH}\right), 5.98$ (dd, J = $6.5 \mathrm{~Hz}$, $J=6.5 \mathrm{~Hz}, 1 \mathrm{H}, 1^{\prime}-\mathrm{H}$ ), 8.03 (s, $\left.1 \mathrm{H}, 8-\mathrm{H}\right), 11.24$ (brs, iBu-NH), 12.47 (brs, 1-NH).

${ }^{13}$ C-NMR $\left(75 \mathrm{MHz}, \mathrm{CDCl}_{3}\right): \delta=-5.52\left(\mathrm{SiCH}_{3}\right),-5.44\left(\mathrm{SiCH}_{3}\right), 18.35\left(\mathrm{SiC}(\mathrm{CH})_{3}\right) 19.03$ $\left(\mathrm{CH}_{3 \mathrm{a}}\right), 19.10\left(\mathrm{CH}_{3 \mathrm{~b}}\right), 25.92\left(\mathrm{SiC}(\underline{\mathrm{CH}})_{3}\right), 36.05\left(\underline{\mathrm{CH}}\left(\mathrm{CH}_{3}\right)_{2}\right), 41.68\left(\mathrm{C}-2^{\prime}\right), 63.76\left(\mathrm{C}-5^{\prime}\right)$, 71.63 (C-3'), 84.37 (C-1'), 87.89 (C-4'), 120.45 (C-5), 137.43 (C-8), 148.33 (C-4), 148.72 (C-2), 156.35 (C-6), 180.69 (Pr-C=O).

Drehwert: $[\alpha]_{D}^{20}=+7.4\left(\mathrm{c}=1.0, \mathrm{CHCl}_{3}\right)$.

Schmelzpunkt: $138^{\circ} \mathrm{C}$.

IR (ATR): $\tilde{v}=1671,1605,1557,1470,1399,1250,1098,1070,831,779$.

UV (MeCN): $\lambda_{\max }(\lg \varepsilon)=200$ (4.48), 257 (4.18), 283 (4.10).

MS $\left(E S I^{+}\right): m / z=452.2[M+H]^{+}$.

$\mathrm{C}_{20} \mathrm{H}_{33} \mathrm{~N}_{5} \mathrm{O}_{5} \mathrm{Si}(451.23)$

ber.: $452.2323[\mathrm{M}+\mathrm{H}]^{+}$

gef.: 452.2324 (ESI+-HRMS).

\subsubsection{2-N-Isobutyryl-5'-O-TBDMS-2'-desoxy-3'-xylo-guanosin 101}

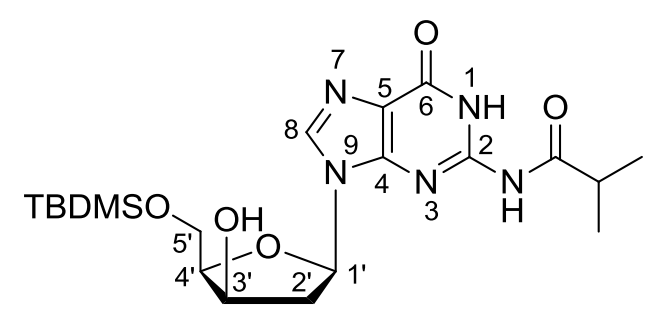

101

Eine Lösung von DMP $(2.82 \mathrm{~g}, 6.65 \mathrm{mmol})$ in $\mathrm{DCM}(40 \mathrm{~mL})$ wurde bei $0^{\circ} \mathrm{C}$ mit $\mathrm{N}$-2Isobutyryl-5'-O-TBDMS-2'-desoxyguanosin 99 (2.00 g, $4.43 \mathrm{mmol})$ versetzt und 20 min bei $0{ }^{\circ} \mathrm{C}$ gerührt. Die Reaktionslösung wurde auf Raumtemperatur gebracht und $7 \mathrm{~h}$ gerührt. Es wurden $\mathrm{iPrOH}(40 \mathrm{~mL})$ dazugegeben und die Lösung auf $-60^{\circ} \mathrm{C}$ gekühlt. Anschließend wurde fein gemörsertes $\mathrm{NaBH}_{4}$ (340 mg, $\left.8.99 \mathrm{mmol}\right)$ 
dazugegeben und die Reaktionslösung $16 \mathrm{~h}$ bei $-60^{\circ} \mathrm{C}$ gerührt. Die erhaltene Suspension wurde mit Aceton $(40 \mathrm{~mL})$ versetzt und in EtOAc $(300 \mathrm{~mL})$ aufgenommen. Die organische Phase wurde mit ges. $\mathrm{NaHCO}_{3}(2 \times 100 \mathrm{~mL})$ und ges. $\mathrm{NaCl}$-Lösung $(100 \mathrm{~mL})$ gewaschen. Die wässrigen Phasen wurden vereint und mit EtOAc $(100 \mathrm{~mL})$ reextrahiert. Die vereinigten organischen Phasen wurden bei vermindertem Druck zur Trockne eingeengt und der Rückstand chromatographisch an Kieselgel gereinigt (DCM/MeOH 95:5).

Ausbeute: Es wurden $1.60 \mathrm{~g}$ (3.55 mmol, 80\%) eines weißen Feststoffs erhalten.

DC: $R_{f}(\mathrm{DCM} / \mathrm{MeOH} 93: 7)=0.36$.

${ }^{1} \mathrm{H}-\mathrm{NMR}\left(300 \mathrm{MHz}, \mathrm{DMSO}-\mathrm{d}_{6}\right): \delta=0.03\left(\mathrm{~s}, 3 \mathrm{H}, \mathrm{SiCH}_{3}\right), 0.04\left(\mathrm{~s}, 3 \mathrm{H}, \mathrm{SiCH}_{3}\right), 0.86$ (s, $\left.9 \mathrm{H}, \quad \mathrm{SiC}\left(\mathrm{CH}_{3}\right)_{3}\right), 1.12\left(\mathrm{~d}, J=6.8 \mathrm{~Hz}, 3 \mathrm{H}, \mathrm{CHCH}_{3 \mathrm{a}}\right), 1.13(\mathrm{~d}, J=6.8 \mathrm{~Hz}, 3 \mathrm{H}$, $\mathrm{CHCH}_{3 b}$ ), 2.23-2.28 (m, $1 \mathrm{H}, 2^{\prime}-\mathrm{H}_{\mathrm{a}}$ ), 2.71 (ddd, $J=14.4 \mathrm{~Hz}, J=8.3 \mathrm{~Hz}, J=5.2 \mathrm{~Hz}$, $1 \mathrm{H}, 2^{\prime}-\mathrm{H}_{\mathrm{b}}$ ), 2.78 (qq, $J=6.8 \mathrm{~Hz}, J=6.8 \mathrm{~Hz}, 1 \mathrm{H}, \mathrm{CHCH}_{3}$ ), 3.78 (dd, $J=10.6 \mathrm{~Hz}$, $\left.J=6.3 \mathrm{~Hz}, 1 \mathrm{H}, 5^{\prime}-\mathrm{H}_{\mathrm{a}}\right)$, 3.94-4.01 (m, $\left.2 \mathrm{H}, 4^{\prime}-\mathrm{H}^{\prime}, 5^{\prime}-\mathrm{H}_{\mathrm{b}}\right), 4.36-4.40\left(\mathrm{~m}, 1 \mathrm{H}, 3^{\prime}-\mathrm{H}\right), 5.36$ (d, $\left.J=3.2 \mathrm{~Hz}, 1 \mathrm{H}, 3^{\prime}-\mathrm{OH}\right), 6.15$ (dd, $\left.J=8.3 \mathrm{~Hz}, J=1.9 \mathrm{~Hz}, 1 \mathrm{H}, 1^{\prime}-\mathrm{H}\right), 8.17(\mathrm{~s}, 1 \mathrm{H}$, 8-H), 11.69 (brs, iBu-NH), 12.07 (brs, 3-NH).

${ }^{13} \mathrm{C}$-NMR $(75 \mathrm{MHz}$, DMSO-d 6$): \delta=-4.82\left(\mathrm{SiCH}_{3}\right),-4.90\left(\mathrm{SiCH}_{3}\right), 18.48\left(\mathrm{SiC}\left(\mathrm{CH}_{3}\right)_{3}\right)$ $19.31\left(\mathrm{CH}_{3 \mathrm{a}}\right), 19.32\left(\mathrm{CH}_{3 \mathrm{~b}}\right), 26.27\left(\mathrm{SiC}\left(\underline{\mathrm{C}} \mathrm{H}_{3}\right)_{3}\right), 35.20\left(\underline{\mathrm{C}} \mathrm{HCH}_{3}\right), 41.51\left(\mathrm{C}-2^{\prime}\right), 62.56$ (C-5'), 69.31 (C-3'), 83.00 (C-1'), 85.84 (C-4'), 120.35 (C-5), 137.49 (C-8), 148.50 (C-4), 148.67 (C-2), $155.32(\mathrm{C}-6), 180.58$ ( $\mathrm{Pr}-\mathrm{C}=\mathrm{O})$.

Drehwert: $[\alpha]_{D}^{20}=-10.8\left(\mathrm{c}=0.99, \mathrm{CHCl}_{3}\right)$.

Schmelzpunkt: $67^{\circ} \mathrm{C}$.

IR (ATR): $\tilde{v}=1670,1604,1556,1399,1247,1093,1065,831,779$.

UV (MeCN): $\lambda_{\max }(\lg \varepsilon)=200$ (4.47), 253 (4.10), 283 (3.98).

MS $\left(\mathrm{ESI}^{+}\right): \mathrm{m} / \mathrm{z}=474.2[\mathrm{M}+\mathrm{Na}]^{+}$.

$\mathrm{C}_{20} \mathrm{H}_{33} \mathrm{~N}_{5} \mathrm{O}_{5} \mathrm{Si}(451.23)$ ber.: $474.2143[\mathrm{M}+\mathrm{Na}]^{+}$ gef.: 474.2146 (ESI+-HRMS). 


\subsubsection{3'-O-Mesyl-2-N-Isobutyryl-5'-O-TBDMS-2'-desoxy-3'-xylo-guanosin Ms-} $101^{[135]}$

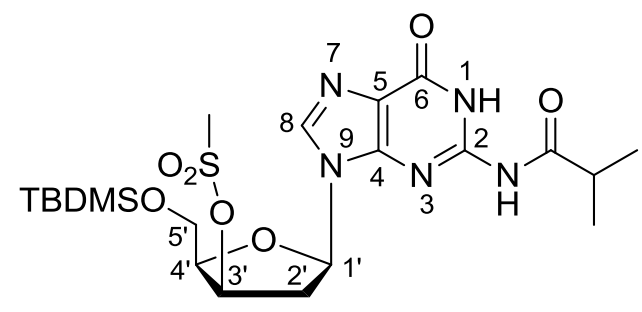

Ms-101

Eine Lösung von 6-N-Benzoyl-5'-O-TBDMS-2'-desoxy-3'-xylo-guanosin 101 (500 mg, $1.11 \mathrm{mmol}$ ) in Pyridin $\left(16 \mathrm{~mL}\right.$ ) wurde bei $0{ }^{\circ} \mathrm{C}$ langsam mit Methansulfon-säurechlorid (430 $\mathrm{L}, 630 \mathrm{mg}, 5.55 \mathrm{mmol}$ ) versetzt. Anschließend wurde die Reaktionslösung auf Raumtemperatur gebracht und $4 \mathrm{~h}$ gerührt. Die Reaktionslösung wurde in Dichlormethan $(100 \mathrm{~mL})$ aufgenommen und mit ges. $\mathrm{NaHCO}_{3}$-Lösung $(50 \mathrm{~mL})$ Wasser $(50 \mathrm{~mL})$ und ges. NaCl-Lösung $(50 \mathrm{~mL})$ gewaschen. Die organische Phase wurde über $\mathrm{Na}_{2} \mathrm{SO}_{4}$ getrocknet und zur Trockne eingeengt. Der ölige Rückstand wurde mit Toluol $(2 \times 4 \mathrm{~mL})$ und Dichlormethan $(10 \mathrm{~mL})$ koevaporiert und die Lösungsmittelreste mittels Hochvakuum entfernt. Das Produkt wurde ohne weitere Reinigung in der nachfolgenden Reaktion eingesetzt.

Ausbeute: $594 \mathrm{mg}$ eines verunreinigten, rotbraunen, zählfüssigen Öls (100\% Ausbeute: $527 \mathrm{mg}, 1.11 \mathrm{mmol}$ ).

${ }^{1} \mathrm{H}-\mathrm{NMR}\left(300 \mathrm{MHz}, \mathrm{CDCl}_{3}\right): \delta=0.06\left(\mathrm{~s}, 3 \mathrm{H}, \mathrm{SiCH}_{3}\right), 0.07$ (s, $\left.3 \mathrm{H}, \mathrm{SiCH}_{3}\right), 0.88$ (s, $\left.9 \mathrm{H}, \mathrm{SiC}\left(\mathrm{CH}_{3}\right)_{3}\right), 1.23$ (d, $\left.J=6.9 \mathrm{~Hz}, 6 \mathrm{H}, \mathrm{CHCH}_{3}\right), 2.75$ (qq, $J=6.8 \mathrm{~Hz}, J=6.8 \mathrm{~Hz}$, $1 \mathrm{H}, \mathrm{CH} \mathrm{CH}_{3}$ ), 2.84 (ddd, $J=15.7 \mathrm{~Hz}, J=8.4 \mathrm{~Hz}, J=5.5 \mathrm{~Hz}, 1 \mathrm{H}, 2^{\prime}-\mathrm{H}_{\mathrm{a}}$ ), $3.04(\mathrm{~s}, 3 \mathrm{H}$, $\mathrm{SO}_{2} \mathrm{CH}_{3}$ ), 3.09 (dd, $J=15.7 \mathrm{~Hz}, J=3.4 \mathrm{~Hz}, 1 \mathrm{H}, 2^{\prime}-\mathrm{H}_{\mathrm{b}}$ ), 3.90-3.94 (m, $\left.2 \mathrm{H}, 5^{\prime}-\mathrm{H}\right), 4.12$ (ddd, $J=6.5 \mathrm{~Hz}, J=6.5 \mathrm{~Hz}, J=3.4 \mathrm{~Hz}, 1 \mathrm{H}, 4^{\prime}-\mathrm{H}$ ), 5.27-5.30 (m, $1 \mathrm{H}, 3^{\prime}-\mathrm{H}$ ), 6.10 (dd, $\left.J=8.4 \mathrm{~Hz}, J=3.4 \mathrm{~Hz}, 1 \mathrm{H}, 1^{\prime}-\mathrm{H}\right), 7.86(\mathrm{~s}, 1 \mathrm{H}, 8-\mathrm{H}), 9.86$ (brs, iBu-NH), 12.12 (brs, $1-\mathrm{NH})$.

${ }^{13}$ C-NMR $\left(75 \mathrm{MHz}, \mathrm{CDCl}_{3}\right): \delta=-5.40\left(\mathrm{SiCH}_{3}\right),-5.36\left(\mathrm{SiCH}_{3}\right), 18.25\left(\mathrm{SiC}(\mathrm{CH})_{3}\right) 18.99$ $\left(\mathrm{CHCH}_{3 \mathrm{a}}\right), 19.32\left(\mathrm{CHCH}_{3 \mathrm{~b}}\right), 25.83\left(\mathrm{SiC}(\underline{\mathrm{CH}})_{3}\right), 36.22\left(\underline{\mathrm{CHCH}}_{3}\right), 38.32\left(\mathrm{SO}_{2} \mathrm{CH}_{3}\right)$, 38.59 (C-2'), 60.03 (C-5'), 79.36 (C-3'), 82.30 (C-4'), 83.61 (C-1'), 121.54 (C-5), 138.00 (C-8), 147.87 (C-4), 148.22 (C-2), 155.79 (C-6), 179.46 (IPr-C=O). 
Diese Verbindung wurde nicht chromatographisch gereinigt und enthielt daher Verunreinigungen. Aus diesem Grund wurde auf die Charakterisierung mittels weiterer analytischer Methoden verzichtet.

\subsubsection{3'-Azido-2-N-Isobutyryl-5'-O-TBDMS-2',3'-didesoxyguanosin 103}

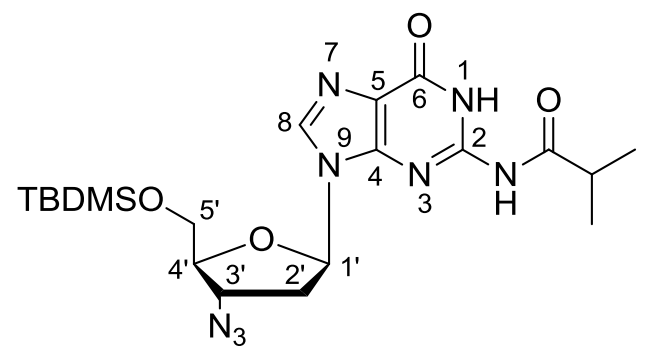

103

Variante $1:[137]$

Eine Suspension von $101(30 \mathrm{mg}, 67 \mu \mathrm{mol})$ und $\mathrm{NaN}_{3}(13 \mathrm{mg}, 0.20 \mathrm{mmol})$ in abs. DMF (0.2 mL) wurde mit einer Lösung von DIAD (20 mg, $0.10 \mathrm{mmol})$ und Dipenyl-2pyridylphosphin $(26 \mathrm{mg}, \quad 0.10 \mathrm{mmol})$ in DMF $(0.1 \mathrm{~mL})$ versetzt und $4 \mathrm{~h}$ bei Raumtemperatur gerührt. Das Reaktionsgemisch wurde mit Wasser $(0.1 \mathrm{~mL})$ versetzt und in Ethylacetat $(5 \mathrm{~mL})$ aufgenommen. Die Phasen wurden getrennt und die organische Phase mit Wasser $(5 \mathrm{~mL})$ und ges. wässriger $\mathrm{NaCl}(5 \mathrm{~mL})$ gewaschen. Die organische Phase wurde über $\mathrm{Na}_{2} \mathrm{SO}_{4}$ getrocknet, filtriert und bei vermindertem Druck eingeengt. Der ölige Rückstand wurde chromatographisch an Kieselgel gereinigt (DCM/EtOAc 2:3). Es konnte kein Produkt isoliert werden.

\section{Variante $2:^{[134]}$}

Eine Lösung von 101 (30 mg, $67 \mu \mathrm{mol})$ in $0.34 \mathrm{~mL}$ abs. DMF wurde mit LiN $\mathrm{L}_{3}(10 \mathrm{mg}$, $0.20 \mathrm{mmol}), \mathrm{PPh}_{3}(26 \mathrm{mg}, 0.10 \mathrm{mmol})$ und DIAD $(20 \mathrm{mg}, 0.10 \mathrm{mmol})$ versetzt und $5 \mathrm{~h}$ bei RT gerührt. Das Reaktionsgemisch wurde mit $0.1 \mathrm{~mL}$ dest. Wasser versetzt und in $5 \mathrm{~mL}$ Ethylacetat aufgenommen. Die Phasen wurden getrennt und die organische Phase mit Wasser $(5 \mathrm{~mL})$ und ges. wässriger $\mathrm{NaCl}(5 \mathrm{~mL})$ gewaschen. Die organische Phase wurde über $\mathrm{Na}_{2} \mathrm{SO}_{4}$ getrocknet, filtriert und bei vermindertem Druck eingeengt. Der ölige Rückstand wurde chromatographisch an Kieselgel gereinigt (DCM/MeOH 97:3). Es konnte kein Produkt isoliert werden. 
Ausbeute: Es wurden $15 \mathrm{mg}$ eines gelben Öls erhalten (100\% Ausbeute: $32 \mathrm{mg}$, $67 \mu \mathrm{mol})$. Anhand von NMR-spektroskopischen Untersuchungen wurde nachgewiesen, dass die erhaltene Verbindung stark durch $\mathrm{PPh}_{3}$ verunreinigt war.

\section{Variante 3:[168]}

Eine Lösung von 101 (360 mg, $0.798 \mathrm{mmol})$ und $\mathrm{PPh}_{3}(314 \mathrm{mg}, 1.20 \mathrm{mmol})$ in abs. THF (3 mL) wurde bei $0{ }^{\circ} \mathrm{C}$ mit einer Lösung von DPPA (269 $\mu \mathrm{L}, 330 \mathrm{mg}, 1.20 \mathrm{mmol}$ ) und DIAD (235 $\mu \mathrm{L}, 242 \mathrm{mg}, 1.20 \mathrm{mmol})$ in abs THF ( $2 \mathrm{~mL})$ versetzt. Anschließend wurde ein Erwärmen der Reaktionslösung auf RT zugelassen und für weitere $5 \mathrm{~h}$ gerührt. Es wurden Ethanol $(1.5 \mathrm{~mL})$ dazugegeben und die Lösung weitere $30 \mathrm{~min}$ gerührt. Das Reaktionsgemisch wurde in Ethylacetat $(50 \mathrm{~mL})$ aufgenommen, mit dest Wasser $(50 \mathrm{~mL})$ und ges. wässriger $\mathrm{NaCl}(50 \mathrm{~mL})$ gewaschen, über $\mathrm{Na}_{2} \mathrm{SO}_{4}$ getrocknet, filtriert und bei vermindertem Druck eingeengt. Der ölige Rückstand wurde chromatographisch an Kieselgel gereinigt (DCM/MeOH 97:3).

Ausbeute: Es wurden $150 \mathrm{mg}$ eines gelben Öls erhalten (100\% Ausbeute: $379 \mathrm{mg}$, $0.798 \mathrm{mmol}$ ). Anhand von NMR-spektroskopischen Untersuchungen wurde nachgewiesen, dass die erhaltene Verbindung verunreinigt war (enthielt ca $30 \%$ Edukt und vermutlich aus dem DIAD gebildete Hydrazinderivate).

\section{Variante $4:[131-132]$}

Eine Lösung von 101 (50 mg, $0.11 \mathrm{mmol}$ ) in einem 10:1-Gemischs aus abs. DCM und abs. Pyridin $(1.1 \mathrm{~mL})$ wurde auf $-30^{\circ} \mathrm{C}$ heruntergekühlt und mit einer Lösung von $\mathrm{Tf}_{2} \mathrm{O}(22 \mu \mathrm{L}, \quad 34 \mathrm{mg}, \quad 0.12 \mathrm{mmol})$ in abs. $\mathrm{DCM}(0.22 \mathrm{~mL})$ versetzt. Die Reaktionsmischung wurde auf RT erwärmt und weitere 15 min gerührt. Anschließend wurde eine Lösung von $\mathrm{LiN}_{3}$ (54 mg, $1.11 \mathrm{mmol}$ ) in abs. DMF (1 mL) dazugegeben. Die resultierende Lösung wurde $2 \mathrm{~h}$ bei Raumtemperatur gerührt und anschließend in ein Gemisch aus DCM (30 mL) und Wasser (10 mL) überführt. Die Phasen wurden getrennt und die organische Phase mit Wasser $(2 \times 10 \mathrm{~mL})$ gewaschen, über $\mathrm{Na}_{2} \mathrm{SO}_{4}$ getrocknet, filtriert und eingeengt. Der Rückstand wurde chromatographisch an Kieselgel gereinigt (DCM/MeOH 97:3). Es konnte kein Produkt isoliert werden.

\section{Variante $5:^{[133]}$}

101 (30 mg, $67 \mu \mathrm{mol})$ und $\mathrm{LiN}_{3}(33 \mathrm{mg}, 0.67 \mathrm{mmol}$ ) wurden mit abs. Toluol coevaporiert $(3 \times 1 \mathrm{~mL})$ und in abs. DMF $(0.2 \mathrm{~mL})$ gelöst. Es wurden 
Tetrabrommethan (44 mg, $0.13 \mathrm{mmol}$ ) und $\mathrm{PPh}_{3}(35 \mathrm{mg}, 0.13 \mathrm{mmol}$ ) dazugegeben. Die resultierende Lösung wurde $24 \mathrm{~h}$ bei RT gerührt. Es konnte per Dünnschichtchromatographie (DCM/MeOH 93:7) nur Zersetzung des Edukts nachgewiesen werden.

\section{Variante $6:^{[135]}$}

Eine Suspension von 3'-O-Mesyl-6-N-Benzoyl-5'-O-TBDMS-2'-desoxy-3'-xyloguanosin Ms-101 (587 mg, $1.11 \mathrm{mmol}$ ) und $\mathrm{NaN}_{3}$ (650 mg, $10.0 \mathrm{mmol}$ ) in DMF (16 mL) wurde $1.5 \mathrm{~h}$ bei $110^{\circ} \mathrm{C}$ gerührt. Nach Abkühlen auf Raumtemperatur wurde die Lösung in Ethylacetat $(100 \mathrm{~mL})$ aufgenommen und mit ges. $\mathrm{NaHCO}_{3}$-Lösung $(2 \times 50 \mathrm{~mL})$, Wasser $(2 \times 50 \mathrm{~mL})$ und ges. NaCl-Lösung $(1 \times 50 \mathrm{~mL})$ gewaschen. Die organische Phase wurde über $\mathrm{Na}_{2} \mathrm{SO}_{4}$ getrocknet und bei vermindertem Druck zur Trockne eingeengt. Der Rückstand wurde chromatographisch an Kieselgel (DCM/MeOH 97:3) gereinigt.

Ausbeute: Es wurden $363 \mathrm{mg}(0.686 \mathrm{mmol}, 69 \%)$ eines farblosen, hochviskosen Öls erhalten.

DC: $R_{f}(\mathrm{DCM} / \mathrm{MeOH} 97: 3)=0.29$.

${ }^{1} \mathrm{H}-\mathrm{NMR}\left(300 \mathrm{MHz}, \mathrm{CDCl}_{3}\right): \delta=0.07\left(\mathrm{~s}, 3 \mathrm{H}, \mathrm{SiCH}_{3}\right), 0.08\left(\mathrm{~s}, 3 \mathrm{H}, \mathrm{SiCH}_{3}\right), 0.89$ (s, $\left.9 \mathrm{H}, \quad \mathrm{SiC}\left(\mathrm{CH}_{3}\right)_{3}\right), 1.25\left(\mathrm{~d}, J=6.1 \mathrm{~Hz}, 3 \mathrm{H}, \mathrm{CHCH}_{3 \mathrm{a}}\right), 1.27(\mathrm{~d}, J=6.1 \mathrm{~Hz}, 3 \mathrm{H}$, $\mathrm{CHCH}_{3 b}$ ), 2.46 (ddd, $J=13.4 \mathrm{~Hz}, J=6.2 \mathrm{~Hz}, J=5.3 \mathrm{~Hz}, 1 \mathrm{H}, 2^{\prime}-\mathrm{H}_{\mathrm{a}}$ ), 2.63 (ddd, $J=13.4 \mathrm{~Hz}, J=6.7 \mathrm{~Hz}, J=6.7 \mathrm{~Hz}, 1 \mathrm{H}, 2^{\prime}-\mathrm{H}_{\mathrm{b}}$ ), 2.75 (qq, $J=6.9 \mathrm{~Hz}, J=6.9 \mathrm{~Hz}, 1 \mathrm{H}$, $\left.\mathrm{CHCH}_{3}\right), 3.81\left(\mathrm{dd}, J=11.4 \mathrm{~Hz}, J=3.2 \mathrm{~Hz}, 1 \mathrm{H}, 5^{\prime}-\mathrm{H}_{\mathrm{a}}\right), 3.85(\mathrm{dd}, J=11.4 \mathrm{~Hz}$, $\left.J=3.8 \mathrm{~Hz}, 1 \mathrm{H}, 5^{\prime}-\mathrm{H}_{\mathrm{b}}\right), 4.00-4.03\left(\mathrm{~m}, 1 \mathrm{H}, 4^{\prime}-\mathrm{H}\right), 4.38$ (ddd, $J=6.7 \mathrm{~Hz}, J=4.9 \mathrm{~Hz}$, $\left.J=4.9 \mathrm{~Hz}, 1 \mathrm{H}, 3^{\prime}-\mathrm{H}\right), 6.12\left(\mathrm{dd}, J=6.2 \mathrm{~Hz}, J=6.2 \mathrm{~Hz}, 1 \mathrm{H}, 1^{\prime}-\mathrm{H}\right), 7.96(\mathrm{~s}, 1 \mathrm{H}, 8-\mathrm{H})$, 9.18 (brs, BBu-NH), 12.11 (brs, 1-NH).

${ }^{13} \mathrm{C}$-NMR $\left(75 \mathrm{MHz}, \mathrm{CDCl}_{3}\right): \delta=-5.54\left(\mathrm{SiCH}_{3}\right),-5.40\left(\mathrm{SiCH}_{3}\right), 18.37\left(\mathrm{Si} \underline{\mathrm{C}}(\mathrm{CH})_{3}\right) 18.95$ $\left(\mathrm{CH}_{3 \mathrm{a}}\right), 19.01\left(\mathrm{CH}_{3 \mathrm{~b}}\right), 25.90\left(\mathrm{SiC}(\underline{\mathrm{CH}})_{3}\right), 36.41\left(\underline{\mathrm{CH}}\left(\mathrm{CH}_{3}\right)_{2}\right), 38.33\left(\mathrm{C}-2^{\prime}\right), 60.53\left(\mathrm{C}-3^{\prime}\right)$, 62.89 (C-5'), 83.70 (C-1'), 84.98 (C-4'), 121.40 (C-5), 136.66 (C-8), 147.73 (C-4), $147.79(\mathrm{C}-2), 155.61(\mathrm{C}-6), 178.81(\mathrm{Pr}-\mathrm{C}=\mathrm{O})$.

Drehwert: $[\alpha]_{D}^{20}=+5.4\left(\mathrm{c}=1.0, \mathrm{CHCl}_{3}\right)$.

IR (ATR): $\tilde{v}=2100,1671,1605,1557,1251,1093,1070,836,779$.

UV $(\mathrm{MeCN}): \lambda_{\max }(\lg \varepsilon)=200$ (4.83), 254 (4.51), 283 (4.40).

MS $\left(E S I^{+}\right): m / z=499.2[\mathrm{M}+\mathrm{Na}]^{+}$. 
$\mathrm{C}_{20} \mathrm{H}_{32} \mathrm{~N}_{8} \mathrm{O}_{4} \mathrm{Si}(476.60)$

ber.: $499.2208[\mathrm{M}+\mathrm{Na}]^{+}$

gef.: 499.2202 (ESI+-HRMS).

\subsubsection{3'-Amino-2-N-Isobutyryl-5'-O-TBDMS-2',3'-didesoxyguanosin 92}

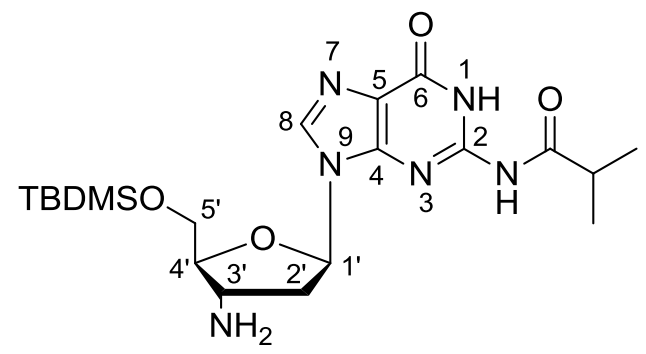

92

Eine Lösung von 3'-Azido-2-N-Isobutyryl-5'-O-TBDMS-2',3'-didesoxyguanosin 103 $(2.34 \mathrm{~g}, 4.91 \mathrm{mmol})$ in Methanol $(150 \mathrm{~mL})$ wurde mit Palladium $(520 \mathrm{mg}, 0.49 \mathrm{mmol}$, $10 \%$ auf Aktivkohle) versetzt und $20 \mathrm{~h}$ unter einer Wasserstoff-Atmosphäre (1 bar) gerührt. Die Suspension wurde durch Filtration über Celite ${ }^{\circledR}$ vom PalladiumKatalysator berfreit und das Filtrat bei vermindertem Druck zur Trockne eingeengt.

Ausbeute: Es wurden $2.03 \mathrm{~g}$ (4.51 mmol, 92\%) eines weißen Feststoffs erhalten.

DC: $R_{f}(\mathrm{DCM} / \mathrm{MeOH} 9: 1)=0.27$.

${ }^{1} \mathrm{H}-\mathrm{NMR}(300 \mathrm{MHz}, \mathrm{MeOD}): \delta=0.08\left(\mathrm{~s}, 3 \mathrm{H}, \mathrm{SiCH}_{3}\right), 0.09\left(\mathrm{~s}, 3 \mathrm{H}, \mathrm{SiCH}_{3}\right), 0.90$ (s, $\left.9 \mathrm{H}, \quad \mathrm{SiC}\left(\mathrm{CH}_{3}\right)_{3}\right), 1.24\left(\mathrm{~s}, 3 \mathrm{H}, \mathrm{CHCH}_{3 \mathrm{a}}\right), 1.25$ (s, $\left.3 \mathrm{H}, \mathrm{CHCH}_{3 \mathrm{~b}}\right), 2.40$ (ddd, $J=13.5 \mathrm{~Hz}, J=7.7 \mathrm{~Hz}, J=7.2 \mathrm{~Hz}, 1 \mathrm{H}, 2^{\prime}-\mathrm{H}_{\mathrm{a}}$ ), 2.69 (ddd, $J=13.5 \mathrm{~Hz}, J=7.3 \mathrm{~Hz}$, $J=3.5 \mathrm{~Hz}, 1 \mathrm{H}, 2^{\prime}-\mathrm{H}_{\mathrm{b}}$ ), 2.74 (qq, $J=6.9 \mathrm{~Hz}, J=6.9 \mathrm{~Hz}, 1 \mathrm{H}, \mathrm{CHCH}_{3}$ ), 3.79 (ddd, $J=7.7 \mathrm{~Hz}, J=7.3 \mathrm{~Hz}, J=6.9 \mathrm{~Hz}, 1 \mathrm{H}, 3^{\prime}-\mathrm{H}$ ), 3.84 (ddd, $J=6.9 \mathrm{~Hz}, J=3.4 \mathrm{~Hz}$, $J=3.2 \mathrm{~Hz}, 1 \mathrm{H}, 4^{\prime}-\mathrm{H}$ ), 3.89 (dd, $J=11.4 \mathrm{~Hz}, J=3.4 \mathrm{~Hz}, 1 \mathrm{H}, 5^{\prime}-\mathrm{H}_{\mathrm{a}}$ ), 3.95 (dd, $\left.J=11.4 \mathrm{~Hz}, J=3.2 \mathrm{~Hz}, 1 \mathrm{H}, 5^{\prime}-\mathrm{H}_{\mathrm{b}}\right), 6.29\left(\mathrm{dd}, J=7.2 \mathrm{~Hz}, J=3.5 \mathrm{~Hz}, 1 \mathrm{H}, 1^{\prime}-\mathrm{H}\right), 8.19$ (s, $1 \mathrm{H}, 8-\mathrm{H})$.

${ }^{13} \mathrm{C}-\mathrm{NMR}(75 \mathrm{MHz}, \mathrm{MeOD}): \delta=-6.67\left(\mathrm{SiCH}_{3}\right), 17.90\left(\mathrm{Si} \underline{\mathrm{C}}(\mathrm{CH})_{3}\right) 17.93\left(\mathrm{CH}_{3 \mathrm{a}}\right), 17.99$ $\left(\mathrm{CH}_{3 b}\right), 25.07\left(\mathrm{SiC}(\underline{\mathrm{CH}})_{3}\right), 36.56\left(\underline{\mathrm{C}} \mathrm{H}\left(\mathrm{CH}_{3}\right)_{2}\right), 40.77$ (C-2'), 50.50 (C-3'), 62.57 (C-5'), 83.98 (C-1'), 87.54 (C-4'), 120.05 (C-5), 137.91 (C-8), 148.23 (C-4), 148.50 (C-2), 156.15 (C-6), 180.31 ( $\mathrm{Pr}-\mathrm{C}=\mathrm{O})$.

Drehwert: $[\alpha]_{D}^{20}=+4.3(\mathrm{c}=1.0, \mathrm{MeOH})$.

Schmelzpunkt: Zersetzung $>170^{\circ} \mathrm{C}$. 
IR (ATR): $\tilde{v}=1676,1614,1566,1470,1399,1251,1070,836,779$.

UV (MeCN): $\lambda_{\max }(\lg \varepsilon)=200$ (4.53), 255 (4.24), 282 (4.09).

MS $\left(E S I^{+}\right): m / z=451.2[M+H]^{+}$.

$\mathrm{C}_{20} \mathrm{H}_{34} \mathrm{~N}_{6} \mathrm{O}_{4} \mathrm{Si}(450.61)$

ber.: $451.2484[\mathrm{M}+\mathrm{H}]^{+}$

gef.: 451.2478 (ESI $\left.{ }^{+}-H R M S\right)$.

\subsubsection{Dimere}

\subsubsection{1 (5'"-O-TBDMS-3"'-aminothymidinyl)-(6'-N-Fmoc-3'-O-TBDMS)-(S)-TAA-} amid 74

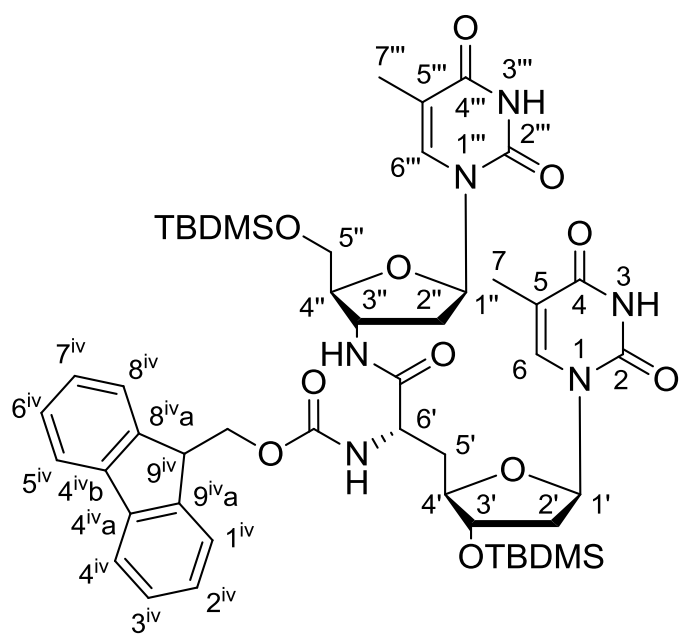

(6'S)-74

Die Synthese der Verbindung (6'S)-74 erfolgte gemäß AAV 1 (7.1.7.1). Es wurden $190 \mathrm{mg}$ (0.299 mmol) TAA (6'S)-73, $3 \mathrm{~mL}$ DCM, $46.8 \mathrm{~g}$ (346 $\mu \mathrm{mol}) \mathrm{HOBt}, 68.3 \mathrm{~g}$

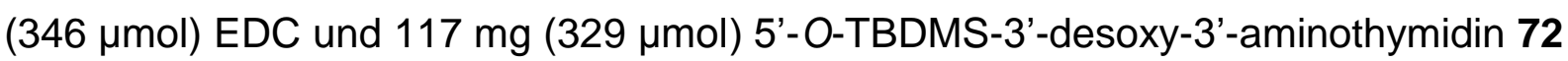
$(117 \mathrm{mg}, \quad 0.329 \mathrm{mmol})$ eingesetzt. Das so erhaltene Rohprodukt wurde chromatographisch an Kieselgel gereinigt (PE/EtOAc 1:2).

Ausbeute: $230 \mathrm{mg}(0.236 \mathrm{mmol}, 79 \%)$ eines weißen Feststoffs.

DC: $R_{\mathrm{f}}(\mathrm{DCM} / \mathrm{MeOH} 12: 1)=0.40$.

${ }^{1} \mathrm{H}-\mathrm{NMR}\left(300 \mathrm{MHz}, \mathrm{C}_{6} \mathrm{D}_{6}, 70^{\circ} \mathrm{C}\right): \delta=0.01-0.12\left(\mathrm{~m}, 10 \mathrm{H}, \mathrm{SiCH}_{3}\right), 0.92(\mathrm{~s}, 18 \mathrm{H}$, $\left.\operatorname{SiC}\left(\mathrm{CH}_{3}\right)_{3}\right), 1.96(\mathrm{~d}, J=0.9 \mathrm{~Hz}, 3 \mathrm{H}, 7$ '”- $\mathrm{H}), 1.98(\mathrm{~s}, 3 \mathrm{H}, 7-\mathrm{H}), 2.03-2.24(\mathrm{~m}, 4 \mathrm{H}$,

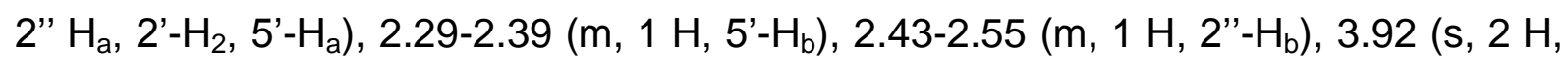
5"-H), 3.97-4.04 (m, 1 H, 4'-H), 4.10-4.19 (m, $2 \mathrm{H}, \mathrm{FmocCH}_{2}, 3$ '-H), 4.20-4.26 (m, $1 \mathrm{H}, 4$ "'- $\mathrm{H}), 4.12\left(\mathrm{~d}, J=7.0 \mathrm{~Hz}, 2 \mathrm{H}, 9^{\mathrm{iv}}-\mathrm{H}\right), 4.56-4.65(\mathrm{~m}, 1 \mathrm{H}, 3$ "'-H), 4.81 (dd, $\left.J=13.3 \mathrm{~Hz}, J=7.1 \mathrm{~Hz}, 1 \mathrm{H}, 6^{\prime}-\mathrm{H}\right), 6.06\left(\mathrm{dd}, J=6.7 \mathrm{~Hz}, J=6.7 \mathrm{~Hz}, 1 \mathrm{H}, 1^{\prime}-\mathrm{H}\right), 6.33$ 
(d, $\left.J=7.1 \mathrm{~Hz}, 1 \mathrm{H}, 6^{\prime}-\mathrm{NH}\right), 6.45$ (dd, $J=7.8 \mathrm{~Hz}, J=5.7 \mathrm{~Hz}, 1 \mathrm{H}, 1$ ''-H), $6.97(\mathrm{~s}, 1 \mathrm{H}$, 6-H), 7.16-7.23 (m, $4 \mathrm{H}, \mathrm{ArH}), 7.54(\mathrm{~d}, J=0.9 \mathrm{~Hz}, 1 \mathrm{H}, 6$ '"'-H), 7.49-7.62 (m, $4 \mathrm{H}$, ArH), 8.10 (d, $J=5.8 \mathrm{~Hz}, 1 \mathrm{H}, 3$ "'-NH), 10.42 (brs, $2 \mathrm{H}, 3-\mathrm{NH}, 3$ "'-NH).

${ }^{13} \mathrm{C}$-NMR $\quad\left(75 \mathrm{MHz}, \quad \mathrm{C}_{6} \mathrm{D}_{6}, \quad 70^{\circ} \mathrm{C}\right): \quad \delta=-5.29 \quad\left(\mathrm{SiCH}_{3}\right), \quad-5.26 \quad\left(\mathrm{SiCH}_{3}\right), \quad-4.58$ $\left(\mathrm{SiCH}_{3}\right), \quad-4.49\left(\mathrm{SiCH}_{3}\right), 12.53$ (C-7), 12.70 (C-7'”), $18.15\left(\mathrm{Si} \underline{\mathrm{C}}\left(\mathrm{CH}_{3}\right)_{3}\right), 18.56$ $\left(\mathrm{Si} \underline{\mathrm{C}}\left(\mathrm{CH}_{3}\right)_{3}\right), 26.00\left(\mathrm{SiC}\left(\underline{\mathrm{C}} \mathrm{H}_{3}\right)_{3}\right), 26.19\left(\mathrm{SiC}\left(\underline{\mathrm{CH}}_{3}\right)_{3}\right), 36.96$ (C-5'), 37.91 (C-2'), 39.74 (C-2"), 47.93 (9iv-C), 51.75 (C-3"), 64.55 (C-5"), $67.51\left(\mathrm{FmocCH}_{2}\right), 76.05$ (C-3'), 83.68 (C-4'), 85.67 (C-4"), 86.58 (C-1'), 87.22 (C-1'), 111.28 (C-5), 111.46 (C-5'”), $120.21\left({\mathrm{C}-4^{\mathrm{iv}}}^{\mathrm{N}}, \mathrm{C}-5^{\mathrm{iv}}\right), 125.52,125.55\left(\mathrm{C}-1^{\mathrm{iv}}, \mathrm{C}-8^{\mathrm{iv}}\right), 127.39\left(\mathrm{C}-3^{\mathrm{iv}}, \mathrm{C}-6^{\mathrm{iv}}\right), 127.90\left(\mathrm{C}-2^{\mathrm{iv}}\right.$,

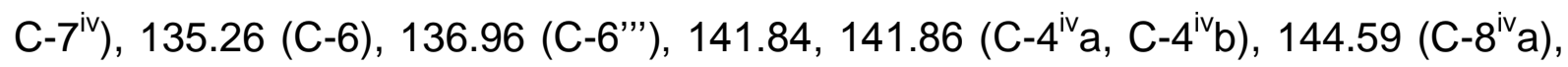
144.63 (C-9iva), 151.05 (C-2), 151.47 (C-2'”), 156.42 (Fmoc-C=O), 164.25 (C-4), 164.37 (C-4"'), 171.66 (3“-Amid-C=O).

Drehwert: $[\alpha]_{D}^{20}=+9.5\left(\mathrm{c}=1.1, \mathrm{CHCl}_{3}\right)$.

Schmelzpunkt: $140{ }^{\circ} \mathrm{C}$.

IR $(\mathrm{KBr}): \tilde{v}=2954,1692,1470,1362,1126,835,779,740,557$.

UV (MeCN): $\lambda_{\max }(\lg \varepsilon)=205$ (4.79), 264 (4.54), 299 (3.75).

MS $\left(\mathrm{ESI}^{+}\right): \mathrm{m} / \mathrm{z}=995.4[\mathrm{M}+\mathrm{Na}]^{+}$.

$\mathrm{C}_{49} \mathrm{H}_{68} \mathrm{~N}_{6} \mathrm{O}_{11} \mathrm{Si}_{2}$ (973.26)

ber.: $995.4382[\mathrm{M}+\mathrm{Na}]^{+}$, gef.: $995.4372\left(\mathrm{ESI}^{+}-\mathrm{HRMS}\right)$.

\subsubsection{2 (5"'-O-TBDMS-3"'-aminothymidinyl)-(6'-N-Fmoc-3'-O-TBDMS)-(R)-TAA-} amid 74

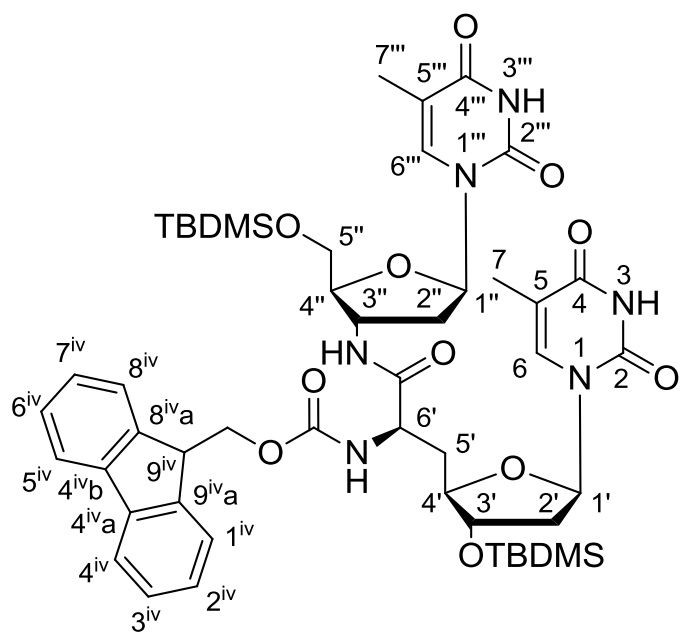

$\left(6^{\prime} R\right)-74$

Die Synthese von (6'R)-74 erfolgte gemäß AAV 1 (7.1.7.1). Es wurden $150 \mathrm{mg}$ $(0.236 \mathrm{mmol})$ TAA $\left(6^{\prime} R\right)-73,35 \mathrm{mg}(260 \mu \mathrm{mol}) \mathrm{HOBt}, 51 \mathrm{mg}(258 \mu \mathrm{mol})$ EDC, $92 \mathrm{mg}$ 
(0.26 mmol) 5'-O-(TBDMS)-3'-desoxy-3'-aminothymidin 72 und $3 \mathrm{~mL} \quad$ DCM eingesetzt. Als Eluent für die chromatographische Reinigung wurde ein Gemisch aus $\mathrm{PE} / \mathrm{EtOAc}(1: 2)$ verwendet.

Ausbeute: $180 \mathrm{mg}(0.185 \mathrm{mmol}, 78 \%)$ eines weißen Feststoffs.

DC: $R_{\mathrm{f}}(\mathrm{DCM} / \mathrm{MeOH} 12: 1)=0.40$.

${ }^{1} \mathrm{H}-\mathrm{NMR}\left(300 \mathrm{MHz}, \mathrm{C}_{6} \mathrm{D}_{6}, 70^{\circ} \mathrm{C}\right): \delta=0.02\left(\mathrm{~s}, 3 \mathrm{H}, \mathrm{SiCH}_{3}\right), 0.04\left(\mathrm{~s}, 3 \mathrm{H}, \mathrm{SiCH}_{3}\right), 0.07$ (s, $\left.3 \mathrm{H}, \mathrm{SiCH}_{3}\right), 0.08$ (s, $\left.3 \mathrm{H}, \mathrm{SiCH}_{3}\right), 0.88\left(\mathrm{~s}, 9 \mathrm{H}, \mathrm{SiC}\left(\mathrm{CH}_{3}\right)_{3}\right), 0.94(\mathrm{~s}, 9 \mathrm{H}$, $\left.\mathrm{SiC}\left(\mathrm{CH}_{3}\right)_{3}\right), 1.79$ (d, J = 1.0 Hz, 3 H, 7'”-H), 1.84-1.97 (m, $\left.2 \mathrm{H}, 2^{\prime}-\mathrm{H}_{\mathrm{a}}, 5^{\prime}-\mathrm{H}_{\mathrm{a}}\right), 1.87$ (d, $J=1.2 \mathrm{~Hz}, 3 \mathrm{H}, 7-\mathrm{H}$ ), 2.03-2.18 (m, $1 \mathrm{H}, 2^{\prime \prime}-\mathrm{H}_{\mathrm{a}}$ ), 2.32 (ddd, $J=14.2 \mathrm{~Hz}, J=11.2 \mathrm{~Hz}$, $J=2.9 \mathrm{~Hz}, 1 \mathrm{H}, 5^{\prime}-\mathrm{H}_{\mathrm{b}}$ ), 2.48 (ddd, $J=6.3 \mathrm{~Hz}, J=5.3 \mathrm{~Hz}, J=1.4 \mathrm{~Hz}, 1 \mathrm{H}, 2^{\prime}{ }^{\prime}-\mathrm{H}_{\mathrm{b}}$ ), 2.66 (ddd, $J=13.3 \mathrm{~Hz}, \quad J=7.3 \mathrm{~Hz}, J=6.1 \mathrm{~Hz}, \quad 1 \mathrm{H}, \quad 2^{\prime}-\mathrm{H}_{\mathrm{b}}$ ), 3.72 (dd, $J=11.4 \mathrm{~Hz}$, $J=2.0 \mathrm{~Hz}, 1 \mathrm{H}, 5$ "'- $\mathrm{H}_{\mathrm{a}}$ ), 3.81 (dd, $J=11.4 \mathrm{~Hz}, J=2.0 \mathrm{~Hz}, 1 \mathrm{H}, 5$ "'- $\mathrm{H}_{\mathrm{b}}$ ), 4.06 (dd, $J=4.2 \mathrm{~Hz}, \quad J=2.0 \mathrm{~Hz}, 1 \mathrm{H}, 4{ }^{\prime \prime}-\mathrm{H}$ ), 4.13-4.21 (m, $2 \mathrm{H}, \quad 3{ }^{\prime}-\mathrm{H}, 9^{\mathrm{iv}}-\mathrm{H}$ ), 4.25 (ddd, $\left.J=5.7 \mathrm{~Hz}, \quad J=2.4 \mathrm{~Hz}, J=2.4 \mathrm{~Hz}, 1 \mathrm{H}, 4^{\prime}-\mathrm{H}\right), 4.45(\mathrm{dd}, J=10.9 \mathrm{~Hz}, J=7.2 \mathrm{~Hz}$, FmocCH$\left.\underline{H}_{a}\right), 4.52\left(\mathrm{dd}, J=10.9 \mathrm{~Hz}, J=7.2 \mathrm{~Hz}, F \operatorname{FocCH} \underline{H}_{b}\right), 4.63-4.74(\mathrm{~m}, 1 \mathrm{H}$, 3"'-H), 4.90 (dd, J=8.8 Hz, J=2.9 Hz, 6'-H), $5.54\left(\mathrm{dd}, J=7.3 \mathrm{~Hz}, J=7.3 \mathrm{~Hz}, 1^{\prime}-\mathrm{H}\right.$ ), $5.91\left(\mathrm{~d}, J=8.8 \mathrm{~Hz}, 1 \mathrm{H}, 6^{\prime}-\mathrm{NH}\right), 6.44\left(\mathrm{~d}, J=1.0 \mathrm{~Hz}, 1 \mathrm{H}, 6^{\prime}{ }^{\prime}-\mathrm{H}\right), 6.61$ (dd, $J=8.9 \mathrm{~Hz}$, $J=5.3 \mathrm{~Hz}, 1$ '"-H), 7.16-7.25 (m, $4 \mathrm{H}, \mathrm{ArH}), 7.48(\mathrm{~d}, J=1.2 \mathrm{~Hz}, 1 \mathrm{H}, 6-\mathrm{H}), 7.52-7.65$ (m, $4 \mathrm{H}, \operatorname{ArH}), 7.98$ (d, J=7.1 Hz, $1 \mathrm{H}, 3$ "-NH), 10.09 (brs, $1 \mathrm{H}, 3-\mathrm{NH}), 10.35$ (brs, $1 \mathrm{H}, 3$ '”-NH).

${ }^{13} \mathrm{C}-\mathrm{NMR}\left(75 \mathrm{MHz}, \mathrm{C}_{6} \mathrm{D}_{6}, 70{ }^{\circ} \mathrm{C}\right): \delta=-5.33\left(\mathrm{SiCH}_{3}\right),-4.56\left(\mathrm{SiCH}_{3}\right), 12.32(\mathrm{C}-7), 12.53$ (C-7"'), $\left.\left.18.21\left(\mathrm{Si} \underline{C}\left(\mathrm{CH}_{3}\right)_{3}\right), 18.50\left(\mathrm{SiC}\left(\mathrm{CH}_{3}\right)_{3}\right), 26.03\left(\mathrm{SiC}(\underline{\mathrm{CH}})_{3}\right)_{3}\right), 26.14\left(\mathrm{SiC}(\underline{\mathrm{CH}})_{3}\right)_{3}\right)$, 36.96 (C-5'), 37.99 (C-2'), 38.06 (C-2”), 47.88 (9'-C), 51.56 (C-3"), 64.72 (C-5"), $67.73\left(\mathrm{FmocCH}_{2}\right), 76.64$ (C-3'), 84.52 (C-4'), 85.22 (C-4'), 87.51 (C-1'), 87.51 (C-1'),

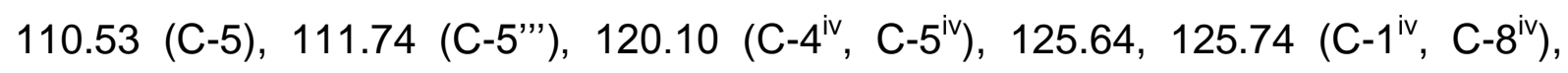

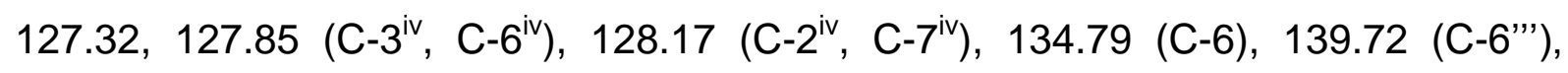
141.83, 141.87 (C-4 ${ }^{\mathrm{iv}} \mathrm{a}, \mathrm{C}-4^{\mathrm{iv} b}$ ), 144.64, 144.79 (C-8 $\left.{ }^{\mathrm{iv}} \mathrm{a}, \mathrm{C}-9^{\mathrm{iv}} \mathrm{a}\right), 150.87$ (C-2), 151.71 (C-2), 157.26 (Fmoc-C=O), 163.48 (C-4), 164.47 (C-4”'), 172.42 (3“-Amid-C=O).

Drehwert: $[\alpha]_{D}^{20}=-45.1\left(\mathrm{c}=1.0, \mathrm{CHCl}_{3}\right)$.

Schmelzpunkt: $127^{\circ} \mathrm{C}$.

IR (KBr): $\tilde{v}=2929,1692,1470,1259,1125,1074,835,778,739$.

UV (MeCN): $\lambda_{\max }(\lg \varepsilon)=204$ (4.80), 264 (4.54), 299 (3.74).

MS $\left(\mathrm{ESI}^{+}\right): \mathrm{m} / \mathrm{z}=995.4[\mathrm{M}+\mathrm{Na}]^{+}$. 
$\mathrm{C}_{49} \mathrm{H}_{68} \mathrm{~N}_{6} \mathrm{O}_{11} \mathrm{Si}_{2}(973.26)$

ber.: $995.4382[\mathrm{M}+\mathrm{Na}]^{+}$,

gef.: 995.4378 (ESI+HRMS).

\subsubsection{3 (3'--Aminothymidinyl)-(6'-N-Fmoc)-(S)-TAA-amid 146}

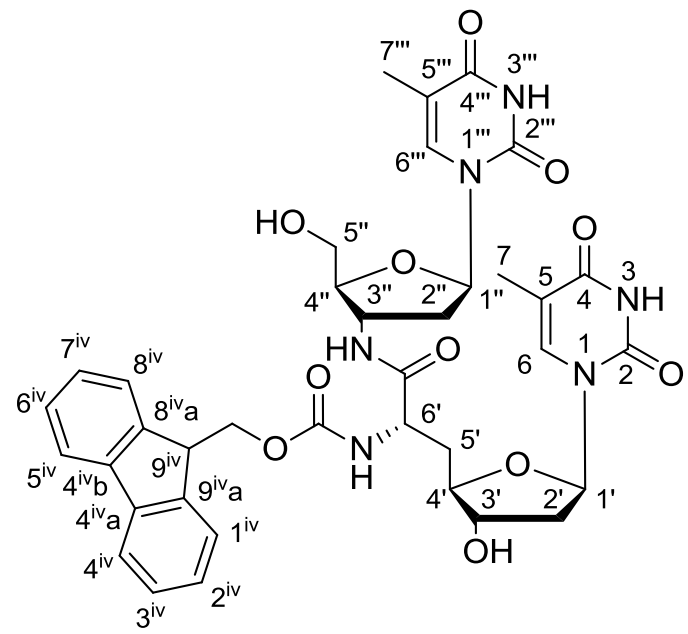

(6'S)-146

Zu einer Lösung von (6'S)-74 (240 mg, $0.247 \mathrm{mmol})$ in abs. Methanol $(5 \mathrm{~mL})$ wurde bei $0{ }^{\circ} \mathrm{C}$ Acetylchlorid ( $3.9 \mathrm{mg}, 50 \mu \mathrm{mol}, 3.5 \mu \mathrm{L}$, gelöst in $52 \mu \mathrm{L}$ abs. Methanol) gegeben und die Lösung ca. $30 \mathrm{~min}$ bei $0^{\circ} \mathrm{C}$ gerührt. Danach wurde das Reaktionsgemisch auf Raumtemperatur erwärmt und für weitere $24 \mathrm{~h}$ bei Raumtemperatur gerührt. Dabei bildete sich ein gallertartiger Niederschlag. Die gebildete Suspension wurde mit einem Tropfen ges. $\mathrm{NaHCO}_{3}$-Lösung versetzt und Pyridin $(3 \mathrm{~mL})$ dazugegeben, sodass eine klare Lösung entstand, die mit Kieselgel versetzt wurde. Das Lösungsmittel wurde im Vakuum entfernt und die auf das Kieselgel aufgetragene Substanz chromatographisch an Kieselgel gereinigt (DCM/MeOH 9:1).

Ausbeute: $167 \mathrm{mg}$ (0.224 mmol, 92\%) eines weißen Feststoffs.

DC: $R_{\mathrm{f}}(\mathrm{DCM} / \mathrm{MeOH} 9: 1)=0.21$.

${ }^{1} \mathrm{H}-\mathrm{NMR}\left(300 \mathrm{MHz}\right.$, Pyridin- $\left.\mathrm{d}_{5}, 50{ }^{\circ} \mathrm{C}\right): \delta=1.87$ (d, $J=0.9 \mathrm{~Hz}, 3 \mathrm{H}, 7^{\prime}$ '”-H), 2.01 (s, $3 \mathrm{H}, 7-\mathrm{H}), 2.29-2.46\left(\mathrm{~m}, 2 \mathrm{H}, 5^{\prime}-\mathrm{H}\right), 2.56$ (ddd, $J=9.8 \mathrm{~Hz}, J=6.7 \mathrm{~Hz}, J=3.9 \mathrm{~Hz}, 1 \mathrm{H}$, 2'- $\left.\mathrm{H}_{\mathrm{a}}\right), 2.62-2.70(\mathrm{~m}, 2 \mathrm{H}, 2$ '- $\mathrm{H}), 2.69-2.79\left(\mathrm{~m}, 1 \mathrm{H}, 2^{\prime}-\mathrm{H}_{\mathrm{b}}\right), 4.17(\mathrm{dd}, J=12.0 \mathrm{~Hz}$, $J=2.8 \mathrm{~Hz}, 1 \mathrm{H}, 5$ " $-\mathrm{H}_{\mathrm{a}}$ ), 4.24 (dd, J=12.0 Hz, J=2.8 Hz, $1 \mathrm{H}, 5$ " $-\mathrm{H}_{\mathrm{b}}$ ), 4.31 (dd, $J=6.5 \mathrm{~Hz}, J=6.5 \mathrm{~Hz}, 1 \mathrm{H}, 9^{\mathrm{iv}}-\mathrm{H}$ ), 4.39 (ddd, $J=5.9 \mathrm{~Hz}, J=2.8 \mathrm{~Hz}, J=2.8 \mathrm{~Hz}, 1 \mathrm{H}$, 
4"'-H), 4.47-4.61 (m, 3 H, 3'-H, 4'-H, FmocCH ${ }_{2}$ ), 5.06 (ddd, J = 8.3 Hz, J=6.4 Hz, $J=6.4 \mathrm{~Hz}, 1 \mathrm{H}, 6^{\prime}-\mathrm{H}$ ), 5.17 (ddd, $J=13.8 \mathrm{~Hz}, J=6.9 \mathrm{~Hz}, J=6.9 \mathrm{~Hz}, 1 \mathrm{H}, 3^{\prime \prime}-\mathrm{H}$ ), 6.70 (dd, $\left.J=6.1 \mathrm{~Hz}, J=6.1 \mathrm{~Hz}, 1 \mathrm{H}, 1^{\prime \prime}-\mathrm{H}\right), 6.86\left(\mathrm{dd}, J=6.7 \mathrm{~Hz}, J=6.7 \mathrm{~Hz}, 1 \mathrm{H}, 1^{\prime}-\mathrm{H}\right.$ ), 7.28 (dd, $J=7.5 \mathrm{~Hz}, J=7.5 \mathrm{~Hz}, 2 \mathrm{H}, 3^{\mathrm{iv}}-\mathrm{H}, 6^{\mathrm{iv}}-\mathrm{H}$ ), 7.40 (dd, $J=7.5 \mathrm{~Hz}, J=7.5 \mathrm{~Hz}$, $2 \mathrm{H}, 2^{\mathrm{iv}}-\mathrm{H}, 7^{\mathrm{iv}}-\mathrm{H}$ ), 7.56 (d, J=0.9 Hz, $\left.1 \mathrm{H}, 6-\mathrm{H}\right), 7.69$ (d, $\left.J=7.5 \mathrm{~Hz}, 2 \mathrm{H}, 1^{\mathrm{iv}}-\mathrm{H}, 8^{\mathrm{iv}}-\mathrm{H}\right)$, $7.83\left(\mathrm{~d}, J=7.5 \mathrm{~Hz}, 2 \mathrm{H}, 4^{\mathrm{iv}}-\mathrm{H}, 5^{\mathrm{iv}}-\mathrm{H}\right), 8.07\left(\mathrm{~d}, J=1.1 \mathrm{~Hz}, 1 \mathrm{H}, 66^{\prime \prime}-\mathrm{H}\right), 8.89$ (d, $J=8.3 \mathrm{~Hz}, 1 \mathrm{H}, 6$ '-NH), 9.73 (d, $J=6.9 \mathrm{~Hz}, 1 \mathrm{H}, 3$ "'-NH), 12.87 (brs, $1 \mathrm{H}, 3$ '”-NH), 12.95 (brs, $1 \mathrm{H}, 3-\mathrm{NH})$.

${ }^{13} \mathrm{C}$-NMR $\left(75 \mathrm{MHz}\right.$, Pyridin- $\left.\mathrm{d}_{5}, 50^{\circ} \mathrm{C}\right): \delta=12.51$ (C-7'”), 12.62 (C-7), 37.67 (C-5'), 38.44 (C-2"), 39.89 (C-2'), 47.92 (C-9 '), 50.26 (C-3"), 53.56 (C-6'), 62.14 (C-5"), $66.82\left(\mathrm{FmocCH}_{2}\right), 74.84$ (C-3'), 84.58 (C-4'), 85.10 (C-1'), 85.47 (C-1'), 86.26 (C-4"),

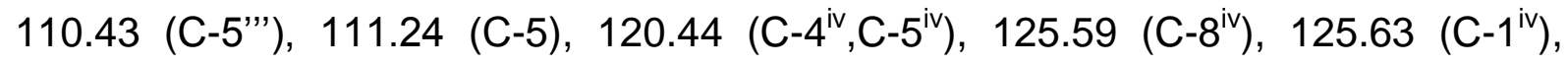

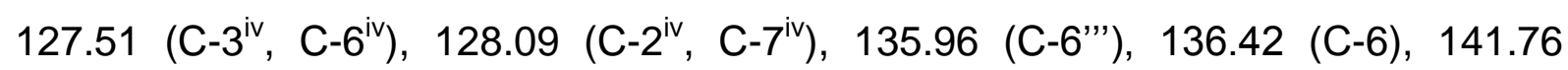
(C-4 $\left.{ }^{\mathrm{iv}} \mathrm{a}, \mathrm{C}-4^{\mathrm{iv}} \mathrm{b}\right), 144.61,144.70$ (C-8 $\left.{ }^{\mathrm{iv}} \mathrm{a}, \mathrm{C}-9^{\mathrm{iv}} \mathrm{a}\right), 150.07$ (Fmoc-C=O), 151.71 (C-2"'), 151.77 (C-2), 164.86 (C-4'”), 164.88 (C-4), 172.62 (3"-Amid-C=O).

Drehwert: $[\alpha]_{D}^{20}=+18.4\left(\mathrm{c}=1.0, \mathrm{CHCl}_{3}\right)$

Schmelzpunkt: $168^{\circ} \mathrm{C}$

IR (KBr): $\tilde{v}=3493,1693,1530,1472,1274,1057,891,738,565$.

UV (MeCN): $\lambda_{\max }(\lg \varepsilon)=205$ (4.74), 264 (4.48), 299 (3.76).

MS $\left(\mathrm{ESI}^{+}\right): \mathrm{m} / \mathrm{z}=767.3[\mathrm{M}+\mathrm{Na}]^{+}$.

$\mathrm{C}_{22} \mathrm{H}_{42} \mathrm{~N}_{2} \mathrm{O}_{5} \mathrm{Si}_{5}$ (744.75)

ber.: $767.2653[\mathrm{M}+\mathrm{Na}]^{+}$, gef.: 767.2640 (ESI+-HRMS). 


\subsubsection{4 (3''-Aminothymidinyl)-(6'-N-Fmoc)-(R)-TAA-amid 146}

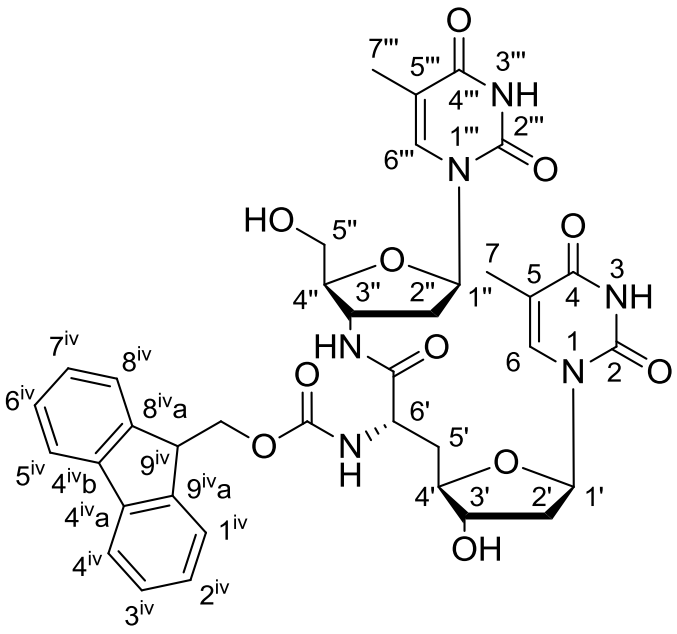

$\left(6^{\prime} R\right)-146$

Die Synthese von (6'S)-146 erfolgte gemäß der Vorschrift zur Synthese von (6'S)-146. Es wurden $153 \mathrm{mg}(0.157 \mathrm{mmol})(6$ ' $R)-74,2.8 \mu \mathrm{L}(3.1 \mathrm{mg}, 39 \mu \mathrm{mol})$ Acetylchlorid und $3 \mathrm{~mL}$ Methanol eingesetzt. Im Unterschied zur Synthese von (6'S)-146 bildete sich während der Reaktion kein Niederschlag. Das Rohprodukt wurde chromatographisch an Kieselgel gereinigt (DCM/MeOH 9:1).

Ausbeute: $104 \mathrm{mg}(0.139 \mathrm{mmol}, 89 \%)$ eines weißen Feststoffs.

DC: $R_{\mathrm{f}}(\mathrm{DCM} / \mathrm{MeOH}$ 9:1) $=0.21$.

${ }^{1} \mathrm{H}-\mathrm{NMR}\left(300 \mathrm{MHz}\right.$, Pyridin- $\left.\mathrm{d}_{5}, 50^{\circ} \mathrm{C}\right): \delta=1.87\left(\mathrm{~d}, J=1.0 \mathrm{~Hz}, 3 \mathrm{H}, 7^{\prime \prime} \cdot-\mathrm{H}\right), 2.01$ (s, $3 \mathrm{H}, 7-\mathrm{H}), 2.51-2.77$ (m, $6 \mathrm{H}, 5$ '-H, 2'-H, 2"'-H), 4.13 (dd, J=12.2 Hz, J = 2.6 Hz, 1 H, 5"- $\mathrm{H}_{\mathrm{a}}$ ), 4.20 (dd, J=12.2 Hz, J=2.6 Hz, $1 \mathrm{H}, \quad 5 "-\mathrm{H}_{\mathrm{b}}$ ), 4.29 (dd, $J=7.1 \mathrm{~Hz}$, $J=7.1 \mathrm{~Hz}, 1 \mathrm{H}, 9^{\mathrm{iv}}-\mathrm{H}$ ), 4.36 (ddd, $J=5.8 \mathrm{~Hz}, J=2.8 \mathrm{~Hz}, J=2.8 \mathrm{~Hz}, 1 \mathrm{H}, 4$ "'-H), 4.48$4.66\left(\mathrm{~m}, 4 \mathrm{H}, 3^{\prime}-\mathrm{H}, 4^{\prime}-\mathrm{H}, \mathrm{FmocCH}\right.$ ), 5.09 (ddd, J=8.1 Hz, J=5.9 Hz, J=5.9 Hz,

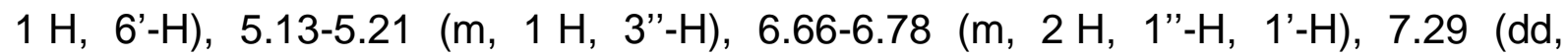
$\left.J=7.4 \mathrm{~Hz}, J=7.4 \mathrm{~Hz}, 2 \mathrm{H}, 3^{\mathrm{iv}}-\mathrm{H}, 6^{\mathrm{iv}}-\mathrm{H}\right), 7.40$ (dd, J=7.4 Hz, J=7.4 Hz, $2 \mathrm{H}, 2^{\mathrm{iv}}-\mathrm{H}$, $\left.7^{\mathrm{iv}}-\mathrm{H}\right), 7.56(\mathrm{~s}, 1 \mathrm{H}, 6-\mathrm{H}), 7.62-7.74\left(\mathrm{~m}, 2 \mathrm{H}, 1^{\mathrm{iv}}-\mathrm{H}, 8^{\mathrm{iv}}-\mathrm{H}\right), 7.83(\mathrm{~d}, J=7.4 \mathrm{~Hz}, 2 \mathrm{H}$, $\left.4^{\mathrm{iv}}-\mathrm{H}, 5^{\mathrm{iv}}-\mathrm{H}\right), 8.08$ (d, J=1.2 Hz, $1 \mathrm{H}, 6$ '”- $\left.-\mathrm{H}\right), 8.73-8.82(\mathrm{~m}, 1 \mathrm{H}, 6$ '-NH), 9.33 (d, $J=6.8 \mathrm{~Hz}, 1 \mathrm{H}, 3$ '”-NH).

${ }^{13} \mathrm{C}-N M R\left(75 \mathrm{MHz}\right.$, Pyridin- $\left.\mathrm{d}_{5}, 50^{\circ} \mathrm{C}\right): \delta=12.61$ (C-7'”, C-7), 37.36 (C-5'), 38.46 (C-2”), 40.07 (C-2'), 47.83 (C-9iv), 50.48 (C-3"), 53.89 (C-6'), 62.15 (C-5”), 66.89 $\left(\mathrm{FmocCH}_{2}\right.$ ), 74.66 (C-3'), 83.89 (C-4'), 85.09 (C-1"), 86.05 (C-1'), 86.21 (C-4"),

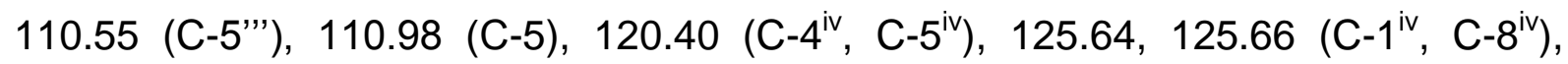




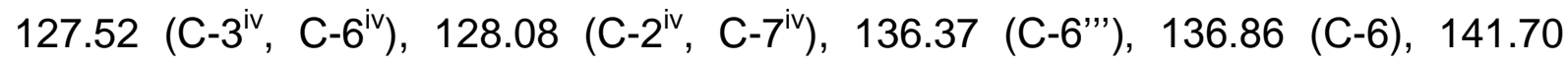
(C-4 $\left.{ }^{i v} a, C-4^{i v} b\right), 144.58,144.66$ (C-8 ${ }^{i v} a, C-9^{i v a}$ ), 150.07 (Fmoc-C=O), 151.71 (C-2"'), 151.77 (C-2), 164.86 (C-4"'), 164.88 (C-4), 172.62 (3"-Amid-C=O).

Drehwert: $[\alpha]_{D}^{20}=+38.5\left(\mathrm{c}=1.1, \mathrm{CHCl}_{3}\right)$.

Schmelzpunkt: $163^{\circ} \mathrm{C}$.

IR $(\mathrm{KBr}): \tilde{v}=3419,3064,1689,1532,1472,1271,1089,741,557$.

UV (MeCN): $\lambda_{\max }(\lg \varepsilon)=205$ (4.60), 264 (4.35), 299 (3.56).

MS $\left(\mathrm{ESI}^{+}\right): \mathrm{m} / \mathrm{z}=767.3[\mathrm{M}+\mathrm{Na}]^{+}$.

$\mathrm{C}_{37} \mathrm{H}_{39} \mathrm{~N}_{5} \mathrm{O}_{12}$ (744.75) ber.: $767.2653[\mathrm{M}+\mathrm{Na}]^{+}$, gef.: 767.2642 (ESI+-HRMS).

\subsubsection{5 (5'-O-DMTr-thymidinyl)-(6'-N-Fmoc)-(S)-TAA-amid 75}

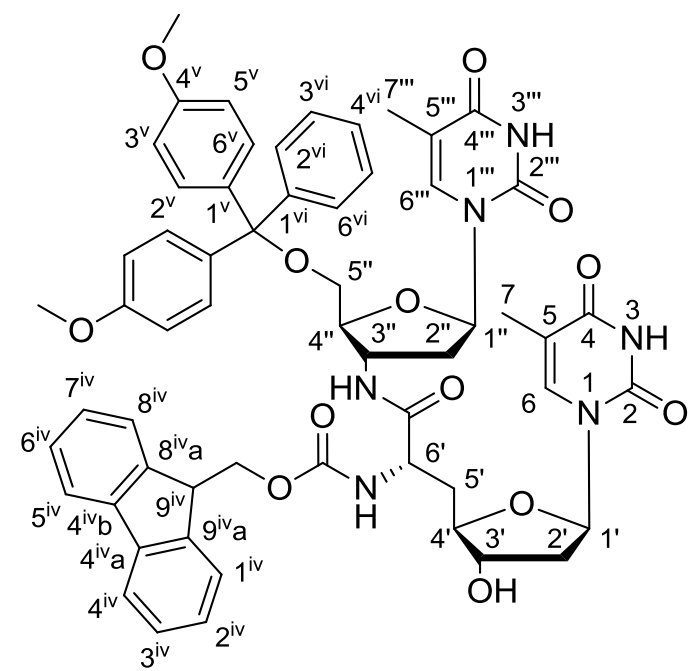

(6'S)-75

Die Synthese erfolgte gemäß AAV 2 (7.1.7.2). Es wurden $160 \mathrm{mg}(0.215 \mathrm{mmol})$ (6'S)-146, DMTr-Chlorid ( $87 \mathrm{mg}, 0.29 \mathrm{mmol}$ ) und $2 \mathrm{~mL}$ abs. Pyridin eingesetzt. Als Eluent für die säulenchromatographische Reinigung wurde ein Gemisch aus $\mathrm{DCM} / \mathrm{MeOH}$ (17:1 mit 0.5\% Pyridin) verwendet.

Ausbeute: $169 \mathrm{mg}(0.161 \mathrm{mmol}, 75 \%)$ eines weißen Feststoffs.

DC: $R_{f}(\mathrm{DCM} / \mathrm{MeOH} 17: 1)=0.18$.

${ }^{1} \mathrm{H}-\mathrm{NMR}\left(600 \mathrm{MHz}\right.$, Pyridin-d $\left.5,50^{\circ} \mathrm{C}\right): \delta=1.73(\mathrm{~s}, 3 \mathrm{H}, 7-\mathrm{H}), 2.02\left(\mathrm{~s}, 3 \mathrm{H}, 7^{\prime}\right.$ '- $\left.\mathrm{H}\right)$, 2.31-2.43 (m, $2 \mathrm{H}, 2$ '- $-\mathrm{H}, 2$ '- $-\mathrm{H})$, 2.51-2.58 (m, $1 \mathrm{H}, 2$ '- $\mathrm{H})$, 2.62-2.74 (m, $3 \mathrm{H}, 2$ '”- $\mathrm{H}$, 5'-H), 3.64-3.79 (m, $2 \mathrm{H}, 5$ "'-H), $3.72\left(\mathrm{~s}, 6 \mathrm{H}, \mathrm{OCH}_{3}\right), 4.28-4.33\left(\mathrm{~m}, 1 \mathrm{H}, 9^{\mathrm{iv}}-\mathrm{H}\right), 4.43-$ 
$4.51\left(\mathrm{~m}, 1 \mathrm{H}, 4\right.$ "'-H), 4.51-4.59 (m, $2 \mathrm{H}, 3^{\prime}-\mathrm{H}, 4$ '- $\left.\mathrm{H}\right)$, 4.61-4.68 (m, $\left.2 \mathrm{H}, \mathrm{FmocCH}_{2}\right)$, 5.00-5.05 (m, $1 \mathrm{H}, 6$ '-H), 5.16-5.24 (m, $\left.1 \mathrm{H}, 3^{\prime \prime}-\mathrm{H}\right), 6.73-6.79\left(\mathrm{~m}, 1 \mathrm{H}, 1^{\prime \prime}-\mathrm{H}\right), 6.79-$ $6.84\left(\mathrm{~m}, 1 \mathrm{H}, 1^{\prime}-\mathrm{H}\right), 7.02\left(\mathrm{~d}, J=8.0 \mathrm{~Hz}, 4 \mathrm{H}, 6^{\mathrm{v}}-\mathrm{H}, 2^{\mathrm{v}}-\mathrm{H}\right), 7.24-7.34\left(\mathrm{~m}, 3 \mathrm{H}, 2^{\mathrm{vi}}-\mathrm{H}\right.$, $\left.3^{\mathrm{iv}}-\mathrm{H}, 6^{\mathrm{iv}}-\mathrm{H}\right), 7.35-7.47\left(\mathrm{~m}, 4 \mathrm{H}, 3^{\mathrm{vi}}-\mathrm{H}, 5^{\mathrm{vi}}-\mathrm{H}, 2^{\mathrm{iv}}-\mathrm{H}, 7^{\mathrm{iv}}-\mathrm{H}\right), 7.56\left(\mathrm{~s}, 1 \mathrm{H}, 6^{\prime \prime}-\mathrm{H}\right), 7.63(\mathrm{~d}$, $\left.J=8.0 \mathrm{~Hz}, 4 \mathrm{H}, 5^{\mathrm{v}}-\mathrm{H}, 3^{\mathrm{v}}-\mathrm{H}\right), 7.67-7.71\left(\mathrm{~m}, 2 \mathrm{H}, 2^{\mathrm{vi}}-\mathrm{H}, 6^{\mathrm{vi}}-\mathrm{H}\right), 7.79(\mathrm{~s}, 1 \mathrm{H}, 6-\mathrm{H}), 7.78$ (d, $J=7.8 \mathrm{~Hz}, 2 \mathrm{H}, 1^{\mathrm{iv}}-\mathrm{H}, 8^{\mathrm{iv}}-\mathrm{H}$ ), $7.83\left(\mathrm{~d}, J=7.4 \mathrm{~Hz}, 2 \mathrm{H}, 4^{\mathrm{iv}}-\mathrm{H}, 5^{\mathrm{iv}}-\mathrm{H}\right), 8.89$ (brs, $1 \mathrm{H}$, 6'-NH), 9.66 (brs, 1 H, 3"'-NH), 12.93 (brs, $2 \mathrm{H}, 3$ '"'-NH, 3-NH).

${ }^{13} \mathrm{C}$-NMR $\left(75 \mathrm{MHz}\right.$, Pyridin- $\left.\mathrm{d}_{5}, 50^{\circ} \mathrm{C}\right): \delta=12.49$ (C-7), 12.70 (C-7'”), 37.71 (C-2'), 38.47 (C-5'), 40.11 (C-2”), 48.04 (C-9iv), 50.96 (C-3"), 53.56 (C-6'), $55.40\left(\mathrm{OCH}_{3}\right)$, 64.36 (C-5"), 66.89 ( $\mathrm{FmocCH}_{2}$ ), 74.87 (C-3'), 84.63 (C-4"), 85.08 (Trityl-C quart), 85.53

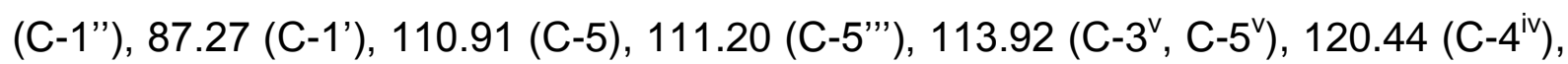

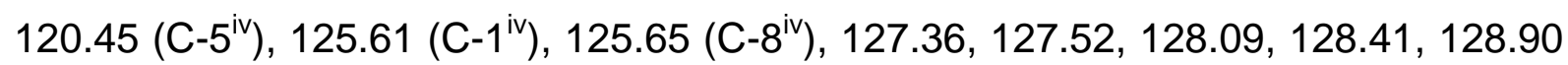
$\left(C-2^{i v}, C-3^{i v}, C-6^{i v}, C-7^{i v}, C-2^{v i}, C-3^{v i}, C-4^{v i}, C-5^{v i}, C-6^{v i}\right), 130.72\left(C_{a}-5^{v}, C_{a}-3^{v}\right), 130.75$ $\left(C_{b}-5^{v}, C_{b}-3^{v}\right), 135.74(C-6), 135.78\left(C-6^{\prime \prime \prime}\right), 136.47\left(C_{a}-1^{v}\right), 136.54\left(C_{b}-1^{v}\right), 141.74$ $\left(\mathrm{C}-5^{\mathrm{iv}}, \mathrm{C}-6^{\mathrm{iv}}\right), 144.59\left(\mathrm{C}-8^{\mathrm{iv}} \mathrm{a}\right), 144.68\left(\mathrm{C}-9^{\mathrm{iv}} \mathrm{a}\right), 145.68$ (C-1 $\left.{ }^{\text {vi }}\right), 151.58(\mathrm{C}-2), 151.69$ (C-2"'), 157.12 (Fmoc-C=O), $159.24\left(\mathrm{C}_{\mathrm{a}}-4^{\mathrm{v}}\right), 159.27\left(\mathrm{C}_{\mathrm{b}}-4^{\mathrm{v}}\right), 164.77(\mathrm{C}-4), 164.81$ (C-4"'), 172.37 (3"-Amid-C=O).

Drehwert: $[\alpha]_{D}^{20}=+24.6\left(\mathrm{c}=1.0, \mathrm{CHCl}_{3}\right)$.

Schmelzpunkt: $135^{\circ} \mathrm{C}$.

IR $(\mathrm{KBr}): \tilde{v}=1688,1509,1466,1251,1177,1034,829,760,585$.

UV (MeCN): $\lambda_{\max }(\lg \varepsilon)=199$ (5.12), 238 (4.40), 265 (4.55), 299 (3.76).

MS $\left(E S I^{+}\right): m / z=1069.4[\mathrm{M}+\mathrm{Na}]^{+}$.

$\mathrm{C}_{58} \mathrm{H}_{58} \mathrm{~N}_{6} \mathrm{O}_{13}(1047.11)$

ber.: $1069.3960[\mathrm{M}+\mathrm{Na}]^{+}$, gef.: 1069.3949 (ESI+-HRMS). 


\subsubsection{6 (5'-O-DMTr-3"'-Aminothymidinyl)-(6'-N-Fmoc)-(R)-TAA-amid 75}

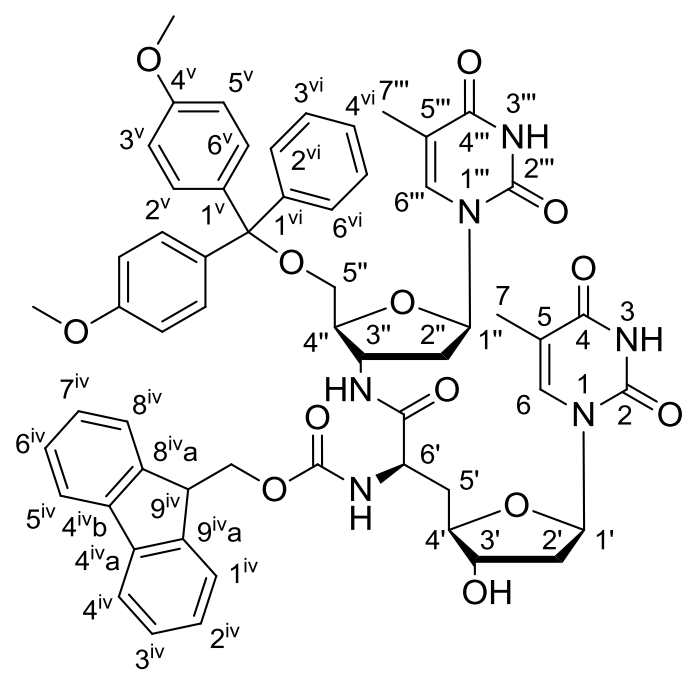

$(6, R)-75$

Die Synthese erfolgte gemäß AAV 2 (7.1.7.2). Es wurden $230 \mathrm{mg}(0.11 \mathrm{mmol})$ $\left(6^{\prime} R\right)-146$ und $120 \mathrm{mg}(0.355 \mathrm{mmol}) \mathrm{DMTrCl}$ eingesetzt. Als Eluent für die säulenchromatographische Reinigung wurde ein Gemisch aus DCM/MeOH (17:1 mit $0.5 \%$ Pyridin) verwendet.

Ausbeute: $241 \mathrm{mg} \mathrm{(230} \mathrm{\mu mol,} \mathrm{75 \% )} \mathrm{eines} \mathrm{weißen} \mathrm{Feststoffs.}$

DC: $R_{\mathrm{f}}(\mathrm{DCM} / \mathrm{MeOH} 17: 1)=0.18$.

${ }^{1} \mathrm{H}-\mathrm{NMR}\left(600 \mathrm{MHz}\right.$, Pyridin- $\left.\mathrm{d}_{5}, 50^{\circ} \mathrm{C}\right): \delta=1.73(\mathrm{~s}, 3 \mathrm{H}, 7-\mathrm{H}), 2.01$ (s, $\left.3 \mathrm{H}, 7^{\prime \prime}-\mathrm{H}\right)$, 2.53-2.79 (m, $6 \mathrm{H}, 2^{\prime}-\mathrm{H}, 2$ '”-H, 5'-H), 3.64-3.75 (m, $2 \mathrm{H}, 5$ '- $\left.-\mathrm{H}\right), 3.69\left(\mathrm{~s}, 6 \mathrm{H}, \mathrm{OCH}_{3}\right)$, 4.29 (dd, J=6.9 Hz, J=6.9 Hz, $\left.1 \mathrm{H}, 9^{\mathrm{iv}}-\mathrm{H}\right), 4.44-4.46(\mathrm{~m}, 1 \mathrm{H}, 4$ "'-H), 4.48-4.56 (m, $\left.2 \mathrm{H}, 3^{\prime}-\mathrm{H}, 4^{\prime}-\mathrm{H}\right), 4.59-4.63\left(\mathrm{~m}, 2 \mathrm{H}, \mathrm{FmocCH}_{2}\right)$, 5.04-5.10 (m, 1 H, 6'-H), 5.19-5.27 (m, $1 \mathrm{H}, 3$ '-H), 6.71 (dd, J=6.2 Hz, J=6.2 Hz, $1 \mathrm{H}, 1^{\prime}-\mathrm{H}$ ), 6.78 (dd, $J=6.5 \mathrm{~Hz}$, $J=6.5 \mathrm{~Hz}, 1 \mathrm{H}, 1$ "'- $\mathrm{H}), 7.00\left(\mathrm{~d}, J=8.8 \mathrm{~Hz}, 4 \mathrm{H}, 6^{\mathrm{v}}-\mathrm{H}, 2^{\mathrm{v}}-\mathrm{H}\right), 7.23-7.32\left(\mathrm{~m}, 3 \mathrm{H}, 4^{\mathrm{vi}}-\mathrm{H}\right.$, $\left.3^{\mathrm{iv}}-\mathrm{H}, 6^{\mathrm{iv}}-\mathrm{H}\right), 7.36-7.43\left(\mathrm{~m}, 4 \mathrm{H}, 3^{\mathrm{vi}}-\mathrm{H}, 5^{\mathrm{vi}}-\mathrm{H}, 2^{\mathrm{iv}}-\mathrm{H}, 7^{\mathrm{iv}}-\mathrm{H}\right), 7.58\left(\mathrm{~s}, 1 \mathrm{H}, 66^{\prime \prime}-\mathrm{H}\right), 7.61$ (d, $\left.J=8.8 \mathrm{~Hz}, 4 \mathrm{H}, 5^{\mathrm{v}}-\mathrm{H}, 3^{\mathrm{v}}-\mathrm{H}\right), 7.64-7.71\left(\mathrm{~m}, 2 \mathrm{H}, 2^{\mathrm{vi}}-\mathrm{H}, 6^{\mathrm{vi}}-\mathrm{H}\right), 7.75(\mathrm{~d}, J=7.5 \mathrm{~Hz}, 2 \mathrm{H}$, $\left.4^{\mathrm{iv}}-\mathrm{H}, 5^{\mathrm{iv}}-\mathrm{H}\right), 7.80(\mathrm{~s}, 1 \mathrm{H}, 6-\mathrm{H}), 7.83\left(\mathrm{~d}, J=7.6 \mathrm{~Hz}, 2 \mathrm{H}, 1^{\mathrm{iv}}-\mathrm{H}, 8^{\mathrm{iv}}-\mathrm{H}\right), 8.72$ (brs, $1 \mathrm{H}$, 6'-NH), 9.32 (brs, 1 H, 3"'-NH), 12.89 (brs, 2 H, 3-NH, 3'”-NH).

${ }^{13} \mathrm{C}-N M R\left(75 \mathrm{MHz}\right.$, Pyridin- $\left.\mathrm{d}_{5}, 50^{\circ} \mathrm{C}\right): \delta=12.51$ (C-7), 12.83 (C-7'”), 37.72 (C-2'), 38.61 (C-5'), 40.23 (C-2”), 47.97 (C-9 $\left.{ }^{\text {iv }}\right), 51.00$ (C-3”), 54.03 (C-6'), $55.37\left(\mathrm{OCH}_{3}\right)$, 64.33 (C-5”), 66.99 (FmocCH ${ }_{2}$ ), 74.77 (C-3'), 84.05 (C-4”), 85.06 (Trityl-C quart), 86.18 (C-1"), 87.25 (C-1'), 108.63 (C-5), 111.01 (C-5'”), $113.90\left(\mathrm{C}_{\mathrm{a}}-6^{\mathrm{v}}, \mathrm{C}_{\mathrm{a}}-2^{\mathrm{v}}\right), 113.99$ $\left(C_{b}-6^{v}, C_{b}-2^{v}\right)$ 120.30, $120.42\left(C-4^{\text {iv }}, C-5^{\text {iv }}\right), 125.68\left(C-1^{\text {iv }}, C-8^{i v}\right), 127.32,127.54$, 
$128.08,128.39,128.87\left(\mathrm{C}-6^{\mathrm{iv}}, \mathrm{C}-3^{\mathrm{iv}}, \mathrm{C}-7^{\mathrm{iv}}, \mathrm{C}-3^{\mathrm{iv}}, \mathrm{C}-2^{\mathrm{vi}}, \mathrm{C}-3^{\mathrm{vi}}, \mathrm{C}-4^{\mathrm{vi}}, \mathrm{C}-5^{\mathrm{vi}}, \mathrm{C}-6^{\mathrm{vi}}\right)$, $130.72\left(C_{a}-5^{v}, C_{a}-3^{v}\right), 130.77\left(C_{b}-5^{v}, C_{b}-3^{v}\right), 135.78$ (C-6), 136.41 (C-6”'), 136.54

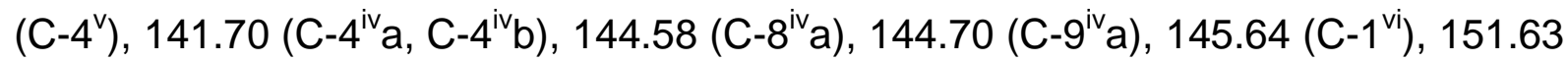
(C-2), 151.68 (C-2"'), 157.17 (Fmoc-C=O), $159.22\left(C_{a}-1^{v}\right), 159.24\left(C_{b}-1^{v}\right), 164.74$ (C-4), 164.75 (C-4"'), 173.06 (3"-Amid-C=O).

Drehwert: $[\alpha]_{D}^{20}=+9.3\left(\mathrm{c}=1.0, \mathrm{CHCl}_{3}\right)$.

Schmelzpunkt: $172^{\circ \circ} \mathrm{C}$.

IR $(\mathrm{KBr}): \tilde{v}=1681,1507,1436,1247,1175,1066,1029,741,702$.

UV (MeCN): $\lambda_{\max }$ (lg $\left.\varepsilon\right)=198$ (4.81), 257 (4.26), 263 (4.26), 300 (3.35).

MS $\left(\mathrm{ESI}^{+}\right): \mathrm{m} / \mathrm{z}=1069.4[\mathrm{M}+\mathrm{Na}]^{+}$.

$\mathrm{C}_{22} \mathrm{H}_{42} \mathrm{~N}_{2} \mathrm{O}_{5} \mathrm{Si}_{5}(1047.11)$

ber.: $1069.3954[\mathrm{M}+\mathrm{Na}]^{+}$, gef.: 1069.3931 (ESI'-HRMS).

\subsubsection{7 (5'-O-DMTr-thymidinyl)-(6'-N-Fmoc-3'-O-( $\beta$-cyanoethoxy- $N, N$ - diisopropylphosphoramidit)-(S)-TAA-amid 69}

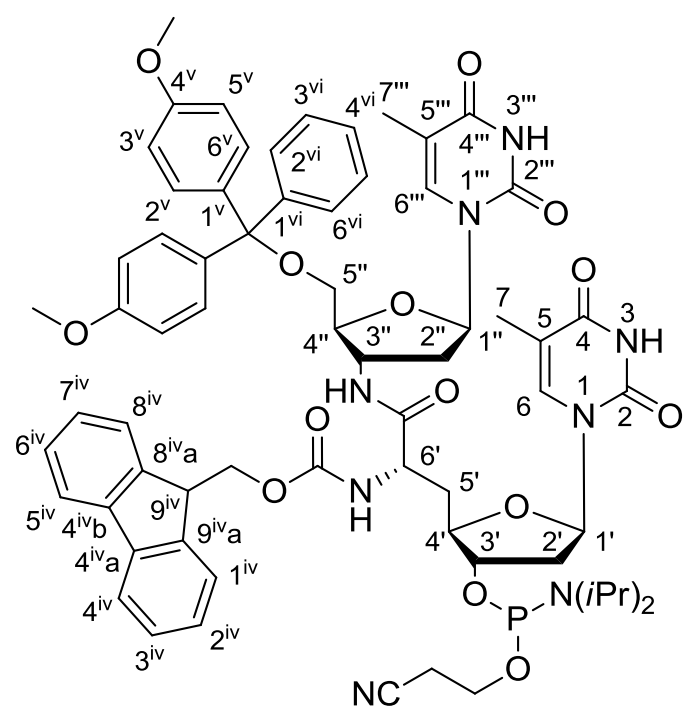

(6'S)-69

$308 \mathrm{mg}$ (0.294 mmol) (6'S)-75 wurden mit Pyridin (3 mL), Toluol (3 mL) und MeCN $(3 \mathrm{~mL})$ coevaporiert und anschließend in DCM $(3 \mathrm{~mL})$ gelöst. Die Reaktionslösung wurde mit $\mathrm{DCl}(35 \mathrm{mg}, 0.294 \mathrm{mmol})$ und mit einer Lösung von Bis- $N, N$ Diisopropylamino-(2-cyanoethyl)-phosphit (106 mg, $0.353 \mathrm{mmol})$ in DCM $(0.8 \mathrm{~mL})$ versetzt und $1 \mathrm{~h}$ bei Raumtemperatur gerührt. Die Reaktionslösung wurde mit DCM $(60 \mathrm{~mL})$ verdünnt und mit ges. $\mathrm{NaHCO}_{3}$-Lösung $(30 \mathrm{~mL})$ gewaschen. Die wässrige Phase wurde mit DCM $(15 \mathrm{~mL})$ reextrahiert und die vereinigten organischen Phasen 
unter vermindertem Druck eingeengt. Der viskose Rückstand wurde chromatographisch an Kieselgel gereinigt (Eluent: DCM/MeOH 15:1 mit 0.5\% Pyridin). Die das Produkt enthaltenden Fraktionen wurden unter vermindertem Druck eingeengt. Das so erhaltene Rohprodukt wurde in DCM $(6 \mathrm{~mL})$ gelöst und durch allmähliches Geben in $n$-Hexan $(60 \mathrm{~mL})$ bei $-20^{\circ} \mathrm{C}$ umkristallisiert.

Ausbeute: $280 \mathrm{mg}(224 \mu \mathrm{mol}, 76 \%)$ eines weißen, feinpulvrigen Feststoffs.

DC: $R_{\mathrm{f}}=0.45\left(\mathrm{EtOAc}, 0.7 \% \mathrm{NEt}_{3}\right)$.

${ }^{31}$ P-NMR (121 MHz, Pyridin- $\left.d_{5}\right): \delta=149.01,149.45$.

MS $\left(E S I^{+}\right): m / z=1269.5[\mathrm{M}+\mathrm{Na}]^{+}$.

$\mathrm{C}_{58} \mathrm{H}_{57} \mathrm{~N}_{5} \mathrm{O}_{14}(1247.33)$ ber.: $1269.5038[\mathrm{M}+\mathrm{Na}]^{+}$, gef.: 1269.5033 (ESI+-HRMS).

\subsubsection{8 (5'-O-DMTr-thymidinyl)-(6'-N-Fmoc-3'-O-( $\beta$-cyanoethoxy- $N, N$ - diisopropylphosphoramidit)-(R)-TAA-amid 69}

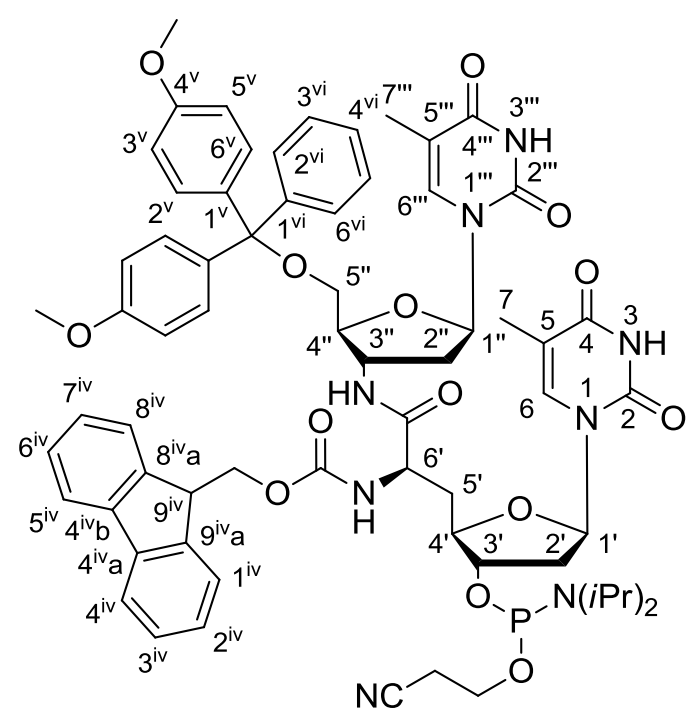

(6'R)-69

Die Synthese von (6'R)-69 erfolgte gemäß der Vorschrift zur Synthese von (6'S)-69 Es wurden $230 \mathrm{mg} \quad(0.220 \mathrm{mmol}) \quad\left(6^{\prime} R\right)-75,79 \mathrm{mg} \quad(0.26 \mathrm{mmol})$ Bis- $N, N-$ Diisopropylamino-(2-cyanoethyl)-phosphit, $26 \mathrm{mg}(0.22 \mathrm{mmol}) \mathrm{DCl}$ und $2.2 \mathrm{~mL} \mathrm{DCM}$ eingesetzt. Der viskose Rückstand wurde chromatographisch an Kieselgel gereinigt (Eluent: DCM/MeOH 15:1 mit 0.5\% Pyridin). Die das Produkt enthaltenden Fraktionen wurden unter vermindertem Druck eingeengt. Das so erhaltene 
Rohprodukt wurde in DCM (4.5 mL) gelöst und durch allmähliches Geben in $n$-Hexan (45 $\mathrm{mL})$ bei $-20^{\circ} \mathrm{C}$ umkristallisiert.

Ausbeute: 204 mg (163 $\mu \mathrm{mol}, 74 \%)$ eines weißen, feinpulvrigen Feststoffs.

DC: $R_{\mathrm{f}}=0.45\left(\mathrm{EtOAc}, 0.7 \% \mathrm{NEt}_{3}\right)$.

${ }^{31} \mathbf{P}-N M R\left(121 \mathrm{MHz}\right.$, Pyridin- $\left.\mathrm{d}_{5}\right): \delta=147.34,147.47$.

MS $\left(E S I^{+}\right): m / z=1269.5[\mathrm{M}+\mathrm{Na}]^{+}$.

$\mathrm{C}_{58} \mathrm{H}_{57} \mathrm{~N}_{5} \mathrm{O}_{14}(1247.33)$

$$
\text { ber.: } 1269.50[\mathrm{M}+\mathrm{Na}]^{+} \text {, }
$$

gef.: $1269.50\left(\mathrm{ESI}^{+}\right)$.

\subsubsection{9 (3"'-Aminothymidinyl)-(S)-TAA-amid 162}

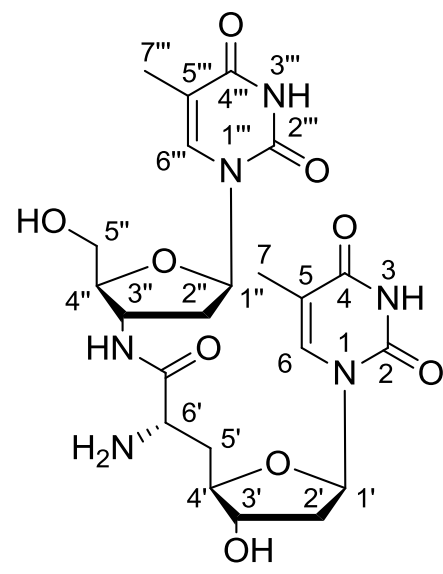

(6'S)-162

Es wurden $30 \mathrm{mg}$ (40 $\mathrm{mmol}$ ) (6'S)-146 in $2 \mathrm{~mL}$ einer 3:1-Mischung aus 25\% wässriger Ammoniaklösung und Ethanol aufgenommen. Die Suspension wurde $6 \mathrm{~h}$ bei $55^{\circ} \mathrm{C}$ gerührt. Die Reaktion wurde dünnschichtchromatographisch verfolgt (Isopropanol/ $\mathrm{H}_{2} \mathrm{O} / \mathrm{AcOH}$ 5/2/1, gesättigt mit $\mathrm{NaCl}$ ). Anschließend wurde das Lösungsmittel im Vakuum entfernt und das Rohprodukt chromatographisch gereinigt (RP-SiO 2 s. 7.1.5, $\left.\mathrm{MeCN} / \mathrm{H}_{2} \mathrm{O} 1: 1\right)$.

Ausbeute: Es wurden $21 \mathrm{mg}(40 \mu \mathrm{mol}$, quant.) eines weißen Pulvers erhalten.

DC: $R_{\mathrm{f}}$ (Isopropanol $\left./ \mathrm{H}_{2} \mathrm{O} / \mathrm{AcOH} 5: 2: 1\right)=0.60$.

${ }^{1} \mathrm{H}-\mathrm{NMR}\left(600 \mathrm{MHz}\right.$, Pyridin- $\left.\mathrm{d}_{5}, 35^{\circ} \mathrm{C}\right): \delta=1.86(\mathrm{~d}, J=1.0 \mathrm{~Hz}, 3 \mathrm{H}, 7-\mathrm{H}), 2.00$ (d, $J=1.0 \mathrm{~Hz}, 3 \mathrm{H}, 7$ '”-H), 2.42-2.50 (m, $1 \mathrm{H}, 2$ '”- $\mathrm{H}_{\mathrm{a}}$ ), 2.53 (dd, $J=13.6 \mathrm{~Hz}, J=6.8 \mathrm{~Hz}$, 
2' $-\mathrm{H}_{\mathrm{a}}$ ), 2.56 (ddd, $J=13.6 \mathrm{~Hz}, \quad J=6.8 \mathrm{~Hz}, \quad J=4.8 \mathrm{~Hz}, \quad 1 \mathrm{H}, \quad 2 '-\mathrm{H}_{\mathrm{b}}$ ), 2.68 (dd, $\left.J=6.5 \mathrm{~Hz}, J=6.5 \mathrm{~Hz}, 2 \mathrm{H}, 5^{\prime}-\mathrm{H}\right), 2.70-2.76\left(\mathrm{~m}, 1 \mathrm{H}, 2^{\prime}{ }^{-} \mathrm{H}_{\mathrm{b}}\right), 4.14$ (dd, $J=12.1 \mathrm{~Hz}$, $\left.J=2.8 \mathrm{~Hz}, 1 \mathrm{H}, 5^{\prime \prime}-\mathrm{H}_{\mathrm{a}}\right), 4.19-25\left(\mathrm{~m}, 1 \mathrm{H}, 3^{\prime}-\mathrm{H}\right), 4.22(\mathrm{dd}, J=12.1 \mathrm{~Hz}, J=2.8 \mathrm{~Hz}, 1 \mathrm{H}$, 5"'- $\mathrm{H}_{\mathrm{b}}$ ), 4.36 (dd, $J=6.5 \mathrm{~Hz}, J=2.9 \mathrm{~Hz}, 1 \mathrm{H}, 4^{\prime}-\mathrm{H}$ ), 4.50 (ddd, $J=8.9 \mathrm{~Hz}, J=4.6 \mathrm{~Hz}$, $1 \mathrm{H}, 3$ "'-H), 4.63 (ddd, $\left.J=6.7 \mathrm{~Hz}, J=4.6 \mathrm{~Hz}, 1 \mathrm{H}, 4^{\prime \prime}-\mathrm{H}\right), 5.11-17\left(\mathrm{~m}, 1 \mathrm{H}, 6^{\prime}-\mathrm{H}\right), 6.74$ (dd, $\left.J=6.2 \mathrm{~Hz}, J=6.2 \mathrm{~Hz}, 1 \mathrm{H}, 1^{\prime \prime}-\mathrm{H}\right), 6.80$ (dd, $J=6.8 \mathrm{~Hz}, J=6.8 \mathrm{~Hz}, 1 \mathrm{H}, 1^{\prime}-\mathrm{H}$ ), 7.62 (s, $1 \mathrm{H}, 6-\mathrm{H}), 8.09$ (s, $1 \mathrm{H}, 6$ "'-H), 9.32 (brs, $1 \mathrm{H}, 3$ "'-NH).

${ }^{13} \mathrm{C}$-NMR $\left(75 \mathrm{MHz}\right.$, Pyridin- $\mathrm{d}_{5}, 35^{\circ} \mathrm{C}$ ): $\delta=12.62$ (C-7), 12.65 (C-7"'), 39.01 (C-2"), 38.40 (C-5'), 39.75 (C-2'), 49.9 (C-6'), 54.02 (C-3"), 61.92 (C-5”), 74.57 (C-4”), 84.85 (C-3"), 84.99 (C-1"), 85.09 (C-1'), 86.10 (C-4'), 110.43 (C-5), 111.11 (C-5"'), 136.21 (C-6), 136.45 (C-6"'), 150.16 (C-2), 151.73 (C-2"'), 164.85 (C-4), 164.86 (C-4"'), 174.91 (Amid-C=O).

Drehwert: $[\alpha]_{D}^{20}=+39.0(\mathrm{c}=1.0$, Pyridin $)$.

Schmelzpunkt: $118^{\circ} \mathrm{C}$.

IR $(\mathrm{KBr}): \tilde{v}=1652,1471,1268,1089,1041,966,825,764,733$.

UV (MeCN): $\lambda_{\max }(\lg \varepsilon)=197$ (3.39), 264 (3.04).

MS $\left(E S I^{+}\right): m / z=523.2[M+H]^{+}$.

$\mathrm{C}_{58} \mathrm{H}_{57} \mathrm{~N}_{5} \mathrm{O}_{14}$ (522.51)

ber.: $523.2147\left[\mathrm{M}+\mathrm{H}^{+}\right]^{+}$, gef.: $523.2138\left(\mathrm{ESI}^{+}-\mathrm{HRMS}\right)$.

7.2.4.10 (5''-O-TBDMS-3"'-aminocytidinyl)-(6'-N-Fmoc-3'-O-TBDMS)-(S)-TAAamid 93

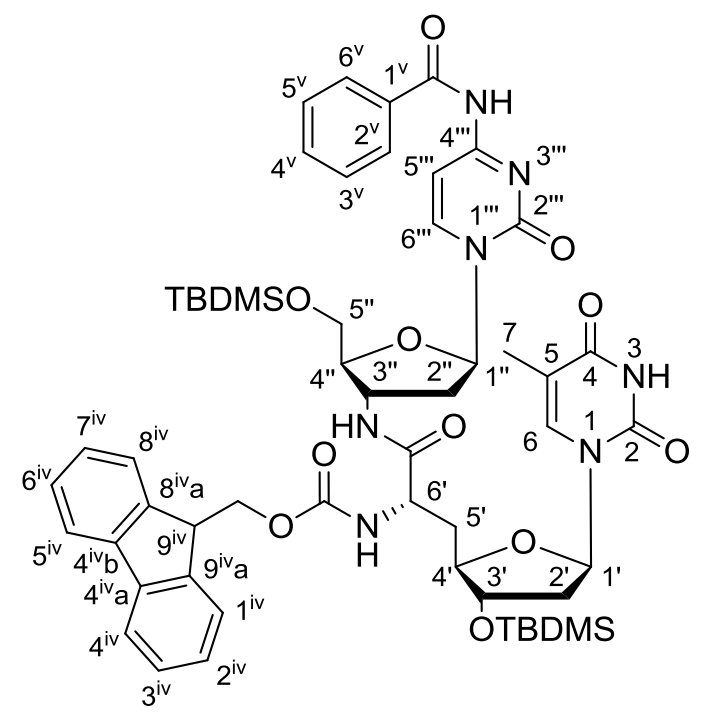

(6'S)-93 
Die Synthese von (6'S)-93 erfolgte gemäß AAV 1 (7.1.7.1). Es wurden $477 \mathrm{mg}$ (0.751 mmol) der TAA (6‘S)-73, $367 \mathrm{mg}$ (0.826 mmol) des 3'-Amino-2'-desoxycytidins 90, $112 \mathrm{mg}(0.826 \mathrm{mmol}) \mathrm{HOBt}, 163 \mathrm{mg}$ (0.826 mmol) EDC und 9.0 mL DCM eingesetzt. Das Rohprodukt wurde chromatographisch an Kieselgel gereinigt (DCM/MeOH 97:3).

Ausbeute: Es wurden $460 \mathrm{mg}(0.433 \mathrm{mmol}, 58 \%)$ eines schwach gelben Feststoffs erhalten.

DC: $R_{\mathrm{f}}(\mathrm{DCM} / \mathrm{MeOH}$ 95:5) $=0.34$.

${ }^{1} \mathrm{H}-\mathrm{NMR}\left(500 \mathrm{MHz}_{\mathrm{CDCl}}, 50^{\circ} \mathrm{C}\right): \delta=0.00$ (s, $\left.3 \mathrm{H}, \mathrm{SiCH}_{3}\right), 0.01$ (s, $\left.3 \mathrm{H}, \mathrm{SiCH}_{3}\right)$, 0.09 (s, $\left.3 \mathrm{H}, \mathrm{SiCH}_{3}\right), 0.10\left(\mathrm{~s}, 3 \mathrm{H}, \mathrm{SiCH}_{3}\right), 0.82$ (s, $\left.9 \mathrm{H}, \operatorname{SiC}\left(\mathrm{CH}_{3}\right)_{3}\right), 0.86(\mathrm{~s}, 9 \mathrm{H}$, $\left.\operatorname{SiC}\left(\mathrm{CH}_{3}\right)_{3}\right), 1.82(\mathrm{~d}, J=0.7 \mathrm{~Hz}, 3 \mathrm{H}, \mathrm{H}-7), 2.04$ (ddd, $J=13.6 \mathrm{~Hz}, J=8.0 \mathrm{~Hz}$, $J=8.0 \mathrm{~Hz}, 1 \mathrm{H}, 2$ '- $\mathrm{H}_{\mathrm{a}}$ ), 2.12 (ddd, J=13.6 Hz, J=8.0 Hz, J=5.5 Hz, $1 \mathrm{H}, 2$ '- $\mathrm{H}_{\mathrm{a}}$ ), 2.21 (ddd, $J=14.2 \mathrm{~Hz}, J=11.3 \mathrm{~Hz}, J=2.9 \mathrm{~Hz}, 1 \mathrm{H}, 5$ '- $\mathrm{H}_{\mathrm{a}}$ ), 2.28-2.35 (m, $1 \mathrm{H}, 5^{\prime}-\mathrm{H}_{\mathrm{b}}$ ), 2.42-2.51 (m, $1 \mathrm{H}, 2$ '- $\left.\mathrm{H}_{\mathrm{b}}\right), 3.14$ (dd, J=13.6 Hz, J=5.6 Hz, $1 \mathrm{H}, 2$ ''- $\left.\mathrm{H}_{\mathrm{b}}\right)$, 3.74-3.83 (m,

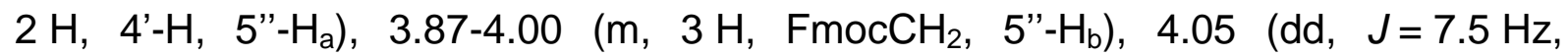
$\left.J=7.5 \mathrm{~Hz}, 1 \mathrm{H}, 9^{\mathrm{iv}}-\mathrm{H}\right), 4.21-4.28$ (m, $2 \mathrm{H}, 3$ '-H, 4"-H), 4.31-4.38 (m, $1 \mathrm{H}, 3$ '”-H), 5.71$5.80\left(\mathrm{~m}, 2 \mathrm{H}, 1^{\prime}-\mathrm{H}, 66^{\prime}-\mathrm{H}\right), 6.07\left(\mathrm{~d}, J=7.2 \mathrm{~Hz}, 1 \mathrm{H}, 6{ }^{\prime}-\mathrm{NH}\right), 6.45$ (dd, J=8.0 Hz, $J=5.6 \mathrm{~Hz}, 1 \mathrm{H}, 1$ '"-H), 6.85-6.89 (m, $1 \mathrm{H}, 6-\mathrm{H})$, 7.09-7.16 (m, $3 \mathrm{H}, \mathrm{ArH})$, 7.26-7.32 (m, $2 \mathrm{H}, \mathrm{ArH}), 7.36-7.43(\mathrm{~m}, 4 \mathrm{H}, \mathrm{ArH}), 7.56(\mathrm{~d}, J=7.5 \mathrm{~Hz}, 1 \mathrm{H}, 5$ '”-H), 7.74-7.79 (m, $2 \mathrm{H}, \mathrm{ArH}), 7.87-7.91(\mathrm{~m}, 2 \mathrm{H}, \mathrm{ArH}), 8.30(\mathrm{~d}, J=7.5 \mathrm{~Hz}, 1 \mathrm{H}, 6$ '”'-H), 10.02 (brs, $1 \mathrm{H}$, 3"-NH), 10.20 (brs, 1 H, 4"'-NH), 11.00 (brs, 1 H, 3-NH).

${ }^{13} \mathrm{C}-\mathrm{NMR} \quad\left(126 \mathrm{MHz}, \quad \mathrm{CDCl}_{3}, \quad 50{ }^{\circ} \mathrm{C}\right): \quad \delta=-5.65 \quad\left(\mathrm{SiCH}_{3}\right), \quad-5.49 \quad\left(\mathrm{SiCH}_{3}\right), \quad-4.85$ $\left(\mathrm{SiCH}_{3}\right),-4.70\left(\mathrm{SiCH}_{3}\right), 12.25(\mathrm{C}-7), 17.80\left(\mathrm{Si} \underline{\mathrm{C}}\left(\mathrm{CH}_{3}\right)_{3}\right), 18.20\left(\mathrm{SiC}\left(\mathrm{CH}_{3}\right)_{3}\right), 25.64$ $\left(\mathrm{SiC}\left(\underline{\mathrm{C}}_{3}\right)_{3}\right), 25.86\left(\mathrm{SiC}\left(\underline{\mathrm{CH}}_{3}\right)_{3}\right), 37.52$ (C-5'), 38.05 (C-2”), 39.55 (C-2'), 46.94 (C-9 $\left.{ }^{\mathrm{iv}}\right)$, 51.27 (C-6'), 53.46 (C-3”), 64.97 (C-5’), 67.33 (FmocCH $\mathrm{F}_{2}$, 75.56 (C-3'), 82.15 (C-4'), 88.54 (C-1', C-4”), 89.42 (C-1"), 96.80 (C-5”'), 111.18 (C-5), 119.87, 119.90 (C-1 ${ }^{\text {iv }}$,

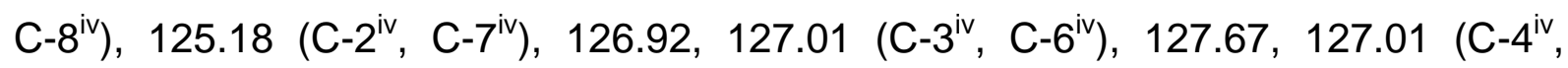
C-5 $\left.{ }^{\mathrm{iv}}\right), 127.98\left(\mathrm{C}-2^{\mathrm{v}}, \mathrm{C}-6^{\mathrm{v}}\right), 128.51\left(\mathrm{C}-3^{\mathrm{v}}, \mathrm{C}-5^{\mathrm{v}}\right), 132.24\left(\mathrm{C}-4^{\mathrm{v}}\right), 133.89\left(\mathrm{C}-1^{\mathrm{v}}\right), 137.56$

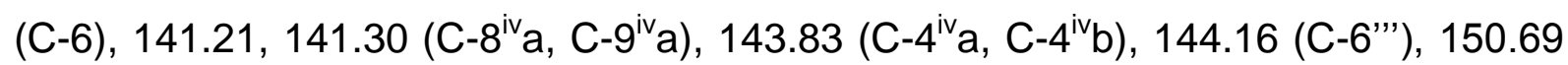
(C-2), 155.68 (Fmoc-C=O), 156.18 (3"'-Amid-C=O), 163.37 (C-4), 164.26 (C-2"'), 167.98 (C-4"'), 171.20 (Bz-C=O).

Drehwert: $[\alpha]_{D}^{20}=+18.5\left(\mathrm{c}=1.2, \mathrm{CHCl}_{3}\right)$.

Schmelzpunkt: $173^{\circ} \mathrm{C}$. 
IR (ATR): $\tilde{v}=1690,1642,1481,1251,1088,1060,835,774,736$.

UV (MeCN): $\lambda_{\max }(\lg \varepsilon)=204$ (4.87), 261 (4.64).

MS $\left(E S I^{+}\right): \mathrm{m} / \mathrm{z}=1084.5[\mathrm{M}+\mathrm{Na}]^{+}$.

$\mathrm{C}_{55} \mathrm{H}_{71} \mathrm{~N}_{6} \mathrm{O}_{11} \mathrm{Si}_{2}(1062.36)$ ber.: $1084.4648[\mathrm{M}+\mathrm{Na}]^{+}$ gef.: 1084.4646 (ESI+-HRMS).

\subsubsection{1 (5''-O-TBDMS-3"'-aminocytidinyl)-(6'-N-Fmoc-3'-O-TBDMS)-(R)-TAA-} amid 93

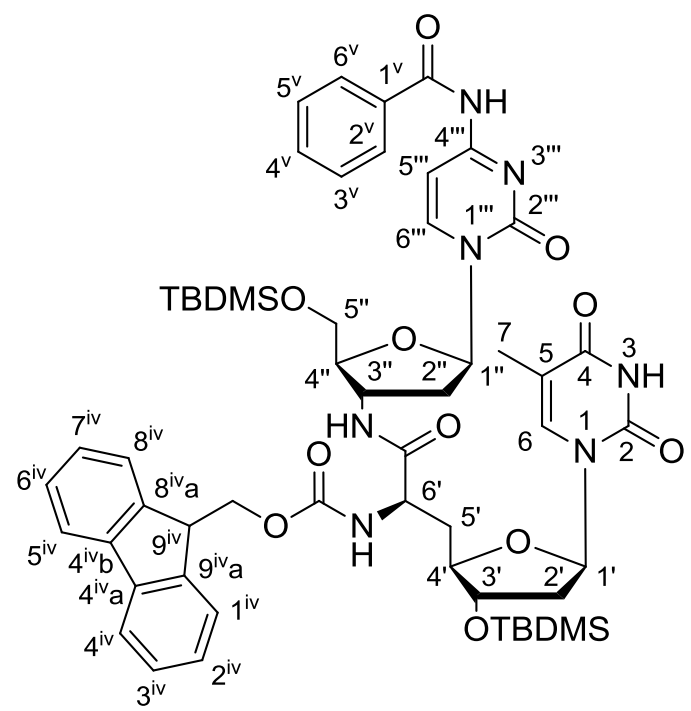

$\left(6^{\prime} R\right)-93$

Die Synthese von (6'R)-93 erfolgte gemäß AAV 1 (7.1.7.1). Es wurden $477 \mathrm{mg}$ $(0.751 \mathrm{mmol})$ der TAA (6'S)-73, $367 \mathrm{mg}(0.826 \mathrm{mmol})$ des 3'-Aminocytidins $\mathbf{9 0}$, $112 \mathrm{mg}(0.826 \mathrm{mmol}) \mathrm{HOBt}, 163 \mathrm{mg}(0.826 \mathrm{mmol})$ EDC und $9.0 \mathrm{~mL}$ DCM eingesetzt. Das Rohprodukt wurde chromatographisch an Kieselgel gereinigt (DCM/MeOH 97:3).

Ausbeute: Es wurden $500 \mathrm{mg}(0.471 \mathrm{mmol}, 63 \%)$ eines schwach gelben Feststoffs erhalten.

DC: $R_{\mathrm{f}}(\mathrm{DCM} / \mathrm{MeOH} 95: 5)=0.34$.

${ }^{1} \mathrm{H}-\mathrm{NMR}\left(500 \mathrm{MHz}\right.$, DMSO-d $\left.6,60^{\circ} \mathrm{C}\right): \delta=0.08\left(\mathrm{~s}, 6 \mathrm{H}, \mathrm{SiCH}_{3}\right), 0.10\left(\mathrm{~s}, 3 \mathrm{H}, \mathrm{SiCH}_{3}\right)$, $0.10\left(\mathrm{~s}, 3 \mathrm{H}, \mathrm{SiCH}_{3}\right), 0.89\left(\mathrm{~s}, 9 \mathrm{H}, \mathrm{SiC}\left(\mathrm{CH}_{3}\right)_{3}\right), 0.90\left(\mathrm{~s}, 9 \mathrm{H}, \mathrm{SiC}\left(\mathrm{CH}_{3}\right)_{3}\right), 1.83$ (d, $J=0.9 \mathrm{~Hz}, 3 \mathrm{H}, \mathrm{H}-7$ ), 1.95-2.01 (m, $2 \mathrm{H}, 5^{\prime}-\mathrm{H}$ ), 2.08 (ddd, $J=13.5 \mathrm{~Hz}, J=6.4 \mathrm{~Hz}$, $J=3.6 \mathrm{~Hz}, 1 \mathrm{H}, 2^{\prime}-\mathrm{H}_{\mathrm{a}}$ ), 2.20 (ddd, $J=13.5 \mathrm{~Hz}, J=8.0 \mathrm{~Hz}, J=4.7 \mathrm{~Hz}, 1 \mathrm{H}, 2^{\prime \prime}-\mathrm{H}_{\mathrm{a}}$ ), 2.30 (ddd, $J=13.5 \mathrm{~Hz}, J=6.8 \mathrm{~Hz}, J=6.8 \mathrm{~Hz}, 1 \mathrm{H}, 2^{\prime}-\mathrm{H}_{\mathrm{b}}$ ), 2.44 (ddd, $J=13.5 \mathrm{~Hz}$, $J=6.7 \mathrm{~Hz}, J=6.7 \mathrm{~Hz}, 1 \mathrm{H}, 2$ "'- $\mathrm{H}_{\mathrm{b}}$ ), $3.78\left(\mathrm{dd}, J=11.6 \mathrm{~Hz}, J=3.5 \mathrm{~Hz}, 1 \mathrm{H}, 5{ }^{\prime}-\mathrm{H}_{\mathrm{a}}\right.$ ), 
3.80-3.86 (m, $\left.1 \mathrm{H}, 4^{\prime}-\mathrm{H}\right), 3.94$ (dd, $\left.1 \mathrm{H}, J=11.6 \mathrm{~Hz}, J=2.2 \mathrm{~Hz}, 5^{\prime \prime}-\mathrm{H}_{\mathrm{b}}\right), 3.98-4.02$ (m, $\left.1 \mathrm{H}, 4{ }^{\prime \prime}-\mathrm{H}\right), 4.11-4.20\left(\mathrm{~m}, 1 \mathrm{H}, 6^{\prime}-\mathrm{H}\right), 4.23\left(\mathrm{dd}, J=7.0 \mathrm{~Hz}, J=7.0 \mathrm{~Hz}, 1 \mathrm{H}, 9^{\mathrm{iv}}-\mathrm{H}\right)$, 4.25-4.33 (m, $\left.3 \mathrm{H}, 3^{\prime}-\mathrm{H}, \mathrm{FmocCH}_{2}\right)$, 4.34-4.41 (m, $1 \mathrm{H}, 3$ '”-H), 6.09 (dd, J = $6.8 \mathrm{~Hz}$, $\left.J=6.8 \mathrm{~Hz}, 1 \mathrm{H}, 1^{\prime}-\mathrm{H}\right), 6.18(\mathrm{dd}, J=6.7 \mathrm{~Hz}, J=4.7 \mathrm{~Hz}, 1 \mathrm{H}, 1$ '- $-\mathrm{H}), 7.29-7.36$ (m, $3 \mathrm{H}$, $\left.5^{\prime \prime \prime}-\mathrm{H}, \quad 3^{\mathrm{v}}-\mathrm{H}, \quad 5^{\mathrm{v}}-\mathrm{H}\right), 7.34-7.44\left(\mathrm{~m}, 3 \mathrm{H}, 6-\mathrm{H}, 2^{\mathrm{iv}}-\mathrm{H}, 7^{\mathrm{iv}}-\mathrm{H}\right), 7.52$ (dd, $J=7.6 \mathrm{~Hz}$, $J=7.6 \mathrm{~Hz}, 2 \mathrm{H}, 3^{\mathrm{iv}}-\mathrm{H}, 6^{\mathrm{iv}}-\mathrm{H}$ ), 7.63 (dd, $J=7.1 \mathrm{~Hz}, J=7.1 \mathrm{~Hz}, 1 \mathrm{H}, 4^{\mathrm{v}}-\mathrm{H}$ ), 7.69 (d, $\left.J=7.1 \mathrm{~Hz}, 2 \mathrm{H}, 2^{\mathrm{v}}-\mathrm{H}, 6^{\mathrm{v}}-\mathrm{H}\right), 7.88\left(\mathrm{~d}, J=7.6 \mathrm{~Hz}, 2 \mathrm{H}, 4^{\mathrm{iv}}-\mathrm{H}, 5^{\mathrm{iv}}-\mathrm{H}\right), 8.03(\mathrm{~d}, J=7.2 \mathrm{~Hz}$, $\left.J=7.2 \mathrm{~Hz}, 2 \mathrm{H}, 1^{\mathrm{iv}}-\mathrm{H}, 8^{\mathrm{iv}}-\mathrm{H}\right), 8.18(\mathrm{~d}, J=7.5 \mathrm{H}, 1 \mathrm{H}, 3$ "'-NH), 8.32-8.39 (m, $1 \mathrm{H}$, 6"'-H), 11.00 (brs, $1 \mathrm{H}, 4$ "'-NH), 11.11 (s, $1 \mathrm{H}, 3-\mathrm{NH})$.

${ }^{13} \mathrm{C}-\mathrm{NMR}\left(126 \mathrm{MHz}, \mathrm{DMSO}_{-} \mathrm{d}_{6}, 60^{\circ} \mathrm{C}\right): \delta=-5.16\left(\mathrm{SiCH}_{3}\right),-5.11\left(\mathrm{SiCH}_{3}\right),-4.32$ $\left(\mathrm{SiCH}_{3}\right),-4.29\left(\mathrm{SiCH}_{3}\right), 12.47(\mathrm{C}-7), 18.07\left(\mathrm{Si} \underline{\mathrm{C}}\left(\mathrm{CH}_{3}\right)_{3}\right), 18.43\left(\mathrm{SiC}\left(\mathrm{CH}_{3}\right)_{3}\right), 26.17$ $\left(\mathrm{SiC}\left(\underline{\mathrm{C}}_{3}\right)_{3}\right), 26.17\left(\mathrm{SiC}\left(\underline{\mathrm{CH}}_{3}\right)_{3}\right), 35.95$ (C-5'), 38.73 (C-2”), 39.21 (C-2'), 47.29 (C-9 $\left.{ }^{\mathrm{iv}}\right)$, 48.56 (C-3”), 52.93 (C-6'), 62.94 (C-5”), 66.34 (FmocCH ${ }_{2}$ ), 75.60 (C-3'), 83.44 (C-4'), 84.98 (C-1'), 85.72 (C-4”), 86.53 (C-1"), 96.35 (C-5”'), 110.24 (C-5), 120.49 (C-4 ${ }^{\mathrm{iv}}$, C- $\left.5^{\text {iv }}\right), 125.60,125.61\left(\mathrm{C}-1^{\text {iv }}, \mathrm{C}-8^{\text {iv }}\right), 127.45\left(\mathrm{C}-3^{\mathrm{v}}, \mathrm{C}-5^{\mathrm{v}}\right), 128.05\left(\mathrm{C}-2^{\mathrm{iv}}, \mathrm{C}-7^{\mathrm{iv}}\right), 128.84$ $\left(\mathrm{C}-2^{v}, \mathrm{C}-6^{v}, \mathrm{C}-3^{\mathrm{iv}}, \mathrm{C}-6^{\mathrm{iv}}\right), 133.04\left(\mathrm{C}-4^{\mathrm{v}}\right), 133.84\left(\mathrm{C}-1^{\mathrm{v}}\right), 136.75\left(\mathrm{C}-3^{\mathrm{v}}, \mathrm{C}-5^{\mathrm{v}}, \mathrm{C}-6\right)$, 141.23, (C-8 ${ }^{\text {iv }}$ a, C-9iva), 144.26, 144.34 (C-4 ${ }^{\text {iv }}$ a, C-4 $\left.{ }^{i v} b\right), 144.80$ (C-6"'), 150.85 (C-2), 155.32 (3"'-Amid-C=O), 156.25 (Fmoc-C=O), 164.07 (C-4), 171.25 (Bz-C=O).

Drehwert: $[\alpha]_{D}^{20}=-90.1\left(\mathrm{c}=1.0, \mathrm{CHCl}_{3}\right)$.

Schmelzpunkt: $167^{\circ} \mathrm{C}$.

IR (ATR): $\tilde{v}=1691,1643,1480,1247,1080,836,779,736,702,688$.

UV (MeCN): $\lambda_{\max }(\lg \varepsilon)=204$ (4.24), 261 (4.01).

MS $\left(E S I^{+}\right): m / z=1062.5[\mathrm{M}+\mathrm{H}]^{+}$.

$\mathbf{C}_{55} \mathrm{H}_{71} \mathrm{~N}_{7} \mathrm{O}_{11} \mathrm{Si}_{2}(1062.36)$

ber.: $1062.4828[\mathrm{M}+\mathrm{H}]^{+}$

gef.: 1062.4825 (ESI $\left.{ }^{+}-\mathrm{HRMS}\right)$. 


\subsubsection{2 (3''-Aminocytidinyl)-(6'-N-Fmoc)-(S)-TAA-amid 147}

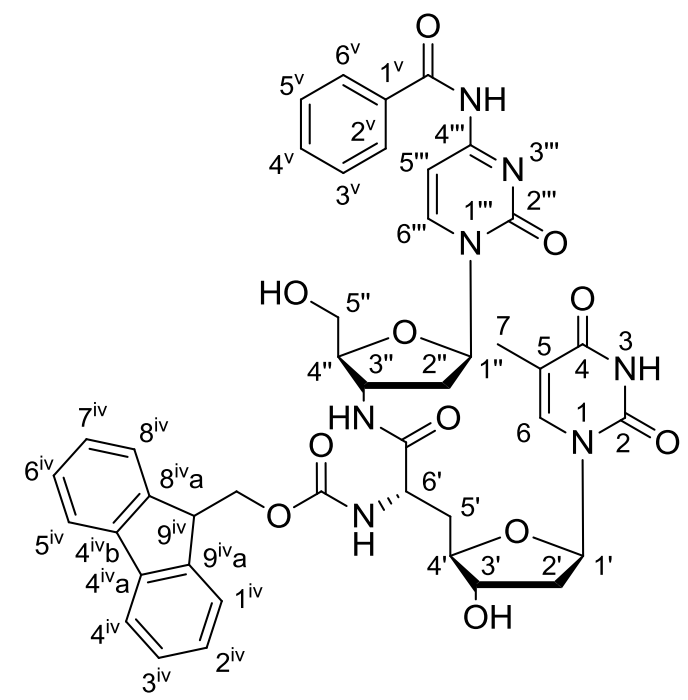

(6'S)-147

\section{Variante 1:}

Eine Lösung von (6'S)-93 (37 mg, $35 \mu \mathrm{mol})$ in $\mathrm{MeOH}(0.7 \mathrm{~mL})$ wurde bei $0{ }^{\circ} \mathrm{C}$ mit $\mathrm{AcCl}(1.3 \mu \mathrm{L}, 1.4 \mathrm{mg}, 18 \mu \mathrm{mol}$, in $0.1 \mathrm{~mL}$ abs. $\mathrm{MeOH})$ versetzt und nach $30 \mathrm{~min}$ auf RT gebracht. Die Reaktionslösung wurde $16 \mathrm{~h}$ bei RT gerührt und mit einem Tropfen ges. $\mathrm{NaHCO}_{3}$-Lösung versetzt. Die resultierende Lösung wurde mit Kieselgel versetzt und das Lösungsmittel bei vermindertem Druck entfernt. Das Rohprodukt wurde chromatographisch an Kieselgel gereinigt (DCM/MeOH 9:1).

Ausbeute: Es wurden 17 mg eines weißen, verunreinigten Feststoffs erhalten (100\% Ausbeute: $29 \mathrm{mg}(35 \mu \mathrm{mol}))$.

\section{Variante 2:}

Zu einer Lösung von (6'S)-93 (10 mg, 9.4 $\mu \mathrm{mol})$ in DMF (0.5 mL) wurde Tris(dimethylamino)sulfonium-difluortrimethylsilicat (13 mg, $47 \mu \mathrm{mol}$ ) gegeben und die resultierende Lösung $1 \mathrm{~h}$ bei Raumtemperatur gerührt. Anhand von Dünnschichtchromatographie (DCM/MeOH 9:1) wurde Zersetzung des Edukts beobachtet. Es konnte keine Bildung des Produkts (6‘ $S)-147$ nachgewiesen werden.

\section{Variante 3:}

Eine Lösung von $500 \mathrm{mg}(0.471 \mathrm{mmol})\left(6^{\prime} S\right)-93$ in abs. $\mathrm{MeOH}(14 \mathrm{~mL})$ wurde mit Ammoniumfluorid (244 mg, $6.6 \mathrm{mmol}$ ) versetzt und $6 \mathrm{~h}$ bei $60^{\circ} \mathrm{C}$ gerührt. Die erhaltene Lösung wurde mit $1 \mathrm{~g}$ Kieselgel versetzt und bei vermindertem Druck zur 
Trockne eingeengt. Das an Kieselgel adsorbierte Produktgemisch wurde chromatographisch gereinigt (DCM/MeOH 9:1), wobei ein Großteil des Edukts (6'S)-93 reisoliert und ein zweites Mal mit einer entsprechenden Menge an Ammoniumfluorid in abs. $\mathrm{MeOH}$ zur Reaktion gebracht wurde. Nach wiederholter chromatographischer Reinigung (DCM/MeOH 9:1) wurde das Produkt in reiner Form erhalten.

Ausbeute: $180 \mathrm{mg}(0.216 \mathrm{mmol}, 46 \%)$ eines schwach gelben Feststoffs.

DC: $R_{\mathrm{f}}(\mathrm{DCM} / \mathrm{MeOH} 9: 1)=0.18$.

${ }^{1} \mathrm{H}-\mathrm{NMR}\left(500 \mathrm{MHz}\right.$, Pyridin- $\left.\mathrm{d}_{5}, 50^{\circ} \mathrm{C}\right): \delta=2.01(\mathrm{~s}, 3 \mathrm{H}, 7-\mathrm{H}), 2.32-2.46(\mathrm{~m}, 2 \mathrm{H}$, 2'- $\mathrm{H}_{\mathrm{a}}$, 5' $^{\prime} \mathrm{H}_{\mathrm{a}}$ ), 2.55 (ddd, J=13.5 Hz, J = 6.6 Hz, J=3.7 Hz, $1 \mathrm{H}$, 2' $^{\prime}-\mathrm{H}_{\mathrm{b}}$ ), 2.64-2.76 (m, $2 \mathrm{H}, 2$ '"- $\mathrm{H}_{\mathrm{a}}, 5^{\prime}-\mathrm{H}_{\mathrm{b}}$ ), 2.90 (ddd, $J=13.5 \mathrm{~Hz}, J=6.8 \mathrm{~Hz}, J=6.6 \mathrm{~Hz}, 1 \mathrm{H}, 2$ '"- $\mathrm{H}_{\mathrm{b}}$ ), 4.20 (dd, $\left.J=12.2 \mathrm{~Hz}, J=3.0 \mathrm{~Hz}, 1 \mathrm{H}, 5{ }^{\prime \prime}-\mathrm{H}_{\mathrm{a}}\right), 4.25(\mathrm{dd}, J=12.2 \mathrm{~Hz}, J=2.3 \mathrm{~Hz}, 1 \mathrm{H}$, 5"- $\mathrm{H}_{\mathrm{b}}$ ), 4.28 (dd, J=6.8 Hz, J=6.8 Hz, $\left.1 \mathrm{H}, 9^{\mathrm{iv}}-\mathrm{H}\right), 4.45-4.53(\mathrm{~m}, 3 \mathrm{H}, 4$ '-H, 4"-H, FmocCHH $\left.\mathrm{C}_{\mathrm{a}}\right), \quad 4.55-4.59\left(\mathrm{~m}, 2 \mathrm{H}, \quad 3{ }^{\prime}-\mathrm{H}, \quad \mathrm{FmocCHH}\right.$ ), 5.10 (dddd, $J=6.8 \mathrm{~Hz}$, $\left.J=6.8 \mathrm{~Hz}, J=6.8 \mathrm{~Hz}, J=6.8 \mathrm{~Hz}, 1 \mathrm{H}, 33^{\prime}-\mathrm{H}\right), 5.15-5.22\left(\mathrm{~m}, 1 \mathrm{H}, 6{ }^{\prime}-\mathrm{H}\right), 6.73$ (dd, $\left.J=6.6 \mathrm{~Hz}, J=4.9 \mathrm{~Hz}, 1 \mathrm{H}, 1{ }^{\prime \prime}-\mathrm{H}\right), 6.83(\mathrm{dd}, J=6.6 \mathrm{~Hz}, J=6.6 \mathrm{~Hz}, 1 \mathrm{H}, 1 '-\mathrm{H}), 7.25-$ $7.31(\mathrm{~m}, 2 \mathrm{H}, \mathrm{ArH}), 7.36-7.41(\mathrm{~m}, 4 \mathrm{H}, \mathrm{ArH}), 7.49$ (dd, $J=7.3 \mathrm{~Hz}, J=7.3 \mathrm{~Hz}, 1 \mathrm{H}$, $\left.4^{\mathrm{v}}-\mathrm{H}\right), 7.56(\mathrm{~s}, 1 \mathrm{H}, 6-\mathrm{H}), 7.62$ (d, J=7.4 Hz, $1 \mathrm{H}, \mathrm{H}-5$ "') $)$ 7.65-7.70 (m, $\left.2 \mathrm{H}, \mathrm{ArH}\right)$, 7.82 (dd, $J=7.5 \mathrm{~Hz}, J=0.7 \mathrm{~Hz}, 2 \mathrm{H}, 4^{\mathrm{iv}}-\mathrm{H}, 5^{\mathrm{iv}}-\mathrm{H}$ ), 8.17-8.21 (m, $\left.2 \mathrm{H}, A r H\right), 8.78$ (d, $J=7.8 \mathrm{~Hz}, 1 \mathrm{H}, 6$ '-NH), 8.83 (d, J=7.4 Hz, $1 \mathrm{H}, 6$ 6"'-H), 9.71-9.82 (m, $1 \mathrm{H}, 3$ '”-NH), 11.76 (brs, 1 H, 4"'-NH), 12.92 (brs, 1 H, 3-NH).

${ }^{13}$ C-NMR (126 MHz, Pyridin- $\mathrm{d}_{5}, 50^{\circ} \mathrm{C}$ ): $\delta=12.25$ (C-7), 37.60 (C-5'), 38.96 (C-2”), 39.65 (C-2'), 47.61 (C-9iv), 49.66 (C-3”), 53.19 (C-6'), 61.66 (C-5’), $66.60\left(\mathrm{FmocCH}_{2}\right)$, 74.57 (C-3'), 84.23 (C-4”), 85.13 (C-4'), 86.99 (C-1'), 87.08 (C-1'), 96.74 (C-5”'), $110.98(\mathrm{C}-5), 120.15\left(\mathrm{C}-4^{\mathrm{iv}}, \mathrm{C}-5^{\mathrm{iv}}\right), 123.50\left(\mathrm{C}-4^{\mathrm{v}}\right), 125.34,125.37\left(\mathrm{C}-1^{\mathrm{iv}}, \mathrm{C}-8^{\mathrm{iv}}\right)$, $127.24\left(\mathrm{C}-2^{v}, \mathrm{C}-6^{v}\right), 127.82\left(\mathrm{C}-3^{v}, \mathrm{C}-5^{v}\right), 128.56,128.69\left(\mathrm{C}-2^{\mathrm{iv}}, \mathrm{C}-7^{\mathrm{iv}}, \mathrm{C}-3^{\mathrm{iv}}, \mathrm{C}-6^{\mathrm{iv}}\right)$, $134.80\left(\mathrm{C}-1^{\mathrm{v}}\right), 135.69$ (C-6), 141.48 (C-8 $\left.{ }^{\mathrm{iv}} \mathrm{a}, \mathrm{C}-9^{\mathrm{iv}} \mathrm{a}\right), 144.32,144.42$ (C-4 $\left.4^{\mathrm{iv}} \mathrm{a}, \mathrm{C}-4^{\mathrm{iv}} \mathrm{b}\right)$, 144.61 (C-6"'), 149.97 (3"'-Amid-C=O), 151.50 (C-2), 163.41 (C-2'”), 164.60 (C-4), $172.44(\mathrm{Bz}-\mathrm{C}=\mathrm{O})$.

Drehwert: $[\alpha]_{D}^{20}=+33.1$ (c=1.0, Pyridin).

Schmelzpunkt: Zersetzung $>160^{\circ} \mathrm{C}$.

IR (ATR): $\tilde{v}=1681,1642,1552,1480,1247,1083,1050,741,698$.

UV (MeCN): $\lambda_{\max }(\lg \varepsilon)=198$ (3.85), 256 (3.62). 
MS $\left(E S I^{+}\right): m / z=856.3[\mathrm{M}+\mathrm{Na}]^{+}$.

$\begin{array}{ll}\mathrm{C}_{43} \mathrm{H}_{43} \mathrm{~N}_{7} \mathrm{O}_{11} \text { (833.84) } & \text { ber.: } 856.3093[\mathrm{M}+\mathrm{Na}]^{+} \\ & \text {gef.: } 856.3099\left(\left.\mathrm{ESI}\right|^{+}-\mathrm{HRMS}\right) .\end{array}$

\subsubsection{3 (5'-O-DMTr-3'"-aminocytidinyl)-(6'-N-Fmoc)-(S)-TAA-amid 150}

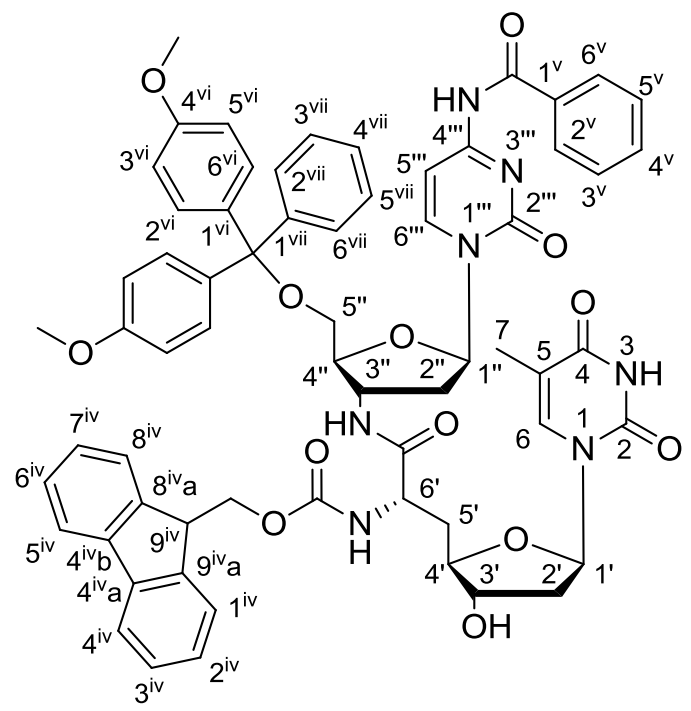

(6'S)-150

Das Edukt (6'S)-147 (150 mg, $0.180 \mathrm{mmol}$ ) wurde mit Pyridin coevaporiert $(3 \times 0.5 \mathrm{~mL})$ und in einem 1:1-Gemisch aus DMF und Pyridin $(0.42 \mathrm{~mL})$ gelöst. Die Lösung wurde mit DMAP $(2.4 \mathrm{mg}, 20 \mu \mathrm{mol})$ und DMTrCl $(67 \mathrm{mg}, 0.198 \mathrm{mmol})$ versetzt und $16 \mathrm{~h}$ bei Raumtemperatur gerührt. Das Lösungsmittelgemisch wurde unter vermindertem Druck entfernt und der Rückstand chromatographisch an Kieselgel gereinigt (DCM/MeOH 95:5 mit 0.5\% Pyridin).

Ausbeute: Es wurden $150 \mathrm{mg}(0.132 \mathrm{mmol}, 73 \%)$ eines gelblich-weißen Feststoffs erhalten.

DC: $R_{\mathrm{f}}(\mathrm{DCM} / \mathrm{MeOH} 9: 1)=0.54$.

${ }^{1} \mathrm{H}-\mathrm{NMR}\left(500 \mathrm{MHz}\right.$, Pyridin- $\left.\mathrm{d}_{5}, 50^{\circ} \mathrm{C}\right): \delta=2.00(\mathrm{~s}, 3 \mathrm{H}, 7-\mathrm{H}), 2.32-2.43(\mathrm{~m}, 2 \mathrm{H}$, 2' $-\mathrm{H}_{\mathrm{a}}, 5^{\prime}-\mathrm{H}_{\mathrm{a}}$ ), 2.55 (ddd, $\left.J=13.4 \mathrm{~Hz}, J=6.5 \mathrm{~Hz}, J=3.6 \mathrm{~Hz}, 1 \mathrm{H}, 2^{\prime}-\mathrm{H}_{\mathrm{b}}\right), 2.65-2.75(\mathrm{~m}$, $2 \mathrm{H}, 2^{\prime \prime}-\mathrm{H}_{\mathrm{a}}, 5^{\prime}-\mathrm{H}_{\mathrm{b}}$ ), 2.90 (ddd, $J=14.1 \mathrm{~Hz}, J=7.3 \mathrm{~Hz}, J=7.0 \mathrm{~Hz}, 1 \mathrm{H}, 2$ '"- $\mathrm{H}_{\mathrm{b}}$ ), 3.75 (dd, $J=10.8 \mathrm{~Hz}, J=2.7 \mathrm{~Hz}, 1 \mathrm{H}, 5$ "'- $\left.\mathrm{H}_{\mathrm{a}}\right), 3.76\left(\mathrm{~s}, 3 \mathrm{H}, \mathrm{OCH}_{3 \mathrm{a}}\right), 3.77\left(\mathrm{~s}, 3 \mathrm{H}, \mathrm{OCH}_{3 \mathrm{~b}}\right.$ ), $3.82\left(\mathrm{dd}, J=10.8 \mathrm{~Hz}, J=3.8 \mathrm{~Hz}, 1 \mathrm{H}, 5{ }^{\prime \prime}-\mathrm{H}_{\mathrm{b}}\right), 4.28(\mathrm{dd}, J=6.8 \mathrm{~Hz}, J=6.8 \mathrm{~Hz}, 1 \mathrm{H}$, $\left.9^{\text {iv }}-\mathrm{H}\right)$, 4.45-4.53 (m, 3 H, 4'-H, 4"'-H, FmocCHH $\left.H_{a}\right)$ 4.55-4.59 (m, $2 \mathrm{H}, 3$ '- $\mathrm{H}$, 
FmocCHH b $^{\text {) }}, 5.09$ (dd, $J=7.6 \mathrm{~Hz}, J=6.7 \mathrm{~Hz}, 1 \mathrm{H}, 6^{\prime}-\mathrm{H}$ ), 5.24 (dddd, $J=7.5 \mathrm{~Hz}$, $J=7.5 \mathrm{~Hz}, J=7.5 \mathrm{~Hz}, J=7.3 \mathrm{~Hz}, 1 \mathrm{H}, 3$ "'-H), 6.59 (dd, $J=7.0 \mathrm{~Hz}, J=4.0 \mathrm{~Hz}, 1 \mathrm{H}$, 1"-H), 6.81 (dd, $\left.J=6.8 \mathrm{~Hz}, J=6.5 \mathrm{~Hz}, 1 \mathrm{H}, 1^{\prime}-\mathrm{H}\right), 7.06\left(\mathrm{~d}, J=8.9 \mathrm{~Hz}, 4 \mathrm{H}, 3^{\mathrm{vi}}-\mathrm{H}\right.$,

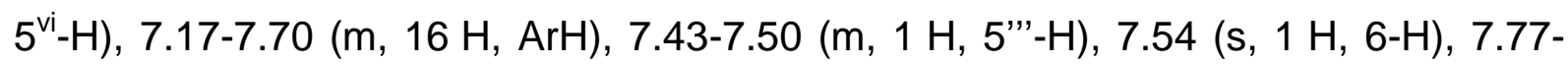
$7.83\left(\mathrm{~m}, 4 \mathrm{H}, 1^{\mathrm{iv}}-\mathrm{H}, 4^{\mathrm{iv}}-\mathrm{H}, 5^{\mathrm{iv}}-\mathrm{H}, 8^{\mathrm{iv}}-\mathrm{H}\right), 8.17-8.21(\mathrm{~m}, 2 \mathrm{H}, \mathrm{ArH}), 8.61(\mathrm{~d}, J=7.5 \mathrm{~Hz}$, $1 \mathrm{H}, 6^{\prime \prime}$ - $-\mathrm{H}$ ), $8.84\left(\mathrm{~d}, J=7.6 \mathrm{~Hz}, 1 \mathrm{H}, 6^{\prime}-\mathrm{NH}\right), 9.51-9.60(\mathrm{~m}, 1 \mathrm{H}, 3$ '”-NH), 11.87 (brs, $1 \mathrm{H}, 4$ "'”-NH), 12.92 (brs, $1 \mathrm{H}, 3-\mathrm{NH})$.

${ }^{13} \mathrm{C}-\mathrm{NMR}\left(126 \mathrm{MHz}\right.$, Pyridin- $\mathrm{d}_{5}, 50{ }^{\circ} \mathrm{C}$ ): $\delta=13.36$ (C-7), 38.53 (C-5'), 40.30 (C-2"), 40.87 (C-2'), 48.76 (C-9 $\left.{ }^{\text {iv }}\right), 50.34$ (C-3”), 54.32 (C-6'), $56.18\left(\mathrm{OCH}_{3}\right), 63.98\left(\mathrm{C}-5^{\prime}\right)$, $67.70\left(\mathrm{FmocCH}_{2}\right.$ ), 75.67 (C-3'), 85.39 (Trityl- $\mathrm{C}_{\text {quart }}$ ), 85.68 (C-4'), 86.30 (C-4'), 87.91 (C-1'), 88.31 (C-1"), 97.92 (C-5"'), 112.05 (C-5), 114.68 (C-3 $\left.3^{\mathrm{vi}}, \mathrm{C}-5^{\mathrm{vi}}\right), 121.28\left(\mathrm{C}-4^{\mathrm{iv}}\right.$,

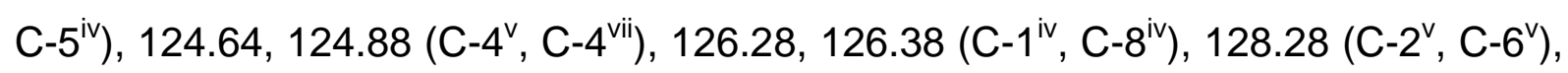
$128.38\left(C-3^{v}, C-5^{v}\right), 128.95,129.34\left(C-2^{i v}, C-3^{i v}, C-6^{i v}, C-7^{i v}\right), 129.73,129.80,129.82$ $\left(C_{a}-2^{v i}, C_{a}-6^{v i}, C_{b}-2^{v i}, C_{b}-6^{v i}, C-2^{v i i}, C-6^{v i i}\right), 133.54\left(C-1^{v}\right), 135.93(C-6), 136.84$, 137.23, 137.39 (C-3 $\left.3^{\text {vii }}, C-5^{\text {vii }}, C_{a}-1^{\text {vi }}, C_{b}-1^{\text {vi }}\right), 142.62$ (C- $\left.{ }^{\text {iv } a}, C-9^{i v} a\right), 145.32\left(C-1^{\text {vii }}\right)$, 145.47, 145.54 (C-4 a a, C-4 ivb), 146.29 (C-6"'), 151.09 (C-2), 151.15 (C-2"'), 152.59 (3"-Amid-C=O), 160.20 (C-4 '), 164.55 (C-4), 165.72 (C-4"'), 173.38 (Bz-C=O).

Drehwert: $[\alpha]_{D}^{20}=+56.7\left(\mathrm{c}=1.0, \mathrm{CHCl}_{3}\right)$.

Schmelzpunkt: $154^{\circ} \mathrm{C}$.

IR (ATR): $\tilde{v}=1691,1661,1642,1503,1480,1247,1083,1032,741,698$.

UV (MeCN): $\lambda_{\max }(\lg \varepsilon)=198$ (4.68), 256 (4.15).

MS $\left(E S I^{+}\right): m / z=1136.21[M+H]^{+}$.

$\mathrm{C}_{64} \mathrm{H}_{61} \mathrm{~N}_{7} \mathrm{O}_{13}(1136.21)$ ber.: $1136.4406[\mathrm{M}+\mathrm{H}]^{+}$ gef.: 1136.4427 (ESI+-HRMS). 


\subsubsection{4 (5'"-O-TBDMS-3"'-aminoadenosinyl)-(6'-N-Fmoc-3'-O-TBDMS)-(S)-TAA-} amid 94

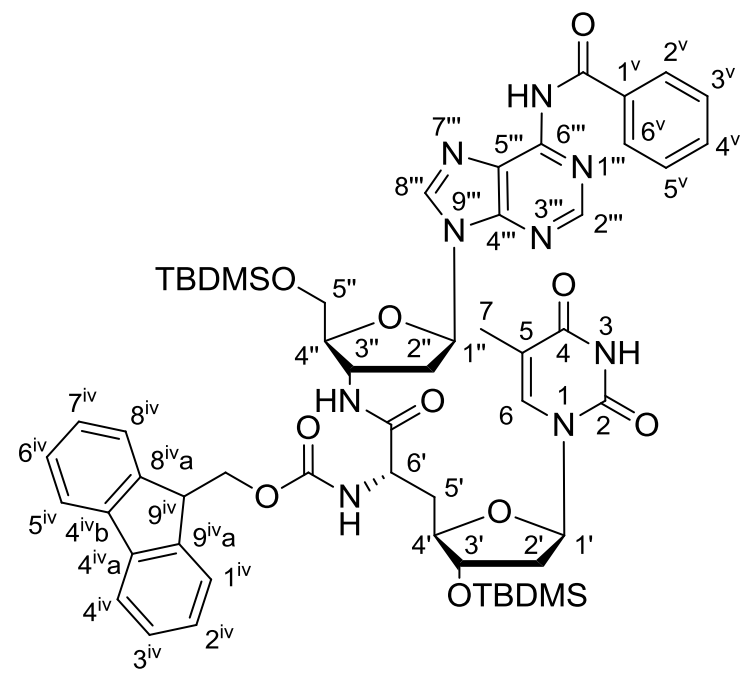

(6'S)-94

Die Synthese erfolgte gemäß AAV 1 (7.1.7.1). Es wurden $690 \mathrm{mg}$ (1.09 mmol) der TAA (6'S)-73, $559 \mathrm{mg}$ (1.20 mmol) des 3'-Aminoadenosins 91, $224 \mathrm{mg}$ (1.14 mmol) EDC, $154 \mathrm{mg}$ (1.14 mmol) HOBt und $13 \mathrm{~mL}$ DCM verwendet. Das Rohprodukt wurde chromatographisch an Kieselgel gereinigt (DCM/MeOH 97:3).

Ausbeute: Es wurden $835 \mathrm{mg}(0.770 \mathrm{mmol}, 71 \%)$ eines bräunlichen Schaums erhalten.

DC: $R_{\mathrm{f}}(\mathrm{DCM} / \mathrm{MeOH}$ 95:5) $=0.24$.

${ }^{1} \mathrm{H}-\mathrm{NMR}\left(500 \mathrm{MHz}, \mathrm{C}_{6} \mathrm{D}_{6}, 70{ }^{\circ} \mathrm{C}\right): \delta=0.03\left(\mathrm{~s}, 3 \mathrm{H}, \mathrm{SiCH}_{3}\right), 0.07$ (s, $\left.3 \mathrm{H}, \mathrm{SiCH}_{3}\right), 0.09$ (s, $\left.6 \mathrm{H}, \mathrm{SiCH}_{3}\right), 0.91$ (s, $\left.9 \mathrm{H}, \mathrm{SiC}\left(\mathrm{CH}_{3}\right)_{3}\right), 0.94$ (s, $\left.9 \mathrm{H}, \mathrm{SiC}\left(\mathrm{CH}_{3}\right)_{3}\right), 1.94$ (s, $\left.3 \mathrm{H}, \mathrm{H}-7\right)$, 1.97-2.05 (m, 2 H, 2'- $-\mathrm{H}), 2.11-2.20\left(\mathrm{~m}, 1 \mathrm{H}, 5^{\prime}-\mathrm{H}_{\mathrm{a}}\right), 2.31-2.40\left(\mathrm{~m}, 1 \mathrm{H}, 5^{\prime}-\mathrm{H}_{\mathrm{b}}\right), 2.71$ (dd, J = 5.9 Hz, 2 H, 2"-H), 3.92 (dd, J=11.2 Hz, J=3.5 Hz, 1 H, 5"'-Ha), 3.97 (dd, $J=11.2 \mathrm{~Hz}, J=2.9 \mathrm{~Hz}, 1 \mathrm{H}, 5{ }^{\prime}-\mathrm{H}_{\mathrm{b}}$ ), 4.03 (ddd, $J=9.6 \mathrm{~Hz}, J=3.4 \mathrm{~Hz}, J=3.4 \mathrm{~Hz}$, $\left.1 \mathrm{H}, 4{ }^{\prime}-\mathrm{H}\right), 4.08\left(\mathrm{dd}, J=6.9 \mathrm{~Hz}, J=6.9 \mathrm{~Hz}, 1 \mathrm{H}, 9^{\mathrm{iv}}-\mathrm{H}\right.$ ), 4.16 (ddd, $J=5.0 \mathrm{~Hz}$, $\left.J=4.4 \mathrm{~Hz}, J=4.4 \mathrm{~Hz}, 1 \mathrm{H}, 3^{\prime}-\mathrm{H}\right), 4.33\left(\mathrm{dd}, J=10.6 \mathrm{~Hz}, J=6.8 \mathrm{~Hz}, 1 \mathrm{H}, \mathrm{FmocCH} \underline{\mathrm{H}}_{\mathrm{a}}\right.$ ), 4.34-4.37 (m, $1 \mathrm{H}, 4$ "'-H), 4.39 (dd, J=10.6 Hz, J=7.1 Hz, $1 \mathrm{H}$, FmocCH$\underline{\mathrm{H}}_{\mathrm{b}}$ ), 4.82 (ddd, J=7.5 Hz, J=5.1 Hz, J=5.1 Hz, $1 \mathrm{H}, 6$ '-H), 4.86-4.92 (m, $1 \mathrm{H}, 3$ '’-H), 6.10 (dd, $\left.J=6.4 \mathrm{~Hz}, J=6.4 \mathrm{~Hz}, 1 \mathrm{H}, 1^{\prime}-\mathrm{H}\right), 6.29-6.37\left(\mathrm{~m}, 1 \mathrm{H}, 6{ }^{\prime}-\mathrm{NH}\right), 6.67$ (dd, $J=6.4 \mathrm{~Hz}, J=6.4 \mathrm{~Hz}, 1 \mathrm{H}, 1$ '"-H), 7.03 (s, $1 \mathrm{H}, 6-\mathrm{H}), 7.06-7.16\left(\mathrm{~m}, 5 \mathrm{H}, \mathrm{C}-2^{\mathrm{v}}, \mathrm{C}-6^{\mathrm{v}}\right.$, C-3 ${ }^{v}, C-5^{v}, C-4^{v}$ ), 7.20 (dd, J=7.4 Hz, J=7.4 Hz, $2 \mathrm{H}, C-3^{\text {iv }}, C-6^{i v}$ ), 7.50 (dd, $\left.J=6.7 \mathrm{~Hz}, J=6.7 \mathrm{~Hz}, 2 \mathrm{H}, \mathrm{C}-2^{\mathrm{iv}}, \mathrm{C}-7^{\mathrm{iv}}\right), 7.55\left(\mathrm{~d}, J=7.4 \mathrm{~Hz}, 2 \mathrm{H}, \mathrm{C}-4^{\mathrm{iv}}, \mathrm{C}-5^{\mathrm{iv}}\right), 7.89-$ 
$8.01\left(\mathrm{~m}, 2 \mathrm{H}, \mathrm{C}-1^{\mathrm{iv}}\right.$, C-8 $\left.{ }^{\mathrm{iv}}\right), 8.23(\mathrm{~d}, J=5.9 \mathrm{~Hz}, 1 \mathrm{H}, 3$ "'-NH), $8.52(\mathrm{~s}, 1 \mathrm{H}, 8$ '”- $-\mathrm{H}), 8.96$ (brs, $1 \mathrm{H}, 2$ '"'-H), 9.42 (brs, $1 \mathrm{H}, \mathrm{BzNH}), 10.78$ (brs, $1 \mathrm{H}, 3-\mathrm{NH}$ ).

${ }^{13} \mathrm{C}-\mathrm{NMR}\left(126 \mathrm{MHz}, \mathrm{C}_{6} \mathrm{D}_{6}, 70{ }^{\circ} \mathrm{C}\right): \delta=-5.64\left(\mathrm{SiCH}_{3}\right),-4.98\left(\mathrm{SiCH}_{3}\right),-4.93\left(\mathrm{SiCH}_{3}\right)$, 11.95 (C-7), $17.72\left(\mathrm{SiC}\left(\mathrm{CH}_{3}\right)_{3}\right), \quad 18.21 \quad\left(\mathrm{Si} \underline{C}\left(\mathrm{CH}_{3}\right)_{3}\right), 25.57 \quad\left(\mathrm{SiC}\left(\underline{\mathrm{C}} \mathrm{H}_{3}\right)_{3}\right), 25.81$ ( $\left.\mathrm{SiC}\left(\mathrm{C}_{3}\right)_{3}\right), 36.45$ (C-5'), 38.18 (C-2"), 39.28 (C-2'), 47.49 (FmocCH), 51.25 (C-3"), 52.67 (C-6'), 64.08 (C-5'), 67.00 ( $\mathrm{FmocCH}_{2}$ ), 75.46 (C-3'), 83.63 (C-4'), 85.03 (C-1"), 86.31 (C-1'), 86.39 (C-4"), 111.04 (C-5), 119.80 (C-4 ${ }^{\text {iv }}, C^{-5^{\text {iv }}}$ ), 124.98 (C-5'”), 125.00 $\left(\mathrm{C}-2^{\mathrm{iv}}, \mathrm{C}-7^{\mathrm{iv}}\right), 126.93\left(\mathrm{C}-3^{\mathrm{iv}}, \mathrm{C}-6^{\mathrm{iv}}\right), 127.49\left(\mathrm{C}-1^{\mathrm{iv}}, \mathrm{C}-8^{\mathrm{iv}}\right), 128.08\left(\mathrm{C}-2^{\mathrm{v}}, \mathrm{C}-6^{\mathrm{v}}\right), 128.26$

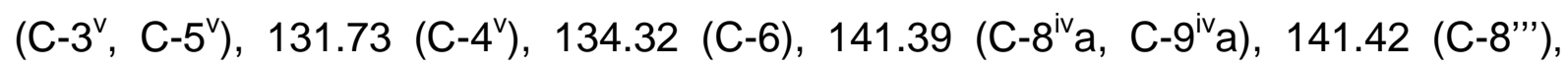
144.09 (C-2"'), 144.16 (C-4 ${ }^{\mathrm{iv} a}$ a, C-4 ${ }^{\mathrm{iv} b}$ ), 149.97 (Fmoc-C=O), 150.67 (C-2), 151.56 (C-4"'), 152.53 (3"'-Amid-C=O), 155.99 (C-6"'), 163.99 (C-4), 171.00 (Bz-C=O).

Drehwert: $[\alpha]_{D}^{20}=-18.1\left(\mathrm{c}=1.0, \mathrm{CHCl}_{3}\right)$.

Schmelzpunkt: $158^{\circ} \mathrm{C}$.

IR (ATR): $\tilde{v}=1685,1609,1447,1250,1223,1075,1037,831,779$.

UV (MeCN): $\lambda_{\max }(\lg \varepsilon)=203$ (4.55), 266 (4.19).

MS $\left(\mathrm{ESI}^{+}\right): \mathrm{m} / \mathrm{z}=1086.5[\mathrm{M}+\mathrm{H}]^{+}$.

$\mathrm{C}_{56} \mathrm{H}_{71} \mathrm{~N}_{9} \mathrm{O}_{10} \mathrm{Si}_{2}$ (1086.39)

ber.: $1086.4935[\mathrm{M}+\mathrm{H}]^{+}$

gef.: 1086.4940 (ESI+-HRMS).

7.2.4.15 (5'"-O-TBDMS-3"'-aminoadenosinyl)-(6'-N-Fmoc-3'-O-TBDMS)-(R)-TAAamid 94

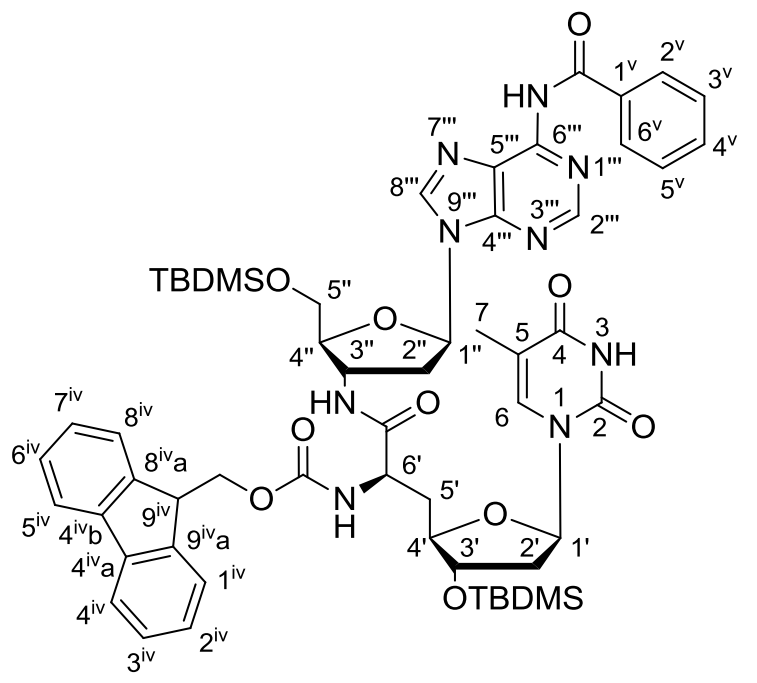

(6'R)-94

Die Synthese erfolgte gemäß AAV 1 (7.1.7.1). Es wurden $530 \mathrm{mg}(0.835 \mathrm{mmol})$ der TAA (6'R)-73, $429 \mathrm{mg}(0.918 \mathrm{mmol})$ des 3'-Amino-2'-desoxyadenosins $91,172 \mathrm{mg}$ 
( $0.878 \mathrm{mmol})$ EDC, $118 \mathrm{mg}(0.878 \mathrm{mmol}) \mathrm{HOBt}$ und $10 \mathrm{~mL}$ DCM verwendet. Das Rohprodukt wurde chromatographisch an Kieselgel gereinigt (DCM/MeOH 97:3).

Ausbeute: Es wurden $620 \mathrm{mg}(0.571 \mathrm{mmol}, 68 \%)$ eines bräunlichen Schaums erhalten.

DC: $R_{\mathrm{f}}(\mathrm{DCM} / \mathrm{MeOH} 95: 5)=0.24$.

${ }^{1} \mathrm{H}$-NMR $\left(500 \mathrm{MHz}, \mathrm{C}_{6} \mathrm{D}_{6}, 70{ }^{\circ} \mathrm{C}\right): \delta=0.05\left(\mathrm{~s}, 3 \mathrm{H}, \mathrm{SiCH}_{3}\right), 0.07\left(\mathrm{~s}, 9 \mathrm{H}, \mathrm{SiCH}_{3}\right), 0.91$ (s, $\left.9 \mathrm{H}, \operatorname{SiC}\left(\mathrm{CH}_{3}\right)_{3}\right), 0.92$ (s, $\left.9 \mathrm{H}, \mathrm{SiC}\left(\mathrm{CH}_{3}\right)_{3}\right), 1.81$ (s, $3 \mathrm{H}, \mathrm{H}-7$ ), 1.88 (ddd, $J=13.3 \mathrm{~Hz}, J=6.3 \mathrm{~Hz}, J=2.6 \mathrm{~Hz}, 1 \mathrm{H}, 2^{\prime}-\mathrm{H}_{\mathrm{a}}$ ), 1.97-2.04 (m, $1 \mathrm{H}, 5^{\prime}-\mathrm{H}_{\mathrm{a}}$ ), 2.32 (ddd, $J=13.8 \mathrm{~Hz}, J=11.2 \mathrm{~Hz}, J=2.9 \mathrm{~Hz}, 1 \mathrm{H}, 5^{\prime}-\mathrm{H}_{\mathrm{b}}$ ), 2.57 (ddd, $J=13.3 \mathrm{~Hz}, J=7.1 \mathrm{~Hz}$, $J=6.3 \mathrm{~Hz}, 1 \mathrm{H}, 2$ '- $\left.\mathrm{H}_{\mathrm{b}}\right), 2.72-2.79\left(\mathrm{~m}, 2 \mathrm{H}, 2^{\prime \prime}-\mathrm{H}\right), 3.87(\mathrm{~d}, J=2.9 \mathrm{~Hz}, 2 \mathrm{H}, 5$ "'-H), 4.094.17 (m, $\left.2 \mathrm{H}, 3^{\prime}-\mathrm{H}, 9^{\mathrm{iv}}-\mathrm{H}\right)$, 4.19-4.26 (m, $\left.2 \mathrm{H}, 4^{\prime}-\mathrm{H}, 4^{\prime \prime}-\mathrm{H}\right), 4.37$ (d, J=7.1 Hz, $2 \mathrm{H}$, FmocCH $\left.{ }_{2}\right), 4.85-4.94\left(\mathrm{~m}, 2 \mathrm{H}, 3^{\prime \prime}-\mathrm{H}, 6^{\prime}-\mathrm{H}\right), 5.67(\mathrm{dd}, J=7.1 \mathrm{~Hz}, J=7.1 \mathrm{~Hz}, 1 \mathrm{H}$, $\left.1^{\prime}-\mathrm{H}\right), 6.19\left(\mathrm{~d}, J=8.4 \mathrm{~Hz}, 1 \mathrm{H}, 6{ }^{\prime}-\mathrm{NH}\right), 6.56(\mathrm{~s}, 1 \mathrm{H}, 6-\mathrm{H}), 6.74(\mathrm{dd}, J=6.6 \mathrm{~Hz}$, $\left.J=6.6 \mathrm{~Hz}, 1 \mathrm{H}, 1^{\prime \prime}-\mathrm{H}\right), 7.08-7.24\left(\mathrm{~m}, 7 \mathrm{H}, \mathrm{C}-2^{v}, \mathrm{C}-6^{v}, \mathrm{C}-3^{v}, \mathrm{C}-5^{v}, \mathrm{C}-4^{v}, \mathrm{C}-3^{\mathrm{iv}}, \mathrm{C}-6^{\mathrm{iv}}\right)$, $7.52\left(\mathrm{dd}, J=9.7 \mathrm{~Hz}, J=7.8 \mathrm{~Hz}, 2 \mathrm{H}, \mathrm{C}-2^{\mathrm{iv}}, \mathrm{C}-7^{\mathrm{iv}}\right), 7.56\left(\mathrm{~d}, J=7.6 \mathrm{~Hz}, 2 \mathrm{H}, \mathrm{C}-4^{\mathrm{iv}}\right.$,

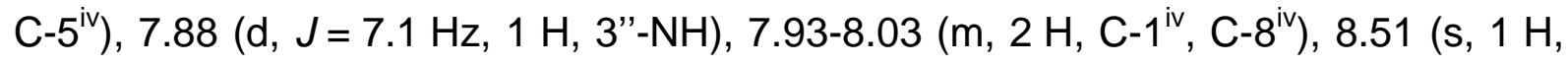
8'"-H), 9.12 (brs, $1 \mathrm{H}, 2$ '"'-H), 9.49 (brs, $1 \mathrm{H}, \mathrm{BzNH}), 10.95$ (brs, $1 \mathrm{H}, 3-\mathrm{NH}$ ).

${ }^{13} \mathrm{C}$-NMR $\left(126 \mathrm{MHz}, \mathrm{C}_{6} \mathrm{D}_{6}, 50^{\circ} \mathrm{C}\right): \delta=-5.67\left(\mathrm{SiCH}_{3}\right),-4.96\left(\mathrm{SiCH}_{3}\right), 11.94(\mathrm{C}-7)$, $17.77\left(\mathrm{Si} \underline{C}\left(\mathrm{CH}_{3}\right)_{3}\right), 18.18\left(\mathrm{Si} \underline{C}\left(\mathrm{CH}_{3}\right)_{3}\right), 25.61\left(\mathrm{SiC}\left(\underline{\mathrm{C}} \mathrm{H}_{3}\right)_{3}\right), 25.80\left(\mathrm{SiC}\left(\underline{\mathrm{C}} \mathrm{H}_{3}\right)_{3}\right), 37.75$ (C-5'), 38.08 (C-2”), 38.59 (C-2'), 47.45 (C-9 '), 51.21 (C-3"), 52.37 (C-6'), 64.18 (C-5”), $67.11\left(\mathrm{FmocCH}_{2}\right.$ ), 76.20 (C-3'), 84.22 (C-4'), 84.32 (C-1"), 86.79 (C-4"),

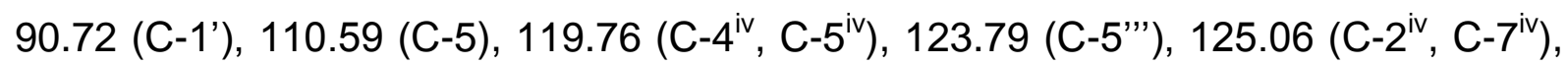
$126.92\left(\mathrm{C}-3^{\mathrm{iv}}, \mathrm{C}-6^{\mathrm{iv}}\right), 127.68\left(\mathrm{C}-1^{\mathrm{iv}}, \mathrm{C}-8^{\mathrm{iv}}\right), 127.86\left(\mathrm{C}-2^{\mathrm{v}}, \mathrm{C}-6^{\mathrm{v}}\right), 128.26\left(\mathrm{C}-3^{\mathrm{v}}, \mathrm{C}-5^{\mathrm{v}}\right)$,

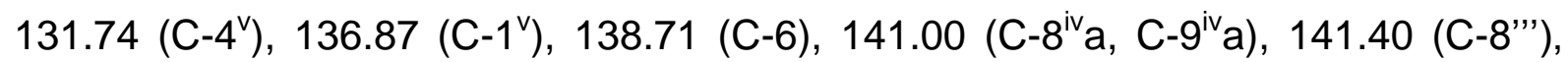
144.17 (C-2"'), 144.25 (C-4 ${ }^{\text {iv } a, ~ C-4 ~}{ }^{\text {iv }}$ b), 150.23 (Fmoc-C=O), 150.60 (C-2), 151.45 (C-4"'), 152.78 (3"-Amid-C=O), 156.45 (C-6"'), 164.03 (C-4), 172.11 (Bz-C=O).

Drehwert: $[\alpha]_{D}^{20}=-111.2\left(\mathrm{c}=1.1, \mathrm{CHCl}_{3}\right)$.

Schmelzpunkt: $157^{\circ} \mathrm{C}$.

IR (ATR): $\tilde{v}=1680,1609,1447,1250,1223,1070,1045,832,774$.

UV (MeCN): $\lambda_{\max }(\lg \varepsilon)=203$ (5.05), 266 (4.68).

MS $\left(\mathrm{ESI}^{+}\right): \mathrm{m} / \mathrm{z}=1086.5[\mathrm{M}+\mathrm{H}]^{+}$.

$\mathrm{C}_{56} \mathrm{H}_{71} \mathrm{~N}_{9} \mathrm{O}_{10} \mathrm{Si}_{2}$ (1086.39) ber.: $1086.4935[\mathrm{M}+\mathrm{H}]^{+}$ gef.: 1086.4935 (ESI+-HRMS). 


\subsubsection{6 (3"'-Aminoadenosinyl)-(6'-N-Fmoc)-(S)-TAA-amid 148}

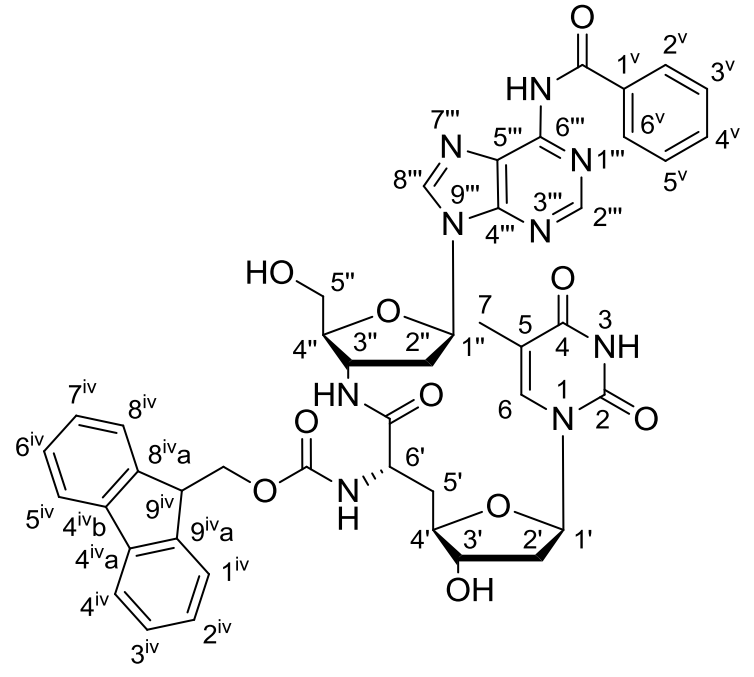

(6'S)-148

Variante 1:

Eine Lösung von (6'S)-94 (10 mg, $9.2 \mu \mathrm{mol}$ ) in $0.3 \mathrm{~mL}$ einer Lösung von $3 \mathrm{HF} \cdot \mathrm{NEt}_{3}$ in THF (5\% v/v) wurde $26 \mathrm{~h}$ bei Raumtemperatur gerührt. Es konnte nur ein sehr geringer Umsatz beobachtet werden.

\section{Variante 2:}

Zu einer Lösung von (6'S)-94 (10 mg, $9.2 \mu \mathrm{mol}$ ) in $0.2 \mathrm{~mL}$ abs. $\mathrm{MeOH}$ wurde AcCl $(0.16 \mu \mathrm{L}, 0.18 \mathrm{mg}, 2.3 \mu \mathrm{mol}$, in $50 \mu \mathrm{L}$ abs. $\mathrm{MeOH})$ gegeben. Die Lösung wurde $22 \mathrm{~h}$ bei Raumtemperatur gerührt. Anschließend wurde weiteres $\mathrm{AcCl}(0.16 \mu \mathrm{L}, 0.18 \mathrm{mg}$, $2.3 \mu \mathrm{mol}$, in $50 \mu \mathrm{L}$ abs. $\mathrm{MeOH})$ dazugegeben. Nach $29 \mathrm{~h}$ wurde kein Umsatz beobachtet. Die Zugabe von weiterem AcCl $(0.32 \mu \mathrm{L}, 0.36 \mathrm{mg}, 4.6 \mu \mathrm{mol}$, in $100 \mu \mathrm{L}$ abs. $\mathrm{MeOH}$ ) führte zur Bildung von zahlreichen Nebenprodukten.

\section{Variante 3:}

Zu einer Lösung von (6'S)-94 (10 mg, $9.2 \mu \mathrm{mol})$ in DMF (0.5 mL) wurde Tris(dimethylamino)sulfonium-difluortrimethylsilicat (13 mg, $47 \mu \mathrm{mol}$ ) dazugegeben. Das Reaktionsgemisch wurde $1 \mathrm{~h}$ bei Raumtemperatur gerührt. Es wurde Zersetzung des Edukts aber keine Bildung des gewünschten Produkts beobachtet.

\section{Variante 4:}

Eine Lösung von (6'S)-94 (650 mg, $0.599 \mathrm{mmol}$ ) in abs. MeOH (10 mL) wurde mit Ammoniumfluorid (249 mg, $6.73 \mathrm{mmol}$ ) versetzt und $4.5 \mathrm{~h}$ bei $60^{\circ} \mathrm{C}$ gerührt. Die so erhaltene Lösung wurde mit Kieselgel versetzt und das Lösungsmittel im Vakuum 
entfernt. Das an Kieselgel adsorbierte Rohprodukt wurde chromatographisch an Kieselgel gereinigt (DCM/MeOH 9:1).

Ausbeute: Es wurden $340 \mathrm{mg}(0.396 \mathrm{mmol}, 66 \%)$ eines gelblichen Feststoffs erhalten.

DC: $R_{\mathrm{f}}(\mathrm{DCM} / \mathrm{MeOH} 9: 1)=0.16$.

${ }^{1} \mathrm{H}-\mathrm{NMR}\left(500 \mathrm{MHz}\right.$, Pyridin- $\left.\mathrm{d}_{5}, 50^{\circ} \mathrm{C}\right): \delta=2.01(\mathrm{~s}, 3 \mathrm{H}, \mathrm{H}-7), 2.32-2.46(\mathrm{~m}, 2 \mathrm{H}$, 2'- $\mathrm{H}_{\mathrm{a}}, 5^{\prime}-\mathrm{H}_{\mathrm{a}}$ ), 2.56 (ddd, $J=13.4 \mathrm{~Hz}, J=6.5 \mathrm{~Hz}, J=3.4 \mathrm{~Hz}, 1 \mathrm{H}, 2^{\prime}-\mathrm{H}_{\mathrm{b}}$ ), 2.73 (ddd, $J=13.0 \mathrm{~Hz}, J=9.4 \mathrm{~Hz}, J=3.5 \mathrm{~Hz}, 1 \mathrm{H}, 5^{\prime}-\mathrm{H}_{\mathrm{b}}$ ), 2.82 (ddd, $J=13.4 \mathrm{~Hz}, J=6.7 \mathrm{~Hz}$, $J=6.7 \mathrm{~Hz}, 1 \mathrm{H}, 2$ '"- $\mathrm{H}_{\mathrm{a}}$ ), 3.09 (ddd, $J=13.4 \mathrm{~Hz}, J=7.9 \mathrm{~Hz}, J=5.4 \mathrm{~Hz}, 1 \mathrm{H}, 2$ '"- $\mathrm{H}_{\mathrm{b}}$ ), 4.17 (dd, $J=12.1 \mathrm{~Hz}, J=3.6 \mathrm{~Hz}, 1 \mathrm{H}, 5^{\prime}$ '- $\mathrm{H}_{\mathrm{a}}$ ), $4.22(\mathrm{dd}, J=12.1 \mathrm{~Hz}, J=3.0 \mathrm{~Hz}, 1 \mathrm{H}$, 5"'- $\mathrm{H}_{\mathrm{b}}$ ), 4.31 (dd, $\left.J=6.6 \mathrm{~Hz}, J=6.6 \mathrm{~Hz}, 1 \mathrm{H}, 9^{\mathrm{iv}}-\mathrm{H}\right), 4.49-4.58\left(\mathrm{~m}, 4 \mathrm{H}, 3^{\prime}-\mathrm{H}, 4^{\prime}-\mathrm{H}\right.$, 4"-H, FmocCH $_{2}, 5.07$ (ddd, $J=8.5 \mathrm{~Hz}, J=5.8 \mathrm{~Hz}, J=5.8 \mathrm{~Hz}, 1 \mathrm{H}, 6^{\prime}-\mathrm{H}$ ), 5.33 (dddd, $J=6.7 \mathrm{~Hz}, \quad J=6.7 \mathrm{~Hz}, J=6.7 \mathrm{~Hz}, J=6.7 \mathrm{~Hz}, 1 \mathrm{H}, 3{ }^{\prime \prime}-\mathrm{H}$ ), $6.76(\mathrm{dd}, J=6.7 \mathrm{~Hz}$, $\left.J=5.4 \mathrm{~Hz}, 1 \mathrm{H}, 1{ }^{\prime}-\mathrm{H}\right), 6.87$ (dd, $\left.J=6.5 \mathrm{~Hz}, J=6.5 \mathrm{~Hz}, 1 \mathrm{H}, 1^{\prime}-\mathrm{H}\right), 7.25-7.30(\mathrm{~m}, 2 \mathrm{H}$, C-2 $2^{\text {iv }}, C^{-} 7^{\text {iv }}$ ), 7.38 (ddd, $2 \mathrm{H}, J=7.5 \mathrm{~Hz}, J=7.5 \mathrm{~Hz}, J=3.9 \mathrm{~Hz}, 2 \mathrm{H}, \mathrm{C}-3^{\text {iv }}, \mathrm{C}^{-6^{\text {iv }}}$ ), 7.43 (dd, $J=7.3 \mathrm{~Hz}, J=7.3 \mathrm{~Hz}, 2 \mathrm{H}, \mathrm{C}-3^{v}, C^{-5}$ ), 7.49 (dd, $J=7.3 \mathrm{~Hz}, J=7.3 \mathrm{~Hz}, 1 \mathrm{H}$, $4^{\mathrm{v}}-\mathrm{H}$ ), 7.54 (s, $\left.1 \mathrm{H}, 6-\mathrm{H}\right), 7.68$ (d, J=7.2 Hz, $2 \mathrm{H}, 1^{\mathrm{iv}}-\mathrm{H}, 8^{\mathrm{iv}}-\mathrm{H}$ ), 7.82 (dd, $J=7.6 \mathrm{~Hz}$, $\left.J=2.4 \mathrm{~Hz}, 2 \mathrm{H}, 4^{\mathrm{iv}}-\mathrm{H}, 5^{\mathrm{iv}}-\mathrm{H}\right), 8.28\left(\mathrm{~d}, J=7.3 \mathrm{~Hz}, 2 \mathrm{H}, 2^{\mathrm{v}}-\mathrm{H}, 6^{\mathrm{v}}-\mathrm{H}\right), 8.84-8.91(\mathrm{~m}, 1 \mathrm{H}$, 6'-NH), 8.86 (s, $1 \mathrm{H}, 8$ '”-H), 8.98 (s, $1 \mathrm{H}, 2$ '"'-H), 9.73 (d, J=5.5 Hz, $1 \mathrm{H}, 3$ '"-NH), 11.86 (brs, $1 \mathrm{H}, 3-\mathrm{NH}$ ).

${ }^{13} \mathrm{C}-N M R\left(126 \mathrm{MHz}\right.$, Pyridin- $\mathrm{d}_{5}, 50{ }^{\circ} \mathrm{C}$ ): $\delta=12.13$ (C-7), 37.38 (C-5'), 38.29 (C-2"), 39.62 (C-2'), 47.66 (C-9 ') 50.69 (C-3"), 53.33 (C-6'), 62.41 (C-5”), 66.57 (FmocCH ${ }_{2}$ ), 74.59 (C-3'), 84.28 (C-4'), 84.81 (C-4'), 85.15 (C-1'), 86.71 (C-1'),

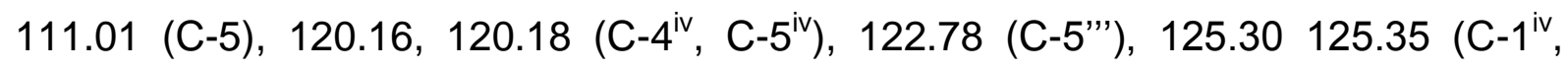
C-8 $\left.8^{\text {iv }}\right), 127.24\left(\mathrm{C}-2^{v}, C^{v}-6^{v}\right), 127.82\left(\mathrm{C}-2^{\mathrm{iv}}, \mathrm{C}-7^{\mathrm{iv}}\right), 128.51\left(\mathrm{C}-3^{v}, \mathrm{C}-5^{\mathrm{v}}\right), 128.84\left(\mathrm{C}-3^{\mathrm{iv}}\right.$,

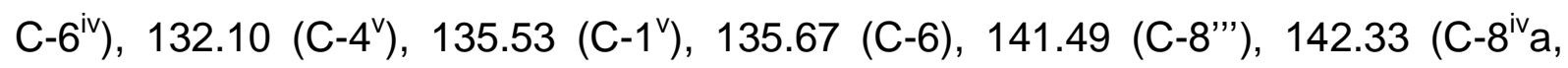

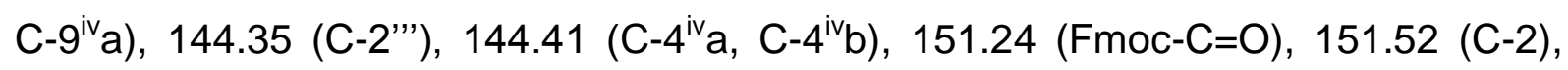
151.94 (3"'-Amid-C=O), 152.18 (C-4"'), 156.89 (C-6"'), 164.59 (C-4), 172.38 (Bz$\mathrm{C}=\mathrm{O})$.

Drehwert: $[\alpha]_{D}^{20}=+6.7(\mathrm{c}=1.1$, Pyridin).

Schmelzpunkt: Zersetzung $>155^{\circ} \mathrm{C}$.

IR (ATR): $\tilde{v}=1681,1666,1609,1513,1447,1250,1222,1050,703$.

UV (MeCN): $\lambda_{\max }(\lg \varepsilon)=199$ (3.94), 256 (3.56). 
MS $\left(E S I^{+}\right): m / z=858.3[M+H]^{+}$.

$\mathrm{C}_{44} \mathrm{H}_{43} \mathrm{~N}_{9} \mathrm{O}_{10}(857.87)$

ber.: $858.3206[\mathrm{M}+\mathrm{H}]^{+}$

gef.: 858.3207 (ESI+-HRMS).

\subsubsection{7 (3'"-Aminoadenosinyl)-(6'-N-Fmoc)-(R)-TAA-amid 148}

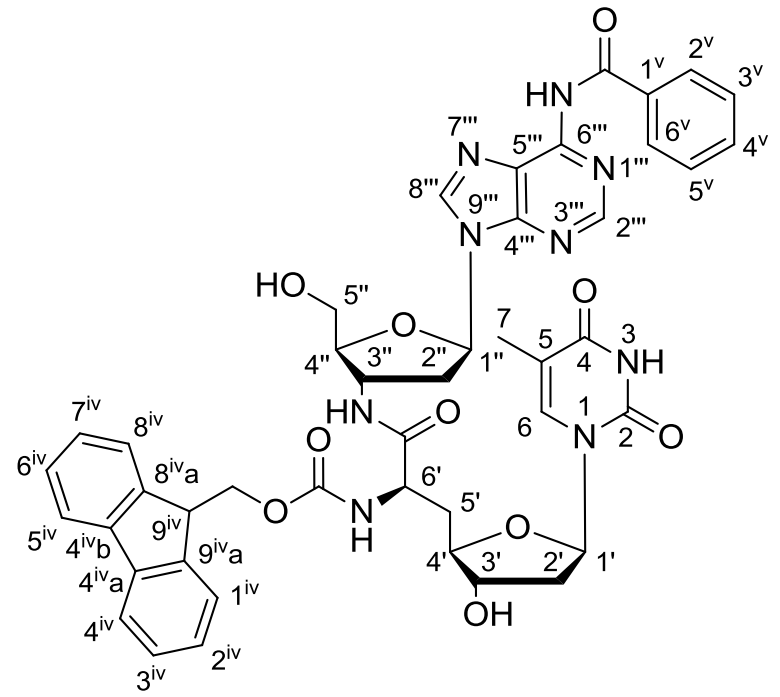

$\left(6^{\prime} R\right)-148$

Die Synthese erfolgte gemäß der Synthese von (6'S)-148. Es wurden $550 \mathrm{mg}$ (0.507 mmol) (6'S)-94, $198 \mathrm{mg}$ (5.35 mmol) Ammoniumfluorid und $10 \mathrm{~mL}$ abs. MeOH verwendet. Das so erhaltene Rohprodukt wurde chromatographisch an Kieselgel gereinigt (DCM/MeOH 9:1).

Ausbeute: Es wurden $287 \mathrm{mg}(0.335 \mathrm{mmol}$, 66\%) eines gelblichen Feststoffs erhalten.

DC: $R_{\mathrm{f}}(\mathrm{DCM} / \mathrm{MeOH} 9: 1)=0.16$.

${ }^{1} \mathrm{H}-\mathrm{NMR}\left(500 \mathrm{MHz}\right.$, Pyridin- $\left.\mathrm{d}_{5}, 50{ }^{\circ} \mathrm{C}\right): \delta=2.01$ (s, $\left.3 \mathrm{H}, \mathrm{H}-7\right), 2.56-2.64\left(\mathrm{~m}, 3 \mathrm{H}, 2^{\prime}-\mathrm{H}\right.$, 5'- $\mathrm{H}_{\mathrm{a}}$ ), 2.69 (ddd, J=14.6 Hz, J=9.3 Hz, J=5.4 Hz, 1 H, 5'- $\mathrm{H}_{\mathrm{b}}$ ), 2.89 (ddd, $J=13.2 \mathrm{~Hz}, J=6.6 \mathrm{~Hz}, J=6.4 \mathrm{~Hz}, 1 \mathrm{H}, 2$ '"- $\mathrm{H}_{\mathrm{a}}$ ), 2.82 (ddd, $J=13.4 \mathrm{~Hz}, J=6.6 \mathrm{~Hz}$, $J=6.4 \mathrm{~Hz}, 1 \mathrm{H}, 2$ '- $\mathrm{H}_{\mathrm{a}}$ ), 3.14 (ddd, J=13.4 Hz, J=7.7 Hz, J=5.7 Hz, $1 \mathrm{H}, 2$ '- $\mathrm{H}_{\mathrm{b}}$ ), $4.13\left(\mathrm{dd}, J=12.1 \mathrm{~Hz}, J=3.5 \mathrm{~Hz}, 1 \mathrm{H}, 5{ }^{\prime}{ }^{-} \mathrm{H}_{\mathrm{a}}\right), 4.19(\mathrm{dd}, J=12.1 \mathrm{~Hz}, J=2.8 \mathrm{~Hz}, 1 \mathrm{H}$, 5"- $\left.\mathrm{H}_{\mathrm{b}}\right), 4.29$ (dd, J=6.7 Hz, J=6.7 Hz, $\left.1 \mathrm{H}, 9^{\mathrm{iv}}-\mathrm{H}\right), 4.49-4.58(\mathrm{~m}, 4 \mathrm{H}, 3$ '- $\mathrm{H}, 4$ '- $-\mathrm{H}$, 4"-H, FmocCH ), 5.10 (ddd, J = 8.0 Hz, J = 5.4 Hz, J=5.4 Hz, 1 H, 6'-H), 5.30 (dddd, $J=6.6 \mathrm{~Hz}, J=6.6 \mathrm{~Hz}, J=6.6 \mathrm{~Hz}, J=6.6 \mathrm{~Hz}, 1 \mathrm{H}, 3{ }^{\prime}-\mathrm{H}$ ), 6.70 (dd, $J=6.6 \mathrm{~Hz}$, 
$\left.J=6.6 \mathrm{~Hz}, 1 \mathrm{H}, 1^{\prime}-\mathrm{H}\right), 6.81$ (dd, $J=6.4 \mathrm{~Hz}, J=6.4 \mathrm{~Hz}, 1 \mathrm{H}, 1{ }^{\prime \prime}-\mathrm{H}$ ), 7.29 (dd, $J=7.2 \mathrm{~Hz}, J=7.2 \mathrm{~Hz}, 2 \mathrm{H}, 2^{\mathrm{iv}}-\mathrm{H}, 7^{\mathrm{iv}}-\mathrm{H}$ ), 7.39 (dd, $2 \mathrm{H}, J=7.5 \mathrm{~Hz}, J=7.5 \mathrm{~Hz}, 2 \mathrm{H}$, $3^{\mathrm{iv}}-\mathrm{H}, 6^{\mathrm{iv}}-\mathrm{H}$ ), 7.43 (dd, $J=7.3 \mathrm{~Hz}, J=7.3 \mathrm{~Hz}, 2 \mathrm{H}, 3^{\mathrm{v}}-\mathrm{H}, 5^{\mathrm{v}}-\mathrm{H}$ ), 7.49 (dd, $J=7.4 \mathrm{~Hz}$, $\left.J=7.4 \mathrm{~Hz}, 1 \mathrm{H}, 4^{\mathrm{v}}-\mathrm{H}\right), 7.55(\mathrm{~s}, 1 \mathrm{H}, 6-\mathrm{H}), 7.67\left(\mathrm{~d}, J=7.2 \mathrm{~Hz}, 1 \mathrm{H}, 1^{\mathrm{iv}}-\mathrm{H}\right), 7.69$ (d, $J=7.2 \mathrm{~Hz}, 1 \mathrm{H}, 8^{\mathrm{iv}}-\mathrm{H}$ ), $7.82\left(\mathrm{~d}, J=7.6 \mathrm{~Hz}, 2 \mathrm{H}, 4^{\mathrm{iv}}-\mathrm{H}, 5^{\mathrm{iv}}-\mathrm{H}\right), 8.28(\mathrm{~d}, J=7.3 \mathrm{~Hz}, 2 \mathrm{H}$,

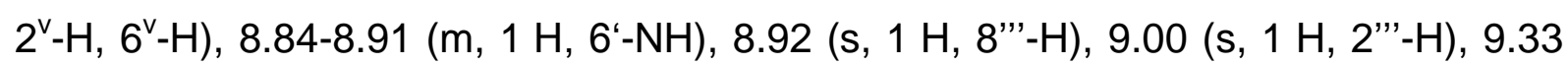
(d, $J=6.6 \mathrm{~Hz}, 1 \mathrm{H}, 3$ "'-NH), 11.85 (brs, $1 \mathrm{H}, 3-\mathrm{NH}$ ).

${ }^{13} \mathrm{C}-N M R\left(126 \mathrm{MHz}\right.$, Pyridin- $\mathrm{d}_{5}, 50{ }^{\circ} \mathrm{C}$ ): $\delta=12.33$ (C-7), 37.14 (C-5'), 38.43 (C-2"), 39.77 (C-2'), 47.60 (C-9 $\left.{ }^{\text {iv }}\right), 50.86$ (C-3"), 53.72 (C-6'), 62.38 (C-5”), 66.65 $\left(\mathrm{FmocCH}_{2}\right), 74.46$ (C-3'), 83.77 (C-4'), 84.76 (C-4'), 85.96 (C-1'), 86.66 (C-1'), 110.76 (C-5), $120.14\left(\mathrm{C}-4^{\mathrm{iv}}, \mathrm{C}^{-5^{\mathrm{iv}}}\right), 122.78\left(\mathrm{C}-5^{\prime \prime \prime}\right), 125.38,125.72\left(\mathrm{C}-1^{\text {iv }}, \mathrm{C}-8^{\mathrm{iv}}\right)$, $127.26\left(\mathrm{C}-2^{v}, C^{v}-6^{v}\right), 127.82\left(\mathrm{C}-2^{\text {iv }}, \mathrm{C}-7^{\mathrm{iv}}\right), 128.51\left(\mathrm{C}-3^{v}, \mathrm{C}-5^{\mathrm{v}}\right), 128.84\left(\mathrm{C}-3^{\mathrm{iv}}, \mathrm{C}-6^{\mathrm{iv}}\right)$,

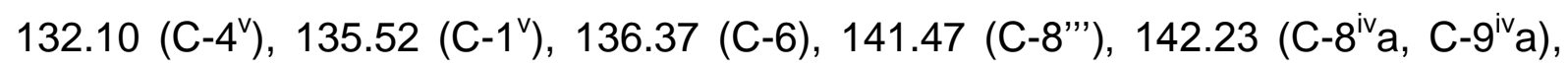

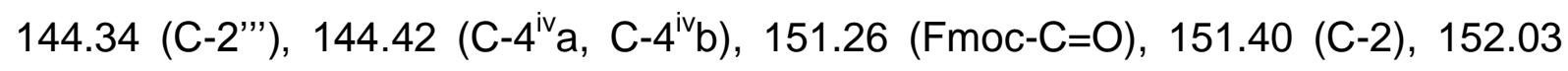
(C-6"'), 152.22 (3"-Amid-C=O), 157.01 (C-4"'), 164.52 (C-4), 173.15 (Bz-C=O).

Drehwert: $[\alpha]_{D}^{20}=+27.6(\mathrm{c}=1.0$, Pyridin).

Schmelzpunkt: Zersetzung $>145^{\circ} \mathrm{C}$.

IR (ATR): $\tilde{v}=1685,1666,1609,1513,1452,1442,1250,1223,1065,703$.

UV (MeCN): $\lambda_{\max }(\lg \varepsilon)=198$ (4.22), 256 (3.86).

MS $\left(\mathrm{ESI}^{+}\right): \mathrm{m} / \mathrm{z}=880.3[\mathrm{M}+\mathrm{Na}]^{+}$.

$\mathrm{C}_{44} \mathrm{H}_{43} \mathrm{~N}_{9} \mathrm{O}_{10}(857.87)$

ber.: $880.3025[\mathrm{M}+\mathrm{Na}]^{+}$ gef.: 880.3022 (ESI+-HRMS). 


\subsubsection{8 (5'-O-DMTr-3''-aminoadenosinyl)-(6'-N-Fmoc)-(S)-TAA-amid 151}

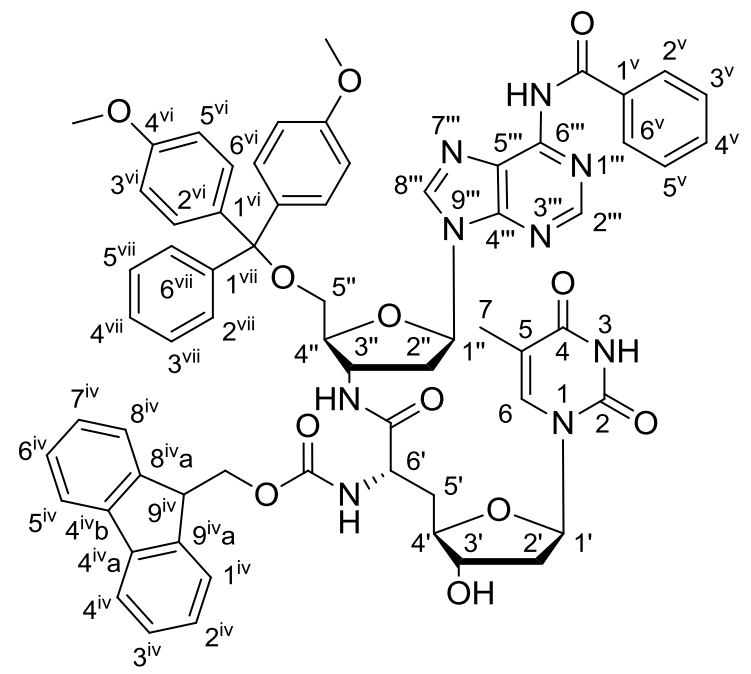

(6'S)-151

Die Synthese von (6'S)-151 erfolgte gemäß AAV 2 (7.1.7.2). Es wurden $320 \mathrm{mg}$ (0.373 mmol) (6'S)-148, $138 \mathrm{mg}(0.410 \mathrm{mmol}) \mathrm{DMTrCl}$ und $0.87 \mathrm{~mL}$ Pyridin verwendet. Als Eluent für die chromatographische Reinigung wurde $\mathrm{DCM} / \mathrm{MeOH} /$ Pyridin 92:7:1 verwendet.

Ausbeute: Es wurden $310 \mathrm{mg}(0.267 \mathrm{mmol}, 72 \%)$ eines farblosen Schaums erhalten.

DC: $R_{f}(\mathrm{DCM} / \mathrm{MeOH} 98: 2)=0.27$.

${ }^{1} \mathrm{H}-N M R\left(500 \mathrm{MHz}\right.$, Pyridin- $\left.\mathrm{d}_{5}, 50^{\circ} \mathrm{C}\right): \delta=2.00(\mathrm{~s}, 3 \mathrm{H}, 7-\mathrm{H}), 2.30-2.43(\mathrm{~m}, 2 \mathrm{H}$, 2'- $\mathrm{H}_{\mathrm{a}}, 5$ ' $-\mathrm{H}_{\mathrm{a}}$ ), 2.55 (ddd, J=13.4 Hz, J=6.6 Hz, J=3.6 Hz, $1 \mathrm{H}, 2^{\prime}-\mathrm{H}_{\mathrm{b}}$ ), 2.70 (ddd, $J=13.6 \mathrm{~Hz}, J=9.0 \mathrm{~Hz}, J=4.4 \mathrm{~Hz}, 1 \mathrm{H}, 5^{\prime}-\mathrm{H}_{\mathrm{b}}$ ), 2.85 (ddd, $J=13.4 \mathrm{~Hz}, J=6.8 \mathrm{~Hz}$, $J=6.7 \mathrm{~Hz}, 1 \mathrm{H}, 2$ ''- $\mathrm{H}_{\mathrm{a}}$ ), 3.21 (ddd, $J=13.4 \mathrm{~Hz}, J=8.0 \mathrm{~Hz}, J=5.6 \mathrm{~Hz}, 1 \mathrm{H}, 2$ '- $\mathrm{H}_{\mathrm{b}}$ ), $3.67\left(\mathrm{~s}, 3 \mathrm{H}, \mathrm{OCH}_{3}\right), 3.68\left(\mathrm{~s}, 3 \mathrm{H}, \mathrm{OCH}_{3}\right), 3.73-3.81(\mathrm{~m}, 2 \mathrm{H}, 5$ '”-H), 4.30 (dd, $J=6.8 \mathrm{~Hz}, J=6.8 \mathrm{~Hz}, 1 \mathrm{H}, 9^{\mathrm{iv}}-\mathrm{H}$ ), 4.47 (ddd, $J=9.5 \mathrm{~Hz}, J=3.8 \mathrm{~Hz}, 1 \mathrm{H}, 4^{\prime}-\mathrm{H}$ ), 4.53 (d, $J=6.8 \mathrm{~Hz}, 1 \mathrm{H}, \mathrm{FmocCHH}$ ), $4.55\left(\mathrm{~d}, J=6.8 \mathrm{~Hz}, 1 \mathrm{H}, \mathrm{FmocCHH}_{\mathrm{b}}\right), 4.67-4.72(\mathrm{~m}$, $1 \mathrm{H}, 4$ 4"-H) $^{\prime} 5.04$ (ddd, $J=8.3 \mathrm{~Hz}, J=8.3 \mathrm{~Hz}, J=6.3 \mathrm{~Hz}, 1 \mathrm{H}, 6{ }^{\prime}-\mathrm{H}$ ), 5.31 (dddd, $J=6.8 \mathrm{~Hz}, J=6.8 \mathrm{~Hz}, J=6.8 \mathrm{~Hz}, J=6.8 \mathrm{~Hz}, 1 \mathrm{H}, 3,-\mathrm{H}$ ), 6.75 (dd, $J=6.7 \mathrm{~Hz}$, $J=5.6 \mathrm{~Hz}, 1 \mathrm{H}, 1{ }^{\prime \prime}-\mathrm{H}$ ), 6.82 (dd, J=6.6 Hz, J=6.6 Hz, $1 \mathrm{H}, 1$ '-H), 6.93 (dd, $\left.J=9.0 \mathrm{~Hz}, J=2.5 \mathrm{~Hz}, 4 \mathrm{H}, 3^{\mathrm{vi}}-\mathrm{H}, 5^{\mathrm{vi}}-\mathrm{H}\right), 7.18-7.23\left(\mathrm{~m}, 2 \mathrm{H}, 2^{\mathrm{v}}-\mathrm{H}, 6^{\mathrm{v}}-\mathrm{H}\right), 7.26$ (ddd, $J=7.5 \mathrm{~Hz}, J=7.5 \mathrm{~Hz}, J=0.8 \mathrm{~Hz}, 1 \mathrm{H}, 2^{\mathrm{iv}}-\mathrm{H}$ ), 7.27 (ddd, $J=7.5 \mathrm{~Hz}, J=7.5 \mathrm{~Hz}$, $J=1.1 \mathrm{~Hz}, 1 \mathrm{H}, 7^{\mathrm{iv}}-\mathrm{H}$ ), 7.34 (dd, $J=7.8 \mathrm{~Hz}, J=7.8 \mathrm{~Hz}, 2 \mathrm{H}, 2^{\mathrm{vii}}-\mathrm{H}, 6^{\text {vii }}-\mathrm{H}$ ), 7.38 (ddd, $J=7.5 \mathrm{~Hz}, J=7.5 \mathrm{~Hz}, J=7.5 \mathrm{~Hz}, 2 \mathrm{H}, 3^{\mathrm{iv}}-\mathrm{H}, 6^{\mathrm{iv}}-\mathrm{H}$ ), 7.42 (dd, $J=7.2 \mathrm{~Hz}, J=7.2 \mathrm{~Hz}$, 
$\left.2 \mathrm{H}, 3^{\mathrm{v}}-\mathrm{H}, 5^{\mathrm{v}}-\mathrm{H}\right), 7.49$ (dd, $\left.J=7.4 \mathrm{~Hz}, J=7.4 \mathrm{~Hz}, 1 \mathrm{H}, 4^{\mathrm{v}}-\mathrm{H}\right), 7.54-7.58\left(\mathrm{~m}, 5 \mathrm{H}, 2^{\mathrm{vi}}-\mathrm{H}\right.$, $\left.6^{\mathrm{vi}}-\mathrm{H}, 6-\mathrm{H}\right), 7.65-7.69\left(\mathrm{~m}, 2 \mathrm{H}, 1^{\mathrm{iv}}-\mathrm{H}, 8^{\mathrm{iv}}-\mathrm{H}\right), 7.69-7.73\left(\mathrm{~m}, 2 \mathrm{H}, 3^{\mathrm{vii}}-\mathrm{H}, 5^{\mathrm{vii}}-\mathrm{H}\right), 7.82(\mathrm{dd}$, $\left.J=7.6 \mathrm{~Hz}, J=2.9 \mathrm{~Hz}, 2 \mathrm{H}, 4^{\mathrm{iv}}-\mathrm{H}, 5^{\mathrm{iv}}-\mathrm{H}\right), 8.71(\mathrm{~s}, 1 \mathrm{H}, 8$ '”- $\mathrm{H}), 8.84(\mathrm{~s}, 1 \mathrm{H}, 2$ '”- $\mathrm{H})$, 8.85-8.92 (m, 1H, 6'-NH), 9.63 (brs, $1 \mathrm{H}, 3$ "'-NH), 12.94 (brs, $1 \mathrm{H}, 3-\mathrm{NH})$.

${ }^{13} \mathrm{C}$-NMR (126 MHz, Pyridin- $\mathrm{d}_{5}, 50{ }^{\circ} \mathrm{C}$ ): $\delta=12.24$ (C-7), 37.25 (C-5'), 37.58 (C-2"), 39.74 (C-2'), 47.66 (C-9'), 51.31 (C-3"), 53.29 (C-6'), $54.98\left(\mathrm{OCH}_{3}\right), 64.54$ (C-5”), $66.56\left(\mathrm{FmocCH}_{2}\right.$ ), 74.53 (C-3'), 84.42 (C-4'), 84.82 (C-4'), 85.11 (C-1'), 86.69 (C-1'), 110.96 (C-5), 113.53 (C-3 $\left.3^{\text {vi }}, C-5^{\text {vi }}\right), 120.16$ (C-4 $\left.4^{\text {iv }}, C-5^{\text {iv }}\right), 123.75$ (C-5"'), 125.35, $125.35\left(\mathrm{C}-1^{\text {iv }}, \mathrm{C}-8^{\mathrm{iv}}\right), 126.92\left(\mathrm{C}-3^{\mathrm{vii}}, \mathrm{C}-5^{\mathrm{vii}}\right), 127.24\left(\mathrm{C}-2^{\mathrm{v}}, \mathrm{C}-6^{\mathrm{v}}\right), 127.82\left(\mathrm{C}-2^{\mathrm{iv}}, \mathrm{C}-7^{\mathrm{iv}}\right)$, $128.00(\mathrm{ArC}), 128.50\left(\mathrm{C}-3^{v}, C^{v} 5^{v}\right), 128.60,128.83\left(\mathrm{C}-3^{\text {iv }}, \mathrm{C}-6^{\mathrm{iv}}\right), 130.37,130.40$ $\left(C_{a}-2^{v i}, C_{a}-6^{v i}, C_{b}-2^{v i}, C_{b}-6^{v i}\right), 132.08\left(C-4^{v}\right), 135.51\left(C-1^{v}\right), 135.70\left(C-4^{v i i}\right), 136.36$

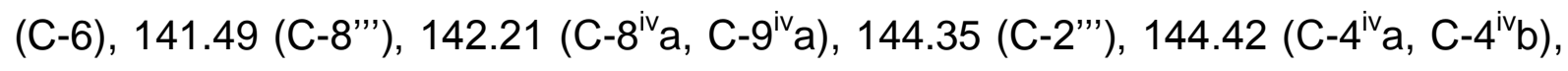
145.45 (C-4 ${ }^{\text {vi }}$ ), 150.03 (C-2), 151.30 (Fmoc-C=O), 151.48 (C-6"'), 152.20 (3"-Amid$\mathrm{C}=\mathrm{O}), 158.89$ (C-4"'), 164.58 (C-4), 172.18 (Bz-C=O).

Drehwert: $[\alpha]_{D}^{20}=-9.9\left(\mathrm{c}=1.0, \mathrm{CHCl}_{3}\right)$

Schmelzpunkt: $130^{\circ} \mathrm{C}$.

IR (ATR): $\tilde{v}=1680,1509,1447,1247,1223,1174,1027,822,703$.

UV (MeCN): $\lambda_{\max }(\lg \varepsilon)=197$ (4.76), 255 (4.23).

MS $\left(E S I^{+}\right): m / z=1160.5[M+H]^{+}$.

$\mathrm{C}_{65} \mathrm{H}_{61} \mathrm{~N}_{9} \mathrm{O}_{12}(1160.23)$ ber.: $1160.4512[\mathrm{M}+\mathrm{H}]^{+}$ gef.: 1160.4509 (ESI'-HRMS). 


\subsubsection{9 (5'-O-DMTr-3'"-aminoadenosinyl)-(6'-N-Fmoc)-(R)-TAA-amid 151}

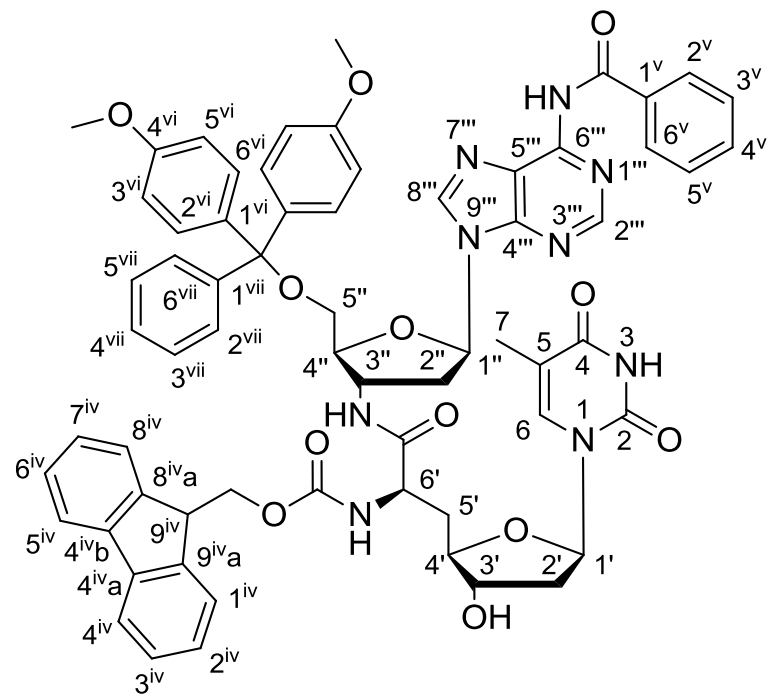

$\left(6^{\prime} R\right)-151$

Die Synthese von (6'R)-151 erfolgte gemäß AAV 2 (7.1.7.2). Es wurden $270 \mathrm{mg}$ (0.315 mmol) (6'R)-148, $117 \mathrm{mg}(0.347 \mathrm{mmol}) \mathrm{DMTrCl}$ und $0.73 \mathrm{~mL}$ abs. Pyridn verwendet. Als Eluent für die chromatographische Reinigung wurde $\mathrm{DCM} / \mathrm{MeOH} /$ Pyridin 92:7:1 verwendet.

Ausbeute: Es wurden $295 \mathrm{mg}(0.254 \mathrm{mmol}$, 81\%) eines farblosen Schaums erhalten.

DC: $R_{\mathrm{f}}(\mathrm{DCM} / \mathrm{MeOH} 98: 2)=0.27$.

${ }^{1} \mathrm{H}-\mathrm{NMR}\left(500 \mathrm{MHz}\right.$, Pyridin- $\left.\mathrm{d}_{5}, 50{ }^{\circ} \mathrm{C}\right): \delta=1.98(\mathrm{~s}, 3 \mathrm{H}, 7-\mathrm{H})$, 2.53-2.61 (m, $3 \mathrm{H}, 2^{\prime}-\mathrm{H}$, 5'- $\mathrm{H}_{\mathrm{a}}$ ), 2.67 (ddd, J=14.6 Hz, J=9.5 Hz, J=5.4 Hz, $1 \mathrm{H}, \quad$ 5'-Hb) 2.91 (ddd, $J=13.4 \mathrm{~Hz}, J=6.5 \mathrm{~Hz}, J=6.3 \mathrm{~Hz}, 1 \mathrm{H}, 2$ "'- $\mathrm{H}_{\mathrm{a}}$ ), 3.25 (ddd, $J=13.4 \mathrm{~Hz}, J=7.8 \mathrm{~Hz}$, $J=5.4 \mathrm{~Hz}, 1 \mathrm{H}, 2$ '"- $\left.\mathrm{H}_{\mathrm{b}}\right), 3.64\left(\mathrm{~s}, 3 \mathrm{H}, \mathrm{OCH}_{3}\right), 3.66$ (s, $\left.3 \mathrm{H}, \mathrm{OCH}_{3}\right), 3.71$ (dd, $J=10.4 \mathrm{~Hz}, J=3.5 \mathrm{~Hz}, 1 \mathrm{H}, 5$ "'- $\left.\mathrm{H}_{\mathrm{a}}\right), 3.75\left(\mathrm{dd}, J=10.4 \mathrm{~Hz}, J=5.2 \mathrm{~Hz}, 1 \mathrm{H}, 5\right.$ '- $\mathrm{H}_{\mathrm{b}}$ ), 4.29 (dd, J=7.0 Hz, J=7.0 Hz, 1 H, 9iv -H), 4.47-4.57 (m, 4 H, 3'-H, 4'-H, FmocCH ${ }_{2}$ ), 4.67-4.72 (m, $1 \mathrm{H}, 4$ "'-H), 5.08 (ddd, J=8.0 Hz, J=8.0 Hz, J=5.9 Hz, $1 \mathrm{H}, 6$ '-H), 5.32 (dddd, $J=5.4 \mathrm{~Hz}, J=5.4 \mathrm{~Hz}, J=5.4 \mathrm{~Hz}, J=5.4 \mathrm{~Hz}, 1 \mathrm{H}, 3$ '- $\mathrm{H}$ ), 6.69 (dd, $\left.J=6.5 \mathrm{~Hz}, J=6.5 \mathrm{~Hz}, 1 \mathrm{H}, 1^{\prime}-\mathrm{H}\right), 6.78\left(\mathrm{dd}, J=6.3 \mathrm{~Hz}, J=6.3 \mathrm{~Hz}, 1 \mathrm{H}, 1^{\prime \prime}-\mathrm{H}\right), 6.90$ $\left(\mathrm{d}, J=8.9 \mathrm{~Hz}, 4 \mathrm{H}, 3^{\mathrm{vi}}-\mathrm{H}, 5^{\mathrm{vi}}-\mathrm{H}\right), 7.17-7.21\left(\mathrm{~m}, 2 \mathrm{H}, 2^{\mathrm{v}}-\mathrm{H}, 6^{\mathrm{v}}-\mathrm{H}\right), 7.25-7.33(\mathrm{~m}, 4 \mathrm{H}$, $\left.2^{\mathrm{iv}}-\mathrm{H}, 7^{\mathrm{iv}}-\mathrm{H}, 2^{\mathrm{vii}}-\mathrm{H}, 6^{\mathrm{vii}}-\mathrm{H}\right), 7.36-7.44\left(\mathrm{~m}, 4 \mathrm{H}, 3^{\mathrm{iv}}-\mathrm{H}, 6^{\mathrm{iv}}-\mathrm{H}, 3^{\mathrm{v}}-\mathrm{H}, 5^{\mathrm{v}}-\mathrm{H}\right), 7.49$ (dd, $\left.J=7.4 \mathrm{~Hz}, J=7.4 \mathrm{~Hz}, 1 \mathrm{H}, 4^{\mathrm{v}}-\mathrm{H}\right), 7.51-7.58\left(\mathrm{~m}, 5 \mathrm{H}, 2^{\mathrm{vi}}-\mathrm{H}, 6^{\mathrm{vi}}-\mathrm{H}, 6-\mathrm{H}\right), 7.63-7.70(\mathrm{~m}$, $\left.4 \mathrm{H}, 1^{\mathrm{iv}}-\mathrm{H}, 8^{\mathrm{iv}}-\mathrm{H}, 3^{\mathrm{vii}}-\mathrm{H}, 5^{\mathrm{vii}}-\mathrm{H}\right), 7.82\left(\mathrm{~d}, J=7.6 \mathrm{~Hz}, 2 \mathrm{H}, 4^{\mathrm{iv}}-\mathrm{H}, 5^{\mathrm{iv}}-\mathrm{H}\right), 8.25-8.29$ (m, 
$\left.2 \mathrm{H}, 1^{\mathrm{iv}}-\mathrm{H}, 8^{\mathrm{iv}}-\mathrm{H}\right), 8.67-72\left(\mathrm{~m}, 2 \mathrm{H}, 6^{\prime}-\mathrm{NH}, 8^{\prime \prime}-\mathrm{H}\right), 8.90(\mathrm{~m}, 1 \mathrm{H}, 2$ '”- $-\mathrm{H})$, 9.27-9.32 (m, $1 \mathrm{H}, 3$ "'-NH), 11.84 (brs, $1 \mathrm{H}, \mathrm{BzNH}), 12.86$ (brs, $1 \mathrm{H}, 3-\mathrm{NH}$ ).

${ }^{13} \mathrm{C}$-NMR (126 MHz, Pyridin- $\mathrm{d}_{5}, 50{ }^{\circ} \mathrm{C}$ ): $\delta=12.34$ (C-7), 37.30 (C-5'), 37.85 (C-2"), 39.83 (C-2'), 47.61 (C-9iv), 51.30 (C-3"), 53.74 (C-6'), $54.96\left(\mathrm{OCH}_{3}\right), 64.48$ (C-5”), $66.66\left(\mathrm{FmocCH}_{2}\right.$ ), 74.46 (C-3'), 83.81 (Trityl- $\mathrm{C}_{\text {quart }}$ ), 84.37 (C-4'), 84.75 (C-4'), 85.97 (C-1"), 86.69 (C-1'), 110.72 (C-5), 113.51 (C-3 $\left.3^{\mathrm{vi}}, \mathrm{C}-5^{\mathrm{vi}}\right), 120.16$ (C-4 $\left.4^{\mathrm{iv}}, \mathrm{C}-5^{\mathrm{iv}}\right), 123.75$ (C-5"'), 125.39, $125.76\left(\mathrm{C}-1^{\text {iv }}, C-8^{\mathrm{iv}}\right), 126.89\left(\mathrm{C}-3^{\mathrm{vii}}, \mathrm{C}-5^{\mathrm{vii}}\right), 127.26\left(\mathrm{C}-2^{\mathrm{v}}, \mathrm{C}-6^{\mathrm{v}}\right)$, $127.82\left(\mathrm{C}-2^{\text {iv }}, C^{-7^{i v}}\right), 127.98(\operatorname{ArC}), 128.50\left(C^{v}-3^{v}, C-5^{v}\right), 128.56,128.83\left(C-3^{\text {iv }}, C-6^{\text {iv }}\right)$, $130.37\left(C_{a}-2^{v i}, C_{a}-6^{v i}, C_{b}-2^{v i}, C_{b}-6^{v i}\right), 132.08\left(C-4^{v}\right), 135.51\left(C-1^{v}\right), 135.70\left(C-4^{v i i}\right)$,

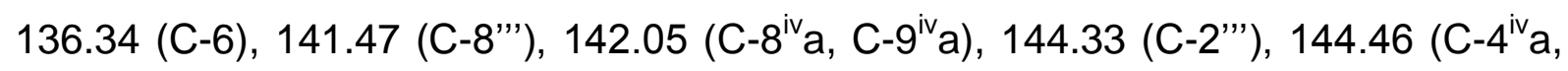
C-4 ${ }^{\text {ivb}), ~} 145.41$ (C-4 $\left.{ }^{\text {vi }}\right), 150.03$ (C-2), 151.33 (Fmoc-C=O), 151.39 (C-6"'), 152.21 (3"'-Amid-C=O), 158.88 (C-4"'), 164.50 (C-4), 172.87 (Bz-C=O).

Drehwert: $[\alpha]_{D}^{20}=-27.4\left(\mathrm{c}=1.0, \mathrm{CHCl}_{3}\right)$.

Schmelzpunkt: $125^{\circ} \mathrm{C}$.

IR (ATR): $\tilde{v}=1678,1509,1437,1247,1217,1174,1070,1032,703$.

UV $(\mathrm{MeCN}): \lambda_{\max }(\lg \varepsilon)=199$ (4.61), 264 (4.01).

MS $\left(E S I^{+}\right): m / z=1160.5[M+H]^{+}$.

$\mathrm{C}_{65} \mathrm{H}_{61} \mathrm{~N}_{9} \mathrm{O}_{12}(1160.23)$ ber.: $1160.4512[\mathrm{M}+\mathrm{H}]^{+}$ gef.: 1160.4509 (ESI+-HRMS).

7.2.4.20 (5"'-O-TBDMS-3"'-aminoguanosinyl)-(6'-N-Fmoc-3'-O-TBDMS)-(S)-TAAamid 95

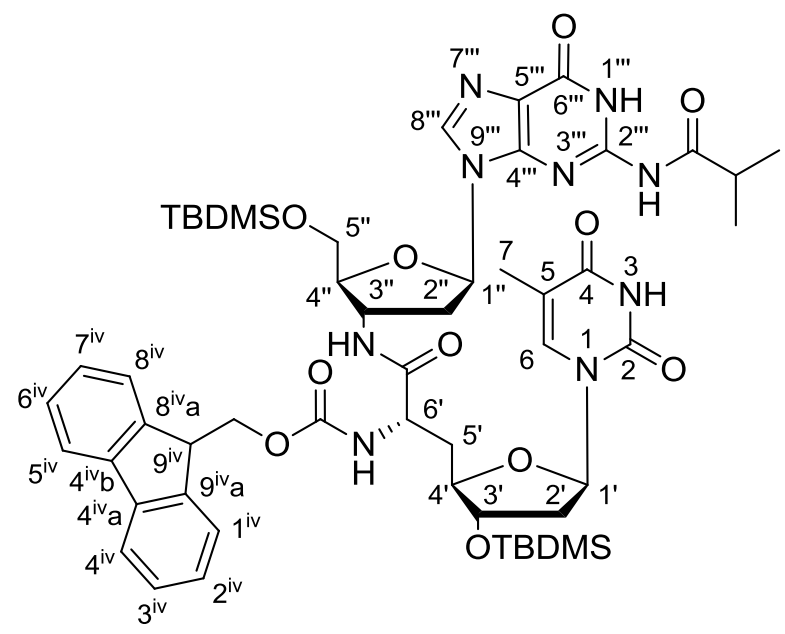

(6'S)-95

Die Synthese von (6'S)-95 erfolgte gemäß AAV 1 (7.1.7.1). Es wurden $660 \mathrm{mg}$ (1.04 mmol) der TAA (6'S)-73, $514 \mathrm{mg}(1.14 \mathrm{mmol})$ des 3'-Aminoguanosins 92 , 
$214 \mathrm{mg}$ (1.09 mmol) EDC, $147 \mathrm{mg}$ (1.09 mmol) HOBt und $13 \mathrm{~mL}$ DCM verwendet. Als Eluent für die chromatographische Reinigung wurde DCM/MeOH 97:3 verwendet.

Ausbeute: Es wurden $730 \mathrm{mg}(0.680 \mathrm{mmol}, 66 \%)$ eines farblosen Schaums erhalten. Mittels Dünnschichtchromatographie konnte der Nachweis erbracht werden, dass die Verbindung sich während der Aufnahme von NMR-Spektren teilweise zersetzte. Dies wurde insbesondere bei der Auswertung von 2D-Spektren, deren Messzeit deutlich höher ist als diejenige von 1D-Spektren, sichtbar. Daher enthielten die NMR-Spektren Signale geringer Intensität, die sich nicht dem Produkt zuordnen lassen.

DC: $R_{\mathrm{f}}(\mathrm{DCM} / \mathrm{MeOH}$ 95:5) $=0.31$.

${ }^{1} \mathrm{H}-\mathrm{NMR}\left(500 \mathrm{MHz}\right.$, Pyridin- $\left.\mathrm{d}_{5}, 50{ }^{\circ} \mathrm{C}\right): \delta=1.24\left(\mathrm{~d}, \mathrm{~J}=6.8 \mathrm{~Hz}, 3 \mathrm{H}, \mathrm{CHC}_{3 \mathrm{a}}\right), 1.24$ (d, $J=6.8 \mathrm{~Hz}, 3 \mathrm{H}, \mathrm{CHC}_{3 \mathrm{a}}$ ), 1.95 (s, $3 \mathrm{H}, 7-\mathrm{H}$ ), 2.09 (ddd, $J=14.4 \mathrm{~Hz}, J=8.9 \mathrm{~Hz}$, $\left.J=4.2 \mathrm{~Hz}, 1 \mathrm{H}, 5^{\prime}-\mathrm{H}_{\mathrm{a}}\right), 2.15-2.28\left(\mathrm{~m}, 3 \mathrm{H}, 2^{\prime}-\mathrm{H}, 5^{\prime}-\mathrm{H}_{\mathrm{b}}\right), 2.40$ (ddd, $J=13.3 \mathrm{~Hz}$, $J=5.7 \mathrm{~Hz}, J=2.8 \mathrm{~Hz}, 1 \mathrm{H}, 2$ '-H), 2.63 (ddd, $J=13.6 \mathrm{~Hz}, J=7.5 \mathrm{~Hz}, J=7.5 \mathrm{~Hz}, 1 \mathrm{H}$, 2"-H), 2.79 (qq, J=6.8 Hz, J=6.8 Hz, $1 \mathrm{H}, \mathrm{CH} \mathrm{CH}_{3}$ ), 3.79-3.84 (m, $2 \mathrm{H}, 5$ "'-H), 3.95 (ddd, $\left.J=8.8 \mathrm{~Hz}, J=3.8 \mathrm{~Hz}, J=3.8 \mathrm{~Hz}, 1 \mathrm{H}, 4^{\prime}{ }^{-}-\mathrm{H}\right), 4.06-4.10\left(\mathrm{~m}, 1 \mathrm{H}, 4^{\prime}-\mathrm{H}\right), 4.18$ (dd, J=7.0 Hz, J=7.0 Hz, $\left.1 \mathrm{H}, 9^{\mathrm{iv}}-\mathrm{H}\right), 4.31-4.35\left(\mathrm{~m}, 1 \mathrm{H}, 3^{\prime}-\mathrm{H}\right), 4.36-4.41(\mathrm{~m}, 3 \mathrm{H}$, 6'-H, FmocCH $\mathrm{CH}_{2}$, 4.63-4.69 (m, $1 \mathrm{H}, 3$ ''-H), 6.16 (d, J=7.8 Hz, $1 \mathrm{H}, 6$ '-NH), 6.16-6.21 (m, $\left.2 \mathrm{H}, 1^{\prime}-\mathrm{H}, 1^{\prime \prime}-\mathrm{H}\right), 7.23-7.29\left(\mathrm{~m}, 2 \mathrm{H}, 2^{\mathrm{iv}}-\mathrm{H}, 7^{\mathrm{iv}}-\mathrm{H}\right), 7.33-7.39\left(\mathrm{~m}, 3 \mathrm{H}, 3^{\mathrm{iv}}-\mathrm{H}, 6^{\mathrm{iv}}-\mathrm{H}\right)$, 7.53-7.56 (m, $\left.2 \mathrm{H}, 1^{\mathrm{iv}}-\mathrm{H}, 8^{\mathrm{iv}}-\mathrm{H}\right), 7.61-7.60\left(\mathrm{~m}, 1 \mathrm{H}, 3\right.$ "'-NH), 7.70-7.74 (m, $2 \mathrm{H}, 4^{\mathrm{iv}}-\mathrm{H}$, 5 iv -H), 7.94 (s, 1 H, 8'"'-H), 9.72 (s, 1 H, 2'"'-NH), 10.07 (s, 1 H, 3"'-NH), 12.17 (s, 1 H, 3-NH).

${ }^{13}$ C-NMR (126 MHz, Pyridin- $\left.d_{5}, 50{ }^{\circ} \mathrm{C}\right): \delta=-5.55\left(\mathrm{SiCH}_{3}\right),-5.45\left(\mathrm{SiCH}_{3}\right),-4.84$ $\left(\mathrm{SiCH}_{3}\right),-4.79\left(\mathrm{SiCH}_{3}\right), 11.99(\mathrm{C}-7), 17.80\left(\mathrm{Si} \underline{\mathrm{C}}\left(\mathrm{CH}_{3}\right)_{3}\right), 18.32\left(\mathrm{SiC}\left(\mathrm{CH}_{3}\right)_{3}\right), 18.81$ $\left(\mathrm{CH}_{\underline{C}} \mathrm{H}_{3 \mathrm{a}}\right), 18.97\left(\mathrm{CH}_{\underline{C}} \mathrm{H}_{3 \mathrm{~b}}\right), 25.60\left(\mathrm{SiC}\left(\underline{\mathrm{CH}}_{3}\right)_{3}\right), 25.90\left(\mathrm{SiC}\left(\underline{\mathrm{C}} \mathrm{H}_{3}\right)_{3}\right), 35.96\left(\underline{\mathrm{CHCH}}_{3}\right)$, 36.50 (C-2”), 38.48 (C-2'), 39.36 (C-5'), 47.27 (C-9 'iv), 51.45 (C-6’), 51.78 (C-3’'), 64.08 (C-5”), $67.24\left(\mathrm{FmocCH}_{2}\right), 74.78$ (C-3'), 83.85 (C-1'), 83.95 (C-4”), 85.78 (C-1"), 86.26 (C-4'), 112.04 (C-5), 119.96 (C-4 $\left.{ }^{\text {iv }, ~ C-5 ~}{ }^{\text {iv }}\right), 121.38$ (C-5"'), 124.89 (C-1 ${ }^{\text {iv }}$, C-8 $\left.{ }^{\text {iv }}\right), 127.00$ (C-2 $\left.{ }^{\text {iv }}, C^{\text {iv }}\right), 127.00,127.70\left(\mathrm{C}-3^{\text {iv }}\right.$, C-6 $\left.{ }^{\text {iv }}\right), 136.57(\mathrm{C}-6), 136.88$

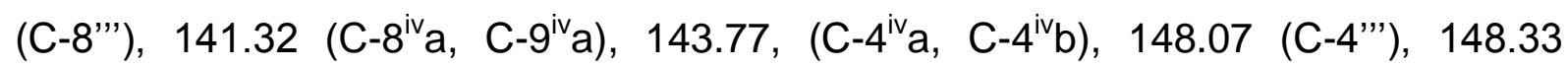

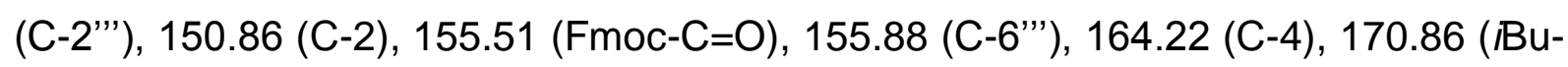
$\mathrm{C}=\mathrm{O}), 179.46$ (3"-Amid-C=O).

Drehwert: $[\alpha]_{D}^{20}=-9.7\left(c=1.0, \mathrm{CHCl}_{3}\right)$. 
Schmelzpunkt: $175^{\circ} \mathrm{C}$.

IR (ATR): $\tilde{v}=1676,1605,1250,1098,1065,1037,835,779,736$.

UV (MeCN): $\lambda_{\max }(\lg \varepsilon)=203$ (4.85), 255 (4.72).

MS $\left(E S I^{+}\right): m / z=1090.5[\mathrm{M}+\mathrm{Na}]^{+}$.

$\mathrm{C}_{53} \mathrm{H}_{73} \mathrm{~N}_{9} \mathrm{O}_{11} \mathrm{Si}_{2}(1068.37)$

ber.: $1090.4860[\mathrm{M}+\mathrm{Na}]^{+}$

gef.: 1090.4855 (ESI+HRMS).

\subsubsection{1 (5"-O-TBDMS-3"'-aminoguanosinyl)-(6'-N-Fmoc-3'-O-TBDMS)-(R)-TAA-} amid 95

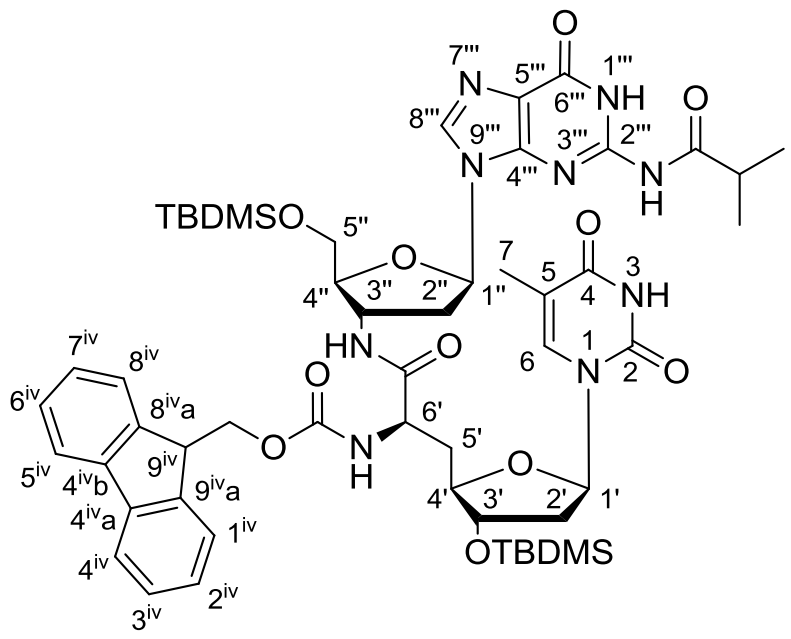

$\left(6^{\prime} R\right)-95$

Die Synthese von (6'S)-95 erfolgte gemäß AAV 1 (7.1.7.1). Es wurden $525 \mathrm{mg}$ (0.826 mmol) der TAA (6'S)-73, $409 \mathrm{mg}(0.909 \mathrm{mmol})$ des 3'-Aminoguanosins 92 , $171 \mathrm{mg}(0.867 \mathrm{mmol}) \mathrm{EDC}, 117 \mathrm{mg}(0.867 \mathrm{mmol}) \mathrm{HOBt}$ und $13 \mathrm{~mL}$ DCM verwendet. Als Eluent für die chromatographische Reinigung wurde $\mathrm{DCM} / \mathrm{MeOH}$ 97:3 verwendet.

Ausbeute: Es wurden $650 \mathrm{mg}(0.609 \mathrm{mmol}, 74 \%)$ eines farblosen Schaums erhalten.

DC: $R_{\mathrm{f}}(\mathrm{DCM} / \mathrm{MeOH} 95: 5)=0.31$.

${ }^{1} \mathrm{H}-\mathrm{NMR}\left(500 \mathrm{MHz}, \mathrm{CDCl}_{3}, 60^{\circ} \mathrm{C}\right): \delta=0.08\left(\mathrm{~s}, 6 \mathrm{H}, \mathrm{SiCH}_{3}\right), 0.13\left(\mathrm{~s}, 3 \mathrm{H}, \mathrm{SiCH}_{3}\right)$, $0.14\left(\mathrm{~s}, 3 \mathrm{H}, \mathrm{SiCH}_{3}\right), 0.90\left(\mathrm{~s}, 9 \mathrm{H}, \mathrm{SiC}\left(\mathrm{CH}_{3}\right)_{3}\right), 0.95\left(\mathrm{~s}, 9 \mathrm{H}, \mathrm{SiC}\left(\mathrm{CH}_{3}\right)_{3}\right), 1.19$ (d, $\left.J=6.8 \mathrm{~Hz}, 3 \mathrm{H}, \mathrm{CHCH}_{3 \mathrm{a}}\right), 1.26\left(\mathrm{~d}, J=6.8 \mathrm{~Hz}, \mathrm{CHCH}_{3 \mathrm{~b}}\right), 1.80$ (ddd, $J=14.0 \mathrm{~Hz}$, $\left.J=9.8 \mathrm{~Hz}, J=2.5 \mathrm{~Hz}, 1 \mathrm{H}, 5^{\prime}-\mathrm{H}_{\mathrm{a}}\right), 1.95(\mathrm{~s}, 3 \mathrm{H}, 7-\mathrm{H}), 2.03$ (dd, $J=12.8 \mathrm{~Hz}$, $J=5.8 \mathrm{~Hz}, 1 \mathrm{H}, 2$ "'- $\mathrm{H}_{\mathrm{a}}$ ), 2.23 (ddd, $J=13.6 \mathrm{~Hz}, J=12.3 \mathrm{~Hz}, J=1.2 \mathrm{~Hz}, 1 \mathrm{H}, 5^{\prime}-\mathrm{H}_{\mathrm{b}}$ ), $2.52\left(\mathrm{dd}, J=13.2 \mathrm{~Hz}, J=5.6 \mathrm{~Hz}, 1 \mathrm{H}, 2^{\prime}-\mathrm{H}_{\mathrm{a}}\right.$ ), $2.72(\mathrm{ddd}, J=13.3 \mathrm{~Hz}, J=9.2 \mathrm{~Hz}$, 
$J=7.4 \mathrm{~Hz}, 1 \mathrm{H}, 2^{\prime}-\mathrm{H}_{\mathrm{b}}$ ), 2.88 (qq, $J=6.8 \mathrm{~Hz}, 1 \mathrm{H}, \mathrm{CH} \mathrm{CH}_{3}$ ), 3.10 (ddd, $J=12.9 \mathrm{~Hz}$, $J=9.4 \mathrm{~Hz}, J=4.8 \mathrm{~Hz}, 1 \mathrm{H}, 2$ "'- $\mathrm{H}_{\mathrm{b}}$ ), $3.82\left(\mathrm{dd}, J=11.3 \mathrm{~Hz}, J=2.5 \mathrm{~Hz}, 1 \mathrm{H}, 5\right.$ ' $-\mathrm{H}_{\mathrm{a}}$ ), 3.90 (dd, $J=11.3 \mathrm{~Hz}, J=2.6 \mathrm{~Hz}, 1 \mathrm{H}, 5^{\prime \prime}-\mathrm{H}_{\mathrm{b}}$ ), 4.04-4.07 (m, $\left.1 \mathrm{H}, 4^{\prime}-\mathrm{H}\right), 4.18-4.25$ (m, $3 \mathrm{H}, 3^{\prime}-\mathrm{H}, 4$ "'-H, 9iv $-\mathrm{H}$ ), 4.38 (d, $J=7.2 \mathrm{~Hz}, 2 \mathrm{H}, \mathrm{FmocCH}_{2}$ ), 4.55 (dd, $J=9.0 \mathrm{~Hz}$, $\left.J=9.0 \mathrm{~Hz}, 1 \mathrm{H}, 6^{\prime}-\mathrm{H}\right), 4.66\left(\mathrm{dd}, J=7.2 \mathrm{~Hz}, J=7.2 \mathrm{~Hz}, 1 \mathrm{H}, 3{ }^{\prime \prime}-\mathrm{H}\right), 5.69-5.75(\mathrm{~m}, 1 \mathrm{H}$, 6'-NH), 5.71 (dd, $J=9.2 \mathrm{~Hz}, J=5.8 \mathrm{~Hz}, 1 \mathrm{H}, 1^{\prime \prime}-\mathrm{H}$ ), 6.39 (dd, $J=9.3 \mathrm{~Hz}, J=5.5 \mathrm{~Hz}$, $1 \mathrm{H}, 1^{\prime}-\mathrm{H}$ ), 7.18 (s, $1 \mathrm{H}, 6-\mathrm{H}$ ), 7.28 (dd, $J=7.5 \mathrm{~Hz}, J=7.5 \mathrm{~Hz}, 2 \mathrm{H}, 2^{\mathrm{iv}}-\mathrm{H}, 7^{\mathrm{iv}}-\mathrm{H}$ ), 7.35$7.39\left(\mathrm{~m}, 1 \mathrm{H}, 3\right.$ "'-NH), 7.38 (dd, $J=7.5 \mathrm{~Hz}, J=7.5 \mathrm{~Hz}, 2 \mathrm{H}, 3^{\mathrm{iv}}-\mathrm{H}, 6^{\mathrm{iv}}-\mathrm{H}$ ), 7.56-7.61 (m, $\left.2 \mathrm{H}, 1^{\mathrm{iv}}-\mathrm{H}, 8^{\mathrm{iv}}-\mathrm{H}\right), 7.74\left(\mathrm{~d}, J=7.5 \mathrm{~Hz}, 2 \mathrm{H}, 4^{\mathrm{iv}}-\mathrm{H}, 5^{\mathrm{iv}}-\mathrm{H}\right), 8.08\left(\mathrm{~s}, 1 \mathrm{H}, 8^{\prime \prime \prime}-\mathrm{H}\right), 9.51$ (s, $1 \mathrm{H}, 2$ '"'-NH), 10.93 (s, $1 \mathrm{H}, 3$ '"'-NH), 12.37 (s, $1 \mathrm{H}, 3-\mathrm{NH}$ ).

${ }^{13} \mathrm{C}-\mathrm{NMR} \quad\left(126 \mathrm{MHz}, \quad \mathrm{CDCl}_{3}, \quad 60{ }^{\circ} \mathrm{C}\right): \quad \delta=-5.54 \quad\left(\mathrm{SiCH}_{3}\right), \quad-5.38 \quad\left(\mathrm{SiCH}_{3}\right), \quad-4.84$ $\left(\mathrm{SiCH}_{3}\right),-4.79\left(\mathrm{SiCH}_{3}\right), 11.67(\mathrm{C}-7), 17.94\left(\mathrm{SiC}\left(\mathrm{CH}_{3}\right)_{3}\right), 18.41\left(\mathrm{SiC}\left(\mathrm{CH}_{3}\right)_{3}\right), 18.86$ $\left.\left(\mathrm{CH}_{\underline{C}} H_{3 \mathrm{a}}\right), 18.96\left(\mathrm{CH} \underline{\mathrm{C}} \mathrm{H}_{3 \mathrm{~b}}\right), 25.71\left(\mathrm{SiC}\left(\underline{\mathrm{CH}}_{3}\right)_{3}\right), 25.97\left(\mathrm{SiC}(\underline{\mathrm{CH}})_{3}\right)_{3}\right), 35.70\left(\underline{\mathrm{C}} \mathrm{HCH}_{3}\right)$, 36.18 (C-2”), 38.31 (C-2'), 39.98 (C-5'), 47.30 (C-9iv), 50.82 (C-6'), 51.79 (C-3'), 64.77 (C-5”), $67.32\left(\mathrm{FmoCH}_{2}\right.$ ), 76.29 (C-3'), 83.36 (C-1'), 84.81 (C-4”), 87.83 (C-4'),

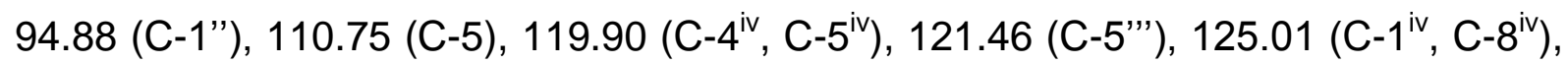

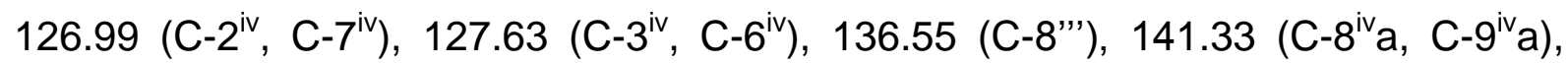
142.36 (C-6), 143.89, 144.05 (C-4"a, C-4" b), 148.26 (C-4"'), 149.34 (C-2"'), 150.38 (C-2), 155.26 (Fmoc-C=O), 156.51 (C-6”'), 165.19 (C-4), 171.68 (Bu-C=O), 180.04 (3"-Amid-C=O).

Drehwert: $[\alpha]_{D}^{20}=+29.7\left(\mathrm{c}=1.1, \mathrm{CHCl}_{3} /\right.$ Pyridin 10:2).

Schmelzpunkt: Zersetzung $>240^{\circ} \mathrm{C}$.

IR (ATR): $\tilde{v}=1676,1605,1247,1103,1075,1045,831,774,736$.

UV (MeCN): $\lambda_{\max }(\lg \varepsilon)=204$ (4.84), 263 (4.56).

MS $\left(\mathrm{ESI}^{+}\right): \mathrm{m} / \mathrm{z}=1068.5[\mathrm{M}+\mathrm{H}]^{+}$.

$\mathrm{C}_{53} \mathrm{H}_{73} \mathrm{~N}_{9} \mathrm{O}_{11} \mathrm{Si}_{2}$ (1068.37)

ber.: $1068.5041[\mathrm{M}+\mathrm{H}]^{+}$

gef.: 1068.5046 (ESI+-HRMS). 


\subsubsection{2 (3''-Aminoguanosinyl)-(6'-N-Fmoc)-(S)-TAA-amid 149}

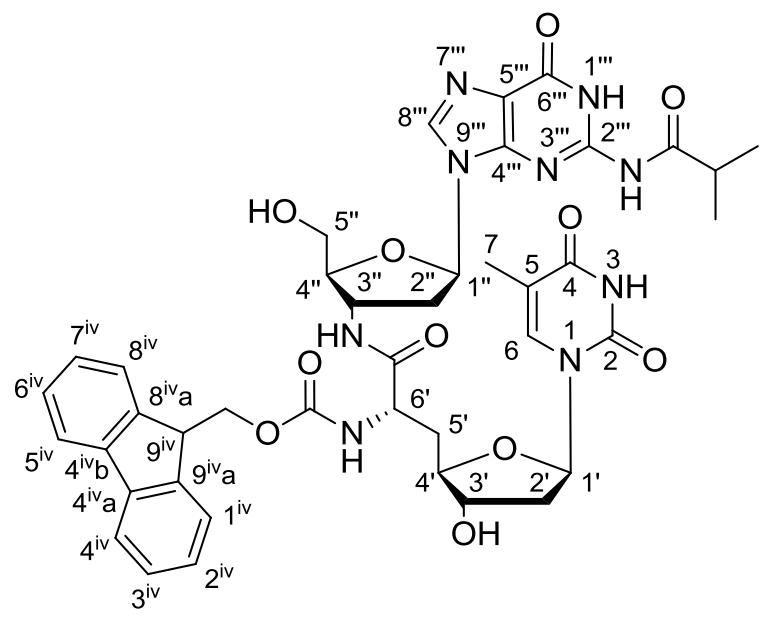

(6'S)-149

\section{Variante 1:}

Eine Lösung von (6'S)-95 (10 mg, $9.4 \mu \mathrm{mol}$ ) in $0.3 \mathrm{~mL}$ einer Lösung von $3 \mathrm{HF} \cdot \mathrm{NEt}_{3}$ in THF (5\% v/v) wurde $26 \mathrm{~h}$ bei Raumtemperatur gerührt. Es konnte ein nur geringer Umsatz beobachtet werden.

\section{Variante 2:}

Zu einer Lösung von (6'S)-95 (10 mg, $9.4 \mu \mathrm{mol})$ in $0.2 \mathrm{~mL}$ abs. $\mathrm{MeOH}$ wurde $\mathrm{AcCl}$ $(0.16 \mu \mathrm{L}, 0.18 \mathrm{mg}, 2.3 \mu \mathrm{mol}$, in $50 \mu \mathrm{L}$ abs. $\mathrm{MeOH})$ gegeben. Die Lösung wurde $22 \mathrm{~h}$ bei Raumtemperatur gerührt. Anschließend wurde weiteres $\mathrm{AcCl}(0.16 \mu \mathrm{L}, 0.18 \mathrm{mg}$, $2.3 \mu \mathrm{mol}$, in $50 \mu \mathrm{L}$ abs. $\mathrm{MeOH}$ ) dazugegeben. Nach $29 \mathrm{~h}$ wurde kein Umsatz beobachtet. Die Zugabe von weiterem AcCl $(0.32 \mu \mathrm{L}, 0.36 \mathrm{mg}, 4.6 \mu \mathrm{mol}$, in $100 \mu \mathrm{L}$ abs. $\mathrm{MeOH}$ ) führte zur Bildung von zahlreichen Nebenprodukten.

\section{Variante 3:}

Zu einer Lösung von (6'S)-95 (10 mg, $9.4 \mu \mathrm{mol})$ in $0.5 \mathrm{~mL}$ DMF wurde Tris(dimethylamino)sulfonium-difluortrimethylsilicat (13 mg, $47 \mu \mathrm{mol}$ ) gegeben. Das Reaktionsgemisch wurde $1 \mathrm{~h}$ bei Raumtemperatur gerührt. Es wurde Zersetzung des Edukts aber keine Bildung des gewünschten Produkts beobachtet.

\section{Variante 4:}

Eine Lösung von (6'S)-95 (530 mg, $0.496 \mathrm{mmol}$ ) in abs $\mathrm{MeOH}$ (10 mL) wurde mit Ammoniumfluorid (183 mg, $4.96 \mathrm{mmol}$ ) versetzt und $4.5 \mathrm{~h}$ bei $60^{\circ} \mathrm{C}$ gerührt. Die erhaltene Lösung wurde mit Kieselgel versetzt und das Lösungsmittel im Vakuum 
entfernt. Das an Kieselgel adsorbierte Rohprodukt wurde chromatographisch an Kieselgel gereinigt (DCM/MeOH 85:15).

Ausbeute: Es wurden $170 \mathrm{mg}(0.203 \mathrm{mmol}, 41 \%)$ eines gelblichen Feststoffs erhalten.

DC: $R_{\mathrm{f}}(\mathrm{DCM} / \mathrm{MeOH} 9: 1)=0.18$.

${ }^{1} \mathrm{H}-\mathrm{NMR}\left(500 \mathrm{MHz}\right.$, Pyridin- $\mathrm{d}_{5}, 50{ }^{\circ} \mathrm{C}$ ): $\delta=1.25\left(\mathrm{~d}, J=6.8 \mathrm{~Hz}, 6 \mathrm{H}, \mathrm{CHC}_{3}\right.$ ), 2.01 (s, $3 \mathrm{H}, 7-\mathrm{H}), 2.31-2.46\left(\mathrm{~m}, 2 \mathrm{H}, 2{ }^{\prime}-\mathrm{H}_{\mathrm{a}}, 5{ }^{\prime}-\mathrm{H}_{\mathrm{a}}\right), 2.57$ (ddd, $J=13.5 \mathrm{~Hz}, J=6.6 \mathrm{~Hz}$, $J=3.5 \mathrm{~Hz}, 1 \mathrm{H}, 2^{\prime}-\mathrm{H}_{\mathrm{b}}$ ), 2.69-2.78 (m, $2 \mathrm{H}, 2{ }^{\prime \prime}-\mathrm{H}_{\mathrm{a}}, 5^{\prime}-\mathrm{H}_{\mathrm{b}}$ ), 2.91 (qq, $J=6.8 \mathrm{~Hz}, 1 \mathrm{H}$,

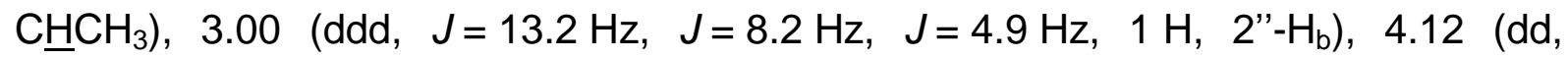
$J=12.1 \mathrm{~Hz}, J=4.0 \mathrm{~Hz}, 1 \mathrm{H}, 5{ }^{\prime \prime}-\mathrm{H}_{\mathrm{a}}$ ), $4.18\left(\mathrm{dd}, J=12.1 \mathrm{~Hz}, J=3.1 \mathrm{~Hz}, 1 \mathrm{H}, 5\right.$ "'- $\mathrm{H}_{\mathrm{b}}$ ), 4.30 (dd, $J=6.8 \mathrm{~Hz}, J=6.8 \mathrm{~Hz}, 1 \mathrm{H}, 9^{\mathrm{iv}}-\mathrm{H}$ ), 4.50 (ddd, $J=9.6 \mathrm{~Hz}, J=3.6 \mathrm{~Hz}$, $J=3.6 \mathrm{~Hz}, 1 \mathrm{H}, 4$ "'-H), $4.54\left(\mathrm{~d}, J=6.8 \mathrm{~Hz}, 1 \mathrm{H}, \mathrm{FmocCHH}_{\mathrm{a}}\right), 4.53-4.58\left(\mathrm{~m}, 1 \mathrm{H}, 3^{\prime}-\mathrm{H}\right)$, $4.56(\mathrm{~d}, J=6.8 \mathrm{~Hz}, 1 \mathrm{H}, F \operatorname{mocCHH}$ ), 5.05 (ddd, $J=8.5 \mathrm{~Hz}, J=8.5 \mathrm{~Hz}, J=5.9 \mathrm{~Hz}$, $1 \mathrm{H}, 6^{\prime}-\mathrm{H}$ ), 5.15 (dddd, $J=7.2 \mathrm{~Hz}, J=7.2 \mathrm{~Hz}, J=7.2 \mathrm{~Hz}, J=7.2 \mathrm{~Hz}, 1 \mathrm{H}, 3^{\prime \prime}-\mathrm{H}$ ), 6.44 (dd, $\left.J=6.7 \mathrm{~Hz}, J=4.9 \mathrm{~Hz}, 1 \mathrm{H}, 1^{\prime \prime}-\mathrm{H}\right), 6.87$ (dd, $J=6.6 \mathrm{~Hz}, J=6.6 \mathrm{~Hz}, 1 \mathrm{H}, 1^{\prime}-\mathrm{H}$ ), 7.26 (dd, $J=7.5 \mathrm{~Hz}, J=7.5 \mathrm{~Hz}, 1 \mathrm{H}, 2^{\mathrm{iv}}-\mathrm{H}$ ), 7.27 (ddd, J=7.5 Hz, J=7.5 Hz, $J=1.1 \mathrm{~Hz}, 1 \mathrm{H}, 7^{\mathrm{iv}}-\mathrm{H}$ ), 7.38 (dd, $J=7.4 \mathrm{~Hz}, J=7.4 \mathrm{~Hz}, 1 \mathrm{H}, 3^{\mathrm{iv}}-\mathrm{H}$ ), 7.39 (dd, $\left.J=7.5 \mathrm{~Hz}, J=7.5 \mathrm{~Hz}, 1 \mathrm{H}, 6^{\mathrm{iv}}-\mathrm{H}\right), 7.56(\mathrm{~d}, J=1.1 \mathrm{~Hz}, 6-\mathrm{H}), 7.64-7.70\left(\mathrm{~m}, 2 \mathrm{H}, 1^{\mathrm{iv}}-\mathrm{H}\right.$, $\left.8^{\mathrm{iv}}-\mathrm{H}\right), 7.82\left(\mathrm{~d}, J=7.5 \mathrm{~Hz}, 2 \mathrm{H}, 4^{\mathrm{iv}}-\mathrm{H}, 5^{\mathrm{iv}}-\mathrm{H}\right), 8.06(\mathrm{~s}, 1 \mathrm{H}, 8$ '”- $-\mathrm{H}), 8.89-8.94(1 \mathrm{H}$, 6'-NH), 9.60-9.70 (m, $1 \mathrm{H}, 3$ "'-NH), 12.38 (brs, $1 \mathrm{H}, 2$ '"'-NH), 12.91 (brs, $1 \mathrm{H}, 3-\mathrm{NH}$ ).

${ }^{13} \mathrm{C}-\mathrm{NMR}\left(126 \mathrm{MHz}\right.$, Pyridin- $\left.\mathrm{d}_{5}, 50{ }^{\circ} \mathrm{C}\right): \delta=12.23(\mathrm{C}-7), 18.83\left(\mathrm{CHCH}_{3 \mathrm{a}}\right), 18.93$ $\left(\mathrm{CH}^{-} \mathrm{H}_{3 \mathrm{~b}}\right), 35.93\left(\underline{\mathrm{C}} \mathrm{HCH}_{3}\right), 37.38$ (C-5'), $38.21\left(\mathrm{C}-2^{\prime \prime}\right), 39.60$ (C-2'), $47.63\left(\mathrm{C}-9^{\mathrm{iv}}\right)$, 50.33 (C-3"), 53.36 (C-6'), 62.17 (C-5'), $66.60\left(\mathrm{FmocCH}_{2}\right.$ ), 74.57 (C-3'), 84.22 (C-4'), 84.31 (C-1"), 85.10 (C-1'), 86.25 (C-4"), 111.07 (C-5), 120.17 (C-4 $\left.{ }^{\text {iv }}, \mathrm{C}-5^{\text {iv }}\right), 122.00$ (C-5”'), 125.27, $125.34\left(\mathrm{C}-1^{\text {iv }}, \mathrm{C}-8^{\mathrm{iv}}\right), 127.23\left(\mathrm{C}-2^{\mathrm{iv}}, \mathrm{C}-7^{\mathrm{iv}}\right), 127.84\left(\mathrm{C}-3^{\mathrm{iv}}, \mathrm{C}-6^{\mathrm{iv}}\right)$,

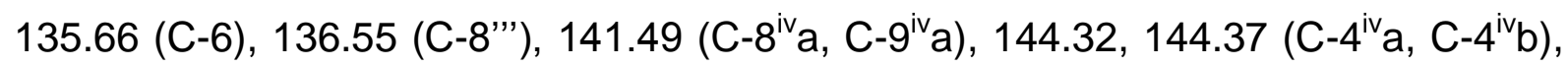
148.65 (C-4"'), 150.13 (C-2"'), 151.54 (C-2), 156.91 (C-6”'), 164.59 (C-4), 172.46 (Bu-C=O), 179.93 (3"'-Amid-C=O).

Drehwert: $[\alpha]_{D}^{20}=+15.2(\mathrm{c}=1.1$, Pyridin).

Schmelzpunkt: Zersetzung $>140^{\circ} \mathrm{C}$.

IR (ATR): $\tilde{v}=1666,1604,1557,1438,1247,1055,1032,741,703$.

UV (MeCN): $\lambda_{\max }(\lg \varepsilon)=198$ (4.22), 255 (4.05).

MS $\left(E S I^{+}\right): \mathrm{m} / \mathrm{z}=840.4[\mathrm{M}+\mathrm{H}]^{+}$. 
$\mathrm{C}_{41} \mathrm{H}_{45} \mathrm{~N}_{9} \mathrm{O}_{11}$ (839.85)

ber.: $840.3311[\mathrm{M}+\mathrm{H}]^{+}$

gef.: 840.3314 (ESI+-HRMS).

\subsubsection{3 (3''-Aminoguanosinyl)-(6'-N-Fmoc)-(R)-TAA-amid 149}

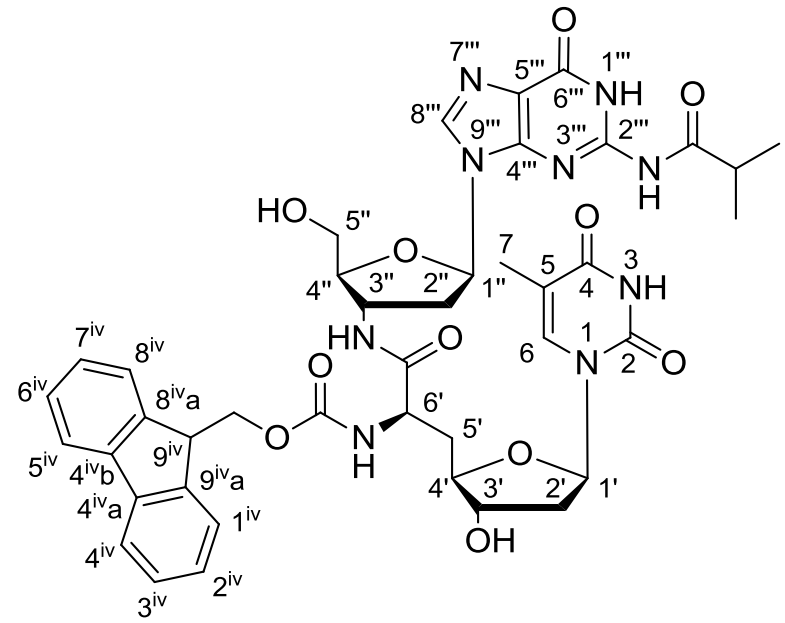

$\left(6^{\prime} R\right)-149$

Eine Lösung von (6'R)-95 (600 mg, $0.562 \mathrm{mmol})$ in abs. $\mathrm{MeOH}(10 \mathrm{~mL})$ wurde mit Ammoniumfluorid (208 mg, $5.62 \mathrm{mmol}$ ) versetzt und $4.5 \mathrm{~h}$ bei $60^{\circ} \mathrm{C}$ gerührt. Die so erhaltene Lösung wurde mit Kieselgel versetzt und das Lösungsmittel entfernt. Das an Kieselgel adsorbierte Rohprodukt wurde chromatographisch an Kieselgel gereinigt (DCM/MeOH 85:15).

Ausbeute: Es wurden $180 \mathrm{mg}(0.214 \mathrm{mmol}$, 38\%) eines blassgelben Feststoffs erhalten.

DC: $R_{f}(\mathrm{DCM} / \mathrm{MeOH}$ 9:1) $=0.18$.

${ }^{1} \mathrm{H}-\mathrm{NMR}\left(500 \mathrm{MHz}\right.$, Pyridin- $\left.\mathrm{d}_{5}, 50^{\circ} \mathrm{C}\right): \delta=1.26\left(\mathrm{~d}, J=6.8 \mathrm{~Hz}, 6 \mathrm{H}, i \operatorname{Pr}\left(\mathrm{CH}_{3}\right)_{2}\right), 1.98$ (s, $3 \mathrm{H}, 7-\mathrm{H}), 2.55-2.64\left(\mathrm{~m}, 3 \mathrm{H}, 2^{\prime}-\mathrm{H}, 5^{\prime}-\mathrm{H}_{\mathrm{a}}\right), 2.68$ (ddd, J=14.2 Hz, J=9.6 Hz, $J=5.9 \mathrm{~Hz}, 1 \mathrm{H}, 5{ }^{\prime}-\mathrm{H}_{\mathrm{b}}$ ), 2.82 (ddd, $J=13.5 \mathrm{~Hz}, J=6.8 \mathrm{~Hz}, J=6.7 \mathrm{~Hz}, 1 \mathrm{H}, 2$ ''- $\mathrm{H}_{\mathrm{a}}$ ), 2.94 (qq, $J=6.8 \mathrm{~Hz}, J=6.8 \mathrm{~Hz}, 1 \mathrm{H}, \mathrm{PrCH}$ ), 3.06 (ddd, $J=13.1 \mathrm{~Hz}, J=7.7 \mathrm{~Hz}$, $J=5.3 \mathrm{~Hz}, 1 \mathrm{H}, 2$ '"- $\mathrm{H}_{\mathrm{b}}$ ), 4.09 (dd, $J=12.1 \mathrm{~Hz}, J=3.9 \mathrm{~Hz}, 1 \mathrm{H}, 5$ '- $\mathrm{H}_{\mathrm{a}}$ ), 4.14 (dd, $J=12.1 \mathrm{~Hz}, J=3.1 \mathrm{~Hz}, 1 \mathrm{H}, 5$ "'- $\left.\mathrm{H}_{\mathrm{b}}\right), 4.29$ (dd, $\left.J=6.9 \mathrm{~Hz}, J=6.9 \mathrm{~Hz}, 1 \mathrm{H}, 9^{\mathrm{iv}}-\mathrm{H}\right), 4.49$ (ddd, J=6.6 Hz, J=3.1 Hz, J=3.1 Hz, $\left.1 \mathrm{H}, 4{ }^{\prime \prime}-\mathrm{H}\right), 4.51-4.56 \quad\left(\mathrm{~m}, 3 \mathrm{H}, 4^{\prime}-\mathrm{H}\right.$, FmocCH $\mathrm{CH}_{2}$, 4.57-4.62 (m, $\left.1 \mathrm{H}, 3^{\prime}-\mathrm{H}\right), 5.06$ (ddd, $J=7.8 \mathrm{~Hz}, J=7.8 \mathrm{~Hz}, J=5.9 \mathrm{~Hz}$, $1 \mathrm{H}, 6$ '-H), 5.14 (dddd, $J=6.9 \mathrm{~Hz}, J=6.9 \mathrm{~Hz}, J=6.8 \mathrm{~Hz}, J=6.6 \mathrm{~Hz}, 1 \mathrm{H}, 3$ '’-H), 6.49 
(dd, $J=6.7 \mathrm{~Hz}, J=5.3 \mathrm{~Hz}, 1 \mathrm{H}, 1^{\prime \prime}-\mathrm{H}$ ), 6.71 (dd, $J=6.5 \mathrm{~Hz}, J=6.5 \mathrm{~Hz}, 1 \mathrm{H}, 1^{\prime}-\mathrm{H}$ ),

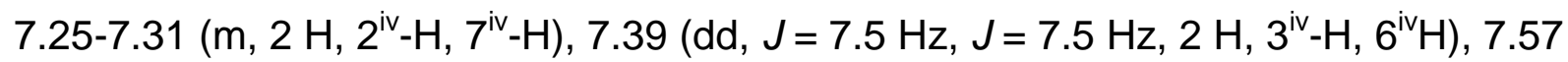
(s, $1 \mathrm{H}, 6-\mathrm{H}), 7.64-7.70\left(\mathrm{~m}, 2 \mathrm{H}, 1^{\mathrm{iv}}-\mathrm{H}, 8^{\mathrm{iv}}-\mathrm{H}\right), 7.82\left(\mathrm{~d}, J=7.5 \mathrm{~Hz}, 2 \mathrm{H}, 4^{\mathrm{iv}}-\mathrm{H}, 5^{\mathrm{iv}}-\mathrm{H}\right)$, $8.62\left(\mathrm{~s}, 1 \mathrm{H}, 8^{\prime \prime \prime}-\mathrm{H}\right), 8.74-8.86\left(\mathrm{~m}, 1 \mathrm{H}, 6^{\prime}-\mathrm{NH}\right), 9.19-9.27$ (m, $1 \mathrm{H}, 3$ "'-NH), 12.30 (brs, $1 \mathrm{H}, 2$,'"-NH), 12.81 (brs, $1 \mathrm{H}, 3-\mathrm{NH})$.

${ }^{13} \mathrm{C}-\mathrm{NMR}\left(126 \mathrm{MHz}\right.$, Pyridin-d $\left.\mathrm{d}_{5}, 50^{\circ} \mathrm{C}\right): \delta=12.28(\mathrm{C}-7), 18.86\left(\mathrm{CH}^{\mathrm{C}} \mathrm{H}_{3 \mathrm{a}}\right), 18.93$ $\left(\mathrm{CHCH}_{3 \mathrm{~b}}\right), 35.93\left(\mathrm{CHCH}_{3}\right), 37.12\left(\mathrm{C}-5^{\prime}\right), 38.16\left(\mathrm{C}-2^{\prime \prime}\right), 39.64\left(\mathrm{C}-2^{\prime}\right), 47.58\left(\mathrm{C}-9^{\mathrm{iv}}\right)$, 50.50 (C-3"), 53.85 (C-6'), 62.10 (C-5'), $66.69\left(\mathrm{FmocCH}_{2}\right), 74.49$ (C-3'), 83.90 (C-4'), 84.36 (C-1"), 85.94 (C-1'), 86.19 (C-4"), 110.70 (C-5), 120.16 (C-4 ${ }^{\text {iv }}, \mathrm{C}^{-5^{\mathrm{iv}}}$ ), 122.01

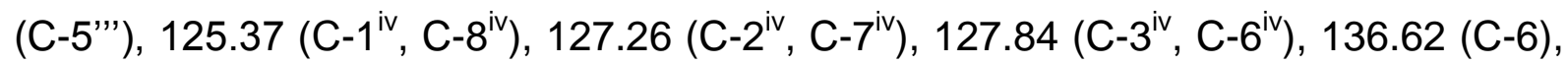
137.48 (C-8"'), 141.46 (C-8 $\left.{ }^{i v} a, C-9^{i v a}\right), 144.32,144.39$ (C-4 $\left.{ }^{i v} a, C-4^{i v b}\right), 148.68$ (C-4"'), 149.95 (C-2"'), 151.38 (C-2), 155.87 (C-6"'), 164.73 (C-4), 173.21 (iBu-C=O), 179.97 (3"-Amid-C=O).

Drehwert: $[\alpha]_{D}^{20}=+22.8(\mathrm{c}=1.0$, Pyridin).

Schmelzpunkt: Zersetzung $>140^{\circ} \mathrm{C}$.

IR (ATR): $\tilde{v}=1671,1604,1552,1537,1470,1447,1251,1060,736$.

UV (MeCN): $\lambda_{\max }(\lg \varepsilon)=199$ (4.37), 248 (4.17), 255 (4.30).

MS $\left(E S I^{+}\right): \mathrm{m} / \mathrm{z}=840.4[\mathrm{M}+\mathrm{H}]^{+}$.

$\mathrm{C}_{41} \mathrm{H}_{45} \mathrm{~N}_{9} \mathrm{O}_{11}$ (839.85)

ber.: $840.3311[\mathrm{M}+\mathrm{H}]^{+}$

gef.: 840.3315 (ESI+-HRMS).

\subsubsection{4 (5'-O-DMTr-3'--aminoguanosinyl)-(6'-N-Fmoc)-(S)-TAA-amid 152}

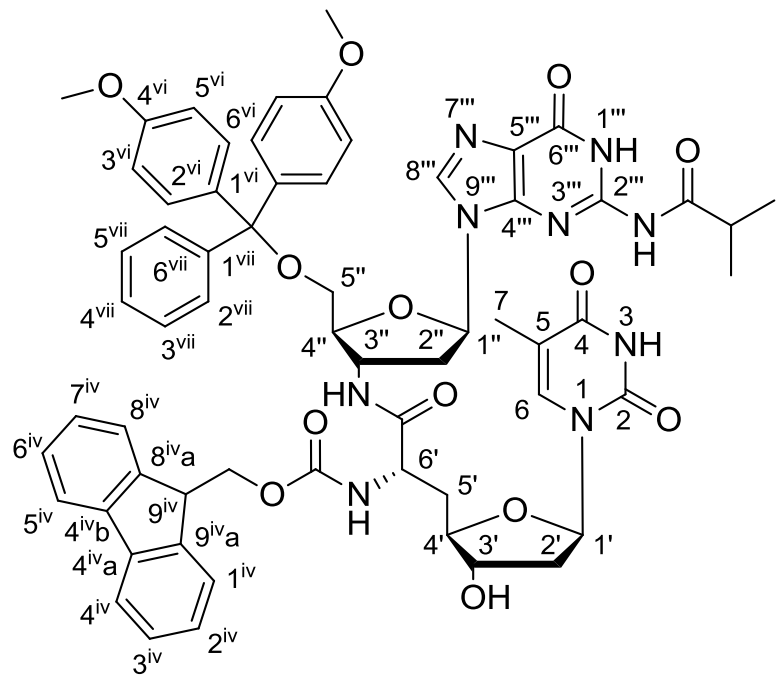

(6'S)-152 
Die Synthese erfolgte gemäß AAV 2 (7.1.7.2). Es wurden $135 \mathrm{mg}(0.161 \mathrm{mmol})$ (6'S)-149, $60 \mathrm{mg} \quad(0.18 \mathrm{mmol})$ DMTrCl verwendet und $0.39 \mathrm{~mL}$ abs. Pyridin verwendet. Als Eluent für die chromatographische Reinigung wurde $\mathrm{DCM} / \mathrm{MeOH} /$ Pyridin 90:9:1 verwendet.

Ausbeute: Es wurden $140 \mathrm{mg}(0.123 \mathrm{mmol}, 76 \%)$ eines farblosen Schaums erhalten.

DC: $R_{\mathrm{f}}(\mathrm{DCM} / \mathrm{MeOH} 9: 1)=0.43$.

${ }^{1} \mathrm{H}-\mathrm{NMR}\left(500 \mathrm{MHz}\right.$, Pyridin- $\left.\mathrm{d}_{5}, 50^{\circ} \mathrm{C}\right): \delta=1.26\left(\mathrm{~d}, J=7.0 \mathrm{~Hz}, 3 \mathrm{H}, \mathrm{CHCH}_{3 \mathrm{a}}\right), 1.27$ (d, $\left.J=7.0 \mathrm{~Hz}, 3 \mathrm{H}, \mathrm{CHCH}_{3 \mathrm{~b}}\right), 2.00(\mathrm{~s}, 3 \mathrm{H}, 7-\mathrm{H}), 2.27-2.44\left(\mathrm{~m}, 3 \mathrm{H}, 2^{\prime}-\mathrm{H}_{\mathrm{a}}, 5^{\prime}-\mathrm{H}_{\mathrm{a}}\right), 2.55$ (ddd, $J=13.4 \mathrm{~Hz}, J=6.1 \mathrm{~Hz}, J=3.7 \mathrm{~Hz}, 1 \mathrm{H}, 5$ '- $\left.\mathrm{H}_{\mathrm{b}}\right)$, 2.65-2.70 (m, $2 \mathrm{H}, 2$ '”- $\mathrm{H}_{\mathrm{a}}, 5-\mathrm{H}_{\mathrm{b}}$ ), 2.93 (qq, $J=7.0 \mathrm{~Hz}, J=7.0 \mathrm{~Hz}, 1 \mathrm{H}, \mathrm{CHCH}_{3}$ ), 3.12 (ddd, $J=13.5 \mathrm{~Hz}, J=8.1 \mathrm{~Hz}$, $J=5.1 \mathrm{~Hz}, 1 \mathrm{H}, 2$ "'- $\left.\mathrm{H}_{\mathrm{b}}\right), 3.64-3.73(\mathrm{~m}, 2 \mathrm{H}, 5$ "'- $\mathrm{H}), 3.68\left(\mathrm{~s}, 3 \mathrm{H}, \mathrm{OCH}_{3}\right), 3.69(\mathrm{~s}, 3 \mathrm{H}$, $\mathrm{OCH}_{3}$ ), 4.29 (dd, $J=6.9 \mathrm{~Hz}, J=6.9 \mathrm{~Hz}, 1 \mathrm{H}, 9^{\mathrm{iv}}-\mathrm{H}$ ), 4.43 (ddd, $J=9.6 \mathrm{~Hz}, J=3.7 \mathrm{~Hz}$, $3 \mathrm{H}, 4^{\prime}-\mathrm{H}$ ), 4.52 (d, $J=6.9 \mathrm{~Hz}, 1 \mathrm{H}, \mathrm{FmocCH} \underline{H}_{\mathrm{a}}$ ), 4.54 (d, $J=6.9 \mathrm{~Hz}, \mathrm{FmocCH} \underline{\mathrm{H}}_{\mathrm{b}}$ ), 4.53-4.58 (m, $1 \mathrm{H}, 3$ '-H), 4.63-4.69 (m, $1 \mathrm{H}, 4$ '-H), 5.00 (ddd, J=8.4 Hz, J=6.2 Hz, $J=6.2 \mathrm{~Hz}, 1 \mathrm{H}, 6^{\prime}-\mathrm{H}$ ), 5.07 (dddd, $J=6.9 \mathrm{~Hz}, J=6.9 \mathrm{~Hz}, J=6.9 \mathrm{~Hz}, J=6.9 \mathrm{~Hz}, 1 \mathrm{H}$, 3"'-H), 6.45-6.50 (m, $1 \mathrm{H}, 1$ '"-H), 6.69 (dd, J = 6.7 Hz, J = 6.7 Hz, $\left.1 \mathrm{H}, 1^{\prime}-\mathrm{H}\right), 6.92-6.97$ (m, $\left.4 \mathrm{H}, 3^{\mathrm{vi}}-\mathrm{H}, 5^{\mathrm{vi}}-\mathrm{H}\right), 7.18-7.21\left(\mathrm{~m}, 1 \mathrm{H}, 1^{\mathrm{vii}}-\mathrm{H}\right), 7.23-7.29\left(\mathrm{~m}, 2 \mathrm{H}, 2^{\mathrm{iv}}-\mathrm{H}, 7^{\mathrm{iv}}-\mathrm{H}\right), 7.32$

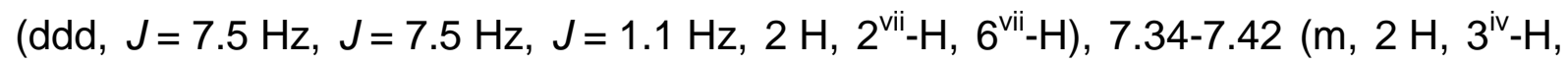
$\left.6^{\text {iv }}-\mathrm{H}\right), 7.52-7.57\left(\mathrm{~m}, 5 \mathrm{H}, 2^{\mathrm{vi}-}-\mathrm{H}, 6^{\mathrm{vi}}-\mathrm{H}, \mathrm{H}-6\right), 7.64-7.71\left(\mathrm{~m}, 4 \mathrm{H}, 3^{\mathrm{vii}}-\mathrm{H}, 5^{\mathrm{vii}}-\mathrm{H}, 1^{\mathrm{iv}}-\mathrm{H}\right.$, $\left.8^{\mathrm{iv}}-\mathrm{H}\right), 7.80-7.84\left(\mathrm{~m}, 2 \mathrm{H}, 4^{\mathrm{iv}}-\mathrm{H}, 5^{\mathrm{iv}}-\mathrm{H}\right), 8.36\left(\mathrm{~s}, 1 \mathrm{H}, 8^{\prime \prime}-\mathrm{H}\right), 8.84-8.94\left(\mathrm{~m}, 1 \mathrm{H}, 6^{\prime}-\mathrm{NH}\right)$, 9.53 (d, $J=6.2 \mathrm{~Hz}, 1 \mathrm{H}, 3$ "'-NH), 12.35 (brs, $1 \mathrm{H}, 2$ '"'-NH), 12.96 (brs, $1 \mathrm{H}, 3-\mathrm{NH}$ ).

${ }^{13} \mathrm{C}-\mathrm{NMR}\left(126 \mathrm{MHz}\right.$, Pyridin- $\left.\mathrm{d}_{5}, 50{ }^{\circ} \mathrm{C}\right): \delta=12.23(\mathrm{C}-7), 18.84\left(\mathrm{CHCH}_{3 \mathrm{a}}\right), 18.90$ $\left(\mathrm{CH}^{\mathrm{C}} \mathrm{H}_{3 \mathrm{~b}}\right), 35.96\left(\underline{\mathrm{C}} \mathrm{HCH}_{3}\right), 37.22$ (C-5'), 37.74 (C-2'), 39.71 (C-2'), 47.64 (C-9iv), 51.04 (C-3"), 54.98 (C-6'), $64.47\left(\mathrm{OCH}_{3}\right), 66.57\left(\mathrm{FmocCH}_{2}\right) 74.51$ (C-3'), 84.05 (C-4'), 84.12 (Trityl-C quart), 84.29 (C-1"), 85.07 (C-4"), 86.68 (C-1'), 111.02 (C-7), $113.52\left(\mathrm{C}-3^{\mathrm{vi}}, \mathrm{C}-5^{\mathrm{vi}}\right), 120.01,120.20\left(\mathrm{C}-4^{\mathrm{iv}}, \mathrm{C}-5^{\mathrm{iv}}\right), 122.16\left(\mathrm{C}-5^{\prime \prime \prime}\right), 123.75\left(\mathrm{C}-1^{\mathrm{vii}}\right)$, 125.24, $125.31\left({\mathrm{C}-1^{\mathrm{iv}}}, \mathrm{C}-8^{\mathrm{iv}}\right), 127.23,127.36\left(\mathrm{C}-2^{\mathrm{iv}}, \mathrm{C}-7^{\mathrm{iv}}\right), 127.84,128.01\left(\mathrm{C}-3^{\mathrm{iv}}\right.$, C-6 $\left.{ }^{\text {iv }}\right), 128.58$ (C-2 $\left.{ }^{\text {vii }}, C-6^{\text {vii }}\right), 129.05$ (C-3 $\left.3^{\text {vii }}, C-5^{\text {vii }}\right), 130.29\left(C_{a}-2^{\text {vi }}, C_{a}-6^{\text {vi }}\right), 130.35$ $\left(C_{b}-2^{v i}, C_{b}-6^{v i}\right), 130.39$ (C-1 $\left.{ }^{v i i}\right), 135.51\left(C-4^{v i i}\right), 135.71\left(C_{a}-1^{v i}\right), 136.27\left(C_{b}-1^{v i}\right), 136.60$

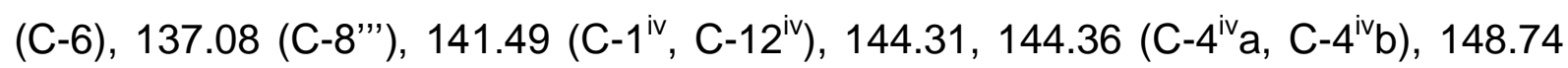
(C-4"'), 149.96 (C-2"'), 150.03 (C-2), 155.83 (C-6"'), 158.92 (C-4"i), 164.56 (C-4), $172.72(\mathrm{Bu}-\mathrm{C}=\mathrm{O}), 179.90$ (3"'-Amid-C=O). 
Drehwert: $[\alpha]_{D}^{20}=+149.9\left(\mathrm{c}=1.0, \mathrm{CHCl}_{3}\right)$.

Schmelzpunkt: Zersetzung $>160^{\circ} \mathrm{C}$.

IR (ATR): $\tilde{v}=1676,1604,1552,1503,1442,1247,1180,1032,741,703$.

UV (MeCN): $\lambda_{\max }(\lg \varepsilon)=198$ (4.89), 247 (4.35), 255 (4.43).

MS $\left(\mathrm{ESI}^{+}\right): \mathrm{m} / \mathrm{z}=1142.5[\mathrm{M}+\mathrm{H}]^{+}$.

$\mathrm{C}_{62} \mathrm{H}_{63} \mathrm{~N}_{9} \mathrm{O}_{13}(1142.22)$

ber.: $1142.4618[\mathrm{M}+\mathrm{H}]^{+}$

gef.: $1142.4612\left(\mathrm{ESI}^{+}-\mathrm{HRMS}\right)$.

\subsubsection{5 (5'-O-DMTr-3''-aminoguanosinyl)-(6'-N-Fmoc)-(R)-TAA-amid 152}

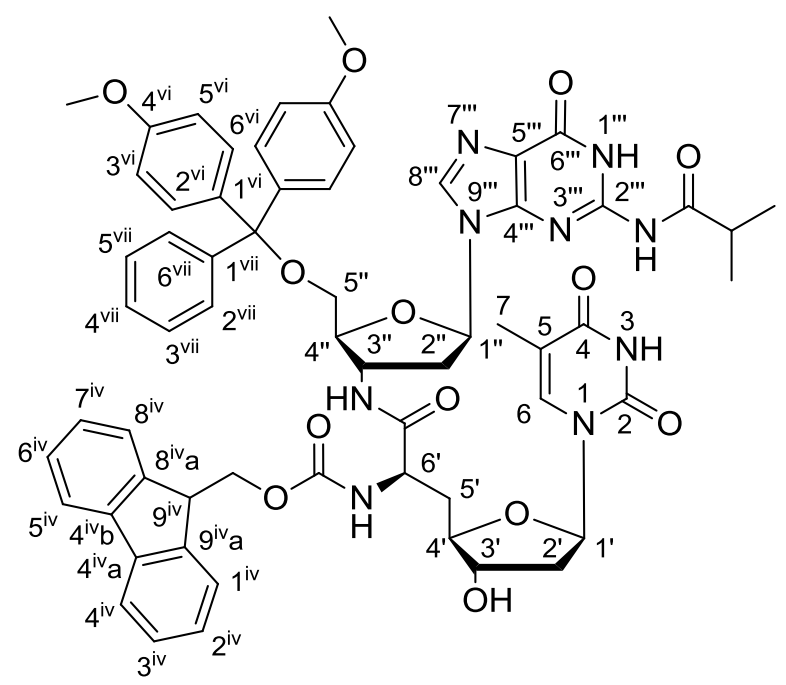

(6'R)-152

Die Synthese erfolgte gemäß AAV 2 (7.1.7.2). Es wurden $140 \mathrm{mg}(0.166 \mathrm{mmol})$ $\left(6^{\prime} R\right)-149,62 \mathrm{mg}(0.18 \mathrm{mmol}) \mathrm{DMTrCl}$ und $0.39 \mathrm{~mL}$ abs Pyridin verwendet. Als Eluent für die chromatographische Reinigung wurde $\mathrm{DCM} / \mathrm{MeOH} /$ Pyridin 90:9:1 verwendet.

Ausbeute: Es wurden $160 \mathrm{mg}(0.140 \mathrm{mmol}, 84 \%)$ eines farblosen Schaums erhalten.

DC: $R_{\mathrm{f}}(\mathrm{DCM} / \mathrm{MeOH} 9: 1)=0.43$.

${ }^{1} \mathrm{H}-\mathrm{NMR}\left(500 \mathrm{MHz}\right.$, Pyridin- $\left.\mathrm{d}_{5}, 50^{\circ} \mathrm{C}\right): \delta=1.26\left(\mathrm{~d}, J=6.8 \mathrm{~Hz}, 3 \mathrm{H}, \mathrm{CHCH}_{3 \mathrm{a}}\right), 1.27$ (d, $\left.J=6.8 \mathrm{~Hz}, 3 \mathrm{H}, \mathrm{CHCH}_{3 b}\right), 1.97(\mathrm{~s}, 3 \mathrm{H}, 7-\mathrm{H}), 2.53-2.60\left(\mathrm{~m}, 3 \mathrm{H}, 2^{\prime}-\mathrm{H}, 5^{\prime}-\mathrm{H}_{\mathrm{a}}\right), 2.66$ (ddd, $J=14.1 \mathrm{~Hz}, \quad J=9.7 \mathrm{~Hz}, J=5.7 \mathrm{~Hz}, \quad 1 \mathrm{H}, \quad 5^{\prime}-\mathrm{H}_{\mathrm{b}}$ ), 2.80 (ddd, $J=13.5 \mathrm{~Hz}$, $J=6.7 \mathrm{~Hz}, J=6.7 \mathrm{~Hz}, 1 \mathrm{H}, 2^{\prime \prime}-\mathrm{H}_{\mathrm{a}}$ ), 2.93 (qq, $J=6.8 \mathrm{~Hz}, J=6.8 \mathrm{~Hz}, 1 \mathrm{H}, \mathrm{CHCH}_{3}$ ), 3.12 (ddd, $J=13.2 \mathrm{~Hz}, J=7.8 \mathrm{~Hz}, J=7.8 \mathrm{~Hz}, 1 \mathrm{H}, 2$ "'- $\mathrm{H}_{\mathrm{b}}$ ), 3.63 (dd, $J=10.4 \mathrm{~Hz}$, 
$J=3.3 \mathrm{~Hz}, 1 \mathrm{H}, 5$ "'- $\left.\mathrm{H}_{\mathrm{a}}\right), 3.66\left(\mathrm{~s}, 3 \mathrm{H}, \mathrm{OCH}_{3}\right), 3.66\left(\mathrm{~s}, 3 \mathrm{H}, \mathrm{OCH}_{3}\right), 3.66-3.71(\mathrm{~m}, 1 \mathrm{H}$, 5"'- $\mathrm{H}_{\mathrm{b}}$ ), $4.28\left(\mathrm{dd}, J=7.0 \mathrm{~Hz}, J=7.0 \mathrm{~Hz}, 1 \mathrm{H}, 9^{\mathrm{iv}}-\mathrm{H}\right), 4.44-4.51(\mathrm{~m}, 3 \mathrm{H}, 4$ ' $-\mathrm{H}, 4$ "'- $\mathrm{H}$, FmocCH$\left.\underline{H}_{a}\right)$, 4.53-4.63 (m, $\left.2 \mathrm{H}, 3^{\prime}-\mathrm{H}, \mathrm{FmocCH} \underline{H}_{\mathrm{b}}\right), 4.99-5.12\left(\mathrm{~m}, 2 \mathrm{H}, 3^{\prime \prime}-\mathrm{H}, 6{ }^{\prime}-\mathrm{H}\right)$, $6.50\left(\mathrm{dd}, J=6.7 \mathrm{~Hz}, J=5.2 \mathrm{~Hz}, 1 \mathrm{H}, 1{ }^{\prime}-\mathrm{H}\right), 6.69(\mathrm{dd}, J=6.7 \mathrm{~Hz}, J=6.7 \mathrm{~Hz}, 1 \mathrm{H}$, $1^{\prime}-\mathrm{H}$ ), 6.91 (dd, $\left.J=8.9 \mathrm{~Hz}, J=1.5 \mathrm{~Hz}, 4 \mathrm{H}, 3^{\mathrm{vi}}-\mathrm{H}, 5^{\mathrm{vi}}-\mathrm{H}\right), 7.18-7.21\left(\mathrm{~m}, 1 \mathrm{H}, 1-\mathrm{H}^{\mathrm{vii}}\right)$,

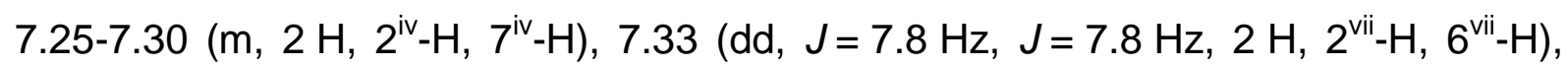
7.37-7.42 (m, $\left.2 \mathrm{H}, 3^{\mathrm{iv}}-\mathrm{H}, 6^{\mathrm{iv}}-\mathrm{H}\right), 7.51\left(\mathrm{~d}, J=8.9 \mathrm{~Hz}, 2 \mathrm{H}, 2^{\text {vi }}-\mathrm{H}_{\mathrm{a}}, 6^{\text {vi }}-\mathrm{H}_{\mathrm{a}}\right), 7.52(\mathrm{~d}$, $\left.J=8.9 \mathrm{~Hz}, 2 \mathrm{H}, 2^{\mathrm{vi}}-\mathrm{H}_{\mathrm{b}}, 6^{\mathrm{vi}}-\mathrm{H}_{\mathrm{b}}\right), 7.53-7.56(\mathrm{~m}, 1 \mathrm{H}, \mathrm{H}-6), 7.64-7.69\left(\mathrm{~m}, 4 \mathrm{H}, 3^{\text {vii }}-\mathrm{H}\right.$, $\left.5^{\text {vii }-H}, 1^{\text {iv }}-\mathrm{H}, 8^{\text {iv }}-\mathrm{H}\right), 7.83\left(\mathrm{~d}, J=7.6 \mathrm{~Hz}, 2 \mathrm{H}, 4^{\mathrm{iv}}-\mathrm{H}, 5^{\mathrm{iv}}-\mathrm{H}\right), 8.36(\mathrm{~s}, 1 \mathrm{H}, 8$ "'- $-\mathrm{H}), 8.70-$

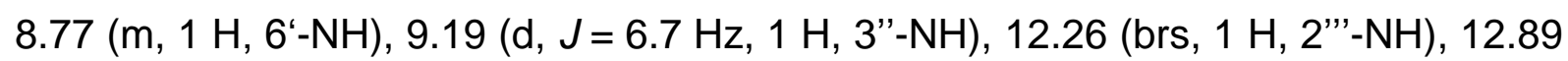
(brs, $1 \mathrm{H}, 3-\mathrm{NH}$ ).

${ }^{13} \mathrm{C}-\mathrm{NMR}\left(126 \mathrm{MHz}\right.$, Pyridin- $\left.\mathrm{d}_{5}, 50{ }^{\circ} \mathrm{C}\right): \delta=12.29(\mathrm{C}-7), 18.87\left(\mathrm{CHCH}_{3 \mathrm{a}}\right), 18.90$ $\left(\mathrm{CH}^{\mathrm{C}} \mathrm{H}_{3 \mathrm{~b}}\right), 35.96\left(\underline{\mathrm{C}} \mathrm{HCH}_{3}\right), 37.28\left(\mathrm{C}-5^{\prime}\right), 37.77\left(\mathrm{C}-2^{\prime \prime}\right), 39.68\left(\mathrm{C}-2^{\prime}\right), 47.60\left(\mathrm{C}-9^{\text {iv }}\right)$, 51.06 (C-3'), 54.96 (C-6'), $64.37\left(\mathrm{OCH}_{3}\right), 66.82\left(\mathrm{FmocCH}_{2}\right), 74.50$ (C-3'), 83.99 (C-4'), 84.37 (C-1"), 85.97 (C-4"), 86.66 (C-1'), 110.68 (C-7), 113.50 (C-3 ${ }^{\text {vi }}, C^{-}-5^{\text {vi }}$ ),

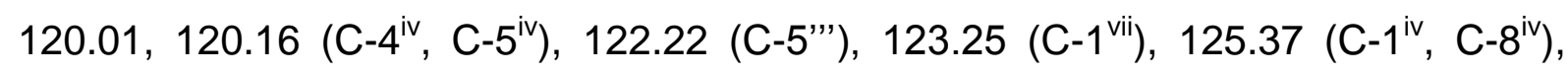
127.26, $127.36\left(\mathrm{C}-2^{\text {iv }}, \mathrm{C}-7^{\mathrm{iv}}\right), 127.85,127.98\left(\mathrm{C}-3^{\mathrm{iv}}, \mathrm{C}-6^{\mathrm{iv}}\right), 128.54\left(\mathrm{C}-2^{\mathrm{vii}}, \mathrm{C}-6^{\mathrm{vii}}\right)$, 129.05 (C-3 $\left.3^{\text {vii }}, C-5^{v i i}\right), 130.35\left(C_{a}-2^{v i}, C_{a}-6^{v i}\right), 130.37\left(C_{b}-2^{v i}, C_{b}-6^{v i}\right), 130.42\left(C-1^{v i i}\right)$, 135.51 (C-4 $\left.{ }^{\text {vii }}\right), 135.70\left(\mathrm{C}_{\mathrm{a}}-1^{\mathrm{vi}}\right), 136.22$ ( $\left.\mathrm{C}_{\mathrm{b}} \mathrm{-1}^{\mathrm{vi}}\right), 136.60$ (C-6), 137.11 (C-8"'), 141.47 (C-8 $\left.{ }^{i v} a, C-9^{i v b}\right), 144.30,144.43$ (C-4 $\left.{ }^{\text {iv } a, ~ C-4 ~}{ }^{i v} b\right), 148.72$ (C-4"'), 149.96 (C-2"'), 151.36 (C-2), 155.81 (C-6”'), 158.89 (C-4 ${ }^{\text {vi }), ~} 164.73$ (C-4), 172.92 (Bu-C=O), 179.93 (3"'-Amid-C=O).

Drehwert: $[\alpha]_{D}^{20}=-56.7\left(\mathrm{c}=1.0, \mathrm{CHCl}_{3}\right)$.

Schmelzpunkt: Zersetzung $>160^{\circ} \mathrm{C}$.

IR (ATR): $\tilde{v}=1676,1605,1552,1503,1442,1247,1070,1027,741,703$.

UV (MeCN): $\lambda_{\max }(\lg \varepsilon)=198$ (4.35), 247 (3.93), 255 (4.03).

MS $\left(\mathrm{ESI}^{+}\right): \mathrm{m} / \mathrm{z}=1142.5[\mathrm{M}+\mathrm{H}]^{+}$.

$\mathrm{C}_{62} \mathrm{H}_{63} \mathrm{~N}_{9} \mathrm{O}_{13}(1142.22)$ ber.: $1142.4618[\mathrm{M}+\mathrm{H}]^{+}$ gef.: 1142.4621 (ESI+-HRMS). 


\subsubsection{Synthese der NAA (6'S)-104 und (6'R)-104}

\subsubsection{3'-Desoxy-3'-azidothymidin 154}

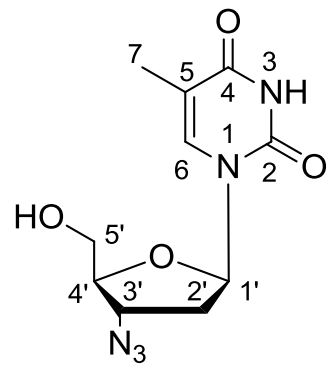

154

Eine Lösung von 5'-O-TBDMS-3'-desoxy-3'-azidothymidin 118 (300 mg, 0.787 mmol) in Methanol (16 mL) wurde auf $0^{\circ} \mathrm{C}$ gekühlt und mit einer Lösung von $\mathrm{AcCl}(14 \mu \mathrm{L}$, $15 \mathrm{mg}, 0.20 \mathrm{mmol})$ in Methanol $(0.14 \mathrm{~mL})$ versetzt. Die Reaktionslösung wurde nach 30 min auf Raumtemperatur gebracht und $20 \mathrm{~h}$ gerührt. Anschließend wurde die Reaktionslösung mit ges. $\mathrm{NaHCO}_{3}$-Lösung $(1 \mathrm{~mL})$ versetzt und weitere $15 \mathrm{~min}$ gerührt. Die Reaktionslösung wurde in DCM $(50 \mathrm{~mL})$ aufgenommen und mit Wasser $(1 \times 30 \mathrm{~mL})$ und ges. wässriger $\mathrm{NaCl}(1 \times 30 \mathrm{~mL})$ gewaschen. Die organische Phase wurde unter vermindertem Druck zur Trockne eingeengt und der Rückstand chromatographisch an Kieselgel (DCM/MeOH 19:1) gereinigt.

Ausbeute: Es wurden $132 \mathrm{mg}$ (0.494 mmol, 63\%) eines bräunlichen, zähen Harzes erhalten.

DC: $R_{\mathrm{f}}(\mathrm{DCM} / \mathrm{MeOH}$ 95:5) $=0.25$.

${ }^{1} \mathrm{H}-\mathrm{NMR}(500 \mathrm{MHz}, \mathrm{MeOD}): \delta=1.90(\mathrm{~d}, J=1.2 \mathrm{~Hz}, 3 \mathrm{H}, 7-\mathrm{H}), 2.35-2.45(\mathrm{~m}, 2 \mathrm{H}$, 2'-H), 3.76 (dd, J=12.1 Hz, J=3.5 Hz, 1 H, 5'- $\mathrm{H}_{\mathrm{a}}$ ), 3.84 (dd, J=12.1 Hz, J=3.5 Hz, $1 \mathrm{H}, 5{ }^{\prime}-\mathrm{H}_{\mathrm{b}}$ ), 3.92 (ddd, J=5.0 Hz, J=3.5 Hz, J=3.5 Hz, $1 \mathrm{H}, 4^{\prime}-\mathrm{H}$ ), 4.36 (ddd, $\left.J=6.9 \mathrm{~Hz}, J=5.0 \mathrm{~Hz}, 1 \mathrm{H}, 3^{\prime}-\mathrm{H}\right), 6.21\left(\mathrm{dd}, J=6.5 \mathrm{~Hz}, J=6.5 \mathrm{~Hz}, 1 \mathrm{H}, 1^{\prime}-\mathrm{H}\right), 7.74$ (q, $J=0.3 \mathrm{~Hz}, 1 \mathrm{H}, 6-\mathrm{H})$.

${ }^{13}$ C-NMR (126 MHz, MeOD): $\delta=11.42$ (C-7), 36.88 (C-2'), 60.41 (C-3'), 61.15 (C-5'), 84.56 (C-1'), 84.82 (C-4'), 110.40 (C-5), 136.28 (C-6), 153.24 (C-2), 168.07 (C-4).

Drehwert: $[\alpha]=+51.5(\mathrm{c}=1.0, \mathrm{MeOH})$.

IR (ATR): $\tilde{v}=2101,1661,1466,1366,1265,1199,1098,1050,764$.

UV (MeCN): $\lambda_{\max }(\lg \varepsilon)=207$ (4.15), 264 (4.18).

MS $\left(\mathrm{ESI}^{+}\right): \mathrm{m} / \mathrm{z}=290.1[\mathrm{M}+\mathrm{Na}]^{+}$. 
$\mathrm{C}_{10} \mathrm{H}_{13} \mathrm{~N}_{5} \mathrm{O}_{4} \mathrm{Si}(267.24)$

ber.: $290.0865[\mathrm{M}+\mathrm{Na}]^{+}$

gef.: 290.0860 (ESI+-HRMS).

\subsubsection{3'-Desoxy-3'-azidothymidin-5'-aldehyd 105}

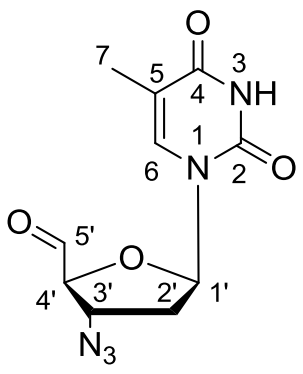

105

Eine Lösung von 3'-Desoxy-3'-azidothymidin 154 (55 mg, $0.21 \mathrm{mmol}$ ) in $2 \mathrm{~mL} \mathrm{MeCN}$ (2 mL) wurde mit IBX (157 mg, $0.562 \mathrm{mmol}$ ) versetzt und $45 \mathrm{~min}$ unter Rückfluss gerührt. Die auf Raumtemperatur abgekühlte Lösung wurde durch Filtration vom IBX getrennt und der Filterkuchen mit EtOAc nachgewaschen $(3 \times 2 \mathrm{~mL})$. Die vereinigten Filtrate wurden unter vermindertem Druck eingeengt und der Rückstand mehrere Stunden unter Hochvakuum aufbewahrt. Das erhaltene Rohprodukt wurde ohne weitere Reinigung in der nachfolgenden Reaktion eingesetzt.

Ausbeute: Es wurden $50 \mathrm{mg}(0.19 \mathrm{mmol}, 91 \%)$ eines farblosen Feststoffs erhalten.

${ }^{1} \mathrm{H}$-NMR $\left(300 \mathrm{MHz}, \mathrm{CDCl}_{3}\right): \delta=1.90(\mathrm{~d}, J=1.2 \mathrm{~Hz}, 3 \mathrm{H}, 7-\mathrm{H}$ ), 2.39 (ddd, $J=13.8 \mathrm{~Hz}$, $J=6.6 \mathrm{~Hz}, J=5.1 \mathrm{~Hz}, 1 \mathrm{H}, 2^{\prime}-\mathrm{H}_{\mathrm{a}}$ ), 2.52 (ddd, $J=13.8 \mathrm{~Hz}, J=7.5 \mathrm{~Hz}, J=6.6 \mathrm{~Hz}$, $1 \mathrm{H}, 2^{\prime}-\mathrm{H}_{\mathrm{b}}$ ), $3.81\left(\mathrm{dd}, J=11.8 \mathrm{~Hz}, J=2.3 \mathrm{~Hz}, 1 \mathrm{H}, 5^{\prime}-\mathrm{H}_{\mathrm{a}}\right), 3.92-4.01\left(\mathrm{~m}, 2 \mathrm{H}, 5^{\prime}-\mathrm{H}_{\mathrm{b}}\right.$, 4'-H), 4.39 (ddd, $J=7.5 \mathrm{~Hz}, J=5.1 \mathrm{~Hz}, J=5.1 \mathrm{~Hz}, 1 \mathrm{H}, 3^{\prime}-\mathrm{H}$ ), 6.07 (dd, $J=6.6 \mathrm{~Hz}$, $\left.J=6.6 \mathrm{~Hz}, 1 \mathrm{H}, 1^{\prime}-\mathrm{H}\right), 7.41(\mathrm{q}, J=1.2 \mathrm{~Hz}, 1 \mathrm{H}, 6-\mathrm{H}), 9.26$ (brs, $1 \mathrm{H}, 5^{\prime}-\mathrm{H}$ ).

Diese Verbindung wurde aufgrund ihrer Labilität nicht chromatographisch gereinigt und es wurde auf eine Charakterisierung mittels weiterer analytischer Methoden verzichtet. 


\subsubsection{3 (Z)-6'-N-Boc-O-Bn-5',6'-didehydro-3'-desoxy-3'-azido-TAA 110}

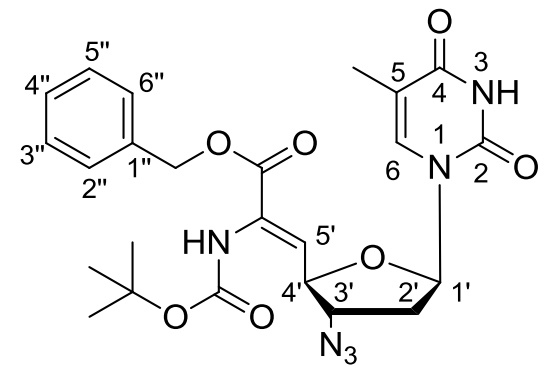

110

$\mathrm{Zu}$ einer auf $-78^{\circ} \mathrm{C}$ gekühlten Suspension von $\mathrm{KO}{ }^{t} \mathrm{Bu}(37 \mathrm{mg}, 0.33 \mathrm{mmol})$ in $2 \mathrm{~mL}$ THF wurde langsam eine Lösung von $N$-(tert-Butyloxycarbonyl)-2(dimethylphosphoryl)-glycinbenzylester 109 (77 mg, $0.21 \mathrm{mmol})$ in $1.7 \mathrm{~mL}$ THF gegeben. Die resultierte Lösung wurde $5 \mathrm{~min}$ bei $-78^{\circ} \mathrm{C}$ gerührt und anschließend allmählich mit einer Lösung von 3'-Desoxy-3'-azidothymidin-5'-aldehyd 105 (50 mg, $0.19 \mathrm{mmol}$ ) in $12 \mathrm{~mL}$ THF versetzt. Die Reaktionslösung wurde $16 \mathrm{~h}$ gerührt und im Laufe dieses Zeitraums langsam auf Raumtemperatur gebracht. Es wurde anhand von Dünnschichtchromatographie (DCM/MeOH 95:5) kein Umsatz der Edukte beobachtet.

\subsubsection{5'-O-TBDMS-3-N-BOM-3'-desoxy-3'-azidothymidin 119}

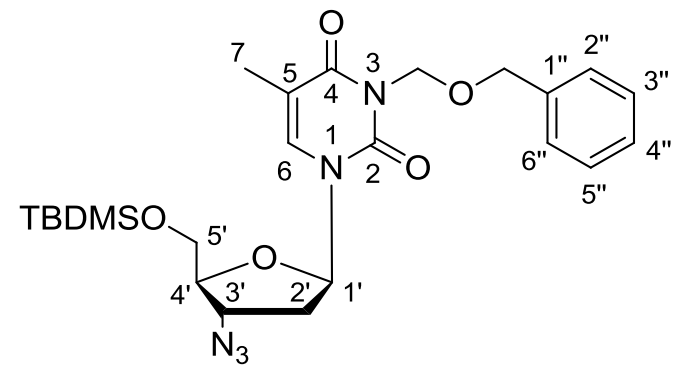

119

Eine Suspension von $\mathrm{NaH}$ (231 mg, 60\% in Mineralöl, $9.63 \mathrm{mmol})$ in DMF (15 mL) wurde bei $-10^{\circ} \mathrm{C}$ langsam mit einer Lösung von 5'-O-TBDMS-3'-desoxy-3'azidothymidin $118(2.04 \mathrm{~g}, 5.35 \mathrm{mmol})$ in DMF (8 mL) versetzt und $30 \mathrm{~min}$ bei -3 bis $-5^{\circ} \mathrm{C}$ gerührt. Anschließend wurde die Reaktionslösung tropfenweise mit Benzyloxymethylchlorid $(1.00 \mu \mathrm{L}, 1.01 \mathrm{mg}, 6.42 \mathrm{mmol})$ versetzt und $3 \mathrm{~h}$ bei $0{ }^{\circ} \mathrm{C}$ gerührt. Die resultierende Lösung wurde mit Ethylacetat $(100 \mathrm{~mL})$ verdünnt. Die organische Phase wurde mit ges. wässriger $\mathrm{NH}_{4} \mathrm{Cl}(1 \times 50 \mathrm{~mL})$, ges. wässriger $\mathrm{NaHCO}_{3}(50 \mathrm{~mL})$, Wasser $(2 \times 50 \mathrm{~mL})$ und ges. wässriger $\mathrm{NaCl}(50 \mathrm{~mL})$ gewaschen, 
über $\mathrm{Na}_{2} \mathrm{SO}_{4}$ getrocknet, filtriert und im Vakuum eingeengt. Der Rückstand wurde mit Toluol koevaporiert $(3 \times 10 \mathrm{~mL})$. Das so erhaltene Rohprodukt wurde chromatographisch an Kieselgel gereingt (Hex/EtOAc 8:2).

Ausbeute: Es wurden $2.68 \mathrm{~g}$ ( $5.35 \mathrm{mmol}$, quantitativ) eines hochviskosen, farblosen Öls erhalten.

DC: $R_{\mathrm{f}}(\mathrm{iHex} / \mathrm{EtOAc} 8: 2)=0.22$.

${ }^{1} \mathrm{H}-\mathrm{NMR}\left(300 \mathrm{MHz}, \mathrm{CDCl}_{3}\right): \delta=0.13\left(\mathrm{~s}, 6 \mathrm{H}, \mathrm{SiCH}_{3}\right), 0.94\left(\mathrm{~s}, 9 \mathrm{H}, \mathrm{SiC}\left(\mathrm{CH}_{3}\right)_{3}\right), 1.92$ (d, $J=1.2 \mathrm{~Hz}, 3 \mathrm{H}, 7-\mathrm{H}$ ), 2.19 (ddd, $J=13.7 \mathrm{~Hz}, J=7.0 . \mathrm{Hz}, J=6.7 \mathrm{~Hz}, 1 \mathrm{H}, 2^{\prime}-\mathrm{H}_{\mathrm{a}}$ ), 2.44 (ddd, $\left.J=13.7 \mathrm{~Hz}, J=6.3 \mathrm{~Hz}, J=4.4 \mathrm{~Hz}, 1 \mathrm{H}, 2^{\prime}-\mathrm{H}_{\mathrm{b}}\right), 3.78-3.82\left(\mathrm{~m}, 1 \mathrm{H}, 5^{\prime}-\mathrm{H}_{\mathrm{a}}\right.$ ), 3.92-3.97 (m, $2 \mathrm{H}, 5^{\prime}-\mathrm{H}_{\mathrm{b}}, 4^{\prime}-\mathrm{H}$ ), 4.20 (ddd, $J=7.0 \mathrm{~Hz}, J=4.4 \mathrm{~Hz}, J=4.4 \mathrm{~Hz}, 1 \mathrm{H}$, 3'-H), 4.70 (s, $2 \mathrm{H}, \mathrm{NCH}_{2} \mathrm{OCH}_{2}$ ), 5.49 (s, $\left.2 \mathrm{H}, \mathrm{NCH}_{2} \mathrm{O}\right), 6.21$ (dd, $J=6.7 \mathrm{~Hz}$, $\left.J=6.3 \mathrm{~Hz}, 1 \mathrm{H}, 1^{\prime}-\mathrm{H}\right)$, 7.23-7.27 (m, $1 \mathrm{H}, 4$ "'-H), 7.29-7.33 (m, $2 \mathrm{H}, 3$ 3"-H, 5"'-H), 7.367.38 (m, $2 \mathrm{H}, 2$ "'-H, 6"-H), 7.39 (q, J=1.2 Hz, $1 \mathrm{H}, 6-\mathrm{H}$ ).

${ }^{13} \mathrm{C}$-NMR $\left(75 \mathrm{MHz}, \mathrm{CDCl}_{3}\right): \delta=-5.44\left(\mathrm{SiCH}_{3 \mathrm{a}}\right),-5.34\left(\mathrm{SiCH}_{3 \mathrm{~b}}\right), 13.24(\mathrm{C}-7), 18.38$ $\left(\mathrm{Si} \underline{\mathrm{C}}\left(\mathrm{CH}_{3}\right)_{3}\right), 25.93\left(\mathrm{SiC}\left(\underline{\mathrm{C}} \mathrm{H}_{3}\right)_{3}\right), 38.06$ (C-2'), 60.30 (C-3'), 62.80 (C-5'), 70.58 $\left(\mathrm{NCH}_{2} \mathrm{O}\right), 72.27\left(\mathrm{NCH}_{2} \mathrm{O}_{2} \mathrm{H}_{2}\right), 84.51$ (C-4'), 85.23 (C-1'), 110.25 (C-5), 127.60 (C-4"), 127.62 (C-2", C-6"), 128.27 (C-3", C-5"), 133.72 (C-6), 138.08 (C-1"), 150.84 (C-2), 163.36 (C-4).

Drehwert: $[\alpha]=+44.4\left(\mathrm{c}=1.0, \mathrm{CHCl}_{3}\right)$.

IR (ATR): $\tilde{v}=2101,1709,1652,1461,1256,1075,832,774,731,698$.

UV (MeCN): $\lambda_{\max }(\lg \varepsilon)=208$ (4.36), 267 (4.07).

MS $\left(E S I^{+}\right): m / z=524.2[\mathrm{M}+\mathrm{Na}]^{+}$.

$\mathrm{C}_{24} \mathrm{H}_{35} \mathrm{~N}_{5} \mathrm{O}_{5} \mathrm{Si}(501.65)$ ber.: $524.2300[\mathrm{M}+\mathrm{Na}]^{+}$ gef.: 524.2296 (ESI+-HRMS). 


\subsubsection{3-N-BOM-3'-desoxy-3'-azidothymidin 153}

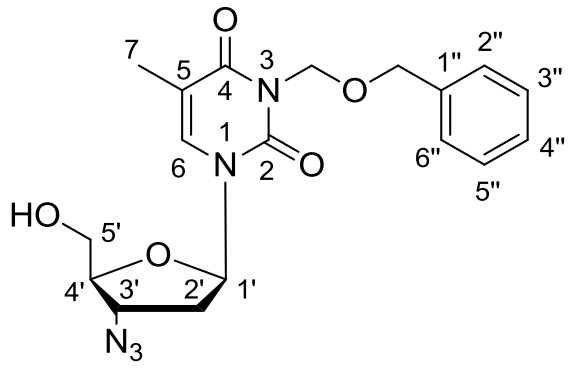

153

Eine Lösung von 5'-O-TBDMS-3-N-BOM-3'-desoxy-3'-azidothymidin 119 (2.60 g, $5.19 \mathrm{mmol})$ in Methanol $(100 \mathrm{~mL})$ wurde auf $0^{\circ} \mathrm{C}$ gekühlt und mit $\mathrm{AcCl}(183 \mu \mathrm{L}$, $202 \mathrm{mg}, 2.59 \mathrm{mmol}$ ) versetzt. Die Reaktionslösung wurde nach $30 \mathrm{~min}$ auf Raumtemperatur gebracht und $1.5 \mathrm{~h}$ gerührt. Anschließend wurde die Reaktionslösung mit ges. $\mathrm{NaHCO}_{3}$-Lösung $(5 \mathrm{~mL})$ versetzt und weitere $15 \mathrm{~min}$ gerührt. Die Reaktionslösung wurde in EtOAc $(150 \mathrm{~mL})$ aufgenommen und mit Wasser $(1 \times 80 \mathrm{~mL})$ und ges. NaCl-Lösung $(1 \times 80 \mathrm{~mL})$ gewaschen. Die organische Phase wurde unter vermindertem Druck zur Trockne eingeengt und der Rückstand chromatographisch an Kieselgel (iHex/EtOAc 3:2) gereinigt.

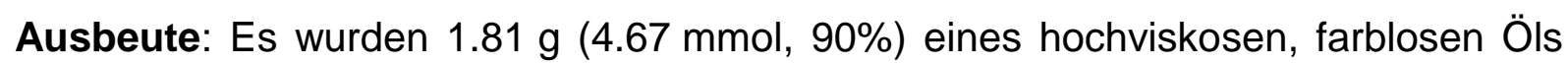
erhalten.

DC: $R_{\mathrm{f}}(\mathrm{DCM} / \mathrm{MeOH} 9: 1)=0.43$.

${ }^{1} \mathrm{H}-\mathrm{NMR}\left(500 \mathrm{MHz}, \mathrm{CDCl}_{3}\right): \delta=1.90(\mathrm{~d}, J=1.2 \mathrm{~Hz}, 3 \mathrm{H}, 7-\mathrm{H}), 2.36$ (ddd, $J=13.8 \mathrm{~Hz}$, $J=6.7 \mathrm{~Hz}, J=5.3 \mathrm{~Hz} 1 \mathrm{H}, 2^{\prime}-\mathrm{H}_{\mathrm{a}}$ ), 2.42 (ddd, $J=13.8 \mathrm{~Hz}, J=7.4 \mathrm{~Hz}, J=6.2 \mathrm{~Hz}$, $\left.1 \mathrm{H}, 2{ }^{\prime}-\mathrm{H}_{\mathrm{b}}\right), 3.75-3.81\left(\mathrm{~m}, 1 \mathrm{H}, 5^{\prime}-\mathrm{H}_{\mathrm{a}}\right), 3.91-3.97\left(\mathrm{~m}, 2 \mathrm{H}, 4^{\prime}-\mathrm{H}, 5^{\prime}-\mathrm{H}_{\mathrm{b}}\right), 4.33$ (ddd, $J=7.4 \mathrm{~Hz}, J=5.3 \mathrm{~Hz}, J=5.3 \mathrm{~Hz}, 1 \mathrm{H}, 3^{\prime}-\mathrm{H}$ ), 4.69 (s, $\left.2 \mathrm{H}, \mathrm{NCH}_{2} \mathrm{OC}_{2}\right), 5.47$ (s, $2 \mathrm{H}$, $\mathrm{NCH}_{2} \mathrm{O}$ ), 6.07 (dd, $\left.J=6.4 \mathrm{~Hz}, J=6.4 \mathrm{~Hz}, 1 \mathrm{H}, 1^{\prime}-\mathrm{H}\right), 7.22-7.27(\mathrm{~m}, 1 \mathrm{H}, 4$ ''-H), 7.28$7.32(\mathrm{~m}, 2 \mathrm{H}, 3$ "'-H, 5"-H), 7.33-7.35 (m, $2 \mathrm{H}, 2$ '"-H, 6"'-H), 7.43 (q, J=1.2 Hz, $1 \mathrm{H}$, 6-H).

${ }^{13}$ C-NMR (126 MHz, $\mathrm{CDCl}_{3}$ ): $\delta=13.18$ (C-7), 37.50 (C-2'), 59.88 (C-3'), 61.86 (C-5'), $\left.70.62\left(\mathrm{NCH}_{2} \mathrm{O}\right), 72.34\left(\mathrm{NCH}_{2} \mathrm{O}_{\mathrm{CH}}\right)_{2}\right), 84.54$ (C-4'), 86.84 (C-1'), 110.38 (C-5), 127.64 (C-4”), 127.70 (C-2”, C-6”), 128.31 (C-3”, C-5”), 135.32 (C-6), 137.91 (C-1”), 150.92 (C-2), 163.39 (C-4).

Drehwert: $[\alpha]_{D}^{20}=+49.1\left(\mathrm{c}=1.1, \mathrm{CHCl}_{3}\right)$.

IR (ATR): $\tilde{v}=2101,1704,1637,1466,1266,1093,1070,774,731,698$.

UV (MeCN): $\lambda_{\max }(\lg \varepsilon)=208$ (4.14), 267 (3.89) 
MS $\left(E S I^{+}\right): \mathrm{m} / \mathrm{z}=388.2[\mathrm{M}+\mathrm{H}]^{+}$.

$\begin{array}{ll}\mathrm{C}_{14} \mathrm{H}_{19} \mathrm{~N}_{5} \mathrm{O}_{5} \mathrm{Si}(387.39) & \text { ber.: } 388.1615[\mathrm{M}+\mathrm{H}]^{+} \\ & \text {gef.: } 388.1610\left(\left.\mathrm{ESI}\right|^{+}-\mathrm{HRMS}\right) .\end{array}$

\subsubsection{3-N-BOM-3'-desoxy-3'-azidothymidin-5'-aldehyd 106}

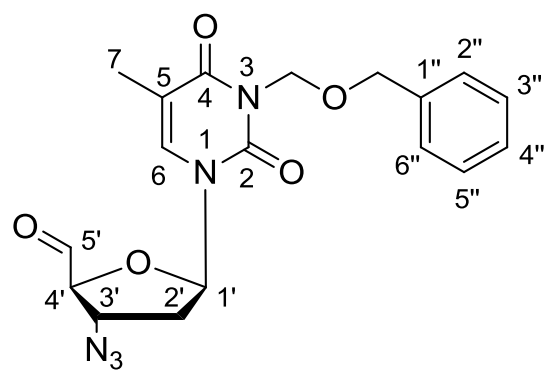

106

Eine Lösung von 3-N-BOM-3'-desoxy-3'-azidothymidin $153(1.74 \mathrm{~g}, 4.49 \mathrm{mmol})$ in MeCN (43 mL) wurde mit IBX $(3.15 \mathrm{~g}, 11.2 \mathrm{mmol})$ versetzt und $45 \mathrm{~min}$ unter Rückfluss gerührt. Die auf Raumtemperatur abgekühlte Lösung wurde durch Filtration vom IBX getrennt und der Filterkuchen mit EtOAc nachgewaschen $(3 \times 20 \mathrm{~mL})$. Die vereinigten Filtrate wurden unter vermindertem Druck eingeengt und der Rückstand mehrere Stunden unter Hochvakuum aufbewahrt. Das erhaltene Rohprodukt wurde ohne weitere Reinigung in der nachfolgenden Reaktion eingesetzt.

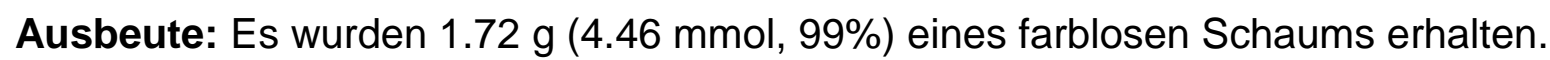

${ }^{1} \mathrm{H}-\mathrm{NMR}\left(500 \mathrm{MHz}, \mathrm{CDCl}_{3}\right): \delta=1.94(\mathrm{~d}, J=1.2 \mathrm{~Hz}, 3 \mathrm{H}, 7-\mathrm{H}), 2.35-2.45(\mathrm{~m}, 1 \mathrm{H}$, 2' $-\mathrm{H}_{\mathrm{a}}$ ), 2.43 (ddd, $J=14.1 \mathrm{~Hz}, J=6.7 \mathrm{~Hz}, J=4.0 \mathrm{~Hz}, 1 \mathrm{H}, 2^{\prime}-\mathrm{H}_{\mathrm{b}}$ ), $4.42(\mathrm{~d}, J=3.4 \mathrm{~Hz}$, $1 \mathrm{H}, 4^{\prime}-\mathrm{H}$ ), 4.60 (ddd, $J=7.0 \mathrm{~Hz}, J=3.5 \mathrm{~Hz}, J=3.4 \mathrm{~Hz}, 1 \mathrm{H}, 3^{\prime}-\mathrm{H}$ ), $4.68(\mathrm{~s}, 2 \mathrm{H}$, $\left.\mathrm{NCH}_{2} \mathrm{OCH}_{2}\right), 5.46\left(\mathrm{~s}, 2 \mathrm{H}, \mathrm{NCH}_{2} \mathrm{O}\right), 6.00\left(\mathrm{dd}, J=6.7 \mathrm{~Hz}, J=6.6 \mathrm{~Hz}, 1 \mathrm{H}, 1^{\prime}-\mathrm{H}\right), 7.23-$ 7.35 (m, $6 \mathrm{H}, 6-\mathrm{H}, 2$ "'-H, 3"'-H, 4"-H, 5"-H, 6"-H).

${ }^{13} \mathrm{C}-\mathrm{NMR}\left(126 \mathrm{MHz}, \mathrm{CDCl}_{3}\right): \delta=13.11$ (C-7), 36.60 (C-2'), 61.68 (C-3'), 70.57 $\left(\mathrm{NCH}_{2} \mathrm{O}_{2} \mathrm{H}_{2}\right), 72.35\left(\mathrm{NCH}_{2} \mathrm{O}\right), 88.59$ (C-1'), 90.36 (C-4'), 110.70 (C-5), 127.63 (C-4"), 127.74 (C-2", C-6"), 128.31 (C-3", C-5"), 135.32 (C-6), 137.91 (C-1"), 150.69 (C-2), 163.23 (C-4), 198.34 (C-5'). 
Die erhaltene Verbindung wurde aufgrund ihrer geringen Stabilität nicht chromatographisch gereinigt und es wurde auf eine Charakterisierung mittels weiterer analytischer Methoden verzichtet.

\subsubsection{7 (Z)-6'-N-Boc-O-Bn-5',6'-didehydro-3-N-BOM-3'-desoxy-3'-azido-TAA 111}

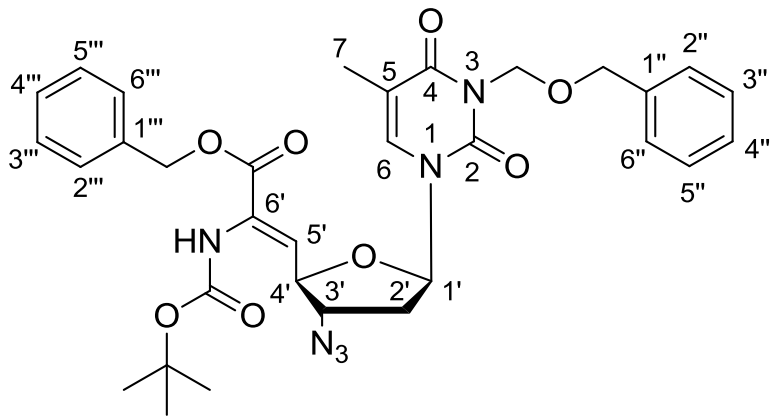

$(Z)-111$

$\mathrm{Zu}$ einer auf $-78^{\circ} \mathrm{C}$ gekühlten Lösung von $\mathrm{KO}{ }^{t} \mathrm{Bu}(504 \mathrm{mg}, 4.49 \mathrm{mmol})$ in THF (43 mL) wurde langsam eine Lösung von $N$-(tert-Butyloxycarbonyl)-2(dimethylphosphoryl)-glycinbenzylester 109 (1.67 g, $4.49 \mathrm{mmol})$ in THF (34 mL) dazugegeben. Die resultierende Lösung wurde $5 \mathrm{~min}$ bei $-78^{\circ} \mathrm{C}$ gerührt und anschließend allmählich mit einer Lösung von 3-N-BOM-3'-desoxy-3'-azidothymidin5'-aldehyd 106 (1.45 g, $2.95 \mathrm{mmol})$ in THF (18 mL) versetzt. Die Reaktionslösung wurde $16 \mathrm{~h}$ gerührt und im Laufe dieses Zeitraums langsam auf Raumtemperatur gebracht. Die Reaktionslösung wurde auf $0^{\circ} \mathrm{C}$ gekühlt, mit Methanol $(5 \mathrm{~mL})$ versetzt und mit Ethylacetat $(200 \mathrm{~mL})$ verdünnt. Die organische Phase wurde mit Wasser $(1 \times 100 \mathrm{~mL})$ und ges. $\mathrm{NaCl}$-Lösung $(1 \times 100 \mathrm{~mL})$ gewaschen, über $\mathrm{Na}_{2} \mathrm{SO}_{4}$ getrocknet und filtriert. Das Lösungsmittel wurde unter vermindertem Druck entfernt und der Rückstand chromatographisch an Kieselgel gereinigt (iHex/EtOAc 3:2).

Ausbeute: Es wurden $2.06 \mathrm{~g}$ (3.26 mmol, 73\%, Diastereomerengemisch Z/E 93:7) eines farblosen Schaums erhalten.

DC: $R_{\mathrm{f}}(\mathrm{Hex} / \mathrm{EtOAc} 4: 6)=0.62$.

${ }^{1} \mathrm{H}-\mathrm{NMR}\left(500 \mathrm{MHz}, \mathrm{CDCl}_{3}\right): \delta=1.48\left(\mathrm{~s}, 9 \mathrm{H}, \mathrm{C}\left(\mathrm{CH}_{3}\right)_{3}\right), 1.83(\mathrm{~d}, J=1.2 \mathrm{~Hz}, 3 \mathrm{H}, 7-\mathrm{H})$, 2.24 (ddd, $J=13.9 \mathrm{~Hz}, J=7.4 \mathrm{~Hz}, J=6.6 \mathrm{~Hz}, 1 \mathrm{H}, 2^{\prime}-\mathrm{H}_{\mathrm{a}}$ ), 2.49 (ddd, $J=13.9 \mathrm{~Hz}$, $J=5.9 \mathrm{~Hz}, J=2.9 \mathrm{~Hz}, 1 \mathrm{H}, 2^{\prime}-\mathrm{H}_{\mathrm{b}}$ ), 4.35 (ddd, $J=6.0 \mathrm{~Hz}, J=3.0 \mathrm{~Hz}, J=3.0 \mathrm{~Hz}, 1 \mathrm{H}$, 3'-H), 4.69 (s, $2 \mathrm{H}, \mathrm{NCH}_{2} \mathrm{OCH}_{2}$ ), 4.86 (dd, J=8.4 Hz, J=2.8 Hz, $1 \mathrm{H}, 6$ '-H), 5.22 (d, 
$\left.J=12.2 \mathrm{~Hz}, \quad 2 \mathrm{H}, \quad \mathrm{CbzCH} \underline{H}_{\mathrm{a}}\right), \quad 5.27\left(\mathrm{~d}, \quad J=12.2 \mathrm{~Hz}, 2 \mathrm{H}, \quad \mathrm{CbzCH} \underline{H}_{\mathrm{b}}\right), \quad 5.46$ (d, $J=9.7 \mathrm{~Hz}, 1 \mathrm{H}, \mathrm{NCH} \underline{H}_{a} \mathrm{O}$ ), $5.48\left(\mathrm{~d}, J=9.7 \mathrm{~Hz}, 1 \mathrm{H}, \mathrm{NCH} \underline{H}_{b} \mathrm{O}\right), 6.07$ (dd, $J=7.4 \mathrm{~Hz}$, $J=6.0 \mathrm{~Hz}, 1 \mathrm{H}, 1^{\prime}-\mathrm{H}$ ), 6.31 (d, $J=8.4 \mathrm{~Hz}, 1 \mathrm{H}, 5^{\prime}-\mathrm{H}$ ), 6.60 (s, $\left.1 \mathrm{H}, 6^{\prime}-\mathrm{NH}\right), 7.09$ (q, $J=1.2 \mathrm{~Hz}, 1 \mathrm{H}, 6-\mathrm{H}), 7.22-7.26(\mathrm{~m}, 1 \mathrm{H}, \mathrm{ArH}), 7.28-7.33(\mathrm{~m}, 2 \mathrm{H}, \mathrm{ArH}), 7.34-7.39(\mathrm{~m}$, $7 \mathrm{H}, \mathrm{ArH})$.

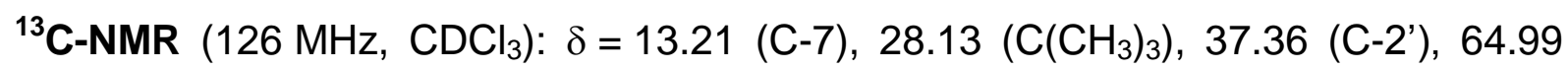
(C-3'), $68.05\left(\mathrm{CbzCH}_{2}\right), 70.59\left(\mathrm{NCH}_{2} \mathrm{O}\right), 72.30\left(\mathrm{NCH}_{2} \mathrm{O} \underline{\mathrm{CH}} \mathrm{H}_{2}\right), 81.87(\mathrm{C}-6), 87.68$ (C-1'), 110.43 (C-5), 125.29 (C-5'), 127.63, 128.27, 128.51, 128.73, 128.73, (ArC), 134.02 (ArC), 134.90 (C-6), 138.40 (ArC), 150.70 (C-2), 153.13 (Boc-C=O), 163.23 (C-4), 163.92 (COO).

IR (ATR): $\tilde{v}=2101,1708,1652,1242,1151,1065,1027,769,736,693$.

UV (MeCN): $\lambda_{\max }(\lg \varepsilon)=206$ (4.56), 261 (4.17).

MS $\left(E S I^{+}\right): m / z=655.3[\mathrm{M}+\mathrm{Na}]^{+}$.

$\mathrm{C}_{32} \mathrm{H}_{36} \mathrm{~N}_{6} \mathrm{O}_{8}$ (623.67)

ber.: $655.2492[\mathrm{M}+\mathrm{Na}]^{+}$

gef.: 655.2487 (ESI+-HRMS).

\subsubsection{6'-N-Boc-O-Bn-3-N-BOM-3'-desoxy-3'-azido-(S)-TAA 115}

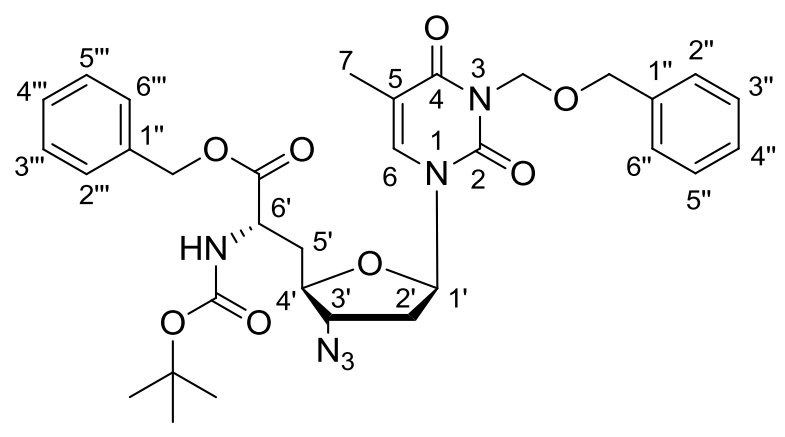

(6'S)-115

Die Reaktion wurde unter striktem Sauerstoff-Ausschluss durchgeführt. Durch eine Lösung des (Z)-Olefins 111 (950 mg, $1.503 \mathrm{mmol}$ ) in abs. $\mathrm{MeOH}(50 \mathrm{~mL}$ ) wurde $15 \mathrm{~min}$ ein Argonstrom geleitet. Anschließend wurde die Lösung mit (S,S)-MeDuPHOS-Rh $(19 \mathrm{mg}, 32 \mu \mathrm{mol})$ versetzt und $3 \mathrm{~d}$ bei Raumtemperatur unter einer Wasserstoff-Atmosphäre (1 bar) gerührt. Es wurde eine weitere Portion $(S, S)$-MeDuPHOS-Rh (19 mg, $32 \mu \mathrm{mol})$ dazugegeben und die Reaktion weitere $4 \mathrm{~d}$ gerührt. Die Lösung wurde mit Kieselgel versetzt und das Lösungsmittel im Vakuum entfernt. Das Rohprodukt wurde säulenchromatographisch an Kieselgel gereinigt ( $\mathrm{Hex} / \mathrm{EtOAc}$ 3:2). 
Ausbeute: Es wurden $800 \mathrm{mg}(1.26 \mathrm{mmol}$, 84\%, Diastereomerengemisch 6' S/6' $R$ 85:15) eines farblosen Schaums erhalten.

DC: $R_{\mathrm{f}}(\mathrm{HHex} / \mathrm{EtOAc} 1: 1)=0.62$.

${ }^{1} \mathrm{H}-\mathrm{NMR}\left(300 \mathrm{MHz}, \mathrm{C}_{6} \mathrm{D}_{6}, 70{ }^{\circ} \mathrm{C}\right): \delta=1.39\left(\mathrm{~s}, 9 \mathrm{H}, \mathrm{C}\left(\mathrm{CH}_{3}\right)_{3}\right), 1.68$ (ddd, $J=13.8 \mathrm{~Hz}$, $\left.J=8.0 \mathrm{~Hz}, \quad J=6.0 \mathrm{~Hz}, \quad 1 \mathrm{H}, \quad 2^{\prime}-\mathrm{H}_{\mathrm{a}}\right), 1.76-1.84\left(\mathrm{~m}, 2 \mathrm{H}, 2{ }^{\prime}-\mathrm{H}_{\mathrm{b}}, 5-\mathrm{H}_{\mathrm{a}}\right), 1.88$ (d, $J=1.1 \mathrm{~Hz}, 7-\mathrm{H}), 2.01$ (ddd, $J=14.4 \mathrm{~Hz}, J=6.6 \mathrm{~Hz}, J=4.0 \mathrm{~Hz}, 1 \mathrm{H}, 5{ }^{\prime}-\mathrm{H}_{\mathrm{b}}$ ), 3.28 (ddd, $J=7.4 \mathrm{~Hz}, J=6.0 \mathrm{~Hz}, J=6.0 \mathrm{~Hz}, 1 \mathrm{H}, 3^{\prime}-\mathrm{H}$ ), 3.64 (ddd, $J=8.7 \mathrm{~Hz}, J=6.2 \mathrm{~Hz}$, $\left.J=4.0 \mathrm{~Hz}, 1 \mathrm{H}, 4^{\prime}-\mathrm{H}\right), 4.50-4.58\left(\mathrm{~m}, 1 \mathrm{H}, 6{ }^{\prime}-\mathrm{H}\right), 4.70$ (s, $2 \mathrm{H}, \mathrm{NCH}_{2} \mathrm{OC}_{2}$ ), 4.90 (d, $\left.J=12.3 \mathrm{~Hz}, 1 \mathrm{H}, \mathrm{CbzCH}_{2}\right), 4.93\left(\mathrm{~d}, J=12.3 \mathrm{~Hz}, 1 \mathrm{H}, \mathrm{CbzCH}_{2}\right), 5.11(\mathrm{~d}, J=7.4 \mathrm{~Hz}$, $1 \mathrm{H}, 6$ '- $\mathrm{NH}$ ), 5.51 (s, $2 \mathrm{H}, \mathrm{NCH}_{2} \mathrm{O}$ ), 5.68 (dd, J=6.0 Hz, J=6.0 Hz, $\left.1 \mathrm{H}, 1^{\prime}-\mathrm{H}\right), 6.75$ (brs, $1 \mathrm{H}, 6-\mathrm{H}), 7.00-7.13(\mathrm{~m}, 8 \mathrm{H}, \mathrm{ArH}), 7.31-7.34(\mathrm{~m}, 2 \mathrm{H}, \mathrm{ArH})$.

${ }^{13} \mathrm{C}-N M R\left(126 \mathrm{MHz}, \mathrm{C}_{6} \mathrm{D}_{6}, 70{ }^{\circ} \mathrm{C}\right): \delta=12.55(\mathrm{C}-7), 27.95\left(\mathrm{C}\left(\underline{\mathrm{CH}}_{3}\right)_{3}\right), 35.64\left(\mathrm{C}-5^{\prime}\right)$, 36.42 (C-2'), 51.14 (C-6'), 62.76 (C-3'), $66.84\left(\mathrm{CbzCH}_{2}\right), 70.63\left(\mathrm{NCH}_{2} \mathrm{O}\right), 72.16$ $\left(\mathrm{NCH}_{2} \mathrm{O}^{\mathrm{C}} \mathrm{H}_{2}\right), 79.61\left(\underline{\mathrm{C}}\left(\mathrm{CH}_{3}\right)_{3}\right), 80.10$ (C-4'), 85.86 (C-1'), 110.06 (C-5), 133.74 (C-6), 127.14, 127.86, 127.92, 127.99, 128.15, 128.31 (ArC), 135.44 (C-1"), 138.74 (C-1"'), 150.43 (Boc-C=O), 154.87 (C-2), 162.53 (C-4), 171.08 (COO).

IR (ATR): $\tilde{v}=2101,1704,1652,1452,1250,1156,1070,774,736,698$.

UV (MeCN): $\lambda_{\max }(\lg \varepsilon)=206$ (4.65), 266 (4.19).

MS $\left(\mathrm{ESI}^{+}\right): \mathrm{m} / \mathrm{z}=633.3[\mathrm{M}-\mathrm{H}]^{-}$.

$\mathrm{C}_{32} \mathrm{H}_{38} \mathrm{~N}_{6} \mathrm{O}_{8}(634.68)$

ber.: $633.2678[\mathrm{M}-\mathrm{H}]^{-}$

gef.: 633.2675 (ESI'-HRMS).

\subsubsection{6'-N-Boc-O-Bn-3-N-BOM-3'-desoxy-3'-azido-(R)-TAA 115}

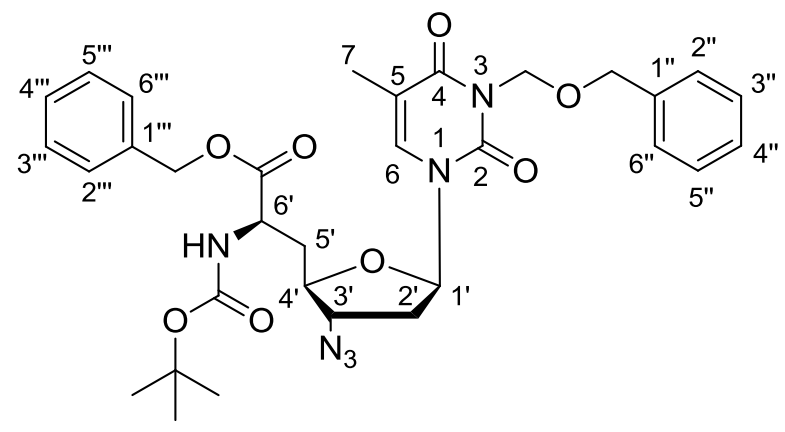

$\left(6^{\prime} R\right)-115$ 
Die Synthese erfolgte gemäß der Vorschrift zur Synthese der TAA (6'S)-115. Es wurden $950 \mathrm{mg}$ des (Z)-Olefins 111, $38 \mathrm{mg}(64 \mu \mathrm{mol})(R, R)$-Me-DuPHOS-Rh und $50 \mathrm{~mL}$ Methanol eingesetzt. Die Reaktionsdauer betrug $14 \mathrm{~d}$.

Ausbeute: Es wurden $541 \mathrm{mg}(0.853 \mathrm{mmol}, 54 \%$, Diastereomerengemisch 6'R/6'S 95:5) eines farblosen Schaums erhalten.

DC: $R_{\mathrm{f}}($ Hex/EtOAc 1:1) $=0.62$.

${ }^{1} \mathrm{H}-\mathrm{NMR}\left(300 \mathrm{MHz}, \mathrm{C}_{6} \mathrm{D}_{6}, 70^{\circ} \mathrm{C}\right): \delta=1.39\left(\mathrm{~s}, 9 \mathrm{H}, \mathrm{C}\left(\mathrm{CH}_{3}\right)_{3}\right), 1.72-1.85\left(\mathrm{~m}, 3 \mathrm{H}, 2^{\prime}-\mathrm{H}_{\mathrm{a}}\right.$, 2'- $\left.\mathrm{H}_{\mathrm{b}}, 5^{\prime}-\mathrm{H}_{\mathrm{a}}\right), 1.78(\mathrm{~d}, J=1.2 \mathrm{~Hz}, 7-\mathrm{H}), 1.86-1.95\left(\mathrm{~m}, 1 \mathrm{H}, 5^{\prime}-\mathrm{H}_{\mathrm{b}}\right), 3.27-3.34(\mathrm{~m}, 1 \mathrm{H}$, 3'-H), 3.61 (ddd, $\left.J=9.4 \mathrm{~Hz}, J=6.4 \mathrm{~Hz}, J=3.2 \mathrm{~Hz}, 1 \mathrm{H}, 4{ }^{\prime}-\mathrm{H}\right), 4.50-4.58(\mathrm{~m}, 1 \mathrm{H}$, 6'- $-\mathrm{H}), 4.70\left(\mathrm{~s}, 2 \mathrm{H}, \mathrm{NCH}_{2} \mathrm{OCH}_{2}\right), 4.89\left(\mathrm{~d}, J=12.3 \mathrm{~Hz}, 1 \mathrm{H}, \mathrm{CbzCH}_{2}\right), 5.00$ (d, $\left.J=12.3 \mathrm{~Hz}, 1 \mathrm{H}, \quad \mathrm{CbzCH}_{2}\right), \quad 5.01-5.06\left(\mathrm{~m}, 1 \mathrm{H}, \quad 6{ }^{\prime}-\mathrm{NH}\right), 5.44(\mathrm{dd}, J=6.8 \mathrm{~Hz}$, $\left.J=5.4 \mathrm{~Hz}, 1 \mathrm{H}, 1^{\prime}-\mathrm{H}\right), 5.45\left(\mathrm{~d}, J=9.3 \mathrm{~Hz}, 2 \mathrm{H}, \mathrm{NCH}_{\mathrm{H}} \mathrm{O}\right.$ ), $5.50(\mathrm{~d}, J=9.3 \mathrm{~Hz}, 2 \mathrm{H}$, $\left.\mathrm{NCH} \underline{H}_{b} \mathrm{O}\right)$, 6.44-6.47 (m, $\left.1 \mathrm{H}, 6-\mathrm{H}\right)$, 7.02-7.16 (m, $\left.8 \mathrm{H}, \mathrm{ArH}\right)$, 7.31-7.34 (m, $\left.2 \mathrm{H}, \mathrm{ArH}\right)$.

${ }^{13} \mathrm{C}$-NMR $\left(126 \mathrm{MHz}, \mathrm{C}_{6} \mathrm{D}_{6}, 70{ }^{\circ} \mathrm{C}\right): \delta=12.65(\mathrm{C}-7), 27.96\left(\mathrm{C}\left(\mathrm{CH}_{3}\right)_{3}\right), 35.53$ (C-5'), 36.35 (C-2'), 51.79 (C-6'), 63.08 (C-3'), $66.82\left(\mathrm{CbzCH}_{2}\right), 70.62\left(\mathrm{NCH}_{2} \mathrm{O}\right), 72.18$ $\left.\left(\mathrm{NCH}_{2} \mathrm{O}_{\mathrm{CH}}\right)_{2}\right), 79.53\left(\underline{\mathrm{C}}\left(\mathrm{CH}_{3}\right)_{3}\right), 80.49\left(\mathrm{C}-4^{\prime}\right), 86.75\left(\mathrm{C}-1^{\prime}\right), 109.83(\mathrm{C}-5), 127.15$, 127.30, 127.67, 128.00, 128.09, 128.30 (ArC), 133.88 (C-6), 135.63 (C-1"), 138.74 (C-1"'), 150.25 (Amid-C=O), 155.08 (C-2), 162.44 (C-4), 171.33 (COO).

IR (ATR): $\tilde{v}=2101,1704,1652,1455,1270,1250,1156,1075,736,698$.

UV $(\mathrm{MeCN}): \lambda_{\max }(\lg \varepsilon)=267$ (3.99).

MS $\left(\mathrm{ESI}^{+}\right): \mathrm{m} / \mathrm{z}=633.3[\mathrm{M}-\mathrm{H}]^{-}$.

$\mathrm{C}_{32} \mathrm{H}_{38} \mathrm{~N}_{6} \mathrm{O}_{8}$ (634.68)

ber.: $633.2678[\mathrm{M}-\mathrm{H}]^{-}$

gef.: 633.2679 (ESI-HRMS). 


\subsubsection{6'-N-Boc-3-N-BOM-3'-desoxy-3'-N-Fmoc-(R)-TAA 158}

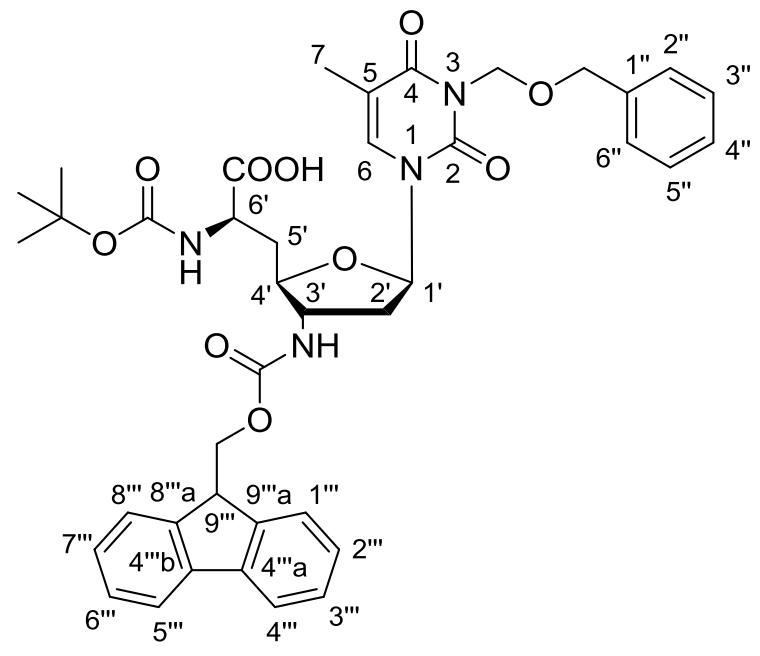

$\left(6^{\prime} R\right)-158$

Hydrogenolytische Spaltung der Bn- und Cbz-Schutzgruppen:

Eine Lösung der TAA (6'R)-115 (100 mg, $157 \mu \mathrm{mol})$ in abs. $\mathrm{MeOH}(4 \mathrm{~mL})$ wurde mit 1,4-Cyclohexadien (146 $\mu \mathrm{L}, 122 \mathrm{mg}, 1.53 \mathrm{mmol}$ ) und Palladium (17 mg, $16 \mu \mathrm{mol}$, $10 \%$ auf Aktivkohle) versetzt und $28 \mathrm{~h}$ bei RT gerührt. Die Suspension wurde über Celite filtriert und das Flltrat im Vakuum eingeengt. Es wurden $80 \mathrm{mg}$ eines weißen, verunreinigten Feststoffs erhalten, der direkt in der nächsten Reaktion eingesetzt wurde.

\section{Einführung der Fmoc-Schutzgruppe:}

Das Reaktionsprodukt der Hydrogenolytischen Spaltung von (6'R)-115 (80 mg) wurde bei $0{ }^{\circ} \mathrm{C}$ in THF (1.2 mL) gelöst und mit NEt $3(53 \mu \mathrm{L}, 39 \mathrm{mg}, 0.39 \mathrm{mmol})$ sowie $\mathrm{FmocCl}$ (48 mg, $0.19 \mathrm{mmol})$ versetzt. Die Reaktionslösung wurde $30 \mathrm{~min}$ bei $0{ }^{\circ} \mathrm{C}$ gerührt, mit einem Tropfen Wasser versetzt und im Vakuum eingeengt. Der Rückstand wurde chromatographisch an Kieselgel gereinigt (DCM/MeOH 9:1). Das so erhaltene Produkt wurde 16 h lyophilisiert.

Ausbeute: Es wurden 26 mg eines weißen, verunreinigten Feststoffs erhalten (100\% Ausbeute über 2 Stufen: $116 \mathrm{mg}$ ).

${ }^{1} \mathrm{H}-\mathrm{NMR}\left(300 \mathrm{MHz}, \mathrm{MeOD}, 60^{\circ} \mathrm{C}\right): \delta=1.43\left(\mathrm{~s}, 9 \mathrm{H}, \mathrm{C}\left(\mathrm{CH}_{3}\right)\right), 1.94(\mathrm{~s}, 3 \mathrm{H}, 7-\mathrm{H}), 2.01-$ $2.38\left(\mathrm{~m}, 4 \mathrm{H}, 2{ }^{\prime}-\mathrm{H}, 5^{\prime}-\mathrm{H}\right), 3.82-4.05\left(\mathrm{~m}, 2 \mathrm{H}, 4^{\prime}-\mathrm{H}, 6^{\prime}-\mathrm{H}\right), 4.18-4.26(\mathrm{~m}, 2 \mathrm{H}$, FmocCH $\left.\mathrm{CH}_{2}\right)$ 4.40-4.45 (m, 1 H, 3'-H), 4.63-4.68 (m, $1 \mathrm{H}, 9$ '”- $\left.\mathrm{H}\right), 4.69(\mathrm{~s}, 2 \mathrm{H}$, 
$\mathrm{NCH}_{2} \mathrm{OC}_{2}$ ), $5.51\left(\mathrm{~s}, 2 \mathrm{H}, \mathrm{NCH}_{2} \mathrm{O}\right), 6.00-6.18\left(\mathrm{~m}, 1 \mathrm{H}, 1^{\prime}-\mathrm{H}\right), 7.20-7.48(\mathrm{~m}, 9 \mathrm{H}, \mathrm{ArH})$, 7.65 (d, J = $7.4 \mathrm{~Hz}, 2 \mathrm{H}, 1^{\prime \prime \prime-H, ~ 8 ' "-H), ~} 7.79$ (d, J = 7.4 Hz, $2 \mathrm{H}, 4$ "''-H, 5'”-H).

$\mathrm{C}_{32} \mathrm{H}_{38} \mathrm{~N}_{6} \mathrm{O}_{8}(749.81)$ ber.: $739.2985[\mathrm{M}-\mathrm{H}]^{-}$ gef.: 739.2982 (ESI-HRMS).

Auf die Untersuchung des erhaltenen Produkts mittels weiterer analytischer Methoden wurde aufgrund der darin enthaltenen Verunreinigungen verzichtet.

\subsubsection{5'-O-TBDMS-3'-desoxy-3'-N-Cbz-aminothymidin 120}

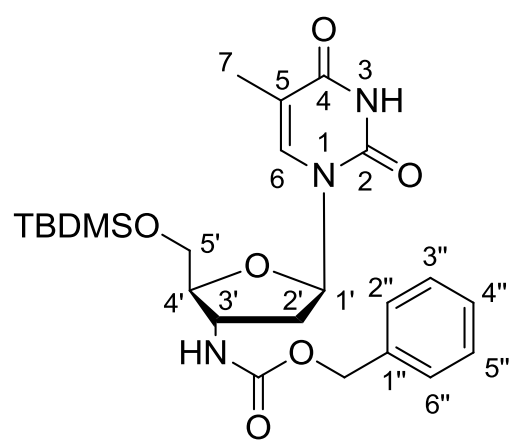

120

Eine Lösung von 5'-O-TBDMS-3'-desoxy-3'-aminothymidin $72(6.00 \mathrm{~g}, 17.0 \mathrm{mmol})$ in THF $(150 \mathrm{~mL})$ wurde bei $0^{\circ} \mathrm{C}$ mit DMAP $(10 \mathrm{mg}, 82 \mu \mathrm{mol})$, Triethylamin $(5.89 \mathrm{~mL}$, $4.30 \mathrm{~g}, \quad 42.0 \mathrm{mmol})$ und Chlorameisensäurebenzylester $(2.66 \mathrm{~mL}, \quad 3.18 \mathrm{~g}$, $18.7 \mathrm{mmol}$ ) versetzt und $30 \mathrm{~min}$ bei $0^{\circ} \mathrm{C}$ gerührt. Die erhaltene Lösung wurde mit Ethylacetat $(500 \mathrm{~mL})$ verdünnt und mit ges. $\mathrm{NaHCO}_{3}$-Lösung $(2 \times 200 \mathrm{~mL})$ sowie ges. $\mathrm{NaCl}$-Lösung $(200 \mathrm{~mL})$ gewaschen. Die organische Phase wurde über $\mathrm{Na}_{2} \mathrm{SO}_{4}$ getrocknet, filtriert und im Vakuum eingeengt. Der Rückstand wurde chromatographisch an Kieselgel gereinigt (DCM/MeOH 40:1).

Ausbeute: $7.05 \mathrm{~g}$ (17.0 mmol, 85\%) eines farblosen Schaums.

DC: $R_{\mathrm{f}}(\mathrm{DCM} / \mathrm{MeOH} 20: 1)=0.36$.

${ }^{1} \mathrm{H}-\mathrm{NMR}\left(500 \mathrm{MHz}, \mathrm{CDCl}_{3}\right): \delta=0.09\left(\mathrm{~s}, 6 \mathrm{H}, \mathrm{SiCH}_{3}\right), 0.92\left(\mathrm{~s}, 9 \mathrm{H}, \mathrm{SiC}\left(\mathrm{CH}_{3}\right)_{3}\right), 1.87$ (d, $J=1.0 \mathrm{~Hz}, 3 \mathrm{H}, 7-\mathrm{H}), 2.29$ (dd, $\left.J=6.6 \mathrm{~Hz}, J=6.6 \mathrm{~Hz}, 2 \mathrm{H}, 2^{\prime}-\mathrm{H}\right)$, 3.77-3.85 (m, $\left.1 \mathrm{H}, \quad 5^{\prime}-\mathrm{H}_{\mathrm{a}}\right), 3.88-3.95\left(\mathrm{~m}, 2 \mathrm{H}, 4^{\prime}-\mathrm{H}, 5^{\prime}-\mathrm{H}\right), 4.29$ (ddd, $J=6.6 \mathrm{~Hz}, J=6.6 \mathrm{~Hz}$, $\left.J=5.5 \mathrm{~Hz}, 1 \mathrm{H}, 3^{\prime}-\mathrm{H}\right), 5.06\left(\mathrm{~d}, J=13.0 \mathrm{~Hz}, 1 \mathrm{H}, \mathrm{BnCH}_{2 \mathrm{a}}\right), 5.10(\mathrm{~d}, J=13.0 \mathrm{~Hz}, 1 \mathrm{H}$, $\left.\mathrm{BnCH}_{2 b}\right), 6.17\left(\mathrm{dd}, J=6.6 \mathrm{~Hz}, 1 \mathrm{H}, 1^{\prime}-\mathrm{H}\right), 7.22-7.37(\mathrm{~m}, 5 \mathrm{H}, \mathrm{ArH}), 7.57$ (d, $J=1.0 \mathrm{~Hz}, 1 \mathrm{H}, 7-\mathrm{H})$. 
${ }^{13} \mathrm{C}$-NMR $\left(126 \mathrm{MHz}, \mathrm{CDCl}_{3}\right): \delta=-5.27\left(\mathrm{SiCH}_{3}\right),-5.21\left(\mathrm{SiCH}_{3}\right), 12.58(\mathrm{C}-7), 19.28$ $\left(\mathrm{C}\left(\mathrm{CH}_{3}\right)_{3}\right), 26.47\left(\mathrm{SiC}\left(\mathrm{CH}_{3}\right)_{3}\right), 39.25$ (C-2'), 52.22 (C-3'), 64.22 (C-5'), 67.65 ( $\mathrm{CbzCH}_{2}$ ), 85.98 (C-1'), 86.48 (C-4'), 111.50 (C-5), 128.88 (C-2",C-6"), 129.04 (C-3", C-4", C-5"), 129.47 (C-1"), 137.36 (C-6), 152.26 (C-2), 166.23 (C-4).

Drehwert: $[\alpha]_{D}^{20}=-28.8\left(\mathrm{c}=1.0, \mathrm{CHCl}_{3}\right)$.

Schmelzpunkt: $79^{\circ} \mathrm{C}$.

IR (ATR): $\tilde{v}=1680,1466,1256,1123,1065,1003,831,774,698$.

UV (MeCN): $\lambda_{\max }(\lg \varepsilon)=207$ (4.19), 265 (3.91).

MS $\left(\mathrm{ESI}^{+}\right): \mathrm{m} / \mathrm{z}=488.2[\mathrm{M}-\mathrm{H}]^{-}$.

$\mathrm{C}_{24} \mathrm{H}_{35} \mathrm{~N}_{3} \mathrm{O}_{6} \mathrm{Si}$ (489.64) ber.: $488.2222[\mathrm{M}-\mathrm{H}]^{-}$ gef.: 488.2219 (ESI-HRMS).

\subsubsection{3'-Desoxy-3'-N-Cbz-aminothymidin 156}

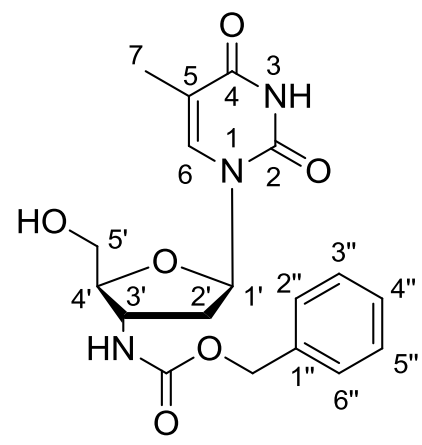

156

Eine Lösung von 5'-O-TBDMS-3'-desoxy-3'- $\mathrm{N}$-Cbz-aminothymidin 120 (150 mg, $0.307 \mathrm{mmol}$ ) in Methanol $(6 \mathrm{~mL})$ wurde bei $0{ }^{\circ} \mathrm{C}$ mit Acetylchlorid $(12 \mathrm{mg}, 11 \mu \mathrm{L}$, $0.154 \mathrm{mmol}$ ) versetzt. Die Lösung wurde auf Raumtemperatur gebracht und bis zum vollständigen Umsatz des Ausgangsmaterials gerührt. Die resultierende Lösung wurde mit ges. $\mathrm{NaHCO}_{3}$-Lösung $(1 \mathrm{~mL})$ versetzt und anschließend in $\mathrm{DCM}(30 \mathrm{~mL})$ aufgenommen, mit Wasser $(10 \mathrm{~mL})$ und ges. NaCl-Lösung $(10 \mathrm{~mL})$ gewaschen und über $\mathrm{Na}_{2} \mathrm{SO}_{4}$ getrocknet. Die organische Phase wurde bei vermindertem Druck zur Trockne eingeengt und der Rückstand chromatographisch an Kieselgel gereinigt (DCM/MeOH 19:1).

Ausbeute: Es wurden $100 \mathrm{mg}(0.266 \mathrm{mmol}, 87 \%)$ eines weißen Feststoffs erhalten.

DC: $R_{\mathrm{f}}(\mathrm{DCM} / \mathrm{MeOH} 9: 1)=0.39$. 
${ }^{1} \mathrm{H}-\mathrm{NMR}(500 \mathrm{MHz}, \mathrm{MeOD}): \delta=1.90(\mathrm{~d}, J=1.1 \mathrm{~Hz}, 3 \mathrm{H}, 7-\mathrm{H}$ ), 2.33 (ddd, $J=13.8 \mathrm{~Hz}$, $J=6.6 \mathrm{~Hz}, J=6.6 \mathrm{~Hz}, 1 \mathrm{H}, 2^{\prime}-\mathrm{H}_{\mathrm{a}}$ ), 2.37 (ddd, $J=13.8 \mathrm{~Hz}, J=8.0 \mathrm{~Hz}, J=5.8 \mathrm{~Hz}$, $1 \mathrm{H}, 2^{\prime}-\mathrm{H}_{\mathrm{b}}$ ), $3.74\left(\mathrm{dd}, J=12.1 \mathrm{~Hz}, J=3.6 \mathrm{~Hz}, 1 \mathrm{H}, 5^{\prime}-\mathrm{H}_{\mathrm{a}}\right.$ ), $3.86(\mathrm{dd}, J=12.1 \mathrm{~Hz}$, $J=2.7 \mathrm{~Hz}, 1 \mathrm{H}, 5^{\prime}-\mathrm{H}_{\mathrm{b}}$ ), 3.89 (ddd, $J=3.6 \mathrm{~Hz}, J=2.7 \mathrm{~Hz}, J=2.7 \mathrm{~Hz}, 1 \mathrm{H}, 4^{\prime}-\mathrm{H}$ ), 4.33 (ddd, $J=8.0 \mathrm{~Hz}, J=6.4 \mathrm{~Hz}, J=6.4 \mathrm{~Hz}, 1 \mathrm{H}, 3^{\prime}-\mathrm{H}$ ), 5.06 (s, $2 \mathrm{H}, \mathrm{CbzCH}_{2}$ ), 6.17 (dd, $\left.J=6.6 \mathrm{~Hz}, J=5.8 \mathrm{~Hz}, 1 \mathrm{H}, 1^{\prime}-\mathrm{H}\right), 7.28-7.39(\mathrm{~m}, 5 \mathrm{H}, \operatorname{ArH}), 7.83(\mathrm{q}, J=1.1 \mathrm{~Hz}, 1 \mathrm{H}$, 7-H).

${ }^{13} \mathrm{C}-\mathrm{NMR}$ (126 MHz, MeOD): $\delta=10.90$ (C-7), 37.62 (C-2'), 50.46 (C-3'), 61.06 (C-5'), $66.33\left(\mathrm{CbzCH}_{2}\right), 84.59$ (C-1'), 85.20 (C-4'), 110.15 (C-5), 127.44 (C-2",C-6"), 127.63 (C-3", C-4", C-5"), 128.06 (C-1"), 136.68 (C-6), 150.94 (C-2), 164.92 (C-4).

Drehwert: $[\alpha]_{D}^{20}=+25.0(\mathrm{c}=1.1, \mathrm{MeOH})$.

Schmelzpunkt: $188^{\circ} \mathrm{C}$.

IR (ATR): $\tilde{v}=1719,1681,1666,1523,1476,1280,1251,1098,1075$.

UV (MeCN): $\lambda_{\max }(\lg \varepsilon)=207$ (4.33), 265 (4.10).

MS $\left(\mathrm{ESI}^{+}\right): \mathrm{m} / \mathrm{z}=398.1[\mathrm{M}+\mathrm{Na}]^{+}$.

$\mathrm{C}_{18} \mathrm{H}_{21} \mathrm{~N}_{3} \mathrm{O}_{6}$ (375.38)

ber.: $398.1328[\mathrm{M}+\mathrm{Na}]^{+}$

gef.: $398.1332\left(\mathrm{ESI}^{+}-\mathrm{HRMS}\right)$.

\subsubsection{3 (Z)-6'-N-Boc-O-Bn-5',6'-didehydro-3'-desoxy-3'-N-Cbz-amino-TAA 112}

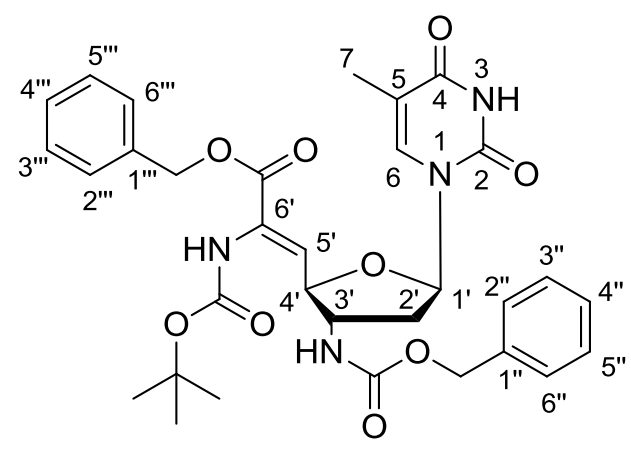

(Z)-112

Synthese des 3'-Desoxy-3'-N-(Cbz)-aminothymidin-5'-aldehyds 107:

Eine Lösung von 3'-Desoxy-3'-N-Cbz-aminothymidin 156 (115 mg, $0.307 \mathrm{mmol})$ in MeCN ( $3 \mathrm{~mL}$ ) wurde mit IBX (215 mg, $0.768 \mathrm{mmol})$ versetzt und die Suspension 45 min unter Rückfluss gerührt. Die auf Raumtemperatur abgekühlte Lösung wurde über eine Glasfritte filtriert und der Filterkuchen mit EtOAc $(3 \times 3 \mathrm{~mL})$ gewaschen. Die vereinigten Filtrate wurden bei vermindertem Druck eingeengt und der erhaltene 
Rückstand mehrere Stunden unter Hochvakuum aufbewahrt. Das Rohprodukt wurde ohne weitere Reinigung direkt in der nachfolgenden Reaktion eingesetzt.

\section{Wittig-Horner-Reaktion:}

Zu einer auf $-78^{\circ} \mathrm{C}$ gekühlten Lösung von $\mathrm{KO}{ }^{t} \mathrm{Bu}(35 \mathrm{mg}, 0.32 \mathrm{mmol})$ in THF ( $3 \mathrm{~mL}$ ) wurde langsam eine Lösung von $\mathrm{N}$-(tert-Butyloxycarbonyl)-2-(dimethylphosphoryl)glycinbenzylester $109(125 \mathrm{mg}, 0.338 \mathrm{mmol})$ in $2.6 \mathrm{~mL}$ THF $(2.6 \mathrm{~mL})$ dazugegeben. Die resultierende Lösung wurde $5 \mathrm{~min}$ bei $-78^{\circ} \mathrm{C}$ gerührt und anschließend allmählich mit einer Lösung von 3'-Desoxy-3'-N-(Cbz)-aminothymidin-5'-aldehyd 107 $(114 \mathrm{mg}, 0.307 \mathrm{mmol})$ in THF $(1.3 \mathrm{~mL})$ versetzt. Die Reaktionslösung wurde $16 \mathrm{~h}$ gerührt und im Laufe dieses Zeitraums langsam auf Raumtemperatur gebracht. Die Reaktionslösung wurde auf $0^{\circ} \mathrm{C}$ gekühlt, mit Methanol $(0.2 \mathrm{~mL})$ versetzt und mit Ethylacetat $(20 \mathrm{~mL})$ verdünnt. Die organische Phase wurde mit dest. Wasser $(1 \times 10 \mathrm{~mL})$ und ges. wässriger $\mathrm{NaCl}(1 \times 10 \mathrm{~mL})$ gewaschen, über $\mathrm{Na}_{2} \mathrm{SO}_{4}$ getrocknet und filtriert. Das Lösungsmittel wurde unter vermindertem Druck entfernt und der Rückstand chromatographisch an Kieselgel gereinigt (DCM/MeOH 40:1).

Ausbeute: Es wurden $128 \mathrm{mg}(0.206 \mathrm{mmol}, 68 \%)$ eines blassgelben Feststoffs erhalten. Die Aufnahme von ${ }^{1} \mathrm{H}-\mathrm{NMR}$ und von ${ }^{13} \mathrm{C}-\mathrm{NMR}$-Spektren bei verschiedenen Temperaturen ergab einen doppelten Signalsatz (Verhältnis der Integrale 1:1). Dies deutete darauf hin, dass es sich bei dem Syntheseprodukt um ein Diastereomerengemisch der E- und Z-Form des Olefins handelte. Versuche das Gemisch durch Säulenchromatographie zu trennen, waren nicht erfolgreich. Eine eindeutige Zuordnung eines der Signalsätze zu einem der beiden Diastereomere war nicht möglich.

${ }^{1} \mathrm{H}-\mathrm{NMR}\left(500 \mathrm{MHz}, \mathrm{CDCl}_{3}\right): \delta=1.45\left(\mathrm{~s}, 9 \mathrm{H}, \mathrm{C}\left(\mathrm{CH}_{3}\right)_{3}\right), 1.47\left(\mathrm{~s}, 9 \mathrm{H}, \mathrm{C}\left(\mathrm{CH}_{3}\right)_{3}\right), 1.88$ (s, $3 \mathrm{H}, 7-\mathrm{H}), 1.95(\mathrm{~s}, 3 \mathrm{H}, 7-\mathrm{H}), 2.25-2.35(\mathrm{~m}, 2 \mathrm{H}, 2$ '- $\mathrm{H}), 2.35-2.43(\mathrm{~m}, 2 \mathrm{H}, 2$ '-H), 4.03-4.09 (m, $\left.1 \mathrm{H}, 3^{\prime}-\mathrm{H}\right)$, 4.09-4.16 (m, $\left.1 \mathrm{H}, 3^{\prime}-\mathrm{H}\right)$, 4.78-4.84 (m, $\left.1 \mathrm{H}, 4^{\prime}-\mathrm{H}\right)$, 5.06-5.28 (m, $\left.9 \mathrm{H}, \mathrm{CbzCH}_{2}, \mathrm{BnCH}_{2}, 4^{\prime}-\mathrm{H}\right), 6.20\left(\mathrm{~d}, J=8.2 \mathrm{~Hz}, 1 \mathrm{H}, 5^{\prime}-\mathrm{H}\right), 6.30$ (dd, J=6.6 Hz, $\left.2 \mathrm{H}, 1^{\prime}-\mathrm{H}\right), 6.77-6.83\left(\mathrm{~m}, 2 \mathrm{H}, 3^{\prime}-\mathrm{NH}, 6^{\prime}-\mathrm{NH}\right), 6.87\left(\mathrm{~d}, J=8.8 \mathrm{~Hz}, 5^{\prime}-\mathrm{H}\right), 7.16(\mathrm{~s}, 1 \mathrm{H}$, 6-H), 7.27-7.42 (m, $21 \mathrm{H}, \mathrm{ArH}, 6-\mathrm{H})$.

${ }^{13} \mathrm{C}$-NMR $\left(126 \mathrm{MHz}, \mathrm{CDCl}_{3}\right): \delta=12.46,12.59(\mathrm{C}-7), 28.12,28.21\left(\mathrm{C}(\underline{\mathrm{C}} \mathrm{H})_{3}\right), 37.73$, 38.30 (C-2'), 56.36, 56.73 (C-3'), 66.99, $67.14\left(\mathrm{CbzCH}_{2}, \mathrm{BnCH}_{2}\right), 79.82,80.49$ $\left(\underline{\mathrm{C}}(\mathrm{CH})_{3}\right), 81.30,81.54$ (C-4'), 84.55, 85.32 (C-1'), 111.81, 111.86 (C-5), 121.41, 
125.03 (C-5'), 128.26, 128.30, 128.38, 128.56, 128.63, 128.72, 128.83, 128.94 (ArC), 134.44, 135.09 (C-1", C-1'”), 136.14, 136.24 (C-6), 150.56 (Boc-C=O), 152.43, 153.36 (C-2), 155.80, 156.58 (Cbz-C=O), 162.93, 163.23 (C-4), 163.37, 164.17 (Ester-C=O).

MS $\left(E S I^{+}\right): m / z=643.2[\mathrm{M}+\mathrm{Na}]^{+}$.

$\mathrm{C}_{18} \mathrm{H}_{21} \mathrm{~N}_{3} \mathrm{O}_{6}$ (620.65)

ber.: $643.2375[\mathrm{M}+\mathrm{Na}]^{+}$

gef.: 643.2374 (ESI+-HRMS).

\subsubsection{5'-O-TBDMS-3-N-BOM-3'-desoxy-3'-N-Cbz-aminothymidin 121}

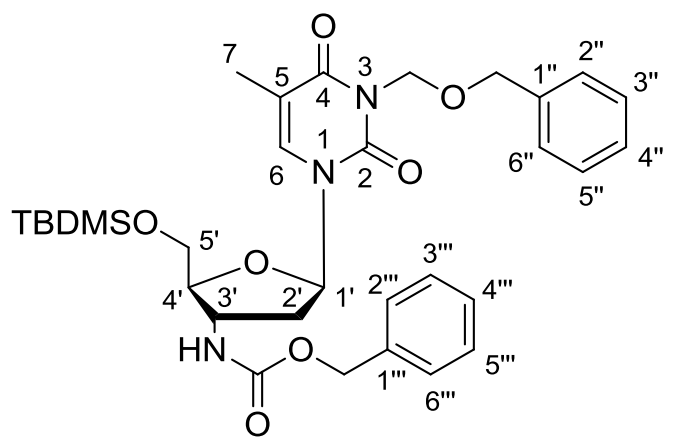

121

Eine Suspension von NaH (572 mg, 60\% in Mineralöl, $14.3 \mathrm{mmol}$ ) in DMF (22 mL) wurde bei $-10^{\circ} \mathrm{C}$ langsam mit einer Lösung von 5'-O-TBDMS-3'-desoxy-3'- N-Cbzaminothymidin $120(6.94 \mathrm{~g}, 14.2 \mathrm{mmol})$ in DMF $(23 \mathrm{~mL})$ versetzt und $30 \mathrm{~min}$ bei 3 bis $-5^{\circ} \mathrm{C}$ gerührt. Anschließend wurde die Reaktionslösung tropfenweise mit Benzyloxymethylchlorid $(2.10 \mathrm{~mL}, 2.30 \mathrm{~g}, 14.3 \mathrm{mmol})$ versetzt und $3 \mathrm{~h}$ bei $0{ }^{\circ} \mathrm{C}$ gerührt. Die resultierende Lösung wurde mit $300 \mathrm{~mL}$ Ethylacetat verdünnt. Die organische Phase wurde mit ges. wässriger $\mathrm{NaHCO}_{3}(150 \mathrm{~mL})$, Wasser $(2 \times 150 \mathrm{~mL})$ und ges. wässriger $\mathrm{NaCl}(150 \mathrm{~mL})$ gewaschen, über $\mathrm{Na}_{2} \mathrm{SO}_{4}$ getrocknet, filtriert und im Vakuum eingeengt. Der Rückstand wurde mit Toluol koevaporiert $(3 \times 20 \mathrm{~mL})$. Das erhaltene Rohprodukt wurde chromatographisch an Kieselgel gereingt (PE/EtOAc 7:3).

Ausbeute: Es wurden $6.94 \mathrm{~g}(11.4 \mathrm{mmol}, 80 \%)$ eines farblosen Öls erhalten.

DC: $R_{\mathrm{f}}(\mathrm{PE} / \mathrm{EtOAC} 7: 3)=0.27$.

${ }^{1} \mathrm{H}-\mathrm{NMR}\left(500 \mathrm{MHz}, \mathrm{CDCl}_{3}\right): \delta=0.12\left(\mathrm{~s}, 6 \mathrm{H}, \mathrm{Si}\left(\mathrm{CH}_{3}\right)_{2}\right), 0.94\left(\mathrm{~s}, 9 \mathrm{H}, \mathrm{SiC}\left(\mathrm{CH}_{3}\right)_{3}\right), 1.89$ (d, $J=0.8 \mathrm{~Hz}, 3 \mathrm{H}, 7-\mathrm{H}$ ), 2.26 (ddd, $J=13.8 \mathrm{~Hz}, J=7.4 \mathrm{~Hz}, J=6.3 \mathrm{~Hz}, 1 \mathrm{H}, 2^{\prime}-\mathrm{H}_{\mathrm{a}}$ ), 
2.33 (ddd, $J=13.8 \mathrm{~Hz}, J=6.4 \mathrm{~Hz}, J=5.8 \mathrm{~Hz}, 1 \mathrm{H}, 2^{\prime}-\mathrm{H}_{\mathrm{b}}$ ), 3.80-3.87 (m, $\left.1 \mathrm{H}, 5^{\prime}-\mathrm{H}\right)$, 3.92-3.98 (m, $2 \mathrm{H}, 4^{\prime}-\mathrm{H}, 5^{\prime}-\mathrm{H}$ ), 4.29 (ddd, $J=8.0 \mathrm{~Hz}, J=5.8 \mathrm{~Hz}, J=5.7 \mathrm{~Hz}, 3^{\prime}-\mathrm{H}$ ), $4.67\left(\mathrm{~s}, 2 \mathrm{H}, \mathrm{NCH}_{2} \mathrm{O}\right.$ ), $5.10\left(\mathrm{~d}, J=12.5 \mathrm{~Hz}, 1 \mathrm{H}, \mathrm{CbzCH}_{\mathrm{a}}\right.$ ), $5.13(\mathrm{~d}, J=12.5 \mathrm{~Hz}, 1 \mathrm{H}$, $\left.\mathrm{CbzCH}_{\mathrm{b}}\right), \quad 5.48\left(\mathrm{~d}, J=9.9 \mathrm{~Hz}, 1 \mathrm{H}, \quad \mathrm{CH}_{2} \mathrm{OCH} \underline{H}_{\mathrm{a}}\right), \quad 5.51(\mathrm{~d}, J=9.9 \mathrm{~Hz}, 1 \mathrm{H}$, $\left.\mathrm{CH}_{2} \mathrm{OCH} \underline{H}_{\mathrm{b}}\right), 6.17$ (dd, $\left.J=6.4 \mathrm{~Hz}, J=6.3 \mathrm{~Hz}, 1 \mathrm{H}, 1^{\prime}-\mathrm{H}\right), 7.21-7.39(\mathrm{~m}, 10 \mathrm{H}, \mathrm{ArH})$, $7.56(\mathrm{~s}, 1 \mathrm{H}, 6-\mathrm{H})$.

${ }^{13}$ C-NMR $\left(126 \mathrm{MHz}, \mathrm{CDCl}_{3}\right): \delta=-6.66\left(\mathrm{SiCH}_{3}\right),-6.57\left(\mathrm{SiCH}_{3}\right), 11.83(\mathrm{C}-7), 17.89$ $\left(\mathrm{Si} \underline{\mathrm{C}}\left(\mathrm{CH}_{3}\right)_{3}\right), 25.09\left(\mathrm{Si} \underline{\mathrm{C}}\left(\mathrm{CH}_{3}\right)_{3}\right), 38.05$ (C-2'), 50.72 (C-3'), 62.77 (C-5'), 66.29 $\left(\mathrm{CbzCH}_{2}\right), 70.62\left(\mathrm{NCH}_{2} \mathrm{O}\right), 71.90\left(\mathrm{CH}_{2} \mathrm{O} \underline{\mathrm{C}} \mathrm{H}_{2}\right), 85.26$ (C-1'), 85.49 (C-4'), 109.34 (C-5), 126.57, 126.81, 127.07, 127.25, 127.51, 127.66, 127.85, 128.09 (ArC), 134.91 (C-6), 138.26 (Cbz-C=O), 150.92 (C-2), 163.79 (C-4).

Drehwert: $[\alpha]_{D}^{20}=+6.5\left(\mathrm{c}=1.2, \mathrm{CHCl}_{3}\right)$.

IR (ATR): $\tilde{v}=1704,1637,1255,1070,1022,827,769,731,698$.

UV (MeCN): $\lambda_{\max }(\lg \varepsilon)=207$ (4.55), 268 (4.08).

MS $\left(\mathrm{ESI}^{+}\right): \mathrm{m} / \mathrm{z}=632.3[\mathrm{M}+\mathrm{Na}]^{+}$.

$\mathrm{C}_{32} \mathrm{H}_{43} \mathrm{~N}_{3} \mathrm{O}_{7} \mathrm{Si}(609.78)$ ber.: $632.2768[\mathrm{M}+\mathrm{Na}]^{+}$ gef.: 632.2760 (ESI+-HRMS).

\subsubsection{3-N-BOM-3'-desoxy-3'-N-Cbz-aminothymidin 155}

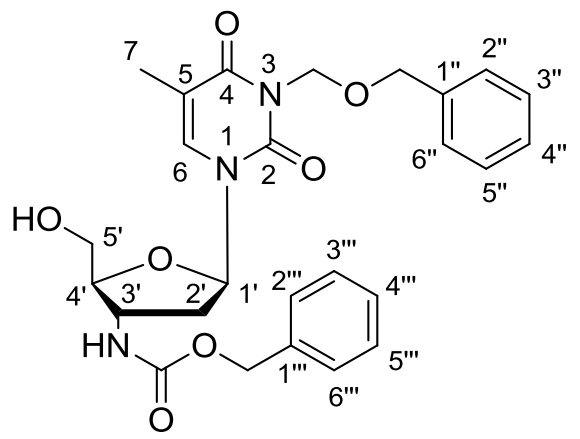

155

Eine Lösung von 5'-O-TBDMS-3-N-BOM-3'-desoxy-3'-N-Cbz-aminothymidin 121 (6.94 mg, $11.5 \mathrm{mmol})$ in abs. Methanol $(200 \mathrm{~mL})$ wurde auf $0{ }^{\circ} \mathrm{C}$ gekühlt und mit Acetylchlorid (180 mg, $164 \mu \mathrm{L}, 2.23 \mathrm{mmol}$ ) versetzt. Die Lösung wurde auf Raumtemperatur gebracht und weitere $3 \mathrm{~h}$ gerührt. Anschließend wurde die Lösung mit Ethylacetat $(300 \mathrm{~mL})$ verdünnt. Die organische Phase wurde mit Wasser $(1 \times 100 \mathrm{~mL})$ und ges. $\mathrm{NaCl}$-Lösung $(1 \times 100 \mathrm{~mL})$ gewaschen, über $\mathrm{Na}_{2} \mathrm{SO}_{4}$ 
getrocknet, filtriert und im Vakuum eingeengt. Der Rückstand wurde chromatographisch an Kieselgel (DCM/MeOH 98:2) gereingt.

Ausbeute: Es wurden $5.31 \mathrm{~g} \mathrm{(10.7} \mathrm{mmol,} \mathrm{94 \% )} \mathrm{eines} \mathrm{farblosen} \mathrm{Schaums} \mathrm{erhalten.}$

DC: $R_{\mathrm{f}}(\mathrm{PE} / \mathrm{EtOAc} 1: 1)=0.28$

${ }^{1} \mathrm{H}$-NMR $\left(500 \mathrm{MHz}, \mathrm{CDCl}_{3}\right): \delta=1.92(\mathrm{~s}, 3 \mathrm{H}, 7-\mathrm{H}), 2.28-2.38\left(\mathrm{~m}, 2 \mathrm{H}, 2^{\prime}-\mathrm{H}\right)$, 3.74-3.86 (m, $2 \mathrm{H}, 4$ ' $-\mathrm{H}, 5$ ' $-\mathrm{H}_{\mathrm{a}}$ ), 3.91-3.98 (m, $\left.1 \mathrm{H}, 5^{\prime}-\mathrm{H}_{\mathrm{b}}\right), 4.29$ (ddd, J=7.8 Hz, J=7.8 Hz, $\left.7.6 \mathrm{~Hz}, 1 \mathrm{H}, 3^{\mathrm{c}}-\mathrm{H}\right), 4.68\left(\mathrm{~s}, 2 \mathrm{H}, \mathrm{NCH}_{2} \mathrm{O}\right), 5.08\left(\mathrm{~d}, J=12.1 \mathrm{~Hz}, 1 \mathrm{H}, \mathrm{CbzCH}_{\mathrm{H}}\right.$ ) , 5.13 $\left(\mathrm{d}, J=12.1 \mathrm{~Hz}, 1 \mathrm{H}, \mathrm{CbzCH} \underline{\mathrm{H}}_{\mathrm{b}}\right), 5.23\left(\mathrm{~d}, J=7.6 \mathrm{~Hz}, 1 \mathrm{H}, 3^{\mathrm{c}}-\mathrm{NH}\right), 5.47(\mathrm{~s}, 2 \mathrm{H}$, $\mathrm{CH}_{2} \mathrm{OC}_{2}$ ) $, 6.13\left(\mathrm{dd}, J=5.5 \mathrm{~Hz}, J=4.9 \mathrm{~Hz}, 1 \mathrm{H}, 1^{\prime}-\mathrm{H}\right), 7.21-7.38(\mathrm{~m}, 10 \mathrm{H}, \mathrm{ArH})$, $7.63(\mathrm{~s}, 1 \mathrm{H}, 6-\mathrm{H})$.

${ }^{13} \mathrm{C}-\mathrm{NMR}\left(126 \mathrm{MHz}, \mathrm{CDCl}_{3}\right.$ ): $\delta=13.26$ (C-7), 38.10 (C-2'), 49.30 (C-3'), 61.30 (C-5'), $67.43\left(\mathrm{CbzCH}_{2}\right), 70.51\left(\mathrm{NCH}_{2} \mathrm{O}\right), 72.28\left(\mathrm{CH}_{2} \mathrm{O}_{\mathrm{C}} \mathrm{H}_{2}\right), 84.95\left(\mathrm{C}-1^{\prime}\right), 85.55\left(\mathrm{C}-4^{\prime}\right)$, 110.13 (C-5), 127.65, 128.22, 128.27, 128.48, 128.66 (ArC), 134.52 (C-6), 135.84 (ArC), 138.01 (Cbz-C=O), 150.94 (C-2), 163.43 (C-4).

Drehwert: $[\alpha]_{D}^{20}=+25.8\left(\mathrm{c}=1.0, \mathrm{CHCl}_{3}\right)$.

Schmelzpunkt: $57^{\circ} \mathrm{C}$.

IR (ATR): $\tilde{v}=1695,1632,1452,1255,1083,1065,1022,774,736,698$.

UV (MeCN): $\lambda_{\max }(\lg \varepsilon)=207$ (4.43), 268 (4.00).

MS $\left(\mathrm{ESI}^{+}\right): \mathrm{m} / \mathrm{z}=518.2[\mathrm{M}+\mathrm{Na}]^{+}$.

$\mathrm{C}_{26} \mathrm{H}_{29} \mathrm{~N}_{3} \mathrm{O}_{7}$ (495.52) ber.: $518.1902[\mathrm{M}+\mathrm{Na}]^{+}$ gef.: 518.1898 (ESI+-HRMS).

\subsubsection{3-N-BOM-3'-desoxy-3'-N-Cbz-aminothymidin-5'-aldehyd 108}

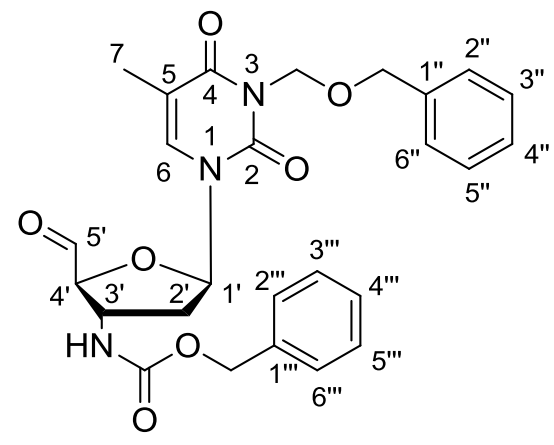


Eine Lösung von 3-N-BOM-3'-desoxy-3'-N-Cbz-aminothymidin $155 \quad(1.46 \mathrm{~g}$, $2.95 \mathrm{mmol})$ in MeCN $(28 \mathrm{~mL})$ wurde mit IBX $(2.07 \mathrm{~g}, 7.38 \mathrm{mmol})$ versetzt und $45 \mathrm{~min}$ unter Rückfluss erhitzt. Die auf Raumtemperatur abgekühlte Suspension wurde filtriert. Der Filterkuchen wurde mit EtOAc $(3 \times 15 \mathrm{~mL})$ nachgewaschen. Das vereinte Filtrat wurde unter vermindertem Druck eingeengt. Der ölige, farblose Rückstand wurde einige Stunden unter Hochvakuum aufbewahrt. Das erhaltene Rohprodukt wurde ohne weitere Reinigung in der nachfolgenden Reaktion eingesetzt.

Ausbeute: Es wurden $1.45 \mathrm{~g}$ (2.95 mmol, quantitativ) eines farblosen Schaums erhalten.

${ }^{1} \mathrm{H}-\mathrm{NMR}\left(500 \mathrm{MHz}, \mathrm{CDCl}_{3}\right): \delta=1.96(\mathrm{~s}, 3 \mathrm{H}, \mathrm{H}-7), 2.06-2.16\left(\mathrm{~m}, 1 \mathrm{H}, 2^{\prime}-\mathrm{H}_{\mathrm{a}}\right)$, 2.38$2.47\left(\mathrm{~m}, 1 \mathrm{H}, 2^{\prime}-\mathrm{H}_{\mathrm{b}}\right), 4.40\left(\mathrm{~m}, 1 \mathrm{H}, 3^{\prime} \cdot \mathrm{H}\right), 4.53-4.59\left(\mathrm{~m}, 1 \mathrm{H}, 4^{\prime}-\mathrm{H}\right), 4.65(\mathrm{~s}, 2 \mathrm{H}$, $\left.\mathrm{NCH}_{2} \mathrm{O}\right)$, 5.04-5.14 (m, $\left.2 \mathrm{H}, \mathrm{CbzCH}_{2}\right), 5.45\left(\mathrm{~s}, 2 \mathrm{H}, \mathrm{CH}_{2} \mathrm{OC}_{2}\right)$, 5.81-5.89 $(\mathrm{m}, 1 \mathrm{H}$, 3'-NH), 6.25-6.35 (m, $\left.1 \mathrm{H}, 1^{\prime}-\mathrm{H}\right)$, 7.20-7.39 (m, $\left.10 \mathrm{H}, \mathrm{ArH}\right), 7.64(\mathrm{~s}, 1 \mathrm{H}, 6-\mathrm{H}), 9.71(\mathrm{~s}$, $\left.1 \mathrm{H}, 5^{\prime}-\mathrm{H}\right)$.

${ }^{13}$ C-NMR (126 MHz, $\mathrm{CDCl}_{3}$ ): $\delta=13.27$ (C-7), 36.50 (C-2'), 51.98 (C-3'), 67.33 $\left(\mathrm{CbzCH}_{2}\right), 70.59\left(\mathrm{NCH}_{2} \mathrm{O}\right), 72.32\left(\mathrm{CH}_{2} \mathrm{O} \underline{\mathrm{C}} \mathrm{H}_{2}\right), 87.70$ (C-1'), 88.54 (C-4'), 110.85 (C-5), 127.69, 127.73, 128.24, 128.28, 128.31, 128.65 (ArC), 134.67 (C-6), 135.67, 135.84 (C-1", C-1'”), 137.85 (Cbz-C=O), 151.02 (C-2), 163.30 (C-4), 197.97 (C-5').

MS $\left(\mathrm{ESI}^{+}\right): \mathrm{m} / \mathrm{z}=492.2[\mathrm{M}-\mathrm{H}]^{-}$.

$\mathrm{C}_{26} \mathrm{H}_{27} \mathrm{~N}_{3} \mathrm{O}_{7}$ (493.50) ber.: $492.1776[\mathrm{M}-\mathrm{H}]^{-}$ gef.: 492.1780 (ESI-HRMS).

Die erhaltene Verbindung wurde aufgrund ihrer geringen Stabilität nicht chromatographisch gereinigt und es wurde auf eine Charakterisierung mittels weiterer analytischer Methoden verzichtet. 


\subsubsection{7 (Z)-6'-N-Boc-O-Bn-5',6'-didehydro-3-N-BOM-3'-desoxy-3'-N-Cbz-amino-}

TAA 113

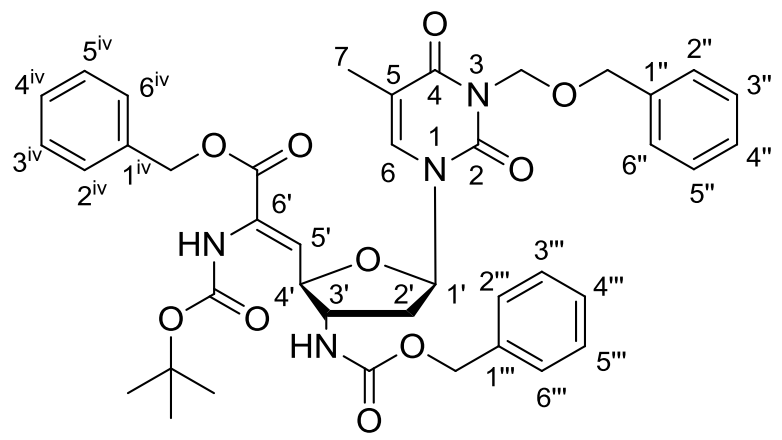

(Z)-113

$\mathrm{Zu}$ einer auf $-78^{\circ} \mathrm{C}$ gekühlten Lösung von $\mathrm{KO} \mathrm{Bu}^{\mathrm{B}}(330 \mathrm{mg}, 2.95 \mathrm{mmol})$ in $\mathrm{THF}$ $(28 \mathrm{~mL}) \quad$ wurde langsam eine Lösung von $\mathrm{N}$-(tert-Butyloxycarbonyl)-2(dimethylphosphoryl)-glycinbenzylester 109 (1.21 g, $3.25 \mathrm{mmol})$ in THF $(25 \mathrm{~mL})$ dazugegeben. Die resultierende Lösung wurde $5 \mathrm{~min}$ bei $-78^{\circ} \mathrm{C}$ gerührt und anschließend allmählich mit einer Lösung von 3-N-BOM-3'-desoxy-3'-N-Cbzaminothymidin-5'-aldehyd 108 (1.45 g, $2.95 \mathrm{mmol})$ in THF (12 mL) versetzt. Die Reaktionslösung wurde $16 \mathrm{~h}$ gerührt und im Laufe dieses Zeitraums langsam auf Raumtemperatur gebracht. Die Reaktionslösung wurde auf $0^{\circ} \mathrm{C}$ gekühlt, mit Methanol $(3 \mathrm{~mL})$ versetzt und mit Ethylacetat $(150 \mathrm{~mL})$ verdünnt. Die organische Phase wurde mit Wasser $(1 \times 80 \mathrm{~mL})$ und ges. NaCl-Lösung $(1 \times 80 \mathrm{~mL})$ gewaschen, über $\mathrm{Na}_{2} \mathrm{SO}_{4}$ getrocknet und filtriert. Das Lösungsmittel wurde unter vermindertem Druck entfernt und der Rückstand chromatographisch an Kieselgel gereinigt (Hex/EtOAc 3:2).

Ausbeute: Es wurden $1.48 \mathrm{~g}(2.01 \mathrm{mmol}, 68 \%)$ eines farblosen Schaums erhalten (Diastereomerengemisch Z/E 10:1). Die Isolierung des E-Isomers durch chromatographische Trennung gelang nicht.

DC: $R_{\mathrm{f}}(\mathrm{Hex} / \mathrm{EtOAc} 1: 1)=0.31$.

${ }^{1} \mathrm{H}-\mathrm{NMR}\left(500 \mathrm{MHz}, \mathrm{CDCl}_{3}, 50{ }^{\circ} \mathrm{C}\right): \delta=1.46\left(\mathrm{~s}, 9 \mathrm{H}, \mathrm{C}\left(\mathrm{CH}_{3}\right)_{3}\right), 1.88(\mathrm{~d}, J=1.1 \mathrm{~Hz}$, $3 \mathrm{H}, 7-\mathrm{H}$ ), 2.40 (ddd, $J=13.9 \mathrm{~Hz}, J=7.0 \mathrm{~Hz}, J=7.0 \mathrm{~Hz}, 1 \mathrm{H}, 2{ }^{\prime}-\mathrm{H}_{\mathrm{a}}$ ), 2.44 (ddd, $\left.J=13.9 \mathrm{~Hz}, J=8.0 \mathrm{~Hz}, J=6.2 \mathrm{~Hz}, 1 \mathrm{H}, 2^{\prime}-\mathrm{H}_{\mathrm{b}}\right), 4.06-4.13(\mathrm{~m}, 1 \mathrm{H}, 3$ '- $\mathrm{H}), 4.69$ (s, $2 \mathrm{H}$, $\left.\mathrm{NCH}_{2} \mathrm{O}\right), 4.79\left(\mathrm{dd}, J=8.4 \mathrm{~Hz}, J=6.4 \mathrm{~Hz}, 1 \mathrm{H}, 4^{\prime}-\mathrm{H}\right), 5.11(\mathrm{~d}, J=12.7 \mathrm{~Hz}, 1 \mathrm{H}$, $\left.\mathrm{CbzCH} \underline{H}_{\mathrm{a}}\right), 5.13\left(\mathrm{~d}, J=12.7 \mathrm{~Hz}, 1 \mathrm{H}, \mathrm{CbzCH} \underline{H}_{\mathrm{b}}\right), 5.23\left(\mathrm{~d}, J=12.6 \mathrm{~Hz}, 1 \mathrm{H}, \mathrm{BnCH} \underline{H}_{\mathrm{a}}\right)$, $5.26\left(\mathrm{~d}, J=12.6 \mathrm{~Hz}, 1 \mathrm{H}, \mathrm{BnCH}_{\mathrm{H}}\right.$ ), 5.47 (d, J=9.7 Hz, $\left.1 \mathrm{H}, \mathrm{CH}_{2} \mathrm{OCH} \underline{H}_{\mathrm{a}}\right), 5.49$ (d, 
$\left.J=9.7 \mathrm{~Hz}, \quad 1 \mathrm{H}, \quad \mathrm{CH}_{2} \mathrm{OCH} \underline{\mathrm{H}}_{\mathrm{b}}\right), \quad 5.95-6.01$ (m, $\left.1 \mathrm{H}, 3{ }^{\prime}-\mathrm{NH}\right), 6.20$ (dd, J=6.2 Hz, $\left.J=6.2 \mathrm{~Hz}, 1 \mathrm{H}, 1^{\prime}-\mathrm{H}\right), 6.31$ (d, J=8.4 Hz, $\left.1 \mathrm{H}, 5^{\prime}-\mathrm{H}\right), 6.85$ (s, $1 \mathrm{H}, 6$ '-NH), 7.09 (s, $1 \mathrm{H}, 6-\mathrm{H}), 7.21-7.40(\mathrm{~m}, 15 \mathrm{H}, \mathrm{ArH})$.

${ }^{13} \mathrm{C}-\mathrm{NMR}\left(126 \mathrm{MHz}, \mathrm{CDCl}_{3}, 50{ }^{\circ} \mathrm{C}\right): \delta=13.11(\mathrm{C}-7), 20.88\left(\underline{\mathrm{C}}\left(\mathrm{CH}_{3}\right)_{3}\right), 28.10\left(\mathrm{C}\left(\underline{\mathrm{CH}} \mathrm{H}_{3}\right)\right)$, 38.66 (C-2'), 55.93 (C-3'), $67.00\left(\mathrm{CbzCH}_{2}\right), 67.96\left(\mathrm{BnCH}_{2}\right), 70.71\left(\mathrm{NCH}_{2} \mathrm{O}\right), 72.31$ $\left(\mathrm{CH}_{2} \mathrm{O} \underline{\mathrm{C}} \mathrm{H}_{2}\right), 79.36$ (C-4'), $81.79\left(\underline{\mathrm{C}}\left(\mathrm{CH}_{3}\right)_{3}\right), 85.78\left(\mathrm{C}-1^{\prime}\right), 125.48\left(\mathrm{C}-5^{\prime}\right), 127.54$, 127.57, 127.95, 128.12, 128.20, 128.45, 128.47, 128.60 (ArC), 128.63 (C-6') 133.50

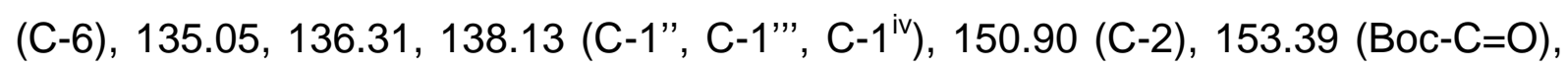
156.33 (Cbz-C=O), 163.12 (C-4), 163.95 (COOBn).

IR (ATR): $\tilde{v}=1704,1648,1452,1250,1151,1065,1027,774,736,698$.

UV (MeCN): $\lambda_{\max }(\lg \varepsilon)=206$ (4.53), 260 (4.03).

MS $\left(\mathrm{ESI}^{+}\right): \mathrm{m} / \mathrm{z}=763.3[\mathrm{M}+\mathrm{Na}]^{+}$.

$\mathrm{C}_{40} \mathrm{H}_{44} \mathrm{~N}_{4} \mathrm{O}_{10}(740.30)$

ber.: $763.2955[\mathrm{M}+\mathrm{Na}]^{+}$

gef.: 763.2953 (ESI+-HRMS).

\subsubsection{6'-N-Boc-O-Bn-3-N-BOM-3'-desoxy-3'-N-Cbz-amino-(S)-TAA 117}

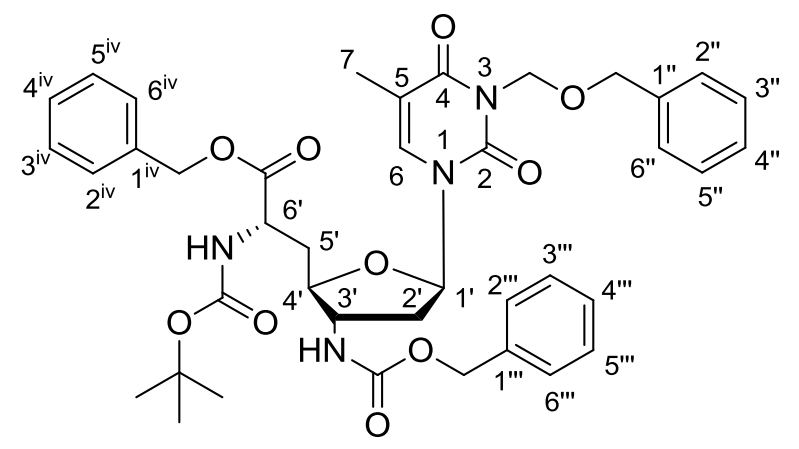

(6'S)-117

Die Reaktion wurde unter striktem Sauerstoff-Ausschluss durchgeführt. Durch eine Lösung des (Z)-Olefins 113 (1.00 g, $1.35 \mathrm{mmol}$ ) in abs. MeOH (49 mL) wurde $15 \mathrm{~min}$ ein Argonstrom geleitet. Anschließend wurde die Lösung mit $(S, S)$-Me-DuPHOS-Rh (16 mg, $27 \mu \mathrm{mol})$ versetzt und $4 \mathrm{~d}$ bei Raumtemperatur unter einer WasserstoffAtmosphäre (1 bar) gerührt. Die Lösung wurde mit Kieselgel versetzt und das Lösungsmittel im Vakuum entfernt. Das Rohprodukt wurde säulenchromatographisch an Kieselgel gereinigt (iHex/EtOAc 1:1).

Ausbeute: Es wurden $918 \mathrm{mg}(1.24 \mathrm{mmol}, 92 \%$, Diastereomerengemisch (6'S/6' $R$ 91:9)) eines farblosen Schaums erhalten. 
Die Hauptkomponente des Diastereomerengemischs konnte durch chromatographische Trennung an einer chiralen stationären Phase (Eluent: $n$ Hexan/EtOAc 73:27) rein erhalten werden. Für die Trennung wurden $1.00 \mathrm{~g}$ (aus mehreren Reaktionen erhalten) des Diastereomerengemischs aus (6'S)-117 und (6'R)-117 (91:9) verwendet.

HPLC (analytisch): $t_{\mathrm{R}}=30.5$ min (Methode: $\mathrm{s}$. Analytische chirale HPLC (7.1.6.8), Injektionsvolumen: $10 \mu \mathrm{L}, \mathrm{c} \sim 4 \mathrm{mg} / \mathrm{mL}$ in EtOAc).

HPLC (semipräparativ): $t_{\mathrm{R}}=32.0$ min (Methode: $\mathrm{s}$. Semipräparative chirale HPLC (7.1.6.9), Injektionsvolumen: $100 \mu \mathrm{L}, \mathrm{c} \sim 100 \mathrm{mg} / \mathrm{mL}$ in EtOAc).

Ausbeute: Es wurden $900 \mathrm{mg}(1.21 \mathrm{mmol}, 90 \%$ bezogen auf das getrennte Gemisch) des reinen (6'S)-Diastereomers (6'S)-117 erhalten.

DC: $R_{\mathrm{f}}(\mathrm{Hex} / \mathrm{EtOAc} 3: 2)=0.31$.

${ }^{1} \mathrm{H}-\mathrm{NMR}\left(500 \mathrm{MHz}, \mathrm{C}_{6} \mathrm{D}_{6}, 50{ }^{\circ} \mathrm{C}\right): \delta=1.39\left(\mathrm{~s}, 9 \mathrm{H}, \mathrm{C}\left(\mathrm{CH}_{3}\right)_{3}\right), 1.68$ (ddd, $J=13.9 \mathrm{~Hz}$, $J=6.9 \mathrm{~Hz}, J=6.9 \mathrm{~Hz}, 1 \mathrm{H}, 2^{\prime}-\mathrm{H}_{\mathrm{a}}$ ), 1.74 (ddd, $J=13.9 \mathrm{~Hz}, J=8.4 \mathrm{~Hz}, J=5.9 \mathrm{~Hz}$, $1 \mathrm{H}, 2^{\prime}-\mathrm{H}_{\mathrm{b}}$ ), $1.88(\mathrm{~s}, 3 \mathrm{H}, 7-\mathrm{H}$ ), 1.95 (ddd, $J=14.4 \mathrm{~Hz}, J=7.3 \mathrm{~Hz}, J=7.2 \mathrm{~Hz}, 1 \mathrm{H}$, 5' $-\mathrm{H}_{\mathrm{a}}$ ), 2.17-2.26 (m, $\left.1 \mathrm{H}, 5^{\prime}-\mathrm{H}_{\mathrm{b}}\right), 3.59$ (ddd, $J=7.3 \mathrm{~Hz}, J=4.2 \mathrm{~Hz}, J=4.2 \mathrm{~Hz}, 1 \mathrm{H}$, H-4'), 3.83-3.94 (m, $\left.1 \mathrm{H}, 3^{\prime}-\mathrm{H}\right), 4.63-4.75\left(\mathrm{~m}, 1 \mathrm{H}, 6^{\prime}-\mathrm{H}\right), 4.71\left(\mathrm{~s}, 2 \mathrm{H}, \mathrm{NCH}_{2} \mathrm{O}\right), 4.91$ (d, $\left.J=12.5 \mathrm{~Hz}, 1 \mathrm{H}, \mathrm{CbzCH} \underline{H}_{\mathrm{a}}\right), 4.95\left(\mathrm{~d}, J=12.5 \mathrm{~Hz}, 1 \mathrm{H}, \mathrm{CbzCH} \underline{H}_{\mathrm{b}}\right), 5.01$ (d, $\left.J=12.3 \mathrm{~Hz}, 1 \mathrm{H}, \mathrm{BnCH}_{2}\right), 5.06\left(\mathrm{~d}, J=12.3 \mathrm{~Hz}, 1 \mathrm{H}, \mathrm{BnCH}_{2}\right), 5.41-5.49(\mathrm{~m}, 1 \mathrm{H}$, 6'- $\mathrm{NH}$ ), 5.51 (s, $2 \mathrm{H}, \mathrm{CH}_{2} \mathrm{OCH}_{2}$ ), 5.97 (dd, $\left.J=5.9 \mathrm{~Hz}, J=5.9 \mathrm{~Hz}, 1 \mathrm{H}, 1^{\prime}-\mathrm{H}\right), 6.93$ (brs, $1 \mathrm{H}, 6-\mathrm{H}), 6.99-7.19(\mathrm{~m}, 11 \mathrm{H}, \mathrm{ArH})$, 7.23-7.27 (m, $2 \mathrm{H}, \mathrm{ArH})$, 7.33-7.37 (m, $2 \mathrm{H}$, ArH).

${ }^{13} \mathrm{C}$-NMR $\left(126 \mathrm{MHz}, \mathrm{C}_{6} \mathrm{D}_{6}, 50{ }^{\circ} \mathrm{C}\right): \delta=12.78(\mathrm{C}-7), 28.01\left(\mathrm{C}\left(\mathrm{CH}_{3}\right)_{3}\right), 35.58$ (C-5'), 37.30 (C-2'), 51.21 (C-6'), 54.11 (C-3'), $66.75\left(\mathrm{CbzCH}_{2}\right), 70.62\left(\mathrm{NCH}_{2} \mathrm{O}\right), 72.08$

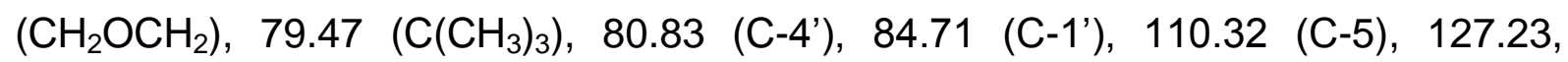
127.53, 127.73, 127.92, 128.00, 128.06, 128.12, 128.32, 128.36 (ArC), 133.35 (C-6), 135.63, 136.68, 138.70 (C-1", C-1"', C-1 ${ }^{\text {iv }), ~} 150.73$ (C-2), 155.18 (Boc-C=O), 155.67 (Cbz-C=O), 162.66 (C-4), 171.50 (COOBn).

Drehwert: $[\alpha]_{D}^{20}=+34.4\left(\mathrm{c}=1.1, \mathrm{CHCl}_{3}\right)$.

Schmelzpunkt: $69^{\circ} \mathrm{C}$. 
IR (ATR): $\tilde{v}=1709,1647,1528,1270,1237,1212,1161,1022,736,693$.

UV (MeCN): $\lambda_{\max }(\lg \varepsilon)=206$ (4.66), 261 (4.27).

MS $\left(\mathrm{ESI}^{+}\right): \mathrm{m} / \mathrm{z}=741.3[\mathrm{M}-\mathrm{H}]^{-}$.

$\mathrm{C}_{40} \mathrm{H}_{46} \mathrm{~N}_{4} \mathrm{O}_{10}(742.81)$

ber.: $741.3141[\mathrm{M}-\mathrm{H}]^{-}$

gef.: 741.3144 (ESI'-HRMS).

\subsubsection{6'-N-Boc-O-Bn-3-N-BOM-3'-desoxy-3'-N-Cbz-amino-(R)-TAA 117}

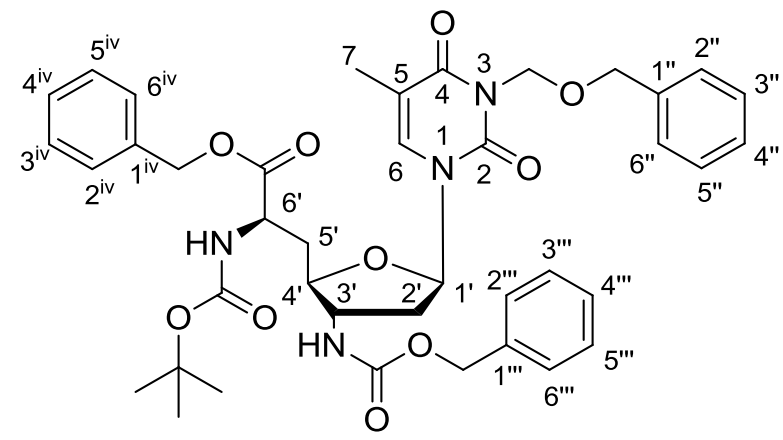

$\left(6^{\prime} R\right)-117$

Die Synthese erfolgte gemäß der Vorschrift zur Synthese der TAA (6'S)-117. Es wurden $300 \mathrm{mg}(0.405 \mathrm{mmol})$ des (Z)-Olefins 113, $10 \mathrm{mg}(16 \mu \mathrm{mol})(R, R)$-MeDuPHOS-Rh und $15 \mathrm{~mL}$ Methanol eingesetzt. Die Reaktionsdauer betrug $14 \mathrm{~d}$.

Ausbeute: Es wurden $220 \mathrm{mg}(296 \mu \mathrm{mol}, 73 \%$, Diastereomerengemisch 6'R:6'S 88:12) eines farblosen Schaums erhalten.

Die Hauptkomponente des Diastereomerengemischs konnte durch chromatographische Trennung an einer chiralen stationären Phase (Eluent: $n$-Hexan/EtOAc 73:27) rein erhalten werden. Für die Trennung wurden $430 \mathrm{mg}$ (aus mehreren Reaktionen erhalten) des Diastereomerengemischs aus (6'R)-117 und (6'S)-117 (88:12) verwendet.

HPLC (analytisch): $t_{\mathrm{R}}=37.5$ min (Methode: $s$. Analytische chirale HPLC (7.1.6.8), Injektionsvolumen: $10 \mu \mathrm{L}, \mathrm{c} \sim 4 \mathrm{mg} / \mathrm{mL}$ in EtOAc).

HPLC (semipräparativ): $t_{\mathrm{R}}=39.0$ min (Methode: $\mathrm{s}$. Semipräparative chirale HPLC (7.1.6.9), Injektionsvolumen: $100 \mu \mathrm{L}, \mathrm{c} \sim 100 \mathrm{mg} / \mathrm{mL}$ in EtOAc). 
Ausbeute: Es wurden $370 \mathrm{mg}(0.499 \mathrm{mmol}, 86 \%$ bezogen auf das getrennte Gemisch) des reinen (6' $R)$-Diastereomers $\left(6^{\prime} R\right)$-117 erhalten.

DC: $R_{\mathrm{f}}(\mathrm{iHex} / \mathrm{EtOAc} 3: 2)=0.31$.

${ }^{1} \mathrm{H}-\mathrm{NMR}\left(500 \mathrm{MHz}, \mathrm{C}_{6} \mathrm{D}_{6}, 50^{\circ} \mathrm{C}\right): \delta=1.38\left(\mathrm{~s}, 9 \mathrm{H}, \mathrm{C}\left(\mathrm{CH}_{3}\right)_{3}\right), 1.60-1.69(\mathrm{~m}, 1 \mathrm{H}$, 2'- $\left.\mathrm{H}_{\mathrm{a}}\right), 1.70-1.80\left(\mathrm{~m}, 1 \mathrm{H}, 2^{\prime}-\mathrm{H}_{\mathrm{b}}\right), 1.76(\mathrm{~s}, 3 \mathrm{H}, 7-\mathrm{H}), 1.88-2.00\left(\mathrm{~m}, 1 \mathrm{H}\right.$, 5' $\left.^{\prime}-\mathrm{H}_{\mathrm{a}}\right), 2.00-$ $2.09\left(\mathrm{~m}, 1 \mathrm{H}, 5^{\prime}-\mathrm{H}_{\mathrm{b}}\right), 3.52-3.59\left(\mathrm{~m}, 1 \mathrm{H}, \mathrm{H}-4^{\prime}\right), 3.77-3.87\left(\mathrm{~m}, 1 \mathrm{H}, 3^{\prime}-\mathrm{H}\right), 4.60-4.70(\mathrm{~m}$, $1 \mathrm{H}, 6$ '-H), 4.71 (s, $2 \mathrm{H}, \mathrm{NCH}_{2} \mathrm{O}$ ), 4.89 (d, J=12.2 Hz, $1 \mathrm{H}, \mathrm{CbzCH}_{\mathrm{a}}$ ), 4.97-5.04 (m, $\left.1 \mathrm{H}, \mathrm{CbzCH}_{\mathrm{H}}\right), 5.01$ (d, J=12.5 Hz, $\left.1 \mathrm{H}, \mathrm{BnCH}_{\mathrm{H}}\right), 5.06(\mathrm{~d}, J=12.5 \mathrm{~Hz}, 1 \mathrm{H}$, $\left.\mathrm{BnCH}_{\mathrm{H}_{\mathrm{b}}}\right), 5.19-5.29\left(\mathrm{~m}, 1 \mathrm{H}, 6{ }^{\prime}-\mathrm{NH}\right), 5.48\left(\mathrm{~d}, J=9.5 \mathrm{~Hz}, 1 \mathrm{H}, \mathrm{CH}_{2} \mathrm{OCH}_{\mathrm{a}}\right), 5.51$ (d, $J=9.5 \mathrm{~Hz}, 1 \mathrm{H}, \mathrm{CH}_{2} \mathrm{OCH} \underline{\mathrm{H}}_{\mathrm{b}}$ ), 5.75-5.85 (m, $1 \mathrm{H}, 1$ '- $\mathrm{H}$ ), 6.93 (brs, $\left.1 \mathrm{H}, 6-\mathrm{H}\right), 7.00-7.19$ (m, $11 \mathrm{H}, \mathrm{ArH})$, 7.23-7.27 (m, $2 \mathrm{H}, \mathrm{ArH}), 7.33-7.37$ (m, $2 \mathrm{H}, \mathrm{ArH})$.

${ }^{13} \mathrm{C}$-NMR (126 MHz, $\left.\mathrm{C}_{6} \mathrm{D}_{6}, 50^{\circ} \mathrm{C}\right): \delta=12.86(\mathrm{C}-7), 28.00\left(\mathrm{C}\left(\mathrm{CH}_{3}\right)_{3}\right), 35.70$ (C-5'), 37.28 (C-2'), 51.99 (C-6'), 54.46 (C-3'), $66.74\left(\mathrm{CbzCH}_{2}\right), 70.63\left(\mathrm{NCH}_{2} \mathrm{O}\right), 72.12$ $\left(\mathrm{CH}_{2} \mathrm{OCH}_{2}\right), 79.48\left(\mathrm{C}_{\left.\left(\mathrm{CH}_{3}\right)_{3}\right),} 80.88\left(\mathrm{C}^{\prime}\right)^{\prime}\right), 85.32\left(\mathrm{C}-1^{\prime}\right), 110.13(\mathrm{C}-5), 127.26$, 127.53, 127.73, 127.91, 128.07, 128.13, 128.17, 128.35, 128.39 (ArC), 133.15 (C-6), 135.77, 136.62, 138.69 (C-1"', C-1"', C-1 ${ }^{\text {iv }}$ ), 150.57 (C-2), 155.35 (Boc-C=O), 155.60 (Cbz-C=O), 162.58 (C-4), 171.84 (COOBn).

Drehwert: $[\alpha]_{D}^{20}=+39.1\left(\mathrm{c}=0.87, \mathrm{CHCl}_{3}\right)$.

Schmelzpunkt: $64^{\circ} \mathrm{C}$.

IR (ATR): $\tilde{v}=1700,1642,1452,1255,1156,1075,1022,736,698$.

UV (MeCN): $\lambda_{\max }(\lg \varepsilon)=204$ (4.60), 266 (3.94).

MS $\left(\mathrm{ESI}^{+}\right): \mathrm{m} / \mathrm{z}=741.3[\mathrm{M}-\mathrm{H}]^{-}$.

$\mathrm{C}_{40} \mathrm{H}_{46} \mathrm{~N}_{4} \mathrm{O}_{10}(742.81)$ ber.: $741.3141[\mathrm{M}-\mathrm{H}]^{-}$ gef.: 741.3139 (ESI'-HRMS). 


\subsubsection{6'-N-Boc-3'-desoxy-3'-N-Fmoc-(S)-TAA 104}

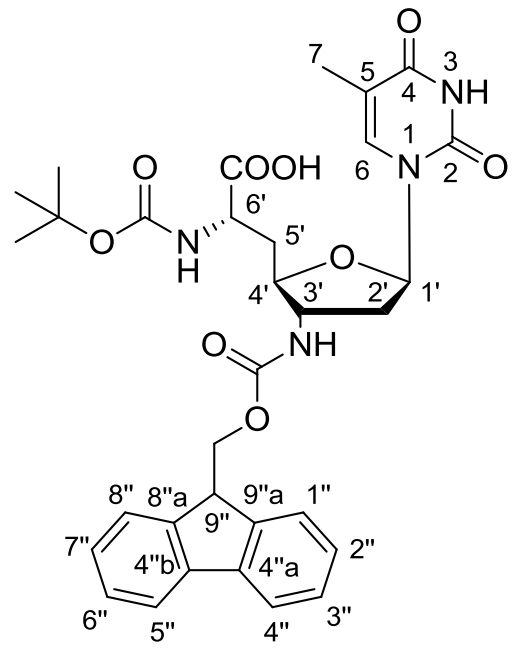

(6'S)-104

Hydrogenolytische Spaltung der Bn-, BOM- und Cbz-Schutzgruppen:

Eine Lösung von 6'-N-Boc-O-Bn-3-N-BOM-3'-desoxy-3'-N-Cbz-amino-(S)-TAA (6'S)-117 (900 mg, $1.21 \mathrm{mmol})$ in abs. Methanol (28 mL) wurde mit Palladium black $(1.28 \mathrm{~g}, 12.0 \mathrm{mmol})$ und $n$-Butylamin $(1.80 \mathrm{~g}, 2.43 \mathrm{~mL}, 24.2 \mathrm{mmol})$ versetzt. Die resultierende Suspension wurde $24 \mathrm{~h}$ unter einer Wasserstoffatmosphäre (1 bar) gerührt. Die Suspension wurde über eine Glasfritte filtriert und der Filterkuchen mit $\mathrm{MeOH}(3 \times 10 \mathrm{~mL})$ nachgewaschen. Das Filtrat wurde zur Trockne eingeengt und der Rückstand mit Pyridin coevaporiert ( $3 \times 4 \mathrm{~mL})$. Der erhaltene weiße Feststoff wurde ohne weitere Reinigung für den nächsten Schritt verwendet.

\section{Einführung der Fmoc-Schutzgruppe an 3'- $\mathrm{NH}_{2}$ :}

Eine Lösung von (6'S)-160 (435 mg, $1.09 \mathrm{mmol}$ ) in $3 \mathrm{~mL}$ eines 1:1-Gemischs aus Aceton und dest. Wasser wurde mit $\mathrm{Na}_{2} \mathrm{CO}_{3}(115 \mathrm{mg}, 1.09 \mathrm{mmol})$ und FmocOSu (368 mg, $1.09 \mathrm{mmol}$ ) versetzt und die resultierende Lösung $1 \mathrm{~h}$ bei Raumtemperatur gerührt. Die erhaltene Suspension wurde mit $2 \mathrm{M} \mathrm{HCl}$ auf $\mathrm{pH}=2$ eingestellt und in einem Gemisch aus DCM (15 mL) und ges. NaCl-Lösung (15 mL) aufgenommen. Die Phasen wurden getrennt und die wässrige Phase auf $\mathrm{pH}$ 1-2 eingestellt. Die wässrige Phase wurde mit DCM (3 x $10 \mathrm{~mL})$ extrahiert. Die vereinigten organischen Phasen wurden über $\mathrm{Na}_{2} \mathrm{SO}_{4}$ getrocknet, filtriert und bei vermindertem Druck zur Trockne eingeengt. Das so erhaltene Rohprodukt wurde chromatographisch an Kieselgel gereinigt (DCM/MeOH 9:1 mit 0.5\% AcOH). Das so erhaltene Produkt wurde mit Toluol coevaporiert $(3 \times 5 \mathrm{~mL})$. 
Ausbeute: Es wurden $393 \mathrm{mg}(0.633 \mathrm{mmol}$, 58\% über zwei Stufen) eines weißen, feinpulvrigen Feststoffs erhalten.

DC: $R_{\mathrm{f}}(\mathrm{DCM} / \mathrm{MeOH} 9: 1)=0.26$.

${ }^{1} \mathrm{H}-\mathrm{NMR}\left(500 \mathrm{MHz}, \mathrm{CD}_{3} \mathrm{OD}\right): \delta=1.44\left(\mathrm{~s}, 9 \mathrm{H}, \mathrm{C}\left(\mathrm{CH}_{3}\right)_{3}\right), 1.93(\mathrm{~s}, 3 \mathrm{H}, 7-\mathrm{H}), 2.06-2.16$ $\left(\mathrm{m}, 1 \mathrm{H}, 5^{\prime}-\mathrm{H}_{\mathrm{a}}\right), 2.21-2.39\left(\mathrm{~m}, 3 \mathrm{H}, 2^{\prime}-\mathrm{H}_{\mathrm{a}}, 2^{\prime}-\mathrm{H}_{\mathrm{b}}, 5^{\prime}-\mathrm{H}_{\mathrm{b}}\right), 3.89-3.97\left(\mathrm{~m}, 1 \mathrm{H}, 4^{\prime}-\mathrm{H}\right), 4.05-$ $4.14(\mathrm{~m}, 1 \mathrm{H}, 3$ '- $\mathrm{H}), 4.18-4.27\left(\mathrm{~m}, 2 \mathrm{H}, \mathrm{FmocCH}_{2}\right)$, 4.32-4.48 (m, 3 H, 9"'-H, 6'- $\mathrm{H}$, 6'-NH), 6.08-6.15 (m, $\left.1 \mathrm{H}, 1^{\prime}-\mathrm{H}\right), 7.31$ (dd, J=7.3 Hz, J=7.3 Hz, 2 H, 2'-H, 7'-H), 7.34 (dd, J=7.3 Hz, J=7.3 Hz, $2 \mathrm{H}, 3$ 3'-H, 6"-H), 7.53 (brs, $1 \mathrm{H}, 6-\mathrm{H}$ ), 7.65 (d, $J=7.3 \mathrm{~Hz}, 2 \mathrm{H}, 4$ "'-H, 5"-H), 7.79 (d, J=7.3 Hz, $2 \mathrm{H}, 1$ "'-H, 8"-H).

${ }^{13} \mathrm{C}-N M R\left(126 \mathrm{MHz}, \mathrm{CD}_{3} \mathrm{OD}\right): \delta=11.05$ (C-7), $27.33\left(\mathrm{C}\left(\underline{\mathrm{CH}}_{3}\right)_{3}\right), 35.27\left(\mathrm{C}-5^{\prime}\right), 36.76$ (C-2'), $46.82\left(\mathrm{FmocCH}_{2}\right), 51.25$ (C-6'), 54.22 (C-3'), 66.36 (C-9'), $79.21\left(\underline{\mathrm{C}}\left(\mathrm{CH}_{3}\right)_{3}\right)$, 81.02 (C-4'), 84.43 (C-1'), 110.49 (C-5), 119.54 (C-1", C-8”), 124.72, 124.78 (C-4”, C-5”), 126.77, 127.39 (C-2", C-7”), 127.82, 128.53 (C-3”, C-6”), 136.44 (C-6), 141.25 (C-8"'a, C-9"'a), 143.86 (C-4"'a, C-4”b), 150.80 (C-2), 156.32 (Boc-C=O), $156.32($ Fmoc-C=O), $164.97(\mathrm{C}-4), 174.35(\mathrm{COOH})$.

Drehwert: $[\alpha]_{\mathrm{D}}^{20}=+39.7\left(\mathrm{c}=1.2, \mathrm{CHCl}_{3}\right)$.

Schmelzpunkt: Zersetzung $>110^{\circ} \mathrm{C}$.

IR (ATR): $\tilde{v}=1680,1519,1447,1250,1161,1050,1022,759,736$.

UV (MeCN): $\lambda_{\max }(\lg \varepsilon)=206$ (4.95), 264 (4.65).

MS $\left(\mathrm{ESI}^{+}\right): \mathrm{m} / \mathrm{z}=643.5[\mathrm{M}+\mathrm{Na}]^{+}$.

$\mathrm{C}_{32} \mathrm{H}_{36} \mathrm{~N}_{4} \mathrm{O}_{9}$ (620.65)

ber.: $643.2368[\mathrm{M}+\mathrm{Na}]^{+}$ gef.: 643.2374 (ESI+-HRMS). 


\subsubsection{6'-N-Boc-O-3'-desoxy-3'-N-Fmoc-(R)-TAA 104}

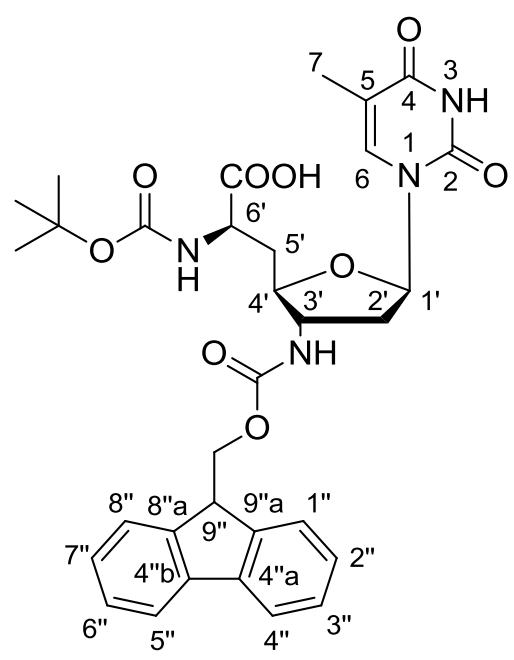

$\left(6^{\prime} R\right)-104$

Die Synthese von (6'R)-104 erfolgte gemäß der Vorschrift zur Synthese von (6'S)104. Für die hydrogenolytische Spaltung der Schutzgruppen wurden $370 \mathrm{mg}$ (0.498 mmol) (6'R)-117, $528 \mathrm{mg} \quad(4.98 \mathrm{mmol}) \quad$ Palladium-black, $\quad 1.80 \mathrm{~g}$ (10.0 mmol,1.00 mL) n-Butylamin und $12 \mathrm{~mL}$ abs. MeOH eingesetzt. Für die darauf folgende Einführung der Fmoc-Schutzgruppe wurden $200 \mathrm{mg}$ (0.502 mmol) $\left(6^{\prime} R\right)-160,53 \mathrm{mg} \mathrm{Na} \mathrm{CO}_{3}(0.50 \mathrm{mmol}), 169 \mathrm{mg}$ (0.502 mmol) FmocOSu und $1.4 \mathrm{~mL}$ Aceton-Wasser-Gemisch (1:1) eingesetzt.

Ausbeute: Es wurden $150 \mathrm{mg}(0.241 \mathrm{mmol}$, 48\% über zwei Stufen) eines weißen, feinpulvrigen Feststoffs erhalten.

DC: $R_{\mathrm{f}}(\mathrm{DCM} / \mathrm{MeOH}$ 9:1) $=0.26$.

${ }^{1} \mathrm{H}-\mathrm{NMR}\left(500 \mathrm{MHz}, \mathrm{CD}_{3} \mathrm{OD}\right): \delta=1.44\left(\mathrm{~s}, 9 \mathrm{H}, \mathrm{C}\left(\mathrm{CH}_{3}\right)_{3}\right), 1.93(\mathrm{~s}, 3 \mathrm{H}, 7-\mathrm{H}), 2.03-2.14$ $\left(\mathrm{m}, 1 \mathrm{H}, 5^{\prime}-\mathrm{H}_{\mathrm{a}}\right), 2.14-2.24\left(\mathrm{~m}, 1 \mathrm{H}, 5^{\prime}-\mathrm{H}_{\mathrm{b}}\right), 2.24-2.32\left(\mathrm{~m}, 1 \mathrm{H}, 2^{\prime}-\mathrm{H}_{\mathrm{a}}\right)$, 2.32-2.42 (m, $\left.1 \mathrm{H}, 2^{\prime}-\mathrm{H}_{\mathrm{b}}\right)$, 3.84-3.91 (m, $\left.1 \mathrm{H}, 4^{\prime}-\mathrm{H}\right), 4.03-4.11\left(\mathrm{~m}, 1 \mathrm{H}, 3^{\prime}-\mathrm{H}\right), 4.19-4.26(\mathrm{~m}, 2 \mathrm{H}$, FmocCH $\mathrm{CH}_{2}$, 4.26-4.35 (m, $1 \mathrm{H}, 6$ '-H), 4.38-4.48 (m, $\left.2 \mathrm{H}, 9^{\prime \prime}-\mathrm{H}, 6^{\prime}-\mathrm{NH}\right), 6.14-6.21$ (m, $1 \mathrm{H}, 1^{\prime}-\mathrm{H}$ ), 7.33 (dd, J=7.3 Hz, J=7.3 Hz, $2 \mathrm{H}, 2$ ''-H, 7'-H), 7.40 (dd, J=7.3 Hz, $J=7.3 \mathrm{~Hz}, 2 \mathrm{H}, 3$ "'-H, 6"'-H), 7.50 (brs, $1 \mathrm{H}, 6-\mathrm{H}$ ), 7.66 (d, J=7.3 Hz, $2 \mathrm{H}, 4$ 4'-H, 5"-H), 7.80 (d, J = 7.3 Hz, $2 \mathrm{H}, 1$ "'-H, 8"'-H).

${ }^{13} \mathrm{C}-N M R\left(126 \mathrm{MHz}, \mathrm{CD}_{3} \mathrm{OD}\right): \delta=11.02(\mathrm{C}-7), 27.34\left(\mathrm{C}\left(\underline{\mathrm{CH}}_{3}\right)_{3}\right), 35.44$ (C-5'), 36.47 (C-2'), $46.84\left(\mathrm{FmocCH}_{2}\right), 51.30$ (C-6'), 54.43 (C-3'), 66.32 (C-9'), $79.21\left(\underline{\mathrm{C}}\left(\mathrm{CH}_{3}\right)_{3}\right)$, 80.64 (C-4'), 84.74 (C-1'), 110.61 (C-5), 119.54 (C-1", C-8”), $124.72,124.90$ (C-4”, C-5”), 126.77, 127.40 (C-2", C-7”), 127.81, 128.53 (C-3”, C-6"), 136.36 (C-6), 
141.26 (C-8"a, C-9"a), 143.85 (C-4"a, C-4"b), 150.82 (C-2), 156.65 (Boc-C=O), 156.99 (Fmoc-C=O), $164.94(\mathrm{C}-4), 174.81(\mathrm{COOH})$.

Drehwert: $[\alpha]_{D}^{20}=+23.5\left(\mathrm{c}=1.1, \mathrm{CHCl}_{3}\right)$.

Schmelzpunkt: Zersetzung $>110^{\circ} \mathrm{C}$.

IR (ATR): $\tilde{v}=1685,1519,1447,1255,1161,1070,1050,1022,759,736$.

UV (MeCN): $\lambda_{\max }(\lg \varepsilon)=206$ (4.58), 264 (4.25).

MS $\left(\mathrm{ESI}^{+}\right): \mathrm{m} / \mathrm{z}=643.5[\mathrm{M}+\mathrm{Na}]^{+}$.

$\mathrm{C}_{32} \mathrm{H}_{36} \mathrm{~N}_{4} \mathrm{O}_{9}$ (620.65) ber.: $643.2373[\mathrm{M}+\mathrm{Na}]^{+}$ gef.: 643.2374 (ESI $\left.{ }^{+}-\mathrm{HRMS}\right)$.

\subsubsection{Oligonucleotide}

\subsubsection{Oligonucleotidsynthese}

Automatisierte DNA-Synthese (Synthesizer: Gene Assembler Plus, Pharmacia LKB) Für die Synthese eines jeden Oligonucleotids wurden ca. $18 \mathrm{mg}$ der Polystylrolmatrix (40 $\mu \mathrm{mol}$ Nucleosid/g Matrix) eingewogen. Als Lösungsmittel für die Phosphoramiditreagenzien diente abs. MeCN $\left(\mathrm{H}_{2} \mathrm{O}<20 \mathrm{ppm}\right)$. Die Entfernung der DMTr-Gruppen erfolgte durch 3\% DCA in DCE. Die Entfernung der Säure erfolgte durch Spülen der Matrix mit abs. DCE. Zum Aktivieren der Phosphoramidit-Funktionalität für die Nucleotidkupplung wurde Benzylthiotetrazol (BTT, $0.25 \mathrm{M}$ in abs. MeCN) eingesetzt. Für Phosphoramidite nicht-modifizierter Nucleoside wurde die Kupplungszeit auf 2 min und für Phosphoramidite NAA-modifizierter Nucleoside auf 4 min gesetzt. Für die Effizienz der Kupplung wurde der Schwellenwert auf $70 \%$ gesetzt. Die Oxidation der gebildeten Phosphit-Triester wurde durch alkalische lodlösung (10 $\mathrm{mM} \mathrm{I}_{2}$ in abs. MeCN/2,4,6-Collidin/ $\mathrm{H}_{2} \mathrm{O}$ im Verhältnis 10:1:5) bewirkt. Zum Schützen nicht gekuppelter 5'-OH-Gruppen („Capping“) wurden zwei Lösungen in Kombination eingesetzt (Lösung A: 0.5 M DMAP in MeCN, Lösung $\mathrm{B}$ : $\mathrm{Ac}_{2} \mathrm{O} / 2,4,6-\mathrm{Collidin} / \mathrm{MeCN}$ 2:3:5).

Automatisierte DNA-Synthese (Synthesizer: $H-8, K \& A$ )

Für die Synthese eines jeden Oligonucleotids wurden mit CPG gefülte Säulen verwendet (Beladung: $200 \mathrm{nmol}$ Nucleosid/Säule). Als Lösungsmittel für die Phosphoramidit-reagenzien diente abs. $\mathrm{MeCN}\left(\mathrm{H}_{2} \mathrm{O}<20 \mathrm{ppm}\right)$. Die Entfernung der DMTr-Gruppen erfolgte durch 3\% TCA in DCM. Die Entfernung der Säure erfolgte 
durch Spülen der Matrix mit abs. $\operatorname{MeCN}\left(\mathrm{H}_{2} \mathrm{O}<20 \mathrm{ppm}\right)$. Zum Aktivieren der Phosphoramidit-Funktionalität für die Nucleotidkupplung wurde Benzylthiotetrazol (BTT, $0.25 \mathrm{M}$ in abs. MeCN) eingesetzt. Für Phosphoramidite nicht-modifizierter Nucleoside wurde die Kupplungszeit auf 2 min und für Phosphoramidite NAAmodifizierter Nucleoside auf 4 min gesetzt. Für die Effizienz der Kupplung wurde der Schwellenwert auf $70 \%$ gesetzt. Die Oxidation der gebildeten Phosphit-Triester wurde durch alkalische lodlösung (20 $\mathrm{mM} \mathrm{I}_{2}$ in abs. Pyridin/ $\mathrm{H}_{2} \mathrm{O}$ im Verhältnis 9:1) bewirkt. Zum Schützen nicht gekuppelter 5'-OH-Gruppen („Capping“) wurden zwei Lösungen in Kombination eingesetzt (Lösung $\mathrm{A}$ : 10\% $\mathrm{Ac}_{2} \mathrm{O}$, 10\% Pyridin, $80 \%$ THF, Lösung B: 16\% 1-Methylimidazol in THF).

\section{Abspaltung der Oligonucleotide vom Träger}

Nach abgeschlossener Synthese folgte die Abtrennung der Oligonuclotide von der Matrix nebst Abspaltung der Schutzgruppen (Fmoc- und $\beta$-Cyanoethylgruppen) durch Inkubieren in einer 3:1-Mischung aus wässriger Ammoniaklösung (25\%) und Ethanol bei $55^{\circ} \mathrm{C}$ für $20 \mathrm{~h}$. Die erhaltenen Suspensionen wurden über eine Glasfritte filtriert, das Lösungsmittel mittels Unterdruck (Rotationsverdampfer) entfernt und der Rückstand in $750 \mu \mathrm{L}$ bidest Wasser aufgenommen. Die Zusammensetzung des jeweiligen Rohprodukts wurde anschließend mittels HPLC untersucht.

\section{Reinigung der Oligonucleotide}

Die Oligonucleotide wurden durch Gelelektrophorese an 20\% Polyacrylamidgel (Schichtdicke $0.7 \mathrm{~mm}$ ) gereinigt. Zur Herstellung eines Gels wurden $18.9 \mathrm{~g}$ Harnstoff, $22.5 \mathrm{~mL}$ Acrylamid und $4.5 \mathrm{~mL} 10$ x TBE-Puffer (Zusammensetzung von $1 \mathrm{~L}: 108 \mathrm{~g}$ Tris(hydroxymethyl)-aminomethan, $55 \mathrm{~g}$ Borsäure, $40 \mathrm{~mL} 0.5 \mathrm{M}$ EDTA, aufgefüllt auf $1 \mathrm{~L}$ mit bidest. Wasser) gerührt, bis eine klare Lösung entstand. Die erhaltene Lösung wurde auf $45 \mathrm{~mL}$ mit bidest. Wasser aufgefült und mit $35 \mu \mathrm{L}$ TMEDA und $250 \mu \mathrm{L}$ APS (10\% in bidest Wasser) versetzt. Die so erhaltene Lösung wurde unmittelbar nach dem Vermischen allmählich zwischen die Glasplatten $(32 \times 20 \mathrm{~cm})$ der Elektrophoresevorrichtung (Modell: LSG-400-20, C. B. S. Scientific Company) gegeben. Anschließend wurde das Gel für die Zeit der Polymerisationsreaktion ca. $1 \mathrm{~h}$ bei Raumtemperatur aufbewahrt. Für eine Trennung wurde der Lösung des jeweiligen Rohprodukts das entsprechende Volumen (enthält $40 \mathrm{nmol}$ Rohprodukt) entnommen, mit dem halben Volumen an Loading Dye (Zusammensetzung von $100 \mathrm{~mL}$ : $80 \mathrm{~mL}$ Formamid, $10 \mathrm{~mL} 10 \times$ TBE-Puffer, $10 \mathrm{~mL} 0.5 \mathrm{M}$ wässrige EDTA 
( $\mathrm{pH}=8), 25 \mathrm{mg}$ Bromphenolblau, $25 \mathrm{mg}$ Xylencyanol) vermischt und für $2 \mathrm{~min}$ auf $95^{\circ} \mathrm{C}$ erwärmt. Die erhaltene Mischung wurde auf das Gel aufgetragen $(40 \mathrm{nmol}$ Rohprodukt in jeweils 2 Kammern, d. h. pro Kammer $20 \mathrm{nmol}$ ). Die Farbstoffe Xylencyanol (obere Grenze) und Bromphenolblau (untere Grenze) dienten zur Markierung des Verlaufs der Elektrophorese. Die Laufzeit der Elektrophorese betrug $2.5 \mathrm{~h}$ bei $35 \mathrm{~W}$. Die Banden der Oligonucleotide wurden anhand ihrer UV-Aktivität $(260 \mathrm{~nm})$ detektiert. Anschließend wurde das Gel von der Glasplatte abgenommen und in eine Plastikfolie gewickelt. Die Oligonucleotid-haltigen Segmente wurden aus dem Gel ausgeschnitten und durch Aufbewahren bei $0{ }^{\circ} \mathrm{C}$ für $16 \mathrm{~h}$ in jeweils $300 \mu \mathrm{L}$ TEN-Puffer (1.0 M Tris(hydroxymethyl)-aminomethan, $0.5 \mathrm{M}$ EDTA, $3.0 \mathrm{M} \mathrm{NaCl}$ ) $2 \mathrm{Mal}$ extrahiert. Die erhaltenen TEN-Lösungen wurden mit $900 \mu \mathrm{L}$ abs. Ethanol versetzt und $20 \mathrm{~min}$ bei $-80^{\circ} \mathrm{C}$ gelagert. Durch anschließende Zentrifugation bei $4{ }^{\circ} \mathrm{C}$ und Entfernen (Dekantieren) des Überstands wurden die Oligonucleotide in kristalliner Form erhalten. Zum Entfernen der Ethanolreste wurden die Pellets in einer Vakuumzentrifuge getrocknet. Der Rückstand wurde in $50 \mu \mathrm{L}$ bidest. Wasser gelöst. Die genaue Bestimmung der erhaltenen Menge an Oligonucleotid erfolgte UVspektroskopisch (Lösungsmittel: Wasser). Aus den Messwerten der Absorbanz der jeweiligen Probe bei $\lambda=260 \mathrm{~nm}$ konnte die Stoffmenge an Oligonucleotid anhand einer vom Lambert-Beerschen Gesetz abgeleiteten Formel berechnet werden:

$$
\frac{A \cdot V}{\varepsilon \cdot d}=n
$$

A: Absorbanz bei $260 \mathrm{~nm}$

$\mathrm{V}$ : Volumen der Probe in $\mathrm{mL}$

$\varepsilon$ : mol. Extinktionskoeffizient des Oligonucleotids in $\mathrm{mL} \cdot \mathrm{mol}^{-1} \cdot \mathrm{cm}^{-1}$ (aus der jeweiligen Sequenz berechnet)

$\mathrm{d}$ : Schichtdicke der Probe in $\mathrm{cm}$

$\mathrm{n}$ : Stoffmenge des Oligonucleotids in mol

Die Einführung der modifizierten Dinucleoside wurde durch Massenspektrometrie untersucht. Zur Überprüfung der Reinheit der synthetisierten Oligonucleotide wurde den zur UV-Messung verwendeten Oligonucleotid-Lösungen je $1 \mu \mathrm{L}$ (ca. 20-30 pmol Substanz) entnommen, auf $25 \mu \mathrm{L}$ mit bidest. Wasser verdünnt $(c=8-10 \mathrm{pmol} / \mu \mathrm{L})$ und die resultierende Probe mittels analytischer HPLC untersucht (s. Kap. 7.1.6.7). 
Tab. 1: Oligonucleotidsynthese: erhaltene Mengen in nmol (Ausbeuten in \%)

\begin{tabular}{|c|c|c|c|c|}
\hline Nr. & Sequenz & $\sigma(\mathrm{x})^{*}$ & Rohprodukt & nach Reinigung \\
\hline 1 & 5'-GGCACGG TxT TT TT TxT GGCACGG-3' & $S$ & $170(24)$ & $19.5(49)$ \\
\hline 2 & & $R$ & $260(36)$ & $11.9(30)$ \\
\hline 3 & 5'-GGCACGG TxT TT TxT TT GGCACGG-3' & $S$ & $215(30)$ & $20.0(50)$ \\
\hline 4 & & $R$ & $196(27)$ & $15.6(39)$ \\
\hline 5 & 5'-GGCACGG TxT TxT TT TT GGCACGG-3' & $S$ & $480(66)$ & $17.0(43)$ \\
\hline 6 & & $R$ & $62(57)^{\star *}$ & $11.4(29)$ \\
\hline 7 & 5'-GGCACGG TxT TT TT TT GGCACGG-3' & $S$ & $145(72)^{\star \star}$ & $11.3(28)$ \\
\hline 8 & & $R$ & $138(69)^{\star *}$ & $13.0(33)$ \\
\hline 9 & 5'-GGCACGG TxT TxT TxT TxT GGCACGG-3' & $S$ & $95(48)^{\star \star}$ & $4.0(10)$ \\
\hline 10 & & $R$ & $69(35)^{\star *}$ & $7.3(18)$ \\
\hline 11 & 5'-G TxT GACG TT GACG TT GACG TT G-3' & $S$ & $245(34)$ & $22.3(56)$ \\
\hline 12 & & $R$ & $83(12)$ & $10.6(27)$ \\
\hline 13 & 5'-G TT GACG TxT GACG TT GACG TT G-3' & $S$ & $215(30)$ & $16.6(42)$ \\
\hline 14 & & $R$ & $137(19)$ & $17.4(44)$ \\
\hline 15 & 5'-G TT GACG TT GACG TxT GACG TT G-3' & $S$ & $200(28)$ & $12.9(32)$ \\
\hline 16 & & $R$ & $188(26)$ & $18.3(46)$ \\
\hline 17 & 5'-G TT GACG TT GACG TT GACG TxT G-3' & $S$ & $148(21)$ & $19.5(49)$ \\
\hline 18 & & $R$ & $147(20)$ & $22.9(57)$ \\
\hline 19 & 5'-G TxT GACG TxT GACG TxT GACG TxT G-3' & $S$ & $65(30)^{\star *}$ & $9.2(23)$ \\
\hline 20 & & $R$ & $52(26)^{\star *}$ & $9.9(25)$ \\
\hline 21 & 5'-GCGC TxT GC TT AAGCAAGCGC-3' & $S$ & $51(26)^{\star *}$ & $11.3(28)$ \\
\hline 22 & & $R$ & $77(39)^{\star *}$ & $13.6(34)$ \\
\hline 23 & 5'-GCGC TT GC TxT AAGCAAGCGC-3' & $s$ & $50(25)^{\star *}$ & $12.3(31)$ \\
\hline 24 & & $R$ & $78(39)^{\star \star}$ & $9.0(23)$ \\
\hline
\end{tabular}

* Stereodeskriptor der eingeführten NAA-Modifikation.

** Die Synthese dieser Oligonucleotide erfolgte am Synthesizer H-8 von $K \& A$ (s. 7.2.6.1). Die anderen Oligonucleotide wurden am Synthesizer Gene Assembler Plus von Pharmacia LKB synthetisiert (s. 7.2.6.1).

Die Ausbeuten der Rohprodukte beziehen sich auf die theoretisch möglichen Mengen an Oligonucleotid, die aus der Beladungsdichte des jeweils verwendeten Trägers hervorgehen. Die Ausbeuten der gereinigten Oligonucleotide beziehen sich auf die zur Elektrophorese entnommene Menge an Rohprodukt (40 nmol). 
Tab. 2: Analytische Daten der Oligonucleotide

\begin{tabular}{|c|c|c|c|c|c|}
\hline \multirow[t]{2}{*}{ Nr. } & \multirow[t]{2}{*}{ Sequenz } & \multirow[t]{2}{*}{$\sigma(x)^{*}$} & \multirow{2}{*}{$\begin{array}{l}\mathrm{t}_{R} \\
{[\mathrm{~min}]}\end{array}$} & \multicolumn{2}{|c|}{ Massenspektrometrie } \\
\hline & & & & berechnet & gefunden $^{+}$ \\
\hline 1 & 5'-GGCACGG TxT TT TT TxT GGCACGG-3' & $S$ & 29.5 & 6742.6 & 6741.6 \\
\hline 2 & & $R$ & 28.5 & & 6742.0 \\
\hline 3 & 5'-GGCACGG TxT TT TxT TT GGCACGG-3' & $S$ & 29.5 & & 6741.8 \\
\hline 4 & & $R$ & 29.2 & & 6742.3 \\
\hline 5 & 5'-GGCACGG TxT TxT TT TT GGCACGG-3' & $S$ & 29.6 & & 6741.5 \\
\hline 6 & & $R$ & $27.0^{\star *}$ & & 6741.1 \\
\hline 7 & 5'-GGCACGG TxT TT TT TT GGCACGG-3' & $S$ & $28.3^{* *}$ & 6765.6 & 6764.7 \\
\hline 8 & & $R$ & $28.1^{\star *}$ & & 6765.2 \\
\hline 9 & 5'-GGCACGG TxT TxT TxT TxT GGCACGG-3' & $S$ & $25.2^{* *}$ & 6714.9 & $6715.1^{++}$ \\
\hline 10 & & $R$ & $24.8^{\star *}$ & 6696.9 & 6692.7 \\
\hline 11 & 5'-G TxT GACG TT GACG TT GACG TT G-3' & $S$ & 30.6 & 6789.6 & 6789.6 \\
\hline 12 & & $R$ & 29.9 & & 6789.6 \\
\hline 13 & 5'-G TT GACG TxT GACG TT GACG TT G-3' & $S$ & 30.0 & & 6789.4 \\
\hline 14 & & $R$ & 29.9 & & 6789.3 \\
\hline 15 & 5'-G TT GACG TT GACG TxT GACG TT G-3' & $S$ & 30.0 & & 6789.6 \\
\hline 16 & & $R$ & 29.8 & & 6789.5 \\
\hline 17 & 5'-G TT GACG TT GACG TT GACG TxT G-3' & $S$ & 29.8 & & 6789.7 \\
\hline 18 & & $R$ & 29.7 & & 6789.8 \\
\hline 19 & 5'-G TxT GACG TxT GACG TxT GACG TxT G-3' & $S$ & $24.7^{\star \star}$ & 6720.9 & 6717.0 \\
\hline 20 & & $R$ & $24.5^{\star *}$ & & 6717.2 \\
\hline 21 & 5'-GCGC TxT GC TT AAGCAAGCGC-3' & $S$ & $13.3^{\star \star *}$ & 6095.1 & 6094.3 \\
\hline 22 & & $R$ & $14.6^{* * *}$ & & 6094.3 \\
\hline 23 & 5'-GCGC TT GC TxT AAGCAAGCGC-3' & $S$ & $14.0^{\star * \star}$ & 6095.1 & 6094.5 \\
\hline 24 & & $R$ & $14.5^{\star * *}$ & & 6094.6 \\
\hline
\end{tabular}

* Stereodeskriptor der eingeführten NAA-Modifikation.

** Die Abweichung kann dadurch zustande gekommen sein, dass der Lauf bei $60^{\circ} \mathrm{C}$ und nicht wie bei den anderen Oligonucleotiden bei $80^{\circ} \mathrm{C}$ durchgeführt wurde.

${ }^{* * *}$ Die palindromen Sequenzen wurden an einer RP-Säule auf Sauberkeit geprüft (s. 7.1.6.8

Palindrome Nucleotidsequenzen).

${ }^{+}$Abweichungen der Ergebnisse von massenspektrometrischen Untersuchungen von Oligonucleotiden liegen bei $0.005 \%-0.1 \%{ }^{[188]}$

${ }^{++}$Hier wurde nur der $\mathrm{M}+\mathrm{NH}_{4}{ }^{+}$-Peak beobachtet. 


\section{Literaturverzeichnis}

[1] F. Miescher; Ueber die Zusammensetzung von Eiterzellen; Med.-Chem. Unters. 1871, 4, 441-460.

[2] A. Kossel; Cytosine; Zeitschr. f. Physiol. Chem. 1903, 38, 49-59.

[3] A. Kossel; Thymine; Zeitschr. f. Physiol. Chem. 1900, 37, 303-306.

[4] P. A. Levene; The structure of yeast nucleic acid: IV. Ammonia hydrolysis; J. Biol. Chem. 1919, 40, 415-424.

[5] E. Chargaff; Chemical Specifity of Nucleic Acids and their Enzymatic Degradation; Experientia 1950, 6, 201-209.

[6] J. D. Watson, F. H. C. Crick; Molecular structure of nucleic acid. A structure of deoxyribose nucleic acid; Nature 1953, 171, 737-738.

[7] G. Felsenfeld, D. R. Davies, A. Rich; Formation of a Three-Stranded Polynucleotide Molecule; J. Am. Chem. Soc. 1957, 79, 2023-2024.

[8] A. H. J. Wang, G. J. Quigley, F. J. Kolpak, J. L. Crawford, J. H. van Boom, G. van der Marel, A. Rich; Molecular structure of a left-handed double helical DNA fragment at atomic resolution; Nature 1979, 282, 680-686.

[9] M. H. Caruthers; Chemical Synthesis of DNA and DNA Analogues; Acc. Chem. Res. 1991, 24, 278-284.

[10] P. C. Zamecnik, M. L. Stephenson; Inhibition of Rous sarcoma virus replication and cell transformation by a specific oligodeoxynucleotide; Proc. Natl. Acad. Sci. 1978, 75, 280-284.

[11] E. Uhlmann, A. Peyman; Antisense Oligonucleotides: A New Therapeutic Principle; Chem. Rev. 1990, 90, 543-585.

[12] A. Fire, S. Xu, M. K. Montgomery, S. A. Kostas, S. E. Driver, C. C. Mello; Potent and specific genetic interference by double-stranded RNA in Caenorhabditis elegans; Nature 1998, 391, 806-811.

[13] J. Kurreck; RNA-Interferenz: von den Grundlagen zur therapeutischen Anwendung; Angew. Chem. 2009, 121, 1404-1426. Angew. Chem. Int. Ed. 2009, 48, 1378-1398.

[14] S. Akhtar, R. Kole, R. L. Juliano; Stability of Antisense DNA Oligodeoxynucleotide Analogs in Cellular Extracts and Sera; Life Sci. 1991, 49, 1793-1801. 
[15] U. Feldkamp, C. M. Niemeyer; Rationaler Entwurf von DNANanoarchitekturen; Angew. Chem. 2006, 118, 1888-1910; Angew. Chem. Int. Ed. 2006, 45, 1856-1876.

[16] N. C. Seeman; Nanomaterials Based on DNA; Annu. Rev. Biochem. 2010, 79, 65-87.

[17] B. Yurke, A. J. Turberfield, A. P. Mills, F. C. Simmel, J. L. Neumann; A DNAfuelled molecular machine made of DNA; Nature 2000, 406, 605-608.

[18] N. L. Rosi, C. A. Mirkin; Nanostructures in Biodiagnostics; Chem. Rev. 2005, 105, 1547-1562.

[19] J.-L. Mergny, L. Lacroix; Analysis of Thermal Melting Curves; Oligonucleotides 2003, 13, 515-537.

[20] T. Lindahl; Instability and decay of the primary structure of DNA; Nature 1993, 362, 709-715.

[21] K. E. Nelson, M. Levy, S. L. Miller; Peptide nucleic acids rather than RNA may have been the first genetic molecule; Proc. Natl. Acad. Sci. USA 2000, 97, 3868-3871.

[22] F. Westheimer; Why nature chose phosphates; Science 1987, 235, 11731178.

[23] S. A. Benner, D. Hutter; Phosphates, DNA, and the Search for Nonterrean Life: A Second Generation Model for Genetic Molecules; Bioorg. Chem. 2002, 30, 62-80.

[24] A. Rich; DNA comes in many forms; Gene 1993, 135, 99-109.

[25] L. H. Koole, J. Plavec, H. Liu, B. R. Vincent, M. R. Dyson, P. L. Coe, R. T. Walker, G. W. Hardy, S. G. Rahim, J. Chattopadhyaya; Conformation of Two 4'-Thio-2'-deoxynucleoside Analogs Studied by $500-\mathrm{MHz}$ proton NMR Spectroscopy and X-ray Crystallography; J. Am. Chem. Soc. 1992, 114, 99369943.

[26] J. K. Watts, B. D. Johnston, K. Jayakanthan, A. S. Wahba, B. M. Pinto, M. J. Damha; Synthesis and Biophysical Characterization of Oligonucleotides Containing a 4'-Selenonucleotide; J. Am. Chem. Soc. 2008, 130, 8578-8579.

[27] N. Inoue, N. Minakawa, A. Matsuda; Synthesis and properties of 4'-ThioDNA: unexpected RNA-like behavior of 4'-O-ThioDNA; Nucleic Acids Res. 2006, 34, 3476-3483. 
[28] S. M. Freier, K.-H. Altmann; The ups and downs of nucleic acid duplex stability: structure-stability studies on chemically-modified DNA:RNA duplexes; Nucleic Acids Res. 1997, 25, 4429-4443.

[29] A. M. Kawasaki, M. D. Casper, S. M. Freier, E. A. Lesnik, M. C. Zounes, L. L. Cummins, C. Gonzales, P. D. Cook; Uniformly Modified 2'-Deoxy-2'-fluoro Phosphorothioate Oligonucleotides as Nuclease-Resistant Antisense Compounds with High Affinity and Specificity for RNA Targets; J. Med. Chem. 1993, 36, 831-841.

[30] B. Cuenoud, F. Casset, D. Hüsken, F. Natt, R. M. Wolf, K.-H. Altmann, P. Martin, H. E. Moser; Zweifache Erkennung von doppelsträngiger DNA durch 2'-Aminoethoxy-modifizierte Oligonucleotide; Angew. Chem. 1998, 110, 13501353; Angew. Chem. Int. Ed. 1998, 37, 1288-1291.

[31] M. Kanazaki, Y. Ueno, S. Shuto, A. Matsuda; Highly Nuclease-Resistant Phosphodiester-Type Oligodeoxynucleotides Containing 4'a-CAminoalkylthymidines Form Thermally Stable Duplexes with DNA and RNA. A Candidate for Potent Antisense Molecules; J. Am. Chem. Soc. 2000, 122, 2422-2432.

[32] A. A. Koshkin, S. K. Singh, P. Nielsen, V. K. Rajwanshi, R. Kumar, M. Meldgaard, C. E. Olsen, J. Wengel; LNA (Locked Nucleic Acids): Synthesis of the Adenine, Cytosine, Guanine, 5-Methylcytosine, Thymine and Uracil Bicyclonucleoside Monomers, Oligomerisation, and Unprecedented Nucleic Acid Recognition; Tetrahedron 1998, 54, 3607-3630.

[33] S. K. Singh, A. A. Koshkin, J. Wengel, P. Nielsen; LNA (locked nucleic acids): synthesis and high-affinity nucleic acid recognition; Chem. Commun. 1998, 455-456.

[34] S. Obika, D. Nanbu, Y. Hari, K.-i. Morio, Y. In, T. Ishida, T. Imanishi; Synthesis of 2'-O,4'-C-Methyleneuridine and -cytidine. Novel Bicyclic Nucleosides Having a Fixed $\mathrm{C}_{3}$-endo Sugar Puckering; Tetrahedron Lett. 1997, 38, 8735-8738.

[35] N. M. Bell, J. Micklefield; Chemical Modification of Oligonucleotides for Therapeutic, Bioanalytical and other Applications; ChemBioChem 2009, 10 , 2691-2703.

[36] V. K. Rajwanshi, A. E. Hakansson, M. D. Soren, S. Pitsch, S. K. Singh, R. Kumar, P. Nielsen, J. Wengel; The Eight Stereoisomers of LNA (Locked Nucleic Acid): A Remarkable Family of Strong RNA Binding Molecules; 
Angew. Chem. 2000, 112, 1722-1725; Angew. Chem. Int. Ed. 2000, 39, 16561659.

[37] E. T. Kool; Preorganization of DNA: Design Principles for Improving Nucleic Acid Recognition by Synthetic Oligonucleotides; Chem. Rev. 1997, 97, 14731488.

[38] J. T. Nielsen, P. C. Stein, M. Petersen; NMR structure of an $\alpha$-L-LNA:RNA hybrid: structural implications for RNase $\mathrm{H}$ recognition; Nucleic Acids Res. 2003, 31, 5858-5867.

[39] A. Ivanova, N. Rösch; The Structure of LNA:DNA Hybrids from Molecular Dynamics Simulations: The Effect of Locked Nucleotides; J. Phys. Chem. A 2007, 111, 9307-9319.

[40] J. K. Watts; Locked nucleic acid: tighter is different; Chem. Commun. 2013, 49, 5618-5620.

[41] K. S. Schmidt, S. Borkowski, J. Kurreck, A. W. Stephens, R. Bald, M. Hecht, M. Friebe, L. Dinkelborg, V. A. Erdmann; Application of locked nucleic acids to improve aptamer in vivo stability and targeting function; Nucleic Acids Res. 2004, 32, 5757-5765.

[42] E. E. Swayze, A. M. Siwkowski, E. V. Wancewicz, M. T. Migawa, T. K. Wyrzykiewicz, G. Hung, B. P. Monia, C. F. Bennett; Antisense oligonucleotides containing locked nucleic acid improve potency but cause significant hepatotoxicity in animals; Nucleic Acids Res. 2007, 35, 687-700.

[43] M. Castoldi, S. Schmidt, V. Benes, M. Noerholm, A. E. Kulozik, M. W. Hentze, M. U. Muckenthaler; A sensitive array for microRNA expression profiling (miChip) based on locked nucleic acids (LNA); RNA 2006, 12, 913-920.

[44] E. Reynisson, M. H. Josefsen, M. Krause, J. Hoorfar; Evaluation of probe chemistries and platforms to improve the detection limit of real-time PCR; J. Microbiol. Meth. 2006, 66, 206-216.

[45] P. I. Pradeepkumar, P. Cheruku, O. Plashkevych, P. Acharya, S. Gohil, J. Chattopadhyaya; Synthesis, Physicochemical and Biochemical Studies of 1',2'-Oxetane Constrained Adenosine and Guanosine Modified Oligonucleotides, and Their Comparison with Those of the Corresponding Cytidine and Thymidine Analogues; J. Am. Chem. Soc. 2004, 126, 1148411499.

[46] H. Kaur, B. R. Babu, S. Maiti; Perspectives on Chemistry and Therapeutic Applications of Locked Nucleic Acid (LNA); Chem. Rev. 2007, 107, 4672-4697. 
[47] K. Morita, C. Hasegawa, M. Kaneko, S. Tsutsumi, J. Sone, T. Ishikawa, T. Imanishic, M. Koizumi; 2'-O,4'-C-Ethylene-Bridged Nucleic Acids (ENA): Highly Nuclease-Resistant and Thermodynamically Stable Oligonucleotides for Antisense Drug; Bioorg. Med. Chem. Lett. 2002, 12, 73-76.

[48] T. S. Kumar, A. S. Madsen, M. E. Østergaard, S. P. Sau, J. Wengel, P. J. Hrdlicka; Functionalized 2'-Amino- $\alpha$-L-LNA: Directed Positioning of Intercalators for DNA Targeting; J. Org. Chem. 2009, 74, 1070-1081.

[49] F. Nagatsugi, S. Sasaki, P. S. Miller, M. M. Seidman; Site-specific mutagenesis by triple helix-forming oligonucleotides containing a reactive nucleoside analog; Nucleic Acids Res. 2003, 31, e31.

[50] F.-X. Barre, S. Ait-Si-Ali, C. Giovannangeli, R. Luis, P. Robin, L. L. Pritchard, C. Hélène, A. Harel-Bellan; Unambiguous demonstration of triple-helixdirected gene modification; Proc. Natl. Acad. Sci. USA 2000, 97, 3084-3088.

[51] A. J. Gutierrez, B. C. Froehler; RNA Duplex Formation by Oligonucleotides Containing C-5 Alkyne and C-5 Thiazole Substituted Deoxyuridine Analogs; Tetrahedron Lett. 1996, 37, 3959-3962.

[52] Y. S. Sanghvi, G. D. Hoke, S. M. Freier, M. C. Zounes, C. Gonzalez, L. Cummins, H. Sasmor, P. D. Cook; Antisense oligodeoxynucleotides: synthesis, biophysical and biological evaluation of oligodeoxynucleotides containing modified pyrimidines; Nucleic Acids Res. 1993, 21, 3197-3203.

[53] H. Hashimoto, M. G. Nelson, C. Switzer; Zwitterionic DNA; J. Am. Chem. Soc. 1993, 115, 7128-7134.

[54] D. A. Barawkar, K. G. Rajeev, V. A. Kumar, K. N. Ganesh; Triplex Formation at Physiological $\mathrm{pH}$ by 5-Me-dC-N4-(Spermine) $[\mathrm{X}]$ Oligodeoxynucleotides: Non Protonation of N3 in $X$ of $X{ }^{*} G: C$ Triad and Effect of Base Mismatch/lonic Strength on Triplex Stabilities; Nucleic Acids Res. 1996, 24, 1229-1237.

[55] J. Bijapur, S. Bergqvist, T. Brown, M. D. Keppler, K. R. Fox; 5-(1propargylamino)-2'-deoxyuridine (UP): A novel thymidine analogue for generating DNA triplexes with increased stability; Nucleic Acids Research 1999, 27, 1802-1809.

[56] V. Roig, U. Asseline; Oligo-2'-deoxyribonucleotides Containing Uracil Modified at the 5-Position with Linkers Ending with Guanidinium Groups; J. Am. Chem. Soc. 2003, 125, 4416-4417.

[57] Y. Ueno, M. Mikawa, A. Matsuda; Nucleosides and Nucleotides. 170. Synthesis and Properties of Oligodeoxynucleotides Containing 5-[N-[2-[N,N- 
Bis(2-aminoethyl)-amino]ethyl]carbamoyl]-2'-deoxyuridine and 5-[N-[3-[N,NBis(3-aminopropyl)amino]propyl]carbamoyl]-2'-deoxyuridine; Bioconjugate Chem. 1998, 9, 33-39.

[58] H. Liu, J. Gao, S. R. Lynch, Y. D. Saito, L. Maynard, E. T. Kool; A Four-Base Paired Genetic Helix with Expanded Size; Science 2003, 302, 868-871.

[59] B. D. Heuberger, C. Switzer; An Alternative Nucleobase Code: Characterization of Purine-Purine DNA Double Helices Bearing GuanineIsoguanine and Diaminopurine 7-Deaza-Xanthine Base Pairs; ChemBioChem 2008, 9, 2779-2783.

[60] Y. Doi, J. Chiba, T. Morikawa, M. Inouye; Artificial DNA Made Exclusively of Nonnatural C-Nucleosides with Four Types of Nonnatural Bases; J. Am. Chem. Soc. 2008, 130, 8762-8768.

[61] R. H. Griffey, H. Sasmor, M. J. Greig; Oligonucleotide charge states in negative ionisation electrospray-mass spectrometry are a function of ammonium ion concentration; J. Am. Chem. Soc. Mass Spectrom. 1997, 8, 155-160.

[62] J. Kumamoto, F. H. Westheimer; The Hydrolysis of Mono- and Dibenzyl Phosphates; J. Am. Chem. Soc. 1955, 77, 2515-2518.

[63] K. Sato, R. Tawarada, K. Seio, M. Sekine; Synthesis and Structural Properties of New Oligodeoxynucleotide Analogues Containing a 2',5'-Internucleotidic Squaryldiamide Linkage Capable of Formation of a Watson-Crick Base Pair with Adenine and a Wobble Base Pair with Guanine at the 3'-Downstream Junction Site; Eur. J. Org. Chem. 2004, 2004, 2142-2150.

[64] S. Spitzer, F. Eckstein; Inhibition of deoxyribonucleases by phosphorothioate groups in oligodeoxyribonucleotides; Nucleic Acids Res. 1988, 16, 1169111704.

[65] M. Stessl, C. R. Noe, J. Winkler; Off-target effects and safety aspects of phosphorothioate oligonucleotides; Nucleic Acids Sequences to Molecular Medicine 2012, 67-83.

[66] C. A. Stein, C. Subasinghe, K. Shinozuka, J. S. Cohen; Physicochemical properties of phosphorothioate oligodeoxynucleotides; Nucleic Acids Res. 1988, 16, 3209-3221.

[67] C. M. Yamada, D. J. Dellinger, M. H. Caruthers; Synthesis and Biochemical Evaluation of Phosphonoformate Oligodeoxyribonucleotides; J. Am. Chem. Soc. 2006, 128, 5251-5261. 
[68] D. Sheehan, B. Lunstad, C. M. Yamada, B. G. Stell, M. H. Caruthers, D. J. Dellinger; Biochemical properties of phosphonoacetate and thiophosphonoacetate oligodeoxyribonucleotides; Nucleic Acids Res. 2003, 31, 4109-4118.

[69] P. de Diesbach, F. N'Kuli, C. Berens, E. Sonveaux, M. Monsigny, A.-C. Roche, P. J. Courtoy; Receptor-mediated endocatosis of phosphodiesterOligonucleotides in the HepG2 cell line: evidence for nonconventional intracellular trafficking; Nucleic Acids Res. 2002, 30, 1512-1521.

[70] A. De Mesmaeker, R. Häner, P. Martin, H. E. Moser; Antisense Oligonucleotides; Acc. Chem. Res. 1995, 28, 366-374.

[71] P. S. Miller, J. Yano, E. Yano, C. Carroll, K. Jayaraman, P. O. P. Ts'o; Nonionic nucleic acid analogs. Synthesis and characterization of dideoxyribonucleoside methylphosphonates; Biochemistry 1979, 18, 51345143.

[72] K. K. Chacko, K. Lindner, W. Saenger, P. S. Miller; Molecular structure of deoxyadenjlyl-3'-methylphosphonate-5'thymidine dihydrate, $\left(\mathrm{d}-\mathrm{ApT}-2 \mathrm{H}_{2} \mathrm{O}\right)$, a dinucleotide monophosphate with neutral phosphodiester backbone. An X-ray crystal study; Nucleic Acids Res. 1983, 11, 2801-2814.

[73] F. Han, W. Watt, D. J. Duchamp, L. Callahan, F. J. Kézdy, K. Agarwal; Molecular structure of deoxycytidyl-3'-ethylphosphonate (RP) 5'deoxyguanidine, $\mathrm{d}[\mathrm{Cp}(\mathrm{CH} 3) \mathrm{G}]$. A neutral dinucleotide with Watson-Crick base pairing and a right handed helical twist; Nucleic Acids Res. 1990, 18, 27592767.

[74] C. Dupouy, N. Iché-Tarrat, M.-P. Durrieu, F. Rodriguez, J.-M. Escudier, A. Vigroux; Watson-Crick Base-Pairing Properties of Nucleic Acid Analogues with Stereocontrolled $\alpha$ and $\beta$ Torsion Angles ( $\alpha, \beta$-D-CNAs); Angew. Chem. 2006, 118, 3705-3709; Angew. Chem. Int. Ed. 2006, 45, 3623-3627.

[75] A. Boissonnet, C. Dupouy, P. Millard, M.-P. Durrieu, N. Tarrat, J.-M. Escudier; $[\alpha],[\beta]-D-C N A$ featuring canonical and noncanonical $[\alpha] /[\beta]$ torsional angles behaviours within oligonucleotides; New J. Chem. 2011, 35, 1528-1533.

[76] A. De Mesmaeker, A. Waldner, J. Lebreton, P. Hoffmann, V. Fritsch, R. M. Wolf, S. M. Freier; Amidverbrückung, eine neue Art der Modifizierung von Oligonucleotidrückgraten; Angew. Chem. 1994, 106, 237-240; Angew. Chem. Int. Ed. 1994, 33, 226-229. 
[77] J. Lebreton, J. A. Walder, V. Fritsch, R. M. Wolf, A. De Mesmaeker; Comparision of two Amides as Backbone Replacement of the Phosphodiester Linkage in Oligodeoxynucleotides; Tetrahedron Lett. 1994, 35, 5225-5228.

[78] A. De Mesmaeker, J. A. Walder, J. Lebreton, P. Hoffmann, V. Fritsch, R. M. Wolf, S. M. Freier; Amides as a Substitute for the Phosphodiester Linkage in Antisense Oligonucleotides; Synlett 1993, 1993, 733-736.

[79] J. Lebreton, A. De Mesmaeker, A. Waldner, F. Fritsch, R. M. Wolf, S. M. Freier; Synthesis of Thymidine Dimer Derivatives Containing an Amide Linkage and their Incorporation into Oligonucleotides; Tetrahedron Lett. 1993, 34, 6383-6386.

[80] C. Selvam, S. Thomas, J. Abbott, S. D. Kennedy, E. Rozners; Amides as Excellent Mimics of Phosphate Linkages in RNA; Angew. Chem. 2011, 123, 2116-2118; Angew. Chem. Int. Ed. 2011, 50, 2068-2070.

[81] R. L. Letsinger, C. N. Singman, G. Histand, M. Salunkhe; Cationic oligonucleotides; J. Am. Chem. Soc. 1988, 110, 4470-4471.

[82] S. Chaturvedi, T. Horn, R. L. Letsinger; Stabilization of Triple-Stranded Oligonucleotide Complexes: Use of Probes Containing Alternating Phosphodiester and Stereo-Uniform Cationic Phosphoramidate Linkages; Nucleic Acids Res. 1996, 24, 2318-2323.

[83] C. P. Bailey, D. L. Weeks, J. M. Dagle; Cationic oligonucleotides can mediate specific inhibition of gene expression in Xenopus oocytes; Nucleic Acids Res. 1998, 26, 4860-4867.

[84] K. M. Vasquez, J. M. Dagle, D. L. Weeks, P. M. Glazer; Chromosome Targeting at Short Polypurine Sites by Cationic Triplex-forming Oligonucleotides; J. Biol. Chem. 2001, 276, 38536-38541.

[85] T. Michel, F. Debart, J.-J. Vasseur; Efficient guanidination of the phosphate linkage towards cationic phosphoramidate oligonucleotides; Tetrahedron Lett. 2003, 44, 6579-6582.

[86] M. L. Jain, P. Y. Bruice, I. E. Szabó, T. C. Bruice; Incorporation of Positively Charged Linkages into DNA and RNA Backbones: A Novel Strategy for Antigene and Antisense Agents; Chem. Rev. 2011, 112, 1284-1309.

[87] B. A. Linkletter, I. E. Szabo, T. C. Bruice; Solid-Phase Synthesis of Deoxynucleic Guanidine (DNG) Oligomers and Melting Point and Circular Dichroism Analysis of Binding Fidelity of Octameric Thymidyl Oligomers with DNA Oligomers; J. Am. Chem. Soc. 1999, 121, 3888-3896. 
[88] D. A. Barawkar, T. C. Bruice; Synthesis, biophysical properties, and nuclease resistance properties of mixed backbone oligodeoxynucleotides containing cationic internucleoside guanidinium linkages: Deoxynucleic guanidine/DNA chimeras; Proc. Natl. Acad. Sci. USA 1998, 95, 11047-11052.

[89] N. Kojima, I. E. Szabo, T. C. Bruice; Synthesis of ribonucleic guanidine: replacement of the negative phosphodiester linkages of RNA with positive guanidinium linkages; Tetrahedron 2002, 58, 867-879.

[90] D. P. Arya, T. C. Bruice; Positively Charged Deoxynucleic Methylthioureas: Synthesis and Binding Properties of Pentameric Thymidyl Methylthiourea; J. Am. Chem. Soc. 1998, 120, 12419-12427.

[91] D. P. Arya, T. C. Bruice; Fidelity of Deoxynucleic S-Methythiourea (DNmt) Binding to DNA Oligomers: Influence of C Mismatches; J. Am. Chem. Soc. 1999, 121, 10680-10684.

[92] H. Challa, T. C. Bruice; Incorporation of Positively Charged Deoxynucleic SMethylthiourea Linkages into Oligodeoxyribonucleotides; Bioorg. Med. Chem. Lett. 2001, 11, 2423-2427.

[93] N. Mignet, S. M. Gryaznov; Zwitterionic oligodeoxyribonucleotide N3'-P5'phosphoramidates: synthesis and properties; Nucleic Acids Res. 1998, 26, 431-438.

[94] D. Stein, E. Foster, S.-B. Huang, D. Weller, J. Summerton; A Specifity Comparison of Four Antisense Types: Morpholino, 2'-O-Methyl RNA, DNA, and Phosphorothioate DNA; Antisense Nucleic Acid Drug Dev. 1997, 7, 151157.

[95] E. C. Madsen, P. A. Morcos, B. A. Mendelsohn, J. D. Gitlin; In vivo correction of a Menkes disease model using antisense oligonucleotides; Proc. Natl. Acad. Sci. 2008, 105, 3909-3914.

[96] C. Mitrpant, P. Porensky, H. Zhou, L. Price, F. Muntoni, S. Fletcher, S. D. Wilton, A. H. M. Burghes; Improved Antisense Oligonucleotide Design to Suppress Aberrant SMN2 Gene Transcript Processing: Towards a Treatment for Spinal Muscular Atrophy; PLOS ONE 2013, 8, e62114.

[97] S. Perez-Rentero, J. Alguacil, J. Robles; Novel oligonucleotide analogues containig a morpholinoamidine unit; Tetrahedron 2009, 65, 1171-1179.

[98] P. E. Nielsen, M. Egholm, R. H. Berg, O. Buchardt; Sequence-Selective Recognition of DNA by Strand Displacement with a Thymine-Substituted Polyamide; Science 1991, 254, 1497-1500. 
[99] P. E. Nielsen; Petide Nucleic Acids (PNA) in Chemical Biology and Drug Discovery; Chem. Biodivers. 2010, 7, 786-804.

[100] B. Hyrup, P. E. Nielsen; Peptide Nucleic Acids (PNA): Synthesis, Properties and Potential Applications; Bioorg. Med. Chem. 1996, 4, 5-23.

[101] M. Egholm, O. Buchardt, L. Christensen, C. Behrens, S. M. Freier, D. A. Driver, R. H. Berg, S. K. Kim, B. Norden, P. E. Nielsen; PNA hybridizes to complementary oligonucleotides obeying the Watson-Crick hydrogen-bonding rules; Science 1993, 365, 566-568.

[102] P. Wittung, P. E. Nielsen, O. Buchardt, M. Egholm, B. Norden; DNA-like double helix formed by peptide nucleic acid; Nature 1994, 368, 561-563.

[103] Y.-J. Seo, J. Lim, E.-H. Lee, T. Ok, J. Yoon, J.-H. Lee, H.-S. Lee; Base pair opening kinetics study of the aegPNA:DNA hydrid duplex containing a sitespecific GNA-like chiral PNA monomer; Nucleic Acids Res. 2011, 39, 73297335.

[104] S. Brown, S. Thomson, J. Veal, D. Davis; NMR solution structure of a peptide nucleic acid complexed with RNA; Science 1994, 265, 777-780.

[105] M. Eriksson, P. E. Nielsen; Solution structure of a peptide nucleic acid-DNA duplex; Nat. Struct. Biol. 1996, 3, 410-413.

[106] H. Rasmussen, J. S. Kastrup, J. N. Nielsen, J. M. Nielsen, P. E. Nielsen; Crystal structure of a peptide nucleic acid (PNA) duplex at $1.7 \AA$ resolution; Nat. Struct. Biol. 1997, 4, 98-101.

[107] P. E. Nielsen, G. Haaima, A. Lohse, O. Buchardt; Peptide Nucleic Acids (PNAs) Containing Thymine Monomers Derived from Chiral Amino Acids: Hybridization and Solubility Properties of D-Lysine PNA; Angew. Chem. 1996, 108, 2068-2070; Angew. Chem. Int. Ed. Engl. 1996, 35, 1939-1942.

[108] P. Zhou, A. Dragulescu-Andrasi, B. Bhattachayara, H. O'Keefe, P. Vatta, J. J. Hyldig-Nielsen, D. H. Ly; Synthesis of cell-permeable peptide nucleic acids and characterization of their hybridization and uptake properties; Bioorg. Med. Chem. Lett. 2006, 16, 4931-4935.

[109] N. M. Howarth, L. P. G. Wakelin; a-PNA: A Novel Peptide Nucleic Acid Analogue of DNA; J. Org. Chem. 1997, 62, 5441-5450.

[110] A. Dragulescu-Andrasi, S. Rapireddy, B. M. Frezza, C. Gayathri, R. R. Gil, D. H. Ly; A Simple y-Backbone Modification Preorganizes Peptide Nucleic Acid into a Helical Structure; J. Am. Chem. Soc. 2006, 128, 10258-10267. 
[111] S. Rapireddy, G. He, S. Roy, B. A. Armitage, D. H. Ly; Strand Invasion of Mixed-Sequence B-DNA by Acridine-Linked, y-Peptide Nucleic Acid ( $\mathrm{Y}$-PNA); J. Am. Chem. Soc. 2007, 129, 15596-15600.

[112] N. T. S. De Costa, J. M. Heemstra; Evaluating the Effect of lonic Strength on Duplex Stability for PNA Having Negatively or Positively Charged Side Chains PLOS ONE 2013, 8, e58670.

[113] B. Hyrup, M. Egholm, O. Buchardt, P. E. Nielsen; A flexible and positively charged PNA analogue with an ethylene-linker to the nucleobase: synthesis and hybridization properties; Bioorg. Med. Chem. Lett. 1996, 6, 1083-1088.

[114] B. Schmidtgall; Diplomarbeit, Georg-August-Universität Göttingen 2009.

[115] A. Spork, C. Ducho; Novel 5'-deoxy nucleosyl amino acid scaffolds for the synthesis of muraymycin analogues; Org. Biomol. Chem. 2010, 8, 2323-2326.

[116] M. Winn, R. J. M. Goss, K.-i. Kimura, T. D. H. Bugg; Antimicrobial nucleoside antibiotics targeting cell wall assembly: Recent advances in structure-function studies and nucleoside biosynthesis; Nat. Prod. Rep. 2010, 27, 279-304.

[117] A. Spork, S. Koppermann, C. Ducho; Improved Convergent Synthesis of 5'epi-Analogues of Muraymycin Nucleoside Antibiotics; Synlett 2009, 15, 25032507.

[118] A. P. Spork, D. Wiegmann, M. Granitzka, D. Stalke, C. Ducho; Stereoselective Synthesis of Uridine-Derived Nucleosyl Amino Acids; J. Org. Chem. 2011, 76, 10083-10098.

[119] B. D. Vineyard, W. S. Knowles, M. J. Sabacky, G. L. Bachmann, D. J. Weinkauff; Asymmetric Hydrogenation. Rhodium Chiral Bisphosphine Catalyst; J. Am. Chem. Soc. 1977, 99, 5946-5952.

[120] A. Matsuda, M. Satoh, T. Ueda, H. Machida, T. Sasaki; Synthesis and Biological Activities of 3'-Deoxy-3'-Isothiocyano and Isoselenocyanothymidines; Nucleosides Nucleotides 1990, 9, 587-597.

[121] L. Horner, H. Hoffmann, H. G. Wippel; Phosphororganische Verbindungen, XII. Phosphinoxyde als Olefinierungsreagenzien; Chem. Ber. 1958, 91, 61-63.

[122] W. S. Wadsworth, W. D. Emmons; The Utility of Phosphonate Carbanions in Olefin Synthesis; J. Am. Chem. Soc. 1961, 83, 1733-1738.

[123] A. De Mesmaeker, J. Lebreton, C. Jouanno, V. Fritsch, R. M. Wolf, S. Wendeborn; Amide-Modified Oligonucleotides with Preorganized Backbone and Furanose Rings: Highly Increased Thermodynamic Stability of the 
Duplexes Formed with their RNA and DNA Complements; Synlett 1997, 1997, 1287-1290.

[124] N. D. Sinha, J. Biernat, H. Köster; $\beta$-Cyanoethyl N,N-Dialkylamino/NMorpholinochloro phosphoamidites, new phosphitylating agents facitilitating ease of deprotection and work-up of synthesized oligonucleotides; Tetrahedron Lett. 1983, 24, 5843-5846.

[125] L. A. Carpinho, G. Y. Han; The 9-Fluorenylmethyloxycarbonyl AminoProtecting-Group; J. Org. Chem. 1972, 37, 3404-3409.

[126] M.-O. Schneemann; Nicht publizierte Ergebnisse, 2012.

[127] A. Ochmann; Masterarbeit, Georg-August-Universität Göttingen 2011.

[128] A. T. Khan, E. Mondal; A Highly Efficient and Useful Synthetic Protocol for the Cleavage of TBDMS-Ethers Using a Catalytic Amount of Acetylchloride in Dry Methanol; Synlett 2003, 694-698.

[129] C. B. Reese; Oligo- and poly-nucleotides: 50 years of chemical synthesis; Org. Biomol. Chem. 2005, 3, 3851-3868.

[130] K. L. Agarwal, A. Yamazaki, P. J. Cashion, H. G. Khorana; Chemische Synthese von Polynucleotiden; Angew. Chem. 1972, 84, 489-498; Angew. Chem. Int. Ed. 1972, 11, 451-459.

[131] P. A. M. Herdewijn; Anchimeric assistance of a 5'-O-carbonyl function for inversion of configuration at the $3^{\prime}$-carbon atom of $2^{\prime}$-deoxyadenosine. Synthesis of 3'-azido-2',3'-dideoxyadenosine and 3'-azido-2',3'-dideoxyinosine; J. Org. Chem. 1988, 53, 5050-5053.

[132] P. Herdewijn, J. Balzarini, M. Baba, R. Pauwels, A. Van Aerschot, G. Janssen, E. De Clercq; Synthesis and anti-HIV activity of different sugar-modified pyrimidine and purine nucleosides; J. Med. Chem. 1988, 31, 2040-2048.

[133] I. Yamamoto, M. Sekine, H. Tsujiaki; One-Step synthesis of 5'-azidonucleosides; J. Chem. Soc. Perkin Trans / 1980, 306-310.

[134] J. S. Nelson, K. L. Fearon, M. Q. Nguyen, S. N. McCurdy, J. E. Frediani, M. F. Foy, B. L. Hirschbein; N3 $\rightarrow$ P5' Oligodeoxyribonucleotide Phosphoramidates: A New Method of Synthesis Based on a Phosphoramidite Amine-Exchange Reaction; J. Org. Chem. 1997, 62, 7278-7287.

[135] H. Kuzuhara, M. Kawana; Synthesis of 2'-and 3'-Azido-2',3'dideoxyadenosines. Preparative applications of the deoxygenative [1,2]hydride shift and B-elimination reactions of O-sufonylated adenosines; Carbohydr. Res. 1989, 189, 87-101. 
[136] S. Czernecki, J.-M. Valery; An Efficient Synthesis of 3'-Azido-3'deoxythymidine; Synthesis 1991, 239-240.

[137] R. Eisenhuth, C. Richert; Convenient Syntheses of 3'-Amino-2', 3'dideoxynucleosides, Their 5'-Monophosphates, and 3'-Aminoterminal Oligodeoxynucleotide Primers; J. Org. Chem. 2008, 74, 26-37.

[138] E. Atherton, H. Fox, D. Harkiss, C. Logan, R. Sheppard, B. Williams; A mild procedure for solid phase peptide synthesis: use of fluorenylmethoxycarbonylamino-acids; Chem. Commun. 1978, 537-539.

[139] Y.-h. Ji, W. Bannwarth, B. Luu; Application of the phosphoramidite-phosphite triester approach for the synthesis of combinations between oxygenated sterols and nucleoside analogues linked by phosphodiester bonds; Tetrahedron 1990, 46, 487-502.

[140] U. Schmidt, A. Lieberknecht, J. Wild; Amino Acids and Peptides; XLIII. Dehydroamino Acids; XVIII. Synthesis of Dehydroamino Acids and Amino Acids from N-Acyl-2-(dialkyloxyphosphinyl)-glycine Esters; Synthesis 1984, 1984, 53-60.

[141] A. Spork; Dissertation, Georg-August-Universität Göttingen, 2012.

[142] U. Schmidt, J. Wild; Totalsynthese von Hexaacetylcelenamid A; Liebigs Ann. Chem. 1985, 1985, 1882-1894.

[143] R. Hamzavi, F. Dolle, B. Tavitian, O. Dahl, P. E. Nielsen; Modulation of the Pharmacokinetic Properties of PNA: Preparation of Galactosyl, Mannosyl, Fucosyl, N-Acetylgalactosaminyl, and N-Acetylglucosaminyl Derivatives of Aminoethylglycine Peptide Nucleic Acid Monomers and Their Incorporation into PNA Oligomers; Bioconjugate Chem. 2003, 14, 941-954.

[144] A. Michaelis, R. Kaehne; Über das Verhalten der Jodalkyle gegen die sogen. Phosphorigsäureester oder O-Phosphine; Ber. dtsch. chem. Ges. 1898, 31, 1048-1055.

[145] M. J. Smith, D. Kim, B. Horenstein, K. Nakanishi, K. Kustin; Unraveling the chemistry of tunichrome; Acc. Chem. Res. 1991, 24, 117-124.

[146] A. Duschek, S. F. Kirsch; 2-lodoxybenzoesäure - ein einfaches Oxidationsmittel mit einer Vielfalt an Anwendungsmöglichkeiten; Angew. Chem. 2011, 123, 1562-1590; Angew. Chem. Int. Ed. 2011, 50, 1524-1552.

[147] J. Boeckman, Robert K., P. Shao, J. J. Mullins; The Dess-Martin Periodinane: 1,1,1-Triacetoxy-1,1-dihydro-1,2-benziodoxol-3(1H)-one; Org. Synth. 2000, 77, 141. 
[148] X.-F. Zhu, H. J. Williams, A. I. Scott; Facile and highly selective 5'-desilylation of multisilylated nucleosides; J. Chem. Soc. Perkin Trans. I 2000, 2305-2306.

[149] J. D. More, N. S. Finney; A Simple and Advantageous Protocol for the Oxidation of Alcohols with o-lodoxybenzoic Acid (IBX); Org. Lett. 2002, 4, 3001-3003.

[150] U. Schmidt, H. Griesser, V. Leitenberger, A. Lieberknecht, R. Mangold, R. Meyer, B. Riedl; Diastereoselective Formation of (Z)-Didehydroamino acid esters; Synthesis 1992, 487-490.

[151] R. Mazurkiewicz, A. Kuznik, M. Grymel, N. Kuznik; ${ }^{1} \mathrm{H}-\mathrm{NMR}$ spectroscopic criteria for the configuration of $N$-acyl- $\alpha, \beta$-dehydro- $\alpha$-amino acid esters; Magn. Reson. Chem. 2005, 43, 36-40.

[152] M. J. Burk; C2-symmetric bis(phospholanes) and their use in highly enantioselective hydrogenation reactions; J. Am. Chem. Soc. 1991, 113, 85188519.

[153] T. Masquelin, E. Broger, K. Müller, R. Schmid, D. Obrecht; Synthesis of Enantiomerically Pure D- and L-(Heteroaryl)alanines by Asymmetric Hydrogenation of (Z)- $\alpha$-Amino- $\alpha, \beta$-didehydro Esters; Helv. Chim. Acta 1994, 77, 1395-1411.

[154] J. Halpern; Mechanism and Stereoselectivity of Asymmetric Hydrogenation; Science 1982, 217, 401-407.

[155] H. Möhrle, H. Ehrhardt, R. Kilian, P. Spillmann; Rotamere Amide; Arch. Pharm. 1970, 303, 531-544.

[156] A. G. Martinez, J. O. Barcina, H. G. del Veccio, M. Hanack, L. R. Subramanian; Non-Hydrolystic Cleavage of Esters with Manesium lodide in Aprotic Non-Polar Solvents; Tetrahedron Lett. 1991, 32, 5931-5934.

[157] R. Kaul, Y. Brouillette, Z. Sajjadi, K. A. Hansford, W. D. Lubell; Selective tertButyl Ester Deprotection in the Presence of Acid Labile Protecting Groups with Use of $\mathrm{ZnBr}_{2}$; J. Org. Chem. 2004, 69, 6131-6133.

[158] S. Paul, R. R. Schmidt; A New Base Mediated Method for the Cleavage of tertButyl Esters; Synlett 2002, 2002, 1107-1108.

[159] O. Mitsunobu; The Use of Diethyl Azodicarboxylate and Triphenylphosphine in Synthesis and Transformation of Natural Products; Synthesis 1981, 1-28.

[160] D. L. Hughes; Progress in the Mitsunobu Reaction. A Review; Org. Prep. Proced. Int. 1996, 28, 127-164. 
[161] H. Staudinger, J. Meyer; Über neue organische Phosphorverbindungen III. Phosphinmethylenderivate und Phosphinimine; Helv. Chim. Acta 1919, 2, 635646.

[162] W. Q. Tian, Y. A. Wang; Mechanisms of Staudinger Reactions within Density Functional Theory; J. Org. Chem. 2004, 69, 4299.

[163] G. S. Ti, B. L. Gaffney, R. A. Jones; Transient protection: efficient one-flask syntheses of protected deoxynucleosides; J. Am. Chem. Soc. 1982, 104, 1316-1319.

[164] A. M. Felix, E. P. Heimer, T. J. Lambros, C. Tzougraki, J. Meienhofer; Rapid removal of protecting groups from peptides by catalytic transfer hydrogenation with 1,4-cyclohexadiene; J. Org. Chem. 1978, 43, 4194-4196.

[165] F. Hansske, M. J. Robins; Nucleic Acid Related Compounds. 43. A Convenient Procedure for the Synthesis of 2 ' and 3 '-Ketonucleosides; Tetrahedron Lett. 1983, 24, 1589-1592.

[166] V. Samano, M. J. Robins; Mild Periodinane Oxidation of Protected Nucleosides To Give 2'- and 3'-Ketonucleosides. The First Isolation of a Purine 2'-Deoxy-3'-ketonucleoside Derivative; J. Org. Chem. 1990, 55, 5186-5188.

[167] M. N. S. Rad, S. Behrouz, A. Khalafi-Nezhad; A simple one-pot procedure for the direct conversion of alcohols into azides using TsIm; Tetrahedron Lett. 2007, 48, 3445-3449.

[168] K. S. Krishnakumar, P. Strazewski; Synthesis of a Deoxyxylopuromycine Analogue; Synlett 2010, 7, 1055-1058.

[169] N. Iranpoor, H. Firouzabadi, B. Akhlaghinia, N. Nowrouzi; A novel and highly selective conversion of alcohols, thiols, and silyl ethers to azides using the triphenylphosphine/2,3-dichloro-5,6-dicyanobenzoquinone(DDQ)/n-Bu $\mathrm{NN}_{3}$; system Tetrahedron Lett. 2004, 45, 3291-3294.

[170] R. Brückner, Reaktionsmechanismen, 3. Auflage, Spektrum Akademischer Verlag, München 2004, 97-99.

[171] T. Mukaiyama; Die Oxidations-Reduktions-Kondensation; Angew. Chem. 1976, 88, 111-120; Angew. Chem. Int. Ed. Engl. 1976, 15, 94-103.

[172] R. Appel; Tertiäres Phosphan/Tetrachlormethan, ein vielseitiges Reagens zur Chlorierung, Dehydratisierung und PN-Verknüpfung; Angew. Chem. 1975, 87, 863-874; Angew. Chem. Int. Ed. Engl. 1975, 14, 801-811. 
[173] R. Ranganathan; Modification of the 2'-Position of Purine Nucleosides: Syntheses of 2'- $\alpha$-Subtsituted-2'-deoxyadenosine Analogs; Tetrahedron Lett. 1977, 15, 1291-1294.

[174] K. A. Scheidt, H. Chen, B. C. Follows, S. R. Chemler, D. S. Coffey, W. R. Roush; Tris(dimethylamino)sulfonium Difluorotrimethylsilicate, a Mild Reagent for the Removal of Silicon Protecting Groups; Org. Chem. 1998, 63, 64366437.

[175] E. Westman, R. Strömberg; Removal of $t$-butyldimethylsilyl protection in RNAsynthesis. Triethylamine trihydrofluoride (TEA, 3HF) is a more reliable alternative to tetrabutylammonium fluoride (TBAF); Nucleic Acids Res. 1994, 22, 2430-2431.

[176] D. Zewge, F. Gosselin, R. Sidler, L. DiMichele, R. J. Cvetovich; A Safe and Practical Procedure for Global Deprotection of Oligoribonucleotides; J. Org. Chem. 2010, 75, 5305-5307.

[177] M. C. Pirrung, S. W. Shuey, D. C. Lever, L. Fallon; Convenient Procedure for the Deprotection of Silylated Nucleosides and Nucleotides Using Triethylamine Trihydrofluoride; Bioorg. Med. Chem. Lett. 1994, 4, 1345-1346.

[178] M. Büschleb; Dissertation, Georg-August-Universität Göttingen, 2012.

[179] V. Dzubeck, J. P. Schneider; One-pot conversion of benzyl carbamates into fluorenylmethyl carbamates; Tetrahedron Lett. 2000, 41, 9953-9956.

[180] S. A. Rice, P. Doty; The Thermal Denaturation of Desoxyribose Nucleic Acid; J. Am. Chem. Soc. 1957, 79, 3937-3947.

[181] V. A. Bloomfield, D. M. Crothers, I. Tinoco, Physical Chemistry of Nucleic Acids, Harper and Row, New York 1974.

[182] J.-L. Mergny, J.-C. Maurizot; Fluorescence Resonance Energy Transfer as a Probe for G-Quartet Formation by a Telomeric Repeat; ChemBioChem 2001, 2, 124-132.

[183] P. Cahen, M. Luhmer, C. Fontaine, C. Morat, J. Reisse, K. Bartik; Study by ${ }^{23} \mathrm{Na}-\mathrm{NMR},{ }^{1} \mathrm{H}-\mathrm{NMR}$, and Ultraviolet Spectroscopy of the Thermal Stability of an 11-Basepair Oligonucleotide; Biophys. J. 2000, 78, 1059-1069.

[184] J. Kypr, I. Kejnovská, D. Renčiuk, M. Vorlíčková; Circular dichroism and conformational polymorphism of DNA; Nucleic Acids Res. 2009, 37, 17131725. 
[185] D. M. Gray, A. R. Morgan, R. L. Ratliff; A comparision of the circular dichroism spectra of synthetic DNA sequences of the homopurine homopyrimidine and mixed purine-pyrimidine types; Nucleic Acids Res. 1978, 5, 3679-3696.

[186] I. Ivanovska, A. S. Ball, R. L. Diaz, J. F. Magnus, M. Kibukawa, J. M. Schelter, S. V. Kobayashi, L. Lim, J. Burchard, A. L. Jackson, P. S. Linsley, M. A. Cleary; MicroRNAs in the miR-106b Family Regulate p21/CDKN1A and Promote Cell Cycle Progression; Mol. Cell. Biol. 2008, 28, 2167-2174.

[187] M. E. Gramlich, C. T. Wirges, A. Manetto, T. Carell; Postsynthetische DNAModifizierung mithilfe der kupferkatalysierten Azid-Alkin-Cycloaddition; Angew. Chem. 2008, 120, 8478-8487; Angew. Chem. Int. Ed. 2008, 47, 8350-8358.

[188] C. M. Castleberry, L. P. Rodicio, P. A. Limbach; Electrospray lonization Mass Spectrometry of Oligonucleotides; Curr. Protoc. Nucleic Acid Chem. 2008, 10, 10.12.11-10.12.19. 


\section{Anhang}

\subsection{HPLC-Chromatogramme}

\subsubsection{Verbindungen (6'S)-117 und (6'R)-117}

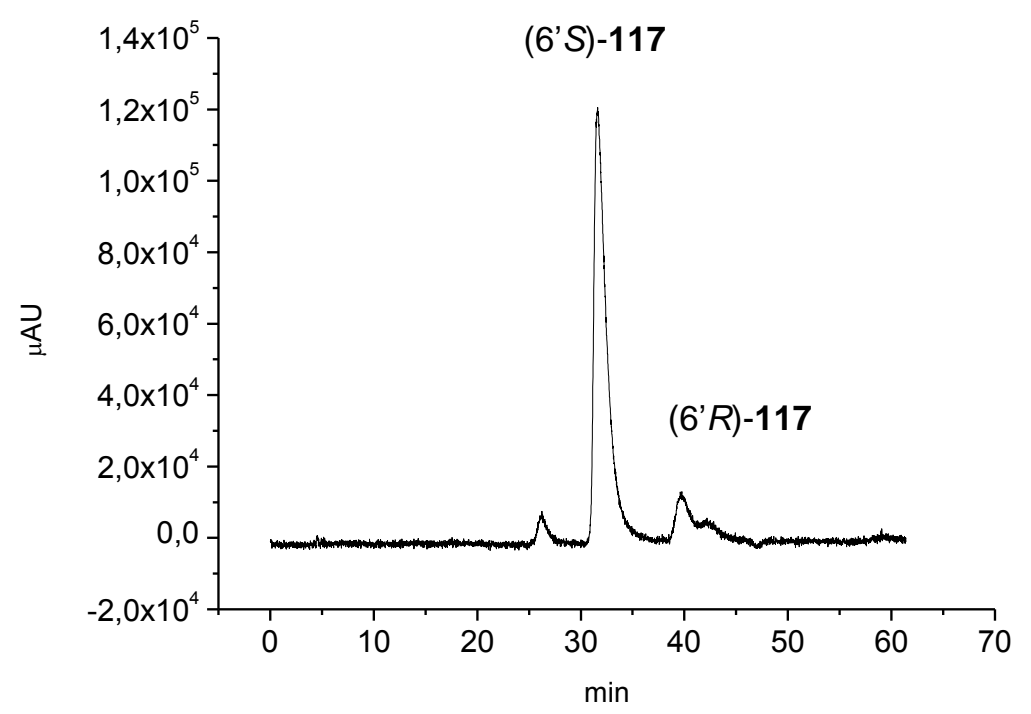

Nach der Synthese erhaltenenes (6'S)-117

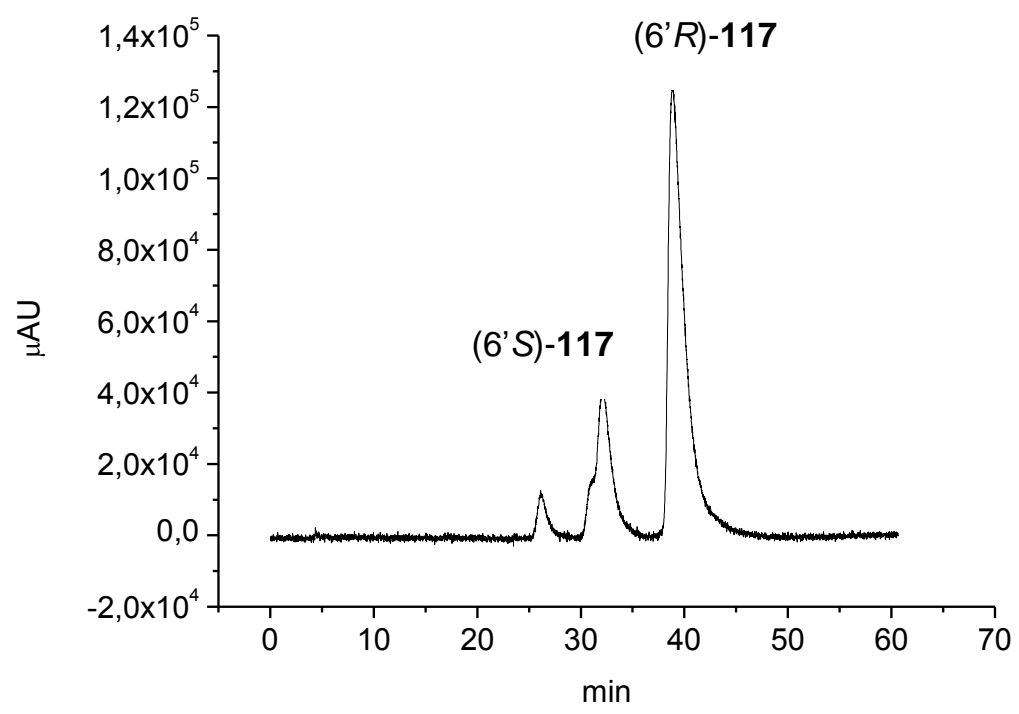

Nach der Synthese erhaltenes $\left(6^{\prime} R\right)-117$ 


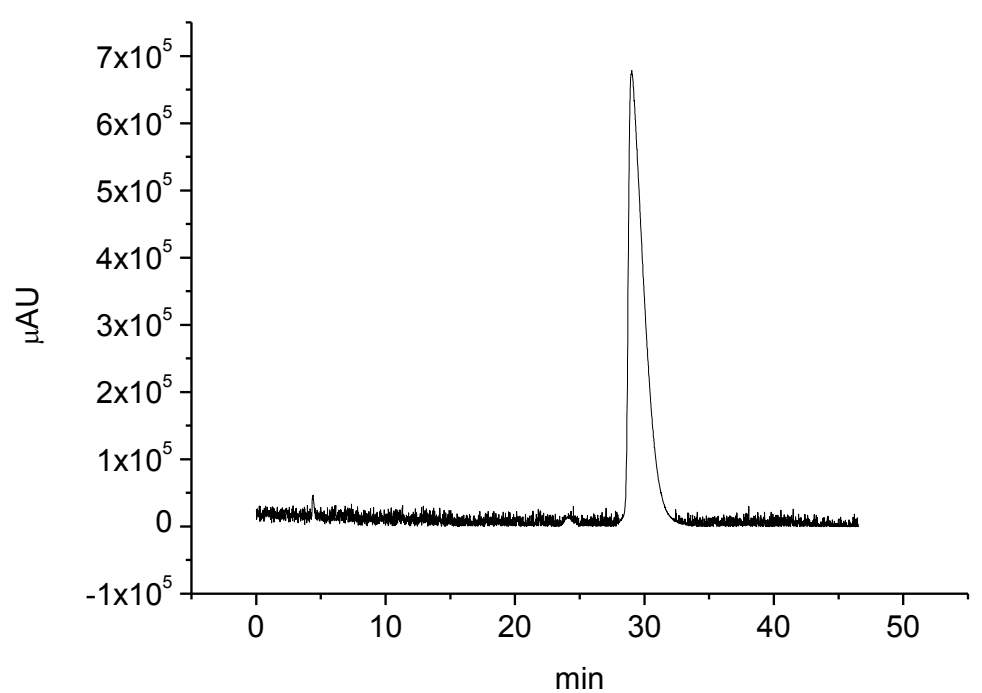

Nach HPLC-Reinigung erhaltenes (6'S)-117

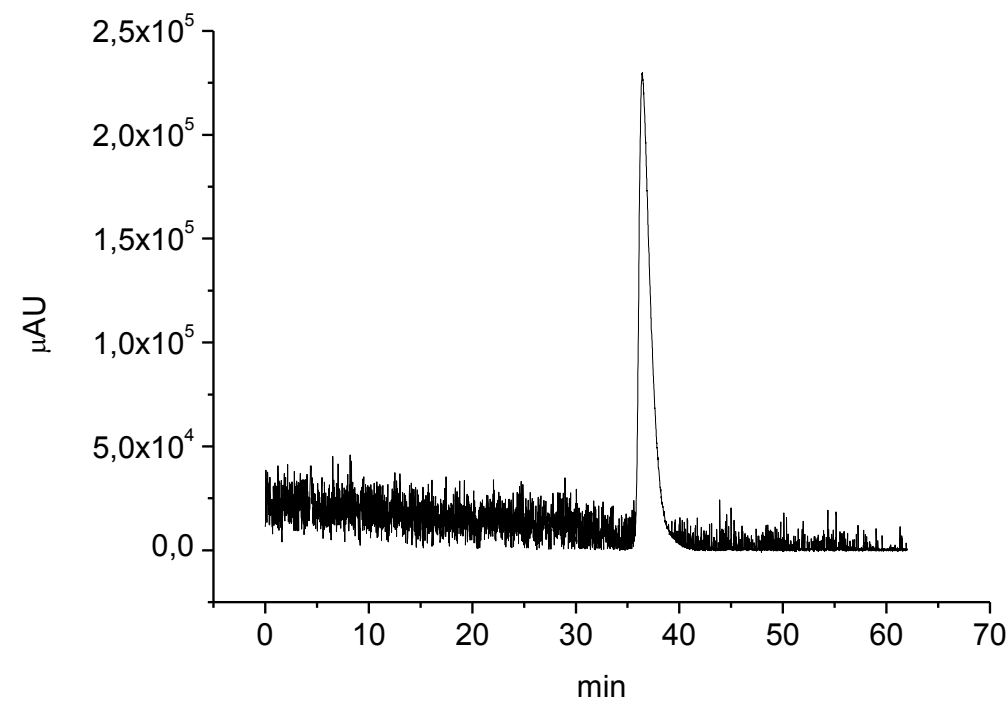

Nach HPLC-Reinigung erhaltenes (6' $R)$-117 


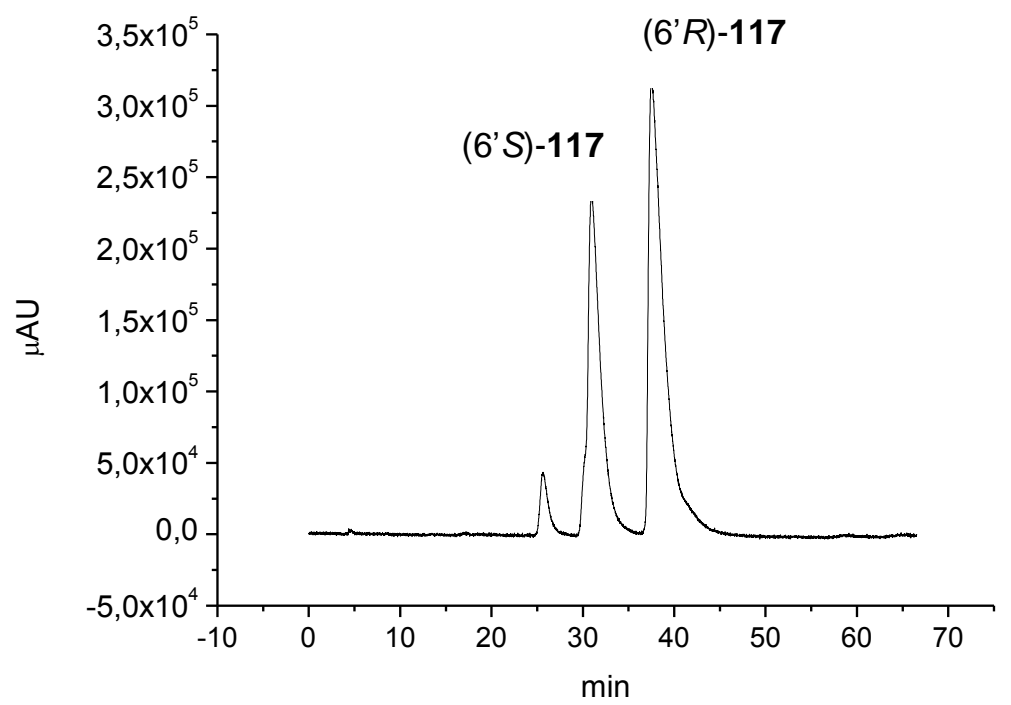

Koinjektion der Diastereomere (6'R)-117 und (6'S)-117

\subsubsection{Oligonucleotide}

\subsubsection{Chromatogramme der gereinigten NAA-modifizierten Oligonucleotide}

Die jeweilige Konfiguration der NAA-Modifikation ist in Klammern angegeben.

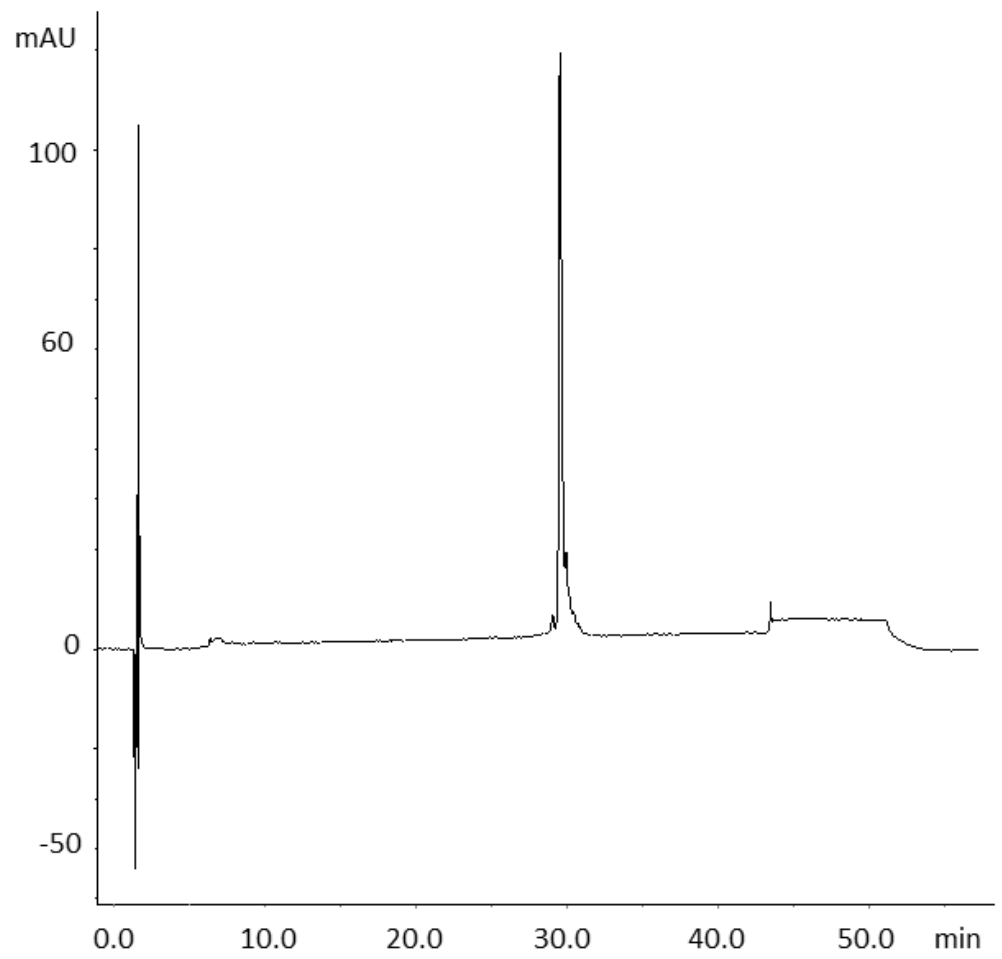

Oligonucleotid 1 (S): 5'-GGCACGG TxT TT TT TxT GGCACGG-3' 


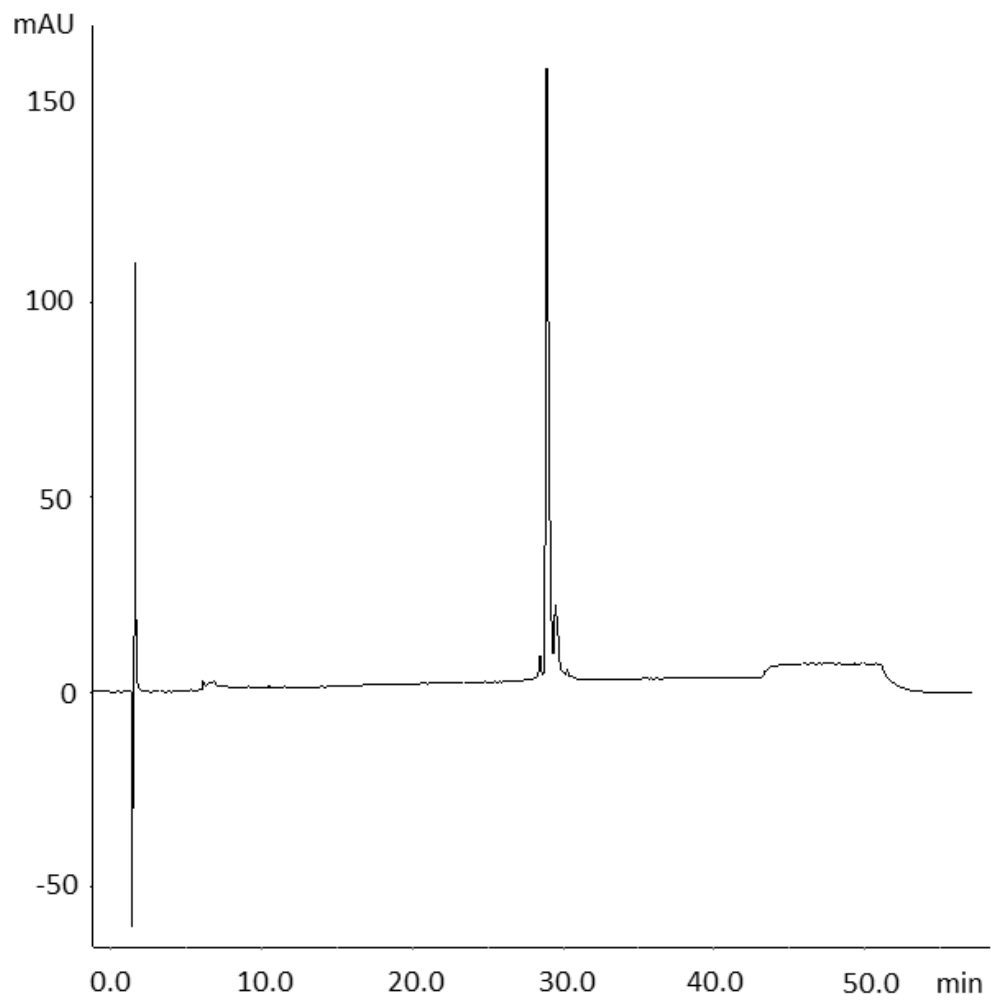

Oligonucleotid 2 (R): 5'-GGCACGG TxT TT TT TxT GGCACGG-3'

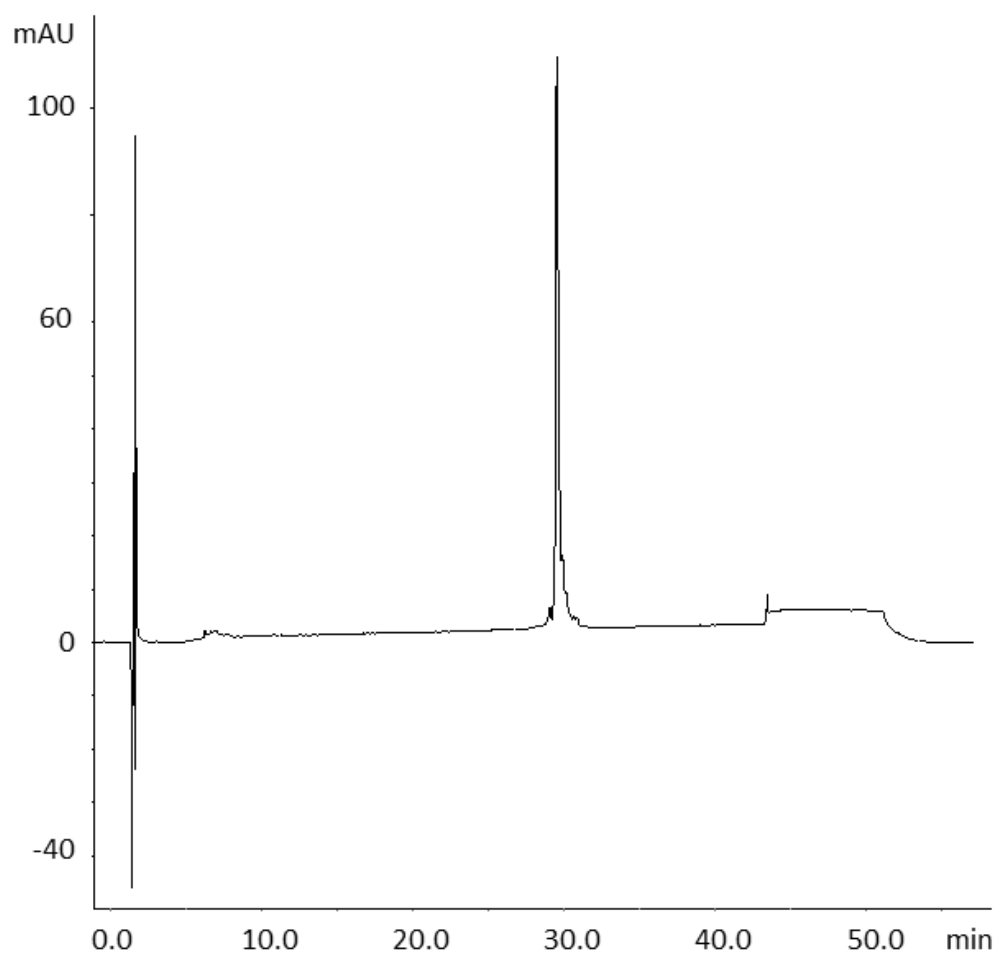

Oligonucleotid $3(S)$ : 5'-GGCACGG TxT TT TxT TT GGCACGG-3' 


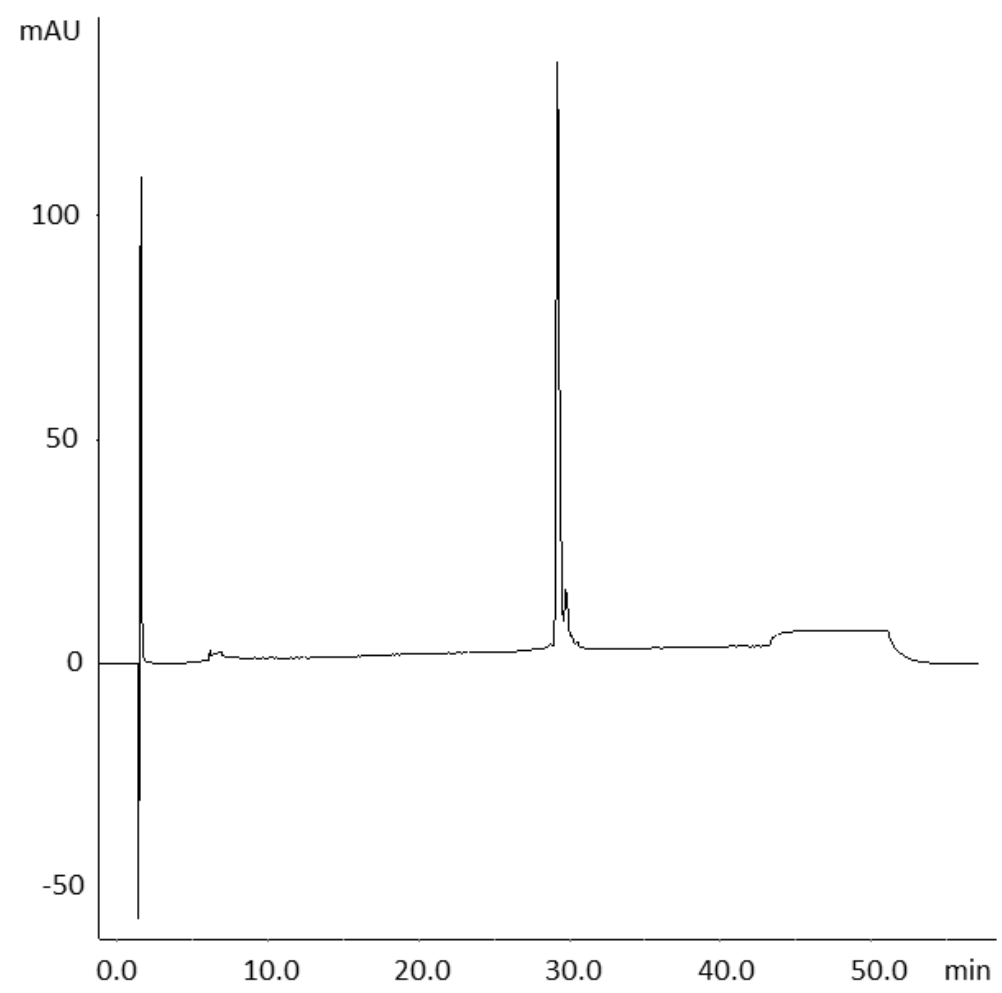

Oligonucleotid $4(R)$ : 5'-GGCACGG TxT TT TxT TT GGCACGG-3

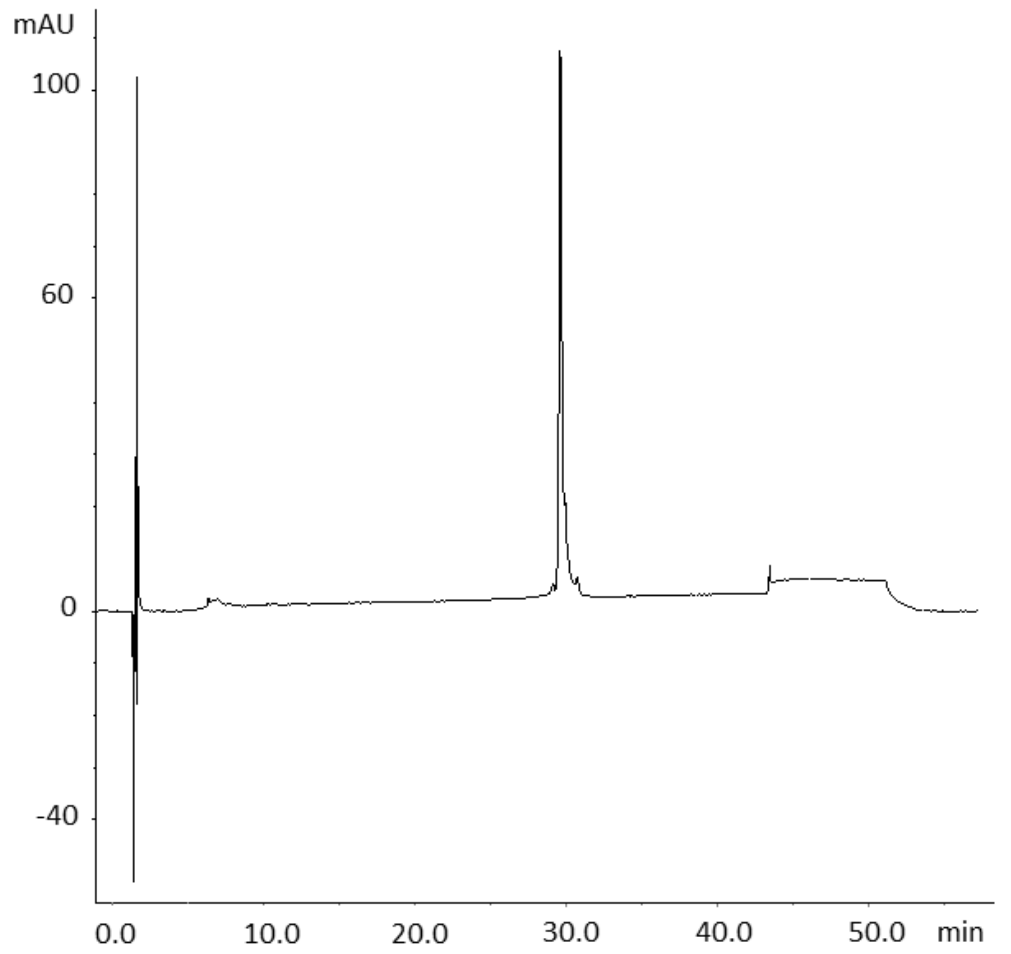

Oligonucleotid 5 (S): 5'-GGCACGG TxT TxT TT TT GGCACGG-3' 


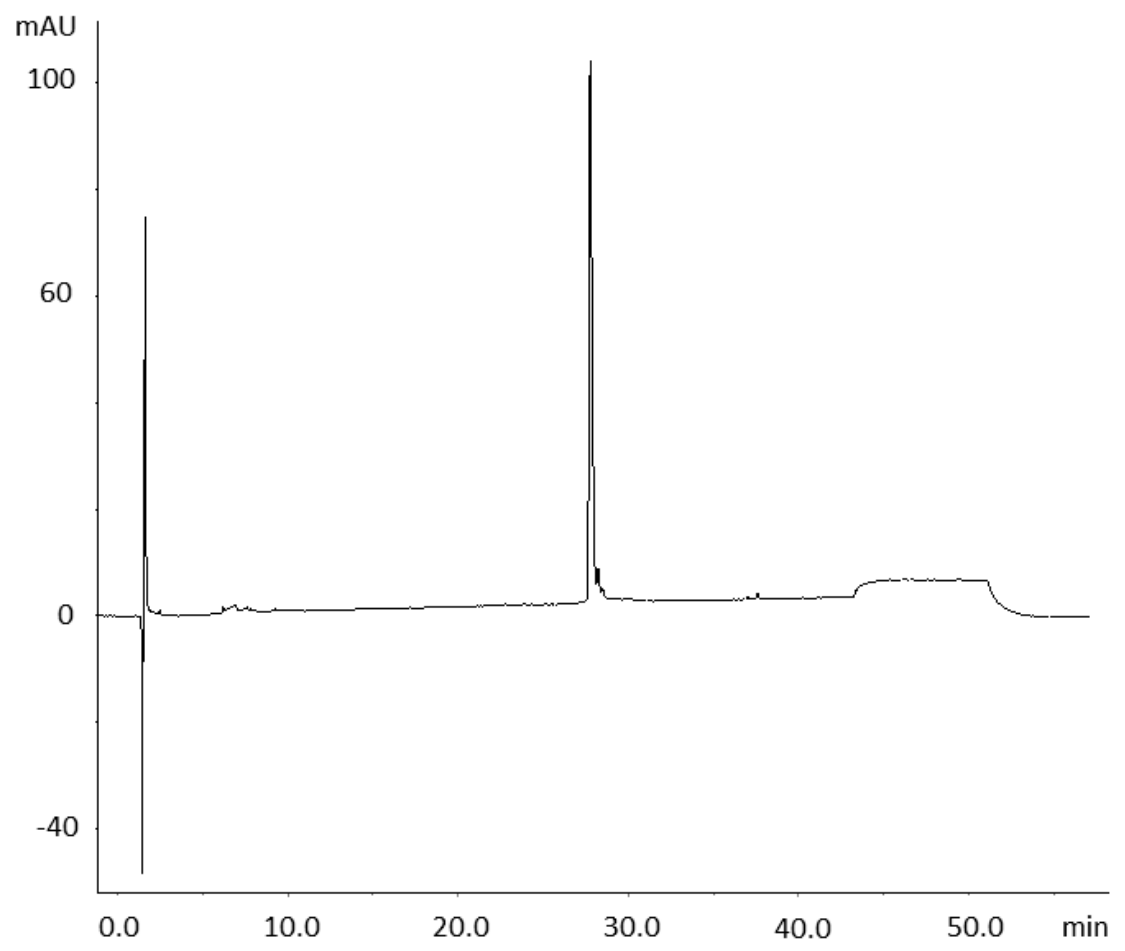

Oligonucleotid $6(R)$ : 5'-GGCACGG TxT TxT TT TT GGCACGG-3'

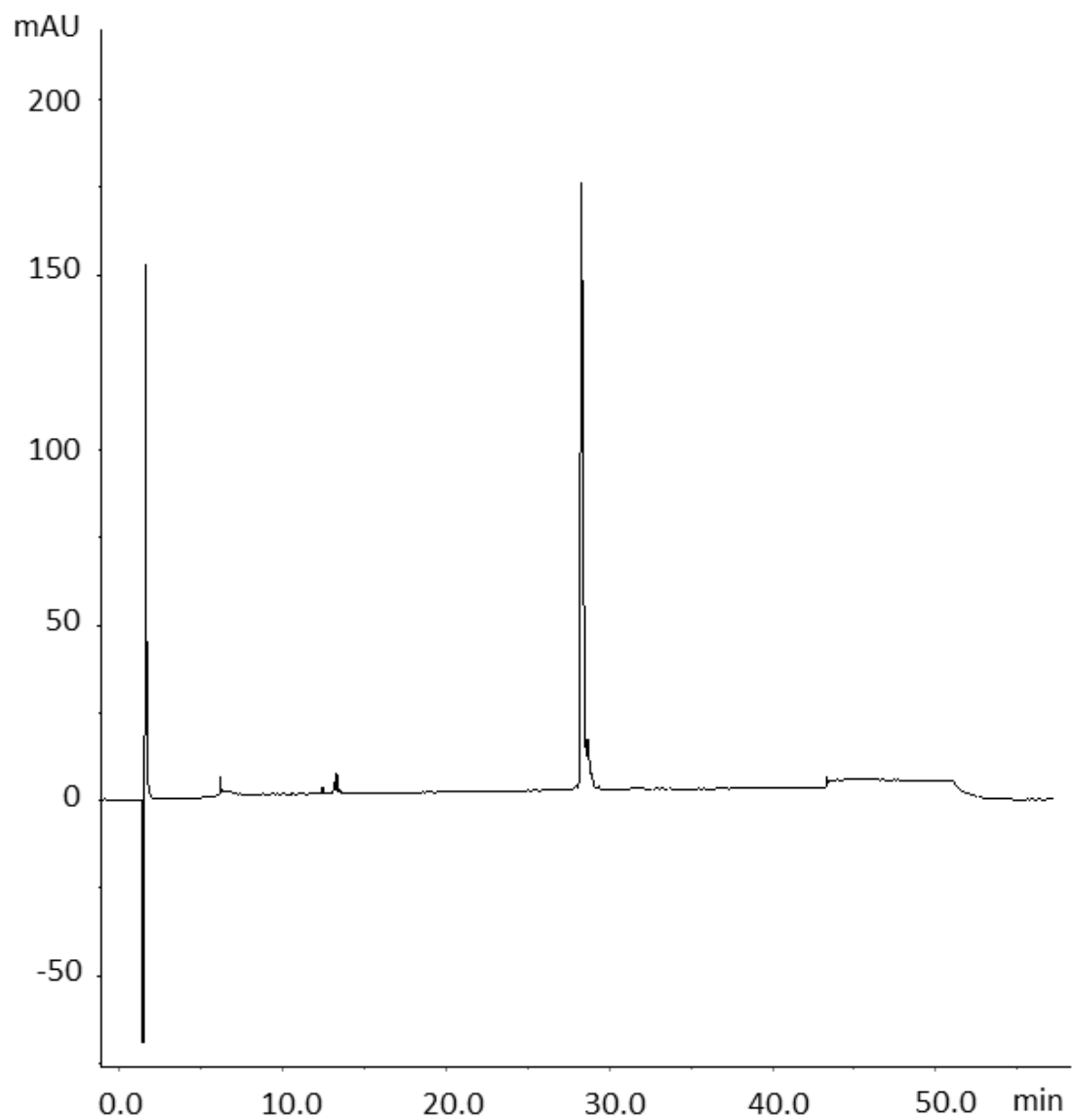

Oligonucleotid 7 (S): 5'-GGCACGG TxT TT TT TT GGCACGG-3' 


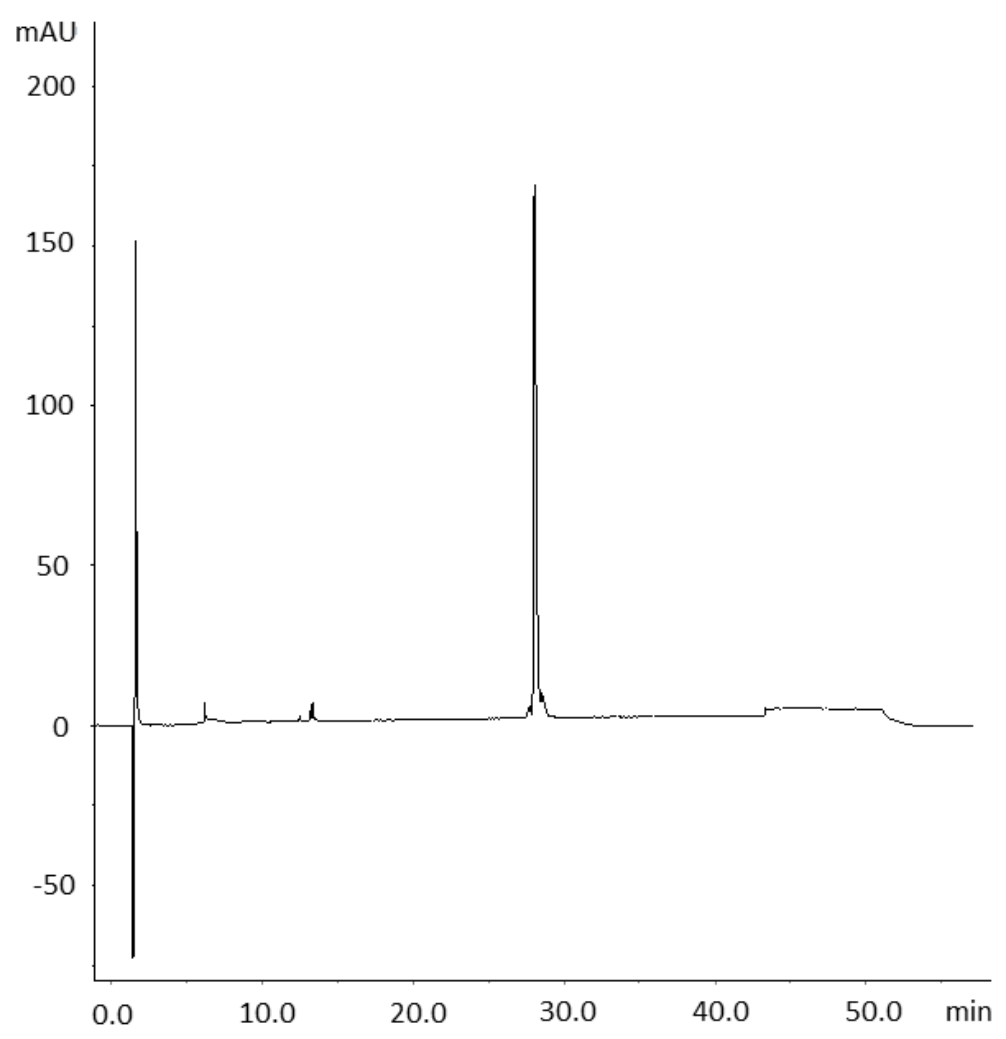

Oligonucleotid $8(R)$ : 5'-GGCACGG TxT TT TT TT GGCACGG-3'

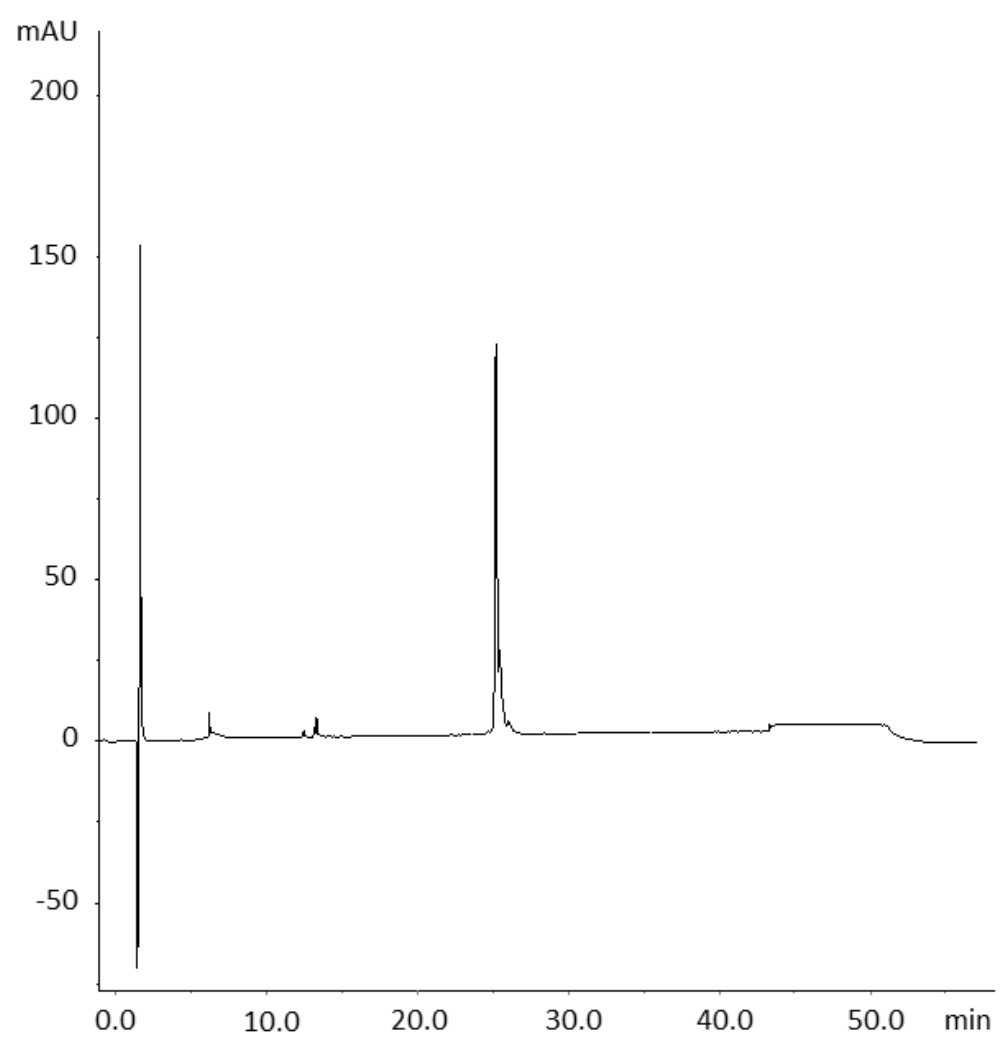

Oligonucleotid 9 (S): 5'-GGCACGG TxT TxT TxT TxT GGCACGG-3' 


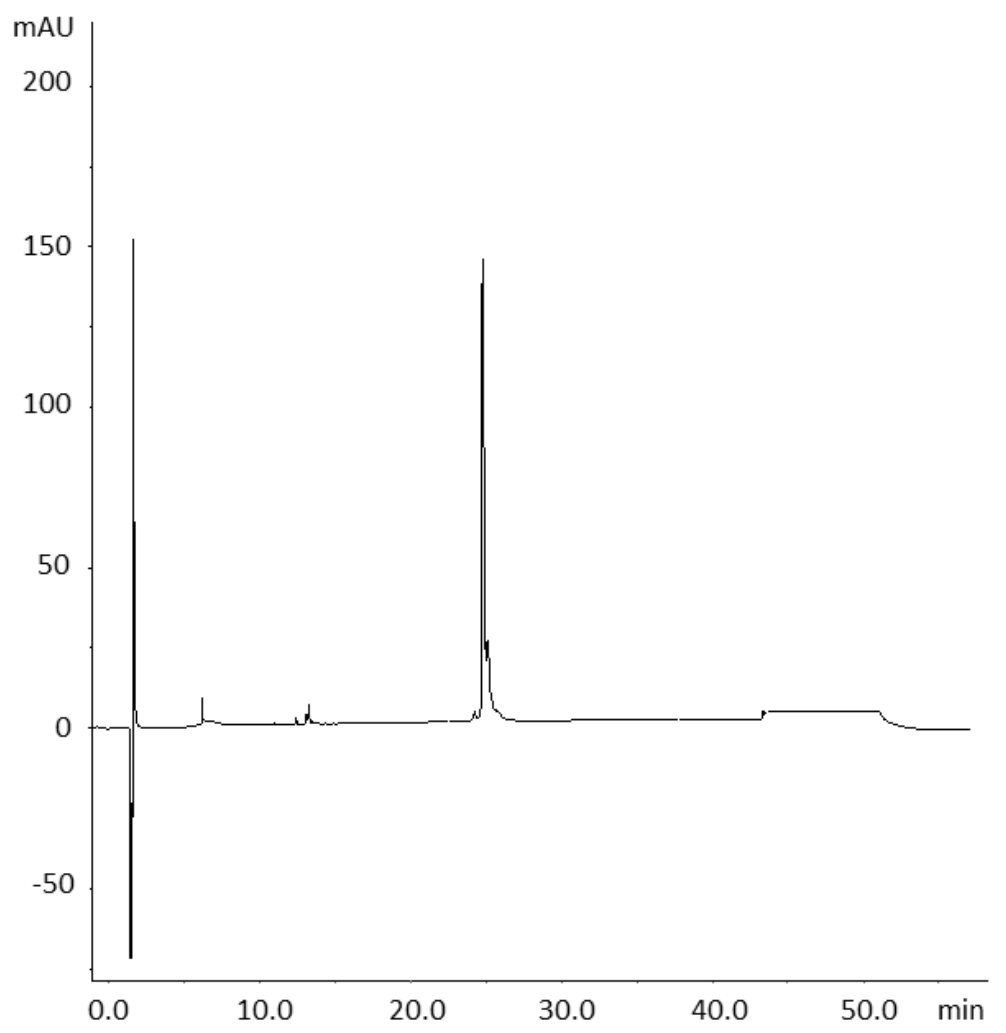

Oligonucleotid $10(R)$ : 5'-GGCACGG TxT TxT TxT TxT GGCACGG-3'

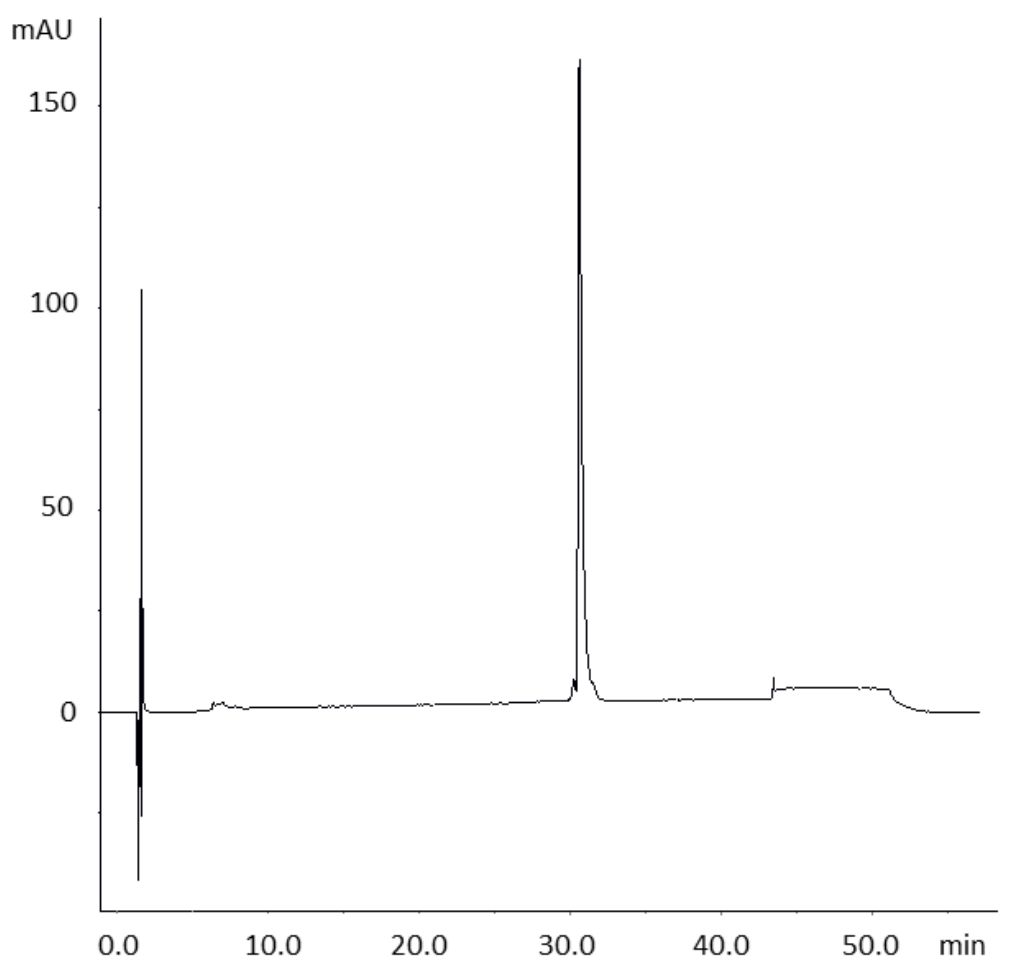

Oligonucleotid 11 (S): 5'-G TxT GACG TT GACG TT GACG TT G-3' 


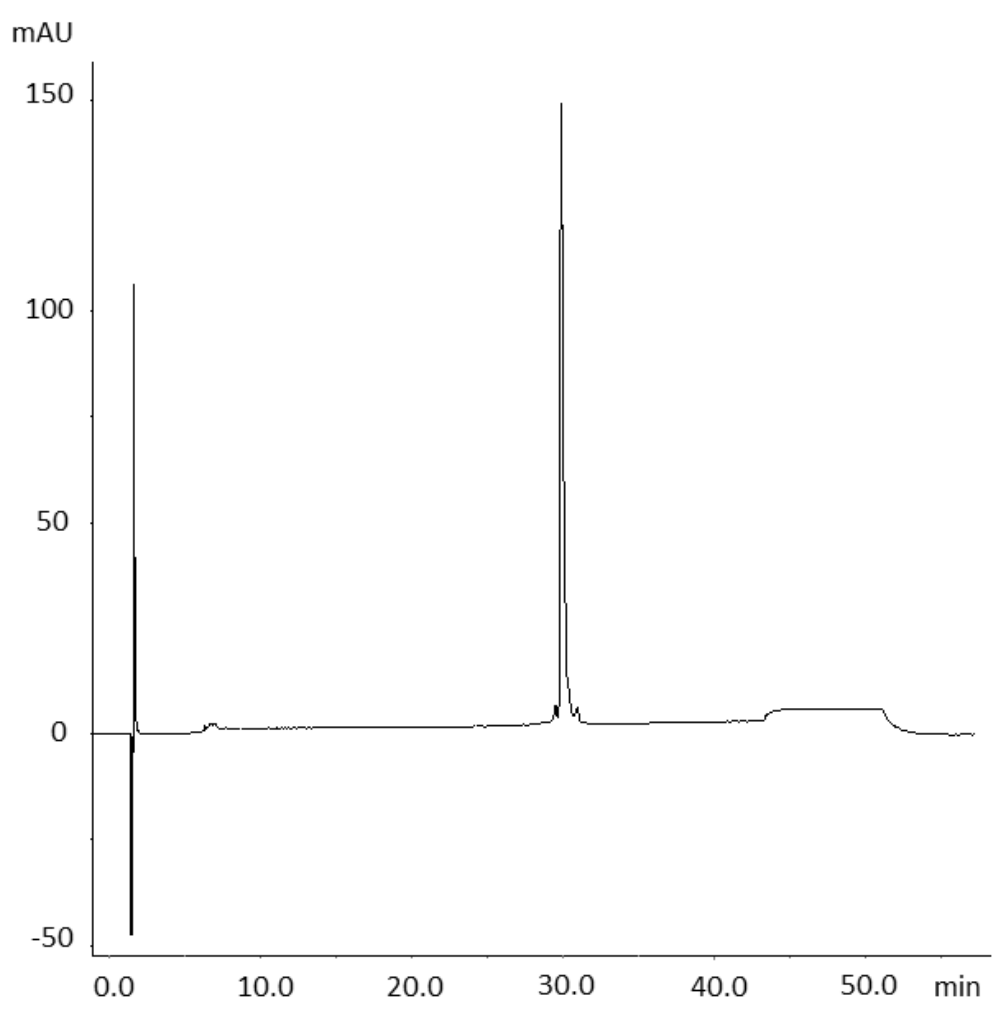

Oligonucleotid $12(R)$ : 5'-G TxT GACG TT GACG TT GACG TT G-3'

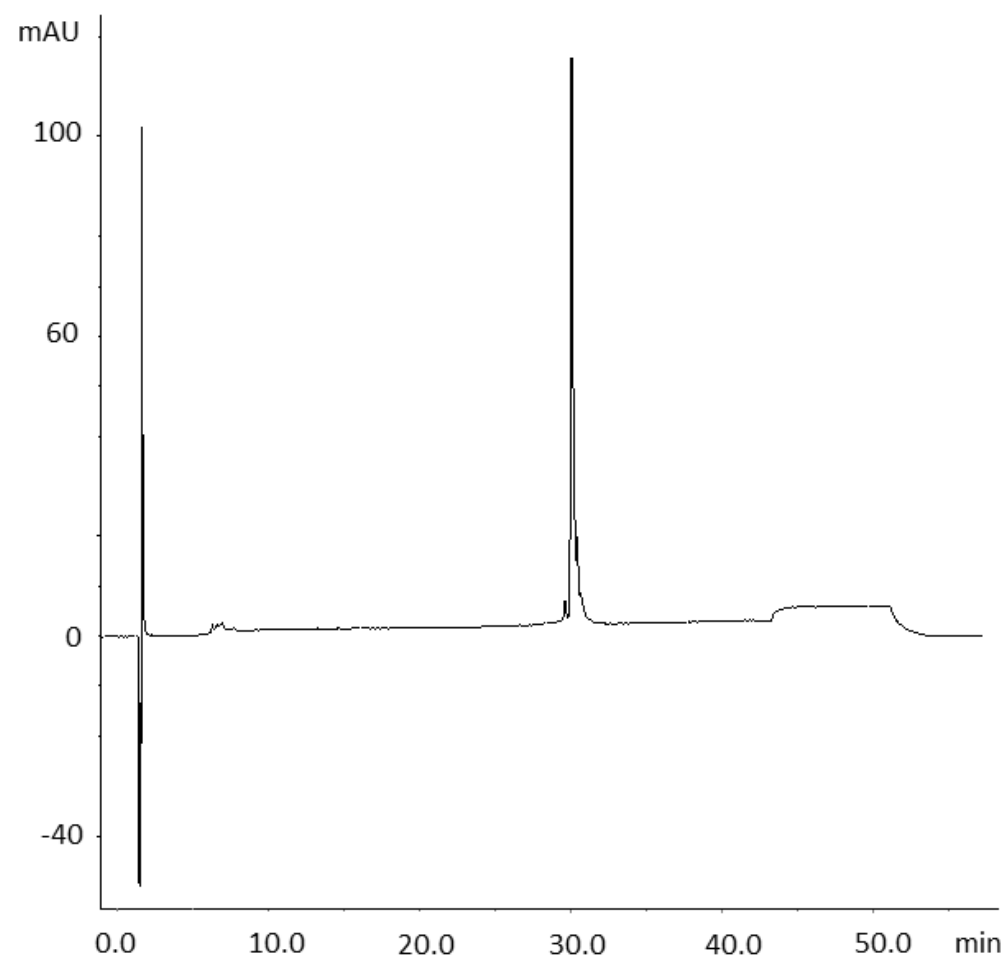

Oligonucleotid 13 (S): 5'-G TT GACG TxT GACG TT GACG TT G-3' 


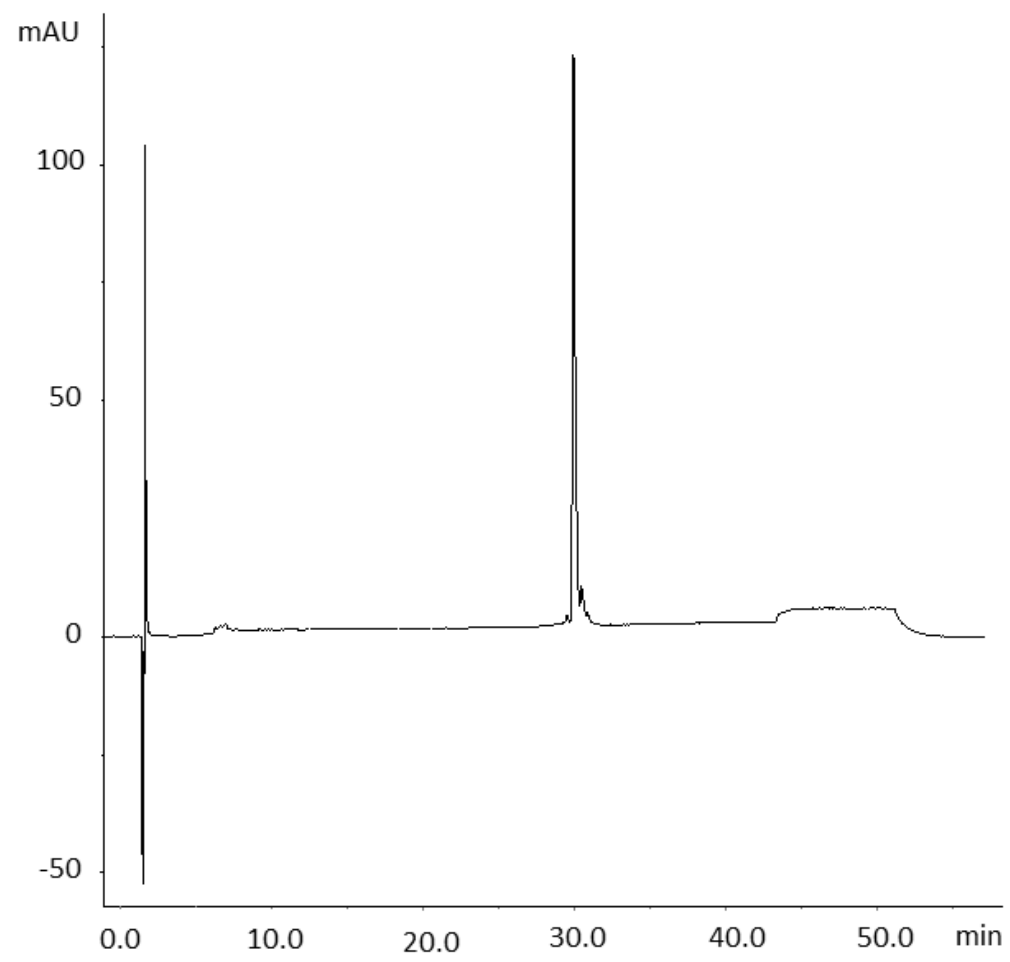

Oligonucleotid 14 (R): 5'-G TT GACG TxT GACG TT GACG TT G-3'

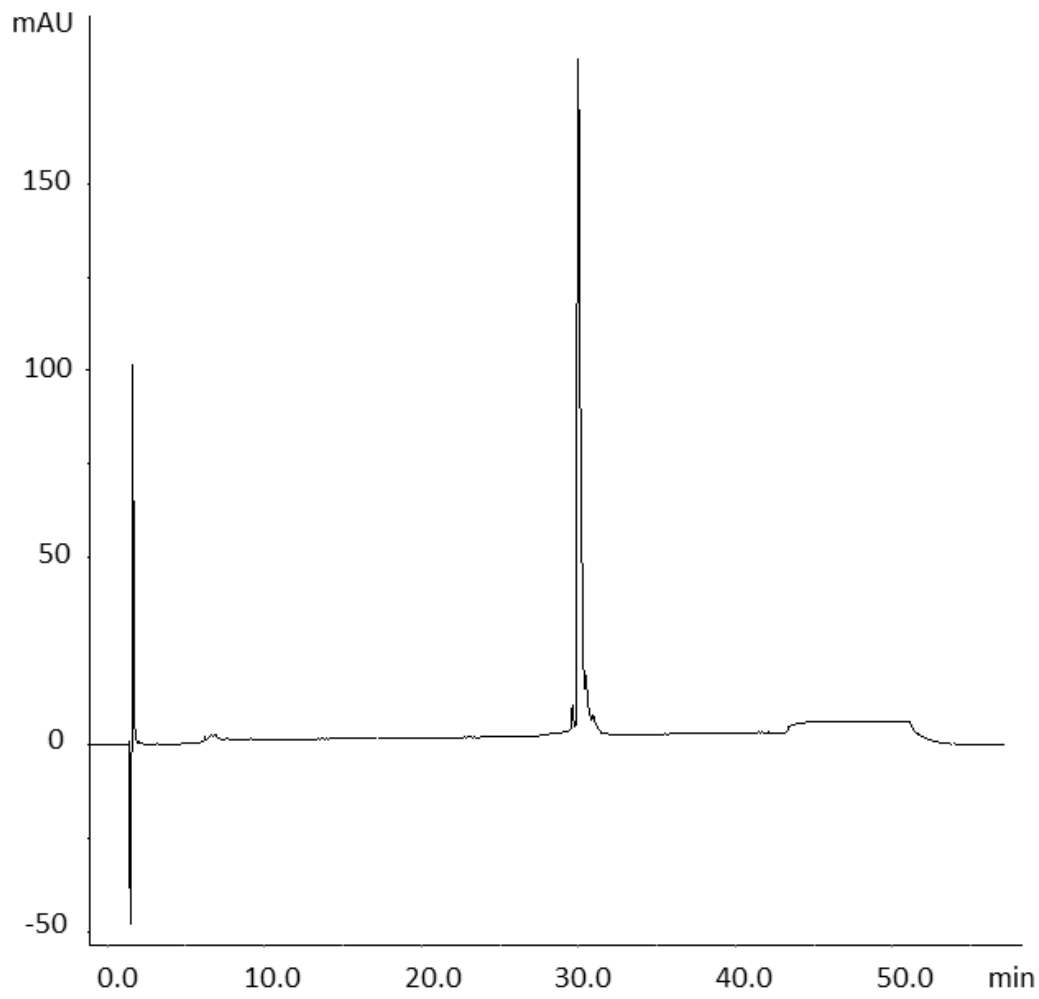

Oligonucleotid 15 (S): 5'-G TT GACG TT GACG TxT GACG TT G-3' 


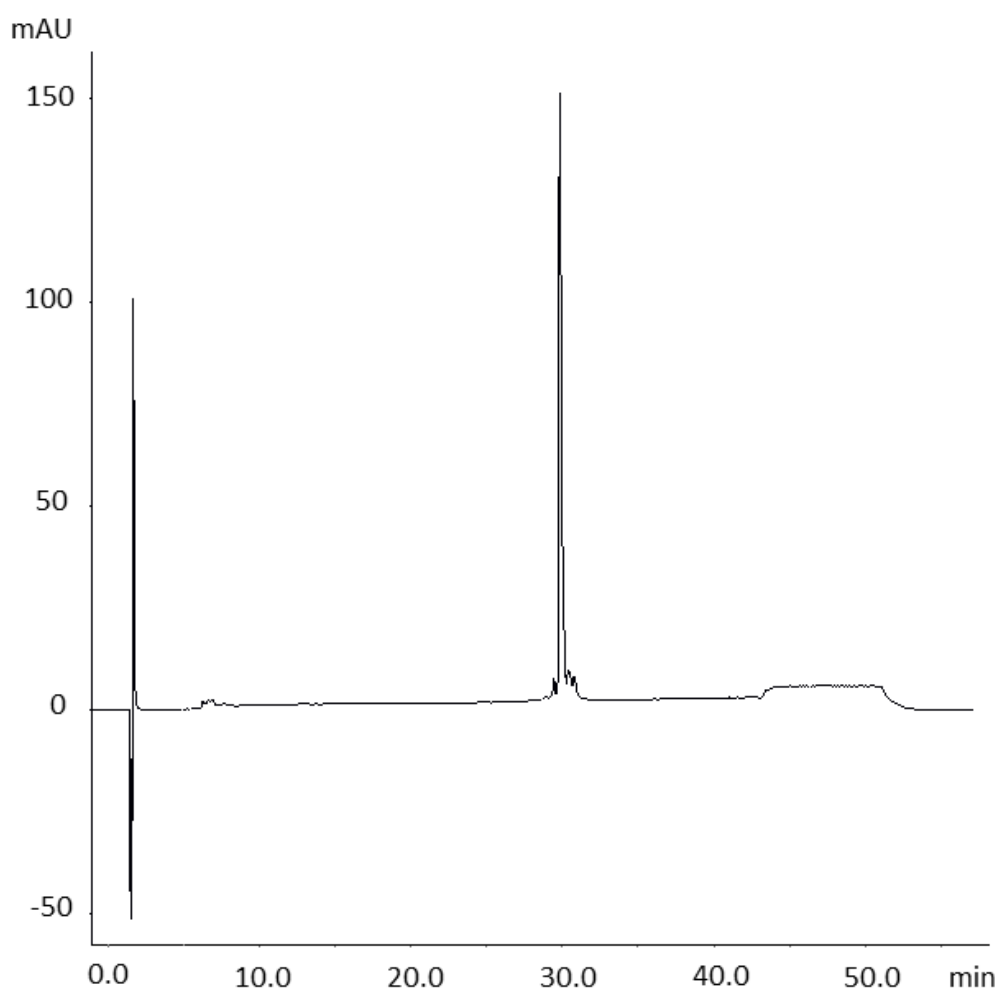

Oligonucleotid $16(R)$ : 5'-G TT GACG TT GACG TxT GACG TT G-3'

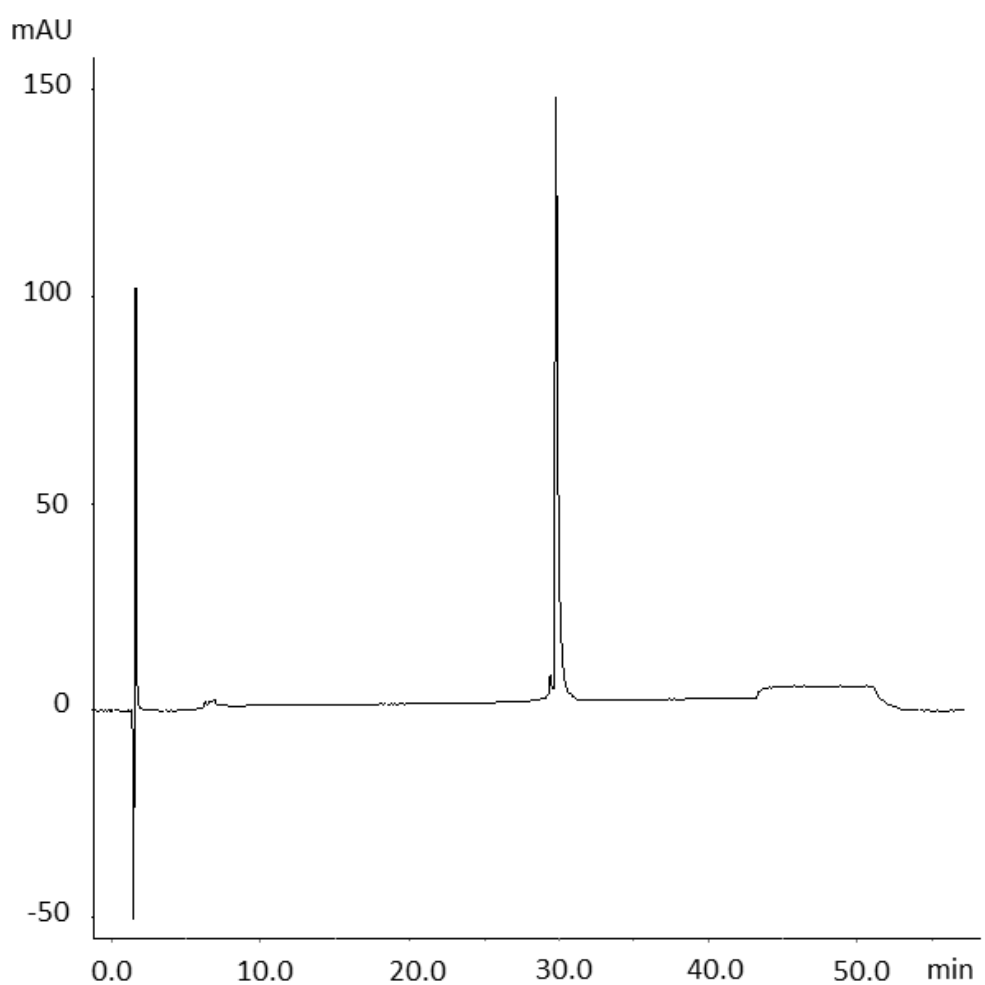

Oligonucleotid 17 (S): 5'-G TT GACG TT GACG TT GACG TxT G-3' 


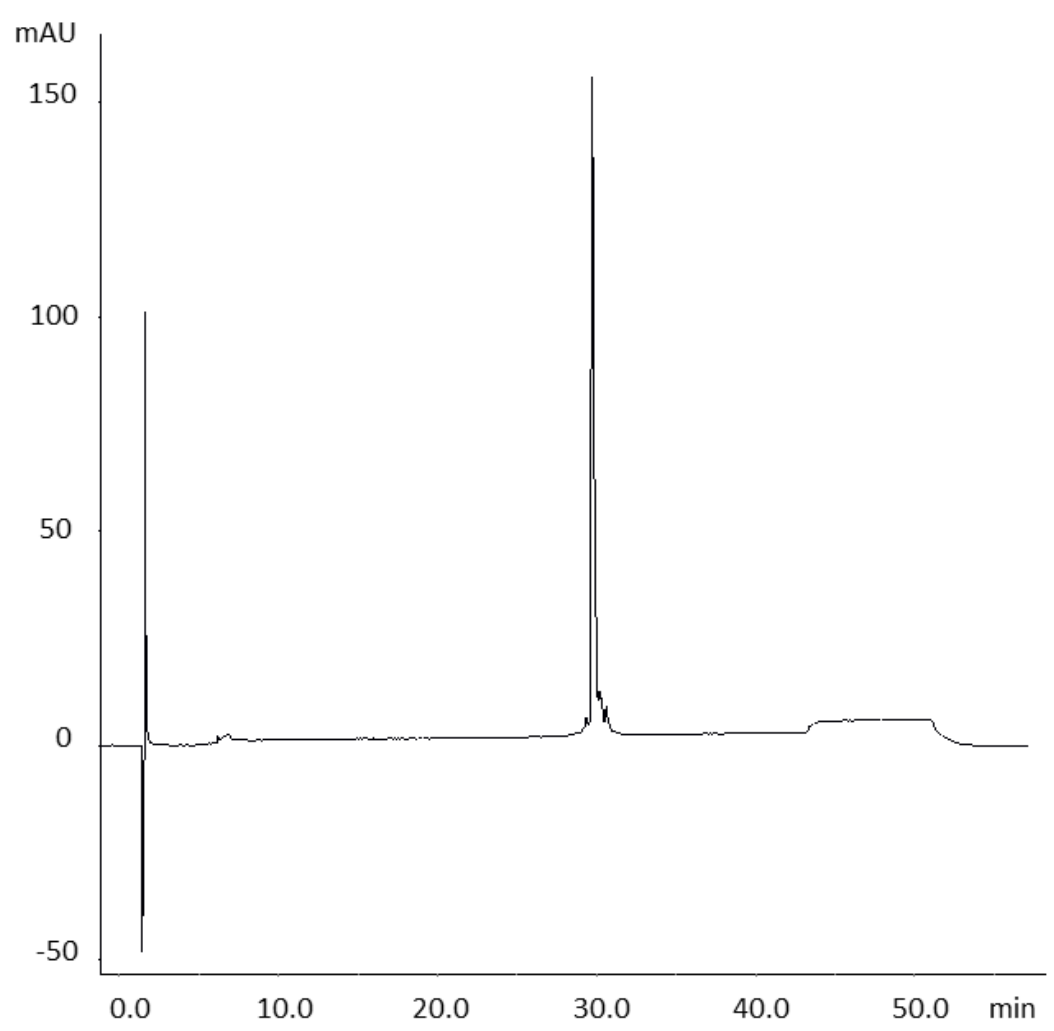

Oligonucleotid 18 (R): 5'-G TT GACG TT GACG TT GACG TxT G-3'

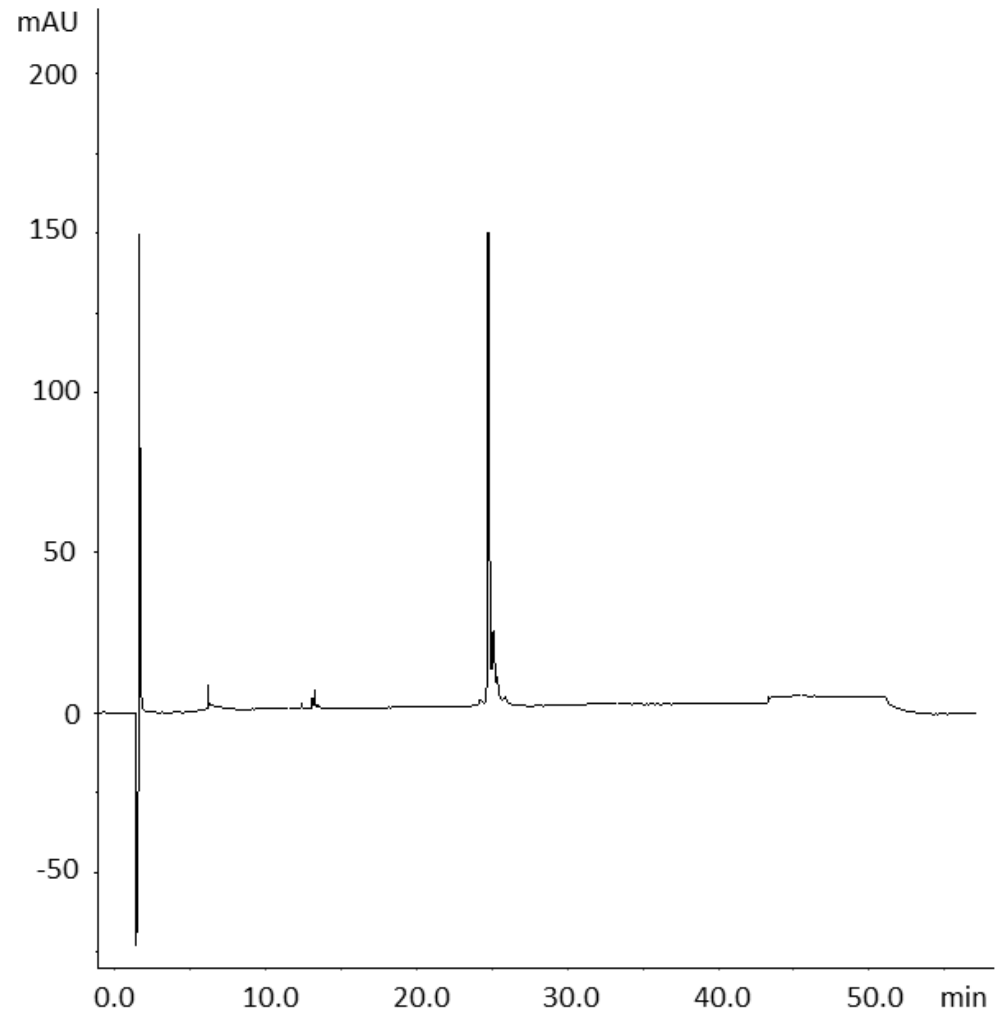

Oligonucleotid 19 (S): 5'-G TxT GACG TxT GACG TxT GACG TxT G-3' 


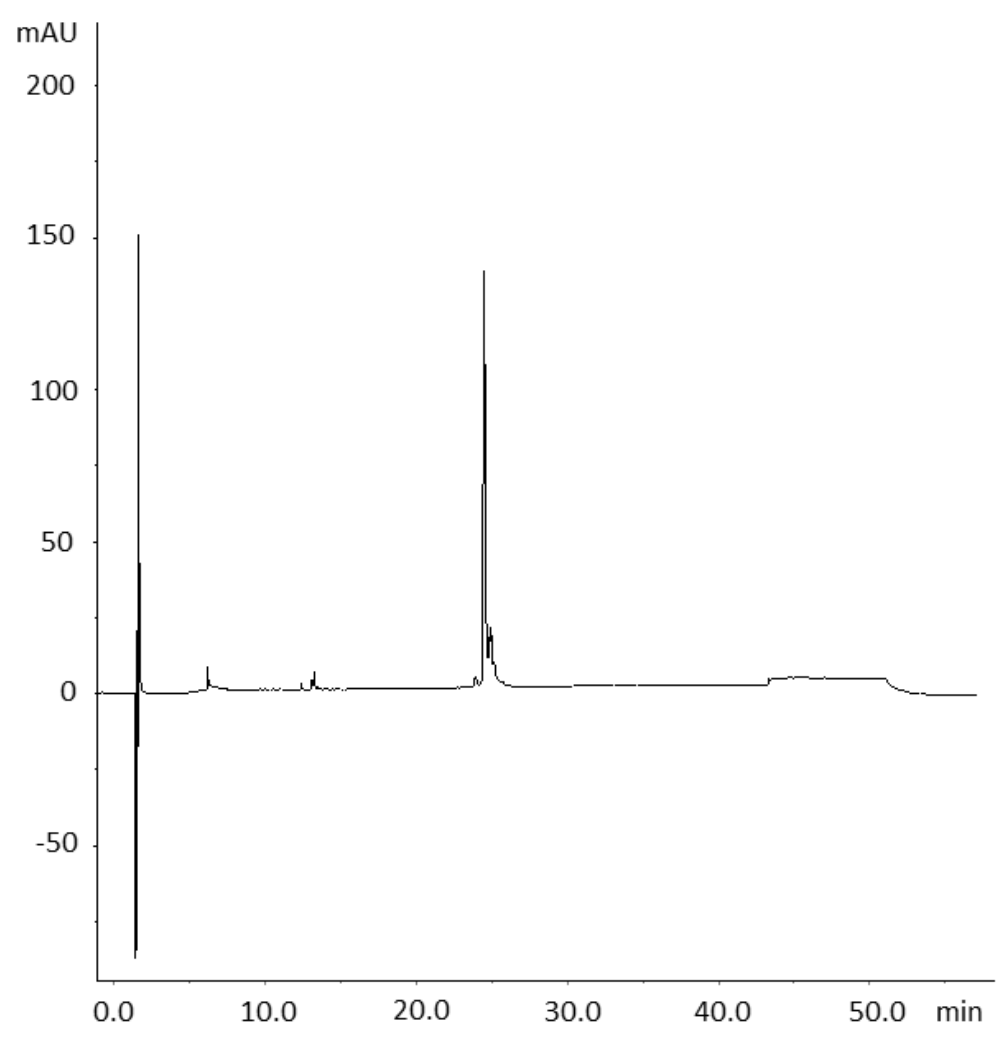

Oligonucleotid $20(R)$ : 5'-G TxT GACG TxT GACG TxT GACG TxT G-3'

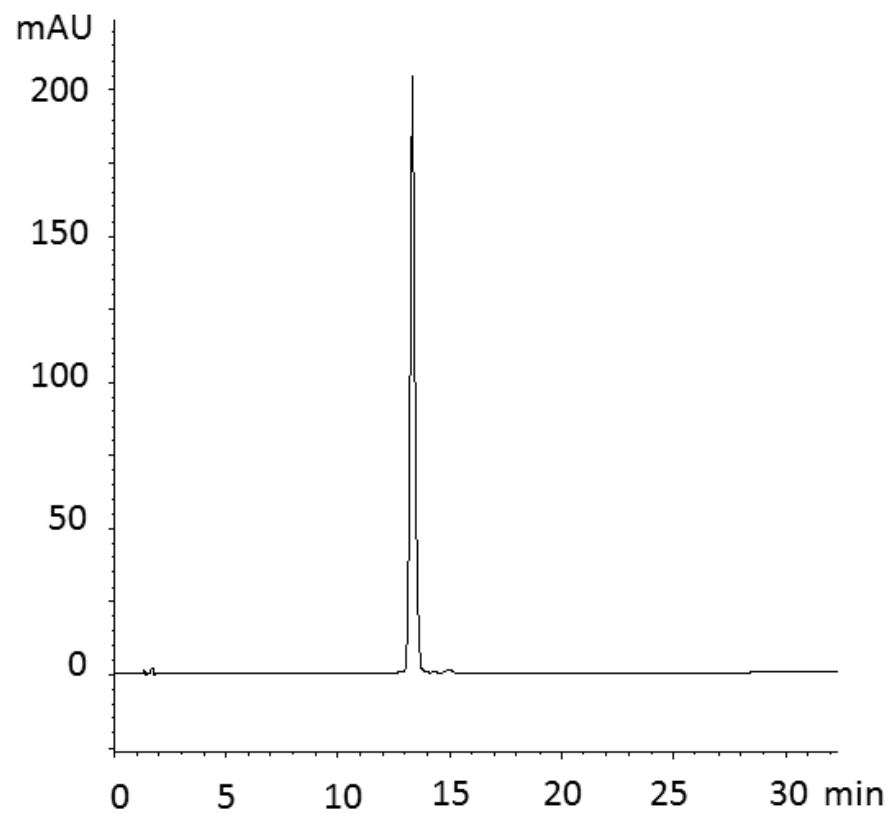

Oligonucleotid 21 (S): 5'-GCGC TxT GC TT AAGCAAGCGC-3' 


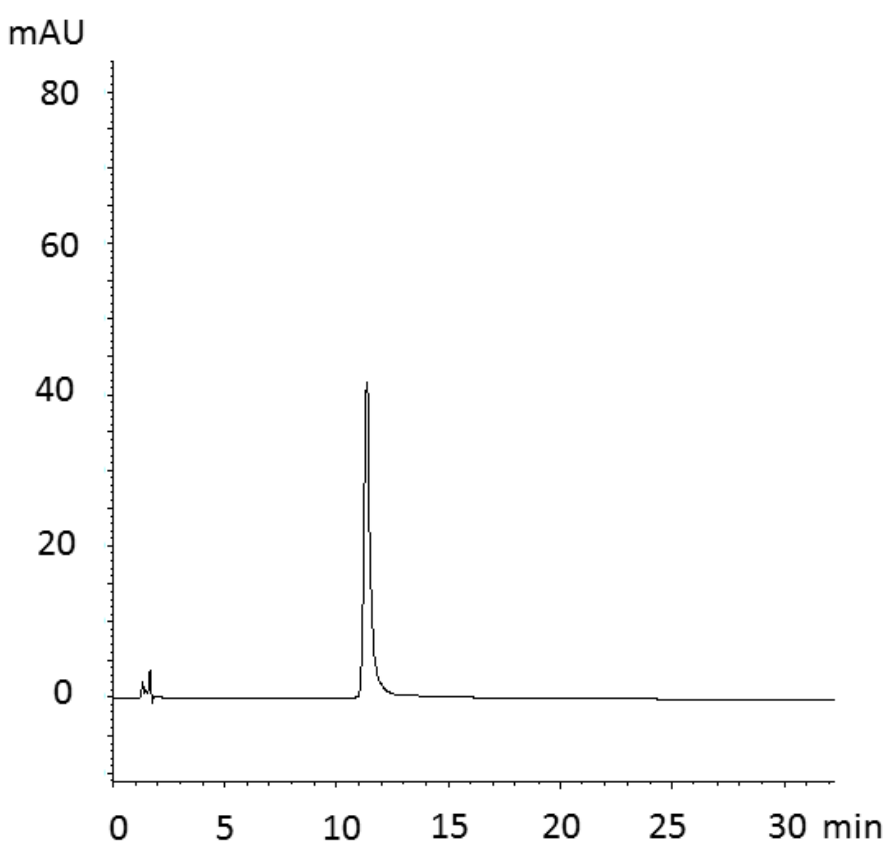

Oligonucleotid $22(R)$ : 5'-GCGC TxT GC TT AAGCAAGCGC-3'

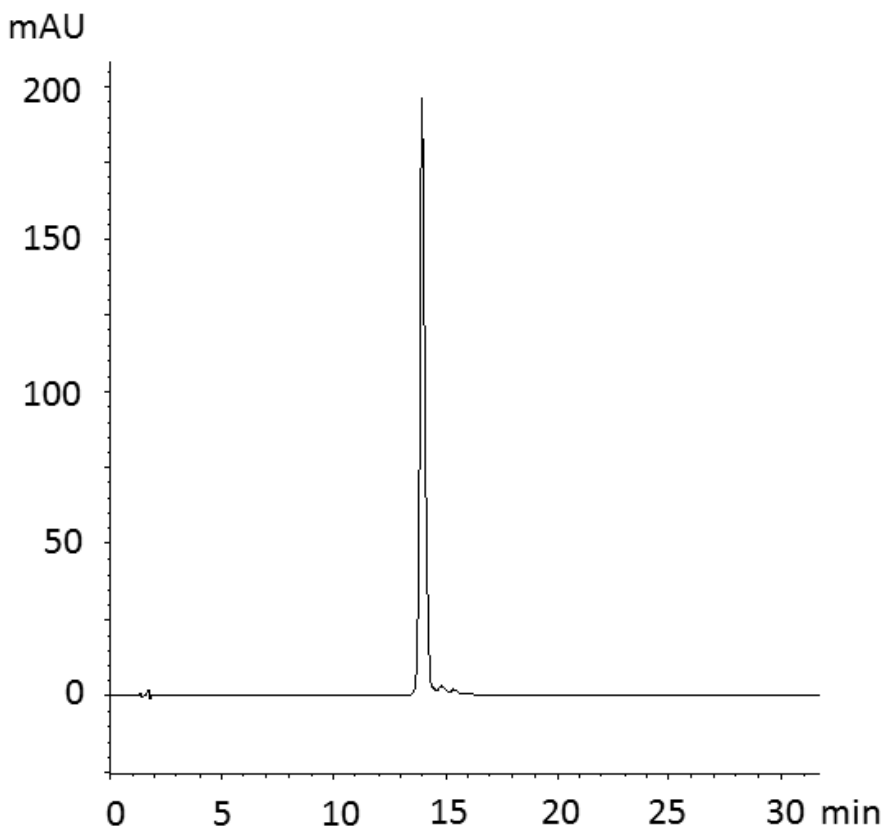

Oligonucleotid 23 (S): 5'-GCGC TT GC TxT AAGCAAGCGC-3' 


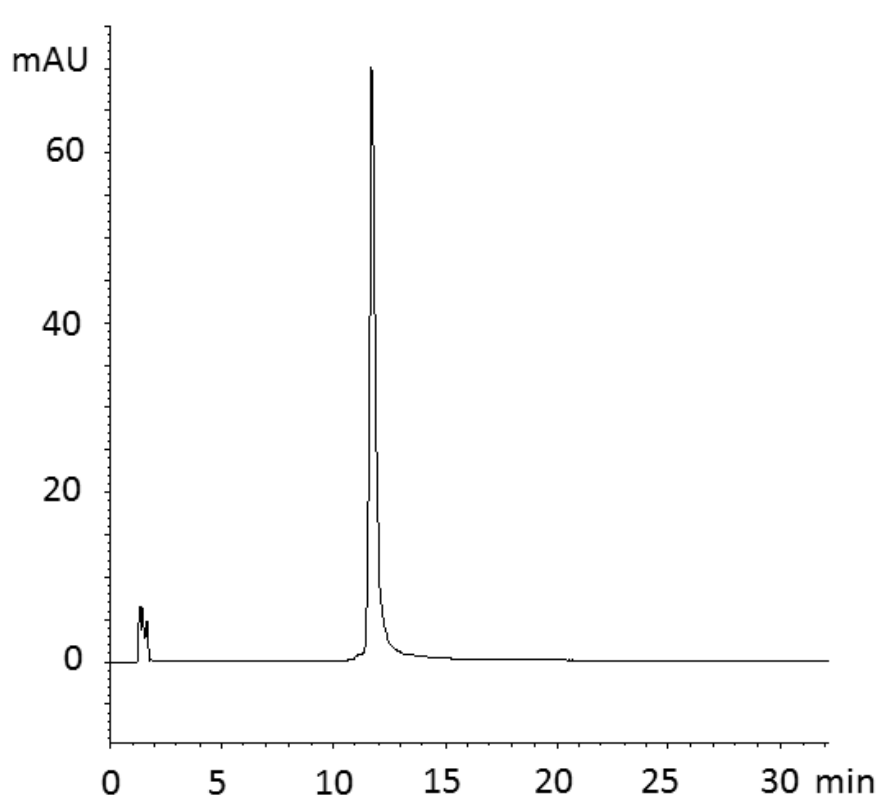

Oligonucleotid $24(R)$ : 5'-GCGC TT GC TxT AAGCAAGCGC-3'

9.1.2.2 Chromatogramme der gereinigten unmodifizierten Oligonucleotide

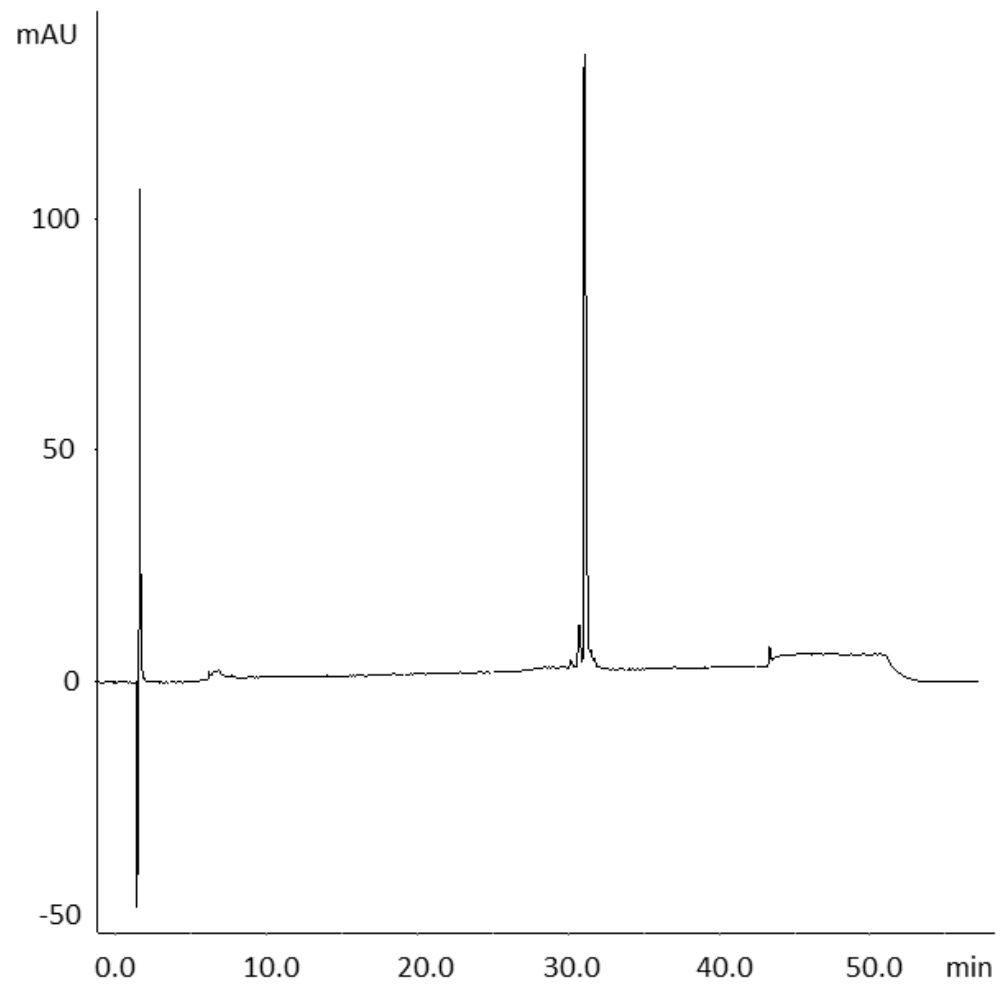

Oligonucleotid 1u: 5'-GGCACGG TT TT TT TT GGCACGG-3' 


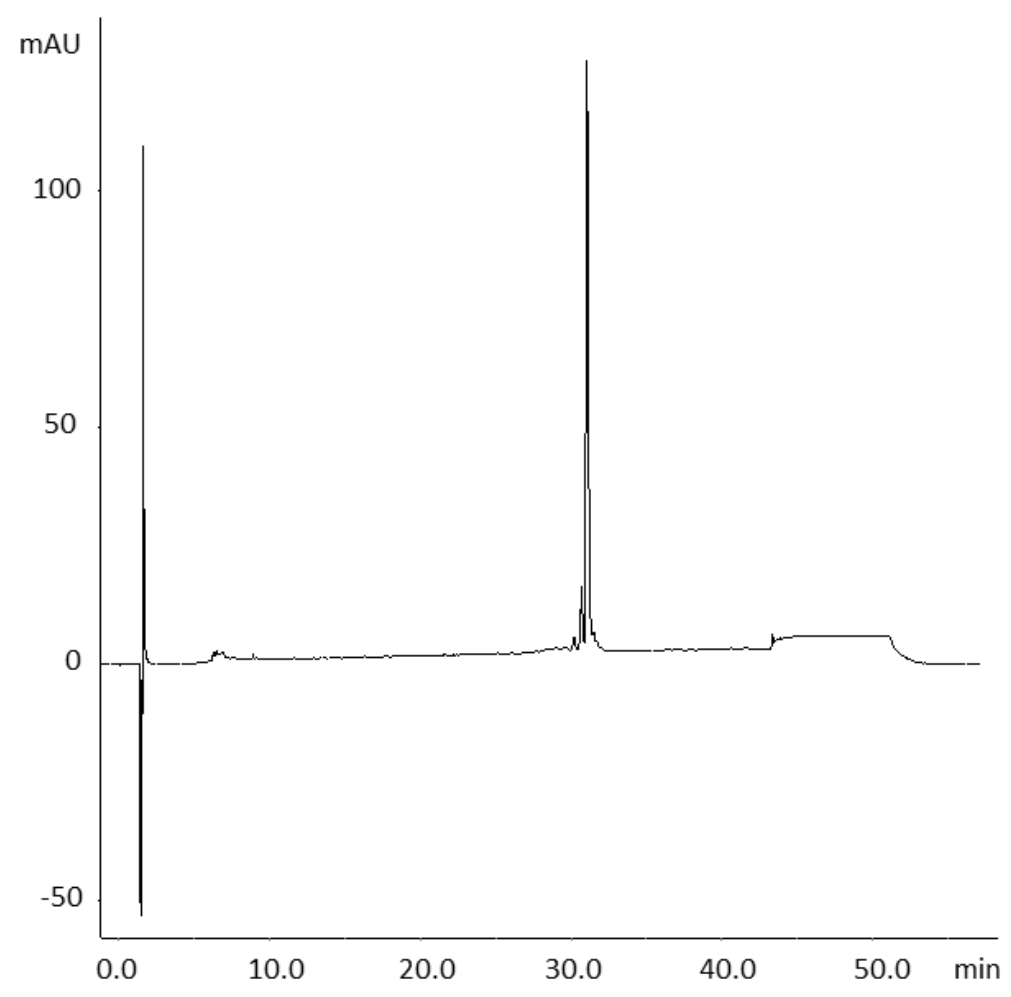

Oligonucleotid 2u: 5'-G TT GACG TT GACG TT GACG TT G-3'

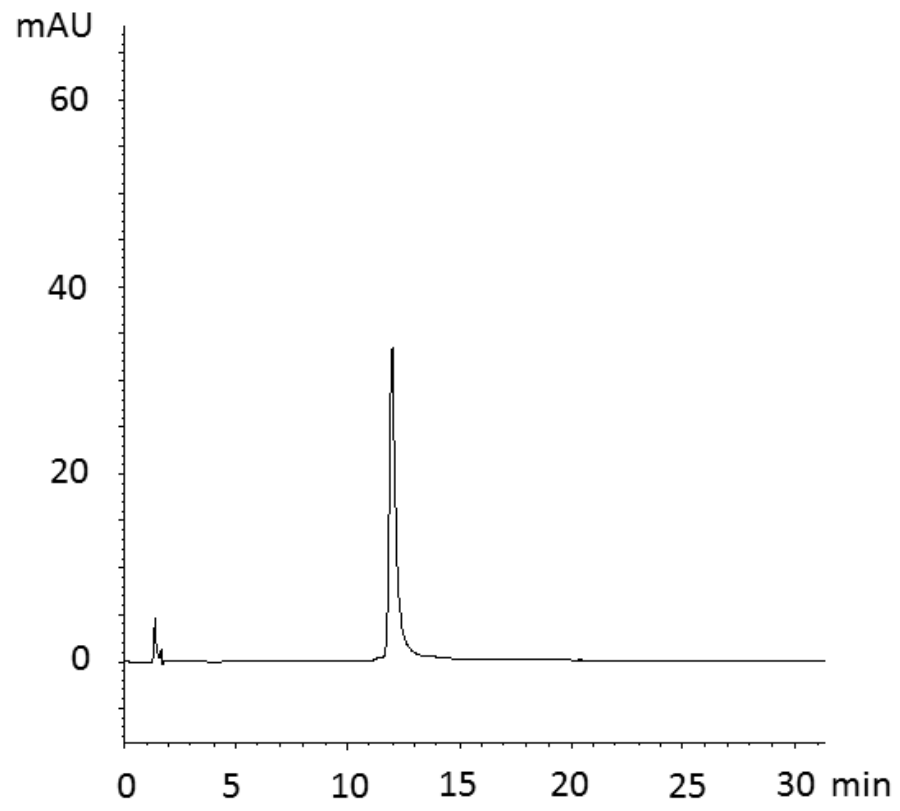

Oligonucleotid 3u: 5'-GCGC TT GC TT AAGCAAGCGC-3' 


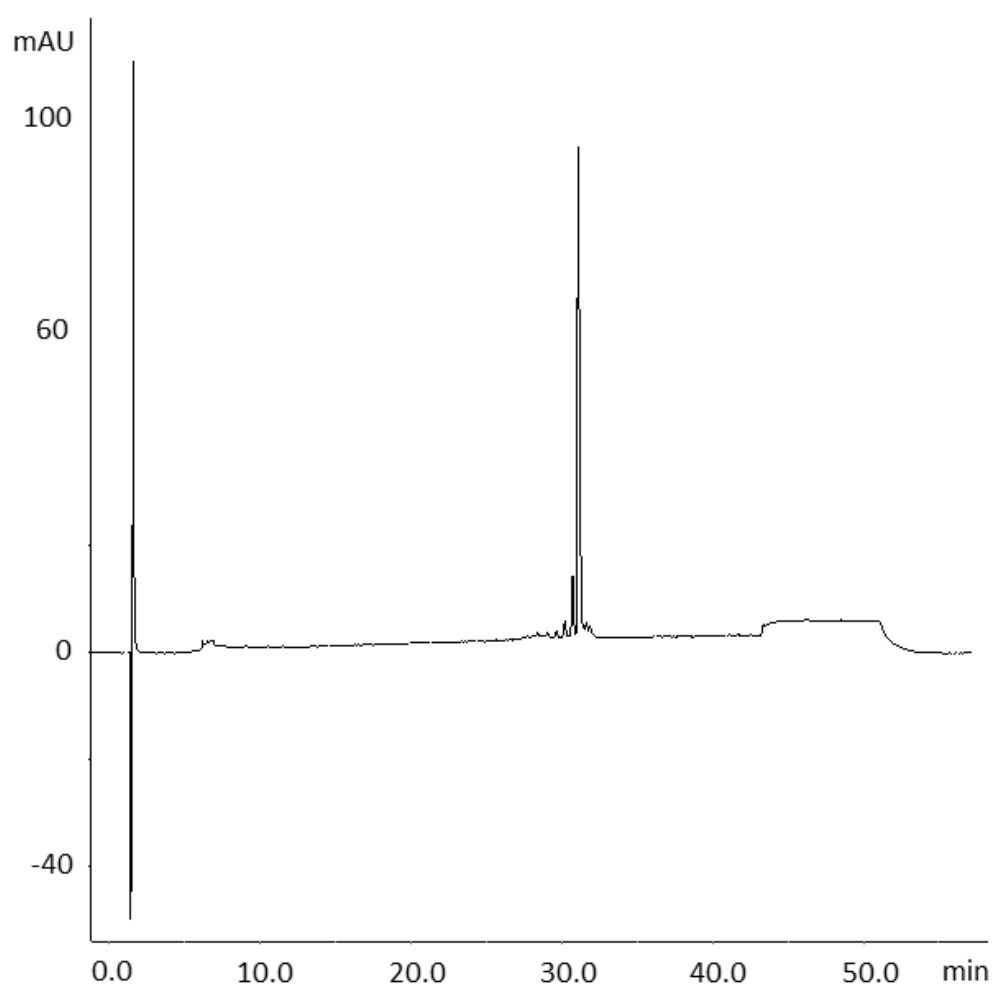

Oligonucleotid 1a: 5'-CCGTGCCAAAAAAAACCGTCCC-3'

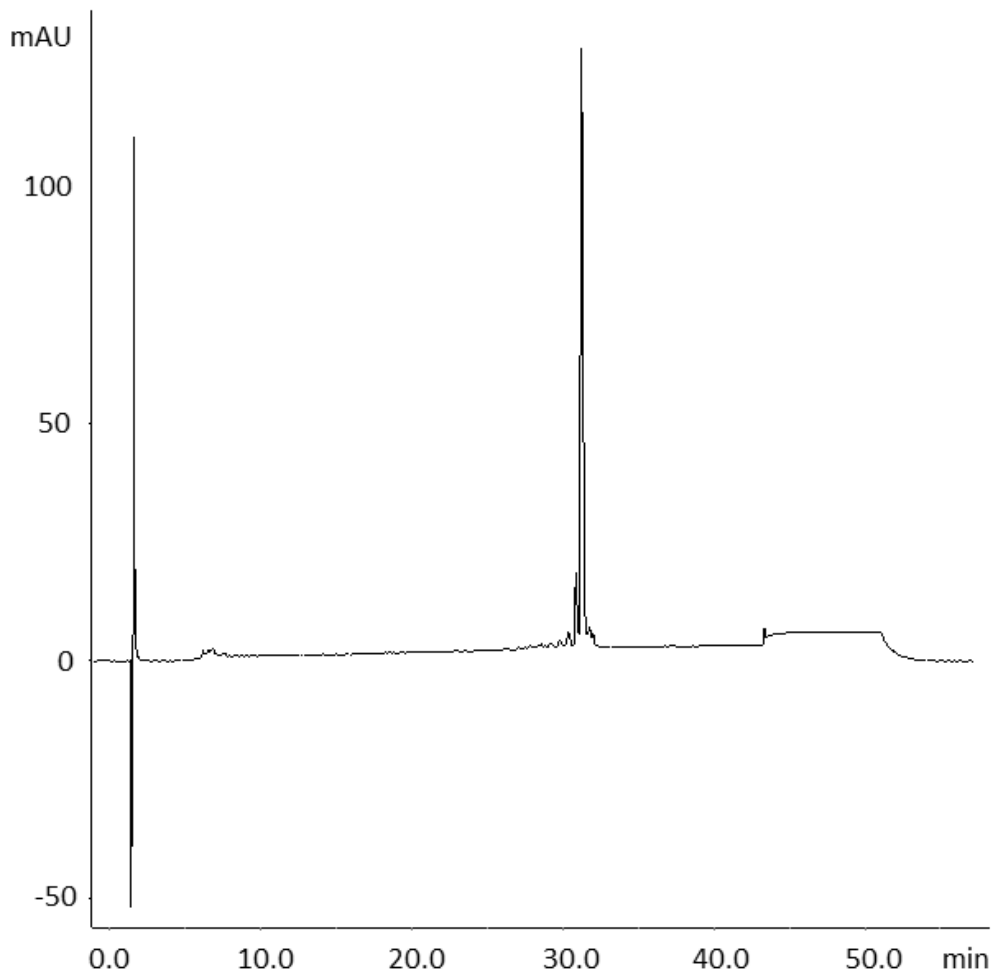

Oligonucleotid 2a: 5'-САACTGCAACTGCAACTGCAAC-3، 


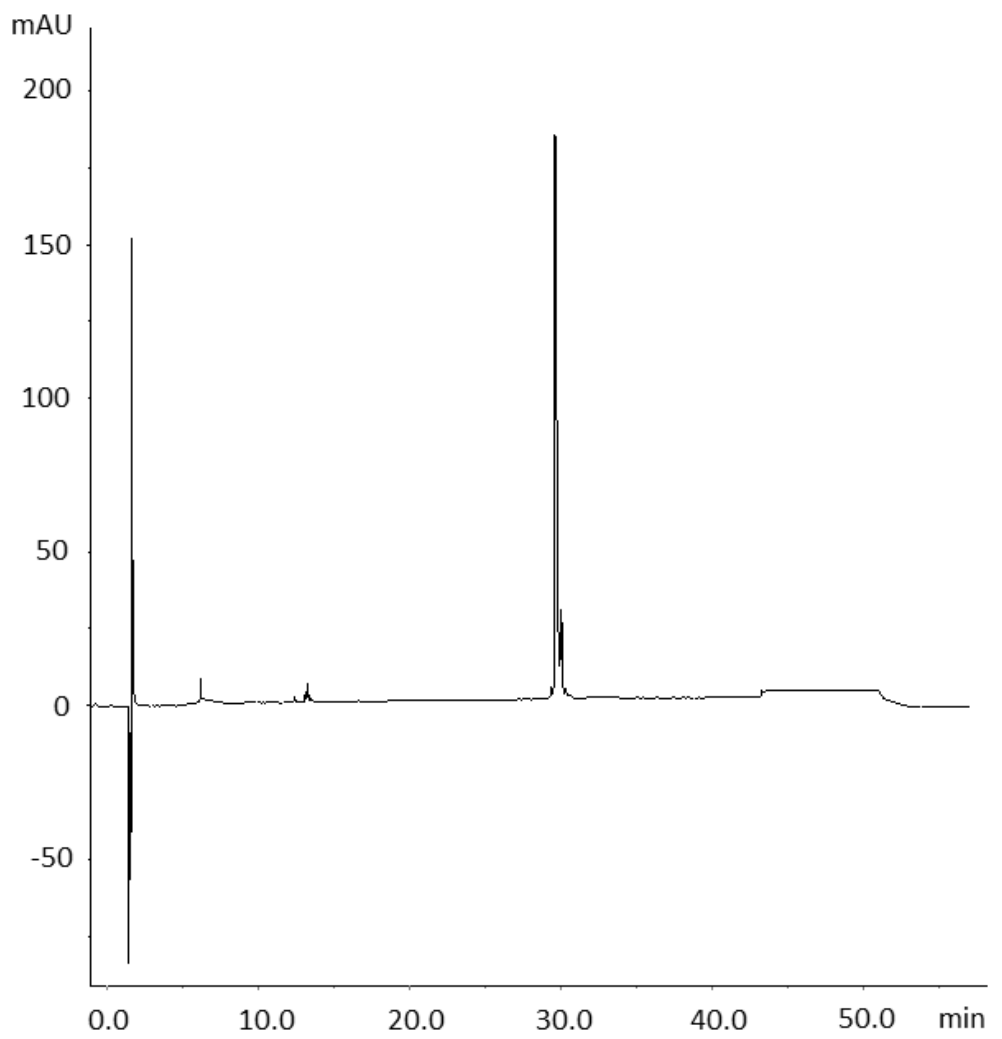

Oligonucleotid 1ra: 5'-CCGUGCCAAAAAAAACCGUCCC-3'

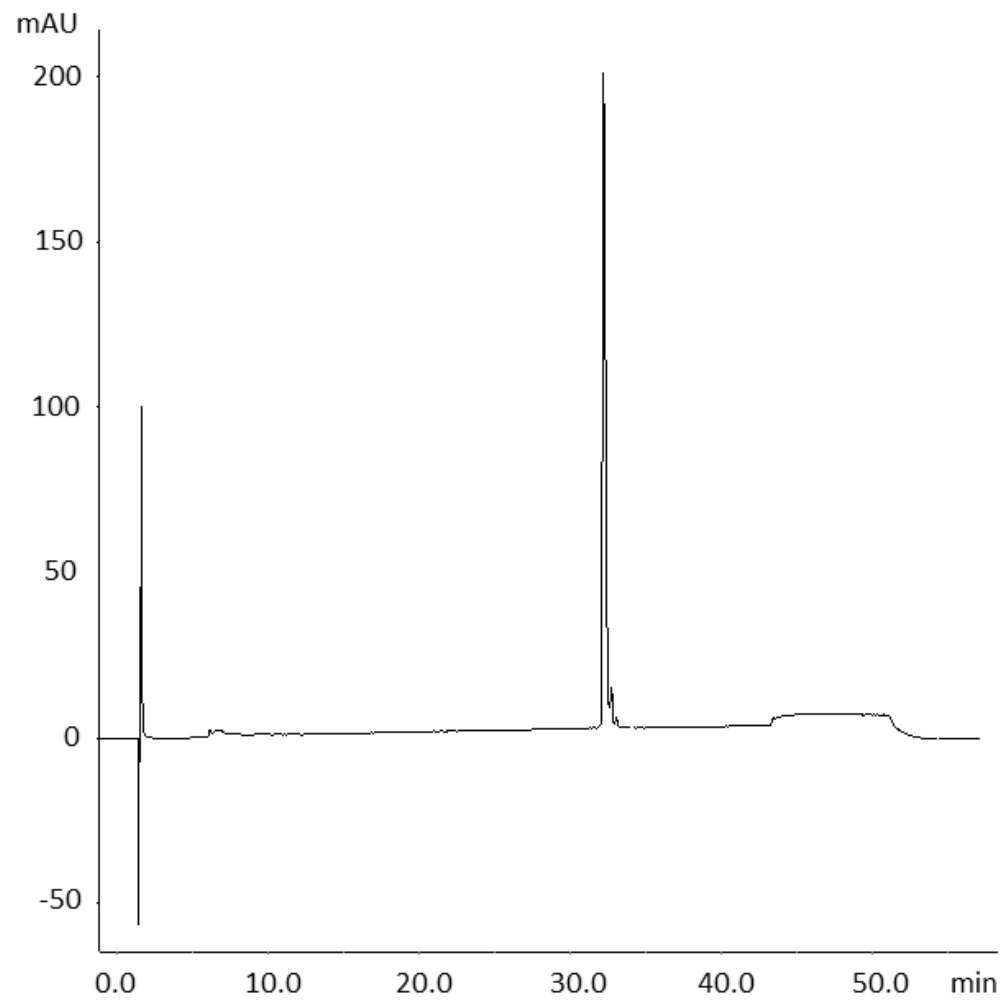

Oligonucleotid 2ra: 5'-CAACUGCAACUGCAACUGCAAC-3' 


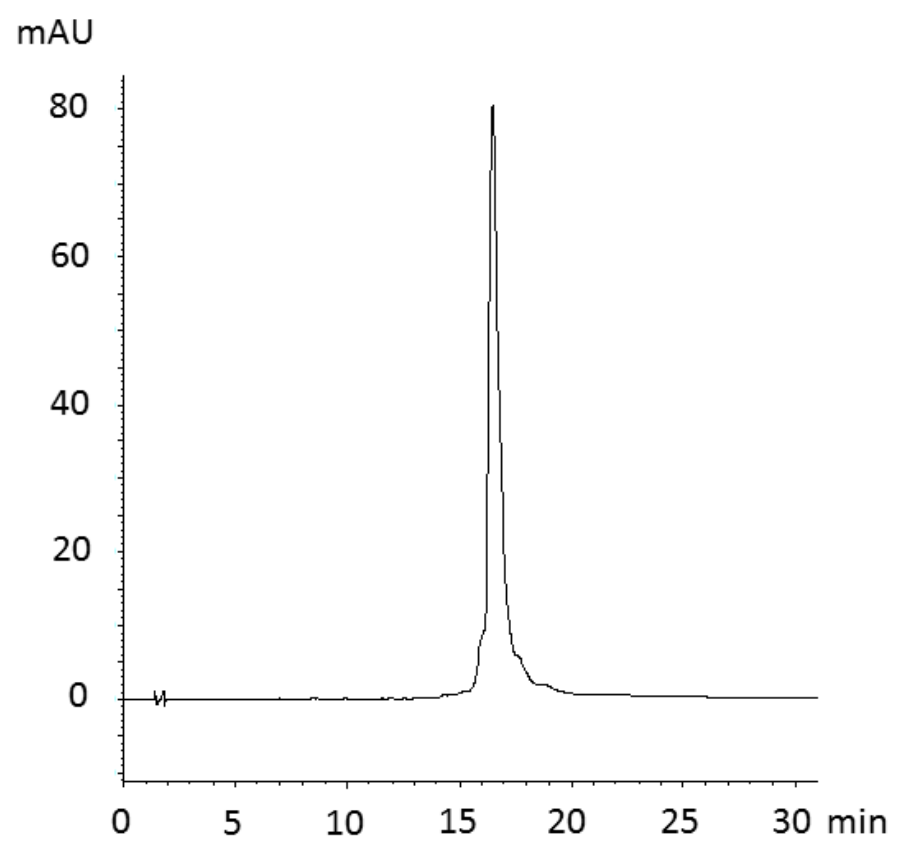

Oligonucleotid 1mt: 5'-CCGTGCCAAAIAAAACCGTCCC-3'

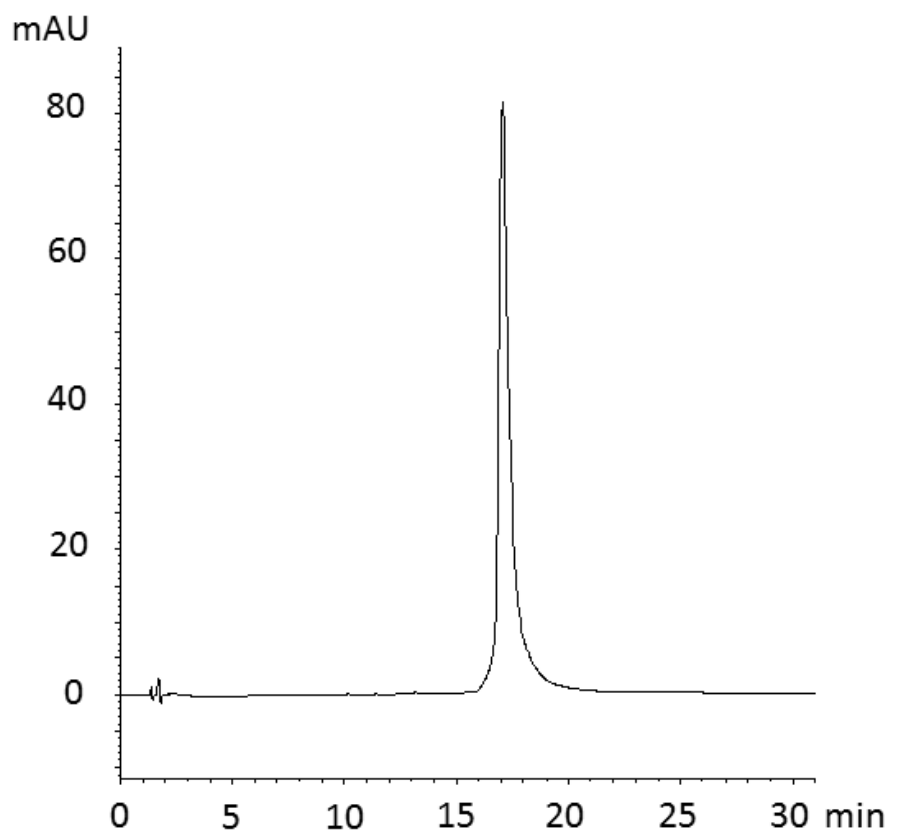

Oligonucleotid 2mt: 5'-CAACTGCAICTGCAACTGCAAC-3" 


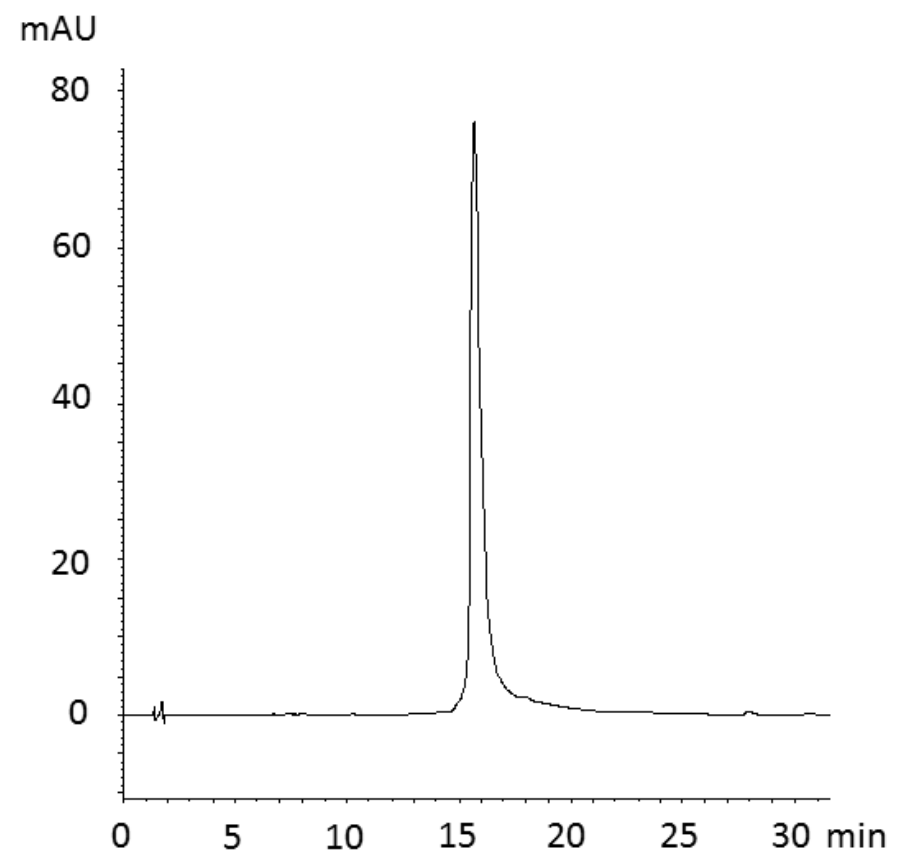

Oligonucleotid 1mc: 5'-CCGTGCCAAACAAAAACCGTCCC-3'

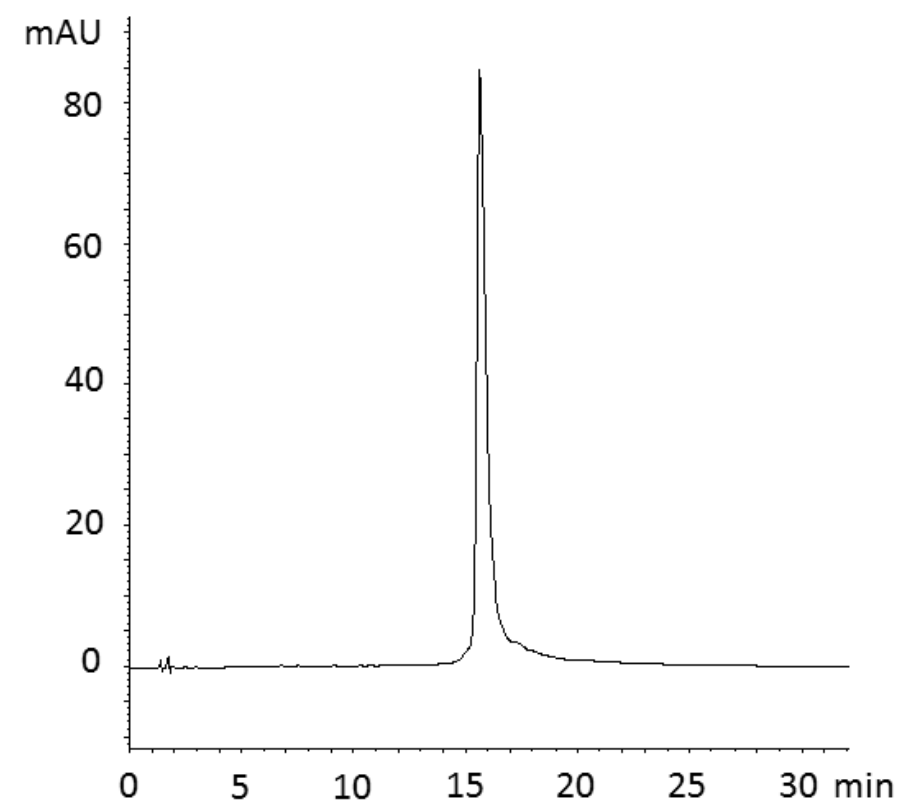

Oligonucleotid 2mc: 5'-CAACTGCACCTGCAACTGCAAC-3“ 


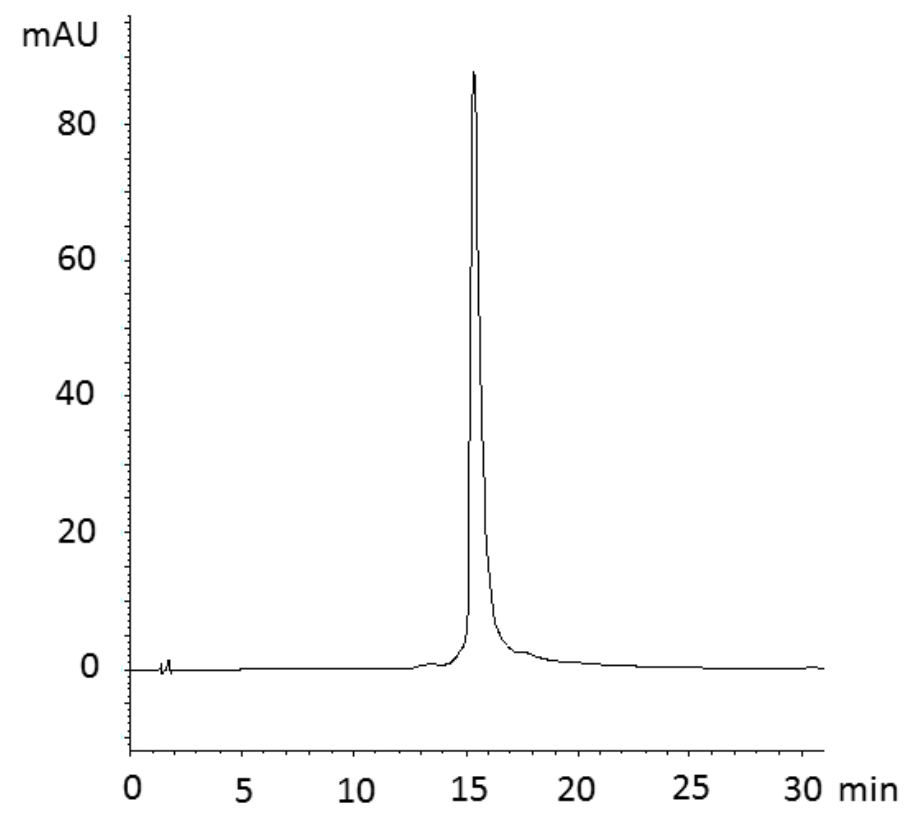

Oligonucleotid 1mg: 5'-CCGTGCCAAAGAAAACCGTCCC-3'

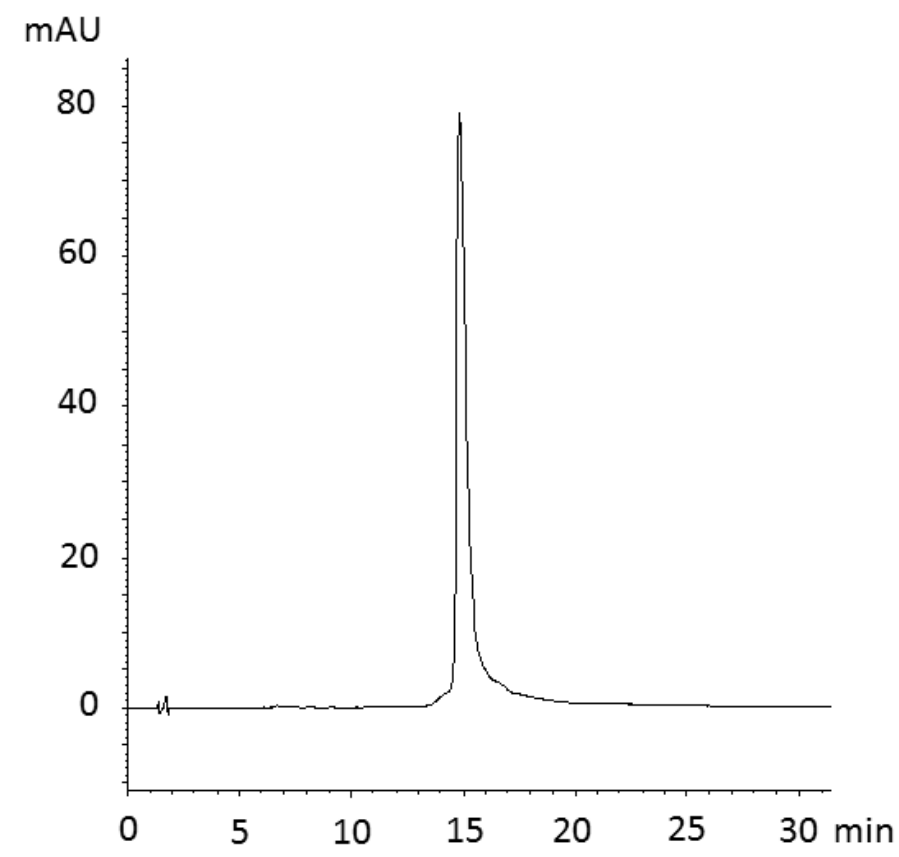

Oligonucleotid 2mg: 5'-CAACTGCAGCTGCAACTGCAAC-3 


\subsection{Daten zur Schmelzkurvenanalyse}

\subsubsection{Schmelzpunkte der untersuchten Duplices}

\subsubsection{Schmelzpunkte von Duplices unter Standardbedingungen (s. 7.1.6.4)}

Tab. 1: Schmelzpunkte und $\Delta \mathrm{T}_{\mathrm{m}}$-Werte von Duplices nicht-palidromer $\mathrm{ON}$ in $\left[{ }^{\circ} \mathrm{C}\right]$

\begin{tabular}{|c|c|c|c|c|c|c|}
\hline $\mathrm{Nr}$. & Sequenz & $\sigma(x)^{*}$ & $\begin{array}{c}\mathrm{T}_{\mathrm{m}} \\
(+\mathrm{DNA})^{\star *}\end{array}$ & $\begin{array}{c}\Delta \mathrm{T}_{\mathrm{m}} \\
/ \mathrm{mod} .\end{array}$ & $\begin{array}{c}\mathrm{T}_{\mathrm{m}} \\
(+\mathrm{RNA})\end{array}$ & $\begin{array}{c}\Delta \mathrm{T}_{\mathrm{m}} \\
/ \mathrm{mod} .\end{array}$ \\
\hline 1 & 5'-GGCACGG TxT TT TT TxT GGCACGG-3' & $S$ & 66.4 & -2.2 & 61.6 & -3.5 \\
\hline 2 & & $R$ & 68.0 & -1.4 & 62.2 & -3.2 \\
\hline 3 & 5'-GGCACGG TxT TT TxT TT GGCACGG-3' & $S$ & 66.3 & -2.2 & 61.4 & -3.6 \\
\hline 4 & & $R$ & 69.1 & -0.8 & 63.4 & -2.6 \\
\hline 5 & 5'-GGCACGG TxT TxT TT TT GGCACGG-3' & $S$ & 66.6 & -2.1 & 61.7 & -3.4 \\
\hline 6 & & $R$ & 69.8 & -0.5 & 63.3 & -2.3 \\
\hline 7 & 5'-GGCACGG TxT TT TT TT GGCACGG-3' & $S$ & 69.5 & -1.2 & 64.7 & -3.8 \\
\hline 8 & & $R$ & 69.2 & -1.5 & 64.4 & -4.1 \\
\hline 9 & 5'-GGCACGG TxT TxT TxT TxT GGCACGG-3' & $S$ & 63.9 & -1.7 & 55.3 & -3.3 \\
\hline 10 & & $R$ & 68.8 & -0.5 & 59.3 & -2.3 \\
\hline 11 & 5'-G TxT GACG TT GACG TT GACG TT G-3' & $S$ & 67.1 & -0.9 & 65.2 & -0.3 \\
\hline 12 & & $R$ & 68.0 & \pm 0.0 & 64.9 & -0.6 \\
\hline 13 & 5'-G TT GACG TxT GACG TT GACG TT G-3' & $S$ & 67.3 & -0.7 & 61.8 & -3.7 \\
\hline 14 & & $R$ & 67.7 & -0.3 & 62.9 & -2.4 \\
\hline 15 & 5'-G TT GACG TT GACG TxT GACG TT G-3' & $S$ & 66.9 & -1.1 & 62.0 & -3.5 \\
\hline 16 & & $R$ & 67.1 & -0.9 & 63.1 & -2.4 \\
\hline 17 & 5'-G TT GACG TT GACG TT GACG TxT G-3' & $S$ & 68.3 & +0.3 & 64.0 & -1.5 \\
\hline 18 & & $R$ & 68.4 & +0.4 & 64.0 & -1.5 \\
\hline 19 & 5'-G TxT GACG TxT GACG TxT GACG TxT G-3' & $S$ & 63.2 & -1.2 & 53.7 & -3.0 \\
\hline 20 & & $R$ & 66.3 & -0.4 & 57.7 & -2.0 \\
\hline $1 u$ & 5'-GGCACGG TT TT TT TT GGCACGG-3' (Ref. 1) & & 70.7 & & 68.5 & \\
\hline $2 u$ & 5'-G TT GACG TT GACG TT GACG TT G-3' (Ref. 2) & & 68.0 & & 65.5 & \\
\hline
\end{tabular}

*Konfiguration der NAA-Modifikation

${ }^{* *}$ Das bedeutet, dass der komplementäre Strang eine unmodifizierte DNA- bzw. RNA-Sequenz ist.

Tab. 2: Schmelzpunkte und $\Delta \mathrm{T}_{\mathrm{m}}$-Werte von Duplices palindromer $\mathrm{ON}$ in $\left[{ }^{\circ} \mathrm{C}\right]$

\begin{tabular}{ccccc}
\hline Nr. & Sequenz & $\sigma(x)$ & $\begin{array}{c}\mathrm{T}_{\mathrm{m}} \\
\text { (+DNA) }\end{array}$ & $\Delta \mathrm{T}_{\mathrm{m}}$ \\
\hline 21 & 5'-GCGC TxT GC TT AAGCAAGCGC-3' & $S$ & 83.6 & -2.0 \\
22 & & $R$ & 83.8 & -1.8 \\
23 & 5'-GCGC TT GC TxT AAGCAAGCGC-3' & $S$ & 85.4 & -0.2 \\
24 & & $R$ & 85.0 & -0.6 \\
34 & 5'-GCGC TT GC TT AAGCAAGCGC-3' (Ref. 3) & & 85.6 & \\
\hline
\end{tabular}


Tab. 3: Schmelzpunkte und $\Delta \mathrm{T}_{\mathrm{m}}$-Werte von Duplices palindromer $\mathrm{ON}$ in $\left[{ }^{\circ} \mathrm{C}\right]$

\begin{tabular}{|c|c|c|c|c|c|c|}
\hline Nr. & Sequenz & $\sigma(x)$ & $\begin{array}{c}T_{m} \\
(+21 / 22)^{*}\end{array}$ & $\Delta \mathrm{T}_{\mathrm{m}}$ & $\begin{array}{c}T_{m} \\
(+23 / 24)^{*}\end{array}$ & $\Delta \mathrm{T}_{\mathrm{m}}$ \\
\hline 21 & 5'-GCGC TxT GC TT AAGCAAGCGC-3' & $S$ & 81.2 & -4.4 & 83.1 & -2.5 \\
\hline 22 & & $R$ & 83.0 & -2.6 & 82.8 & -2.8 \\
\hline 23 & 5'-GCGC TT GC TxT AAGCAAGCGC-3' & $S$ & & & 83.3 & -2.3 \\
\hline 24 & & $R$ & & & 84.1 & -1.5 \\
\hline
\end{tabular}

*Es wurden nur Duplices aus ON mit gleicher Konfiguration der NAA-Modifikation untersucht.

Tab. 4: Schmelzpunkte und $\Delta \mathrm{T}_{\mathrm{m}}-$ Werte von Duplices mit Fehlpaarungen in $\left[{ }^{\circ} \mathrm{C}\right]$

\begin{tabular}{|c|c|c|c|c|c|}
\hline Nr. & Sequenz & $\sigma(x)$ & Mismatch* & $\mathrm{T}_{\mathrm{m}}$ & $\Delta \mathrm{T}_{\mathrm{m}}$ \\
\hline \multirow[t]{3}{*}{1} & 5'-G TT GACG TI GACG TT GACG TT G-3' (Referenz) & & G14 & 65.9 & -2.1 \\
\hline & & & C14 & 62.3 & -5.7 \\
\hline & & & $\mathrm{T} 14$ & 64.2 & -3.8 \\
\hline \multirow[t]{3}{*}{2} & 5'-G TT GACG TxI GACG TT GACG TT G-3' & $S$ & G14 & 62.7 & -4.6 \\
\hline & & & $\mathrm{C} 14$ & 61.4 & -5.9 \\
\hline & & & $\mathrm{T} 14$ & 62.7 & -4.6 \\
\hline \multirow[t]{3}{*}{3} & 5'-G TT GACG TxI GACG TT GACG TT G-3' & $R$ & G14 & 63.8 & -3.9 \\
\hline & & & C14 & 61.6 & -6.1 \\
\hline & & & $\mathrm{T} 14$ & 62.6 & -5.5 \\
\hline \multirow[t]{3}{*}{4} & 5'-G TxT GACG TxI GACG TxT GACG TxT G-3' & $S$ & G14 & 58.4 & -4.8 \\
\hline & & & $\mathrm{C} 14$ & 56.8 & -6.4 \\
\hline & & & $\mathrm{T} 14$ & 58.8 & -4.4 \\
\hline \multirow[t]{3}{*}{5} & 5'-G TxT GACG TxI GACG TxT GACG TxT G-3' & $R$ & G14 & 61.5 & -4.8 \\
\hline & & & C14 & 59.8 & -6.5 \\
\hline & & & $\mathrm{T} 14$ & 61.0 & -5.3 \\
\hline \multirow[t]{3}{*}{6} & 5'-GGCACGG TTTITTTT GGCACGG-3' (Referenz) & & G12 & 65.8 & -4.9 \\
\hline & & & C12 & 64.1 & -6.6 \\
\hline & & & $\mathrm{T} 12$ & 65.5 & -5.2 \\
\hline \multirow[t]{3}{*}{7} & 5'-GGCACGG TxTTxITxTTxT GGCACGG-3' & $S$ & G12 & 59.8 & -4.1 \\
\hline & & & $\mathrm{C} 12$ & 59.3 & -4.6 \\
\hline & & & $\mathrm{T} 12$ & 60.7 & -3.2 \\
\hline \multirow[t]{3}{*}{8} & 5'-GGCACGG TxTTxITxTTxT GGCACGG-3' & $R$ & G12 & 64.8 & -4.0 \\
\hline & & & C12 & 62.4 & -6.4 \\
\hline & & & $\mathrm{T} 12$ & 63.5 & -5.3 \\
\hline
\end{tabular}

*z. B. G14: Guanosin an Position 14 im Gegenstrang

I dem Mismatch entsprechende Position im modifizierten bzw. unmodifizierten Strang 


\subsubsection{Schmelzpunkte von Duplices bei erhöhter NaCl-Konzentration}

\subsection{Schmelzpunkte bei $[\mathrm{NaCl}]=0.5 \mathrm{M}$}

Tab. 1: Schmelzpunkte und $\Delta \mathrm{T}_{\mathrm{m}}$-Werte verschiedener Duplices (DNA-DNA) in $\left[{ }^{\circ} \mathrm{C}\right]$

\begin{tabular}{|c|c|c|c|c|c|c|}
\hline $\mathrm{Nr}$ & Sequenz & $\sigma(x)$ & $\mathrm{T}_{\mathrm{m}}$ & $\Delta \mathrm{T}_{\mathrm{m}}(1)^{*}$ & $\Delta \mathrm{T}_{\mathrm{m}} / \mathrm{mod}$ & $\Delta T_{m}(2)^{\star \star}$ \\
\hline 1 & 5'-GGCACGG TxT TxT TxT TxT GGCACGG-3' & $R$ & 72.6 & -3.9 & -1.0 & +3.8 \\
\hline 2 & 5'-G TxT GACG TxT GACG TxT GACG TxT G-3' & $R$ & 71.0 & -3.3 & -0.8 & +4.7 \\
\hline 3 & & $S$ & 68.7 & -5.6 & -1.4 & +5.5 \\
\hline 4 & 5'-G TT GACG TxT GACG TT GACG TT G-3' & $R$ & 73.1 & -1.2 & -1.2 & +5.4 \\
\hline 5 & & $S$ & 72.8 & -1.5 & -1.5 & +5.5 \\
\hline 6 & $\begin{array}{l}\text { 5'-G TT GACG TT GACG TT GACG TT G-3' } \\
\text { (Referenz) }\end{array}$ & & 74.3 & & & +6.3 \\
\hline 7 & $\begin{array}{l}\text { 5'-GGCACGG TT TT TT TT GGCACGG-3' } \\
\text { (Referenz) }\end{array}$ & & 76.5 & & & +5.8 \\
\hline
\end{tabular}

Tab. 2: Schmelzpunkte und $\Delta \mathrm{T}_{\mathrm{m}}$-Werte verschiedener Duplices (DNA-RNA) in [ $\left.{ }^{\circ} \mathrm{C}\right]$

\begin{tabular}{clccccc}
\hline $\mathrm{Nr}$ & \multicolumn{1}{c}{ Sequenz } & $\sigma(\mathrm{x})$ & $\mathrm{T}_{\mathrm{m}}$ & $\Delta \mathrm{T}_{\mathrm{m}}(1)$ & $\Delta \mathrm{T}_{\mathrm{m}} / \mathrm{mod}$ & $\Delta \mathrm{T}_{\mathrm{m}}(2)$ \\
\hline 1 & 5'-GGCACGG TxT TxT TxT TxT GGCACGG-3' & $R$ & 64.5 & -9.2 & -2.3 & +5.2 \\
2 & 5'-G TxT GACG TxT GACG TxT GACG TxT G-3' & $R$ & 62.5 & -9.3 & -2.3 & +4.8 \\
3 & & $S$ & 59.4 & -12.4 & -3.1 & +5.7 \\
4 & 5'-G TT GACG TxT GACG TT GACG TT G-3' & $R$ & 68.7 & -3.1 & -3.1 & +5.8 \\
5 & & $S$ & 66.9 & -4.9 & -4.9 & +5.8 \\
6 & 5'-G TT GACG TT GACG TT GACG TT G-3' & & 71.8 & & & +6.3 \\
& (Referenz) & & & & & \\
7 & 5'-GGCACGG TT TT TT TT GGCACGG-3' & & 73.7 & & & \\
& (Referenz) & & & & & \\
\end{tabular}

${ }^{\star} \Delta T_{m}$ (1): Differenz der $\mathrm{T}_{\mathrm{m}}$-Werte der modifizierten Duplex und der unmodifizierten Duplex bei der gleichen $\mathrm{NaCl}-$ Konzentration.

${ }^{* *} \Delta T_{m}$ (2): Differenz der $\mathrm{T}_{\mathrm{m}}$-Werte der jeweiligen Duplex bei erhöhter NaCl-Konzentration und derselben Duplex bei Standardbedingungen (150 $\mathrm{mM} \mathrm{NaCl}$ ). 


\subsection{Schmelzpunkte bei $[\mathrm{NaCl}]=1.0 \mathrm{M}$}

Tab. 3: Schmelzpunkte und $\Delta \mathrm{T}_{\mathrm{m}}$-Werte verschiedener Duplices (DNA-DNA) in [ $\left.{ }^{\circ} \mathrm{C}\right]$

\begin{tabular}{clccccc}
\hline $\mathrm{Nr}$ & \multicolumn{1}{c}{ Sequenz } & $\sigma(\mathrm{x})$ & $\mathrm{T}_{\mathrm{m}}$ & $\Delta \mathrm{T}_{\mathrm{m}}(1)^{\star}$ & $\Delta \mathrm{T}_{\mathrm{m}} / \mathrm{mod}$ & $\Delta \mathrm{T}_{\mathrm{m}}(2)^{\star *}$ \\
\hline 1 & 5'-GGCACGG TxT TxT TxT TxT GGCACGG-3' $^{*}$ & $R$ & 74.0 & -4.5 & -1.1 & +5.2 \\
2 & 5'-G TxT GACG TxT GACG TxT GACG TxT G-3' & $R$ & 72.4 & -4.0 & -1.0 & +6.1 \\
3 & & $S$ & 69.4 & -7.0 & -1.8 & +6.2 \\
4 & 5'-G TT GACG TxT GACG TT GACG TT G-3' & $R$ & 74.6 & -1.8 & -1.8 & +6.9 \\
5 & & $S$ & 74.3 & -2.1 & -2.1 & +7.0 \\
6 & 5'-G TT GACG TT GACG TT GACG TT G-3' & & 76.4 & & & +8.4 \\
& (Referenz) & & & & & \\
7 & 5'-GGCACGG TT TT TT TT GGCACGG-3' & & 78.5 & & & +7.8 \\
& (Referenz) & & & & & \\
\hline
\end{tabular}

Tab. 4: Schmelzpunkte und $\Delta \mathrm{T}_{\mathrm{m}}$-Werte verschiedener Duplices (DNA-RNA) in $\left[{ }^{\circ} \mathrm{C}\right]$

\begin{tabular}{clccccc}
\hline $\mathrm{Nr}$ & \multicolumn{1}{c}{ Sequenz } & $\sigma(\mathrm{x})$ & $\mathrm{T}_{\mathrm{m}}$ & $\Delta \mathrm{T}_{\mathrm{m}}(1)^{\star}$ & $\Delta \mathrm{T}_{\mathrm{m}} / \mathrm{mod}$ & $\Delta \mathrm{T}_{\mathrm{m}}(2)^{\star *}$ \\
\hline 1 & 5'-GGCACGG TxT TxT TxT TxT GGCACGG-3' & $R$ & 65.9 & -9.7 & -1.4 & +6.6 \\
2 & 5'-G TxT GACG TxT GACG TxT GACG TxT G-3' & $R$ & 63.8 & -9.7 & -2.4 & +6.1 \\
3 & & $S$ & 61.0 & -12.5 & -3.1 & +7.3 \\
4 & 5'-G TT GACG TxT GACG TT GACG TT G-3' & $R$ & 69.6 & -3.9 & -3.9 & +6.7 \\
5 & & $S$ & 68.7 & -4.8 & -4.8 & +6.9 \\
6 & 5'-G TT GACG TT GACG TT GACG TT G-3' & & 73.5 & & & +8.0 \\
& (Referenz) & & & & & \\
7 & 5'-GGCACGG TT TT TT TT GGCACGG-3' & & 75.6 & & & +7.1 \\
& (Referenz) & & & & & \\
\hline
\end{tabular}

${ }^{*} \Delta T_{m}(1)$ : Differenz der $T_{m}$-Werte der modifizierten Duplex und der unmodifizierten Duplex bei der gleichen NaClKonzentration.

${ }^{* \star} \Delta \mathrm{T}_{\mathrm{m}}$ (2): Differenz der $\mathrm{T}_{\mathrm{m}}$-Werte der jeweiligen Duplex bei erhöhter NaCl-Konzentration und derselben Duplex bei Standardbedingungen (150 $\mathrm{mM} \mathrm{NaCl})$. 


\subsubsection{Schmelzkurvendiagramme}

Im Folgenden sind die $\mathrm{zu}$ den unter 9.2.1 tabellierten $\mathrm{T}_{\mathrm{m}}$-Werten gehörigen Schmelzkurvendiagramme angeführt. Im Sinne der Übersichtlichkeit wurden nur die bei $\lambda=260 \mathrm{~nm}$ aufgenommenen Kurven dargestellt. In jedem dieser Diagramme stellt die schwarze Kurve den Verlauf des Denaturierungs- bzw. Renaturierungsprozesses der NAA-modifizierten Duplices (DNA-DNA oder DNARNA) und die rote Kurve denjenigen der unmodifizierten Duplex (Referenz) dar. Das modifizierte Oligonucleotid ist jeweils unter dem Diagramm angeführt. Die Konfiguration der jeweiligen NAA-Modifikation ist in Klammern angegeben. Die Nummern der Oligonucleotide entsprechen denjenigen in den Tabellen in 9.2.1.

\subsubsection{Schmelzkurven unter Standardbedingungen (s. 7.1.6.4)}

Die Nummern der Oligonucleotide entsprechen denjenigen von 9.2.1.1 (Tab. 1 und Tab. 2). Die Referenzkurven wurden mit den entsprechenden Duplices ohne NAAmodifikation aufgenommen.

\subsection{DNA-DNA-Duplices}

Schmelzkurven von Duplices nicht-palindromer Oligonucleotide

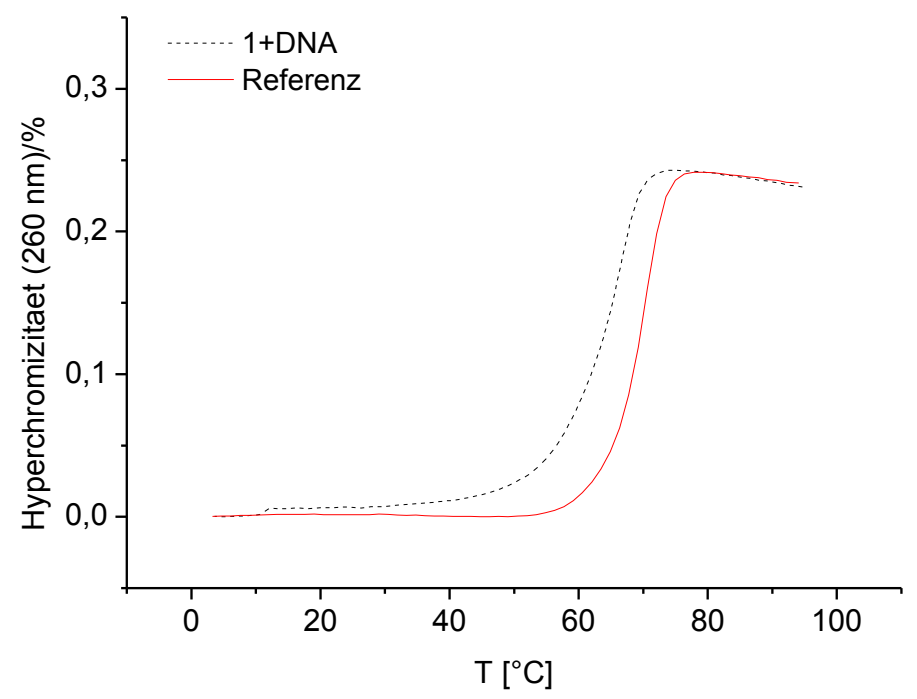

Oligonucleotid 1 (S): 5'-GGCACGG TxT TT TT TxT GGCACGG-3' 


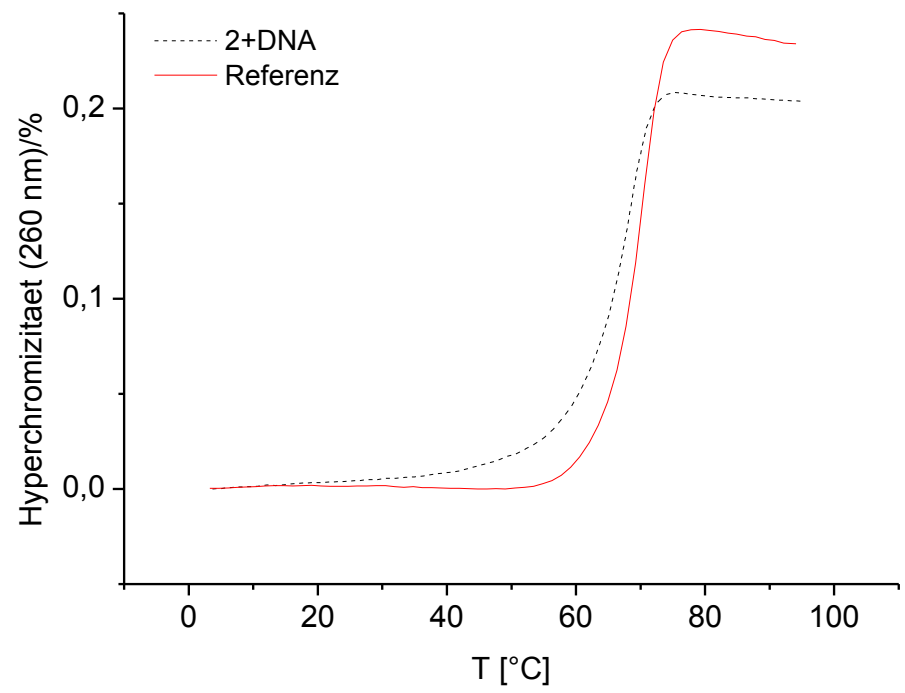

Oligonucleotid $2(R)$ : 5'-GGCACGG TxT TT TT TxT GGCACGG-3'

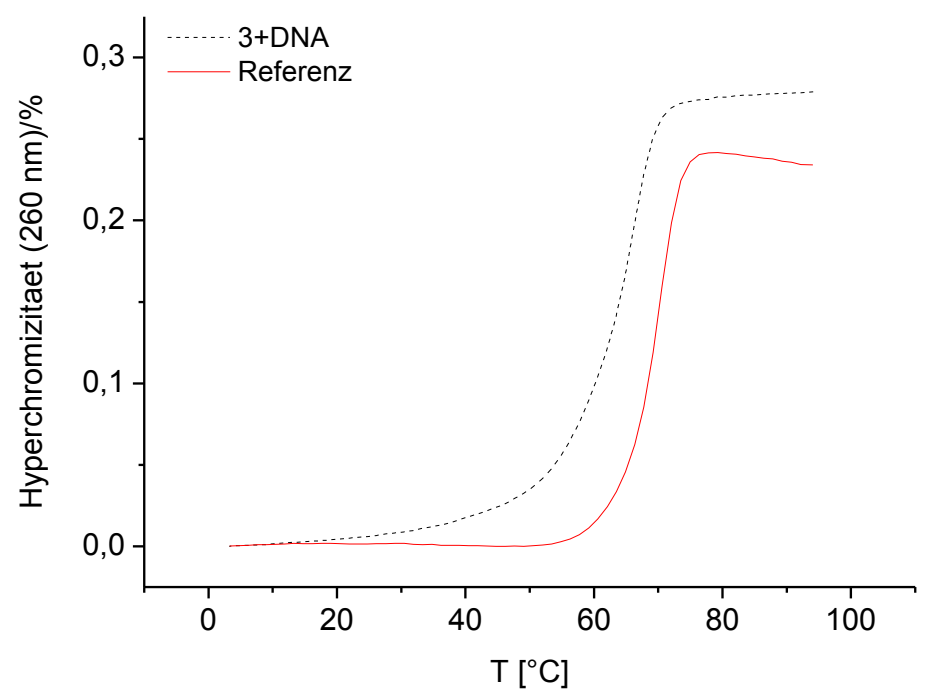

Oligonucleotid 3 (S): 5'-GGCACGG TxT TT TxT TT GGCACGG-3' 


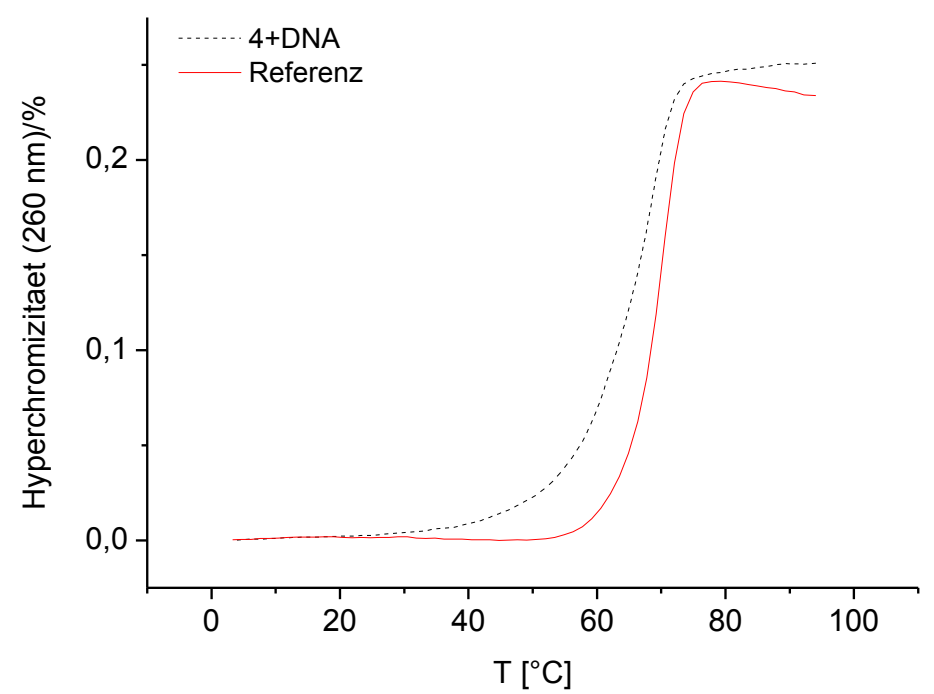

Oligonucleotid $4(R)$ : 5'-GGCACGG TxT TT TxT TT GGCACGG-3'

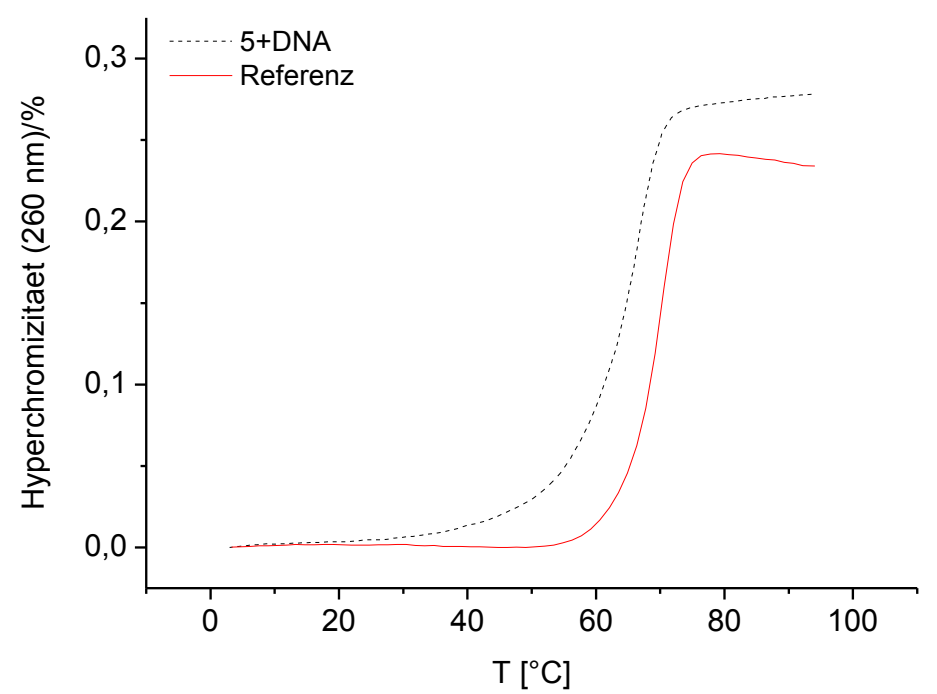

Oligonucleotid 5 (S): 5'-GGCACGG TxT TxT TT TT GGCACGG-3' 


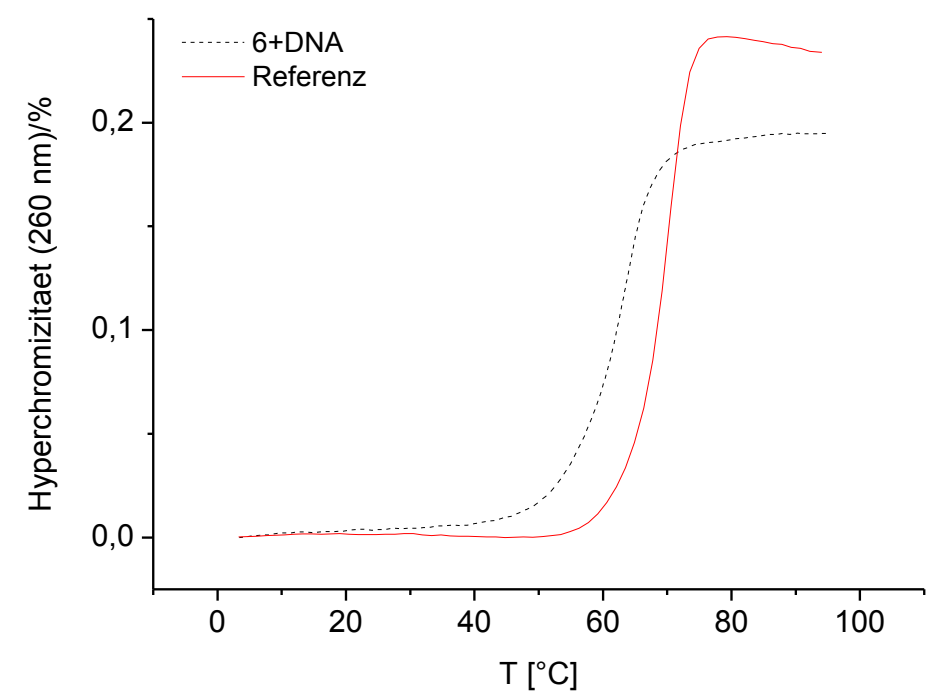

Oligonucleotid $6(R)$ : 5'-GGCACGG TxT TxT TT TT GGCACGG-3'

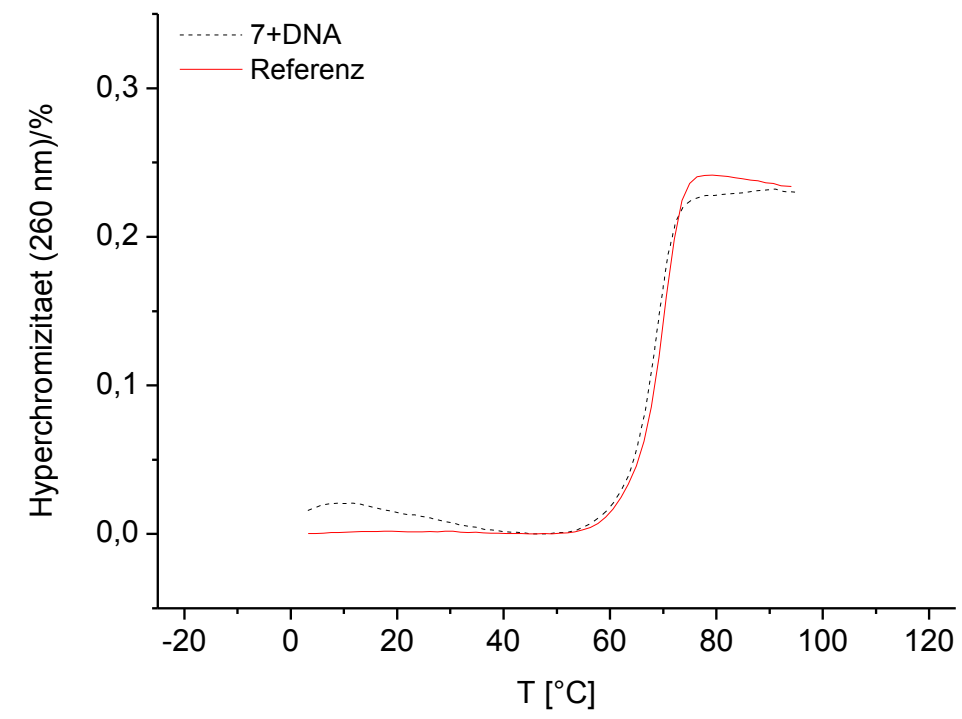

Oligonucleotid 7 (S): 5'-GGCACGG TxT TT TT TT GGCACGG-3' 


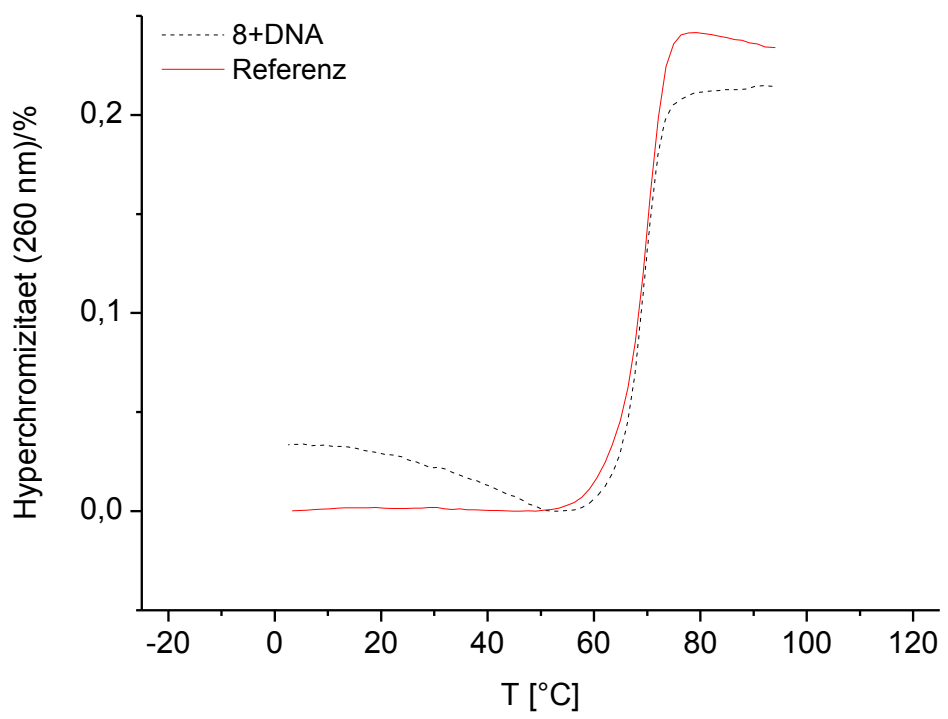

Oligonucleotid 8 (R): 5'-GGCACGG TxT TT TT TT GGCACGG-3'

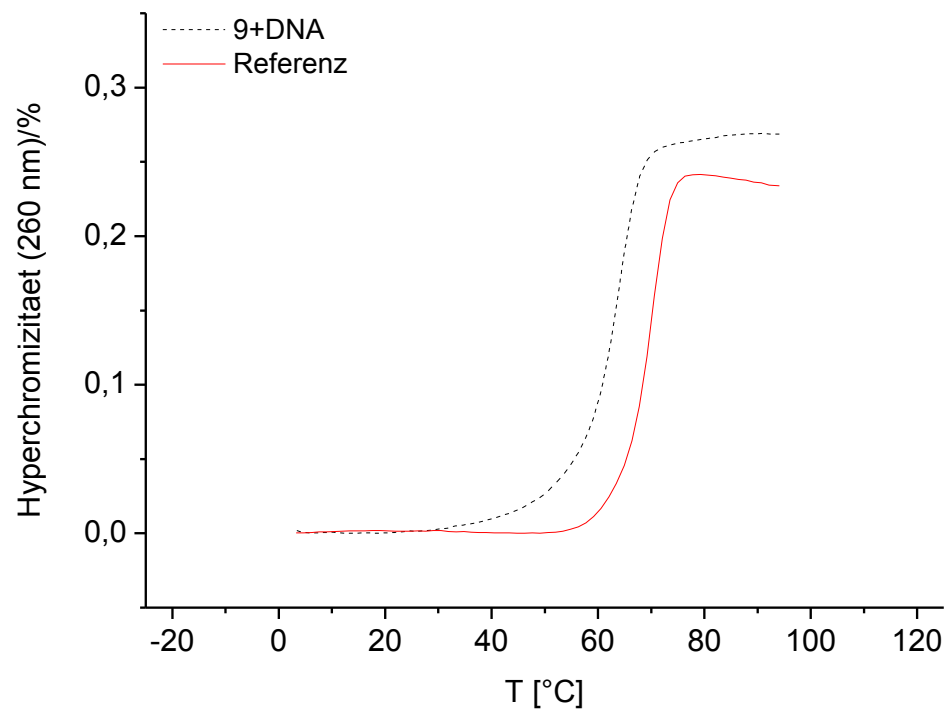

Oligonucleotid 9 (S): 5'-GGCACGG TxT TxT TxT TxT GGCACGG-3' 


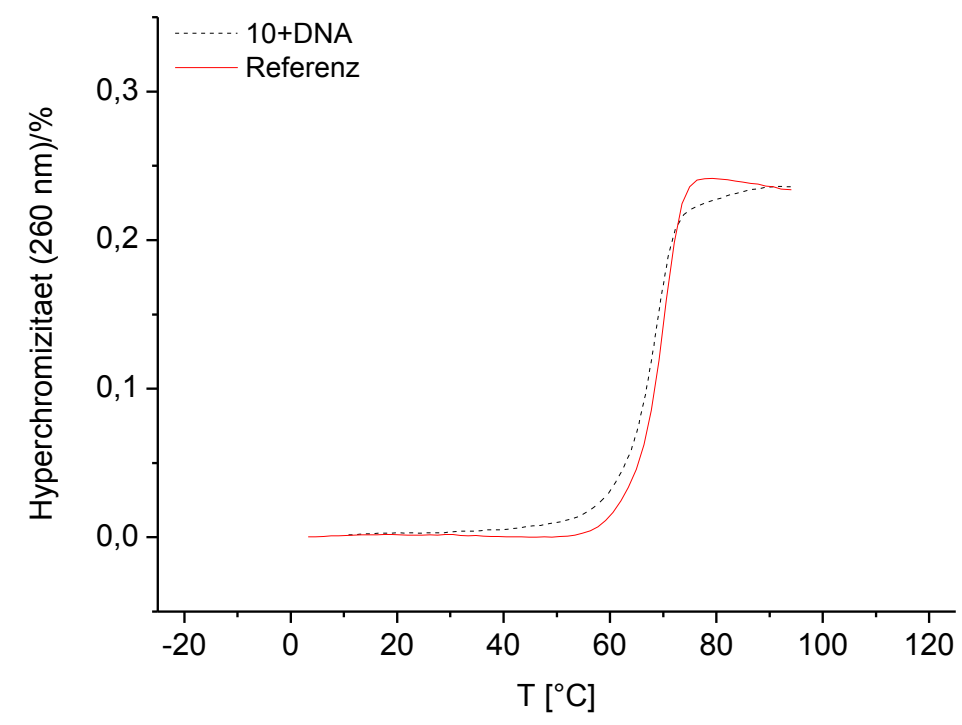

Oligonucleotid $10(R)$ : 5'-GGCACGG TxT TxT TxT TxT GGCACGG-3'

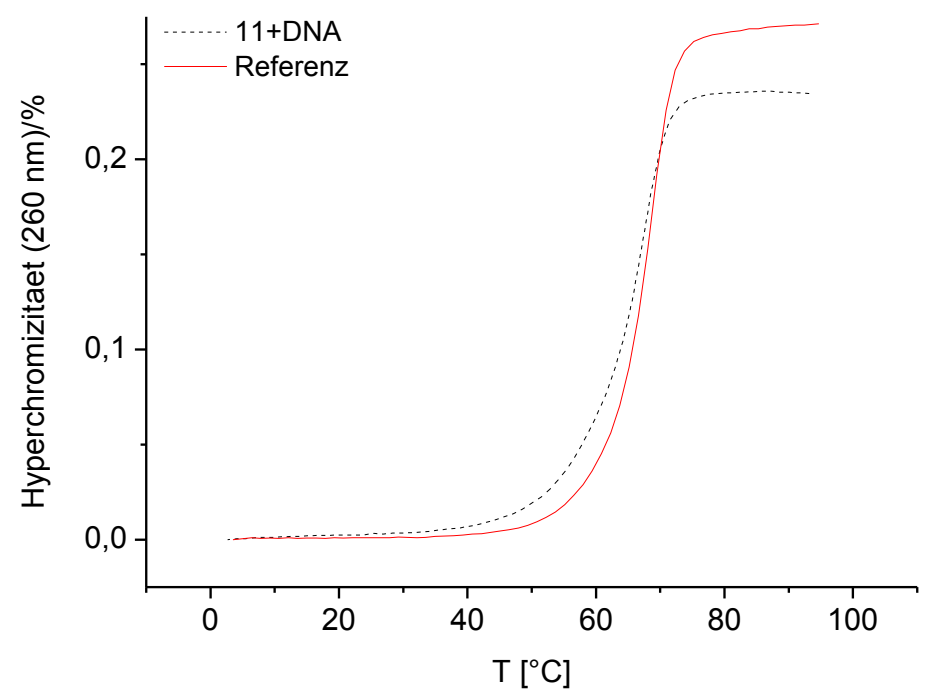

Oligonucleotid 11 (S): 5'-G TxT GACG TT GACG TT GACG TT G-3' 


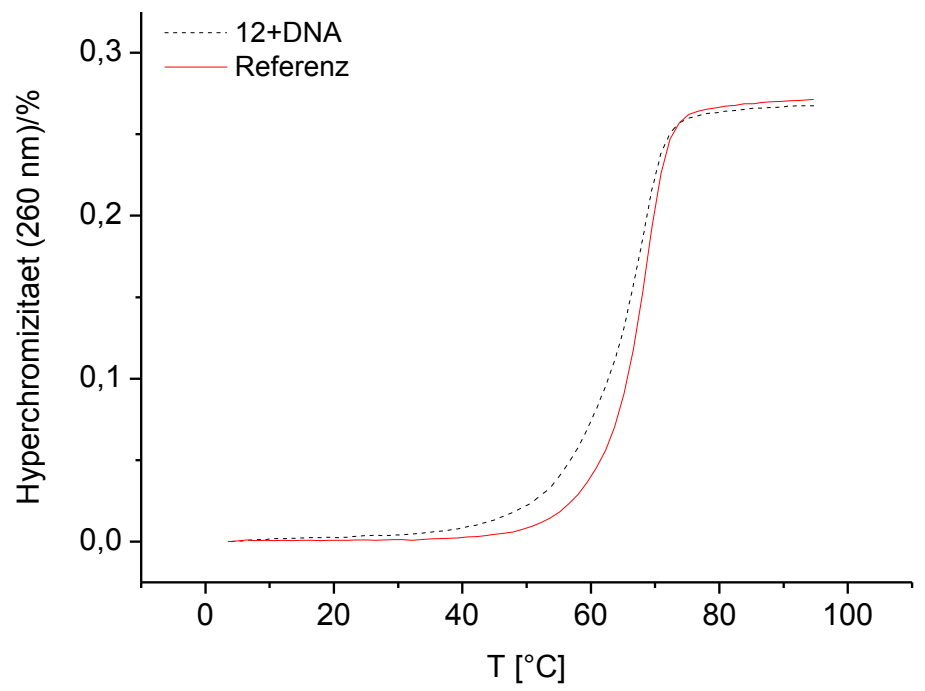

Oligonucleotid $12(R)$ : 5'-G TxT GACG TT GACG TT GACG TT G-3'

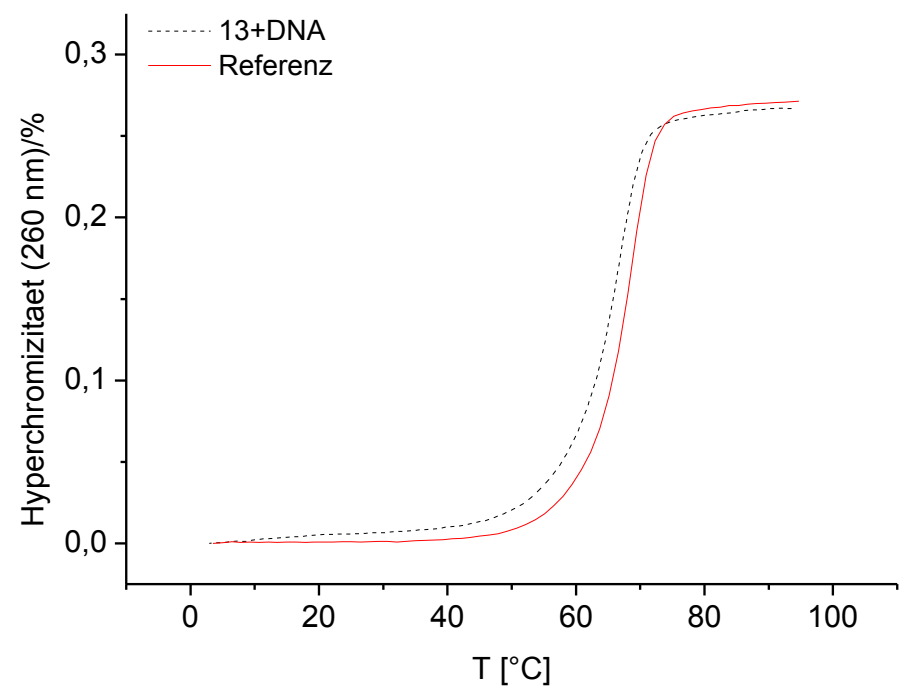

Oligonucleotid 13 (S): 5'-G TT GACG TxT GACG TT GACG TT G-3' 


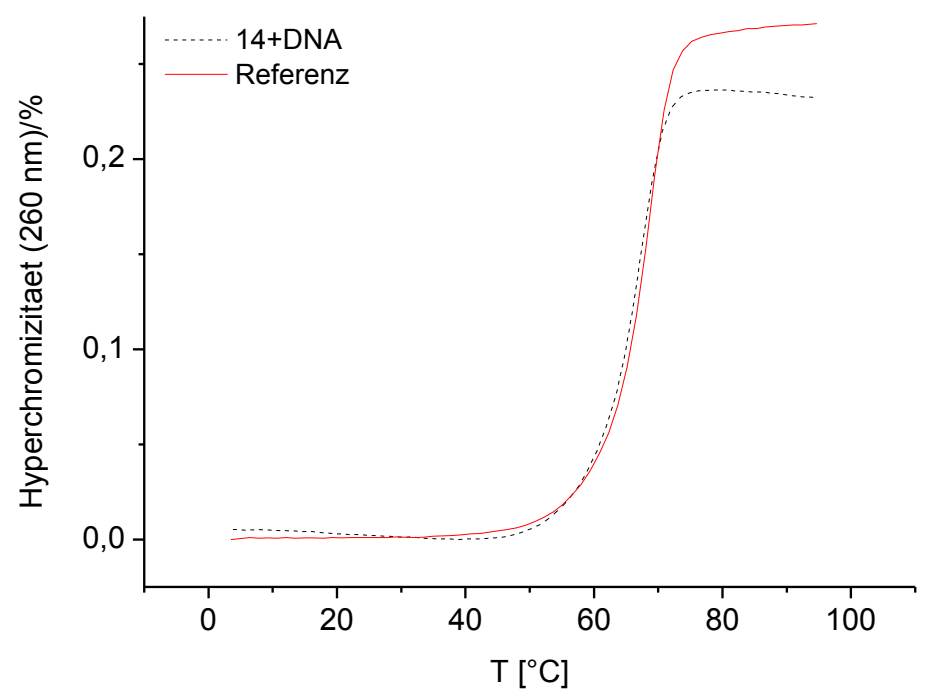

Oligonucleotid $14(R)$ : 5'-G TT GACG TxT GACG TT GACG TT G-3'

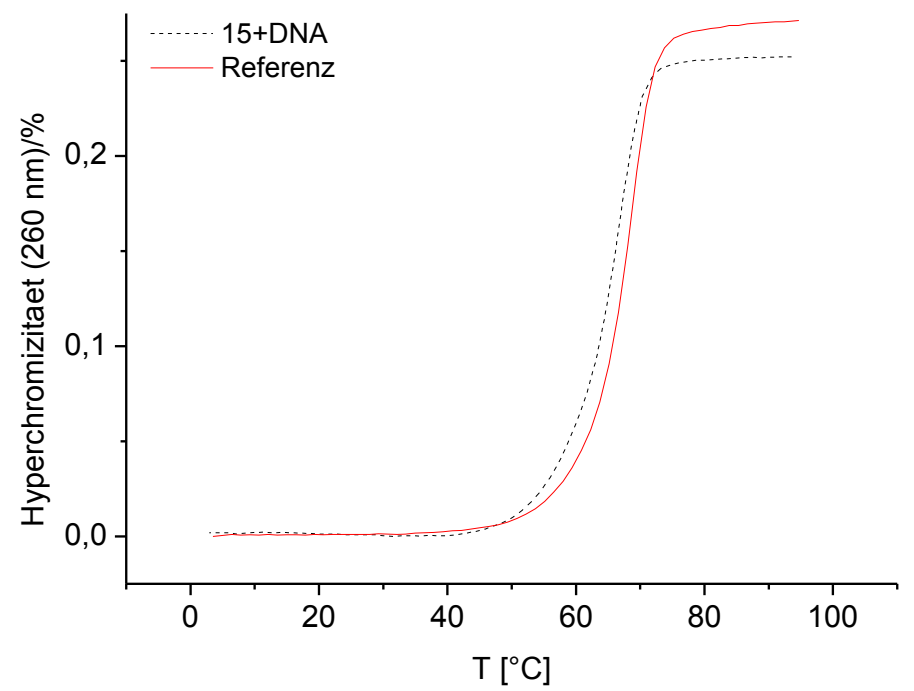

Oligonucleotid 15 (S): 5'-G TT GACG TT GACG TxT GACG TT G-3' 


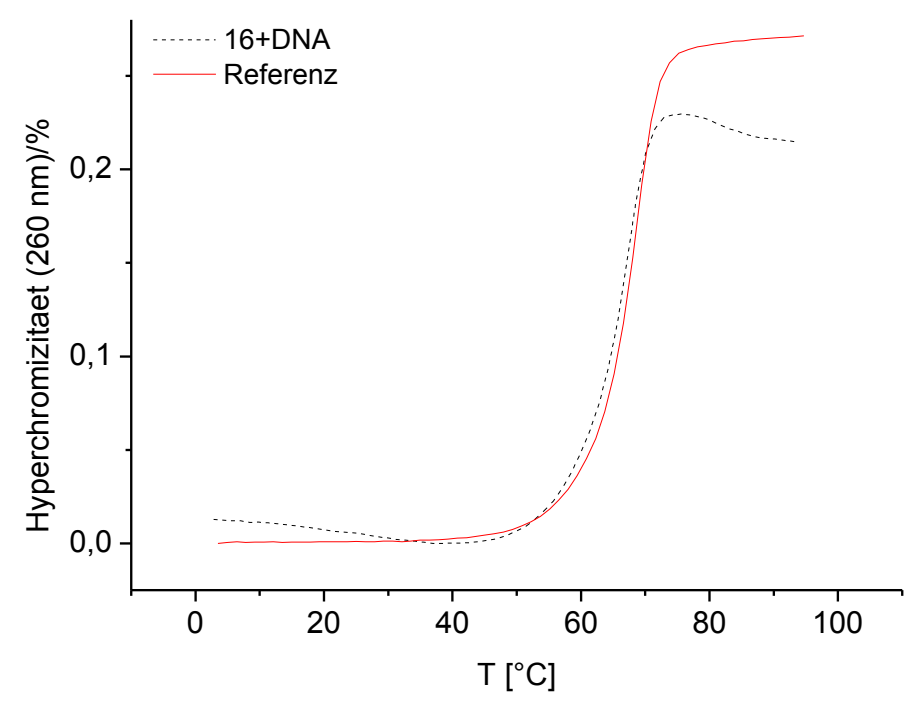

Oligonucleotid $16(R)$ : 5'-G TT GACG TT GACG TxT GACG TT G-3'

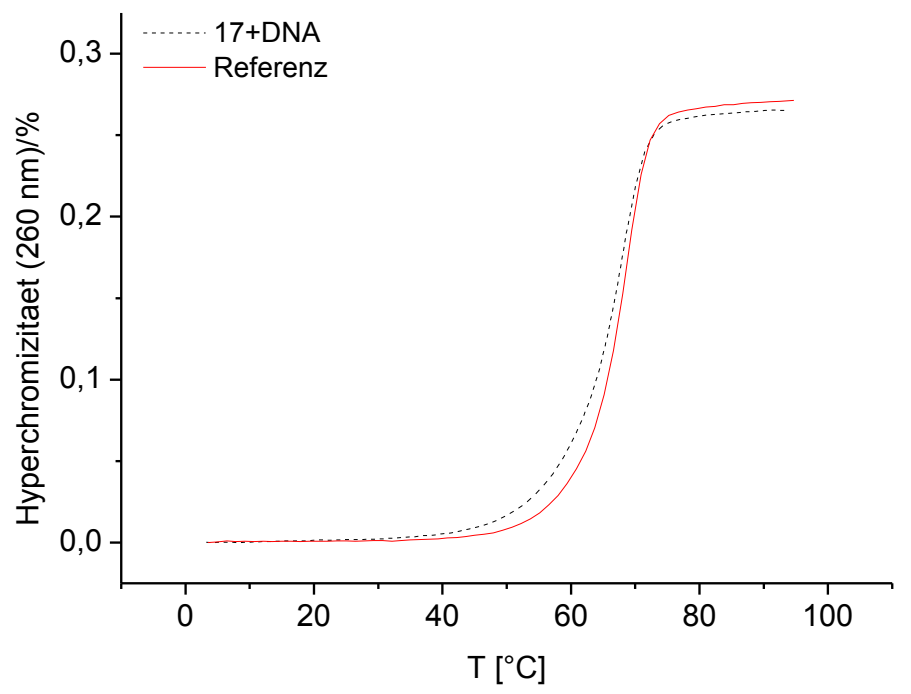

Oligonucleotid 17 (S): 5'-G TT GACG TT GACG TT GACG TxT G-3' 


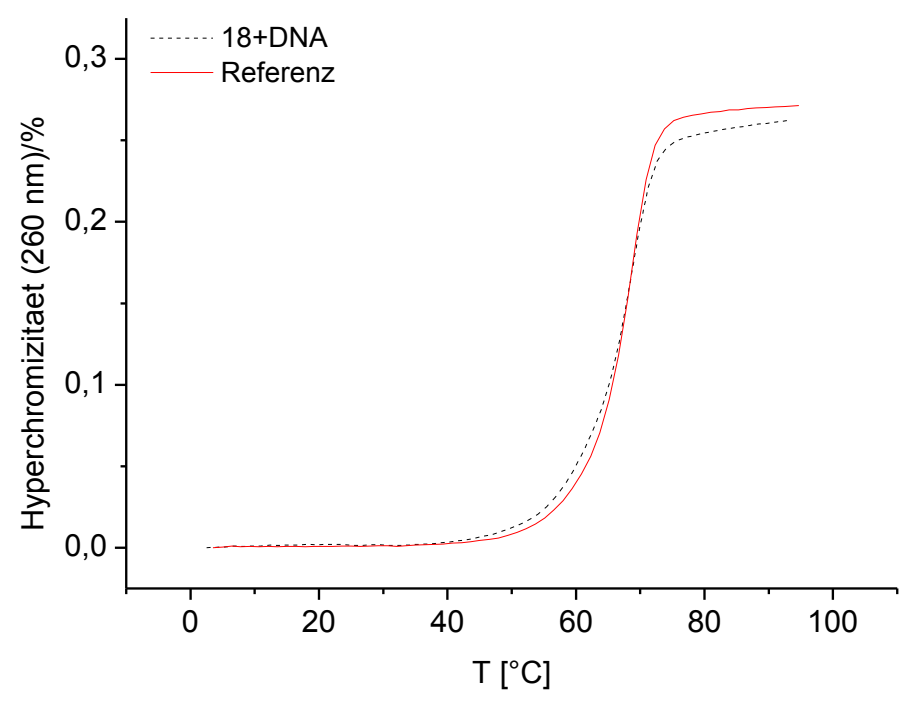

Oligonucleotid $18(R)$ : 5'-G TT GACG TT GACG TT GACG TxT G-3'

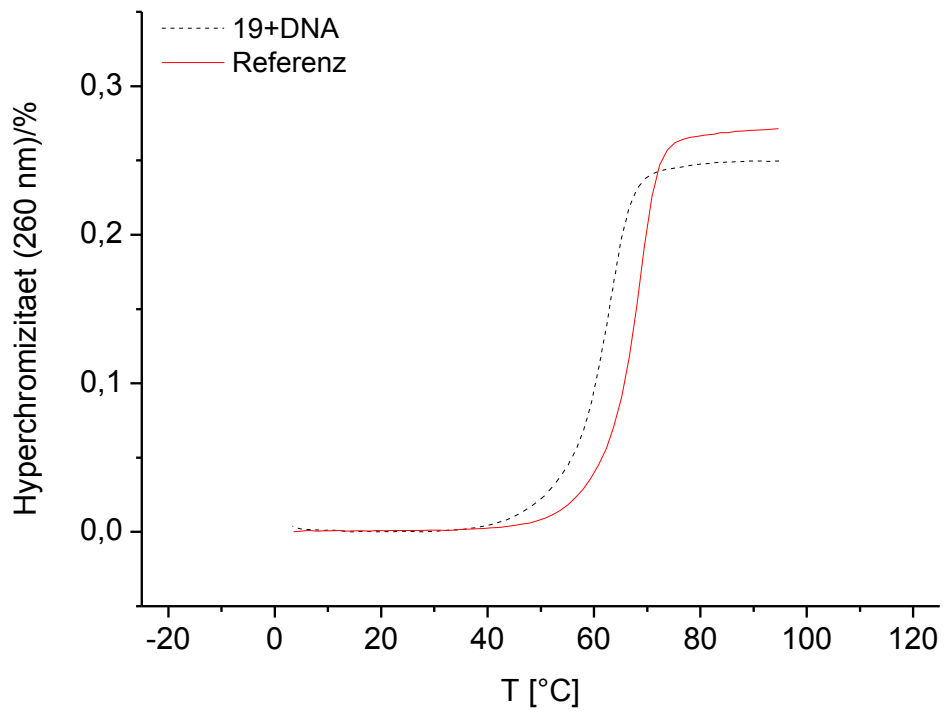

Oligonucleotid 19 (S): 5'-G TxT GACG TxT GACG TxT GACG TxT G-3' 


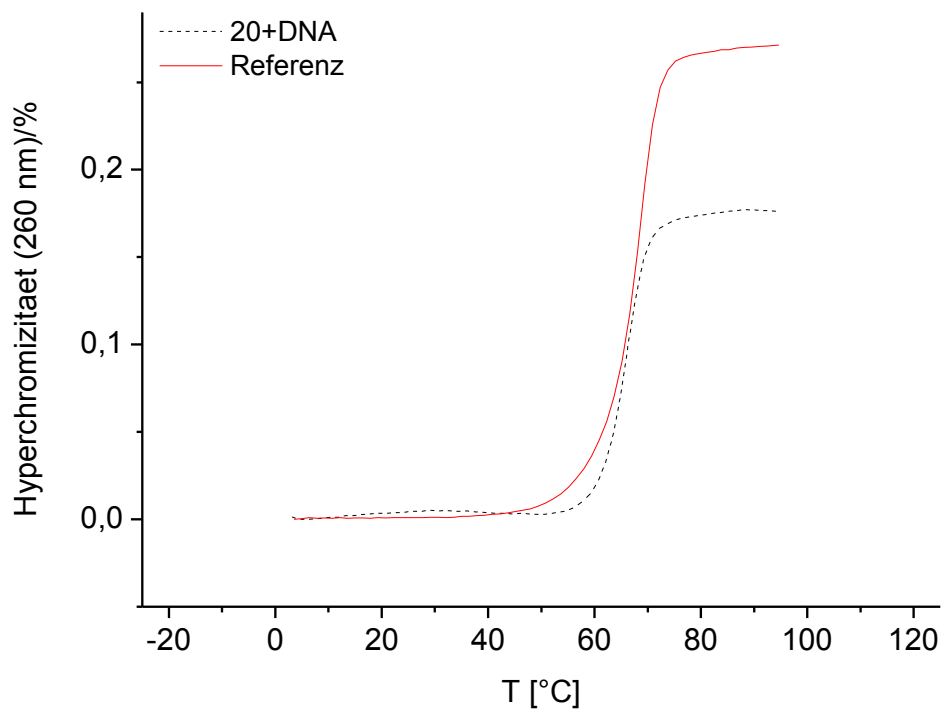

Oligonucleotid $20(R)$ : 5'-G TxT GACG TxT GACG TxT GACG TxT G-3'

Schmelzkurven von Duplices palindromer Oligonucleotide

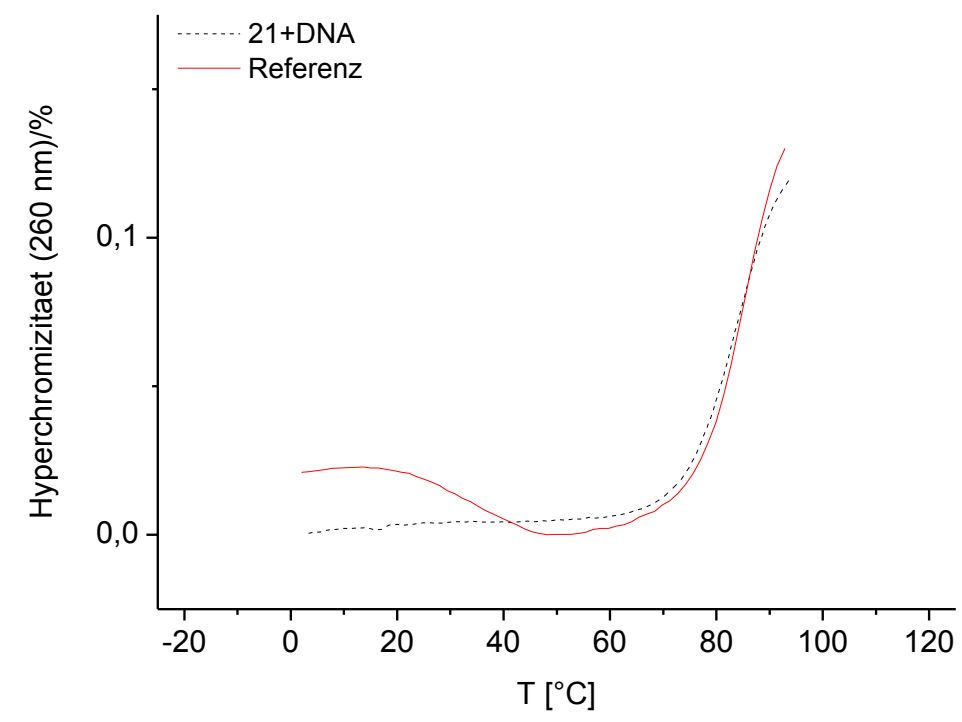

Oligonucleotid 21 (S): 5'-GCGC TxT GC TT AAGCAAGCGC-3' 


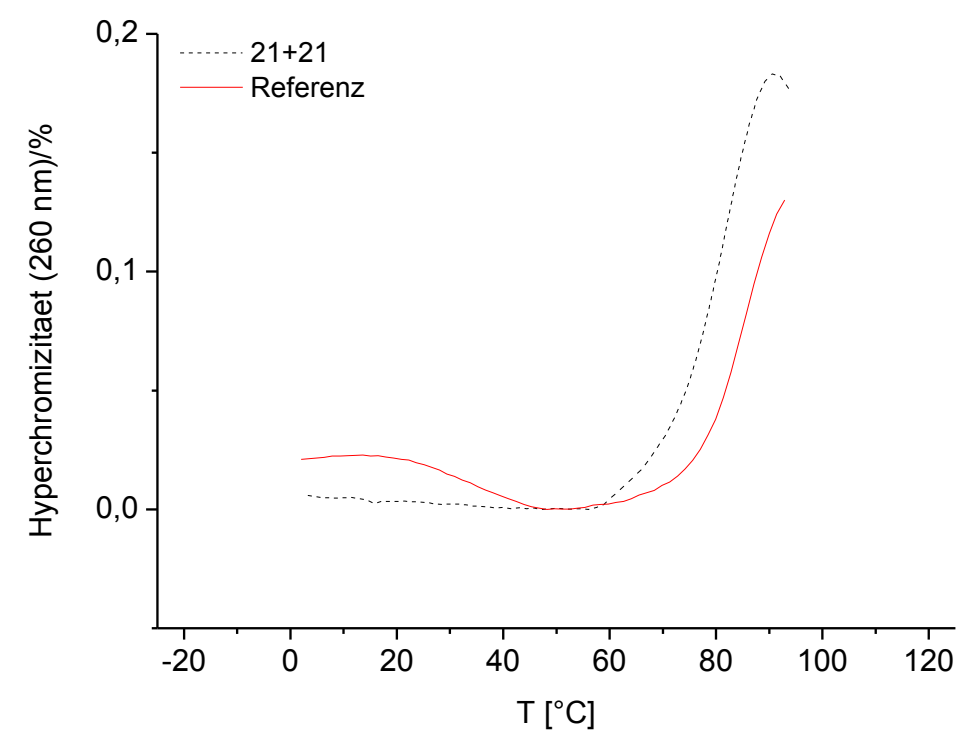

Oligonucleotid 21 (S): 5'-GCGC TxT GC TT AAGCAAGCGC-3'

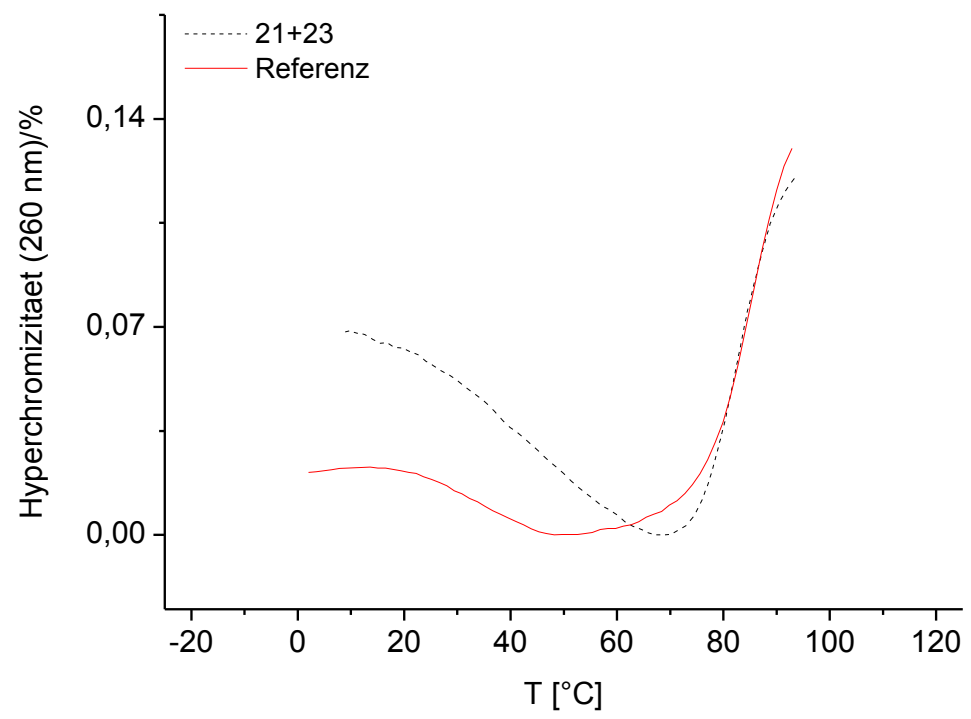

Oligonucleotid 21 (S): 5'-GCGC TxT GC TT AAGCAAGCGC-3' 


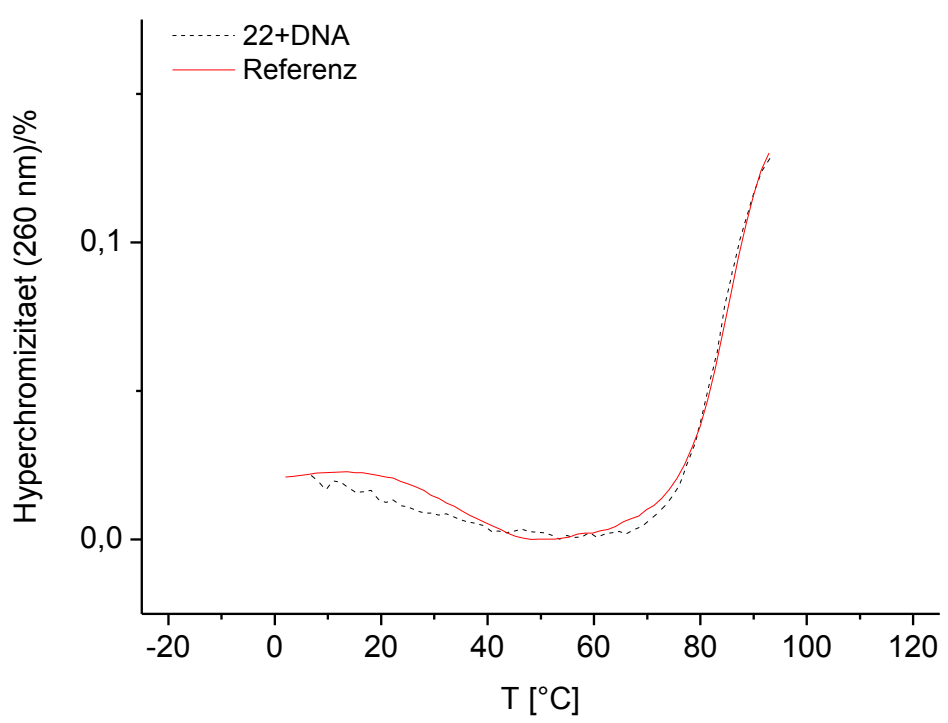

Oligonucleotid $22(R)$ : 5'-GCGC TxT GC TT AAGCAAGCGC-3'

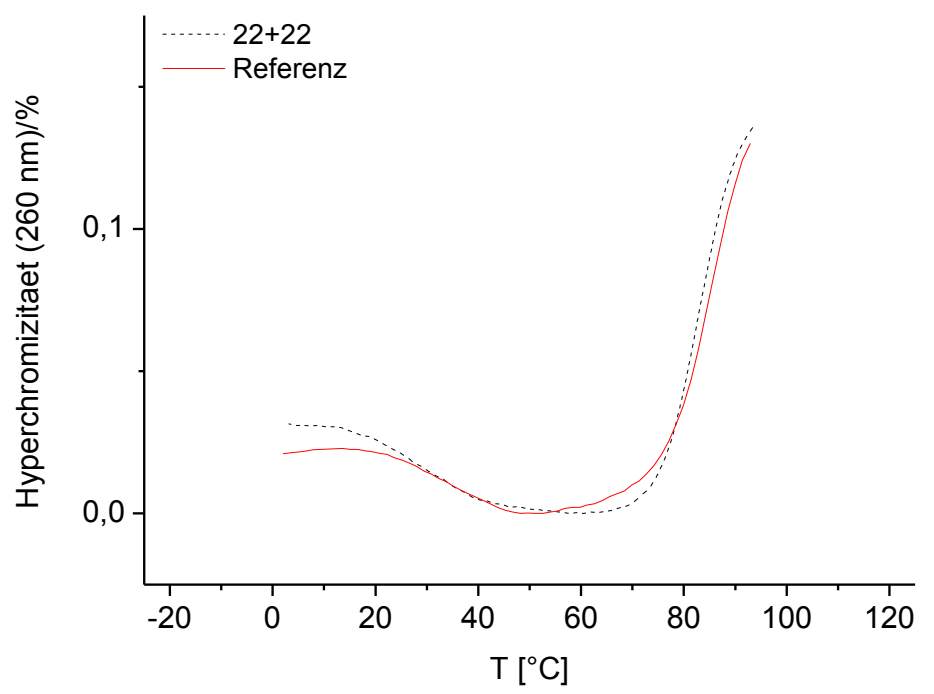

Oligonucleotid $22(R)$ : 5'-GCGC TxT GC TT AAGCAAGCGC-3' 


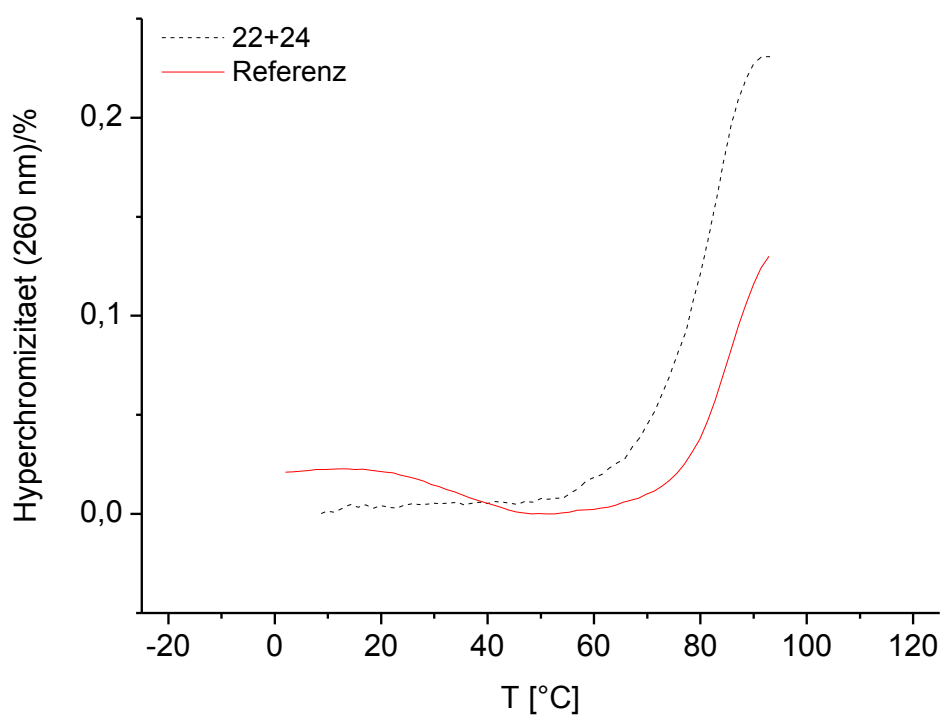

Oligonucleotid $22(R)$ : 5'-GCGC TxT GC TT AAGCAAGCGC-3'

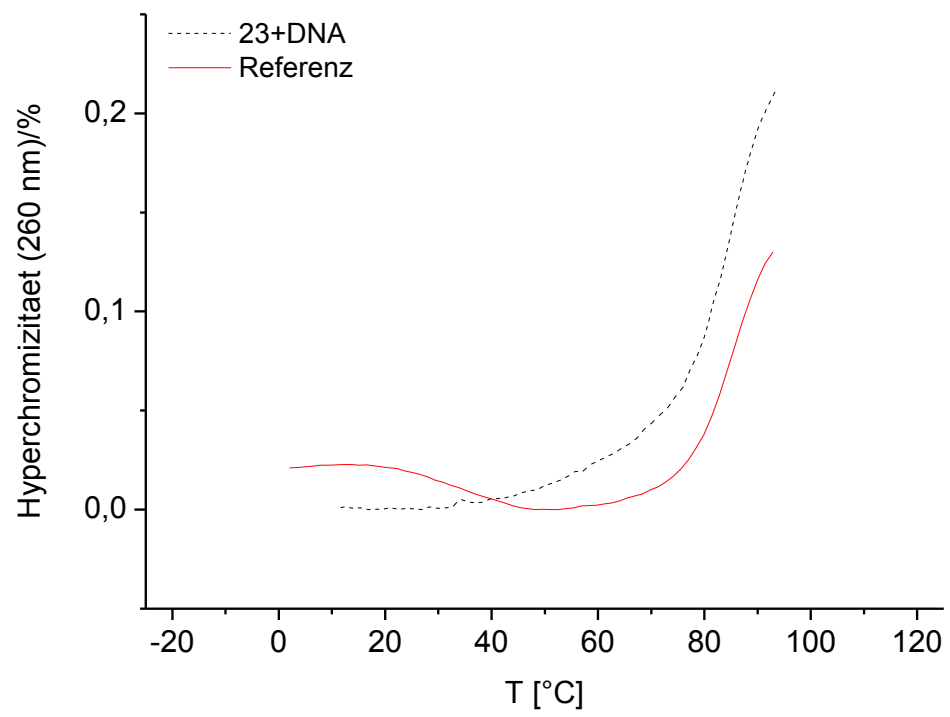

Oligonucleotid $23(R)$ : 5'-GCGC TT GC TxT AAGCAAGCGC-3' 


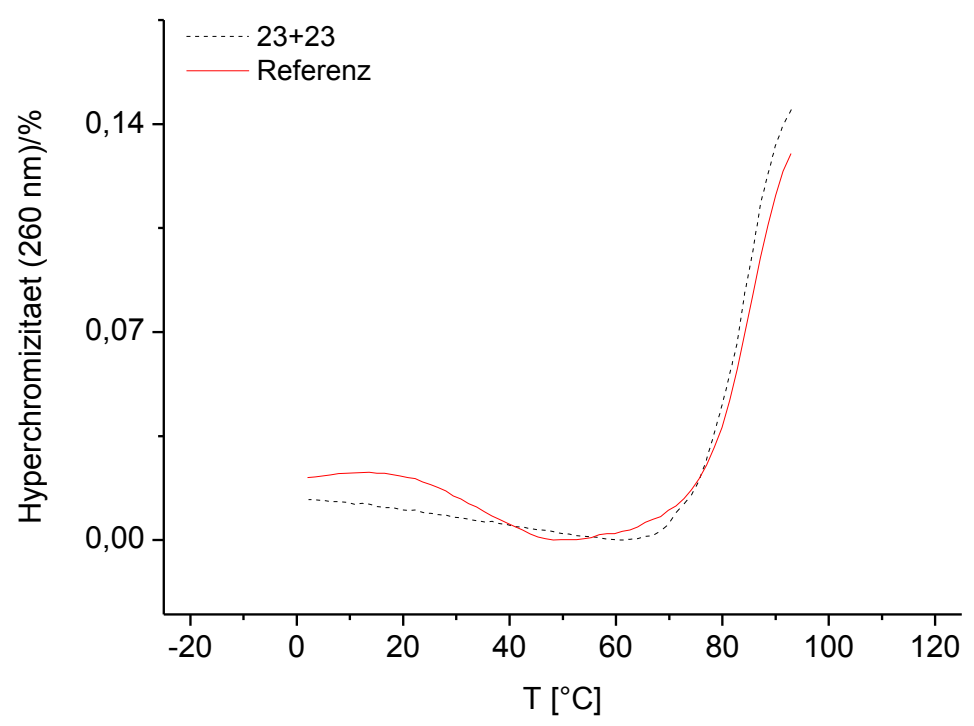

Oligonucleotid $23(S)$ : 5'-GCGC TT GC TxT AAGCAAGCGC-3'

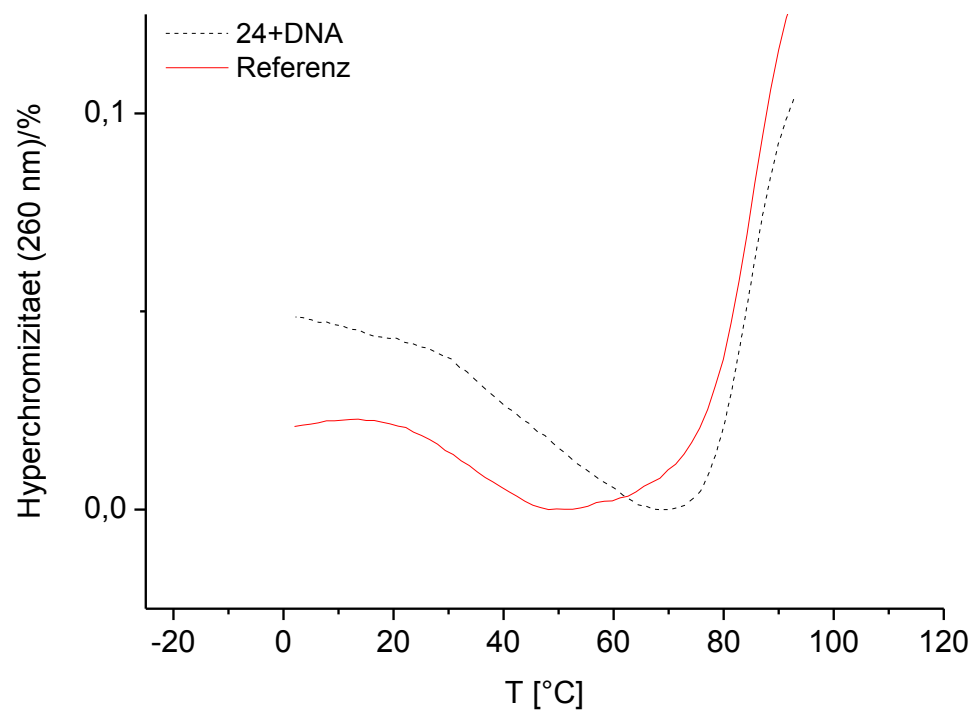

Oligonucleotid $24(R)$ : 5'-GCGC TT GC TxT AAGCAAGCGC-3' 


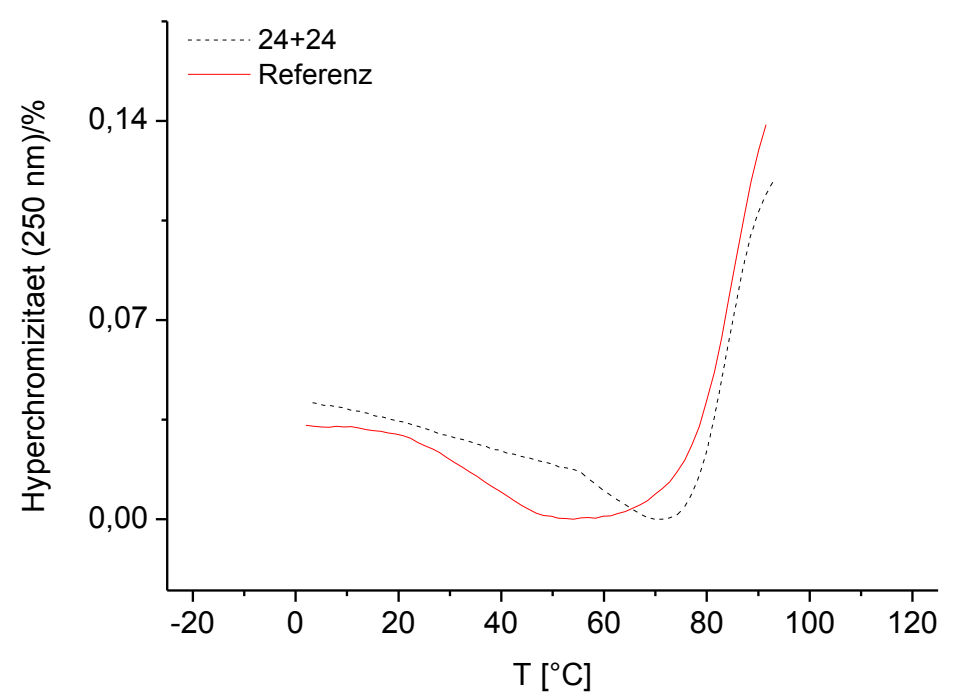

Oligonucleotid $24(R)$ : 5'-GCGC TT GC TxT AAGCAAGCGC-3'

\subsection{DNA-RNA-Duplices}

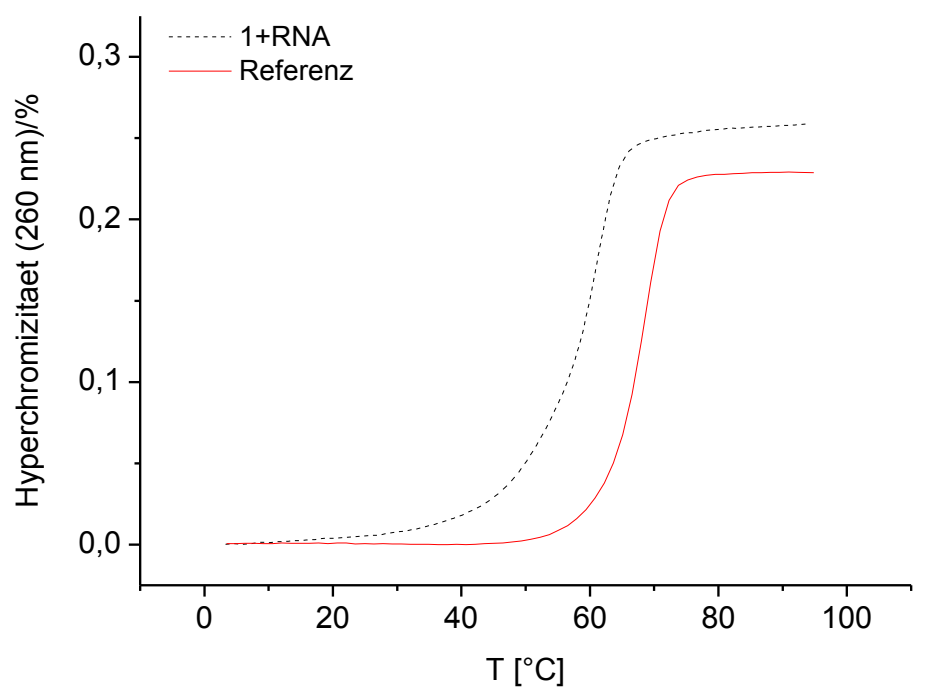

Oligonucleotid 1 (S): 5'-GGCACGG TxT TT TT TxT GGCACGG-3' 


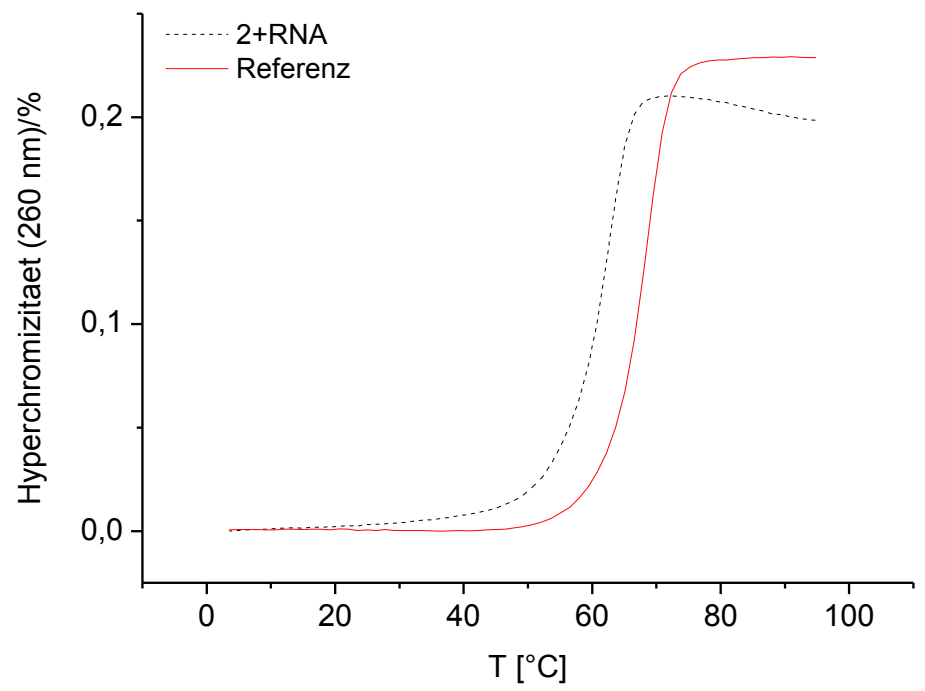

Oligonucleotid $2(R)$ : 5'-GGCACGG TxT TT TT TxT GGCACGG-3'

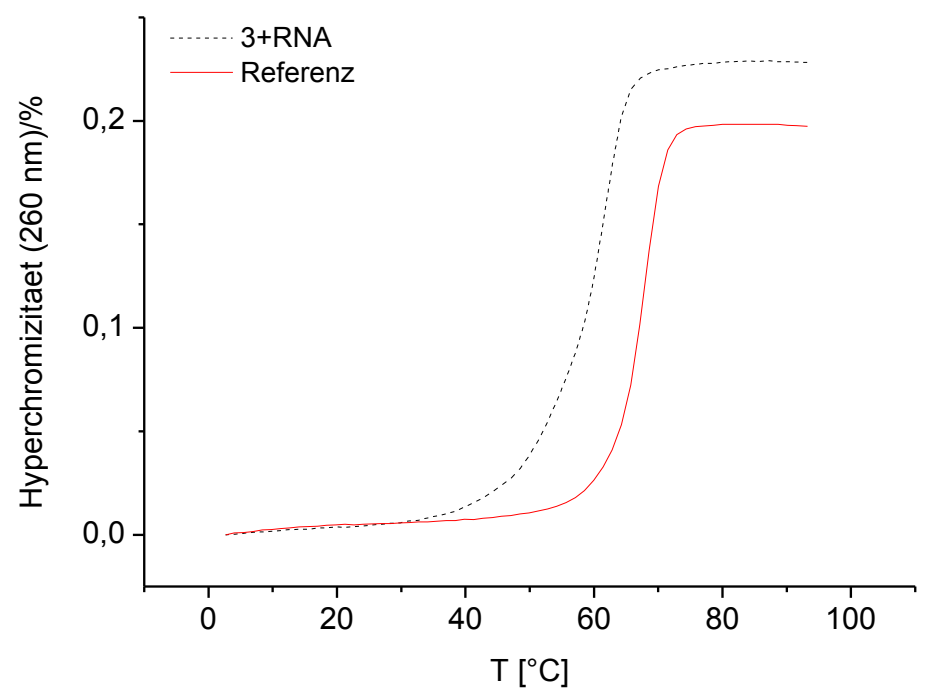

Oligonucleotid 3 (S): 5'-GGCACGG TxT TT TxT TT GGCACGG-3' 


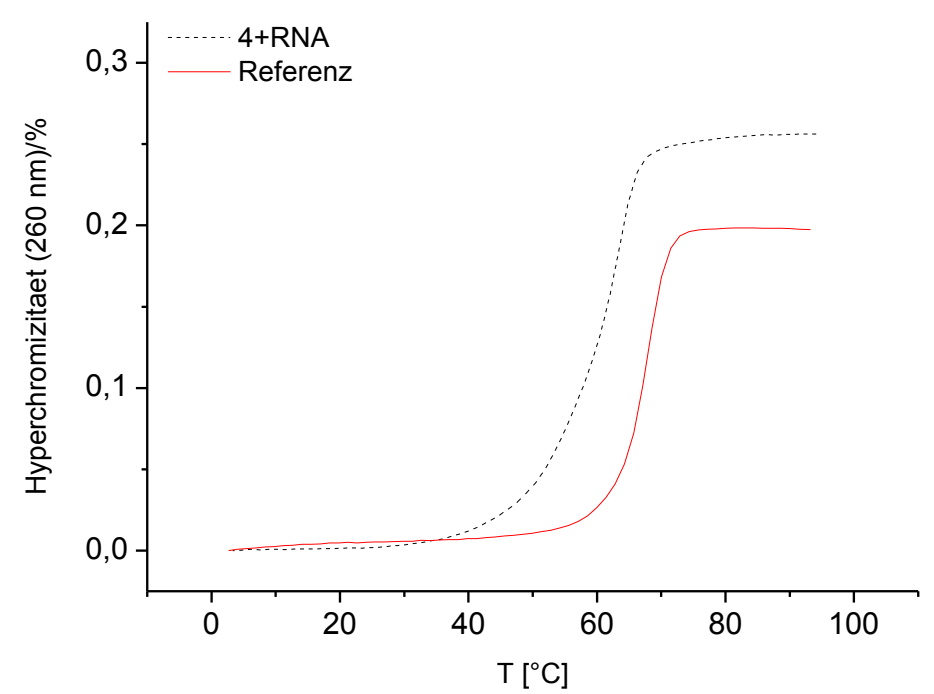

Oligonucleotid $4(R)$ : 5'-GGCACGG TxT TT TxT TT GGCACGG-3'

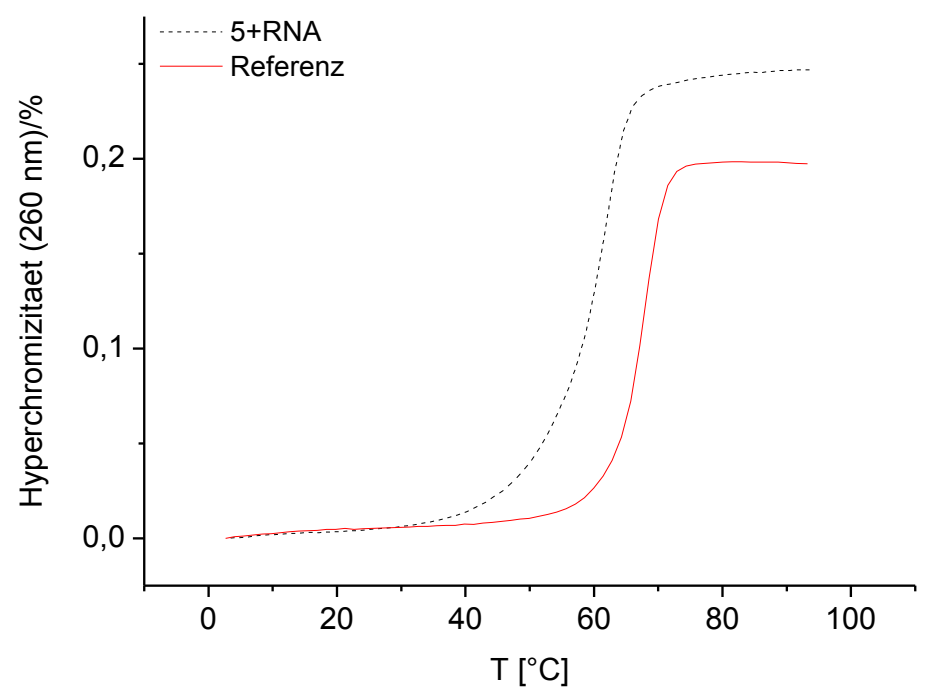

Oligonucleotid 5 (S): 5'-GGCACGG TxT TxT TT TT GGCACGG-3' 


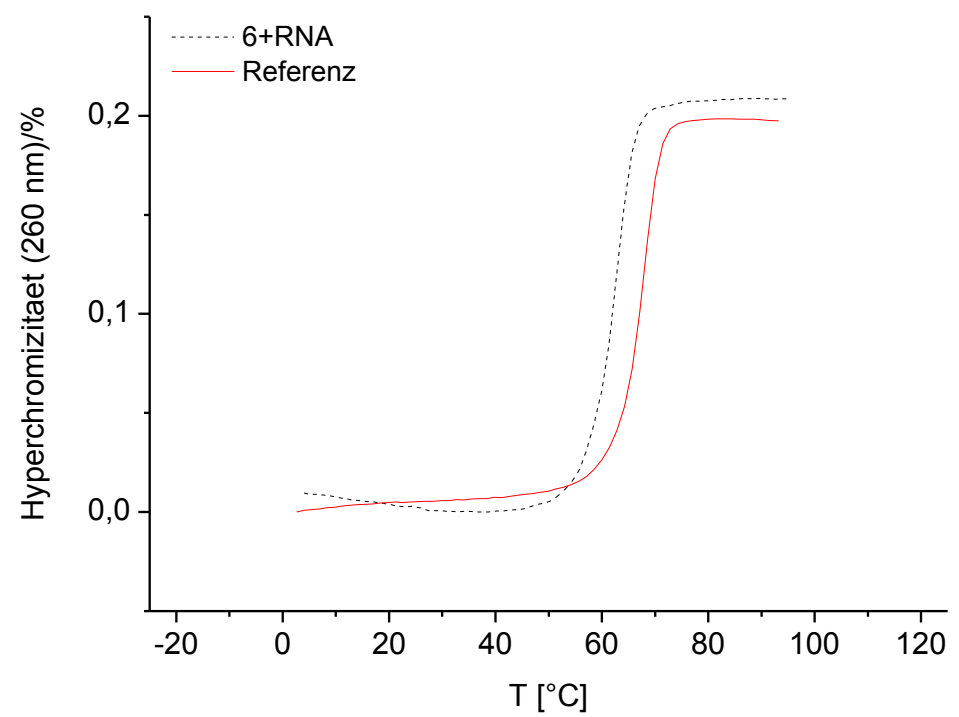

Oligonucleotid $6(R)$ : 5'-GGCACGG TxT TxT TT TT GGCACGG-3'

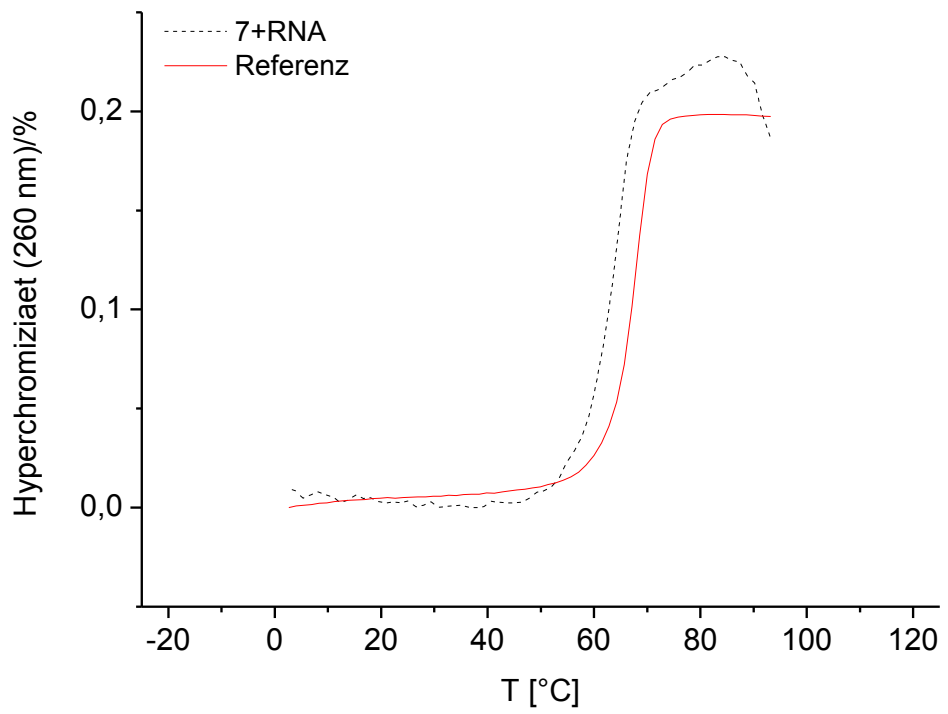

Oligonucleotid 7 (S): 5'-GGCACGG TxT TT TT TT GGCACGG-3' 


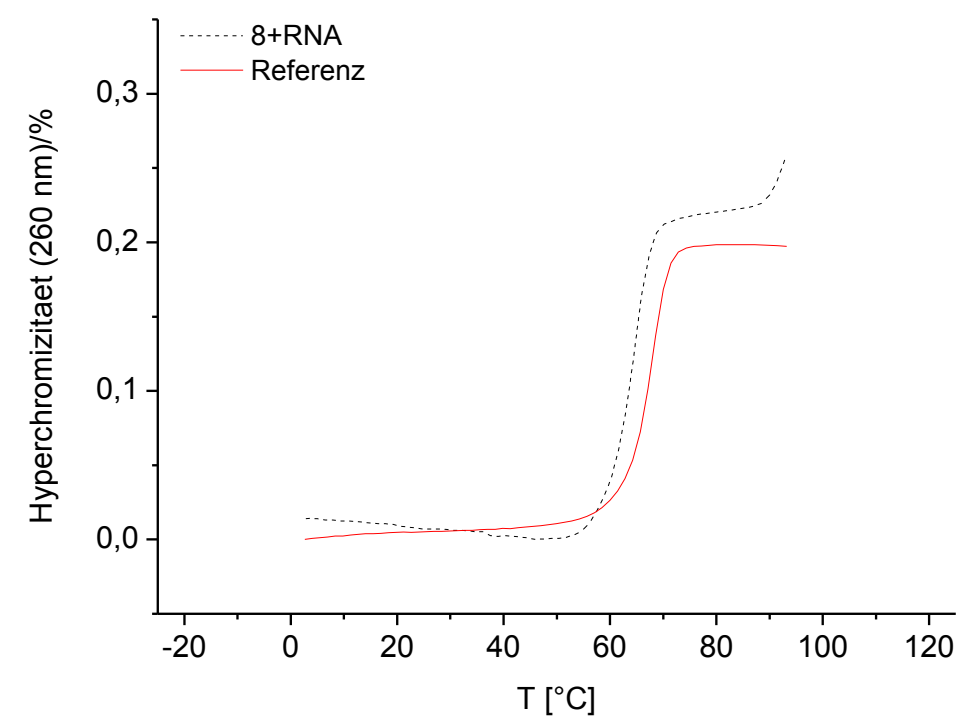

Oligonucleotid $8(R)$ : 5'-GGCACGG TxT TT TT TT GGCACGG-3'

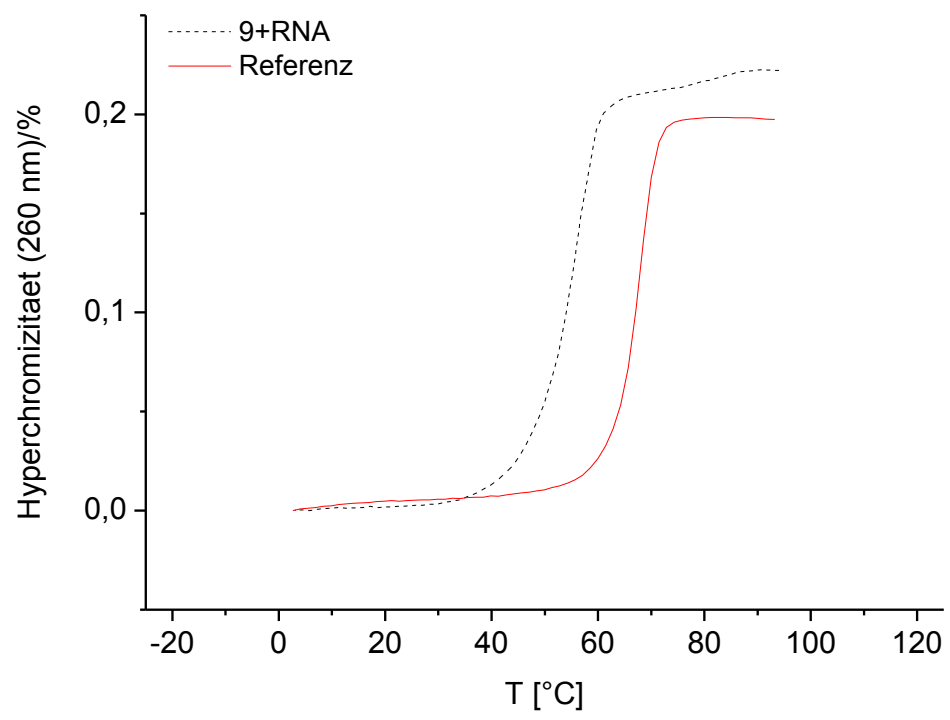

Oligonucleotid 9 (S): 5'-GGCACGG TxT TxT TxT TxT GGCACGG-3' 


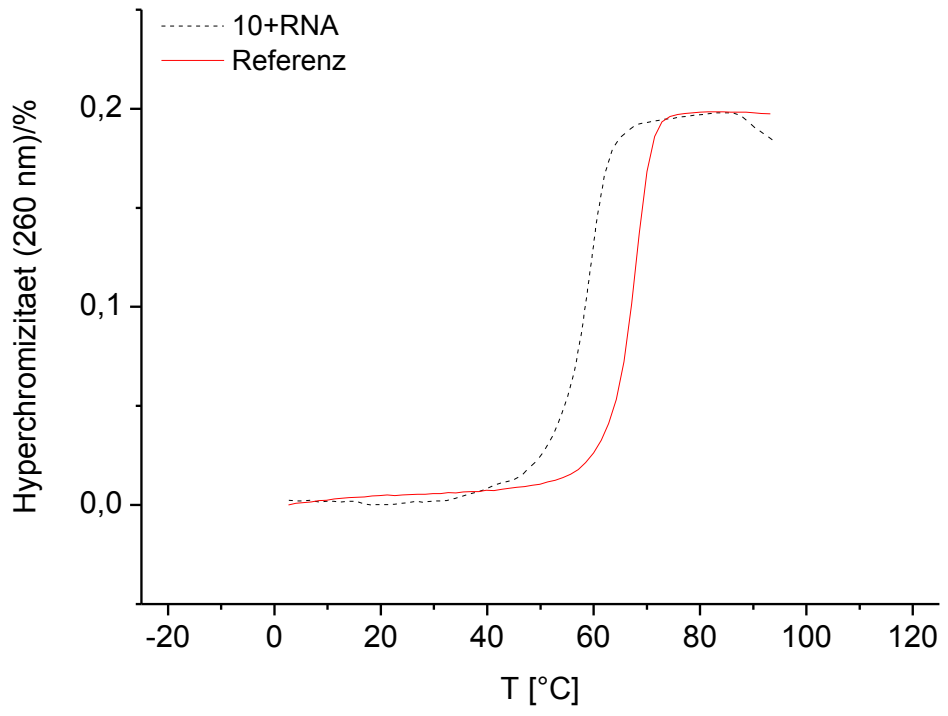

Oligonucleotid $10(R)$ : 5'-GGCACGG TxT TXT TxT TXT GGCACGG-3'

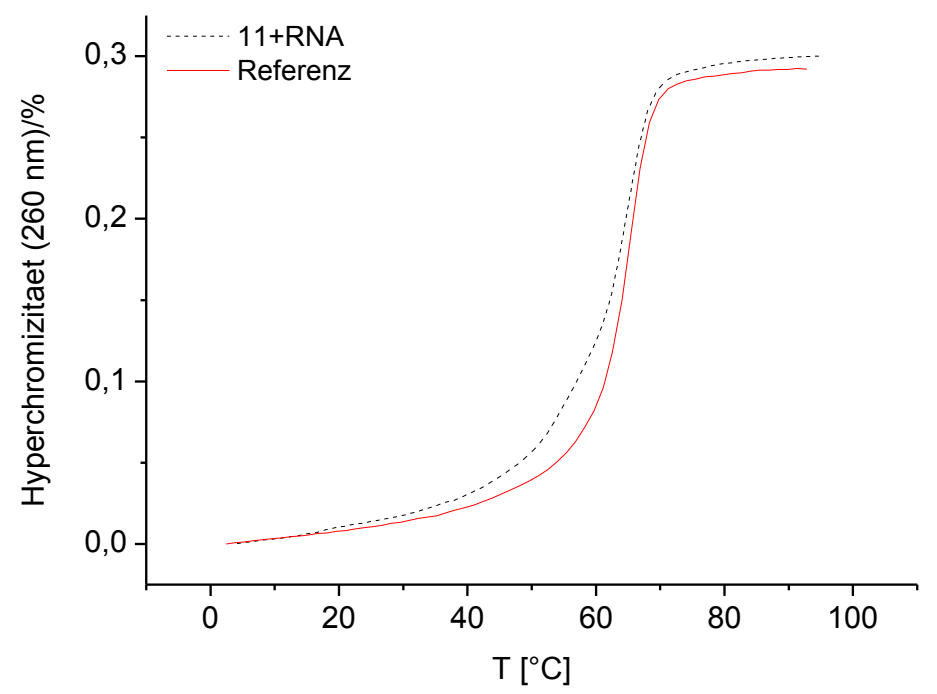

Oligonucleotid 11 (S): 5'-G TxT GACG TT GACG TT GACG TT G-3' 


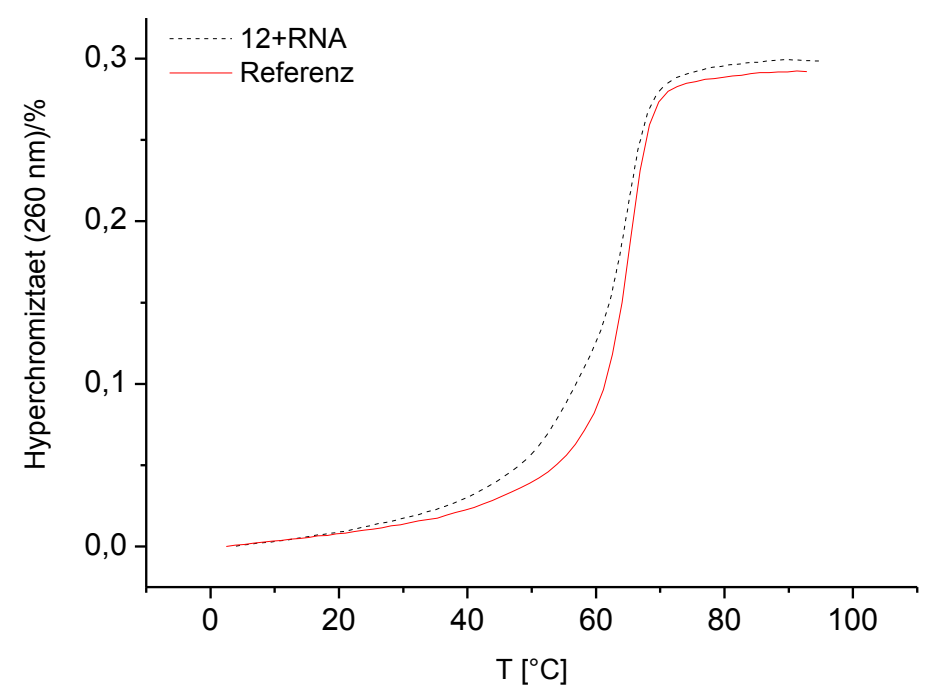

Oligonucleotid $12(R)$ : 5'-G TxT GACG TT GACG TT GACG TT G-3'

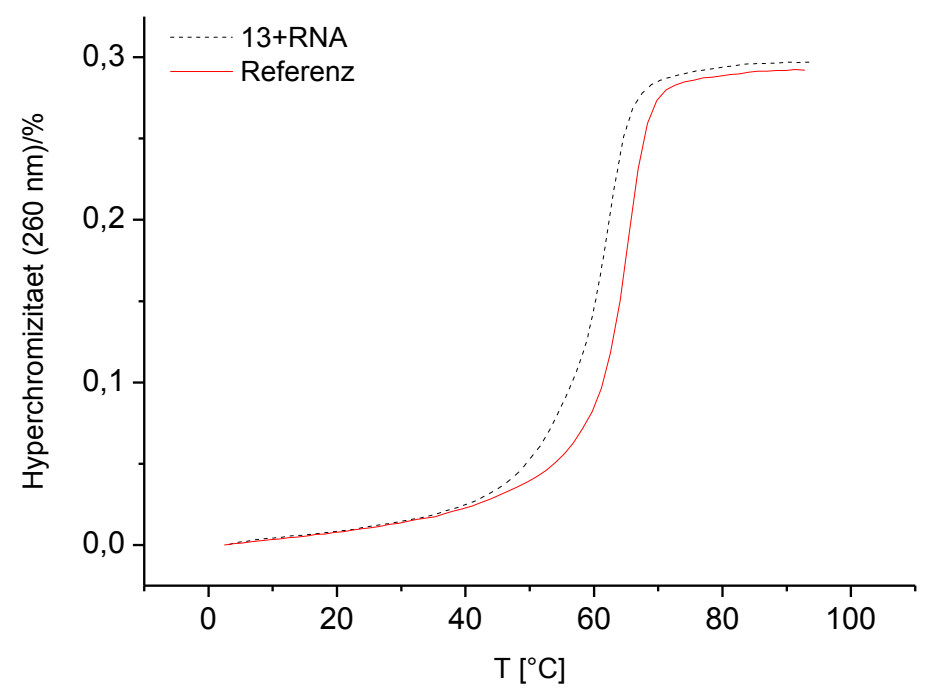

Oligonucleotid 13 (S): 5'-G TT GACG TxT GACG TT GACG TT G-3' 


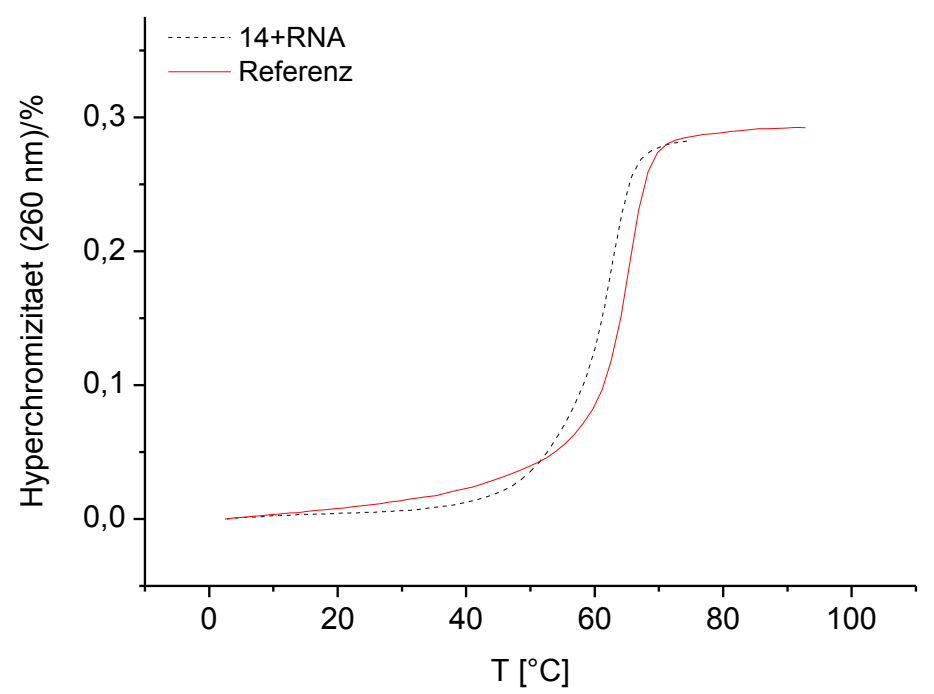

Oligonucleotid $14(R)$ : 5'-G TT GACG TxT GACG TT GACG TT G-3'

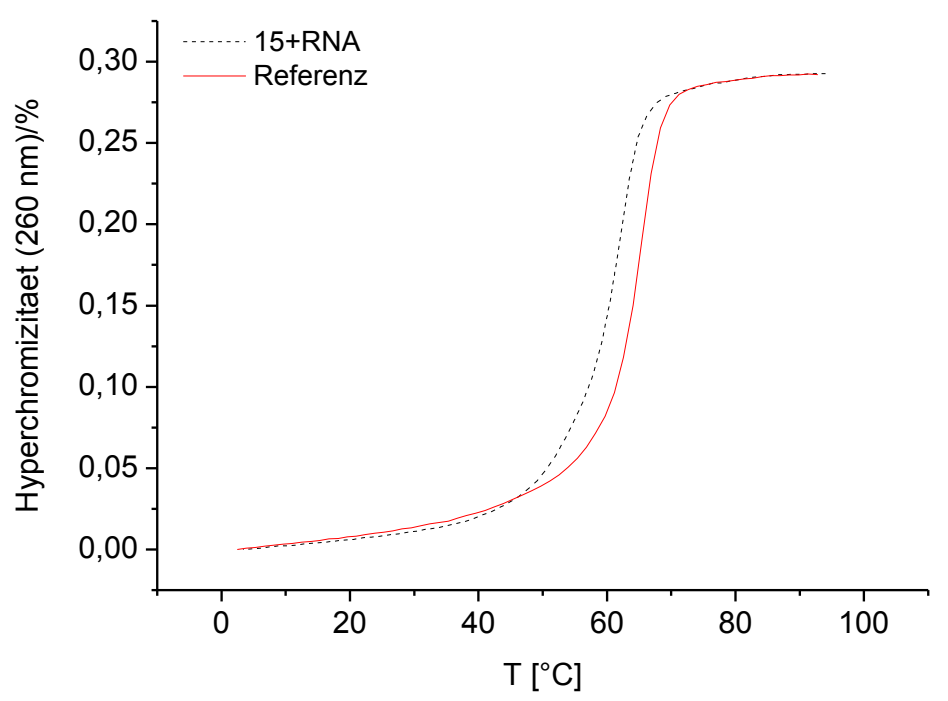

Oligonucleotid 15 (S): 5'-G TT GACG TT GACG TxT GACG TT G-3' 


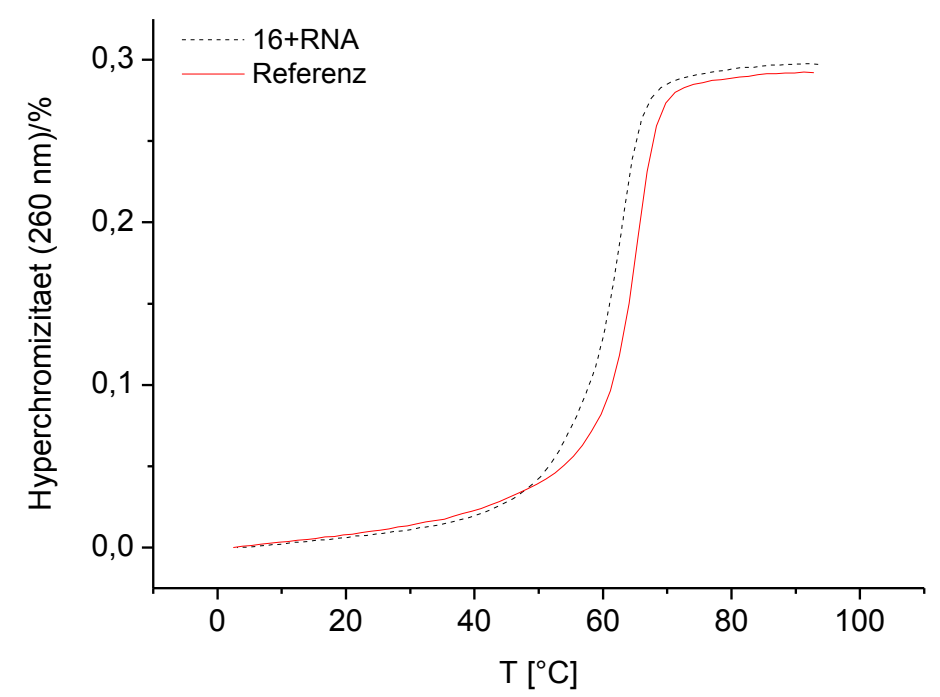

Oligonucleotid $16(R)$ : 5'-G TT GACG TT GACG TxT GACG TT G-3'

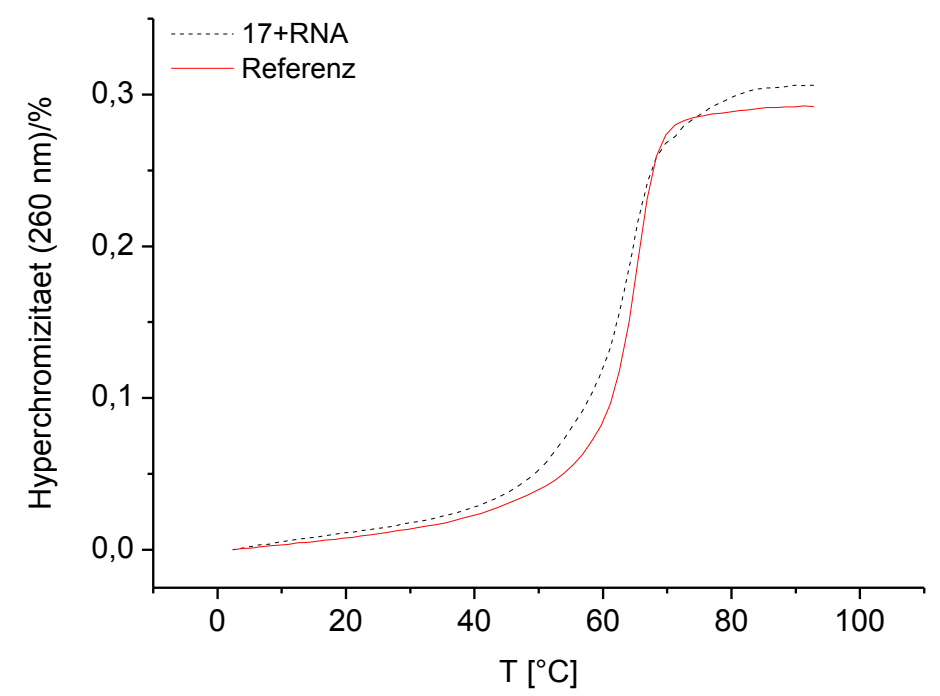

Oligonucleotid 17 (S): 5'-G TT GACG TT GACG TT GACG TxT G-3' 


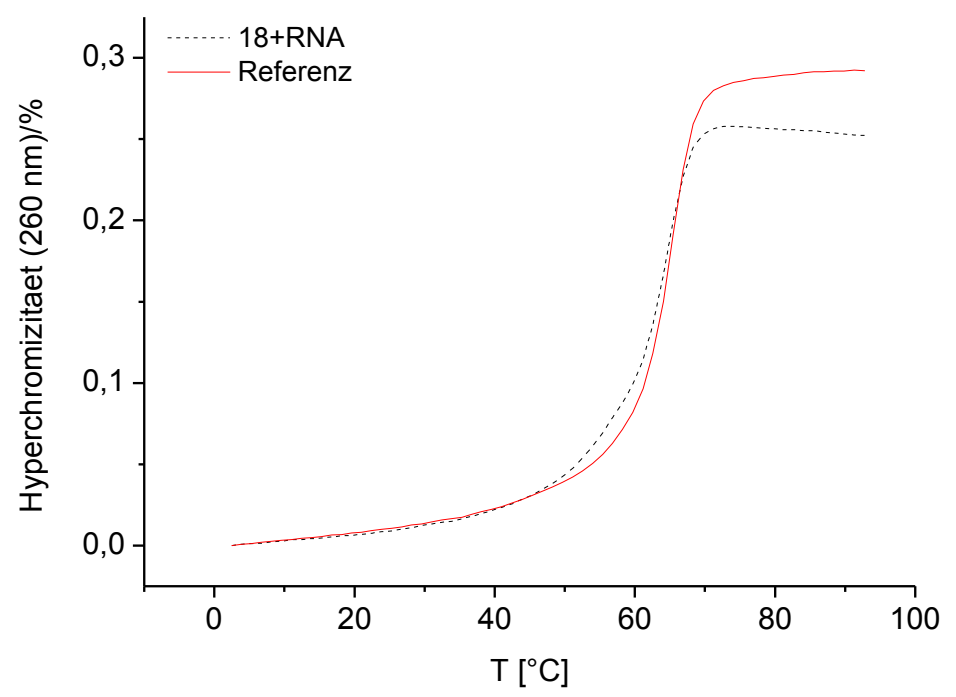

Oligonucleotid $18(R)$ : 5'-G TT GACG TT GACG TT GACG TxT G-3'

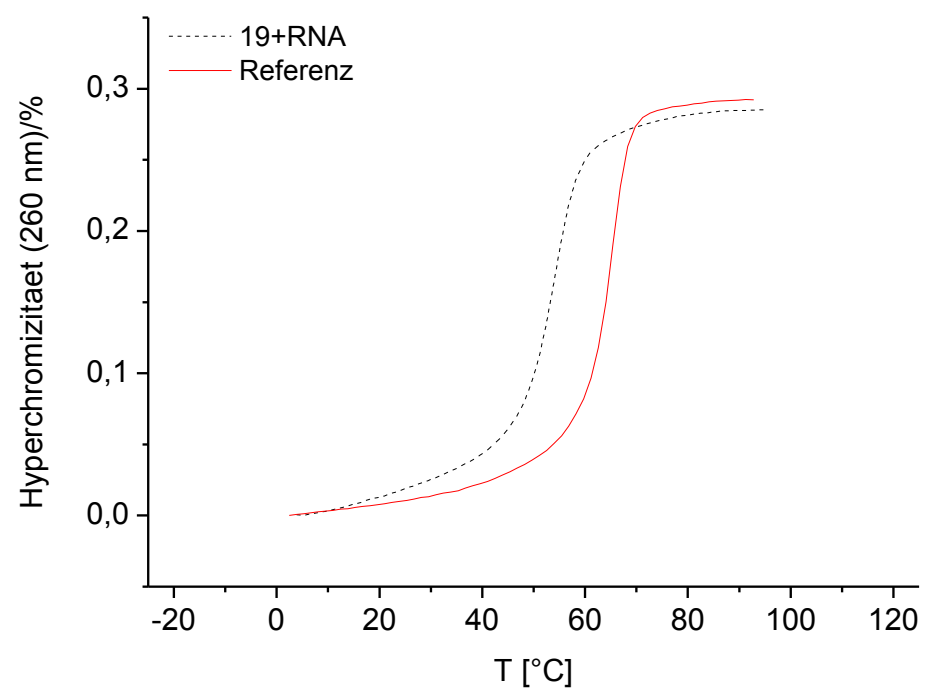

Oligonucleotid 19 (S): 5'-G TxT GACG TxT GACG TxT GACG TxT G-3' 


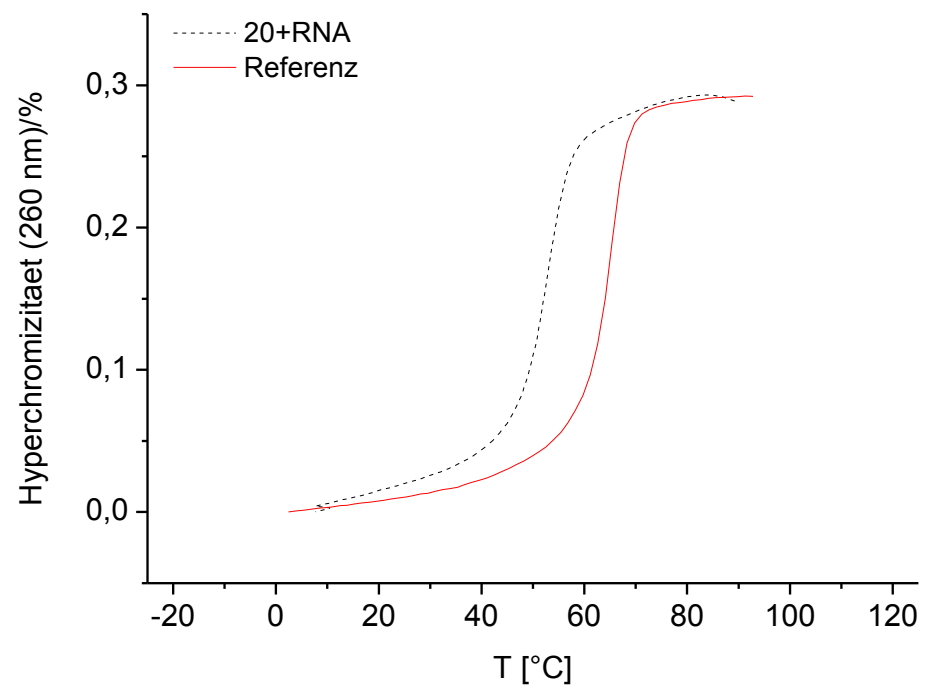

Oligonucleotid $20(R)$ : 5'-G TxT GACG TxT GACG TxT GACG TxT G-3'

\subsubsection{Schmelzkurven von Duplices mit Fehlpaarungen (Mismatch)}

Die Nummern der Oligonucleotide entsprechen denjenigen in 9.2.1.1 (Tab. 4). Die rot gekennzeichneten Nucleotide stellen die Mismatch-Position dar. In jedem Diagramm bildet die rote Kurve den Denaturierungs- und Renaturierungsprozess der Duplex ohne Mismatch ab. Die anderen Kurven geben den entsprechenden Vorgang bei Vorhandensein einer Fehlpaarung wider (z.B. MMC14: Mismatch T-C an Position 14).

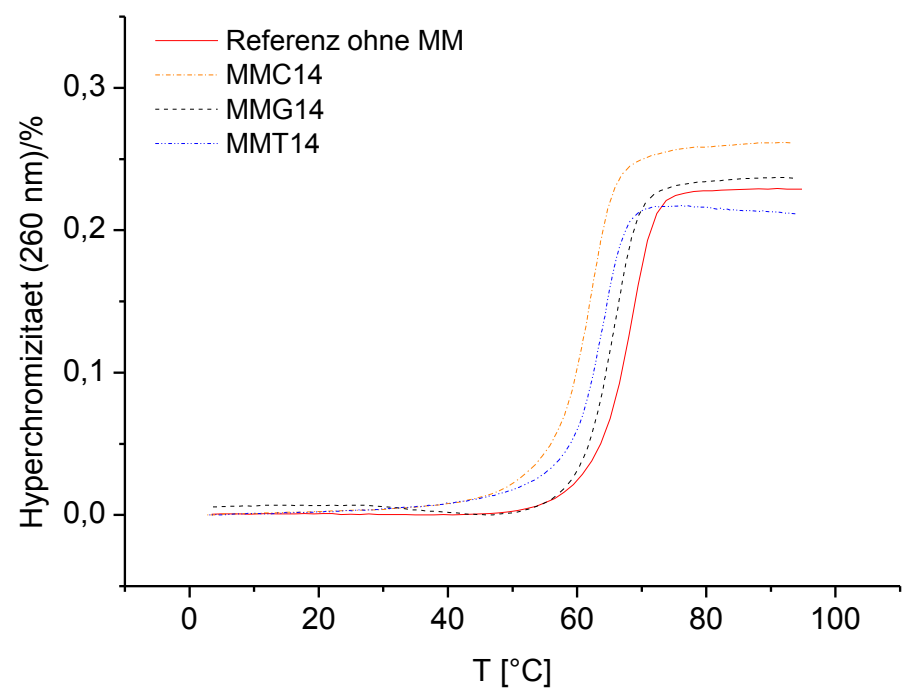

Oligonucleotid 1: 5'-G TT GACG TI GACG TT GACG TT G-3' (Referenz) 


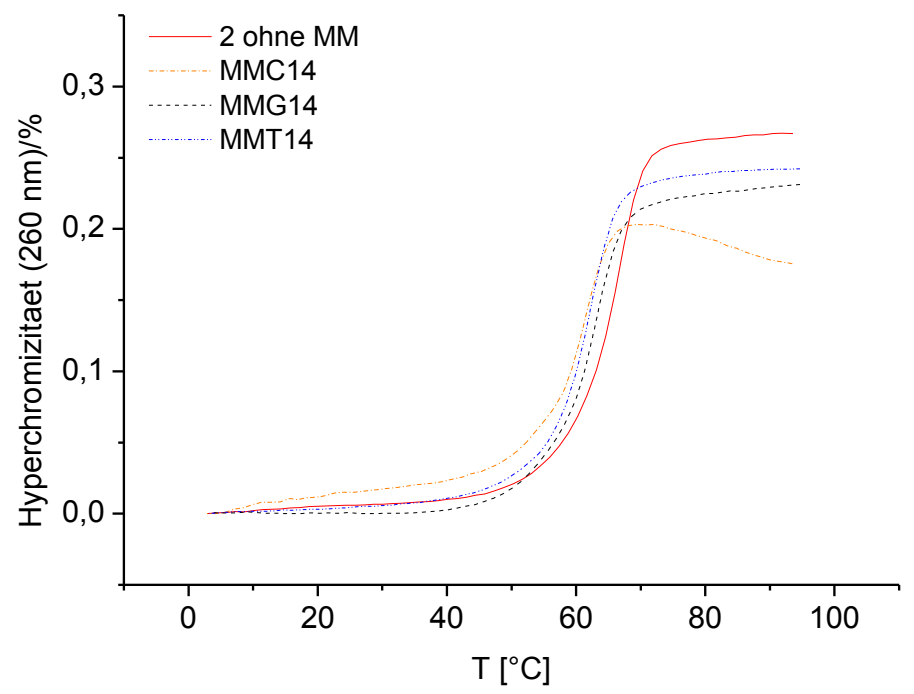

Oligonucleotid 2 (S): 5'-G TT GACG TxI GACG TT GACG TT G-3'

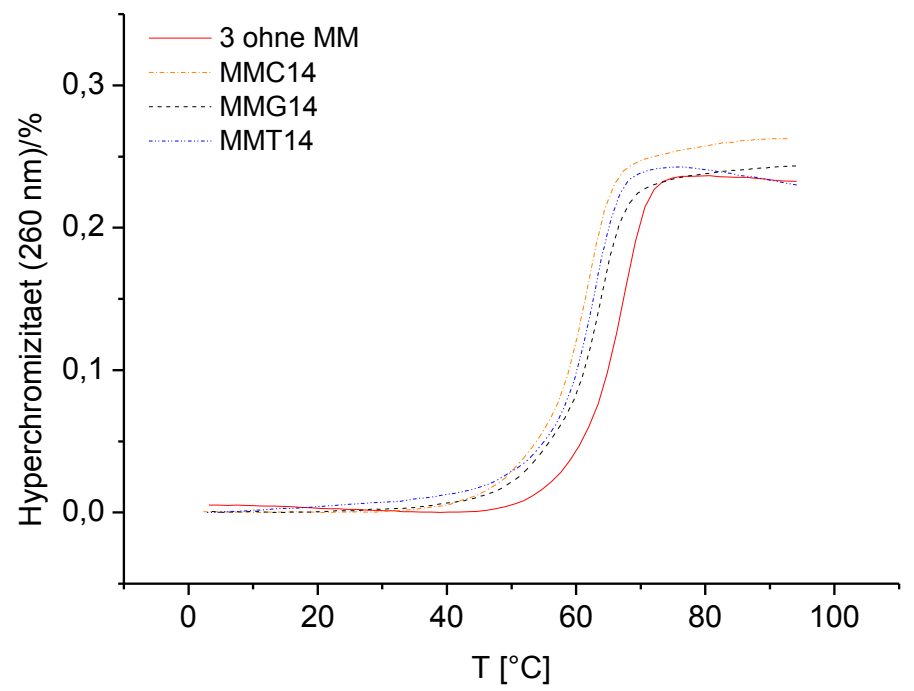

Oligonucleotid $3(R)$ : 5'-G TT GACG TxI GACG TT GACG TT G-3' 


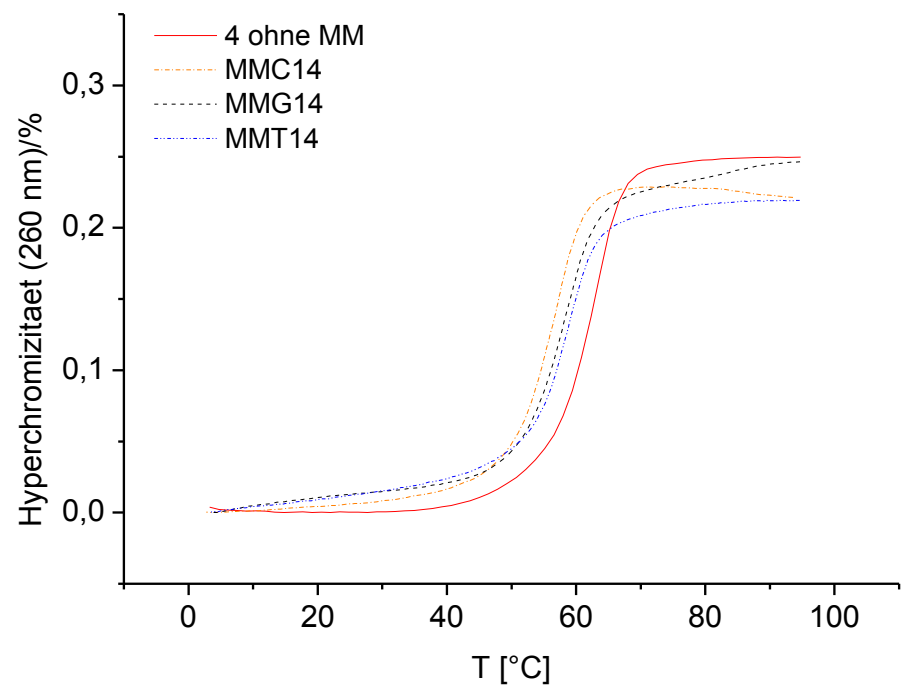

Oligonucleotid 4 (S): 5'-G TxT GACG TxI GACG TxT GACG TxT G-3'

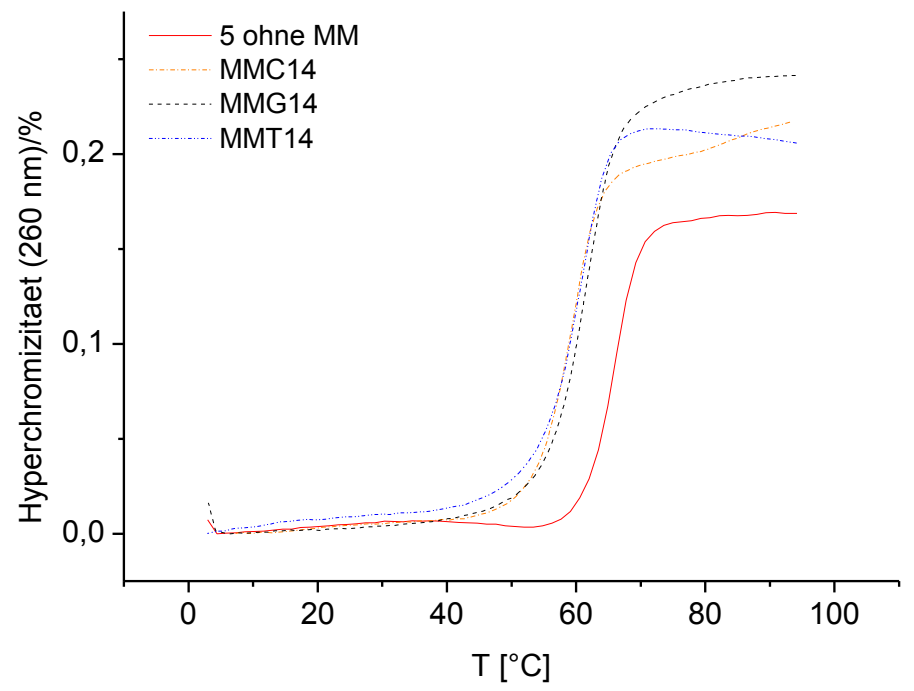

Oligonucleotid $5(R)$ : 5'-G TxT GACG TxI GACG TxT GACG TxT G-3' 


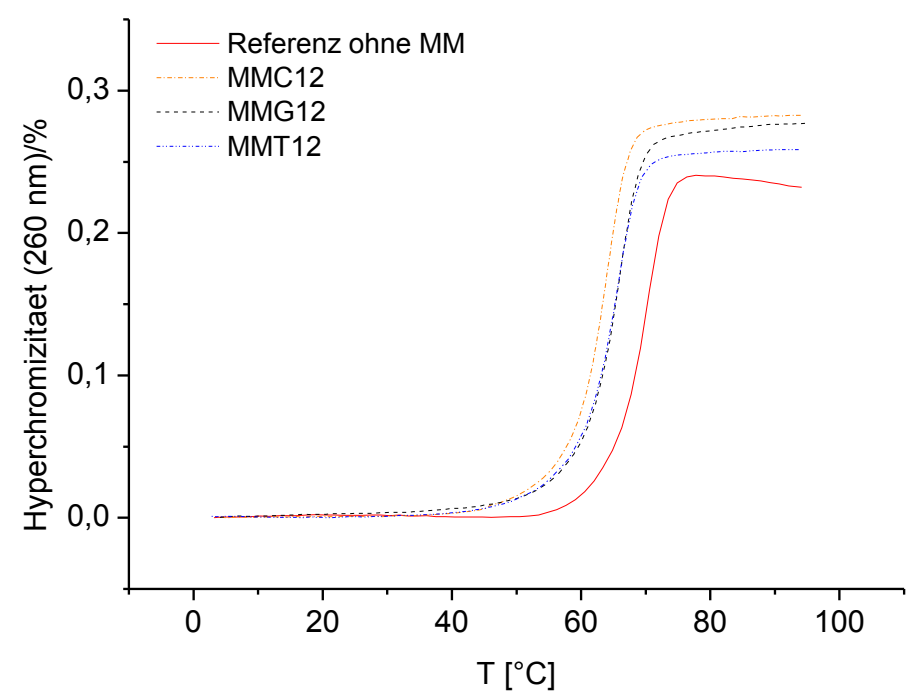

Oligonucleotid 6: 5'-GGCACGG TTTTTTTT GGCACGG-3' (Referenz)

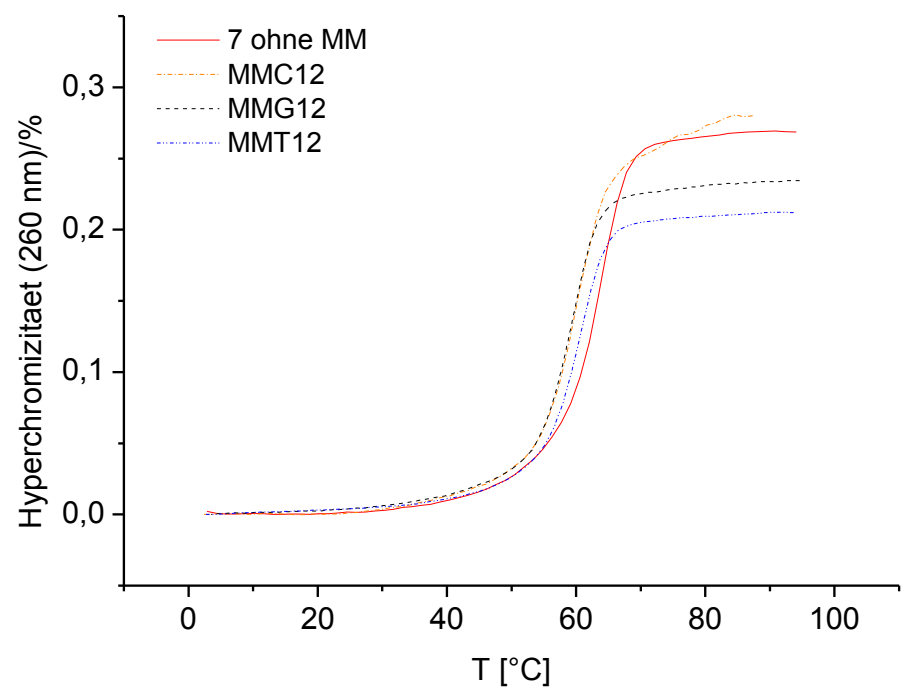

Oligonucleotid 7 (S): 5'-GGCACGG TxTTxITxTTxT GGCACGG-3' 


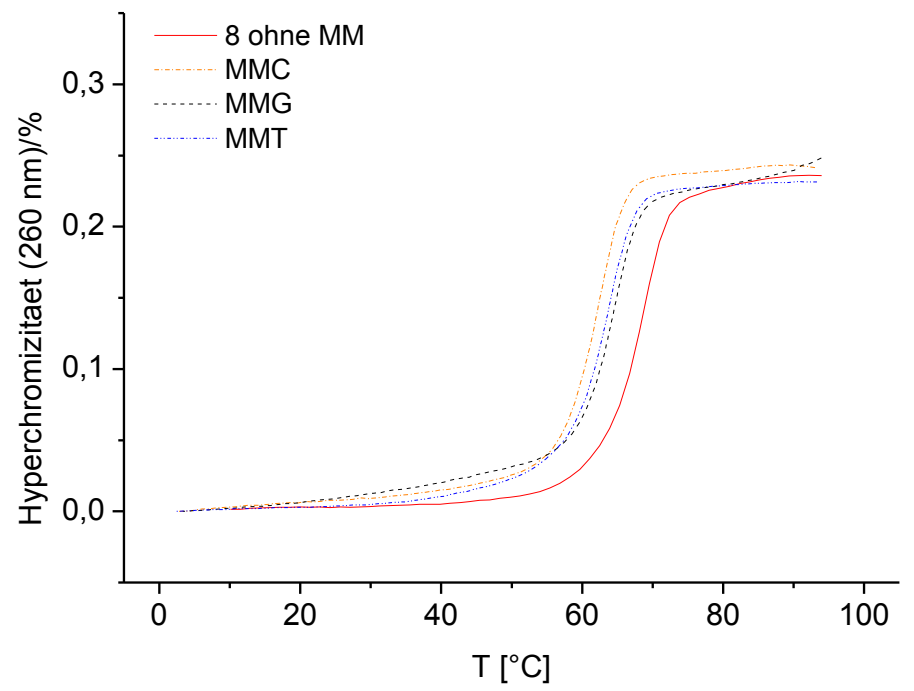

Oligonucleotid $8(R)$ : 5'-GGCACGG TxTTxITxTTxT GGCACGG-3'

\subsubsection{Schmelzkurven bei erhöhter $\mathrm{NaCl}$-Konzentration}

Die Nummern der Oligonucleotide entsprechen denjenigen in 9.2.1.2 (Tabellen 1-4). In jedem Diagramm bildet die rote, durchgängige Kurve den Denaturierungs- und Renaturierungsprozess der jeweiligen Duplex bei Standardbedingungen (s. 7.1.6.4) ab. Die gestrichelten Kurven geben den entsprechenden Vorgang bei erhöhten $\mathrm{NaCl}$ Konzentrationen wieder.

\subsection{DNA-DNA-Duplices}

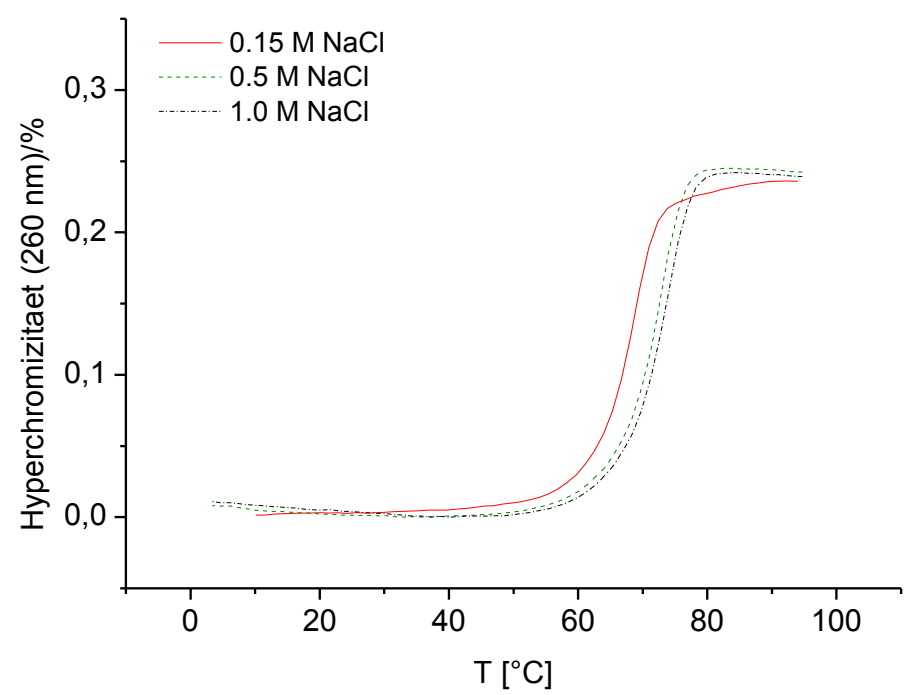

Oligonucleotid $1(R)$ : 5'-GGCACGG TxT TxT TxT TxT GGCACGG-3' 


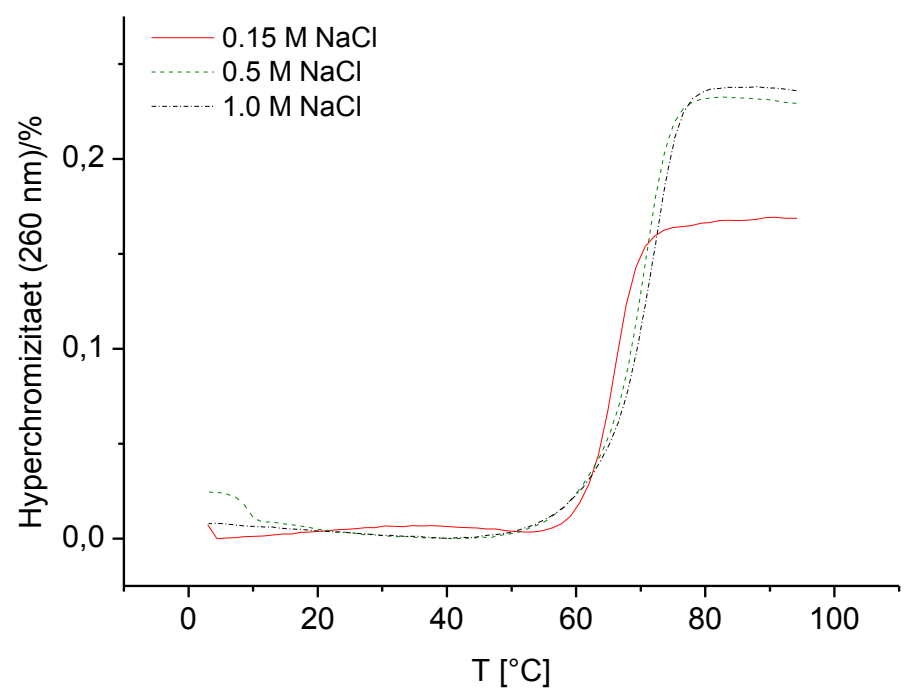

Oligonucleotid $2(R)$ : 5'-G TxT GACG TxT GACG TxT GACG TxT G-3'

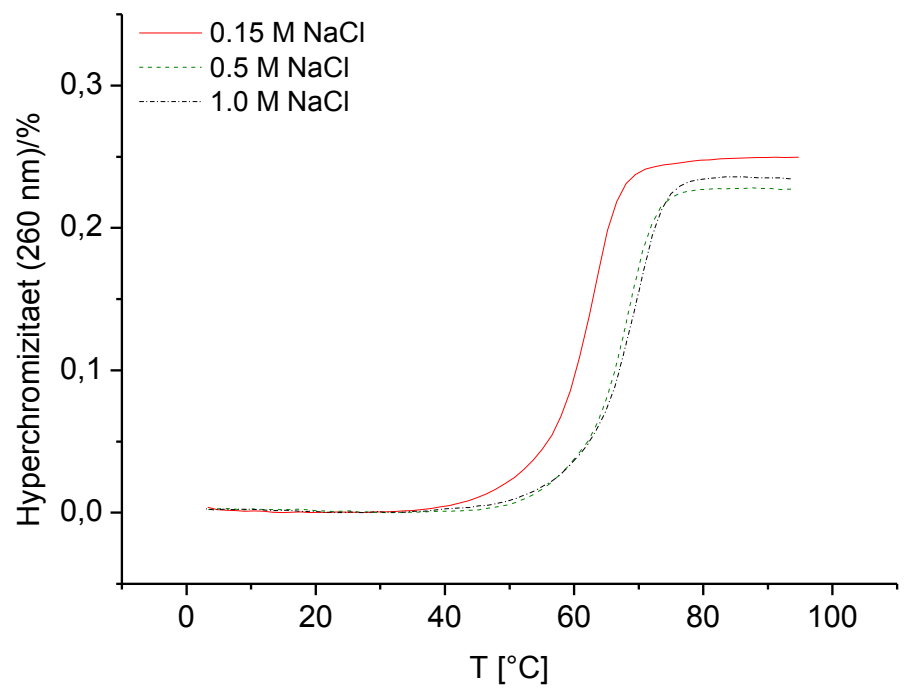

Oligonucleotid 3 (S): 5'-G TxT GACG TxT GACG TxT GACG TxT G-3' 


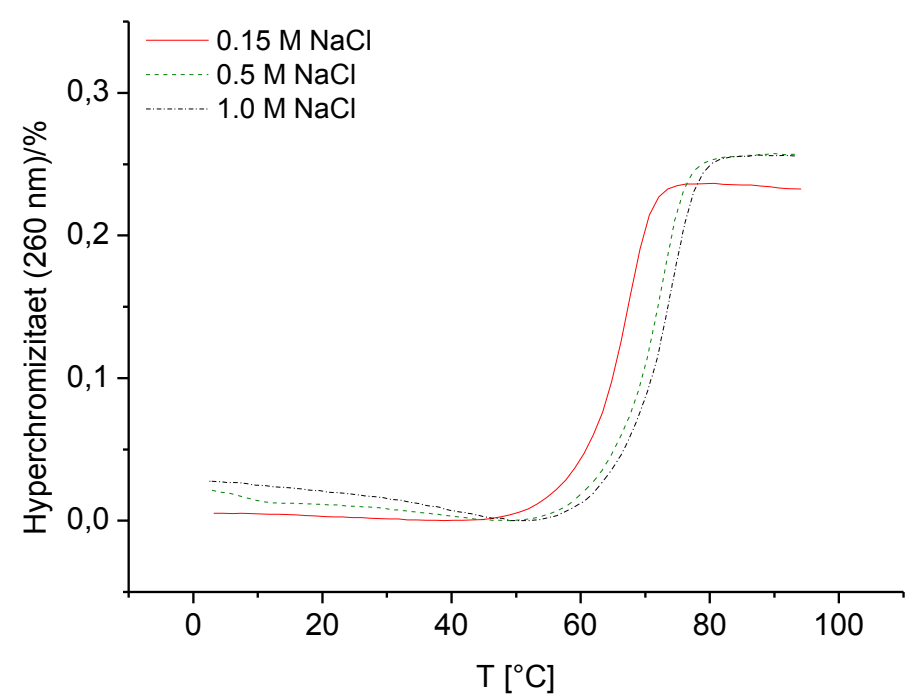

Oligonucleotid $4(R)$ : 5'-G TT GACG TxT GACG TT GACG TT G-3'

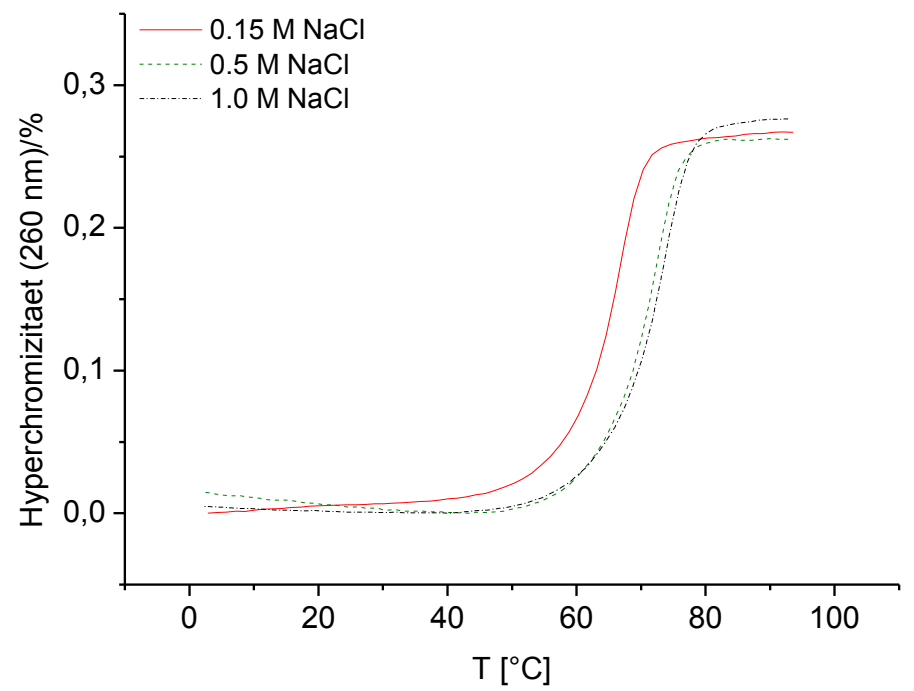

Oligonucleotid 5 (S): 5'-G TT GACG TxT GACG TT GACG TT G-3' 


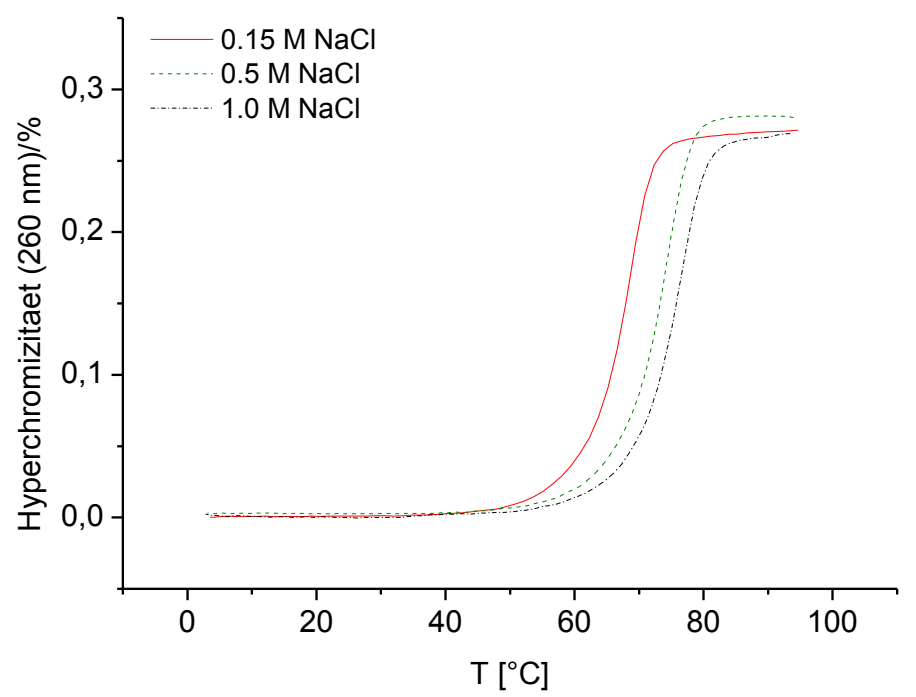

Oligonucleotid 6: 5'-G TT GACG TT GACG TT GACG TT G-3' (Referenz)

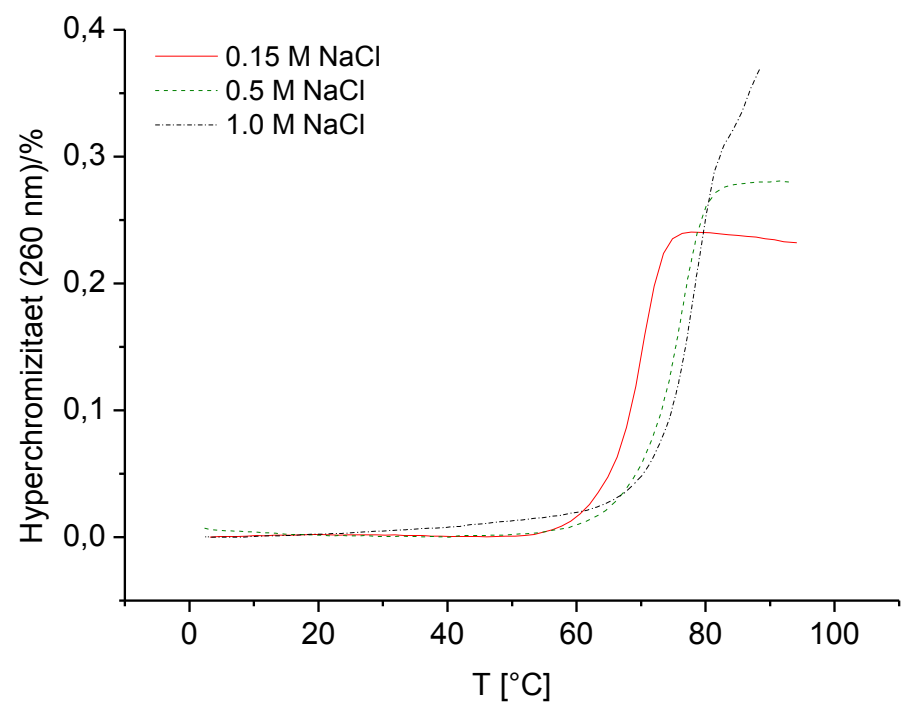

Oligonucleotid 7: 5'-GGCACGG TT TT TT TT GGCACGG-3' (Referenz) 


\subsection{DNA-RNA-Duplices}

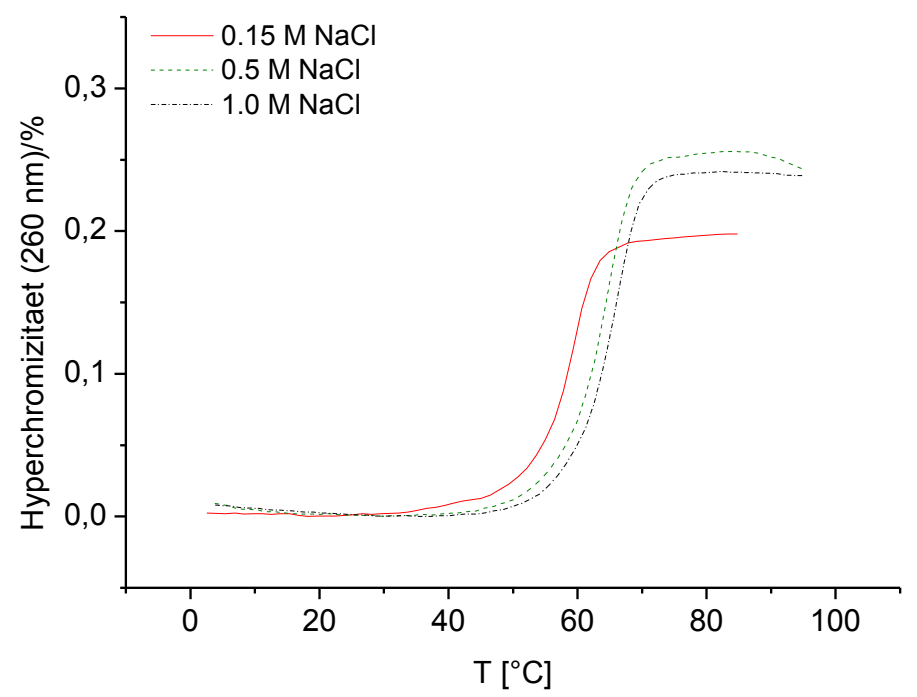

Oligonucleotid $1(R)$ : 5'-GGCACGG TxT TxT TxT TxT GGCACGG-3'

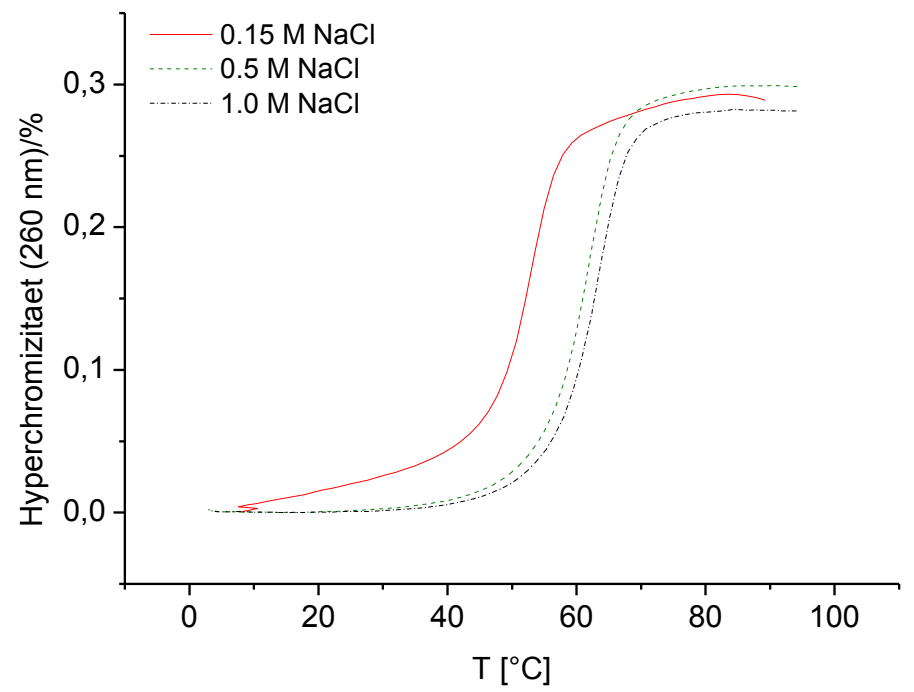

Oligonucleotid $2(R)$ : 5'-G TxT GACG TxT GACG TxT GACG TxT G-3' 


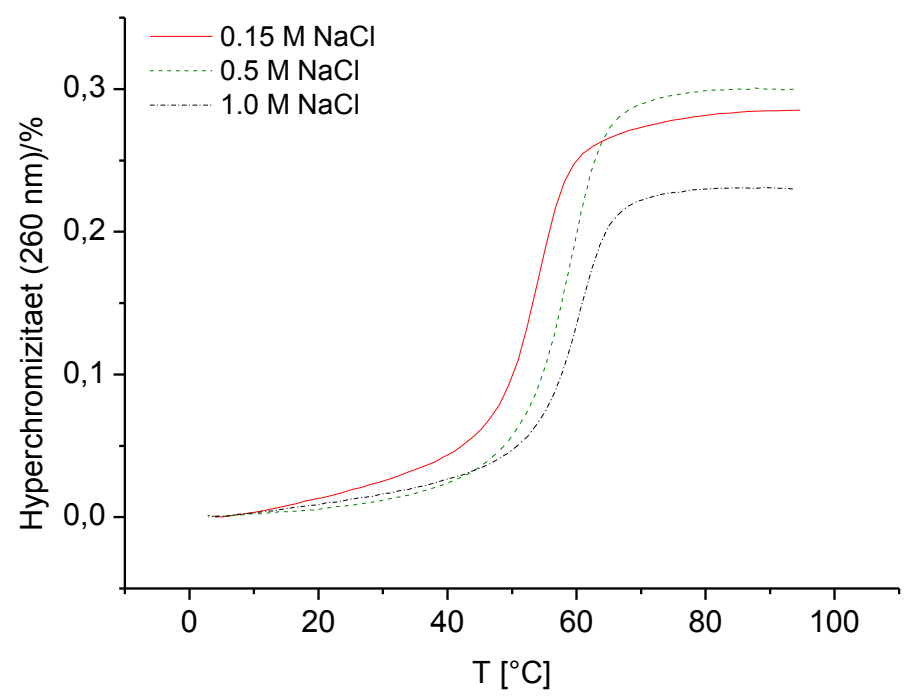

Oligonucleotid 3 (S): 5'-G TxT GACG TxT GACG TxT GACG TxT G-3'

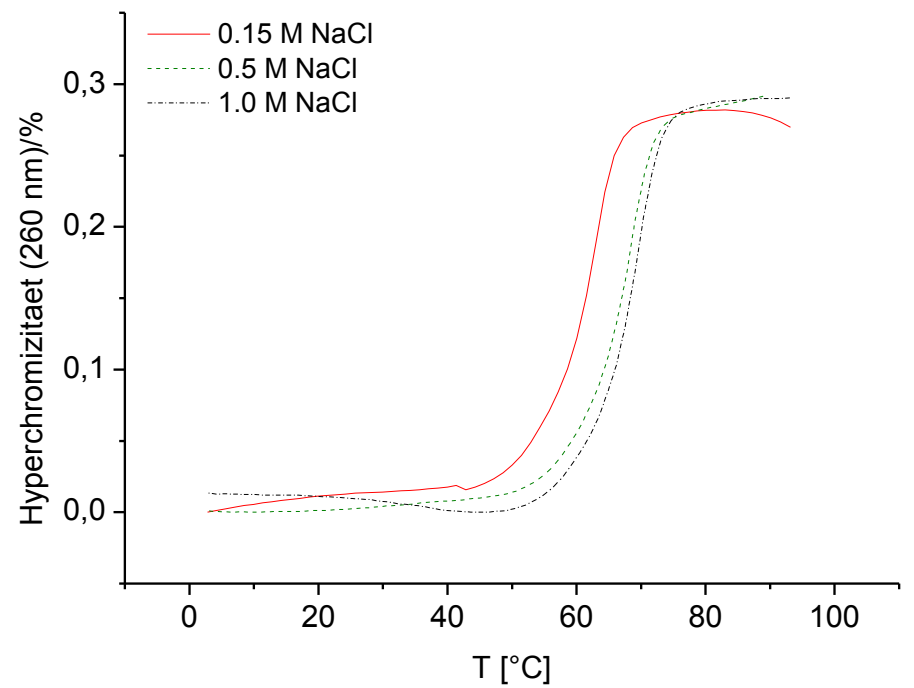

Oligonucleotid $4(R)$ : 5'-G TT GACG TxT GACG TT GACG TT G-3' 


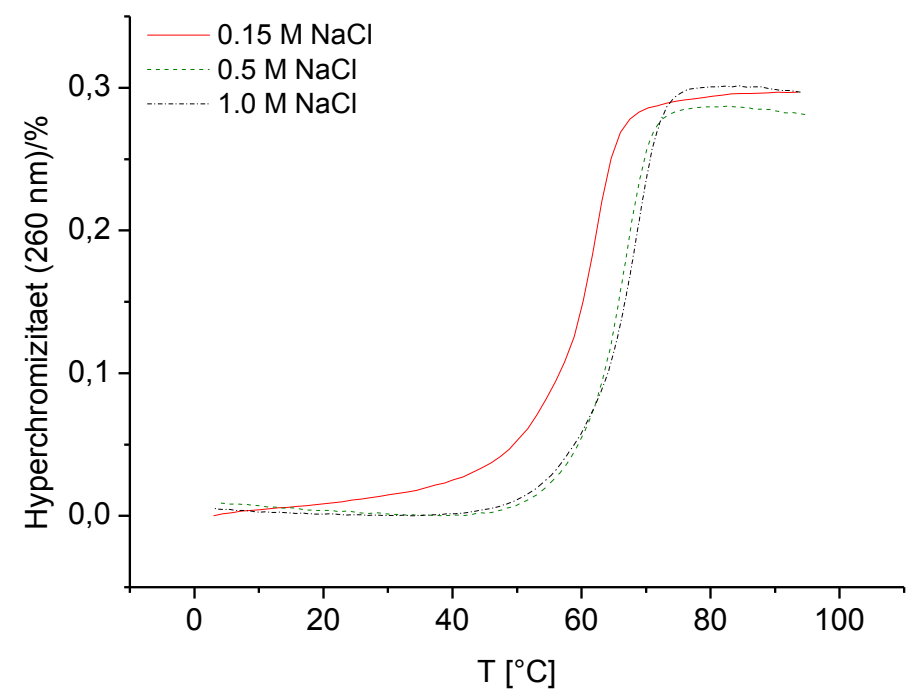

Oligonucleotid 5 (S): 5'-G TT GACG TxT GACG TT GACG TT G-3'

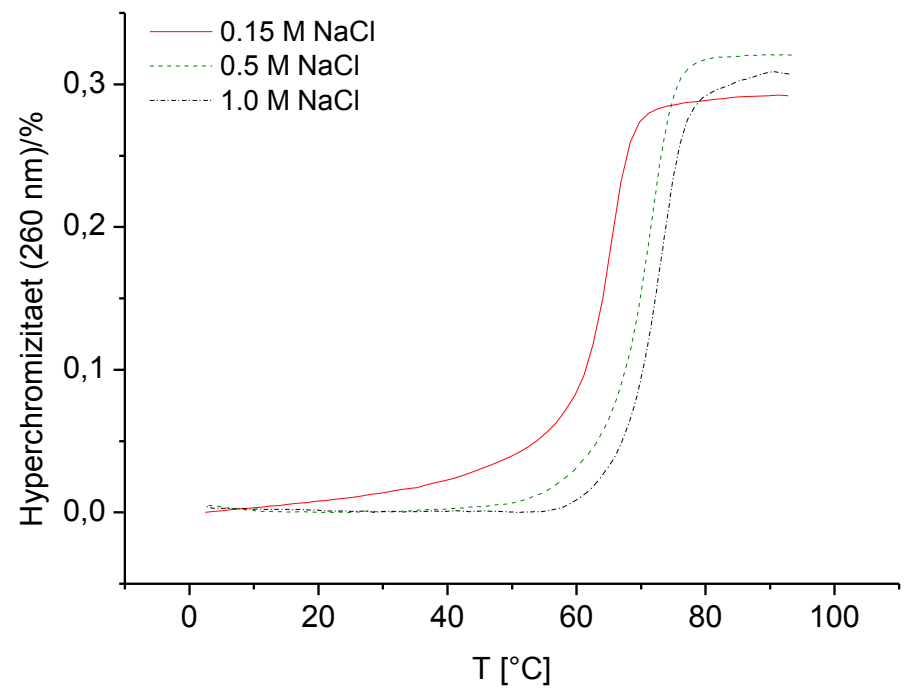

Oligonucleotid 6: 5'-G TT GACG TT GACG TT GACG TT G-3' (Referenz) 


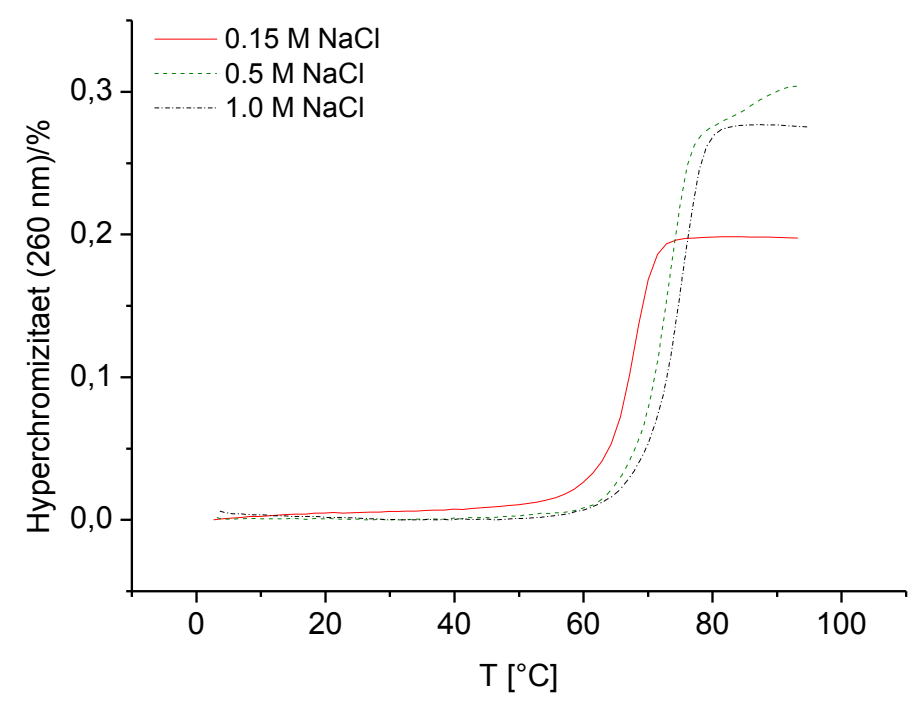

Oligonucleotid 7: 5'-GGCACGG TT TT TT TT GGCACGG-3' (Referenz)

\subsection{Circulardichroismus-Spektren}

Im Folgenden sind die aufgenommenen Circulardichroismus-Spektren angeführt. Die rote, durchgängige Kurve stellt das CD-Spektrum der jeweiligen Referenzduplex dar (ohne NAA-Modifikation), während die schwarze, gestrichelte Kurve das Spektrum der modifizierten Duplex abbildet. Das modifizierte Oligonucleotid ist jeweils unterhalb der Diagramme angeführt. Die Nummerierung der Oligonucleotide entspricht derjenigen in 7.2.6 (Tab. 1 und Tab. 2). 


\subsubsection{DNA-DNA-Duplices}

9.3.1.1 Duplices nicht-palindromer Oligonucleotide

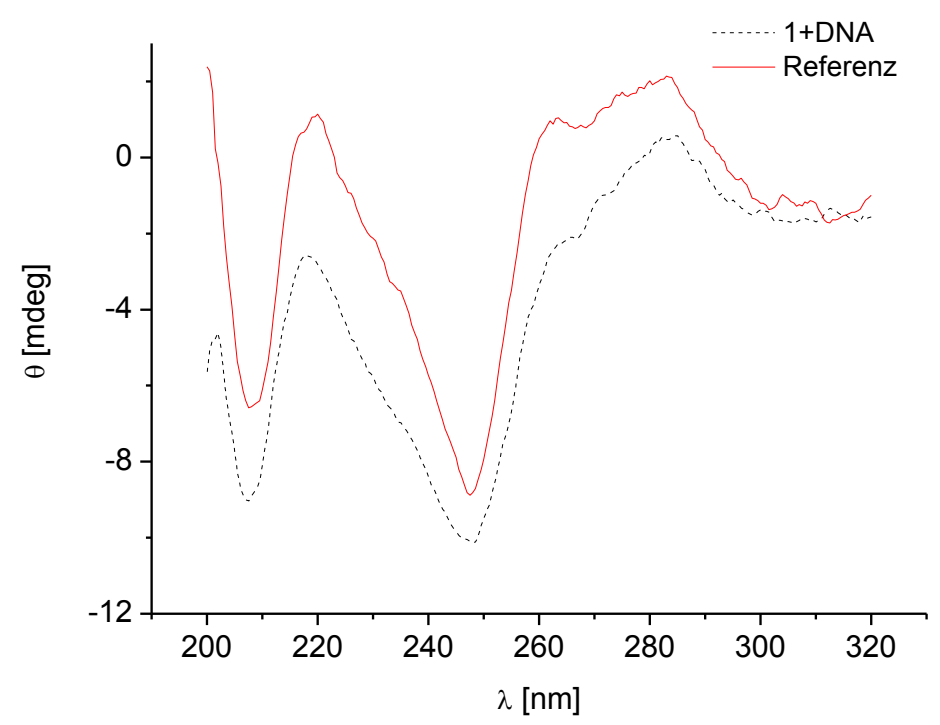

Oligonucleotid 1 (S): 5'-GGCACGG TxT TT TT TxT GGCACGG-3'

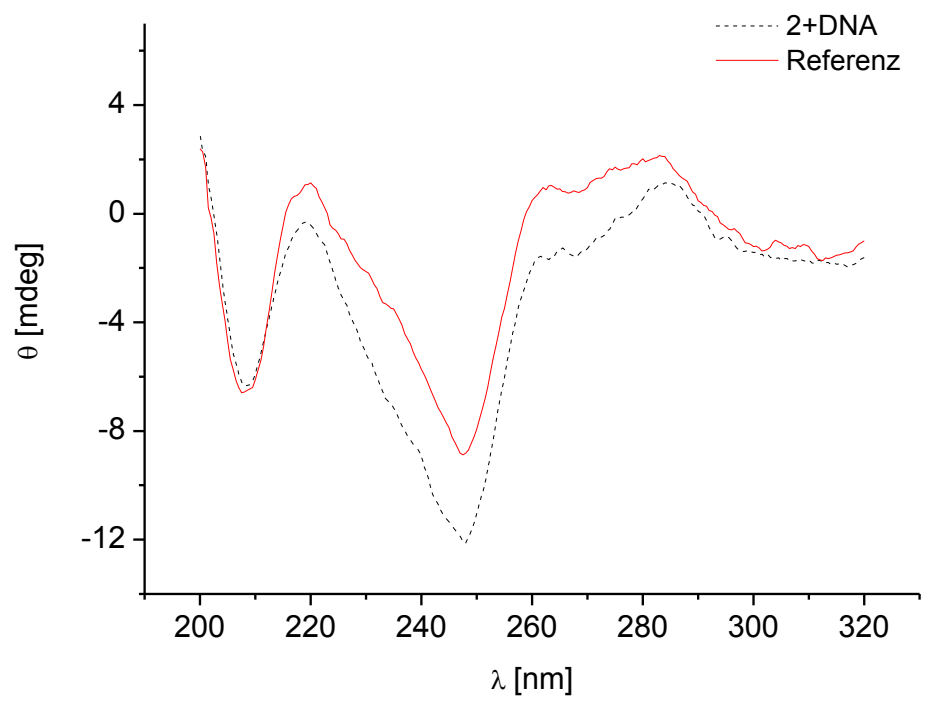

Oligonucleotid $2(R)$ : 5'-GGCACGG TxT TT TT TxT GGCACGG-3' 


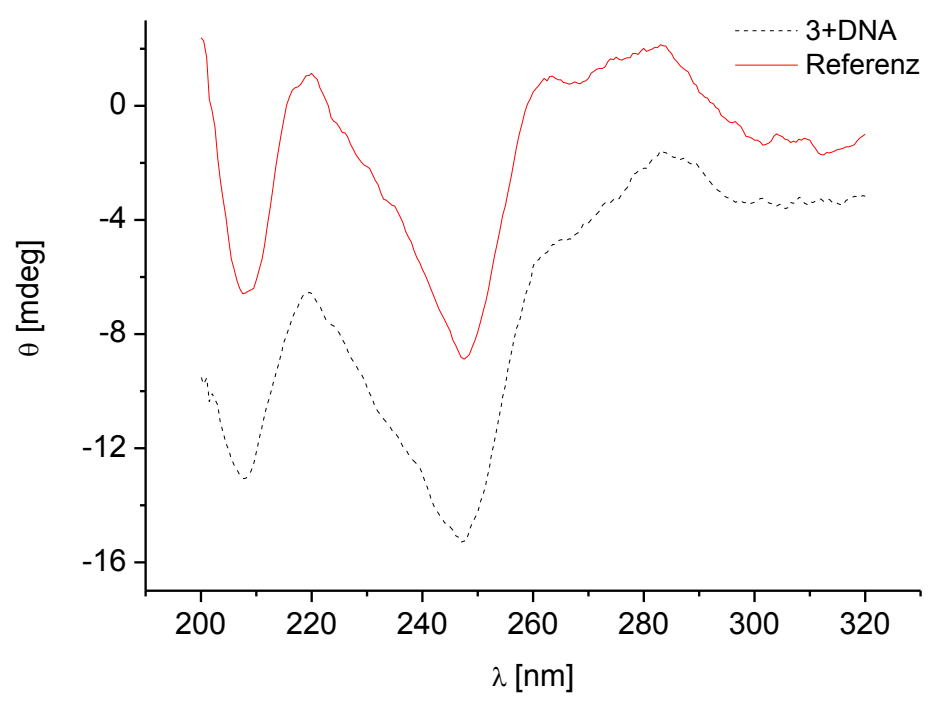

Oligonucleotid 3 (S): 5'-GGCACGG TxT TT TxT TT GGCACGG-3'

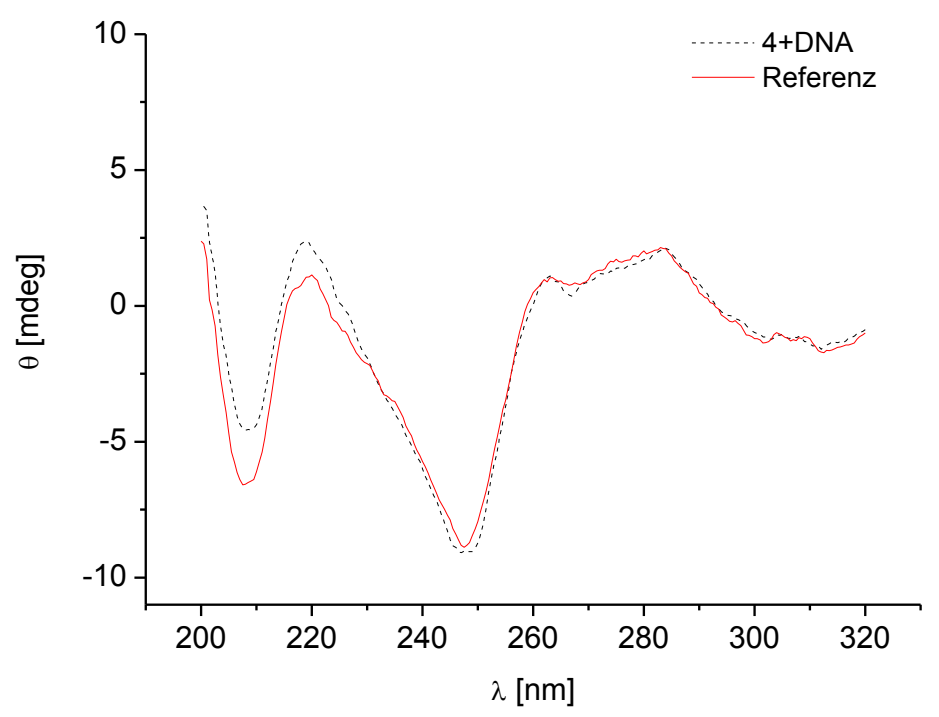

Oligonucleotid $4(R)$ : 5'-GGCACGG TxT TT TxT TT GGCACGG-3' 


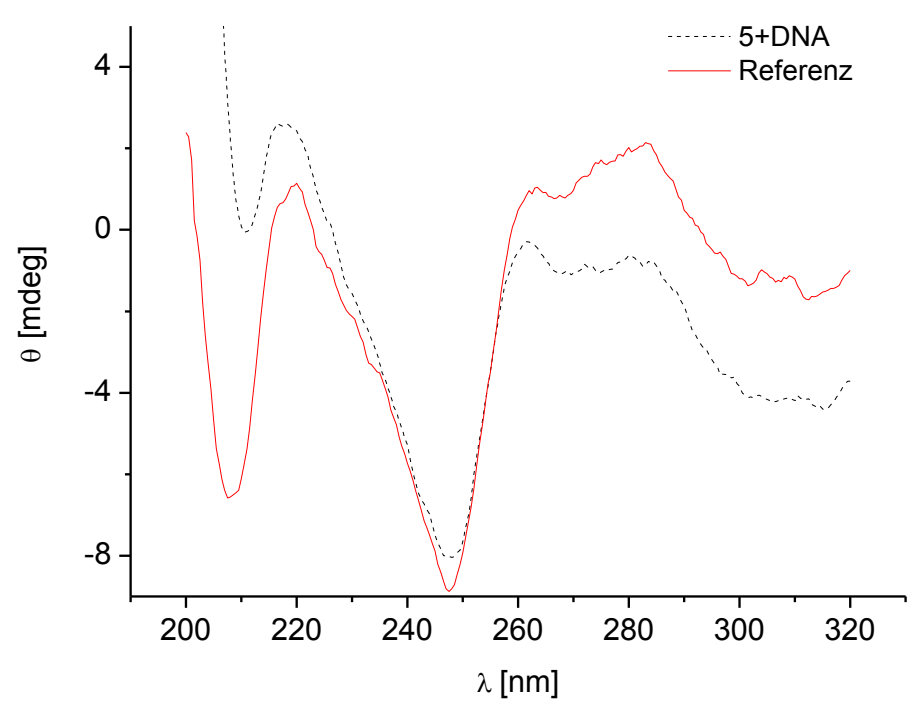

Oligonucleotid 5 (S): 5'-GGCACGG TxT TxT TT TT GGCACGG-3'

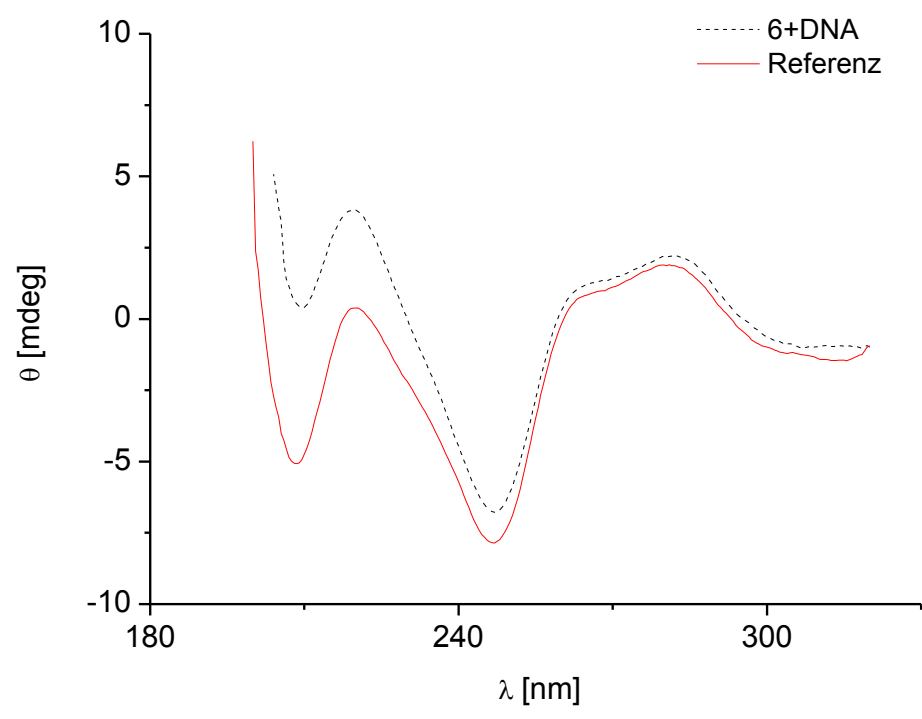

Oligonucleotid $6(R)$ : 5'-GGCACGG TxT TxT TT TT GGCACGG-3' 


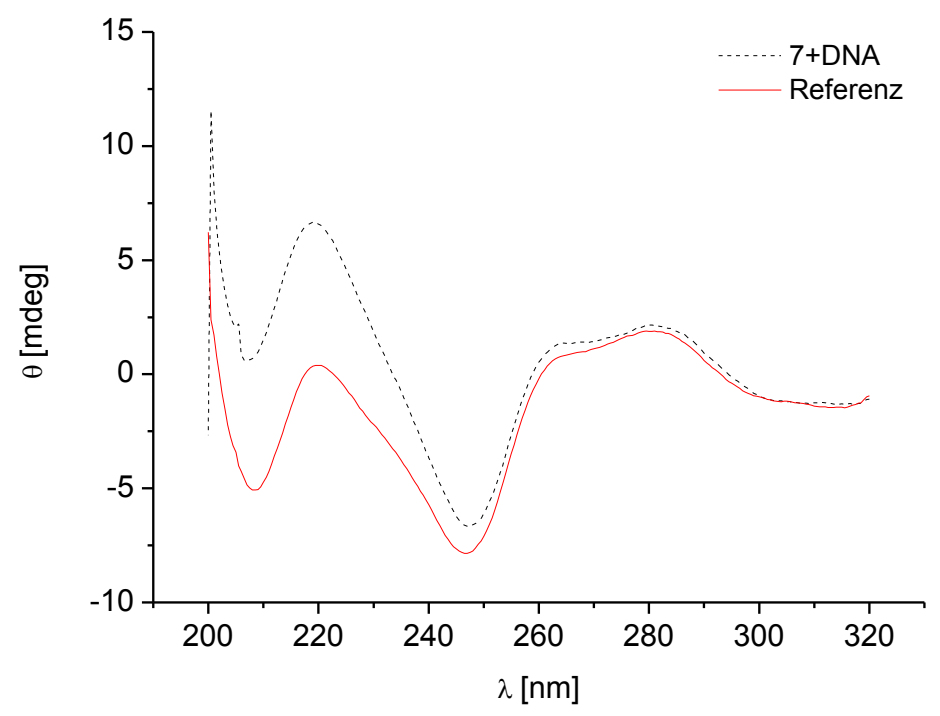

Oligonucleotid 7 (S): 5'-GGCACGG TxT TT TT TT GGCACGG-3'

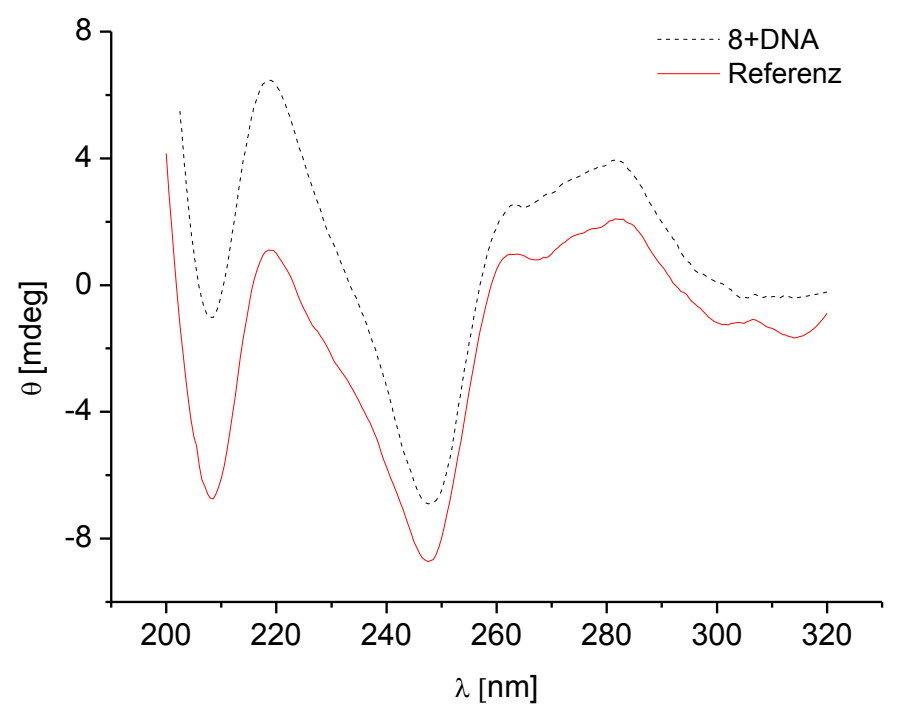

Oligonucleotid $8(R)$ : 5'-GGCACGG TxT TT TT TT GGCACGG-3' 


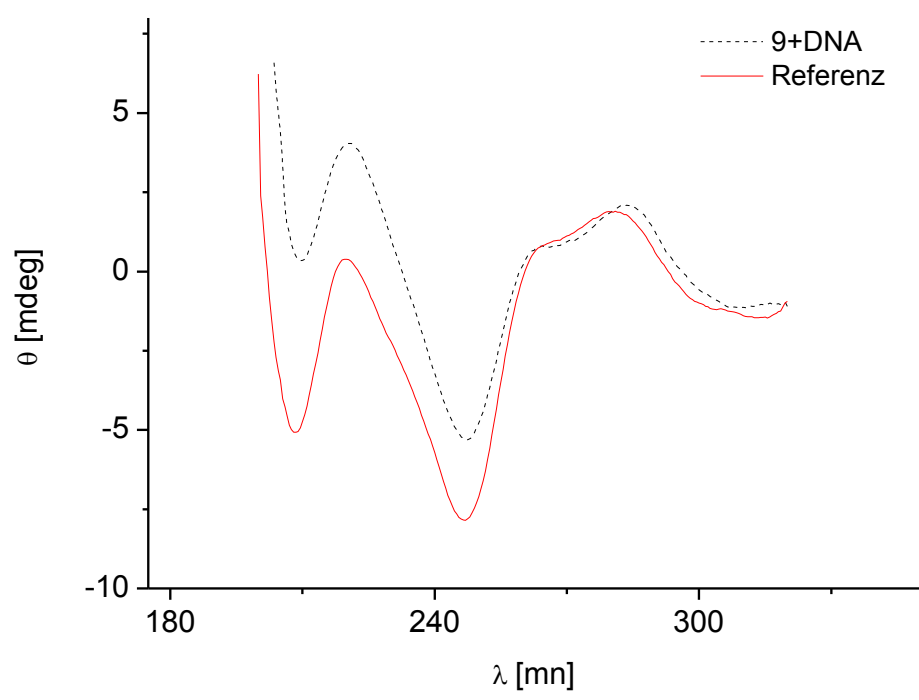

Oligonucleotid 9 (S): 5'-GGCACGG TxT TxT TxT TxT GGCACGG-3'

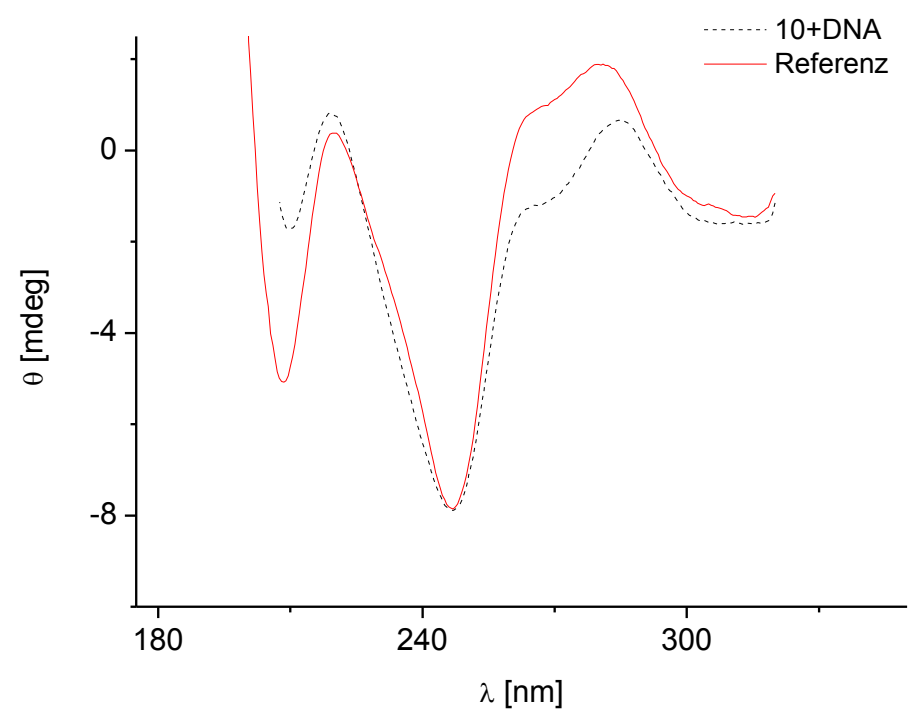

Oligonucleotid $10(R)$ : 5'-GGCACGG TxT TxT TxT TxT GGCACGG-3' 


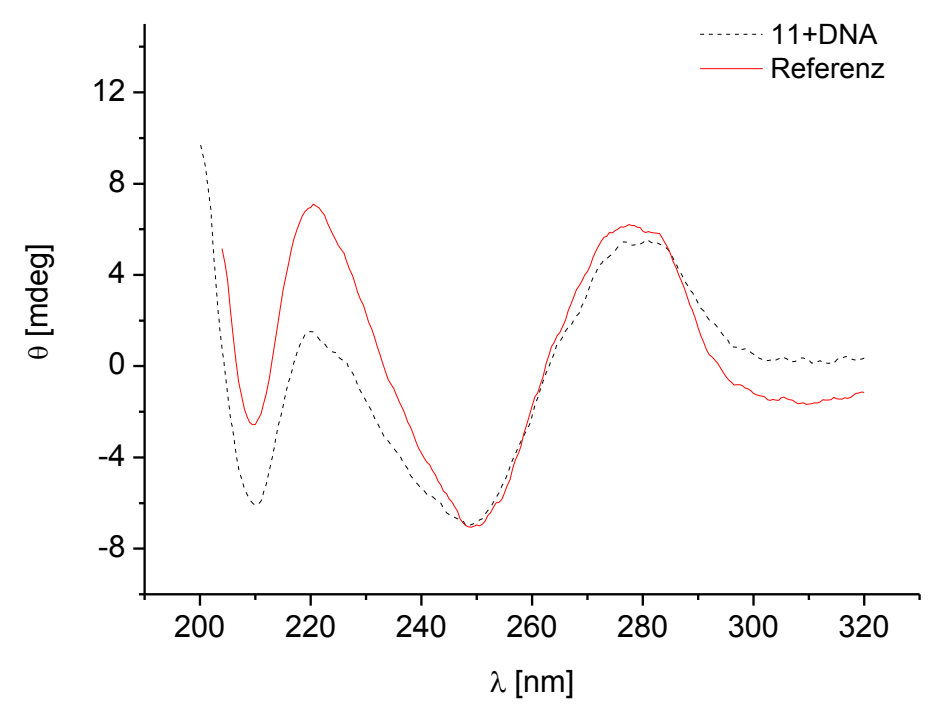

Oligonucleotid 11 (S): 5'-G TxT GACG TT GACG TT GACG TT G-3'

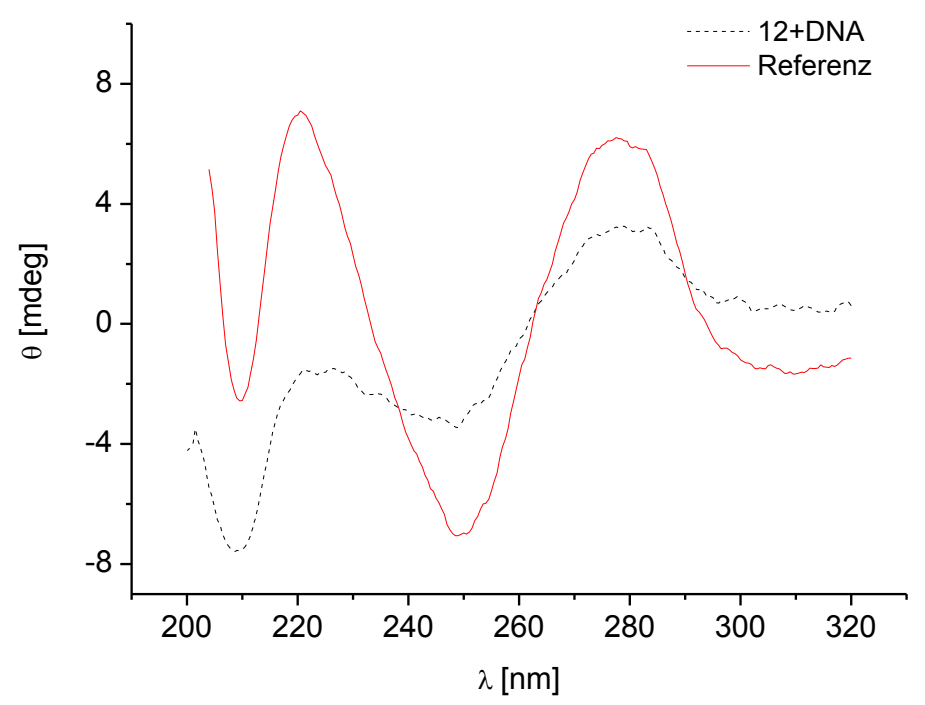

Oligonucleotid $12(R)$ : 5'-G TxT GACG TT GACG TT GACG TT G-3' 


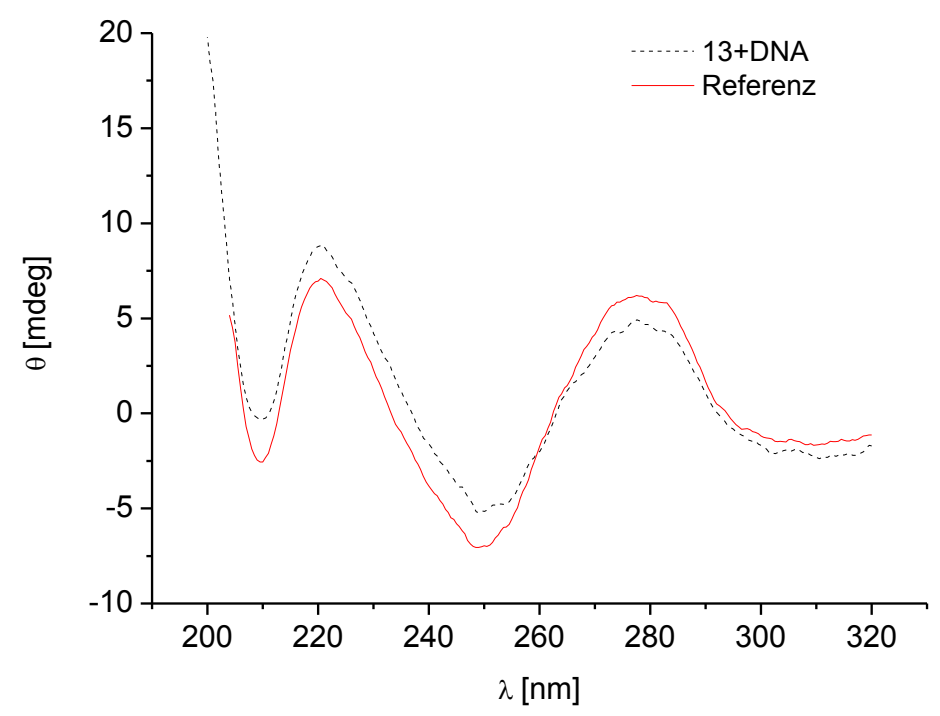

Oligonucleotid 13 (S): 5'-G TT GACG TxT GACG TT GACG TT G-3'

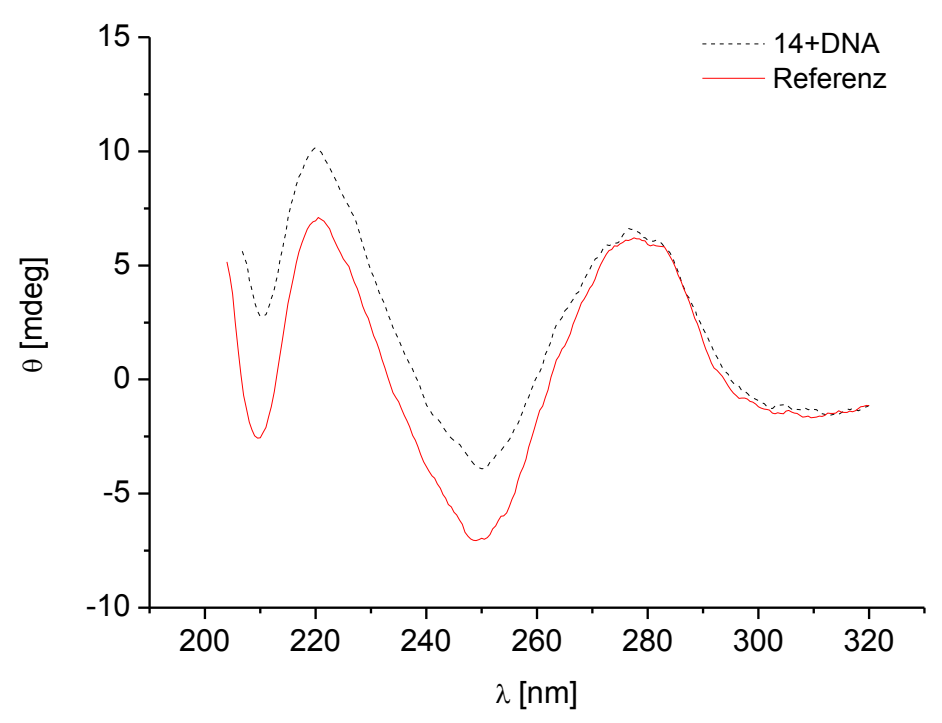

Oligonucleotid 14 (R): 5'-G TT GACG TxT GACG TT GACG TT G-3' 


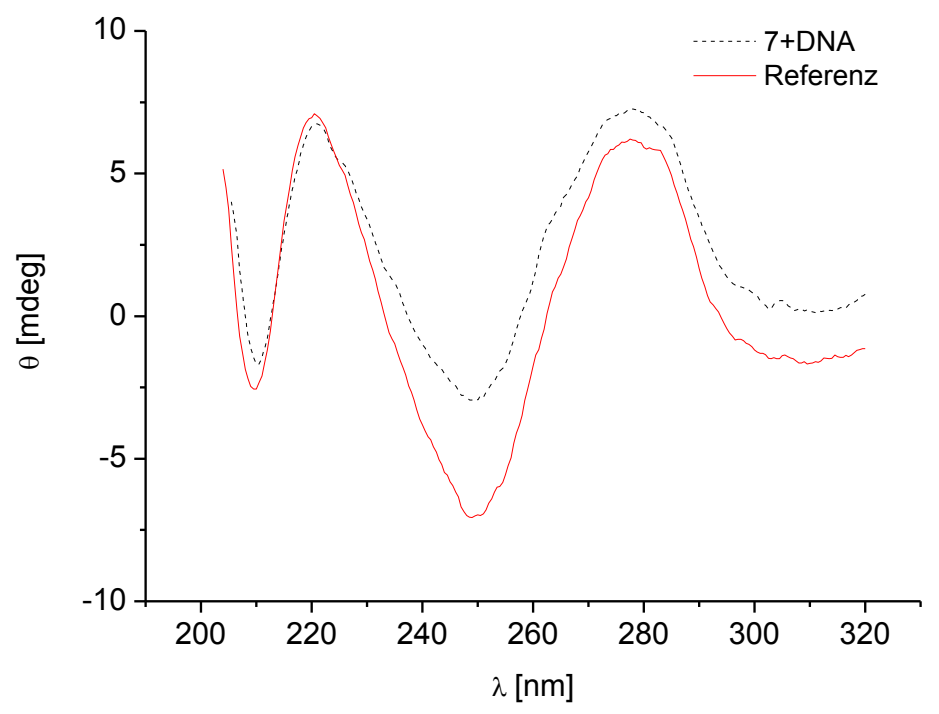

Oligonucleotid 15 (S): 5'-G TT GACG TT GACG TxT GACG TT G-3'

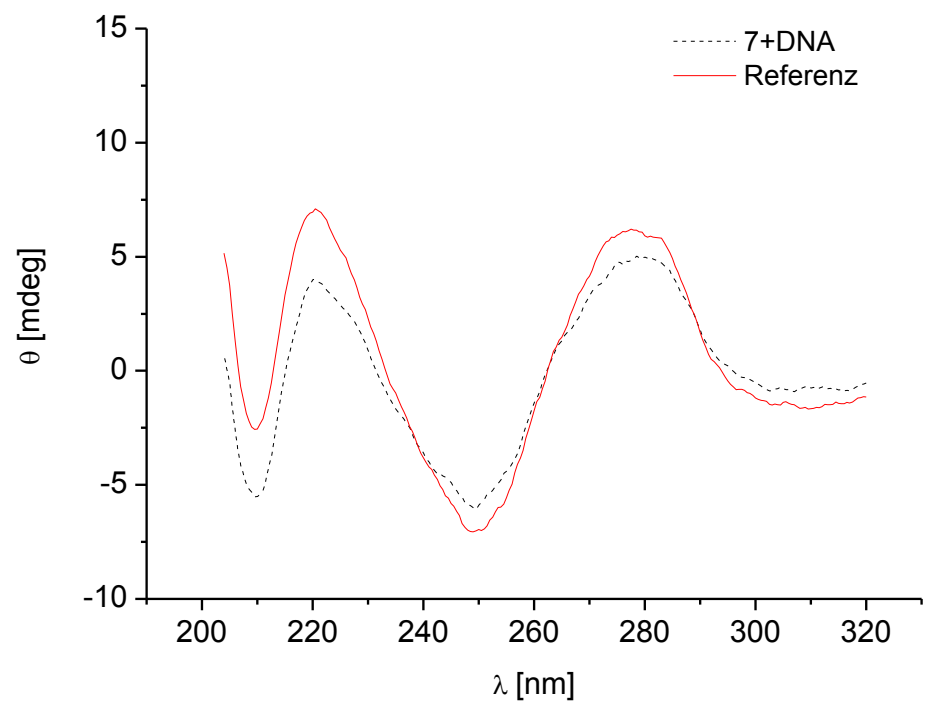

Oligonucleotid $16(R)$ : 5'-G TT GACG TT GACG TxT GACG TT G-3' 


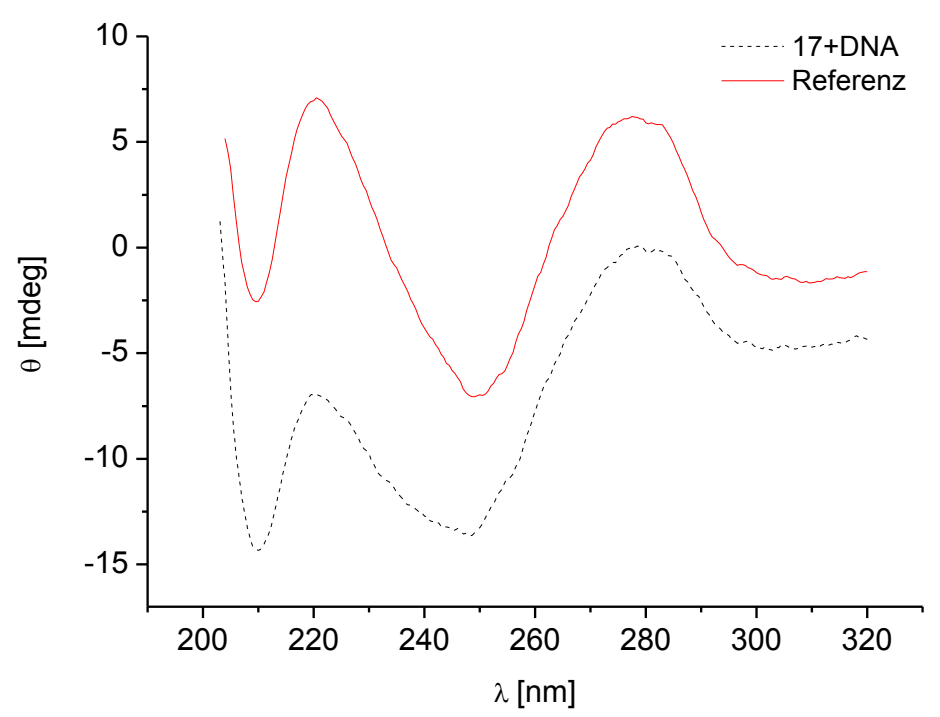

Oligonucleotid 17 (S): 5'-G TT GACG TT GACG TT GACG TxT G-3'

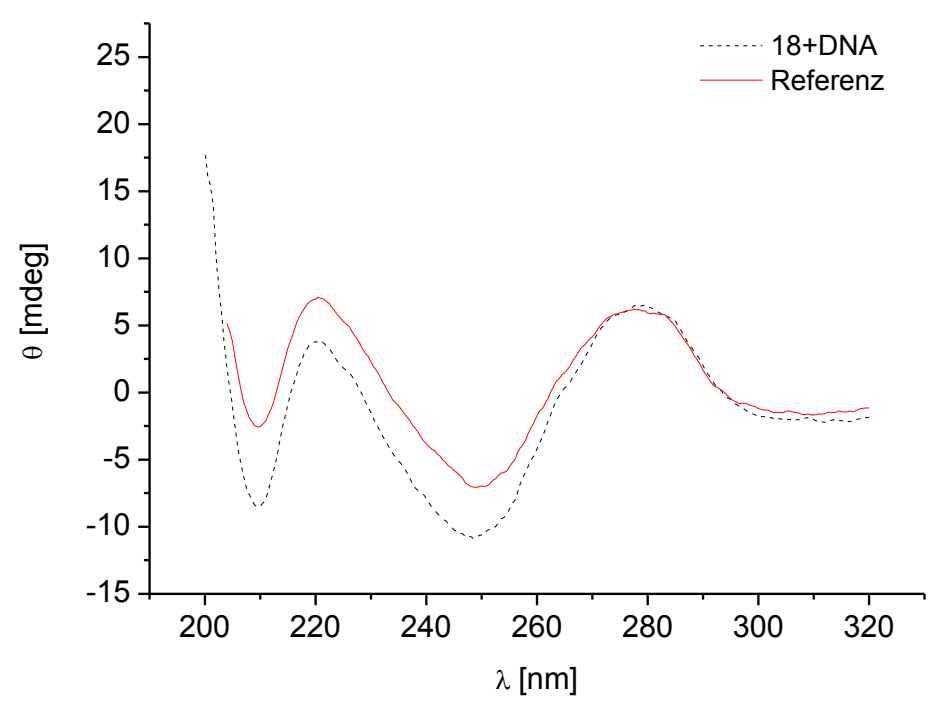

Oligonucleotid $18(R)$ : 5'-G TT GACG TT GACG TT GACG TxT G-3' 


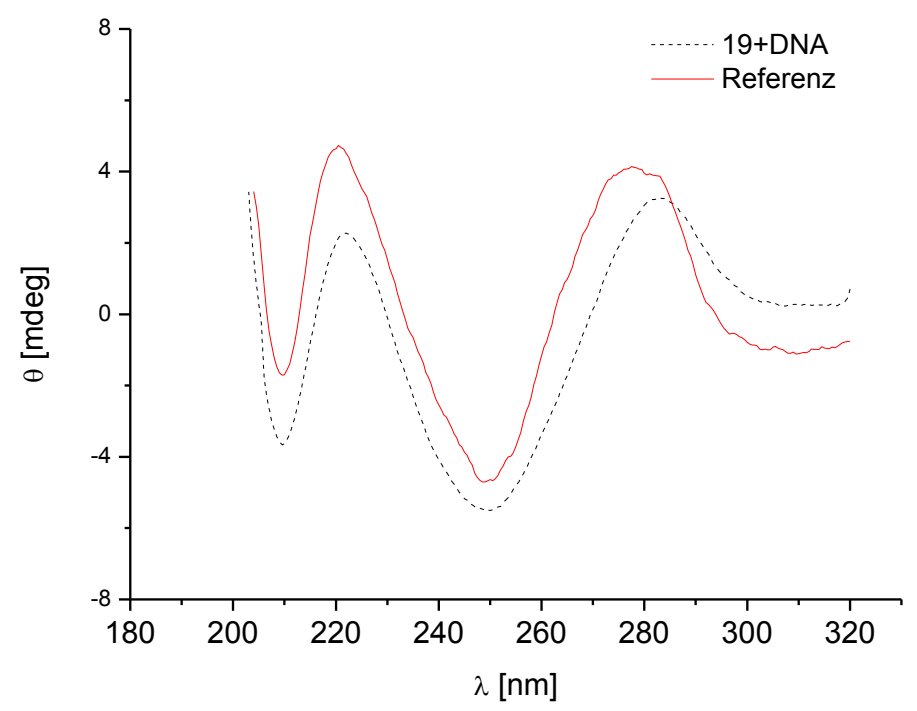

Oligonucleotid 19 (S): 5'-G TxT GACG TxT GACG TxT GACG TxT G-3'

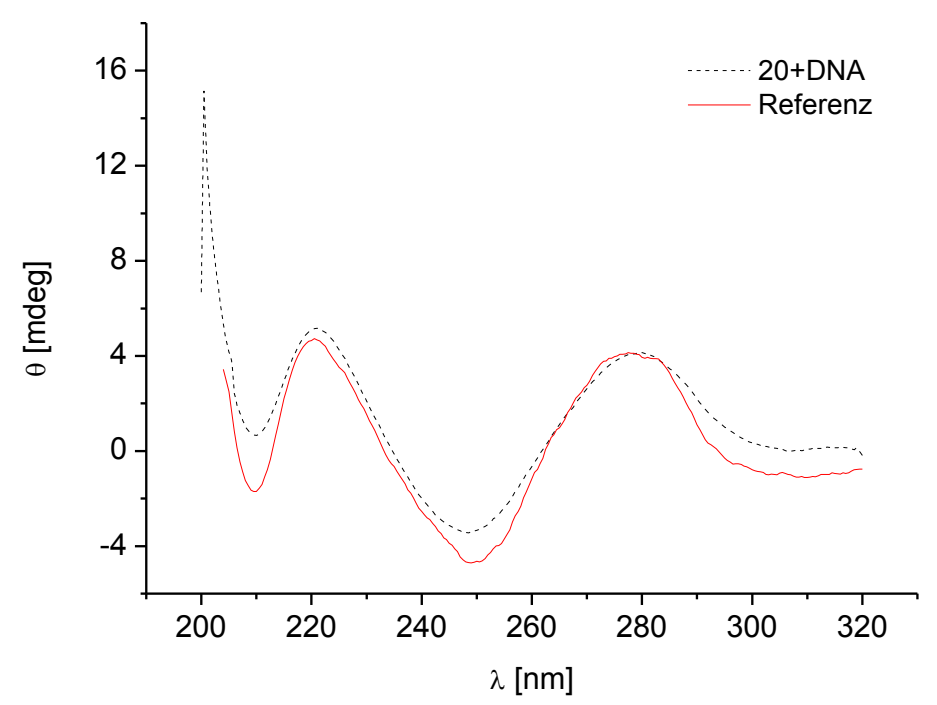

Oligonucleotid $20(R)$ : 5'-G TxT GACG TxT GACG TxT GACG TxT G-3' 


\subsubsection{Duplices palindromer Oligonucleotide}

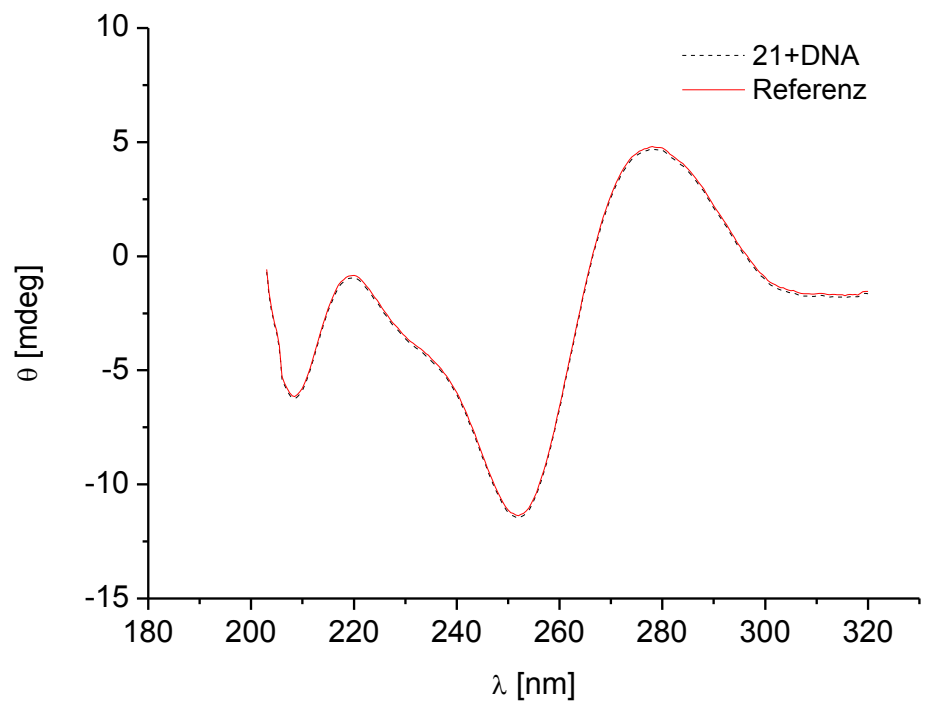

Oligonucleotid 21 (S): 5'-GCGC TxT GC TT AAGCAAGCGC-3'

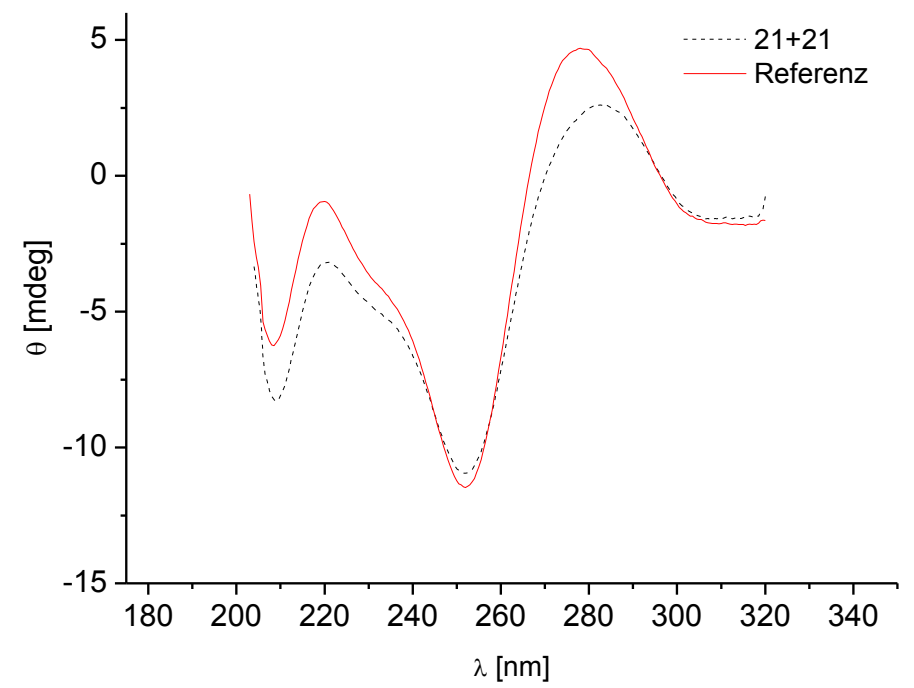

Oligonucleotid 21 (S): 5'-GCGC TxT GC TT AAGCAAGCGC-3' 


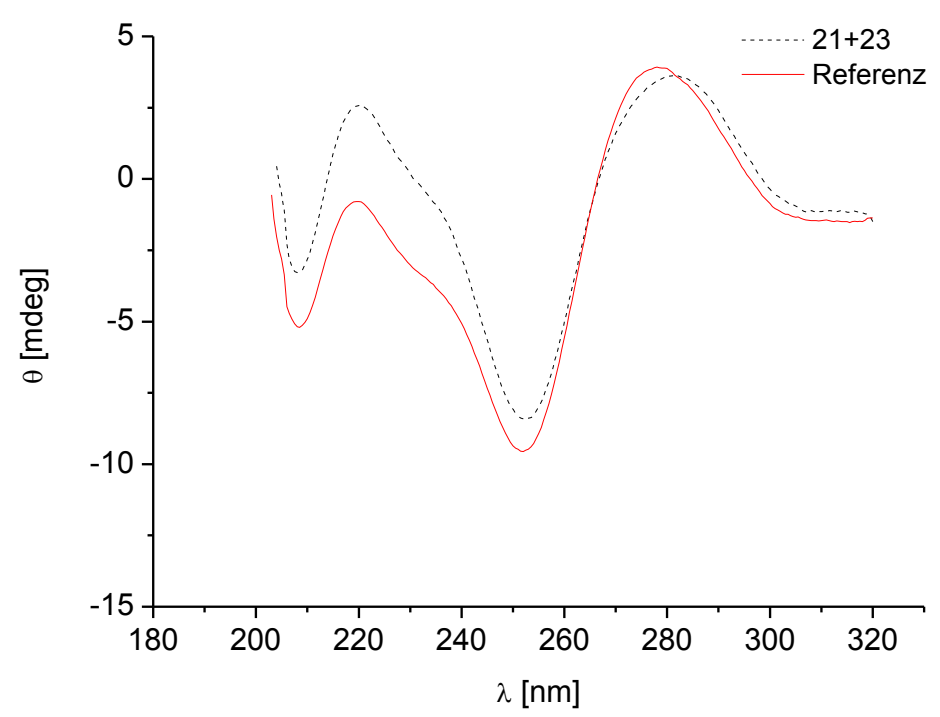

Oligonucleotid 21 (S): 5'-GCGC TxT GC TT AAGCAAGCGC-3'

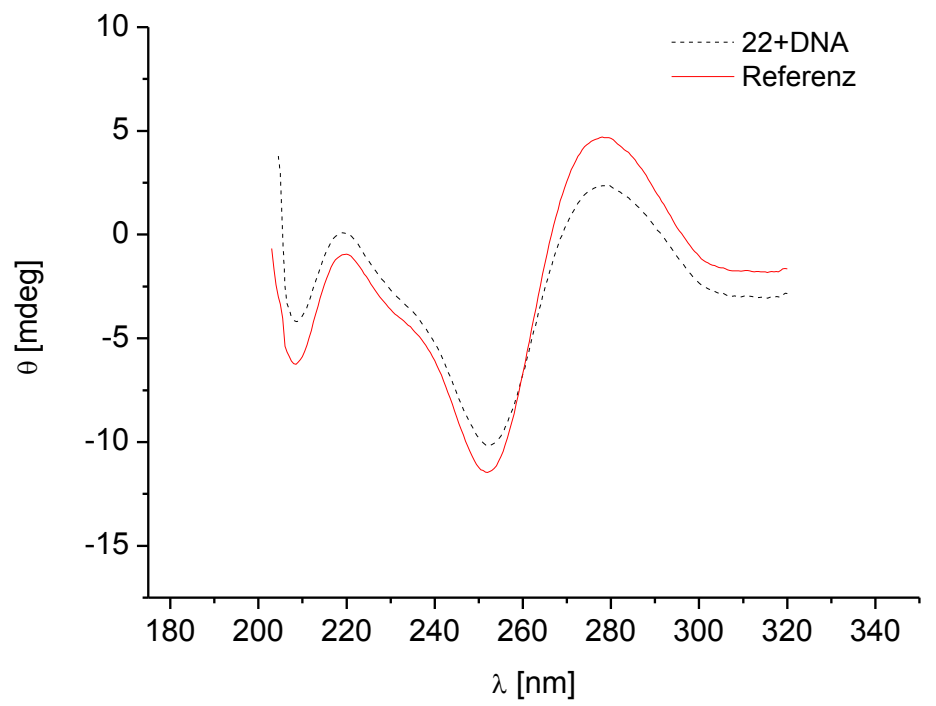

Oligonucleotid $22(R)$ : 5'-GCGC TxT GC TT AAGCAAGCGC-3' 


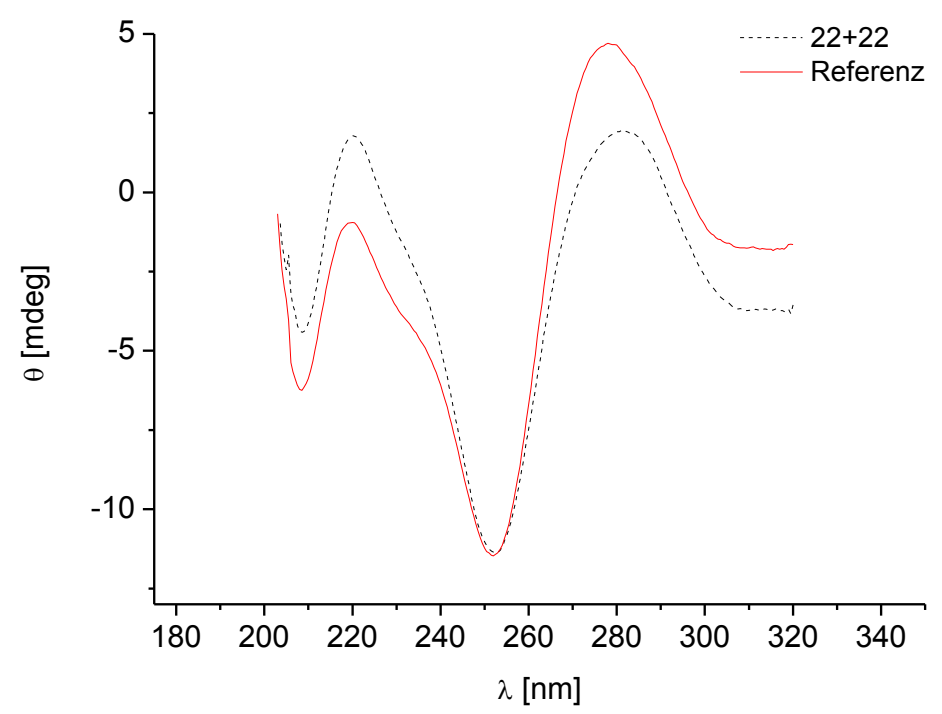

Oligonucleotid $22(R)$ : 5'-GCGC TxT GC TT AAGCAAGCGC-3'

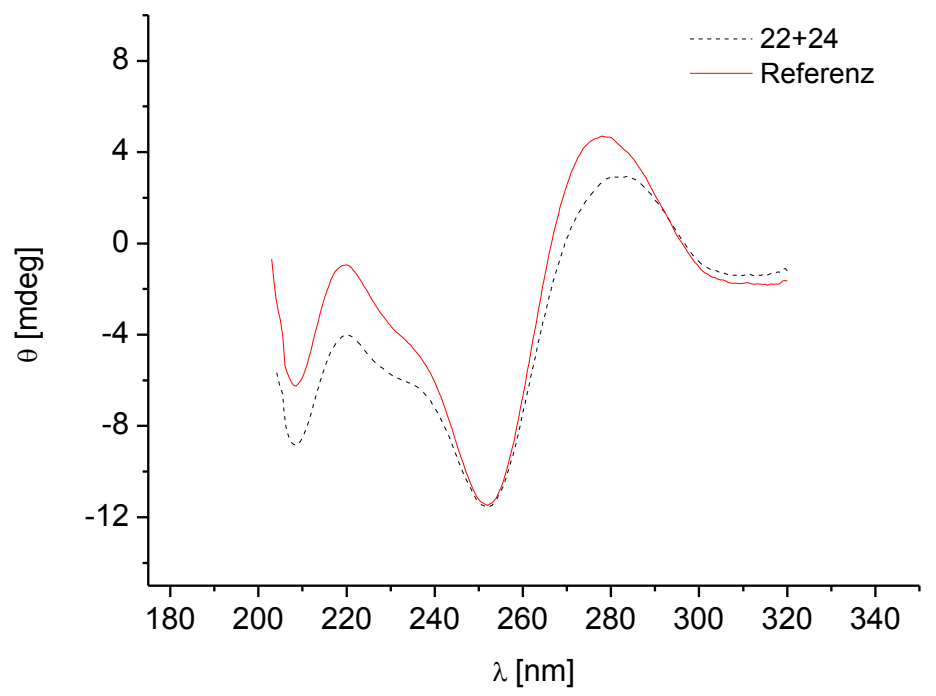

Oligonucleotid $22(R)$ : 5'-GCGC TxT GC TT AAGCAAGCGC-3' 


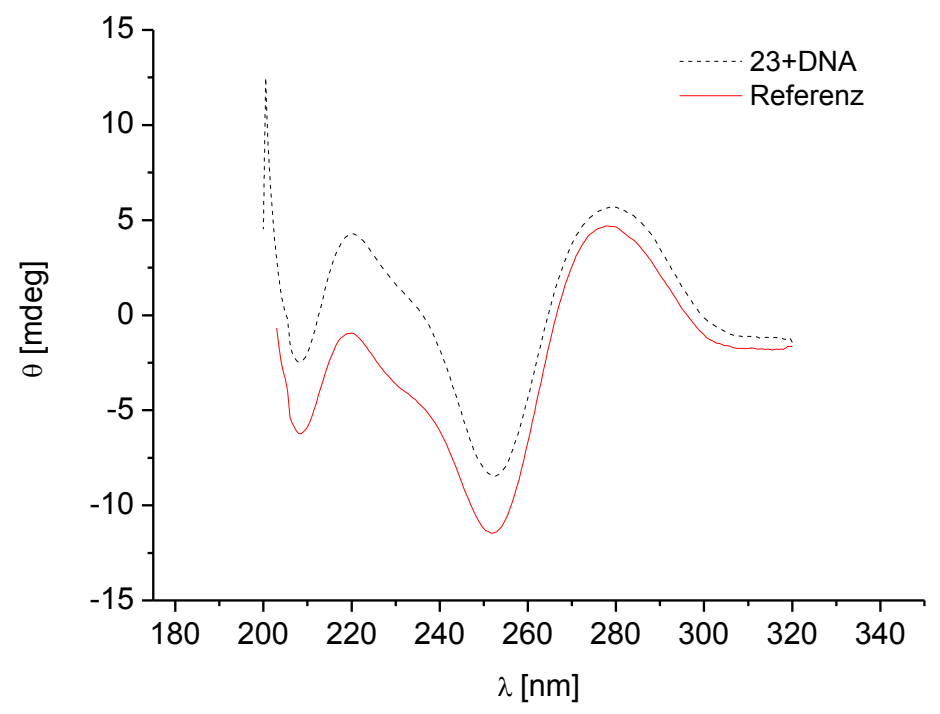

Oligonucleotid $23(S)$ : 5'-GCGC TT GC TxT AAGCAAGCGC-3'

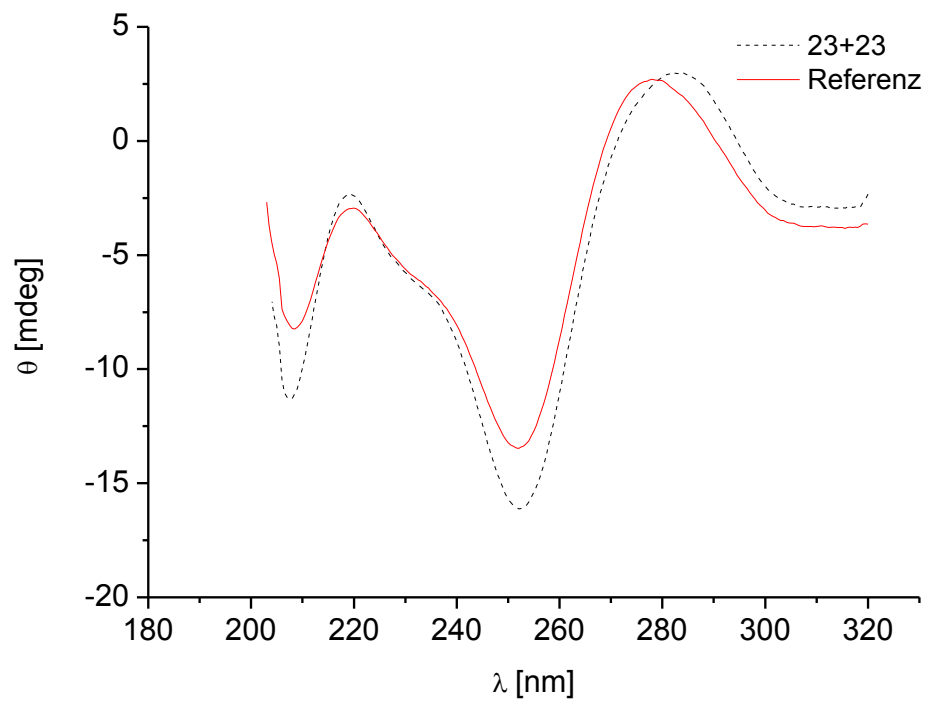

Oligonucleotid $23(S)$ : 5'-GCGC TT GC TxT AAGCAAGCGC-3' 


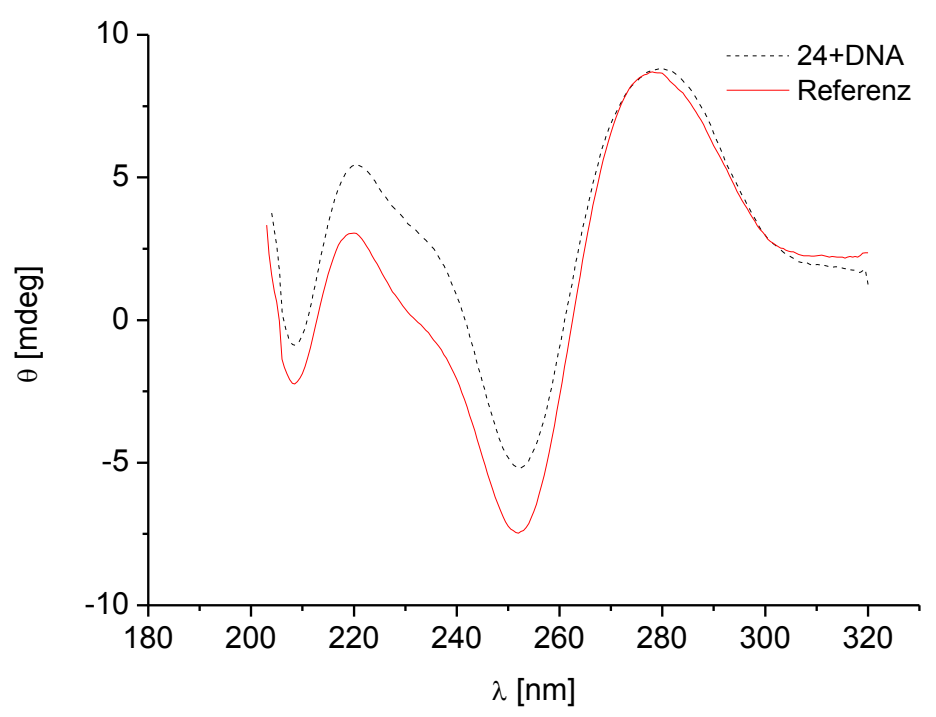

Oligonucleotid $24(R)$ : 5'-GCGC TT GC TxT AAGCAAGCGC-3'

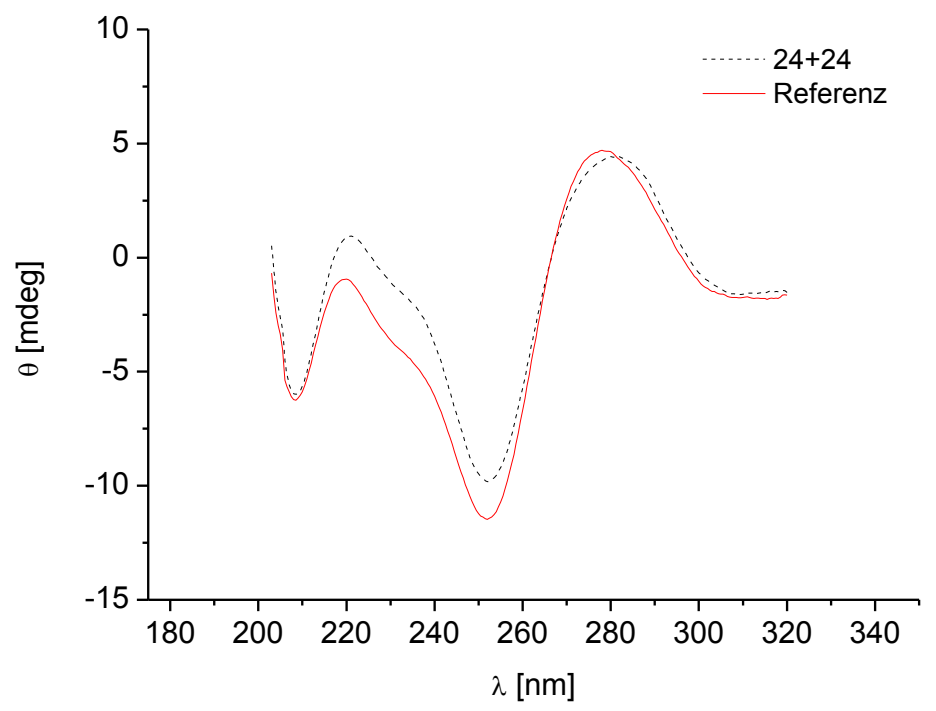

Oligonucleotid $24(R)$ : 5'-GCGC TT GC TxT AAGCAAGCGC-3' 


\subsubsection{DNA-RNA-Duplices}

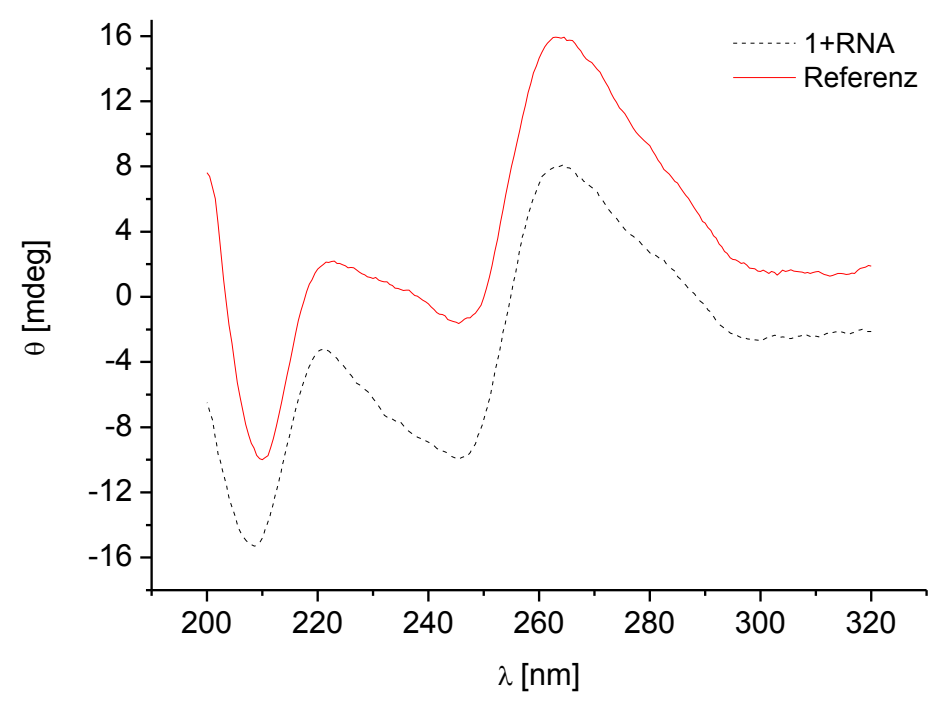

Oligonucleotid 1 (S): 5'-GGCACGG TxT TT TT TxT GGCACGG-3'

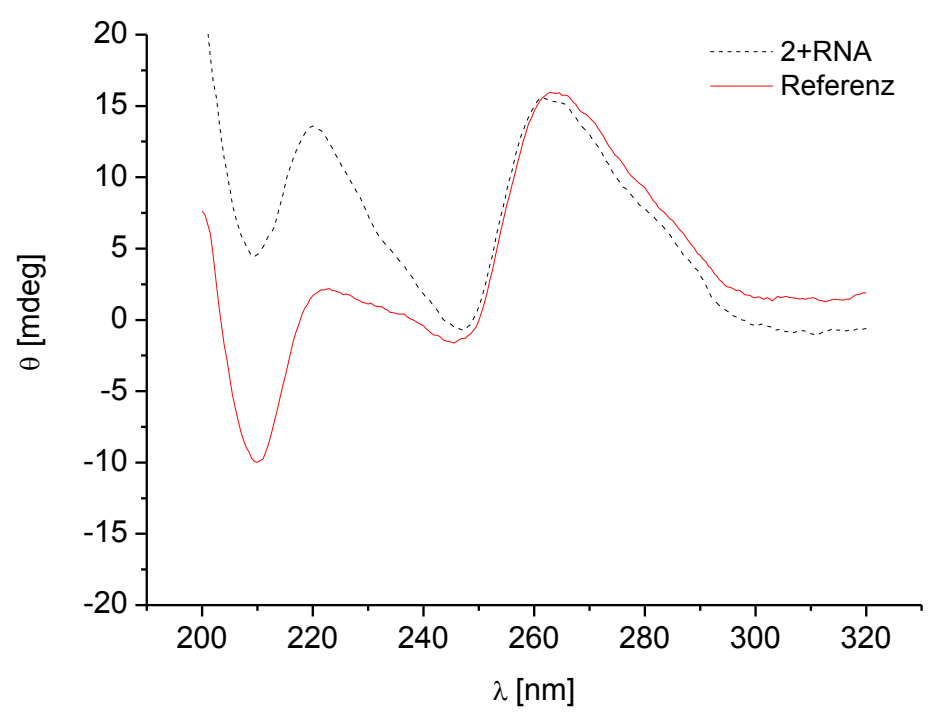

Oligonucleotid $2(R)$ : 5'-GGCACGG TxT TT TT TxT GGCACGG-3' 


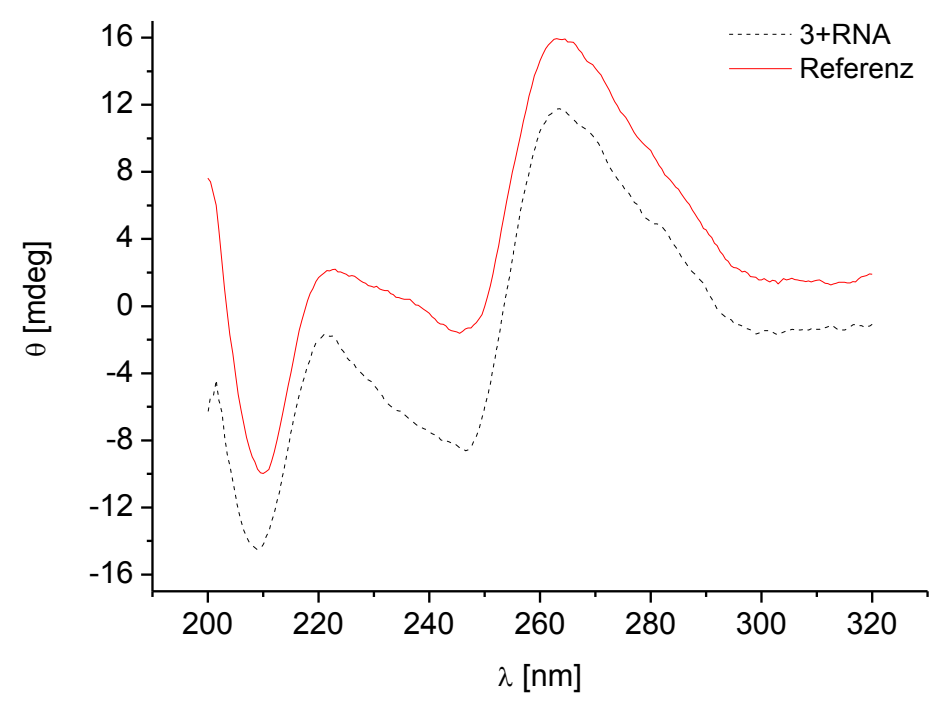

Oligonucleotid 3 (S): 5'-GGCACGG TxT TT TxT TT GGCACGG-3'

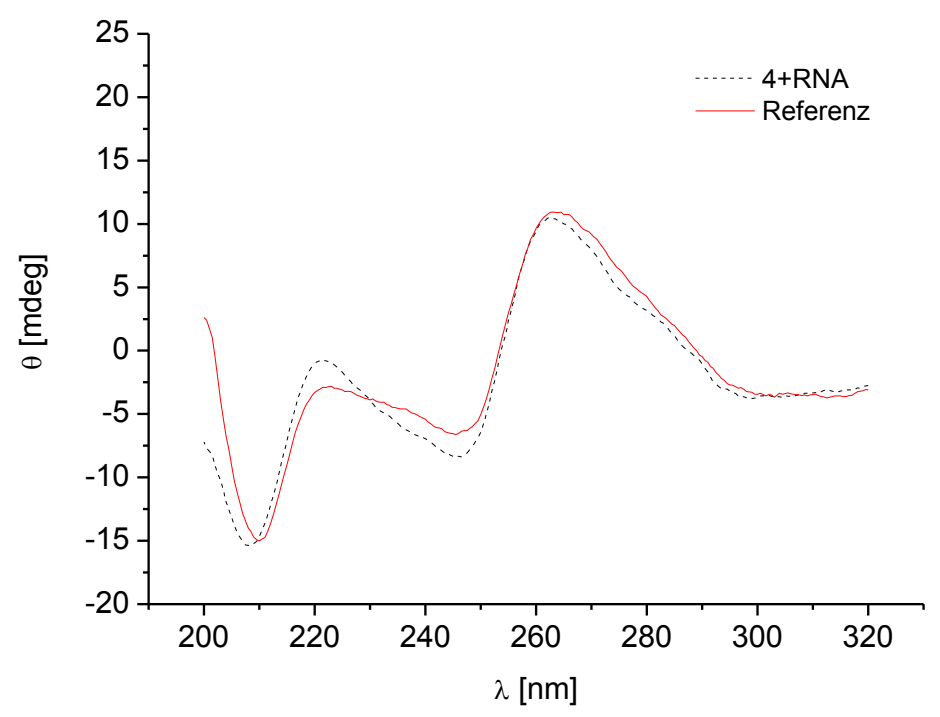

Oligonucleotid $4(R)$ : 5'-GGCACGG TxT TT TxT TT GGCACGG-3' 


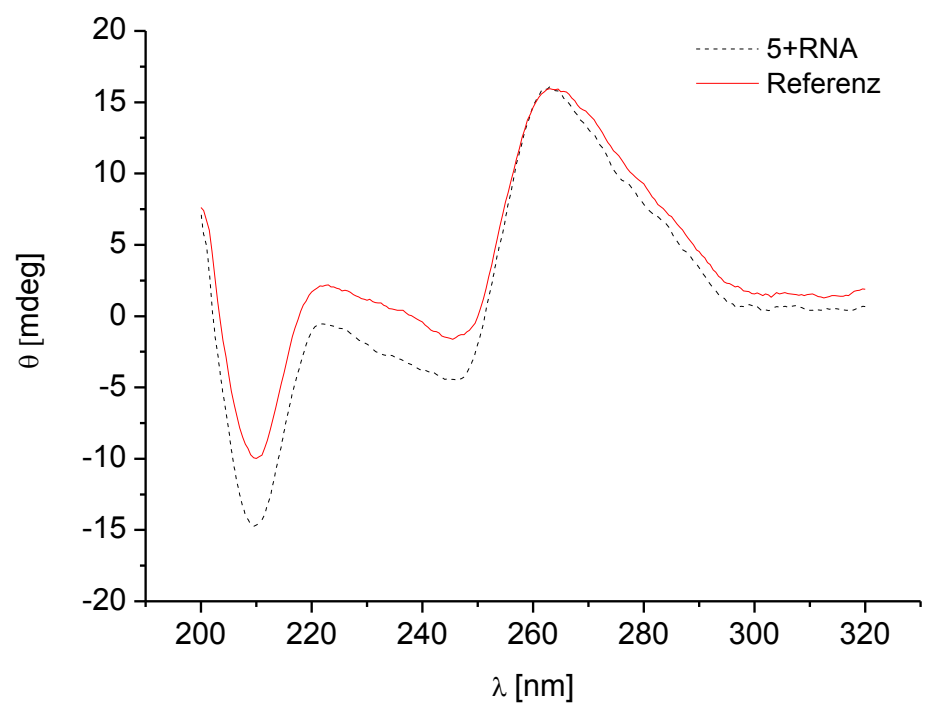

Oligonucleotid 5 (S): 5'-GGCACGG TxT TxT TT TT GGCACGG-3'

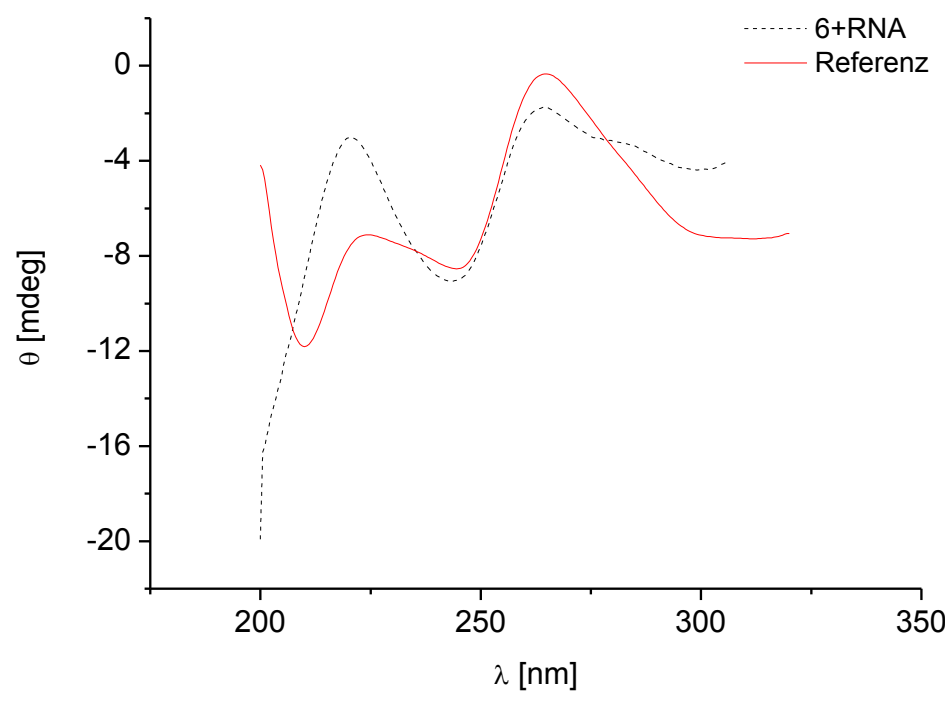

Oligonucleotid $6(R)$ : 5'-GGCACGG TxT TxT TT TT GGCACGG-3' 


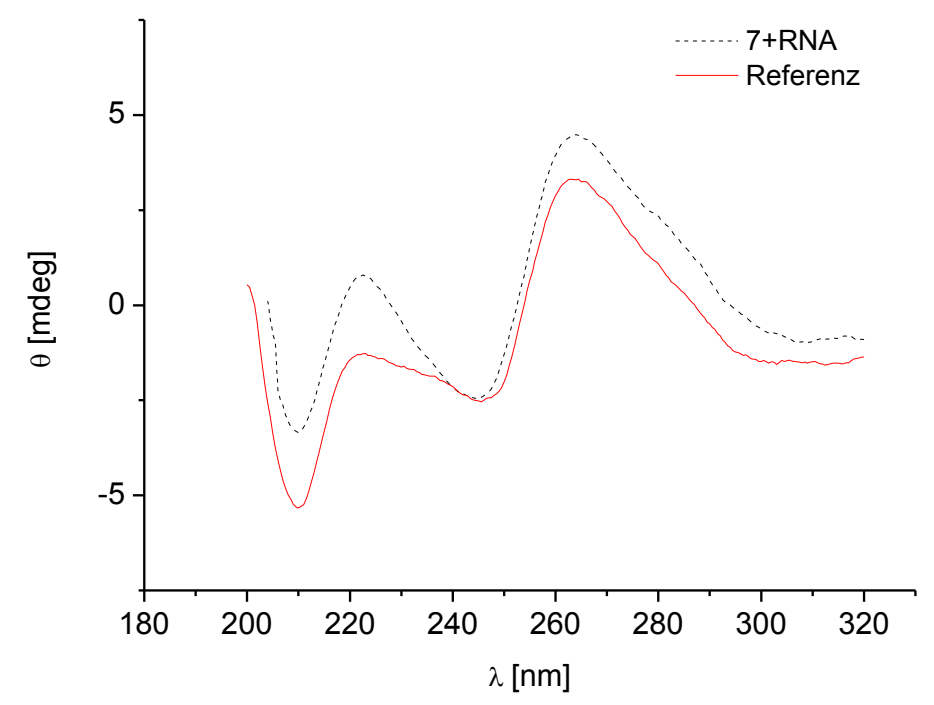

Oligonucleotid 7 (S): 5'-GGCACGG TxT TT TT TT GGCACGG-3'

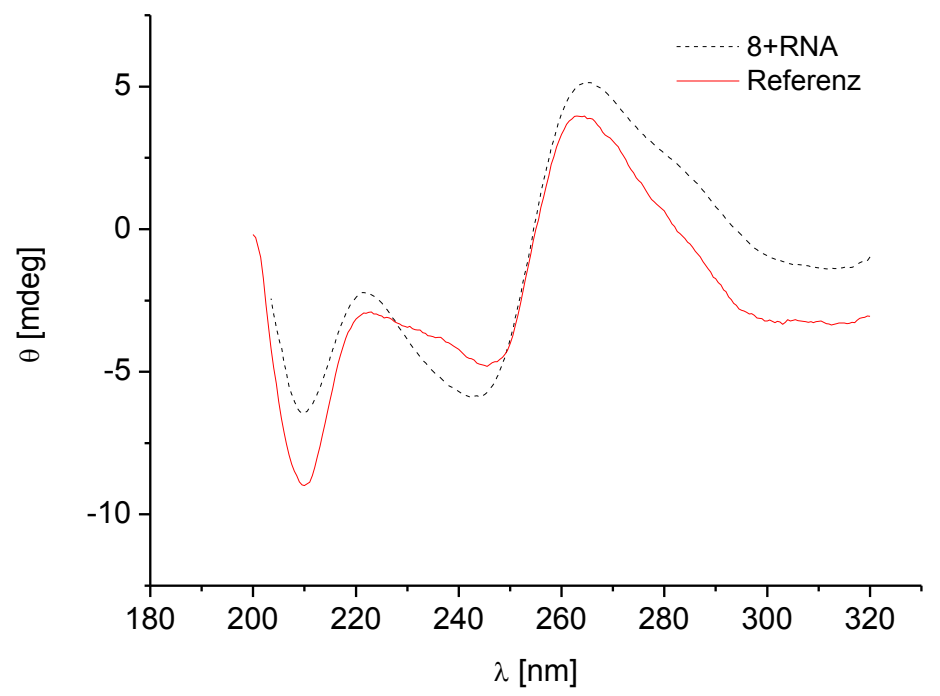

Oligonucleotid $8(R)$ : 5'-GGCACGG TxT TT TT TT GGCACGG-3' 


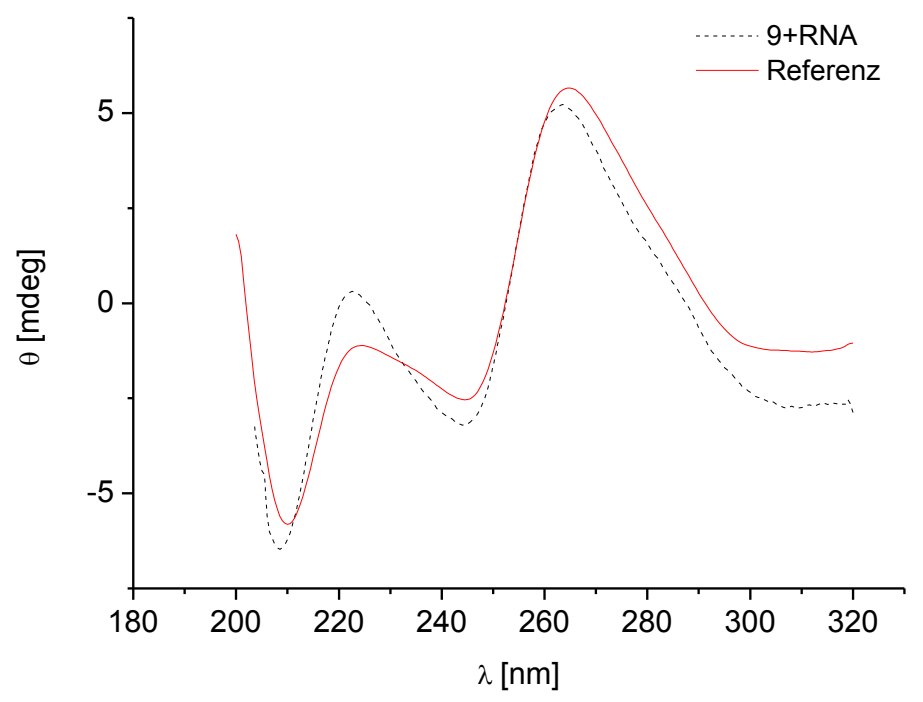

Oligonucleotid 9 (S): 5'-GGCACGG TxT TxT TxT TxT GGCACGG-3'

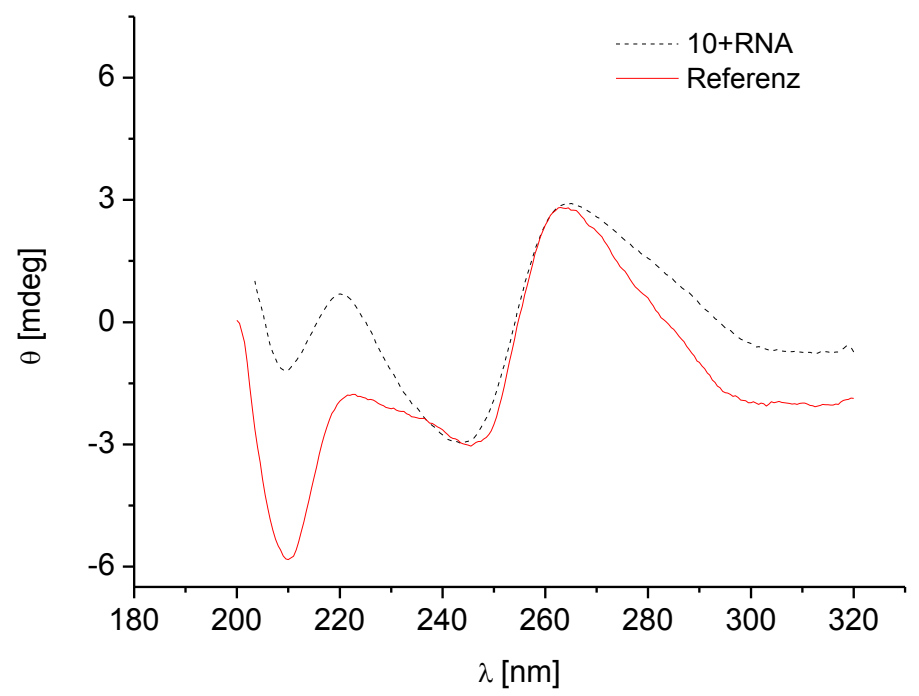

Oligonucleotid $10(R)$ : 5'-GGCACGG TxT TxT TxT TxT GGCACGG-3' 


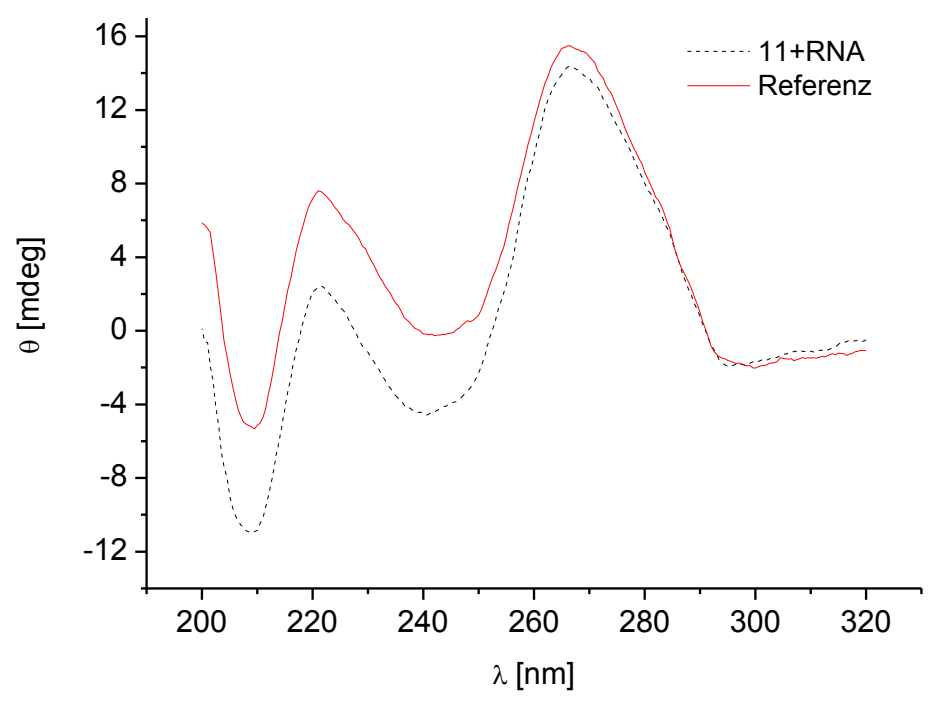

Oligonucleotid 11 (S): 5'-G TxT GACG TT GACG TT GACG TT G-3'

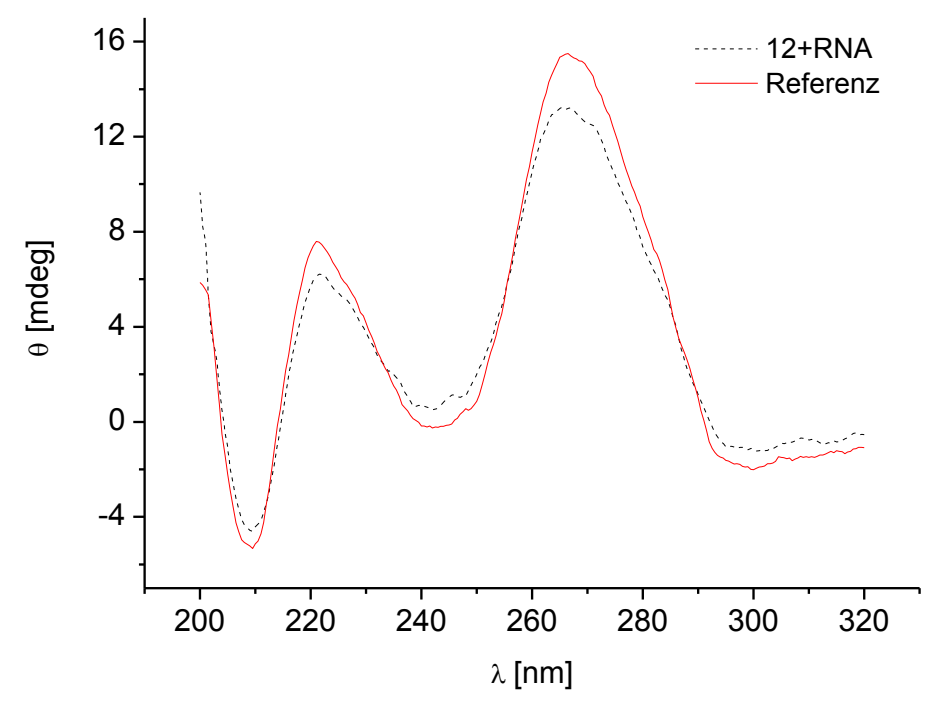

Oligonucleotid $12(R)$ : 5'-G TxT GACG TT GACG TT GACG TT G-3' 


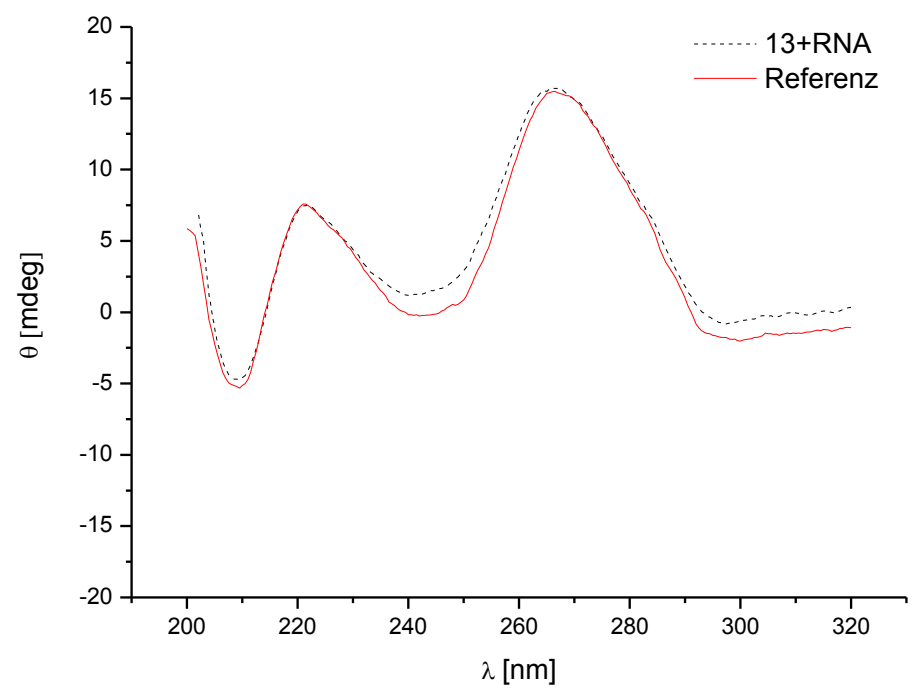

Oligonucleotid 13 (S): 5'-G TT GACG TxT GACG TT GACG TT G-3'

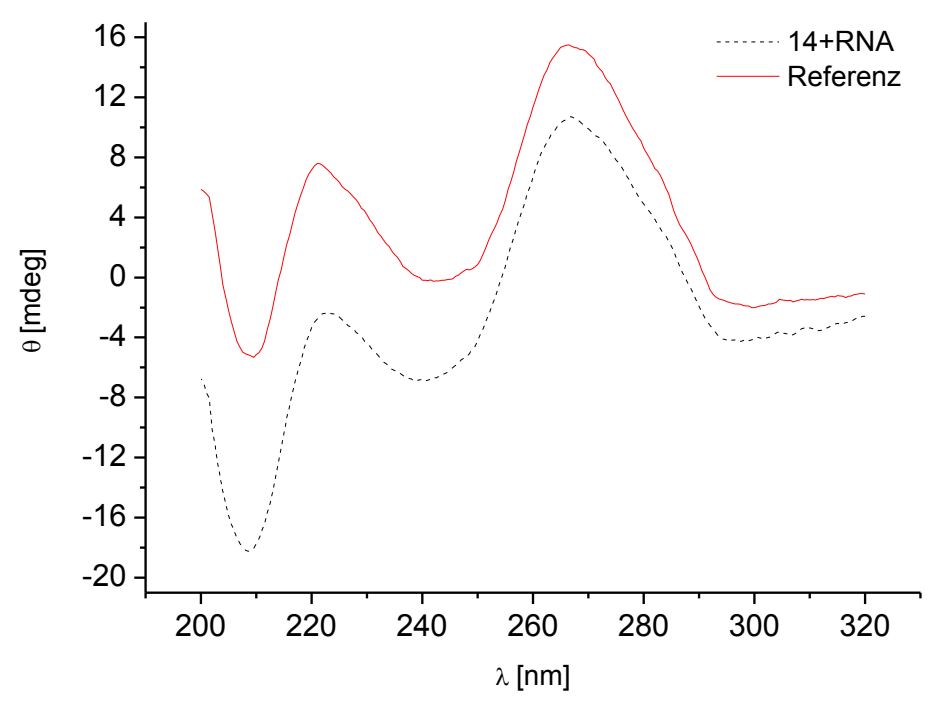

Oligonucleotid $14(R)$ : 5'-G TT GACG TxT GACG TT GACG TT G-3' 


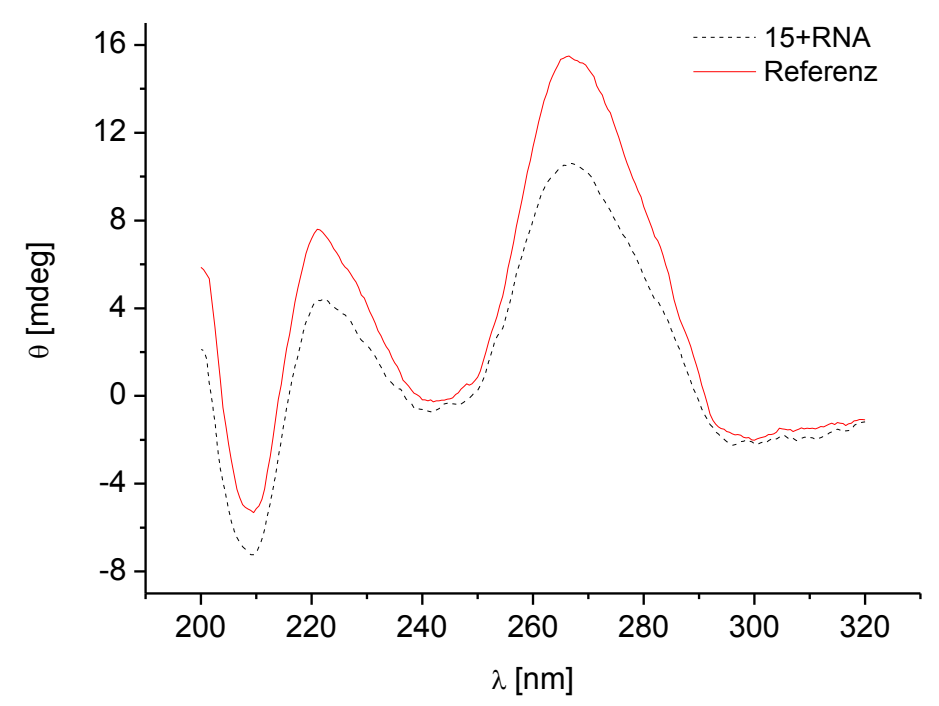

Oligonucleotid 15 (S): 5'-G TT GACG TT GACG TxT GACG TT G-3'

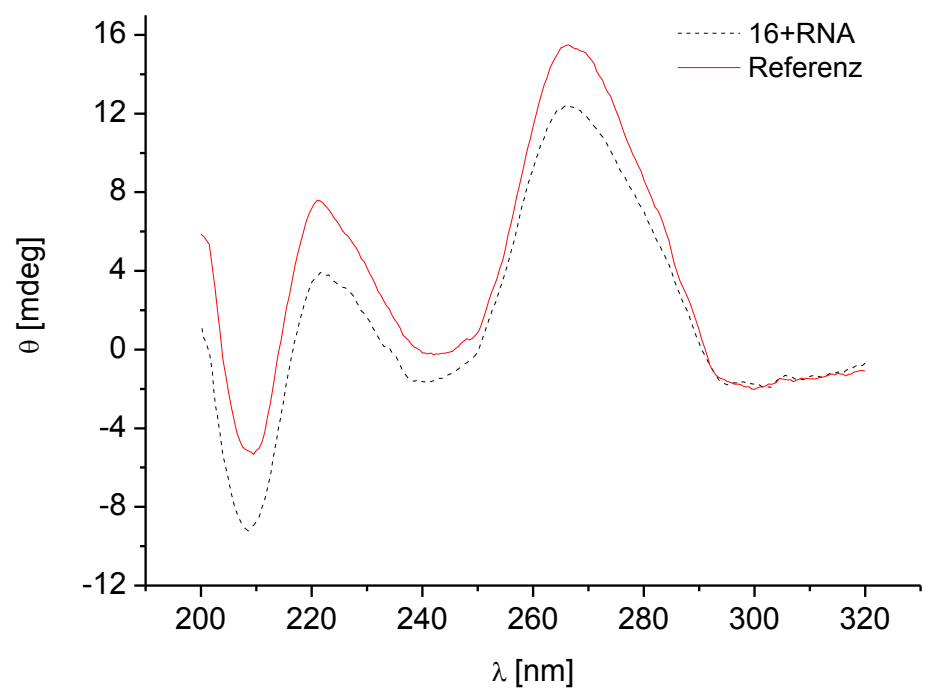

Oligonucleotid 16 (R): 5'-G TT GACG TT GACG TxT GACG TT G-3' 


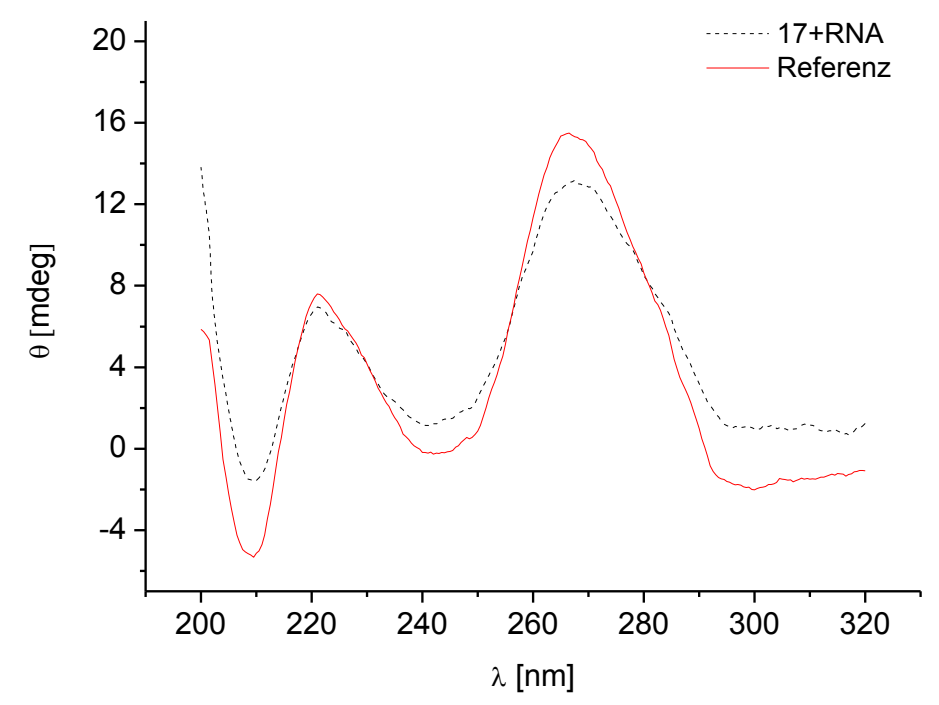

Oligonucleotid 17 (S): 5'-G TT GACG TT GACG TT GACG TxT G-3'

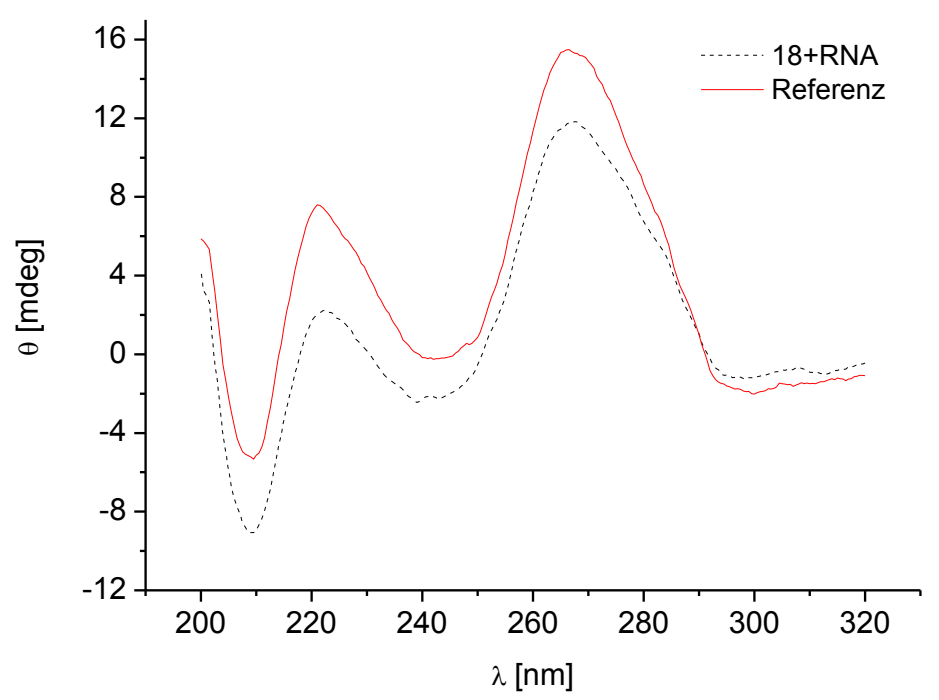

Oligonucleotid $18(R)$ : 5'-G TT GACG TT GACG TT GACG TxT G-3' 


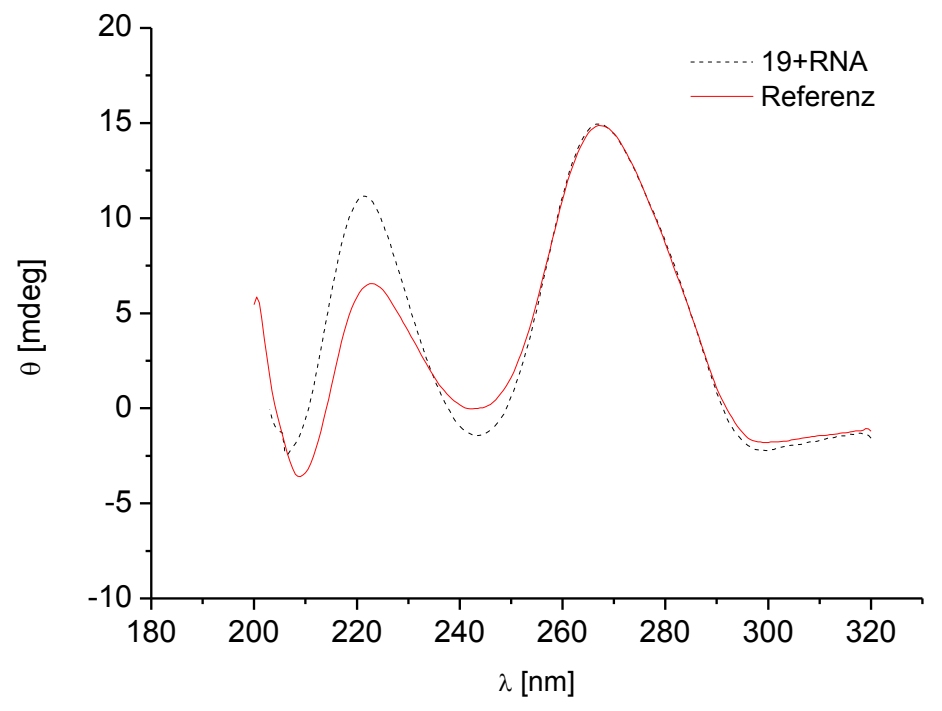

Oligonucleotid 19 (S): 5'-G TxT GACG TxT GACG TxT GACG TxT G-3'

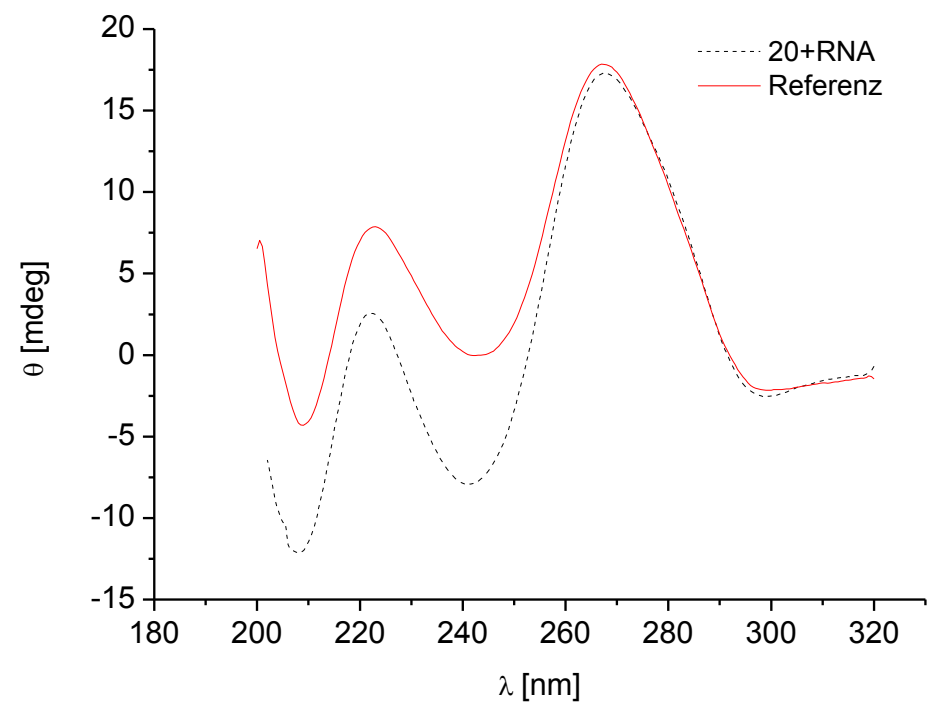

Oligonucleotid $20(R)$ : 5'-G TxT GACG TxT GACG TxT GACG TxT G-3' 


\subsection{Lebenslauf}

\section{Persönliche Angaben}

Name

Boris Schmidtgall

Geburtsdatum

28.08.1983

Geburtsort

Nishnjaja Tura (Russland)

Staatsangehörigkeit

deutsch

Familienstand

Sprachenkenntnisse

verheiratet mit Julia Schmidtgall, geb. Kramer, ein Kind

Deutsch, Russisch (Muttersprache, fließend in Wort und Schrift), Englisch (fließend in Wort und Schrift), Französisch (gute Kenntnisse)

\section{Schulausbildung}

1990-1992

Grundschule in Nishnjaja Tura (Russland)

1992-1995

Emil-Nolde-Grundschule in Bargteheide (Deutschland)

1995-2004

Kreisgymnasium Bargteheide

2004

Abitur

\section{Studium}

2005-2007

Grundstudium der Chemie an der Universität Hamburg

2007

2007-2009

Mai-Dezember 2009 Vordiplom (Note: mit Auszeichnung)

Hauptstudium der Chemie an der Georg-AugustUniversität Göttingen

Diplomarbeit „Nucleosylaminosäuren als Bausteine zur Synthese modifizierter Oligonucleotide" in der Arbeitsgruppe von Prof. Dr. Christian Ducho am Institut für Organische und Biomolekulare Chemie der Georg-AugustUniversität Göttingen

März 2010

Diplom in Chemie (Note: sehr gut)

April 2010

Beginn der Promotion in der Arbeitsgruppe von Prof. Dr. Christian Ducho am Institut für Organische und Biomolekulare Chemie der Georg-August-Universität Göttingen. Thema: „Nucleosylaminosäuren als Bausteine zur Synthese modifizierter Oligonucleotide“ 


\section{Auszeichnungen}

März 2007

Juni 2007-März 2010

Seit November 2010
Auszeichnung des Vordiploms in Chemie an der Universität Hamburg

Stipendium der Studienstiftung des deutschen Volkes

Doktorandenstipendium der Studienstiftung des deutschen Volkes

\section{Vorträge}

24.08.2011

01.06.2012

02.10 .2012

„Präbiotische Entstehung Informationstragender Moleküle“ Sommerakademie der Studienstiftung des Deutschen Volkes, Rot an der Rot, Deutschland.

„Zwitterionische DNA-Strukturen“, Doktorandenforum der Studienstiftung des deutschen Volkes, Bad Homburg, Deutschland.

„Synthesis and Properties of Modified DNA Oligonucleotides with a Zwitterionic Backbone" PhDSeminar der DNG (Deutsche Nucleinsäurechemiegemeinschaft), Bad Herrenalb, Deutschland.

\section{Posterbeiträge}

08.03 .2011

15.09.2011

29.09.2011

Boris Schmidtgall, Falk Wachowius, Claudia Höbartner, Christian Ducho; Nucleosyl Amino Acids as Building Blocks for the Synthesis of Modified Oligonucleotides; $10^{\text {th }}$ German Peptide Symposium Berlin, Deutschland.

Boris Schmidtgall, Falk Wachowius, Claudia Höbartner, Christian Ducho; Synthesis and Properties of Modified DNA Oligonucleotides with a Zwitterionic Backbone; Hochschule trifft Industrie-VII, Schlangenbad, Deutschland.

Boris Schmidtgall, Falk Wachowius, Claudia Höbartner, Christian Ducho; Synthesis and Properties of Modified DNA Oligonucleotides with a Zwitterionic Backbone; V. Nucleinsäurechemie-Treffen, Frankfurt am Main, Deutschland. 
07.08.2012

25.09.2012

19.09.2013

Boris Schmidtgall, Falk Wachowius, Claudia Höbartner, Christian Ducho; Synthesis and Properties of Modified DNA Oligonucleotides with a Zwitterionic Backbone; XX International Roundtable on Nucleosides, Nucleotides and Nucleic Acids, Montreal, Canada.

Boris Schmidtgall, Falk Wachowius, Claudia Höbartner, Christian Ducho; Synthesis and Properties of Modified DNA Oligonucleotides with a Zwitterionic Backbone; Orchem, 18. Lecture Conference, Weimar, Deutschland. Boris Schmidtgall, Falk Wachowius, Claudia Höbartner, Christian Ducho; Synthesis and Properties of Modified DNA Oligonucleotides with a Zwitterionic Backbone; VI. Nucleinsäurechemie-Treffen, Greifswald, Deutschland. 